NUREG/CR-6119

SAND93-2185

Vol. 2

\title{
MELCOR Computer Code Manuals
}

Reference Manuals

Version 1.8.3 September 1994

\author{
RECEIVED \\ MAY 1 - 1995 \\ O STI
}

Prepared by

R. M. Summers, R. K. Cole, Jr., R. C. Smith, D. S. Stuart,

S. L. Thompson, S. A. Hodge, C. R. Hyman, R. L. Sanders

Sandia National Laboratories

Prepared for

U.S. Nuclear Regulatory Commission 


\section{AVAILABILITY.NOTICE}

Availability of Reference Materials Cited in NRC Publications

Most documents cited In NRG publications will be avallable from one of the following sources:

1. The NRC Public Document Room, 2120 L Street, NW., Lower Level, Washington, DC 20555-0001

2. The Superintendent of Documents, U.S. Government Printing Office, P. O. Box 37082, Washington, DC 20402-9328

3. The National Technical Information Service, Springfield, VA 22161-0002

Although the llsting that follows represents the majority of documents cited in NRC publications, it is not intended to be exhaustive.

Referenced documents avallable for inspection and copying for a fee from the NRC Public Document Room Include NRC correspondence and internal NRC memoranda; NRC bulletins, circulars, information notices, inspection and Investigation notices; licensee event reports; vendor reports and correspondence; Commission papers; and applicant and licensee documents and correspondence.

The following documents In the NUREG serles are available for purchase from the Government Printing Office: formal NRC staff and contractor reports, NRC-sponsored conference proceedings, international agreement reports, grantee reports, and NRC booklets and brochures. Also avallable are regulatory guides, NRC regulatlons In the Code of Federal Regulations, and Nuclear Regulatory Commission Issuances.

Documents avallable from the Natlonal Technical Information Service include NUREG-series reports and technical reports prepared by other Federal agencies and reports prepared by the Atomic Energy Commission, forerunner agency to the Nuclear Regulatory Commission.

Documents avallable from public and special technical libraries include all open literature items, such as books, Journal articles, and transactions. Federal Register notices. Federal and State legislation, and congressional reports can usually be obtalned from these libraries.

Documents such as theses, dissertations, foreign reports and translations, and non-NRC conference proceedings are available for purchase from the organization sponsoring the publication cited.

Single coples of NRC draft reports are available free, to the extent of supply, upon written request to the Office of Administration, Distribution and Mail Services Section, U.S. Nuclear Regulatory Commission, Washington, DC 20555-0001.

Coples of Industry codes and standards used in a substantlve manner in the NRC regulatory process are malntained at the NRC Library. Two White Flint North, 11545 Rockville Pike, Rockville, MD 20852-2738, for use by the public. Codes and standards are usually copyrighted and may be purchased from the originating organization or, If they are American National Standards, from the American National Standards Institute. 1430 Broadway, New York, NY 10018-3308.

\section{DISCLAIMER NOTICE}

This report was prepared as an account of work sponsored by an agency of the United States Government. Neither the United States Government nor any agency thereof, nor any of their employees, makes any warranty, expressed or implied, or assumes any legal liability or responsibility for any third party's use, or the results of such use, of any information, apparatus, product, or process disclosed in this report, or represents that its use by such third party would not infringe privately owned rights. 
Vol. 2

\section{MELCOR Computer Code Manuals}

Reference Manuals

Version 1.8.3 September 1994

Manuscript Completed: January 1995

Date Published: March 1995

Prepared by

R. M. Summers, R. K. Cole, Jr., R. C. Smith, D. S. Stuart,

S. L. Thompson, S. A. Hodge, ${ }^{*}$ C. R. Hyman, ${ }^{*}$ R. L. Sanders*

Sandia National Laboratories

Albuquerque, NM 87185-0739

\section{Prepared for}

Division of Systems Technology

Office of Nuclear Regulatory Research

U.S. Nuclear Regulatory Commission

Washington, DC 20555-0001

NRC Job Code A1339

* Oak Ridge National Laboratory

Oak Ridge, TN 37831-8057

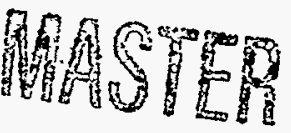




\section{DISCLAIMER}

This report was prepared as an account of work sponsored by an agency of the United States Government. Neither the United States Government nor any agency thereof, nor any of their employees, make any warranty, express or implied, or assumes any legal liability or responsibility for the accuracy, completeness, or usefulness of any information, apparatus, product, or process disciosed, or represents that its use would not infringe privately owned rights. Reference herein to any specific commercial product, process, or service by trade name, trademark, manufacturer, or otherwise does not necessarily constitute or imply its endorsement, recommendation, or favoring by the United States Government or any agency thereof. The views and opinions of authors expressed herein do not necessarily state or reflect those of the United States Government or any agency thereof. 


\section{DISCLAIMER}

Portions of this document may be illegible in electronic image products. Images are produced from the best available original document. 


\begin{abstract}
MELCOR is a fully integrated, engineering-level computer code that models the progression of severe accidents in light water reactor nuclear power plants. MELCOR is being developed at Sandia National Laboratories for the U. S. Nuclear Regulatory Commission as a second-generation plant risk assessment tool and the successor to the Source Term Code Package. A broad spectrum of severe accident phenomena in both boiling and pressurized water reactors is treated in MELCOR in a unified framework. These include: thermal-hydraulic response in the reactor coolant system, reactor cavity, containment, and confinement buildings; core heatup, degradation, and relocation; coreconcrete attack; hydrogen production, transport, and combustion; fission product release and transport; and the impact of engineered safety features on thermal-hydraulic and radionuclide behavior. Current uses of MELCOR include estimation of severe accident source terms and their sensitivities and uncertainties in a variety of applications.

This publication of the MELCOR computer code manuals corresponds to MELCOR 1.8.3, released to users in August, 1994. Volume 1 contains a primer that describes MELCOR's phenomenological scope, organization (by package), and documentation. The remainder of Volume 1 contains the MELCOR Users' Guides, which provide the input instructions and guidelines for each package. Volume 2 contains the MELCOR Reference Manuals, which describe the phenomenological models that have been implemented in each package.
\end{abstract}




\section{Contents}

\section{Volume 2: Reference Manuals}

BWR Lower Plenum Debris Bed (BH) Package Reference Manual ... BH-RM-1

1. INTRODUCTION .......................... BH-RM-9

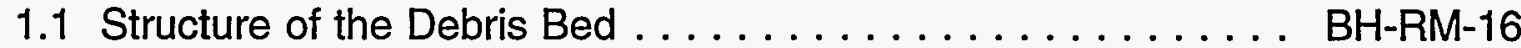

1.1.1 Arrangement of Control Volumes . . . . . . . . BH-RM-19

1.1.2 Initial Setup of Layers One and Two ........... BH-RM-20

1.1.3 The Special Case of Bottom Head LOCA . . . . . . . BH-RM-21

1.1.4 Establishing the Third Debris Layer . . . . . . . . . BH-RM-23

1.2 The Vessel Bottom Head Wall . . . . . . . . . . . . . . . . . BH-RM-24

2. COMPOSITION-DEPENDENT PROPERTIES . . . . . . . . . BH-RM-31

2.1 Debris Porosity . . . . . . . . . . . . . . . . . BH-RM-31

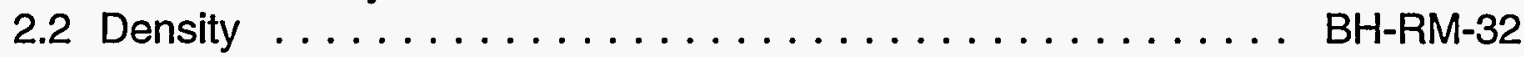

2.3 Specific Heat . . . . . . . . . . . . . . . . . BH-RM-33

2.4 Thermal Conductivity $\ldots \ldots \ldots \ldots \ldots \ldots \ldots \ldots$ BH-RM-43

3. DEBRIS HEAT TRANSFER AND OXIDATION . . . . . . . . . B B-RM-49

3.1 Heat Transfer Between Bed Control Volumes . . . . . . . . . . BH-RM-49

3.2 Heat Transfer With the Vessel Atmosphere . . . . . . . . . . . BH-RM-52

3.2.1 Surface Heat Transfer Coefficients . . . . . . . . . BH-RM-52

3.2.2 Establishing the Debris Bed Surface Temperatures . . BH-RM-56

3.2.3 Exposed Vessel Wall Nodes . . . . . . . . . . . . . BH-RM-57

3.3 Radiation to the Lower Plenum Structures . . . . . . . . . . . BH-RM-60

3.3.1 Heat Transfer Coefficients for Radiation to the Vessel Wall . . . . . . . . . . . . . . . . . BH-RM-60

3.3.2 Direct Radiation Exchange . . . . . . . . . . . BH-RM-62

3.3.3 After Downcomer Dryout . . . . . . . . . . . . . BH-RM-64

3.3.4 Shroud Melting and Relocation ............. BH-RM-64

3.4 Metal-Steam Reaction in the Debris Bed . . . . . . . . . . BH-RM-67

4. DEBRIS MELTING AND RELOCATION $\ldots \ldots \ldots \ldots \ldots \ldots \ldots$ BH-RM-71

4.1 Material Relocation .................... BH-RM-71

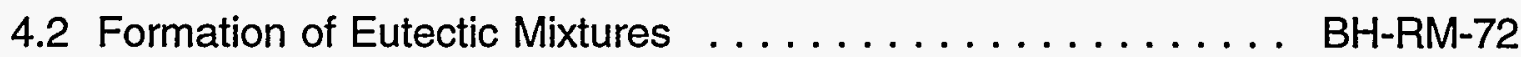

4.3 Adjustment of Control Volume Dimensions . . . . . . . . . . BH-RM-83

4.4 Merging of Bed Control Volumes . . . . . . . . . . . . . BH-RM-85

4.4.1 Merging Criteria . ................ BH-RM-86

4.4.2 Merging Process $\ldots \ldots \ldots \ldots \ldots \ldots \ldots \ldots$ BH-RM-87

5. FAILURE OF THE BOTTOM HEAD $\ldots \ldots \ldots \ldots \ldots \ldots \ldots \ldots$. . . . . BH-RM-89

5.1 Penetration Welds $\ldots \ldots \ldots \ldots \ldots \ldots \ldots \ldots \ldots \ldots$ BH-RM-89

5.2 Instrument Guide Tubes . . . . . . . . . . . . . . . BH-RM-91

5.3 Ablation induced by flow of molten material . . . . . . . . BH-RM-91 
MELCOR 1.8.3 Reference Manuals Contents

5.3.1 Ablation of the Wall . . . . . . . . . . . . . BH-RM-93

5.3.2 Ablation of the Bottom Debris Layer . . . . . . . . . BH-RM-97

5.4 Creep Rupture of the Vessel Wall . . . . . . . . . . . . BH-RM-102

5.5 Gas Blowdown From Vessel . . . . . . . . . . . . . B BH-RM-104

6. EXAMPLES OF CALCULATED RESULTS $\ldots \ldots \ldots \ldots \ldots$ BH-RM-105

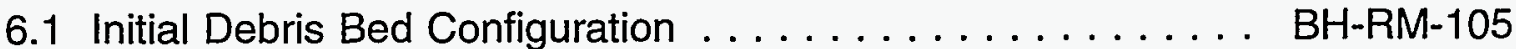

6.2 Formation of the Third Debris Layer . . . . . . . . . . BH-RM-109

6.3 Lower Plenum and Bottom Head Response . . . . . . . . BH-RM-112

6.4 The Case With Penetration Failures $\ldots \ldots \ldots \ldots \ldots \ldots$ BH-RM-116

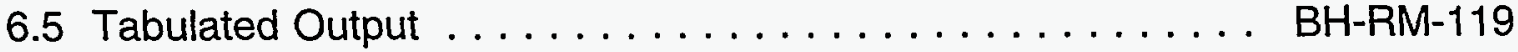

6.6 Special Messages . . . . . . . . . . . . . . . . . . BH-RM-124

7. MODELS FOR WATER IN THE LOWER PLENUM $\ldots \ldots \ldots \ldots$. . BH-RM-127

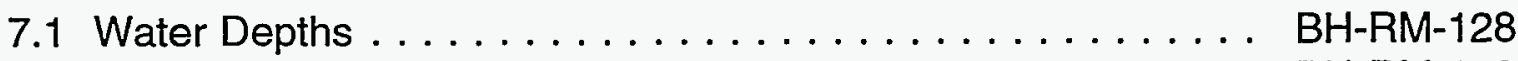

7.2 Dryout Heat Flux $\ldots \ldots \ldots \ldots \ldots \ldots \ldots \ldots \ldots \ldots \ldots$ BH-RM-130

7.2.1 Calculation .................. BH-RM-131

7.2.2 Application to Bed Radial Zones . . . . . . . . . . BH-RM-133

7.2.3 Limited Water Availability . . . . . . . . . . . . B BH-RM-137

7.2.4 Experimental Evidence for Oxidic Debris Bed

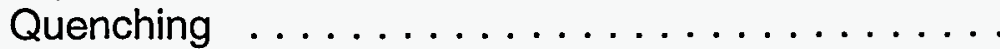

7.3 Effects of Hydrogen Generation

BH-RM-137

BH-RM-139

7.3.1 Metal-Steam Reaction Rate . . . . . . . . . . BH-RM-139

7.3.2 Effect on Dryout Heat Flux . . . . . . . . . . B B-RM-140

7.4 Heat Transfer at the Bed Surface $\ldots \ldots \ldots \ldots \ldots \ldots \ldots$ BH-RM-141

7.4 .1 Critical Heat Flux . . . . . . . . . . . . . . . . BH-RM-142

7.4.2 Film Boiling Coefficient . . . . . . . . . . . . BH-RM-143

7.4.3 Nucleate Boiling Coefficient . . . . . . . . . . BH-RM-144

7.5 Heat Transfer at Exposed Wall Nodes . . . . . . . . . . . . . BH-RM-147

7.6 The Case of Lower Plenum Water with Penetration Failures . BH-RM-147

7.6.1 Water Flow . . . . . . . . . . . . . . . . BH-RM-147

7.6.2 Steam Generation . . . . . . . . . . . . . . . . BH-RM-149

7.6.3 Hydrogen Generation . . . . . . . . . . . . . . . BH-RM-150

7.6.4 Exit Conditions . . . . . . . . . . . . . . . BH-RM-151

7.7 Interaction of Water with Late Debris Pours . . . . . . . . . BH-RM-152

7.8 Special Printed Output . . . . . . . . . . . . . BH-RM-154

8. PACKAGE ORGANIZATION .................. BH-RM-157

8.1 Arrangement of Subroutines and Commons . . . . . . . . BH-RM-157

8.2 Information Exchange with MELCOR . . . . . . . . . . BH-RM-158

8.2.1 Calls to BHQSLU . . . . . . . . . . . . . . BH-RM-172

8.2.2 Calls to BHPENF . . . . . . . . . . . . . BH-RM-180

8.2.3 Special Requirements for MELCOR input . . . . . . BH-RM-181

8.2.4 Deactivating the BH Package . . . . . . . . . BH-RM-183 
MELCOR 1.8.3 Reference Manuals Contents

9. THE MELCOR INTERFACE $\ldots \ldots \ldots \ldots \ldots \ldots \ldots \ldots \ldots \ldots$ BH-RM-185

9.1 Interface Organization . . . . . . . . . . . . . . BH-RM-185

9.2 MELCOR BWR Core Shroud Modeling Enhancements ..... BH-RM-185

9.2.1 Introduction . . . . . . . . . . . . . . . BH-RM-185

9.2.2 Shroud Model Prior to Lower Plenum Dryout . . . . . B BH-RM-186

9.2.3 Shroud Model After Lower Plenum Dryout . . . . . . . . BH-RM-187

9.2.4 Shroud Model After Lower Core Shroud Failure . . . . BH-RM-189 9.2.4.1 Initiation Characteristics and Model DescriptionBH-RM-189

9.2.4.2 Shroud Heat and Mass Balance ......... BH-RM-194

9.2.4.3 Gross Shroud Relocations ........... BH-RM-196

9.3 Interface Modifications for Debris Relocations from the Vessel

to Containment . . . . . . . . . . . . . . . . .

9.4 Fission Product Release from the BH Package Debris Bed ..

9.5 Future BWR MELCOR Modifications .............

9.5.1 Gross Core Plate Failure Due to Combined Thermal and Stress Loading . . . . . . . . . . . . . BH-RM-201

9.5.2 Models for the B4C-Steam Reaction .......... BH-RM-202

9.5.3 Improved Modeling of the BWR Core ........ BH-RM-202

10. APPLICATION TO THE SBWR $\ldots \ldots \ldots \ldots \ldots \ldots \ldots \ldots$ BH-RM-203

11. MASS AND ENERGY BALANCES $\ldots \ldots \ldots \ldots \ldots \ldots \ldots$ BH-RM-205

11.1 Debris Mass Balance $\ldots \ldots \ldots \ldots \ldots \ldots \ldots \ldots \ldots \ldots$ BH-RM-206

11.2 Wall Energy Balance $\ldots \ldots \ldots \ldots \ldots \ldots \ldots \ldots$. . . . . . . . . . . 207

11.3 Bed Energy Balance . . . . . . . . . . . . . . . . . BH-RM-211

12. REFERENCES $\ldots \ldots \ldots \ldots \ldots \ldots \ldots \ldots \ldots \ldots \ldots \ldots \ldots$ BH-RM-215

APPENDIX A: THE PCCS AND ICS MODELS $\ldots \ldots \ldots \ldots \ldots \ldots$ BH-RM-219

A.1 PCCS Model . . ..................... BH-RM-219

A.1.1 Introduction and Concept . . . . . . . . . BH-RM-219

A.1.2 General PCCS Performance . . . . . . . . . . . B BH-RM-220

A.1.3 Operation of the PCCS Model . . . . . . . . . BH-RM-221

A.1.4 The Iterative Procedure $\ldots \ldots \ldots \ldots \ldots \ldots \ldots$ BH-RM-232

A.1.4.1 Purpose . ................. BH-RM-232

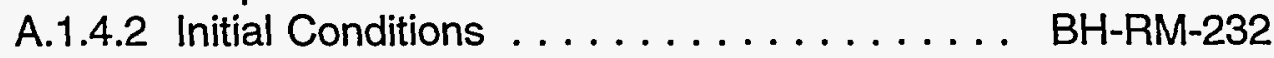

A.1.4.3 Iterative Steps $\ldots \ldots \ldots \ldots \ldots \ldots \ldots \ldots$ BH-RM-232

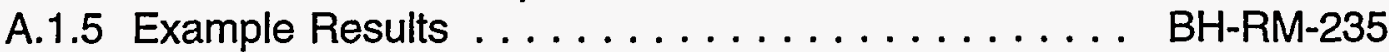

A.1.6 Summary of PCCS Operation . . . . . . . . . . . BH-RM-243

A.2 ICS Model ........................... BH-RM-243

A.2.1 Introduction and Concept . . . . . . . . . . BH-RM-243

A.2.2 Operation of the ICS Model . . . . . . . . . . B BH-RM-244

A.2.3 Example Results . . . . . . . . . . . . . . . BH-RM-246

A.3 Interface with MELCOR $\ldots \ldots \ldots \ldots \ldots \ldots \ldots \ldots$ BH-RM-247 
MELCOR 1.8.3 Reference Manuals Contents

Burn (BUR) Package Reference Manual $\ldots \ldots \ldots \ldots \ldots \ldots \ldots \ldots$ BUR-RM-1

1. INTRODUCTION ....................... BUR-RM-5

1.1 Treatment of Deuterium $\ldots \ldots \ldots \ldots \ldots \ldots \ldots$ BUR-RM-5

2. DETAILED MODELS $\ldots \ldots \ldots \ldots \ldots \ldots \ldots \ldots \ldots$ BUR-RM-7

2.1 Burn Model Logistics $\ldots \ldots \ldots \ldots \ldots \ldots \ldots \ldots$ BUR-RM-7

2.2 Ignition Criteria $\ldots \ldots \ldots \ldots \ldots \ldots \ldots \ldots \ldots \ldots \ldots$ BUR-RM-7

2.3 Combustion Completeness $\ldots \ldots \ldots \ldots \ldots \ldots \ldots \ldots$ BUR-RM-9

2.4 Burn Duration . . . . . . . . . . . . . . . . . . BUR-RM-11

2.5 Combustion Rate $\ldots \ldots \ldots \ldots \ldots \ldots \ldots \ldots \ldots \ldots$ BUR-RM-12

2.6 Propagation Criteria $\ldots \ldots \ldots \ldots \ldots \ldots \ldots \ldots \ldots$ BUR-RM-13

2.7 Detonation $\ldots \ldots \ldots \ldots \ldots \ldots \ldots \ldots \ldots \ldots$ BUR-RM-15

3. TIMESTEP CONTROL $\ldots \ldots \ldots \ldots \ldots \ldots \ldots \ldots \ldots$ BUR-RM-17

4. REFERENCES $\ldots \ldots \ldots \ldots \ldots \ldots \ldots \ldots \ldots \ldots \ldots \ldots \ldots \ldots$ BUR-RM-19

Cavity (CAV) Package Reference Manual $\ldots \ldots \ldots \ldots \ldots \ldots \ldots$ CAV-RM-1

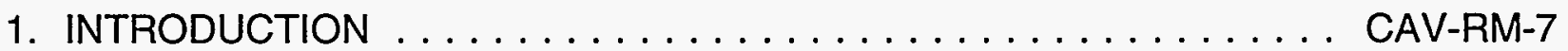

2. PHENOMENOLOGY $\ldots \ldots \ldots \ldots \ldots \ldots \ldots \ldots \ldots$ CAV-RM-9

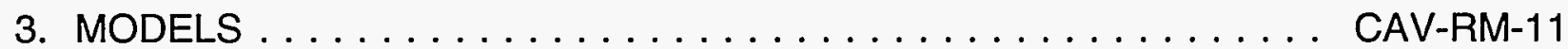

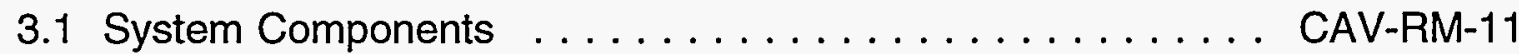

3.2 Debris Layering and Mixing $\ldots \ldots \ldots \ldots \ldots \ldots \ldots \ldots$ CAV-RM-13

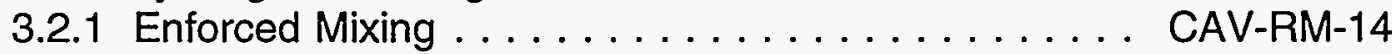

3.2.2 Enforced Stratification . . . . . . . . . . . CAV-RM-14

3.2.3 Mechanistic Mixing . . . . . . . . . . . . . . CAV-RM-15

3.3 Energy Generation and Heat Transfer . . . . . . . . . . CAV-RM-16

3.4 Concrete Ablation and Cavity Shape Change .......... CAV-RM-18

3.5 Chemistry ........................... CAV-RM-19

3.6 Mass Transfer and Associated Heat Effects . . . . . . . . . CAV-RM-20

3.7 Debris Spreading . . . . . . . . . . . . . . . . CAV-RM-22

3.8 Energy Conservation $\ldots \ldots \ldots \ldots \ldots \ldots \ldots \ldots \ldots$ CAV-RM-22

3.9 Material Properties $\ldots \ldots \ldots \ldots \ldots \ldots \ldots \ldots \ldots \ldots \ldots \ldots \ldots$ CAV-RM-22

4. COMPARISON TO STAND-ALONE CORCON . . . . . . . . . CAV-RM-25

5. REFERENCES $\ldots \ldots \ldots \ldots \ldots \ldots \ldots \ldots \ldots \ldots \ldots$ CAV-RM-29

APPENDIX A: Species list for CORCON in MELCOR . . . . . . . CAV-RM-31 
MELCOR 1.8.3 Reference Manuals Contents

Core (COR) Package Reference Manual COR-RM-1

1. INTRODUCTION ......................... COR-RM-7

1.1 Nodalization Scheme ................... COR-RM-8

1.1.1 Core/Lower Plenum . . . . . . . . . . . . . . . . COR-RM-8

1.1.2 Lower Head . . . . . . . . . . . . . . . . . COR-RM-13

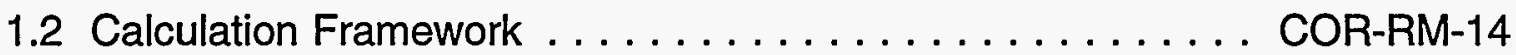

2. HEAT TRANSFER AND OXIDATION MODELS $\ldots \ldots \ldots \ldots \ldots$ COR-RM- 17

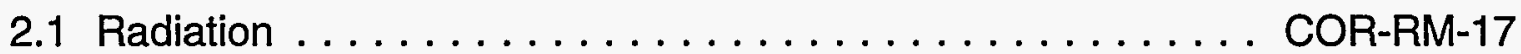

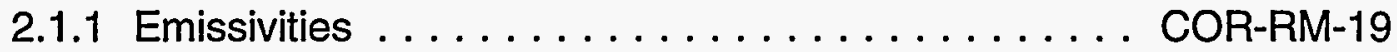

2.1 .2 View Factors . . . . . . . . . . . . . . . . . COR-RM-20

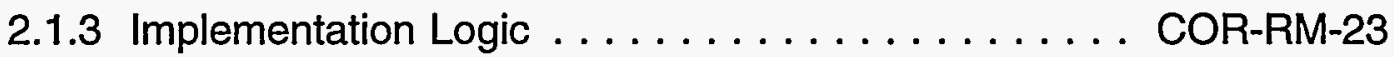

2.2 Conduction $\ldots \ldots \ldots \ldots \ldots \ldots \ldots \ldots \ldots \ldots \ldots \ldots$ COR-RM-25

2.2.1 Axial Conduction . . . . . . . . . . . . . . . . COR-RM-26

2.2.2 Fuel-Cladding Gap Heat Transfer . . . . . . . . . . . . COR-RM-29

2.2.3 Conduction to Boundary Heat Structures . . . . . . . COR-RM-31

2.3 Convection . . . . . . . . . . . . . . . . . . . COR-RM-32

2.3.1 Laminar Forced Convection . . . . . . . . . . . . COR-RM-33

2.3.2 Turbulent Forced Convection . . . . . . . . . . COR-RM-34

2.3.3 Laminar and Turbulent Free Convection . . . . . . . COR-RM-34

2.3.4 Convection from Particulate Debris . . . . . . . . COR-RM-35

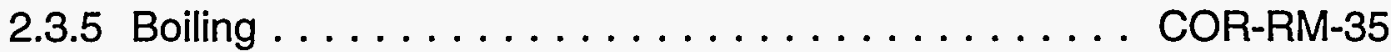

2.3.6 Debris Quenching and Dryout . . . . . . . . . COR-RM-36

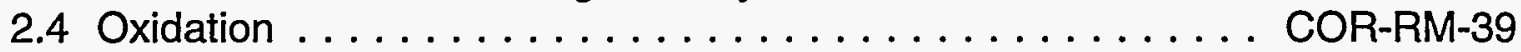

2.4.1 Zircaloy and Steel $\ldots \ldots \ldots \ldots \ldots \ldots \ldots$ COR-RM-40

2.4 .2 Boron Carbide . . . . . . . . . . . . . . . . . . COR-RM-44

2.5 Control Volume Temperature Distribution (dT/dz) Model . . . . COR-RM-46

2.6 Fission Power Generation . . . . . . . . . . . . . . . . . COR-RM-48

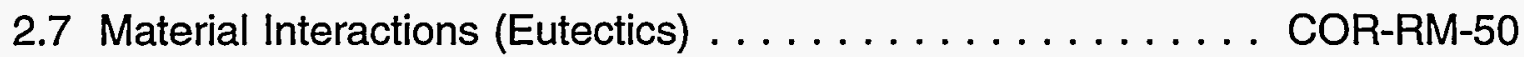

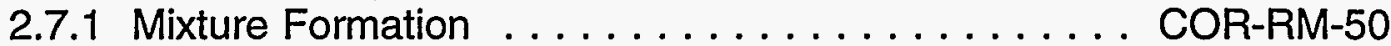

2.7.2 Mixture Properties . . . . . . . . . . . . . COR-RM-51

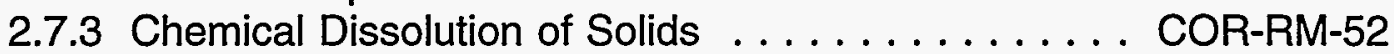

3. MASS RELOCATION MODELS $\ldots \ldots \ldots \ldots \ldots \ldots \ldots \ldots \ldots$ COR-RM-57

3.1 Candling $\ldots \ldots \ldots \ldots \ldots \ldots \ldots \ldots \ldots \ldots \ldots \ldots \ldots$ COR-RM-57

3.1.1 Steady Flow $\ldots \ldots \ldots \ldots \ldots \ldots \ldots \ldots$ COR-RM-57

3.1.2 Flow Blockages . . . . . . . . . . . . . . . COR-RM-61

3.1.3 Holdup by Oxide Shells . . . . . . . . . . . . . COR-RM-63

3.1.4 Solid Material Transport . . . . . . . . . . . . . COR-RM-63

3.1.5 Surface Area Effects of Conglomerate Debris . . . . COR-RM-64

3.2 Radial Relocation . . . . . . . . . . . . . . . . . COR-RM-67

3.2.1 Molten Material . . . . . . . . . . . . . . COR-RM-68

3.2.2 Particulate Debris $\ldots \ldots \ldots \ldots \ldots \ldots \ldots$ COR-RM-68 
MELCOR 1.8.3 Reference Manuals Contents

3.3 Particulate Debris Formation . . . . . . . . . . . . . COR-RM-69

3.3.1 Debris Addition from Heat Structure Melting . . . . . . COR-RM-70

3.4 Gravitational Settling . . . . . . . . . . . . . . COR-RM-71

4. LOWER HEAD MODEL $\ldots \ldots \ldots \ldots \ldots \ldots \ldots \ldots \ldots \ldots$ COR-RM-75

4.1 Heat Transfer . . . . . . . . . . . . . . . . . . COR-RM-75

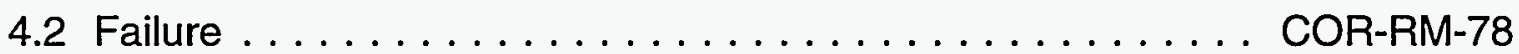

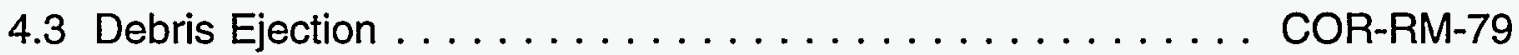

5. DISCUSSION AND DEVELOPMENT PLANS . . . . . . . . . COR-RM-83

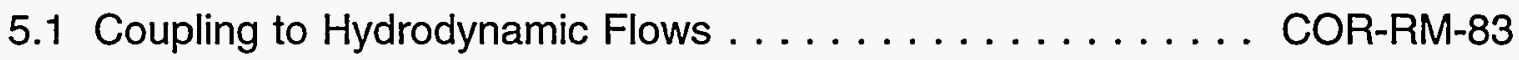

5.2 Radiation . . . . . . . . . . . . . . . . COR-RM-83

5.3 Reflood Behavior . . . . . . . . . . . . . . . . COR-RM-84

5.4 Cladding Ballooning $\ldots \ldots \ldots \ldots \ldots \ldots \ldots \ldots \ldots \ldots$ COR-RM-84

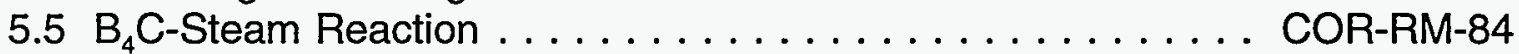

5.6 Coupling of Blockages to $\mathrm{CVH} \ldots \ldots \ldots \ldots \ldots \ldots \ldots$ COR-RM-85

5.7 Structure Support/Crust Failure . . . . . . . . . . . COR-RM-85

5.8 Lower Plenum Debris Behavior and Vessel Failure . . . . . . COR-RM-85

6. REFERENCES $\ldots \ldots \ldots \ldots \ldots \ldots \ldots \ldots \ldots \ldots \ldots \ldots \ldots \ldots$ COR-RM-87

APPENDIX A: Sensitivity Coefficients $\ldots \ldots \ldots \ldots \ldots \ldots \ldots \ldots$ COR-RM-89

Thermal Hydraulic (CVH and FL) Packages Reference Manual ... CVH/FL-RM-1

1. INTRODUCTION AND OVERVIEW $\ldots \ldots \ldots \ldots \ldots \ldots \ldots \ldots$ CVH/FL-RM-7

2. BASIC CONTROL VOLUME CONCEPTS $\ldots \ldots \ldots \ldots \ldots \ldots$ CVH/FL-RM-11

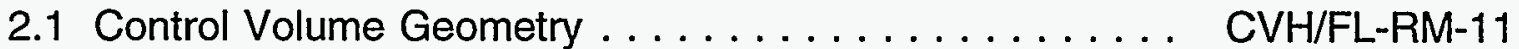

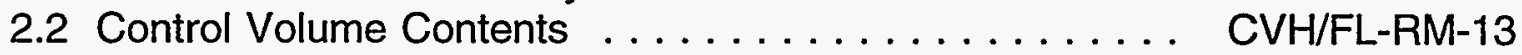

2.3 Control Volume Thermodynamic Properties ........ CVH/FL-RM-13

3. BASIC FLOW PATH CONCEPTS $\ldots \ldots \ldots \ldots \ldots \ldots \ldots \ldots$ CVH/FL-RM-17

3.1 Flow Path Definition $\ldots \ldots \ldots \ldots \ldots \ldots \ldots \ldots \ldots$ CVH/FL-RM-17

3.2 Flow Path Geometry .................. CVH/FL-RM-17

4. GOVERNING EQUATIONS $\ldots \ldots \ldots \ldots \ldots \ldots \ldots \ldots \ldots$ CVH/FL-RM-21

4.1 Ordinary Differential Equations $\ldots \ldots \ldots \ldots \ldots \ldots \ldots$ CVH/FL-RM-21

4.2 Finite Difference Equations . . . . . . . . . . . CVH/FL-RM-24 4.2.1 Inclusion of Bubble-Separation Terms within the Implicit

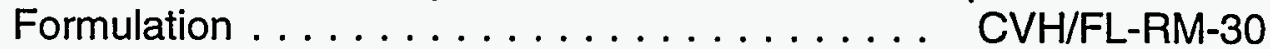

4.3 Solution Strategy $\ldots \ldots \ldots \ldots \ldots \ldots \ldots \ldots \ldots \ldots$ CVH/FL-RM-33

4.4 Definition of Donor Quantities $\ldots \ldots \ldots \ldots \ldots \ldots$ CVH/FL-RM-38 
MELCOR 1.8.3 Reference Manuals Contents

4.5 Timestep Control and Subcycling $\ldots \ldots \ldots \ldots \ldots \ldots$ CVH/FL-RM-41

5. CONSTITUTIVE RELATIONS ................ CVH/FL-RM-45

5.1 Pool/Atmosphere Mass and Energy Transfer . . . . . . CVH/FL-RM-45

5.1.1 Mass Transfer at the Pool Surface ......... CVH/FL-RM-45

5.1.2 Heat Transfer to the Interface . ........... CVH/FL-RM-49

5.1.3 Bubble Rise and Phase Separation ......... CVH/FL-RM-50

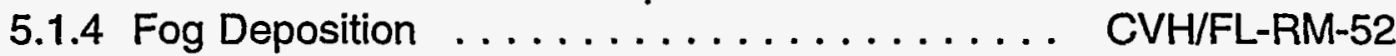

5.2 Flow Path Void Fractions $\ldots \ldots \ldots \ldots \ldots \ldots \ldots \ldots$ CVH/FL-RM-52

5.2.1 Normal Flow Paths ............... CVH/FL-RM-52

5.2.2 Pool-First and Atmosphere-First Flow Paths ... CVH/FL-RM-53

5.3 Hydrostatic (Gravitational) Heads . . . . . . . . . . CVH/FL-RM-54

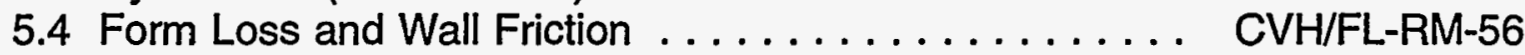

5.4.1 Flow Path Segments ............. CVH/FL-RM-56

5.4.2 Single-Phase Friction Factor . . . . . . . . . CVH/FL-RM-58

5.5 Interphase Forces $\ldots \ldots \ldots \ldots \ldots \ldots \ldots \ldots \ldots \ldots$ CVH/FL-RM-59

5.6 Pumps and Fans $\ldots \ldots \ldots \ldots \ldots \ldots \ldots \ldots \ldots \ldots$ CVH/FL-RM-60

5.6.1 The FANA Model . . . . . . . . . . . . . CVH/FL-RM-60

6. OTHER MODELS $\ldots \ldots \ldots \ldots \ldots \ldots \ldots \ldots \ldots \ldots$ CVH/FL-RM-63

6.1 Bubble Physics .................... CVH/FL-RM-63

6.2 Time-Dependent (Specified) Flow Paths . . . . . . . . . CVH/FL-RM-65

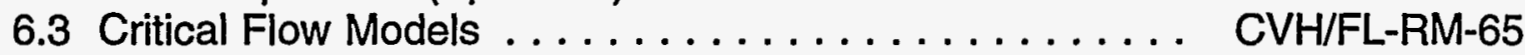

6.3.1 RETRAN Critical Flow Model . ......... CVH/FL-RM-67

6.4 Valves . . . ...................... CVH/FL-RM-67

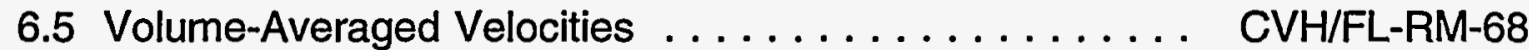

6.6 Special (Time-Specified) Volumes . . . . . . . . . CVH/FL-RM-69

7. DISCUSSION AND DEVELOPMENT PLANS $\ldots \ldots \ldots \ldots \ldots$ CVH/FL-RM-71

7.1 Interphase Forces $\ldots \ldots \ldots \ldots \ldots \ldots \ldots \ldots \ldots \ldots$ CVH/FL-RM-71

7.2 Critical Flow Modeling . . . . . . . . . . . . . . CVH/FL-RM-71

7.3 Flow Blockage Modeling $\ldots \ldots \ldots \ldots \ldots \ldots \ldots$ CVH/FL-RM-71

8. REFERENCES $\ldots \ldots \ldots \ldots \ldots \ldots \ldots \ldots \ldots \ldots \ldots$ CVH/FL-RM-73

APPENDIX A: Sensitivity Coefficients $\ldots \ldots \ldots \ldots \ldots \ldots \ldots$ CVH/FL-RM-75

APPENDIX B: The Interphase Force and the Flooding Curve $\ldots .$. CVH/FL-RM-79

APPENDIX C: Moody Critical Flow $\ldots \ldots \ldots \ldots \ldots \ldots \ldots \ldots$ CVH/FL-RM-83 
MELCOR 1.8.3 Reference Manuals Contents

Control Volume Thermodynamics (CVT) Package Reference Manual . CVT-RM-1

1. INTRODUCTION $\ldots \ldots \ldots \ldots \ldots \ldots \ldots \ldots \ldots \ldots \ldots \ldots$ CVT-RM-5

2. EQUILIBRIUM THERMODYNAMICS $\ldots \ldots \ldots \ldots \ldots \ldots \ldots \ldots$ CVT-RM-7

2.1 Governing Assumptions $\ldots \ldots \ldots \ldots \ldots \ldots \ldots \ldots \ldots$ CVT-RM-7

2.2 Governing Equations $\ldots \ldots \ldots \ldots \ldots \ldots \ldots \ldots$ CVT-RM-8

2.3 Required Derivatives . . . . . . . . . . . . . . CVT-RM-13

2.4 Partition of Liquid Water between Pool and Atmosphere .... CVT-RM-14

3. NONEQUILIBRIUM THERMODYNAMICS $\ldots \ldots \ldots \ldots \ldots \ldots \ldots$ CVT-RM-15

3.1 Governing Assumptions $\ldots \ldots \ldots \ldots \ldots \ldots \ldots \ldots \ldots$ CVT-RM-15

3.2 Governing Equations $\ldots \ldots \ldots \ldots \ldots \ldots \ldots \ldots$ CVT-RM-16

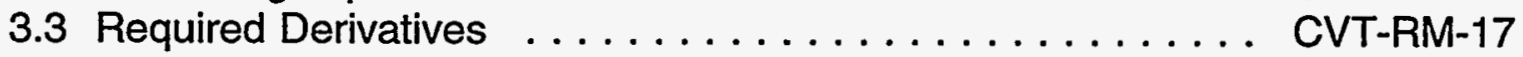

3.4 Limit of Vanishing Pool or Atmosphere ........... CVT-RM-19

4. OTHER REQUIRED PROPERTIES . . . . . . . . . . . CVT-RM-21

4.1 Specific Heat at Constant Pressure . . . . . . . . . . CVT-RM-21

4.2 Sound Speed $\ldots \ldots \ldots \ldots \ldots \ldots \ldots \ldots \ldots \ldots$ CVT-RM-21

APPENDIX A: DERIVATIVES ................. CVT-RM-23

A.1 Derivatives of the Pressure . . . . . . . . . . . . . CVT-RM-23

A.2 Derivatives of the Volume Available to NCG . . . . . . . . CVT-RM-26

A.3 Derivatives of the Vapor Volume . . . . . . . . . . CVT-RM-28

Decay Heat (DCH) Package Reference Manual $\ldots \ldots \ldots \ldots \ldots \ldots$. . . . . . . .

1. INTRODUCTION $\ldots \ldots \ldots \ldots \ldots \ldots \ldots \ldots \ldots \ldots \ldots$ DCH-RM-5

2. ELEMENTAL AND RADIONUCLIDE CLASS DECAY HEAT $\ldots \ldots \ldots$ DCH-RM-7

2.1 SANDIA-ORIGEN Calculations $\ldots \ldots \ldots \ldots \ldots \ldots \ldots$ DCH-RM-7

2.2 Radionuclide Classes . . . . . . . . . . . . . . . DCH-RM-9

3. WHOLE-CORE DECAY HEAT CALCULATION $\ldots \ldots \ldots \ldots \ldots$ DCH-RM-11

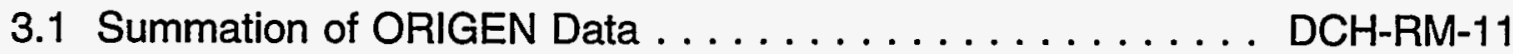

3.2 ANS Standard Calculation . . . . . . . . . . . . . DCH-RM-11

3.3 User-Defined Functions $\ldots \ldots \ldots \ldots \ldots \ldots \ldots \ldots$. . . . . . . . . . . .

4. REFERENCES $\ldots \ldots \ldots \ldots \ldots \ldots \ldots \ldots \ldots \ldots \ldots \ldots \ldots \ldots \ldots$ DCH-RM-17 
MELCOR 1.8.3 Reference Manuals Contents

Fan Cooler (FCL) Package Reference Manual $\ldots \ldots \ldots \ldots \ldots \ldots$. . . . . . . . .

1. INTRODUCTION $\ldots \ldots \ldots \ldots \ldots \ldots \ldots \ldots \ldots \ldots \ldots \ldots$ FCL-RM-5

2. MODEL DESCRIPTION $\ldots \ldots \ldots \ldots \ldots \ldots \ldots \ldots \ldots \ldots$ FCL-RM-7

3. DISCUSSION AND DEVELOPMENT PLANS $\ldots \ldots \ldots \ldots \ldots \ldots$ FCL-RM-11

4. REFERENCES $\ldots \ldots \ldots \ldots \ldots \ldots \ldots \ldots \ldots \ldots \ldots \ldots \ldots \ldots \ldots \ldots \ldots$ FCL-RM-13

APPENDIX A: Sensitivity Coefficients $\ldots \ldots \ldots \ldots \ldots \ldots \ldots \ldots$ FCL-RM-15

Fuel Dispersal Interactions (FDI) Package Reference Manual . . . . . F FI-RM-1

1. INTRODUCTION $\ldots \ldots \ldots \ldots \ldots \ldots \ldots \ldots \ldots \ldots \ldots \ldots$ FDI-RM-5

2. DETAILED MODELS $\ldots \ldots \ldots \ldots \ldots \ldots \ldots \ldots \ldots \ldots \ldots$ FDI-RM-7

2.1 General $\ldots \ldots \ldots \ldots \ldots \ldots \ldots \ldots \ldots \ldots \ldots \ldots \ldots \ldots$ FDI-RM-7

2.2 Low Pressure Melt Ejection (LPME) Modeling . . . . . . . . . F FDI-RM-7

2.3 High Pressure Melt Ejection (HPME) Modeling . . . . . . . . F FDI-RM-11

3. DISCUSSION AND DEVELOPMENT PLANS $\ldots \ldots \ldots \ldots \ldots \ldots$ FDI-RM-21

4. REFERENCES $\ldots \ldots \ldots \ldots \ldots \ldots \ldots \ldots \ldots \ldots \ldots \ldots \ldots \ldots \ldots \ldots$ FDI-RM-23

APPENDIX A: SENSITIVITY COEFFICIENTS $\ldots \ldots \ldots \ldots \ldots \ldots$ FDI-RM-25

Heat Structure (HS) Package Reference Manual . . . . . . . . . . . . HS-RM-1

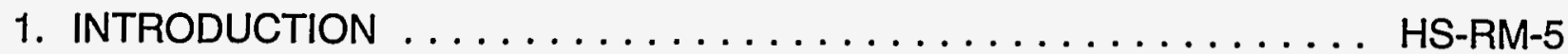

2. DETAILED MODELS $\ldots \ldots \ldots \ldots \ldots \ldots \ldots \ldots \ldots$ HS-RM-11

2.1 Finite-Difference Equations for Interior . . . . . . . . . . . HS-RM-12

2.1.1 Nodalization at Interior Temperature Nodes . . . . . . . . HS-RM-12

2.1.2 Difference Approximation at Interior Nodes . . . . . . . HS-RM-16

2.1.3 Finite-Difference Equations at Interior Temperature

Nodes . . . . . . . . . . . . . . . . . . . . . . HS-RM-17

2.2 Finite-Difference Equations at Boundary Surfaces . . . . . . . . HS-RM-17

2.2.1 Boundary Condition Coefficients . . . . . . . . . . HS-RM-19

2.2.1.1 Symmetry (Adiabatic) . . . . . . . . . . . . . HS-RM-19

2.2.1.2 Convective (Calculated or Specified Heat Transfer

Coefficients) $\ldots \ldots \ldots \ldots \ldots \ldots \ldots$ HS-RM-19 
MELCOR 1.8.3 Reference Manuals Contents

2.2.1.3 Specified Surface Heat Flux . . . . . . . . . . HS-RM-20

2.2.1.4 Specified Surface Temperature . . . . . . . . . HS-RM-20

2.2.2 Nodalization at Boundary Temperature Nodes . . . . . HS-RM-20

2.2.3 Difference Approximation at Boundary Nodes .... . . HS-RM-24

2.2.3.1 Finite-Difference Equation at Left (Inside)

Boundary

HS-RM-24

2.2.3.2 Finite-Difference Equation at Right (Outside)

Boundary

HS-RM-27

HS-RM-27

HS-RM-27

HS-RM-28

2.3.1 Internal Power Sources

HS-RM-28

2.3.3 Energy Transferred by Other Packages . . . . . . . . .

2.4 Pool Fractions

HS-RM-29

2.4.1 Rectangular Geometry . . . . . . . . . . . .

2.4.2 Cylindrical Geometry

HS-RM-31

HS-RM-31

2.4.3 Spherical Geometry . . . . . . . . . . . . . . . . . .

2.4.4 Hemispherical Geometry . . . . . . . . . . . .

2.5 Thermal Properties

HS-RM-33

HS-RM-33

HS-RM-33

2.5.1 Thermal Conductivity and Volumetric Heat Capacity . .

2.5.2 Modifications for Degassible Materials . . . . . . . . . .

2.6 Heat Transfer

HS-RM-33

HS-RM-33

HS-RM-34

2.6.1 Atmosphere Convection Heat Transfer

2.6.1.1 Conduction/convection through Liquid Films

(film-tracking inactive)

HS-RM-37

HS-RM-41

2.6.1.2 Conduction/convection through Liquid Films

(film-tracking active) .

2.6.2 Atmosphere Radiation Heat Transfer

2.6.3 Pool Convection Heat Transfer . . . . . . . . . . . . . . .

2.6.4 Pool Boiling Heat Transfer . . . . . . . . . . . . . . .

2.6.4.1 Nucleate Boiling ...............

2.6.4.2 Critical Heat Flux ...............

2.6.4.3 Minimum Film Boiling Heat Flux . . . . . . .

2.6.4.4 Stable Film Boiling ...............

2.6.4.5 Transition Boiling .................

2.6.4.6 Radiation During Boiling ............

2.6.5 Energy Transfer to Control Volumes . . . . . . . . HS-RM-53

2.7 Mass Transfer . . . . . . . . . . . . . . . . . . . . . . . HS-RM-54

2.7.1 Sherwood Number for Diffusion Mass Transfer . . . . HS-RM-55

2.7.2 Condensation and Evaporation with Noncondensibles HS-RM-56

2.7.3 Mass-Energy Transfer to Control Volumes . . . . . . . . HS-RM-57

2.8 Liquid Film Modeling . . . . . . . . . . . . . . . .

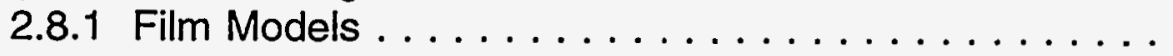

2.8.2 Film-Tracking Model . . . . . . . . . . . . .

HS-RM-59

HS-RM-59

HS-RM-60

2.9 Stored Energy of a Heat Structure

HS-RM-61 
MELCOR 1.8.3 Reference Manuals Contents

2.10 Degassing Model

HS-RM-63

2.11 Ice Condenser Model

HS-RM-64

2.12 Steel Melt Model

HS-RM-65

2.13 Communication with Other Packages

HS-RM-65

3. SOLUTION METHODS

HS-RM-67

3.1 Iteration Strategy

HS-RM-67

3.2 Steady-state Convergence Criteria

HS-RM-69

3.3 Transient Convergence Criteria

HS-RM-70

3.4 CVH Heat Transfer Damping .

HS-RM-71

4. TIME-STEP CONTROL

HS-RM-75

5. REFERENCES

HS-RM-77

APPENDIX A: Sensitivity Coefficients

HS-RM-79

Material Properties (MP) Package Reference Manual

MP-RM-1

1. DEFAULT MATERIAL PROPERTIES

MP-RM-7

2. SPECIFIC ENTHALPY AS A FUNCTION OF TEMPERATURE

MP-RM-11

2.1 Zircaloy

MP-RM-12

2.2 Zirconium Oxide

MP-RM-12

2.3 Uranium Dioxide

MP-RM-13

2.4 Stainless Steel

MP-RM-14

2.5 Stainless Steel Oxide

MP-RM-15

2.6 Boron Carbide

MP-RM-15

2.7 Silver-Indium-Cadmium

MP-RM-16

2.8 Uranium Metal

MP-RM-16

2.9 Graphite

MP-RM-17

2.10 Aluminum

MP-RM-17

2.12 Cadmium

MP-RM-18

2.13 Stainless Steel 304

MP-RM-19

2.14 Lithium Aluminum

MP-RM-20

2.15 Uranium Aluminum

MP-RM-21

3. TEMPERATURE AS A FUNCTION OF SPECIFIC ENTHALPY $\ldots .$. MP-RM-23

4. SPECIFIC HEAT CAPACITY AS A FUNCTION OF TEMPERATURE . MP-RM-25

4.1 Zircaloy

MP-RM-25

4.2 Zirconium Oxide

MP-RM-26

4.3 Uranium Dioxide

MP-RM-26 
MELCOR 1.8.3 Reference Manuals Contents

4.4 Stainless Steel $\ldots \ldots \ldots \ldots \ldots \ldots \ldots \ldots \ldots \ldots \ldots$ MP-RM-27

4.5 Stainless Steel Oxide $\ldots \ldots \ldots \ldots \ldots \ldots \ldots \ldots \ldots \ldots$ MP-RM-27

4.6 Boron Carbide . . . . . . . . . . . . . . . . . . . MP-RM-27

4.7 Silver-Indium-Cadmium $\ldots \ldots \ldots \ldots \ldots \ldots \ldots \ldots \ldots$ MP-RM-28

4.8 Uranium Metal $\ldots \ldots \ldots \ldots \ldots \ldots \ldots \ldots \ldots \ldots \ldots \ldots \ldots \ldots \ldots$ MP-RM-28

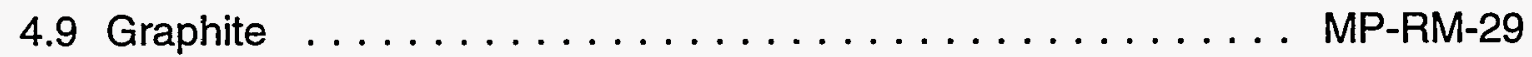

4.10 Concrete $\ldots \ldots \ldots \ldots \ldots \ldots \ldots \ldots \ldots \ldots \ldots$ MP-RM-29

4.11 Aluminum $\ldots \ldots \ldots \ldots \ldots \ldots \ldots \ldots \ldots \ldots \ldots \ldots \ldots \ldots \ldots$ MP-RM-30

4.12 Aluminum Oxide $\ldots \ldots \ldots \ldots \ldots \ldots \ldots \ldots \ldots$ MP-RM-31

4.13 Cadmium $\ldots \ldots \ldots \ldots \ldots \ldots \ldots \ldots \ldots \ldots \ldots \ldots \ldots \ldots \ldots$ MP-RM-31

4.14 Stainless Steel $304 \ldots \ldots \ldots \ldots \ldots \ldots \ldots \ldots \ldots \ldots$ MP-RM-32

4.15 Lithium Aluminum $\ldots \ldots \ldots \ldots \ldots \ldots \ldots \ldots$ MP-RM-33

4.16 Uranium Aluminum $\ldots \ldots \ldots \ldots \ldots \ldots \ldots \ldots$ MP-RM-34

5. THERMAL CONDUCTIVITY AS A FUNCTION OF TEMPERATURE . MP-RM-35

5.1 Tabular . .............................

5.1 .1 Water $\ldots \ldots \ldots \ldots \ldots \ldots \ldots \ldots \ldots \ldots \ldots \ldots \ldots \ldots$ MP-RM-36

5.1 .2 Steam $\ldots \ldots \ldots \ldots \ldots \ldots \ldots \ldots \ldots \ldots$ MP-RM-37

5.1 .3 Air $\ldots \ldots \ldots \ldots \ldots \ldots \ldots \ldots \ldots \ldots \ldots \ldots$ MP-RM-38

5.1 .4 Zircaloy $\ldots \ldots \ldots \ldots \ldots \ldots \ldots \ldots \ldots \ldots$ MP-RM-40

5.1 .5 Zirconium Oxide ................. MP-RM-40

5.1.6 Uranium Dioxide ... . . . . . . . . . . . . MP-RM-41

5.1 .7 Stainless Steel (SS) $\ldots \ldots \ldots \ldots \ldots \ldots \ldots$ MP-RM-41

5.1 .8 Stainless Steel Oxide $\ldots \ldots \ldots \ldots \ldots \ldots \ldots \ldots$ MP-RM-42

5.1 .9 Boron Carbide $\ldots \ldots \ldots \ldots \ldots \ldots \ldots \ldots$ MP-RM-42

5.1.10 Silver-Indium-Cadmium . . . . . . . . . . . . MP-RM-42

5.1 .11 Uranium Metal $\ldots \ldots \ldots \ldots \ldots \ldots \ldots$ MP-RM-43

5.1 .12 Graphite $\ldots \ldots \ldots \ldots \ldots \ldots \ldots \ldots \ldots$ MP-RM-44

5.1 .13 Concrete $\ldots \ldots \ldots \ldots \ldots \ldots \ldots \ldots \ldots$ MP-RM-44

5.1 .14 Aluminum $\ldots \ldots \ldots \ldots \ldots \ldots \ldots \ldots$. . . . . . . . . . . . .

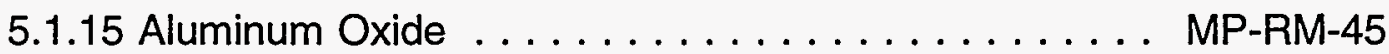

5.1 .16 Cadmium . ................... MP-RM-46

5.1.17 Stainless Steel $304 \quad \ldots \ldots \ldots \ldots \ldots \ldots \ldots$. . . . . . . . . . . . .

5.1.18 Lithium Aluminum $\ldots \ldots \ldots \ldots \ldots \ldots$. . . . . . . . . . . .

5.1.19 Uranium Aluminum . . . . . . . . . . . . . MP-RM-49

5.2 Eucken Correlation for a Single, Pure Gas ............ MP-RM-50

5.3 Wassijewa Equation for a Combination of Low Pressure Gases MP-RM-51

6. DYNAMIC VISCOSITY AS A FUNCTION OF TEMPERATURE $\ldots .$. MP-RM-53

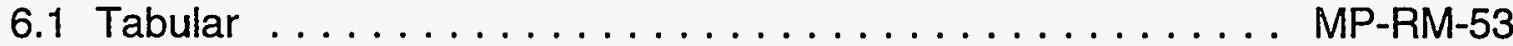

6.1 .1 Water $\ldots \ldots \ldots \ldots \ldots \ldots \ldots \ldots \ldots \ldots$ MP-RM-54

6.1 .2 Steam $\ldots \ldots \ldots \ldots \ldots \ldots \ldots \ldots \ldots \ldots$ MP-RM-55

6.1 .3 Air $\ldots \ldots \ldots \ldots \ldots \ldots \ldots \ldots \ldots \ldots$ MP-RM-56

6.1 .4 Hydrogen $\ldots \ldots \ldots \ldots \ldots \ldots \ldots \ldots \ldots$ MP-RM-56 
MELCOR 1.8.3 Reference Manuals Contents

6.1.5 Deuterium

MP-RM-57

6.2 Chapman-Enskog Equation for a Single, Pure Gas . . . . . . MP-RM-58

6.3 Chapman-Enskog Equation for a Combination of Low Pressure Gases

MP-RM-60

7. BINARY MASS DIFFUSION COEFFICIENT $\ldots \ldots \ldots \ldots \ldots \ldots$ MP-RM-61

7.1 Binary Mass Diffusion Coefficient as a Function of Temperature and

Pressure ...................... MP-RM-61

7.2 Chapman-Enskog Equation for a Pair of Low Pressure Gases MP-RM-62

7.3 Chapman-Enskog Equation for a Combination of Low Pressure Gases

MP-RM-64

8. DENSITY

MP-RM-65

8.1 Constant Density . . . . . . . . . . . . . . . MP-RM-65

8.2 Tabular as a Function of Temperature $\ldots \ldots \ldots \ldots \ldots$ MP-RM-66

8.2.1 Zircaloy $\ldots \ldots \ldots \ldots \ldots \ldots \ldots \ldots \ldots \ldots \ldots$ MP-RM-66

8.2.2 Zirconium Oxide $\ldots \ldots \ldots \ldots \ldots \ldots \ldots \ldots$ MP-RM-67

8.2.3 Uranium Dioxide . . . . . . . . . . . . . MP-RM-67

8.2.4 Stainless Steel . . . . . . . . . . . . . . . . MP-RM-67

8.2.5 Stainless Steel Oxide $\ldots \ldots \ldots \ldots \ldots \ldots \ldots \ldots$ MP-RM-67

8.2.6 Boron Carbide . . . . . . . . . . . . . . . MP-RM-68

8.2.7 Silver-Indium-Cadmium . . . . . . . . . . . MP-RM-68

8.2.8 Uranium Metal $\ldots \ldots \ldots \ldots \ldots \ldots \ldots \ldots$ MP-RM-69

8.2 .9 Graphite $\ldots \ldots \ldots \ldots \ldots \ldots \ldots \ldots \ldots \ldots$ MP-RM-69

8.2.10 Concrete $\ldots \ldots \ldots \ldots \ldots \ldots \ldots \ldots \ldots \ldots$ MP-RM-69

8.2.11 Aluminum $\ldots \ldots \ldots \ldots \ldots \ldots \ldots \ldots$ MP-RM-70

8.2.12 Aluminum Oxide $\ldots \ldots \ldots \ldots \ldots \ldots \ldots \ldots$ MP-RM-70

8.2.13 Cadmium ................... MP-RM-71

8.2.14 Stainless Steel $304 \ldots \ldots \ldots \ldots \ldots \ldots$. . . . . . . . . . . .

8.2.15 Lithium Aluminum $\ldots \ldots \ldots \ldots \ldots \ldots \ldots$ MP-RM-73

8.2.16 Uranium Aluminum . . . . . . . . . . . . . MP-RM-73

8.3 Calculated as a Function of Temperature and Pressure .... MP-RM-74

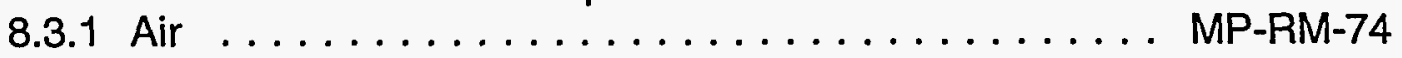

8.3.2 Steam $\ldots \ldots \ldots \ldots \ldots \ldots \ldots \ldots \ldots \ldots \ldots \ldots$ MP-RM-74

9. CONSTANT MELTING TEMPERATURE $\ldots \ldots \ldots \ldots \ldots \ldots$ MP-RM-79

10. CONSTANT LATENT HEAT OF FUSION $\ldots \ldots \ldots \ldots \ldots \ldots$ MP-RM-81

11. REFERENCES $\ldots \ldots \ldots \ldots \ldots \ldots \ldots \ldots \ldots \ldots \ldots \ldots \ldots$ MP-RM-83 
MELCOR 1.8.3 Reference Manuals Contents

NonCondensible Gas (NCG) and Water (H2O) Packages

Reference Manual

NCG/H2O-RM-1

1. NCG EQUATION OF STATE

NCG/H2O-RM-5

1.1 Integration Constants in the Energy Function

NCG/H2O-RM-6

2. H2O EQUATION OF STATE

NCG/H2O-RM-9

2.1 Single-Phase Properties

NCG/H2O-RM-9

2.2 Mixed-Phase Properties

NCG/H2O-RM-9

3. NCG LIBRARY

NCG/H2O-RM-11

Hydrogen

NCG/H2O-RM-11

Deuterium

NCG/H2O-RM-11

Helium

NCG/H2O-RM-12

Nitrogen

NCG/H2O-RM-12

Oxygen

NCG/H2O-RM-12

Argon

NCG/H2O-RM-13

Methane

$\mathrm{NCG} / \mathrm{H} 2 \mathrm{O}-\mathrm{RM}-13$

Carbon Monoxide

NCG/H2O-RM-13

Carbon Dioxide

NCG/H2O-RM-14

Acetylene

NCG/H2O-RM-14

Ethylene

NCG/H2O-RM-14

Ammonia

NCG/H2O-RM-15

Nitrogen Monoxide

NCG/H2O-RM-15

Nitrous Oxide

NCG/H2O-RM-15

User Defined Gases

NCG/H2O-RM-16

4. REFERENCES

NCG/H2O-RM-17

RadioNuclide (RN) Package Reference Manual

RN-RM-1

1. INTRODUCTION

RN-RM-7

2. DETAILED MODELS $\ldots \ldots \ldots \ldots \ldots \ldots \ldots \ldots \ldots \ldots$ RN-RM-11

2.1 General $\ldots \ldots \ldots \ldots \ldots \ldots \ldots \ldots \ldots \ldots \ldots$ RN-RM-11

2.2 Initial Radionuclide Inventories $\ldots \ldots \ldots \ldots \ldots \ldots \ldots \ldots$ RN-RM-14

2.3 Release of Radionuclides $\ldots \ldots \ldots \ldots \ldots \ldots \ldots \ldots$ RN-RM-17

2.3.1 Core Release . . . . . . . . . . . . . . . RN-RM-18

2.3.1.1 CORSOR

RN-RM-20

2.3.1.2 CORSOR-M

RN-RM-20

2.3.1.3 CORSOR-Booth

RN-RM-20

2.3.1.4 Surface-to-Volume Ratio

RN-RM-23

2.3.1.5 Class Combination at Release

RN-RM-23 
MELCOR 1.8.3 Reference Manuals Contents

2.3.2 Fuel-Cladding Gap . . . . . . . . . . . . . . . RN-RM-24

2.3.3 Cavity Release $\ldots \ldots \ldots \ldots \ldots \ldots \ldots \ldots \ldots \ldots$. RN-RM-24

2.4 Aerosol Dynamics $\ldots \ldots \ldots \ldots \ldots \ldots \ldots \ldots \ldots \ldots \ldots$ RN-RM-25

2.4.1 Aerosol Mass and Size Distributions . . . . . . . . RN-RM-28

2.4.2 MAEROS Equations . . . . . . . . . . . . . . RN-RM-30

2.4.2.1 Agglomeration . . . . . . . . . . . . . RN-RM-34

2.4.2.2 Deposition, Settling, and Fallout . . . . . . . RN-RM-36

2.4.2.3 Numerical Implementation . . . . . . . . . . RN-RM-43

2.4 .3 Sources $\ldots \ldots \ldots \ldots \ldots \ldots \ldots \ldots \ldots \ldots \ldots$ RN-RM-46

2.4.4 Resuspension .................. RN-RM-47

2.5 Condensation/Evaporation $\ldots \ldots \ldots \ldots \ldots \ldots \ldots \ldots$ RN-RM-47

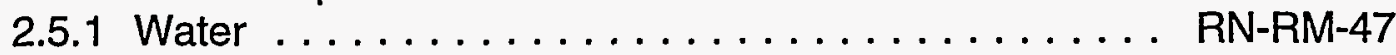

2.5.2 Fission Product Vapors $\ldots \ldots \ldots \ldots \ldots \ldots \ldots$ RN-RM-51

2.6 Decay Heat Distribution $\ldots \ldots \ldots \ldots \ldots \ldots \ldots \ldots \ldots$ RN-RM-55

2.7 ESF Models . . . . . . . . . . . . . . . . . . . . . . . RN-RM-57

2.7.1 Pool Scrubbing . . . . . . . . . . . . . . RN-RM-57

2.7.1.1 Pool Entrance Region . . . . . . . . . . RN-RM-58

2.7.1.2 Bubble Rise Region . . . . . . . . . . . . RN-RM-58

2.7.2 Filters $\ldots \ldots \ldots \ldots \ldots \ldots \ldots \ldots \ldots \ldots \ldots$ RN-RM-61

2.7.3 Sprays $\ldots \ldots \ldots \ldots \ldots \ldots \ldots \ldots \ldots \ldots \ldots$ RN-RM-62

2.8 Fission Product Chemistry $\ldots \ldots \ldots \ldots \ldots \ldots \ldots \ldots \ldots$ RN-RM-66

2.8.1 Class Reactions . . . . . . . . . . . . . . . RN-RM-67

2.8.2 Class Transfers $\ldots \ldots \ldots \ldots \ldots \ldots \ldots \ldots \ldots \ldots$ RN-RM-68

2.8.3 Example $\ldots \ldots \ldots \ldots \ldots \ldots \ldots \ldots \ldots \ldots \ldots$ RN-RM-68

3. DISCUSSION AND DEVELOPMENT PLANS . . . . . . . . RN-RM-71

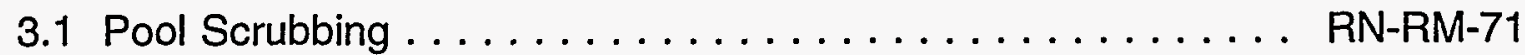

3.2 RCS Deposition ........................ RN-RM-71

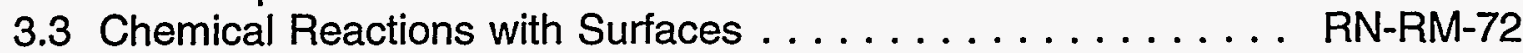

3.4 Aqueous Chemistry $\ldots \ldots \ldots \ldots \ldots \ldots \ldots \ldots \ldots$ RN-RM-72

3.5 Removal by ESFs $\ldots \ldots \ldots \ldots \ldots \ldots \ldots \ldots \ldots \ldots$ RN-RM-72

4. REFERENCES $\ldots \ldots \ldots \ldots \ldots \ldots \ldots \ldots \ldots \ldots \ldots \ldots \ldots \ldots$ RN-RM-73

APPENDIX A: RN Package Sensitivity Coefficients $\ldots \ldots \ldots \ldots \ldots$ RN-RM-77

APPENDIX B: Agglomeration Kernels $\ldots \ldots \ldots \ldots \ldots \ldots \ldots \ldots$ RN-RM-87

APPENDIX C: Aerosol Surface Area $\ldots \ldots \ldots \ldots \ldots \ldots \ldots \ldots$ RN-RM-91

APPENDIX D: Pool Scrubbing Deposition Velocities ........... RN-RM-93 
MELCOR 1.8.3 Reference Manuals Contents

Containment Sprays (SPR) Package Reference Manual $\ldots . . . .$. SPR-RM-1

1. INTRODUCTION $\ldots \ldots \ldots \ldots \ldots \ldots \ldots \ldots \ldots \ldots \ldots$ SPR-RM-5

2. MODEL DESCRIPTION $\ldots \ldots \ldots \ldots \ldots \ldots \ldots \ldots \ldots$ SPR-RM-7

3. REFERENCES $\ldots \ldots \ldots \ldots \ldots \ldots \ldots \ldots \ldots \ldots \ldots$ SPR-RM-11 
MELCOR 1.8.3 Reference Manuals Contents

\section{List of Figures}

\section{BWR Lower Plenum Debris Bed (BH) Package Reference Manual}

1.1 BWR reactor vessel internal components $\ldots \ldots \ldots \ldots \ldots \ldots$ BH-RM-12

1.2 Arrangement of BWR core, core plate, control rod guide tubes, and supporting components ................... BH-RM-12

1.3 Mechanical arrangement of one of the 43 local power range detector assemblies ........................ BH-RM-13

1.4 Mechanical arrangement of one of the four source range and eight intermediate range detector assemblies $\ldots \ldots \ldots \ldots \ldots \ldots . . .6 \mathrm{BH}-\mathrm{RM}-13$

1.5 Control rod guide tube spacing and available open flow area in the BWR reactor vessel lower plenum $\ldots \ldots \ldots \ldots \ldots \ldots \ldots$ BH-RM-14

1.6 Description of models and illustration of control volumes employed BH-RM-14

1.7 The BWR reactor vessel bottom head $\ldots \ldots \ldots \ldots \ldots \ldots \ldots$ BH-RM-15

1.8 The BWR control rod drive mechanism assemblies and in-core instrument tubes ............................ BH-RM-15

1.9 A to-scale representation of the control volume arrangement for a wholecore debris bed . . . . . . . . . . . . . . . . . . BH-R-18

1.10 Nodalization of the reactor vessel bottom head wall . . . . . . . BH-RM-28

1.11 Each vessel bottom head wall node divided into three radial segmentsBH-RM-29

1.12 The baffle plate and lower core shroud separate the downcomer region from the reactor vessel lower plenum . . . . . . . . . . BH-RM-30

2.1 Material densities considered in calculation of debris bed control volume

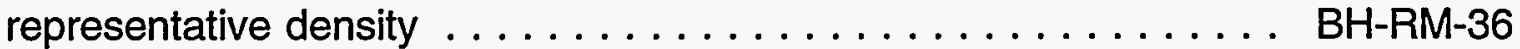

2.2 Material specific heats considered in calculation of debris bed control volume mass-averaged specific heat $\ldots \ldots \ldots \ldots \ldots \ldots \ldots$ BH-RM-39

2.3 Material thermal conductivities considered in calculation of debris bed control volume mass-averaged thermal conductivity . . . . . . . BH-RM-45 
MELCOR 1.8.3 Reference Manuals Contents

3.1 Arrangement of BWR reactor vessel lower plenum structures . . . . BH-RM-59

3.2 Typical lower plenum structure indices $\ldots \ldots \ldots \ldots \ldots \ldots$ BH-RM-66

6.1 Initial configuration of the lower plenum debris bed and the initial bottom head wall temperatures $\ldots \ldots \ldots \ldots \ldots \ldots \ldots$ BH-RM-108

6.2 Lower plenum debris bed and vessel wall response for the example calculation at the time that debris layer three is established .... BH-RM-111

6.3 Lower plenum debris bed and vessel wall response at time 196 minutes after scram . . . . . . . . . . . . . . . . . . BH-RM-115

6.4 The calculated situation just before bottom head creep rupture for the case without penetration failures $\ldots \ldots \ldots \ldots \ldots \ldots$ BH-RM-117

6.5 Results for a case with penetration failures $\ldots \ldots \ldots \ldots \ldots$ BH-RM-118

11.1 Energy transfers considered in the energy balance for the BWR vessel bottom head wall . . . . . . . . . . . . . . . . BH-RM-210

A.1 The noncondensable gas mole fraction decreases rapidly when steam is released directly into the drywell atmosphere during the final stage of an SBWR reactor vessel depressurization $\ldots \ldots \ldots \ldots \ldots \ldots$ BH-RM-240

A.2 The drywell-to-wetwell pressure differential delpre and the differential pressure reqpre at which flow through the PCCS vent line is initiatedBH-RM-241

A.3 The available PCCS heat exchanger capacity is primarily determined by the drywell noncondensable gas mole fraction . . . . . . . . BH-RM-241

A.4 The available PCCS (three-unit) heat exchanger capacity and the power e2adic actually utilized $\ldots \ldots \ldots \ldots \ldots \ldots \ldots \ldots \ldots$ BH-RM-242

A.5 The total mass flow pltifl through the PCCS vent line and the associated flow pltnfl of noncondensable gases . . . . . . . . . . . . . BH-RM-242

\section{Cavity (CAV) Package Reference Manual}

1. Cavity System Components $\ldots \ldots \ldots \ldots \ldots \ldots \ldots \ldots$ CAV-RM-12 . . . . . .

2. Position and Motion of Body Points $\ldots \ldots \ldots \ldots \ldots \ldots \ldots$ CAV-RM-19 
MELCOR 1.8.3 Reference Manuals Contents

Core (COR) Package Reference Manual

1.1.1 Core/lower plenum nodalization $\ldots \ldots \ldots \ldots \ldots \ldots \ldots$ COR-RM-9

1.1.2 Core cell components . . . . . . . . . . . . . . . . COR-RM-10

1.1.3 Typical COR-CVH nodalization interface (2D) $\ldots \ldots \ldots \ldots \ldots$ COR-RM-12

1.1.4 Typical COR-CVH nodalization interface (3D) $\ldots \ldots \ldots \ldots \ldots$ COR-RM-13

1.1.5 Lower head nodalization (one ring) $\ldots \ldots \ldots \ldots \ldots \ldots \ldots$ COR-RM-15

2.1.1 Radiative heat transfer framework-BWR cell cross-section . . . . COR-RM-22

2.1.2 Radiation model logic flow chart $\ldots \ldots \ldots \ldots \ldots \ldots \ldots$ COR-RM-24

2.2.1 Component axial temperature gradient across liquid level . . . . . COR-RM-27

2.7.1 Two-phase construction for material mixture $\ldots \ldots \ldots \ldots \ldots$ COR-RM-53

3.1.1 Candling process steps $\ldots \ldots \ldots \ldots \ldots \ldots \ldots \ldots \ldots$ COR-RM-60

3.1.2 Flow blockage formation during candling $\ldots \ldots \ldots \ldots \ldots \ldots$ COR-RM-62

3.1.3 Conglomerate debris geometry in fuel rod bundles . . . . . . . . COR-RM-65

3.4.1 Cell volumes $\ldots \ldots \ldots \ldots \ldots \ldots \ldots \ldots \ldots \ldots \ldots \ldots$ COR-RM-72

4.1.1 Lower head nodalization $\ldots \ldots \ldots \ldots \ldots \ldots \ldots \ldots \ldots$ COR-RM-76

Control Volume Hydrodynamics (CVH) Package Reference Manual

2.1.1 Relation of Spatial Volume to Volume/Altitude Table ..... CVH/FL-RM-11

2.1.2 Virtual Volume and Associated Volume/Altitude Tables .... CVH/FL-RM-12

2.2.1 Control Volume Contents and Pool Surface $\ldots \ldots \ldots \ldots$ CVH/FL-RM-14

3.2.1 Junction Geometry $\ldots \ldots \ldots \ldots \ldots \ldots \ldots \ldots \ldots \ldots \ldots$ CVH/FL-RM-18

3.2.2 Relationship among Junction Opening, Pool Surface Elevation, and Void Fraction ........................ CVH/FL-RM-19 
MELCOR 1.8.3 Reference Manuals Contents

3.2.3 Multiple Flow Paths Connecting Two Volumes, to Model Natural Circulation ...........................

4.3.1 Solution of Hydrodynamics Equations $\ldots \ldots \ldots \ldots \ldots \ldots$ CVH/FL-RM-34

4.3.2 Linearization of Pressure vs Mass $\ldots \ldots \ldots \ldots \ldots \ldots$ CVH/FL-RM-37

5.3.1 Elevations Involved in Gravitational Head Terms . . . . . . . . CVH/FL-RM-54

5.6.1 Fan Model Operating Characteristics $\ldots \ldots \ldots \ldots \ldots \ldots$ CVH/FL-RM-61

B.1 Drift Flux Lines and the Flooding Curve $\ldots \ldots \ldots \ldots \ldots$ CVH/FL-RM-80

C.1 Moody Critical Flow Data and Approximate Fit $\ldots \ldots \ldots$ CVH/FL-RM-84

RadioNuclide (RN) Package Reference Manual

2.4.1 MAEROS Aerosol Model $\ldots \ldots \ldots \ldots \ldots \ldots \ldots \ldots \ldots$ RN-RM-27

D-1. Bubble Geometry $\ldots \ldots \ldots \ldots \ldots \ldots \ldots \ldots \ldots \ldots$ RN-RM-94 
MELCOR 1.8.3 Reference Manuals Contents

\section{List of Tables}

Core (COR) Package Reference Manual

2.1.1 Steam emissivity vs. temperature and optical depth . . . . . . COR-RM-21

2.7.1 Core eutectic reactions $\ldots \ldots \ldots \ldots \ldots \ldots \ldots \ldots \ldots$ COR-RM-52

2.7.2 Solid dissolution hierarchy $\ldots \ldots \ldots \ldots \ldots \ldots \ldots \ldots \ldots \ldots$ COR-RM-55

3.1.1 Primary and alternate refreezing components $\ldots \ldots \ldots \ldots \ldots$ COR-RM-61

Decay Heat (DCH) Package Reference Manual

1. Default Radionuclide Classes $\ldots \ldots \ldots \ldots \ldots \ldots \ldots \ldots$ DCH-RM-10

2. Tabular Values from ANS Standard Used in MELCOR . . . . . . . DCH-RM-12

3. DCH Package Input Variables for ANS Decay Heat Power . . . . . . DCH-RM-17

RadioNuclide (RN) Package Reference Manual

2.1.1 RN Class Compositions . . . . . . . . . . . . . . RN-RM-12

2.1.2 COR Material to RN Class Mapping $\ldots \ldots \ldots \ldots \ldots \ldots \ldots$ RN-RM-13

2.1.3 RN Class to VANESA Species Mapping $\ldots \ldots \ldots \ldots \ldots \ldots$ RN-RM-14

2.1.4 VANESA Species to RN Class Mapping $\ldots \ldots \ldots \ldots \ldots \ldots$ RN-RM-15 



\section{Acknowledgment}

The current authors wish to acknowledge the many contributors to the project over the years. In addition to those already listed as authors or contributors to various package users' guides and reference manuals, many others have participated in phenomenological reviews, code assessment analyses, and project/program management and support activities. In particular, we would like to mention Dave Aldrich, Sud Basu (NRC), Larry Buxton, Rupe Byers, Mark Cunningham (NRC), Arnold Elsbernd, Ron Foulds (NRC), Sherrell Greene (ORNL), Eric Haskin, John Kelly, Luba Kmetyk, Randy Longenbaugh, Gale Martinez, Larry Ott (ORNL), Dana Powers, Jeremy Sprung, Tim Tautges, and Gil Weigand. The list could go on, and the success of MELCOR is attributable to the quality efforts of all those involved.

\section{Dedication}

This report is dedicated to the memory of Dr. Samuel L. Thompson. Sam was twice the manager of the department at Sandia in which the MELCOR code was developed. The first period, from 1982 to 1984, saw the definition of the code architecture, development of the foundational models, and release of the first working versions of MELCOR. The second period, from 1990 to 1994, culminated in the writing of this document and the release of MELCOR 1.8.3.

Sam was far more than a manager to the MELCOR project and its staff. From his broad experience as a prominent researcher and innovator in computational analysis, Sam brought to the MELCOR project a high degree of professionalism and technical excellence. In addition, he was-far more than most managers-an important individual technical contributor, focusing on developing features such as interactive interrupts and the plotting system that make the code more useful to the analyst. An important part of Sam's legacy will be the example of technical excellence, productivity, and personal integrity that he set for all who worked with him. 


\section{Executive Summary}

MELCOR is a fully integrated, engineering-level computer code that models the progression of severe accidents in light water reactor nuclear power plants. MELCOR is being developed at Sandia National Laboratories for the U. S. Nuclear Regulatory Commission as a second-generation plant risk assessment tool and the successor to the Source Term Code Package. A broad spectrum of severe accident phenomena in both boiling and pressurized water reactors is treated in MELCOR in a unified framework. Current uses of MELCOR include estimation of severe accident source terms and their sensitivities and uncertainties in a variety of applications.

MELCOR is composed of an executive driver and a number of major modules, or packages, that together model the course of a severe accident. Characteristics of severe accidents that can be treated with MELCOR include:

- the thermal-hydraulic response in the reactor coolant system, reactor cavity, containment, and confinement buildings;

- core heatup, degradation, and relocation;

- core-concrete attack;

- hydrogen production, transport, and combustion;

- fission product release, transport, and deposition; and

- the impact of engineered safety features on thermal-hydraulic and radionuclide behavior.

The various code packages have been written using a carefully designed modular structure with well-defined interfaces between them. This allows the exchange of complete and consistent information among them so that all phenomena are explicitly coupled at every time step. The structure also facilitates maintenance and upgrading of the code.

Initially, the developers and the NRC believed that relatively simple parametric models would be adequate in most areas. However, the initial assessment of phenomenology and modeling indicated that this would not be acceptable the reactor safety community. Therefore, most MELCOR models are mechanistic, with capabilities approaching those of the most detailed codes of a few years ago. The use of models that are strictly parametric is limited, in general, to areas of high phenomenological uncertainty where there is no consensus concerning an acceptable mechanistic approach.

However, the intended uses of MELCOR include uncertainty analyses and sensitivity studies. To facilitate these uses, many of the mechanistic models have been coded with optional adjustable parameters. This does not affect the mechanistic nature of the 
modeling, but it does allow the analyst to easily address questions of how particular modeling parameters affect the course of a calculated transient. Parameters of this type, as well as such numerical parameters as convergence criteria and iteration limits, are coded in MELCOR as sensitivity coefficients, which may be modified through optional code input.

Both integrated and detailed codes are provided for under the NRC's two-tier philosophy of code development. MELCOR has been developed as an integrated code, modeling a wide range of phenomena and their interactions. At the same time, the development of a set of more detailed codes, such as CONTAIN and SCDAP/RELAP5, has been continued along with MELCOR. It is the function of these detailed codes to advance the state of the art in modeling specific areas of severe accident phenomenology, while MELCOR's function is to incorporate what is learned into an integrated analysis tool that is complete, flexible, and user friendly.

MELCOR modeling is general and flexible. No specific nodalization of a system is forced on the user, which allows a choice of the degree of detail appropriate to the task at hand. Reactor-specific geometry is imposed only in modeling the reactor core. Even here, one basic model suffices for representing either a boiling water (BWR) or a pressurized water reactor (PWR) core, and a wide range of levels of modeling detail is possible.

Thus, with a relatively simple nodalization, MELCOR can function as a second-generation probabilistic risk assessment (PRA) tool. On the other hand, when a more complicated nodalization is employed, MELCOR calculations can often approach the resolution and accuracy of the more detailed codes. MELCOR should not be expected to compete with one of the detailed codes within the specific limits for which the latter was designed. However, the greater flexibility and range of phenomena modeled by MELCOR, together with the inclusion of coupling and feedback effects and a faster running time, may make it the better tool for modeling large, complicated systems.

This publication of the MELCOR computer code manuals corresponds to MELCOR version 1.8.3, released to users in August, 1994. Volume 1 contains a primer that describes MELCOR's phenomenological scope, organization (by package), and documentation. The remainder of Volume 1 contains the MELCOR Users' Guides, which provide the input instructions and guidelines for each package. Volume 2 contains the MELCOR Reference Manuals, which describe the phenomenological models that have been implemented in each package. 


\title{
BWR Lower Plenum Debris Bed (BH) Package Reference Manual
}

\author{
Engineering Technology Division \\ Oak Ridge National Laboratory \\ Oak Ridge, TN 37831-8057
}

\author{
Contributors: \\ Stephen A. Hodge \\ Clifton R. Hyman \\ Robert L. Sanders
}

The Lower Plenum Debris Bed $(\mathrm{BH})$ Package calculates the thermal response of the lower plenum debris, the heatup of the reactor vessel bottom head, and the release of core and structural materials from the reactor vessel to the drywell. Calculations are initiated for most severe accident sequences at the time of lower plenum dryout, when previously quenched materials are incorporated into a debris bed. For bottom head LOCA, calculations are initiated when (and if) sufficient debris accumulates within the lower plenum to form a debris bed. In either case, materials subsequently relocated downward from the core region (solids and liquids) are added to the upper surface of the bed. Materials released from the lower plenum via penetration failures or bottom head creep rupture are transferred to the containment drywell. Metal/water reactions within the bed due to the entrance of steam are calculated.

The basic $\mathrm{BH}$ package models were originally developed by Larry J. Ott at Oak Ridge National Laboratory (ORNL) for use with the Boiling Water Reactor Severe Accident Response (BWRSAR) Code. In this form, they have been recently applied in severe accident analyses for the Containment Performance Improvement (CPI) Program and the Mark I shell survivability study (NUREG/CR-5423), and in recent assessments of candidate accident management strategies (NUREG/CR-5869). Subsequently, these models have been modified first to operate independently and then to operate (with restart capability) while driven directly by MELCOR in an interactive mode. When exercised with MELCOR, these models constitute the working level routines of the $\mathrm{BH}$ Package.

This document provides a description of the physical models employed in the $\mathrm{BH}$ Package including several additions and modifications to the version that was released 


\section{BH Package Reference Manual}

(March 1993) with MELCOR 1.8.2. Section 1 discusses the control volume arrangement for the lower plenum debris bed and the nodalization of the bottom head wall. Section 2 describes the method of setting composition-dependent properties for the debris bed control volumes. Section 3 addresses the calculation of heat transfer and metal oxidation within the debris.

Information concerning the formation of eutectic mixtures and the relocation of molten materials within the bed is provided in Section 4 . Section 5 describes the models for failure of the bottom head penetrations or creep rupture of the vessel wall. Some examples of calculated results are discussed in Section 6.

Section 7 describes the special BH package models that have been developed for use in cases where water is introduced into the lower plenum after debris bed dryout. These models are entirely new; this capability did not exist for the version of the $\mathrm{BH}$ Package that was released with MELCOR 1.8.2.

Section 8 explains the basic organization of the $\mathrm{BH}$ Package and the arrangements for exchange of information between this Package and MELCOR. Section 9 describes the operation of the MELCOR interface subroutines and discusses currently planned modifications to improve the compatibility of the interface with the general MELCOR code structure.

Arrangements to extend applicability of the BH Package to the Simplified Boiling Water Reactor (SBWR) design are discussed in Section 10. This involves the use of several special subroutines that include proprietary information. Accordingly, none of these special routines are included with the general MELCOR releases.

The operation of the automatic mass and energy balances for the BH Package is described in Section 11.

The references cited in the text are listed in Section 12.

Some special measures must be taken in order to run MELGEN and MELCOR with the $\mathrm{BH}$ Package activated. Procedures for accomplishing this and a description of the associated user-input quantities are provided in the BH Package Users' Guide. Integration into the MELCOR architecture and timestep advancement characteristics are described in the BH Package Programmer's Guide. 


\section{Contents}

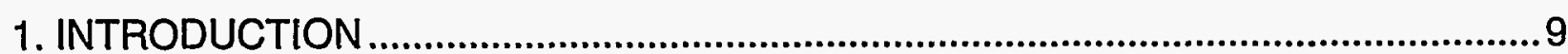

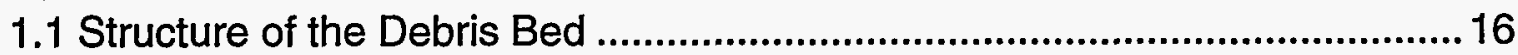

1.1.1 Arrangement of Control Volumes................................................... 19

1.1.2 Initial Setup of Layers One and Two .............................................20

1.1.3 The Special Case of Bottom Head LOCA ........................................21

1.1.4 Establishing the Third Debris Layer .................................................23

1.2 The Vessel Bottom Head Wall ..................................................................24

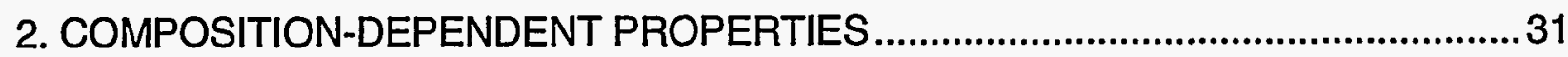

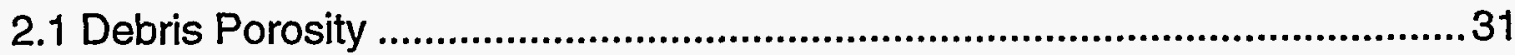

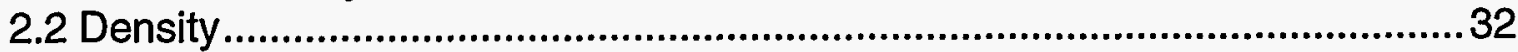

2.3 Specific Heat........................................................................................................ 33

2.4 Thermal Conductivity .................................................................................... 43

3. DEBRIS HEAT TRANSFER AND OXIDATION ….....................................................49

3.1 Heat Transfer Between Bed Control Volumes ................................................49

3.2 Heat Transfer With the Vessel Atmosphere ................................................52

3.2.1 Surface Heat Transfer Coefficients ...............................................52

3.2.2 Establishing the Debris Bed Surface Temperatures .........................56

3.2.3 Exposed Vessel Wall Nodes ............................................................57

3.3 Radiation to the Lower Plenum Structures .................................................6 60

3.3.1 Heat Transfer Coefficients for Radiation to the Vessel Wall ............60

3.3.2 Direct Radiation Exchange.................................................................62 62

3.3.3 After Downcomer Dryout...............................................................64

3.3.4 Shroud Melting and Relocation .....................................................64 64

3.4 Metal-Steam Reaction in the Debris Bed.....................................................6 67

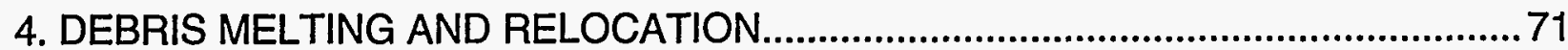

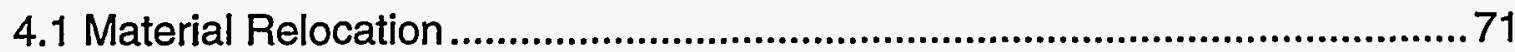

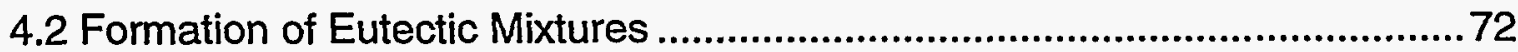

4.3 Adjustment of Control Volume Dimensions ..................................................... 83

4.4 Merging of Bed Control Volumes.....................................................................8 85

4.4.1 Merging Criteria ........................................................................... 86

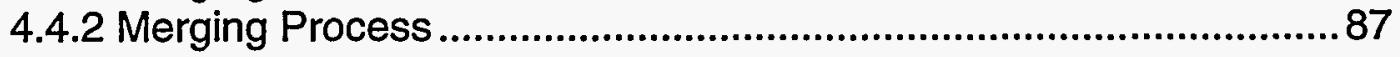

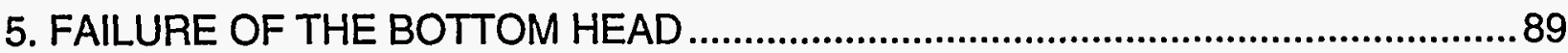

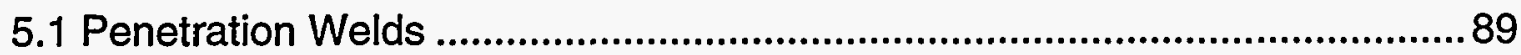

5.2 Instrument Guide Tubes ...............................................................................91

5.3 Ablation induced by flow of molten material .................................................91

5.3.1 Ablation of the Wall .........................................................................93

5.3.2 Ablation of the Bottom Debris Layer .................................................97

5.4 Creep Rupture of the Vessel Wall ................................................................. 102 
BH Package Reference Manual

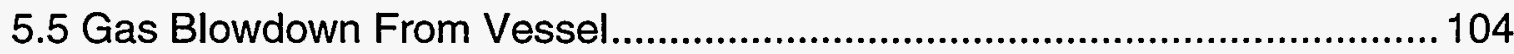

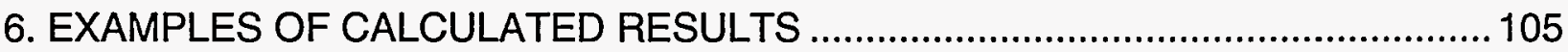

6.1 Initial Debris Bed Configuration ................................................................105

6.2 Formation of the Third Debris Layer........................................................ 109

6.3 Lower Plenum and Bottom Head Response............................................ 112

6.4 The Case With Penetration Failures.....................................................116

6.5 Tabulated Output ............................................................................. 119

6.6 Special Messages................................................................................... 124

7. MODELS FOR WATER IN THE LOWER PLENUM ............................................. 127

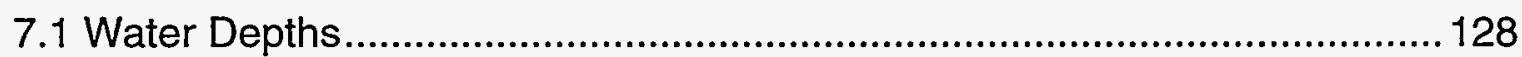

7.2 Dryout Heat Flux............................................................................. 130

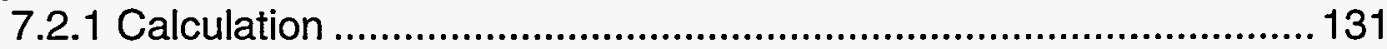

7.2.2 Application to Bed Radial Zones ............................................ 133

7.2.3 Limited Water Availability ....................................................... 137

7.2.4 Experimental Evidence for Oxidic Debris Bed Quenching .............137

7.3 Effects of Hydrogen Generation ............................................................ 139

7.3.1 Metal-Steam Reaction Rate ..................................................... 139

7.3.2 Effect on Dryout Heat Flux.......................................................... 140

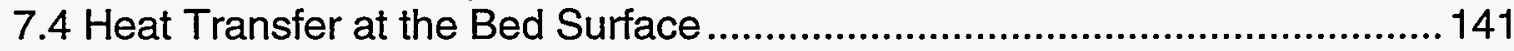

7.4.1 Critical Heat Flux................................................................ 142

7.4.2 Film Boiling Coefficient................................................................. 143

7.4.3 Nucleate Boiling Coefficient ...................................................... 144

7.5 Heat Transfer at Exposed Wall Nodes .................................................... 147

7.6 The Case of Lower Plenum Water with Penetration Failures ..................... 147

7.6.1 Water Flow............................................................................. 147

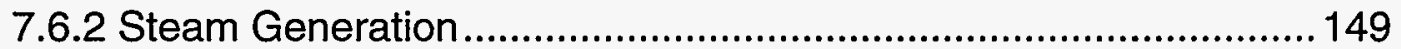

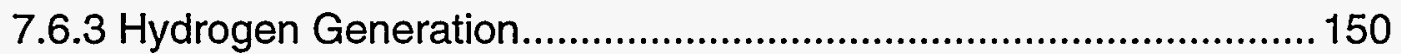

7.6.4 Exit Conditions ........................................................................ 151

7.7 Interaction of Water with Late Debris Pours ...........................................152

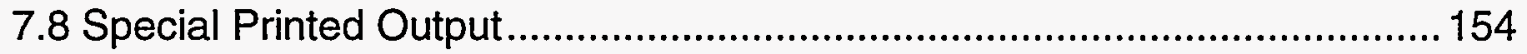

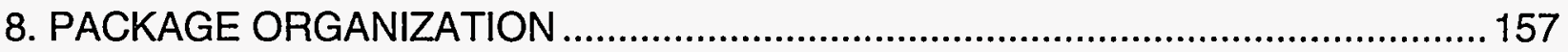

8.1 Arrangement of Subroutines and Commons ......................................... 157

8.2 Information Exchange with MELCOR ...................................................158

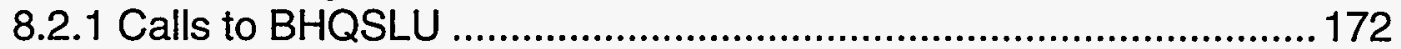

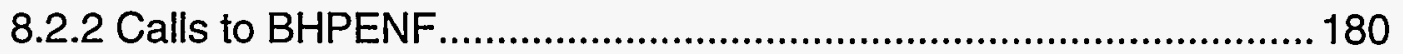

8.2.3 Special Requirements for MELCOR Input ................................ 181

8.2.4 Deactivating the BH Package ..................................................... 183

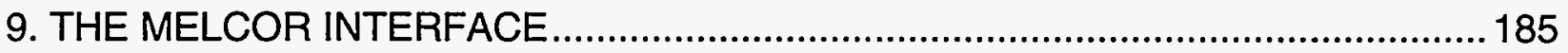

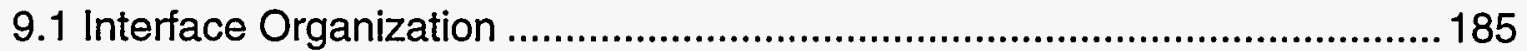

9.2 MELCOR BWR Core Shroud Modeling Enhancements ........................... 185

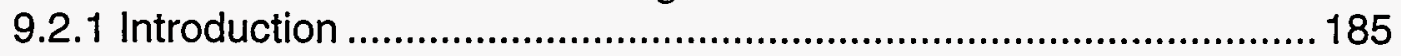

9.2.2 Shroud Model Prior to Lower Plenum Dryout............................... 186 
9.2.3 Shroud Model After Lower Plenum Dryout................................... 187

9.2.4 Shroud Model After Lower Core Shroud Failure ............................ 189

9.2.4.1 Initiation Characteristics and Model Description .............. 189

9.2.4.2 Shroud Heat and Mass Balance.................................... 194

9.2.4.3 Gross Shroud Relocations .............................................. 196

9.3 Interface Modifications for Debris Relocations from the Vessel to

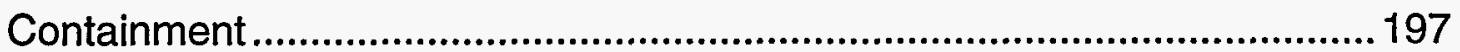

9.4 Fission Product Release from the BH Package Debris Bed ....................... 199

9.5 Future BWR MELCOR Modifications........................................................201

9.5.1 Gross Core Plate Failure Due to Combined Thermal and Stress Loading.........................................................................201

9.5.2 Models for the B4C-Steam Reaction...........................................202

9.5.3 Improved Modeling of the BWR Core .........................................202

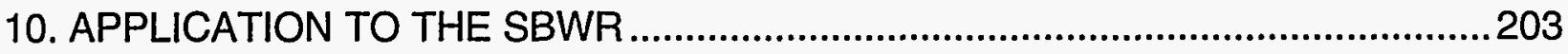

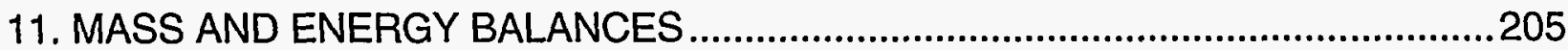

11.1 Debris Mass Balance....................................................................206

11.2 Wall Energy Balance ............................................................................207

11.3 Bed Energy Balance .............................................................................211

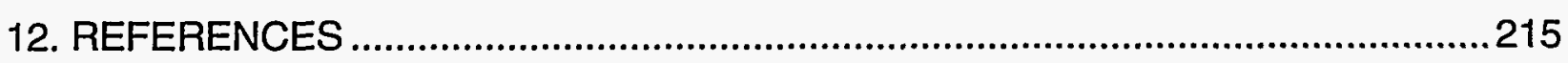

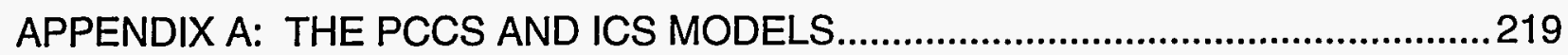

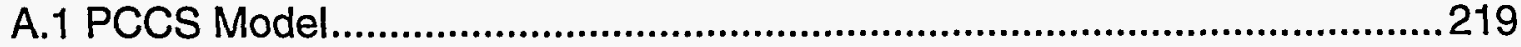

A.1.1 Introduction and Concept ......................................................219

A.1.2 General PCCS Performance ..................................................220

A.1.3 Operation of the PCCS Model ..................................................221

A.1.4 The Iterative Procedure .............................................................232

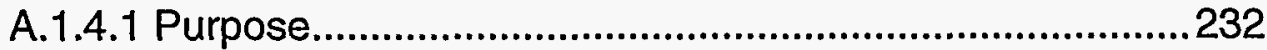

A.1.4.2 Initial Conditions............................................................232

A.1.4.3 Iterative Steps ..............................................................2232

A.1.5 Example Results......................................................................235

A.1.6 Summary of PCCS Operation.......................................................243

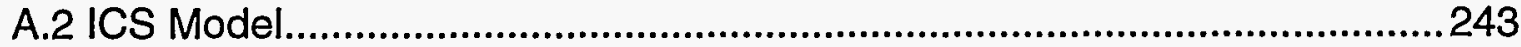

A.2.1 Introduction and Concept ..............................................................243

A.2.2 Operation of the ICS Model .........................................................244

A.2.3 Example Results......................................................................246

A.3 Interface with MELCOR.......................................................................247 


\section{List of Figures}

1.1 BWR reactor vessel internal components ............................................................12

1.2 Arrangement of BWR core, core plate, control rod guide tubes, and supporting components.........................................................................................12

1.3 Mechanical arrangement of one of the 43 local power range detector assemblies .............................................................................................................. 13

1.4 Mechanical arrangement of one of the four source range and eight intermediate range detector assemblies ............................................................. 13

1.5 Control rod guide tube spacing and available open flow area in the BWR reactor vessel lower plenum ........................................................................... 14

1.6 Description of models and illustration of control volumes employed......................14

1.7 The BWR reactor vessel bottom head .................................................................. 15

1.8 The BWR control rod drive mechanism assemblies and in-core instrument

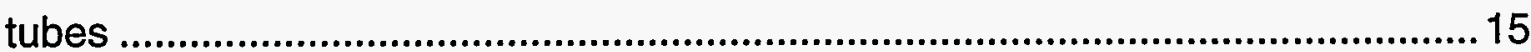

1.9 A to-scale representation of the control volume arrangement for a wholecore debris bed .................................................................................................... 18

1.10 Nodalization of the reactor vessel bottom head wall ............................................2.29

1.11 Each vessel bottom head wall node divided into three radial segments ................30

1.12 The baffle plate and lower core shroud separate the downcomer region from the reactor vessel lower plenum

2.1 Material densities considered in calculation of debris bed control volume representative density ............................................................................................38

2.2 Material specific heats considered in calculation of debris bed control volume mass-averaged specific heat

2.3 Material thermal conductivities considered in calculation of debris bed control volume mass-averaged thermal conductivity

3.1 Arrangement of BWR reactor vessel lower plenum structures.............................61

3.2 Typical lower plenum structure indices ..............................................................68

6.1 Initial configuration of the lower plenum debris bed and the initial bottom head wall temperatures.

6.2 Lower plenum debris bed and vessel wall response for the example calculation at the time that debris layer three is established

6.3 Lower plenum debris bed and vessel wall response at time 196 minutes after scram

6.4 The calculated situation just before bottom head creep rupture for the case without penetration failures

6.5 Results for a case with penetration failures....................................................... 120

11.1 Energy transfers considered in the energy balance for the BWR vessel bottom head wall.

A.1 The noncondensable gas mole fraction decreases rapidly when steam is released directly into the drywell atmosphere during the final stage of an SBWR reactor vessel depressurization.

A.2 The drywell-to-wetwell pressure differential delpre and the differential pressure reqpre at which flow through the PCCS vent line is initiated. 


\section{BH Package Reference Manual}

A.3 The available PCCS heat exchanger capacity is primarily determined by the drywell noncondensable gas mole fraction.

A.4 The available PCCS (three-unit) heat exchanger capacity and the power e2adic actually utilized

A.5 The total mass flow pltifl through the PCCS vent line and the associated flow pltnfl of noncondensable gases 
BH Package Reference Manual

\section{INTRODUCTION}

Boiling Water Reactors (BWRs) have unique features (Figures 1.1 and 1.2) for which special models must be provided if best-estimate severe accident calculations are to be performed. The Boiling Water Reactor Severe Accident Technology (BWRSAT) Program at ORNL has developed and incorporated into its BWRSAR code several advanced models for application to BWR severe accident analyses ${ }^{1,2,3}$. All of these models have been made publicly available as they were developed, tested, and used in ongoing BWR severe accident studies at Oak Ridge. Many, particularly the earlier models applicable to the period of the accident sequence before relocation of core material into the lower plenum, have been incorporated into other codes such as MELCOR. The lower plenum debris bed formation and behavior models, however, have remained unique to the BWRSAR code until recently.

It is the purpose of this Section to explain the operation of the models that establish the lower plenum debris bed from the materials and associated energies passed from the core region through the core plate. The discussion begins with a brief description of the structures within the BWR lower plenum and the numerous penetrations of the bottom head itself. The illustrative dimensions are those applicable to the $6.38 \mathrm{~m}(251 \mathrm{in}$.) ID BWR-4 reactor vessel installed at 1067 MWe plants such as Peach Bottom and Browns Ferry.

The portion of the BWR reactor vessel below the elevation of the core plate is formed by a cylindrical section joined with a hemispherical section of radius $3.19 \mathrm{~m}$ (125$1 / 2$ in.). As shown in Figures 1.1 and 1.2, much of the volume immediately beneath the core plate is occupied by the control rod guide tubes. Also passing through this volume are source range, intermediate range, and power range detector assemblies as indicated on Figures 1.3 and 1.4.

Fortunately, the development of BWR reactor vessel lower plenum debris bed models can proceed without the necessity for prior resolution of the numerous uncertainties regarding the means by which relocating core and structural material might pass through the core plate boundary. This is true because the lower plenum models have been established in such a manner that they can be driven by information provided by a separate and independent calculation of material relocation from the core region. This is the approach that has been taken with the lower plenum debris bed and bottom head response models, which in effect are driven by the masses and associated energies entering from the region at and above the core plate. The operation of these models when driven by MELCOR in an interactive mode ${ }^{12}$ is described in this Reference Manual.

It is important to recognize, however, that these models are initiated at the time that sufficient solid debris has accumulated within the lower plenum following dryout. The argument that the falling heated masses of core debris would be quenched in the reactor vessel lower plenum is buttressed by the geometry of the structures and the 


\section{BH Package Reference Manual}

large water mass initially present in the BWR lower head. For the Peach Bottom example, there are 185 control rod guide tubes of $28 \mathrm{~cm}$ (11 in.) outer diameter on a $30.5 \mathrm{~cm}$ (12 in.) pitch in the vessel lower plenum; thus, within a unit cell, the debris must pass through a $0.032 \mathrm{~m}^{2}\left(0.340 \mathrm{ft}^{2}\right)$ opening (see Figure 1.5$)$ that is $3.66 \mathrm{~m}(12 \mathrm{ft}$ ) in length. This, plus the fact that the initial water mass in the lower plenum [73000$95000 \mathrm{~kg}(160,000-210,000 \mathrm{lbs})$, depending on the temperature] is sufficient to completely quench more than one molten core, leads to the conclusion that the relocating debris would be quenched as it falls through the water.

The rate of quench of the relocating debris is determined by algorithms within the MELCOR Core (COR) Package. The user must override the default COR package input in order to permit the calculation of lower plenum dryout; this requirement plus other special requirements for user input when using the BH Package are described in Section 8.2.3.

As the relocated core material accumulates in the BWR reactor vessel lower plenum, it is expected that the composition of the quenched debris bed would vary with height. Lowermost in the bed would be the debris first relocated into the lower plenum. This normally would comprise mostly metallic debris (control blades, canisters, candled clad and dissolved fuel) that had either accumulated on the core plate before local plate failure or had subsequently relocated downward within the same local region before fuel pellet stack collapse. Higher, within the middle region of the bed, would be the collapsed fuel and $\mathrm{ZrO}_{2}$ from the central region of the core. The initial local core plate structural failures would cause temporary bursts of steaming as the relocating metallic debris was quenched; however, with the collapse of the central core fuel pellet stacks, a constant heat source (the decay heat associated with the pellets) would be introduced to the lower plenum reservoir, initiating a continuous boiloff of the remaining water.

After lower plenum dryout, the debris bed temperature would increase, causing thermal attack and failure of the control rod guide tube and instrument tube structures in the lower plenum, which the debris would completely surround to a depth of about $3 \mathrm{~m}$ (10 ft). Since the control rod drive mechanism assemblies and the control rod guide tubes support the core, the remaining standing outer regions of the core would be expected to collapse into the vessel lower plenum when these support columns fail. Thus, the uppermost portion of the completed lower plenum debris bed should primarily consist of the collapsed metallic and fuel material from the relatively undamaged outer regions of the core. The stainless steel of the control rod guide tubes and mechanism assemblies, the instrument tubes, and other lower plenum structures would be subsumed into the surrounding debris as it becomes molten.

The lower plenum debris bed control volume arrangement is illustrated in Figure 1.6 together with a brief summary listing of the models employed for the calculation of the bed response. The vessel bottom head is represented at each debris bed control volume in contact with the wall, while the wall itself is sectioned into three radial segments with the outer segment capable of transferring heat to the containment 
atmosphere or water pool (for the case of drywell flooding). The debris bed and bottom head representations are described in greater detail in the following Sections.

There are more than 200 bottom head penetrations as necessary to accommodate the 185 control rod drive mechanism assembly penetrations, 55 instrument guide tube penetrations, and a $5.1 \mathrm{~cm} \mathrm{(2} \mathrm{in.)} \mathrm{drain} \mathrm{line} \mathrm{penetration} \mathrm{near} \mathrm{the} \mathrm{low} \mathrm{point} \mathrm{of} \mathrm{the} \mathrm{bottom}$ head. The general arrangement of the in-core instrument housings and the stub tubes for the control rod drive mechanism assemblies is indicated in Figure 1.7.

The BWR bottom head is clad with Inconel [thickness $0.32 \mathrm{~cm}(0.125 \mathrm{in}$.)] while the control rod drive mechanism assembly and instrument guide tube penetrations are stainless steel. Cross-sections of the control rod drive mechanism assembly and instrument tube penetrations and their weldments are illustrated in Figure 1.8. Each incore instrument tube is held in place by an Inconel-to-stainless steel weld located at the inner surface of the bottom head wall, whereas the control rod drive mechanism assemblies are held in place by similar welds at the upper ends of the Inconel stub tubes. These latter welds would be located about $10 \mathrm{~cm}$ (4 in.) within the lower plenum debris bed expected to be formed during an unmitigated BWR severe accident.

Given the perforated status of the BWR bottom head, it is reasonable to expect that the initial pressure boundary failure after lower plenum debris bed dryout might occur through the vessel penetrations and not by failure of the $21 \mathrm{~cm}(8-7 / 16 \mathrm{in}$.) thick bottom head itself. The question of the mode of bottom head penetration failure will be addressed in Section 5. 

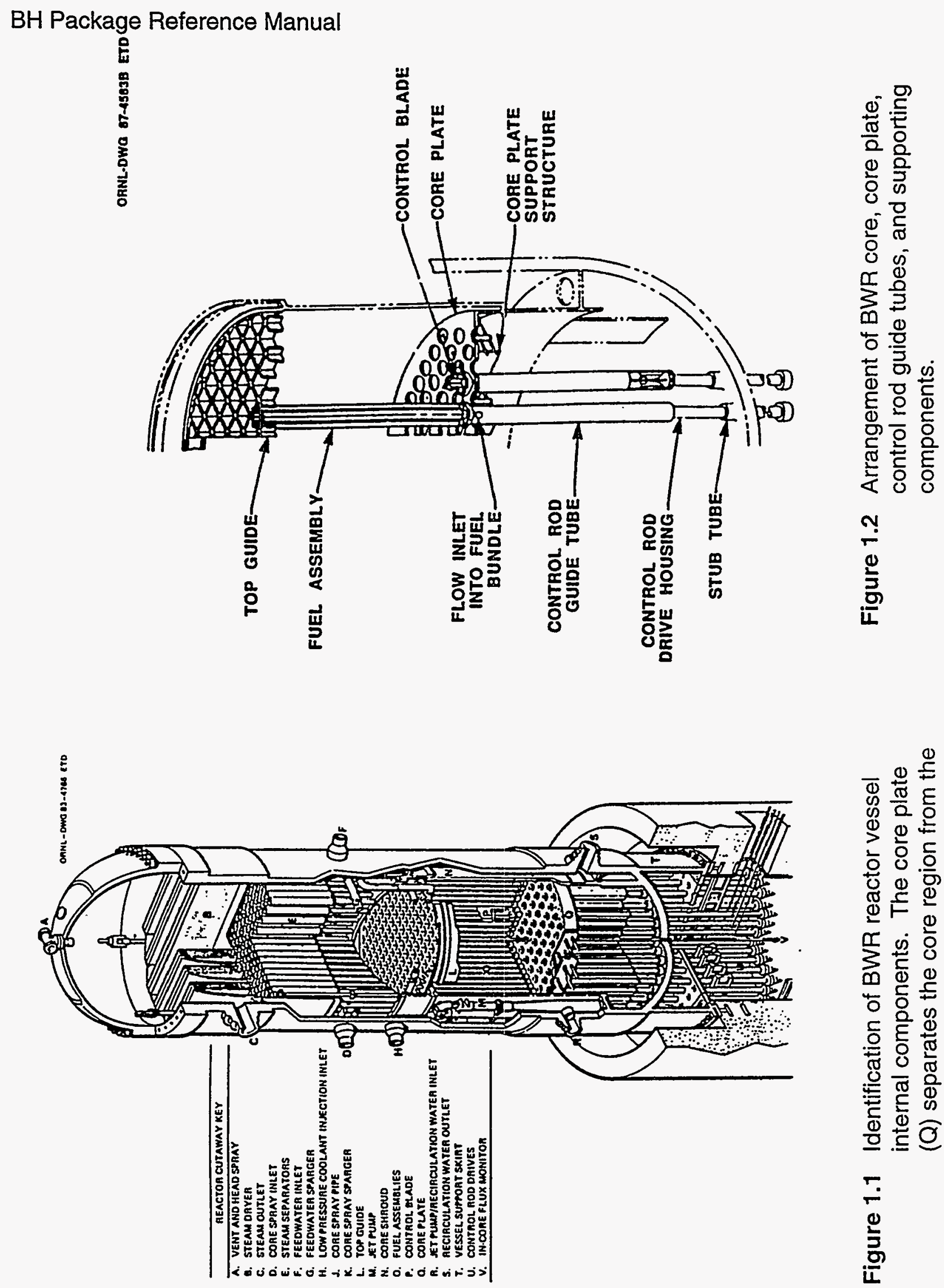

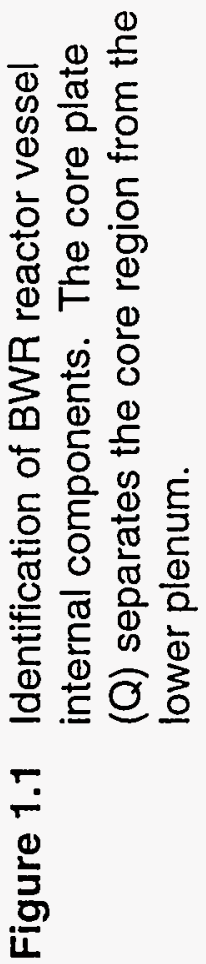




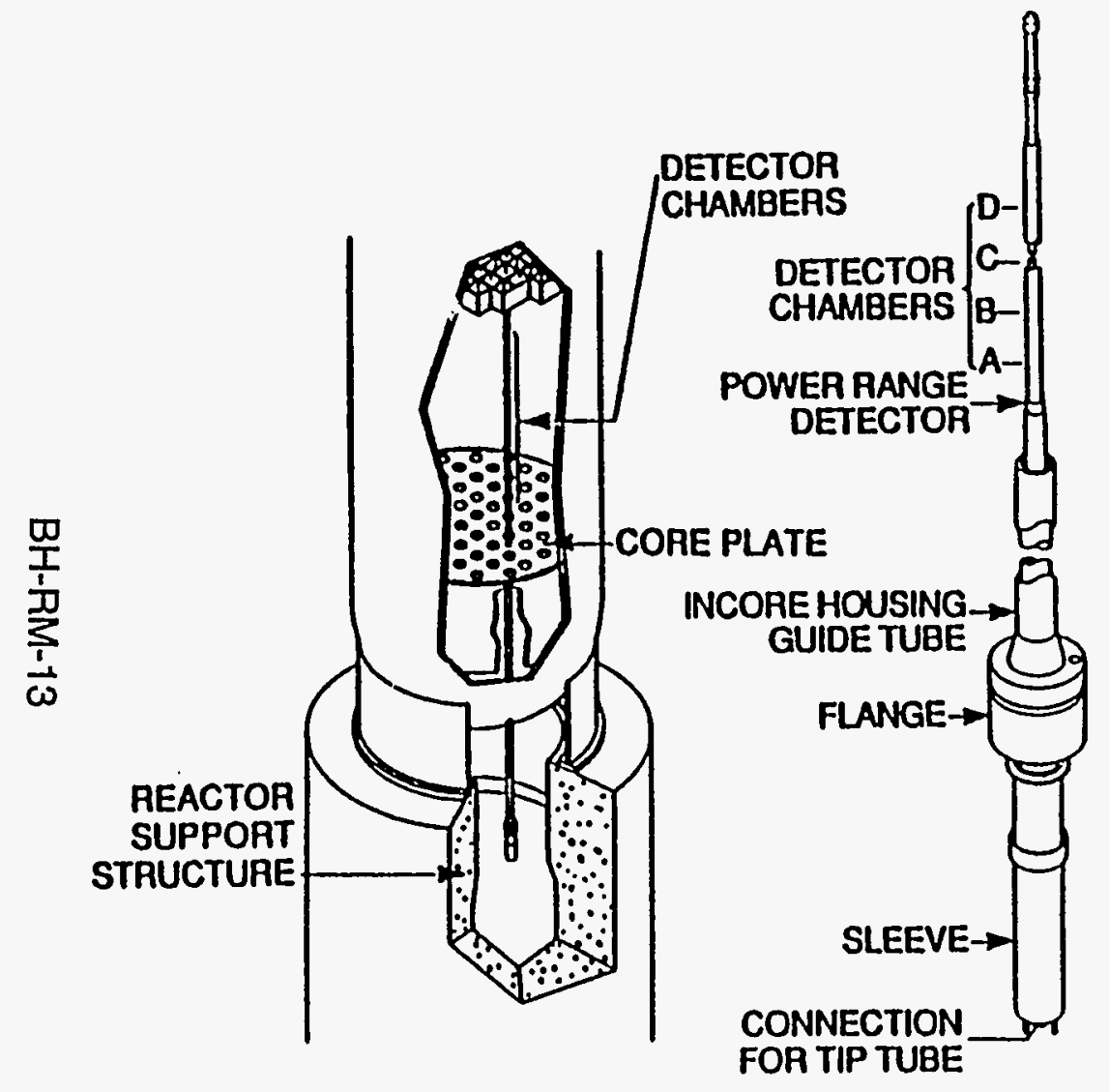

Figure 1.3 Mechanical arrangement of one of the 43 local power range detector assemblies. The annular gap clearance between the in-core housing guide tube and the instrument tube is specified as 0.40 inches $(1.02 \mathrm{~cm})$.

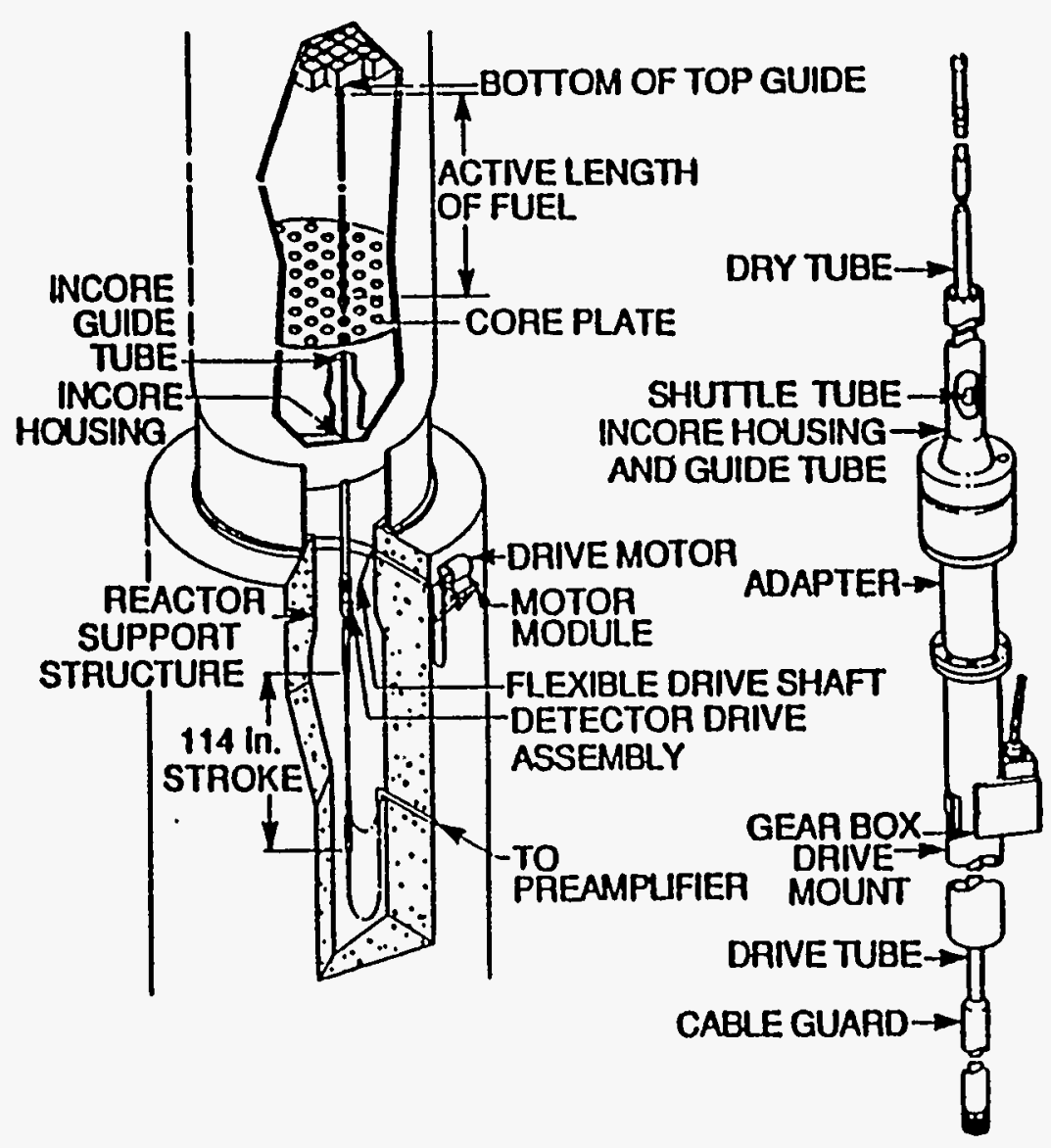

Figure 1.4 Mechanical arrangement of the four source range and eight intermediate range detector in-core instrument assemblies. 


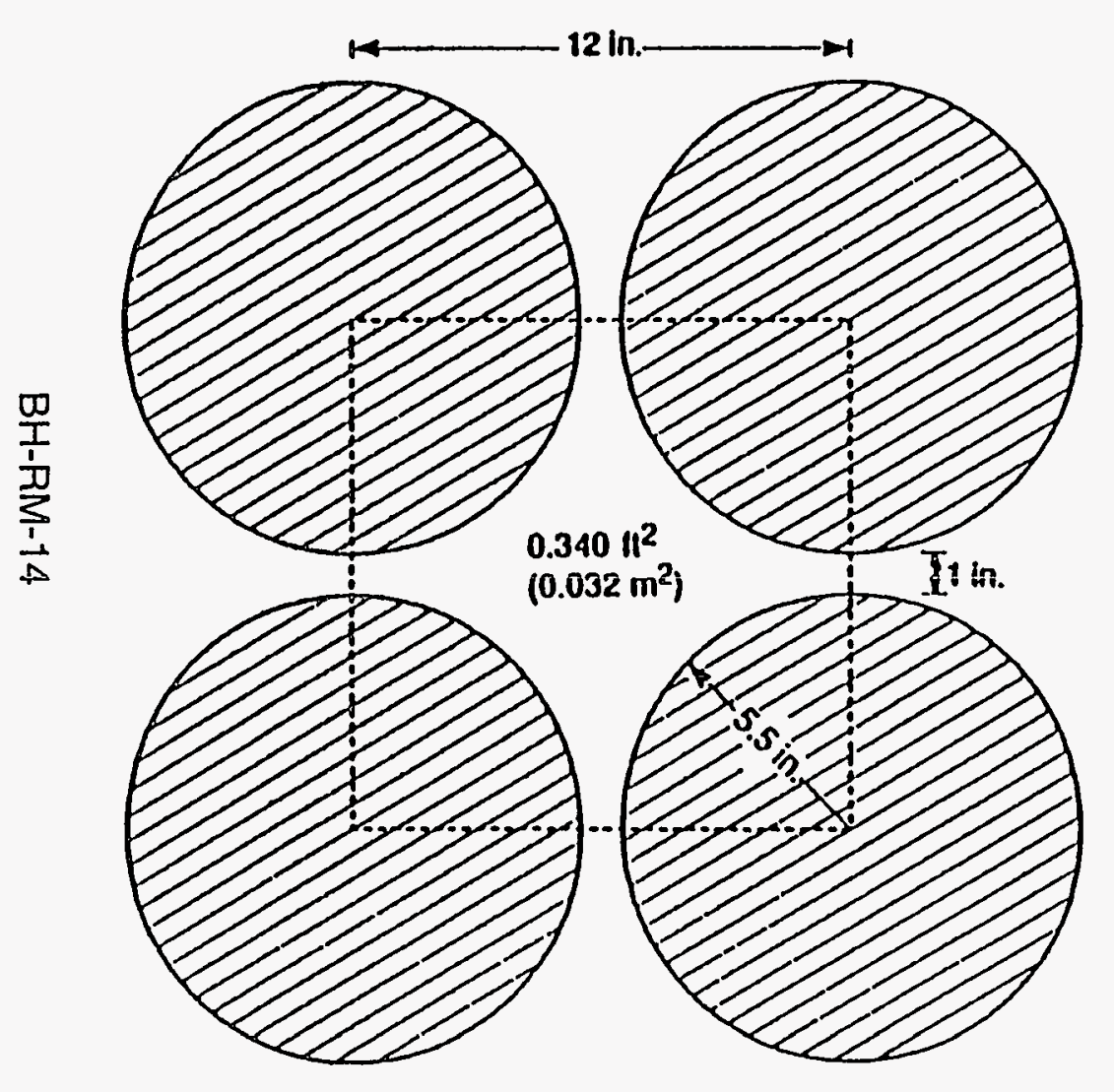

Figure 1.5 Control rod guide tube spacing and available open flow area in the BWR reactor vessel lower plenum.

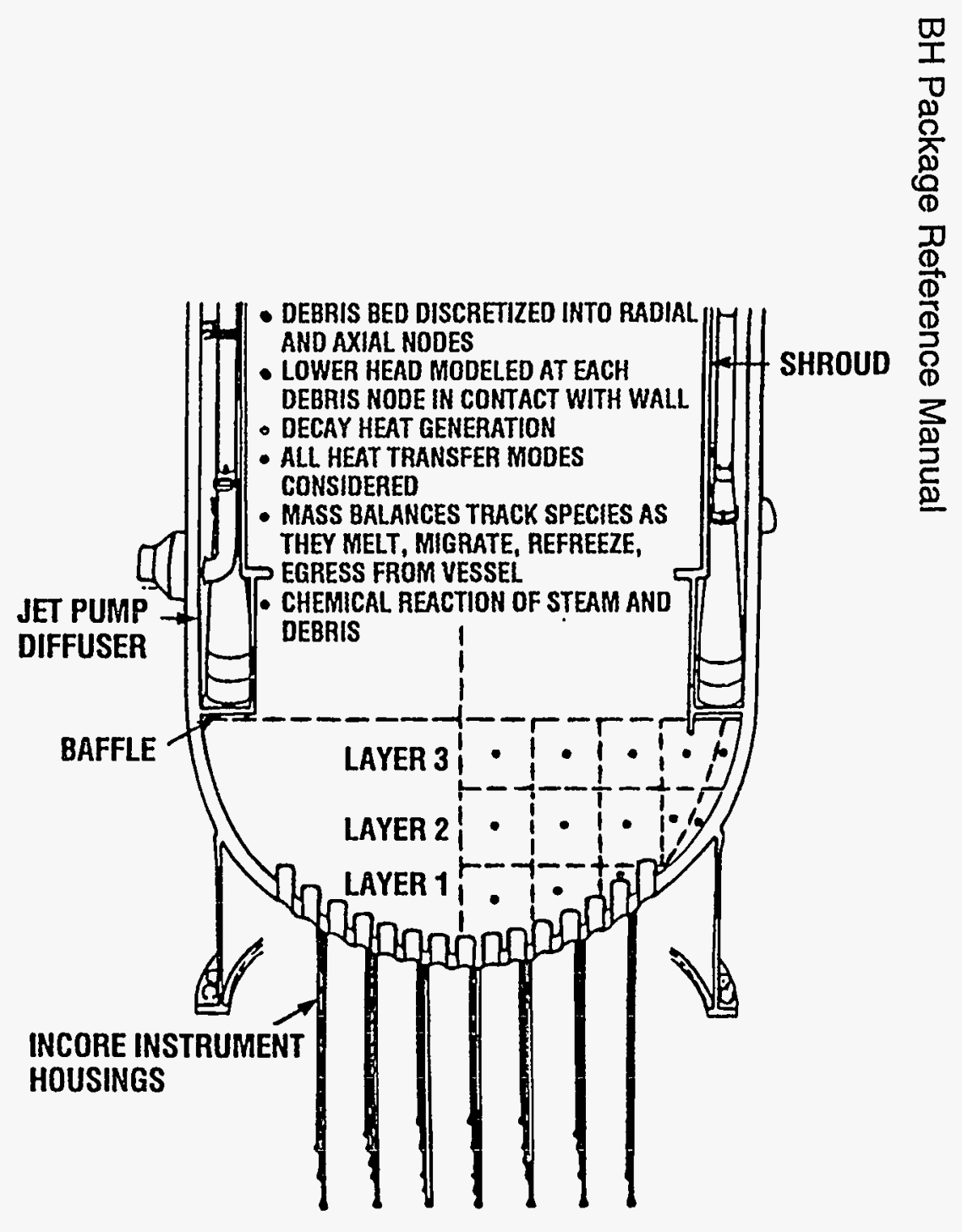

Figure 1.6 Description of models and illustration of control volume structure employed for the BWR reactor vessel bottom head debris bed. 


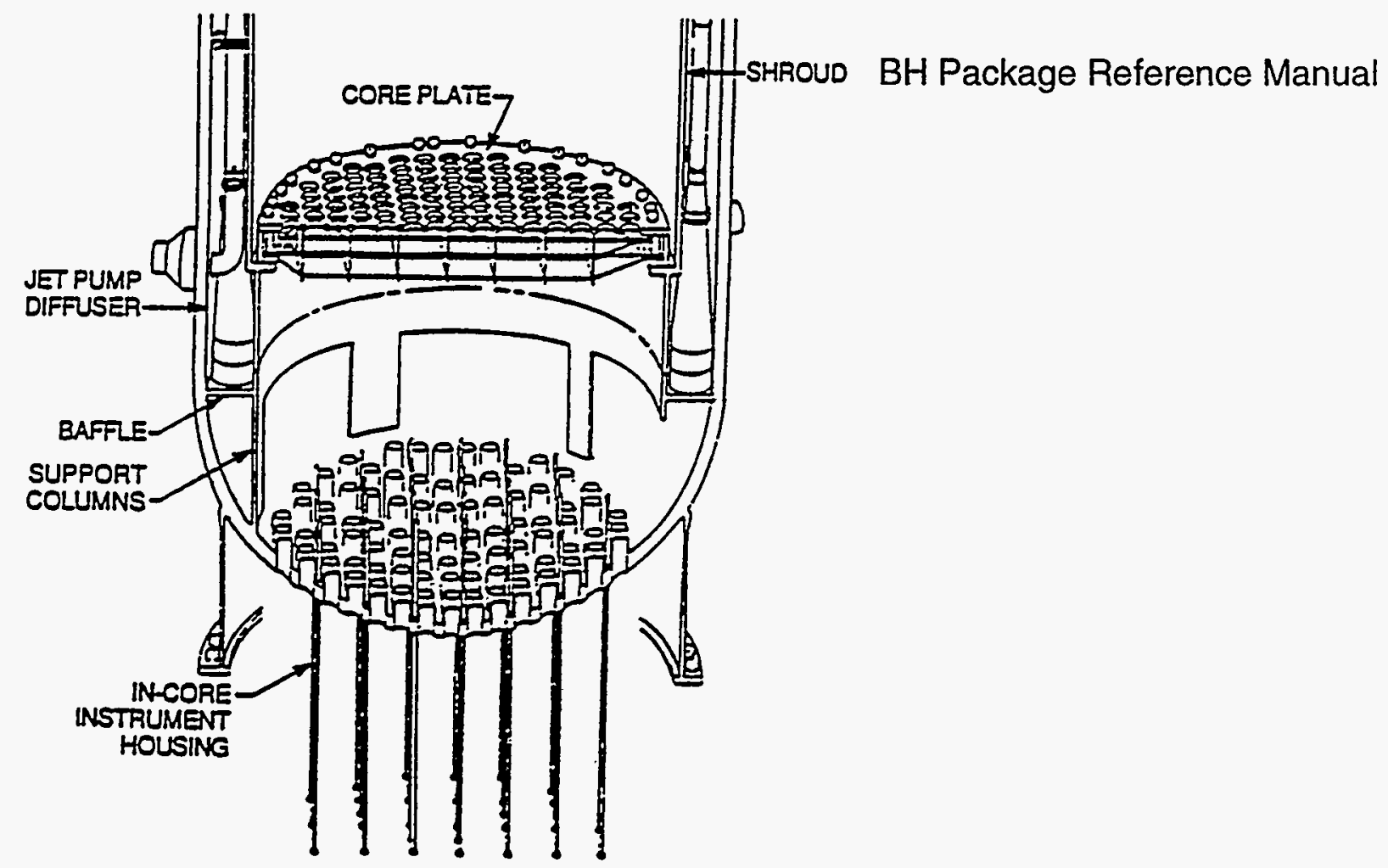

Figure 1.7 The BWR reactor vessel bottom head accomodates 241 penetrations and, therefore, is thicker than the remainder of the reactor vessel pressure boundary.
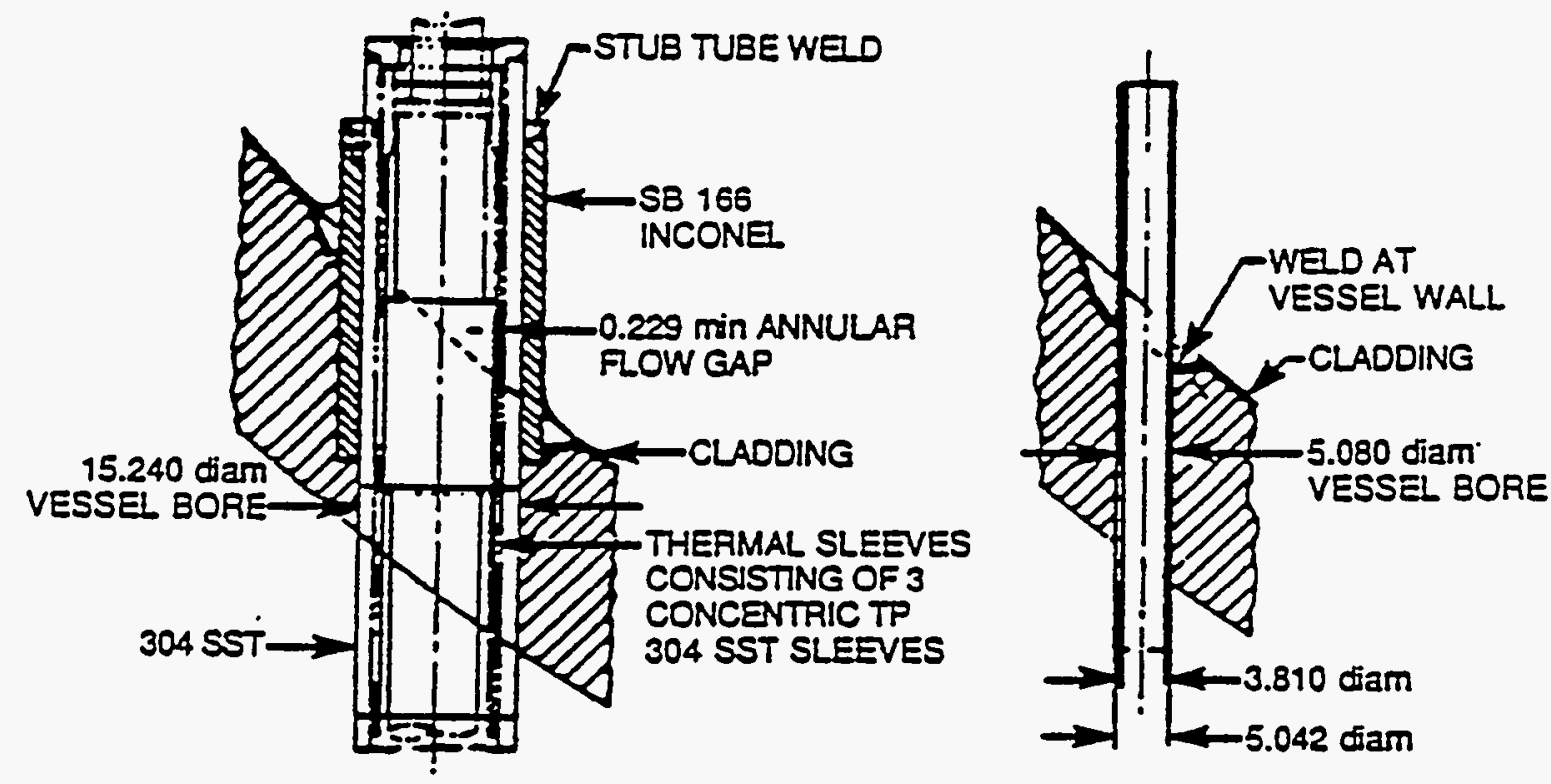

DIMENSIONS IN centimeters

Figure 1.8 The BWR control rod drive mechanism assemblies are held in place by stainless steel-to-inconel welds at the upper ends of the stub tubes, whereas the in-core instrument tubes are supported by stainless steelto-Inconel welds at the vessel wall. 
BH Package Reference Manual

\subsection{Structure of the Debris Bed}

The initial structure of the lower plenum debris bed is established in Subroutine BHHEDN. A drawing of the debris bed control volumes initially employed for a recent calculation of the late phase of a short-term blackout severe accident sequence is provided in Figure 1.9. In this calculation, the debris relocations from the core region were predicted by the BWRSAR code. The initial debris bed temperatures were sufficiently high to cause failure of the control rod guide tubes so that the remaining standing portions of the core entered the lower plenum immediately after lower plenum dryout. While this is not expected to be predicted by MELCOR calculations, the results demonstrate a typical arrangement of a whole-core debris bed. The drawing is toscale, correctly indicating the relative sizes of the calculational control volumes as initially established. These volumes (surfaces of revolution) are listed in the following Table.

Table 1.1 Reactor vessel control volumes considered in the lower plenum debris bed calculation

\begin{tabular}{|c|c|c|}
\hline $\begin{array}{c}\text { Nodal } \\
\text { Designation }\end{array}$ & \multicolumn{2}{|c|}{ Volume } \\
\hline $\begin{array}{l}(1,1) \\
(1,2) \\
(1,3)\end{array}$ & $\begin{array}{l}1.784 \\
1.784 \\
1.784\end{array}$ & $\begin{array}{l}63.0 \\
63.0 \\
63.0\end{array}$ \\
\hline $\begin{array}{l}(2,1) \\
(2,2) \\
(2,3) \\
(2,4) \\
(2,5)\end{array}$ & $\begin{array}{r}4.117 \\
5.273 \\
10.109 \\
15.889 \\
1.625\end{array}$ & $\begin{array}{r}145.4 \\
186.2 \\
357.0 \\
561.1 \\
57.4\end{array}$ \\
\hline $\begin{array}{l}(3,1) \\
(3,3) \\
(3,2) \\
(3,4) \\
(3,5)\end{array}$ & $\begin{array}{r}1.515 \\
1.937 \\
3.715 \\
10.568 \\
0.597\end{array}$ & $\begin{array}{r}53.5 \\
68.4 \\
131.2 \\
373.2 \\
21.1\end{array}$ \\
\hline TOTAL & 60.697 & 2143.5 \\
\hline
\end{tabular}


BH Package Reference Manual

It should be noted that the entire debris bed is contained below the center of curvature of the bottom head hemisphere. The volume occupied by the debris is of course dependent upon the assumed bed porosity, which is user-input. Normally, a porosity of 0.40 is employed for the solid oxides and a porosity of 0.20 is employed for the metals; these are considered to be reasonable values based upon the available data ${ }^{4}$. 


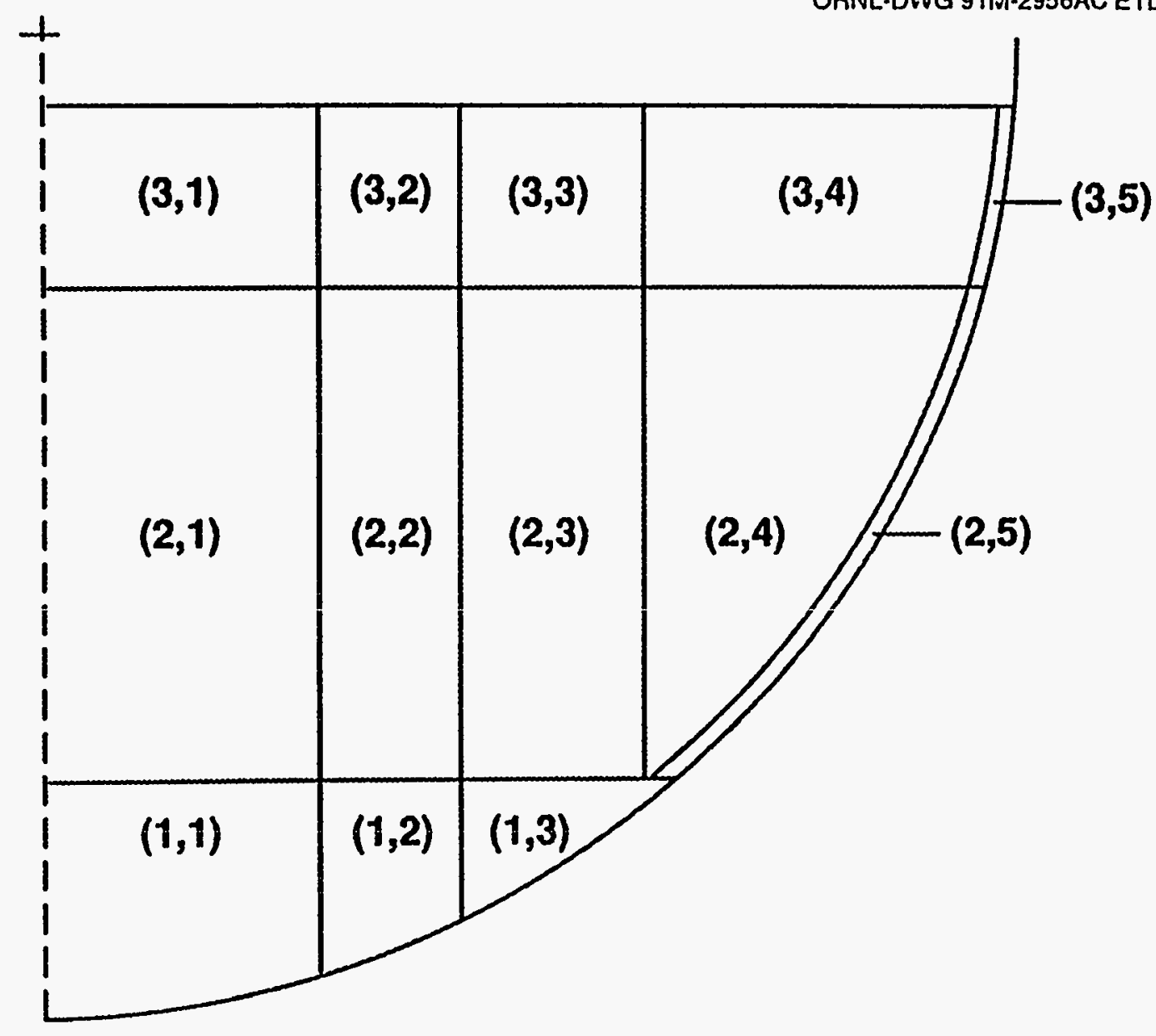

Figure 1.9 A representation (to-scale) of the control volume arrangement for the lower plenum debris bed as established for a short-term station blackout calculation based upon the Peach Bottom plant. (The entire core has relocated into the lower plenum.) 
BH Package Reference Manual

\subsubsection{Arrangement of Control Volumes}

The lower plenum debris bed model constructs the bed control volumes in the following manner. Record is kept of the accumulation of the different material species as they relocate into the lower plenum, and of their associated internal energies. As many as 20 different material species can be considered.

The first debris layer is intended to comprise the control blade, channel box, and candling clad material that relocates prior to any fuel pellet relocation. While the composition of the first debris layer should be primarily metallic, it includes the small amount of $\mathrm{ZrO}_{2}$ and $\mathrm{UO}_{2}$ that was predicted to be carried downward with the candling clad as a eutectic mixture. For this calculation, layers one and two were established at the time of lower plenum dryout. A maximum (lower) height for the first layer can be set by the user, and material present within the lower plenum at the time of dryout that is not included within layer one is used to initiate layer two.

Figure 1.9 shows that the first layer is divided into three control volumes. The vertical interfaces are established so that these three volumes are equal, as indicated on Table 1.1.

The second debris layer begins to be formed at the time that layer one is established and comprises material relocated into the lower plenum from that time forward [until the third layer is initiated (Section 1.1.3)]. If, however, the user has chosen to limit the height of the first layer, the excess material above that height that would otherwise have been included with the first layer is instead used to initiate the second layer inventory.

The second layer consists of five control volumes, as shown on Figure 1.9. The vertical interfaces between control volumes $(2,1),(2,2)$, and $(2,3)$ are simple extensions of the interfaces between control volumes $(1,1),(1,2)$, and $(1,3)$. Therefore, as indicated in Table 1.1 , volumes $(2,1)$ and $(2,2)$ are not equal.

Control volume $(2,5)$ is intended to represent the cooler mass of oxidic debris expected to exist close to the heat sink of the bottom head wall. (Such a provision is not considered necessary for the bottom debris layer, since it is relatively small and is intended to represent primarily metallic debris.) User input determines the width of control volume $(2,5)$ perpendicular to the wall.

Finally, the vertical interface between control volumes $(2,3)$ and $(2,4)$ is established so that these volumes are equal. There is, however, a restriction that the radial separation between this vertical (cylindrical) interface and the point of intersection of the inner boundary of control volume $(2,5)$ with the upper surface of layer one must be at least $2.5 \mathrm{~cm}$ (1 in.). This is to provide a minimum floor area for control volume $(2,4)$; this restriction is invoked whenever the user chooses to limit the height of layer one, as in 


\section{BH Package Reference Manual}

this example. As indicated in Table 1.1, control volumes $(2,3)$ and $(2,4)$ are the largest within the second layer of the debris bed.

The vertical interfaces between the layer three control volumes are extensions of the interfaces between the layer two control volumes, as shown on Figure 1.9. The vessel structural masses as they existed at the initiation of the lower plenum debris bed for the recent calculation of Peach Bottom short-term station blackout are outlined in Table 1.2. (Layer three was established immediately after lower plenum dryout in this calculation.)

\subsubsection{Initial Setup of Layers One and Two}

Now that the control volume arrangement for the whole-core debris bed has been explained, the actual time-dependent debris bed structure that emerges during a typical MELCOR calculation will be described. The following discussion is based upon a shortterm station blackout accident sequence with actuation of the automatic depressurization system (ADS). (The special case of accident sequences involving early drainage of the reactor vessel lower plenum will be described in Section 1.1.3.) The modeled plant is Grand Gulf.

MELCOR typically predicts for short-term station blackout that about two-thirds of the core and structural debris has relocated into the lower plenum at the time of bottom head dryout. This debris consists of mixed metals and oxides, since MELCOR does not predict an early series of primarily metallic relocations. This material is apportioned between the bottom and middle debris bed layers; the upper layer is not yet defined. The user can limit the amount of debris included in the bottom layer by use of the input parameter H1MAX (BH0500), which is the maximum permitted height (above vessel zero) of the upper surface of the bottom layer. The size of the lower layer should be limited for MELCOR calculations, since these three bottom control volumes in effect serve as a crust layer. 
BH Package Reference Manual

Table 1.2 Material masses $(\mathrm{kg})$ included in the initial setup of the debris bed layers for Peach Bottom short-term station blackout

\begin{tabular}{|c|c|c|c|c|}
\hline Material & $\begin{array}{c}\text { Layer } \\
1\end{array}$ & $\begin{array}{c}\text { Layer } \\
2\end{array}$ & $\begin{array}{c}\text { Layer } \\
3\end{array}$ & Total \\
\hline $\begin{array}{l}\mathrm{Zr} \\
\mathrm{Fe} \\
\mathrm{Cr} \\
\mathrm{Ni} \\
\mathrm{B}_{4} \mathrm{C}\end{array}$ & $\begin{array}{r}12147 . \\
12724 . \\
3095 . \\
1378 . \\
269 .\end{array}$ & $\begin{array}{r}32349 . \\
38412 . \\
9344 . \\
4164 . \\
753 .\end{array}$ & $\begin{array}{r}5398 . \\
41797 . \\
10167 . \\
4519 . \\
84 .\end{array}$ & $\begin{array}{r}49894 . \\
92933 . \\
22605 . \\
10061 . \\
1106 .\end{array}$ \\
\hline $\begin{array}{l}\mathrm{ZrO}_{2} \\
\mathrm{FeO} \\
\mathrm{Fe}_{3} \mathrm{O}_{4} \\
\mathrm{Cr}_{2} \mathrm{O}_{3} \\
\mathrm{NiO} \\
\mathrm{B}_{2} \mathrm{O}_{3} \\
\mathrm{UO}_{2}\end{array}$ & $\begin{array}{r}837 . \\
24 . \\
41 . \\
17 . \\
3 . \\
6 . \\
892 .\end{array}$ & $\begin{array}{r}11850 . \\
84 . \\
197 . \\
74 . \\
14 . \\
15 . \\
120757 .\end{array}$ & $\begin{array}{r}4337 . \\
0 . \\
23 . \\
6 . \\
2 . \\
0 . \\
40298 .\end{array}$ & $\begin{array}{r}17024 . \\
108 . \\
261 . \\
97 . \\
19 . \\
20 . \\
161947 .\end{array}$ \\
\hline Totals & 31432. & 218013 & 106631. & 356076. \\
\hline
\end{tabular}

A reasonable value for H1MAX is $0.6096 \mathrm{~m}$ (24 in.) for the Grand Gulf reactor vessel (about $17.5 \%$ of the bottom head radius). This causes the middle layer to initially extend from $0.6096 \mathrm{~m}$ (24 in.) to $1.8796 \mathrm{~m}$ (74 in.) above vessel zero. Should the user choose not to limit the size of the lower layer by setting a large value of H1MAX, then the code logic will still reserve $1 \%$ of the debris present at the time of lower plenum dryout to initiate the middle (second) layer.

Thus, the bottom debris layer is completely established at the time of lower plenum dryout and the middle layer is initiated. The bottom head pressure boundary is intact and all debris is in the solid phase. The calculation proceeds to determine the response of these two debris layers and of the vessel bottom head. As additional material (solid or liquid) is relocated downward from the core region, it is added to the middle layer, which continues to grow. Meanwhile, the temperature of the debris within both layers increases, under the impetus of decay heating.

\subsubsection{The Special Case of Bottom Head LOCA}

For most BWR severe accident sequences, bottom head dryout would occur only after a lengthy process of heat transfer from quenched debris to water, driven by the decay heating provided by the relocated fission products. Thus a large amount of quenched debris would be present within the lower plenum at the time of dryout to serve as the 


\section{BH Package Reference Manual}

solid foundation for a lower plenum debris bed, whose size would increase as additional materials (both solid and liquid) were relocated downward from the core region.

It is necessary, however, for the lower plenum debris bed models to also have the capability to calculate the progression of events for accident sequences in which an initiating break occurs in the bottom head penetration assembly welds or the vessel drain lines such that lower plenum dryout occurs before any debris has relocated from the core region. For these scenarios, the MELCOR calculation (with use of the $\mathrm{BH}$ Package permitted) proceeds as follows:

1. Dryout of the lower plenum due to LOCA.

2. Debris relocates into lower plenum.

3. Depending upon user input, the MELCOR COR Package may predict release of debris through failed bottom head drain or other penetration failures.

4. When (and if) sufficient solid debris accumulates in the lower plenum to form a debris bed, the BH Package is called to perform the lower plenum debris bed and bottom head response calculation for the remainder of the accident sequence.

It should be noted that the lower plenum debris bed and bottom head models will never be called if the loss of debris from the lower plenum as calculated by the MELCOR COR Package is such that sufficient solid debris to form a bed does not accumulate within the lower plenum. The operating requirements of the BH Package are such that roughly one-fourth of the core mass is required to be present within the lower plenum to permit the debris bed calculation to be initiated.

Certain special features of Subroutine BHHEDN address the status of the control rod guide tubes, instrument tubes, and other lower plenum structural steel at the time the lower plenum debris bed is initially established. If MELCOR has predicted that some of this lower plenum structural steel is in the liquid phase at the time the BH Package is initiated, then all structural steel beneath the surface of the debris bed will be initially liquid within the BH Package. If, in this case, the liquid structural steel mass predicted by MELCOR differs from the structural steel mass underneath the debris bed surface in the $\mathrm{BH}$ package initialization, then an adjustment is made in the initial debris temperature as necessary to preserve the debris energy balance.

It is virtually certain that the MELCOR prediction and the $\mathrm{BH}$ package determination of the amount of liquid structural steel will differ when the BH Package is initiated because MELCOR has no representation of the debris as a bed filling the volume within a portion of the bottom head hemisphere. As an example from an actual calculation, if MELCOR predicts that $7975 \mathrm{~kg}$ of structural steel is molten within a debris mass of $105,493 \mathrm{~kg}$ then the BH Package will determine that the debris will extend to a height of $105 \mathrm{~cm}$ within the SBWR lower plenum, surrounding $13,679 \mathrm{~kg}$ of structural steel, which 
is in the liquid phase (since the debris temperature is greater than the melting temperature of steel). The debris temperature, $2011 \mathrm{~K}$ in the MELCOR calculation will, therefore, be adjusted downward to represent the energy removal necessary to melt $5704 \mathrm{~kg}(13679-7975)$ of steel. In this case, the temperature difference is $72 \mathrm{~K}$ so the BH Package is initiated with a debris temperature of $1939 \mathrm{~K}$ and with all $13,679 \mathrm{~kg}$ of submerged steel in the liquid phase.

If the initial debris temperature provided by MELCOR is below the steel melting temperature $(1733 \mathrm{~K})$, then both MELCOR and the BH Package consider the lower plenum structural steel to be in the solid phase and no adjustment is necessary. As indicated in the previous Section, this is the usual case for non-LOCA severe accident sequence calculations, where the BH Package is initiated at the time of bottom head dryout and all debris present within the lower plenum at that time has been quenched.

Returning to the bottom head LOCA case, if some of the lower plenum structural steel is considered by MELCOR to have escaped from the reactor vessel via the bottom head drain or other penetration failure, then this is recognized when the $\mathrm{BH}$ package lower plenum debris bed model is initiated. Specifically, an appropriate amount of additional void is introduced into the debris in place of the steel that would normally be introduced, thereby increasing the local bed porosity. The released steel is considered to have been taken from the bottom of the lower plenum structures upward and the associated voids are introduced into the bottom, middle, and upper debris bed layers, in that order, to the extent necessary to account for the total escaped mass.

\subsubsection{Establishing the Third Debris Layer}

The upper (third) debris layer will be formed at the time that the temperature of any middle layer control volume exceeds TFAIL2. This temperature parameter is userinput, but subsequently modified (reduced) by code logic as necessary to not exceed the lowest melting temperature of any pure species or eutectic mixture (input record series $\mathrm{BH} 08 \mathrm{II}$ ). This modification is necessary since the middle (second) layer must be complete in order to properly account for the movement of liquids within the bed. Note that liquids will be present within the bed upon initial setup for the bottom head LOCA cases discussed in Section 1.1.3; for other cases, the user can also cause the upper layer to be established immediately after lower plenum dryout by setting a low value of TFAIL2 in input (BH0700).

MELCOR does not provide for collapse of all remaining standing portions of the core when temperature TFAIL2 is exceeded. Therefore, the upper layer will initially comprise all of the stainless steel structure within the lower plenum above the surface of the middle debris layer (as given by the steel volume vs height table entered on input record $\mathrm{BH}$ 04II), plus any debris that happens to be relocated downward from the core region during the timestep in which the upper layer is established. Subsequently, all relocating debris is added to the third layer. Whether the surface of the upper layer rises or falls as the calculation proceeds depends upon the relative rates of debris 


\section{BH Package Reference Manual}

addition from the core region and bed settling as a result of material melting and relocation or escape from the vessel via penetration failures. If the bed has settled, debris relocating from the core region is preferentially added to the sunken regions so that the tendency is to restore a level surface. Relocating liquids run into any available interstitial pores of the third layer solid debris whereas relocating solids (with their inherent porosity) are added to the layer surface.

\subsection{The Vessel Bottom Head Wall}

The nodalization employed for the reactor vessel bottom head wall and the placement of these nodes relative to the debris bed boundary control volumes are shown in Figure 1.10. To facilitate the explanation of the wall configuration, debris bed control volumes $(2,5)$ and $(3,5)$ are shown oversized on Figure 1.10 , and the interfaces between control volumes $(2,3)$ and $(2,4)$ and between control volumes $(3,3)$ and $(3,4)$ have been deleted. (The location of these interfaces is shown to scale on Figure 1.9.)

The eight wall nodes placed adjacent to debris bed layer one are allocated as three abutting control volume $(1,1)$, two abutting control volume $(1,2)$, and three abutting control volume $(1,3)$. Bed control volume $(2,5)$ forms the entire wall boundary for debris layer two, and six wall nodes abut this narrow crust control volume. Similarly, bed control volume $(3,5)$ forms the wall (crust) boundary for the relatively small upper debris layer and two wall nodes (numbered 15 and 16 on Figure 1.10) abut this control volume. This arrangement is intended to provide wall nodes of approximately equal length along the wall. Once layer three is established, the wall nodalization does not change during a calculation.

Wall node 17 represents the portion of the wall between the top of debris layer three and the bottom of the shroud baffle. One wall node (node 18 in Figure 1.10) represents the wall adjacent to the water trapped above the shroud baffle in the downcomer region; the upper surface of this last node is at the elevation of the center of curvature of the hemispherical bottom head. [Special provision is made for cases in which the shroud baffle is located less than $0.076 \mathrm{~m}$ (three inches) below the center of curvature. Here the length of node 18 is set to $0.076 \mathrm{~m}$ and some (or all) of node 18 will extend above the center of curvature.]

Logic within Subroutine BHHEDN continues to adjust the structure of the second debris layer and the nodal divisions of the adjacent wall until the third layer is established. During the period before the third debris layer is formed, the lower plenum debris bed model simply divides the bottom head wall volume extending from the (moving) upper surface of debris layer two to the bottom of the shroud baffle into three equal nodes. The total number of nodes and the placement of the uppermost wall node adjacent to the downcomer region above the shroud baffle remain the same.

For the purpose of calculating the bottom head wall temperatures, each wall node is divided into three equal-volume segments as shown in Figure 1.11. Heat is transferred 
BH Package Reference Manual

from the adjacent debris bed control volumes into the inner segment of each wall node by conduction. Heat transport along and across the wall by conduction from segmentto-segment is also calculated. Exposed inner wall segments above the elevation of the upper debris bed surface receive heat transfer by radiation and convection from the lower plenum atmosphere and by radiation from the upper surfaces of the bed control volumes.

Although not indicated in Figure 1.11, the thickness of the BWR reactor vessel wall increases at some point (plant-specific) between the cylindrical section of the vessel and the lower portion of the bottom head where the penetrations are located. The vessel wall nodalization established for the bottom head within Subroutine BHHEDN recognizes the user-input location of this transition point [HD1D2 (BH0500)] and adjusts the thickness of the wall nodes above and below this location accordingly.

Furthermore, the lengths of the two adjacent wall nodes are adjusted (one shortened, one lengthened) so that the transition point falls exactly on their nodal boundary.

The rate of heat transfer from the inner segment of the uppermost wall node (number 18 in Figures 1.10 and 1.11) to the water in the downcomer region is governed by nucleate boiling and conduction through the wall. While water remains, this rate is calculated in Subroutine BHHED2 as

$$
\text { AH } \frac{\text { TMASJP }- \text { THD }}{\frac{1.0}{H N B}+\frac{L H}{2 \times \text { BHAKCS }}} \quad \text { Watt }
$$

where

$$
\begin{aligned}
\text { AH } & \text { AHEAD(1,NWALL), inner surface area of wall node NWALL, } \mathrm{m}^{2} \\
\text { HNB } & =\text { nucleate boiling heat transfer coefficient, } \mathrm{W} /\left(\mathrm{m}^{2} \cdot \mathrm{K}\right) \\
\text { NWALL }= & \text { index of uppermost wall node } \\
\text { TMASJP }= & \text { temperature of downcomer water, } \mathrm{K} \\
\text { THD } & \text { THDWO(1,NWALL), temperature of the inner segment of wall } \\
& \text { node NWALL, K } \\
\text { LH } & \begin{array}{l}
\text { XLHEAD }(1, N W A L L), \text { radial thickness of the inner segment of wall } \\
\text { node NWALL, } \mathrm{m}
\end{array} \\
\text { BHAKCS }= & \text { Function BHAKCS }(\mathrm{THD}), \text { temperature-dependent conductivity of } \\
& \text { carbon steel, W/(m.K). }
\end{aligned}
$$

The nucleate boiling coefficient HNB is determined by a fit to results calculated by the Rohsenow correlation based upon current pressure and the wall inner surface temperature. This approximate solution is considered adequate since the majority of the resistance to heat transfer lies in the carbon steel conduction path.

Water remains in the downcomer region because of the method of reactor vessel depressurization. Boiling water reactors are fitted with an Automatic Depressurization System (ADS) that, upon actuation, causes rapid opening of several (five at Peach 


\section{BH Package Reference Manual}

Bottom) of the reactor vessel safety/relief valves (SRVs). The BWR Emergency Procedure Guidelines 5 direct the operators, under severe accident conditions, to manually actuate the ADS when the core has become partially uncovered (but before any significant core damage has occurred). The flashing attendant to the resulting rapid depressurization of the reactor vessel provides temporary core cooling while causing rapid loss of all water from the core region and core plate dryout. However, much of the cooler water in the downcomer region between the lower core shroud and the vessel wall would not be flashed during this maneuver.

After lower plenum debris bed dryout, the water surrounding the jet pump assemblies in the downcomer region is the only water remaining in the reactor vessel. The proximity of the baffle plate and lower core shroud boundaries of this water-filled region to the bottom head hemisphere is illustrated in Figure 1.12.

In the lower plenum debris bed energy balances, heat transfer by conduction is calculated between the bed control volumes and from the outer bed control volumes to the vessel wall. Additionally, radiation and convection from the bed upper surface to the vessel atmosphere and to intact structures above the bed are considered. Radiation to the lower core shroud from the bed surface, radiation and convection to the lower core shroud from the vessel atmosphere, and axial conduction along the vessel wall all contribute to heating and evaporation of the water trapped in the downcomer region.

While water remained in the downcomer region, the lower core shroud would be maintained at a temperature close to the saturation temperature of the water, which, with the reactor vessel depressurized, would be in the neighborhood of $420 \mathrm{~K}\left(296^{\circ} \mathrm{F}\right)$. Since this is much lower than the temperature of the upper surface of the debris bed, it is obvious that the core shroud would constitute a major heat sink for radiation from the upper bed.

While the reactor vessel bottom head remained intact, steam generated within the downcomer region would escape from the reactor vessel to the wetwell pressure suppression pool via the SRVs. Reactor vessel bottom head penetration failure would, however, create a leakage pathway from the vessel to the drywell atmosphere via the lower plenum debris bed. The pathway for the steam generated from the water surrounding the jet pumps would be up through the downcomer region, down through the core region, and out through the debris bed, reacting with any available zirconium metal during its passage. Representation of the associated energy release is important in determining the thermal response of the debris bed control volumes, as described in Section 3.4.

In general, dryout of the reactor vessel downcomer region will not be predicted for calculations in which bottom head penetration failures are permitted to occur. As described in Section 5.3, ablation of the vessel bottom head by the flowing debris will induce early failure of the wall and release of all remaining lower plenum debris into the drywell. 
For calculations in which bottom head penetration failures are not permitted to occur, however, all liquid debris will be retained within the lower plenum until some portion of the reactor vessel bottom head has been heated (by conduction) to a temperature sufficient to induce local failure by creep rupture. This is a much slower process, and dryout of the downcomer region will be predicted for this case. After the water in the downcomer region has boiled away, the shroud temperature would increase to its melting temperature $\left[1672 \mathrm{~K}\left(2550^{\circ} \mathrm{F}\right)\right]$ and the shroud would melt. The resulting liquid stainless steel would then enter the debris bed, providing a cooling effect while increasing the volume of the molten pool.

Heat transfer from the outer segment of each wall node to the drywell atmosphere is calculated by the application of convective heat transfer coefficients determined within the Heat Structures (HS) Package of MELCOR. (This determination is described in Section 2.6.1 of the HS Package Reference Manual.) Different drywell atmosphere temperatures are used for the portions of the vessel wall above and below the attachment point of the vessel support skirt (shown at the base of node 13 in Figure 1.11 and as item T in Figure 1.1). This is because the temperature of the atmosphere within the pedestal region of the drywell would be much higher than the temperature in the remainder of the drywell, especially after molten debris had begun to leave the vessel. The skirt attachment point (height above vessel zero) is identified by user input HSKIRT (BH0600).

Provision has also been made for use of the BH Package to study the effects of drywell flooding as a severe accident mitigation technique. Briefly, drywell flooding to surround the vessel bottom head with water has been proposed 13,14 as a means to maintain the core debris within the reactor vessel throughout a severe accident progression that includes formation of a lower plenum debris bed. If the MELCOR calculation predicts that water comes into contact with the outer surface of the reactor vessel, then the pool heat transfer coefficient for the outer surface of each covered wall node is determined as described in Sections 2.6.3 and 2.6.4 of the HS Package Reference Manual.

The local heat transfer coefficient and the local heat sink temperature for each wall node outer surface are passed from MELCOR to the BH Package by means of array HTCT $(2,20)$ of Common /BHCHED/. Here

$$
\operatorname{HTCT}(1, J)=\text { heat transfer coefficient }\left[W /\left(m^{2} \cdot K\right)\right]
$$

and

$\operatorname{HTCT}(2, \mathrm{~J})=$ heat sink temperature $(\mathrm{K})$ at the outer surface of wall node $\mathrm{J}$.

The calculated energy transfer from the outer vessel surface to the drywell atmosphere or surrounding pool is appropriately introduced into the MELCOR calculation of containment response. 


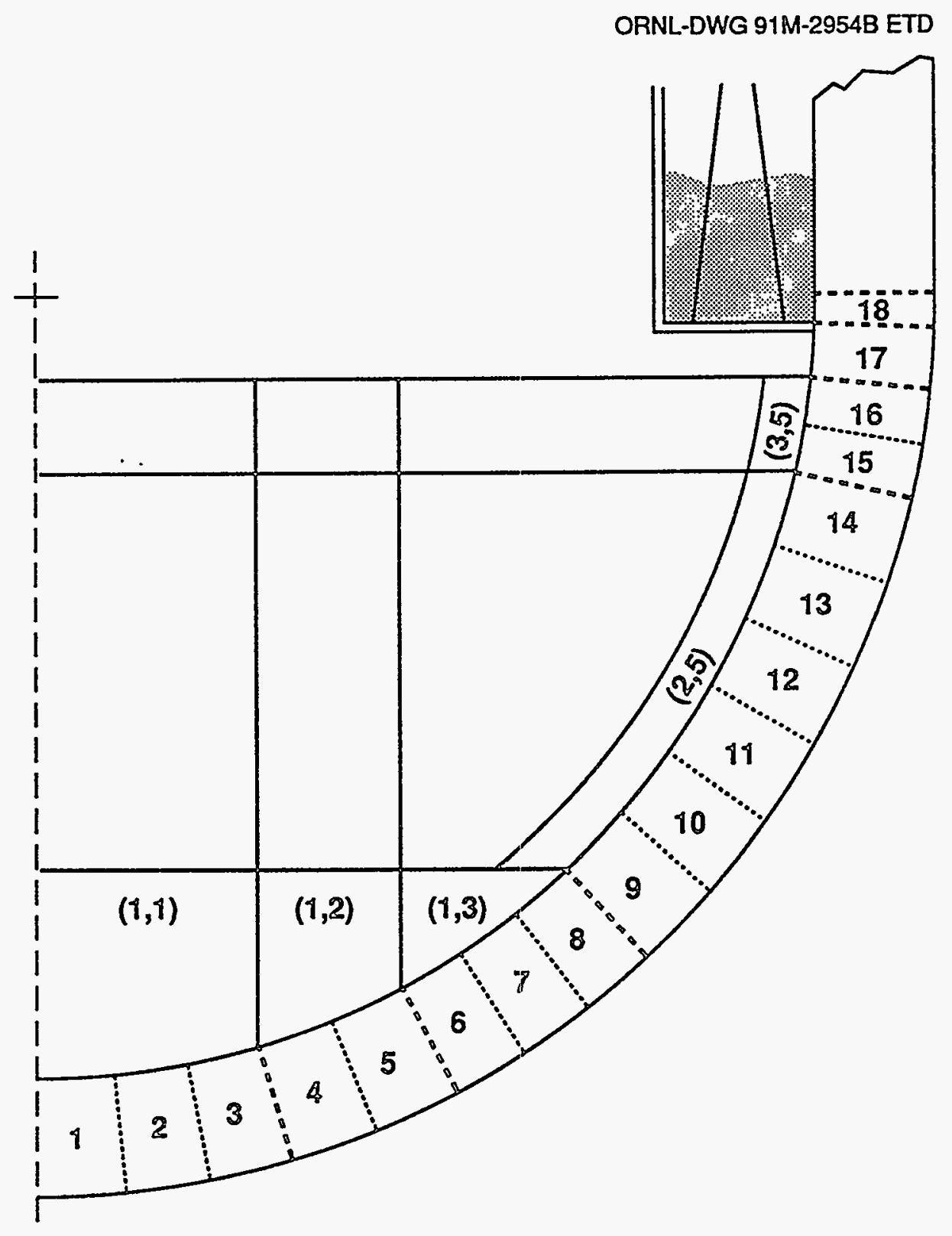

Figure 1.10 The reactor vessel bottom head is divided into calculational nodes extending to the downcomer region. 
BH Package Reference Manual

ORNL-DWG 91M-2955B ETD

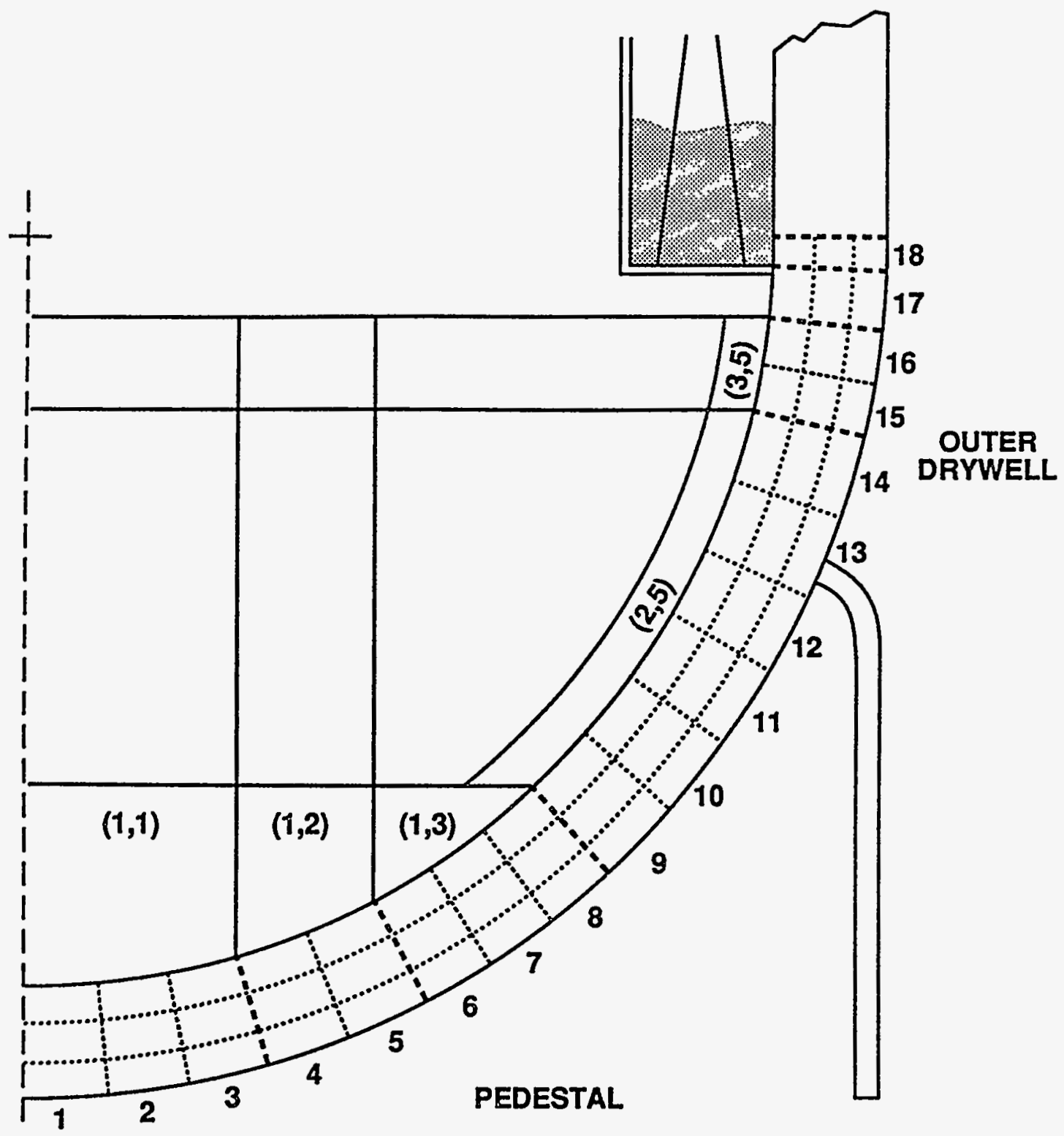

Figure 1.11 Each reactor vessel bottom head wall node is divided into three radial segments for the temperature calculation. 


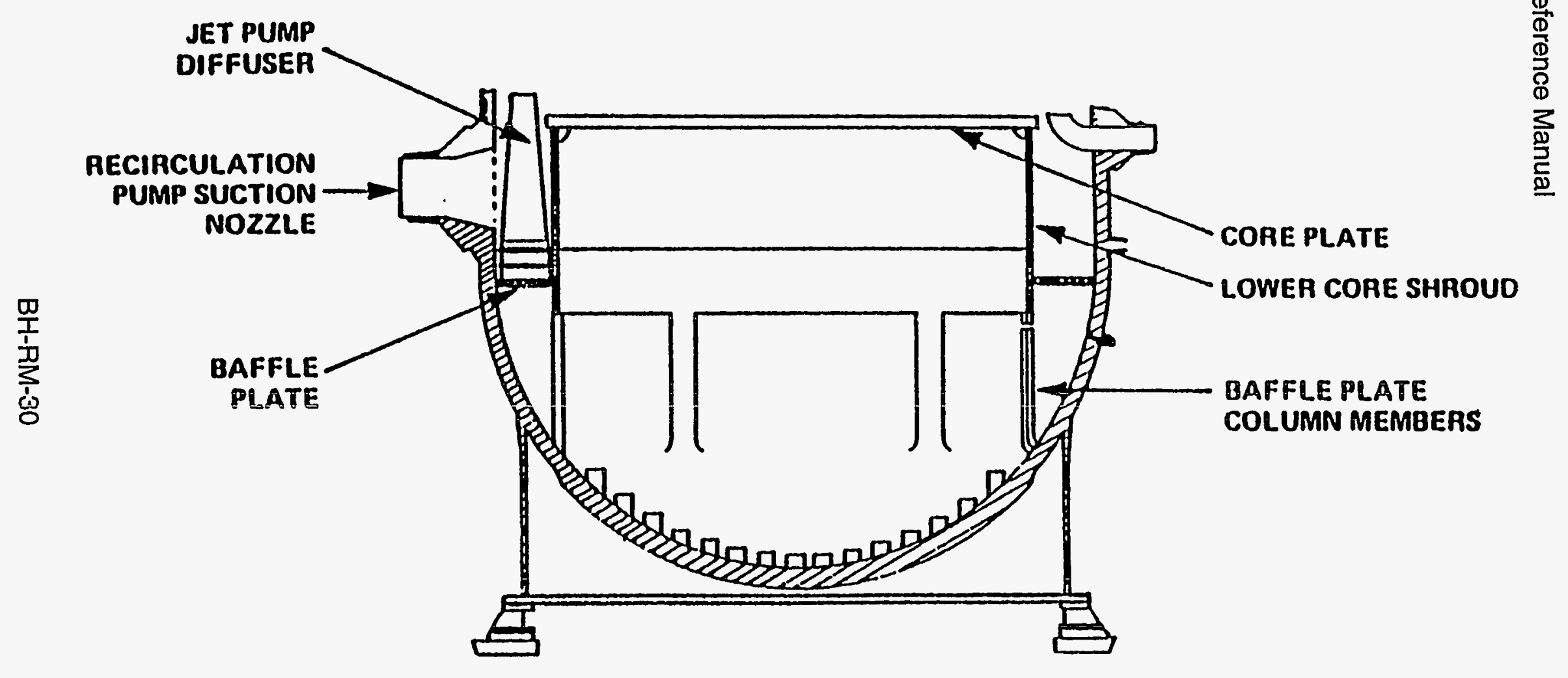

Figure 1.12 The baffle plate and lower core shroud separate the downcomer region from the reactor vessel lower plenum. 
BH Package Reference Manual

\section{COMPOSITION-DEPENDENT PROPERTIES}

This Section provides a discussion of the improvements to the BWR lower plenum debris bed model that have been implemented for use with MELCOR to determine composition-dependent properties for each calculational control volume each timestep. As described previously, the lower-melting temperature metals in the upper portion of the debris bed are predicted to melt during the course of the calculation and to relocate downward into the interstitial voids of the still-solid debris of the bottom layer. Therefore, with the passage of time, the metals-to-oxides ratio decreases in the upper portion of the debris bed and increases in the lower portion. Accordingly, it is the purpose of the code modifications described in the following Sections to account for this shifting composition by establishing the representative material properties within each control volume each timestep.

\subsection{Debris Porosity}

The porosity of the debris within each calculational control volume is established each timestep as derived from the relative masses of solid metals and solid oxides within the volume. The user provides input values (BH0500) of PORBM and PORBOX as the porosities of metallic and oxidic debris, respectively. The representative porosity for an individual control volume is then

$$
\frac{\text { oxide mass } \times \text { PORBOX }+ \text { metals mass } x \text { PORBM }}{\text { oxide mass }+ \text { metals mass }} \text {, }
$$

which is the mass-averaged value.

Typical input values are PORBOX $=0.40$ and $\mathrm{PORBM}=0.20$. The effect of these input quantities upon the total calculated debris bed volume is substantial.

The individual control volume mass-averaged porosities are calculated in Subroutine BHHED2 and stored in the array PORB $(I, J)$, where $I$ is the index of the debris layer $(I=$ $1,3)$ and $J$ is the index of the control volume within the layer $(J=1,5)$. [It should be noted from Figure 1.9 that the debris bed model considers five control volumes in the upper layer, five control volumes in the middle layer, and three control volumes in the bottom layer for a total of thirteen. Thus, there are no control volumes $(1,4)$ or $(1,5)$.] If liquid material exists within a control volume, the (available) porosity for the solid material within that control volume is appropriately reduced. 


\section{BH Package Reference Manual}

\subsection{Densiťy}

A representative density is calculated each timestep for each debris bed control volume, based upon the relative masses of each debris constituent within the control volume.

The mass of each debris constituent within a bed control volume $(1, J)$ is contained within the array

\section{$A M L P(I, J, K, M)$}

where: $K$ is the constituent index $(K=1,20)$

$M$ is the phase index $(M=1,2)$.

As indicated, there are 20 slots (index $K$ ) reserved within this array to identify the various materials making up the debris within a control volume $(\mathrm{I}, \mathrm{J})$. The material species currently represented are listed in the second column of Table 2.1. It should be noted that seven slots $(K=5-9,19,20)$ are available for future addition of other material species to be considered in the calculation.

It is also important to note that although a slot has been reserved within the array for $\mathrm{Fe}_{2} \mathrm{O}_{3}(\mathrm{~K}=13)$, the presence of this material species is not currently calculated within the bed.

The phase index $M$ is used to indicate the mass of constituent $K$ that is solid ( $M=1)$ or liquid $(M=2)$.

The report Materials Properties Models for Severe Core Damage Analysis 6 provides information concerning the temperature-dependent densities of Zircaloy, stainless steel, boron carbide, and the oxides $\mathrm{ZrO}_{2}$ and $\mathrm{UO}_{2}$. The associated plots from this report are shown in Figure 2.1 (three pages). Based upon this information, the arrays RHOSOL $(K)$ and RHOLIQ $(K)$ have been defined within the lower plenum debris bed model to provide single values for the densities of the solid and liquid phases of each constituent. The values assigned within these arrays are listed for each constituent in Table 2.1.

With the exception of stainless steel, it is not considered necessary to provide for treatment of the temperature dependence of density for the solid debris bed constituents, although the change in density associated with melting is significant and has been incorporated. Each of the constituents of stainless steel $(\mathrm{Fe}, \mathrm{Cr}$, Ni) has been assigned the density of stainless steel for consistency. Should a future code user desire to treat these debris constituents as distinct species, it would be a simple matter to modify the calculation (Subroutine BHHED2) of the associated elements of these arrays. 
BH Package Reference Manual

The RHOSOL and RHOLIQ arrays are used within Subroutine BHHED2 to calculate volume-averaged and phase-averaged values of the representative density within each debris bed control volume. The representative density for a bed control volume $(I, J)$ is

$$
\frac{\sum_{K=1}^{20}[A M L P(l, J, K, 1)+A M L P(l, J, K, 2)]}{\sum_{K=1}^{20}[A M L P(I, J, K, 1) / R H O S O L(K)+A M L P(l, J, K, 2) / R H O L I Q(K)]}
$$

The calculated representative control volume densities are stored within the array RHODB(l,J).

The RHOLIQ array is also used within Subroutines BHDBME, BHDBMX, and BHQSLU. Subroutine BHDBME provides for the movement (both downward relocation to a lower layer and horizontal spreading within the same layer) of molten material species within the bed. Subroutine BHDBMX calculates the release of flowing liquids from the debris bed by means of failed reactor vessel penetration assemblies.

\subsection{Specific Heat}

A representative specific heat is calculated each timestep for each debris bed control volume, based upon the relative masses of each debris constituent (as listed under "material" in Table 2.1) within the control volume.

The temperature dependencies of the specific heats of Zircaloy, stainless steel, boron carbide, and the oxides $\mathrm{ZrO}_{2}$ and $\mathrm{UO}_{2}$ as provided by Reference 6 are shown in Figure 2.2 (three pages). Based upon this information and considering the temperature range of interest of the debris bed calculations, the array CPMAT(K) has been placed within the lower plenum debris bed model to provide values of the specific heat for each control volume constituent. These values are listed in Table 2.2.

As indicated in footnote $b$ to Table 2.2, the variations in the specific heats of the stainless steel components [see Figure 2.2(b)] and of $\mathrm{ZrO}_{2}$ and $\mathrm{UO}_{2}$ [see Figures 2.2(d) and 2.2(e) respectively] with temperature are considered significant over the range of interest for the debris bed response calculations and are considered in the setting of the representative specific heat for each control volume.

The specific heat for the stainless steel components is set according to Hagrman ${ }^{6}$ as

$$
326.0+\operatorname{TF} \times(0.298-0.0000956 \times \text { TF })
$$

where $T F$ is the temperature $(K)$ of interest. This relation follows the curve of Figure 2.2(b).

The specific heat for the local mass of $\mathrm{ZrO}_{2}$ for each control volume each timestep is 
BH Package Reference Manual

calculated within Subroutine BHMENT as

$$
600.0+0.226316 \times(\mathrm{TF}-2000 .) \quad \mathrm{J} /(\mathrm{kg} \cdot \mathrm{K})
$$

where $T F$ is the current control volume temperature $(K)$. This simple relation has been developed as a fit to the portion of the curve of Figure 2.2(d) lying between $2000 \mathrm{~K}$ $\left(3140^{\circ} \mathrm{F}\right)$ and $2950 \mathrm{~K}\left(4850^{\circ} \mathrm{F}\right)$. The $\mathrm{ZrO}_{2}$ specific heat is further constrained to lie between 600.0 and $815.0 \mathrm{~J} /(\mathrm{kg} \cdot \mathrm{K})$, which follows the curve of Figure 2.2(d) for temperatures below and above this range.

The specific heat of the local mass of $\mathrm{UO}_{2}$ within each bed control volume is also calculated as a temperature-dependent value each timestep. This dependence, shown in Figure 2.2(e), is approximated over the range of interest as

$$
360.0+0.184615 \times(\mathrm{TF}-2100 .) \quad \mathrm{J} /(\mathrm{kg} \cdot \mathrm{K})
$$

and the $\mathrm{UO}_{2}$ specific heat is constrained to not be less than $330.0 \mathrm{~J} /(\mathrm{kg} \cdot \mathrm{K})$.

The material specific heats obtained by calls to Subroutine BHMENT are used within Subroutine BHHED2 to calculate mass-averaged values of the representative specific heat for each bed control volume. Based upon the plotted trends shown in Figure 2.2, a phase correction is not required. These representative specific heats are stored within the array $\mathrm{CPDEB}(\mathrm{l}, \mathrm{J})$.

Material specific heats obtained by calls to BHMENT are also used within Subroutine BHDBME, which calculates the movement of molten debris liquids within the bed, and Subroutine BHDBMX, which calculates the release of debris liquids from the lower plenum after penetration failures are predicted to have occurred. Other subroutines calling BHMENT are listed in Table 8.1.

The heat of fusion associated with melting or freezing for each constituent is entered separately and is considered to be consumed or liberated at the melting temperature. The heat of fusion, the melting temperature, and the molecular weight of each constituent are entered on input record BH02JJ. 
BH Package Reference Manual

Table 2.1 Array elements for material densities

\begin{tabular}{|cccc|}
\hline $\begin{array}{c}\text { Material Index } \\
\mathrm{K}\end{array}$ & Material & $\begin{array}{c}\mathrm{RHOSOL}(\mathrm{K})^{\mathrm{a}} \\
\mathrm{kg} / \mathrm{m}^{3}\end{array}$ & $\begin{array}{c}\mathrm{RHOLIQ(K)} \\
\mathrm{kg} / \mathrm{m}^{3}\end{array}$ \\
\hline 1 & $\mathrm{Zr}$ & 6420.2 & 6184.7 \\
2 & $\mathrm{Fe}$ & 7190.7 & 6940.8 \\
3 & $\mathrm{Cr}$ & 7190.7 & 6940.8 \\
4 & $\mathrm{Ni}$ & 7190.7 & 6940.8 \\
5 & - & 0.0 & 0.0 \\
6 & - & 0.0 & 0.0 \\
7 & - & 0.0 & 0.0 \\
8 & - & 0.0 & 0.0 \\
9 & - & 0.0 & 0.0 \\
10 & $\mathrm{~B}_{4} \mathrm{C}$ & 2399.6 & 2349.9 \\
11 & $\mathrm{ZrO}_{2}$ & 5859.6 & 5989.3 \\
12 & $\mathrm{FeO}_{10}$ & 5699.8 & 5699.8 \\
13 & $\mathrm{Fe}_{2} \mathrm{O}_{3}$ & 0.0 & 0.0 \\
14 & $\mathrm{Fe}_{3} \mathrm{O}_{4}$ & 5177.2 & 5177.2 \\
15 & $\mathrm{Cr}_{2} \mathrm{O}_{3}$ & 5125.9 & 5125.9 \\
16 & $\mathrm{NiO}_{17}$ & 6666.9 & 6666.9 \\
18 & $\mathrm{~B}_{2} \mathrm{O}_{3}$ & 1848.5 & 1848.5 \\
19 & $\mathrm{UO}_{2}$ & 10008.3 & 7999.6 \\
20 & - & 0.0 & 0.0 \\
\hline
\end{tabular}

a The RHOSOL Array is provided via DATA statements in Subroutines BHHED2 and BHQSLU.

b The RHOLIQ Array is provided in Subroutines BHHED2, BHDBME, BHDBMX, and BHQSLU. 


\section{E-WY-HQ}

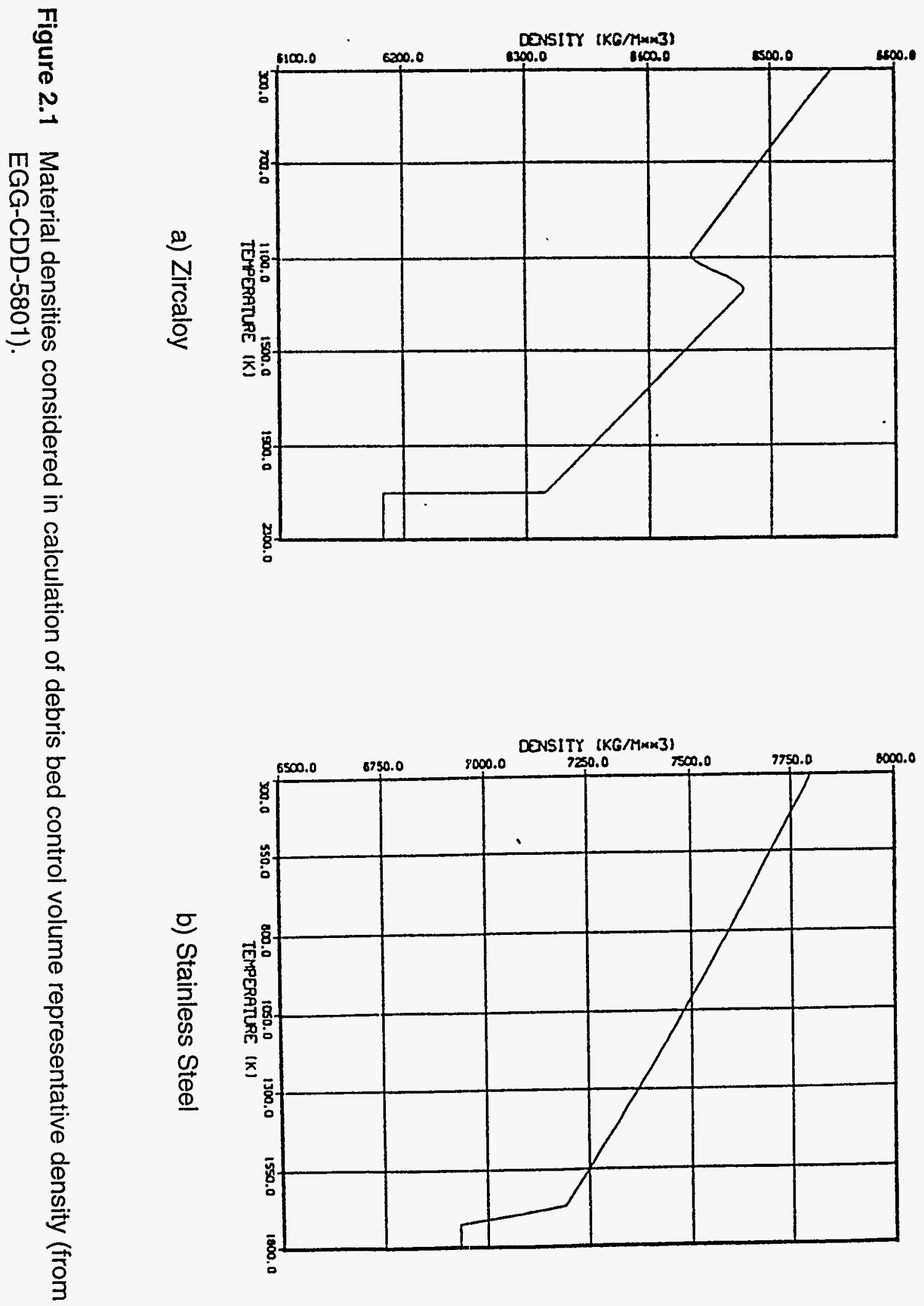

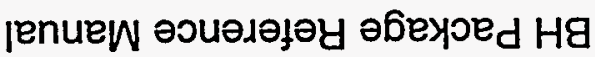



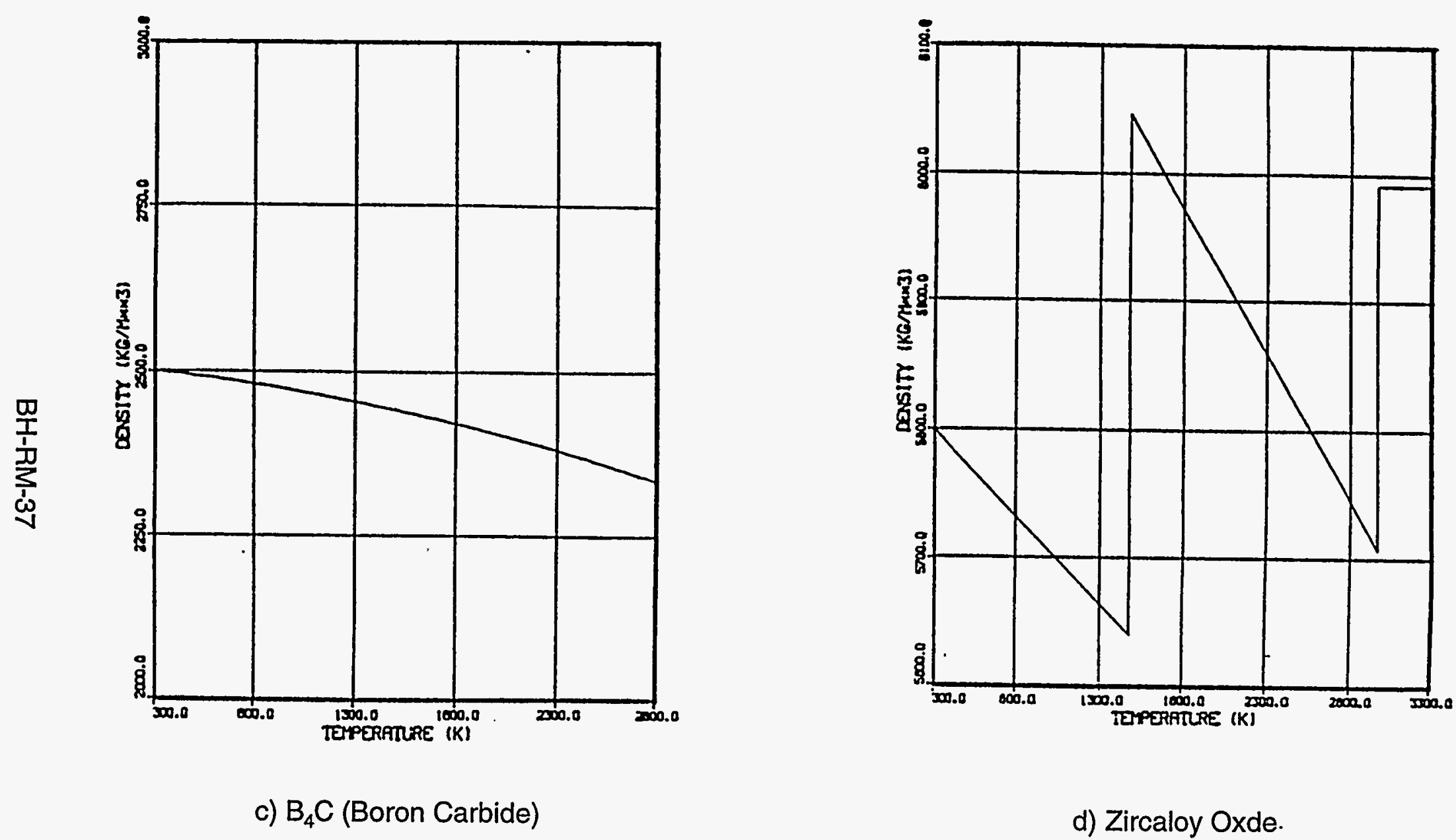

d) Zircaloy Oxde.

Figure 2.1 (Continued) Material densities considered in calculation of debris bed control volume representative density (from EGG-CDD-5801). 


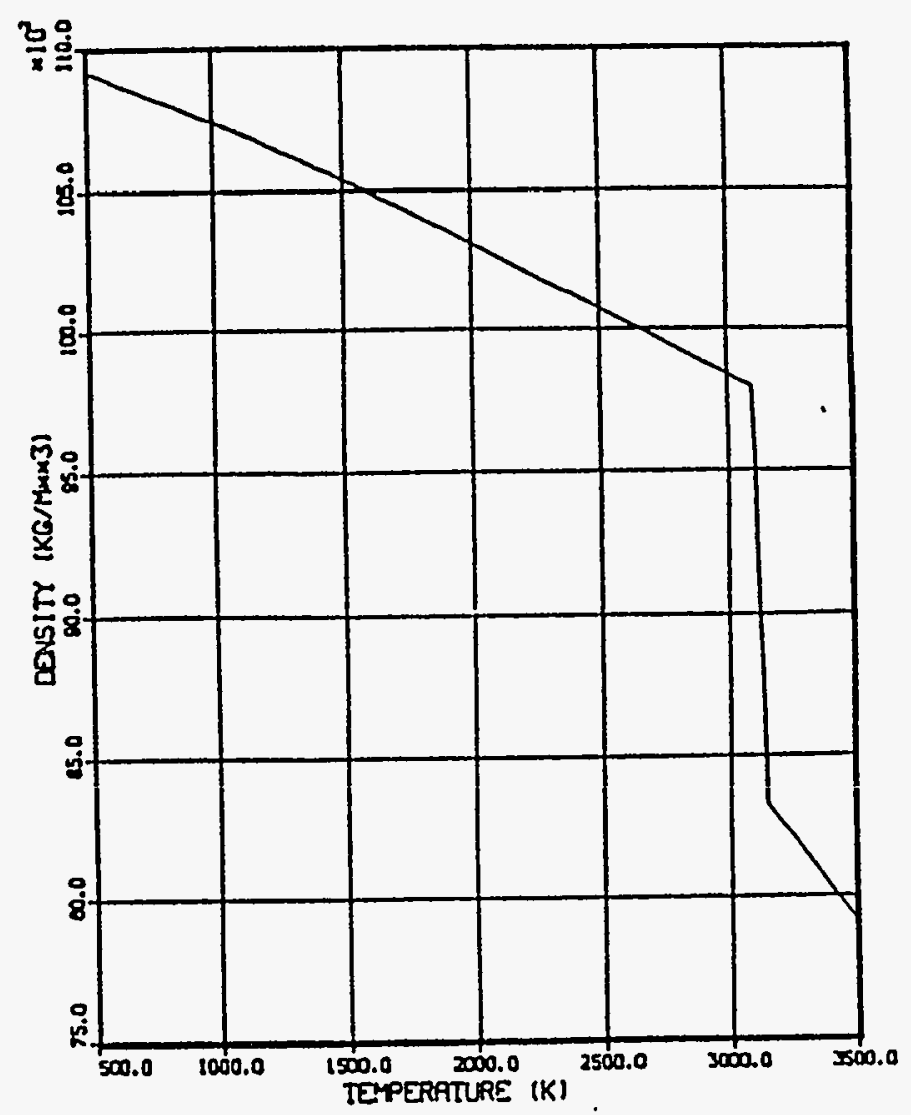

e) Fuel $\left(\mathrm{UO}_{2}\right)$

Figure 2.1 (Continued) Material densities considered in calculation of debris bed control volume representative density (from EGG-CDD-5801). 
BH Package Reference Manual

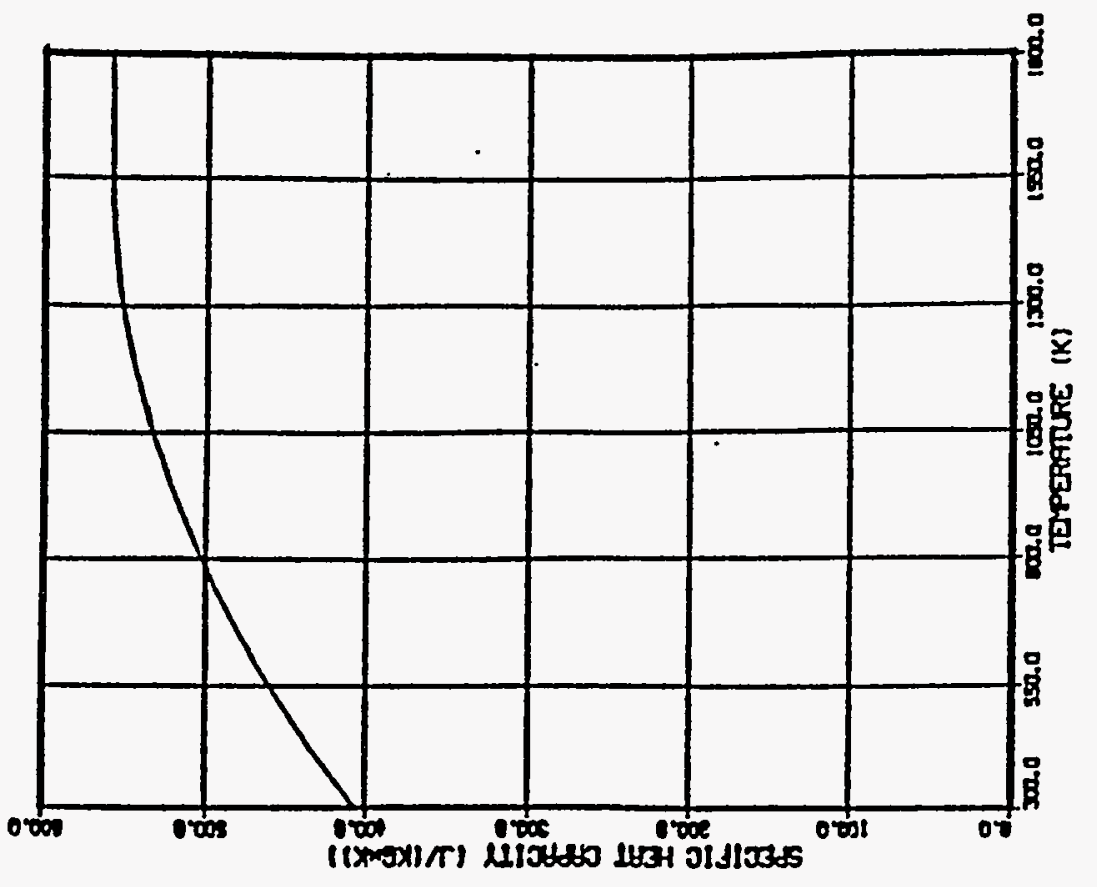

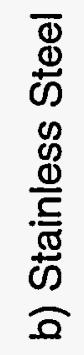
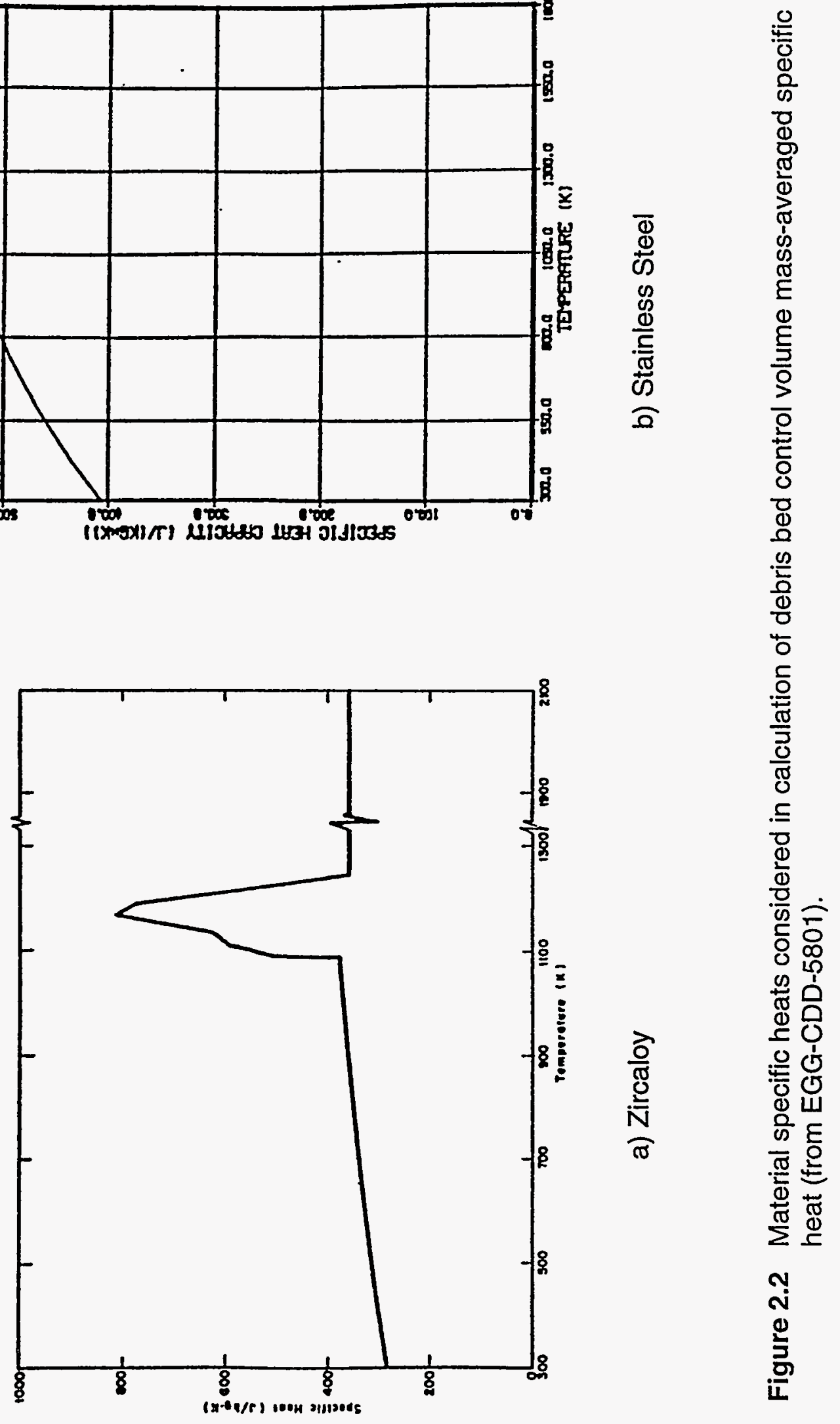

BH-RM-39 


\section{BH Package Reference Manual}
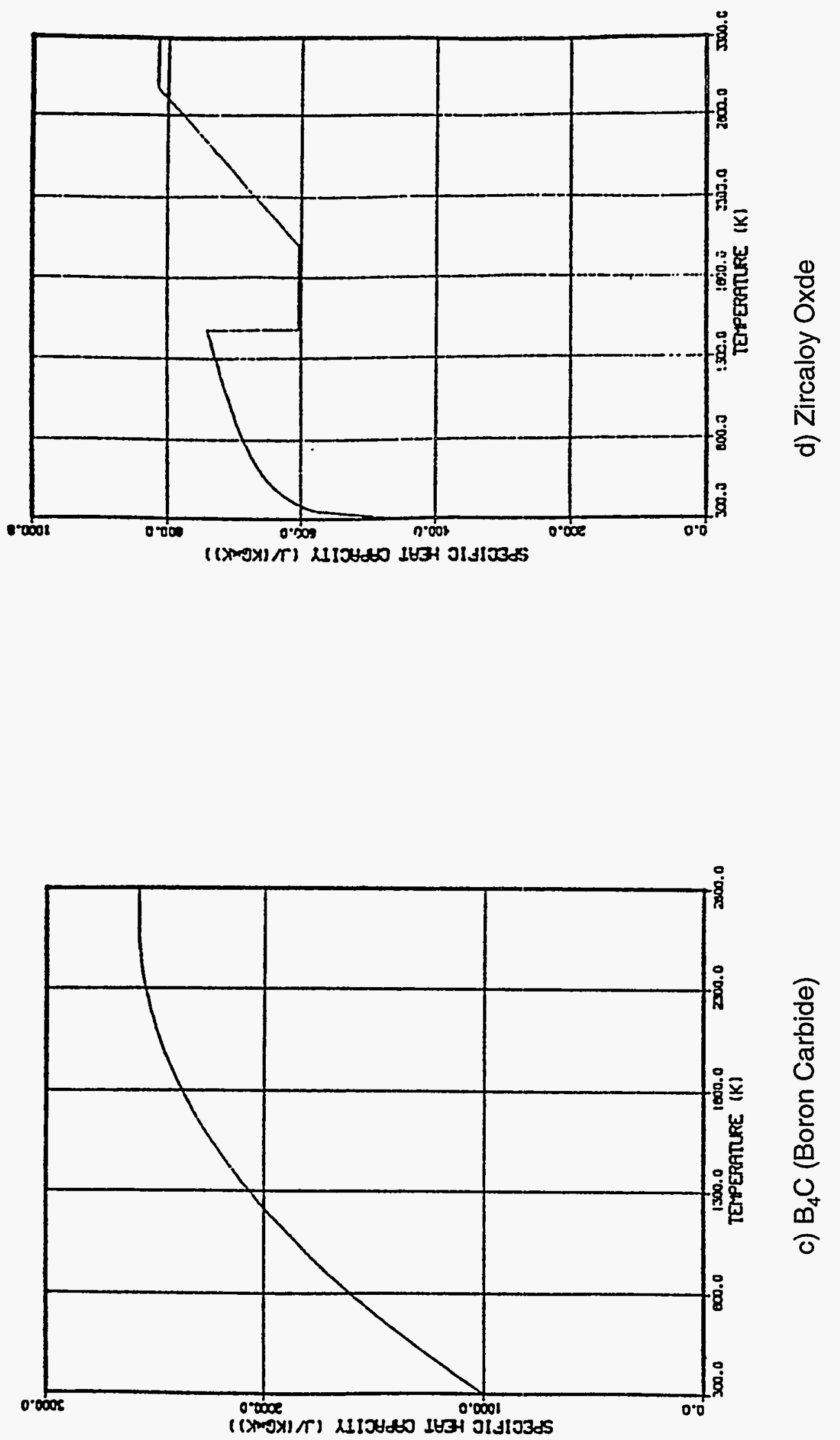

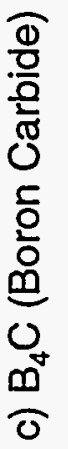

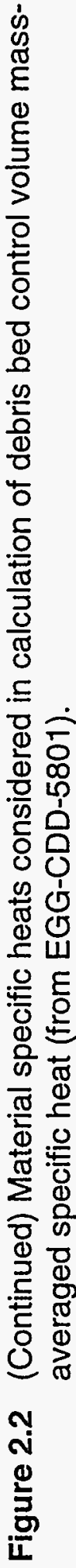


BH Package Reference Manual
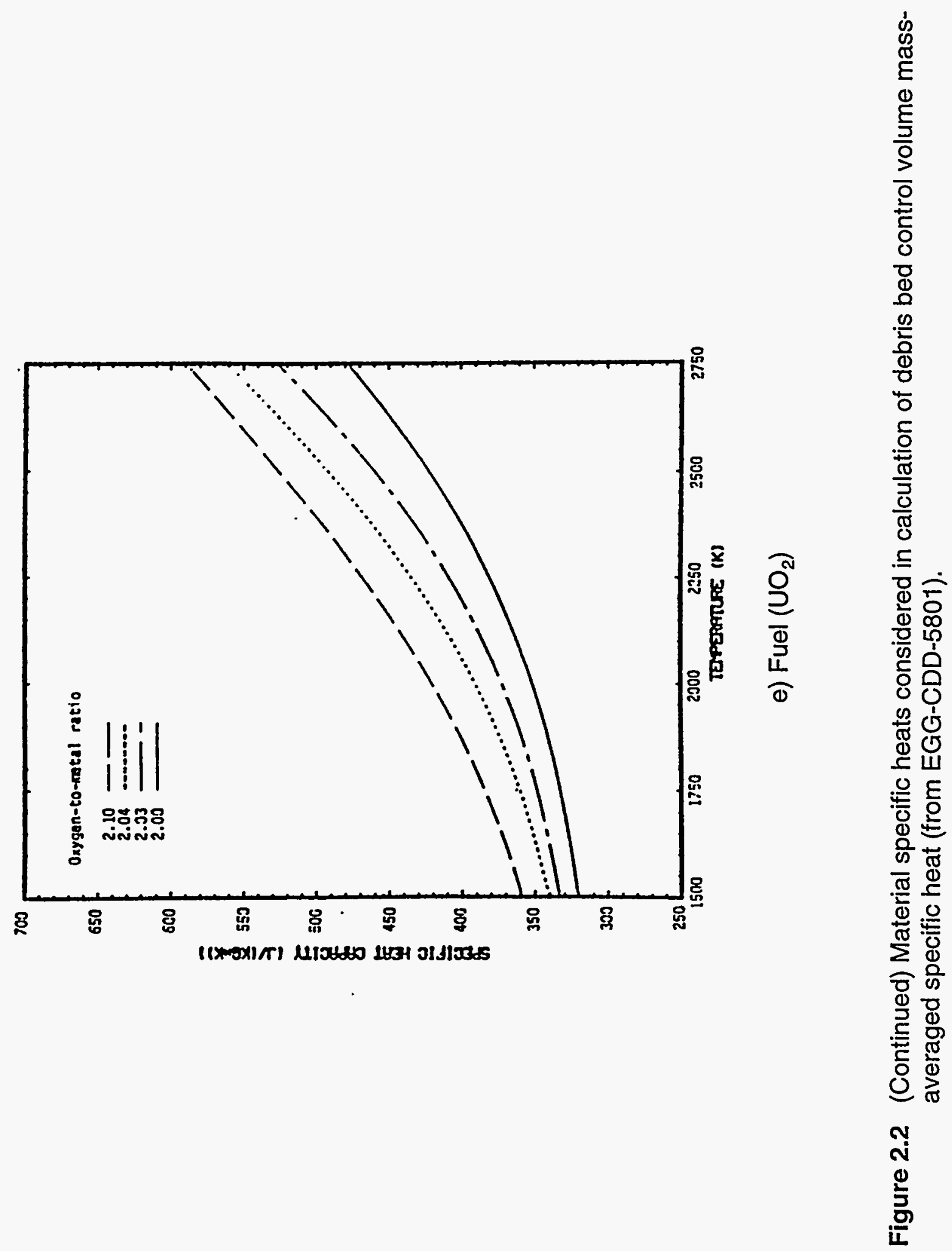
BH Package Reference Manual

Table 2.2 Array elements for solid material specific heats

\begin{tabular}{|c|c|c|c|}
\hline $\begin{array}{l}\text { Material Index } \\
\mathrm{K}\end{array}$ & Material & $\begin{array}{c}{\operatorname{CPMAT}(K)^{a}}^{\mathrm{J} /(\mathrm{kg} \cdot \mathrm{K})}\end{array}$ & \\
\hline 1 & $\mathrm{Zr}$ & 355.88 & \\
\hline 2 & $\mathrm{Fe}$ & 558.10 & \\
\hline 3 & $\mathrm{Cr}$ & 558.10 & $\begin{array}{l}\text { temperature- } \\
\text { dependent } \mathrm{b}\end{array}$ \\
\hline 4 & $\mathrm{Ni}$ & 558.10 & \\
\hline 5 & - & 0.0 & \\
\hline 6 & - & 0.0 & \\
\hline 7 & - & 0.0 & \\
\hline 8 & - & 0.0 & \\
\hline 9 & - & 0.0 & \\
\hline 10 & $\mathrm{~B}_{4} \mathrm{C}$ & 2499.94 & \\
\hline 11 & $\mathrm{ZrO}_{2}$ & 816.43 & $\begin{array}{l}\text { temperature- } \\
\text { dependent }\end{array}$ \\
\hline 12 & $\mathrm{FeO}$ & 837.36 & \\
\hline 13 & $\mathrm{Fe}_{2} \mathrm{O}_{3}$ & 0.0 & \\
\hline 14 & $\mathrm{Fe}_{3} \mathrm{O}_{4}$ & 1130.44 & \\
\hline 15 & $\mathrm{Cr}_{2} \mathrm{O}_{3}$ & 1130.44 & \\
\hline 16 & $\mathrm{NiO}$ & 782.93 & \\
\hline 17 & $\mathrm{~B}_{2} \mathrm{O}_{3}$ & 1842.19 & \\
\hline 18 & $\mathrm{UO}_{2}$ & 481.48 & $\begin{array}{l}\text { temperature- } \\
\text { dependent }\end{array}$ \\
\hline 19 & - & 0.0 & \\
\hline 20 & - & 0.0 & \\
\hline
\end{tabular}

a The CPMAT Array is provided via a DATA statement in Subroutine BHMENT.

$\mathrm{b}$ The Table entries listed here are for the material near the melting point. Within Subroutine BHMENT, temperature-dependent values are substituted for these materials each timestep (see text). 
BH Package Reference Manual

\subsection{Thermal Conductivity}

Since heat transport within the debris bed is primarily by conduction and relocation of molten materials, the representative value of thermal conductivity for each control volume is of primary importance. With the code improvements implemented for use with MELCOR, a representative thermal conductivity is calculated each timestep for each bed control volume, based upon the relative masses of each debris constituent phase within the control volume.

Figure 2.3 (three pages) provides plotted information showing the temperature dependencies of the thermal conductivities of Zircaloy, stainless steel, boron carbide, and the oxides $\mathrm{ZrO}_{2}$ and $\mathrm{UO}_{2}$ as taken from Reference 6. Based upon this information and considering the temperature range of interest for the BWR lower plenum debris bed calculations, the arrays TCSOL(K) and TCLIQ(K) have been placed within Subroutine BHHED2. These arrays are used to provide values for the thermal conductivity of the solid phase (TCSOL) and liquid phase (TCLIQ) of each debris bed constituent, as listed in Table 2.3.

As indicated in footnote $b$ of Table 2.3, the variations in the thermal conductivities of the solid-phase zirconium metal and the stainless steel components [see Figures 2.3.a and 2.3.b respectively] with temperature are considered significant over the range of interest and are included in the setting of the representative thermal conductivity for each control volume.

The variation of the solid-phase thermal conductivity of zirconium metal as shown for Zircaloy in Figure 2.3(a) is approximated within the lower plenum debris bed models as

$$
\operatorname{TCSOL}(1)=7.511+\operatorname{TF} \times[0.02088-T F \times(1.45 E-05-7.668 E-09 \times T F)] \quad W /(m \cdot K)
$$

whereas the thermal conductivity of the solid-phase stainless steel components follows Figure 2.3(b) as

$$
7.58+0.0189 \times T F \quad \text { for } T F<1671 K
$$

and

$$
610.94-0.34218 \times \text { TF } \quad \text { for } T F>1671 K
$$

with a minimum value of $20.0 \mathrm{~W} /(\mathrm{m} \cdot \mathrm{K})$.

The representative debris bed control volume thermal conductivities determined within Subroutine BHHED2 are stored within array $\operatorname{CONDB}(\mathrm{l}, \mathrm{J})$. These values are adjusted to reflect the effect of radiative heat transfer between the particles of the debris bed using the method described in Section 2.3.1 of Reference 7. At low porosity, the thermal conductivity represents conduction through the solid and liquid phases of the debris. 


\section{BH Package Reference Manual}

As the control volume porosity increases, the thermal conductivity increasingly represents particle-to-particle radiation in a steam atmosphere. Therefore, the effect of increasing voids is to lower the control volume representative thermal conductivity, even at high temperatures.

It should be noted, however, that control volume porosities greater than 0.50 are not normally predicted by the lower plenum debris bed model. This is because molten material relocating downward from the middle debris layer leads to adjustment of control volume dimensions (Section 4.3) or merging with the overlying layer three control volumes before such large porosities can develop. The models for control volume merging are discussed in Section 4.4.

Most lower plenum debris bed response calculations are performed with the assumption that bottom head penetration failures do occur as conditions warrant. Accordingly, the liquid fraction within any calculational control volume remains small since the liquid drains from the reactor vessel as it is formed. The model can be exercised, however, with the provision that penetration failures cannot occur, in which case the control volumes will eventually consist primarily or even totally of liquid. Within the upper liquid regions of the debris bed, heat transport would be greatly enhanced by the buoyancy-driven circulation of molten liquids. While the model has no representation of this liquid circulation, the associated increase in heat transport is represented by increasing the effective mass-averaged and phase-averaged thermal conductivity by a factor of ten whenever the liquid mass within a control volume exceeds two-thirds of the total control volume mass. 
BH Package Reference Manual
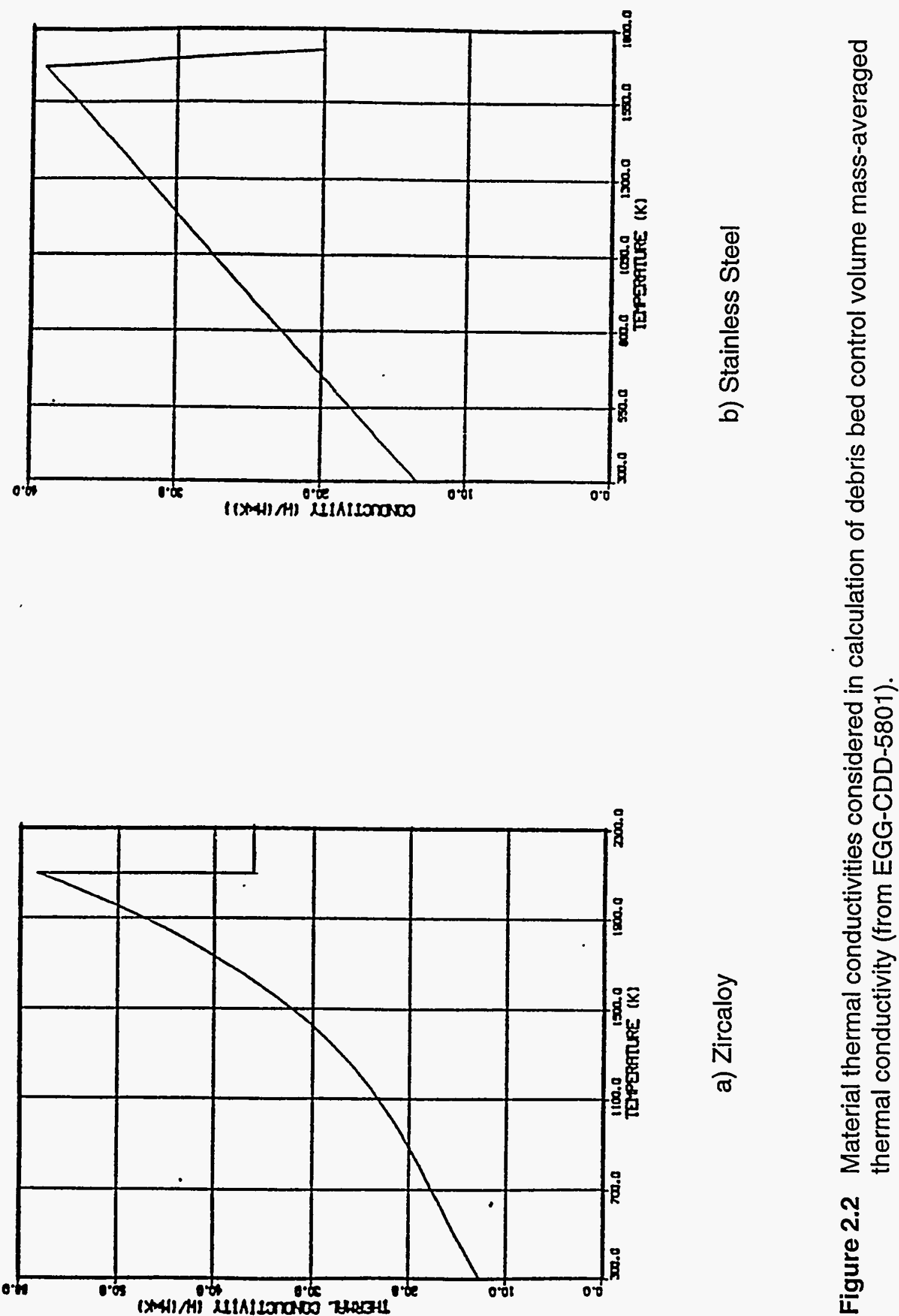

BH-RM-45 


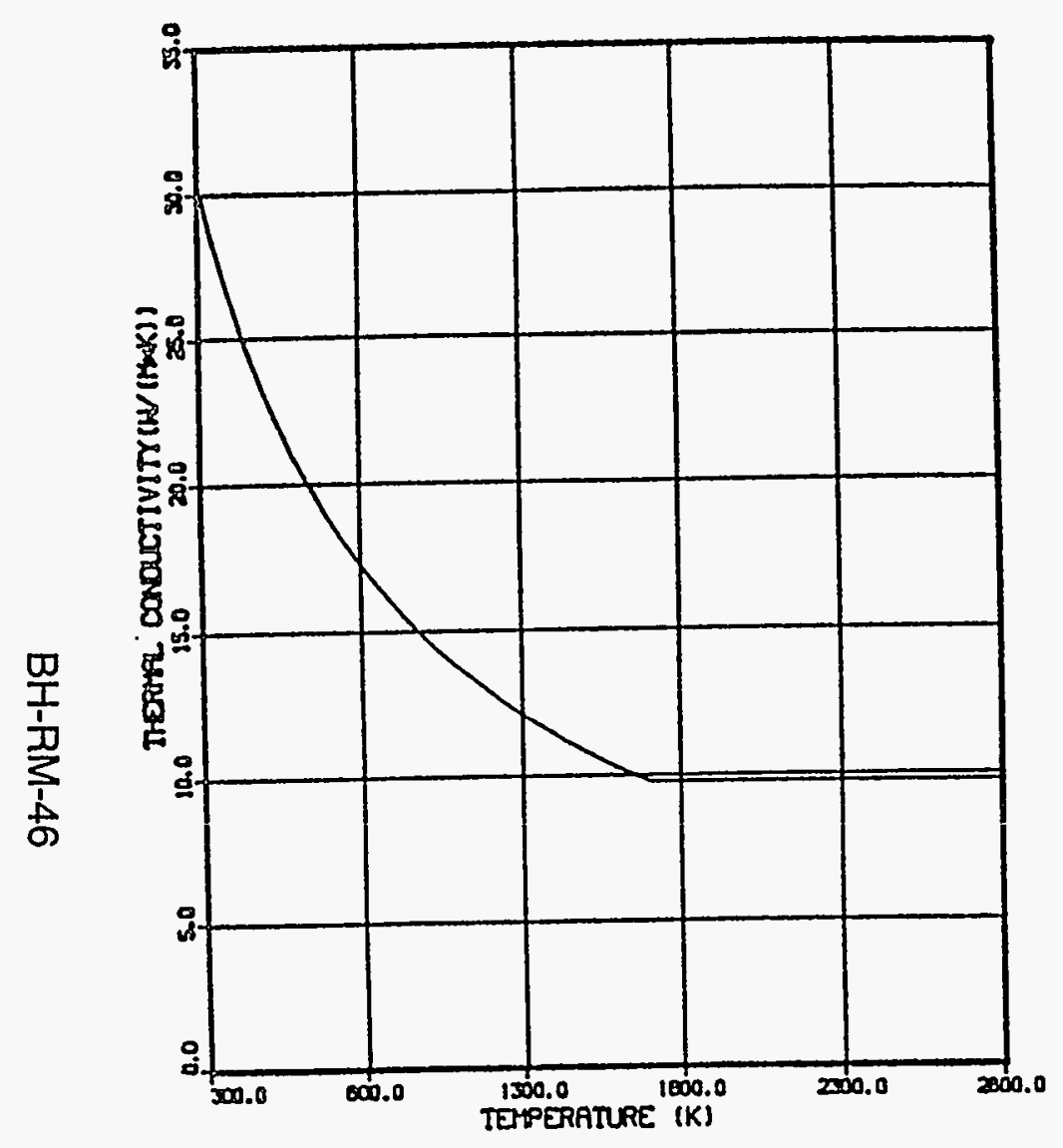

c) $\mathrm{B}_{4} \mathrm{C}$ (Boron Carbide)

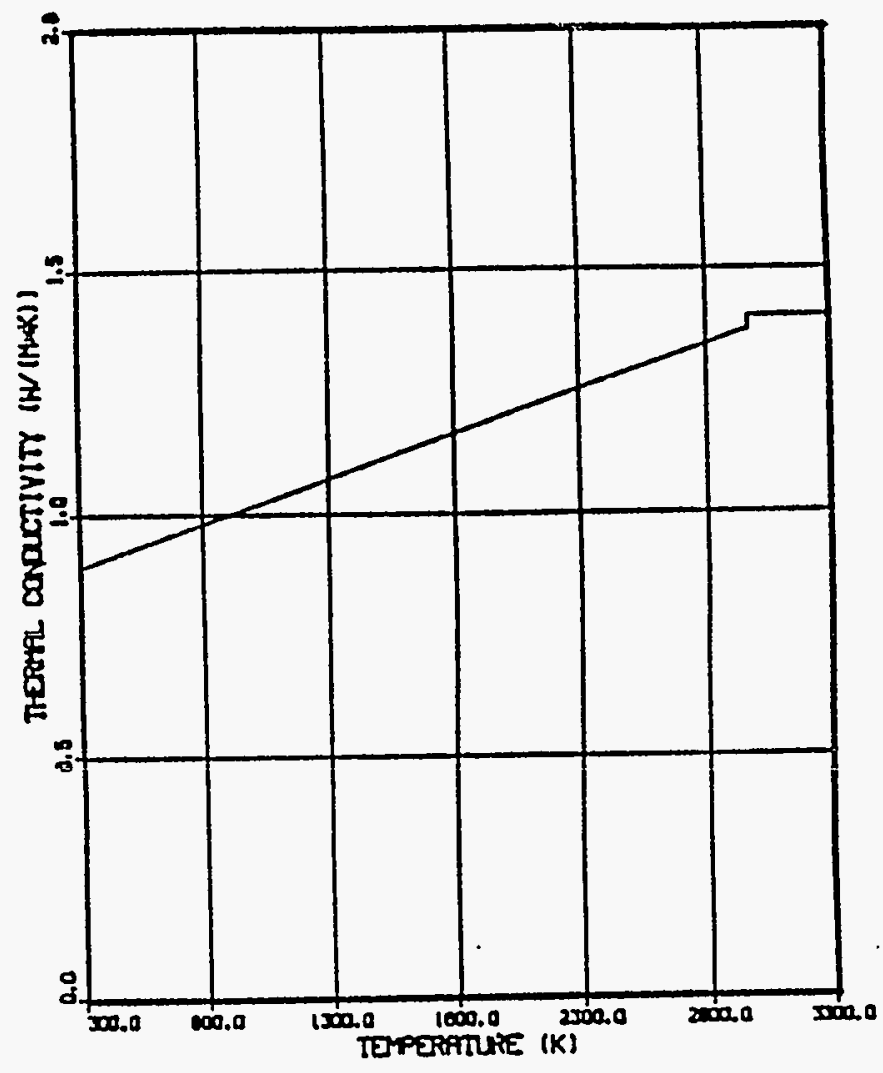

d) Zircaloy Oxde

Figure 2.3 (Continued) Material thermal conductivities considered in calculation of debris bed control volume mass-averaged thermal conductivity (from EGG-CDD-5801). 


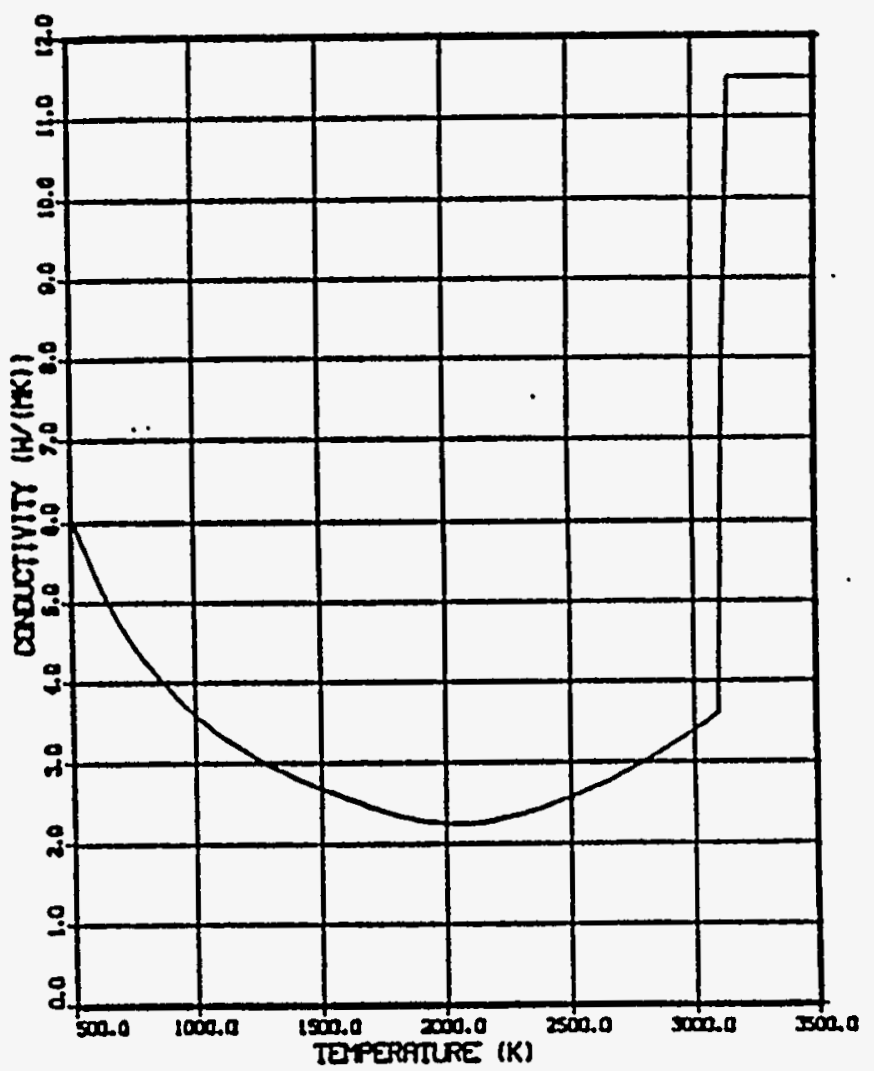

e) Fuel $\left(\mathrm{UO}_{2}\right)$

Figure 2.3 (Continued) Material thermal conductivities considered in calculation of debris bed control volume mass-averaged thermal conductivity (from EGG-CDD-5801). 
BH Package Reference Manual

Table 2.3 Array elements for material thermal conductivities

\begin{tabular}{|c|c|c|c|}
\hline $\begin{array}{l}\text { Material Index } \\
\mathrm{K}\end{array}$ & Material & $\begin{array}{c}\mathrm{TCSOL}(\mathrm{K})^{\mathrm{a}} \\
\mathrm{W} /(\mathrm{m} \cdot \mathrm{K})\end{array}$ & $\begin{array}{c}\text { TCLIQ }(\mathrm{K})^{\mathrm{a}} \\
\mathrm{W} /(\mathrm{m} \cdot \mathrm{K})\end{array}$ \\
\hline 1 & $\mathrm{Zr}$ & $40.427^{b}$ & 36.003 \\
\hline 2 & $\mathrm{Fe}$ & $38.703^{b}$ & 20.000 \\
\hline 3 & $\mathrm{Cr}$ & $38.703^{b}$ & 20.000 \\
\hline 4 & $\mathrm{Ni}$ & $38.703^{b}$ & 20.000 \\
\hline 5 & - & 0.0 & 0.0 \\
\hline 6 & - & 0.0 & 0.0 \\
\hline 7 & - & 0.0 & 0.0 \\
\hline 8 & - & 0.0 & 0.0 \\
\hline 9 & - & 0.0 & 0.0 \\
\hline 10 & $\mathrm{~B}_{4} \mathrm{C}$ & 9.969 & 9.751 \\
\hline 11 & $\mathrm{ZrO}_{2}$ & 1.277 & 1.402 \\
\hline 12 & $\mathrm{FeO}$ & 1.558 & 1.662 \\
\hline 13 & $\mathrm{Fe}_{2} \mathrm{O}_{3}$ & 0.0 & 0.0 \\
\hline 14 & $\mathrm{Fe}_{3} \mathrm{O}_{4}$ & 1.558 & 1.662 \\
\hline 15 & $\mathrm{Cr}_{2} \mathrm{O}_{3}$ & 1.558 & 1.662 \\
\hline 16 & $\mathrm{NiO}$ & 1.558 & 1.662 \\
\hline 17 & $\mathrm{~B}_{2} \mathrm{O}_{3}$ & 1.558 & 1.662 \\
\hline 18 & $\mathrm{UO}_{2}$ & 3.001 & 11.506 \\
\hline 19 & - & 0.0 & 0.0 \\
\hline 20 & - & 0.0 & 0.0 \\
\hline
\end{tabular}

a The TCSOL and TCLIQ Arrays are provided via DATA statements in Subroutine BHHED2.

$\mathrm{b}$ The TCSOL elements for $\mathrm{Zr}$ and the stainless steel constituents are updated each timestep with temperature-dependent values (see text). 
BH Package Reference Manual

\section{DEBRIS HEAT TRANSFER AND OXIDATION}

The heat balances for each debris control volume are initiated at the time of lower plenum dryout. Heat transfer by conduction is calculated for control volume-to-control volume and control volume-to-wall energy transfer. Additionally, radiation and convection from the surfaces of the upper debris layer control volumes to the vessel atmosphere and to intact structures above the debris bed are considered. Radiation to the shroud and axial conduction along the vessel wall causes boiloff of water remaining in the downcomer jet pump region. Also included in the control volume heat balances are the change-of-phase heat of fusion of pure species or eutectic mixtures as they melt or refreeze within the bed.

The heat balance for control volumes beneath the surface layer of the bed is described in Section 3.1. The additional heat transfer terms applicable to the control volumes that interface with the vessel atmosphere are discussed in Sections 3.2 and 3.3. These calculations are performed within Subroutine BHHED2 of the BWR Lower Plenum Debris Bed (BH) Package.

\subsection{Heat Transfer Between Bed Control Volumes}

The debris bed is considered to consist of a solid porous medium in the presence of liquid. The amount of liquid occupying the interstitial pores can vary from insignificant to overwhelming, in which case individual control volumes have become almost entirely or even completely liquid.

The radial heat transfer between control volumes in the same debris layer is represented in the heat balance as

$$
\begin{gathered}
A_{C V} \frac{T_{R}-T_{C V}}{\frac{X R_{C V}-R_{C V}}{C O N_{C V}}+\frac{R_{R}-X R_{C V}}{C O N_{R}}} \\
+\quad A_{L} \frac{T_{L}-T_{C V}}{\frac{X R_{L}-R_{L}}{C O N_{L}}+\frac{R_{C V}-X R_{L}}{C O N_{C V}}} \quad \text { Watts }
\end{gathered}
$$

where

$$
\begin{aligned}
\mathrm{AR}= & \text { interface area AINFCR }(I, J) \text { at the right vertical boundary of the control } \\
& \text { volume, } \mathrm{m}^{2} \\
\mathrm{~T}= & \text { control volume temperature TMLPO }(\mathrm{I}, \mathrm{J}), \mathrm{K} \\
\mathrm{XR}= & \text { radius } \mathrm{XRT}(\mathrm{I}, \mathrm{J}) \text { from the lower plenum centerline to the right vertical } \\
& \text { boundary of control volume }(I, J), \mathrm{m}
\end{aligned}
$$




\section{BH Package Reference Manual}

$\mathrm{R}=$ radius $\mathrm{RNODE}(\mathrm{I}, \mathrm{J})$ from the lower plenum centerline to the center of mass of control volume $(\mathrm{I}, \mathrm{J}), \mathrm{m}$

$\mathrm{CON}=$ representative thermal conductivity $\operatorname{CONDB}(\mathrm{I}, \mathrm{J})$ for the debris within control volume $(\mathrm{l}, \mathrm{J}), \mathrm{W} /(\mathrm{m} \cdot \mathrm{K})$.

The subscripts identify the relative radial positions of the three control volumes as:

$\mathrm{CV}=$ control volume for which the heat balance is being performed,

$\mathrm{L} \quad=$ control volume to the left, and

$\mathrm{R}=$ control volume to the right.

Only the first radial heat transfer term is used for the centerline control volume in each debris layer; conversely, the outermost control volume uses only the second term.

Axial heat transfer for the middle (second) debris layer control volumes is represented in the heat balance as

$$
\begin{array}{r}
A A_{B} \frac{T_{B}-T_{C V}}{\frac{Y T_{B}-H_{B}}{C O N_{B}}+\frac{H_{C V}-Y T_{B}}{C O N_{C V}}} \\
+ \\
A A_{C V} \frac{T_{U}-T_{C V}}{\frac{Y T_{C V}-H_{C V}}{C O N_{C V}}+\frac{H_{U}-Y T_{C V}}{C O N_{U}}} \quad \text { Watts }
\end{array}
$$

where

$$
\begin{aligned}
\mathrm{AA}= & \text { upper surface area AINFCA }(I, J) \text { of the control volume, } \mathrm{m}^{2} \\
\mathrm{YT}= & \text { elevation YRT(I,J) of the upper surface of the control volume above } \\
& \text { vessel zero, } \mathrm{m}
\end{aligned}
$$

As before, the subscript CV identifies the control volume for which the heat balance is being performed. The other subscripts identify the relative axial positions of the adjacent control volumes as:

$\mathrm{B}=$ the control volume below, and

$\mathrm{U}=$ the overlying control volume.

Layer three control volumes employ only the first axial heat transfer term while layer one control volumes use only the second term.

Each control volume heat balance incorporates central heat sources and sinks as follows: 


\begin{tabular}{|c|c|}
\hline QDOT(I,J) & $\begin{array}{l}=\text { control volume decay power heat source (based upon } \\
\text { amount of } \mathrm{UO}_{2} \text { present), Watts }\end{array}$ \\
\hline QPFGS(I,J) & $\begin{array}{l}=\text { heat sink to the gas mixture passing through the control } \\
\text { volume (after penetration failure), Watts }\end{array}$ \\
\hline QPFMW(I,J) & $\begin{array}{l}=\text { metal-steam reaction heat source within control } \\
\text { volume, Watts }\end{array}$ \\
\hline MLD & $\begin{aligned}= & \text { heat source to layer one control volumes (only) by } \\
& \text { liquid flow through penetration failures, Watts. }\end{aligned}$ \\
\hline
\end{tabular}

The rationale for QPFGS $(I, J)$ and QPFMW(I,J) is described in Section 3.4. The basis for QMLDEB $(\mathrm{J})$ is described in Section 5.3. Any of these three control volume heat transfer rates can have negative values, for which sources become sinks and viceversa.

All debris bed control volumes in layer one plus control volumes $(2,5)$ and $(3,5)$ abut the reactor vessel bottom head wall (Figure 1.10). For these control volumes, conduction into the adjacent wall is considered within the heat balance. This is accomplished by summing over the wall nodes adjacent to the control volume:

$$
A H \frac{T H D-T_{C V}}{\frac{L W}{C O N}+\frac{L H}{2 \times B H A K C S}} \quad \text { Watts }
$$

where

$$
\begin{aligned}
& \mathrm{AH}=\operatorname{AHEAD}(\mathrm{M}) \text {, inner surface area of wall node } \mathrm{M}, \mathrm{m}^{2} \\
& \text { THD = THDWO }(1, M) \text {, temperature of the first (inner) segment of wall node } \\
& \mathrm{M}, \mathrm{K} \\
& \mathrm{LW}=\mathrm{XLW}(\mathrm{I}, \mathrm{J}) \text {, radial distance from center of mass of control volume }(\mathrm{I}, \mathrm{J}) \\
& \text { perpendicular to the adjacent wall, } m \\
& \text { LH }=X \operatorname{LHEAD}(1, M) \text {, radial thickness of the inner segment of wall node } M \text {, } \\
& \mathrm{m} \text {. } \\
& \text { BHAKCS = Function BHAKCS(THD), temperature-dependent conductivity of } \\
& \text { carbon steel, } \mathrm{W} /(\mathrm{m} \cdot \mathrm{K}) \text {. }
\end{aligned}
$$

Provision is made to account for slippage of the debris downward past the wall nodes as the bed settles. Array elements HTW(M) are set to 0.0 for each wall node above the bed surface and to 1.0 for each wall node in contact with a debris bed control volume at the time of lower plenum dryout. Array elements HTW2(M) are also set to zero at this time. As the bed settles, the HTW(M) array elements are reset to zero if wall node $M$ loses contact with its original adjacent debris bed control volume. Furthermore, the elements of the HTW2(M) array are reset from 0.0 to 1.0 as control volume $(3,5)$ slides 


\section{BH Package Reference Manual}

down and replaces control volume $(2,5)$ as adjacent to wall node $M$. The calculated heat conduction rates to the wall are then multiplied by HTW(M) or HTW2(M) as appropriate to adjust for changes in the bed geometry.

\subsection{Heat Transfer With the Vessel Atmosphere}

Radiation and convection from the upper surface of the debris bed to the vessel atmosphere are considered by the lower plenum model. The general arrangement of the BWR reactor vessel lower plenum structures is shown in Figure 3.1. The entire debris bed would be contained within the portion of the lower plenum beneath the downcomer region baffle plate. Individual surface temperatures are calculated for each of the five control volumes of the upper debris layer.

Before entering into a detailed description of the heat transfer calculations, it should be noted that the general concept of the "vessel atmosphere" differs for the periods before and after the third debris layer is established. As described in Sections 1.1.2 and 1.1.3, the second debris layer is initiated at the time of lower plenum dryout and continues to build until its temperature is sufficient to trigger the initiation of layer three.

During the period while layer two continues to build, the heat sink associated with the vessel atmosphere is considered to be dominated by the metallic mass of the remaining portions of the control rod guide tubes and other lower plenum structures above the current elevation of the debris bed surface. Accordingly, the temperature (TGRID2) of this stainless steel mass is calculated within the BH Package each timestep, based upon the heat transfer from the bed surface. The MELCOR interface routine BHRUN1 then provides a calculation of heat transfer between the control rod guide tubes and the lower plenum atmosphere, based upon the temperature TGRID2.

When debris bed layer three is established, however, all remaining lower plenum structural mass is considered to be subsumed within this layer. Therefore, from this time forward, the vessel atmosphere heat sink consists only of the lower plenum gases above the bed surface. The bed surface-to-atmosphere heat transfer rates established within the BH Package are not applied within this Package, but instead are passed back to MELCOR, where the current vessel atmosphere temperature is calculated each timestep.

\subsubsection{Surface Heat Transfer Coefficients}

The coefficients for heat transfer between the reactor vessel atmosphere and the debris bed surfaces or exposed segments of the bottom head wall are calculated within Subroutine BHHED2 by means of calls to Subroutines BHST2P and BHHRST. These seven coefficients include the effects of both natural convection and radiation and are stored in the array $\operatorname{HSURF}(\mathrm{N})$. The seven surfaces represented are defined in the 
BH Package Reference Manual

following Table, where the control volume layer index NT is initially 2 , then becomes 3 after the third debris bed layer is established.

Table 3.1 Surfaces considered for heat transfer with the vessel atmosphere

\begin{tabular}{|cl|}
\hline Surface N & \multicolumn{1}{c|}{ Definition } \\
\hline 1 & Debris control volume (NT,1) upper surface \\
2 & Debris control volume (NT,2) upper surface \\
3 & Debris control volume (NT,3) upper surface \\
4 & Debris control volume (NT,4) upper surface \\
5 & Debris control volume (NT,5) upper surface \\
6 & Inner segment of wall node 17 \\
7 & Exposed bottom head wall segments between the bed surface \\
& and the bottom of wall node 17 \\
\hline
\end{tabular}

Wall node 17 is located just below the shroud baffle as shown on Figure 1.10. The surface temperatures are stored in the array TDBSUR(N) while the characteristic lengths (area-to-perimeter ratios) for each surface are stored in array CLS(N).

The calculation of the surface heat transfer coefficients is controlled by Subroutine BHHED2. For each surface N, the first step is to call Subroutine BHST2P with the constituent masses of the lower plenum atmosphere, the atmosphere temperature TGXXXX, the vessel pressure PVSL, and the surface temperature. Table 3.2 indicates the information returned. 
BH Package Reference Manual

Table 3.2 Mixture parameters returned by Subroutine BHST2P

\begin{tabular}{|ll|c|}
\hline Parameter & Definition & Mixture \\
\hline CONDMR $\quad$ Mixture thermal conductivity $\mathrm{W} /(\mathrm{m} \cdot \mathrm{K})$ & $\begin{array}{c}\text { Constituent } \\
\text { gases } \\
\text { at PVSL and } \\
\text { TDBSUR(N) }\end{array}$ \\
\hline VISMB $\quad$ Mixture viscosity $\mathrm{kg} /(\mathrm{m} \cdot \mathrm{s})$ & $\begin{array}{c}\text { Constituent } \\
\text { gases } \\
\text { at PVSL and } \\
\text { TGXXXX }\end{array}$ \\
\hline
\end{tabular}

Provision is made for consideration of a mixture of the constituent gases steam, hydrogen, carbon monoxide, carbon dioxide, and methane. Although MELCOR normally considers only the first two of these to compose the vessel atmosphere, the user can choose (by appropriate code input) to represent the reaction of $\mathrm{B}_{4} \mathrm{C}$ powder with steam, which will produce the latter three gases.

The next step is to calculate the natural convection heat transfer coefficient based upon the Grashof number

$$
\mathrm{GR}=\mathrm{Cg} \times\left(\frac{\mathrm{RHOMB}}{\mathrm{VISMB}}\right)^{2} \times \mathrm{BETA} \times[\mathrm{TS}-\mathrm{TG}] \times(\mathrm{CL})^{3}
$$

where

$\mathrm{Cg}=$ acceleration of gravity, $9.81 \mathrm{~m} / \mathrm{s}^{2}$

TS = surface temperature TDBSUR(N), K

TG = atmosphere temperature TGXXXX, $\mathrm{K}$

$\mathrm{BETA}=\frac{1.0}{\frac{\mathrm{TS}+\mathrm{TG}}{2}}, \mathrm{~K}^{-1}$

$\mathrm{CL} \quad=$ characteristic length equal to twice the area-to-perimeter ratio $\mathrm{CLS}(\mathrm{N}), \mathrm{m}$. For the annular bed surfaces, this is the outer radius minus the inner radius. For the exposed wall nodes, $\mathrm{CL}$ is the vertical nodal height. 
BH Package Reference Manual

The natural convection coefficient is then

$$
\mathrm{HNC}=\mathrm{C}_{1} \times \text { CONDMR } \times \frac{[\mathrm{GR} \times \mathrm{PRMR}]^{\mathrm{C}_{2}}}{\mathrm{CL}} \mathrm{W} /\left(\mathrm{m}^{2} \cdot \mathrm{K}\right)
$$

where $\mathrm{C}_{1}$ and $\mathrm{C}_{2}$ are constants with values determined by the Grashof number as indicated in the following Table.

Table 3.3 Values of $C_{1}$ and $C_{2}$ (Reference 22)

\begin{tabular}{|c|c|c|}
\hline CONSTANT & \multicolumn{2}{|c|}{ Value } \\
& GR $\times$ PRMR $<1.0 \times 10^{8}$ & GR $\times$ PRMR $\geq 1.0 \times 10^{8}$ \\
\hline$C_{1}$ & 0.54 & 0.14 \\
$C_{2}$ & 0.25 & 0.33 \\
\hline
\end{tabular}

While these $C_{1}$ values strictly apply only for an upward-facing horizontal surface, the differences for a vertical surface are slight and the same values are used. The $\mathrm{C}_{2}$ values are identical.22

The heat transfer coefficient for radiation between the surface $\mathrm{N}$ and the atmosphere is now determined by means of a call to Subroutine BHHRST with the surface temperature TDBSUR(N), the atmosphere temperature TGXXXX, and the steam partial pressure PSV. The stainless steel emissivity is calculated within BHHRST as

$$
\text { EMISSW }=0.25617+0.000348 \times \text { [TDBSUR(N) }-616.67]
$$

based upon information provided in Reference 16. The absorptivity of steam ABSOR is obtained by a call to MELCOR Core (COR) package subroutine CORABS, where interpolation of tabular data taken from Reference 17 is performed based upon the surface temperature, the steam partial pressure and temperature, and the lower plenum beam length.

The radiative heat flux is calculated within Subroutine BHHRST by a parallel plane model

$$
\text { QRADFX }=5.6686 \times \mathrm{R} \times\left[\left(\frac{\mathrm{TS}}{100}\right)^{4}-\left(\frac{\mathrm{TG}}{100}\right)^{4}\right] \mathrm{W} / \mathrm{m}^{2}
$$


BH Package Reference Manual

where

$\mathrm{R}$

$$
=\frac{1.0}{\frac{1.0}{E M I S S W}+\frac{1.0}{A B S O R}-1.0}
$$

TS = surface temperature TDBSUR(N), $\mathrm{K}$

$\mathrm{TG}=$ vessel atmosphere temperature TGXXXX, $\mathrm{K}$.

The radiation heat transfer coefficient is then

$$
\text { HRAD }=\frac{\text { QRADFX }}{T S-T G} \quad W /\left(m^{2} \cdot K\right),
$$

where the absolute value is taken.

Finally, the overall surface heat transfer coefficient is established within Subroutine BHHED2 as

$$
\operatorname{HSURF}(\mathrm{N})=\mathrm{HNC}+\mathrm{HRAD} \quad \mathrm{W} /\left(\mathrm{m}^{2} \cdot \mathrm{K}\right),
$$

for each of the seven surfaces.

\subsubsection{Establishing the Debris Bed Surface Temperatures}

Heat transfer from the upper debris layer to the vessel atmosphere is calculated based upon the temperature difference between each debris control volume and the vessel atmosphere. Then the control volume surface temperature TDBSUR(N) is calculated for use in determining the surface heat transfer coefficient in the manner explained in Section 3.2.1.

For each of the five upper layer control volumes, the rate of heat transfer to the vessel atmosphere is established within Subroutine BHHED2 as

$$
\text { QTOGAS }=A A_{C V} \frac{T_{C V}-T G}{\frac{Y T_{C V}-H_{C V}}{C O N_{C V}}+\frac{1.0}{H S}} \quad \text { Watts }
$$


where
$\mathrm{AA}_{\mathrm{CV}}=$ upper surface area AINFCA(NT,J) of the control volume, $\mathrm{m}^{2}$
NT = index of the upper debris layer, either 2 or 3
$\mathrm{J}=\quad=$ index of control volume within layer NT, $\mathrm{J}=1$ to 5 .
$\mathrm{YT}_{\mathrm{CV}}=$ elevation $\mathrm{YRT}(\mathrm{NT}, \mathrm{J})$ of the control volume upper surface, $\mathrm{m}$
$\mathrm{H}_{\mathrm{CV}} \quad=$ elevation HNODE(NT,J) of the control volume center of mass, $\mathrm{m}$
$\mathrm{CON}_{\mathrm{CV}}=$ representative thermal conductivity $\operatorname{CONDB}(\mathrm{NT}, \mathrm{J})$ for the control volume debris, $\mathrm{W} /(\mathrm{m} \cdot \mathrm{K})$
HS = surface heat transfer coefficient $\operatorname{HSURF}(\mathrm{J}), \mathrm{W} /\left(\mathrm{m}^{2} \cdot \mathrm{K}\right)$.

This heat transfer is considered in the control volume heat balance along with the conduction terms described in Section 3.1. The index NT is 2 until the third debris layer is established, when it becomes 3 . It remains 3 unless and until the layer 3 and layer 2 control volumes within a radial zone are merged late in the calculation. It can occur that NT will be 3 in some radial zones and 2 in others.

The control volume surface temperature is based upon the heat transfer rate as follows:

$$
\operatorname{TDBSUR}(J)=\frac{\text { QTOGAS }}{\operatorname{AINFCA(NT,J)~} \times \operatorname{HSURF}(J)}+\operatorname{TGXXXX\quad K}
$$

where $J$ is the index of the control volume within debris layer NT.

\subsubsection{Exposed Vessel Wall Nodes}

As described in Section 1, the lower plenum debris bed and bottom head response model is initiated at the time of lower plenum dryout. At this time debris layer three does not exist and there will be three wall nodes exposed to the reactor vessel atmosphere between the bed surface and the bottom of the shroud baffle. With reference to Figure 1.11, these are wall nodes 15,16 , and 17; wall node 18 is adjacent to the water in the downcomer region. When the third layer is formed (the situation illustrated in Figure 1.11), then only node 17 will be exposed to the vessel atmosphere. However, the bed may settle later in the calculation causing control volume $(3,5)$ to slide downward so that wall nodes 16 and 15 may again be exposed.

Heat transfer between the vessel atmosphere and any exposed vessel wall node is calculated within Subroutine BHHED2 as

$$
\text { AH } \frac{T G-T H D}{\frac{1.0}{H S}+\frac{L H}{2 \times B H A K C S}} \quad \text { Watts }
$$




\section{BH Package Reference Manual}

where
$\mathrm{AH}=\operatorname{AHEAD}(1, M)$, inner surface area of exposed wall node $M, \mathrm{~m}^{2}$
TG = vessel atmosphere temperature, $\mathrm{K}$
THD = THDWO $(1, M)$, temperature of the inner segment of wall node $M, K$
HS = HSURF(6), surface heat transfer coefficient for exposed portion of wall, $W /\left(m^{2} \cdot K\right)$
LH $=\operatorname{XLHEAD}(1, M)$, radial thickness of inner segment of wall node $M, m$
BHAKCS = Function BHAKCS(THD), temperature-dependent conductivity of carbon steel, $W /(m \cdot K)$. 


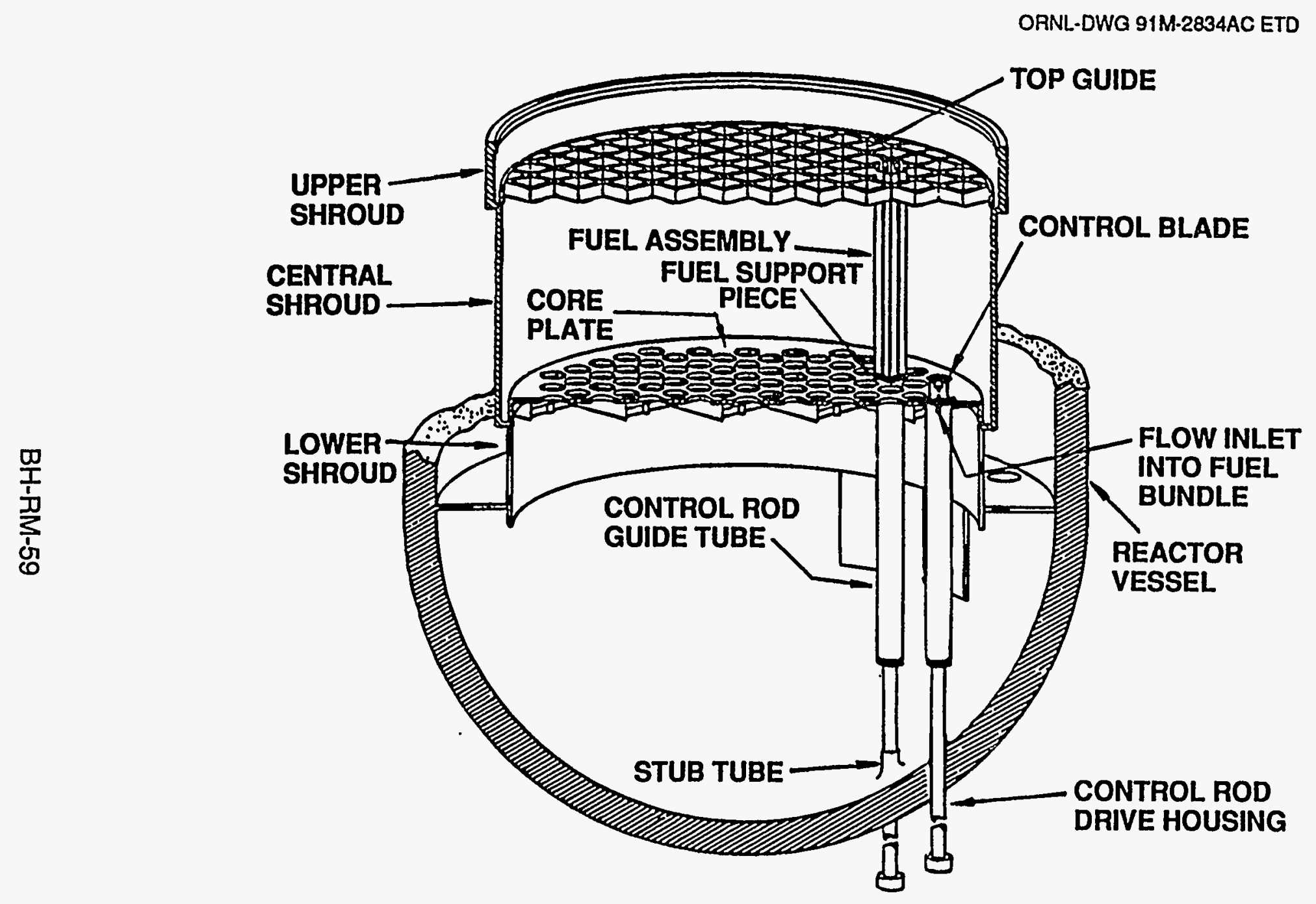

Figure 3.1 Arrangement of BWR reactor vessel lower plenum structures. 
BH Package Reference Manual

\subsection{Radiation to the Lower Plenum Structures}

After lower plenum dryout, direct radiation from the upper surfaces of the debris bed would not only heat the vessel atmosphere, but would also fall upon the core plate, the core shroud and downcomer region baffle plate, and the exposed portion of the bottom head wall. See Figures 3.1 and 1.12 for the orientation of these structures.

Heat transfer from the vessel atmosphere to the lower core shroud is calculated within the Heat Structures (HS) Package of MELCOR. The temperature TMASJP of the water within the downcomer region is then provided each timestep to the BH Package, where it is used as the heat sink temperature associated with convective heat transfer from the inner surface of the uppermost bottom head wall node NWALL.

Radiation from the debris bed surfaces to the exposed portion of the inner surface of the vessel wall is calculated within the BH Package, as explained in Sections 3.3.1 and 3.3.2. Radiation from the debris surfaces to the core plate, the lower core shroud, and the downcomer region baffle plate is calculated within the COR Package of MELCOR, and the radiation rates each timestep are passed to the BH Package.

\subsubsection{Heat Transfer Coefficients for Radiation to the Vessel Wall}

The heat transfer coefficients employed for the direct radiation pathways from the debris bed surfaces to the exposed (i.e., not covered by debris) vessel wall nodes are calculated within Subroutine BHHED2 and stored in the array HRADIT(N). The five heat transfer pathways represented are listed in the following Table.

\section{Table 3.4 Lower plenum debris-to-wall heat transfer pathways calculated by the BH Package}

\begin{tabular}{|ccc|}
\hline $\begin{array}{c}\text { Pathway No. } \\
\text { N }\end{array}$ & $\begin{array}{c}\text { From Upper Surface } \\
\text { Debris Bed Control Volume }\end{array}$ & To \\
\hline 1 & $(\mathrm{NT}, 1)$ & Exposed vessel wall \\
2 & $(\mathrm{NT}, 2)$ & Exposed vessel wall \\
3 & $(\mathrm{NT}, 3)$ & Exposed vessel wall \\
4 & $(\mathrm{NT}, 4)$ & Exposed vessel wall \\
5 & $(\mathrm{NT}, 5)$ & Exposed vessel wall \\
\hline
\end{tabular}

As before, the control volume layer index NT indicates the bed layer (either 2 or 3) with which the uppermost control volume within a debris bed radial zone is associated. 
BH Package Reference Manual

The heat flux from each debris bed surface to the exposed portion of the vessel wall is based upon the direct radiation interchange (reflections are neglected). The calculation follows the method suggested in Section 13.6 of Reference 22:

$$
\text { QRADTW }=\text { VF } \times \text { FACTR } \times\left[(T S)^{4}-(\text { TEX })^{4}\right] W / m^{2}
$$

where

$\begin{array}{cccccc}\text { View Factor }(\mathrm{VF})= & 0.135 & 0.154 & 0.191 & 0.376 & 0.564 \\ \text { for radial zone } & 1 & 2 & 3 & 4 & 5\end{array}$

$\begin{array}{lll}\text { FACTR } & = & \text { constant }=3.40116 \mathrm{E}-8 \\ \text { TS } & = & \text { bed surface temperature TDBSUR(N), } \mathrm{K} \\ \text { TEX } & \text { area-averaged temperature TDBSUR(6) of the exposed } \\ & \text { bottom head wall nodes, } \mathrm{K} .\end{array}$

The view factors listed above are the default values based upon a fully developed (three-layer) debris bed within the lower plenum of a 251-inch ID BWR reactor vessel such as installed at the Grand Gulf facility. These default values were calculated by the codes and techniques described in References 18 and 19. However, as explained in the BH Package Users' Guide [see entry VIEW2(II,JJ) on input record BH18JJKK], these view factors as well as the view factors from the debris bed surfaces to the lower core shroud and to the core plate can be modified within the input deck. Once established, however, radiation from the debris bed to the overlying structures is based on these view factors throughout the MELCOR calculation.

The constant FACTR is the product of the Stefan-Boltzman coefficient (5.6686E-8) and a radiation exchange conductance term taken to be 0.6 for the (gray) materials within the BWR lower plenum. (The conductance term is the product of the emissivities of the two surfaces involved in the radiation exchange, both assumed to be oxidized stainless steel.) The reader should recognize that the bed surface temperatures used in the calculation of QRADTW are determined from the conditions of the lower plenum atmosphere as explained in Section 3.2.2.

Finally, based upon the individual values of QRADTW for $N=1$ through $N=5$,

$$
\operatorname{HRADIT}(\mathrm{N})=\frac{\text { QRADTW }}{[\mathrm{TS}-\mathrm{TEX}]} \quad \mathrm{W} /\left(\mathrm{m}^{2} \cdot \mathrm{K}\right)
$$

are the heat transfer coefficients for direct radiation exchange between the exposed vessel wall nodes and debris bed radial zones 1 through 5, respectively. Radiation to the exposed wall surfaces from the three inner debris bed radial zones is neglected during the period while the control rod guide tubes remain intact since the associated views are considered to be blocked during this period. 


\section{BH Package Reference Manual}

\subsubsection{Direct Radiation Exchange}

For each of the five upper debris bed control volumes, radiative heat transfer based upon the bed surface temperatures TDBSUR(N) to the exposed portion of the vessel wall is calculated within the BH Package. Radiation from these surfaces to the upper reactor vessel structures, however, is calculated within the COR Package of MELCOR. The upper reactor vessel structures are comprised of the structural components of the lower core shroud, as established by HS package input, and the structural components of the core plate, as established by the COR package input. The calculated radiation heat transfer rates are passed to the BH Package each timestep by means of the array QFMTOS, via the Subroutine BHQSLU argument list. (See Section 8.2.1.)

The first dimension of array QFMTOS(N,NSW) is the index of the debris bed radial zone, $N=1,5$. The second dimension is the index of the lower plenum structure receiving radiation from the bed surfaces as defined in the following Table.

Table 3.5 Lower plenum structure indices

\begin{tabular}{|cc|}
\hline Index NSW & Lower Plenum Structure \\
\hline 1 & Exposed portion of vessel wall \\
2 & Downcomer region baffle plate \\
3 through & Cylindrical (vertical) sections of lower core shroud \\
NSHDLP +1 & \\
NSHDLP +2 & Core plate sections \\
through & \\
$1+$ NSHDLP + NRAD & \\
\hline
\end{tabular}

As may be inferred from the information provided in this Table, NSHDLP is the number of lower core shroud sections (including the downcomer baffle plate) while NRAD is the number of radial sections into which the core plate is divided. Both are determined by user input provided in record BH1800 (NSHDLP) and record COR00000 (NRAD).

The arrangement of the lower plenum upper structures for a typical calculation is shown in Figure 3.2. Here user input has divided the lower core shroud into two vertical sections (NSHDLP $=3$ ) and the core plate into four sections $(N R A D=4)$. For this example arrangement, array QFMTOS would be dimensioned as QFMTOS $(5,8)$.

For the exposed reactor vessel bottom head wall nodes, the heat transfer from each upper bed control volume as calculated in Subroutine BHHED2 is 
BH Package Reference Manual

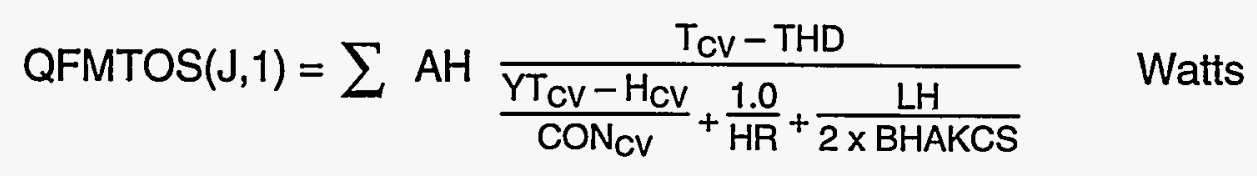

where the summation is taken over the exposed wall nodes and

$$
\begin{aligned}
& \mathrm{J}=\text { control volume index within layer NT, } 1 \text { to } 5 \\
& \text { NT = upper debris layer index (2 or } 3 \text { ) } \\
& \mathrm{AH}=\operatorname{AHEAD}(1, M) \text {, inner surface area of exposed wall node } M, \mathrm{~m}^{2} \\
& \text { THD = THDWO }(1, \mathrm{M}) \text {, temperature of the inner segment of exposed wall } \\
& \text { node } \mathrm{M}, \mathrm{K} \\
& \mathrm{YT}_{\mathrm{CV}}=\text { elevation } \mathrm{YRT}(\mathrm{NT}, \mathrm{J}) \text { of control volume upper surface, } \mathrm{m} \\
& \mathrm{H}_{\mathrm{CV}}=\text { elevation HNODE(NT,J) of control volume center of mass, } m \\
& \mathrm{CON}_{\mathrm{CV}}=\text { representative thermal conductivity } \operatorname{CONDB}(\mathrm{NT}, \mathrm{J}) \text { for the control } \\
& \text { volume debris, } \mathrm{W} /(\mathrm{m} \cdot \mathrm{K}) \\
& \mathrm{HR}=\text { direct radiation heat transfer coefficient } \operatorname{HRADIT}(\mathrm{J}), \mathrm{W} /\left(\mathrm{m}^{2} \cdot \mathrm{K}\right) \text {. } \\
& \text { LH }=\operatorname{XLHEAD}(1, M) \text {, radial thickness of the inner segment of wall node } \\
& \mathrm{M}, \mathrm{m} \\
& \text { BHAKCS = Function BHAKCS(THD), temperature-dependent conductivity of } \\
& \text { carbon steel, } W /(m \cdot K) \text {. }
\end{aligned}
$$

It is important to note that although all radiation from bed control volume $\mathrm{J}$ to the exposed wall nodes is stored in the single array element QFMTOS $(J, 1)$, the radiation received by the individual exposed wall nodes is accounted for separately within the $\mathrm{BH}$ Package. In other words, separate energy balances are performed for each individual wall node.

As described previously, elements QFMTOS $(\mathrm{J}, 2)$ through QFMTOS $(\mathrm{J}, 8)$ for the example arrangement shown in Figure 3.2 pertain to sections of the lower core shroud and the core plate and would be calculated within MELCOR. None of the surface radiation pathways are calculated for the central three control volumes of debris bed layer two during the period before layer three is established, because it is considered that the intact control rod guide tube structures would block the radiation pathways to the wall, shroud, and core plate. All calculated energy transfers from the debris bed surfaces to the exposed wall nodes and to the shroud and core plate are appropriately entered into the debris bed control volume heat balances and the vessel wall response calculations. Similarly, all radiative heat loads to the core plate and core shroud are passed into the COR and HS Packages, where their effects are properly represented.

The upper debris bed surface radiation exchange calculations provide a reasonable representation of heat transfer with the core plate, the core shroud, the downcomer region baffle plate, and the exposed portion of the vessel wall. The thermal response of the lower plenum debris bed is primarily determined by the decay heating, which is the dominant factor. Since the lower plenum debris bed would be large, its rate of 


\section{BH Package Reference Manual}

temperature increase would be relatively slow with important events such as the melting of individual species or eutectic mixtures occurring over a period of hours.

The current version of the BH Package permits the user to divide the representation of the core plate and the lower core shroud into several sections and to provide individual view factors from each debris bed radial zone to each section. As mentioned previously, however, the decay heat release dominates the events within the lower plenum debris bed. Although the integrated transfer of energy from the bed surface to the overlying structures is an important consideration to the overall calculation, the precise rate of energy transfer at any particular time is not.

\subsubsection{After Downcomer Dryout}

While water remains in the vessel downcomer region, heat transfer to this water from the uppermost bottom head wall node NWALL is modeled within the BH Package (Section 1.2). After downcomer dryout, however, radiation heat transfer between the shroud and the uppermost wall node (number 18 in Figure 1.10) can become important.

With the downcomer region dry, the radiation heat transfer from the shroud to the uppermost wall node NWALL is calculated each timestep within the MELCOR-BH package interface and passed to the BH Package as variable QRNWAL(1) (Joules) within the Subroutine BHQSLU argument list. The calculation is based upon the lower shroud temperatures as determined by the MELCOR HS Package and the temperature THDWO(1,NWALL) of the inner segment of wall node NWALL as determined within the BH Package.

After downcomer dryout, radiation from the debris bed surfaces can elevate the temperature of the lower core shroud to the stainless steel melting point; hence, consideration of the radiative exchange between the core shroud and the vessel wall is important. Within the BH Package, the temperature of wall node NWALL is appropriately adjusted each timestep in response to the energy transfer represented by the variable QRNWAL(1).

\subsubsection{Shroud Melting and Relocation}

As the calculated bed surface temperatures increase, radiative energy exchange with the overlying structures causes the evaporation (or boiling) of the water trapped within the downcomer region. The shroud temperature remains approximately equal to the water temperature and therefore (while the reactor vessel remains depressurized) approximately constant. For calculations in which bottom head penetration failures are modeled, failure of the vessel wall (and release of the remaining debris from the lower plenum) will (in general) occur before the water in the downcomer region is exhausted. 
BH Package Reference Manual

For calculations in which bottom head penetration failures are not represented, dryout of the vessel downcomer region will (in general) occur while the bottom head remains intact. The temperature of the lower core shroud will then increase, leading to a corresponding increase in the debris bed surface temperatures. Eventually, the shroud temperature will reach the steel melting temperature. All of these events are appropriately predicted to occur by the radiation exchange calculations.

The structural relocations associated with the shroud heatup and melting are calculated within the MELCOR-BH Package interface. First, the entire shroud would move downward because the baffle plate (Figure 3.2) would lose strength at elevated temperature and could no longer support the weight." For the calculation, this movement occurs whenever the predicted baffle plate temperature exceeds the userinput failure temperature TFAILS (BH1800). At this time, the baffle plate component masses are added to the upper debris layer via the AMCRPT array (Section 8.2.1). Also, to recognize that the relocated shroud would now interpose between the central portion of the debris bed and the vessel wall, the elements of the VIEW2 array representing the view factors between surfaces I, II, and III (Figure 3.2) and the exposed vessel wall are set to zero.

Radiation from the relocated shroud to the exposed wall nodes is calculated within the MELCOR-BH Package interface and passed to the BH Package via the QRNWAL array. Whereas QRNWAL(1) represents the radiation (J) from the shroud to wall node 18 for all timesteps after downcomer dryout, QRNWAL(2) and QRNWAL(3) remain zero until the time of baffle plate failure. Subsequently, these represent the radiation energy transfers from the relocated shroud to wall nodes 17 and 16, respectively. (See Figure 1.10 for the locations of the wall nodes.)

When the lower portion of the relocated shroud reached the melting temperature, a period of continuous melting would begin. As the lower shroud disintegrated, the liquid steel would be added to the upper layer of the debris bed and the upper shroud would move downward to take its place. These occurrences are modeled in the MELCOR-BH Package interface with the liquid steel transferred to the BH Package via the AMCRPT array.

More information concerning the shroud melting and relocation model is provided in Section 9.2.

\footnotetext{
- The support columns (best shown on Figure 1.7) are immersed in the debris bed and would have failed shortly after lower plenum dryout.
} 
BH Package Reference Manual

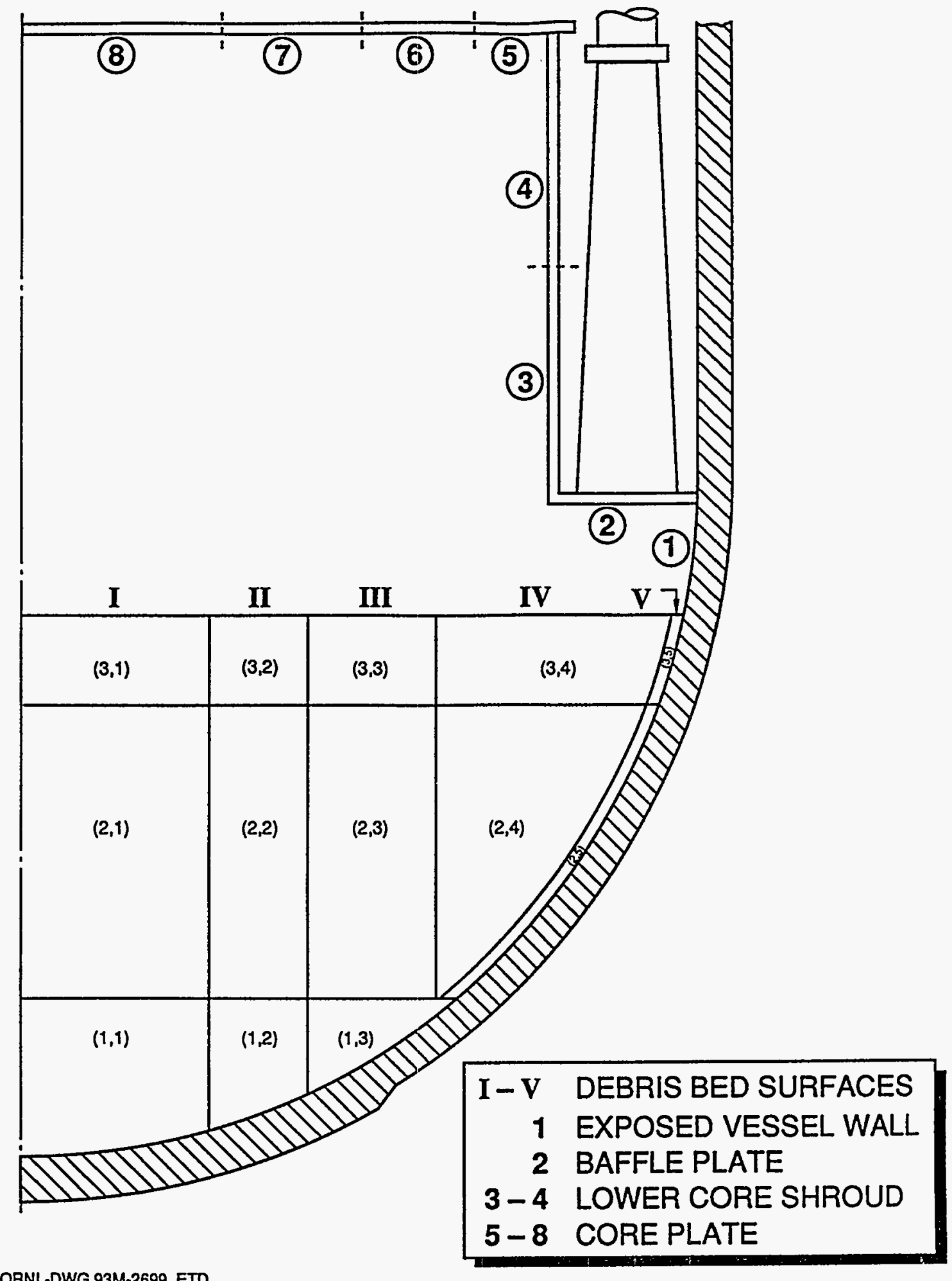

Figure 3.2 Typical nodalization of the upper structures for the radiative heat transfer within the BWR lower plenum. 
BH Package Reference Manual

\subsection{Metal-Steam Reaction in the Debris Bed}

BWR bottom head penetration failure mechanisms are described in Section 5 . Here we consider the metal-steam reaction within the debris bed that would be initiated by opening of an escape pathway for steam through the bed. In brief, for the case of heatup of a quenched debris bed, failure is expected to occur by overflow of molten materials into the instrument housing guide tubes. Since the temperature of the middle layer increases much more rapidly after bottom head dryout than does that of the bottom layer, melting of the in-core housing guide tubes would occur first in the middle layer. The criteria employed for initiation of reactor vessel blowdown through the incore instrument housing guide tubes are first, that the middle layer debris bed temperature be above the melting point of stainless steel and second, that the level of liquid components of the debris within the reactor vessel lower plenum has risen into the middle debris layer so that molten material is locally available to pour into the failed portion of the tubes.

After failure of the reactor vessel pressure boundary, a leak path from the vessel to the drywell atmosphere is created. Subsequently, the vessel gaseous content blows down if the reactor vessel is at pressure or, if the vessel is depressurized, slowly leaks out as the gas temperature increases and the water in the reactor vessel downcomer region surrounding the jet pumps is boiled away. The leak path for the steam generated from the water surrounding the jet pumps is up through the downcomer region, down through the core region, and out through the debris bed. Thus, the steam available in the vessel after the time of pressure boundary failure would pass through the debris and would react with the zirconium metal during its passage.

The metal-steam reaction is calculated in Subroutine BHMWDE for each debris bed control volume through which steam is passing. The reaction rate as limited by solid state diffusion is calculated as:

$$
\text { XDTO }=\left(\frac{A}{X_{0}}\right) e^{-\frac{B}{T_{c v}}} \quad \mathrm{~m} / \mathrm{s}
$$

where

$$
\begin{array}{ll}
\mathrm{A}, \mathrm{B} & =\text { reaction constants } \\
\mathrm{T}_{\mathrm{CV}} & =\text { control volume temperature } \mathrm{TMLPO}(\mathrm{I}, \mathrm{J}), \mathrm{K} \\
\mathrm{Xo} & =\text { initial thickness of oxide on particle surface, } \mathrm{m} .
\end{array}
$$

The oxide thickness $X o$ is taken to be $1.0 \times 10^{-8} \mathrm{~m}$ for the debris bed particles. The Cathcart relation ${ }^{8}$ is used for control volume temperatures $T_{c v}$ less than or equal to $1853 \mathrm{~K}$ so that

$$
\begin{array}{lll}
\mathrm{A} & =0.0003483 \mathrm{~m}^{2} / \mathrm{s} \\
\mathrm{B} & =20100.6 \mathrm{~K} .
\end{array}
$$




\section{BH Package Reference Manual}

For control volume temperatures greater than $1853 \mathrm{~K}$, the Baker-Just relation ${ }^{9}$ is used for which
A

$$
=0.00394
$$$$
\mathrm{m}^{2} / \mathrm{s}
$$
B

$$
=22900.0
$$
$\mathrm{K}$.

The reaction rate as limited by gaseous diffusion is calculated for the debris bed particles by the Cathcart relation 8 :

$$
\text { XDTO1 }=1.849 \times 10^{-9} \frac{\left(\frac{D F R A G}{2}\right) \times T_{f}^{0.68}}{\left(\frac{D F R A G}{2}-X_{0}\right)^{2}} \mathrm{~m} / \mathrm{s}
$$

where

$$
\begin{aligned}
\text { DFRAG } & =\text { diameter of debris particles, } \mathrm{m} \\
\mathrm{T}_{f} & =\text { film temperature, } \\
& =\frac{T_{\mathrm{CV}}+\frac{T_{\text {in }}-T_{\text {out }}}{2}}{2} \mathrm{~K}
\end{aligned}
$$$$
\mathrm{T}_{\text {in }} \quad=\text { temperature of steam entering control volume, } \mathrm{K}
$$$$
\text { Tout } \quad=\text { temperature of steam leaving control volume, } \mathrm{K} \text {. }
$$

The reaction rate used for zirconium metal within the debris bed control volume is then

$$
\text { XDTO }=\frac{\text { AMIN1 [XDTO, XDTO1] }}{\text { SFCRDB }} \mathrm{m} / \mathrm{s},
$$

which is the minimum of the rates limited by solid state diffusion and gaseous diffusion divided by the user-input shape factor (BH0700).

The shape factor SFCRDB is intended to permit the user to adjust for the noncylindrical geometry and decreased surface-to-volume ratio that may be associated with the debris particles in the lower plenum. In effect, the zirconium-steam reaction rate is calculated for the current conditions assuming cylindrical geometry and then divided by the shape factor. Since the actual representative geometry for the debris particles is unknown, this permits the user to parametrically investigate the effect of particle shape and other uncertainties that might contribute to reduction of the metalsteam reaction rate.

It is next necessary to apply the reaction rate XDTO over the surface area of zirconium metal. First, the total surface area of the debris particles is estimated as 
BH Package Reference Manual

$$
\text { BDAREA }=\frac{V_{\mathrm{CV}} \times 6.0 \times(1-\mathrm{PORB})}{\text { DFRAG }} \mathrm{m}^{2}
$$

where

$\mathrm{V}_{\mathrm{CV}} \quad=\mathrm{VLP}(\mathrm{l}, \mathrm{J})$, total volume within control volume, $\mathrm{m}^{3}$

PORB = PORB $(I, J)$, porosity of control volume solid debris

and the particles are assumed to be of cylindrical shape with length equal to diameter (typical of BWR fuel pellets).

Second, the fraction of the total debris surface area that is zirconium metal is taken to be the same as the mass fraction of zirconium within the debris:

$$
\text { FZRNOD }=\frac{\text { ZRAVIL }}{\operatorname{AMSUM}(\mathrm{I}, \mathrm{J})}
$$

where

$$
\begin{aligned}
\text { ZRAVIL }= & \text { total mass (solid + liquid) of zirconium within the control } \\
& \text { volume, } \mathrm{kg} \\
\operatorname{AMSUM}(I, \mathrm{~J})= & \text { total mass within control volume, } \mathrm{kg} .
\end{aligned}
$$

Finally, the power produced by the metal-steam reaction within the control volume is the minimum of

$$
\text { 4.179013 } \times 10^{10} \times \text { XDTO } \times \text { BDAREA } \times \text { FZRNOD Watts }
$$

and

$$
1.6282 \times 10^{7} \times \text { WSO Watts, }
$$

where WSO is the rate $(\mathrm{kg} / \mathrm{s})$ at which steam is entering the upper surface of the control volume. [There are $1.6282 \times 10^{7}$ Joules released per $\mathrm{kg}$ of steam reacted with zirconium.]

It should be noted that the shape factor SFCRDB can also be employed as a means to reduce the zirconium-steam reaction rate to represent the effect of steam tunneling. The logic described above permits all of the steam entering the control volume to enter into the reaction; use of a shape factor greater than one will limit the reaction rate. Another way to represent that not all of the zirconium within the control volume would be exposed to steam is to set the input parameter FRZMX2 (BH0700) to a fraction less than 1.00. This will, each timestep, reduce the mass of zirconium within the control volume that is available for reaction with steam to

$$
\text { FRZMX2 x ZRAVIL } \mathrm{kg} \text {, }
$$




\section{BH Package Reference Manual}

which will cause a corresponding reduction in the value of FRZNOD.

Both the shape factor SFCRDB and the parameter FRZMX2 have the effect of limiting the reaction rate during each timestep, but they do not permanently exclude any of the zirconium from reaction with steam. This can be done by use of the input parameter FRZMX1 (BH0700); all metal-water reaction within the lower plenum will be terminated whenever the fraction FRZMX1 of the mass of zirconium initially present (at the time of first penetration failure) has been reacted.

The mass of liquid zirconium within the control volume is reduced as necessary to adjust for the amount of metal oxidized and if this is insufficient, then the remaining mass of metal oxidized is subtracted from the solid zirconium present. The mass of solid zirconium oxide within the control volume is increased appropriately.

The mass flow of steam leaving the lower surface of the control volume is equal to the entering flow minus the steam consumption rate. The mass flow of hydrogen leaving the control volume is equal to the entering flow plus the hydrogen production equivalent to the steam consumption, which is

$$
\left(\frac{2.01594}{18.01534}\right) \times \text { DWSBO } \mathrm{kg} / \mathrm{s} \text {, }
$$

where DWSBO is the steam consumption rate $(\mathrm{kg} / \mathrm{s})$.

The metal-water reaction energy release within a control volume is transferred to the debris. The gas mixture flowing through the control volume is assumed to exit at the control volume temperature and the appropriate amount of energy for this is transferred between the debris and the gas. The gas mixture leaving one control volume enters the next lower control volume or escapes from the vessel, as appropriate to the location of the control volume in the gas escape pathway.

Only the steam/zirconium reaction is represented in the lower plenum debris bed model, but this is a major heat source in the control volume energy balances, particularly for cases in which the reactor vessel is pressurized at the time of penetration failure. Stainless steel oxidation in the bottom head debris is not represented since this is expected to be a secondary effect and because the temperatures at which rapid stainless steel oxidation occurs are close to the melting point; thus, stainless steel tends to relocate rather than to undergo excessive oxidation. The upshot of this is that much of this metal is expected to leave the vessel in a molten state without oxidizing. 
BH Package Reference Manual

\section{DEBRIS MELTING AND RELOCATION}

This Section describes the melting and relocation of pure species and eutectic mixtures within the debris bed. Information concerning the melting temperatures, molecular weights, and heat of fusion for the pure species is provided as user input (BH0200). Additional user input is required if the formation of eutectic mixtures is to be considered.

\subsection{Material Relocation}

Within the debris bed, molten material moves downward from one control volume to another as long as void space (free volume) remains within the lower control volume. Once the interstitial void in the underlying control volume is filled, the molten liquid can move horizontally within the bed as necessary to keep the liquid level approximately constant within a layer. An exception occurs in the case of the two outermost control volumes in layer two if penetration weld failure occurs at the wall. For control volumes $(2,4)$ and $(2,5)$, simultaneous movement downward to the void space in the (single) underlying control volume $(1,3)$ and horizontally to exit the vessel through the failed penetration welds can occur.

In all cases, the rate of movement of molten material through the debris bed is controlled by a user-input time constant DTHEAD (BH0500), usually set at one minute. Thus, for example, if the calculational timestep for the lower plenum model is 0.2 minute (and with the one-minute time constant), $20 \%$ of the molten material within a control volume can move vertically downward each timestep. Horizontal movement of molten material proceeds at one-half the rate of vertical movement.

As liquid debris relocates from one control volume to another or escapes from the lower plenum, the free volume associated with the interstitial voids in the source control volume is increased. In the former case, the transfer of liquids within the bed is calculated by Subroutine BHDBME. In the latter case, the escape of liquids from the lower plenum via penetration failures is calculated by Subroutine BHDBMX.

In either case, the increase of free volume within the source control volume is

$$
\sum_{K=1}^{20} \frac{\operatorname{MTRAN}(K)}{\operatorname{RHOLIQ}(K)} \quad m^{3}
$$

where

$\operatorname{MTRAN}(\mathrm{K})=$ liquid mass of material $\mathrm{K}$ currently being transferred, $\mathrm{kg}$ $\mathrm{RHOLIQ}(\mathrm{K})=$ density of liquid $\mathrm{K}, \mathrm{kg} / \mathrm{m}^{3}$ 


\section{BH Package Reference Manual}

and the summation is over the 20 debris materials. (Several of the array elements available to represent the debris materials are currently vacant, however-see Table 2.1.)

If the liquid transfer is to another bed control volume, then the free volume of the receiver is decreased by an identical amount. Furthermore, the temperature of the receiver control volume is adjusted as necessary to compensate for the inflow of energy and liquid mixture mass. If the transfer causes cooling of the relocating liquid and heating of the receiver control volume, then logic within Subroutine BHDBME freezes an appropriate portion of the higher-melting temperature constituents of the liquid mixture and checks for induced melting of a portion of the solid material originally present.

If, on the other hand, the liquid transfer causes cooling of the receiver control volume and heating of the transferred liquid, then the code logic checks for freezing of any of the liquid materials originally present (before the transfer).

One important effect of the downward relocation of molten material occurs relatively early in the debris bed response calculation. As discussed in Section 1.1, MELCOR normally predicts a large fraction of oxides to be included among the debris present within the BWR lower plenum at the time of bed dryout. Since the bottom bed layer comprises a representative sampling of this debris, the mass ratio of oxides to metals in the layer one control volumes can initially be quite high (typically in the vicinity of 0.60 ).

This large initial fraction of oxides, however, in turn produces a significant representative porosity for the solid debris of the bottom layer control volumes. As the temperature of the central region of the bed reaches the melting points of its constituent metals and metallic mixtures, liquid metals relocate downward to the bottom debris layer. This results in an early temperature increase for the bottom layer combined with elimination of the local free volume and significant reduction of the oxides-to-metals ratio. The large additional metallic heat sink provided by this early relocation then significantly delays the subsequent temperature increases within the bottom debris layer.

\subsection{Formation of Eutectic Mixtures}

As the temperature of the debris increases, the lower plenum model calculates the melting, migration, freezing, and remelting of the materials within the control volumes that represent the bed. Both melting of materials as pure species and melting of materials as constituents of eutectic mixtures are represented. The compositions of the eutectic mixtures to be considered (as many as ten) are specified by user input. As a guide toward the realistic formulation of this input, the eutectic mixtures formed and the associated melting temperatures determined in a recent small-scale experiment ${ }^{10}$ to investigate the melting and relocation of BWR debris are listed in Table 4.1. 
BH Package Reference Manual

Table 4.1 Eutectic mixture compositions determined for the lower plenum debris bed

\begin{tabular}{|c|c|c|c|}
\hline \multirow[t]{2}{*}{ Eutectic Mixture } & \multirow[t]{2}{*}{ Mole Fractions } & \multicolumn{2}{|c|}{ Melting Temperature } \\
\hline & & $\mathrm{K}$ & ${ }^{\circ} \mathrm{F}$ \\
\hline $\mathrm{Zr}-\mathrm{SS}^{\mathrm{a}}$ & $0.193-0.807$ & 1723 & 2642. \\
\hline $\mathrm{Fe}-\mathrm{Cr}-\mathrm{Ni}^{b}$ & $0.731-0.190-0.079$ & 1733 & 2660. \\
\hline $\mathrm{Zr}-\mathrm{SS}-\mathrm{UO}_{2}$ & $0.300-0.600-0.100$ & 1873 & 2912. \\
\hline $\mathrm{ZrO}_{2} \cdot \mathrm{UO}_{2}$ & $0.750-0.250$ & 2573 & 4172. \\
\hline
\end{tabular}

a SS represents stainless steel.

${ }^{b}$ This is the stainless steel eutectic mixture.

The information listed in Table 4.1 or other combinations of materials and melting temperatures to form eutectic mixtures is specified by means of input records $\mathrm{BH} 0800$, $\mathrm{BH} 0900$, and $\mathrm{BH} 1000$.

It is instructive to see how the melting temperatures of the eutectic mixtures described in Table 4.1 relate to the melting temperatures of the pure material species considered in a typical calculation. Table 4.2 provides the list of debris constituents represented in a recent example, in order of increasing melting temperature. 
BH Package Reference Manual

Table 4.2 Debris constituents considered in a typical calculation

\begin{tabular}{|lc|}
\hline Constituent & $\begin{array}{c}\text { Melting } \\
\text { Temperature }(\mathrm{K})\end{array}$ \\
\hline $\mathrm{FeO}$ & 1650 \\
Mixture 1 & 1723 \\
Mixture 2 & 1733 \\
$\mathrm{Fe} \mathrm{O}_{4}$ & 1839 \\
$\mathrm{Mixture} \mathrm{3}$ & 1873 \\
$\mathrm{Ni}$ & 1900 \\
$\mathrm{Fe}$ & 1900 \\
$\mathrm{Zr}$ & 2125 \\
$\mathrm{Cr}$ & 2144 \\
$\mathrm{NiO}$ & 2244 \\
$\mathrm{Cr} \mathrm{O}_{3}$ & 2572 \\
$\mathrm{Mixture} 4$ & 2573 \\
$\mathrm{~B}_{4} \mathrm{C}$ & 2728 \\
$\mathrm{~B}_{2} \mathrm{O}_{3}$ & 2728 \\
$\mathrm{ZrO}_{2}$ & 2978 \\
$\mathrm{UO}_{2}$ & 3011 \\
\hline
\end{tabular}

These constituents and melting temperatures are considered to provide a reasonable representation of the actual debris bed composition that would be formed in an unmitigated BWR severe accident; these are the constituents that were represented when the calculations whose results are discussed in Section 6.0 were performed.

Within each bed control volume, the question of debris constituent melting is pursued in a stepwise fashion as the temperature increases. As the temperature reaches the melting point of a pure species, additional energy released within or transferred into the control volume is consumed in melting the remaining mass of the species. But when the control volume temperature reaches the melting point of a eutectic mixture, the question as to how much of the mixture can be formed from the locally available constituents must be answered before the amount of energy consumed in melting the mixture can be determined.

Eutectic mixtures are treated within the lower plenum debris bed model by Subroutines BHEUTM, BHEUTF, and BHEUTK. The amount of the mixture that can be formed within a control volume given the current constituent masses is determined by BHEUTK. The energy transfers associated with heatup or cooldown past the eutectic melting point are determined by BHEUTM or BHEUTF, respectively. The operation of these subroutines is described in detail in the following paragraphs. 
BH Package Reference Manual

Subroutine BHEUTF is called on a control volume basis whenever the local temperature is decreasing. The purpose is to identify any pure species or eutectic mixture that should begin a phase transition from liquid to solid, to carry out the appropriate portion of this transition, and to determine the final control volume temperature. The major steps in this process are outlined below.

1. Each of the 20 pure material species that may be present within the debris (Table 2.1) is evaluated to establish how much of the liquid mass currently present within the control volume is tied up with eutectic mixtures that have freezing temperatures lower than the current control volume temperature. Any remaining liquid masses are identified as potential candidates for freezing and stored in the array AMINSP(20).

2. The second step is to establish the order in which pure species and eutectic mixtures (if any) are in line for freezing. This is done by evaluating each constituent liquid that is represented within array AMINSP(20) by a mass of at least $0.1 \mathrm{~kg}$ to determine which of these, if any, have freezing temperatures equal to or higher than the current control volume temperature. From this group, the constituent with the highest freezing temperature is first in line and the constituent with the freezing temperature closest to the current control volume temperature is identified as last in line for freezing.

3. Steps 3 through 7 are carried out for each constituent liquid present within the control volume that is in line for freezing. Beginning with the first (highest freezing point) constituent, the amount of energy that would be required to increase the current control volume temperature to the freezing point of the constituent is

where

$$
\text { DELQ }=\text { AMSUM } \times \text { CPDEB } \times[\text { TMLTBH }- \text { TMLP }] \quad \text { Joule }
$$

$$
\begin{aligned}
\operatorname{AMSUM}(\mathrm{l}, \mathrm{J})= & \text { total mass within the control volume, } \mathrm{kg} \\
\operatorname{CPDEB}(\mathrm{l}, \mathrm{J})= & \text { representative control volume specific heat, } \\
& \mathrm{J} /(\mathrm{kg} \cdot \mathrm{K}) \\
\mathrm{TMLTBH} & \text { freezing temperature of the constituent liquid } \\
& \text { mass, } \mathrm{K} \\
\operatorname{TMLP}(\mathrm{l}, \mathrm{J})= & \text { control volume temperature, } \mathrm{K} .
\end{aligned}
$$

4. Subroutine BHEUTK is called to determine whether the available subcooled liquid is present as a pure species or as a member of a eutectic mixture. The number of moles of liquid available for freezing is determined in either case. If a eutectic mixture is involved, this includes the number of moles contributed by the other liquid material components. (Additional information concerning the operation of Subroutine BHEUTK is provided at the end of this Section.) 
BH Package Reference Manual

5. The energy that would be released by freezing all of the available subcooled liquid is

where

$$
\text { DUFREZ }=\text { MRX } \times \text { AMLF Joule }
$$

MRX = moles of liquid available for freezing

AMLF = heat of fusion, Joule/mole,

and the sum is taken over all of the component liquids if a eutectic mixture is involved.

6. The fraction of the available subcooled liquid to be frozen is then

$$
F R A C=\frac{\text { DELQ }}{\text { DUFREZ }},
$$

constrained to be not more than 1.0.

7. The control volume temperature increase associated with the freezing of the identified fraction of the available subcooled liquid is then calculated as

\section{FRAC $\times$ DUFREZ}

AMSUM $\times$ CPDEB

K.

The cycle consisting of steps 3 through 7 is repeated in turn for each pure species or eutectic mixture in line for freezing until either the new control volume temperature exceeds the freezing temperature of the next constituent liquid in the line or all of the constituents originally in the line have been frozen.

Subroutine BHEUTM is called on a control volume basis whenever the local temperature is increasing, which is the normal situation after lower plenum debris bed dryout. The purpose is to identify any pure species or eutectic mixture that should begin a phase transition from solid to liquid, to carry out the appropriate portion of this transition, and to determine the final control volume temperature. The major steps carried out within Subroutine BHEUTM are described below.

1. A search is conducted to identify any solid debris constituents within the control volume with melting temperatures below the current control volume temperature.

2. If any such solid superheated debris constituents exist, they are treated in order, starting from the available superheated solid with the lowest melting point. 
BH Package Reference Manual

3. Steps 3-7 are repeated for each of the superheated solids. The energy release that would be attained by lowering the current control volume temperature to the melting temperature of the superheated solid is

$$
\text { DUMELT }=\text { AMSUM } \times \text { CPDEB } \times[T M L P-T M L T B H] \quad J o u l e,
$$

where TMLTBH represents the melting temperature of the superheated solid.

4. Subroutine BHEUTK is called to determine whether the available superheated solid is present as a pure species or as a member of a eutectic mixture; the number of moles available for melting is established in either case. [If a eutectic mixture is involved, this includes the number of moles contributed by the other solid material components.]

5. The energy that would be required to melt all of the available superheated solid is

where

$$
\text { DUMELX }=\text { MRX } \times \text { AMLF Joule }
$$

$$
\begin{array}{ll}
\text { MRX } & =\text { moles of solid available for melting } \\
\text { AMLF } & =\text { heat of fusion, Joule/mole, }
\end{array}
$$

and the sum is taken over all of the component solids if a eutectic mixture is involved.

6. The fraction of the available superheated solid to be melted is

$$
F R A C=\frac{\text { DUMELT }}{\text { DUMELX }}
$$

constrained to be not more than 1.0 .

7. The reduction in control volume temperature associated with melting of the identified fraction of the available superheated solid is then

$$
\frac{\text { FRAC } \times \text { DUMELX }}{\text { AMSUM } \times \text { CPDEB }} \quad \mathrm{K} \text {. }
$$

The cycle consisting of steps 3 through 7 is repeated in turn for each superheated pure species or eutectic mixture until either the new control volume temperature is below the melting temperature of the next solid in line or all of the solids originally identified as superheated have been melted.

As noted above, Subroutines BHEUTF and BHEUTM both call Subroutine BHEUTK to determine the nature of the debris constituent about to undergo a change of phase, which is termed the "key" constituent. The question is whether this key constituent is to 


\section{BH Package Reference Manual}

be treated as a pure species or as the identifying component of a eutectic mixture; in the latter case, what are the other components of the mixture and how much of the mixture can be formed within the control volume?

Subroutine BHEUTK finds the number of moles of the key constituent as

where

$$
\text { DDMRX }=\frac{\text { AMSCV }}{\text { AMMLWT }} \quad k g \text {-moles }
$$

$\operatorname{AMSCV}(\mathrm{KEY}) \quad=$ mass of the key constituent within the control volume, $\mathrm{kg}$ $A M M L W T(K E Y)=$ molecular weight of the key constituent, $\mathrm{kg} / \mathrm{kg}-\mathrm{mole}$.

For calls from Subroutine BHEUTF, AMSCV is constrained to exclude any constituent liquids that are components of eutectic mixtures that have freezing temperatures lower than the current control volume temperature.

The total number of moles to undergo phase change is then

$$
\text { AMTOT }=\frac{\text { DDMRX }}{\text { FRNKEY } \quad \text { kg-moles }}
$$

where FRNKEY(KEY) is the mole fraction of the key constituent within its associated eutectic mixture and is set to 1.0 for a pure species. If AMTOT is equal to DDMRX, then the key constituent is to be treated as a pure species and the call to Subroutine BHEUTK is returned.

If AMTOT is greater than DDMRX, however, then the key constituent is the identifying component of a eutectic mixture and the other components must now be identified. To do this, Subroutine BHEUTK makes use of the two series identified in Table 4.3.

The material series at the left of Table 4.3 is derived from user input and is the same as has been discussed previously (see, for example, Table 2.1). The constituent series at the right of Table 4.3 is derived from the material series (neglecting the vacant slots) plus the list of eutectic mixtures to be considered. That both series as listed on Table 4.3 have 20 members is a matter of coincidence. This occurs because the four vacant slots $(8,9,19,20)$ of the material series are exactly counterbalanced by the four eutectic mixtures considered in this calculation. Since as many as ten eutectic mixtures can be specified, the constituent species can have up to 30 members (if all 20 slots in the material species were utilized). On the other hand, since only 16 members of the material species are currently represented, the number (NSPECS) of constituent series members can be as few as 16 , if no eutectic mixtures are specified.

It should be noted that the members of the constituent series are arranged in order of ascending melting temperatures, which are indicated in Table 4.2. [Although slots are reserved in the material series for $\mathrm{C}, \mathrm{B}, \mathrm{U}$, and $\mathrm{Fe}_{2} \mathrm{O}_{3}$, current $\mathrm{BH}$ Package logic does 
BH Package Reference Manual

not actually produce any of these materials within the lower plenum debris bed and hence, for simplicity, they have been omitted from Table 4.2.]

Returning to the discussion of the method by which Subroutine BHEUTK identifies the materials to undergo phase change, the key constituent is identified within Subroutines BHEUTF or BHEUTM as a member of the constituent series. As an example, suppose that the control volume temperature has just increased above $1839 \mathrm{~K}$; then any $\mathrm{Fe}_{3} \mathrm{O}_{4}$ within the control volume would be identified within Subroutine BHEUTM as a superheated solid [Table 4.2]. The index of the key constituent would be 6 [Table 4.3]. The index within the material series would be 14, which is stored in the NEUKEY(30) array as element NEUKEY(6). Since FRNKEY(6) has a value of 1.0, Subroutine BHEUTK identifies the debris constituent about to undergo melting as the pure species $\mathrm{Fe}_{3} \mathrm{O}_{4}$.

As an example involving a eutectic mixture, suppose that the control volume temperature has just increased above $1873 \mathrm{~K}$, which is the melting temperature of the third eutectic mixture (Tables 4.1 and 4.2). As indicated in Table 4.4, the key (identifying) component of this mixture, which occupies position 7 in the constituent series, is $\mathrm{Zr}$, which occupies position 1 in the material series. (The key components for each mixture are assigned by user input.) The mole fraction FRNKEY(7) of $\mathrm{Zr}$ within mixture 3 is 0.300 (Table 4.1). Therefore, Subroutine BHEUTK provides a first estimate for the maximum number of moles of mixture 3 that could be formed within the control volume of

$$
\text { AMTOT }=\frac{\operatorname{DDMRX}(1)}{0.300} \quad \mathrm{~kg} \text {-moles, }
$$

where DDMRX(1) is the number of moles of $\mathrm{Zr}$ locally available.

The other components of the eutectic mixture are identified through use of the array $\mathrm{NEU}(\mathrm{K}, \mathrm{KEY})$, whose elements have a value of 1 if the material with index $\mathrm{K}$ in the material series is a component of the mixture with index KEY in the constituent series. As indicated in Table 4.4, KEY has a value of 7 for the third eutectic mixture and the elements $\mathrm{NEU}(\mathrm{K}, 7)$ have values of 1 for $\mathrm{K}=1(\mathrm{Zr}), \mathrm{K}=2(\mathrm{Fe}), \mathrm{K}=3(\mathrm{Cr}), \mathrm{K}=4(\mathrm{Ni})$, and $\mathrm{K}=18\left(\mathrm{UO}_{2}\right)$.

If any mixture component has a mass of less than $0.1 \mathrm{~kg}$ within the control volume, then logic within Subroutine BHEUTK concludes that the eutectic mixture cannot be formed and the call is returned indicating that no mixture is available for melting. If, on the other hand, sufficient quantities of each component are present within the control volume, then Subroutine BHEUTK employs the array

$$
\text { XNEU(K,KEY) }
$$

to determine if the maximum number of moles AMTOT [based upon the amount of the key (identifying) component] can be formed. 


\section{BH Package Reference Manual}

The elements of array XNEU (K,KEY) represent the mole fractions of each material $\mathrm{K}$ within mixture KEY of the constituent series. The amount of material $\mathrm{K}$ required to form the maximum possible amount of mixture is

$$
\text { XNEU(K,KEY) } \times \text { AMTOT kg-moles. }
$$

If each component $\mathrm{K}$ has at least this many moles locally available, then AMTOT moles of mixture can be formed and the call is returned. If any component has fewer than the required number of moles available, however, then the maximum possible amount of mixture that can be formed within the control volume must be recalculated, based upon the most limiting of the components.

Logic within Subroutine BHEUTK identifies the most limiting component by calculating the ratio of moles available to moles required for each material for which NEU(K,KEY) is equal to 1 . The component $K$ with the smallest value of this ratio is most limiting. $A$ new value for the number of moles AMTOT of mixture that can be formed is then established by dividing the locally available number of moles of the limiting component by the mole fraction $\mathrm{XNEU}(\mathrm{K}, \mathrm{KEY})$ of this component within the mixture. Finally, Subroutine BHEUTK returns the (real value) array

$$
\operatorname{MRX}(20) \quad \mathrm{kg} \text {-moles, }
$$

whose elements represent the number of moles of the materials (in the material series) that would be included in the key mixture if the maximum possible amount were formed within the control volume. The actual amount that is formed and melted (or frozen) depends upon the available energy and is determined within Subroutine BHEUTM ( or BHEUTF), as previously described. 
BH Package Reference Manual

Table 4.3 Constituent series employed

by Subroutine BHEUTK with example

of use of cross-reference index

for a pure species

\begin{tabular}{|c|c|c|c|}
\hline & $\begin{array}{l}\text { Material Series } \\
\text { Elements } 1 \text { through } \\
20\end{array}$ & $\begin{array}{c}\text { Constituent Series } \\
\text { Elements } 1 \text { through } \\
\text { NSPECS }\end{array}$ & $\begin{array}{l}\text { Mixture Key } \\
\text { Component }\end{array}$ \\
\hline & 1. $\mathrm{Zr}$ & 1. U & \\
\hline & 2. $\mathrm{Fe}$ & 2. $\mathrm{FeO}$ & \\
\hline & 3. $\mathrm{Cr}$ & 3. Mixture 1 & $\mathrm{Fe}$ \\
\hline & 4. $\mathrm{Ni}$ & 4. $\mathrm{Fe}_{2} \mathrm{O}_{3}$ & \\
\hline & 5. C & 5. Mixture 2 & $\mathrm{Cr}$ \\
\hline & 6. $\mathrm{B}$ & KEY 6. $\mathrm{Fe}_{3} \mathrm{O}_{4}$ & \\
\hline & 7. $U$ & 7. Mixture 3 & $\mathrm{Zr}$ \\
\hline & 8. - & 8. $\mathrm{Ni}$ & \\
\hline & 9. - & 9. $\mathrm{Fe}$ & \\
\hline & 10. $\mathrm{B}_{4} \mathrm{C}$ & 10. $\mathrm{Zr}$ & \\
\hline & 11. $\mathrm{ZrO}_{2}$ & 11. $\mathrm{Cr}$ & \\
\hline & 12. $\mathrm{FeO}$ & 12. $\mathrm{NiO}$ & \\
\hline & 13. $\mathrm{Fe}_{2} \mathrm{O}_{3}$ & 13. $\mathrm{B}$ & \\
\hline \multirow[t]{7}{*}{ NEUKEY(KEY) } & 14. $\mathrm{Fe}_{3} \mathrm{O}_{4}$ & 14. $\mathrm{Cr}_{2} \mathrm{O}_{3}$ & \\
\hline & 15. $\mathrm{Cr}_{2} \mathrm{O}_{3}$ & 15. Mixture 4 & $\mathrm{ZrO}_{2}$ \\
\hline & 16. $\mathrm{NiO}$ & 16. $\mathrm{B}_{4} \mathrm{C}$ & \\
\hline & 17. $\mathrm{B}_{2} \mathrm{O}_{3}$ & 17. $\mathrm{B}_{2} \mathrm{O}_{3}$ & \\
\hline & 18. $\mathrm{UO}_{2}$ & 18. $\mathrm{ZrO}_{2}$ & \\
\hline & 19. - & 19. $\mathrm{UO}_{2}$ & \\
\hline & 20. - & 20. C & \\
\hline
\end{tabular}


BH Package Reference Manual

Table 4.4 Constituent series employed

by Subroutine BHEUTK with example

of use of cross-reference index

for a eutectic mixture

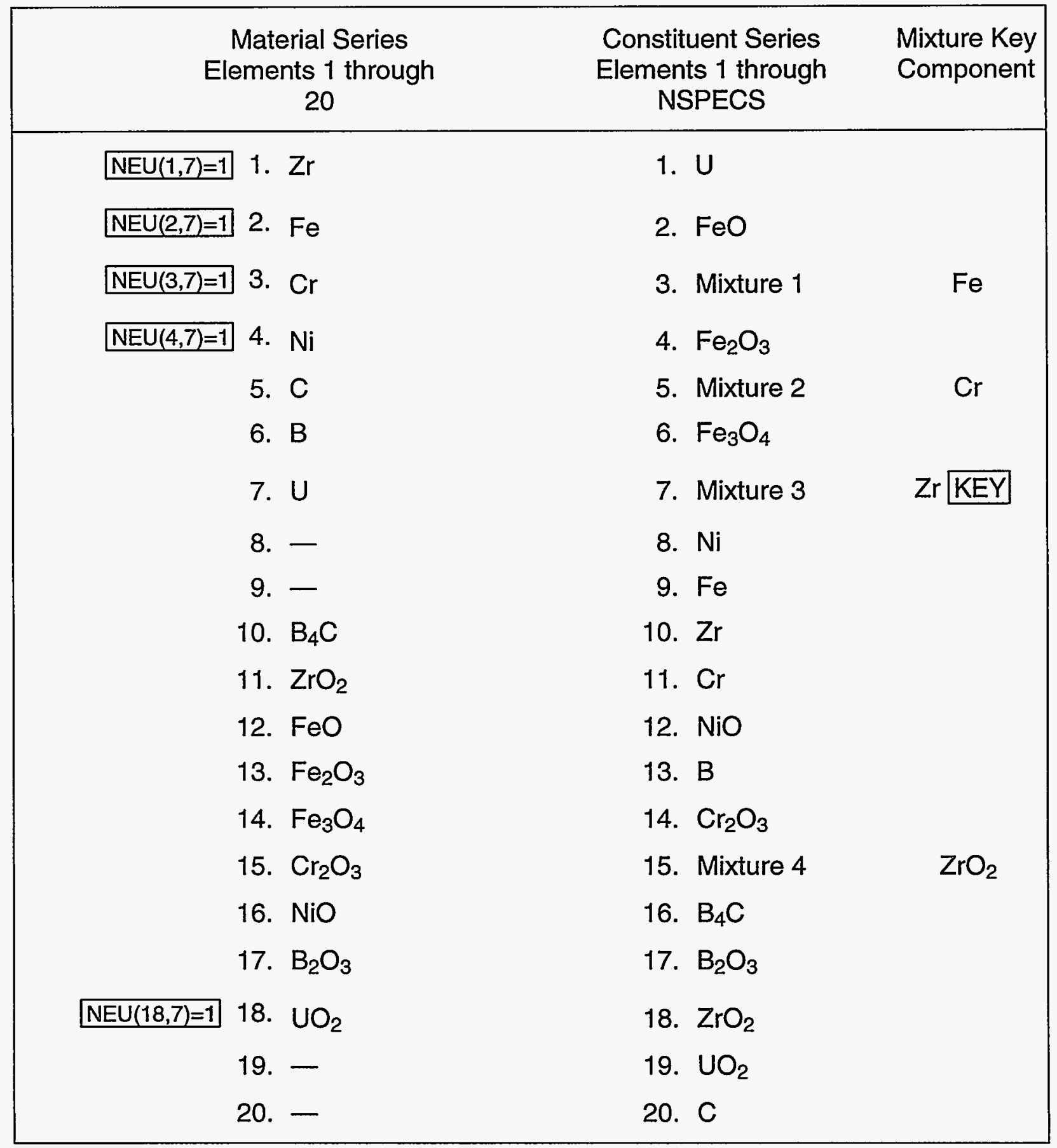




\subsection{Adjustment of Control Volume Dimensions}

As individual constituent pure species or material mixtures within the debris bed melt and relocate downward, provision is made to reconfigure the dimensions of the source control volumes in recognition of the shrinking mass. This is accomplished by means of calls to Subroutine BHDCHA, which adjusts the control volume interface radii, bottom and surface heights, location of center of mass, and heat transfer lengths.

Within Subroutine BHDCHA, bed control volumes are selected for redimensioning if the internal free volume has increased by one or more percent since the dimensions were last set, or if more than one-third of the current control volume mass is in the liquid phase. The first step in the redimensioning process is to set the new total volume.

$$
\operatorname{VLP}(I, J)=\frac{A M S U M}{R H O D B \times(1.0-P O R B)} \mathrm{m}^{3}
$$

where

$$
\begin{array}{ll}
\mathrm{I} & =\text { layer index } \\
\mathrm{J} & =\text { radial zone index } \\
\operatorname{AMSUM}(I, J) & =\text { total control volume mass, } \mathrm{kg} \\
\operatorname{RHODB}(I, J) & =\text { representative density, } \mathrm{kg} / \mathrm{m}^{3} \\
\operatorname{PORB}(I, J) & =\text { representative porosity. }
\end{array}
$$

The representative porosity and density for each control volume are calculated each timestep in Subroutine BHHED2, as explained in Sections 2.1 and 2.2.

Based upon the new total volume, the new free volume is

$$
\operatorname{FVLP}(l, J)=\operatorname{PORB}(I, J) \times \operatorname{VLP}(I, J) \quad \mathrm{m}^{3} .
$$

It is important to recognize that the porosity represents the fraction of the total volume that is occupied by neither solid nor liquid debris. Thus, the porosity can be zero for control volumes in which some solid material remains, if the interstitial regions between the solid particles is filled with liquid.

The next step in the redimensioning process is to establish the new locations of the boundary points defining the control volume cross-sections as shown in Figure 1.9. These locations are set in the cylindrical coordinate system as explained in the following Table. 
BH Package Reference Manual

Table 4.5 Cylindrical coorclinates of boundary points for debris bed control volume $(1, J)$

\begin{tabular}{|c|c|}
\hline Coordinates & Definition \\
\hline $\begin{array}{l}X L T(I, J) \\
\text { YLT(I,J) }\end{array}$ & $\begin{array}{l}\text { radial distance to left upper corner } \\
\text { elevation of left upper corner }\end{array}$ \\
\hline $\begin{array}{l}\mathrm{XRT}(\mathrm{I}, \mathrm{J}) \\
\mathrm{YRT}(\mathrm{I}, \mathrm{J})\end{array}$ & $\begin{array}{l}\text { radial distance to right upper corner } \\
\text { elevation of right upper corner }\end{array}$ \\
\hline $\begin{array}{l}X R B(I, J) \\
\text { YRB(l,J) }\end{array}$ & $\begin{array}{l}\text { radial distance to right lower corner } \\
\text { elevation of right lower corner }\end{array}$ \\
\hline $\begin{array}{l}X L B(I, J) \\
\text { YLB }(1, J)\end{array}$ & $\begin{array}{l}\text { radial distance to left bottom corner } \\
\text { elevation of left bottom corner }\end{array}$ \\
\hline
\end{tabular}

The radial distances cited in Table 4.5 are measured from the lower plenum centerline. The elevations are measured from vessel zero.

Not all of the coordinates listed in Table 4.5 are involved in the redimensioning process for each bed control volume. For example, $X L B(I, 1)$ and $X L T(I, 1)$ (for the center radial zone) are always zero. In general, $\mathrm{XLB}(\mathrm{l}, \mathrm{J})$ will equal $\mathrm{XLT}(\mathrm{l}, \mathrm{J})$ for all control volumes in radial zones one through four while $X R B(I, J)$ will equal $X R T(I, J)$ in the central three radial zones.

If a bottom layer control volume is redimensioned, then both overlying control volumes (in the middle and upper debris layers) will automatically be redimensioned also. Similarly, if a middle layer control volume is redimensioned, then the dimensions of the overlying layer three control volume (if it exists) will also be adjusted. In this manner, tight contact is maintained between the vertically aligned bed control volumes.

After the debris bed control volume dimensions have been revised as appropriate, logic within Subroutine BHDCHA calculates the new vertical thickness and sets the new vertical length of the right boundary of each (interior) control volume as

$$
\text { and } \begin{aligned}
\operatorname{HLAYER}(\mathrm{I}, \mathrm{J})=\mathrm{YLT}(\mathrm{I}, \mathrm{J})-\mathrm{YLB}(\mathrm{I}, \mathrm{J}) \mathrm{m} \\
\operatorname{HINFC}(\mathrm{I}, \mathrm{J})=\mathrm{YRT}(\mathrm{I}, \mathrm{J})-\mathrm{YRB}(\mathrm{I}, \mathrm{J}) \mathrm{m},
\end{aligned}
$$

respectively. Other geometric parameters affecting conduction heat transfer that are recalculated within BHDCHA at this time are defined in Table 4.6. 
Table 4.6 Heat transfer geometric parameters recalculated in BHDCHA whenever the debris bed is reconfigured

\begin{tabular}{|c|c|c|}
\hline Parameter & Definition & Units \\
\hline HNODE(l,J) & Elevation of control volume center of mass & $\mathrm{m}$ \\
\hline RNODE(I,J) & $\begin{array}{l}\text { Radial distance from lower plenum centerline to control volume } \\
\text { center of mass }\end{array}$ & $\mathrm{m}$ \\
\hline AINFCR(I,J) & $\begin{array}{l}\text { Interface area for radial heat transfer at the outer vertical } \\
\text { boundary of the control volume }\end{array}$ & $m^{2}$ \\
\hline$X L W(I, J)$ & $\begin{array}{l}\text { Distance from control volume center of mass to inner surface of } \\
\text { vessel wall (only for control volumes that abut the wall) }\end{array}$ & $\mathrm{m}$ \\
\hline XLR2(3) & $\begin{array}{l}\text { Distance from center of mass of control volume }(2,4) \text { to control } \\
\text { volume boundary along path between centers of control } \\
\text { volumes }(2,4) \text { and }(2,5)\end{array}$ & $\mathrm{m}$ \\
\hline $\mathrm{XLR} 2(4)$ & $\begin{array}{l}\text { Distance from center of mass of control volume }(2,5) \text { to control } \\
\text { volume boundary along path between centers of control } \\
\text { volumes }(2,4) \text { and }(2,5)\end{array}$ & $\mathrm{m}$ \\
\hline $\mathrm{XLR3(3)}$ & $\begin{array}{l}\text { Distance from center of mass of control volume }(3,4) \text { to control } \\
\text { volume boundary along path between centers of control } \\
\text { volumes }(3,4) \text { and }(3,5)\end{array}$ & $\mathrm{m}$ \\
\hline $\mathrm{XLR3}(4)$ & $\begin{array}{l}\text { Distance from center of mass of control volume }(3,5) \text { to control } \\
\text { volume boundary along path between centers of control } \\
\text { volumes }(3,4) \text { and }(3,5)\end{array}$ & $\mathrm{m}$ \\
\hline
\end{tabular}

As the central portion of the debris bed settles, the upper surface of one control volume may sink beneath the lower surface of an adjacent control volume. Whenever this happens, the appropriate element of the array

$$
\operatorname{HTR}(\mathrm{I}, \mathrm{J})
$$

is shifted from a value of 1.0 to 0.0 . The elements of this array in effect serve as on-off gates for conduction from control volume $(l, J)$ to control volume $(I, J+1)$ within each bed layer. In this manner, they fulfill the same purpose for conduction within the bed as do the elements of array HTW (discussed in Section 3.1) for conduction from the bed to the bottom head wall.

\subsection{Merging of Bed Control Volumes}

Code logic provides for merging of two lower plenum debris bed control volumes within the same radial zone whenever continued representation of the local bed region as a 


\section{BH Package Reference Manual}

three-layered or two-layered structure would not be realistic. Merging can occur only for control volumes vertically aligned; it does not encompass joining of two control volumes within the same debris layer.

\subsubsection{Merging Criteria}

The checking of current bed conditions to determine whether or not merging of any two control volumes should occur is carried out each timestep within Subroutine BHHED2. The criteria considered are as follows:

1) Any bed control volume is flagged for merging if:

a) its current mass is less than $20 \%$ of the debris mass within its boundaries at the time that the third debris layer was established or

b) more than $44 \%$ of the solid mass within the control volume has been ablated.

2) In addition, any of the three layer one control volumes are flagged for merging if bottom head penetration failures are considered and

a) their current mass is less than $10 \%$ of the overlying layer two control volume mass, or

b) their volume has been reduced to the point that the right-hand corner of the (descending) overlying layer two control volume has come into contact with the bottom head wall .

3) Additional special criteria are applied to flag layer two control volumes for merging if the overlying layer three control volume exists and

a) more than $66.7 \%$ of the layer two control volume is in the liquid phase, or

b) if the right adjacent layer three control volume does not exist, or

c) if the current elevation of the layer two control volume upper surface is less than the elevation of the right adjacent layer one control volume upper surface.

All of these criteria have been developed as results of experience, gained by a process of exercising the lower plenum debris bed and bottom head response models over a series of BWR severe accident sequences, with and without bottom head penetration failures. As before, the goal is to maintain a realistic representation of the bed configuration as materials melt and relocate.

Each criterion has its own rationale. For example, criterion $1(\mathrm{~b})$ above is necessary for calculations for which bottom head penetration failures are considered and significant ablation of the bottom layer debris is predicted to occur. [See Section 5.3 for a description of this process, which is largely controlled by user-input.] This protection is necessary because code logic does not increase available free volume in response to 
BH Package Reference Manual

material ablation. Consequently, control volume settling is not predicted and a situation can develop in which vertical "worm-holes" have enlarged around the original penetration locations within the debris while the original elevation of the control volume surface is maintained.

The solution provided by criterion 1 (b) is based upon the assumption that it is reasonable to expect collapse of the standing debris whenever the "worm-hole" volume exceeds $80 \%$ of the volume currently occupied by solid debris. Stated another way, this is equivalent to ablation of $44.4 \%$ of the material initially within the control volume.

\subsubsection{Merging Process}

Once the code logic in Subroutine BHHED2 has selected a debris bed control volume for merging, the actual merging process is accomplished by means of a call to Subroutine BHMERG. If the selected control volume has a counterpart in an overlying debris layer, then the merging is accomplished from above. Otherwise, the selected control volume merges with its counterpart below.

The temperature of the new control volume is established as the mass-averaged temperature of its two constituent sources. If this is less than the previous temperature of the control volume in this location, Subroutine BHEUTF is called to check for and, as necessary, compensate for sudden freezing of pure material species or mixtures. If, on the other hand, the merging has caused the representative control volume temperature to increase, then Subroutine BHEUTM is called to adjust, as necessary, for material melting.

The porosity of the new control volume is established as the volume-averaged porosity of its two constituent sources. Finally, its free volume and surface elevation are determined by a call to Subroutine BHDCHA, which also provides boundary dimensions for the new control volume in a manner similar to that described in Section 4.3. 

BH Package Reference Manual

\section{FAILURE OF THE BOTTOM HEAD}

The BWR Lower Plenum Debris Bed (BH) Package will consider penetration failures if the user specifies that bottom head penetrations exist. This is done by setting non-zero values for the array NPIPES via input record $\mathrm{BH} 1100$. The bottom head failure models will then recognize two different modes of reactor vessel bottom head penetration failure. The first involves creep rupture of the welds holding the instrument tubes and the control rod drive mechanism assemblies within the reactor vessel and is described in Section 5.1. The second, described in Section 5.2, involves direct melting of the instrument guide tubes within the interior of the debris bed. (It is assumed that exvessel tube failure will follow the entry of molten debris into the tube.)

As explained in the User's Guide, array elements NPIPES(1) through NPIPES(3) represent the numbers of instrument guide tubes passing through the central, middle, and outermost control volumes of debris bed layer one, respectively. These numbers are employed to determine the regional material ablation rates after instrument guide tube failures have been predicted and a flow of molten liquids through the tube locations has been initiated. The models for debris and wall ablation are described in Section 5.3. If, however, it is desired that penetration failures not be considered in the calculation, then NPIPES(1) through NPIPES (3) should each be set to zero and all debris liquids will be retained within the lower plenum until creep rupture of the bottom head itself is predicted. The models for bottom head creep rupture are described in Section 5.4 .

\subsection{Penetration Welds}

As described in Section 1.0, many penetration welds are located at or near the inner surface of the lower portion of the vessel bottom head (see Figures 1.7 and 1.8). The $\mathrm{BH}$ Package recognizes the potential for failure of these welds over the region represented by wall nodes one through nine (see Figure 1.10). For the lowest wall node adjacent to the middle debris layer (wall node nine), these welds are modeled to fail when the temperature of control volume $(2,5)$ [a narrow strip of debris (input parameter THKCRS) adjacent to the wall] satisfies creep rupture criteria (input parameters THK6 and THK60, provided via input record BH0600.) Within the bottom debris layer (wall nodes one through eight), the welds will fail whenever the average of the temperature of the inner wall segment and the temperature of the adjacent debris control volume exceeds the creep rupture criteria. The failure time for these Inconelstainless steel welds is established as follows.

For each timestep while the penetration welds remain intact, a remaining time before failure is established within Subroutine BHHED2 for wall nodes one through nine as

$$
\text { DTFAIL }=e^{\text {ATF } \times T_{\text {WELD }}+\text { BTF }} \text { seconds }
$$


BH Package Reference Manual

where

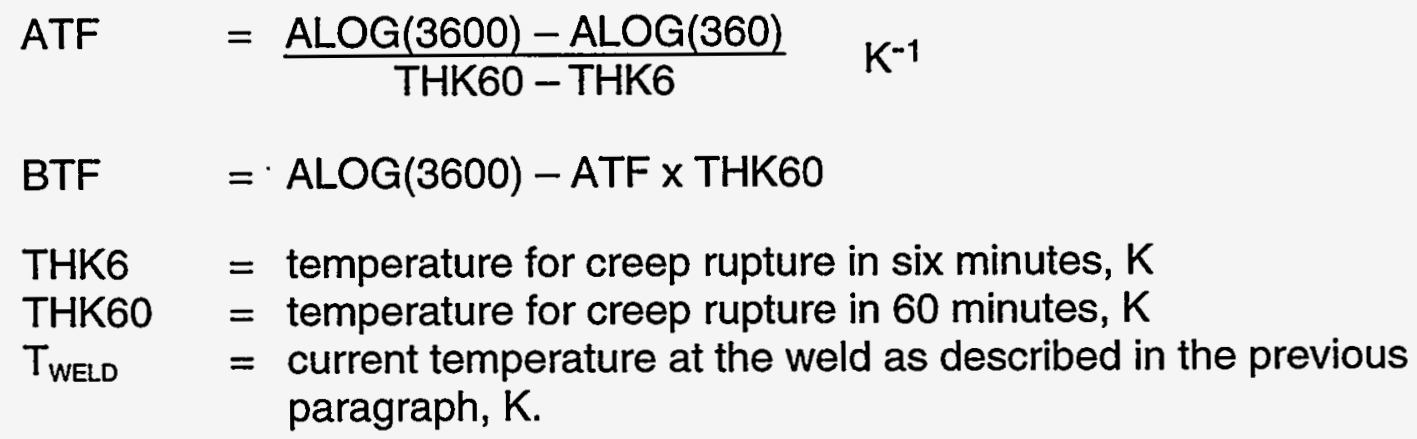

As indicated, ATF and BTF are constants based upon user input; their values are established within MELCOR at the time of lower plenum dryout prior to the first call to BH package Subroutine BHQSLU.

Based upon the individual values of DTFAlL, a local weld failure time is then associated with each wall node adjacent to the bottom debris layer (wall nodes one through eight) and with the lowest wall node adjacent to the middle debris layer (wall node nine) in the array

$$
\operatorname{TIMFAL}(I)=\text { ATIME + DTFAIL } S
$$

where $l$ is the wall node index and ATIME is the current problem calculation time (seconds).

The predicted bottom head penetration weld creep rupture failure times stored in array TIMFAL are never allowed to increase, once set. [They can, of course, decrease as temperatures ascend.] Whenever the current problem time ATIME exceeds a previously-set weld failure time, penetration weld failure is assumed to occur at that wall node and a special output message is written (Section 6.5). Note that the user should adjust the input values of THK6 and THK60 as necessary to conform with the expected reactor vessel pressure at the time that high debris bed temperatures would begin to challenge the weld integrity.

When weld failure is predicted to occur, gas blowdown from the reactor vessel to the drywell is permitted through a user-defined break area intended to represent several failed penetrations. Thus, the predicted gas blowdown (Section 5.5) is rapid. It is important, however, to recognize that the rate of transfer of molten debris from the reactor vessel to the drywell floor is not determined by the size of this opening. Rather, molten material is transferred from control volume to control volume within the lower plenum debris bed and from the control volumes adjacent to the vessel wall to the drywell floor in accordance with the input time constant DTHEAD (input record BH0500). In actuality, use of realistic values of DTHEAD will always produce the result that the rate of material transfer from the lower plenum to the drywell is determined by the rate of material melting. 
BH Package Reference Manual

Penetration weld failures can occur only as the initial failure mode within a debris layer. If instrument tube failures (discussed in the following Section) have previously occurred within a layer, subsequent weld failures are not considered. Furthermore, if release of debris liquids from the lower plenum is initiated by means of penetration weld failure and instrument tube failures occur subsequently, then liquid release at the penetration welds is terminated and release through the instrument tubes is initiated.

\subsection{Instrument Guide Tubes}

The second mode of reactor vessel bottom head penetration failure recognized by the BWR lower plenum debris bed models involves the establishment of a leakage pathway through the reactor vessel wall by means of the instrument guide tubes. (Failure of the tubes ex-vessel is assumed to occur as a consequence of the entry of molten debris.) Such a pathway will be established within the middle layer control volumes whenever three conditions are met. First, the debris bed control volume temperatures within the middle layer must exceed the melting temperature of the (stainless steel) guide tubes; second, sufficient molten material must have been relocated into the underlying bottom debris layer control volume to reduce its free volume to no more than $10 \%$ of the total volume; third, molten material must be available in the middle layer to flow into the guide tubes. Instrument guide tube failures are normally predicted to occur in more than one middle layer control volume during the period of a calculation. This is an important consideration, since liquid debris materials must move within the bed (based upon input time constant DTHEAD) to the location where the penetration failure has occurred in order to be released.

Instrument guide tube failure can also occur within any of the bottom layer control volumes, if the local temperature exceeds the stainless steel melting temperature. Once this occurs, debris liquids are released equally from all three bottom layer control volumes, regardless of the location of the initial bottom layer penetration failure (weld or instrument guide tube).

The opening associated with the instrument tubes for the purpose of gas blowdown is the same as used for the case of penetration weld failure. The flow of molten material from the reactor vessel through the instrument guide tube locations (input parameter NPIPES) is augmented by ablation of the surrounding debris of the bottom layer and of the bottom head itself, as described in the following Section.

\subsection{Ablation Induced by Flow of Molten Material}

As previously discussed, failure of the instrument housing guide tubes within the middle debris layer provides a path for molten materials in the vicinity to pour through the bottom debris layer and the reactor vessel bottom head wall. The lower plenum debris bed and bottom head response model considers the potential for this flowing liquid to 


\section{BH Package Reference Manual}

ablate the material surrounding the original instrument housing guide tube locations in both the bottom debris layer and in the vessel wall.

The user-input parameters ( $\mathrm{BH} 1100)$ employed by the model that are most important in determining the calculated reactor vessel wall temperatures are listed in the following Table.

\section{Table 5.1 User-input parameters affecting the vessel wall temperature calculation}

\begin{tabular}{|c|c|c|c|}
\hline \multirow[b]{2}{*}{ DPIPES } & \multirow{2}{*}{$\begin{array}{l}\text { Parameter } \\
\text { Inner diameter of instrument } \\
\text { guide tubes }\end{array}$} & \multicolumn{2}{|c|}{ Representative Value } \\
\hline & & $0.0457 \mathrm{~m}$ & $(0.150 \mathrm{ft})$ \\
\hline HPIPES & $\begin{array}{l}\text { Coefficient for heat transfer } \\
\text { between molten material } \\
\text { flowing through the } \\
\text { instrument tube locations in } \\
\text { the bottom debris layer and } \\
\text { the surrounding metallic } \\
\text { debris and bottom head wall }\end{array}$ & $1022.1 \frac{W}{m^{2} K}$ & $\left(180.0 \frac{\mathrm{Btu}}{\mathrm{h} \mathrm{ft}^{2}{ }^{\circ} \mathrm{F}}\right)$ \\
\hline NPIPES(3) & $\begin{array}{l}\text { Number of instrument guide } \\
\text { tubes through debris bed } \\
\text { lower layer control volumes } \\
(1,1),(1,2) \text {, and }(1,3)\end{array}$ & $19,19,20$ & \\
\hline TABLAT & $\begin{array}{l}\text { Ablation temperature for solid } \\
\text { material in bottom debris } \\
\text { layer }\end{array}$ & $1756 \mathrm{~K}$ & $\left(2700^{\circ} \mathrm{F}\right)$ \\
\hline THKCRS & $\begin{array}{l}\text { Thickness of the debris node } \\
\text { adjacent to the vessel wall }\end{array}$ & $5.08 \mathrm{~cm}$ & $(0.167 \mathrm{ft})$ \\
\hline
\end{tabular}

As described in Sections 5.1 and 5.2, movement of the molten material through the bed to the instrument housing guide tubes is controlled by input time constant DTHEAD. The augmentation of this flow by ablation of the surrounding metallic material of the bottom layer and the vessel bottom head is controlled by input parameters HPIPES and TABLAT. Heat transfer from the melting (ablating) surfaces surrounding the flowing debris to the interior of the remaining solid portions of the bottom layer or wall nodes is calculated by the model. 


\subsubsection{Ablation of the Wall}

The ablation of the reactor vessel bottom head wall is calculated in Subroutine BHDBMX. The procedure is based upon information provided in References 20 and 21 and basically follows the methodology originally developed by Pilch and Tarbell.

As explained previously, if instrument guide tube (or penetration weld) failures are predicted to occur in any one of the three control volumes of the bottom debris layer, then they are assumed to also occur (simultaneously) in the other two. The calculation considers each bottom layer control volume separately, based upon the local quantity of liquid available for release and the number of penetrations passing through the control volume.

The uppermost wall node adjacent to each bottom layer control volume is taken to be representative. With reference to Figure 1.10, these are wall node three for control volume $(1,1)$; wall node five for control volume $(1,2)$; and wall node eight for control volume $(1,3)$. Calculations are then performed for each of the three wall segments that make up wall nodes 3,5 , and 8 (see Figure 1.11).

The temperature of the liquid entering the penetration pathways through the bottom head wall is taken to be the temperature of the source control volume. The temperature of the inner surfaces of the penetration pathways within the wall are taken to be the melting temperature of carbon steel [1811 $\left.\mathrm{K}\left(2800^{\circ} \mathrm{F}\right)\right]$. As long as the temperature of the flowing liquid exceeds this temperature, then heat is transferred from the liquid to the wall. Some of this energy is further transferred into the interior of the wall segment, increasing its average temperature; the remainder of this energy is consumed in ablation of the wall at the inner surface of the penetration.

Material ablated from the wall is added to the flowing liquid, increasing its mass and lowering its temperature. Thus, the temperature decreases as the liquid passes through the three wall segments. If the temperature of the flow falls below the carbon steel melting temperature, then heat transfer with the wall in the remaining wall segment(s) is not calculated and the flowing liquid enters the drywell at this temperature.

For each bottom layer control volume, calculation of the ablation of the adjacent vessel wall proceeds as follows.

1. The liquid mass entering the wall during the timestep is

$$
\text { SUMLJ }=\sum_{\mathrm{K}=1}^{20} A M L P(K) \times \text { DTR } \quad \mathrm{kg}
$$

where

$$
\begin{aligned}
\operatorname{AMLP}(1, \mathrm{~J}, \mathrm{~K}, 2)= & \begin{array}{l}
\text { mass of the liquid phase of material } \mathrm{K} \text { within the } \\
\text { control volume, } \mathrm{kg}
\end{array}
\end{aligned}
$$


BH Package Reference Manual

$\mathrm{J}$

$=$ index of the control volume within layer one

$=$ index of material in the material series

(Table 4.3)

and DTR is the ratio of the current timestep length to the user-input time constant DTHEAD (provided via input record $\mathrm{BH} 0500$ ). The initial temperature of the liquid mixture (as it enters the wall) is taken to be the representative temperature of the source control volume.

2. The liquid mass per instrument guide tube is

$$
\text { SUMLIN }=\frac{\text { SUMLJ }}{\text { APIPES }} \quad \mathrm{kg}
$$

where APIPES is simply the floating point value of NPIPES(J).

3. Steps 3 through 9 are carried out for each of the three wall segments of the representative (uppermost) adjacent wall node. The inner surface area of the cylindrical penetration pathways is

where

$$
\text { AREAD }=\pi \times \text { DABWHL } \times \text { XLHEAD } \mathrm{m}^{2}
$$

$$
\begin{array}{ll}
\operatorname{DABWHL}(J, M) & =\text { diameter of penetrations in segment } M, m \\
M & =\text { index of wall segment } \\
\operatorname{XLHEAD}(M, N) & =\text { radial thickness of segment } M \text { within wall node } \\
& N, m \\
N & =\text { index of representative wall node. }
\end{array}
$$

DABWHL(J,M) is initially set to DPIPES (Table 5.1 ) but, as indicated in step 7 below, its value can increase during the calculation. Use of XLHEAD to determine AREAD is not strictly correct, since the instrument guide tube passage through the wall is in the vertical, not radial direction. However, the instrument tubes pass through only the lower portion of the vessel wall so the associated error is small.

4. The heat transferred to the inner surface of the cylindrical penetration opening is QLD, taken as the minimum of

$$
\text { AREAD } \times \text { HPIPES } \times(\text { TLLIQ - AMCS) } \times \text { DTM Joule }
$$

and

$$
\text { SUMLIN } \times \text { CPLIQ } \times(\text { TLLIQ - AMCS) Joule, }
$$

where the second quantity serves as a check that no more energy will be transferred than would cause the liquid temperature to decrease to the 
BH Package Reference Manual

carbon steel melting temperature. Terms used in these expressions that have not previously been defined are

\begin{tabular}{|c|c|}
\hline HPIPES & $\begin{array}{l}=\text { user-input heat transfer coefficient (Table 5.1), } \\
\mathrm{W} /\left(\mathrm{m}^{2} . \mathrm{K}\right)\end{array}$ \\
\hline TLLIQ & $\begin{array}{l}=\text { temperature of the flowing liquid as it enters wall } \\
\text { segment } M, K\end{array}$ \\
\hline AMCS & $=$ carbon steel melting temperature, $\mathrm{K}$ \\
\hline DTM & $=$ length of $\mathrm{BH}$ Package timestep, $s$ \\
\hline CPLIQ & $\begin{array}{l}=\text { mass-averaged specific heat of the flowing liquid, } \\
\mathrm{J} /(\mathrm{kg} \cdot \mathrm{K}) \text {. }\end{array}$ \\
\hline
\end{tabular}

5. The heat transferred from the cylindrical penetration inner surface to the wall segment is

where

$$
\text { QMLD }=\text { AREAD } \times \frac{\text { AMCS }- \text { THDWO }}{\left(\frac{0.0509}{\text { BHAKCS }}\right)} \times \text { DTM Joule }
$$

$$
\begin{aligned}
& \text { THDWO(M,N) = temperature of the wall segment at the } \\
& \text { beginning of the timestep, } \mathrm{K} \\
& \text { BHAKCS = function BHAKCS(THDWO) for temperature- } \\
& \text { dependent conductivity of carbon steel, } \\
& \mathrm{W} /(\mathrm{m} \cdot \mathrm{K}) \text {. }
\end{aligned}
$$

The constant in the denominator of this equation reflects an approximation that the average distance between the inner surface of the penetration and the wall segment center-of-mass is $0.0509 \mathrm{~m}$ (two inches).

6. The energy per unit volume required to bring this wall segment to the melting temperature and to melt it is

$$
\text { QMELT }=\text { RHOCS } \times \text { [AMLAMF + BHCPCS } \times(\text { AMCS }- \text { THDWO })] \mathrm{J} / \mathrm{m}^{3}
$$
where

$$
\begin{aligned}
\text { RHOCS } & =\text { carbon steel density, } \mathrm{kg} / \mathrm{m}^{3} \\
\text { AMLAMF(2) }= & \text { iron heat of fusion, } \mathrm{J} / \mathrm{kg} \\
\text { BHCPCS } & \text { function BHCPCS }(\text { THDWO) for temperature- } \\
& \text { dependent specific heat of carbon steel, } \mathrm{J} /(\mathrm{kg} \cdot \mathrm{K}) .
\end{aligned}
$$

The volume that will be ablated from the inner surface of the penetration within this wall segment this timestep is then 
BH Package Reference Manual

$$
D E L V=\frac{Q L D-Q M L D}{Q M E L T} \quad \mathrm{~m}^{3},
$$

where the numerator is the portion of the energy transfer from the flowing liquid to the wall that is retained for surface melting.

7. The ablation enlarges the penetration diameter so that

$$
\mathrm{DABWHL}_{\mathrm{N}}=\sqrt{\mathrm{DABWHL}_{\mathrm{O}}{ }^{2}+\left(\frac{4.0}{\pi}\right) \frac{\mathrm{DELV}}{\mathrm{XLHEAD}}} \mathrm{m},
$$

where the subscripts $N$ and $O$ represent the new and old values, respectively. The mass of wall surface ablated within the wall segment is

$$
A W M E L T=D E L V \times \text { RHOCS } \mathrm{kg} \text {. }
$$

8. The temperature of the flowing liquid is reduced in passing through the wall segment by the heat transfer to the wall so that

$$
T_{L L I Q_{N}}=T_{L L I Q_{0}}-\frac{\text { QLD }}{\text { SUMLIN } \times \text { CPDEB }} \quad \mathrm{K} .
$$

This temperature is further reduced by the infusion of liquid carbon steel from the ablated wall. Allowing for this,

$$
T L L I Q_{N N}=\frac{\text { SUMLIN } \times \text { TLLIQN }+ \text { AWMELT x AMCS }}{\text { SUMLIN }+ \text { AWMELT }} \mathrm{K}
$$

is used as the entrance temperature for the liquid flowing into the next wall segment.

9. The mass entering the next wall segment (or, for segment three, escaping into the drywell) is then

$$
\text { SUMLIN }_{N}=\text { SUMLIN }+ \text { AWMELT } \mathrm{kg} .
$$

The representative temperature of the liquid release to the drywell during the timestep is the mass-averaged temperature of the release from all of the bottom layer control volumes.

Predicted penetration weld failures in wall node nine [the lowest of the wall nodes adjacent to control volume $(2,5)$ ] provide a direct release pathway for liquid materials in control volumes $(2,3),(2,4)$, and $(2,5)$. [Inclusion of control volume $(2,3)$ in the direct release pathway is necessary because control volumes $(2,4)$ and $(2,5)$ are normally at lower temperatures so that liquid moving laterally from $(2,3)$ would freeze before becoming eligible for release in a two-step pathway.] The associated flows will produce 
BH Package Reference Manual

the same effects of wall segment heatup and surface ablation described above for the bottom layer control volumes.

Once instrument tube failure occurs in the middle debris layer, the liquid release point is shifted away from the wall, which introduces the effects of prior interaction with and ablation of the debris surrounding the instrument guide tube locations in the bottom debris layer. As described in the following Section, this will alter the characteristics of the flow before the liquid reaches the inner wall surface.

\subsubsection{Ablation of the Bottom Debris Layer}

As explained in the previous Section, liquids generated within the middle debris layer can flow through the bottom debris layer if local (middle layer) instrument guide tube failures have been predicted to occur. Within the bottom debris layer, the flowing liquid would quickly ablate the surrounding stainless steel tubes, then begin to ablate the surrounding debris.

Calculation of debris ablation within the bottom bed layer is more complicated than the calculation of vessel wall ablation because several solid materials are involved and the length of the release pathway is not constant. The structural foundation for the calculation is set in Subroutine BHHEDN at the time of lower plenum dryout, when the bottom and middle debris layers are first established.

Since each of the three bottom layer control volumes is shaped by the curvature of the vessel bottom head, the average lengths of the instrument guide tube pathways through these control volumes are different. For control volumes $(1,1)$ and $(1,2)$, this average length is

$$
\text { YHMEAN }=\frac{Y L T(1, J)-Y L B(1, J)+Y R T(1, J)-Y R B(1, J)}{2.0}
$$

whereas for control volume $(1,3)$ the right corners coincide (see Figure 1.9) and the instrument guide tubes pass through the central portion so

$$
\text { YHMEAN }=Y L T(1, J)-Y L B(1, J) \quad m .
$$

As defined in Table 4.5, the terms on the right side of these expressions represent the elevations of the control volume boundary points above vessel zero.

The representative (average) instrument guide tubes for each bottom layer control volume are then divided into not more than ten axial segments, each at least three inches in length. The number of axial segments in each control volume is stored in the array

NABHOL(J), 


\section{BH Package Reference Manual}

where $J$ is the control volume index $(1,2$, or 3$)$ within the bottom layer. The initial segment lengths within each control volume are stored in the array

$$
\operatorname{HABHOL}(J, M)=\frac{\text { YHMEAN }}{\operatorname{NABHOL}(J)} m,
$$

where $M$ is the segment index. As established within Subroutine BHHEDN, all segment lengths within a given control volume are equal. The initial diameters of all instrument tube segments in all control volumes are equal and are stored in the array

$$
\operatorname{DABHOL}(J, M)=\text { DPIPES } \mathrm{m} \text {. }
$$

DPIPES is the user-input value for the inner diameter of the instrument guide tubes as defined in Table 5.1 and input on record ( $\mathrm{BH} 1100)$.

As in the case of the vessel wall, the ablation calculations for the bottom debris layer are carried out within Subroutine BHDBMX.

1. The liquid mass entering the bottom layer control volume during the timestep is

$$
\text { SUML }=\sum_{K=1}^{20} A M L P(K) \times D T R \quad k g
$$

where

$$
\begin{array}{ll}
\operatorname{AMLP}(2, \mathrm{~J}, \mathrm{~K}, 2)= & \text { liquid mass within the overlying layer two control } \\
& \text { volume(s), } \mathrm{kg} \\
\mathrm{K} & \text { material index (Table 4.3) } \\
\mathrm{DTR} & \text { ratio of timestep length to liquid relocation time } \\
& \text { constant DTHEAD (input record BH0500). }
\end{array}
$$

The initial temperature of the liquid mixture (as it enters the bottom layer control volume) is taken to be the representative temperature of the source (layer two) control volume. However, since the combined drainage from bed control volumes $(2,3),(2,4)$, and $(2,5)$ enters bottom layer control volume $(1,3)$, the entering temperature of the combined flows to this control volume is the flow-averaged temperature of its three source control volumes.

2. The liquid mass per instrument guide tube is

$$
\text { SUMLIN }=\frac{\text { SUML }}{\text { APIPES }} \quad \mathrm{kg}
$$

where APIPES is the number of instrument guide tubes passing through the bottom layer control volume. 
BH Package Reference Manual

3. Steps 3 through 10 are carried out for each of the NABHOL(J) axial segments of the representative instrument tube passing through bottom layer control volume $(1, \mathrm{~J})$. The inner surface area of each representative cylindrical instrument guide tube pathway is

$$
\text { AREAD }=\pi \times \text { DABHOL } \times \text { HABHOL } \mathrm{m}^{2},
$$

where independent values of DABHOL and HABHOL are stored for each axial segment of each control volume, as explained above.

4. The heat transferred to the inner surface of the cylindrical instrument guide tube pathways is QLD, taken as the minimum of

AREAD $\times$ HPIPES $\times($ TLLIQ - TABLAT) $\times$ DTM Joule

and

$$
\text { SUMLIN x CPLIQ x (TLLIQ - TABLAT) Joule. }
$$

The second quantity serves as a check that no more energy will be transferred from the liquid than would cause its temperature to decrease to the user-input debris ablation temperature TABLAT. See Table 5.1 for representative values of TABLAT and the heat transfer coefficient HPIPES. The other terms used in these expressions that have not been previously defined in this Section are

$$
\begin{array}{ll}
\text { TLLIQ } & =\text { temperature of the flowing liquid as it enters the } \\
& \text { bottom layer control volume, } \mathrm{K} \\
\text { DTM } & =\text { length of BH package timestep, } \mathrm{s} \\
\text { CPLIQ } & =\text { mass-averaged specific heat of the flowing liquid, } \\
& \mathrm{J} /(\mathrm{kg} \cdot \mathrm{K}) .
\end{array}
$$

5. The heat transferred from the inner surface of the representative instrument guide tube pathway to the surrounding control volume debris is

where

$$
\text { QMLD }=\text { AREAD } \frac{\text { TABLAT }- \text { TMLPO }}{\left(\frac{0.0509}{\text { CONDB }}\right)} \times \text { DTM Joule }
$$

$$
\begin{aligned}
\operatorname{TMLPO}(1, \mathrm{~J})= & \begin{array}{l}
\text { control volume temperature at the beginning of } \\
\text { the timestep, } \mathrm{K}
\end{array} \\
\operatorname{CONDB}(1, \mathrm{~J})= & \text { thermal conductivity of the control volume } \\
& \text { debris, } \mathrm{W} /(\mathrm{m} \cdot \mathrm{K}) .
\end{aligned}
$$




\section{BH Package Reference Manual}

The representative thermal conductivity for the debris within each bed control volume is determined each timestep within Subroutine BHHED2. The constant in the denominator of this equation reflects an approximation that the average distance from the inner surface of each instrument guide tube pathway to the center-of-mass of the associated control volume debris is $0.0509 \mathrm{~m}$ (two inches).

6. The heat per unit volume required to bring the debris associated with the representative instrument tube to the melting temperature and to melt it is

$\mathrm{QMELT}=\mathrm{RHODB} \times[\mathrm{HFMN}+\mathrm{CPDEB} \times(\mathrm{TABLAT}-\mathrm{TMLPO})] \mathrm{J} \mathrm{J}\left(\mathrm{l} / \mathrm{m}^{3}\right.$ where

$$
\begin{array}{ll}
\operatorname{RHODB}(1, \mathrm{~J})= & \begin{array}{r}
\text { representative density of control volume debris, } \\
\mathrm{kg} / \mathrm{m}^{3}
\end{array} \\
\mathrm{HFMN} & =\begin{array}{l}
\text { mass-averaged heat of fusion for control volume } \\
\text { materials, } \mathrm{J} / \mathrm{kg}
\end{array} \\
\mathrm{CPDEB}(1, \mathrm{~J})= & \begin{array}{l}
\text { mass-averaged specific heat of control volume } \\
\text { debris, } \mathrm{J} /(\mathrm{kg} \cdot \mathrm{K}) .
\end{array}
\end{array}
$$

7. The volume of instrument guide tube pathway inner surface that will be (radially) ablated this timestep is

$$
D E L V=\frac{\text { QLD }- \text { QMLD }}{\text { QMELT }} \quad \mathrm{m}^{3}
$$

where the numerator is the portion of the energy transfer from the flowing liquid to the surrounding debris that is retained for surface melting.

8. The ablation enlarges the flow area associated with the representative instrument guide tube so that

$$
\mathrm{DABHOL}_{N}=\sqrt{\mathrm{DABHOL}_{\circ}{ }^{2}+\left(\frac{4.0}{\pi}\right) \frac{\mathrm{DELV}}{\mathrm{HABHOL}}} \mathrm{m}
$$

is the new (end-of-timestep) diameter for this pathway. The mass of debris ablated from this axial segment of the bottom layer control volume during this timestep is

$$
A M E L T=D E L V \times R H O D B \quad \mathrm{~kg} .
$$

9. The temperature of the liquid passing downward through the axial segment is reduced by the heat transfer to the surrounding debris so that 
BH Package Reference Manual

$$
T_{L L I Q}=T_{N} L L I Q_{0}-\frac{\text { QLD }}{\text { SUMLIN x CPLIQ }} \mathrm{K} \text {. }
$$

The temperature of the flow is also reduced by the infusion of the liquid debris ablated from the instrument guide tube pathway inner surface so that

$$
T_{L L I Q}=\frac{\text { SUMLIN } \times \text { TLLIQN }_{N}+\text { AMELT } \times \text { TABLAT }}{\text { SUMLIN }+ \text { AMELT }} \mathrm{K}
$$

is used as the entrance temperature for the liquid flowing into the next axial segment of the control volume.

10. The mass entering the next axial segment (or, for the last axial segment, entering the vessel wall) is then

$$
\text { SUMLIN }_{N}=\text { SUMLIN }_{\mathrm{O}}+\text { AMELT } \mathrm{kg} .
$$

The total debris mass ablated from bottom layer control volume $(1, \mathrm{~J})$ during the timestep is

$$
\text { AMMELT = APIPES } x \quad \sum_{M=1}^{\text {NABHOL(J) }} \operatorname{AMELT(M)~} \mathrm{kg},
$$

which is appropriately subtracted from the remaining mass.

The total heat transfer from the ablating instrument guide tube pathway surfaces to the surrounding debris is

$$
\text { QMLDEB }(J)=\frac{\text { APIPES }}{\text { DTM }} \times \sum_{M=1}^{\text {NABHOL(J) }} \text { QMLD(M) Joule/s, }
$$

where DTM is the timestep length (seconds). This is the heat source to the layer one control volumes by molten liquid flow through penetration failures that is utilized in the control volume heat balance, as described in Section 3.1.

Since the moving liquid would cool as it flowed through the bottom layer debris, the calculated ablation is greatest in the first axial segment and decreases as the flow continues through the layer. Thus, the ablating surface comes to resemble the sloping shape of a funnel. Ablation of the material in the bottom layer reduces the debris mass retained within the control volume(s) through which the molten material is flowing. As described in Section 4.4.1, provision is made to merge the bottom layer control volume if the enlarged (worm-hole) volume around the instrument guide tubes exceeds $80 \%$ of the volume currently occupied by solid debris. Once a bottom layer control volume has been merged, the instrument guide tube pathways are considered to be destroyed and ablation ceases. (Ablation of the bottom head wall continues.) 


\section{BH Package Reference Manual}

\subsection{Creep Rupture of the Vessel Wall}

All liquid and solid debris remaining within the reactor vessel lower plenum is immediately transferred to the containment drywell whenever structural failure of the wall is predicted to occur.

As described in Section 1.2, each vessel bottom head wall node is divided into three radial segments. The criterion for bottom head creep rupture is satisfied for any wall node beneath the skirt attachment if the current problem time exceeds the local failure time, which is established each timestep within the code in the following manner.

(1) The wall tensile stress is determined by the weight of the debris in the lower plenum and the differential pressure DP $(\mathrm{Pa})$ between the reactor vessel and the drywell:

$$
\text { WTENS }=\frac{9.80 \times \text { DEBMAS }+\pi(R X I D X)^{2} \times D P}{A C S W \times 10^{6}} \mathrm{MPa}
$$

where

$$
\begin{aligned}
& \text { DEBMAS = mass of bottom head debris plus mass of vessel } \\
& \text { wall and pendant assemblies beneath this wall } \\
& \text { node, } \mathrm{kg} \\
& \text { RXIDX = vessel inner radius, } m \\
& \text { ACSW }=\text { cross-sectional area of vessel wall based upon } \\
& \text { local wall thickness including effect of any local } \\
& \text { wall melting, } \mathrm{m}^{2} \text {. }
\end{aligned}
$$

(2) The local Larson-Miller parameter is then determined from the wall tensile stress as

$$
\begin{array}{lll}
\text { or } & 31.11-0.9880 \times(\text { WTENS - 2.0) } & \text { WTENS }<5.0 \\
\text { or } & 28.06-0.3221 \times(\text { WTENS }-5.5) & 5.0 \leq \text { WTENS }<20.0 \\
& 22.83-0.0955 \times(\text { WTENS }-30.0) & \text { WTENS } \geq 20.0 .
\end{array}
$$

This approximate solution for the Larson-Miller parameter is based upon the results of the recent (1991) series of carbon steel creep rupture tests ${ }^{11}$ performed at Idaho National Engineering Laboratory (INEL) for the SA533B1 carbon steel of the BWR reactor vessel. These experiments extend the range of available data into the very low wall tensile stress regime, which is applicable to the depressurized BWR reactor vessel. 
The potential for failure by creep rupture is applicable only to the wall nodes beneath the skirt attachment because the nodes above the attachment point would not be in tension with the reactor vessel depressurized. The wall tensile stress imposed by the dead weight of the core and structural debris and the bottom head itself is typically about $1.9 \mathrm{MPa}$ beneath the skirt attachment. Thus, the first expression given above for the Larson-Miller parameter is used for the depressurized BWR severe accident sequences.

(3) For each timestep while the bottom head remains intact, a remaining time before failure is established for each wall node beneath the vessel skirt as

$$
e^{B W F-A W F X T A V C R} \quad \text { seconds }
$$

where

$$
\begin{array}{ll}
\text { AWF } & =\frac{A L O G(3600)-\operatorname{ALOG}(360)}{\mathrm{TF} 6-\mathrm{TF} 60} \mathrm{~K}^{-1} \\
\text { BWF } & =\text { ALOG(3600)+AWF } \times \text { TF60 } \\
\text { TF6 } & =52.6316 \times \mathrm{ALMP} \quad \mathrm{K} \\
\text { TF60 } & =50.0 \times \mathrm{ALMP} \quad \mathrm{K} \\
\text { ALMP } & =\text { Larson-Miller parameter, determined in step (2) } \\
\text { TAVCR } & =\text { current average wall node temperature, } \mathrm{K} .
\end{array}
$$

The variables TF6 and TF60 are the temperatures for creep rupture of carbon steel in six minutes and sixty minutes, respectively, as determined by the current value of the Larson-Miller parameter. It is easy to show by substitution of variables that BWF has a constant value equal to 51.9378 .

(4) The local creep rupture failure time is established for each wall node beneath the skirt attachment by adding the time-to-failure established in step (3) to the current problem calculation time ATIME (s). These predicted failure times are stored in the array TCRPHD (I) where $I$ is the wall node index.

The predicted bottom head wall node creep rupture failure times stored in array TCRPHD can decrease as local temperatures ascend, but are never permitted to increase. Whenever the current problem time ATIME exceeds a previously set nodal failure time, creep rupture failure of the bottom head is assumed to occur and a special output message is written (Section 6.5). As mentioned previously, all liquid and solid debris within the lower plenum is immediately transferred to the drywell. However, since the status of the remaining wall nodes (carbon steel that has not previously been ablated) is unknown, no logic has been added to include the remaining wall nodes with the debris. 


\section{BH Package Reference Manual}

After bottom head creep rupture, the lower plenum debris bed model responds to calls from MELCOR simply by reclassifying the entering debris (from the core region) as released debris (to the drywell). No debris bed calculations are performed; the transfers between storage arrays are made, and the call is returned.

\subsection{Gas Blowdown From Vessel}

The mass flow rate through failed penetrations is determined within the MELCOR interface by the equation for orifice flow:

$$
W=C A \sqrt{2 \times \rho \times D P} \mathrm{~kg} / \mathrm{s}
$$

where

$$
\begin{aligned}
& \mathrm{C} \quad=0.583 \\
& \text { A }=\text { user-defined break size }\left(\mathrm{m}^{2}\right) \text {. (See input record BH1900, entry } 3 \\
& \text { for IABCFN) } \\
& \rho=\text { density of lower plenum atmosphere after heating to the average } \\
& \text { temperature of the debris bed layer in which the failure occurs; } \\
& \left(\mathrm{kg} / \mathrm{m}^{3}\right) \\
& \text { DP differential pressure between the vessel and the drywell; }(\mathrm{Pa}) \text {. }
\end{aligned}
$$

The FL package routine FLCOK is then called to limit the flow to no more than that at the velocity of sound at the user-input break area, taken to be the minimum section of the orifice. 
BH Package Reference Manual

\section{EXAMPLES OF CALCULATED RESULTS}

Two pages of printed output are generated within Subroutine BHHED2 at the completion of each user-specified printout interval for the Lower Plenum Debris Bed $(\mathrm{BH})$ Package. A portion of the first output page is dedicated to the presentation of certain calculated results in a pictorial display. It is the purpose of this Section to provide an explanation of the information contained in this display as well as the additional information printed in tabular format. This is facilitated by means of discussion of the printed results for an example calculation, which was recently performed (1992) to investigate the short-term station blackout accident sequence based upon the Peach Bottom plant configuration. At the time of lower plenum dryout, the $\mathrm{BH}$ package calculation was initiated for debris bed layers one and two; the third (uppermost) debris layer had not yet been formed.

\subsection{Initial Debris Bed Configuration}

The pictorial display of the initial configuration of the lower plenum debris bed immediately after dryout is reproduced as Figure 6.1. The left-hand portion of this figure represents the thirteen debris bed control volumes, which are numbered and shown to scale in Figure 1.9. However, since the outermost control volumes $(2,5)$ and $(3,5)$ are relatively small, they are shown on an expanded scale at the center of Figure 6.1. As mentioned previously, none of the layer three control volumes have yet been formed.

For each debris bed control volume, the current temperature $(\mathrm{K})$, total mass of debris $(\mathrm{kg})$, and embedded free volume (fraction of total volume) are listed on Figure 6.1. (The individual material masses contained within the bed layers of the initial configuration are provided in Table 6.1.) Since all of the initial control volume temperatures are below the melting temperatures of the first eutectic mixture (Table 4.1) and the first debris constituent (Table 4.2), all of the bed materials are entirely solid at this time.

Immediately above the outline of each control volume in Figure 6.1 is indicated the local height above vessel zero of the control volume upper surface, in centimeters. In this initial bed configuration, the upper surface heights of all control volumes within a layer are equal (196 centimeters for layer two, for example). As the calculation proceeds, however, the debris constituents will melt and relocate downward, causing the bed to settle. The basic pictorial representation of the bed structure will remain the same as shown in Figure 6.1 while the current local control volume heights (which will change during the calculation) will be indicated numerically. The heights indicated to the left of the vertical dashed center line will, however, always represent the initial bed layer heights. 


\section{BH Package Reference Manual}

The right-hand portion of Figure 6.1 represents the reactor vessel bottom head wall. (The wall nodalization and the division of each node into three radial segments has been described in Section 1.2 and illustrated in Figures 1.10 and 1.11). Wall nodes 1 through 17 are numbered along the inner wall surface in Figure 6.1. Within the wall, temperatures are indicated for each wall segment. Along the outer wall surface are indicated the heights above vessel zero $(\mathrm{cm})$ of the inner wall termini of the dividing lines between the 8 wall nodes originally adjacent to debris layer one, the 6 nodes adjacent to debris layer two, the two nodes adjacent to debris layer three, the single node (17) between the upper bed surface and the bottom of the shroud baffle, and the single node (18) adjacent to the lower portion of the downcomer region. While the wall node locations will never change, the debris control volumes adjacent to the wall can settle downward. For example, bed control volume $(3,5)$ might be adjacent to wall node 14 late in the calculation instead of control volume $(2,5)$ as in the original configuration shown in Figure 6.1.

Finally, Figure 6.1 also provides information as to the mass and temperature of the water remaining in the downcomer region between the core shroud and the vessel wall. This information is listed under the heading "SHROUD WATER" adjacent to the inner surface of the uppermost wall node. As indicated, the initial mass $(35581 \mathrm{~kg})$ is significant. The source of this water and the effect that the water has upon the debris bed response calculation have been discussed in Section 1.2. 
Table 6.1 Material masses $(\mathrm{kg})$ included in the initial setup of the debris bed layers for Peach Bottom short-term station blackout

\begin{tabular}{|lrrr|}
\hline \multicolumn{1}{|c}{ Material } & \multicolumn{1}{c}{ Layer } & Layer & Total \\
\hline $\mathrm{Zr}$ & 1 & 2 & \\
$\mathrm{Fe}$ & 3414. & 24453. & 27867. \\
$\mathrm{Cr}$ & 5593. & 17528. & 23121. \\
$\mathrm{Ni}$ & 1360. & 4264. & 5624. \\
$\mathrm{~B}_{4} \mathrm{C}$ & 605. & 1895. & 2500. \\
$\mathrm{ZrO}_{2}$ & 50. & 356. & 406. \\
$\mathrm{FeO}_{\mathrm{Cr}}$ & 423. & 3032. & 3455. \\
$\mathrm{NiO}$ & 32. & 231. & 263. \\
$\mathrm{UO}_{2}$ & 9. & 64. & 73. \\
$\mathrm{Totals}$ & 4. & 25. & 29. \\
\hline
\end{tabular}




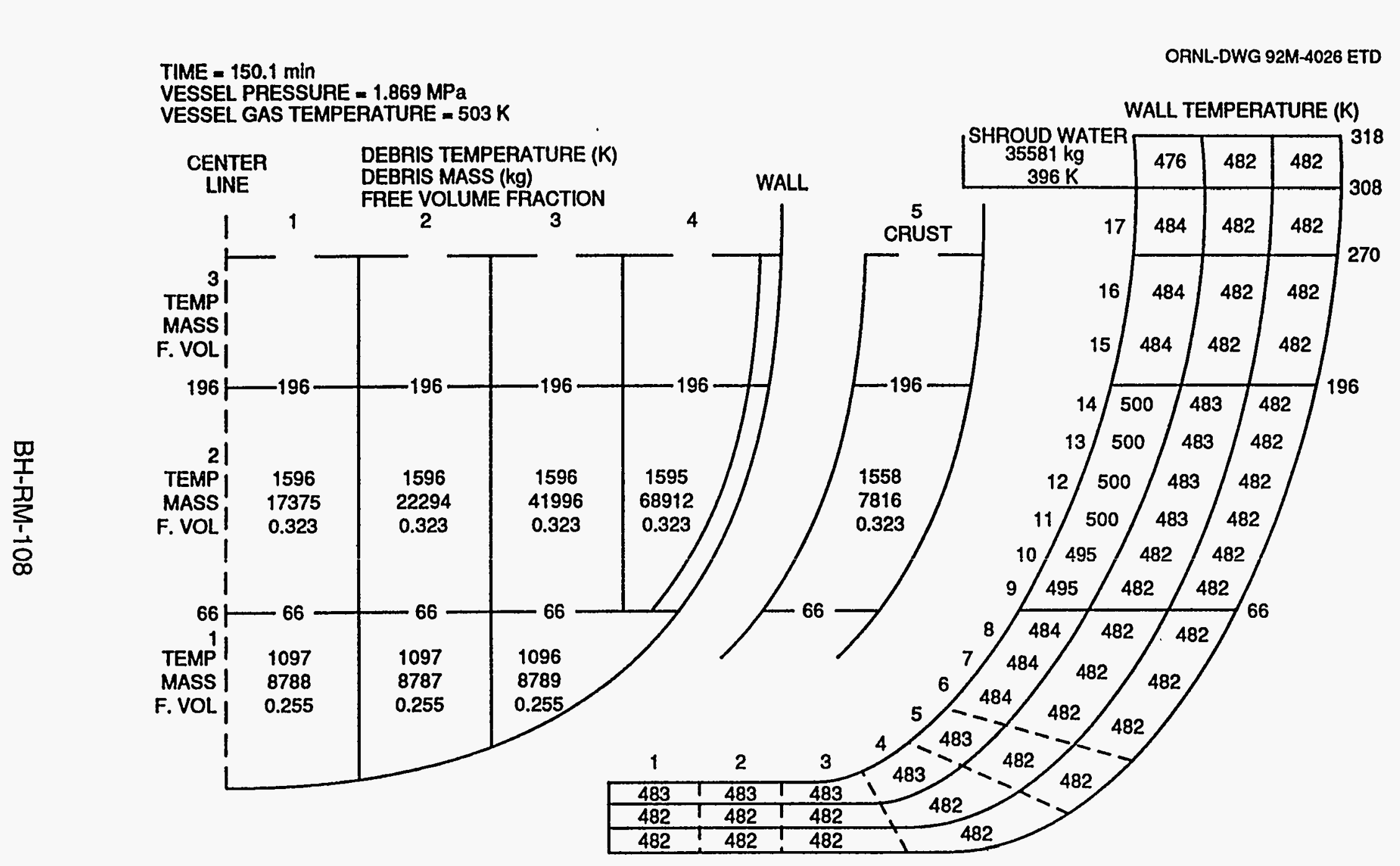

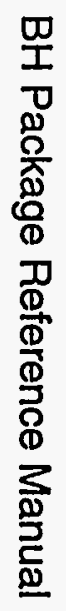

Figure 6.1 Initial configuration of the lower plenum debris bed and the initial bottom head wall temperatures. 
BH Package Reference Manual

\subsection{Formation of the Third Debris Layer}

The example MELCOR calculation proceeds after lower plenum dryout with an average timestep length of about 11 seconds. By timestep 19 of the example calculation, the predicted temperatures at the central portion of the debris bed have increased to the point where melting of the $\mathrm{FeO}$ constituent can begin. (Melting temperatures of the debris constituents are listed in Table 4.2.) As explained in Section 1.1.4, the predicted presence of material liquids within the bed triggers the initial setup of debris layer three. Figure 6.2 illustrates the printed output at timestep 20, including the initial configuration of the upper layer.

The individual debris constituent masses within each bed layer at the time that layer three is established are listed in Table 6.2. As indicated, layer three is initially comprised entirely of stainless steel components, which are derived from the portion of the lower plenum structures (represented by input record series BH04II) previously considered to be suspended above the surface of debris bed layer two.

As indicated in Figure 6.2, layer three is initially small and relatively cold, extending to a height of $231 \mathrm{~cm}$ above vessel zero. This is sufficient to cover wall node 15 , but the inner surface of wall node 16 remains exposed. As the calculation proceeds, additional solid material relocating downward from the core region is added to the upper surface of layer three as will be described in Section 6.3. (Relocating liquids will be added to the layer three interstitial voids.)

It should be noted that the total debris mass listed in Table 6.2 for layer one has increased slightly $(15 \mathrm{~kg})$ over that listed for layer one in Table 6.1, whereas the total mass associated with layer two has decreased accordingly; this small shift is caused by the downward relocation of some of the liquid $\mathrm{FeO}$ from layer two into layer one.

The radial temperature profile across the vessel wall is significantly developed by timestep 20 after lower plenum dryout, as may be seen by comparing the wall temperatures shown in Figures 6.2 and 6.1. The temperature of control volume $(2,5)$ has decreased as heat has been transferred to the wall. About $825 \mathrm{~kg}$ of water has evaporated from the downcomer region during the intervening period of about 3.7 minutes.

As time proceeds, the effects of material relocations play an increasingly important role in determining the predicted results for the example calculation. Specifically, metallic liquids forming within bed layer two relocate into the interstitial voids among the solid particles of layer one, while the composition of layer three is dramatically altered and the size of this layer is increased by the downward relocation of metals and oxides from the core region. 


\section{BH Package Reference Manual}

The reader is cautioned that the results described here are intended only to demonstrate the operation of the BH Package; no conclusions with respect to severe accident progression at Peach Bottom should be derived from these examples of code printed output.

Table 6.2 Material masses $(\mathrm{kg})$ at the initial setup of debris bed layer three for Peach Bottom short-term station blackout

\begin{tabular}{|c|c|c|c|c|}
\hline Material & $\begin{array}{c}\text { Layer } \\
1\end{array}$ & $\begin{array}{c}\text { Layer } \\
2\end{array}$ & $\begin{array}{c}\text { Layer } \\
3\end{array}$ & Total \\
\hline $\begin{array}{l}\mathrm{Zr} \\
\mathrm{Fe} \\
\mathrm{Cr} \\
\mathrm{Ni} \\
\mathrm{B}_{4} \mathrm{C}\end{array}$ & $\begin{array}{r}3414 . \\
5593 . \\
1360 . \\
605 . \\
50 .\end{array}$ & $\begin{array}{r}24453 . \\
17528 . \\
4264 . \\
1895 . \\
356 .\end{array}$ & $\begin{array}{r}0 . \\
42190 . \\
10263 . \\
4561 . \\
0 .\end{array}$ & $\begin{array}{r}27867 . \\
65311 . \\
15887 . \\
7061 . \\
406 .\end{array}$ \\
\hline $\begin{array}{l}\mathrm{ZrO}_{2} \\
\mathrm{FeO} \\
\mathrm{Cr}_{2} \mathrm{O}_{3} \\
\mathrm{NiO} \\
\mathrm{UO}_{2}\end{array}$ & $\begin{array}{r}423 . \\
47 . \\
9 . \\
4 . \\
14874 .\end{array}$ & $\begin{array}{r}3032 . \\
216 . \\
64 . \\
25 . \\
106545 .\end{array}$ & $\begin{array}{l}0 . \\
0 . \\
0 . \\
0 . \\
0 .\end{array}$ & $\begin{array}{r}3455 . \\
263 . \\
73 . \\
29 . \\
121419 . \\
\end{array}$ \\
\hline Totals & 26379. & 158378. & 57014. & 241771. \\
\hline
\end{tabular}




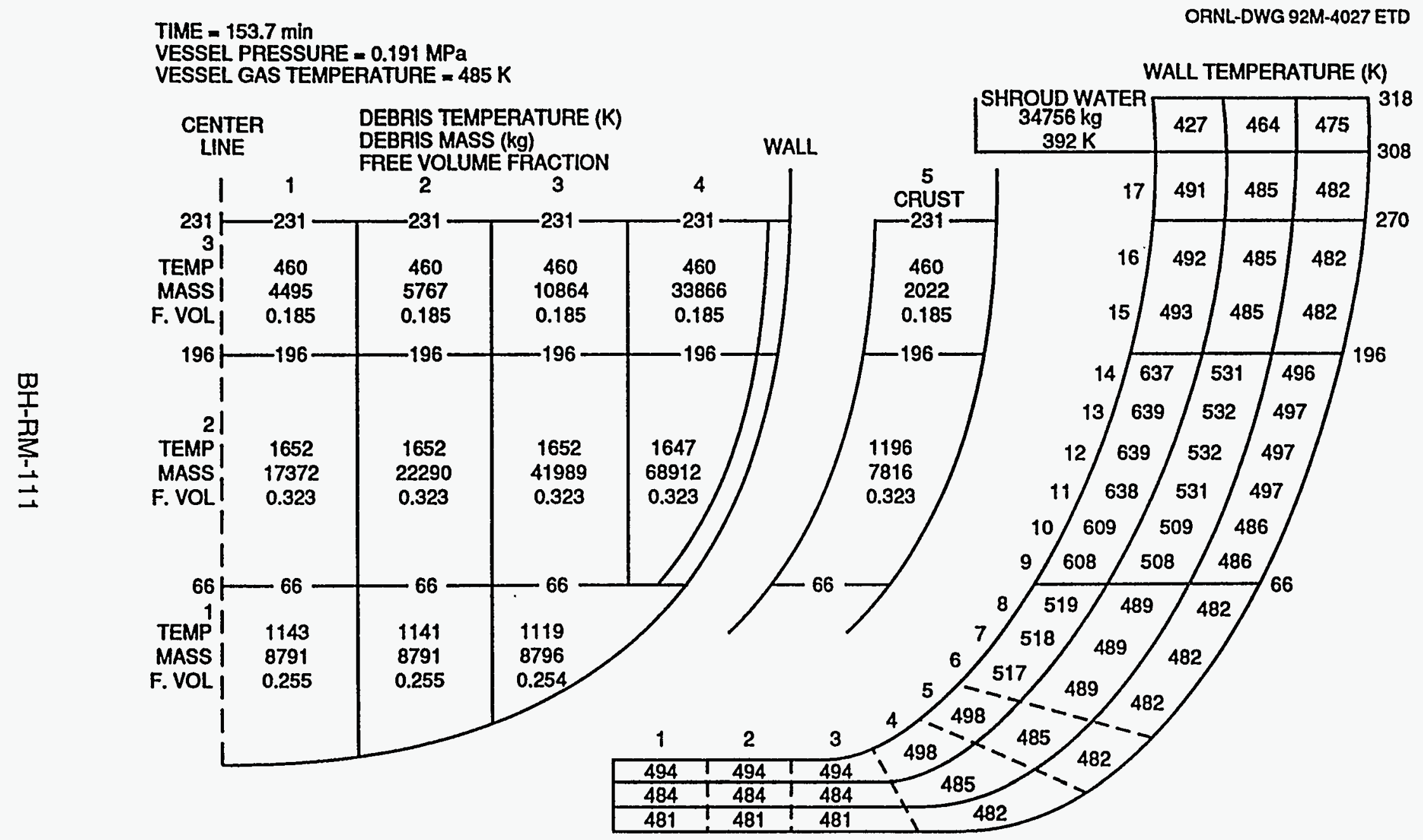

Figure 6.2 Lower plenum debris bed and vessel wall response for the example calculation at the time that debris layer three is established. 
BH Package Reference Manual

\subsection{Lower Plenum and Bottom Head Response}

With all three bed layers represented, the calculated lower plenum debris bed and reactor vessel bottom head response will be described for the case without penetration failures at time 196 minutes and at time 533 minutes, which is just prior to bottom head creep rupture. The initial debris bed configuration just after the time of lower plenum dryout (150.1 minutes after the inception of the accident) has been provided in Figure 6.1 and described in Section 6.1. The bed configuration at the time (153.7 minutes) that the third debris layer is established is described in Section 6.2.

The calculated situation at time 196 minutes is reproduced in Figure 6.3. No free volume remains in the layer one control volumes since molten materials relocating from layer two have filled the previously existing interstitial region voids. The increased masses and temperatures of the layer one control volumes also reflect the effects of these material relocations. However, since the layer one temperatures are well below the melting temperature $(1723 \mathrm{~K})$ of the first eutectic mixture, almost all of the relocating liquids have solidified within layer one. [A small amount of $\mathrm{FeO}$ within control volume $(1,1)$ is in the liquid phase at this time.]

Large amounts of molten debris materials exist at this time within layer two. As indicated, the temperatures of the central four control volumes of this layer exceed the melting temperatures of the first three eutectic mixtures (Table 4.1). The height of the central region of layer two has been reduced and much of the previously existing free volume within this layer has disappeared as the interstitial pores filled with liquid. The temperature of the thin crust control volume $(2,5)$ is close to the temperature of the wall. The mass within this control volume has increased since debris bed dryout and the free volume has disappeared as liquid materials from the adjacent control volume $(2,4)$ relocated laterally and solidified.

All of the debris in layer three remains in the solid phase at this time. The layer three mass has increased considerably, however, as materials have continued to relocate downward from the core region. The effects of this relocation can be seen by comparing the layer masses listed in Table 6.3 with those listed for layer three in Table 6.2.

While the size of debris layer three has increased, however, the elevations of the lower boundaries of the control volumes within the central region have been reduced as the layer two control volumes collapsed beneath them. While the net result of mass additions from above and a sinking floor has been that the elevations of the upper surfaces of the central control volumes are about the same as shown in Figure 6.2, the elevation of the upper surface of crust control volume $(3,5)$ is $10 \mathrm{~cm}$ higher than that shown in Figure 6.2. 
BH Package Reference Manual

While the vessel wall temperatures have increased, they have not reached threatening values. About $3,776 \mathrm{~kg}$ of water have evaporated from the downcomer region since debris bed layer three was established. The water temperature will not vary significantly during the calculation since it is for all practical purposes the saturation temperature corresponding to the vessel pressure and the vessel is maintained depressurized.

Moving ahead about 5-1/2 hours to time 533 minutes, the calculated situation is reproduced in Figure 6.4. Without the escape pathways that would be provided by bottom head penetration failures, all liquid debris has remained within the lower plenum and a molten pool has formed in the central region of the bed. As layer two became predominantly liquid, the solid-phase layer three control volumes $(3,1)$ through $(3,4)$ merged with their layer two counterparts. The pool temperature at time 533 minutes is that of liquid $\mathrm{UO}_{2}$ (Table 4.2), so the only remaining solid in control volumes $(2,1)$ through $(2,3)$ and $(1,1)$ is uranium dioxide, which is undergoing a phase transformation. The situation depicted is just before bottom head creep rupture.

It is worthwhile to pause and take note of two points with respect to Figure 6.4. First, it should be noted that the highest wall temperatures adjacent to debris layer two occur within node 12, the node just below the location of the skirt attachment weld. The average temperature of this node is $1518 \mathrm{~K}$, a level at which carbon steel creep rupture would be anticipated (with the reactor vessel depressurized).

Second, it should be noted that slightly more than $23,000 \mathrm{~kg}$ of water are predicted to remain in the downcomer region at this time. Previously, this water has played an important role during the calculation as a vessel heat sink in removing heat from the upper vessel wall and, more importantly, in cooling the vessel shroud. For calculations in which this water is predicted to become exhausted, the upward radiation from the top of the debris bed will cause the shroud temperature to increase to the steel melting point; prior to dryout, this radiation is primarily consumed in evaporating water from the downcomer region.

For calculations in which downcomer dryout is predicted to occur, the shroud water mass is indicated as $0.0 \mathrm{~kg}$ after dryout and the temperature of the lower shroud is displayed. This continues until the time that shroud melting is predicted to begin. Subsequently, the title "SHROUD WATER" is replaced by the message "MELTED MASS =" and the cumulative mass of the shroud that has melted since the time of downcomer dryout is printed. (This includes consideration of the entire shroud; hence, melting may be indicated even though the temperature of the lower shroud has not reached the melting point.) 
BH Package Reference Manual

Table 6.3 Material masses included in debris bed layer three at time 196 minutes after scram

\begin{tabular}{|lc|}
\hline Material & $\begin{array}{c}\text { Mass } \\
(\mathrm{kg})\end{array}$ \\
\hline $\mathrm{Zr}$ & 17674. \\
$\mathrm{Fe}$ & 51672. \\
$\mathrm{Cr}$ & 12569. \\
$\mathrm{Ni}$ & 5586. \\
$\mathrm{~B}_{4} \mathrm{C}$ & 264. \\
$\mathrm{ZrO}_{2}$ & 4702. \\
$\mathrm{FeO}$ & 3241. \\
$\mathrm{Cr}_{2} \mathrm{O}_{3}$ & 896. \\
$\mathrm{NiO}$ & 347. \\
$\mathrm{UO}_{2}$ & 0. \\
$\mathrm{Total}$ & 96951. \\
\hline
\end{tabular}


BH Package Reference Manual

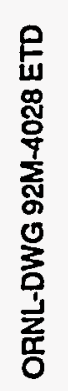

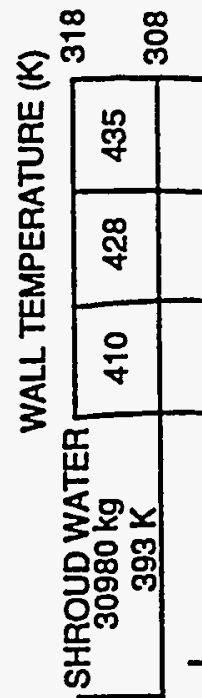

$\stackrel{0}{2}$

$\stackrel{\circ}{\circ}$

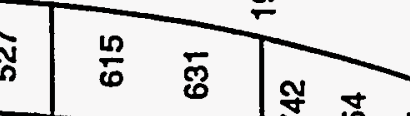

을

$\stackrel{\oplus}{\rightleftharpoons}$

음

$\frac{E}{\frac{\pi}{0}}$

岇

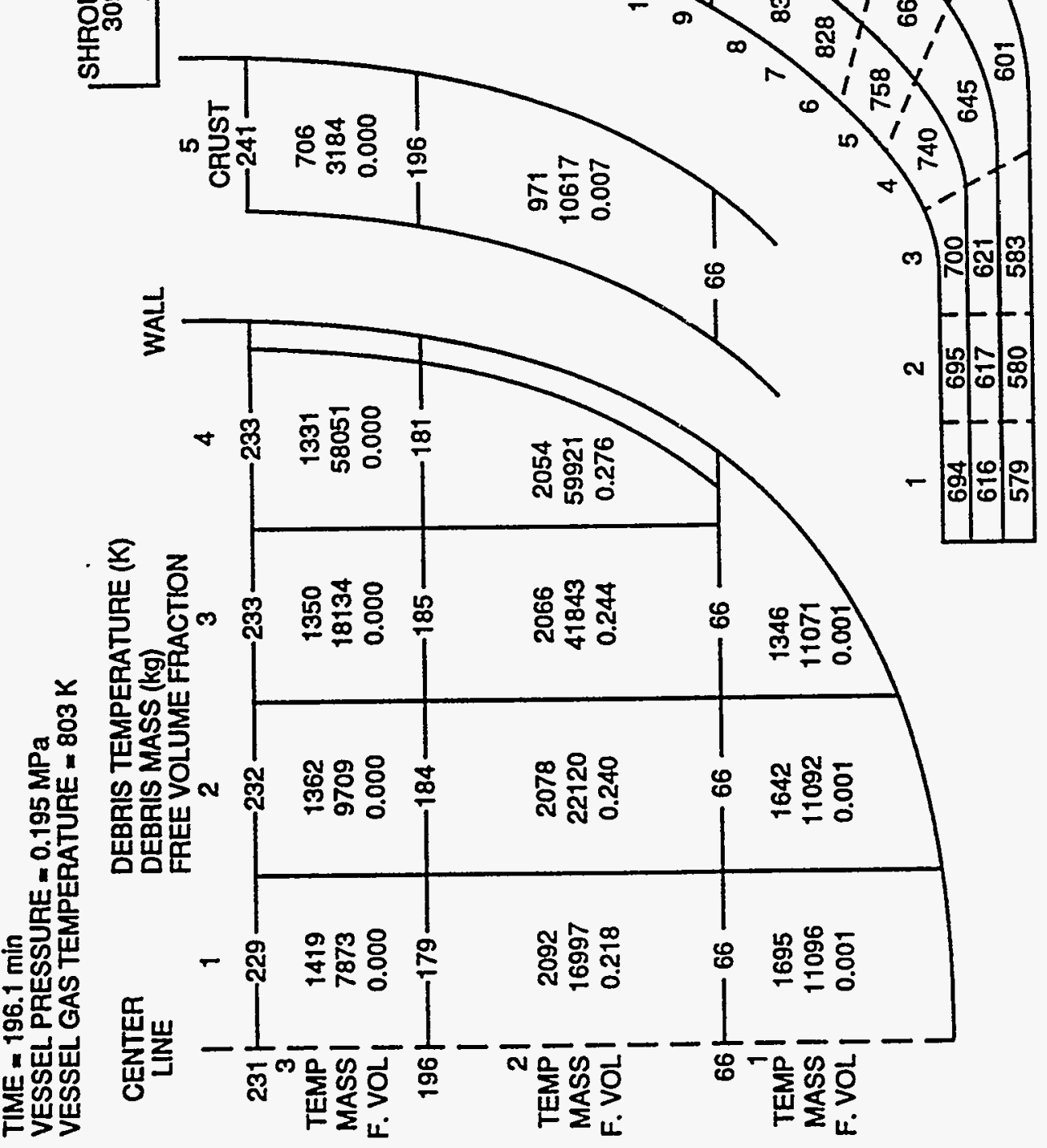

₹

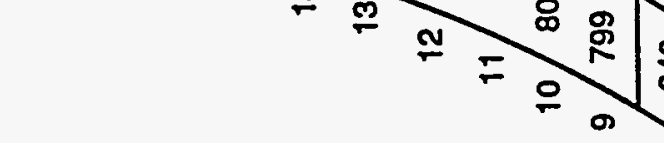


BH Package Reference Manual

\subsection{The Case With Penetration Failures}

If the user permits penetration failures to occur in the calculation (by parameter NPIPES on input record $\mathrm{BH} 1100$ ), then failure of the bottom head structural boundary is accelerated. As described in Section 5.3.1, molten material flowing through the penetration assemblies ablates the wall. The calculated situation just before wall failure for a case in which penetration failures were represented is reproduced in Figure 6.5. This case is identical to that discussed in Sections 6.1 through 6.4 except that penetration failures are allowed. The initial penetration failure is predicted to occur at time 160.6 minutes. Accordingly, Figures 6.1 and 6.2 apply to this case as well.

The first thing to note with respect to Figure 6.5 is that no temperatures are shown for the inner surface (first) segments of wall nodes 1 through 5 . This occurs because the bottom head wall response model has predicted that these wall segments no longer exist; they have been ablated away.

Second, it should be noted that the central portion of the debris bed has collapsed to the extent that the remaining solid debris approaches the shape of the confining (hemispherical) walls. At this point, about $122,000 \mathrm{~kg}$ of mostly metallic debris has been predicted to be released to the drywell while about $170,000 \mathrm{~kg}$ of mostly oxidic debris is predicted to remain in the lower plenum debris bed.

Evidence of a downward slippage of the outer two control volumes of bed layers two and three is also provided. The current elevation of the upper surface of control volume $(3,4)$, which is $199 \mathrm{~cm}$, is only slightly higher than the original elevation $(196 \mathrm{~cm})$ of the lower surface of this control volume. The slippage of the outer crust control volumes $(2,5)$ and $(3,5)$ has been much less, only about three $\mathrm{cm}$ for control volume $(2,5)$.

As indicated in Figure 6.5, the central three control volumes of layer two and layer one control volumes $(1,1)$ and $(1,2)$ have a representative temperature equivalent to the $\mathrm{UO}_{2}$ melting temperature. Because of the prior release of lower-melting materials to the drywell, each of these control volumes comprise at this time only solid $\mathrm{UO}_{2}$ particles plus a relatively small amount of transient $\mathrm{UO}_{2}$ liquid. These control volumes would continue to shrink as mass was lost if the calculation proceeded; however, as previously mentioned, predicted gross failure of the bottom head wall is imminent.

Finally, with reference to Figure 6.5 , it is worth noting that a large amount of water remains in the downcomer region. It is typical of calculations in which bottom head penetration failures are represented to find that clowncomer dryout does not occur before gross failure of the bottom head wall is predicted. 


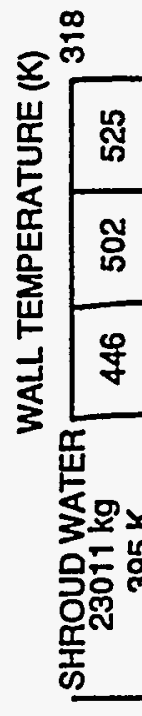

号 :

8

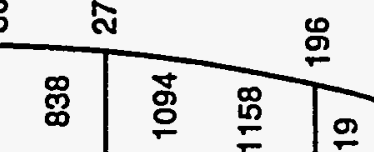

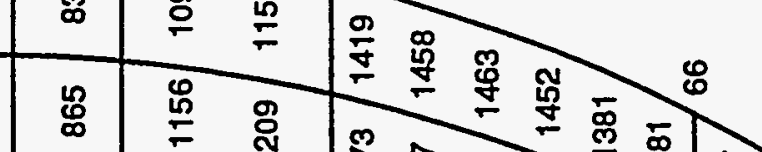

\begin{tabular}{|c|c|}
\hline$\frac{m}{a}$ & : \\
\hline
\end{tabular}

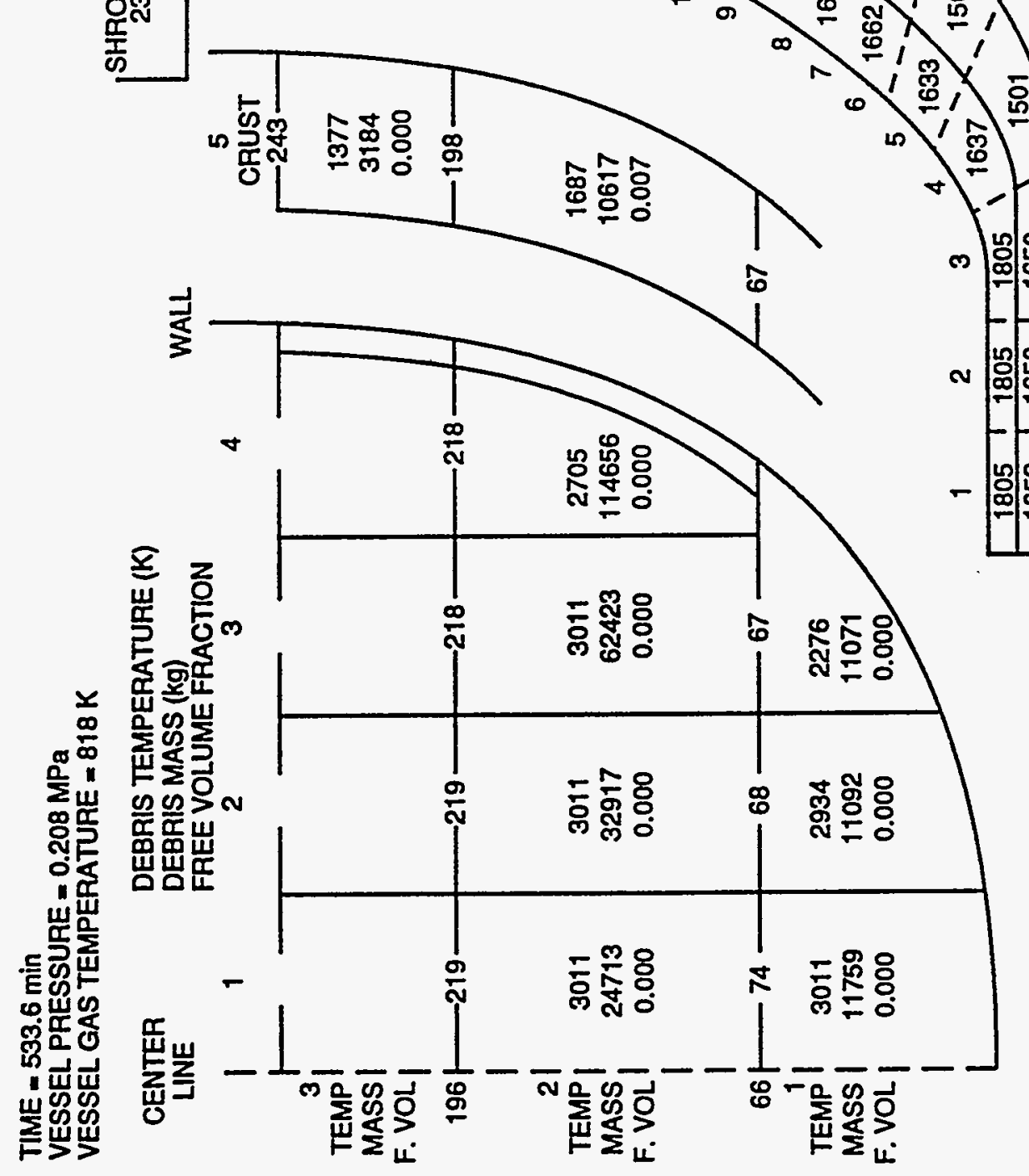

₹ 0 ᄂ

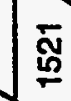




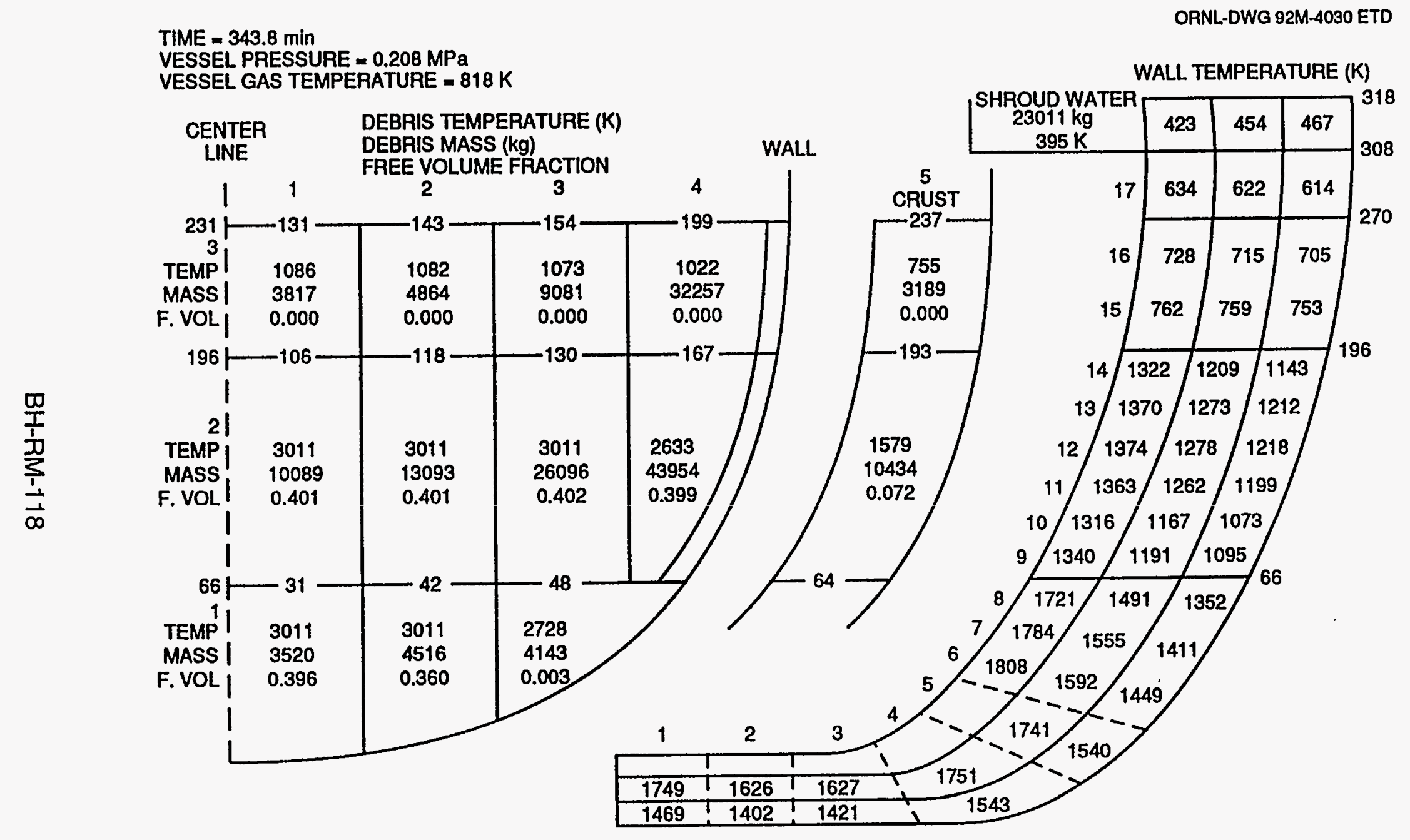

Figure 6.5 Results for a case with penetration failures. 
BH Package Reference Manual

\subsection{Tabulated Output}

On the same first output page and immediately beneath the pictorial representations described in Sections 6.1 through 6.4 is printed certain specific information (not shown) concerning the calculated debris bed response. Six information entries provide both current timestep values and cumulative totals for items such as heat transfer to vessel heat sinks or hydrogen generation. The seventh entry addresses the fraction of metal oxidation. Each of these entries is explained below, followed by a discussion of the tabulated output printed on the second page.

The nature of the first two entries depends upon whether or not the third debris layer has been established. Before the third debris layer is established, the lower plenum atmosphere above the bed surface is considered to be dominated by the presence of the control rod guide tube heat sinks as represented by the VPS array entered via input record BH04ll. The first two items of printed output are:

Temperature of $C R$ guide tubes (above debris) $=\ldots$

Heat transfer from guide tubes to vessel atmosphere and wall:

This timestep $=\ldots$ Joule $\quad$ Total since bottom head dryout $=$ Joule.

In effect, code logic recognizes that the mass of the lower plenum atmosphere is insignificant compared to the mass of the control rod guide tubes (and other lower plenum structures above the surface of the debris bed) and that the atmosphere-toguide tube heat transfer area is large. Heat transfers from the debris bed surfaces are calculated based upon the assumed presence of an atmosphere comprised of the actual lower plenum gases with a temperature equivalent to the temperature of the control rod guide tubes. The intermediate steps of a calculation of an increase in the atmosphere temperature and the concomitant heat transfer from the atmosphere to the control rod guide tubes are considered unnecessary and are omitted. The calculated energy transfers are applied directly to the control rod guide tube mass and a new guide tube temperature is calculated.

Once the third debris bed layer is established, however, all lower plenum structures above the surface of debris layer two are assumed to be subsumed into this layer. Now the code logic recognizes the existence of both the core shroud and an independently-modeled lower plenum atmosphere above the bed surface; the first two routinely printed entries are now:

Net heat transfer to vessel heat sinks (after control rod guide tube failure):

This timestep $=$ Joule Total since guide tube collapse $=$ Joule

Net heat transfer to vessel atmosphere (after control rod guide tube failure): This timestep $=$ Joule Total since guide tube collapse $=$ Joule. 


\section{BH Package Reference Manual}

Thus, without the overwhelming presence of the control rod guide tubes, heat transfers from the bed surfaces to the core shroud and to the vessel atmosphere are calculated separately.

Specifically, the first entry now represents the net heat transfer to the core plate and the lower core shroud (including the baffle plate) from the debris bed upper surfaces and to the downcomer region water from the uppermost bottom head wall node NWALL. After downcomer dryout, this entry represents the net heat transfer to the core plate and lower core shroud plus the radiant heat transfer to the lower core shroud from the uppermost bottom head wall node.

The second entry now represents the net heat transfer to the lower plenum atmosphere from

1) the debris bed upper surfaces and

2) the exposed bottom head wall nodes.

The sum of these two entries now provides a record of the net energy transfer from the debris bed and bottom head wall to the reactor vessel atmosphere, the lower core shroud (including the baffle plate), and the core plate after lower plenum dryout and the establishment of debris bed layer three.

The third item of printed output

Decay heat in debris in vessel bottom head:

This timestep $=$ Joule Total since bottom head dryout = Joule.

simply records the energy release by decay heating within the reactor vessel lower plenum. (Energy released within debris that has escaped to the containment drywell is not included.)

The final three items of printed output reflect the effects of the metal-steam reaction within the debris bed. These are:

Metal/steam reaction energy in debris:

This timestep $=$ Joule Total since bottom head dryout $=$ Joule.

Hydrogen generated in lower plenum debris bed:

This timestep $=$ $\mathrm{kg}$ Total since bottom head dryout = $\mathrm{kg}$.

Fraction of zirconium (below core plate) reacted $=$

Metal-steam reaction within the lower plenum debris bed is of course zero until bottom head penetration failures occur, providing an escape pathway for steam to pass through the bed. The last item, however, is based upon the current ratio of zirconium dioxide to zirconium metal within the lower plenum (or released to the drywell) and, therefore, represents the effects of metal oxidation that occurred in the core region as 
well. It appears at the bottom of the first printed output page only after the third debris layer has been established.

The second page of printed output provides a "Material Breakdown of Debris" in tabular format. An example of these output tables as generated for a typical calculation is illustrated in Table 6.4. (The numbers shown are typical, but are not intended to relate directly to any other example results cited in this text.)

As indicated, the upper set of tables relates to the materials currently present within the lower plenum debris bed and provides a breakdown according to the distribution of these materials among the bottom (1), middle (2), and upper (3) debris layers. This distribution is further subdivided for each material in each layer so as to specify the individual masses of the solid and liquid components.

The list of materials at the left side of the upper set of tables will include only the materials actually present within the debris bed. Late in the calculation, if all of the stainless steel components have been released from the lower plenum, then $\mathrm{Fe}, \mathrm{Cr}$, and $\mathrm{Ni}$ will disappear from this list.

A relevance criterion for the materials to be listed is also applied to the lower portion of Table 6.4. Here the list includes only those materials for which some portion (at least $0.1 \mathrm{~kg}$ ) has escaped from the reactor vessel. It should be obvious that the number of materials listed in this category will increase as the calculation progresses. For example, Table 6.4 indicates that $\mathrm{B}_{4} \mathrm{C}$ is currently present within the lower plenum debris bed, but none has yet (melted and) escaped from the reactor vessel. When it does, the list of materials at the lower portion of Table 6.4 will become longer by the addition of $\mathrm{B}_{4} \mathrm{C}$.

For each material, both the mass released from the reactor vessel during the current timestep and the cumulative mass released since the beginning of the $\mathrm{BH}$ package calculation are displayed. The listed temperature is the mixed-mean temperature of the release during the current timestep. The indicated decay heat is the power associated with the cumulative $\mathrm{UO}_{2}$ release.

It should be noted that the information displayed in the lower portion of Table 6.4 will only be printed after some material release from the reactor vessel has occurred. Therefore, for calculations in which penetration failures are not modeled, no information will be printed in this location until the time that gross failure of the bottom head wall is predicted. At that time, all lower plenum debris will be transferred to the containment drywell during one timestep, and the $\mathrm{BH}$ package calculation will be terminated. Should this occur, logic within Subroutine BHHED2 ensures that this one-time transfer will be recorded (printed) in the format demonstrated in Table 6.4.

As a final note, it should be recognized that only liquid materials are predicted to escape from the reactor vessel via bottom head penetration failures. The only occasion 
BH Package Reference Manual

during the calculation when both solid and liquid materials escape the reactor vessel simultaneously is at the time of gross reactor vessel bottom head failure. 
Table 6.4 Example showing format of second page of printed output.

$* * * * * * * * * * * * * * * * * * * * * * * * * * * * * * * * * * * * * * * * * * * *$ Material Breakdown of Debris*********************************************

Debris masses in vessel bottom head $(\mathrm{kg})$ :

\begin{tabular}{|c|c|c|c|c|c|c|c|c|}
\hline \multirow{2}{*}{ Material } & \multicolumn{2}{|c|}{ Layer No. 1} & \multicolumn{2}{|c|}{ Layer No. 2} & \multicolumn{2}{|c|}{ Layer No. 3} & \multicolumn{2}{|c|}{ ***** All Layers $* * * * *$} \\
\hline & Solid & Liquid & Solid & Liquid & Solid & Liquid & Solid & Liquid \\
\hline $\mathrm{Zr}$ & 5351.5 & 0.0 & 16175.8 & 241.5 & 14743.8 & 0.0 & 36271.1 & 241.5 \\
\hline $\mathrm{Fe}$ & 8569.1 & 0.0 & 1728.5 & 165.4 & 52356.6 & 0.0 & 62654.2 & 165.4 \\
\hline $\mathrm{Cr}$ & 2153.9 & 0.0 & 290.0 & 0.0 & 12735.4 & 0.0 & 15179.3 & 0.0 \\
\hline $\mathrm{Ni}$ & 477.2 & 0.0 & 160.9 & 306.6 & 5660.2 & 0.0 & 6298.3 & 306.6 \\
\hline $\mathrm{B}_{4} \mathrm{C}$ & 57.3 & 0.0 & 459.5 & 0.0 & 184.2 & 0.0 & 701.0 & 0.0 \\
\hline $\mathrm{ZrO}_{2}$ & 400.8 & 0.0 & 3287.3 & 0.0 & 6674.4 & 0.0 & 10362.5 & 0.0 \\
\hline $\mathrm{FeO}$ & 248.0 & 0.0 & 11.5 & 0.0 & 3258.7 & 0.0 & 3518.2 & 0.0 \\
\hline $\mathrm{Cr}_{2} \mathrm{O}_{3}$ & & 0.0 & 63.9 & 0.0 & 900.5 & 0.0 & 972.4 & 0.0 \\
\hline $\mathrm{NiO}$ & 3.1 & 0.0 & 24.7 & 0.0 & 348.5 & 0.0 & 376.3 & 0.0 \\
\hline $\mathrm{UO}_{2}$ & 14090.7 & 0.0 & 111582.3 & 238.3 & 0.0 & 0.0 & 125673.0 & 238.3 \\
\hline Totals & 31359.6 & 0.0 & 133784.4 & 951.8 & 96862.3 & 0.0 & 262006.3 & 951.8 \\
\hline
\end{tabular}

Debris masses ex-vessel:

$\begin{array}{lrr}\text { Material } & \begin{array}{r}\text { This } \\ \text { Timestep }\end{array} & \begin{array}{r}\text { Total } \\ \text { Released }\end{array} \\ \mathrm{Zr} & 49.4 & 7354.1 \\ \mathrm{Fe} & 33.8 & 13090.3 \\ \mathrm{Cr} & 0.2 & 3285.2 \\ \mathrm{Ni} & 62.2 & 1601.6 \\ \mathrm{ZrO} & 0.0 & 0.6 \\ \mathrm{FeO}_{2} & 0.0 & 0.5 \\ \mathrm{UO}_{2} & 49.5 & 1229.6 \\ & -.-5 \\ \text { Total } & 195.1 & 26561.9\end{array}$

Temperature $\quad 1871.0 \mathrm{~K}$

Decay heat in ex-vessel debris $=0.196534 \mathrm{E}+06$ Watt 
BH Package Reference Manual

\subsection{Special Messages}

Special printed output is provided to record the occurrence of important individual events at the time they occur. These messages are printed at the end of and on the same page as the tabular output from the previous regularly-scheduled status update.

As described in Section 3.4, the user can limit the extent of the calculated metal-steam reaction in the lower plenum debris bed by setting the input parameter FZRMX1 [BH0700] to a fraction less than one. If this is done, the message

Bottom head Zr oxidation stopped kg reacted

is printed at the time that the permissible fraction of the initial zirconium inventory has been reacted. This message indicates the mass of zirconium that has been oxidized within the lower plenum since the inception of the $\mathrm{BH}$ package calculation. Code logic precludes the calculation of any additional oxidation after the appearance of this message.

If bottom head penetrations are represented, then creep rupture of a penetration weld at the wall as described in Section 5.1 is reported by the message:

$P$. weld temperature in layer no. exceeds Kat time $=$

Penetration in bottom head assumed to fail

where the index of the debris layer will be indicated as 1 (bottom layer) or 2 (middle layer).

Failure of the instrument guide tubes in the manner described in Section 5.2 (melt overflow from the middle or bottom debris layer) is reported by the message

Inst. tube fails in layer no. , control volume

(temp. $=$ K) at time $=$

where the layer index will be 1 or 2 and the indicated temperature is that of the control volume where the failure is predicted to occur.

Gross failure of the bottom head wall can occur either by ablation (discussed in Section 5.3) or creep rupture (Section 5.4). If an entire wall node is ablated away, then the printed message is

Lower head ablated in wall node at time $=$

All remaining lower plenum debris transferred to the drywell.

If the wall fails by creep rupture, then the message is similar: 
BH Package Reference Manual

Lower head creep rupture in wall node ___ at time $=$ All remaining lower plenum debris transferred to the drywell.

As indicated, the concept is that all remaining debris is released from the vessel at the time of gross wall failure. 
BH Package Reference Manual

\section{MODELS FOR WATER IN THE LOWER PLENUM}

The models described in this Chapter enable the calculation of bed response if the BWR lower plenum is reflooded after debris bed dryout and initiation of the $\mathrm{BH}$ package calculations. For conventional BWR (CBWR) applications, such late-phase introduction of water into the lower plenum might occur as a direct consequence of restoration of electrical power after a prolonged station blackout. For the Simplified Boiling Water Reactor (SBWR) design, failure of the short-term cooling mode of the Gravity Driven Cooling System (GDCS), followed later by operation of the long-term cooling mode, could result in late flooding of a badly degraded core.

In order to cool the inner regions of a debris bed, water must be able to enter the bed, which means that the debris must contain voided regions to serve as water passages. The porosity is defined as the ratio of the voided volume of a region to the total volume of the region. In general, the porosity of a particle bed depends upon the shape of the particles and the manner in which they are fitted together but not upon the size of the particles. For example, the porosity of a bed of uniform solid cubes is zero whereas a bed of uniform spheres can have a porosity ranging from 0.259 for a rhombohedral configuration to 0.476 for a cubic configuration. For debris produced during an actual accident, the bed composition would be nonuniform ${ }^{*}$ so that the local porosities would be expected to vary radially and axially over a range extending from a low of about 0.10 to values as high as 0.60 .

Thus the effects of water introduced over the surfaces of a dry debris bed depend upon the bed porosity; all other boundary conditions are of secondary importance. Yet determination of porosity would require knowledge of particle size distributions, shapes, and weight fractions as well as the local bed configuration. Since these are not known, the best that can be done for purposes of analysis is to vary the assumed porosity over a reasonable range of values. Stated another way, a parametric analysis can be performed to determine the effectiveness of water cooling over a range of potential bed porosities. With the new models described in this Chapter, the set of calculations required for the parametric analysis can be performed with MELCOR by use of the $\mathrm{BH}$ Package. Section 2.12 of the BH Package Users' Guide describes the special control functions necessary for the introduction of water over the lower plenum debris bed.

Subroutine BHBWET has been added to the BH Package subsequent to the release of MELCOR 1.8.2. This permits calculation of heat transfer by convection and radiation to water overlying the bed and by boiling to water within the bed. Subroutine BHBWET calculates the depth of water over the debris bed (Section 7.1), the dryout heat flux for the bed radial zones (Section 7.2), hydrogen generation within the bed (Section 7.3), and the heat transfer at the bed surfaces (Section 7.4) and exposed reactor vessel

\footnotetext{
- For the distribution of debris produced during the TMI accident, see Section 3.7 of Reference 24. For a description of the homogeneous particulate debris that formed from previously molten material, see Reference 36.
} 


\section{BH Package Reference Manual}

inner wall surfaces (Section 7.5). The total heat transfer to the lower plenum water is returned to MELCOR, and the time-dependent mass of water overlying the bed surface and the temperature of this water are calculated within the MELCOR-BH Package interface. Hydrogen generated as a result of water addition to the lower plenum debris is added to the vessel atmosphere.

Special provisions are necessary if water is predicted to exist within the lower plenum after penetration failures have occurred. The code logic utilized for this case is discussed in Section 7.6. Late debris pours from the core region would interact with any water overlying the debris bed, and the methodology employed for calculating these effects is described in Section 7.7. The special printed output associated with the effects of water in the lower plenum is demonstrated in Section 7.8.

\subsection{Water Depths}

Subroutine BHBWET includes provision for calculation of water height within the reactor vessel lower plenum and the individual water depths over the upper surface of each bed radial zone. The logic applies also to cases in which a limited amount of water becomes available late in the accident sequence so that the central (sunken) portion of the bed is covered while the outer radial zones remain dry.

The following time-dependent variables reflect the amount of water in the lower plenum and the configuration of the bed surface.

$$
\begin{array}{ll}
\text { AMASLP }= & \text { mass of water in lower plenum, } \mathrm{kg} \\
\text { TMASLP }= & \text { temperature of lower plenum water, } \mathrm{K} \\
\mathrm{YLT} & =\mathrm{YLT}(\mathrm{I}, \mathrm{J}), \text { height of control volume surface above vessel zero, } \mathrm{m} \\
\mathrm{I}, \mathrm{J} & =\text { indices of bed layer }(\mathrm{I}=1,3) \text { and radial zone }(\mathrm{J}=1,5) \\
\mathrm{IT} & \mathrm{IT}(\mathrm{J}), \text { flag indicating the upper layer index for each radial zone } \\
\mathrm{IVLP} & =\operatorname{IVLP}(\mathrm{I}, \mathrm{J}), \text { flag changing value from } 1 \text { to } 0 \text { to indicate that a bed } \\
& \text { control volume no longer exists. }
\end{array}
$$

Bed control volumes cease to exist whenever their internal debris masses and energies are merged with those of another control volume, as described in Section 4.4. It should be noted that $\operatorname{IVLP}(1,4)$ and $\operatorname{IVLP}(1,5)$ are zero from the beginning of the calculation since these bed control volumes are never formed (see Figure 1.9).

The time-dependent variables that are calculated in Subroutine BHBWET to describe the water depths are

$$
\begin{array}{ll}
\text { YLIQ } & =\text { height of water surface above vessel zero, } m \\
\text { HWAT } & =H W A T(J), \text { depth of water above the surface of radial zone } \mathrm{J}, \mathrm{m}
\end{array}
$$


BH Package Reference Manual

IWET = IWET(J), flag changing value from 0 to 1 to indicate that water covers the surface of a bed radial zone.

Table 7.1 indicates typical values of the IT and IVLP arrays late in a calculation with penetration failures.

Table 7.1 Typical values of the IT and IVLP arrays after bed settling and control volume merging

\begin{tabular}{|l|llcll|}
\hline Array & \multicolumn{5}{|c|}{ Radial Zone } \\
& 1 & 2 & 3 & 4 & 5 \\
\hline $\operatorname{IT}(J)$ & 2 & 2 & 2 & 3 & 3 \\
$\operatorname{IVLP}(3, J)$ & 0 & 0 & 0 & 1 & 1 \\
$\operatorname{IVLP}(2, \mathrm{~J})$ & 1 & 1 & 1 & 1 & 1 \\
$\operatorname{IVLP}(1, \mathrm{~J})$ & 1 & 1 & 1 & 0 & 0 \\
\hline
\end{tabular}

The IWET array elements are used within Subroutine BHHED2 to determine whether heat transfer from each bed surface should be to atmosphere (IWET=0) or to an overlying water pool (IWET=1). As the central portion of the bed sinks, some radial zones may be dry while others are covered with water. It should also be recognized that after merging occurs, the bed surface may be comprised of layer two control volumes in the central region and layer three control volumes near the wall (as in the bed configuration represented by Table 7.1).

The height of the lower plenum water surface is used to determine which of the exposed reactor vessel wall nodes (those with centerlines above the debris surface) are subject to water cooling. (Wall node indices are indicated in Figure 1.10.) The sixth and seventh elements of the IWET(7) array are used as flags changing value from 0 to 1 to indicate that the inner surfaces of the exposed bottom head wall nodes are covered by water:

$$
\begin{aligned}
& \operatorname{MET}(6)=\text { Flag for wall node } 17 \\
& \operatorname{IWET}(7)=\text { Flag for wall nodes } 9 \text { through } 16 .
\end{aligned}
$$

As indicated, all of any water-covered wall region below node 17 is treated as a single region. This is for the purpose of determining surface heat transfer coefficients and is consistent with the method used for heat transfer to the lower plenum atmosphere, as described in Section 3.2.1. Actual heat transfer is calculated separately for each node.

An exposed wall node is considered to be covered by water if

$$
Y L I Q>\frac{Y L T W(M)+Y L T W(M-1)}{2.0}
$$




\section{BH Package Reference Manual}

where

$\mathrm{M} \quad$ = wall node index

YLTW = height of upper boundary of inner nodal surface above vessel zero, $\mathrm{m}$.

Heat transfer at the inner surface of water-covered exposed wall nodes might be either by nucleate or film boiling, depending upon the temperature differential between the surface and the water.

\subsection{Dryout Heat Flux}

If the water initially introduced over the bed surface is subcooled, condensation of the steam within the bed would rapidly draw water into the upper debris voids. This initial water entry would quickly be evaporated, however, and countercurrent flows of upwardflowing steam and downward-flowing water would soon be established. 25 As explained in Reference 26, the extent of water penetration is not uniform over the bed crosssection but rather takes the form of water channels between scattered pockets of bypassed hot, dry debris. However,

"the average quench rate of the bed can be predicted reasonably well based on the assumption that the supply of water to the bed is controlled by the hydrodynamics of countercurrent two-phase flow.... The prediction can be made using a one-dimensional model without considering the water penetration pattern."26

Stated another way, the bed quench rate and steam generation are flow-limited rather than particle-water heat transfer limited. Thus, the dryout heat flux (the power per unit area removed at the bed surface) establishes the average rate of bed quenching.

The preeminence of the dryout heat flux in determining the heat removal from a debris bed by water cooling is also evident from the information provided in Reference 27 , where experimental results again demonstrate that:

"the mechanism that limits the bed cooling rate in both transient quench and steady state dryout is two-phase countercurrent bed hydrodynamics." and

"the steady-state models provide reasonable characterization of the transient bed quench steam generation rate." 27

Thus, importantly, it is not necessary to attempt to calculate the details of the water penetration process. 


\subsubsection{Calculation}

The dryout heat flux is calculated within Subroutine BHBWET by the method of Lipinski.28 Its magnitude decreases rapidly as the bed porosity decreases; hence, the efficacy of the water will depend upon the state of the bed at the time that the water is introduced. (After lower plenum dryout, melting and relocation of lower-melting temperature materials progressively reduce the porosity in the lower portions of the bed.)

For each water-covered bed radial zone, the dryout heat flux is determined for each control volume as

$$
\operatorname{DFLX}(I, J)=\operatorname{QT} x\left[\sqrt{1.0+\left(\frac{\mathrm{QT}}{2 \times \mathrm{QL}}\right)^{2}}-\frac{\mathrm{QT}}{2 \times \mathrm{QL}}\right] \quad \frac{\text { Watts }}{\mathrm{m}^{2}}
$$

where

$$
\begin{aligned}
& \text { QT } \quad=\text { QT1 } \times \sqrt{\frac{\varepsilon^{3}}{1-\varepsilon}} \\
& \varepsilon \quad=\operatorname{PORB}(\mathrm{I}, \mathrm{J}) \text {, control volume porosity } \\
& \text { QT1 }=H L V \times \sqrt{\frac{\rho s \times \rho l \times(\rho l-\rho s) \times G \times D F R A G}{F 6}} \\
& \text { HLV = heat of vaporization for water, } \mathrm{J} / \mathrm{kg} \\
& \text { ps } \quad=\text { steam density, } \mathrm{kg} / \mathrm{m}^{3} \\
& \text { pl } \quad=\text { liquid density, } \mathrm{kg} / \mathrm{m}^{3} \\
& \mathrm{G}=\text { acceleration of gravity, } \mathrm{m} / \mathrm{s}^{2} \\
& \text { DFRAG = particle diameter, } m \\
& \text { F6 } \quad=1.75 \times\left(\rho s^{1 / 6}+\rho 1^{1 / 6}\right)^{6} \\
& \text { QL } \quad=\text { QL1 } \times \frac{\varepsilon^{3}}{[1.0-\varepsilon]^{2}} \\
& \text { QL1 }=H L V \times \frac{(\rho l-\rho s) \times G \times D_{F R A G}^{2}}{F 4} \\
& \text { F4 } \quad=150 \times\left(\mathrm{VKS}^{1 / 4}+\mathrm{VKL}^{1 / 4}\right)^{4} \\
& \text { VKS = steam viscosity } \mathrm{m}^{2} / \mathrm{s} \\
& \text { VKL = water viscosity } \mathrm{m}^{2} / \mathrm{s} \text {. }
\end{aligned}
$$


BH Package Reference Manual

Property values together with calculated intermediate terms and final results for an example calculation are shown in the following Table.

Table 7.2 Example results for the dryout heat flux calculation

\begin{tabular}{|c|c|c|c|}
\hline Parameter & \multicolumn{2}{|c|}{ Value } & Source \\
\hline DFRAG & $0.01^{a}$ & m & Geometric \\
\hline$\varepsilon$ & $0.2088^{b}$ & & Quantities (Given) \\
\hline$\rho s$ & 1.037 & $\mathrm{~kg} / \mathrm{m}^{3}$ & Property Values for \\
\hline$\rho l$ & 945.011 & $\mathrm{~kg} / \mathrm{m}^{3}$ & Vessel Pressure \\
\hline HLV & $2208.85 \times 10^{3}$ & $\mathrm{~J} / \mathrm{kg}$ & of $0.186 \mathrm{MPa}$ \\
\hline VKS & $1.2353 \times 10^{-5}$ & $\mathrm{~m}^{2} / \mathrm{s}$ & \\
\hline VKL & $2.5564 \times 10^{-7}$ & $\mathrm{~m}^{2} / \mathrm{s}$ & \\
\hline F6 & 8795.3 & $\mathrm{~kg} / \mathrm{m}^{3}$ & Calculated \\
\hline QT1 & 7096.5 & $\mathrm{~W} / \mathrm{m}^{2}$ & Quantities \\
\hline F4 & 0.00671 & $\mathrm{~m}^{2} / \mathrm{s}$ & \\
\hline QL1 & $305.0 \times 10^{6}$ & $\mathrm{~W} / \mathrm{m}^{2}$ & \\
\hline QT & $758.9 \times 10^{3}$ & $W / m^{2}$ & \\
\hline QL & $4434.1 \times 10^{3}$ & $W / m^{2}$ & \\
\hline DFLX & $696.73 \times 10^{3}$ & $W / m^{2}$ & Final Resultc-e \\
\hline
\end{tabular}

a The particle diameter DFRAG for this example is representative of the size of a $\mathrm{UO}_{2}$ fuel pellet.

$b$ The control volume porosity $\varepsilon$ has been lowered from its initial value because molten material from elsewhere in the bed has previously relocated into the volume.

c Reducing the particle diameter to $0.001 \mathrm{~m}$ while holding all else constant in this example decreases the calculated value of DFLX to $42.95 \times 10^{3} \mathrm{~W} / \mathrm{m}^{2}$.

d Use of a particle diameter of $0.001 \mathrm{~m}$ combined with a bed porosity of 0.40 while holding all else constant produces a calculated DFLX of $389.29 \times 10^{3} \mathrm{~W} / \mathrm{m}^{2}$. e In general, the dryout heat flux increases with both particle diameter and bed porosity. Curves illustrating these trends are provided in Section 6.5 of Reference 24. 
BH Package Reference Manual

\subsubsection{Application to Bed Radial Zones}

Given the dryout heat flux DFLX, the maximum power that can be removed through the upper surface area AINFCA of bed control volume $(I, J)$ is

$$
\operatorname{QSUR}(I, J)=\operatorname{AINFCA}(I, J) \times \operatorname{DFLX}(I, J) \quad \text { Watts. }
$$

This is the maximum power that can be removed from the control volume by means of boiling heat transfer; that is, through the mechanism of saturated water flowing in (downward) and saturated steam flowing out (upward). For this maximum power to be attained, the upward flow of steam at the control volume surface must not be impeded.

Since the lower plenum debris bed is normally arranged in three layers, it is necessary to consider the effect of the overlying debris in blocking the escape of steam from the middle and lower layer control volume surfaces. At the same time, the effects of steam entering the middle and upper layer control volumes from below must be considered. Accordingly, the effectiveness of water cooling within each of the three stacked control volumes must be calculated separately.

For the upper control volume,

$$
\operatorname{QWET}(3, \mathrm{~J})=\text { QSUR }(3, \mathrm{~J}) \text { - QSUR(2,J) Watts }
$$

is the internal boiling power based upon the dryout heat flux limitation at the control volume surface and the maximum power inflow from the middle control volume. Based upon this relation, the calculated boiling power within the upper control volume will be severely curtailed if the calculated value of QSUR $(2, J)$ is large. This is not realistic, however, since the downward-flowing water enters the upper control volume first. In recognition of this, the calculated value of $\operatorname{QWET}(3, \mathrm{~J})$ is adjusted, if necessary, to be no less than $80 \%$ of QSUR( $3, \mathrm{~J})$.

It will be shown below how the final value of QWET(3,J) is applied in the determination of the cooling effectiveness in the central control volume. First, however, it is necessary to consider the potential for reduction in the calculated value of QWET(3,J) as the debris temperature TMLPO $(3, \mathrm{~J})$ approaches the saturation temperature TSAT. As the bed loses superheat, it becomes necessary to consider the local decay power QDOT(3,J), which will become the dominant source of energy for transfer to water. The approach is described in the following Table, which is applicable to any bed control volume $(\mathrm{I}, \mathrm{J})$ and addresses four possibilities. 
BH Package Reference Manual

Table 7.3 Effect of debris temperature upon boiling power

\begin{tabular}{|c|c|}
\hline $\begin{array}{c}\text { Debris Temperature }(\mathrm{K}) \\
\text { TMLPO }(\mathrm{I}, \mathrm{J})\end{array}$ & $\begin{array}{c}\text { Maximum Boiling Power }(\mathrm{W}) \\
\text { QWET }(\mathrm{I}, \mathrm{J})\end{array}$ \\
\hline$\leq$ TSAT & 0.0 \\
\hline TSAT $\leq$ TMLPO $\leq$ TSAT+2.0 & QDOT \\
\hline TSAT+2.0 $<$ TMLPO < TSAT+10.0 & $\begin{array}{c}\text { QDOT + [QWET - QDOT] } \mathrm{x} \\
\left(\frac{\mathrm{TMLPO}-\mathrm{TSAT}}{10.0}\right)\end{array}$ \\
\hline$\geq$ TSAT +10.0 & No change \\
\hline
\end{tabular}

As indicated in Table 7.3, the calculated value of QWET(3,J) will not be reduced as long as the local debris temperature exceeds the saturation temperature by at least $10 \mathrm{~K}$. This is in line with the reasoning that the local water boiling serves only to remove a portion of the debris superheat; therefore, there is no need to address the decay power separately when calculating the boiling power.*

For debris temperatures between $2 \mathrm{~K}$ and $10 \mathrm{~K}$ greater than saturation temperature, the adjusted value of QWET $(3, \mathrm{~J})$ will vary linearly between the decay power QDOT $(3, \mathrm{~J})$ and the original value of $\mathrm{QWET}(3, \mathrm{~J})$, which was derived (as described in the previous paragraphs) solely by consideration of the local countercurrent two-phase flow limitation. In other words, the original value of $\operatorname{QWET}(3, \mathrm{~J})$ is based upon an assumption that the boiling rate is not limited by the particle-to-water heat transfer mechanism. The purpose of the logic described here is to accomplish a smooth transition from the countercurrent flow limiting condition to the heat transfer rate limitation, where the debris is quenched and only the decay power is transmitted to the water, while continuing to produce steam.

The effect of this logic is that once the control volume debris is quenched at constant pressure, the heat transfer rate will be controlled so that the debris temperature will be maintained within $2 \mathrm{~K}$ of the saturation temperature while the decay power is removed by boiling. In the actual case, however, the vessel pressure will not be constant and the constraints described in Table 7.3 will cause the calculated boiling power to vary in a manner such that the control volume debris temperature follows the saturation temperature.

\footnotetext{
- The decay power is of course considered in the overall control volume energy balance, which is performed in Subroutine BHHED2. As part of this energy balance, QDOT $(1, \mathrm{~J})$ is added and QWET $(I, J)$ is subtracted.
} 
BH Package Reference Manual

With the upper control volume boiling power QWET(3,J) known, the middle layer situation can be established. First, the power QTOP2 that can be removed by steam passage through the upper surface of the middle layer control volume is limited to the minimum of

$$
\text { QSUR(3,J) - QWET(3,J) }
$$

and

$$
\text { QSUR(2,J). }
$$

The first of these quantities is the portion of the power transfer capacity through the surface of the upper control volume that is not required to transmit the boiling power generated within the upper control volume itself. The second is the maximum power that can be removed through the surface of the middle control volume, based upon the debris properties within the volume.

It is now necessary to consider the effect of any steam entering the middle control volume from the bottom control volume in limiting the local boiling power:

$$
\operatorname{QWET}(2, J)=\text { QTOP2 }-\operatorname{QSUR}(1, \mathrm{~J}) \quad \text { Watts. }
$$

However, similar to the reasoning employed in the case of the upper control volume, this calculated value for QWET(2,J) is adjusted, if necessary, to be no less than $80 \%$ of QTOP2.

The logic described in Table 7.3 to cause the local boiling power to approach the decay power as the local debris temperature approaches the saturation temperature is also applied, as appropriate, as a final adjustment to QWET(2,J).

For the bottom control volume, the power $\operatorname{QWET}(1, \mathrm{~J})$ removed by boiling is the amount that can be removed by steam passage through the upper surface. It is limited to the minimum of

$$
\begin{aligned}
& \text { QSUR(3,J)-QWET(3,J) - QWET(2,J) } \\
& \text { and } \\
& \operatorname{QSUR}(1, \mathrm{~J}) .
\end{aligned}
$$

The first comparative quantity is the remaining power transfer capability through the surface of the upper control volume. The second is the power that could be removed by steam flow through the surface of the bottom control volume, if there were no overlying debris.

The logic described in Table 7.3, which comes into play to further limit $\operatorname{QWET}(1, \mathrm{~J})$ if the local debris temperature $\operatorname{TMLPO}(1, \mathrm{~J})$ is within $10 \mathrm{~K}$ of the saturation temperature, is also applied to the lower control volume. 


\section{BH Package Reference Manual}

The calculations described in this Section for the upper, middle, and bottom control volumes are applied sequentially to each of the five radial zones of the lower plenum debris bed. Special provisions (described by COMMENT statements in Subroutine BHBWET) are employed for radial zones four and five to recognize that control volume $(1,3)$ constitutes the bottom control volume for these radial zones as well as for radial zone three. (See Figure 1.9.)

For a superheated debris bed comprised of three-mm particles unencumbered by local porosity restrictions and with ample water available, the power QSUR $(3, J)$ that can be removed from radial zone $\mathrm{J}$ by means of steam flow through the upper bed surface will be taken $80 \%$ from control volume (3,J), $16 \%$ from control volume $(2, \mathrm{~J})$, and $4 \%$ from control volume $(1, \mathrm{~J})$. Once the upper layer is quenched, the local decay power will be removed by boiling and the remaining capacity through the bed upper surface will be taken $80 \%$ from control volume $(2, \mathrm{~J})$ and $20 \%$ from control volume $(1, \mathrm{~J})$.

The way that the QSUR $(3, J)$ power should be allocated among the upper, middle, and lower control volumes of a bed radial zone has been demonstrated experimentally to be a function of the particle size. The $80 \%-16 \%-4 \%$ allocation cited in the previous paragraph has been used in this discussion for illustrative purposes, but within Subroutine BHBWET applies only to cases for which the user-input particle diameter DPART is equal to $3.0 \mathrm{~mm}$.

The experimental evidence demonstrates that the quench front for large particles (greater than three $\mathrm{mm}$ ) is two-dimensional in that fingers of liquid penetrate through the entire bed producing local quenching but leaving stable surrounding dry regions which act as steam escape pathways. These dry regions subsequently become quenched from the bottom up as the accumulating water pool rises from the bottom of the bed. To approximate the effect of size for large particles, the portion of QSUR(3,J) that is allocated to the upper control volume is determined by a linear relation within Subroutine BHBWET; this allocation ranges from $80 \%$ for three-mm particles through $56 \%$ for particles with diameters of $20.0 \mathrm{~mm}$. (For the case of $20-\mathrm{mm}$ particles, the overall allocation will be $56 \%-25 \%-19 \%$ for the upper, middle, and bottom control volumes, respectively. Forty-mm particles would have an allocation of $27 \%-20 \%-53 \%$.)

As the bed particle size becomes smaller, the experimental observations are that the quench front tends to become one-dimensional and to progress uniformly downward. In Subroutine BHBWET, this behavior is approximated by having the portion of QSUR $(3, \mathrm{~J})$ that is allocated to the upper control volume increase linearly from $80 \%$ for particles of $3.0 \mathrm{~mm}$ diameter to $96 \%$ for particles of $0.50 \mathrm{~mm}$ diameter (or less). The allocation to the upper control volume is not allowed to reach $100 \%$ because of the original existence of the control rod guide tubes and instrument tubes within the debris. Although the stainless steel of these guide tubes is assumed to be assimilated into the debris, it is reasonable to expect that axial columns of locally reduced porosity would exist within the original locations of these tubes; the effect of this for small particle beds can best be approximated by ensuring that at least a small portion of any introduced water will be represented to reach the bottom of the bed. 
BH Package Reference Manual

\subsubsection{Limited Water Availability}

Should evaporation of all of the water existing within the lower plenum at the beginning of a calculational timestep prove insufficient to consume the sum of the calculated QWET(I,J) boiling powers across the bed control volumes during the timestep, then the QWET(I,J) quantities must be reduced. This is accomplished for each radial zone and individually for each control volume within each radial zone as follows.

$$
\text { QWET }(I, J)=\text { QWET }(I, J) \times \frac{\text { QZNE }}{\text { SQWT } \quad \text { Watts }}
$$

where

$$
\begin{array}{ll}
\text { QZNE } & =\text { HWAT } \times \text { AINFCA } \times \text { RHOL } \times \text { HLV, } J \\
\text { HWAT } & =\text { HWAT(J), depth of water above the control volume surface, } m \\
\text { AINFCA } & =\text { AINFCA }[I T(J), J], \text { surface area of upper control volume, } m^{2} \\
\text { IT } & =I T(J), \text { flag indicating the upper layer index for each radial zone } \\
\text { SQWT } & =[Q W E T(1, J)+Q W E T(2, J)+Q W E T(3, J)] \times \text { DTM, } J \\
\text { DTM } & =\text { timestep length, } s .
\end{array}
$$

It is readily evident that QZNE represents the energy required to evaporate all of the water overlying the radial zone. The quantity SQWT represents the energy release by the boiling powers calculated for the radial zone during the timestep based upon the bed configuration and current water/steam properties.

\subsubsection{Experimental Evidence for Oxidic Debris Bed Quenching}

The logic made operational within Subroutine BHBWET as described in Sections 7.2.1 through 7.2.3 is based upon the experimental results discussed in References 24-28. In general, the experiments cited were performed with metallic particles of spherical shape. It is intended, however, that Subroutine BHBWET will be applied to consideration of the effects of water in cooling the hypothetical debris beds that might form in a BWR lower plenum under severe accident conditions. These beds would be comprised of both metallic and oxidic particles, of various sizes, and various shapes. This Section provides a brief discussion of the available experimental results concerning the introduction of water into nonuniform oxidic debris.

The Degraded Core Coolability (DCC) series of experiments was conducted at Sandia National Laboratories during 1983-1985 for the purpose of determining the coolability of fission-heated $\mathrm{UO}_{2}$ rubble beds in water. Experiments DCC-1 and DCC-2 examined the coolability of $0.5 \mathrm{~m}$ ( $1.64 \mathrm{ft}$ ) deep homogeneous beds comprised of small- and medium-sized (respectively) $\mathrm{UO}_{2}$ particulates and are described in Reference 29. The 


\section{BH Package Reference Manual}

DCC-3 experiment addressed a stratified bed (small particles overlying large particles) and is described in Reference 30.

References 29 and 30 provide a wealth of information concerning the effects of particle size, size distributions, and stratification. Most important to the purpose here, however, is that the experimental results they describe support application of the Lipinski dryout heat flux calculational methodology to internally heated oxidic debris. This point can best be demonstrated by quoting from the CONCLUSIONS section of Reference 30:

"The DCC experimental series has provided a data base for debris coolability in which prototypic materials are used and prototypic pressures are realized.... The dryout behavior of beds composed of prototypic materials appears to be consistent with that observed in out-of-pile experiments using simulant materials at low pressures.

The behavior of debris beds at this point is reasonably well understood. Several analytical models, among them the Lipinski model, do a reasonable job of predicting dryout heat fluxes. The obvious problem is in determining the proper debris bed configuration for LWR reactor accidents. In particular, more information is needed on the particle size distribution, void fraction, bed depth, and degree of stratification (if it occurs). Given this information, reasonably accurate predictions can be made about the coolability of a prototypic debris bed...."

The DCC series test results also demonstrate the same dependence of quench behavior upon particle size that was observed in the previous tests with metals and which is described in the last two paragraphs of Section 7.2.2. Since similar results are observed for tests with pure metal particles and for tests with pure oxide particles, some degree of confidence is obtained for application of the dryout and quenching models to BWR lower plenum debris, which would be comprised of a mixture of oxides and metals.

Recent tests at Argonne National Laboratory 35 have demonstrated the quenching of high-temperature $\left(3000 \mathrm{~K}\right.$ ) liquid pours of $60 \% \mathrm{UO}_{2}, 16 \% \mathrm{ZrO}_{2}$, and $24 \%$ stainless steel entering water at atmospheric pressure. In all cases, quenched beds were formed with some oxidation of the stainless steel, but never a steam explosion.

Nevertheless, neither the DCC series, the recent Argonne pours, nor any of the other debris bed experiments have included zirconium metal within their superheated beds and, therefore, the consequences of hydrogen generation after water entry have not been assessed experimentally. The next Section describes the models within Subroutine BHBWET that are employed to represent the effects of internal hydrogen generation upon the bed internal flows. 
BH Package Reference Manual

\subsection{Effects of Hydrogen Generation}

Water entry to superheated debris bed control volumes will produce steam at rates corresponding to the boiling powers calculated as described in Section 7.2. The way that the countercurrent flow limitation restricts the amount of bed cooling that can be provided by lower plenum flooding is described there. That discussion, however, is based solely upon the available experimental evidence and, following the experiments, neglects the effects of hydrogen generation within the bed. It is now necessary to consider the hydrogen generation that would occur as a consequence of the availability of this steam to the metal surfaces within each control volume.

The calculation of hydrogen generation is described in Section 7.3.1. The effectiveness of rising steam and hydrogen in blocking the downward entry of water is expected to be, based upon physical principles, much greater than the blocking effect of steam alone. As described in Section 4.1.5 of Reference 32, an estimate of the magnitude of the increase can be based upon an application of the Wallis flooding correlation. ${ }^{33}$ The way that this is accomplished within Subroutine BHBWET is described in Section 7.3.2.

\subsubsection{Metal-Steam Reaction Rate}

With water introduced into the lower plenum debris bed, steam is first generated by contact with hot particles, then metal-steam reaction calculations predict the associated hydrogen generation. The steam generation rate for a bed control volume is

$$
W S O=\frac{Q W E T(I, J)}{H L V} \quad \mathrm{~kg} / \mathrm{s}
$$

where

$$
\begin{array}{ll}
\text { QWET(I,J) } & =\text { local boiling power, } W \\
H L V & =\text { heat of vaporization, } \mathrm{J} / \mathrm{kg} .
\end{array}
$$

The amount of hydrogen generated is obtained by means of a call to Subroutine BHMWDE with the arguments WSO and a steam temperature equivalent to the saturation temperature. The calculational process that occurs within this subroutine is described in Section 3.4.

Subroutine BHMWDE returns the rate of hydrogen generation WHO $(\mathrm{kg} / \mathrm{s})$, the hydrogen temperature TOUT $(K)$, and the metal-steam reaction energy release rate QMWDB (W). In addition, the magnitude of the variable WSO is reduced correspondingly; subsequent to the call, it represents the effective steam generation rate after the steam consumption associated with hydrogen generation has been subtracted.

The metal-steam reaction energy release rate for each control volume is stored in the array 
BH Package Reference Manual

$$
\text { QPFMW }(I, J)=\text { QMWDB } \quad \text { Watts }
$$

and is included as a positive term in the control volume energy balance carried out each timestep within Subroutine BHHED2. The local hydrogen generation is stored in the array

$$
W H S(I, J)=W H O \quad \mathrm{~kg} / \mathrm{s} .
$$

Here $\mathrm{I}$ is the debris bed layer index and $\mathrm{J}$ is the index of the radial zone.

The energy associated with any remaining steam is added to the overlying water pool together with the energy required to cool the hydrogen gas to the saturation temperature. For each control volume, the associated energy release rates are

$$
\text { WSO } \times \text { HLV + WHS(I,J) } \times \text { CPH } \times(\text { TOUT - TSAT) Watts }
$$

where CPH is the specific heat of the hydrogen gas and TSAT is the saturation temperature corresponding to the current reactor vessel pressure. The sum of these energy release rates over all control volumes is QH2LPW (W).

Within Subroutine BHHED2, the quantity

$$
\text { QLPWAT }=(\text { QTOLPW + QH2LPW) } \times \text { DTM J }
$$

represents the total heat transfer to the water during a timestep of length DTM. (Here QTOLPW is the energy transfer rate by nucleate or film boiling at the bed surface, obtained as described in Section 7.4.) The quantity QLPWAT $(\mathrm{J})$ is returned to the MELCOR interface, where it is applied each timestep as an energy addition to the lower plenum water pool.

The total gas generation during the timestep is

$$
H 2 L P W=\sum W H S(l, J) \times \text { DTM } \quad k g
$$

and this hydrogen mass is added to the vessel atmosphere at temperature TSAT. The corresponding amount of water

$$
\text { H2LPW } \times \frac{18.01534}{2.01594} \quad \mathrm{~kg}
$$

is subtracted from the mass of the lower plenum water.pool.

\subsubsection{Effest on Dryout Heat Flux}

The rate at which water can enter the upper surface of a debris control volume under dryout conditions will be increased if the countercurrent flow consists of a mixture of 
hydrogen and steam instead of steam alone. As explained in Section 4.1.5 of Reference 32,

$$
W S W H=\sqrt{\frac{R H O G \times(R H O L-R H O G)}{R H O S L S}} \times W S N H-W H S T \quad \mathrm{~kg} / \mathrm{s}
$$

where

$$
\begin{array}{ll}
\text { WSWH } & =\text { steam escape with hydrogen, } \mathrm{kg} / \mathrm{s} \\
W S N H & =\text { steam escape without hydrogen, } \mathrm{kg} / \mathrm{s} \\
\text { WHST } & =\text { hydrogen generation rate, } \mathrm{kg} / \mathrm{s} \\
\text { RHOG } & =\frac{\text { WSWH }+ \text { WHST }}{\frac{W S W H}{\text { RHOS }}+\frac{\text { WHST }}{\text { RHOH }}}, \text { average density } \mathrm{kg} / \mathrm{m}^{3} \\
\text { RHOS } & =\text { steam density, } \mathrm{kg} / \mathrm{m}^{3} \\
\text { RHOH } & =\text { hydrogen density, } \mathrm{kg} / \mathrm{m}^{3} \\
\text { RHOSLS } & =\text { RHOS } \times(\mathrm{RHOL}-\mathrm{RHOS}), \mathrm{kg} / \mathrm{m}^{3} \\
\text { RHOL } & =\text { water density, } \mathrm{kg} / \mathrm{m}^{3} .
\end{array}
$$

In practice, an iterative procedure is applied to determine WSWH since the average density RHOG depends upon its value.

Once the reduced steam flow is known, then the maximum power that can be removed from a control volume by boiling is redefined as

$$
\text { QSUR }(I, J)=\left(W S W H+\frac{18.01534}{2.01594} \times \text { WHST }\right) \times \text { HLV Watts. }
$$

It is then this increased value of QSUR that is used to determine the boiling power QWET for each control volume as described in Section 7.2.2.

\subsection{Heat Transfer at the Bed Surface}

Radiation from the upper surfaces of water-covered debris bed radial zones to the upper vessel structures and to the vessel atmosphere is terminated at the time that water is introduced to the vessel lower plenum. Representation of convective heat transfer to the overlying pool begins for each covered zone at the time that the local radiation calculation is terminated.

Heat transfer to the overlying pool can be by film boiling for large surface-to-water temperature differences or by nucleate boiling at lower temperature differentials. The 


\section{BH Package Reference Manual}

critical heat flux is the maximum power per unit area that can be maintained over a surface by nucleate boiling.

\subsubsection{Critical Heat Flux}

The critical heat flux is calculated by application of Equation 2.6.34 as described in Section 2.6.4.2 of the MELCOR HS Package Reference Manual. [This is the Zuber relation given as Equation (2-4.27) of Reference 31, with modification of the leading coefficient.] However, rather than solve this equation each timestep, and recognizing that the critical heat flux is a function only of vessel pressure, a set of empirical fits has been implemented within Subroutine BHHED2. These empirical relations are listed in the following Table.

Table 7.4 Empirical fits for the critical heat flux

\begin{tabular}{|c|c|}
\hline $\begin{array}{c}\text { Reactor Vessel Pressure Range } \\
(\mathrm{Pa})\end{array}$ & $\begin{array}{c}\text { Critical Heat Flux } \\
\left(\mathrm{W} / \mathrm{m}^{2}\right)\end{array}$ \\
\hline PVSL $<551581$. & $9.748 \times 10^{5}+5.79321 \times \mathrm{PVSL}$ \\
& $-4.1095 \times 10^{-6} \times(\mathrm{PVSL})^{2}$ \\
\hline 551581. $\leq \mathrm{PVSL}<827371$. & $2.04 \times 10^{6}+1.59542 \times \mathrm{PVSL}$ \\
\hline 827371. $\leq \mathrm{PVSL}<4136854$. & $2.044 \times 10^{6}+1.93848 \times \mathrm{PVSL}$ \\
& $\begin{array}{c}-4.552 \times 10^{-7} \times(\mathrm{PVSL})^{2} \\
+4.10 \times 10^{-14} \times(\mathrm{PVSL})^{3}\end{array}$ \\
\hline PVSL $\geq 4136854$. & $4.85 \times 10^{6}+0.07977 \times \mathrm{PVSL}$ \\
\hline
\end{tabular}

To provide a feel for the numbers, it may be observed that the critical heat flux is $2.26 \mathrm{MW} / \mathrm{m}^{2}$ at $0.276 \mathrm{MPa}$ (40 psia) and is $3.96 \mathrm{MW} / \mathrm{m}^{2}$ at $1.379 \mathrm{MPa}(200 \mathrm{psia})$. If the reactor vessel were to remain fully pressurized, the critical heat flux would be $5.40 \mathrm{MW} / \mathrm{m}^{2}$ at $6.895 \mathrm{MPa}(1000 \mathrm{psia})$.

In practice, the critical heat flux is calculated each timestep in Subroutine BHHED2 and then used to determine the corresponding surface temperature TCRIT for each watercovered surface as follows:

$$
T C R I T=T R E C+\frac{Q C R I T}{H S F} \quad K
$$


where

$$
\begin{array}{ll}
\text { TREC } & =\text { water temperature, } \mathrm{K} \\
\text { QCRIT } & =\text { critical heat flux, } \mathrm{W} / \mathrm{m}^{2} \\
\mathrm{HSF} & =\text { heat transfer coefficient for nucleate boiling, } \mathrm{W} /\left(\mathrm{m}^{2} \cdot \mathrm{K}\right)
\end{array}
$$

If the actual surface temperature TDBSUR is higher than TCRIT, then the surface is too hot to maintain nucleate boiling. In this case, the film boiling heat transfer coefficient is used to determine the surface-to-water heat transfer rate.

\subsubsection{Film Boiling Coefficient}

The film boiling heat transfer coefficient is calculated by application of the modified Bromley correlation listed as Equation 2.6.36 in Section 2.6.4.4 of the HS Package Reference Manual. [See also Reference 31 with respect to the discussion of Equation (2-4.35).] In Subroutine BHBWET,

$$
\text { HFILM }=0.943 \times(\text { TRM1 }+ \text { TRM2 })^{1 / 4}+\text { FACTR } \times\left[(\text { TDBSUR })^{4}-(\text { TSAT })^{4}\right] \quad \mathrm{W} /\left(\mathrm{m}^{2} \cdot \mathrm{K}\right)
$$

where the second term represents the effect of radiation across the film and

$$
\begin{aligned}
\text { TRM1 }= & \frac{\rho s \times(\rho l-\rho s) \times G \times(C O N D V)^{3}}{\text { VISV }} \\
\text { CONDV = } & \text { vapor thermal conductivity } \quad \mathrm{W} /(\mathrm{m} \cdot \mathrm{K}) \\
\mathrm{VISV}= & \text { vapor dynamic viscosity } \mathrm{kg} /(\mathrm{m} \cdot \mathrm{s}) \\
\text { TRM2 }= & \frac{\text { HLV }+1 / 2 \times \text { TDIF } \times \text { SPHEAT }}{\text { TDIF } \times \mathrm{CL}} \\
\text { HLV }= & \text { heat of vaporization for water, J/kg } \\
\text { TDIF }= & \text { TDBSUR }- \text { TSAT, } \mathrm{K} \\
\text { SPHEAT = } & \text { vapor heat capacity, J } /(\mathrm{kg} \cdot \mathrm{K}) \\
\mathrm{CL}= & \text { characteristic length equal to twice the area-to-perimeter ratio } \\
& \text { CLS }(\mathrm{N}), \text { m. For the annular bed surfaces, this is the outer radius } \\
& \text { minus the inner radius. For the exposed wall nodes, CL is the } \\
& \text { vertical nodal height } \\
= & 0.60 \times \text { Stefan-Boltzman coefficient }=3.40116 \times 10^{-8} .
\end{aligned}
$$

It should be noted that the terms CONDV and VISV are evaluated at the average of the surface and saturation temperatures whereas SPHEAT is evaluated at the saturation temperature. 
BH Package Reference Manual

\subsubsection{Nucleate Boiling Coefficient}

The Rohsenow correlation for nucleate boiling has been implemented within Subroutine BHHED2 for calculations of the heat transfer coefficient for surfaces where the local temperature TDBSUR is below the value required to induce film boiling. This correlation is expressed as Equation 2.6.32 of the HS Package Reference Manual and is discussed in Section 2.6.4.1 of that manual and in Section 2-4 of Reference 31.

Rather than solve the Rohsenow correlation directly for each surface each timestep, the nucleate boiling heat transfer coefficients are calculated in Subroutine BHHED2 of the BH Package as

$$
\mathrm{HSF}=\mathrm{CNB} \times(\text { TDBSUR }- \text { TREC })^{2} \quad \mathrm{~W} /\left(\mathrm{m}^{2} \cdot \mathrm{K}\right) .
$$

The factor CNB depends only upon vessel pressure and is determined once each timestep as indicated in the following Table.

Table 7.5 Empirical fits for the nucleate boiling calculation

\begin{tabular}{|c|c|}
\hline $\begin{array}{c}\text { Reactor Vessel Pressure Range } \\
(\mathrm{Pa})\end{array}$ & $\begin{array}{c}\text { Factor CNB } \\
\mathrm{W} /\left(\mathrm{m}^{2} \cdot \mathrm{K}^{3}\right)\end{array}$ \\
\hline $\mathrm{PVSL}<551581$. & $24.84+6.207 \times 10^{-4} \times \mathrm{PVSL}$ \\
\hline $551581 . \leq \mathrm{PVSL}<827371$. & $215.71+2.794 \times 10^{-4} \times \mathrm{PVSL}$ \\
\hline $827371 . \leq \mathrm{PVSL}<4136854$. & $420.07+3.229 \times 10^{-5} \times \mathrm{PVSL}$ \\
\hline $\mathrm{PVSL} \geq 4136854$. & $301.96+6.084 \times 10^{-5} \times \mathrm{PVSL}$ \\
\hline
\end{tabular}

It should be noted that the pressure intervals expressed on the left side of Table 7.5 are the same as those listed in Table 7.4, which simplifies the coding required to implement these empirical fits.

As a practical demonstration of the $\mathrm{BH}$ package surface heat transfer algorithms for water-covered surfaces, Table 7.6 lists results for a case with the reactor vessel at atmosphere pressure. 
BH Package Reference Manual

Table 7.6 Surface heat transfer parameters and calculated results

\begin{tabular}{|ll|rl|}
\hline \multicolumn{1}{|c|}{ Parameter } & \multicolumn{2}{c|}{ Value } \\
\hline Vessel pressure & PVSL & 101353. & Pa \\
Saturation temperature & TSAT & 373.15 & $\mathrm{~K}$ \\
Critical heat flux & QCRIT & $1.52 \times 10^{6}$ & $\mathrm{~W} /\left(\mathrm{m}^{2} \cdot \mathrm{K}\right)$ \\
Nucleate boiling factor & CNB & 87.74 & $\mathrm{~W} /\left(\mathrm{m}^{2} \cdot \mathrm{K}^{3}\right)$ \\
Critical temperature & TCRIT & 399.03 & $\mathrm{~K}$ \\
Assumed surface temperature & TDBSUR & 399.03 & $\mathrm{~K}$ \\
Nucleate boiling coefficient & HSF & 58766. & $\mathrm{~W} /\left(\mathrm{m}^{2} \cdot \mathrm{K}\right)$ \\
Characteristic length & CL & .8572 & $\mathrm{~m}$ \\
Film boiling coefficient & HFILM & 165.5 & $\mathrm{~W} /\left(\mathrm{m}^{2} \cdot \mathrm{K}\right)$ \\
\hline
\end{tabular}

Here the characteristic length of $0.8572 \mathrm{~m}$ corresponds to the actual value for the surface of the debris bed central radial zone in the example calculation. The nucleate boiling and film boiling heat transfer coefficients are evaluated at the transition point, since the local bed surface temperature is assumed to be equal to the critical temperature for this example. The large difference between the nucleate boiling and film boiling heat transfer coefficients at the transition point is evident.

Table 7.7 provides an example of how the film boiling and nucleate boiling coefficients are predicted to change as the debris surface temperature decreases through the transition point. These example results, which pertain to the upper control volume $(3,1)$ of the central debris bed radial zone, are taken from an actual MELCOR calculation. Water was introduced into the lower plenum at timestep 209, when the surface temperature of the central zone was $904 \mathrm{~K}$. Timestep 325 begins $9.67 \mathrm{~min}(580 \mathrm{~s})$ later, when the central zone surface temperature has decreased to $416 \mathrm{~K}$ through the combined mechanisms of internal boiling and surface cooling (also by boiling).

A standard length of five seconds was used for each of the timesteps represented in Table 7.7. Film boiling occurs during timesteps 325 and 326 (the nucleate boiling heat transfer coefficients are shaded to indicate that they are not used). The transition to nucleate boiling occurs during timestep 327 , when the calculated surface temperature TDBSUR falls below the critical temperature for the first time. Subsequent to timestep 327 , the surface temperature decreases much more rapidly because of the much 
BH Package Reference Manual

greater surface heat transfer coefficients (here the shading over the film boiling heat transfer coefficients indicates that they are not used.)

Table 7.7 Example results for water cooling of the central radial zone

\begin{tabular}{|ll|c|c|c|c|c|}
\hline \multicolumn{2}{|c|}{ Parameter } & \multicolumn{5}{|c|}{ Timestep } \\
\cline { 3 - 7 } & & 325 & 326 & 327 & 328 & 329 \\
\hline PVSL & $\mathrm{Pa}$ & 188111. & 188131. & 188114. & 188146. & 188151. \\
TSAT & $\mathrm{K}$ & 390.67 & 390.67 & 390.67 & 390.67 & 390.67 \\
QCRIT & $\mathrm{W} /\left(\mathrm{m}^{2} \cdot \mathrm{K}\right)$ & 1919173. & 1919259. & 1919186. & 1919323. & 1919341. \\
TCRIT & $\mathrm{K}$ & 411.15 & 412.96 & 414.95 & 487.37 & 761.89 \\
TDBSUR & $\mathrm{K}$ & 416.39 & 415.33 & 414.29 & 402.51 & 396.72 \\
TDIF & $\mathrm{K}$ & 25.72 & 24.66 & 23.63 & 11.84 & 6.04 \\
HSF & $\mathrm{W} /\left(\mathrm{m}^{2} \cdot \mathrm{K}\right)$ & 93676.3 & 86113.5 & 79042.5 & 19849.9 & 5170.4 \\
HFILM & $\mathrm{W} /\left(\mathrm{m}^{2} \cdot \mathrm{K}\right)$ & 196.4 & 198.4 & 200.0 & 233.9 & $*$ \\
QTOGAS & $\mathrm{W}$ & 10699.7 & 10331.9 & 11801.8 & 11322.6 & 10812.6 \\
\hline
\end{tabular}

* HFILM is not calculated for values of TDIF less than $10 \mathrm{~K}$.

The last entry QTOGAS in Table 7.7 is the heat transfer rate (Watts) from the upper control volume $(3,1)$ to the overlying water during the timestep. It is calculated in the same manner as the heat transfer to the lower plenum atmosphere for the dry case, as described in Section 3.2.2, except that HSF or HFILM is used in lieu of HSURF. The value of QTOGAS does not increase radically during the transition from film to nucleate boiling because the majority of the resistance to heat transfer lies not at the debris surface but rather along the conduction pathway through the upper half of the debris control volume.

Finally, it is important to appreciate the relative magnitudes of the internal boiling and surface heat transfer contributions to debris cooling in the upper bed. During the period covered by Table 7.7, the temperature at the center of the upper control volume in the central radial zone is predicted to decrease from $537 \mathrm{~K}$ to $514 \mathrm{~K}$ while the internal boiling power increases slightly, from $1.842 \mathrm{MW}$ to $1.856 \mathrm{MW}$. Thus the internal boiling power is about 185 times the surface heat transfer rate and continues to be significant long after the surface temperature has closely approached the saturation temperature. 
BH Package Reference Manual

\subsection{Heat Transfer at Exposed Wall Nodes}

Exposed reactor vessel bottom head wall nodes are by definition those not covered by debris. With reference to Figure 1.10, wall node 17 is the only exposed node at the time that debris bed layer three is formed. Wall nodes 16,15 , and lower may, however, become exposed as the debris volume shrinks by the effects of internal melting and downward material relocation and, for cases with consideration of penetration failures, by the release of materials into the drywell. The criterion for a wall node to be exposed is that there is no adjacent debris extending above the lower nodal boundary.

If the water level YLIQ within the lower plenum becomes sufficiently high that the exposed wall nodes become covered by water, then their internal surface areas will undergo heat transfer by either nucleate or film boiling. In either case, the appropriate heat transfer coefficient is determined in the same manner as for the debris bed radial zones, as described in Section 7.3. The criterion for an exposed wall node to be considered to be water-covered is that YLIQ is greater than the height of the middle of the node.

\subsection{The Case of Lower Plenum Water with Penetration Failures}

For the case with water in the lower plenum after bottom head penetration failures have occurred, countercurrent flow would not limit the introduction of water into the upper bed control volumes. Rather, the steam (and any hydrogen) produced within the bed would escape from the bottom of the vessel via the failed penetration assemblies. The absence of a countercurrent flow limitation in the presence of a lower gas escape pathway has been observed experimentally as described in Reference 26.

This Section describes the special provisions within Subroutine BHBWET for application to calculations for which the existence of failed bottom head penetration assemblies is combined with the presence of water overlying the debris bed. The prediction of water flow into the upper bed surface is explained in Section 7.6.1. The calculations of steam and hydrogen generation are discussed in Sections 7.6.2 and 7.6 .3 , respectively. The gases reaching the bottom of the bed are released into the drywell with exit conditions determined as described in Section 7.6.4.

\subsubsection{Water Flow}

The water flow into the bed surface (without countercurrent flow limitation) is assumed to be equal to the rate at which steam can escape (via the failed penetrations) from the bottom of the reactor vessel. Although hydrogen would be mixed with the steam in the actual case and the water flow would be unsteady for some period after initial introduction, this approach is considered to yield a reasonable approximation to the actual flow.

The water flow WLTOBD into the bed surface is calculated in Subroutine BHBWET as 
BH Package Reference Manual

ABRK $\times$ CBRK $\times \sqrt{2.0 \times R H O S \times[D P+Y L I Q \times R H O L} \times \mathrm{G}] \quad \mathrm{kg} / \mathrm{s}$

where

$\begin{array}{ll}\text { ABRK } & =\text { penetration flow area, } \mathrm{m}^{2} \\ \text { CBRK } & =\text { orifice coefficient }(=0.583) \\ \text { RHOS } & =\text { steam density, } \mathrm{kg} / \mathrm{m}^{3} \\ \mathrm{DP} & =\text { reactor vessel-to-drywell pressure differential, } \mathrm{Pa} \\ \mathrm{YLIQ} & =\text { height of liquid within the vessel, } \mathrm{m} \\ \mathrm{RHOL} & =\text { water density, } \mathrm{kg} / \mathrm{m}^{3} \\ \mathrm{G} & =\text { the acceleration of gravity. }\end{array}$

The value of $A B R K$ is the same user-defined break area as is used for gas flow through failed penetrations in the absence of water (Section 5.5). The actual flow area that would be associated with failed instrument guide tubes under severe accident conditions is of course unknown. A value of $0.010 \mathrm{~m}^{2}$ would be representative of the opening provided by several failed guide tubes.

It should be noted that the calculated flow into the bed will increase with reactor vessel pressure and with the height of water within the vessel. As an example, predicted water flow into the bed surface is $2.35 \mathrm{~kg} / \mathrm{s}$ for an initial reactor vessel pressure of $188000 \mathrm{~Pa}$ (27.3 psia), a break area of $0.010 \mathrm{~m}^{2}$, a differential pressure DP of $54,000 \mathrm{~Pa}(7.8 \mathrm{psi})$, and a water height YLIQ of $2.70 \mathrm{~m}(8.8 \mathrm{ft})$.

The overall water flow WLTOBD is apportioned among the upper bed control volumes according to their relative free volumes (or porosities). ${ }^{*}$ Furthermore, the overall water flow exiting the upper control volumes is reapportioned among the middle bed control volumes according to the relative porosities there, and the same reapportionment of flow occurs for flow exiting the middle control volumes and entering the bottom control volumes. Stated another way, the flow is modeled to follow the larger-porosity pathways (the paths of least resistance) to the bottom of the bed.

If there is no free volume within the set of upper radial zone control volumes then the flow is considered to be blocked and no water enters the bed. Similarly, if there is no free volume within the set of middle (or lower) bed control volumes, then the flow is considered to be blocked at the middle (or lower) level.

\footnotetext{
- The fraction of the total flow that enters each upper control volume is the local free volume divided by the sum of the free volumes for all upper control volumes.
} 
BH Package Reference Manual

The same apportionment of flow occurs for any steam or hydrogen generated within the bed control volumes. As described in the next Section, steam generation occurs within any control volume with a debris temperature greater than TSAT for which water is predicted to enter. Hydrogen generation is discussed in Section 7.6.3.

\subsubsection{Steam Generation}

Since the dryout heat flux concept is not applicable to debris bed control volumes for which the water and steam flow are in the same (downward) direction, it is necessary in this case to make a straightforward estimate of the particle-to-water heat transfer rate. This is accomplished in Subroutine BHBWET by means of an assumption that the debris particles constitute a set of uniform spheres. Then, the heat transfer coefficient appropriate for the overall surface area of these spheres is determined in a manner identical to that described in Section 7.4.3. (As appropriate to the exiting conditions, either nucleate or film boiling is represented to occur over the collective surface area of the spheres.)

The total particle surface area within a control volume is:

$$
\text { PSA }=(\text { VLP-FVLP }) \times \frac{6.0}{\text { DFRAG }} \quad \mathrm{m}^{2}
$$

where

$$
\begin{array}{ll}
\operatorname{VLP} & =\operatorname{VLP}(\mathrm{I}, \mathrm{J}), \text { total local volume, } \mathrm{m}^{3} \\
\mathrm{FVLP} & =\mathrm{FVLP}(\mathrm{I}, \mathrm{J}), \text { local free volume, } \mathrm{m}^{3} \\
\text { DFRAG } & =\text { particle diameter, } \mathrm{m} .
\end{array}
$$

It should be noted that the quantity 6.0/DFRAG represents not only the surface-tovolume ratio of a sphere, but also the surface-to-volume ratio for a cylinder with height equal to diameter (typical of BWR fuel pellets).

The boiling power QWET $(I, J)$ based upon particle heat transfer within a debris bed control volume is then:

$$
\text { PSA } \times \frac{\text { TMLPO }- \text { TSAT }}{\frac{0.1127 \times \text { DFRAG }}{\text { CONDB }}+\frac{1.0}{H S}} \quad \text { Watts }
$$

where

TMLPO = TMLPO $(1, \mathrm{~J})$, local debris temperature, $\mathrm{K}$

$\operatorname{CONDB}=\operatorname{CONDB}(l, J)$, local debris thermal conductivity, $\mathrm{W} /(\mathrm{m}-\mathrm{K})$ 


\section{BH Package Reference Manual}

HS = local surface heat transfer coefficient, $W /\left(m^{2}-K\right)$.

The use of the factor 0.1127 in the denominator of this expression derives from a recognition that TMLPO does not represent the temperature at the center of the particles, but rather represents the volume-averaged temperature of the particles. Thus, the effective heat transfer length of conduction through the debris is less than the particle radius.

The local boiling power QWET $(I, J)$ is constrained to be not more than the power necessary to evaporate all of the water entering the control volume. Any water not evaporated is considered to enter the underlying set of bed control volumes or if appropriate, to exit the vessel.

\subsubsection{Hydrogen Generation}

As downward-flowing water is increasingly converted to steam while passing through the bed control volumes, the steam becomes available to drive the metal-steam reactions that produce hydrogen. Within each bed control volume, the local steam availability WSO $(\mathrm{kg} / \mathrm{s})$ is the combination of steam entering from above plus the local steam generation.

Subroutine BHMWDE is called with the arguments WSO and the average steam temperature within the control volume. (The calculational process within this subroutine is described in Section 3.4.) The rate of hydrogen generation WHO $(\mathrm{kg} / \mathrm{s})$, the hydroger temperature TOUT (K), and the metal-steam reaction energy release rate QMWDB (W) are returned. In addition, the steam availability WSO is reduced appropriately. Subsequent to the call, WSO represents the effective steam generation rate after the sieam consumption associated with hydrogen generation has been subtracted.

The metal-steam reaction energy release rate is stored in the array

$$
\operatorname{QPFMW}(I, J)=\text { QMWDB Watts }
$$

and is included as a positive term in the bed control volume energy balance carried out each timestep in Subroutine BHHED2. The local hydrogen generation is stored in the array

$$
W H S(l, J)=W H O \quad \mathrm{~kg} / \mathrm{s} .
$$

Here $\mathrm{I}$ is the debris bed layer index and $\mathrm{J}$ is the index of the radial zone.

As the remaining steam flows downward through the bed, its temperature follows the local debris temperature. The associated transfer rate of energy from the debris to the flowing steam within each control volume is 
BH Package Reference Manual

QPFGS $(l, J)=$ WSO $\times$ SPHEAT $\times($ TMLPO - TSTMA $) \quad$ Watts

where
SPHEAT = steam specific heat, $\mathrm{J} /(\mathrm{kg}-\mathrm{K})$
TSTMA $=$ average temperature of steam entering or generated within the control volume, $\mathrm{K}$.

The term QPFGS(I,J) is entered as a negative term in the control volume energy balances carried out within Subroutine BHHED2.

\subsubsection{Exit Conditions}

For the case with penetration failures, water flows downward into the surface of the debris bed. Within the bed control volumes some (or all) of this water is converted to steam. During the period while local debris temperatures remain high and zirconium metal remains present, some (or all) of the steam is converted to hydrogen. Therefore, the fluid release from the reactor vessel lower plenum to the drywell is comprised of liquid water plus a mixture of hydrogen and steam.

Depending upon bed conditions, any of these three fluids may not exist at the vessel exit. In general, all water will be evaporated and all steam will be consumed in reactions with zirconium during the initial period after water is introduced so that only hydrogen will enter the drywell. Later, when bed temperatures are reduced and much of the original zirconium has been consumed, a mixture of steam and hydrogen will be predicted to enter the drywell. Still later, when the bed has cooled so that the calculated hydrogen generation is insignificant, a mixture of water and steam will exit the vessel. Finally, when the bed is quenched, the steam generation will be limited to that necessary to remove decay heat and all excess water will enter the drywell.

Any water entering the drywell is assumed to exit the vessel at the saturation temperature corresponding to the vessel pressure. For the steam-hydrogen mixture, the average temperature is

$$
\frac{\text { MSTM } \times \text { CPS } \times \text { TSTM }+ \text { MHYD } \times \text { CPH } \times \text { THYD }}{\text { MSTM } \times \text { CPS }+ \text { MHYD } \times \text { CPH }} \mathrm{K} .
$$

where

$$
\begin{array}{ll}
\text { MSTM, } & =\text { mass flows of steam and hydrogen, } \mathrm{kg} / \mathrm{s} \\
\text { MHYD } & =\text { specific heats of steam and hydrogen, } \mathrm{J} /(\mathrm{kg}-\mathrm{K})
\end{array}
$$


BH Package Reference Manual

TSM, THYD = steam and hydrogen gas temperatures at the bottom of the bed, $\mathrm{K}$.

Within the MELCOR-BH package interface, the water is added to the pool overlying the drywell floor, whereas the steam and hydrogen are added to the drywell atmosphere.

\subsection{Interaction of Water with Late Debris Pours}

As explained in Section 1.1.4, the third (upper) debris layer is formed when the bed temperature increases after lower plenum dryout. Subsequently, any material relocating downward from the core region as predicted by MELCOR is added to the upper debris bed control volumes throughout the period of the $\mathrm{BH}$ package calculation. In general, these predicted late (after lower plenum dryout) debris pours occur intermittently and vary in both material composition and quantity. If water has been reintroduced into the lower plenum and overlies the bed surface, then these late material pours will interact with this water to produce steam and (if zirconium is present) hydrogen above the bed surface. Models for this debris-water interaction are provided in Subroutines BHBWET and BHHED2.

Recently-obtained information concerning the jet breakup length and fragmentation of corium melt streams in water is provided by Reference 35. Based upon that information, a uniform diameter of $0.005 \mathrm{~m}$ is assigned to the (spherical) particles of the swarm formed after jet breakup. Heat transfer is assumed to be by film boiling over the total particle surface area as defined by the pour constituent masses and densities. The film boiling heat transfer coefficient HFLMPR is determined within Subroutine BHBWET by the method described in Section 7.4.2 (but using the pour temperature TPOUR in lieu of TDBSUR).

Again following Reference 35, the jet breakup length over each of the bed radial zones is taken to be equal to 12 jet diameters. The actual diameters of the various flow passages through the core plate are, of course, unknown. A representative value of $0.0254 \mathrm{~m}$ (one inch) for the jet diameters is employed in Subroutine BHBWET.

The duration DTMPR (s) of the transit of the particle swarm through water for each bed radial zone is obtained by subtracting the jet breakup length from the local water depth and dividing by the assumed fall speed of $1.0 \mathrm{~m} / \mathrm{s} . \dagger$ A first estimate of the energy transfer QPRCV to water is then obtained by applying the film boiling heat transfer coefficient HFLMPR over the total particle surface area for this duration. This estimate will then be reduced if it exceeds the energy transfer corresponding to the permissible quench fraction for the pour, which (following Reference 35 ) varies linearly from 0.35 for saturated water to 0.72 for water subcooled by $40 \mathrm{~K}$ or more.

t A minimum value of $0.01 \mathrm{~s}$ is imposed for DTMPR for applications in which the jet breakup length exceeds the local water depth. 
BH Package Reference Manual

The predicted steam production during the pour is equal to the calculated energy transfer divided by the energy per kilogram required to bring the lower plenum water to saturation temperature and for evaporation. ${ }^{*}$ The fraction of this steam that is produced in the vicinity of zirconium is assumed equal to the volume fraction of zirconium within the pour. One-third [STMREA $(\mathrm{kg})$ ] of this local steam generation is assumed to be available to drive the metal-steam reaction.

The first estimate for metal-steam reaction energy release during the pour is

$$
\text { QPRMW }=1.6282 \times 10^{7} \times \text { STMREA Joules, }
$$

where the constant term is the energy release $(J)$ associated with the consumption of one kilogram of steam in the reaction with zirconium. This estimate will then be reduced if the corresponding metal oxidation fraction exceeds that observed in the experiments of Reference 35. The metal oxidation limit as imposed in Subroutine BHBWET decreases from 0.34 for saturated water to 0.02 for water subcooled $40 \mathrm{~K}$ or more.

The hydrogen production during the pour is

$$
\text { H2DRP }=\frac{2.01594}{18.01534} \times \text { STMREA } \mathrm{kg},
$$

which originates at the debris temperature. The energy required to cool this gas to the water saturation temperature is

$$
\text { QH2CL }=\text { H2DRP } \times(H H Y D P-H H Y D W) \text { Joules }
$$

where HHYDP and HHYDW are the specific enthalpies of hydrogen at the pour temperature and the water temperature, respectively.

The debris-to-water heat transfer plus the hydrogen cooling energy transfer are additive terms in the lower plenum water energy balance carried out within the MELCOR interface. (All of the metal-steam reaction energy release is assumed to remain with the falling debris.)

The amount of zirconium consumed is calculated in Subroutine BHHED2 as

$$
W Z R R=R H O Z R \times \frac{Q P R M W}{4.179013 \times 10^{10}} \quad \mathrm{~kg}
$$

where the constant term in the denominator is the energy release $(\mathrm{J})$ associated with oxidation of one cubic meter of zirconium. The associated production of $\mathrm{ZrO}_{2}$ is

\footnotetext{
- Appropriate constraints (applied for each bed radial zone) ensure that the predicted local steam generation cannot exceed the locally available water mass.
} 
BH Package Reference Manual

$$
\text { WZRO2C }=\frac{123.219}{91.22} \times \text { WZRR } \mathrm{kg} .
$$

The appropriate subtraction of zirconium metal and addition of zirconium dioxide is made to correct the debris inventories for the upper control volume of each radial zone that receives the pour.

It is important to recognize, for a given mass of lower plenum water, that the water depth will vary over the bed radial zones, especially for cases with debris loss through penetration failures so that the bed surface has a cupped shape (see, for example, Figure 6.5). This means that the debris-water interaction will occur over a longer period of time in the central radial zones. Consequently, if zirconium is present in the pour, the central zone upper control volumes will exhibit a higher temperature than the peripheral zones after the pour. The converse is true if the pour does not include zirconium, since the cooling effect of the water will dominate.

\subsection{Special Printed Output}

The message

$$
\text { Water level in lower plenum }=
$$
$\mathrm{cm}$

is printed each timestep when water is present. When appropriate, this message will appear at the upper center of the standard pictorial display of the BH package output, examples of which are shown in Figures 6.1 through 6.5. The printed value is YLIQ, as defined in Section 7.1, but converted to centimeters for compatibility with the other heights listed on the pictorial display.

The tabulated output for standard BH package calculations (without water in the lower plenum) is discussed in Section 6.5. Here the special printed output obtained only when water is present is described.

With water in the lower plenum, the message

$$
\text { and to pool }=
$$
Joule

Total to overlying water pool $=$ Joule

reports the debris surface heat transfer during the timestep while the message

$$
\text { plus boiling }=
$$
Joule

Total to boiling within debris $=$ Joule

reports the energy transfer associated with the internal boiling. These two special messages are listed consecutively and immediately follow the standard message

Net heat transfer to vessel atmosphere (after control rod guide tube failure): This timestep = Joule

Total since guide tube collapse = Joule, 
BH Package Reference Manual

which appears in the dry case. Some bed surface-to-atmosphere heat transfer can occur with water in the lower plenum if the height of the water surface is insufficient to cover all oi the debris. 
$\cdots \cdots$ 
BH Package Reference Manual

\section{PACKAGE ORGANIZATION}

This Section describes the basic organization of the Lower Plenum Debris Bed (BH) Package and the exchange of information across the interface of this Package with MELCOR.

\subsection{Arrangement of Subroutines and Commons}

The Lower Plenum Debris Bed (BH) Package comprises 33 Subroutines and 19 Commons for the internal exchange of information. The package Subroutines are listed in Table 8.1, together with cross-reference information defining the exchange of calls among them. For example, Subroutine BHAXCO (second table entry) is called by Subroutine BHHED2 and calls Subroutine BHAKCS (which, as the table earlier reveals, is also called by three other subroutines).

A brief description of the purpose that each Subroutine fulfills in the overall $\mathrm{BH}$ package calculation is provided in Table 8.2. As indicated, the primary interface with MELCOR occurs within two package Subroutines, BHQSLU and BHPENF. Calls are made to MELCOR Core (COR) package Subroutines CORABS and CORPOL.

A cross-reference of Subroutines and Commons is provided in Tables 8.3 and 8.4. Not all of the package Subroutines depend upon common statements for information transfer. Those that do are listed in the first column of Table 8.3 with their included Commons listed in the second column. The obverse of this matrix is provided in Table 8.4 , where each of the 15 package internal Commons is listed in the first column and the Subroutines that include each Common are listed in the second column.

As indicated in Table 8.4, Commons /BHBWLV/, /BHCHAR/, /BHCHED/, /BHDBML/, /BHDMXXI, /BHHABL, /BHHDIN/, /BHHEDM/, /BHHEDKI, /BHLPXX/, /BHPROP/, /BHVER/, and /BHVLVX/ also extend into MELCOR. This is for the purpose of loading the appropriate user-input information described in the BH Package User's Guide and for convenience in the provision of restart capability.

Included among the Commons listed in Table 8.4 are five special-purpose Commons identified as /BHRSS1/ through /BHRSS5/, which are intended primarily for the transmission of restart information between MELCOR and BH package Subroutines BHQSLU, BHHED2, BHHEDN, BHMWDE, and BHDBME, respectively. These specialpurpose Commons are listed, opposite to their parent Subroutines, in the right column of Table 8.3. (Commons /BHRSS1/ through /BHRSS4/ are also used to convey internal information for mass/energy balance purposes as indicated in Table 8.4.) 
BH Package Reference Manual

\subsection{Information Exchange with MELCOR}

The BH Package is initiated whenever sufficient solid debris has accumulated within the lower plenum following dryout. Subsequently, calls from MELCOR to Subroutine BHQSLU are made each timestep, sending and receiving information pertaining to the calculated debris bed response. If reactor vessel bottom head penetration failures are predicted to occur, then calls from MELCOR to Subroutine BHPENF also exchange pertinent information from that time forward. It is the purpose of this Section to provide a detailed description of these information transfers. 
Table 8.1 BH package

subroutine organization

\begin{tabular}{|c|c|c|}
\hline Subroutine & Calls & Is Called By \\
\hline BHAKCS & & $\begin{array}{l}\text { BHAXCO } \\
\text { BHDBMX } \\
\text { BHHED2 } \\
\text { BHLPLN }\end{array}$ \\
\hline BHAXCO & BHAKCS & BHHED2 \\
\hline BHBWET & $\begin{array}{l}\text { BHMWDE } \\
\text { BHTHTH } \\
\text { BHTHTS }\end{array}$ & BHHED2 \\
\hline BHCPCS & BHLPOL & $\begin{array}{l}\text { BHDBMX } \\
\text { BHHED2 } \\
\text { BHHEDN } \\
\text { BHLPLN }\end{array}$ \\
\hline BHDBME & $\begin{array}{l}\text { BHDPOL } \\
\text { BHEUTF } \\
\text { BHEUTM } \\
\text { BHMENT }\end{array}$ & BHHED2 \\
\hline BHDBMX & $\begin{array}{l}\text { BHAKCS } \\
\text { BHCPCS } \\
\text { BHLPOL } \\
\text { BHMENT }\end{array}$ & BHHED2 \\
\hline BHDCHA & BHFALS & $\begin{array}{l}\text { BHHED2 } \\
\text { BHMERG }\end{array}$ \\
\hline BHDPOL & & BHDBME \\
\hline BHEUTF & BHEUTK & $\begin{array}{l}\text { BHDBME } \\
\text { BHHED2 } \\
\text { BHMERG }\end{array}$ \\
\hline BHEUTK & & $\begin{array}{l}\text { BHEUTF } \\
\text { BHEUTM }\end{array}$ \\
\hline
\end{tabular}


BH Package Reference Manual

Table 8.1 (Continued) BH Package subroutine organization

\begin{tabular}{|c|c|c|}
\hline Subroutine & Calls & Is Called By \\
\hline BHEUTM & BHEUTK & $\begin{array}{l}\text { BHDBME } \\
\text { BHHED2 } \\
\text { BHMERG }\end{array}$ \\
\hline BHFALS & $\begin{array}{l}\text { BHVLPL } \\
\text { BHVOLL }\end{array}$ & $\begin{array}{l}\text { BHDCHA } \\
\text { BHHEDN }\end{array}$ \\
\hline BHFPST & & BHHED2 \\
\hline BHHED2 & $\begin{array}{l}\text { BHAKCS } \\
\text { BHAXCO } \\
\text { BHBWET } \\
\text { BHCPCS } \\
\text { BHDBME } \\
\text { BHDBMX } \\
\text { BHDCHA } \\
\text { BHEUTF } \\
\text { BHEUTM } \\
\text { BHLPOL } \\
\text { BHHEDN } \\
\text { BHHRST } \\
\text { BHLPLN } \\
\text { BHMENT } \\
\text { BHMERG } \\
\text { BHPAGE } \\
\text { BHST2P }\end{array}$ & BHQSLU \\
\hline BHHEDN & $\begin{array}{l}\text { BHFALS } \\
\text { BHCPCS } \\
\text { BHLPOL } \\
\text { BHMENT }\end{array}$ & BHHED2 \\
\hline BHHRST & CORABS & BHHED2 \\
\hline BHLPLN & $\begin{array}{l}\text { BHAKCS } \\
\text { BHCPCS }\end{array}$ & BHHED2 \\
\hline
\end{tabular}


Table 8.1 (Continued) BH package subroutine organization

\begin{tabular}{|c|c|c|}
\hline Subroutine & Calls & Is Called By \\
\hline BHLPOL & & $\begin{array}{l}\text { BHCPCS } \\
\text { BHDBMX } \\
\text { BHHED2 } \\
\text { BHHEDN }\end{array}$ \\
\hline BHMENT & & $\begin{array}{l}\text { BHDBME } \\
\text { BHDBMX } \\
\text { BHHED2 } \\
\text { BHHEDN } \\
\text { BHMWDE } \\
\text { BHQSLU }\end{array}$ \\
\hline BHMERG & $\begin{array}{l}\text { BHDCHA } \\
\text { BHEUTF } \\
\text { BHEUTM }\end{array}$ & BHHED2 \\
\hline BHMWDE & & $\begin{array}{l}\text { BHBWET } \\
\text { BHMENT } \\
\text { BHPENF }\end{array}$ \\
\hline BHPAGE & & BHHED2 \\
\hline BHPENF & $\begin{array}{l}\text { BHMWDE } \\
\text { BHST3P }\end{array}$ & MELCOR \\
\hline BHQSLU & $\begin{array}{l}\text { BHHED2 } \\
\text { BHMENT }\end{array}$ & MELCOR \\
\hline BHST2P & $\begin{array}{l}\text { BHTCH4 } \\
\text { BHTHTH } \\
\text { BHTHTS } \\
\text { BHTTPO } \\
\text { BHTTP2 }\end{array}$ & BHHED2 \\
\hline BHST3P & $\begin{array}{l}\text { BHTCH4 } \\
\text { BHTHTH } \\
\text { BHTHTS } \\
\text { BHTTPO } \\
\text { BHTTP2 }\end{array}$ & BHPENF \\
\hline
\end{tabular}


BH Package Reference Manual

Table 8.1 (Continued) BH package subroutine organization

\begin{tabular}{|c|l|l|}
\hline Subroutine & Calls & Is Called By \\
\hline \hline BHTCH4 & CORPOL & $\begin{array}{l}\text { BHST2P } \\
\text { BHST3P }\end{array}$ \\
\hline BHTHTH & CORPOL & $\begin{array}{l}\text { BHBWET } \\
\text { BHST2P } \\
\text { BHST3P }\end{array}$ \\
\hline BHTHTS & CORPOL & BHBWET \\
& & BHST2P \\
& BHST3P \\
\hline BHTTP2 & CORPOL & BHST2P \\
& & BHST3P \\
\hline BHTTPO & CORPOL & BHST2P \\
& MHSLCOR & BHFP \\
\hline BHVLPL & & BHFALS \\
\hline BHVOLL & & \\
\hline
\end{tabular}


BH Package Reference Manual

Table 8.2 Purpose of BH Package Subroutines

\begin{tabular}{|c|l|}
\hline Subroutine & \multicolumn{1}{|c|}{ Purpose } \\
\hline BHAKCS & $\begin{array}{l}\text { Function for temperature-dependent thermal conductivity of carbon } \\
\text { steel. }\end{array}$ \\
\hline BHAXCO & Calculates axial conduction in the reactor vessel bottom head wall. \\
\hline BHBWET & $\begin{array}{l}\text { Calculates the water height above each bed radial zone and the dryout } \\
\text { heat flux for each debris control volume; used only for calculations in } \\
\text { which the lower plenum is reflooded after initiation of the BH Package. }\end{array}$ \\
\hline BHCPCS & $\begin{array}{l}\text { Function subprogram for temperature-dependent specific heat of } \\
\text { carbon steel. }\end{array}$ \\
\hline BHDBME & $\begin{array}{l}\text { Controls melting, relocation, and freezing of materials within the lower } \\
\text { plenum debris bed. }\end{array}$ \\
\hline BHDBMX & $\begin{array}{l}\text { Calculates liquid release from lower plenum via failed penetrations and } \\
\text { associated material ablation along escape pathway. }\end{array}$ \\
\hline BHDCHA & $\begin{array}{l}\text { Adjusts control volume dimensions in response to material relocations } \\
\text { and recalculates heat transfer lengths. }\end{array}$ \\
\hline BHDPOL & Linear interpolator used by the BHDBME subroutine. \\
\hline BHEUTF & Controls freezing of liquid material within each control volume. \\
\hline BHEUTK & $\begin{array}{l}\text { Determines the control volume debris constituents to be included in the } \\
\text { melting or freezing processes. }\end{array}$ \\
\hline BHEUTM & Calculates melting of solid materials within each control volume. \\
\hline BHFALS & Utility solver for finding roots by the method of regula falsi. \\
\hline BHFPST & $\begin{array}{l}\text { Initializes fission product inventories in the BH debris bed control } \\
\text { volumes; partitions fission products relocating from the core region into } \\
\text { the appropriate BH debris bed control volumes. }\end{array}$ \\
\hline BHHED2 & $\begin{array}{l}\text { Main program for the BH Package; calculates energy balances and } \\
\text { heat transfers within the lower plenum debris bed and generates } \\
\text { printed output. }\end{array}$ \\
\hline
\end{tabular}


BH Package Reference Manual

Table 8.2 (Continued) Purpose of BH Package Subroutines

\begin{tabular}{|c|c|}
\hline Subroutine & Purpose \\
\hline BHHEDN & $\begin{array}{l}\text { Establishes lower plenum debris bed layers one and two at time of } \\
\text { lower plenum dryout and initiates layer three upon temperature flag; } \\
\text { establishes nodal structure for the bottom head wall. }\end{array}$ \\
\hline BHHRST & $\begin{array}{l}\text { Calculates wall-to-steam radiation heat transfer coefficients for debris } \\
\text { bed surfaces, exposed portions of the vessel wall, and the lower core } \\
\text { shroud. }\end{array}$ \\
\hline BHLPLN & Calculates reactor vessel bottom head structural heatup and melting. \\
\hline BHLPOL & Linear interpolator. \\
\hline BHMENT & Returns the material enthalpies and material average specific heats. \\
\hline BHMERG & $\begin{array}{l}\text { Calculates the merging process for vertically aligned bed control } \\
\text { volumes. }\end{array}$ \\
\hline BHMWDE & $\begin{array}{l}\text { Calculates the zirconium-steam reaction within debris bed control } \\
\text { volumes after bottom head penetration failure and for cases without } \\
\text { penetration failure if water enters the lower plenum after bed dryout. }\end{array}$ \\
\hline BHPAGE & Prints output page header. \\
\hline BHPENF & $\begin{array}{l}\text { Package entry point after bottom head penetration failures occur; } \\
\text { calculates gas blowdown rate and heat transfer between flowing gas } \\
\text { and lower plenum debris. }\end{array}$ \\
\hline BHQSLU & $\begin{array}{l}\text { Package entry point throughout calculation. Performs conversion of } \\
\text { units and loads materials relocated from core region into appropriate } \\
\text { arrays. }\end{array}$ \\
\hline BHST2P & $\begin{array}{l}\text { Determines the thermophysical properties of a flowing gas stream } \\
\text { comprised of steam, hydrogen, carbon monoxide, carbon dioxide, and } \\
\text { methane. }\end{array}$ \\
\hline BHST3P & $\begin{array}{l}\text { Given the temperature, pressure, and composition of a mixture of } \\
\text { steam, hydrogen, carbon monoxide, carbon dioxide, and methane, } \\
\text { returns the gas specific enthalpies and weight fractions, plus the } \\
\text { mixture specific heat. }\end{array}$ \\
\hline BHTHTH & Thermodynamic and transport properties of hydrogen. \\
\hline BHTHTS & Thermodynamic and transport properties of steam. \\
\hline BHTTPO & Thermodynamic and transport properties of carbon monoxide. \\
\hline
\end{tabular}


BH Package Reference Manual

Table 8.2 (Conținued) Purpose of BH Package Subroutines

\begin{tabular}{|c|l|}
\hline Subroutine & \multicolumn{1}{|c|}{ Purpose } \\
\hline \hline BHTTP2 & Thermodynamic and transport properties of carbon dioxide. \\
\hline BHTCH4 & Thermodynamic and transport properties of methane. \\
\hline BHVLPL & $\begin{array}{l}\text { Function subprogram primarily used by BHFALS when called by } \\
\text { BHDCHA. Calculates total volume vs height for control volumes } \\
\text { whose outer boundaries reflect the bottom head curvature. }\end{array}$ \\
\hline BHVOLL & $\begin{array}{l}\text { Function subprogram primarily used by BHFALS when called by } \\
\text { BHHEDN. Calculates total volume versus cylindrical radius to right } \\
\text { vertical boundary for the bottom layer control volumes }(1,1) \text { and }(1,2) .\end{array}$ \\
\hline
\end{tabular}


BH Package Reference Manual

Table 8.3 Cross-reference index of subroutines and commons

\begin{tabular}{|c|c|}
\hline Subroutine & Commons \\
\hline BHBWET & $\begin{array}{l}\text { /BHCHED/ } \\
\text { /BHDBML/ } \\
\text { /BHDMXX/ } \\
\text { /BHHABL/ } \\
\text { /BHHDIN/ } \\
\text { /BHPROP/ }\end{array}$ \\
\hline BHDBME & $\begin{array}{l}\text { /BHDBML/ } \\
\text { /BHDMXX/ } \\
\text { /BHHED3/ } \\
\text { /BHRSS5/ } \\
\text { /BHVLVX/ }\end{array}$ \\
\hline BHDBMX & $\begin{array}{l}\text { /BHDBML/ } \\
\text { /BHDMXX/ } \\
\text { /BHHABL/ } \\
\text { /BHHDIN/ } \\
\text { /BHHEDM/ }\end{array}$ \\
\hline BHDCHA & $\begin{array}{l}\text { /BHDBML/ } \\
\text { /BHDMXX/ } \\
\text { /BHHABL/ } \\
\text { /BHLPXX/ } \\
\text { /BHVLVX/ }\end{array}$ \\
\hline BHEUTF & $\begin{array}{l}\text { /BHDBML/ } \\
\text { /BHHED3/ } \\
\text { /BHHEDM/ } \\
\text { /BHHEDK }\end{array}$ \\
\hline BHEUTK & $\begin{array}{l}\text { /BHDBML/ } \\
\text { /BHHED3/ } \\
\text { /BHHEDM/ }\end{array}$ \\
\hline BHEUTM & $\begin{array}{l}\text { /BHDBML/ } \\
\text { /BHHED3/ } \\
\text { /BHHEDM/ } \\
\text { /BHHEDK/ }\end{array}$ \\
\hline
\end{tabular}


BH Package Reference Manual

Table 8.3 (Continued) Cross-reference index of subroutines and commons

\begin{tabular}{|c|c|}
\hline Subroutine & Commons \\
\hline BHFALS & /BHLPXXI \\
\hline BHFPST & $\begin{array}{l}\text { /BHDBML/ } \\
\text { /BHHEDM/ } \\
\text { /BHRSS3/ } \\
\text { /BHRSS1/ }\end{array}$ \\
\hline BHHED2 & $\begin{array}{l}\text { /BHCHAR/ } \\
\text { /BHCHED/ } \\
\text { /BHDBML/ } \\
\text { /BHDMXX/ } \\
\text { /BHHABL/ } \\
\text { /BHHDIN/ } \\
\text { /BHHEDM/ } \\
\text { /BHLPXX/ } \\
\text { /BHPROP/ } \\
\text { /BHRSS2/ } \\
\text { /BHRSS4/ } \\
\text { /BHVLVX/ }\end{array}$ \\
\hline BHHEDN & $\begin{array}{l}\text { /BHBWLV/ } \\
\text { /BHCHED/ } \\
\text { /BHDBML/ } \\
\text { /BHDMXX/ } \\
\text { /BHHABL/ } \\
\text { /BHHDIN/ } \\
\text { /BHHEDM/ } \\
\text { /BHHEDK/ } \\
\text { /BHLPXX/ } \\
\text { /BHRSS3/ } \\
\text { /BHVLVX/ }\end{array}$ \\
\hline BHMERG & /BHDBML/ \\
\hline BHMWDE & $\begin{array}{l}\text { /BHCHED/ } \\
\text { /BHDBML } \\
\text { /BHRSS4/ }\end{array}$ \\
\hline BHPAGE & /BHVER/ \\
\hline
\end{tabular}


BH Package Reference Manual

Table 8.3 (Continued) Cross-reference index of subroutines and commons

\begin{tabular}{|c|l|}
\hline Subroutine & Commons \\
\hline \hline BHPENF & /BHDBML/ \\
& /BHDMXX/ \\
& /BHPROP/ \\
\hline BHQSLU & /BHHEDM/ \\
& /BHRSS1/ \\
& /BHRSS/ \\
\hline BHVLPL & /BHDBML/ \\
& /BHDMXX/ \\
& /BHVLVX/ \\
\hline BHVOLL & /BHLPXX/ \\
\hline
\end{tabular}


Table 8.4 Cross-reference index of commons and subroutines

\begin{tabular}{|c|c|}
\hline Commons & Subroutine \\
\hline /BHBWLV/ & $\begin{array}{l}\text { BHHEDN } \\
\text { MELCOR }\end{array}$ \\
\hline /BHCHAR/ & $\begin{array}{l}\text { BHHED2 } \\
\text { MELCOR }\end{array}$ \\
\hline /BHCHED/ & $\begin{array}{l}\text { BHBWET } \\
\text { BHHEDN } \\
\text { BHHED2 } \\
\text { BHMWDE } \\
\text { MELCOR }\end{array}$ \\
\hline /BHDBML/ & $\begin{array}{l}\text { BHBWET } \\
\text { BHBWET } \\
\text { BHDBME } \\
\text { BHDBMX } \\
\text { BHDCHA } \\
\text { BHEUTF } \\
\text { BHEUTK } \\
\text { BHEUTM } \\
\text { BHFPST } \\
\text { BHHEDN } \\
\text { BHHED2 } \\
\text { BHMERG } \\
\text { BHMWDE } \\
\text { BHPENF } \\
\text { BHVLPL } \\
\text { MELCOR }\end{array}$ \\
\hline /BHDMXX/ & $\begin{array}{l}\text { BHBWET } \\
\text { BHDBME } \\
\text { BHDBMX } \\
\text { BHDCHA } \\
\text { BHHEDN } \\
\text { BHHED2 } \\
\text { BHPENF } \\
\text { BHVLPL } \\
\text { MELCOR }\end{array}$ \\
\hline
\end{tabular}


BH Package Reference Manual

Table 8.4 (Continued) Cross-reference index of commons and subroutines

\begin{tabular}{|c|c|}
\hline Commons & Subroutine \\
\hline /BHHABL/ & $\begin{array}{l}\text { BHBWET } \\
\text { BHDBMX } \\
\text { BHDCHA } \\
\text { BHHEDN } \\
\text { BHHED2 } \\
\text { MELCOR }\end{array}$ \\
\hline /BHHDIN/ & $\begin{array}{l}\text { BHBWET } \\
\text { BHDBMX } \\
\text { BHHEDN } \\
\text { BHHED2 } \\
\text { MELCOR }\end{array}$ \\
\hline /BHHED3/ & $\begin{array}{l}\text { BHDBME } \\
\text { BHEUTF } \\
\text { BHEUTK } \\
\text { BHEUTM }\end{array}$ \\
\hline /BHHEDK/ & $\begin{array}{l}\text { BHEUTF } \\
\text { BHEUTM } \\
\text { BHHEDN } \\
\text { MELCOR }\end{array}$ \\
\hline /BHHEDM/ & $\begin{array}{l}\text { BHDBMX } \\
\text { BHEUTF } \\
\text { BHEUTK } \\
\text { BHEUTM } \\
\text { BHFPST } \\
\text { BHHEDN } \\
\text { BHHED2 } \\
\text { BHQSLU } \\
\text { MELCOR }\end{array}$ \\
\hline /BHLPXX/ & $\begin{array}{l}\text { BHDCHA } \\
\text { BHFALS } \\
\text { BHHEDN } \\
\text { BHHED2 } \\
\text { BHVOLL } \\
\text { MELCOR }\end{array}$ \\
\hline
\end{tabular}


BH Package Reference Manual

Table 8.4 (Continued) Cross-reference index of commons and subroutines

\begin{tabular}{|c|c|}
\hline Commons & Subroutine \\
\hline /BHPROP/ & $\begin{array}{l}\text { BHBWET } \\
\text { BHHED2 } \\
\text { BHPENF } \\
\text { MELCOR }\end{array}$ \\
\hline /BHRSS1/ & $\begin{array}{l}\text { BHFPST } \\
\text { BHQSLU } \\
\text { MELCOR }\end{array}$ \\
\hline /BHRSS2/ & $\begin{array}{l}\text { BHHED2 } \\
\text { BHQSLU } \\
\text { MELCOR }\end{array}$ \\
\hline /BHRSS3/ & $\begin{array}{l}\text { BHFPST } \\
\text { BHHEDN } \\
\text { MELCOR }\end{array}$ \\
\hline /BHRSS4/ & $\begin{array}{l}\text { BHHED2 } \\
\text { BHMWDE } \\
\text { MELCOR }\end{array}$ \\
\hline /BHRSS5/ & $\begin{array}{l}\text { BHDBME } \\
\text { MELCOR }\end{array}$ \\
\hline /BHVER/ & $\begin{array}{l}\text { BHPAGE } \\
\text { MELCOR }\end{array}$ \\
\hline /BHVLVXI & $\begin{array}{l}\text { BHDBME } \\
\text { BHDCHA } \\
\text { BHHEDN } \\
\text { BHHED2 } \\
\text { BHVLPL } \\
\text { MELCOR }\end{array}$ \\
\hline
\end{tabular}


BH Package Reference Manual

\subsubsection{Calls to BHQSLU}

The argument list for the call from MELCOR to Subroutine BHQSLU provides the following information needed to drive the lower plenum debris bed and bottom head response calculation. (These driver items are listed in the same order that they appear as call arguments).

1. DPART is the debris bed representative particle diameter $(\mathrm{m})$. It is used in the calculation of effective thermal conductivity for the bed control volumes (Section 2.4) and in the calculation of the zirconium-steam reaction (Section 3.4).

2. AMASJP is the mass of water $(\mathrm{kg})$ surrounding the jet pumps in the downcomer region of the reactor vessel. While water remains, it is an important lower plenum heat sink (Section 3.3) and source of steam for the metal-water reaction in the bed control volumes (after bottom head penetration failure).

3. TMASJP is the temperature $(K)$ of the downcomer region water pool and is the receiver temperature (Section 3.3) for convective heat transfer from the uppermost bottom head wall node to this water. After dryout of the downcomer annulus, TMASJP is the temperature of the lower shroud wall. and is used within the BH Package only in the printed output.

4. $\quad$ PVSL is the reactor vessel pressure $(\mathrm{Pa})$. It is used in the calculation of wall-to-steam heat transfer coefficients (Section 3.3.1).

5. DKDROP is the current decay power (Watts) associated with the cumulative $\mathrm{UO}_{2}$ that has escaped from the lower plenum to the drywell.

6. TDB is the temperature $(K)$ of the debris relocated from the core region this timestep. If no debris is relocated, this temperature will not be used.

7. NSTEP is the index of the BH package timestep, used only for the printed output. NSTEP is initiated as 1 at the time of lower plenum dryout.

8. $\mathrm{CH}_{4}$ is the mass $(\mathrm{kg})$ of methane in the lower plenum atmosphere.

9. $\mathrm{CO}$ is the mass $(\mathrm{kg})$ of carbon monoxide in the lower plenum atmosphere.

10. $\mathrm{CO}_{2}$ is the mass $(\mathrm{kg})$ of carbon dioxide in the lower plenum atmosphere.

11. HYD is the mass $(\mathrm{kg})$ of hydrogen in the lower plenum atmosphere. 
12. $\mathrm{PSV}$ is the partial pressure of steam $(\mathrm{Pa})$ in the lower plenum atmosphere. It is used in the calculation of wall-to-steam heat transfer coefficients (Section 3.3.1),

13. STM is the mass $(\mathrm{kg})$ of steam in the lower plenum atmosphere.

14. TGX is the temperature $(K)$ of the lower plenum atmosphere. It is the receiver temperature for wall-to-atmosphere heat transfer (Section 3.2).

15. $\mathrm{DP}$ is the differential pressure $(\mathrm{Pa})$ between the lower plenum atmosphere and the containment drywell. It is used to determine the gas flow through the debris bed if penetration failures occur; otherwise, it is used in the calculations for gross failure of the bottom head wall by creep rupture (Section 5.4).

16. TSHWAL is the initial temperature $(K)$ of the vessel wall node adjacent to the lower downcomer region (node 18 as shown in Figure 1.10). It is set within MELCOR to the saturation temperature corresponding to the pressure within the lower plenum CVH control volume.

17. DELSMT is an array DELSMT(2) that transmits information concerning the initial status of the lower plenum structural steel. The first array element DELSMT(1) is the structural steel mass $(\mathrm{kg})$ that melted and entered the debris, but is solid at the debris temperature when the BH Package is first called. DELSMT(2) is the mass of structural steel that has melted and remains in the liquid phase.

18. QGDATM is the current heat transfer rate (W) from the control rod guide tubes to the lower plenum atmosphere, calculated within MELCOR. It is used only during the period before debris bed layer 3 is established.

19. TGRID2 is the initial temperature $(K)$ of the lower plenum stainless steel structure mass that has never melted. After the initial setup of the lower plenum debris bed, this temperature is calculated within the BH Package and returned to MELCOR.

20. THEAD is the initial temperature $(K)$ of the vessel bottom head wall nodes beneath the shroud. It is used only to establish the initial temperatures of the wall segments (Section 1.2).

21. AMCRPT is an array AMCRPT $(20,2)$ that transmits information concerning the debris constituent masses $(\mathrm{kg})$ that are relocating from the core region to the lower plenum this timestep. The first array counter ( 1 to 20$)$ indicates the material species (Table 4.3) while the second counter (1 or 2) identifies the phase (solid or liquid). 


\section{BH Package Reference Manual}

22. ATIME is the MELCOR problem time (s) at the beginning of the current $\mathrm{BH}$ package timestep. It is used only for the printed package output.

23. DTM is the timestep (s) to be used for the BH calculation. Since the BH Package is called for each MELCOR timestep, this is the same as the MELCOR timestep. It is worth noting, however, that the relatively slow progression of events within the lower plenum debris bed would justify the use of a much larger timestep.

24. DTPNTB is the time interval (s) to elapse between BH package printed outputs.

25. NOUT is the output device to be used for printing the BH package output.

26. IRTYP indicates the type of reactor under consideration. Normal BH package calculations proceed for IRTYP $=0$, which indicates a conventional BWR. IRTYP $=1$ indicates a PWR and any calls to the BH Package with this signal would initiate a Program STOP. IRTYP=2 indicates the SBWR.

27. CRLSMS is the mass $(\mathrm{kg})$ of lower plenum structural steel that has been released from the BWR lower plenum into the drywell as predicted by MELCOR at the time the BH Package is initiated. It is used only in the initial setup of the debris bed control volumes. The sum

CRLSMS + DELSMT(1) + DELSMT(2) is the total structural mass that ever melted before lower plenum dryout.

28. QCNWAL is the heat $(\mathrm{J})$ conducted into the uppermost bottom head wall node NWALL from the overlying (cylindrical) portion of the vessel wall this timestep.

29. QRNWAL is an array containing the energies $(\mathrm{J})$ radiated from the core shroud to uncovered portions (if any) of the bottom head wall this timestep. QRNWAL(1) is the radiation to node NWALL (node 18); QRNWAL(2) is the radiation to node 17; and QRNWAL(3) is the radiation to node 16.

30. NRAD is the number of radial rings representing the core plate within the COR Package. These rings are recognized within the BH Package as heat sinks for radiation from the debris bed surfaces.

31. NSHDLP is the number of core shroud and downcomer region baffle plate structures below the core plate. These structures are recognized as heat sinks for radiation from the surfaces of the lower plenum debris bed.

32. VIEW2 is an array VIEW2 $(5,1+$ NSHDLP + NRAD $)$ that transmits the view factors between the debris bed surfaces and the exposed wall nodes, the baffle plate and lower shroud structures, and the core plate structures. Only the view factors to the exposed wall are used within the BH Package. (See Section 3.3.1.) 
33. QFMTOS is an array QFMTOS $(5,1+$ NSHDLP + NRAD) that transmits the current heat transfer rates $(W)$ for radiation from debris bed surfaces 1 through 5 to lower plenum structures 1 through $(1+$ NSHDLP + NRAD). The heat transfer rates between the bed surfaces and the exposed portions of the vessel wall are set within the BH Package; all others are set within MELCOR.

34. AMASLP is the mass $(\mathrm{kg})$ of water in the reactor vessel lower plenum. Calculations within Subroutine BHBWET of the BH Package predict the interactions of this water with the wetted portions of the debris bed surface and any wetted reactor vessel wall nodes above the bed surface.

35. TMASLP is the temperature $(K)$ of the lower plenum water mass AMASLP. It is calculated each timestep within MELCOR.

36. XMSHDT is the total shroud mass $(\mathrm{kg})$ that has melted and been relocated into the lower plenum debris bed after the time of downcomer dryout. It is used within the BH Package solely for the purpose of printed output. [The associated liquid stainless steel components are added to the bed upper layer by means of array AMCRPT (item 21 above).]

37. CVDH is an array CVDH $(3,5)$ that provides the decay heat (Watts) within each of the bed control volumes this timestep.

38. ABRK is the user-defined total flow area $\left(m^{* *} 2\right)$ of failed penetrations; set by evaluation of a user-prescribed control function; used to calculate gas flow into the dry debris bed (Section 5.5) or water flow into the debris bed (Section 7.6.1).

39. NMCLSX is the maximum number of fission product classes allowed by the RN Package (currently equal to 20).

40. NUMCLS is the actual number of fission product classes employed by the MELCOR user.

41. NNCAV is the maximum of one and the actual number of CAV Package cavities represented by the MELCOR user.

42. XFPMOV is an array XFPMOV(NUMCLS) that represents the mass (kg) of each fission product class that is added to the $\mathrm{BH}$ debris bed each system cycle from the core region.

43. $\mathrm{XMBH}$ is an array $\mathrm{XMBH}(\mathrm{NCRMAT})$ of COR package material masses $(\mathrm{kg})$ that have ever been relocated into the $\mathrm{BH}$ debris bed from the core region.

44. FPMBH is an array FPMBH(NUMCLS) that represents the mass $(\mathrm{kg})$ of each fission product class that has ever been relocated from the core region into the $\mathrm{BH}$ debris bed. 


\section{BH Package Reference Manual}

45. IDRYO is the beginning of cycle value of the BH Package lower plenum dryout flag used to initialize $\mathrm{BH}$ package operation(0-water remains $==>$ no BH operation, 1-water exhausted $==>B H$ may commence if sufficient solid debris exists in the lower plenum).

As explained previously, the items listed above are established within MELCOR and transmitted each timestep to the BH Package. These calls to Subroutine BHQSLU also return information calculated within the BH Package for use within MELCOR. Before proceeding to a discussion of these items of returned information, however, it is necessary to clarify some points with respect to the calls to BHQSLU at the time of initial setup of the debris bed control volumes.

At the time that sufficient solid debris has accumulated after lower plenum dryout, MELCOR calls Subroutine BHQSLU twice. [This is the only time that a double call (two calls for one timestep) is made.] Most of the items in these two call argument lists are identical. The differences lie in item 21 (AMCRPT) above.

The purpose of this double call is to permit MELCOR to differentiate between the initial compositions of the debris to be included within the bottom and middle debris layers. The bottom debris layer will be comprised of the material identified by the AMCRPT array in the first call; any overflow [as determined by the H1MAX parameter (input record $\mathrm{BH}$ 0500)] will be used to initiate the second layer. The remainder of the initial volume of the second layer will then be filled with the additional material relocated to the lower plenum by the AMCRPT array during the second call to Subroutine BHQSLU.

Items of calculated information returned from the BH Package to MELCOR via Subroutine BHQSLU include the following (listed in order of appearance in the argument list):

1. QTOWAT is the net energy (Joules) transferred to the water in the vessel downcomer region during the $\mathrm{BH}$ package timestep. (After downcomer dryout, QTOWAT is merely set to zero.)

2. IFAIL is a flag indicating the status of the debris bed and bottom head wall; see item 5 below.

3. IFAlL1 is a flag reset from 0 to 1 in Subroutine BHHED2 to indicate that penetration failures (either weld or instrument guide tube) have occurred within the bottom debris layer.

4. QDBGAS is the upward energy transier (Joules) from the bed surface during the $\mathrm{BH}$ package timestep; see the following item.

5. QVATWL is the energy transfer (Joules) from the lower plenum atmosphere to the vessel structures. The heat transfer pathways depend upon the value of IFAIL in the following manner. 
BH Package Reference Manual

a) IFAIL $=0$ : debris bed layer three does not exist; QDBGAS represents heat transfer from the upper surfaces of the layer two control volumes to the lower plenum structures and QVATWL represents heat transfer from the lower plenum structures to the exposed portions of the vessel wall.

b) IFAIL=1: debris bed layer three has been established and the lower plenum structures have been subsumed within the debris. QDBGAS represents heat transfer from the bed surfaces to the lower plenum atmosphere. QVATWL represents heat transfer from the lower plenum atmosphere to the exposed regions of the bottom head wall. The net heat transfer to the lower plenum atmosphere is QDBGASQVATWL (Joules).

c) IFAIL=2: penetration or instrument tube failures have occurred.

d) IFAIL=3 : bottom head creep rupture; all remaining debris transferred to drywell; BH package calculations terminated.

6. QRVDWL is an array QRVDWL (20) that returns the calculated energy transfer (Joules) from the outer surface of each reactor vessel bottom head wall node to the drywell atmosphere or water pool (for the case of drywell flooding) this timestep. The heat transfer coefficient and sink temperature used for the calculation at the external surface of each bottom head wall node are calculated within the MELCOR interface and are stored in array HTCT in Common BHCHED.

7. AMLOS is an array AMLOS $(20,2)$ that returns information concerning the debris constituent masses $(\mathrm{kg})$ that have escaped from the lower plenum and entered the pedestal region of the drywell during this timestep. The first array counter identifies the material species (Table 2.1) while the second counter (1 or 2) identifies the phase (solid or liquid).

Liquid transfers (only) are permitted from the vessel lower plenum to the drywell pedestal region while the bottom head wall remains intact. At the time of gross bottom head failure by creep rupture or ablation, all remaining lower plenum debris (solid and liquid) is transferred to the drywell and the $\mathrm{BH}$ package calculations are terminated.

8. TLLOS is the mixed-mean temperature $(K)$ of the materials escaping from the lower plenum this timestep.

9. The array TDBSUR (7) contains the current surface temperatures $(K)$ for the surfaces considered for heat transfer with the lower plenum atmosphere (see Section 3.2.1).

10. The elements of the array IWET(7) are reset from 0 to 1 to indicate that the associated surfaces are covered by water: 


\section{BH Package Reference Manual}

$$
\begin{array}{ll}
\text { IWET(1-5) } & \text { for the debris bed radial zones } \\
\text { IWET(6) } & \text { for bottom head wall node } 17 \\
\text { IWET(7) } & \text { for wall nodes below node } 17 .
\end{array}
$$

The bed-to-shroud radiation calculations normally carried out within the MELCOR-BH package interface are not performed for bed radial zones for which the IWET flag is set to 1 .

11. QLPWAT is the total energy transfer $(\mathrm{J})$ this timestep from the debris bed radial zones and the exposed vessel wall nodes to the mass AMASLP of lower plenum water. QLPWAT includes both energy transfer by internal boiling within the bed and the contribution of nucleate or film boiling at the bed or wall surface.

12. H2LPW is the hydrogen $(\mathrm{kg})$ generated by water interacting with the lower plenum debris bed this timestep (see Section 7.3.1).

13. The array UTRAN $(4,5,4,5)$ reports the movement of $\mathrm{UO}_{2}(\mathrm{~kg})$ into the lower plenum debris bed from the core region. These $\mathrm{UO}_{2}$ additions are defined by elements UTRAN (ITO,JTO, 4,1) where ITO and JTO identify the bed layer and radial zone indices receiving the pour. The magnitudes of the $\mathrm{UO}_{2}$ relocations are used to define the partitioning of fission products as they accompany $\mathrm{UO}_{2}$ relocation from the core. Elements UTRAN (ITO,JTO,IFROM,JFROM) for IFROM_4 and JFROM_1 are currently unused.

14. $\mathrm{XMSBHN}$ is an array $\mathrm{XMSBHN}(\mathrm{NMCLSX}=20, \mathrm{NUMAXL}=3, \mathrm{NUMRAD}=5$ ) that identifies the fission product class inventories $(\mathrm{kg})$ in each of the debris bed control volumes. Fission products are moved between control volumes in the same proportions as $\mathrm{UO}_{2}$ inventories are relocated.

15. BMSCAV is an array BMSCAV(NUMCLS,NNCAV) that identifies the fission product class masses $(\mathrm{kg})$ ejected to the drywell each system cycle subsequent to either penetration or bottom head failure.

16. XFPMXV is an array XFPMXV(NUMCLS) that represents the cumulative fission product class masses $(\mathrm{kg})$ ejected to the drywell subsequent to either penetration or bottom head failure.

17. BHFPM is an array BHFPM(NUMCLS) that represents the current total fission product class inventories $(\mathrm{kg})$ extant in the entire $\mathrm{BH}$ debris bed.

18. $\mathrm{XMLY} 3$ mass of $\mathrm{UO}_{2}(\mathrm{~kg})$ that may be temporarily withheld (due to geometric constraints) from debris bed representation until debris bed layer three is formed.

19. XFPLY3 is an array XFPLY3(NUMCLS) of fission product class masses $(\mathrm{kg})$ associated with XMLY3. 
BH Package Reference Manual

Several items in the BHQSLU argument list are included simply to facilitate the restart capability for the BH Package. In the order of their listing, these are:

1. WHBK2 is the mass $(\mathrm{kg})$ of hydrogen leaving the debris bed (via penetration failures) this timestep.

2. WHBKI is the mass $(\mathrm{kg})$ of hydrogen entering the debris bed from the lower plenum atmosphere this timestep.

3. The array AOVRP (20) contains the area-to-perimeter ratios $(\mathrm{m})$ of the bottom head wall nodes.

4. The array CLS (7) contains the characteristic lengths $(m)$ for the surfaces considered for heat transfer with the lower plenum atmosphere (see Section 3.2.1).

5. The array CPDEB $(3,5)$ contains the representative specific heats $[\mathrm{J} /(\mathrm{kg} \cdot \mathrm{K})]$ for the lower plenum debris nodes.

6. The array CSAWAL $(3,20)$ contains the cross-sectional area $\left(\mathrm{m}^{2}\right)$ for the bottom head wall segments.

7. The array XLWALL $(3,20)$ contains the lengths $(m)$ along (not across) the wall for the bottom head wall segments.

8. The array RELOCM $(20,2)$ contains the solid $(K, 1)$ and liquid $(K, 2)$ masses $(\mathrm{kg})$ for each considered material $(\mathrm{K}=1,20)$ that enters the lower plenum after the initial setup of debris layer 3 . After these material masses are added to the debris bed, the array elements are reset to zero.

9. RELOCP is the specific heat $[\mathrm{J} /(\mathrm{kg} \cdot \mathrm{K})]$ associated with material entering the lower plenum after debris bed layer 3 has been established.

10. RELOQ is the energy $(\mathrm{J})$ associated with material entering the lower plenum after debris bed layer 3 has been established.

11. The array THDW $(3,20)$ contains the current temperatures $(K)$ for the bottom head wall segments.

In general, these eleven time-dependent quantities and arrays are initially set to zero within MELCOR and then reset as appropriate within the BH Package during the period of the calculation. 
BH Package Reference Manual

\subsubsection{Calls to BHPENF}

The $\mathrm{BH}$ package subroutine BHPENF is called after bottom head penetration failure is predicted to occur (IFAIL $=2$ ). The argument list provides the following information in this order:

1. PVSL is the reactor vessel pressure $(\mathrm{Pa})$, used to determine the mixture properties of the reactor vessel atmosphere. (PVSL is also present in the Subroutine BHQSLU argument list.)

2. IFAIL is a flag indicating the status of the debris bed and bottom head wall (also present in the Subroutine BHQSLU argument list). It is set within the BH Package during the call to Subroutine BHQSLU as described in Section 8.2.1. Within Subroutine BHPENF, it is used only to flag the time of bottom head creep rupture after which the calculations associated with gas flow and metal water reaction within the debris bed are bypassed.

3. IFAIL1 is a flag indicating whether or not a penetration failure has occurred within debris layer one (also present in the Subroutine BHQSLU argument list).

4. DPART is the representative diameter $(m)$ for the bottom head debris bed particles (also present in the Subroutine BHQSLU argument list).

5. STM is the mass $(\mathrm{kg})$ of steam in the lower plenum atmosphere (also present in the Subroutine BHQSLU argument list).

6. HYD is the mass $(\mathrm{kg})$ of hydrogen in the lower plenum atmosphere (also present in the Subroutine BHQSLU argument list).

7. $\quad \mathrm{CO}$ is the mass $(\mathrm{kg})$ of carbon monoxide in the lower plenum atmosphere (also present in the Subroutine BHQSLU argument list).

8. $\mathrm{CO}_{2}$ is the mass $(\mathrm{kg})$ of carbon dioxide in the lower plenum atmosphere (also present in the Subroutine BHQSLU argument list).

9. $\mathrm{CH}_{4}$ is the mass $(\mathrm{kg})$ of methane in the lower plenum atmosphere (also present in the Subroutine BHQSLU argument list).

10. TGX is the temperature $(K)$ of the lower plenum atmosphere and is used as the temperature of the gas flow entering the upper surface of the debris bed. (TGX is also present in the Subroutine BHQSLU argument list.)

11. $\mathrm{DP}$ is the differential pressure $(\mathrm{Pa})$ between the lower plenum atmosphere and the containment drywell. Within the MELCOR interface, positive values of DP are used to calculate the gas flow through the debris bed. If DP as set by MELCOR is zero or negative, then debris bed gas flow is set to zero. (DP is also present in the Subroutine BHQSLU argument list.) 
12. DTM is the timestep ( $\mathrm{s}$ ) used for the $\mathrm{BH}$ package calculation. (DTM is also present in the Subroutine BHQSLU argument list.)

13. WGBRK is the mass flow $(\mathrm{kg} / \mathrm{s})$ from the vessel atmosphere to the drywell via bottom head penetration failures. It is calculated within the MELCOR interface.

Items of calculated information returned from the BH Package to MELCOR via the Subroutine BHPENF argument list include the following:

1. WGII is an array WGII (5) containing the individual masses $(\mathrm{kg})$ of the gases entering the upper surface of the debris bed during the $\mathrm{BH}$ package timestep. The five gases, in the order that they are stored within the array, are steam, hydrogen, carbon monoxide, carbon dioxide, and methane.

2. WGOO is an array WGOO (5) containing the individual masses $(\mathrm{kg})$ of the gases exiting the debris bed and entering the drywell atmosphere during the $\mathrm{BH}$ package timestep. The five gases are stored in array WGOO (5) in the same order as they are stored in array WGIl (5).

3. TGBOUT is the temperature $(K)$ of the gas mixture exiting the debris bed and entering the drywell during the $\mathrm{BH}$ package timestep.

4. WATRL is the mass of water $(\mathrm{kg})$ exiting the debris bed and entering the drywell during the $\mathrm{BH}$ package timestep.

\subsubsection{Special Requirements for MELCOR Input}

Several special measures are required for use of the BH Package with MELCOR. Before describing these measures, however, it is important to note that all of the coding associated with the BH Package and the BH Package-MELCOR interface can be easily isolated. This permits code checkout by the MELCOR development staff at Sandia National Laboratories of their local code modifications without interference from coding changes introduced at Oak Ridge. It also permits users to easily obtain and compare results for cases calculated with and without use of the BWR-specific lower plenum debris bed and bottom head models of the BH Package ${ }^{23}$.

In order to exercise the BH Package in a MELCOR calculation, it is first necessary to install the $\mathrm{BH}$ package Routine and Include Libraries during MELCOR installation. Instructions for doing this are provided under the heading "BH Package Information" and were distributed with the MELCOR 1.8.3 documentation. Basically, the steps are to:

1. Delete bhrtn.prl and bhinc.prl

2. Copy bhrornl.prl to bhrtn.prl

3. Copy bhiornl.prl to bhinc.prl

(default "dummy" BH package libraries)

(BH Package Routine Library)

(BH Package Include Library). 


\section{BH Package Reference Manual}

Without these steps, the default libraries load dummy subroutines in lieu of the functional $\mathrm{BH}$ package subroutines.

Second, it is necessary to specify "BWR" or "SBWR" on input record COR00002 as explained in Section 2.1 of the BH Package Users' Guide. This permits access to the coding associated with the BH Package and the BH Package-MELCOR interface.

The third special measure that must be taken when the BH Package is to be used is to provide representation of the gas exchange between the reactor vessel lower plenum and the containment after gross failure of the vessel bottom head. As explained in Section 3 of the BH Package Users' Guide, this is done by means of an FL package flow path whose area fraction is specified by the $\mathrm{BH}$ package control function variable BH-FFLAG and which provides for continued calculation of the bottom head/containment gas flow after gross bottom head failure. [Prior to gross failure of the bottom head, gas flow through the failed penetrations is calculated within the BH/MELCOR interface routines using FL package-type models. See the discussion in Section 5.5 and the description of BH input parameter IABCFN (input record BH1900) in Section 2.12 of the BH Package Users' Guide.]

In addition to changes to the interface with the FL Package, two modifications have been made to allow the BH Package to more fully interface with the HS Package. The first is achieved by use of a control function to represent an internal volumetric power source within an HS structure. In order to mimic conduction up the wall from $\mathrm{BH}$ Package lower plenum wall node 18 to the lowest "active" reactor vessel wall heat structure (Figure 1.11), the user must include a control function (MELCOR input record $\mathrm{HSCCCCC} 300$ ) to identify an internal power source, using the $\mathrm{BH}$ control function variable $\mathrm{BH}-\mathrm{COND}-\mathrm{POW}$ as one of the arguments to the control function.

The second modification permits the user to input stainless steel as a degassing source in the HS Package Degassing Model (input records HSDGCCCCC0 and HSDGCCCCC1). With the use of stainless steel as the input material, the degassing model provides a mechanism to simulate melting of the core shroud wall, as explained by the discussion in Section 9.2.2.

Finally, the user must construct the COR package input in a manner that permits reactor vessel lower plenum dryout to be predicted by the MELCOR debris quenching model. In effect, the user must override the default COR package input variables including sensitivity coefficients (SC) that affect the debris quenching calculation. These are identified in Table 8.5.

The values listed in the second column of Table 8.5 have been successfully employed at Oak Ridge to produce lower plenum dryout. Although the debris quenching models are parametric (i.e., simple and allowing the user to control the major characteristics), the suggested values in column two of Table 8.5 are considered to be realistic. Other combinations to produce a prediction of lower plenum dryout are possible. It has been found most important, however, to slow the rate of debris fall through the water-covered lower plenum structures (parameter VFALL) and to increase the penetration failure 
BH Package Reference Manual

temperature TPFAIL. (Otherwise, the COR Package will unrealistically predict underwater failure of the penetration assemblies prior to lower plenum dryout.)

Table 8.5 The user must override MELCOR default COR package input to permit lower plenum dryout

\begin{tabular}{|c|c|c|c|}
\hline Variable & $\begin{array}{c}\text { BH Package } \\
\text { Calculation } \\
\text { Example }\end{array}$ & MELCOR Default & $\begin{array}{c}\text { MELCOR Input } \\
\text { Location }\end{array}$ \\
\cline { 2 - 4 } & 0.1 & 5.0 & COR00012 \\
\hline VFALL (m/s) & 750.0 & - & COR00012 \\
\hline HDBH20 (w/m²-k) & 0.01 & - & CORIJJ04 \\
\hline DHYDP (m) & 360.0 & 3.0 & SC1020(1) \\
\hline TSPRS (s) & 60.0 & 1.0 & SC1020(2) \\
\hline TSPRM (s) & 0.4 & 0.15 & SC1244(3) \\
\hline $\begin{array}{c}\text { Minimum Lipinski } \\
\text { Porosity }\end{array}$ & 1700.0 & 1273.15 & COR00009 \\
\hline TPFAIL (K) & \multicolumn{3}{c}{} \\
\hline
\end{tabular}

\subsubsection{Deactivating the BH Package}

Having prepared working MELGEN/MELCOR input decks and utilizing the BH Package to perform debris/bottom head analyses as described in Section 8.2.3, the user can, if desired, perform subsequent MELCOR calculations without employing the BH Package by making only minor modifications to the previously-prepared MELGEN/MELCOR input decks. First, the BH Package will not be active within MELCOR if the $\mathrm{BH} 0000$ input record does not exist. $\mathrm{BH} 0000$ can be effectively removed by inserting a comment character ${ }^{1 * 1}$ in front of the line. All remaining BH Package input records will be ignored and will be identified as never having been read at the end of the MELGEN output listing. The BH package portion of the overall MELCOR data base will not be allocated and all calls of the $\mathrm{BH}$ package executive level routines will be bypassed.

A second required modification is that the flow path representing vessel failure, the $\mathrm{FL}$ flow path utilizing the $\mathrm{BH}$ package control function variable BH-FFLAG, must be either removed or modified as necessary to refer to a similar variable in the COR Package.

The third required modification for deactivation of the BH Package is the removal of the internal volumetric power source via the $\mathrm{BH}$ control function $\mathrm{BH}-\mathrm{COND}-\mathrm{POW}$. This can be accomplished by changing the control function input from:
CFAAAjj
1.0
0.0
BH-COND-POW

to:

CFAAAjj $\quad 0.0 \quad 0.0 \quad$ TIME $\quad$ * Will always produce a value of 0.0 .

Finally, if the BH Package is not active, the MELCOR logic will automatically ignore the stainless steel degassing source input and will print an appropriate warning message. 
BH Package Reference Manual

If the user decides not to use the BH Package, then the original COR package algorithms will be employed throughout the calculation. Thus, after dryout of the lower plenum water pool (as produced by the default clata of Table 8.5), the debris/bottom head calculation will continue to be calculated by the COR Package. Therefore, the user must ensure that all COR package input is appropriate. Examples include TPFAIL, HDBPN, and HDBLH on input record COR00009 and input associated with the CORLHDii and CORPENnn input records. 
BH Package Reference Manual

\section{THE MELCOR INTERFACE}

The MELCOR-BH Package interface is comprised of special logic passing information to and from the BH Package when it is active. In several instances, preexisting subroutines have been modified as appropriate for $\mathrm{BH}$ package requirements. In others, entirely new subroutines have been added. In all cases, logic necessary for the BH Package is bypassed if the MELCOR user chooses not to execute the BH Package.

The organization of the MELCOR interface is described in Section 9.1. Section 9.2 describes the interface model development required to represent the behavior of the BWR core shroud not previously represented in MELCOR. An introduction is provided in Section 9.2.1. Section 9.2.2 describes modifications to the HS and COR Packages necessary to model BWR core shroud melting prior to downcomer dryout and core shroud failure. Section 9.2.3 describes a model calculating radiative heat transfer from the surfaces of the $\mathrm{BH}$ lower plenum debris bed to the overlying structures of the $\mathrm{COR}$ and HS Packages. Section 9.2.4 describes new models developed to continue the core shroud heatup, melting, and melt mass relocation after the core shroud has failed.

Debris relocations from the BH Package to the CAV Package are described in Section 9.3. Section 9.4 describes fission product release calculations performed for the $\mathrm{BH}$ package debris bed.

Section 9.5 provides a brief discussion of several additional modifications to the interface that have been approved/proposed for future implementation; these modifications are intended to enhance BWR modeling capability.

\subsection{Interface Organization}

Several of the subroutines that are employed by the MELCOR-BH Package interface are listed in Table 9.1 together with a brief statement of the purpose of each of these routines.

Additional information concerning information flow and the execution order of these and all other interface subroutines is provided in the BH Package Programmer's Guide.

\subsection{MELCOR BWR Core Shroud Modeling Enhancements}

\subsubsection{Introduction}

The core shroud of a large (251 in. diameter) BWR is a massive structure surrounding the core and extends from the baffle plate at the bottom of the downcomer annulus to the upper dome at the top of the upper plenum. Its mass is on the order of $60000 \mathrm{~kg}$ and is a significant fraction of the mass of steel associated with the core and lower 


\section{BH Package Reference Manual}

plenum structures. Typically the core shroud constitutes the radial boundary structures of the various axial segments of the COR Package and the upper axial boundary structure for each COR Package radial ring. In addition, the core shroud is heated directly by the core structures (including particulate debris) and fluid on its inner surface but is cooled by radiation to the vessel wall and by convection to the relatively cool fluid in the downcomer annulus. The downcomer fluid is cool for much of the period of a MELCOR calculation because of the slow boiloff of the water pool trapped in the downcomer region surrounding the jet pumps.

However, if the downcomer water inventory is completely boiled dry or the shroud experiences direct radiative heating by debris lying on the core plate above the water level in the downcomer annulus, the core shroud may become partially molten with attendant steel relocation into either the core region or into the lower plenum region. Since the boundary COR Package structures are modeled by the HS Package, no previous capability existed to directly calculate the melting and relocation of this shroud material. Simple extension of COR Package input to include the shroud as another OS component in a separate radial ring bypass region was judged unacceptable as the COR Package performs OS component convective heat transfer with a single fluid region (not with two, as would be required to model the hot core-side fluid and the cold downcomer-side fluid). Therefore, the purpose of this section is to describe the modeling enhancements implemented to perform core shroud heat-up and melt relocation during the various periods of a MELCOR calculation. In some cases, new routines have been developed and included with the BH Package. In others, existing routines have been modified in the HS and COR Packages.

\subsubsection{Shroud Model Prior to Lower Plenum Dryout}

The HS package degassing model has been modified to calculate BWR core shroud melting. Stainless steel (SS) has been added as a valid degassible material and inputs to the model consist of the melting temperature range and the latent heat of melting. Because stainless steel is not a hydrodynamic material treated in the CVH Package, the normal disposition of molten steel mass degassing from a core shroud structure to either the atmosphere or pool of the adjacent CVH volume has been discontinued. The molten steel instead is redirected into the degraded core mass relocation logic of the COR Package where its disposition as particulate debris within the vessel is calculated. The allowance of stainless steel as a degassible material is currently restricted to calculations employing the $\mathrm{BH}$ Package. If $\mathrm{BH}$ is not employed, the stainless steel degassing option is simply ignored.

More information concerning the details of the required HS and COR package modifications in this effort is presented in the BH Package Programmer's Guide. Briefly, the modifications of the COR Package consisted of adding an element (LVHSST) to the array VOLU to represent the volume of unmelted mass of any HS package heat structure associated with a given core cell IA, IR, where IA is the axial segment index and IR is the radial ring index. Thus, VOLU(LVHSST, IA, IR) represents 
BH Package Reference Manual

the volume of unmelted HS structure material, and for the BWR shroud, only the outer radial ring (IR=NRAD) entries have non-zero values. In essence, this entry in the VOLU array serves as a pseudo-component of the COR Package with the entries 1 to KCMP being the fuel, cladding, canister not by blade, canister by blade, control blade, and particulate debris. KCMP is thus 6 and, therefore, LVHSST is 7. Likewise, the COR cell total volume entry, LVTOT, of VOLU was also modified to include this HS structure volume. Because the mass relocation logic within the COR Package depends on the availability of free volume into which particulate debris may relocate, the logic calculating the fluid and free volume (LVFLU and LVFRE) entries of the VOLU array has also been modified to consider the remaining material volume of this pseudo core component for each IA, IR.

The HS Package calculates the mass melted for each system cycle for each core shroud component identified by the IHSOF2 array in BH package input (input record $\mathrm{BH} 181 \mathrm{KK})$. The molten mass for each structure is saved in array XMLTSS and passed to the COR Package. The COR Package then determines the elevation of the origin of each entry of the XMLTSS array and enters the molten shroud masses as particulate debris into the outermost ring core cell at the corresponding axial COR segment.

Because the BWR shroud extends well above the core and may also be subject to severe heating and melting, several structures of the IHSOF2 array may lie above the core. The modified COR package logic accepts molten steel originating from these structures and identifies it as originating from the uppermost axial segment of the outermost ring of the core. These above-core structures are not represented as pseudo-components of the core and thus their volumes are not represented in the VOLU(LVHSST, NAXL, NRAD) entry. As such, molten steel is added as an external source and the associated virtual volume changes within the $\mathrm{CVH}$ volumes due to melting are explicitly represented.

Melting/"degassing" of the core shroud is calculated until the cumulative mass melted (XMSHML) for each shroud segment in IHSOF2 is within a user-specified amount (C4205) from the initial mass (HTCICE). The C4205 quantity is specified as an HS package sensitivity coefficient and has a current default value of $10 \mathrm{~kg}$. When the difference in cumulative molten mass and HTCICE for each segment reaches C4205, the heat structure is deactivated and all thermal interactions of the shroud segment with the COR Package are discontinued.

\subsubsection{Shroud Model After Lower Plenum Dryout}

After initial lower plenum dryout, the BH Package is functional, and the shroud modeling (as described above) continues to be exercised for portions of the core shroud at and above the core plate. It also operates for shroud segments below the core plate but any molten steel produced is transferred directly into the BH Package lower plenum debris bed via the AMCRPT array loaded in BH routine BHRUN1. 


\section{BH Package Reference Manual}

Because the lower plenum is dry, the core shroud structures overlying the debris bed are exposed to intense radiative heating from the lower plenum debris bed.

A BH Package model has been developed to evaluate this radiative heat transfer and the various inputs required for it are described in the BH Package Users' Manual for the BH18 series of input records. COR Package routines CORDBD, CORRN1, and CORRN3 have been modified to incorporate this model. The overlying structures are identified in user input and consist of the baffle plate at the bottom of the shroud downcomer, the segments of the core shroud below the core plate, and the radial segments of the core plate. The radiation model is evaluated in the COR Package because the COR Package is called before the BH and HS Packages and because of the desire to incorporate the associated radiative heat loads within the appropriate packages all on the same system cycle. If the model were evaluated in either the $\mathrm{BH}$ or HS Packages, then a system cycle offset would be necessary in incorporating the radiative heat loads to the affected portions of the core plate in the COR Package.

The lower plenum debris-to-structure radiation model is executed with a call of routine BHRAD2 from CORRNB on all subcycles of the COR Package. The call of BHRAD2 is conditioned on $M O N B H=1$, IRTYP $=0$ or 2 , and IDRY $=1$. The radiative heat loads calculated by BHRAD2 are evaluated using beginning-of-cycle database information from the $\mathrm{BH}$ and HS Packages. End-of-subcycle data base information is used from the COR Package.

The radiative heat loads calculated each subcycle are passed to routines CORRN1 and CORRN3, which are also called each COR subcycle. CORRN1 has been modified to update the energy balance of the core plate with the calculated radiative heat loads at axial level NTLP if the BH Package is active (MONBH=1), if IRTYP $=0$ or 2 , and if IDRY $=1$. CORRN3 has been modified to call HSECOM to pass the radiative heat loads for the affected core shroud surfaces to the appropriate structures of the HS Package.

The calculated radiative heat transfers $(J)$ from the debris bed surface to the overlying structures are accumulated over the various subcycles of the system cycle and are stored in the QFMTOS $(I, J)$ array. (Radiative heat transfer from the debris bed surface to the exposed vessel wall above the debris QFMTOS $(I, 1)$ is calculated within BHHED2 as described in Sections 3.3.1 and 3.3.2.) At the end of subcycling across a system cycle, routine BHRUN1 converts the accumulated heat loads from Joules back to Watts by dividing by the system cycle length. The QFMTOS $(\mathrm{I}, \mathrm{J})$ array is then passed to the $\mathrm{BH}$ Package routine BHQSLU where the various transfers from debris surface I are summed over surfaces $\mathrm{J}$, where $\mathrm{J}$ is the overlying structure surface index. The net radiative debris surface heat loss is incorporated into the appropriate debris bed upper layer control volume energy balance. 
BH Package Reference Manual

\subsubsection{Shroud Model After Lower Core Shroud Failure}

As mentioned previously, the fluid in the downcomer annulus is relatively cool due to steaming produced due to the boiloff of the water pool trapped around the jet pumps. Thus most of the core shroud tends to remain relatively cool and intact for much of the MELCOR calculation. The boiling rate increases when the lower core shroud is subjected to the intense radiative heating from the dry lower plenum debris bed. However, once the annulus water inventory is depleted, the temperatures of the lower portions of the core shroud and the baffle plate rapidly increase.

It is expected that the baffle plate will reach a temperature where it can no longer support the weight of the core shroud and any remaining core structures supported by the intact core plate. It is postulated that the baffle plate would fail at high temperature and would result in the relocation downward of the entire length of remaining intact core shroud onto the lower plenum debris bed. Because the core plate would relocate when the baffle plate fails, it is also postulated that the remaining core structures and core debris supported by the core plate would also relocate into the lower plenum.

A new model is required because the HS Package cannot represent the gross movements of the upper shroud downward toward the debris bed after lower portions have melted.

The purpose of this Section is to describe the model that has been developed for the BH Package to represent the continued heating of the core shroud (after downcomer dryout and failure of the baffle plate), melting of the lower core shroud, relocation of the molten steel into the debris bed, and gross movement of the upper shroud downward after lower portions have completely melted and relocated. This interface description is an extension of the discussion provided in Section 3.3 and the reader is urged to read that Section prior to reading the material here.

\subsubsection{Initiation Characteristics and Model Description}

Logic has been developed to track the average baffle plate temperature throughout the period when the BH Package is operating. (The baffle plate is shown in Figure 3.2 as Surface 2, is the upper structure closest to the debris, is subjected to the most intense radiative heating after downcomer dryout, and is the structure most likely to thermally fail.) The baffle plate temperature tracking logic exists in routine BHRUNO and calculates the volume-averaged temperature each cycle, which is compared to the user-specified failure temperature TFAILS (see BH1800 input record in the BH Package Users' Guide). Once the average temperature meets or exceeds TFAlLS and the downcomer annulus has boiled dry, the model flag IFLGSN is changed from 0 to 1 indicating that the shroud has failed. At this point, the model is initialized and HS package modeling of the core shroud is discontinued. 


\section{BH Package Reference Manual}

Model initialization is performed in routine BHSHSL where several segments of the lower shroud are modeled separately while the entire mass of the upper shroud is represented as a single section. Arrays initialized include steel mass (XMSLHS), specific energy (XESLHS), temperature (TSLHS), volume(VLSLHS), and surface area (ARSLHS) for each shroud section modeled. Information required to initialize these arrays is taken from the HS Package for those structures identified by user input as representing the entire length of the core shroud (see array IHSOF2 on input record $\mathrm{BH} 181 \mathrm{KK})$. Having initialized the model, the HS package structures representing the shroud are deactivated via calls of IHSOFF in routine BHRUN3. Because the baffle plate has failed, its mass, temperature, and melt fraction are loaded into the shroud material transfer variables XMSHD, XTSHD, XFSHD respectively. This mass and energy information is passed to BHRUN1 where it is reformatted and added to the debris bed through the normal COR-to-BH Package material relocation array AMCRPT.

After the baffle plate has failed and relocated into the bed, no support remains for the core shroud or for the core components remaining above the core plate. Therefore, Core (COR) package routine CORSLU has been modified to collapse the remaining portions of the core into the lower plenum at baffle plate failure. Since any remaining portion of the core plate is also collapsed into the lower plenum at this time, the upper bed surface has a clear view of the entire inner surface of the core shroud. This fact permits the continued use of the debris-to-overlying structures view factors that are utilized prior to core shroud failure (see array VIEW2 on input record BH18JJKK).

The view factor array VIEW2 is defined with respect to the surfaces shown in Figure 3.2:

$$
\begin{aligned}
& \text { VIEW2 }(I, J)=\text { view factor between the upper debris surface index } I(1 \leq I \leq 5) \text { and } \\
& \text { the overlying surface } J[1 \leq \mathrm{J} \leq(1+\mathrm{NSHDLP}+\mathrm{NRAD})] \\
& \text { NSHDLP = number of baffle plate and lower core shroud HS package } \\
& \text { structures } \\
& \text { NRAD = number of core plate radial sections (COR package radial rings). }
\end{aligned}
$$

Therefore, the total number of overlying structures prior to core shroud failure is

$$
1+\text { NSHDLP + NRAD. }
$$

The number of debris bed upper control volume surfaces is 5 .

After shroud failure, the view factors corresponding to the core plate radial sections for each debris surface are lumped together to form the new view factor from the surface to the entire length of the core shroud previously above the core plate. This view factor lumping is performed in BHSHSL for each upper layer debris control volume I and may be represented as: 
BH Package Reference Manual

$$
\begin{aligned}
& \text { VIEW2 }(I, 1+N S H D L P+1)=\sum_{J} \text { VIEW2 }(I, 1+N S H D L P+J) \\
& 1 \leq J \leq N R A D \text {, e.g., summed over all core plate rings. }
\end{aligned}
$$

The portions of the lower shroud identified via the ISHDLP array on input record BH18JJ continue to provide a convenient nodalization scheme representing the lower core shroud after baffle failure. Lumping of lower segments of the shroud (as described above for the upper shroud) is not appropriate as these shroud portions are closest to the debris bed and are more apt to melt due to the intense radiative heating. Thus the VIEW2 view factor information between the debris and the lower shroud sections (shown in Figure 3.2) is retained after baffle plate failure even though the entire shroud is assumed to have moved downward and come to rest on the debris bed. This is acceptable due to the uncertainties caused by the changing debris bed configuration as the porous bed melts and collapses upon itself and the unknown extent to which the shroud would sink into the bed.

Because the core shroud has relocated downward, the view between the central bed surface and the exposed reactor vessel wall (above the debris) is blocked by the intervening shroud. Thus the elements of VIEW2 corresponding to the exposed wall are zeroed for debris surfaces I, II, and III. Likewise the view factors corresponding to the lowermost portion of the core shroud, e.g., Surface 3 in Figure 3.2, are correspondingly enhanced. That is, for debris surfaces $I=1,2$, and 3 :

$$
\begin{aligned}
& \operatorname{VIEW2}(I, 3)=\operatorname{VIEW} 2(I, 3)+\operatorname{VIEW} 2(I, 1) \\
& \operatorname{VIEW2}(I, 1)=0.0 .
\end{aligned}
$$

Zeroing the view factors from the interior debris bed surfaces to the exposed vessel wall eliminates radiative heat transfer from these surfaces to the exposed vessel wall as described in Section 3.3.1. Debris surfaces IV and V continue to radiate directly to the exposed wall with the appropriate (unmodified) VIEW2 factors.

Finally, since the baffle plate has failed and relocated into the debris bed and because the entire core shroud has moved downward to rest upon the bed surface, the elements of VIEW2 corresponding to the lowermost portion of the core shroud are enhanced by the baffle view factors, which are then zeroed. Therefore, for debris surfaces $I=1$ through 5:

$$
\begin{aligned}
& \operatorname{VIEW} 2(I, 3)=\operatorname{VIEW} 2(1,3)+\operatorname{VIEW} 2(I, 2) \\
& \operatorname{VIEW2}(1,2)=0.0 .
\end{aligned}
$$

Radiation heat transfer from the outer surface of the core shroud to the vessel wall is also a very important consideration as it provides a very significant energy removal mechanism. Because of its importance, the view factor between the lowermost core shroud section and the exposed reactor vessel wall immediately above the debris bed is calculated in routine BHRNG4 (using formula 28 from Appendix C of Reference 34) 


\section{BH Package Reference Manual}

and stored in VIEW1 $(1,1)$. For shroud segments above the lowest, the view factor information input via records BH14JJKK for the intact core shroud geometry are no longer applicable, and the view factors VIEW1 $(I, J)$ are redefined as follows:

$$
\begin{aligned}
\operatorname{VIEW} 1(\mathrm{I}, 1)= & 0.0 \text { for } \mathrm{I}>1 \text { and } \mathrm{I} \text { is the core shroud index } 1 \text { to NSHRD } \\
\operatorname{VIEW} 1(1, \mathrm{~J})= & 0.0 \text { for } \mathrm{J}>1 \text { and } \mathrm{J} \text { is the vessel wall index } 1 \text { to NVWALL } \\
\text { NSHRD }= & \text { number of core shroud HS package structures entered on } \\
& \mathrm{BH} 1400 \\
\text { NVWALL }= & \text { number of vessel wall HS package structures entered on } \\
& \mathrm{BH} 1400(>1) \\
\operatorname{VIEW} 1(\mathrm{I}, \mathrm{J})= & 1.0 /(\mathrm{NVWALL}-1) \text { for } \mid>1 \text { and } \mathrm{J}>1 .
\end{aligned}
$$

This is in recognition that the view factor between the core shroud and the vessel wall is unity; the view factor is simply divided among the number of HS package structures the user has defined for the vessel wall above the lower head.

It should also be noted from the definitions above, that VIEW1 $(1, \mathrm{~J})=0.0$ for $\mathrm{J}>1$. For this to be realistic, the view factor VIEW1 $(1,1)$ must be large and therefore requires that the lowermost core shroud section be sufficiently long. A warning message is printed from routine BHRUNO whenever the calculated VIEW1 $(1,1)$ from routine BHRNG4 is less than 0.5. Since the user inputs the geometry of this lowermost section in the original HS package input to MELCOR, the message suggests that the user increase the length of this section so that the view factor is enhanced. (A length of $1.3 \mathrm{~m}$ should be sufficient to avoid this condition for typical 251-inch ID reactor vessel BWR geometry.)

As described above, the geometry represented in the shroud heatup, melting, and relocation model is the same as that shown in Figure 3.2 with the exceptions that the entire shroud has moved downward to rest upon the debris bed, the core region structures no longer exist, and the upper core shroud above the core plate location is represented as a single mass. Thus, five debris bed surfaces are represented as are NSHDLP +1 core shroud surfaces (with the first being a dummy surface). A total of $1+\mathrm{NSHDLP}+1$ surfaces overlying the debris bed are represented, the first being the exposed wall above the debris followed by NSHDLP +1 core shroud surfaces. 
BH Package Reference Manual

Table 9.1 Purpose of BH Package Interface Subroutines

\begin{tabular}{|c|c|}
\hline Subroutine & Purpose \\
\hline CAVDOP & $\begin{array}{l}\text { Driver routine for passing debris relocations into CAV from TP } \\
\text { Package. For BH applications [and fuel dispersal interaction (FDI) } \\
\text { inactive], the LIQSL2 option flag and special TSOL and TLIQ values } \\
\text { are passed to routine CCCPEN }\end{array}$ \\
\hline CCCPEN & $\begin{array}{l}\text { Calculates debris enthalpy as function of TLLOS; latent heat } \\
\text { modification made if the argument list contains the IOPT }=-1 \text { option } \\
\text { flag, and TSOL and TLIQ are appropriately defined }\end{array}$ \\
\hline CCCFND & $\begin{array}{l}\text { Determines pure species' melting temperature and latent heat of } \\
\text { melting; provides information necessary to determine pure species' } \\
\text { enthalpy at TLLOS }\end{array}$ \\
\hline BHORB8 & $\begin{array}{l}\text { Reformats BH package debris relocations from vessel into form } \\
\text { acceptable to the TP Package; solids and liquids processed separately }\end{array}$ \\
\hline BHRUN3 & $\begin{array}{l}\text { Passes debris relocation information from BH to TP by calling routine } \\
\text { TPIN separately for debris solids and liquids }\end{array}$ \\
\hline BHRAD2 & $\begin{array}{l}\text { Calculates debris-to-overlying surface radiation model. Called by } \\
\text { CORRNB; calls CORRDG; accumulates QFMTOS(l,J) over the various } \\
\text { COR package subcycles as heat loads (J); QFMTOS(l,J) converted } \\
\text { back to Watts in BH routine BHRUN1 prior to calling BHQSLU. }\end{array}$ \\
\hline BHRAD3 & $\begin{array}{l}\text { Calculates debris-to-core shroud radiation (QFMTOS array) after the } \\
\text { baffle plate has failed and the remaining structures of the core have } \\
\text { collapsed and relocated into the lower plenum debris bed; called by } \\
\text { BHRUNO. }\end{array}$ \\
\hline BHRAD4 & $\begin{array}{l}\text { Calculates core shroud-to-vessel wall radiation (QRAD1 array) after } \\
\text { the baffle plate has failed; called by BHRUNO. }\end{array}$ \\
\hline BHRAD5 & $\begin{array}{l}\text { Calculates gas-to-core shroud radiation (QRGAS array) for inner and } \\
\text { outer surfaces of the core shroud after the baffle plate has failed; } \\
\text { called by BHRUNO. }\end{array}$ \\
\hline BHRNG4 & $\begin{array}{l}\text { Calculates VIEW1 }(1,1) \text { for the lowermost core shroud segment to the } \\
\text { exposed vessel wall after the baffle plate has failed; called by } \\
\text { BHRUNO. }\end{array}$ \\
\hline BHPAC1 & $\begin{array}{l}\text { Performs heatup, melting, and upper core shroud relocations as the } \\
\text { lower core shroud melts and moves into the lower plenum debris bed } \\
\text { after baffle plate failure; called by BHRUNO. }\end{array}$ \\
\hline
\end{tabular}


BH Package Reference Manual

Table 9.1 (Continued) Purpose of BH Package Interface Subroutines

\begin{tabular}{|c|l|}
\hline Subroutine & \multicolumn{1}{|c|}{ Purpose } \\
\hline \hline BHSHSL & $\begin{array}{l}\text { Initialization routine for the shroud heatup, melting, and mass } \\
\text { relocation model after baffle plate failure; called by BHRUNO. }\end{array}$ \\
\hline BHCNV & $\begin{array}{l}\text { Calculates convective heat transfer (QCNV array) from the inner and } \\
\text { outer surfaces of the core shroud after baffle plate failure; called by } \\
\text { BHRUNO. }\end{array}$ \\
\hline
\end{tabular}

\subsubsection{Shroud Heat and Mass Balance}

The heat and mass balances for the relocated core shroud are performed in routine BHPAC1 after the various heat loads are calculated for a given timestep and passed into BHPAC1. [The heat loads are calculated within various subroutines indicated below and the reader should directly examine the FORTRAN (and local comment statements) if more information is desired.)] The energy balance for each section of the core shroud is as follows:

DENET = (QFMTOS $-($ QCNV(1)+QCNV(2))) $\times$ DT+QRAD1(2)+QRGAS(1)+QRGAS(2) where

$$
\begin{aligned}
& \text { DENET = net energy }(\mathrm{J}) \text { added to core shroud structure over the system } \\
& \text { QFMTOS = sum of the radiative powers }(W) \text { from all debris bed surfaces to } \\
& \text { core shroud structure; QFMTOS is determined in BHRAD3 } \\
& \text { QCNV(1) = convective power (W) from shroud inner surface; calculated in } \\
& \text { BHCNV } \\
& \text { QCNV(2) = convective power (W) from shroud outer surface; calculated in } \\
& \text { BHCNV } \\
& \text { DT = system cycle timestep (s) } \\
& \text { QRAD1(2) = radiative heat load to the outer surface }(\mathrm{J}) \text { due to radiative } \\
& \text { exchange with the vessel wall; calculated in BHRAD4 } \\
& \text { QRGAS(1) = radiative heat load }(J) \text { to inner shroud surface due to gas/shroud } \\
& \text { radiation; calculated in BHRAD5 } \\
& \text { QRGAS(2) = radiative heat load }(\mathrm{J}) \text { to outer shroud surface due to gas/shroud } \\
& \text { radiation; calculated in BHRAD5. }
\end{aligned}
$$


BH Package Reference Manual

The DENET variable is passed along with the shroud segment specific energy XE $(\mathrm{J} / \mathrm{kg})$ and mass XM $(\mathrm{kg})$ to COR package routine CORUV1. Returned from CORUV1 are updated values of specific energy XE and the equilibrated temperature XT. The variables $X E, X M$, and $X T$ are local working variables within BHPAC1 and are initialized to beginning-of-timestep values of the database variables XESLHS, XMSLHS, and TSLHS.

Melting is next considered if XE is greater than COR package variable EMLT(SS) e.g., the specific energy of solid stainless steel at its melting temperature. If no melting has occurred, then:

$$
\begin{gathered}
\text { XESLHS }=X E \\
T S L H S=X T
\end{gathered}
$$

and no updating of the XMSHD and XESHD material relocation variables or the segment mass XMSLHS is required. It should be recognized that the XMSHD and XESHD variables are defined as follows:

XMSHD = cumulative shroud steel mass melted over the cycle $(\mathrm{kg})$ from all segments of the shroud; initialized to 0.0 at beginning of cycle

XESHD $=$ enthalpy associated with XMSHD above $(\mathrm{J})$.

If melting is indicated, the melted fraction FRACM is determined by routine BHFMLT, which interpolates with XE between EMLT and EMLT+ELHF, where ELHF is the steel latent heat of melting. The melt mass XMLT for the shroud segment is

$$
\mathrm{XMLT}=\mathrm{XMSLHS} \times \mathrm{FRACM}
$$

and the segment mass is decreased by this amount

$$
\text { XMSLHS }=\text { XMSLHS }- \text { XMLT } \text {. }
$$

If the updated XMSLHS is zero, then all of the structure is melted and XESLHS, TSLHS, VLSLHS, and ARSLHS are all zeroed. (VLSLHS and ARSLHS are the volume and surface area of the structure.) If XMSLHS remains greater than zero, then the energy, temperature, and volume are set as follows:

$$
\begin{aligned}
& \text { XESLHS }=\text { EMLT } \\
& \text { TSLHS }=\text { TMLT } \\
& \text { VLSLHS }=\text { XMSLHS/RHOM, }
\end{aligned}
$$

where RHOM is the COR package steel density and TMLT is the steel melting temperature. In addition, if the shroud segment corresponds to the portion above the core plate, then the area (ARSLHS) is reduced to reflect the higher temperatures (compared to the average) near the bottom of this long structure. This contrasts with the lower shroud structures for which no modification is made to the segment surface 


\section{BH Package Reference Manual}

areas. The lower portions of the shroud are assumed to melt radially outward from the inner surface and not from the bottom upward.

If melting is indicated from the energy balance, then the accumulation variables XMSHD and XESHD are incremented for the melt mass and energy. Having looped through all of the 1+NSHDLP shroud structures in the manner described above, the total mass and energy of molten steel from the entire shroud is stored in XMSHD and XESHD. Routine CORUV1 is called again to determine the mass-averaged temperature XTSHD of this molten steel, and the melt fraction XFSHD is determined by a call to BHFMLT. The variables XMSHD, XTSHD, and XFSHD are then passed into routine BHRUN1, which reformats them into the normal interface AMCRPT mass array and debris pour temperature TDB as described in Section 8.2. Also updated in routine BHRUN1 is the XMSHDT variable, which represents the cumulative shroud mass that has melted and relocated directly into the lower plenum debris bed after the time of downcomer and lower plenum dryout.

\subsubsection{Gross Shroud Relocations}

An outcome of the heat and mass balance procedure described in Section 9.2.2 is that the lower segments of the core shroud may become empty. Whenever this occurs, a procedure developed in the last portion of routine BHPAC1 acts to relocate shroud mass and energy from upper portions of the shroud into the (vacant) lower segment locations. This is done to represent the gross settling of the shroud as lower portions are consumed by the lower plenum debris bed.

The magnitude of gross shroud movement is such that the original mass within the empty lower shroud segment is completely restored. The algorithm searches upward from the empty segment through the remaining shroud sections until sufficient mass is identified. This searching process may extend over several segments as the upper shroud mass may have become reduced due to local melting. Since the temperature and therefore the specific energy of each of these segments may differ, the energy associated with the mass taken from each is accumulated so that a total energy associated with the required mass is identified. Likewise, the mass and energy of each of the overlying structures is reduced as they are processed in the searching procedure.

Once sufficient mass has been identified to restore the empty shroud segment, then the restored segment's temperature is determined by a call of CORUV1 using the mass and the total energy from the upper segments. Having restored the empty shroud segment, the procedure proceeds to the next higher shroud segment and the process is repeated until the last segment corresponding to the shroud section above the core plate $(1+N S H D L P)$ has been processed. 
BH Package Reference Manual

\subsection{Interface Modifications for Debris Relocations from the Vessel to Containment}

The capability of CAVDOP, CCCPEN, and CCCFND routines of MELCOR 1.8.3 have been extended to appropriately represent the energy state of eutectic materials leaving the BH Package via the Transport Process Package (TP). The MELCOR 1.8.3 modification is active only if the $\mathrm{BH}$ Package is operational, and debris is passed directly from the BH Package into the CAV Package (via TP) without passing through the Fuel Dispersal Interaction (FDI) Package. No modification has been made to the debris equation of state of the FDI Package to represent BH package eutectics. The following paragraphs describe the MELCOR 1.8.3 BH-to-CAV debris transfer process.

The BH Package provides the amounts of liquid and solid released from the reactor vessel to the containment each timestep for each material as elements of the AMLOS array; the associated average release temperature is TLLOS. Both pure species and eutectic mixtures are considered to exist within the lower plenum debris bed. When materials melt as constituents of eutectic mixtures, they can be released from the reactor vessel at temperatures below their pure species' melting temperatures. (The pure species considered within the BH Package are listed in Table 4.3 and the formation of eutectic mixtures is described in Section 4.2). Formatting of the debris releases into a form acceptable to the TP Package is performed in BHORB8 separately for the solid and liquid debris ejections. Loading of these relocations into TP is performed in BHRUN3 near the end of BH processing for a given system cycle by calling routine TPIN twice (one parcel each for the liquids and solids). The temperature associated with the parcels are loaded as TLLOS for the solids and-TLLOS for the liquids.

For the interface between the TP and CAV Packages, enthalpies are determined by performing two sets of calculations corresponding directly to the solid and liquid entries of the AMLOS array for each parcel at the release temperature TLLOS. The solidus/liquidus method previously employed by the interface subroutine CAVDOP is bypassed for the material transfers from the BH Package.

If the debris parcels corresponds to the solid debris portion of AMLOS (T=TLLOS), then pure species' debris energies are evaluated initially at TLLOS in routine CCCPEN called by CAVDOP. In addition, if TLLOS is greater than the melting temperature of each species present in the solid debris pour (solids occur only during the single cycle following the gross failure of the bottom head) then the pure species' latent heat of fusion is removed so that the enthalpy returned to routine CAVDOP contains no latent heat. (That the latent heat is to be removed from the $\mathrm{BH}$-originated debris is identified by special flags passed in the CCCPEN argument list.)

Likewise, if the debris parcel corresponds to the liquid debris portion of AMLOS ( $T=-$ TLLOS), then the pure species' debris energies are evaluated initially at TLLOS again in routine CCCPEN called by CAVDOP. In addition, if TLLOS is less than the melting temperature of each species present in the liquid pour, then the pure species' 


\section{BH Package Reference Manual}

latent heat of fusion is added so that the enthalpy returned to CAVDOP reflects the addition of latent heat. Again, special flags are passed to routine CCCPEN to identify that the debris is liquid and that it originates from the BH Package.

The actual mapping employed by the $\mathrm{BH}$-to-CAV material transfers is indicated in Table 9.2. The materials are first mapped into an intermediate material array (BMEJ) for the TP Package from the BH Package (via routines BHORB8, BHRUN3, and TPIN) and then into the CAV metal and oxide mass arrays (via routine CAVDOP). The procedure followed in this mapping is analogous to that employed by the COR Package. Note that materials $\mathrm{B}_{4} \mathrm{C}$ and $\mathrm{B}_{2} \mathrm{O}_{3}$ are not mapped into $\mathrm{CAV}$ and are, therefore, not represented in the CORCON calculation. This is necessary because of the lack of representation of boron and its compounds for boiling water reactor (BWR) applications in the CAV material database and, again, is analogous to the procedure adopted for material releases originating within the COR Package. Finally, $\mathrm{BH}$ material index $14\left(\mathrm{Fe}_{3} \mathrm{O}_{4}\right)$ is mapped into CAV material $3(\mathrm{FeO})$ due to lack of CAV representation of $\mathrm{Fe}_{3} \mathrm{O}_{4}$.

It is important to note that the procedure for treating material liquids/solids in the AMLOS array does not necessarily imply full melting/freezing of each of the species at the release temperature TLLOS as represented in the CAV Package. The energy states as represented within the BH Package for the liquid/solid materials leaving the reactor vessel are preserved in the CAV Package. These energy states will be reflected by the CAV Package (and introduced into CORCON) as partially-liquid mixtures of pure species at individual temperatures different from the single-release temperature TLLOS.

In summary, the material masses released by the $\mathrm{BH}$ Package are loaded via two calls to the TP routine TPIN, one each for the solids and liquids. The enthalpies of the solids to be added to the CAV package debris bed are calculated as a function of temperature TLLOS and reduced by the latent heat if TLLOS is greater than the pure species' melting temperature. The enthalpies for the liquids, however, are those for the pure species at TLLOS enhanced by the latent heat if TLLOS is less than the pure species' melting temperature. 
BH Package Reference Manual

Table 9.2. BH to CAV Material Mapping

\begin{tabular}{|c|c|c|}
\hline BH Index & -TO- & CAV Index \\
\hline $1(Z r)$ & & $46(\mathrm{Zr})$ \\
\hline $2(\mathrm{Fe})$ & & $43(\mathrm{Fe})$ \\
\hline $3(\mathrm{Cr})$ & & $44(\mathrm{Cr})$ \\
\hline $4(\mathrm{Ni})$ & & $45(\mathrm{Ni})$ \\
\hline 5 (blank) & & -- \\
\hline 6 (blank) & & -- \\
\hline 7 (blank) & & -- \\
\hline 8 (blank) & & -- \\
\hline 9 (blank) & & -- \\
\hline $10\left(\mathrm{~B}_{4} \mathrm{C}\right)$ & & -- \\
\hline $11\left(\mathrm{ZrO}_{2}\right)$ & & $21\left(\mathrm{ZrO}_{2}\right)$ \\
\hline $12(\mathrm{FeO})$ & & $3(\mathrm{FeO})$ \\
\hline 13 (blank) & & -- \\
\hline $14\left(\mathrm{Fe}_{3} \mathrm{O}_{4}\right)$ & & $3(\mathrm{FeO})$ \\
\hline $15\left(\mathrm{Cr}_{2} \mathrm{O}_{3}\right)$ & & $22\left(\mathrm{Cr}_{2} \mathrm{O}_{3}\right)$ \\
\hline $16(\mathrm{NiO})$ & & $23(\mathrm{NiO})$ \\
\hline $17\left(\mathrm{~B}_{2} \mathrm{O}_{3}\right)$ & & -- \\
\hline $18\left(\mathrm{UO}_{2}\right)$ & & $20\left(\mathrm{UO}_{2}\right)$ \\
\hline 19 (blank) & & -- \\
\hline 20 (blank) & & -- \\
\hline
\end{tabular}

\subsection{Fission Product Release from the BH Package Debris Bed}

With the original installation of the BH Package within MELCOR 1.8.2 (NM), fission products were not released from the lower plenum debris as the bed temperature increased, but rather were carried along with debris pours into the drywell and released there. Work to provide for lower plenum fission product release to be calculated by the BH Package has been recently completed for MELCOR 1.8.3 and is summarized in the following paragraphs.

An approach analogous to that employed for fission product release determinations within the COR Package has been implemented. The initial radioactive fission product mass totals are provided (by default) by the Decay Heat Package (DCH) and are grouped (typically) into 15 separate classes. (The BWR fission product inventories and the associated decay powers stored in DCH were determined by an ORIGEN calculation for a large BWR.)

The initial fission product inventories associated with the $\mathrm{BH}$ package debris are identified from COR package array XMSCOR for materials in COR cells below the core plate at the time of $\mathrm{BH}$ package initiation. These initial fission product inventories are then redistributed among the control volumes of the $\mathrm{BH}$ package debris bed in routine 


\section{BH Package Reference Manual}

BHFPST (subject to the existence of UO2 in the control volume). These control volume inventories are then modified each system cycle to account for (1) additions from the core, (2) releases due to volatilization, (3) gross transfers due to UO2 relocations from control volume to control volume within the debris bed, and (4) transfers due to UO2 relocations from the vessel to the drywell.

The new fission product release model is based on the release modeling of the COR Package and includes the CORSOR and CORSOR-M models both with and without the surface area-to-volume ratio option. (The CORSOR-Booth model is currently unavailable for $\mathrm{BH}$ package fission product release calculations.) The primary input to the release models is the debris temperatures for each of the 13 control volumes of the BH Package debris bed. Because of the uncertainty in determining the surface area-tovolume ratio for a two-phase mixture of solid/molten debris, the surface area-to-volume ratio is simply set to 6/D where $D$ is the diameter of debris particles used throughout the $\mathrm{BH}$ Package and is input via COR package input record CORIJJ04. Because the surface area-to-volume ratio is important to release modeling, the user may vary the calculated release rates by modifying the surface area-to-volume ratio base defined by RN Package sensitivity coefficient 7104 (default value of $422.5 \mathrm{~m}^{-1}$ ).

The fractional release for each RN class is calculated each system cycle for each $\mathrm{BH}$ debris bed control volume within routine BHRLS after the major portion of the physics advancement for $\mathrm{BH}$ is performed for the system cycle. These fractional releases are then multiplied by the existing class inventories to determine the released class masses. The released class mass is summed over all the control volumes of the debris bed and stored in the XMRCOR array, which is then passed into the RN Package where partitioning into either aerosols or vapors is performed. Releases of both radioactive and non-radioactive materials are calculated.

The releases are directed to the atmosphere of the lower plenum CVH volume. No modification of RN package routines was necessary as the XMRCOR array already processes fission product releases from the COR Package. A new input record BHRN10K, Section 2.13 of the BH Package Users' Guide, has been developed to specify the mapping employed between the 20 pure species materials of the $\mathrm{BH}$ Package and the various classes of the RN Package. Defaults are provided based on analogy with the mapping employed by the COR Package.

An important feature of the fission product release model is the new ability to track fission product relocations into, within, and from the debris bed. A new array UTRAN has been defined (Section 8.2.1) such that the disposition of relocating $\mathrm{UO}_{2}$ mass (sum of solid and liquid) from the core region into the lower plenum debris control volumes is stored for each system cycle. New routine BHFPST is called by BHHED2 to perform an equivalent redistribution of relocating core fission products. Fission product relocations are also represented within the debris bed as $\mathrm{UO}_{2}$ moves between control volumes. Routines BHDBME and BHMERG have been modified to perform these intrabed relocations. Finally, routines BHDBMX and BHHED2 have been modified to track $\mathrm{UO}_{2}$ 
relocations from the lower plenum to the drywell after bottom head failure. Once again, fission product relocations of the same relative magnitudes as $\mathrm{UO}_{2}$ relocations are calculated to leave the lower plenum and enter the drywell. The total fission product class inventories entering the drywell each timestep are stored in the BMSCAV array.

A new routine BHRUN2 has been implemented to update the RN package fission product inventory array XMSCOR to account for fission product relocations from the lower plenum to the drywell. Fission products extant in all COR package cells below the core plate are coalesced into the particulate debris component storage bin for the innermost radial ring in the lowermost axial segment, e.g., XMSCOR (NCMATA, IDP $=6, \mathrm{CELL}=1,1 \ldots$ NUMCLS). The inventories in this storage location are then decreased in BHRUN2 to account for relocations to the drywell so that the RN package mass accounting logic can accurately determine the location of all fission products. BHRUN2 also performs mass checks on each fission product class to ensure that the sum of the inventories stored in the XMSBHN array for all debris bed control volumes matches the inventories stored in both the debris bed global XMSCOR and BHFPM arrays.

The previously described updating of the fission product inventories is performed prior to the calculation of the CORSOR releases. The control volume class inventories stored in the XMSBHN array are updated based on the CORSOR releases and the resulting inventories are saved in the data base for consideration during the next timestep.

\subsection{Future BWR MELCOR Modifications}

The modifications discussed here will have a direct impact upon the timing and magnitude of MELCOR calculated quantities regarding BWR severe accident analysis. Although these modifications are not available in the 1.8.3 release of MELCOR, they either have been approved by the NRC for incorporation into MELCOR or will be recommended for future incorporation.

\subsubsection{Gross Core Plate Failure Due to Combined Thermal and Stress Loading}

As a result of the manual Automatic Depressurization System (ADS) actuation directed by the Emergency Procedure Guidelines (EPGs) for BWR accident sequences in which the core becomes partially uncovered with reactor vessel injection unavailable, the remainder of the core would rapidly be uncovered. Subsequently, structural deformation and downward relocation of molten control blade, channel box, candling clad, and fuel (in that order) would occur within a totally dry region above the core plate, and heat transfer from the relocated material would increase the temperature of the core plate structure. Each radial region of the core plate would probably fail due to the accumulated load and loss of strength. A proper representation of these phenomena is very important for the late-phase core melt progression behavior. 


\section{BH Package Reference Manual}

It is intended that these new MELCOR models will make use of the results of the exreactor experiments to be performed at Sandia National Laboratories as appropriate to improve the representation of core plate heat-up and failure. Provision will also be made for representation of the collapse of the core peripheral regions upon failure of the supporting control rod guide tube structure. These modifications are applicable to the SBWR as well as to the existing BWR facilities.

\subsubsection{Models for the $\mathrm{B}_{4} \mathrm{C}$-Steam Reaction}

Advanced $\mathrm{B}_{4} \mathrm{C}$-steam reaction models are currently being developed for implementation within MELCOR by Sandia National Laboratories (SNL). These models derive from those currently operational within the BWRSAR code developed at ORNL. The reaction of boron carbide with steam produces, among other gases, methane. Although the effectiveness of the BWR pressure suppression pool in retaining Csl is well known, the addition of methane from the $\mathrm{B}_{4} \mathrm{C}$-steam reaction would induce transformation of some of the iodine into the much more volatile methyl iodine form. Therefore, it is important that the reaction of $\mathrm{B}_{4} \mathrm{C}$ powder with steam be considered in any BWR severe accident thermal-hydraulic calculation that is to provide boundary conditions for fission product transport analysis.

\subsubsection{Improved Modeling of the BWR Core}

The following modifications affect the MELCOR modeling of the core region and are applicable to the SBWR as well as to existing BWR facilities. (The fuel design for the SBWR does not differ significantly from the conventional BWR fuel design.)

1. Models will be provided for the allocation of steam between the cladding and the inner channel box wall based upon the relative perimeters. This modeling improvement is particularly important for the steam-starved conditions that would occur in the BWR reactor core following ADS actuation.

2. Models will be provided for gamma heating of the structures within the interstitial region of the BWR core. In order to properly model the flashing of water in the interstitial region, the heat sources to that water must be properly represented. One of these heat sources is gamma heating of the embedded structures such as control blades, instrument tubes, and channel box walls. Modeling of this phenomenon is important to the calculation of oxidation of the control blade materials and of the channel box walls. 
BH Package Reference Manual

\section{APPLICATION TO THE SBWR}

The capabilities of the BH Package have recently (1992) been extended to include severe accident calculations based upon the Simplified Boiling Water Reactor (SBWR) design ${ }^{15}$. The basic arguments for formation of a quenched lower plenum debris bed under accident conditions are enhanced for the SBWR design. In comparison to a conventional BWR of similar reactor vessel size, the SBWR has the same mass of water in the lower plenum but a reduced core size and a reduced core power density.

Since calculations based upon the SBWR design necessarily involve the use of proprietary information, special subroutines have been prepared for use with the $\mathrm{BH}$ Package for this purpose. The role of these five special subroutines is identified in the following Table.

\section{Table 10.1 BH package subroutine equivalents for application to conventional BWRs and to the SBWR}

\begin{tabular}{|c|c|}
\hline $\begin{array}{c}\text { Conventional } \\
\text { BWR }\end{array}$ & SBWR \\
\hline BHDCHA & BHSBCl \\
BHHED2 & BHSBDI \\
BHHEDN & BHSBNI \\
BHVLPL & BHSBVV \\
BHVOLL & BHSBVP \\
\hline
\end{tabular}

Arrangements are made within Subroutines BHQSLU, BHFALS, and BHMERG to call either the conventional BWR or the SBWR subroutines listed in this Table depending upon the value of user-input parameter IRTYP.

The five special subroutines listed on the right side of Table 10.1 are withheld from the general release of the BH Package. In their place for the general release are dummy subroutines that simply provide a program STOP if called. Upon the application of a user that is authorized access to the SBWR proprietary information and with the approval of the NRC sponsors of the development of these special subroutines, the proprietary versions can be provided. 

BH Package Reference Manual

\section{MASS AND ENERGY BALANCES}

This Chapter describes the automatic mass and energy balances that have recently (1994) been installed for the BH Package. Information was previously provided in the tabulated package output (described in Section 6.5) as necessary to accommodate a hand-calculated energy balance whenever desired by the code user. Items provided for this purpose (both for the current timestep and cumulative for the calculation to date) include net heat transfer to the vessel heat sinks, net heat transfer to the vessel atmosphere, the decay heat release within the debris bed, and the metal/steam reaction energy release within the bed. The current masses within each control volume and the current control volume temperatures are also provided each timestep, as is information from which the mass ablated from the vessel wall can be determined. Finally, the current timestep and cumulative values of the debris masses released exvessel can also be employed in an overall hand-calculated mass and energy balance.

This provision of information to support hand-calculated mass and energy balances proved adequate for use at ORNL in support of code development activities. A crude energy balance calculation could be completed with about two hours' effort, whereas a careful balance involving individual consideration of all debris constituents required about one day. Peer reviewers, however, consistently cited the need for an automatic energy balance for the benefit and convenience of the code users.

There is an additional consideration concerning the need for a $\mathrm{BH}$ package energy balance in that currently the overall MELCOR Core (COR) package energy balance is disrupted whenever the BH Package is used. This occurs because material relocated from the core region into the lower plenum disappears from the COR package inventories, but is not properly accounted for in the energy transfers considered either by the COR package energy balance or by the global energy balance. The effects of energy transfers at the boundaries between the COR package domain (such as the core plate) and the BH package domain (debris bed) have not yet been factored into the COR package energy balance.

Authorization to establish an automatic energy balance for the BH Package with results available each timestep and to restore proper operation of the COR package energy balance when the BH Package is utilized was granted by the NRC in December 1993. Most of the first portion of this effort is complete as of the time (May 1994) of release of MELCOR 1.8.3, and the associated code logic is included with this release. As implemented, the automatic mass and energy accounting with respect to the $\mathrm{BH}$ Package is comprised of three parts: the debris mass balance, the bottom head wall energy balance, and the debris bed energy balance. Each of these is described in the following sections of this Chapter.

The second portion of the new effort, to restore proper operation of the COR package (and the global) energy balance has not been accomplished in time for the release of MELCOR 1.8.3, but rather will be included in the next follow-on release. In the 


\section{BH Package Reference Manual}

meantime, the user should be aware that use of the $\mathrm{BH}$ package option will render the automatic COR package energy balance inoperable, which will also affect the global energy balance. This should not, however, be construed as an indication that the results of the calculations are in error. Only the accounting algorithms of the automatic energy balance are affected by the missing logic.

\subsection{Debris Mass Balance}

The lower plenum debris bed mass balance within the BH Package is carried out separately for each of the elements of the material series listed in the second column of Table 2.1. The mass error is calculated for each species each timestep as

$$
\operatorname{WDIFF}(K)=\text { WLPNOW }(K)-[\text { WLPINT(K) }+ \text { WLPADD }(K)-\text { TAMLOS }(K)]
$$

where

$$
\begin{aligned}
& \text { WLPNOW }(\mathrm{K})=\text { Mass of element } \mathrm{K} \text { currently within the lower plenum, } \mathrm{kg} \\
& \mathrm{WLPINT}(\mathrm{K})=\text { Mass of element } \mathrm{K} \text { originally within the lower plenum, } \mathrm{kg} \\
& W L P A D D(K)=\text { Cumulative transfer of material } K \text { into the lower plenum from } \\
& \text { the core region, } \mathrm{kg} \\
& \operatorname{TAMLOS}(\mathrm{K})=\text { Cumulative release of material } \mathrm{K} \text { from the lower plenum to } \\
& \text { the drywell, } \mathrm{kg} \text {. }
\end{aligned}
$$

The array element WLPADD(2) also contains the mass of Fe (iron) added to the bed if melting of the inner surface of the carbon steel wall (treated as pure iron) occurs.

The effects of consumption of $\mathrm{Zr}$ metal and production of $\mathrm{ZrO}_{2}$ by the $\mathrm{Zr}$-steam reaction upon the masses of the individual species are addressed by the following logic:

$$
\begin{aligned}
& \operatorname{WDIFF}(1)=\operatorname{WDIFF}(1)+\operatorname{TZRREA} \\
& \operatorname{WDIFF}(11)=\operatorname{WDIFF}(11)-\text { TZRREA } \times \text { ZRRAT }
\end{aligned}
$$

where TZRREA is the total mass of zirconium reacted and ZRRAT is the ratio (123.219/91.22) of the molecular weights of $\mathrm{ZrO}_{2}$ and $\mathrm{Zr}$.

If ablation of the vessel bottom head wall is predicted to occur during the calculation (as described in Section 5.3.1), then the entry of the ablated iron into the pouring debris liquids is accounted for by the adjustment

$$
\operatorname{WDIFF}(2)=\operatorname{WDIFF}(2)-\text { WABLAT }
$$


BH Package Reference Manual

where WABLAT is the total ablated mass. This is necessary because the array

TAMLOS contains all of the material released from the vessel into the drywell, including any contribution by wall ablation. This adjustment compensates for the presence of the mass WABLAT within the element TAMLOS(2).

To evaluate the significance of the overall mass balance error, the terms

$$
\text { WDIFT }=\sum A B S[W D I F F(K)]
$$

and

$$
\text { TMASS }=\sum[\text { WLPINT }(K)+\text { WLPADD }(K)]
$$

are evaluated. The percent mass error is then

$$
\text { PMEER }=100 \times \frac{\text { WDIFT }}{\text { TMASS }} .
$$

The cumulative debris bed mass error WDIFT and its expression as a percentage of the total mass originally within or subsequently added to the lower plenum are then printed each timestep (after the first) for which a set of $\mathrm{BH}$ package output is specified (by user input). The printed message, which appears at the end of the second page of output (see Table 6.4), is

\section{Sum of individual mass errors = (WDIFT) $\mathrm{kg}$ or (PMEER) \% of total initial plus added lower plenum mass.}

The calculated difference WDIFT between the debris mass in the lower plenum at any time and the sum of the initial mass (at the beginning of the calculation) plus the added mass minus the removed mass remains less than $0.01 \%$ throughout a typical CBWR or SBWR calculation.

\subsection{Wall Energy Balance}

For energy balance purposes, the bottom head wall is treated as a separate entity. The terms treated in the bottom head wall energy balance are illustrated in Figure 11.1 and have the following definitions:

$$
\begin{aligned}
\text { EHDINT = } & \begin{array}{l}
\text { initial wall stored energy (based on the wall temperature as } \\
\text { predicted by MELCOR at the time of lower plenum dryout), } \mathrm{J}
\end{array} \\
\text { EWLOS = } & \begin{array}{l}
\text { energy associated with wall mass that has melted and run into the } \\
\text { debris bed, } \mathrm{J}
\end{array}
\end{aligned}
$$


BH Package Reference Manual

$$
\begin{aligned}
& \text { QCNWLT = energy conducted into the uppermost bottom head wall node } \\
& \text { NWALL (node } 18 \text { on Figure 1.10) from the upper vessel wall, } J \\
& \text { QDBTW = energy conducted from the debris bed into the adjacent wall, } \mathrm{J} \\
& \text { QDWNT = energy radiated from the bed surface to the exposed portion of } \\
& \text { the vessel wall, } \mathrm{J} \\
& \text { QGWT = energy transfer from lower plenum atmosphere (or water pool) to } \\
& \text { the exposed vessel wall, } \mathrm{J} \\
& \text { QJPWT = energy transfer from the fluid (gas or water) in the downcomer (jet } \\
& \text { pump) region to the uppermost bottom head wall node NWALL, } J \\
& \text { QMWALT = energy transfer from the debris liquid flow through failed } \\
& \text { penetrations to the vessel wall, } \mathrm{J} \\
& \text { QSTWT = radiation from the shroud to the inner surface of the vessel wall } \\
& \text { (after downcomer dryout), J } \\
& \text { TQRVDW = energy transfer from the outer surface of the bottom head wall to } \\
& \text { the drywell atmosphere, J. }
\end{aligned}
$$

The combination WABLAT $\times$ HLFE shown on Figure 11.1 represents the energy carried away by the ablation of wall material; HLFE is the enthalpy of liquid iron.

The current bottom head wall energy balance error is calculated as follows:

$$
\begin{aligned}
\text { EWDIFF }= & \text { EWNOW }- \text { EHDINT }-(\text { TENWIN }- \text { EWLOS }- \text { WABLAT } \times \text { HLFE - } \\
\text { TQRVDW }) & \text { HE }
\end{aligned}
$$

where

$$
\begin{aligned}
\text { EWNOW = } & \text { total energy }(J) \text { currently stored within the bottom head wall nodes } \\
\text { TENWIN = } & \text { QCNWLT + QDBTW + QDWNT + QGWT + QJPWT + QMWALT + } \\
& \text { QSTWT } \\
& \text { which is the total energy }(J) \text { transferred into the bottom head wall } \\
& \text { since the beginning of the calculation. }
\end{aligned}
$$

The energy addition terms that constitute TENWIN are as defined above.

A special feature of the bottom head wall calculation has required some special handling in the wall energy balance. As explained in Section 1.2, the portion of the bottom head wall above the debris bed surface is simply divided into three equal nodes during the period before debris bed layer three is formed. The final detailed calculation 
of the configuration of the upper wall is then performed just once, during the timestep in which the third debris layer is established. Accordingly, special logic has been provided to redefine the initial wall stored energy EHDINT during this timestep as necessary to address the energy differences associated with the configuration changes.

The percent wall energy error is

$$
\text { PWEERR }=100 \times \frac{\text { EWDIFF }}{\text { EHDINT }+ \text { TENWIN }}
$$

and the message

$$
\begin{gathered}
\text { Current bottom head energy error = (EWDIFF) J or (PWEERR) \% } \\
\text { of total initial plus added wall energy }
\end{gathered}
$$

is printed each timestep (after the first) for which a set of $\mathrm{BH}$ package output is specified.

The calculated energy difference (current - initial - added + removed) for the bottom head wall nodes remains less than $0.25 \%$ throughout a typical CBWR or SBWR calculation, including periods while the upper wall is melting or the lower wall is being extensively ablated. 


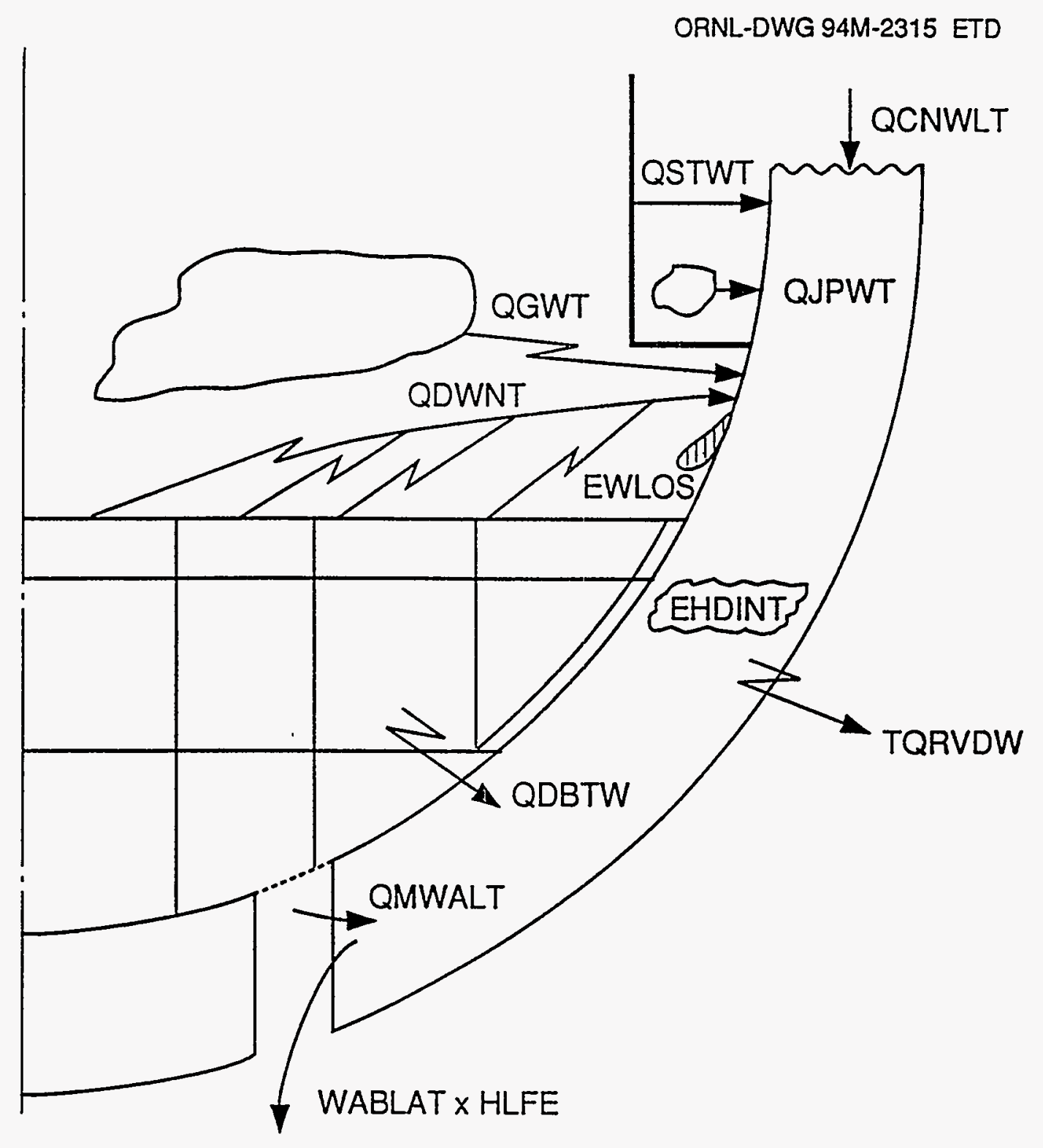

Figure 11.1 Energy transfers considered in the energy balance for the BWR vessel bottom head wall. 
BH Package Reference Manual

\subsection{Bed Energy Balance}

By far the most difficult and demanding of the overall mass and energy balances that evaluate the internal accounting of the BH Package is the debris bed energy balance. Similar to the case for the bed mass balance described in Section 11.1, the lower plenum debris bed energy balance within the BH Package is carried out separately for each of the elements of the material series listed in the second column of Table 2.1. The energy error is calculated within Subroutine BHHED2 for each species each timestep as

$$
\operatorname{EDIFF}(\mathrm{K})=\operatorname{ELPNOW}(\mathrm{K})-[\operatorname{ELPINT}(\mathrm{K})+\operatorname{ELPADD}(\mathrm{K})-\operatorname{EAMLOS}(\mathrm{K})]
$$

where

$$
\begin{array}{ll}
\text { ELPNOW }(\mathrm{K})= & \begin{array}{l}
\text { Energy associated with mass of material } \mathrm{K} \text { currently within } \\
\text { the lower plenum, } \mathrm{J}
\end{array} \\
\text { ELPINT(K) }= & \begin{array}{l}
\text { Energy associated with mass of material } \mathrm{K} \text { originally within } \\
\text { the lower plenum, } \mathrm{J}
\end{array} \\
\operatorname{ELPADD}(\mathrm{K})= & \begin{array}{l}
\text { Cumulative addition of energy associated with material } \mathrm{K} \text { into } \\
\text { the lower plenum from the core region, } \mathrm{J}
\end{array} \\
\mathrm{EAMLOS}(\mathrm{K})= & \begin{array}{l}
\text { Integrated energy removal associated with the release of } \\
\text { material } \mathrm{K} \text { from the lower plenum debris bed via penetration } \\
\text { failure pathways, } \mathrm{J} .
\end{array}
\end{array}
$$

The array element ELPADD(2) also includes the energy associated with any Fe (iron) added to the bed if melting of the inner surface of the carbon steel wall (treated as pure iron) is predicted to occur.

The elements of the EAMLOS array, which are loaded in Subroutine BHDBMX, primarily represent the energies associated with the debris liquids that enter the penetration failure pathways from the control volumes located within bed layers one or two. Here the released energy added to the EAMLOS (K) element is the released mass of material $\mathrm{K}$ times the enthalpy of the liquid at the control volume temperature. However, the EAMLOS array elements are also used to represent the energies associated with debris ablation within the layer one control volumes.

As explained in Section 5.3.2, liquids generated within layer two and flowing through layer one on their way out of the vessel can ablate the surrounding layer one debris. When this occurs, the energies of the ablated materials are added to the corresponding elements of the EAMLOS array as the energies of the respective liquids at the userinput debris ablation temperature TABLAT. The energy QLDTOT that is transferred from the flowing liquid into the surrounding layer one debris is considered in the energy balance as explained in the next paragraph. A portion of this energy causes the 


\section{BH Package Reference Manual}

material ablation; the remainder simply serves to increase the layer one temperature (see Section 5.3.2).

To evaluate the significance of the overall energy balance error, the terms

$$
\begin{aligned}
\text { EDIFT }=\sum \text { EDIFF }(K) & - \text { TDHDB }- \text { TMWDB }- \text { QLDTOT }- \text { TZRCE } \\
& + \text { QDBTW }+ \text { QDWNT + TQDBGS + QGWT } \\
& + \text { TQUP + QPFGST + TQGRID + TQWET } \\
& + \text { TQTLPW }
\end{aligned}
$$

and

$$
\text { TENRG }=\sum[\text { ELPINT(K) }+\operatorname{ELPADD}(\mathrm{K})]
$$

are evaluated. The terms used in the calculation of EDIFT that have not been defined in Section 11.2 are:

$$
\begin{aligned}
& \text { QLDTOT = Integrated energy transfer to layer one debris from liquids } \\
& \text { originating in layer two and passing through layer one via } \\
& \text { penetration failure pathways, } J \\
& \text { QPFGST = Integrated energy transfer from debris to gases traversing the bed } \\
& \text { after penetration failures, } \mathrm{J} \\
& \text { TDHDB = Integrated decay heat release within the bed, } \mathrm{J} \\
& \text { TMWDB = Integrated energy release by metal-steam reaction, } \mathrm{J} \\
& \text { TQDBGS = Portion of the energy transfer from the bed surfaces to the vessel } \\
& \text { atmosphere that is retained by the atmosphere (not transferred } \\
& \text { from the atmosphere to the wall), } \mathrm{J} \\
& \text { TQGRID = Integrated energy transfer from control rod guide tubes to vessel } \\
& \text { atmosphere and exposed wall surfaces before layer } 3 \text { is formed, } J \\
& \text { TQUP = Integrated energy transfer from bed surfaces upward to the lower } \\
& \text { shroud and to the core plate, } \mathrm{J}
\end{aligned}
$$

The sum of the terms TQDBGS + QGWT is the total energy transfer from the debris bed surfaces to the vessel atmosphere. 
BH Package Reference Manual

The percent error associated with the current debris bed energy is then

$$
\text { PEERR }=100 \times \frac{\text { EDIFT }}{\text { TENRG }+ \text { TDHDB }+ \text { TMWDB }} \cdot
$$

The cumulative debris bed energy error EDIFT and its expression as a percentage of the total energy originally within or subsequently added to the lower plenum are then printed each timestep (after the first) for which a set of $\mathrm{BH}$ package output is specified (by user input). The printed message appears immediately following the end of the second page of output, an example of which is shown as Table 6.4. The message is:

\section{Sum of energy error values = (EDIFT) J or (PEERR) \% of total initial plus added bed energies.}

The calculated difference EDIFT between the total debris energy in the lower plenum at any time and the sum of the initial total energy (at the beginning of the calculation) plus the added energy minus the removed energy does not exceed about one-half of one percent during a typical CBWR or SBWR calculation employing five-second timesteps.

This bed energy error, which is very small at the beginning of a calculation but increases steadily as the calculation proceeds is typical of explicit solution schemes, when applied to cases characterized by increasing control volume temperature for which temperature-dependent specific heats are employed. Briefly, the control volume temperature increases during each timestep so that the representative specific heat at the end of the timestep is higher than that at the beginning of the timestep. However, the begin-timestep specific heat is used throughout the timestep. The consequence is very small for any single timestep, but over hundreds of timesteps the effect becomes noticeable in the form of a non-physical apparent creation of energy. Use of smaller timesteps will alleviate the effect. ${ }^{*}$

There are many other consequences of the use of timestep-constant specific heats than illustrated by this simple example. In the lower plenum debris bed calculation we have solids melting, liquids freezing, interchange of liquids among bed control volumes, and control volume merging as significant energy exchange events. For each of these, use of the begin-timestep specific heat instead of a timestep-average value plays a role in establishing the current magnitude of the overall energy balance error. Whenever one of these events causes a control volume temperature to decrease during a timestep, the cumulative error is reduced. (For a calculation in which the control volume temperature increases were exactly offset by subsequent temperature decreases, the timestep-constant specific heat error would be eliminated; however,

\footnotetext{
- On the other hand, use of smaller timesteps will increase the total number of calculations and hence will increase the roundoff error. The net effect upon the overall energy balance error must be determined by trial.
}

BH-RM-213 


\section{BH Package Reference Manual}

BWR lower plenum debris bed calculations generally involve steadily increasing control volume temperatures.)

The current end-of-calculation overall bed energy excess of no more than one-half of one percent is considered acceptable and practical. Stated another way, the effort that would be required for implementation of an implicit solution scheme or a predictorcorrector process and the additional CPU time that would be required for each calculation are considered to be neither justified nor practical in view of the numerous uncertainties involved in these severe accident calculations. 
BH Package Reference Manual

\section{REFERENCES}

1. L. J. Ott, "Advanced Severe Accident Response Models for BWR Application," Nuclear Engineering and Design, 115, 289-303 (1989).

2. L. J. Ott, "Advanced Severe Accident Response Models for BWR Application," presented at the Fifteenth Water Reactor Safety Information Meeting, National Bureau of Standards, Gaithersburg, Maryland, October 29, 1987.

3. S. A. Hodge and L. J. Ott, Boiling Water Reactor Severe Accident Response (BWRSAR) Code Description and Assessment, Letter Report to Dr. Thomas J. Walker, Division of Systems Research, RES, USNRC, February 1, 1989.

4. G. E. Mueller and A. Sozer, Oak Ridge National Laboratory, Thermal-Hydraulic and Characteristic Models for Packed Debris Beds, NUREG/CR-4689 (ORNL/TM10117), December 1986.

5. The BWR Owners' Group Emergency Procedure Guidelines, Revision 4, March 1987.

6. D. L. Hagrman, Idaho National Engineering Laboratory, Materials Properties Models for Severe Core Damage Analysis, informal report (EGG-CDD-5801), May 1982.

7. S. S. Dosanjh, Sandia National Laboratories, Melt Progression, Oxidation, and Natural Convection in a Severely Damaged Reactor Core, NUREG/CR-5316, SAND88-3476, February 1990.

8. J. V. Cathcart, Oak Ridge National Laboratory, Quarterly Progress Report on the Zirconium Metal-Water Oxidation Kinetics Program Sponsored by the NRC Division of Reactor Safety Research for October-December 1976, ORNL/NUREG/TM-87.

9. L. Baker and C. Just, Argonne National Laboratory, "Studies of Metal-Water Reactions at High Temperatures III. Experimental and Theoretical Studies of the Zirconium-Water Reaction," ANL-6548 (May 1962).

10. G. W. Parker, L. J. Ott, and S. A. Hodge, "Small-Scale BWR Core Debris Eutectics Formation and Melting Experiment," Nuclear Engineering and Design, 121, 341347 (1990).

11. J. L. Rempe et al., Idaho National Engineering Laboratory, Light Water Reactor Lower Head Failure Analysis, NUREG/CR-5642, EGG-2618, October 1993. 
BH Package Reference Manual

12. S. A. Hodge, C. R. Hyman, and L. J. Ott, "BWR Lower Plenum Debris Bed Models for MELCOR," presented at the Nineteenth Water Reactor Safety Information Meeting, Bethesda, Maryland, October 28, 1991.

13. S. A. Hodge et al., Martin Marietta Energy Systems, Inc., Oak Ridge National Laboratory, Identification and Assessment of BWR In-Vessel Severe Accident Mitigation Strategies, USNRC Report, NUREG/CR-5869 (ORNL/TM-12080), October 1992.

14. S. A. Hodge and W. J. McAfee, Thermal Shock Considerations for External Flooding of a BWR Reactor Vessel, letter report (ORNL/NRC/LTR-92/23) to Dr. James T. Han, Reactor and Plant Systems Branch, Division of Systems Research, RES, USNRC, September 30, 1992.

15. C. R. Hyman et al., "MELCOR Modifications for SBWR Applications," presented at the Twentieth Water Reactor Safety Information Meeting, Bethesda, Maryland, October 23, 1992.

16. "FRS Surface Emissivity," (Equation 8.6), pp. 72-79 in Thermal-Hydraulic Test Facility Bundle 3 In-Core Instrumentation and Operating History, [NUREG/CR2609 (ORNL/NUREG-75)], by L. J. Ott, 1982.

17. C. B. Ludwig and C. C. Ferris, "Prediction of Total Emissivity of NitrogenBroadened and Self-Broadened Hot Water Vapor," Journal of Quantitative Spectroscopy and Radiative Transfer, 7, 7-26 (1982).

18. J. K. Lovin et al., User's Manual for RAVFAC a Radiation View Factor Digital Computer Program, Lockheed Missiles and Space Co., Inc., Huntsville Research and Engineering Center, LMSC/HREC D148620-A (August 1973).

19. E. F. Puccinelli, "View Factor Computer Program (Program VIEW) User's Manual," Goddard Space Flight Center, X-324-73-272 (July 1973).

20. D. A. Powers, "Erosion of Steel Structures by High-Temperature Melts," Nuclear Science and Engineering, 88, 357-366, June 1984.

21. M. Pilch and W. W. Tarbell, High Pressure Ejection of Melt From a Reactor Pressure Vessel-The Discharge Phase, NUREG/CR-4383, SAND85-0012, September 1985.

22. W. H. Giedt, Principles of Engineering Heat Transfer, p. 217, D. van Nostrand Company, Inc., Princeton, New Jersey, 1964.

23. S. A. Hodge, C. R. Hyman, and R. L. Sanders, "BWR-Specific Models for MELCOR," presented at the 1993 Cooperative Severe Accident Research Program (CSARP) Review Meeting, Bethesda, Maryland, May 6, 1993. 
BH Package Reference Manual

24. G. E. Mueller, et al., Thermal-Hydraulic and Characteristic Models for Packed Debris Beds, NUREG/CR-4689, ORNL/TM-10117, December 1986.

25. V. E. Schrock, et al., Steam-Water Flooding in Debris Beds and Its Role in Dryout, EPRI NP-3858, University of California at Berkeley, March 1985.

26. D. H. Cho et al., "On the Pattern of Water Penetration into a Hot Particle Bed," Nuclear Technology, 65, 23, April 1984.

27. T. Ginsberg, et al., An Experimental and Analytical Investigation of Quenching of Superheated Debris Beds Under Top-Reflood Conditions, NUREG/CR-4493, BNLNUREG-51951, January 1986.

28. R. J. Lipinski, "A Coolability Model for Post Accident Nuclear Reactor Debris," Nuclear Technology, Vol. 65, April 1984.

29. A. W. Reed et al., DCC-1/DCC-2 Degraded Core Coolability Analysis, NUREG/CR-4390, SAND85-1967R3, October 1985.

30. K. R. Boldt et al., DCC Degraded Core Coolability: Experiment and Analysis, NUREG/CR-4606, SAND86-1033, September 1986.

31. L. S. Tong, Boiling Heat Transfer and Two-Phase Flow, John Wiley and Sons, Inc., New York, 1965.

32. R. O. Wooten et al., March 2 (Meltdown Accident Response Characteristics) Code Description and Users' Manual, NUREG/CR-3988, August 1984.

33. G. B. Wallis, One Dimensional Two-Phase Flow, McGraw-Hill Book Company, New York (1969).

34. R. Siegel and J. R. Howell, Thermal Radiation Heat Transfer, Appendix C, formula 28, p. 828, 2d ed., McGraw-Hill Book Company, New York (1981).

35. B. W. Spencer et al., Fragmentation and Quench Behavior of Corium Melt Streams in Water, NUREG/CR-6133, ANL-93/32, February 1994.

36. D. W. Akers et al., Examination of Relocated Fuel Debris Adjacent to the Lower Head of the TMI-2 Reactor Vessel, NUREG/CR-6195, EGG-2732, March 1994. 
BH Package Reference Manual

\section{APPENDIX A: THE PCCS AND ICS MODELS}

This Appendix describes the Passive Containment Cooling System (PCCS) and Isolation Condenser System (ICS) models developed at Oak Ridge National Laboratory (ORNL) for use with MELCOR whenever severe accident calculations are to be performed for the Simplified Boiling Water Reactor (SBWR) design. Other special BH package models for use in SBWR calculations are described in Chapter 10. This Appendix is divided into three sections. Section A.1 describes the PCCS model, while Section A.2 describes the extension of the basic PCCS model to provide calculational capability for the ICS. Finally, the interface with MELCOR for both the PCCS and ICS models is described in Section A.3.

\section{A.1 PCCS Model}

\section{A.1.1 Introduction and Concept}

The PCCS is a safety-related passive system designed to remove the core decay heat that would be introduced into the SBWR containment during a design basis accident (LOCA). It is described in Section 6.2.2 of the SBWR Standard Safety Analysis Report (SSAR).

The basic operation of the PCCS derives from the natural circulation of some of the drywell atmosphere to the wetwell airspace via the PCCS whenever the drywell-towetwell pressure differential is sufficient to clear the water from the vent line terminus within the pressure suppression pool. The venting pathway through the PCCS includes a heat exchanger in which the gases are cooled and some (or all) of the steam vapor is condensed; the condensate is drained to the Gravity-Driven Cooling System (GDCS) pool within the drywell. The noncondensable gases and any steam carryover through the vent line are released into the pressure suppression pool, where the gases bubble to the pool surface. The intermittent nature of the venting process causes the thermalhydraulic behavior of the PCCS to be much more complex than the normallyencountered heat exchanger-condenser applications for which the flow is continuous.

The PCCS model described here is based upon the concept that the MELCOR code should adequately represent the effects of the PCCS under the boundary conditions that would be imposed by severe accidents. It is not intended that the MELCOR calculation should attempt to predict the performance of these heat exchangercondenser systems based upon basic physical.considerations; this is done by more sophisticated thermal hydraulic codes and is a task not compatible with the role that a fast-running PRA analytical tool should play. Furthermore, test calculations performed with MELCOR demonstrate that attempts to us'e the basic code "building block" approach to connect control volumes, flow paths, and heat sink structures as necessary to directly simulate the PCCS heat exchanger-condensers will result in severe code 


\section{BH Package Reference Manual}

difficulties; these include oscillations in the predicted flows and energy exchanges, a demand for extremely small time steps, and impractically large CPU and wall clock time consumption.

\section{A.1.2 General PCCS Performance}

Based upon the available information in the literature concerning the PCCS design and the results of equipment tests reported by the development consortium to date, it is clear that any PCCS component model must have the following basic attributes:

(a) Capacity limited to gravity drainage of steam condensing in the tubes until drywell pressure exceeds suppression chamber pressure by a margin [about $7.25 \mathrm{kPa}$ (1.05 psid)] sufficient to overcome PCCS vent line submergence. With normal pressure suppression pool water level, the uppermost vent line exit hole lies at the depth of $0.75 \mathrm{~m}$. $(2.5 \mathrm{ft})$. The pool water level may vary during the course of an accident and'this must be considered in the model.

(b) For long-term cooling situations of practical interest for severe accident calculations, the drywell-to-suppression chamber pressure differential is limited to about $15.9 \mathrm{kPa}$ ( $2.3 \mathrm{psid}$ ) by the submergence of the upper drywellto-pressure suppression pool horizontal vents.

(c) Capacity increases as the drywell-to-suppression pool pressure differential (vent line flow) increases over the small range between PCCS vent line clearance and clearance of the main horizontal vents.

(d) Capacity decreases with increasing partial pressure of noncondensable gases in the upper drywell because of the interference of the gas boundary layer within the PCCS tubes with the steam-to-wall heat transfer.

(e) Whenever the wetwell pressure approaches (or exceeds) the drywell pressure so that vent line flow is zero, the PCCS heat exchanger-condenser is subject to filling with noncondensable gases as the condensing steam is continuously replaced with a mixture of steam and noncondensable gas from the drywell. The PCCS is said to be "bound" when it contains only cool noncondensable gas so that all heat exchange and condensing operation is terminated.

(f) The average PCCS capacity over the long term is determined by the heat transfer from the outer surface of the PCCS heat exchanger tubes to the surrounding ICS/PCC pool. For the LOCA analysis presented in Section 6.2 of the SSAR, the General Electric Company has employed a constant heat transfer coefficient of $4500 \mathrm{~W} /\left(\mathrm{m}^{2}-\mathrm{K}\right)\left[792.5 \mathrm{Btu} /\left(\mathrm{h}-\mathrm{ft}^{2}-\mathrm{F}\right)\right]$ for the tube outer surface area. 
BH Package Reference Manual

A general model interacting with MELCOR has'been constructed from the available information and tested satisfactorily. Nevertheless, the most recent detailed information concerning experimental measurements or the results of sophisticated calculations of PCCS performance as a function of the ICS/PCC pool temperature, the drywell-to-wetwell pressure differential, and the noncondensable gas fraction in the drywell atmosphere should be used to refine the input for this model whenever production calculations are performed.

\section{A.1.3 Operation of the PCCS Model}

The PCCS model is contained within the new MELCOR Subroutine BHCOND. In this Section, the operation of the model is described as a 28-step process. Not all steps are executed each calculational timestep. One of the steps involves an iterative procedure, which is described in detail in Section A.1.4. Those readers not interested in pursuing the level of understanding offered by a detailed discussion of model operation are encouraged to skip to Section A.1.5, which provides an overview in the form of an example of calculated results.

It is important to recognize that the PCCS model operates on the assumption that the pressure within the PCCS remains equal to the drywell pressure and constant during a calculational timestep. Whenever material is removed as, for example, when steam condenses and the condensate is transferred to the GDCS, a void is considered to be created within the PCCS. An uptake of mixture from the drywell atmosphere is required to fill this void at drywell pressure and the subsequent equilibrium conditions within the PCCS are calculated. This approach is taken to avoid the penalties (described in Section A.1.1) of a constant volume model for which mass transfers between the drywell and the relatively small PCCS would be based upon calculated pressure differentials.

The variable names mentioned in the following discussions and in Section A.1.4 are the same as those used within Subroutine BHCOND. The interested reader is encouraged to compare the stepwise operations described here with the actual FORTRAN in a listing of Subroutine BHCOND; the COMMENT statements that will be obtained with the program listing will provide additional detailed information.

Before beginning the step-by-step discussion of model operation, it is necessary to define a few of the variable names that will be encountered (the meaning of the others will be obvious from the text.) 


\section{BH Package Reference Manual}

NUMMAT is the total number of materials considered present (or potentially present) within a control volume. These include the water pool, fog droplets, steam, and the noncondensable gases.

$\mathrm{I}$ is the index of a particular material within a control volume.

\begin{tabular}{cc} 
Index & Material \\
\cline { 2 - 2 } 2 & water pool \\
2 & fog \\
3 & vapor \\
4 through NUMMAT & noncondensable gas
\end{tabular}

The control volume atmosphere is comprised of materials 2 through NUMMAT. The control volume total pressure is the sum of the partial pressures of materials 3 through NUMMAT.

CEFIC represents the running total kept within the model of the remaining PCCS heat exchanger capacity in Joules. The available capacity is established at the beginning of each timestep from tabular input supplied by the MELCOR user. This initial value depends upon the current ICS/PCC pool temperature, the current drywell-to-wetwell pressure differential, and the current mole fraction of noncondensable gas in the drywell atmosphere. It should be noted that the reduction in PCCS performance due to a buildup of noncondensable gas within the heat exchanger is not established from the tabular input, but rather is calculated by the PCCS model.

ENGIC(I) is the array containing the internal energies of the material within the PCCS at the beginning of the timestep. During the timestep, the - running values of these internal energies are contained in the array ETOTIC(I), which is copied to the ENGIC(I) array at the end of each timestep.

VLICMT is the volume of the materials (steam, fog, noncondensable gases) that constitute the atmosphere within the PCCS. Since the PCCS atmosphere is constrained to remain at a pressure equal to drywell pressure, this volume can be less than the actual PCCS structural volume if material is removed from the PCCS atmosphere during the calculation. 


\section{PCCS MODEL STEPS}

\section{Steps 1-4: Establish Initial Conditions}

These initial steps establish the equilibrium conditions within the PCCS with the volume filled at drywell pressure. Some of the available capacity is utilized to cool any noncondensable gas carried over from the previous timestep. Mixture is taken up from the drywell as required to maintain the PCCS at drywell pressure.

1. Set the currently available heat removal capacity CEFIC based upon the drywell-to-wetwell pressure differential and the noncondensable gas fraction in the drywell atmosphere. The dependence upon the pressure differential is obtained from user-input tabular function IPCDPR. The dependence upon the noncondensable gas mole fraction is obtained by interpolation between the user-input tabular functions IPLTMP (for $323.16 \mathrm{~K}$ ) and IPCNCN (for $373.16 \mathrm{~K}$ ) for ICS/PCC pool temperatures of $50^{\circ} \mathrm{C}$ and $100^{\circ} \mathrm{C}$. [See Users' Guide for input record BHSBWR0200.]

2. Cool any noncondensable gases remaining within the PCCS at the end of the previous timestep. The gas temperature is reduced (at constant pressure) to the ICS/PCC pool temperature TICPL.

- Reduce the internal energies ENGIC(I) accordingly

- Reduce the available capacity CEFIC.

3. Take up enough mixture from the drywell atmosphere to make the calculated PCCS equilibrium pressure equal to the drywell pressure. (Section A.1.4 provides a discussion of the iterative procedure used.)

- Reduce the drywell gas, vapor, and fog masses and energies accordingly.

- Output of the equilibration routine includes

ETOTIC(I) total internal energies and

XMSICN(l) masses

of the fog, vapor, and noncondensable gases.

- Set the PCCS material volume VLICMT equal to the internal volume of the PCCS structure.

4. Determine if there will be vent line flow this timestep

- If No, continue with steps 5-9.

- If Yes, continue with steps 10-27. 


\section{Steps 5-9: No Vent Line Flow}

The PCCS is now full at drywell pressure and with its contents at an equilibrium temperature. If there was a void remaining at the end of the previous timestep, or if some cooling of the noncondensable gases occurred, then some steam (and fog) taken up with the mixture from the drywell atmosphere will be included. CEFIC has already been reduced (step 2) as necessary to account for the cooling of noncondensable gas.

5. If no steam exists within the PCCS (No void at the end of the previous timestep and no noncondensable gas cooling or no steam in drywell atmosphere.)

- Energy to ICS/PCC pool limited to that used to cool the noncondensable gases.

Go TO STEP 28

6. Condense the steam (and cool the fog) within the PCCS.

- May be limited because of insufficient energy CEFIC remaining after the cooling of the noncondensable gas (step 2).

- Add the masses and energies to the GDCS Pool.

- Reduce ETOTIC(I) and XMSICN(I) for steam and fog accordingly.

- Set RMVLIC equal to the accumulated void within the PCCS.

- Reduce the available capacity CEFIC accordingly. 
7. If CEFIC $>0.0$ and RMVLIC $>0.0$ Take up enough mixture from the drywell atmosphere to use the available capacity and to partially fill the void (with noncondensable gas). On the other hand, it is possible that the noncondensable gas takeup will completely fill the void without using all of the available capacity.

- The steam and fog taken up are never actually added to the PCCS volume within the model but rather are removed from the drywell atmosphere and added directly to the GDCS pool as saturated liquid.

- Reduce the available capacity CEFIC by the amount of energy used in condensing the steam and cooling the fog.

- For the noncondensable gas takeup: Increase XMSICN(I) and ETOTIC(I) for these gases and remove the associated masses and energies from the drywell.

- Reduce the void RMVLIC according to the takeup of noncondensable gas (only) — note that RMVLIC will remain greater than zero only if the takeup from the drywell atmosphere was limited by the available heat exchange and condensing capacity.

8. Set VLICMT = VLICMT - RMVLIC. There will be a void within the PCCS at the beginning of the next timestep if RMVLIC $>0.0$ here.

9. $\quad$ Add the energy used in cooling the noncondensable gases (step 2) and in condensing the steam/cooling the fog (steps 6 and 7) to the ICS/PCC pools.

GO TO STEP 28

\section{Steps 10-27: With Vent Line Flow}

At this point, the PCCS is full at drywell pressure and with its contents at an equilibrium temperature. If a void remained at the end of the previous timestep or if some cooling of the noncondensable gases occurred, then some steam (and fog) taken up with the mixture from the drywell atmosphere will be included. CEFIC has already been reduced (step 2) to account for any cooling of the noncondensable gas. 
BH Package Reference Manual

10. Calculate the PCCS vent line mass transfer XMS2FL. The transfer is based upon the pressure differential between the drywell and the vent line terminus, which is submerged in the pressure suppression pool.

11. Move noncondensable gases from PCCS to wetwell and reduce the running total for XMS2FL accordingly.

- RMVLIC is the associated PCCS void.

- Reduce the values of XMSICN(I) masses and for the noncondensable gases.

ETOTIC(I) internal energies

- At this point, either:

$\mathrm{XMS2FL}=0.0$; some noncondensable gas remains in PCCS

or

XMS2FL $>0.0$; all noncondensable gas has been removed . so that only steam and fog remain within the PCCS.

12. Condense the steam within the PCCS up to the limits of the available capacity CEFIC. Place the liquids in the GDCS pool.

- XMSREM is the mass of steam condensed

- Reduce CEFIC accordingly

- Reduce XMSICN(I) and ETOTIC(I) for the steam.

13. If some steam remains in the PCCS and if some vent line mass transfer remains (XMS2FL $>0.0)$ then

- Move the steam (uncondensed) through the vent line to the pressure suppression pool.

- Reduce XMS2FL accordingly.

- Increase XMSREM so it now represents both the condensed steam drained to the GDCS and the uncondensed steam moved to the pressure suppression pool.

- Reduce XMSICN(I) and ETOTIC(I) for the steam. 
14. Increase RMVLIC to account for the void created by both the steam condensed and drained to the GDCS pool and the steam moved to the pressure suppression pool via the PCCS vent line.

Note: Steps 12-14 are actually performed (in sequence) for fog, steam, and any water pool that has formed within the PCCS volume. The handling of steam is demonstrated in this discussion; the fog and water pool (if it exists) are treated in a similar manner.

15. Reduce the PCCS material volume VLICMT by subtracting the void RMVLIC.

$$
\begin{array}{ll}
\text { Set } & \text { VOLINT }=0.0 \\
& \text { VINTNC }=0.0 \\
\text { XMNNST }=0.0
\end{array}
$$

16. If both the remaining heat exchanger capacity CEFIC and the remaining vent line mass transfer XMS2FL have been reduced to zero

$$
\text { GO TO STEP } 28 .
$$

\section{Steps 17-18: Heat Removal Capacity/Vent Line Mass Transfer Imbalance}

It is unlikely that the amount of mixture that must be taken up from the drywell in order to utilize the remaining heat removal capacity will provide exactly the amount of noncondensable gas required to satisfy the remaining mass transfer requirement. These two steps determine the remaining model logic to be employed, based upon the sign of the imbalance.

$$
\begin{aligned}
\text { Set VOLINT }= & \begin{array}{l}
\text { Mixture volume required from drywell to use all } \\
\text { remaining capacity CEFIC in condensing the associated } \\
\text { steam and cooling the associated fog. }
\end{array} \\
\text { XMNNST }= & \text { Mass of noncondensable gas associated with VOLINT. } \\
\text { VL2FL }= & 0.0
\end{aligned}
$$


BH Package Reference Manual

18. Will XMNNST satisfy the remaining mass transfer requirement XMS2FL?

If No:

STEPS 19-21

If Yes:

STEPS 22-25

\section{Steps 19-21: Mass Transfer Dominates}

XMNNST (based upon use of all of the available heat exchanger-condenser capacity) is insufficient to satisfy the remaining mass transfer requirement XMS2FL.

19. Set ADDRVL = mixed volume to be taken up from drywell solely to satisfy the mass transfer requirement.

20. Add the steam (uncondensed) and fog associated with ADDRVL directly to the pressure suppression pool and remove them from the drywell atmosphere.

Transfer the noncondensable gases from the drywell to the wetwell atmosphere, while representing the heat transfer to the water that would occur during their bubbly passage through the pressure suppression pool. 
BH Package Reference Manual

21. Set VLICMT $=0.0$

All material originally within the PCCS and all new material taken up from the drywell has been passed through the vent line. Also, all available heat exchanger capacity has been utilized.

GO TO STEP 26

Note that VINTNC is 0.0 here while VOLINT is the mixture volume taken up from the drywell to satisfy the heat exchanger capacity.

\section{Steps 22-25: Heat Removal Capacity Dominates}

XMNNST (based upon satisfying the heat exchanger capacity requirement) exceeds the remaining mass transfer requirement XMS2FL. VOLINT (set in step 17) is the mixture volume associated with XMNNST.

22. Set VINTNC $=$ noncondensable gas volume associated with VOLINT.

23. Set $\mathrm{VL2FL}=$ noncondensable gas volume associated with $\mathrm{XMS} 2 \mathrm{FL}$. This is the volume that will flow through the PCCS vent line this timestep based upon XMS2FL. 
BH Package Reference Manual

24. If VINTNC > (RMVLIC + VL2FL $)$

$\left\|\begin{array}{l}\text { Cannot take up all of the } \\ \text { mass XMNNST (associated } \\ \text { with volume VINTNC) }\end{array}\right\|$

- Reduce the mixed volume to be taken up from the drywell.

$$
\text { VOLINT }=\text { VOLINT } \times\left(\frac{\text { RMVLIC }+ \text { VL2FL }}{\text { VINTNC }}\right)
$$

- Reduce the available heat capacity by the amount used

$$
\text { CEFIC }=\text { CEFIC }- \text { CEFIC } \times\left(\frac{\text { RMVLIC }+ \text { VL2FL }}{\text { VINTNC }}\right)
$$

- Reduce VINTNC to a value sufficient to fill the available PCCS void plus provide the remaining vent line mass transfer.

$$
\text { VINTNC }=\text { RMVLIC + VL2FL }
$$

Else

$$
\mathrm{CEFIC}=0.0
$$

25. Adjust the material volume within the PCCS VLICMT $=$ VLICMT+VINTNC-VL2FL
All available energy is utilized if VINTNC is less than (RMVLIC+VL2FL)

Here VINTNC is the noncondensable gas volume to be taken up from the drywell and added to the PCCS volume. 


\section{Steps 26 and 27: Transfer of Steam, Fog, and Gas from the Drywell Atmosphere}

26. Remove the noncondensable gases associated with VOLINT from the drywell atmosphere and add them to the PCCS volume and the wetwell airspace.

If VINTNC is greater than zero here, then some of the noncondensable gases taken up from the drywell to satisfy the available heat removal capacity are not passed through to the pressure suppression pool, but rather remain within the PCCS.

Increase XMSICN $(I)$ and ETOTIC $(I)$ for the noncondensable gases accordingly.

For the portion of the noncondensable gases (maybe all) that are passed to the pressure suppression pool, add the masses to the wetwell atmosphere and represent the heat transfer from the bubbles to the pool, adding the residual energies to the wetwell atmosphere.

27. Remove the steam and fog associated with VOLINT from the drywell atmosphere and add the condensate to the GDCS pool.

\section{Step 28: Set PCCS Internal Energies for the Next Timestep}

28. Set ENGIC $(I)=E T O T I C(I)$ for the steam, fog, and noncondensable gases within the PCCS.

This is the last step in each calculation of PCCS operation. Any material remaining within the PCCS is considered to remain at drywell pressure and may or may not fill the PCCS volume. 
BH Package Reference Manual

\section{A.1.4 The Iterative Procedure}

\section{A.1.4.1 Purpose}

The iterative procedure serves to fill the PCCS volume with the mixture of gases, fog, and vapor from the drywell atmosphere that will make the PCCS pressure equal to the drywell pressure. The iteration constitutes step 3 of the PCCS operation as described in Section A.1.3 and is performed at the beginning of each timestep, depending upon the initial conditions within the PCCS volume.

\section{A.1.4.2 Initial Conditions}

The initial conditions within the PCCS are those established at the end of the previous timestep, and fall into three categories.

a) The PCCS may be bound with noncondensable gases at the temperature of the ICS/PCC pool and the pressure of the drywell atmosphere.

b) The PCCS may be completely voided, or contain only steam and fog; in either event, there are no noncondensable gases within the PCCS.

c) The PCCS may contain a mixture of noncondensable gas and steam. If the temperature of this mixture exceeds the temperature of the ICS/PCC pool, then the noncondensable gases are cooled to the pool temperature (as explained in Section A.1.3) before the iteration begins.

Initial filling of the PCCS volume from the drywell atmosphere is necessary only for cases b) and c), and is accomplished by means of the steps described below.

\section{A.1.4.3 Iterative Steps}

1. Call the MELCOR equilibrium routine CVTWGE with input

$$
\begin{array}{ll}
\text { CVMS }(I) & \text { initial masses, } \\
\text { CVEM(I) } & \text { internal energies, and } \\
\text { XNMCLS } \times \text { VOLIC } & \text { the total PCCS volume. }
\end{array}
$$

The calculated output includes the equilibrium

$\begin{array}{ll}\text { XMSICN }(I) & \text { masses, } \\ \text { ETOTIC }(I) & \text { internal energies, } \\ \text { PRIC } & \text { pressure, and }\end{array}$


TEMPIC temperature.

For the equilibration calculation, the index $\mid$ represents fog $(l=2)$, steam $(l=3)$, and noncondensable gases ( $l=4$, NUMMAT).

This first step is skipped in the first iteration if the PCCS is initially totally voided; in this case, the pressure PRIC is simply set to zero.

2. Check to see if the pressure in the PCCS exceeds the pressure in the drywell after the initial equilibration calculation, which would indicate a current drywell pressure less than the pressure at the end of the previous timestep.

If the condition is met, then determine the expanded volume of the noncondensable gases at the new drywell pressure. If the expanded volume is greater than the volume of the condensers plus the source line volume, allow material to flow back from the PCCS to the drywell. The fraction of PCCS noncondensable gases to be removed from the condensers and transferred back to the drywell is:

$$
\text { F2FLBK }=1-\frac{\text { PCCS VOLUME }}{\text { VICDRY - PCCS VOLUME - PCCS SOURCE LINE VOLUME }}
$$

where VICDRY is the expanded volume of the noncondensable gases at the new drywell pressure:

$$
\text { VICDRY }=\frac{\text { PCCS PRESSURE X PCCS VOLUME }}{\text { DRYWELL PRESSURE }}
$$

FLMULT is then set to zero and the execution sequence is continued with step 6.

3. The mass transfer multiplier FLMULT is set depending upon the relative values of the PCCS pressure PRIC and the upper and lower boundaries of a pressure range centered upon the drywell pressure PRES(IVPCSO):

PRES(IVPCSO) +100

\section{PRES(IVPCSO)}

$$
\text { PRES(IVPCSO) }-100 .
$$

As indicated, the total width of the acceptable pressure range is $200 \mathrm{~Pa}$ (about 0.03 psi). 


\section{BH Package Reference Manual}

If PRIC is less than the lower boundary limit, then FLMULT is set to a positive value. Conversely, if PRIC is greater than the upper boundary limit, then FLMULT is set to a negative value. In either case, the absolute value of FLMULT is reduced by a factor of two each trip through the iterative loop.

When PRIC finally lies within the acceptable boundaries, FLMULT is simply set to zero.

4. The volume to be transferred from the drywell to the PCCS this iterative step is established as

$$
\text { VOL2FL }=[P C C S \text { VOLUME }- \text { VLICMT }] \times \text { FLMULT }
$$

where VLICMT is the material volume at the end of the previous timestep, reduced by 10 percent. The value of VLICMT set in the initial iterative pass is used without change during all subsequent passages through the loop.

Returning to a consideration of the possible initial conditions, it should be recognized that VLICMT will be zero at the end of the previous timestep if the PCCS is completely voided, in which case taking away ten percent would have no effect. The ten percent reduction is intended for cases in which noncondensable gases are present and are cooled before the iterative procedure is begun; some of the drywell atmospheric mixture must be brought into the PCCS to maintain a pressure equal to drywell pressure, and the iterative procedure accomplishes exactly this.

In fact, for the case with the PCCS completely voided at the end of the previous timestep, there is no need for iteration at all. The PCCS volume is very small in comparison with the drywell volume. Therefore, it is reasonable to assume that the PCCS will be filled with a material mass and energy composition identical to that of the drywell. One pass through the iteration loop is made to confirm that the calculated PCCS pressure after filling is equal (within limits) to the drywell pressure.

What about the case in which the PCCS is bound (filled with cooled noncondensable gas) and at drywell pressure? Reducing VLICMT by ten percent here has no effect since FLMULT is zero and hence VOL2FL is zero regardless of the value of VLICMT.

The upshot of this rather complicated discussion is that VOL2FL will normally be positive during the first pass through the iterative loop. An exception occurs if the PCCS pressure is already equal (within limits) to the drywell pressure. In that case, VOL2FL will be zero and the iteration will not be extended beyond a single passage through the loop. 
5. At this point, VOL2FL may be negative if the PCCS volume was overfilled during the previous passage through the iterative loop. Depending upon the sign of VOL2FL, the masses ADEM(I) and internal energies ADEM(l) of the steam, fog, and noncondensable gases within this volume of drywell atmosphere are added to (subtracted from) the PCCS volume. These masses and associated enthalpies are subtracted from (added to) the drywell control volume.

In these exchanges, portions of the drywell atmosphere are being transferred. Internal energy is added to or subtracted from the PCCS because a void is being either eliminated or created, as is the associated PV work term. For the drywell, gases entering or leaving do flow work upon (compression) or derive work from (expansion) the remaining gases. Hence enthalpy transfer is appropriate.

6. CVEM(I) and CVMS $(I)$ are adjusted depending upon the values of ADEM(I) and ADMS(I) for all materials within the PCCS atmosphere and the calculation returns to iterative step 1 unless FLMULT is zero. [FLMULT = zero signifies that the PCCS pressure equals (within limits) the drywell pressure.]

7. Once convergence is satisfied, VLICMT is set equal to the PCCS structural volume.

\section{A.1.5 Example Results}

This Section provides a discussion of the calculated PCCS operation for a MELCOR representation of the SBWR station blackout accident sequence. While reading this description, it is important to bear in mind that the available PCCS heat exchangercondenser capacity (based upon current operating parameters) is assumed to be known each timestep; the purpose of the model is to determine the associated heat transfers and fluid flows, with due consideration of the current status of the PCCS with respect to binding.

For an unmitigated station blackout accident sequence, reactor vessel depressurization would automatically occur when the vessel level reached a point about $3.6 \mathrm{~m}$ (12 ft) above the top of the core. The SBWR depressurization involves stepped opening of the safety relief valves, which discharge into the pressure suppression pool, followed by stepped opening of the six depressurization valves (DPVs), which discharge directly into the drywell atmosphere. The example results discussed here cover the period from just before the initial DPV actuation to five minutes thereafter.

Figure A.1 shows the effect of the DPV openings, which begin at time 11161 seconds, upon the noncondensable gas fraction in the drywell. The actual DPV opening 


\section{BH Package Reference Manual}

sequence is two valves at 11161 seconds, two valves at 11206 seconds, and two valves at 11251 seconds.

The reactor vessel depressurization also increases the drywell-to-wetwell differential pressure, as indicated by the response of variable delpre, shown in Figure A.2. The variable reqpre, also plotted on this figure, represents the differential pressure required to induce flow through the PCCS vent line. It increases slightly during the period of the calculation as the height of the pressure suppression pool surface above the vent line terminus increases.

At this point, it is necessary to consider the variation in PCCS performance in accordance with current conditions. The PCCS heat exchanger capacity is determined at the beginning of each timestep based (in order of increasing importance) upon (1) the current drywell-to-wetwell differential pressure and (2) the current mole fraction of noncondensable gas in the drywell (considering the current ICS/PCC pool temperature and interpolating between values for two reference pool temperatures). The tabular input employed for this example calculation is listed in Tables A.1 through A.3. The basic capacity per PCCS unit is $10 \mathrm{MW}_{\mathrm{t}}$ at an ICS/PCC pool temperature (saturation) of $374.15 \mathrm{~K}\left(213.8^{\circ} \mathrm{F}\right)$, a drywell-to-wetwell pressure differential of $7239.5 \mathrm{~Pa}$ (1.05 psi), and a drywell noncondensable gas fraction of 0.0 (pure saturated steam).

The example calculation represents the operation of all three PCCS units. Changes in the ICS/PCC pool temperature are assumed to have no effect upon the PCCS system performance, chiefly because the pool is sufficiently large that its temperature increase is small during the period of the calculation. It may be noted by comparing the variation factors listed in Tables A.2 and A.3 that no credit has been given for enhancement of the PCCS heat exchanger capacity for IC/PCCS temperatures below saturation. At the time that this example calculation was performed, no information concerning this enhancement was available. Subsequently, it has become apparent that such enhancement should be represented, by providing different values in Tables A.2 and A.3. (See the BH Package Users' Guide with respect to input card BHSBWR0200 for additional information.)

The drywell-to-wetwell differential pressure affects the heat exchanger performance because it determines the velocity within the heat exchanger tubes, which affects the heat transfer coefficient at the inner surface of the tubes. Based on the Nusselt number for forced convection:

$$
\mathrm{Nu}=0.023(\mathrm{~K} / \mathrm{D}) \mathrm{Pr}^{0.4} \mathrm{Re}^{0.8},
$$

the heat transfer coefficient for various differential pressures between the drywell and the wetwell can be represented (assuming all other variables are constant) by

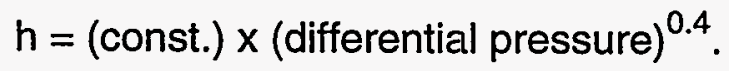


Thus, as indicated in Table A.1, the PCCS capacity is enhanced as the differential pressure increases.

By far the largest effect upon PCCS capacity derives from changes in the noncondensable gas fraction of the gas entering the PCCS from the drywell. This large influence can be observed in Figure A.3, which compares the current (three-unit) PCCS capacity to the drywell non-condensable gas mole fraction (also shown in Figure A.1). It is obvious that the increase in available capacity shown in Figure A.3 is inversely proportional to the decrease in noncondensable gas mole fraction. This large effect of the noncondensable gas fraction in reducing the condensation effectiveness is well known. The tabular input reproduced in Tables A.2 and A.3 is derived from information provided in the paper Heat Removal of Isolation Condenser Applied as a Passive Containment Cooling System by H. Nagasaka et al., of the Nuclear Energy Group, Toshiba Corporation.

The available (three-unit) PCCS capacity is shown again, as variable pltcef on Figure A.4. It should be recognized that three PCCS units operating under base conditions would have a combined capacity of $30 \mathrm{MW}_{\mathrm{t}}$ whereas the maximum value of pltcef shown on Figure A.4 is about $17 \mathrm{MW}_{\mathrm{t}}$. Again, this reduction is primarily due to the presence of noncondensable gas in the drywell atmosphere, which will always be the case.

Also shown on Figure A.4 is the variable e2adic, which is the heat exchanger power actually being utilized. As indicated, none of the available capacity is utilized before the reactor vessel depressurization begins. This is because the PCCS heat exchanger tubes are "bound," or filled with noncondensable gas. Once reactor vessel depressurization begins, however, (1) the available heat exchanger capacity greatly increases, and (2) all of this capacity is utilized.

The reason that all of the available capacity is utilized during the period immediately after DPV opening is that the vent line flow induced by the increasing drywell pressure now sweeps the noncondensable gases from the PCCS each timestep, permitting the mixture of gases and steam within the drywell to enter. The total vent line flow pltifl and the noncondensable gas vent line flow pltnfl are shown in Figure A.5. It should be noted that the vent line flow initially consists entirely of noncondensable gas; all of the steam entering the PCCS during this initial period is condensed.

Steam flow through the vent (the difference between the two plotted variables) does not begin until about 20 seconds after vent line flow begins. Carryover of steam begins at this time because the concentration of steam in the drywell atmosphere has reached a level beyond the available heat exchanger capacity (even though the available capacity is also increasing; see Figure A.3).

It is instructive to consider the events illustrated on these figures that occur just prior to time 11300 seconds. As shown on Figure A.2, the drywell-to-wetwell differential pressure drops below the value needed to sustain PCCS vent line flow. This is 


\section{BH Package Reference Manual}

substantiated by Figure A.5, where the vent line flow is shown to be zero during this period. Figure A.4 shows that the portion of available PCCS heat exchanger capacity actually used during this period decreases toward and ultimately reaches zero. This demonstrates that some time is required for the PCCS to fill with noncondensable gases and become bound after vent line flow ceases.

Almost exactly at time 11300 seconds, the drywell-to-wetwell differential pressure becomes sufficient to restore vent line flow (Figure A.2), vent line flow (all noncondensable gas) is restored (Figure A.5), and all available capacity is used (Figure A.4) to condense the steam brought in with the mixed atmosphere from the drywell.

After time 11300 seconds, the drywell-to-wetwell differential pressure oscillates about the value required to induce vent line flow (Figure A.2). During the periods when vent line flow occurs, this flow consists entirely of noncondensable gas (Figure A.5). During the periods when vent line flow does not occur, the portion of the available capacity that is actually used decreases (Figure A.4) as the PCCS tends to fill with cooled noncondensable gas. However, a fully bound condition is never attained.

That a fully bound condition is never attained during this final period of the example calculation is a testimony to the effectiveness of the PCCS system in controlling the drywell-to-wetwell differential pressure. Whenever the PCCS performance falters, this differential pressure increases, clearing the vent line and restoring the PCCS performance.

Table A.1 Tabular input example for variation of PCCS performance with drywell-wetwell differential pressure

\begin{tabular}{rrr}
\hline \multicolumn{2}{c}{ Differential Pressure } & Variation Factor \\
\hline $\mathbf{P a})$ & $(\mathbf{p s i})$ & \\
\hline 0.0 & 0.00 & 1.000 \\
8239.5 & 1.05 & 1.000 \\
1034.5 & 1.25 & 1.072 \\
12065.1 & 1.50 & 1.153 \\
13789.5 & 1.75 & 1.227 \\
15423.6 & 2.00 & 1.294 \\
& 2.24 & 1.353 \\
\hline
\end{tabular}


BH Package Reference Manual

Table A.2 Tabular input example for variation of PCCS

performance with the drywell noncondensable gas mole fraction at an ICS/PCC pool

temperature of $323.16 \mathrm{~K}$

\begin{tabular}{cc}
\hline Noncondensable Gas Mole Fraction & Variation Factor \\
\hline 1.00 & 0.0 \\
0.10 & 0.60 \\
0.05 & 0.82 \\
0.02 & 0.90 \\
0.01 & 0.96 \\
0.00 & 1.00 \\
\hline
\end{tabular}

Table A.3 Tabular input example for variation of PCCS performance with the drywell noncondensable gas mole fraction at an ICS/PCC pool temperature of $373.16 \mathrm{~K}$

\begin{tabular}{cc}
\hline Noncondensable Gas Mole Fraction & Variation Factor \\
\hline 1.00 & 0.0 \\
0.10 & 0.60 \\
0.05 & 0.82 \\
0.02 & 0.90 \\
0.01 & 0.96 \\
0.00 & 1.00 \\
\hline
\end{tabular}




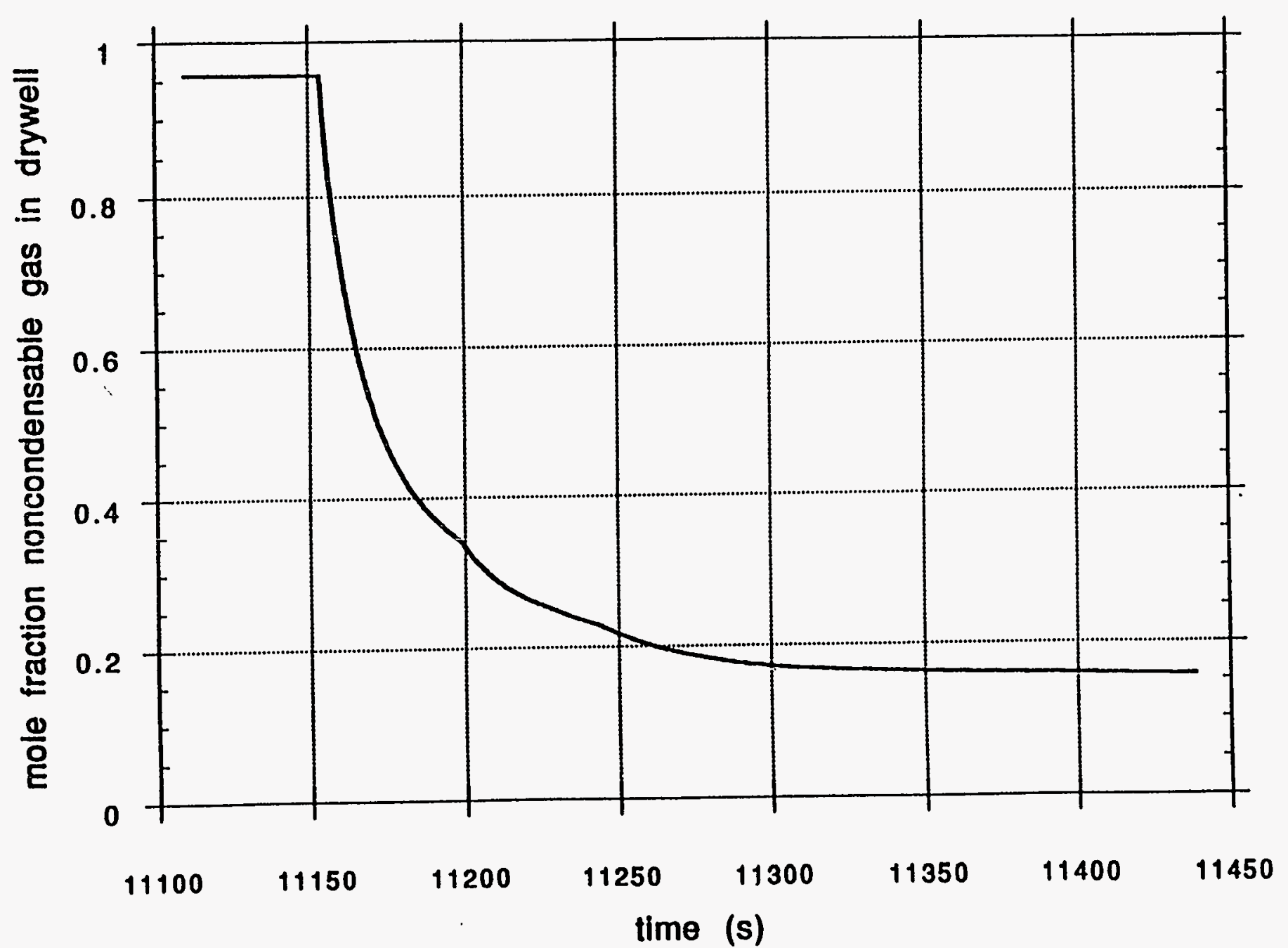

Figure A.1 The noncondensable gas mole fraction decreases rapidly when steam is released directly into the drywell atmosphere during the final stages of an SBWR reactor vessel depressurization. 


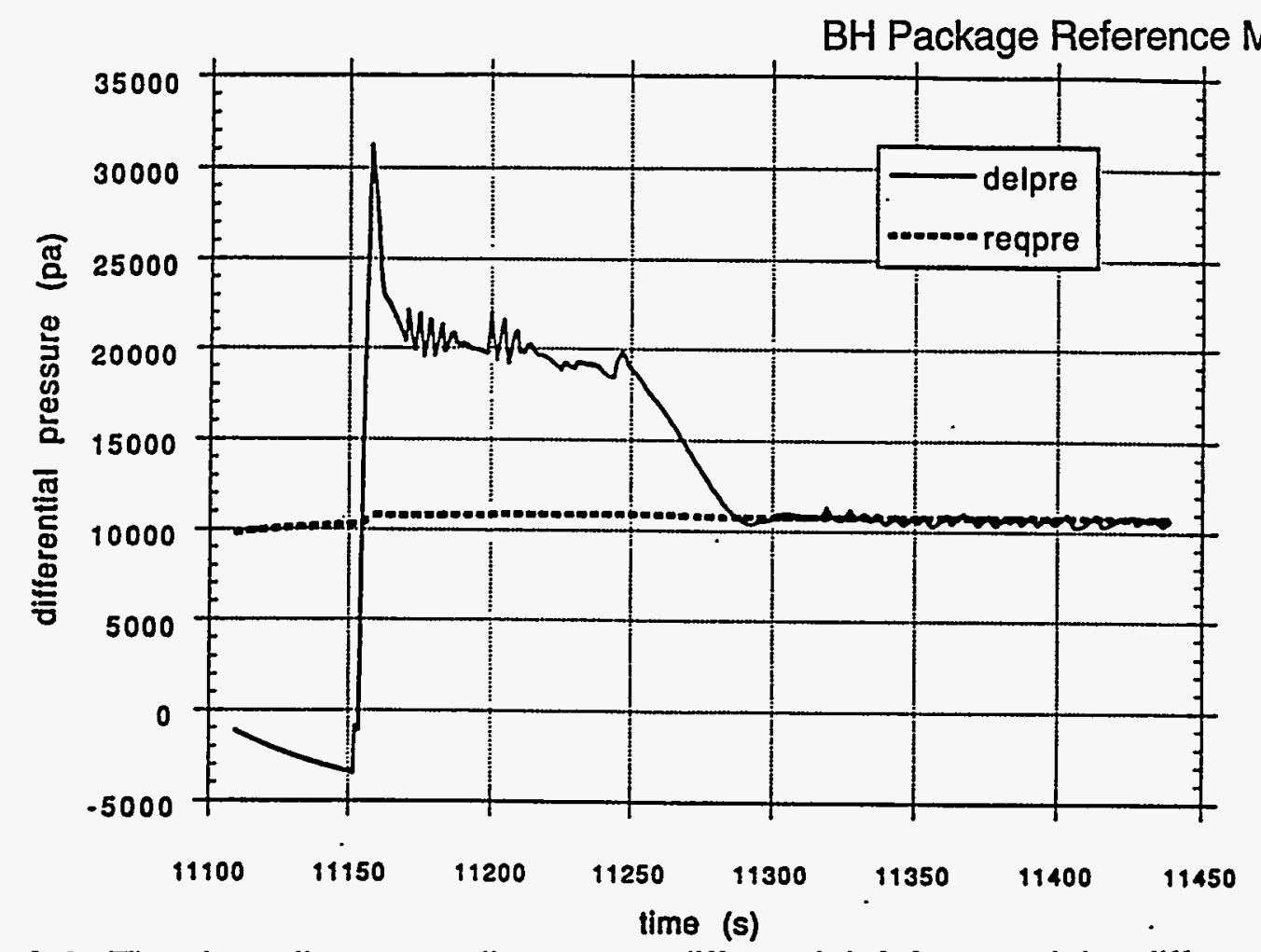

Figure A.2 The drywell-to-wetwell pressure differential delpre and the differential pressure reqpre at which flow through the PCCS vent line is initiated.

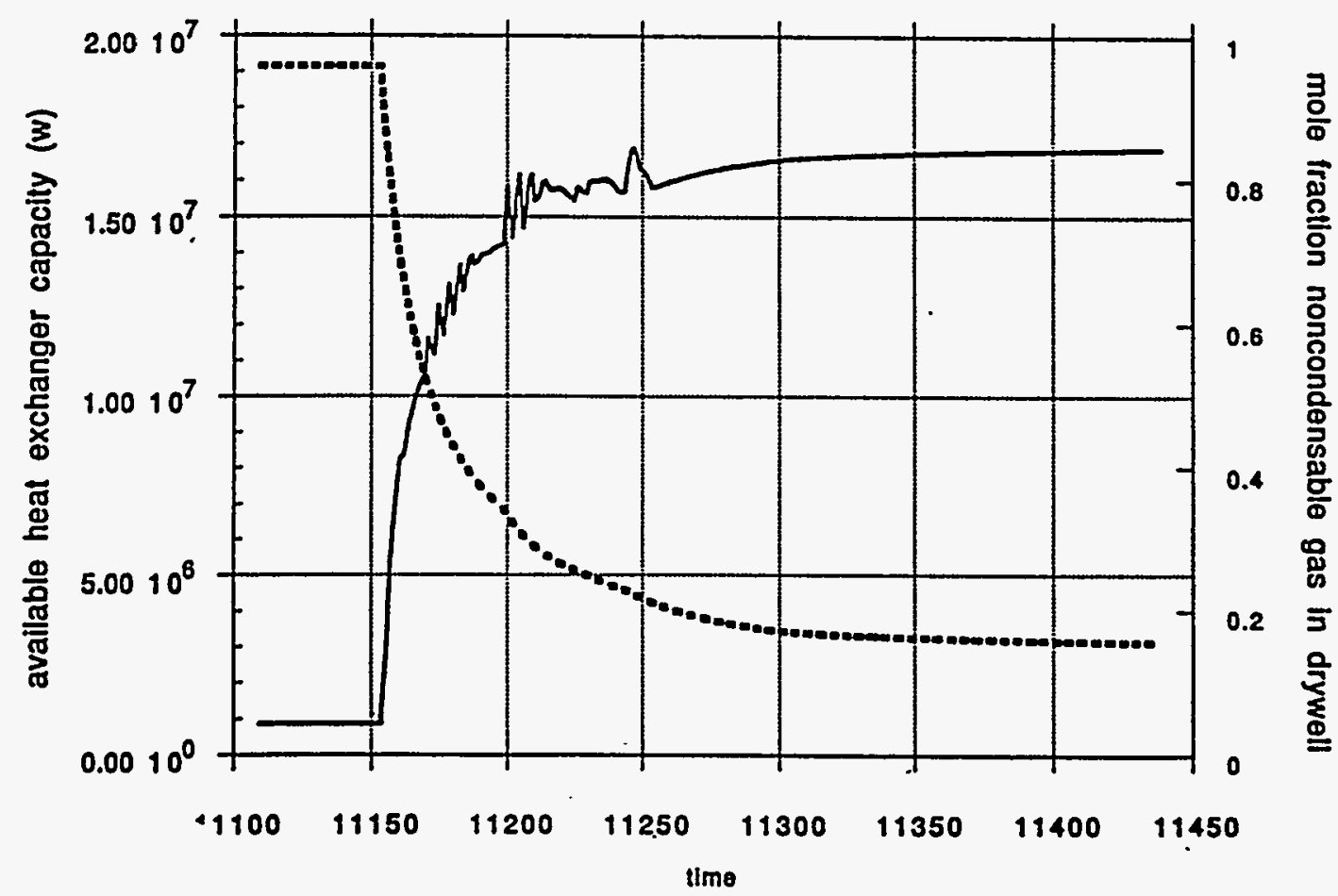

Figure A.3 The available PCCS heat exchanger capacity is primarily determined by the drywell noncondensable gas mole fraction. 
BH Package Reference Manual

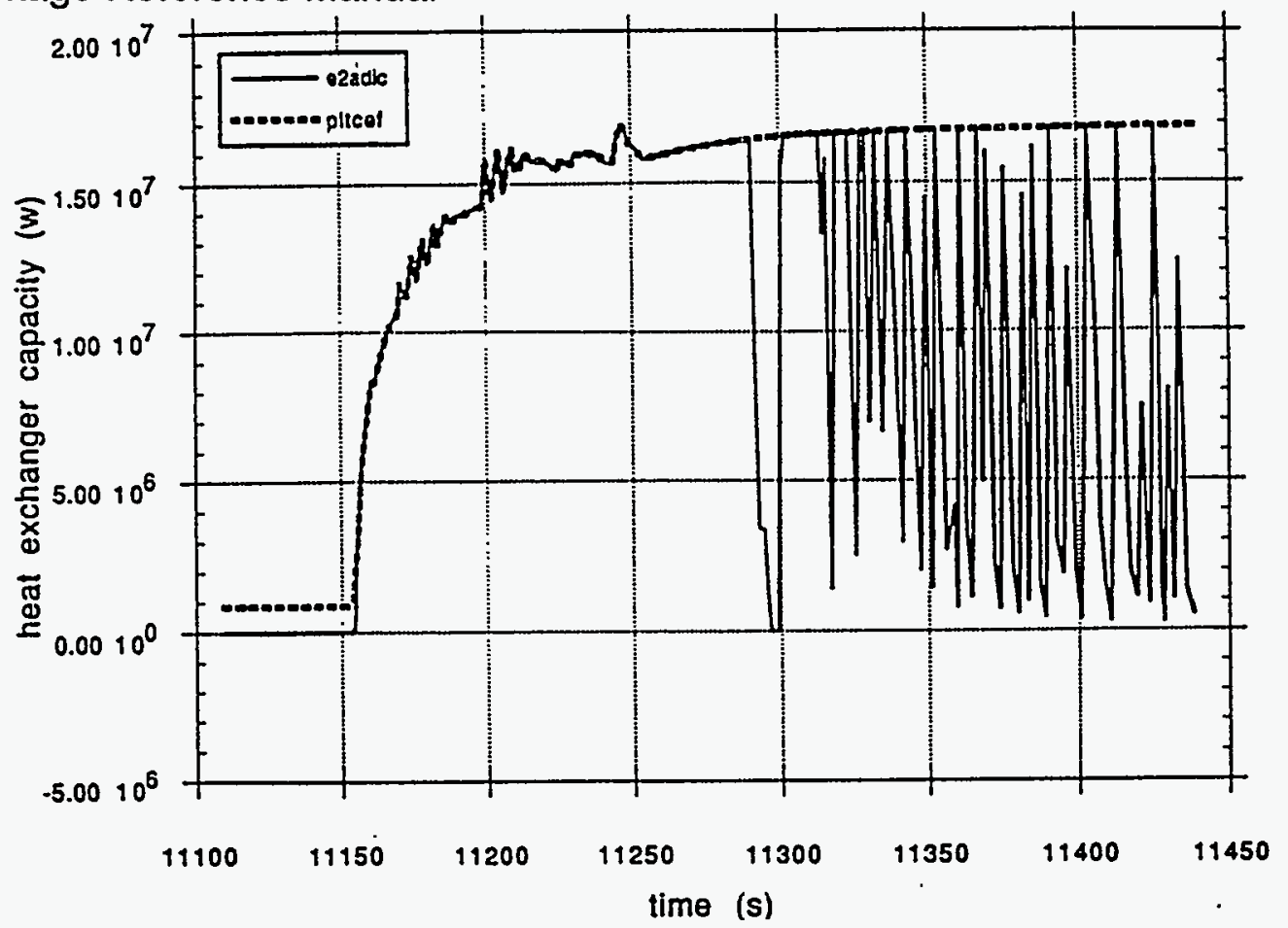

Figure A.4 The available PCCS (three-unit) heat exchanger capacity and the power e2adic actually utilized.

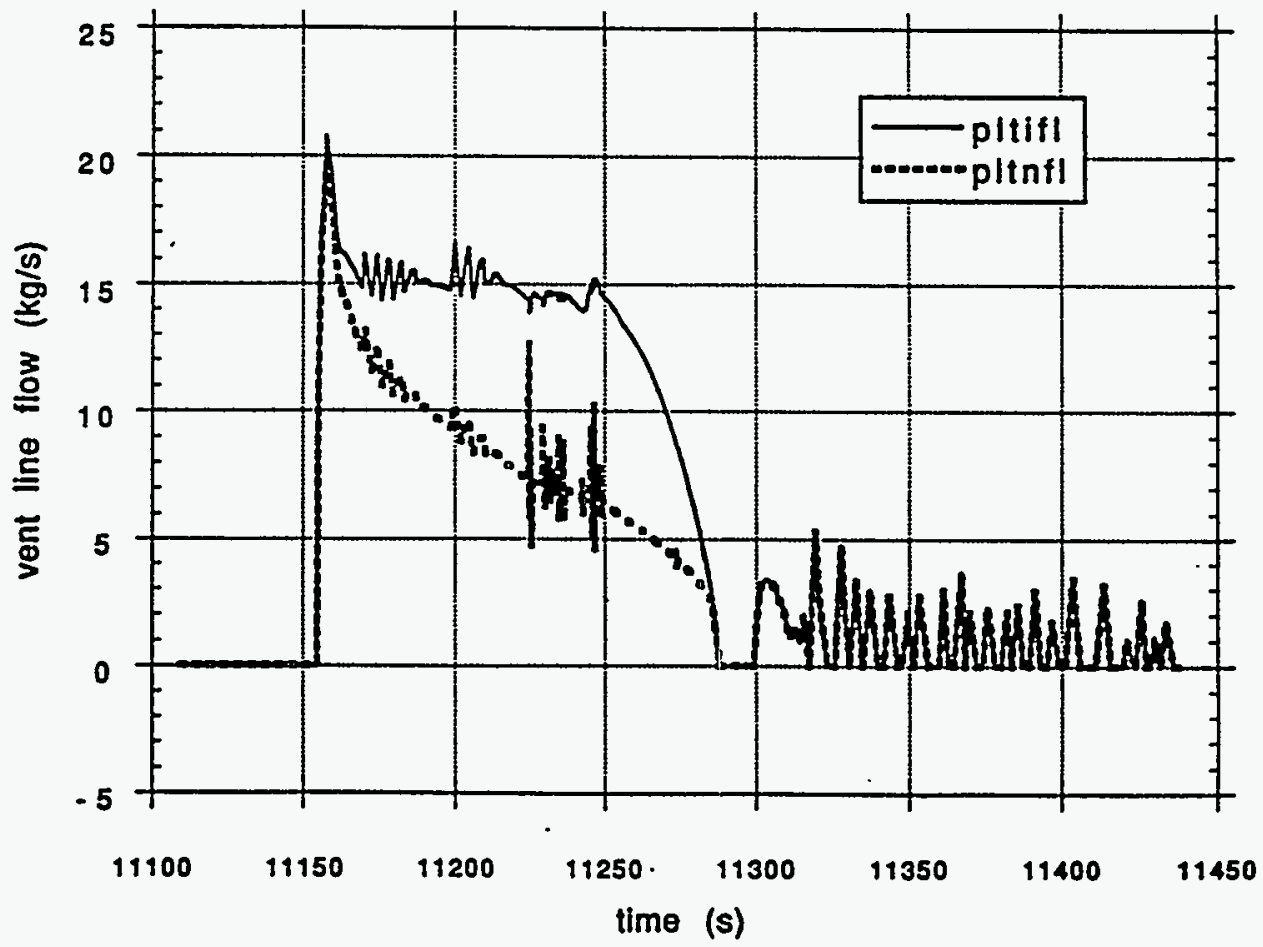

Figure A.5 The total mass flow pltifl through the PCCS vent line and the associated flow pltnfl of noncondensable gases. 
BH Package Reference Manual

\section{A.1.6 Summary of PCCS Operation}

The nominal capacity of each PCCS heat exchanger-condenser is reported in the SSAR (Section 6.2.2.1) as $10 \mathrm{MW}_{\mathrm{t}}$ for conditions where the tubes are filled with pure saturated steam at $308 \mathrm{kPa}(45 \mathrm{psia})$ and $407 \mathrm{~K}\left(273^{\circ} \mathrm{F}\right)$, and the ICS/PCC pool temperature is $374 \mathrm{~K}\left(214^{\circ} \mathrm{F}\right)$. The available capacity under severe accident conditions is, however, never more than about sixty percent of this because of the presence of noncondensable gases in the drywell atmosphere. Furthermore, the available capacity is wholly utilized only during periods when the PCCS vent line flow is sufficient to prevent the accumulation of noncondensable gases within the PCCS.

The new PCCS model, which operates with MELCOR for SBWR severe accident applications, recognizes the effects of an increasing drywell-to-wetwell pressure differential in initiating (and then increasing) the vent line flow. For calculational timesteps without vent line flow, the rapid termination of condenser effectiveness due to the trapping of noncondensable gases is properly represented. With vent line flow, the noncondensable gases and any carryover of steam and fog are continuously transferred to the pressure suppression pool while the PCCS condensers continue to operate. In either case, the condensate is transferred to the GDCS pool and the ICS/PCCS pool temperature is increased accordingly.

It should be noted that compression of the nonconcensable gases as drywell pressure increases (but before reaching the level necessary to induce flow to the wetwell through the PCCS) is represented. Therefore, the small amount of gas/steam mixture that would enter the inactive PCCS during heatup and expansion of the drywell atmosphere is considered. However, such a slow pressurization of the drywell would occur only for cases such as station blackout with loss of drywell coolers and not during the rapid blowdown following a LOCA or depressurization valve (DPV) operation. Because of the low humidity of the drywell atmosphere under station blackout conditions, only a small amount of condensate is produced by the mass transfer into the PCCS caused by slow pressurization of the drywell.

\section{A.2 ICS Model}

\section{A.2.1 Introduction and Concept}

The ICS is a safety-related passive operating system designed to remove the core decay heat directly from the reactor vessel following reactor shutdown and isolation. It is described in Section 5.4.6 of the SBWR Standard Safety Analysis Report (SSAR). Unlike the PCCS, the ICS is not continuously in operation. A motor-operated valve must be opened (or, if power is lost, a nitrogen-operated bypass valve must open) in order to initiate operation of the ICS. 


\section{BH Package Reference Manual}

Flow through the ICS is first induced by the action of condensate draining from the condenser tubes into the reactor vessel annulus. The drainage draws in steam from the upper portion of the reactor vessel; this stearn is condensed and returned to the vessel annulus. In the event that the ICS becomes "bound" by noncondensable gases, a vent line is provided to permit release of the gases trapped within the ICS to the pressure suppression pool.

The flow through the vent line is started and stopped by an active control system that continuously monitors the reactor vessel pressure. Once the vessel pressure reaches the vent opening setpoint (implying the ICS is bound), the valves on the vent line open allowing the accumulated noncondensable gases to escape to the pressure suppression pool, thereby reinitiating operation of the ICS.

The vent line valves are signaled to close once the vessel pressure has decreased below the reset (closing) setpoint for the vent. A time delay circuit is integrated into the logic to protect the vent valves from excessive cycling.

The ICS modeling concept is the same as for the PCCS in that it is recognized that it is not a purpose of the MELCOR code to predict ICS performance based upon first principles. Rather, based upon the available experiment evidence, MELCOR should adequately represent the effects of the IC heat exchanger-condenser system under the boundary conditions that would be imposed by severe accidents.

\section{A.2.2 Operation of the ICS Model}

The same basic algorithms, contained in Subroutine BHCOND, are used to model both the ICS and the PCCS. There is, however, a block of coding specific to the ICS. This coding block mimics the operation of the ICS vent line control logic, which has no counterpart within the PCCS (the flow through the PCCS vent line is limited only by the submergence depth of the vent line in the pressure suppression pool). The following is a description of the significant differences between the operating characteristics of the ICS and the PCCS and the logic enhancements required to represent the ICS.

1. The ICS operates at pressures near normal reactor vessel pressure, approximately $7 \mathrm{MPa}$, as compared to the PCCS, which operates at post accident drywell pressures of less then $0.50 \mathrm{MPa}$.

Because of the difference in operating pressures, allowances had to be made in the calculation of the vent line capacity to limit the flow to sonic velocity (choked flow) at the exit conditions. This was done by the use of the Modified Darcy Formula taken from the Crane Technical Paper No. 410. The Darcy Formula estimates a mass flow rate for compressible flow using a net expansion factor through the pipe and the differential pressure between the reactor vessel and the choke point at the pipe exit. (The pressure at the exit condition can be easily determined if the flow is choked.) The determination 
of the net expansion factor serves to limit the flow through the pipe to sonic velocity at the pipe exit conditions.

The mass flow rate is determined in a new subroutine BHICFL, which is used for both the PCCS and the ICS vent line flow calculations. BHICFL first determines the resistance coefficient for the vent line. Using the resistance coefficient, the maximum net expansion factor and the maximum delta P/P for sonic velocity are found by interpolating between the values found on page A-22 of the Crane Technical Paper for a $k$ value of 1.4. If the pressure in the PCCS/ICS minus the wetwell pressure divided by the PCCS/ICS pressure is greater than the value found for delta $P / P$, then the flow is choked. If the flow is not choked, then a linear interpolation is performed between zero and the calculated differential pressure to determine the net expansion factor. If the flow is choked, then the maximum delta P/P is used to determine the pressure at the exit condition, and the net expansion factor is simply equal to its maximum value. The mass flow rate can then be estimated.

Because of the higher pressures at which the ICS condensers operate, the condenser tube walls are significantly thicker than for the PCCS condensers. This greater tube wall thickness may require a different performance degradation curve to represent system response to increases in noncondensable gas mole fractions. Provision is made for this new curve, when available, to be represented in the ICS set of user-input tabular functions, which are applied in a manner identical to the PCCS tabular functions described in detail in Section A.1.3.

2. The heat removal capacity of a single ICS unit is at least $30 \mathrm{MWt}$ at a reactor pressure of $7.420 \mathrm{MPa}(1050 \mathrm{psig})$ when fed by pure saturated steam. The large (factor of 3 ) increase in capacity over the PCCS is a direct result of the increase in steam density at reactor vessel pressure (where $1 \mathrm{~m}^{3}$ of steam contains approximately 8 times the mass of the same volume at drywell conditions). Therefore, the ICS has a greater amount of stored energy within the fluid contained in the condenser tubes.

3. As described in Section A.2.1, the vent line for each ICS unit contains a motor-operated valve, which is actuated upon a high pressure within the reactor vessel such as would occur whenever the condenser tubes become bound with noncondensable gases.

4. Unlike the PCCS, the ICS condensers are not expected to operate after the equalization of reactor vessel and drywell pressures that would occur under severe accident conditions as a result of ADS actuation and DPV sequencing. This conclusion is not stated explicitly in the SSAR, but follows from information contained in Section 5.4.6 and the control diagrams provided in Volume 15 of the SSAR. The control diagrams indicate that the 


\section{BH Package Reference Manual}

controllers for the vent line valves receive their signals for automatic operation from reactor vessel pressure sensors exclusively.

After blowdown, these controllers would no longer receive a high pressure signal since the vessel would be at the same pressure as the drywell. Thus, the ICS would quickly become bound by noncondensable gases with no provision for venting except by means of operator intervention. However, no guidance to the operator concerning this action can be found in the SBWR Emergency Procedure Guidelines (EPGs).

5. The drain line from the ICS returns condensate directly to the reactor vessel annulus. The elevation of the ICS condensers provides a sufficient gravity head so that the condensate will drain to the vessel annulus even though the annulus water level may be several meters above the condensate return line. A loop seal is provided in the drain line to prevent steam from entering the condensers via this line should the water level fall below the connection point to the reactor vessel.

\section{A.2.3 Example Results}

Several test calculations have been performed utilizing the ICS model with two units in operation for various accident sequences. The accident sequences considered are loss of offsite power (station blackout), a main steam line LOCA, and a break in the bottom head drain line. For the station blackout calculation, the ICS was predicted to operate continuously and to cause depressurization of the reactor vessel without SRV or ADS actuation, thus preventing loss of reactor coolant inventory and circumventing core degradation.

For the bottom head LOCA calculation, the ICS was predicted to operate until shortly after ADS actuation, when drywell atmosphere begins to be pulled into the reactor vessel (through the open DPVs) as the water drains from the bottom of the vessel. Subsequently, the presence of noncondensable gases within the reactor vessel causes rapid binding of the IC condenser tubes and without vent valve actuation, ICS operation terminates. The main steam line LOCA calculation shows a similar behavior with the ICS slowly becoming bound with the noncondensable gases that arise from hydrogen generation in the core and from the small amount of drywell atmosphere that mixes with the reactor vessel atmosphere after vessel depressurization.

To test the logic of the vent line control valve, adclitional calculations were performed in which a large amount of nitrogen was arbitrarily placed into the reactor vessel upper head for the station blackout and for the main steam line LOCA accident sequences. This provides an overpressure of noncondensable gas such that the vessel water is initially subcooled. The large noncondensable gas mole fraction at the isolation condenser inlet limits the ICS capacity (while operating) to a value insufficient to 
BH Package Reference Manual

remove the decay heat. These test calculations show a very short period of ICS operation prior to binding.

Because of the inability of the ICS to remove any energy while bound, the calculated pressure in the reactor vessel increases until the vent valve opening setpoint is reached. The vent valve then opens to remove noncondensable gases from the ICS tubes to the wetwell and thereby restore ICS operation. While the vent line is open, the pressure in the reactor vessel decreases slightly, which leads to closing of the vent valve.

This predicted cyclic behavior continues with increasing frequency until the water within the reactor vessel reaches the saturation temperature and the rate of vessel pressurization increases markedly. Subsequent ICS vent actuation does not provide sufficient gas release through the small vent line to prevent the increasing vessel pressure from reaching the SRV opening setpoint. The action of opening the SRV's forces most of the nitrogen out of the reactor vessel and reduces the noncondensable gas mole fraction from approximately fifty percent to less than one percent. This produces a steam-rich environment within the ICS so that operation can resume.

For the main steam line LOCA, the ICS also becomes quickly bound, but flow through the break removes most of the imposed nitrogen from the reactor vessel. However, the break flow also serves to prevent the reactor vessel pressure from ever increasing above the vent valve opening setpoint; therefore, the ICS remains bound after operating for only a short time after the accident is initiated. (Possible operator action to remote-manually open the vent valve was not considered in this calculation.)

\section{A.3 Interface with MELCOR}

Several of the MELCOR mass and energy balance bookkeeping subroutines have been modified to incorporate the required storage of the variables for the new PCCS/ICS subroutine in the MELCOR database. A special routine to process PCCS/ICS model input has also been added for use in SBWR calculations for which these models are to be exercised. These modifications to the MELCOR database are bypassed (as are the PCCS/ICS model routines BHCOND and BHICFL) unless the PCCS and/or ICS input cards are included in the MELGEN input deck. The BH Package Programmer's Guide provides a description of the function of each subroutine and an overall flowchart of the BH Package.

If the user requests that the PCCS model be invoked for an SBWR calculation, then it is necessary that the control volume numbers representing the drywell, wetwell, ICS/PCC pool, and the Gravity-Driven Cooling System (GDCS) be provided on a dedicated MELGEN input card. If the user does not provide this card, the PCCS model will be bypassed. An additional dedicated card is required to indicate the tabular functions that represent the PCCS performance adjustments (depending upon operating parameters). 


\section{BH Package Reference Manual}

If the ICS model is to be exercised in a calculation, the user must provide the control volume numbers for the reactor vessel upper head and annulus, ICS/PCC pool(s), and the wetwell. Similar to the case for the PCCS, if the input card carrying this information is not provided, the ICS model will be bypassed.

A few simple descriptive input numbers for the PCCS and/or ICS are also required when these models are to be exercised. This special input consists of the volume of the condensers, the source line volume, the basic capacity of one unit of the condensers, and the dimensions of the vent line (minimum diameter and equivalent length) used in determining the mass flow. The user also inputs the number of units (maximum of three) that are to be considered to be operating.

For the ICS, the setpoints for the vent valve control logic are also required. The number of operating condensers may be changed during the course of a calculation. Appendix A of the BH Package Users' Guide describes the input to both MELGEN and MELCOR required for operation of the PCCS and/or ICS models, and the plot variables and associated special external data files that may be created. 


\title{
Burn (BUR) Package Reference Manual
}

\author{
MELCOR Code Development Group \\ Modeling and Analysis Department \\ Nuclear Energy Technology Center \\ Sandia National Laboratories \\ Albuquerque, NM 87185-0739
}

Contributors:

Stephen W. Webb

Randall M. Summers

The Burn (BUR) package models the combustion of gases in control volumes. The models consider the effects of burning on a global basis without modeling the actual reaction kinetics or tracking the actual flame front propagation. The BUR package models are based on the deflagration models in the HECTR 1.5 code.

This Reference Manual describes the models employed in the BUR package. Detailed descriptions of the user input requirements can be found in the BUR Package Users' Guide. 


\section{Contents}

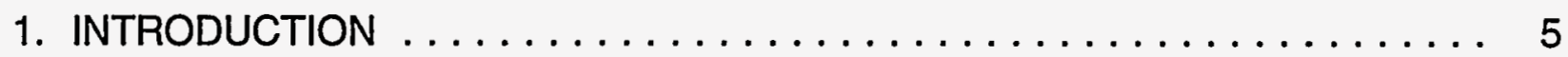

1.1 Treatment of Deuterium $\ldots \ldots \ldots \ldots \ldots \ldots \ldots \ldots \ldots$

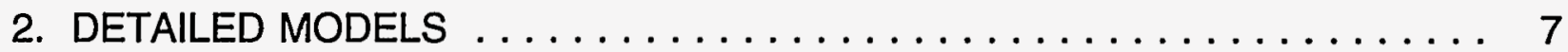

2.1 Burn Model Logistics $\ldots \ldots \ldots \ldots \ldots \ldots \ldots \ldots \ldots \ldots \ldots \ldots$

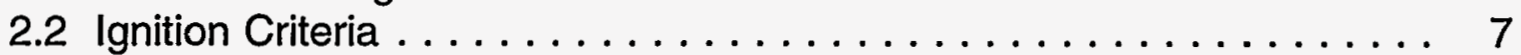

2.3 Combustion Completeness $\ldots \ldots \ldots \ldots \ldots \ldots \ldots \ldots \ldots$

2.4 Burn Duration ......................... 11

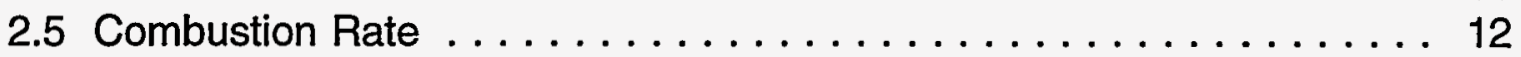

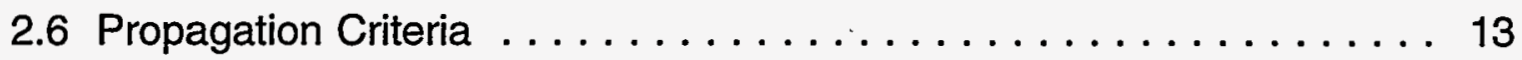

2.7 Detonation ........................ 15

3. TIMESTEP CONTROL $\ldots \ldots \ldots \ldots \ldots \ldots \ldots \ldots \ldots \ldots \ldots \ldots \ldots$

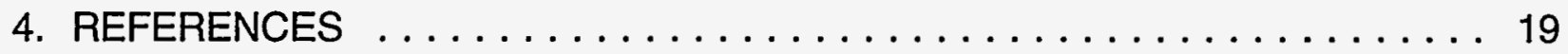


BUR Package Reference Manual

BUR-RM-4. 
BUR Package Reference Manual

\section{INTRODUCTION}

The Burn (BUR) package models the combustion of gases in control volumes. These models consider the effects of burning on a global basis without modeling the actual reaction kinetics or tracking the actual flame front propagation. The models in the BUR package are based on the deflagration models in the HECTR 1.5 code [1]. The only significant modifications made were to provide more direct user control of the models through the implementation of sensitivity coefficients and to include optional model parameters that are used to override the nominal parameters in control volumes in which direct containment heating (DCH) is occurring.

Briefly, a burn is initiated if certain criteria are satisfied in a control volume, causing the reactants (hydrogen, carbon monoxide and oxygen) to be converted during the burn to steam and carbon dioxide. The conversion occurs over a time interval called the burn duration. The reaction may or may not be complete, depending on the conditions in the control volume. After a burn is initiated in a control volume, it can be propagated to adjoining control volumes if a second set of criteria is satisfied. These criteria, as well as the duration and completeness of the burns, are discussed in Section 2. The modeling follows the recommendations of the MELCOR Assessment on Combustible Gas Treatment [2]. The default values and correlations used to calculate burn effects are those used in Reference 1.

For user convenience, the BUR package also prints messages to warn the user when the detonability criteria are satisfied in a control volume. A detonation is combustion in which the flame front travels at supersonic speeds, whereas a deflagration travels at subsonic speeds. In the BUR package, only deflagrations are modeled; detonations are merely flagged and no other action is taken.

The gases hydrogen $\left(\mathrm{H}_{2}\right)$, carbon monoxide $(\mathrm{CO})$, carbon dioxide $\left(\mathrm{CO}_{2}\right)$, and oxygen $\left(\mathrm{O}_{2}\right)$ must be defined in the NonCondensible Gas (NCG) package whenever the BUR package is active. Steam $\left(\mathrm{H}_{2} \mathrm{O}\right)$ is automatically present for all MELCOR calculations, so no special action need be taken to include it in a calculation.

\subsection{Treatment of Deuterium}

The BUR package currently has a limited capability to burn deuterium gas $\left(D_{2}\right)$. For purposes of combustion, $D_{2}$ is treated as equivalent to $\mathrm{H}_{2}$ on a mole-for-mole basis. Therefore, one mole of $D_{2}$ will combine with one-half mole of $\mathrm{O}_{2}$ to produce one mole of $\mathrm{H}_{2} \mathrm{O}$ (not $\mathrm{D}_{2} \mathrm{O}$ ), and mass will not be conserved. Some equivalence must be assumed in the absence of a $D_{2} \mathrm{O}$ equation of state comparable in quality to the equation of state used in MELCOR for $\mathrm{H}_{2} \mathrm{O}$. Equivalence on a molar basis was chosen because the equations of state of $\mathrm{D}_{2} \mathrm{O}$ and $\mathrm{H}_{2} \mathrm{O}$ are much more similar on a molar basis than on 


\section{BUR Package Reference Manual}

mass basis, particularly in the gas phase. In addition, the former gives a more accurate value for the heat of combustion.

The same mole-for-mole equivalence is assumed in ignition, detonation, and completeness calculations, and input (or default) data for $\mathrm{H}_{2}$ will be applied to $D_{2}$ and $\mathrm{H}_{2}$ $/ \mathrm{D}_{2}$ mixtures. We believe that the error is small: for example, the ideal combustion limits for $D_{2}$ are 5.0 to 95.0 mole percent compared to 4.0 to 94.0 mole percent for $H_{2}$. 
BUR Package Reference Manual

\section{DETAILED MODELS}

In the following equations, variables that are defined by user input are referred to by the same names as described in the Burn Package Users' Guide. Thus, there is a direct correspondence between the variables in the Users' Guide and those in the Reference Manual.

\subsection{Burn Model Logistics}

A burn is initiated in a control volume if the ignition criteria discussed in Section 2.2 are satisfied. As soon as a burn is initiated, calculations (described in Sections 2.3 and 2.4) are performed to determine the completeness of the burn and its duration. During subsequent time steps, the reactants are converted to the products in that control volume according to the reactions

$$
\begin{aligned}
& \mathrm{H}_{2}+1 / 2 \mathrm{O}_{2} \rightarrow \mathrm{H}_{2} \mathrm{O} \\
& \mathrm{CO}+1 / 2 \mathrm{O}_{2} \rightarrow \mathrm{CO}_{2}
\end{aligned}
$$

The rate of burning varies during the burn duration to account for inter-compartment flow and gas sources, as described in Section 2.5.

After a burn is initiated in a control volume, it can be propagated to adjoining control volumes if a second set of criteria is satisfied. These criteria are discussed in Section 2.6. After a burn propagates into a control volume, the same steps as outlined above for ignition are followed to calculate the burn effects.

\subsection{Ignition Criteria}

A deflagration is initiated in a control volume if the mole fraction composition satisfies a form of LeChatelier's formula (not LeChatelier's principle, which describes the effects of changes in an equilibrium). Control volumes that are specified to contain igniters are tested against a different limit than control volumes without igniters, and a separate limit may be specified for use when direct containment heating (DCH) is occurring in a control volume. For all cases, LeChatelier's formula is used to determine the threshold of ignition, such that ignition occurs when the following inequality is satisfied:

$$
\mathrm{X}_{\mathrm{H} 2}+\mathrm{X}_{\mathrm{CO}}\left\{\mathrm{L}_{\mathrm{H} 2 \text {,ign }} / \mathrm{L}_{\mathrm{CO}, \mathrm{ign}}\right\} \geq \mathrm{L}_{\mathrm{H} 2 \text {,ign }}
$$

where

$$
\mathrm{X}_{\mathrm{H} 2}=\text { hydrogen mole fraction in the control volume; }
$$


BUR Package Reference Manual

$\mathrm{X}_{\mathrm{co}}=$ carbon monoxide mole fraction in the volume;

$L_{H 2, \text { ign }}=\quad X H 2 I G N$, if there is no igniter in the volume and $D C H$ is not occurring, or

$\mathrm{XH} 2 \mathrm{IGY}$, if there is an igniter in the volume and $\mathrm{DCH}$ is not occurring, or

$\mathrm{XH} 2 \mathrm{DCH}$, if $\mathrm{DCH}$ is occurring in the volume;

$L_{C O, \text { ign }}=X$ COIGN, if there is no igniter in the volume and $D C H$ is not occurring, or

$\mathrm{XCOIGY}$, if there is an igniter in the volume and $\mathrm{DCH}$ is not occurring, or

$\mathrm{XCODCH}$, if $\mathrm{DCH}$ is occurring in the volume;

XH2IGN = LeChatelier hydrogen mole fraction limit for ignition without igniters, when DCH is not occurring, input on record BUR001 (default =0.10);

XH2IGY = LeChatelier hydrogen mole fraction limit for ignition with igniters, when DCH is not occurring, input on record BUR001 (default =0.07);

$\mathrm{XH} 2 \mathrm{DCH}=$ LeChatelier hydrogen mole fraction limit for ignition during $\mathrm{DCH}$, input on record BUR001 (default = XH2IGY);

XCOIGN = LeChatelier carbon monoxide mole fraction limit for ignition without igniters, when DCH is not occurring, input on record BUR001 (default $=0.167$ );

XCOIGY = LeChatelier carbon monoxide mole fraction limit for ignition with igniters, when DCH is not occurring, input on record BUR001 (default $=0.129$ );

$\mathrm{XCODCH}=$ LeChatelier carbon monoxide mole fraction limit for ignition during $\mathrm{DCH}$, input on record BUR001 (default $=\mathrm{XCOIGY)}$.

The preceding tests are made only for the presence of sufficient combustible gases. Tests are also made to determine whether there is sufficient oxygen and to determine whether the amount of steam and carbon dioxide is below the inerting level. The same values are used when igniters are present as when there are no igniters, but separate values may be specified for use during $\mathrm{DCH}$. The oxygen and inerting tests are

$$
\begin{aligned}
& \mathrm{X}_{\mathrm{O} 2} \geq \mathrm{XO2IG} \text { (or XO2DCH during } \mathrm{DCH} \text { ) } \\
& \mathrm{X}_{\mathrm{H} 2 \mathrm{O}}+\mathrm{X}_{\mathrm{CO} 2}<\mathrm{XMSCIG} \text { (or XINDCH during } \mathrm{DCH} \text { ) }
\end{aligned}
$$


BUR Package Reference Manual

where

$$
\begin{aligned}
& \mathrm{X}_{\mathrm{O} 2}=\text { oxygen mole fraction in the control volume; } \\
& \mathrm{X}_{\mathrm{H} 2 \mathrm{O}}=\text { steam mole fraction in the control volume; } \\
& \mathrm{X}_{\mathrm{CO} 2}=\text { carbon dioxide mole fraction in the volume; } \\
& \mathrm{XO2IG}=\text { minimum oxygen mole fraction for ignition, input on record BUR001 } \\
& \text { (default = 0.05); } \\
& \mathrm{XO} 2 \mathrm{DCH}=\text { minimum oxygen mole fraction for ignition during } \mathrm{DCH} \text {, input on } \\
& \text { record BUR001 (default = XO2IG); }
\end{aligned}
$$

If all three tests are satisfied (Equations 2.2.1-3), i.e., there is enough hydrogen and carbon monoxide, enough oxygen, and not too much steam and carbon dioxide, a burn is initiated. The burn duration and combustion completeness will be discussed in Sections 2.3 and 2.4. If too much steam and carbon dioxide is present, the control volume is considered inert, and is identified as such in the printed edits. A message is printed to the output file and to the special message file and a plot dump is written (if specified by the user) when a deflagration begins and ends in any control volume.

\subsection{Combustion Completeness}

In MELCOR, deflagrations are not required to be complete; that is, all of the combustible gases present in a control volume at the start of a deflagration are not required to be burned during the deflagration. The combustion completeness is used to determine the amounts of combustible gases that should be present in a control volume at the end of an incomplete burn. In the BUR package, the combustion completeness, $\mathrm{CC}$, is defined as

$$
C C=1-Y_{\min } / Y_{\max }
$$

where $\mathrm{Y}$ is given by the LeChatelier formula,

$$
\mathrm{Y}=\mathrm{X}_{\mathrm{H} 2}+\mathrm{X}_{\mathrm{CO}}\{\mathrm{YH} 2 \mathrm{CC} / \mathrm{YCOCC}\}
$$




\section{BUR Package Reference Manual}

and

$$
\begin{aligned}
& \mathrm{Y}_{\max } \quad=\text { value of LeChatelier formula evaluated at the start of the burn } \\
& \text { (initial amount of combustibles); } \\
& \mathrm{Y}_{\min } \quad=\text { value of LeChatelier formula that is desired at the end of the burn } \\
& \text { (final amount of combustibles); } \\
& \mathrm{YH} 2 \mathrm{CC}=\mathrm{XH} 2 \mathrm{CC} \text {, if } \mathrm{DCH} \text { is not occurring, or } \\
& =\mathrm{XH} 2 \mathrm{CCD} \text {, if } \mathrm{DCH} \text { is occurring; } \\
& \mathrm{YCOCC}=\mathrm{XCOCC} \text {, if } \mathrm{DCH} \text { is not occurring, or } \\
& =X C O C C D \text {, if } D C H \text { is occurring; } \\
& \mathrm{XH} 2 \mathrm{CC}=\text { LeChatelier hydrogen mole fraction for calculating combustion } \\
& \text { completeness, input on record BUR003 (default }=0.08 \text { ); } \\
& \mathrm{XH} 2 \mathrm{CCD}=\text { LeChatelier hydrogen mole fraction for calculating combustion } \\
& \text { completeness during } \mathrm{DCH} \text {, input on record BUR003 (default = } \\
& \mathrm{XH} 2 \mathrm{CC}) \text {; } \\
& \text { XCOCC = LeChatelier carbon monoxide mole fraction for calculating }
\end{aligned}
$$

The combustion completeness is first evaluated by the method described below, then it is used to determine the value for $Y_{\min }$ for the current deflagration in the control volume. The burning rate is adjusted as necessary (see Section 2.5) to achieve this value at the end of the burn.

The combustion completeness can be input as a constant value, calculated from a user-specified control function, or calculated from a correlation. The default correlation for combustion completeness, which was obtained from the HECTR 1.5 code and derived from experimental data, is dependent on the mole fraction of combustible gases present at the start of the burn, $Y_{\max }$, and is given by

$$
\begin{aligned}
C C & =0.0 & & \text { for } Y_{\max } \leq 0.03746 \\
& =23.4116\left(Y_{\max }-0.03746\right) & & \text { for } Y_{\max }>0.03746
\end{aligned}
$$


BUR Package Reference Manual

The constants in this correlation have been implemented in sensitivity coefficient array 2202.

\subsection{Burn Duration}

The burn duration is calculated by dividing a user-specified characteristic dimension by the flame speed. The flame speed can be input as a constant value, calculated from a user-specified control function, or calculated from a correlation. Optional input can be specified to determine the flame speed with a different constant, control function or correlation when $\mathrm{DCH}$ is occurring in the control volume. The default correlation, obtained from the HECTR 1.5 code [1], was derived from experimental data. However, few data were available regarding the effect of large amounts of diluents (steam and carbon dioxide) on flame speed, so the correlation is questionable in mixtures with high diluent concentration. For these mixtures, sensitivity studies should be conducted to bound the expected pressure rises. The default correlation for the flame speed, $\mathrm{V}$, is

$$
V=V_{\text {base }} \times C_{\text {dil }}
$$

where

$$
\begin{aligned}
& V_{\text {base }}=59.2 Y_{\max }+1.792 \quad \text { if } 0.0 \leq Y_{\max } \leq 0.1 \text {, } \\
& =172.88 Y_{\max }-9.576 \quad \text { if } 0.1<Y_{\max } \leq 0.2 \text {, } \\
& =50 . Y_{\max }+15 . \quad \text { if } 0.2<Y_{\max } \leq 0.3 \text {, } \\
& =-50 . Y_{\max }+45 . \quad \text { if } 0.3<Y_{\max } \leq 0.4 \text {, } \\
& =-75 . Y_{\max }+55 . \quad \text { if } 0.4<Y_{\max } \leq 0.6 \text {, } \\
& =-64.3 Y_{\max }+48.58 \quad \text { if } 0.6<Y_{\max } \leq 1.0 \\
& \mathrm{C}_{\text {dif }}=\max \left\{.05,1.0-4.53 X D+5.37 X D^{2}\right\} \quad \text { if } 0.0 \leq Y_{\max } \leq 0.2 \\
& =\max \left\{.05,1.0-4.53 X D+5.37 X D^{2}\right\}\left\{0.3-Y_{\max }\right\} / 0.1 \\
& +\max \{0 ., 1.0-1.29 X D\}\left\{Y_{\max }-0.2\right\} / 0.1 \text { if } 0.2<Y_{\max } \leq 0.3 \\
& =\max \{0 ., 1.0-1.29 X D\} \quad \text { if } 0.3<Y_{\max } \leq 1.0 \\
& X D=\text { diluent concentration }\left(X_{\mathrm{H} 2 \mathrm{O}}+\mathrm{X}_{\mathrm{CO} 2}\right) \text {. }
\end{aligned}
$$


BUR Package Reference Manual

The constants in this correlation have been implemented in sensitivity coefficient array 2200. The burn duration, $t_{c o m b}$, is calculated by dividing the flame speed into a characteristic dimension of the control volume, CDIM (or CDDH when DCH is occurring), input on record BUR1XX:

$$
\begin{aligned}
t_{\text {comb }} & =C D I M / V \text { if } D C H \text { is not occurring, or } \\
& =C D D H / V \text { if } D C H \text { is occurring. }
\end{aligned}
$$

\subsection{Combustion Rate}

The combustion rate (amount of hydrogen, carbon monoxide, and oxygen converted to steam and carbon dioxide per time step) is not constant during a burn. Rather, it is adjusted at each time step to account for inter-compartment flows and gas sources in an effort to match the desired final conditions. In other words, the combustion rate is adjusted so that the mole fractions corresponding to the calculated combustion completeness and the desired burn duration are simultaneously achieved. At each time step, the burn rate, YRATE, is calculated as

$$
\text { YRATE }=\left\{Y(t)-Y_{\text {min }}\right\} /\left\{t_{o}+t_{c o m b}-t\right\}
$$

where

$$
\begin{aligned}
& t_{0}=\text { time that burn was initiated, and } \\
& t=\text { current time in calculation. }
\end{aligned}
$$

Once the rate is calculated, it is used to determine the decrease in the inventory of the combustible gases for the current MELCOR system time step:

$$
\begin{aligned}
& \text { DELH2 }=X_{H 2}(t) \times \text { YRATE } \times D T / Y(t) \\
& \text { DELCO }=X_{C O}(t) \times \text { YRATE } \times D T / Y(t)
\end{aligned}
$$

where

$$
\begin{aligned}
& \text { DELH2 = decrease in hydrogen moles in the control volume during the time } \\
& \text { DT = MELCOR system time step (s). }
\end{aligned}
$$


At the end of the burn, the value $Y_{\min }$ would be reached exactly if there were no flow or sources. These values are updated on every time step to reflect the changing conditions. DELH2 and DELCO are constrained to prevent burning more moles of either gas than are present in the control volume.

The energies of formation are included in the water and noncondensible gases equations

of state. With this formulation, simply changing the relative masses of the reactants and products will automatically result in the appropriate pressure and temperature increase. Thus, it is not necessary to calculate a combustion energy release to a control volume. The total mass and energy of a control volume are not changed by the BUR package, but the masses of individual species are changed to reflect the reactions listed in Section 2.1. (That is, DELH2, DELCO, and $0.5 \times$ DELH2 $+0.5 \times$ DELCO moles of hydrogen, carbon monoxide, and oxygen are subtracted from the control volume while DELH2 and DELCO moles of steam and carbon dioxide are added to the control volume). Because the specific enthalpy of each species properly accounts for the energy of formation, the conversion of the reactants to the products increases the temperature and pressure of the burning control volume, even though the total energy remains unchanged.

\subsection{Propagation Criteria}

Propagation from a burning control volume to connected control volumes is allowed after a user-controlled time period has elapsed. This delay is intended to account for the time it would take for a flame to reach the edge of a control volume if a flame front were actually being modeled. Different delay periods may be specified depending upon whether or not $\mathrm{DCH}$ is occurring in the control volume. Propagation will then occur if the propagation criteria are satisfied in the connected control volume. The propagation delay, $t_{\text {prop }}$, is calculated to be

$$
t_{\text {prop }}=\text { FRAC } \times t_{\text {comb }}
$$

where

$$
\begin{aligned}
& \text { FRAC }=\text { TFRAC, if DCH is not occurring in the control volume, or } \\
& =\text { TFDH, if DCH is occurring in the control volume; and } \\
& \text { TFRAC }=\text { propagation time fraction input on record BUR1XX (default }=0) \\
& \text { TFDH }=\begin{array}{l}
\text { override value of TFRAC during DCH, input on record BUR1XX } \\
\text { (default }=\text { TFRAC). }
\end{array}
\end{aligned}
$$




\section{BUR Package Reference Manual}

Note that if TFRAC equals zero, propagation is possible as soon as a control volume begins burning. If TFRAC equals 1.0, propagation is only considered at the end of the control volume burn.

For propagation, LeChatelier's formula is still applicable if appropriate values are used for the $L$ parameters. Propagation is allowed if the following inequality is satisfied

$$
X_{\mathrm{H} 2}+X_{\text {CO }}\left\{L_{H 2, p p} / L_{\text {co,prp }}\right\} \geq L_{H 2, p p p}
$$

where

\begin{tabular}{|c|c|c|}
\hline$L_{H 2, p p p}$ & $=$ & $\begin{array}{l}\text { XH2PUP, for upward propagation, or } \\
\text { XH2PHO, for horizontal propagation, or } \\
\text { XH2PDN, for downward propagation; }\end{array}$ \\
\hline$L_{\text {co,prp }}$ & $\begin{array}{l}= \\
=\end{array}$ & $\begin{array}{l}\text { XCOPUP, for upward propagation, or } \\
\text { XCOPHO, for horizontal propagation, or } \\
\text { XCOPDN, for downward propagation; }\end{array}$ \\
\hline
\end{tabular}

XH2PUP $=$ LeChatelier hydrogen mole fraction limit for upward propagation, input on record BUR003 (default $=0.041$ ).

$\mathrm{XH} 2 \mathrm{PHO}=$ LeChatelier hydrogen mole fraction limit for horizontal propagation, input on record BUR003 (default $=0.06$ ).

$\mathrm{XH} 2 \mathrm{PDN}=$ LeChatelier hydrogen mole fraction limit for downward propagation, input on record BUR003 (default $=0.09$ ).

XCOPUP $=$ LeChatelier carbon monoxide mole fraction limit for upward propagation, input on record BUR003 (default $=0.125$ ).

$\mathrm{XCOPHO}=$ LeChatelier carbon monoxide mole fraction limit for horizontal propagation, input on record BUR003 (default $=0.138$ ).

XCOPDN $=$ LeChatelier carbon monoxide mole fraction limit for downward propagation, input on record BUR003 (default $=0.15$ ).

The propagation direction is determined directly from the flow path input using the from and to elevations (see the FL Package Users' Guide). If a flow path is not open, or if the flow path is covered by water, propagation is not allowed.

A message is printed to the output file and to the special message file and a plot dump is written (if specified by the user) when a deflagration due to propagation begins in any control volume. 
BUR Package Reference Manual

\subsection{Detonation}

MELCOR does not contain a detonation model. However, tests are performed in each control volume, and a warning message is written indicating the possibility of a detonation if all of the following mole fractions limits are satisfied:

$$
\begin{aligned}
& X_{\mathrm{H} 2}>\text { XH2DET } \\
& X_{\mathrm{O} 2}>\text { XO2DET } \\
& X_{\text {H2O }}<X H 2 O D T
\end{aligned}
$$

where

$$
\begin{aligned}
& \text { XH2DET }=\quad \begin{array}{l}
\text { minimum hydrogen mole fraction for detonable mixture, input } \\
\text { on record BUR002 (default }=0.14),
\end{array} \\
& \text { XO2DET }=\quad \begin{array}{l}
\text { minimum oxygen mole fraction for detonable mixture, input on } \\
\text { record BUR002 (default }=0.09 \text { ), and }
\end{array} \\
& \text { XH2ODT }=\quad \begin{array}{l}
\text { maximum steam mole fraction for detonable mixture, input on } \\
\text { record BUR002 (default }=0.30) .
\end{array}
\end{aligned}
$$

No detonation calculation is performed when a detonable mixture is detected. The warning message is written, but the calculation continues under the control of the deflagration model. The detonation model is mainly intended as a user convenience to flag potentially dangerous conditions that may require separate analysis. 
BUR Package Reference Manual 


\section{TIMESTEP CONTROL}

When a burn first occurs, the Burn package requests a fallback with the time step reduced to the value specified by the BURTIM record. In addition, tests are included to prevent excessive overshoot of the ignition limit. A time step is repeated if the ignition limit is crossed during that time step and either the increase in combustible gas concentration is more than 0.005 or the reduction in diluent concentration is more than 0.01 . These maximum overshoots can be adjusted through sensitivity coefficient 2201. 
BUR Package Reference Manual 
BUR Package Reference Manual

\section{REFERENCES}

1. S. E. Dingman, et al., HECTR Version 1.5 User's Manual, SAND86-0101, NUREG/CR-4507 (April 1986).

2. G. G. Weigand, ed., Thermal-Hydraulic Process Modeling in Risk Analysis: An Assessment of the Relevant Systems, Structures, and Phenomena, SAND84-1219, NUREG/CR-3986 (August 1984). 


\title{
Cavity (CAV) Package Reference Manual
}

\author{
MELCOR Code Development Group \\ Modeling and Analysis Department \\ Nuclear Energy Technology Center \\ Sandia National Laboratories \\ Albuquerque, NM 87185-0739
}

Contributors:

Randall K. Cole, Jr.

Randall M. Summers

Samuel L. Thompson

\begin{abstract}
The MELCOR Cavity (CAV) package models the attack on the basemat concrete by hot (often molten) core materials. The effects of heat transfer, concrete ablation, cavity shape change, and gas generation are included, using models taken from the CORCONMod3 code. The coding of the models is identical to that in CORCON-Mod3, but interfaces have been modified for integration into the MELCOR framework. This integration couples the Cavity package models to thermal-hydraulic boundary conditions in the Control Volume Hydrodynamics (CVH) package, to sources of core debris from the Core (COR) and/or Fuel Dispersal Interactions (FDI) package, and to the standard MELCOR input, output, plotting, and restart capabilities. The fission-product release models in CORCON-Mod3 - originally developed as the separate VANESA code-are included in MELCOR as part of the RadioNuclide (RN) package.
\end{abstract}

This Reference Manual provides an overview of modeling in the CAV package. User input for running MELGEN and MELCOR with the CAV package activated is described in the CAV Package Users' Guide. The fission-product release models (VANESA) and available input are described in the RN Reference Manual and Users' Guide, respectively. 
- . 


\section{Contents}

1. INTRODUCTION $\ldots \ldots \ldots \ldots \ldots \ldots \ldots \ldots \ldots \ldots \ldots \ldots \ldots \ldots \ldots \ldots \ldots \ldots$

2. PHENOMENOLOGY $\ldots \ldots \ldots \ldots \ldots \ldots \ldots \ldots \ldots \ldots \ldots$

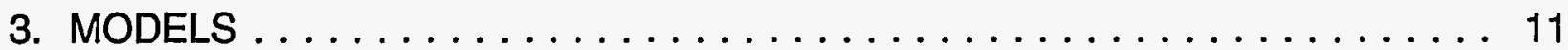

3.1 System Components ...................... 11

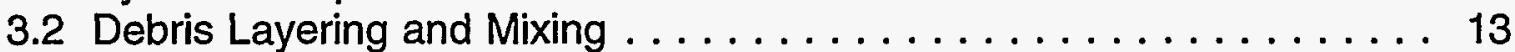

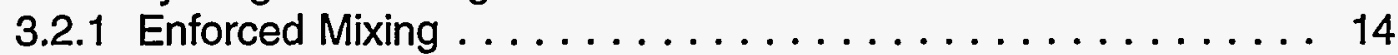

3.2.2 Enforced Stratification $\ldots \ldots \ldots \ldots \ldots \ldots \ldots \ldots \ldots$

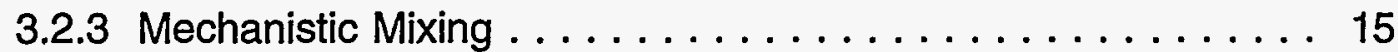

3.3 Energy Generation and Heat Transfer . . . . . . . . . . . . 16

3.4 Concrete Ablation and Cavity Shape Change ............ 18

3.5 Chemistry ............................ 19

3.6 Mass Transfer and Associated Heat Effects . . . . . . . . . . 20

3.7 Debris Spreading . . . . . . . . . . . . . . . . . 22

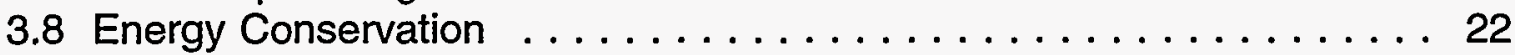

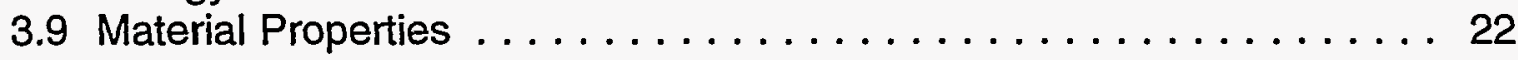

4. COMPARISON TO STAND-ALONE CORCON . . . . . . . . . . . . . 25

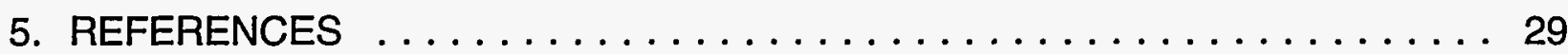

APPENDIX A: Species list for CORCON in MELCOR . . . . . . . . . 31 
CAV Package Reference Manual

CAV-RM-4 
CAV Package Reference Manual

\section{Figures}

1. Cavity System Components $\ldots \ldots \ldots \ldots \ldots \ldots \ldots \ldots \ldots \ldots \ldots$

2. Position and Motion of Body Points $\ldots \ldots \ldots \ldots \ldots \ldots \ldots \ldots \ldots$ 


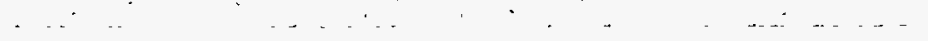


CAV Package Reference Manual

\section{INTRODUCTION}

The Cavity (CAV) package in MELCOR models the attack on the basemat concrete by hot, often molten core materials. The effects of heat transfer, concrete ablation, cavity shape change, gas generation, and debris/gas chemistry are included. The package consists of models'taken from the CORCON-Mod3 code [1] together with all necessary interfaces to the MELCOR database and to other packages in MELCOR.

Before the initial release version of CORCON-Mod3 [2] was incorporated into MELCOR and into CONTAIN: [3], a number of modifications were made to the coding that had no effect on results calculated by the stand-alone code, but allowed the direct use of all routines containing,phenomenological models and properties data without modification in the systems codes. These changes involved a restructuring of the internal database, and the definition of clear interfaces to input and output routines (including diagnostics and plotting) and to routines that provide boundary conditions for the CORCON models.

Boundary conditions for temperature and pressure used by the cavity models are obtained from an associated $\mathrm{CVH}$ control volume, rather than from user input as in standalone CORCON. Any overlying coolant (water) pool is considered part of the boundary condition rather than part of the cavity model and is modeled by CVH. Heat and evolved gases are delivered as sources to the associated $\mathrm{CVH}$ volume.

Debris from the Core (COR) package, the Fuel Disijersal Interactions (FDI) package, or the External Data File (EDF) package is ordinarily deposited into the cavity through the Transfer Process (TP) package. However, initial contents may also be defined in CAV input and arbitrary addition rates may be prescribed by input to the TP package. When debris is deposited, no spreading calculation is performed because it is assumed to spread instantaneously to the maximum area permitted by the cavity geometry.

The CAV packages: continues to use the CORCON-Mod3 properties routines, which are currently independent of the general Materials Properties (MP) package in MELCOR.

The phenomena modeled by the CAV package may be treated in more than one location in a MELCOR calculation. Transfer of material between cavities is allowed based on three tests: axial rupture, radial rupture, or a transfer triggered by a Control Function. Each of the three types of rupture (axial, radial, and triggered) can overflow to a separate cavity, but only "one-way" transfers are allowed. That is, if material can overflow from cavity 1 to cavity 2 , it is not permitted to flow from cavity 2 back to cavity 1 , either directly or through intermediate cavities. These ruptures can be used to model such phenomena as failure of the pedestal in a BWR Mk I or of the diaphragm slab in a BWR Mk II. Triggered transfers may also simulate (in a qualitative way) the effects of the spreading of debris across a flat floor. 


\section{CAV Package Reference Manual}

The VANESA model [4] was integrated into CORCON-Mod3 to calculate the release of fission products and the generation of aerosols from debris in the cavity. The structure of MELCOR requires that radionuclides associated with debris in the cavity be treated by the RadioNuclide (RN) package, which maintains time-dependent inventories for each RN class in each cavity. The relevant subroutines from CORCON-Mod3 were therefore made part of the RN package. They are identical to the routines in the latest stand-alone code and in CONTAIN; an interface is provided through a utility entry in the RN package that duplicates the functionality in the stand-alone code. See the RN package Reference Manual for more details.

Several options for direct user input of internal heating of the debris by fission products are allowed, but this heating is ordinarily calculated by the $\mathrm{RN}$ and $\mathrm{DCH}$ packages, based on $\mathrm{RN}$ inventories. Therefore, the effects on internal heating of relocation of debris into or between cavities, as well as the effects of RN releases within each cavity, are automatically accounted for. 
CAV Package Reference Manual

\section{PHENOMENOLOGY}

This section gives a qualitative description of the processes modeled in the CAV package in MELCOR, and the physical picture on which the models are based. The information is largely derived from Section 2.1 of the CORCON-Mod3 Manual [1]. Interfaces to other MELCOR packages are noted in the discussion.

The attack of core debris on concrete in a light water reactor is primarily thermal and may be considered quasi-steady for much of the period of a reactor accident. Decay heat and heat from chemical reactions is generated in the debris and is lost either through its top surface or to concrete. Boundary conditions at the surface, including temperature and the presence or absence of water, are obtained from the associated control volume in $\mathrm{CVH}$. Heat lost from the surface is treated by $\mathrm{CVH}$ as a source in that control volume.

The quasi-steady partition of the heat loss between concrete and surface is determined by the ratio of the corresponding thermal resistances. Thus, debris behavior and concrete ablation are dominated by conservation of energy, with heat transfer relations providing the most important constitutive relations.

Under the conditions visualized by the CORCON developers, the heat flux to concrete is sufficient to decompose it, releasing water vapor (from both adsorbed water and hydroxides) and carbon dioxide (from carbonates) and melting the residual oxides. The surface of the concrete is ablated at several centimeters per hour typically, and molten oxides and molten steel from reinforcing bars in the concrete are added to the debris pool. The decomposition gases are strongly oxidizing at debris temperatures and will be reduced, primarily to hydrogen and carbon monoxide, on contact with metals in the debris. Ultimately, the reacted and unreacted gases enter the atmosphere above the debris pool, where they may or may not burn immediately. (Modeling of these containment phenomena is not included in CORCON.) These gases (with appropriate enthalpies) are treated as sources in the associated control volume in $\mathrm{CVH}$. The possibility that the combustible gases will burn is considered by the BUR package.

The full concrete response is extremely complicated, with elements of ablation, transient conduction, decomposition of hydroxides and carbonates in advance of the ablation front, and transport of gases and liquid water through the pores of the concrete. Further, the scale of the temperature profile is often comparable to the size of the coarse aggregate in concrete, making any assumption of homogeneous properties questionable.

In CORCON and in CAV, concrete response is modeled as quasi-steady ablation. The thermal diffusivity of concrete is extremely small, a few times $10^{-7} \mathrm{~m}^{2} / \mathrm{s}$. Over the time scale of interest in cavity phenomena (hours), the amount of heat which can be transferred into concrete (by transient conduction) under nonablative conditions is usually small compared to the amount of heat which must be removed from core debris through other mechanisms to maintain its temperature below the ablation temperature. Therefore, 


\section{CAV Package Reference Manual}

if the debris temperature is below the ablation temperature, the concrete surface is modeled as an adiabatic boundary.

Gas released at the bottom of the debris pool is assumed to rise through it as bubbles. Gas released at the side of the pool may also form bubbles that rise to the surface. At sufficiently high gas release rates, a stable gas film may form at either the bottom or side interfaces. Gas bubbles rising through the debris pool increase its volume. This "level swell" increases the depth of the pool and area of its radial interface with concrete.

The rising bubbles also promote the production of aerosols containing fission products stripped from the fuel debris. The processes involved, reactive vaporization and bubble bursting, are treated by the VANESA model [4] in the RN package in MELCOR. This model calculates the removal and relocation of fission products and the resulting sources of aerosols for the MAEROS aerosol physics model (also part of the RN package). All necessary data concerning the temperature and bulk composition of the debris and the gas generation rates are passed by CAV to a utility entry in $\mathrm{RN}$; the fission product inventories themselves are part of the RN database. The subroutines that implement VANESA in the RN package are identical to those that implement it in CORCON-Mod3.

Experimental evidence (cited in Reference 1) shows that the various oxidic species in the melt are highly miscible, as are the metallic species, but that the two groups are mutually immiscible. Previous versions of CORCON assumed that the core debris would stratify into distinct layers based on the relative densities of the phases. The passage of gas bubbles through the interface between layers can overcome this separation if the gas flux is high or the density difference is small by entraining droplets of the lower (denser) and mixing them into the upper one. If entrainment occurs, the degree of mixing achieved is determined by a balance between entrainment and reseparation as the denser droplets settle out under the influence of gravity. The debris may therefore be fully stratified, partially mixed, or fully mixed, and the state may change as the densities and gas fluxes change during a debris-concrete interaction.

There is a possibility that an overlying coolant layer (water) could interact with molten debris so as to break it up and form a coolable debris bed. In the MAAP code [5], this breakup and quenching is assumed to occur; it is not considered in CORCON, nor is it included in the current version of the MELCOR CAV model.

As the interaction progresses, the debris pool grows as concrete oxides are added to it; its surface area increases, and internal heating decreases. Therefore, debris temperatures and heat fluxes decrease, and the possibility of refreezing arises. Substantial freezing of the metal phase may occur. However, the large internal heating and small thermal conductivity of the oxidic phase prevent steady, solid crusts thicker than a few centimeters. Therefore, unless the debris is spread over an extremely large area, the interior of the oxidic phase will remain molten for a long time, probably for weeks. 
CAV Package Reference Manual

\section{MODELS}

Documentation of the CORCON-Mod3 [1] remains the primary reference for most of the submodels in the Cavity package. The following subsections briefly summarize the material contained there, while noting modifications made for incorporation into MELCOR.

\subsection{System Components}

The physical system considered by the Cavity package consists of an axisymmetric concrete cavity, a multilayered debris pool, and a set of boundary conditions (provided by $\mathrm{CVH}$ ) at the top surface of the debris, as illustrated in Figure 1.

The shape of the concrete cavity is described by a series of so-called body points lying in a vertical cross-section of the concrete surface. The initial shape is defined by user input. The concrete itself is described by specifying an average chemical composition; its thermochemical 'properties are then obtained from an internal database of properties for the component species. A number of standard compositions are available by name as built-in defaults, or the user may define composition and melting temperatures through input.

The modeling assumes that all oxidic species in the debris are mutually miscible, as are all metallic species, but that oxides are not miscible with metals. If the densities of the phases are different, the debris will tend to separate into distinct oxidic and metallic phases under the influence of gravity, but this stratification may be partially or completely overcome by the stirring effect of gas bubbles. If the density difference is sufficiently small and the gas bubbles sufficiently large, droplets of a lower (denser) layer can be entrained across the interface to mix with a lighter layer above it.

The debris pool is modeled as a number of layers filling some part of the concrete cavity. Pure-phase and mixed-phase layers may be included, and the ordering of the layers is assumed to be determined by their densities, with the densest on the bottom and the lightest on top. Many configurations are possible, as discussed in Section 3.2. Layer volumes, including the swelling effects of gas bubbles, determine the elevations of layer interfaces and of the debris surface. 
CAV Package Reference Manual

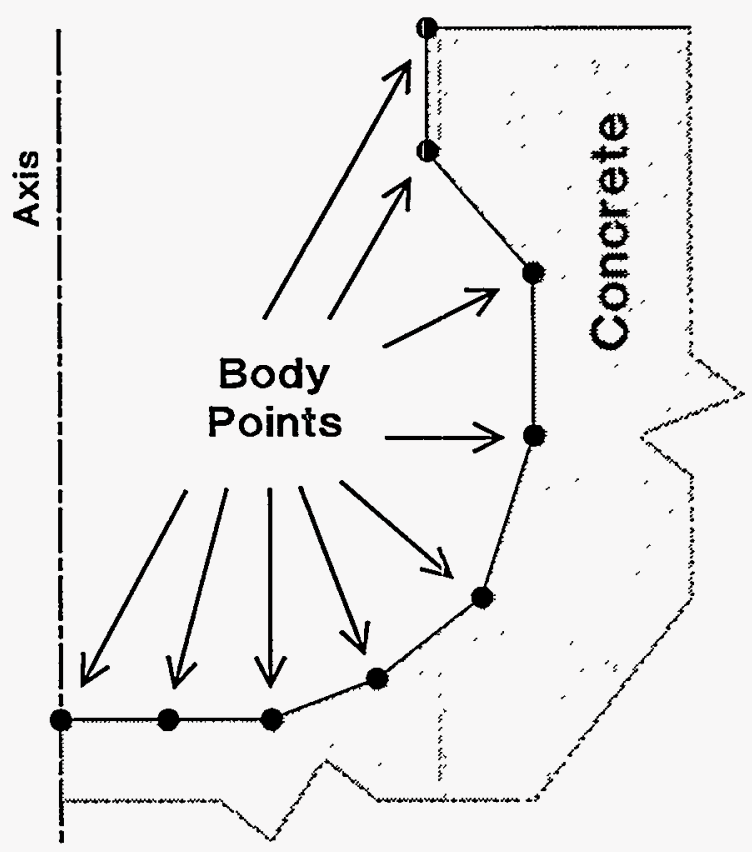

(a) Cavity Geometry

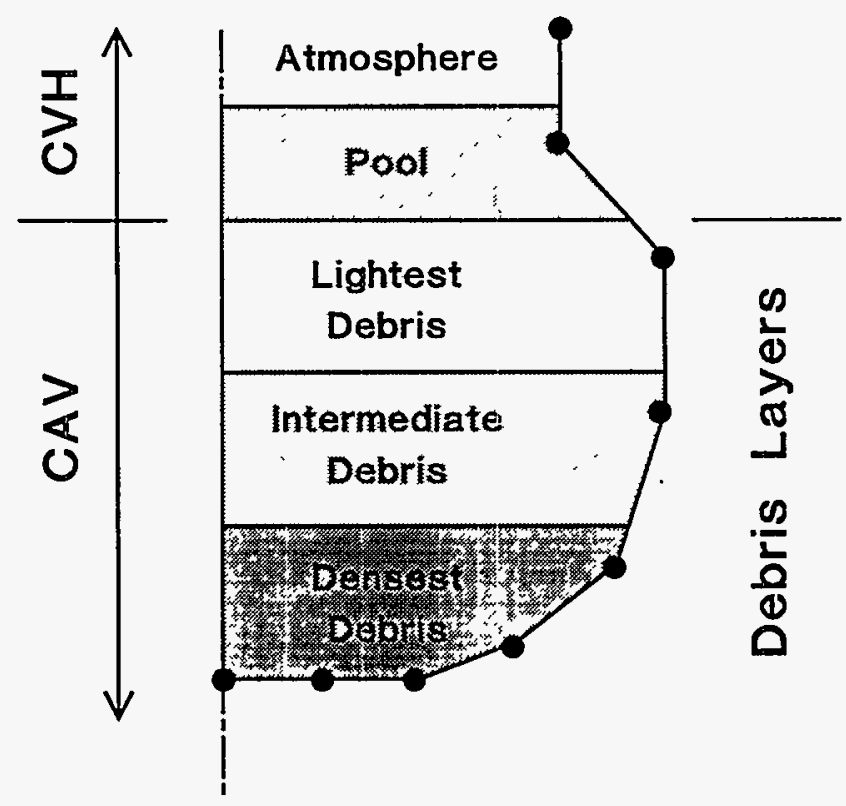

(b) Cavity Contents and Boundary Conditions

Figure 1. Cavity System Components 
CAV Package Reference Manual

\subsection{Debris Layering and Mixing}

Five possible types of debris layers are considered in CORCON; each has a conventional three-letter designation in the associated documentation. In order of increasing density they are:

LOX: Pure oxide, less dense than the metallic phase;

LMX: Mixed phases, less dense than the metallic phase;

MET: Pure metal;

HMX: Mixed phases, more dense than the metallic phase; and

HOX: Pure oxide, more dense than the metallic phase.

If only oxides are present, the debris is called LOX by convention. The possibility of creating mixed-phase layers was introduced as part of the enhanced modeling in CORCON-Mod3. The major assumptions concerning these mixed layers is very specific:

The LMX layer is formed by entrainment of metal from MET or HMX into a previously-existing LOX layer, and consists of a suspension of discrete droplets of metal in a less-dense continuous oxidic phase. The mixing is assumed to be complete so that the LOX layer is converted to an LMX layer in the process; LMX and LOX cannot exist simultaneously. The entrainment competes with settling of the denser metal droplets from LMX back into the lower layer (or to form a new MET layer if there is no lower metal-containing layer present).

The HMX layer is formed by entrainment of oxides from HOX into a previouslyexisting MET layer, and consists of a suspension of discrete droplets of oxide in a less-dense continuous metallic phase. The mixing is assumed to be complete so that the MET layer is converted to an HMX layer in the process; HMX and MET cannot exist simultaneously. The entrainment competes with settling of the denser oxide droplets from HMX back into HOX (or to form a new HOX layer if there is none present).

Under these assumptions, there are 15 possible configurations of the debris. These can be summarized as follows:

\begin{tabular}{|c|c|c|c|c|c|c|c|c|c|c|c|c|c|c|}
\hline LOX & 1 & 2 & 3 & $\begin{array}{l}4 \\
\times\end{array}$ & $\begin{array}{l}5 \\
\times\end{array}$ & $\begin{array}{l}6 \\
x\end{array}$ & 7 & 8 & 9 & 10 & $\begin{array}{l}11 \\
x\end{array}$ & 12 & 13 & 14 \\
\hline LMX & & & & & & & $x$ & $x$ & $x$ & $x$ & & $x$ & $x$ & \\
\hline MET & $x$ & & & $X$ & & & $x$ & & & & $x$ & $x$ & & $x$ \\
\hline $\begin{array}{l}\text { HMX } \\
\text { HOX }\end{array}$ & $x$ & $\begin{array}{l}x \\
x\end{array}$ & $X$ & & $X$ & $x$ & & y & $X$ & $x$ & & & & \\
\hline
\end{tabular}

where " $\mathrm{X}$ " denotes the presence of the layer. 


\section{CAV Package Reference Manual}

Three options are available for the treatment of layering and mixing of debris in CORCON. They are (1) enforcement of complete mixing, (2) enforcement of complete stratification, and (3) mechanistic modeling of the entrainment and separation processes. The first of these (complete mixing) is the default in the CAV package in MELCOR, but the user may specify any of the options by input of MIXING on the CAVnnak record.

\subsubsection{Enforced Mixing}

This is the simplest of the options, with the debris always considered to form a single layer. If both metals and oxides are present, the layer will be HMX or LMX (configuration 3 or 13), depending on the relative densities of the phases. If there is only a single phase, it will be either MET or LOX (configuration 14 or 15). As noted previously, this is the default treatment in MELCOR.

\subsubsection{Enforced Stratification}

This was the only option available in CORCON in versions prior to Mod3, in which the possible creation of heterogenous mixtures of metals and oxides was not considered. It was therefore the only option available in versions of MELCOR prior to 1.8.3.

When this option is specified, the possibility of two oxidic layers, physically separated by a metallic layer, is allowed for. If the initial oxide phase is sufficiently rich in $\mathrm{UO}_{2}$ (fuel) to be more dense than the initial metallic phase, it is assumed to form an oxidic layer beneath the one containing the metals. An oxide slag, rich in concrete and steel oxides and less dense than the metals will then accumulate on top of the metal layer. Thus, the most general structure of the debris pool is a light oxide layer (LOX), over a metallic layer (MET), over a heavy oxide layer (HOX).

This three-layer configuration (configuration 4) can persist until dilution by less dense concrete oxides renders the HOX layer less dense than the MET layer. The configuration is then (instantaneously) converted to one containing only MET and LOX (configuration 11 ), with the latter layer combining the previous contents of HOX and LOX. Addition of $\mathrm{UO}_{2}$-rich debris to a debris pool in the LOX-over-MET configuration can result in an oxide mixture that is denser than the contents of MET. When this occurs, the LOX is eliminated and the configuration is (instantaneously) converted to one of MET over HOX (configuration 1). These changes in configuration are effected by checking the relative densities of adjacent layers at every step of the calculation, and relocating and/or combining the layers as appropriate. 
CAV Package Reference Manual

\subsubsection{Mechanistic Mixing}

The most general option uses mechanistic models for entrainment and separation developed by Greene [6-8] to predict the occurrence and extent of mixing. One consequence of this modeling is to eliminate the instantaneous change in debris configuration (often referred to as "layer flip") resulting from an insignificant change in the relative densities of the debris phases. Instead, the phases will become increasingly strongly mixed whenever their densities approach equality (unless there is no gas flow to drive the mixing).

The entrainment model assumes that bubbles passing through the interface between two layers may carry material from the lower layer into the upper one if they are large enough. The critical diameter depends on density ratios and on the surface tension of the liquid-liquid interface; above the threshold, a correlation is used to determine the volume of condensed-phase material entrained by each gas bubble. The separation model is based on the terminal velocity of falling droplets of a size corresponding to the critical Weber number for the onset of droplet oscillations.

Competition between these processes defines the net rate of mixing or separation at the various layer interfaces. The model considers entrainment of oxides from HOX into HMX or LMX, or into MET to form HMX, and of metal from MET or HMX into LMX or into LOX to form LMX. It also considers the possibility that a mixed layer is unstable and will separate to produce a new HOX layer below HMX or a new MET layer below LMX.

After release of the initial version of CORCON-Mod3 [2], the numerical implementation of the models was modified to provide numerical stability with reasonable timesteps. The entrainment rate depends primarily on the gas flux; therefore, over a finite timestep,

$$
\dot{m}_{\theta}(t) \approx \dot{m}_{\theta}(0)
$$

However, the separation rate is proportional to the mass of the discontinuous phase in the mixed layer, and has the form

$$
\dot{m}_{s}(t)=\frac{M_{D}(t) v_{\text {settle }}}{L_{M}}
$$

where $v_{\text {settle }}$ is the settling velocity, $M_{D}$ is the mass of droplets suspended in the mixed layer, and $L_{M}$ is thickness of that layer.

The mass of suspended droplets therefore satisfies

$$
\frac{d M_{D}}{d t}=\dot{m}_{\theta}(t)-\dot{m}_{s}(t) \approx \dot{m}_{\theta}(0)-\frac{M_{D}(t) .}{\tau_{s}}
$$

where 
CAV Package Reference Manual

$$
\tau_{s} \equiv \frac{L_{M}}{V_{\text {settle }}}
$$

is the time constant for separation. Equation 3 has the analytic solution

$$
M_{D}(t)=M_{D}(0)+\left(\dot{m}_{\theta}(0) \tau_{s}-M_{D}(0)\right)\left(1-\theta^{-t / \tau_{s}}\right)
$$

Equation 5 expresses the fact that entrainment and separation approach a balance where the mass of suspended droplets is

$$
M_{D}^{s s}=\dot{m}_{\theta} \tau_{s}
$$

with a characteristic time $\tau_{s}$. Independent treatment of the competing processes will be numerically unstable unless the timestep, $\Delta t$, is less than $\tau_{s}$, and the results will be dependent on timestep unless $\Delta t$ is much less than $\tau_{s}$. Because the time constant may be relatively short compared to the rates at which conditions are changing, the revised version of CORCON-Mod3 applies the analytic solution given by Equation 5 over a timestep. This requires moving a net mass

$$
\Delta m_{\theta}^{n \theta t}=\left(m_{\theta}^{0} \tau_{s}-M_{D}^{0}\right)\left(1-e^{-\Delta t / \tau_{s}}\right)
$$

from the lower layer to the upper layer during the timestep, where superscript 0 denotes evaluation at the start of the step. If the net move is positive, it must be limited to the contents of the lower layer. If it is negative, it cannot-by its very form-exceed the mass of droplets initially suspended in the upper layer. This change in numerical implementation has eliminated almost all of the instabilities observed in layer mixing in the initially-released version of CORCON-Mod3.

\subsection{Energy Generation and Heat Transfer}

The fuel/concrete interaction is driven primarily by decay heat power generated within the debris pool, with heat from oxidation reactions also contributing. In stand-alone CORCON, the decay heating is calculated by an internal model based on an initial fission product inventory and fits to the decay powers for each of the 27 elements in it. In MELCOR, this heating is calculated by the RN and DCH packages; the model is conceptually very similar to that in CORCON (see the RadioNuclide (RN) and Decay Heat (DCH) Package Reference Manuals and Reference 1), but the CAV database contains no information on the location-or relocation-of the fission products. (The exact model used in stand-alone CORCON is therefore not available, even as an option, in MELCOR.) Heat sources based on control functions and/or tabular functions are also permitted, primarily for simulation of experiments. 
CAV Package Reference Manual

For the calculation of energy conservation, each debris layer is treated as a lumped mass with a single (average) temperature. The heat flux between the interior of each layer and each of its interfaces (with another layer, with concrete, or with the pool or the atmosphere in the bounding control volume)'is treated separately. Continuity of the heat flux determines the temperature of each interface.

The possible heat transfer regimes within each debris layer are conduction and natural convection, based on conventional correlations, and bubble-enhanced convection based on Kutateladze [9] and surface renewal [10] models. The correlations are implemented in such a way that they reproduce correlations for convective heat transfer in internally heated fluid layers (in the absence of gas flows) developed by Kulacki and co-workers [11-13] with a maximum error of 30 percent, and an average error closer to 10 percent. An enhancement factor developed by Farmer [i4] is applied at the top surface of the debris (adjacent to the coolant or the atmosphere) to account for the greater surface area of the unstable surface.

The modeling includes the possibility that the interior of a layer may be fluid, with heat transfer by convection, while one or more of its axial and radial surfaces is covered by a solid crust, with heat transfer by conduction [15]. In all cases, only one-dimensional effects are considered, and the situation is assumed to be quasi-steady.

Losses from the surface are calculated, based either on radiation and convection in the absence of overlying water or on a complete pool boiling curve in its presence. The representation of the boiling curve is the, one used in CORCON [1], and includes convection, nucleate boiling, transition boiling, and film boiling regimes. In the film boiling regime, the effects of coolant subcooling and of gas barbotage (injection of noncondensible gas at the coolant interface), both of which can greatly increase both the film boiling heat flux and the temperature at which the film collapses (the Leidenfrost point), are also included.

The concrete surface is treated using a quasi-steady ablation model. If concrete is ablating, it presents a constant temperature boundary condition defined by the ablation temperature, $T_{a}$. This temperature is obtained either from internal data or user input. Under quasi-steady conditions, changes in the sensible heat content of the preheated region in advance of the ablation front may be neglected. (As mentioned in Section 2, the thermal diffusivity of concrete is extremely small. The total heat content of this region is therefore small, and is neglected.) The rate of ablation is then proportional to the heat flux from the debris to the concrete surface. Their ratio is simply the inverse of the heat of ablation $h_{a}$.

If the heat flux to a concrete surface at an assumed temperature of $T_{a}$ would be negative, no ablation can be taking place, and heat transfer can affect only the thermal boundary layer in the concrete. Under these conditions, change in the heat content of this 


\section{CAV Package Reference Manual}

boundary layer is neglected and the concrete surface is treated as an adiabatic boundary. Further decomposition of concrete in advance of ablation is also neglected.

An additional thermal resistance is included between the debris and the concrete. CORCON-Mod3 allows this resistance to be calculated using either a gas film or a slag film model. In each case, separate models are provided for the bottom and side surfaces of the debris.

The gas film models are based on the assumption of a gas film between the debris and the concrete. An analog of Taylor-instability-bubbling film boiling is used on nearly horizontal surfaces [16], and an analog of attached-flow film boiling is used on strongly inclined surfaces. A transition from bubbling to flow is made over a range of inclination angles. Details of the model are presented in Reference 1.

A detailed slag film model was developed by Bradley [17], based on a picture of transient growth and removal. He found that when the resulting thermal resistance of the slag film was combined with the resistance within the debris layer, the net heat transfer coefficient between the interior of the debris and the concrete surface could be adequately represented as a constant multiple (0.29) of the latter coefficient over a wide range of conditions. The heat transfer coefficient for the slag film model is therefore calculated in CORCON as 0.41 times the heat transfer coefficient between the interior of the debris and its surface, for either the bottom and side surfaces of the debris, so that the net heat transfer coefficient is $1.0 \cdot 0.41 /(1.0+0.41)=0.29$ times the internal heat transfer coefficient.

The model to be used may be selected independently for the bottom and side surfaces of the debris. The default in MELCOR 1.8.3 is to use the gas film model in both places, consistent with previous versions of MELCOR. The user may specify which model is to be used on the bottom or side surfaces by input of GFILMBOTT or GFILMSIDE on the CAVnnak record, as described in the CAV Package Users' Guide. (There is no default for the choice of models in stand-alone CORCON-Mod3, and the Manual [1] provides no recommendation.)

\subsection{Concrete Ablation and Cavity Shape Change}

In steady-state ablation, the incident heat flux and the ablation rate are directly proportional; the ratio is simply the volumetric ablation enthalpy. Therefore, the heat flux to the concrete at each body point in the cavity profile is used to calculate the local ablation rate. A new position of the body point is then calculated, displaced along the local normal to the surface. To maintain calculational stability, the cavity profile is then rezoned, and the body points are interpolated back onto a series of guiding lines termed rays, as illustrated in Figure 2. The effect of the rezone is that the body points must follow the rays, and their spacing along the cavity profile is constrained. As shown in the 


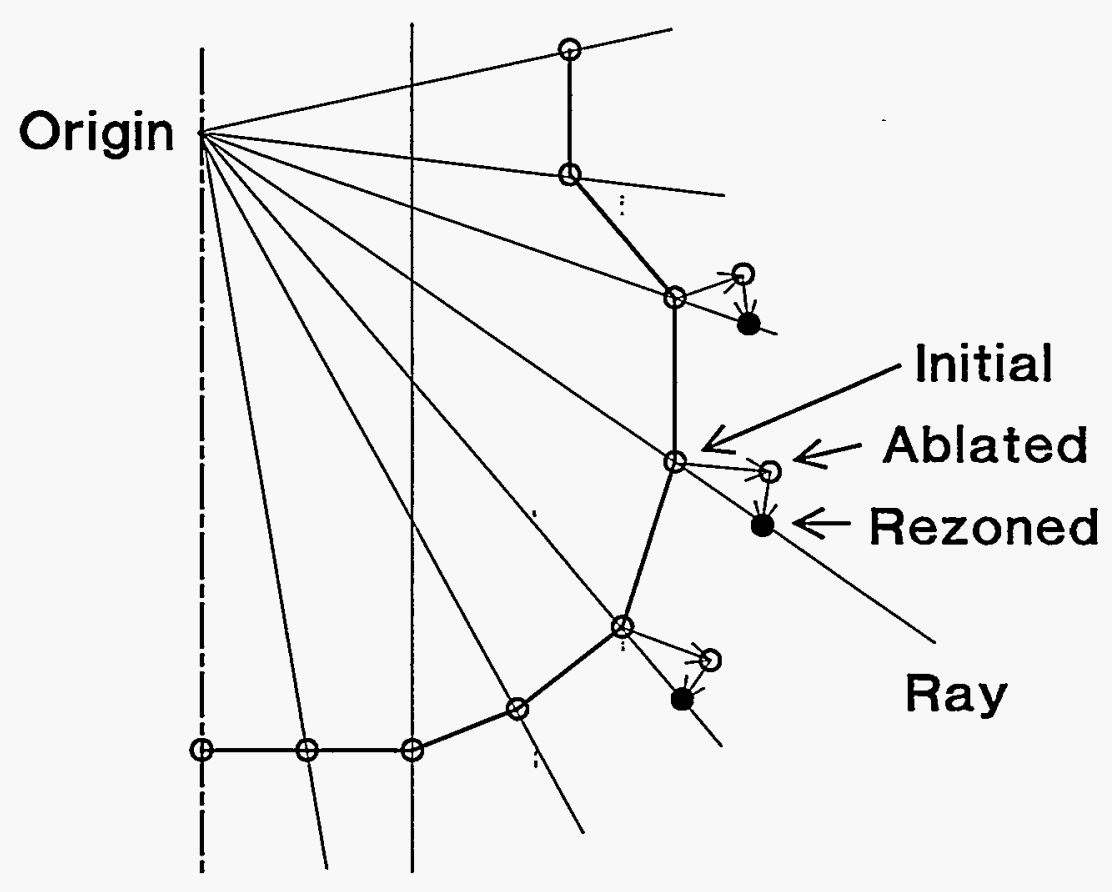

Figure 2. Position and Motion of Body Points

figure, all but one of the rays pass through a user-defined origin. The final ray lies parallel to the axis, through the outermost point on the flat bottom of the cavity, and serves to ensure that this flat bottom remains flat. The scheme evolved from the CASCET model [18] written by ACUREX/Aerotherm Corporation under contract to Sandia.

\subsection{Chemistry}

The chemistry considered in the Cavity package of MELCOR involves interactions between concrete decomposition products and metallic species in the debris pool. Equilibrium chemistry is assumed, without consideration of rate limiting effects. The calculational method is very general and is based on minimization of the total Gibbs function for a metallic phase, a gaseous phase, and an oxidic phase. Each of the three phases is treated as an ideal solution; that is, the entropy of mixing is considered, but any heat-of-solution effects are ignored.

Two separate reactions are considered. The first involves reactions in the interior of the debris. For a pure metal layer, it is modeled as mutual equilibrium among the metal layer and the gas bubbles and concrete decomposition oxides passing through it. For a mixedphase layer, the oxidic constituents of the layer are included as reactants. The primary effect is the oxidation of metals by the $\mathrm{H}_{2} \mathrm{O}$ and $\mathrm{CO}_{2}$ in the bubbles. However, if the 


\section{CAV Package Reference Manual}

metallic phase contains significant amounts of $\mathrm{Zr}$, it can also reduce the concrete oxides to produce metallic $\mathrm{Al}, \mathrm{Ca}$, and $\mathrm{Si}$. The user may specify elimination of these reactions (as in older versions of CORCON) through input of CTOXYREA on record CAVnnak; in this case, only the products of metal oxidation are included in the oxide phase.

The second reaction involves mutual equilibrium among the metal layer, the gas film at its radial boundary, and the products of metal oxidation. Concrete decomposition (and other) oxides are not included in this reaction.

The gaseous reactants are $\mathrm{H}_{2} \mathrm{O}$ and $\mathrm{CO}_{2}$, and the principal gaseous products are $\mathrm{H}_{2}$ and CO. The full equilibrium calculation in CORCON predicts the formation of small amounts of additional gaseous species including hydrocarbons and various dissociation products such as atomic hydrogen. Most, if not all, of these species are predicted to occur in quantities insufficient to warrant their inclusion in the control volume inventories. To ignore them would violate mass conservation, and there is insufficient information to unambiguously convert them to "equivalent" amounts of significant species. The problem can be avoided by imposing constraints in minimization of the Gibbs function to eliminate consideration of any gaseous species other than $\mathrm{H}_{2} \mathrm{O}, \mathrm{CO}_{2}, \mathrm{H}_{2}$, and $\mathrm{CO}$. This option was added to stand-alone CORCON-Mod3 after it's initial release, and is used in MELCOR. The results conserve mass and represent a restricted equilibrium state consistent with the modeling of atmosphere chemistry in MELCOR. We believe this to be a reasonable approach. If it were desired to include additional gases such as methane, only a trivial change to coding would be required. This is because the Gibbs function to be minimized has not been changed, but only the domain over which it is minimized.

The equilibrium calculation sometimes predicts the "coking" reaction in which $\mathrm{CO}_{2}$ is fully reduced to condensed carbon (rather than simply to $\mathrm{CO}$ ), primarily in the presence of metallic $Z r$. Because simulant experiments have not provided overwhelming evidence either for or against the occurrence of coking, the user is permitted to specify whether this reaction will be permitted in CORCON. The default in MELCOR is to suppress the production of condensed carbon, but the user may specify either option be input of COKE on the CAVnnak record.

In stand-alone CORCON, the chemistry includes an extremely simplified consideration of fission products; in MELCOR, this calculation is entirely replaced by the VANESA model [4] in the RN package.

\subsection{Mass Transfer and Associated Heat Effects}

The processes involved include the injection of concrete decomposition products (condensed and gaseous) into the debris pool, the addition of core and structural materials from other packages through the mediation of TP, the addition of debris from rupture or overflow of another cavity, and the production of condensed-phase materials 
from chemical reactions. Also involved is the transport of all these materials to their proper locations, whether within a debris layer in CAV or in a CVH volume. These processes modify both the mass inventories and the energy contents of the various debris layers and determine the mass source delivered to $\mathrm{CVH}$ and its associated enthalpy.

The masses and enthalpies of all debris layers are updated for mass transfer and associated heat transfer in two passes. These passes follow the paths of gaseous and condensed-phase concrete decomposition products, and of the products of chemical reactions involving these materials. The updating procedure is designed to account for successive interactions of transported materials, from the location where they are born to the location where they are considered to reside at the conclusion of the advancement procedure.

The first pass, upward through the debris pool, follows the rising gases and rising condensed-phase materials from concrete decomposition or melt/gas reactions. (The direction of motion of condensed-phase materials is, of course, determined by the density relative to the local layer material.) The materials are thermally equilibrated with any layers they pass through, and their mass and energy are ultimately added to the layer where they remain (condensed phases) or to the associated CVH volume (gases). For condensed-phase materials, this final layer is assumed to be the first layer encountered that already contains that phase: HMX, MET, or LMX for metals, and any layer but MET for oxides. A new LOX layer may be formed to accommodate rising oxides from concrete ablation or metal oxidation if none already exists. . Similarly, a new MET layer may be created to accommodate steel from melting reinforcing bars in concrete if the pool contains only a dense oxide layer.

Melt/gas chemical reactions are evaluated during this upward pass, following rising bubbles and flowing films. The composition of the layer involved is modified to reflect the effects of the reaction and, if the reaction takes place in the pure metal layer (MET), the condensed phase oxidic products are added to' the rising inventory. The gas composition is modified appropriately, and the heat of reaction is assumed to remain with the layer in which the reaction occurs.

The second pass, downward through the debris pool, is similar: it follows any material entering from above (from another cavity or from TP), and any sinking reaction and/or concrete ablation products. If use of the mechanistic mixing model, mixing calculations are done during the downward pass. This differs from the initially-released version of CORCON-Mod3 [2]. The change was made because separation of a mixed layer can create a new pure-phase layer below it, and the revised order of calculations greatly simplifies the logic in treatment of this possibility. 


\section{CAV Package Reference Manual}

\subsection{Debris Spreading}

In general, CORCON assumes that debris will spread uniformly and instantaneously across the full width of any cavity into which it is deposited. CORCON-Mod3 added an optional parametric capability to simulate the finite rate of debris spreading by prescribing a maximum radius of the spread debris as a function of time. This can be used to confine the debris as a slowly spreading or non-spreading glob in the center of the floor for some period of time and/or to delay its contact with the side walls of the cavity for as long as may be desired. One effect will be to reduce the surface area of the debris, thus reducing the rate at which it can lose heat. This modeling may affect the timing of the debris-concrete interaction in cases where the initial debris is largely solidified, and is incapable of ablating concrete at a significant rate until it has become more fluid as a result of continued heating by internal decay heat.

In stand-alone CORCON the maximum radius must be specified as a function of time by an input table. In MELCOR, it may be specified by a tabular function, a control function, or a channel in an external data file. In most MELCOR calculations, debris will not appear in the cavity until after the reactor vessel fails, and the time of this event will not be known in advance. The control function option allows the radius to be defined as a function of time relative to debris deposition. It could also be used to consider the debris temperature (as an indicator of its viscosity) in estimating the spreading rate.

In the initially-released version of CORCON-Mod3, the radial surface of spreading debris was subjected to the same thermal boundary condition as the top surface. A subsequent revision allows optional treatment of this boundary as adiabatic. This capability is available in MELCOR.

\subsection{Energy Conservation}

CORCON uses a formulation for the energy equation for debris in the cavity in which temperature driven heat transfers between layers are treated semi-implicitly, as described in Reference 1. Numerical difficulties associated: with addition of new debris were observed during incorporation into MELCOR. The implementation of the equation was substantially modified to improve stability by including modifications made to previous versions of CORCON in the CAV package of MELCOR 1.8.2. The revised numerical treatment is now included in the stand-alone code as well as in MELCOR.

\subsection{Material Properties}

The material properties in the Cavity package are those of the stand-alone CORCON code. They include internally consistent specific heats, enthalpies, and chemical potentials for a large number of condensed and gaseous species, based on fits to JANAF 
[19] and other data. All enthalpies are based on the JANAF thermochemical reference point. All heats of reaction are therefore implicitly contained in the enthalpy data. Also included are data on thermal expansivity and density, thermal conductivity, viscosity, and surface tension.

The list of materials for which properties are defined is contained in Appendix A. These data are independent of the MELCOR data contained in the Water $(\mathrm{H} 2 \mathrm{O})$, NonCondensible Gas (NCG), and Material Properties (MP) packages. They are retained both for consistency with the stand-alone CORCON. code and to facilitate incorporating future upgrades to CORCON modeling into MELCOR. Appropriate adjustments to enthalpies are made whenever materials are passed into or out of the Cavity package.

Additional models are included for evaluating the properties of mixtures. Details of the material properties models, and further references, are contained in Reference 1. Most are quite conventional, but two deserve further discussion in this Reference Manual.

In determining the enthalpy of a mixture as a function of temperature, a submodel is used to determine its melting range as defined by solidus and liquidus temperatures. Below the solidus temperature of the mixture, properties for the solid phase of each speciesextrapolated, if necessary-are used. Similarly, liquid phase properties (possibly extrapolated) are used above the liquidus temperature. Between solidus and liquidus, the enthalpy is interpolated as a linear function of temperature (corresponding to a constant specific heat).

The melting range for the metallic phase is determined from a fit to the ternary phase diagram for $\mathrm{Cr}-\mathrm{Fe}-\mathrm{Ni}$; other elements $(\mathrm{Zr}, \mathrm{C})$ are simply ignored. If the metal phase contain no $\mathrm{Cr}, \mathrm{Fe}$, or $\mathrm{Ni}$, however, the melting point of $\mathrm{Zr}$ will be used. The melt range for an oxidic phase is determined by reference to a pseudo-binary phase diagram based on an ideal solution model for the liquid and solid, phases. One component is high melting and is assumed to consist of fuel $\left(\mathrm{UO}_{2}\right.$ and $\left.\mathrm{ZrO}_{2}\right)$; the second component is low melting and includes everything else. The corresponding melting temperatures and effective latent heats are taken from internal data for fuel for the first component and from the properties of the concrete oxides for the second

Also modeled is the effect of $\mathrm{SiO}_{2}$ content on the viscosity of oxidic mixtures, based on a modification of a correlation derived by Shaw [20]. The original correlation was fit to a database containing geologic data for materials with relatively high silica contents; no consideration was given to application of the correlation outside of the range of compositions included in the original database. As implemented in CORCON and in MELCOR, the original correlation has been modified to avoid nonphysical extrapolation characteristics. It is coupled to a conventional Kendell-Monroe [21] mixture model in such a way that the viscosity is a continuous function of composition over an unrestricted range of compositions. Details are given in Reference 22. 
CAV Package Reference Manual

CAV-RM-24 
CAV Package Reference Manual

\section{COMPARISON TO STAND-ALONE CORCON}

As stated in Section 1, the Cavity package in MELCOR consists primarily of the CORCON-Mod3 code [1]. The calculational routines are identical to those in the standalone code, but input, output, and interfaces to boundary conditions are different. The MELCOR implementation includes several sensitivity coefficients to allow user control of submodels in CORCON. The sensitivity coefficients currently available are:

(1) an additive modification to the concrete ablation enthalpy, and

(2) coefficients in many heat transfer 'relations.

In future versions, we expect to expand this list to allow access to more of the so-called "user flexibility" options available in CORCON-Mod3.

Additional similarities and differences with respect to CORCON-Mod3 are summarized in Table 1. 
CAV Package Reference Manual

Table 1

Comparison of Stand-Alone CORCON-Mod3 [1] and MELCOR Cavity Package

\section{Feature}

Concrete Cavity, Layered Debris, Debris/Concrete, Heat Transfer, Concrete Ablation

Ablation Delay

Overlying Water

Atmosphere and Surroundings

Debris/Water or Debris/Atmosphere Interface

Fission Product (F.P.) Inventories

Internal Heating

Fission Product Release
Stand-Alone MELCOR
Not permitted

Treated by CORCON. Simple equilibration of rising gases

User-input tabular boundary conditions
Optional control function

Part of CVH SPARC bubble model for rising gases

Boundary conditions from CVH Package

Models and correlations identical; numerics of solution modified

Six "pseudo-species" (coarse grouping) included in CORCON; separate detailed inventory for VANESA

Internal model based on F.P. inventories, or input table
Treated in detail by RN package (not part 
CAV Package Reference Manual

Table 1 (cont.)

\begin{tabular}{|c|c|c|}
\hline Feature & Stand-Alone & MELCOR \\
\hline $\begin{array}{l}\text { Cavity Rupture/ } \\
\text { Debris Overflow }\end{array}$ & Not modeled & $\begin{array}{l}\text { Mechanistic melt- } \\
\text { through or "triggered" } \\
\text { failure; overflow } \\
\text { to lower cavity }\end{array}$ \\
\hline Debris Addition & User-input table & $\begin{array}{l}\text { Through TP package, } \\
\text { from other MELCOR } \\
\text { package or table input, } \\
\text { or from other cavity } \\
\text { overflow or rupture }\end{array}$ \\
\hline Debris Spreading & $\begin{array}{l}\text { Parametric model; } \\
\text { requires user-input } \\
\text { table vs time }\end{array}$ & $\begin{array}{l}\text { Same model, but allows } \\
\text { calculation using } \\
\text { control functions }\end{array}$ \\
\hline $\begin{array}{l}\text { Associated F.P. } \\
\text { Addition }\end{array}$ & $\begin{array}{l}\text { Based on added } \mathrm{UO}_{2}, \\
\text { or user-input table }\end{array}$ & $\begin{array}{l}\text { Calculated by RN for } \\
\text { package providing } \\
\text { debris source, or } \\
\text { table input }\end{array}$ \\
\hline $\begin{array}{l}\text { User Control of } \\
\text { Modeling }\end{array}$ & $\begin{array}{l}\text { Provided through "user } \\
\text { flexibility" input }\end{array}$ & $\begin{array}{l}\text { Provided by user input } \\
\text { and sensitivity coefficients; } \\
\text { not all user flexibility } \\
\text { inputs currently connected }\end{array}$ \\
\hline $\begin{array}{l}\text { Restart/Fallback } \\
\text { Capability }\end{array}$ & Not available & $\begin{array}{l}\text { Provided as part of } \\
\text { MELCOR structure }\end{array}$ \\
\hline User Input & Fixed format & $\begin{array}{l}\text { MELCOR free-field } \\
\text { format }\end{array}$ \\
\hline Printed Output & $\begin{array}{l}\text { Controlled by } \\
\text { CORCON input }\end{array}$ & $\begin{array}{l}\text { Essentially identical; } \\
\text { controlled by MELCOR } \\
\text { input }\end{array}$ \\
\hline Plotted Output & $\begin{array}{l}\text { Latest version allows } \\
\text { use of HISPLTM }\end{array}$ & $\begin{array}{l}\text { Plots available in } \\
\text { normal MELCOR manner } \\
\text { using HISPLTM }\end{array}$ \\
\hline
\end{tabular}




\section{CAV Package Reference Manual}

The differences between the MELCOR Cavity package and stand-alone CORCON-Mod3 listed in Table 1 fall into three distinct groups:

\section{Coupling of Phenomena}

These differences include the use of calculated boundary conditions such as temperature, pressure, and debris addition rates rather than user-supplied tabular data which must be generated from some independent source, and the provision to allow debris to be relocated between two or more locations when cavity boundaries fail. CAV allows the use of tabular boundary conditions by defining time-specified volumes in $\mathrm{CVH}$ and/or tabular debris addition rates through TP and EDF. Both CORCON-Mod3 and MELCOR can calculate internal decay heating based on fission product inventories, with these inventories subject to reduction by a coupled fission product release calculation using VANESA. In MELCOR, the decay heat is based directly on the detailed inventories calculated by VANESA; in CORCON-Mod3, these inventories must be approximately mapped back into the coarse group inventories used by the CORCON decay heat model.

The basic reason for existence of MELCOR is to allow the effects of coupling of various phenomena to be included in severe reactor accident calculations.

\section{User Control}

MELCOR is intended for use as a PRA code while versions of CORCON prior to Mod3 were developed as best-estimate codes. Therefore, MELCOR 1.8.2 allowed more user control of modeling options than did the then-existing versions of CORCON. "User flexibility inputs" were made available in CORCON-Mod3. Although there was some overlap in capabilities, several of the sensitivity coefficients in the MELCOR 1.8.2 CAV package have not been reconnected to CORCON-Mod3, and many of the user flexibility variables in that code have not yet been made accessible from MELCOR input. This situation will be corrected in later versions of MELCOR.

User Interface, User Convenience

These differences include revised input formats, restart and fallback capabilities, and plot capabilities, which have no effect on modeling of physical phenomena.

Although the CAV package in MELCOR and the stand-alone CORCON-Mod3 code contain identical versions of all subroutines incorporating phenomenological models and materials properties, they should be viewed as distinct entities because of the differences in treatment of interfaces and calculation of boundary conditions. However, because the basic modeling is identical, it is possible to run equivalent calculations with the two codes under appropriate choices of options and restrictions on boundary conditions. 
CAV Package Reference Manual

\section{REFERENCES}

1. D. R. Bradley and D. R. Gardner, CORCON-MOD3: An Integrated Computer Model for Analysis of Molten Core-Concrete Interactions. Users Manual, NUREG/CR5843, SAND92-0167, Sandia National Laboratories, Albuquerque, NM (October 1993).

2. K. E. Washington, Letter Report to Sudhamay Basu, USNRC, "CORCON Mod3 Code Integration," under FIN L1484 (February 1993).

3. R. O. Griffith, et al., CONTAIN 1.2 Users Manual, SAND94-2358, Sandia National Laboratories, Albuquerque, NM (1994).

4. D. A. Powers, J. E. Brockmann, and A. W. Shiver, VANESA: A Mechanistic Model of Radionuclide Release and Aerosol Generation During Core Debris Interactions with Concrete, NUREG/CR-4308, SAND85-1370, Sandia National Laboratories, Albuquerque, NM (July 1986).

5. MAAP, Modular Accident Analysis Program User's Manual, Volumes 1 and 2, IDCOR $(1984,1987)$.

6. G. A. Greene, "Heat, Mass, and Momentum Transfer in a Multi-Fluid Bubbling Pool," Advances in Heat Transfer, Vol. 21, pp. 270-345 (1991).

7. G. A. Greene, J. C. Chen, and M. T. Conklin, "Onset of Entrainment Between Immiscible Liquid Layers Due to Rising Gas Bubbles," International Journal of Heat and Mass Transfer. Vol. 31, p. 1309 (1988).

8. G. A. Greene, J. C. Chen, and M. T. Conklin, "Bubble-Induced Entrainment Between Stratified Liquid Layers," Intemational Journal of Heat and Mass Transfer. Vol. 34, p. 149 (1990).

9. S. S. Kutateladże and I. G. Malenkov, "Boiling and Bubbling Heat Transfer Between a Gas-Liquid System and a Heat Exchange Element," Zhurnal Prikladnoi Khimii (Journal of Applied Chemistry of the USSR, Vol. 35, No. 11 (1962).

10. G. A. Greene and T. F. Irvine, "Heat Transfer Between Stratified Immiscible Liquid Layers Driven by Gas Bubbling Across the Interface," in ANS Proceedings of the 1988 National Heat Transfer Conference, Houston, TX, July 24-27 (1988).

11. F. A. Kulacki and R. J. Goldstein, "Thermal Convection in a Horizontal Fluid Layer with Uniform Volumetric Energy Source," Joumal of Fluid Mechanics, Vol. 55, No. 2, p. 271 (1975). 
CAV Package Reference Manual

12. F. A. Kulacki and M. E. Nagle, Journal of Heat Transfer, Vol. 97, p. 204 (1975).

13. F. A. Kulacki and A. A. Emara, Trans. ANS, Vol. 22, No. 2, p. 447 (1975).

14. M. T. Farmer, J. J. Sienicki, and B. W. Spencer, "CORQUENCH: A Model for Gas Sparging-Enhanced Melt Water Film Boiling Heat Transfer," ANS Special Session on Thermal Hydraulics of Severe Accidents, November 11-15, 1990.

15. R. K. Cole, Jr., "A Crust Formation and Refreezing Model for Molten-Fuel/Concrete Interaction Codes," Paper 12.5 in Proceedings, International Meeting on Light Water Reactor Severe Accident Evaluation, Cambridge, MA (1983).

16. H. Alsmeyer and M. Reimann, "On the Heat and Mass Transport Processes of a Horizontal Melting or Decomposing Layer under a Molten Pool," Nuclear Reactor Safety Heat Transfer, Winter Annual Meeting ASME, Atlanta, GA, pp. 47-53 (1977).

17. D. R. Bradley, "Modeling of Heat Transfer Between Core Debris and Concrete," in ANS Proceedings of the 1988 National Heat Transfer Conference, Houston, Texas, p. 37-49, (July 1988).

18. K. C. Kwong, R. A. S. Beck, and T. C. Derbidge, CORCON Program Assistance, FR-79-10/AS, ACUREX Corporation/Aerotherm Aerospace Division, Mt. View, CA (July 1979).

19. JANAF Thermochemical Tables, DOW Chemical Company, Thermal Research Laboratory, Midland, MI (1965).

20. H. R. Shaw, "Viscosities of Magmatic Silicate Liquids: An Empirical Method of Prediction," American Journal of Science, Vol. 272, pp. 870-893 (1972).

21. J. Kendell and K. P. Monroe, "The Viscosity of Liquids, III Ideal Solution of Solids in Liquids," Journal of the American Chem. Soc., Vol. 39, No. 8, p 1802 (September 1917).

22. R. K. Cole, Jr., D. P. Kelly, and M. A. Ellis, "Molten Fuel/Concrete Interactions Study," in Light Water Reactor Safety Research Program Semiannual Report, April-September 1982, NUREG/CR-3407, SAND83-1576, Nuclear Fuel Cycle Program, Sandia National Laboratories, Albuquerque, NM (October 1982). 
CAV Package Reference Manual

\section{APPENDIX A: Species list for CORCON in MELCOR}

The list of species considered by CORCON and available for use in MELCOR, either as initial contents in the melt or as constituents of concrete, is:

\begin{tabular}{ll} 
OXIDES & METALS \\
\hline SIO2 & FE \\
TIO2 & CR \\
FEO & NI \\
MNO & ZR \\
MGO & MN \\
CAO & C(C) \\
SRO & NA \\
BAO & AL \\
LI2O & U \\
NA2O & SI \\
K2O & UAL3 \\
FE2O3 & UAL2 \\
AL2O3 & CA \\
UO2 & \\
ZRO2 & \\
CR2O3 & \\
NIO & \\
FE3O4 & \\
MN3O4 & \\
PUO2 & \\
UO3 & \\
U3O8 &
\end{tabular}

The observant reader may note that several additional species are included in the corresponding list, Table 2.1, in Reference 1. These include the aluminates, pseudo fission products, and element " $X$ ", which are (or were) used in internal models in standalone versions of CORCON and are not relevant to the implementation in MELCOR. 
CAV Package Reference Manual

There are 5 additional species which may be used in specification of concrete compositions:

CONCRETE CONSTITUENTS

$\mathrm{CO} 2$

H2OCHEM (chemically-bound water)

H2OEVAP (evaporative water)

$\mathrm{CACO} 3$

$\mathrm{CA}(\mathrm{OH}) 2$

These are used only in specification of the concrete composition; in particular, $\mathrm{CACO} 3$ and $\mathrm{CA}(\mathrm{OH}) 2$ are decomposed during initialization into $\mathrm{CAO}$ plus $\mathrm{CO} 2$ and into $\mathrm{CAO}$ plus $\mathrm{H} 2 \mathrm{OCHEM}$, respectively. The difference between H2OCHEM and H2OEVAP is the binding energy which must be overcome to release them from the concrete.

The list of gases in Table 2.1 of Reference 1 is not relevant to MELCOR input, as the composition of the control volume above the debris pool is determined by the CVH package. In addition, production of all trace gaseous species has been suppressed in the chemical reaction routines so that the only gases considered by CORCON in MELCOR are $\mathrm{H} 2, \mathrm{H} 2 \mathrm{O}, \mathrm{CO}$, and $\mathrm{CO} 2$. 


\title{
Core (COR) Package Reference Manual
}

\author{
MELCOR Code Development Group \\ Modeling and Analysis Department \\ Nuclear Energy Technology Center \\ Sandia National Laboratories \\ Albuquerque, NM 87185-0739
}

Contributors:

Randall M. Summers

Russell C. Smith

The MELCOR Core (COR) package calculates the thermal response of the core and lower plenum internal structures, including the portion of the lower head directly below the core. The package also models the relocation of core and lower plenum structural materials during melting, slumping, and debris formation, including failure of the reactor vessel and ejection of debris into the reactor cavity. Energy transfer to and from the Control Volume Hydrodynamics package and the Heat Structure package is calculated. This Reference Manual gives a description of the physical models in the COR package, including the nodalization scheme and calculational framework of the package, the heat transfer and oxidation models, the mass relocation models, and the default lower head model. Debris behavior in the lower plenum in BWRs may also be treated in the Bottom Head package, described in the BH Package Reference Manual.

User input for running MELGEN and MELCOR with the COR package activated is described in the COR Package Users' Guide. 
COR Package Reference Manual

COR-RM-2 


\section{Contents}

1. INTRODUCTION .......................... 7

1.1 Nodalization Scheme $\ldots \ldots \ldots \ldots \ldots \ldots \ldots \ldots \ldots \ldots \ldots$

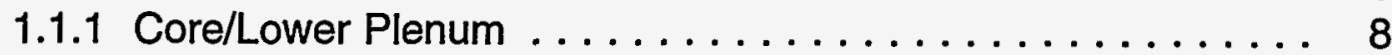

1.1 .2 Lower Head ...................... 13

1.2 Calculation Framework $\ldots \ldots \ldots \ldots \ldots \ldots \ldots \ldots \ldots \ldots$

2. HEAT TRANSFER AND OXIDATION MODELS $\ldots \ldots \ldots \ldots \ldots \ldots \ldots \ldots$

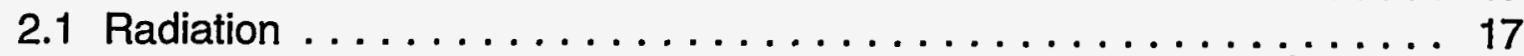

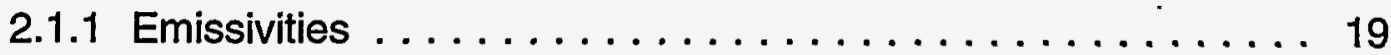

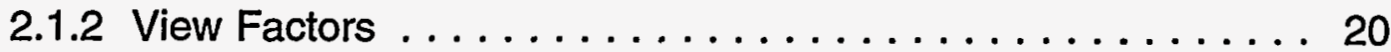

2.1.3 Implementation Logic . . . . . . . . . . . . . . . . 23

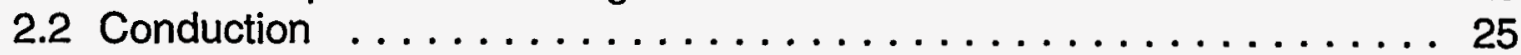

2.2.1 Axial Conduction .................... 26

2.2.2 Fuel-Cladding Gap Heat Transfer . . . . . . . . . . . . 29

2.2.3 Conduction to Boundary Heat Structures . . . . . . . . . 31

2.3 Convection . . . . . . . . . . . . . . . . . . 32

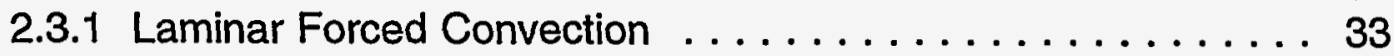

2.3.2 Turbulent Forced Convection ................ 34

2.3.3 Laminar and Turbulent Free Convection ........... 34

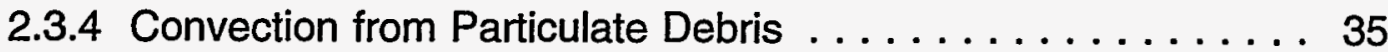

2.3.5 Boiling ........................ 35

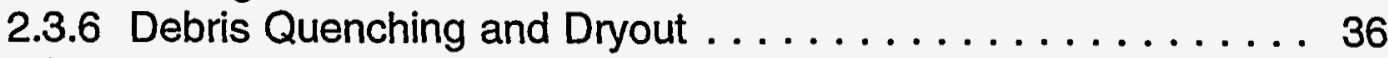

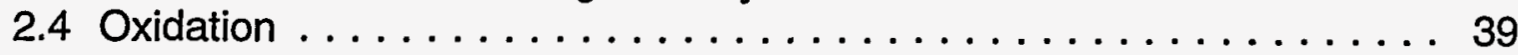

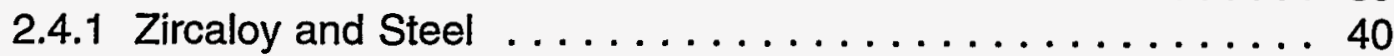

2.4 .2 Boron Carbide ........................ 44

2.5 Control Volume Temperature Distribution (dT/dz) Model . . . . . . . 46

2.6 Fission Power Generation . . . . . . . . . . . . . . . . . 48

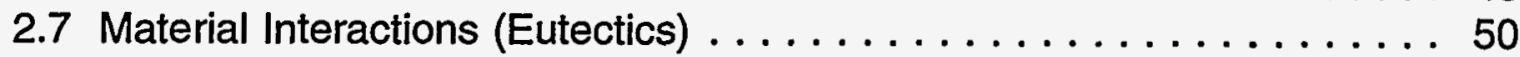

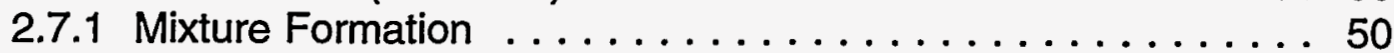

2.7.2 Mixture Properties .................. 51

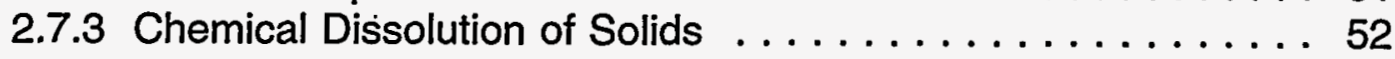

3. MASS RELOCATION MODELS $\ldots \ldots \ldots \ldots \ldots \ldots \ldots \ldots \ldots \ldots \ldots$

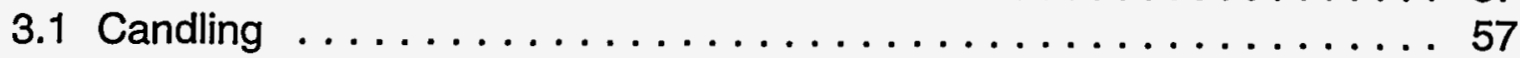

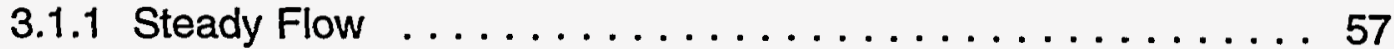

3.1.2 Flow Blockages .................... 61

3.1.3 Holdup by Oxide Shells $\ldots \ldots \ldots \ldots \ldots \ldots \ldots \ldots 63$

3.1.4 Solid Material Transport . . . . . . . . . . . . . . . . 63

3.1.5 Surface Area Effects of Conglomerate Debris ......... 64

3.2 Radial Relocation . . . . . . . . . . . . . . . . . . . . . 67

3.2.1 Molten Material . . . . . . . . . . . . . . . . 68

3.2.2 Particulate Debris $\ldots \ldots \ldots \ldots \ldots \ldots \ldots \ldots \ldots 68 \ldots \ldots \ldots$ 
COR Package Reference Manual

3.3 Particulate Debris Formation . . . . . . . . . . . . . . 69

3.3.1 Debris Addition from Heat Structure Melting . . . . . . . 70

3.4 Gravitational Settling . . . . . . . . . . . . . . . . 71

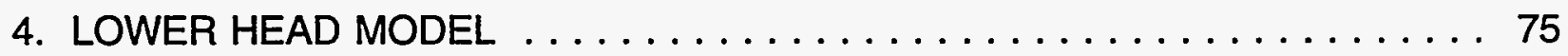

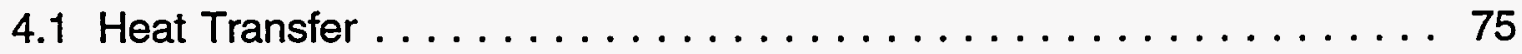

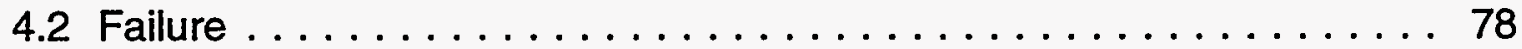

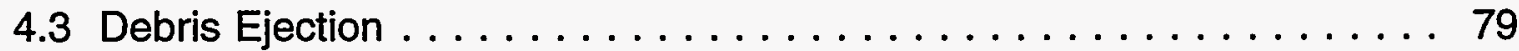

5. DISCUSSION AND DEVELOPMENT PLANS $\ldots \ldots \ldots \ldots \ldots \ldots \ldots$

5.1 Coupling to Hydrodynamic Flows $\ldots \ldots \ldots \ldots \ldots \ldots \ldots \ldots \ldots$

5.2 Radiation .......................... 83

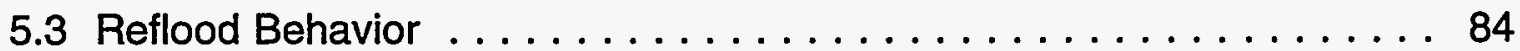

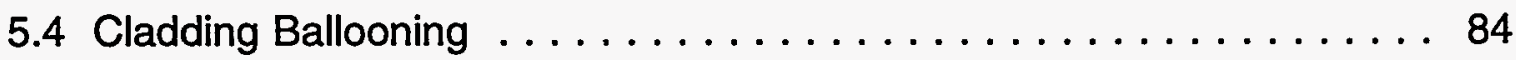

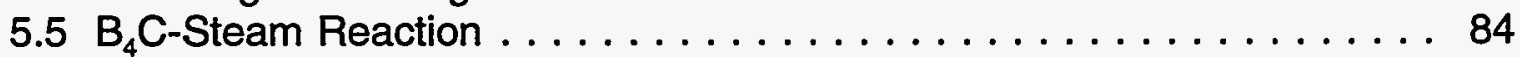

5.6 Coupling of Blockages to $\mathrm{CVH} \ldots \ldots \ldots \ldots \ldots \ldots \ldots \ldots$

5.7 Structure Support/Crust Failure . . . . . . . . . . . . 85

5.8 Lower Plenum Debris Behavior and Vessel Failure . . . . . . . . . 85

6. REFERENCES $\ldots \ldots \ldots \ldots \ldots \ldots \ldots \ldots \ldots \ldots \ldots \ldots \ldots$

APPENDIX A: Sensitivity Coefficients $\ldots \ldots \ldots \ldots \ldots \ldots \ldots \ldots \ldots$ 
COR Package Reference Manual

\section{List of Figures}

1.1.1 Core/lower plenum nodalization $\ldots \ldots \ldots \ldots \ldots \ldots \ldots \ldots \ldots \ldots .9$

1.1.2 Core cell components $\ldots \ldots \ldots \ldots \ldots \ldots \ldots \ldots \ldots \ldots \ldots \ldots \ldots$

1.1.3 Typical COR-CVH nodalization interface.(2D) $\ldots \ldots \ldots \ldots \ldots \ldots \ldots$

1.1.4 Typical COR-CVH nodalization interface (3D) $\ldots \ldots \ldots \ldots \ldots \ldots$

1.1.5 Lower head nodalization (one ring) $\ldots \ldots \ldots \ldots \ldots \ldots \ldots \ldots$

2.1.1 Radiative heat transfer framework-BWR cell cross-section . . . . . . . 22

2.1.2 Radiation model logic flow chart $\ldots \ldots \ldots \ldots \ldots \ldots \ldots \ldots \ldots \ldots \ldots$

2.2.1 Component axial temperature gradient across liquid level ... . . . . . . 27

2.7.1 Two-phase construction for material mixture $\ldots \ldots \ldots \ldots \ldots \ldots \ldots$

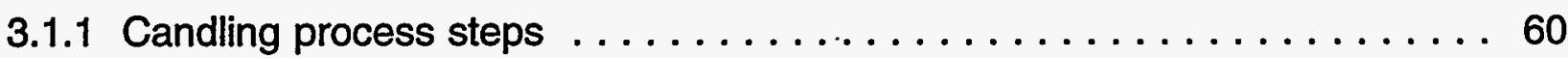

3.1.2 Flow blockage formation during candling $\ldots \ldots \ldots \ldots \ldots \ldots \ldots$

3.1.3 Conglomerate debris geometry in fuel rod bundles $\ldots \ldots \ldots \ldots \ldots \ldots 65$

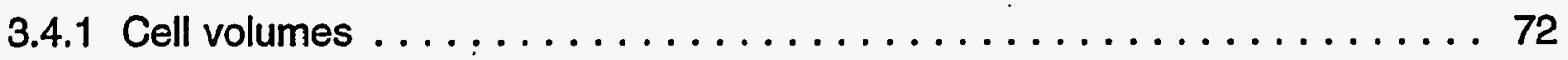

4.1.1 Lower head nodalization $\ldots \ldots \ldots \ldots \ldots \ldots \ldots \ldots \ldots \ldots \ldots$ 
COR Package Reference Manual

\section{List of Tables}

2.1.1 Steam emissivity vs. temperature and optical depth $\ldots \ldots \ldots \ldots \ldots 21$

2.7.1 Core eutectic reactions $\ldots \ldots \ldots \ldots \ldots \ldots \ldots \ldots \ldots \ldots \ldots \ldots \ldots \ldots \ldots \ldots \ldots \ldots$

2.7.2 Solid dissolution hierarchy $\ldots \ldots \ldots \ldots \ldots \ldots \ldots \ldots \ldots \ldots \ldots$

3.1.1 Primary and alternate refreezing components $\ldots \ldots \ldots \ldots \ldots \ldots \ldots$ 
COR Package Reference Manual

\section{INTRODUCTION}

The MELCOR COR package calculates the thermal response of the core and lower plenum structures, including the portion of the lower head directly beneath the core, and models the relocation of core materials during melting, slumping, and debris formation. Fuel pellets, cladding, grid spacers, canister,walls (for BWRs), other structures (e.g., control rods or guide tubes), and particulate debris are modeled separately within individual cells, the basic nodalization unit in the COR package. Either BWR or PWR systems may be modeled, as specified on record COR00002. (For the convenience of the user and the sake of clarity, numerous cross-references are made in this document to specific input records and quantities in the. COR Package Users' Guide. Both documents should be consulted by the user for a more complete understanding of the models and their implementation.)

All important heat transfer processes are modeled in each COR cell. Thermal radiation within a cell and between cells in both the axial and radial directions is calculated, as well as radiation to bouridary structures (e.g., the core shroud or upper plenum, which are modeled by the Heat Structure package) from the outer and upper COR cells. Radiation to a liquid pool (or the lower head if a pool is absent). and to steam is also included. Conduction radially across the fuel-cladding gap and axially between cells, and optionally between the core and radial boundary heat structures, is modeled. An analytical model for axial conduction is applied within structures that are partially covered with liquid pool. Convection to the control volume fluids is modeled for a wide range of fluid conditions and structure surface temperatures, including nucleate and film boiling.

Oxidation of Zircaloy and steel is modeled for both the limiting cases of solid-state diffusion of oxygen through the oxide layer and gaseous diffusion of steam or oxygen through the mixture. The reaction of $\mathrm{B}_{4} \mathrm{C}$ with steam is also treated.

The core degradation model treats eutectic liquefaction and dissolution reactions, candling of molten core materials (i.e., downward flow and refreezing), and the formation and relocation of particulate debris. Geometric variables (e.g., cell surface areas and volumes) are updated for changing core geometry.

Many of the various physics models can be selectively disabled by setting the flags on MELCOR input record CORTST01. This action might be appropriate for testing purposes or to bypass phenomena that are not expected to arise during a particular calculation. 
COR Package Reference Manual

\subsection{Nodalization Scheme}

\subsubsection{Core/Lower Plenum}

The core and lower plenum regions of the reactor vessel are divided into concentric radial rings and axial levels, as shown in Figure 1.1.1; the numbers of rings and levels are input by the user on record COR00000. The number of levels defining the lower plenum alone (which should include the core plate) is defined by the user on this record also. A particular radial ring and a particular axial level designate a COR cell, whose cell number is defined as a three-digit number; the first digit represents the radial ring number and the last two digits represent the axial level number. For example, cell 307 denotes the third radial ring and the seventh axial level. Radial rings are numbered from the center out and axial levels are numbered from the bottom head up. This nodalization scheme applies only to structures treated by the COR package, and is independent of the control volume nodalization specified for the Control Volume Hydrodynamics (CVH) package. The interface between the COR and $\mathrm{CVH}$ packages is discussed later in this section.

Each cell may contain one or more components, as shown in Figure 1.1.2. Five possible intact components are modeled: (1) fuel, (2) cladding, (3) and (4) BWR canister walls, split into two parts: one part not adjacent to the control blade and another part that is, and (5) "other structure" (e.g, control rods). Particulate debris is modeled as a possible sixth component. A lumped parameter treatment is used for each component within a cell; therefore, each component is represented by a single temperature. Heat transfer and oxidation processes are modeled separately for each component. Conglomerate debris, i.e., core material that has melted and resolidified, is modeled as an integral part of the component onto which it has frozen, which may be any one of the six listed above except for intact fuel.

The following table identifies each component by its component number and component identifier, which are often used in the COR package documentation.
1 FU intact fuel component
$2 \mathrm{CL} \quad$ intact cladding
$3 \mathrm{CN}$ intact canister component (portion not adjacent to control blade
$4 \quad \mathrm{CB} \quad$ intact canister component (portion adjacent to control blade)
5 OS or SS "other structure" component
6 PD or DP particulate debris component 


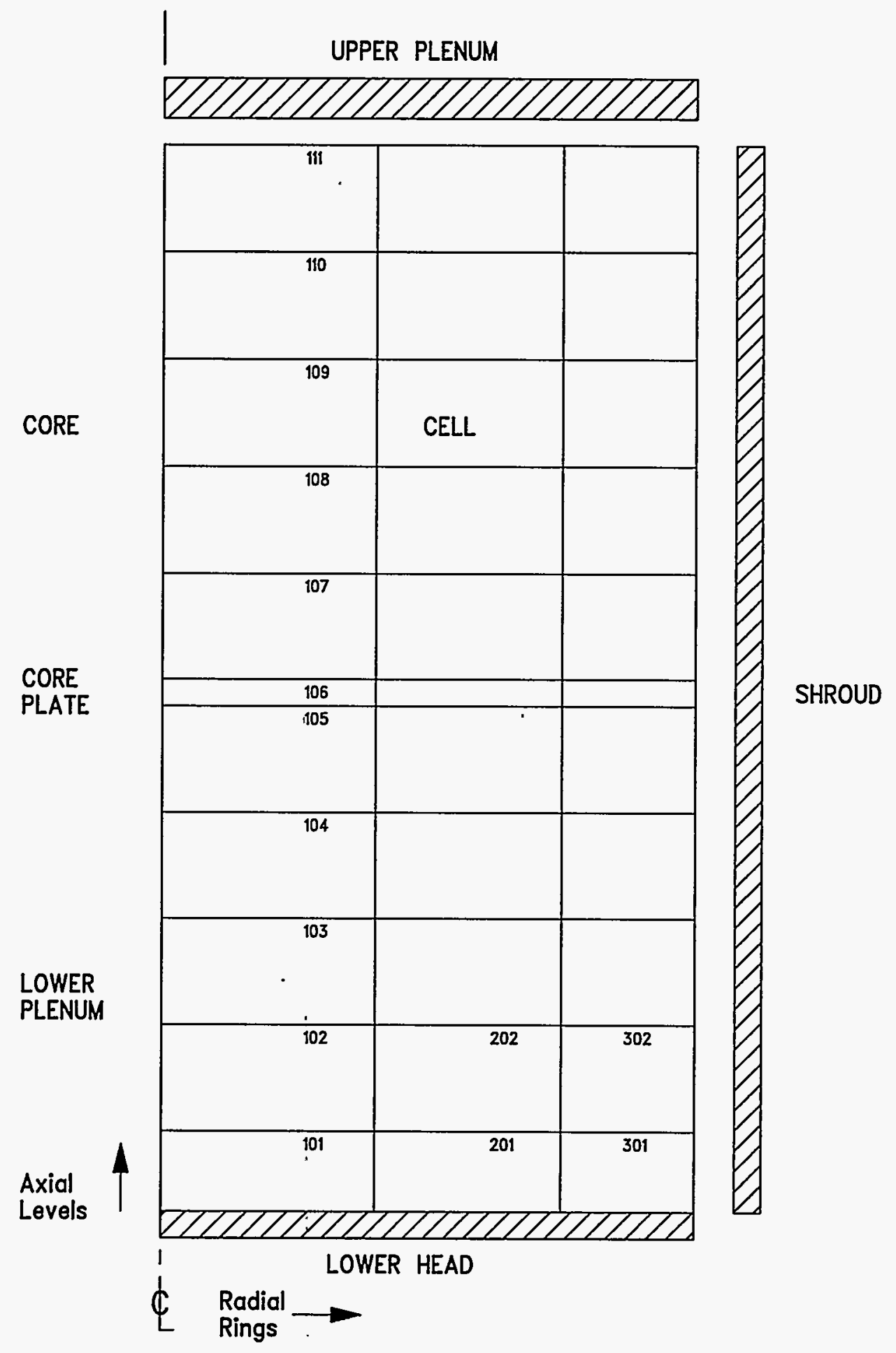

Figure 1.1.1 Core/lower plenum nodalization 


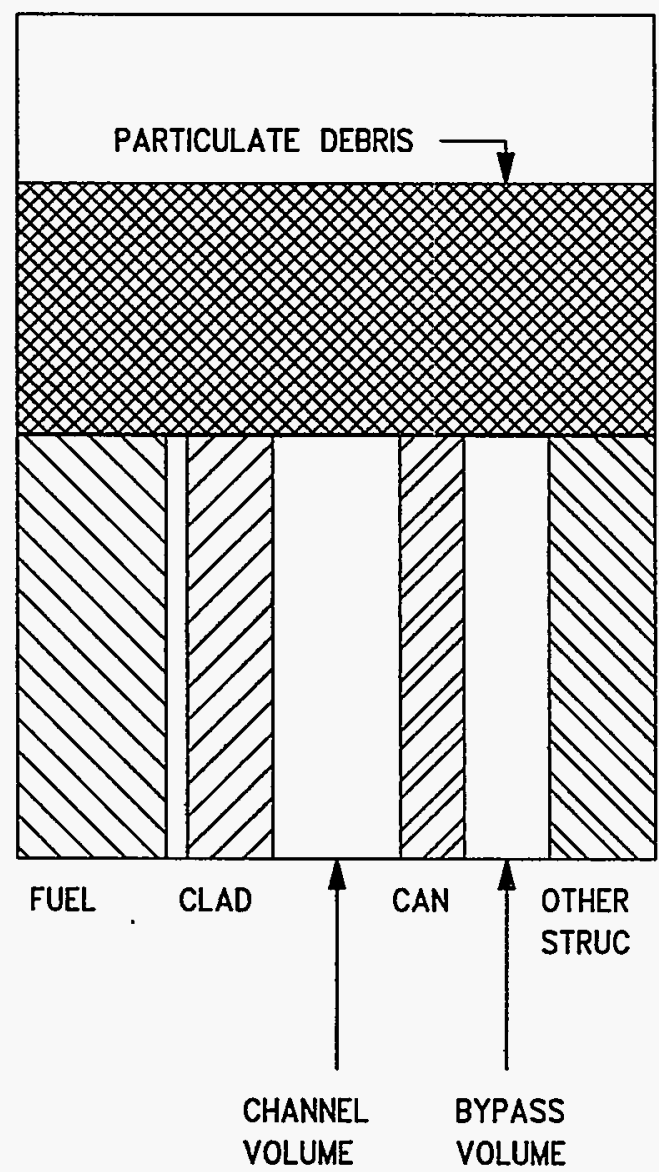

Figure 1.1.2 Core cell components

Eight materials are currently modeled in the COR package: (1) $\mathrm{UO}_{2}$, (2) Zircaloy, (3) steel, (4) $\mathrm{ZrO}_{2}$, (5) steel oxide, (6) control rod poison, which may be either boron carbide $\left(\mathrm{B}_{4} \mathrm{C}\right)$ or silver-indium-cadmium alloy ( $\left.\mathrm{Ag}-\mathrm{In}-\mathrm{Cd}\right)$ as specified on record COR00002, (7) Inconel, and (8) an electric heating element material, specified on record COR00002. Each component may be composed of one or more of these materials, although neither oxide masses for intact components nor any particular debris masses can currently be specified through user input. For example, the cladding component may be composed of Zircaloy, Inconel (to simulate grid spacers), and $\mathrm{ZrO}_{2}$ (calculated by the COR package oxidation models). The melting and candling of materials results in the possibility of any or all materials being found in a given component.

Zircaloy is considered a single material in the COR package, with no distinction made between zirconium and the alloying elements. Steel and steel oxide are also each modeled as single materials within the COR package, but the user must specify the fractions of iron, nickel, and chromium in the steel so that oxidation can be properly 
COR Package Reference Manual

treated and the right amounts of each species can be transmitted to the Cavity (CAV) package during debris ejection. Inconel is treated as a single material, and currently it has the same properties as steel (and is ejected as steel), but it is not permitted to oxidize.

Several geometric variables are defined by the user to further describe the cells and components. Representative dimensions for the intact components are specified on record COR00001, and elevations and lengths (heights) for each cell are input on record CORZjj01. Equivalent diameters for each component in each cell for use in various heat transfer correlations also must be specified on record CORijj04. Cell boundary areas for inter-cell radiation (both axially and radially) are defined by the user on records CORijj05 and CORRii01. Initial volumes of components and the "empty" CVH fluid volume are calculated based on user input for component masses and cell flow areas (records CORijj02 and CORiij05), and are then tracked during core slumping and flow blockage calculations. (Currently, no consistency checks are performed to compare the CVH fluid volume calculated by the COR package using these parameters with the volumes entered into $\mathrm{CVH}$ via the volume-altitude tables; this will be addressed in future code versions.)

For each intact component in each cell, a surface area is input by the user on record CORijj06 for convection and oxidation calculations. (The single surface area value input for a canister is multiplied by elements in sensitivity coefficient array C1501 to obtain values for each side of each canister component to communicate separately with the channel and bypass control volumes.) For particulate debris, a surface area is calculated from the total mass and a user-defined particle size input on record CORijj04. (For oxidation of particulate debris, separate Zircaloy and steel surface areas are calculated.) The effects of conglomerate debris on component surface areas are factored into the heat transfer, oxidation, and candling calculations; this model is described in Section 3.1.5.

As discussed later in Sections 2.3 and 2.5, the Control Volume Hydrodynamics (CVH) package supplies fluid conditions for use by the COR package in calculating heat transfer and oxidation rates, which are then multiplied by the time step and passed back to the $\mathrm{CVH}$ package as energy and mass sources or sinks. The nodalization for the reactor vessel used in the CVH package is typically much coarser than that used in the COR package, but finer CVH nodalizations can be used to simulate in-vessel natural circulation. The COR nodalization applies only to those components in the core and lower plenum treated by the COR package, and is independent of the CVH nodalization, with some restrictions imposed.

Figure 1.1.3 gives a 2-D representation of the interface between the COR and CVH packages, but to more accurately depict the relationship between the two nodalizations requires a 3-D illustration, shown in Figure 1.1.4. Each COR cell interfaces with a CVH control volume (input on record CORijj01) representing the primary flow (channel volume), and typically many core or lower plenum cells will interface with the same control volume. For BWRs, a separate CVH control volume (shown behind the channel volume in Figure 
COR Package Reference Manual

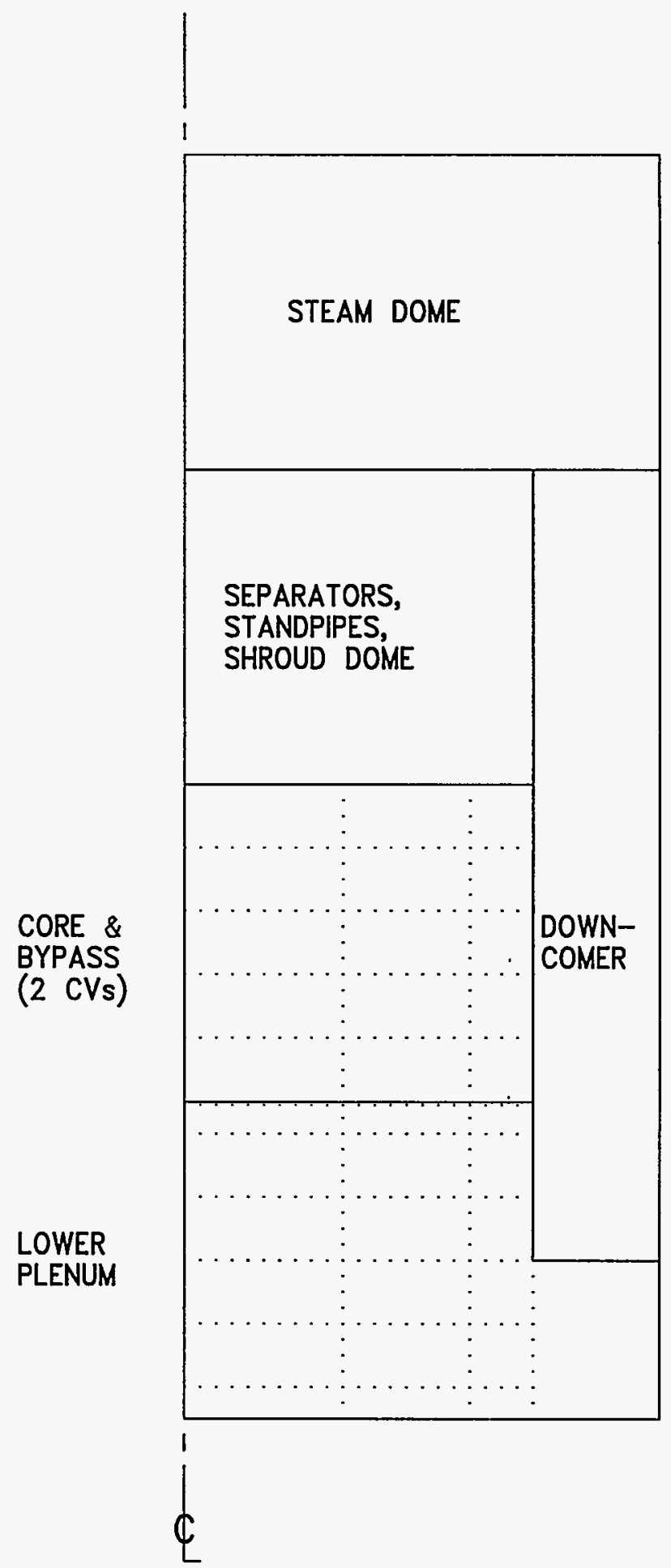

Figure 1.1.3 Typical COR-CVH nodalization interface (2D) 


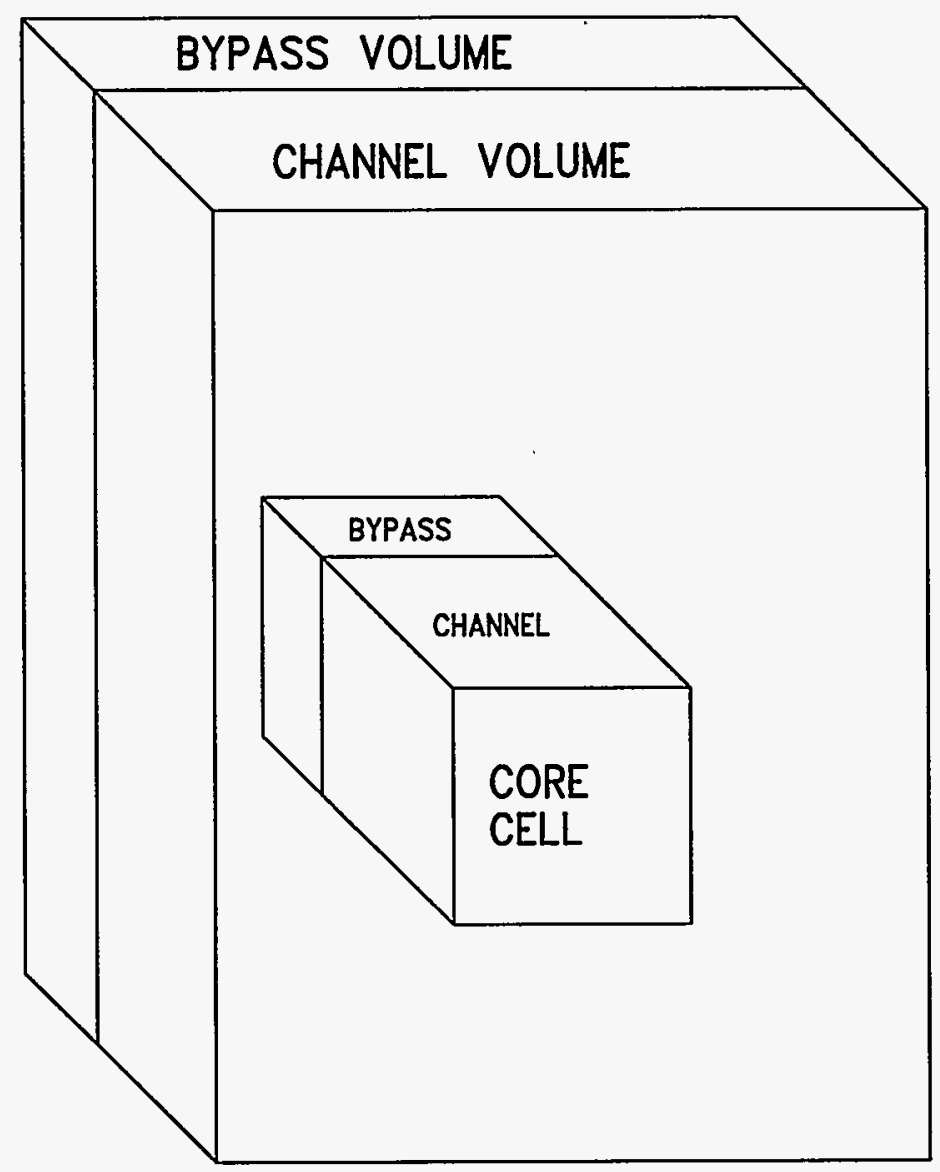

Figure 1.1.4 Typical COR-CVH nodalization interface (3D)

1.1.4) may also be specified for COR cells on record CORijj01 to represent the interstitial space between fuel assemblies (bypass volume). The outer canister surfaces and the "other structure" surface both communicate with this bypass control volume if it is defined, instead of with the channel control volume. The total number of control volumes interfaced to the COR package is a required input quantity on record COR00000. The only restrictions between $\mathrm{CVH}$ and COR nodalizations are that control volumes occupy a rectangular grid of core cells and have boundaries lying either on cell boundaries or entirely outside the core nodalization.

\subsubsection{Lower Head}

The basic elements of the COR package lower head heat transfer model are the portion of the lower head hemisphere directly beneath the core, head penetrations such as instrumentation tubes or guide tubes, and the layer of debris on top of the lower head. 


\section{COR Package Reference Manual}

The lower head is divided into radial rings corresponding to the core/lower plenum nodalization, and its thickness (defined on record COR00001) is divided axially into a number (specified by the user on record COR00000) of equally spaced finite-difference nodes for treating conduction. Figure 1.1.5 illustrates the lower head nodalization for a single radial ring. For each lower head ring, the user can define up to three representative types of penetrations (only one is shown in the figure), specifying the total mass and heat transfer areas associated with, each penetration type and the initial effective diameter of the opening created when a penetration fails. Each penetration communicates thermally with the top lower head node and with the debris. The Heat Structure (HS) package should not be used to model the center portion of the lower head treated by the COR package, but should only be used to model the upper portion of the head hemisphere that does not directly contact the debris. There should be no duplication of head mass or surface area between HS and COR packages. Neither should there be any duplication of mass or surface area between penetrations and structures modeled as other structure in the first axial level of core cells; the user may divide such structures between penetrations and other structure arbitrarily, but the thermal modeling interface is somewhat indirect. The user should also realize that penetration masses are not currently added to core/lower plenum debris masses and cannot be ejected from the reactor vessel. The total number of penetrations in all rings is a required input quantity on record COR00000.

For BWRs, the Bottom Head (BH) package has been developed by Oak Ridge National Laboratories for more detailed treatment of lower plenum debris behavior and bottom head heatup and failure following debris bed dryout. That package may be activated by optional user input and is documented separately with its own Users' Guide and Reference Manual. The BH package is undergoing continued development at ORNL, and its integration into MELCOR is incomplete, with some compatibility problems with other MELCOR models remaining. In particular, mass and energy conservation tracking has not been fully implemented for global MELCOR accounting.

\subsection{Calculation Framework}

All thermal calculations in the COR package (both in the core/lower plenum components and in the lower head) are done using internal energies of the materials (i.e., temperature is a derived variable calculated from the material internal energies; initial temperatures are defined on record CORijj03). The mass and internal energy of each material in each component are tracked separately to conserve total mass and energy to within machine roundoff accuracy.

The COR package uses an explicit numerical scheme for advancing the thermal state of the core, lower plenum, and lower head through time. To mitigate numerical instabilities, a subcycling capability has been developed to allow the COR package to take multiple time steps across a single Executive package time step. All energy generation, heat 


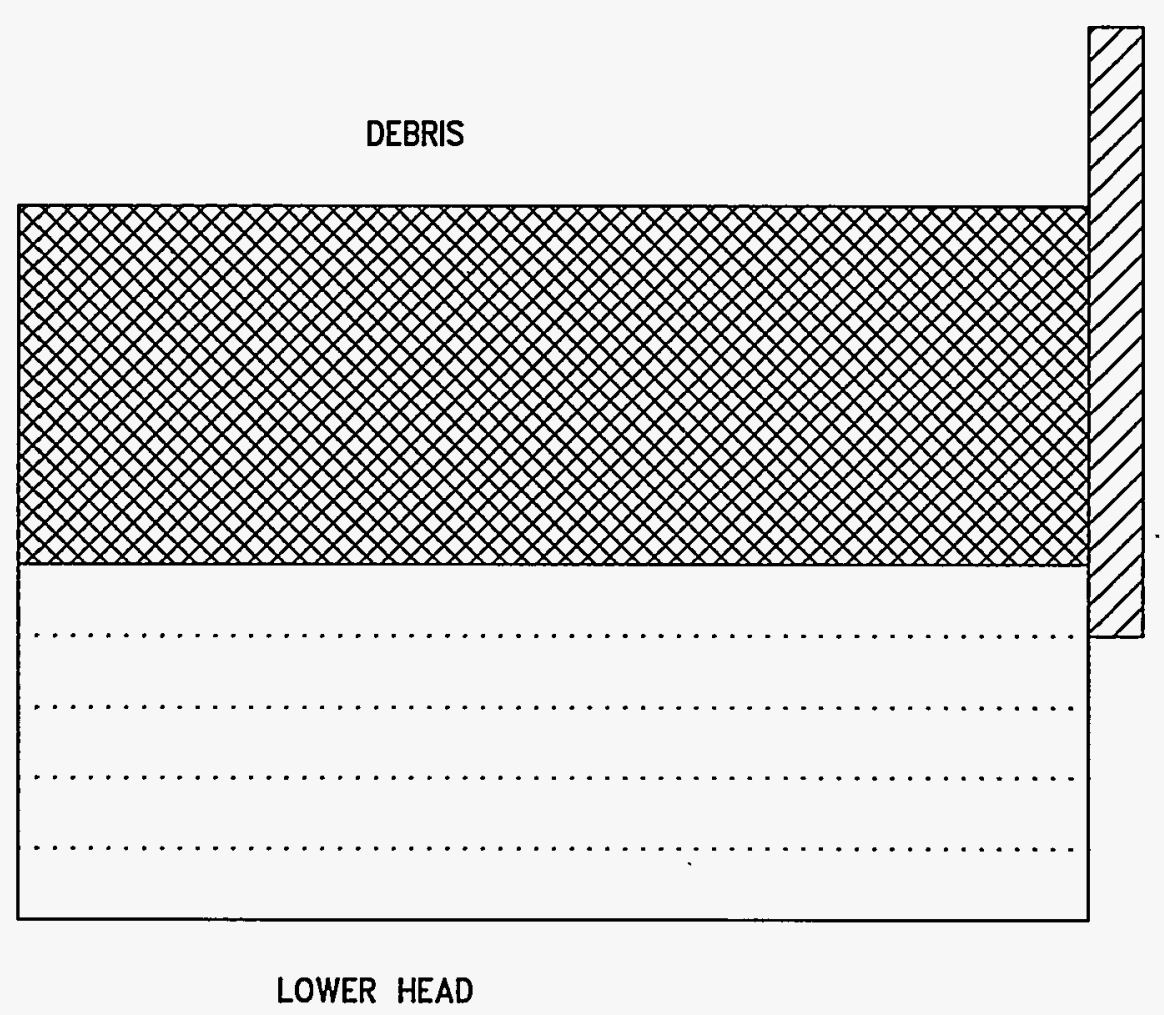

Figure 1.1.5 Lower head nodalization (one ring)

transfer, and oxidation rates are evaluated at the beginning of a COR package subcycle based on current temperatures, geometric conditions, and an estimate of the local fluid conditions (calculated by the COR package $\mathrm{dT} / \mathrm{dz}$ model to reflect the temperature variation within a control volume containing many individual COR cells). The net energy gain (or loss) across the subcycle is determined for each component by multiplying these rates by the COR package time step.

The temperature change of most components is limited to a user-input maximum; if the calculated temperature change for a component is greater than this limit, the COR package subcycle time step is reduced accordingly, but not lower than the minimum time step input by the user for the COR package. Components with a total mass below a critical minimum are not subjected to this limit. If the energy input to any fluid volume changes from previous values in such a way as to possibly result in numeric instability between the COR and control volume packages, the system time step may be cut immediately, or a reduction may be requested for the next Executive time step. The various time step control parameters may be specified by the user on record CORDTCب01 
COR Package Reference Manual

and using sensitivity coefficient arrays C1401 and C1502 (see COR Package Users' Guide).

At the end of a COR package time step, after the thermal state of the core has been updated by the heat transfer and oxidation models described in Section 2 , relocation of core materials and debris formation are calculated by the core degradation models described in Section 3. Molten portions of intact structures are transferred to the conglomerate debris associated with the structure. Liquefaction of intact structures caused by eutectic reactions between materials within the structure and dissolution of intact structures by existing molten material within the core cell are calculated, if the materials interactions model has been activated. Molten materials are relocated downward by the candling model (provided there is no flow blockage) and intact components are converted to debris if various debris formation criteria are met.

Downward relocation of particulate debris from one cell to a lower one by gravitational settling is generally modeled by logical processes (i.e., relocation is performed instantaneously according to certain logic decisions) instead of rate processes, although rate limitations are imposed for the falling debris quench heat transfer model. This relocation is completed over a single time step, with consideration given to constraints imposed by the porosity of the debris, the availability of free (open) volume to hold it, and support by "other structures" such as the core plate. (These constraints are not imposed on molten debris, which will always relocate to lower regions unless the path is totally blocked.) Gravitational leveling of molten pools and debris beds across the core rings is calculated with a user-adjustable time constant. Whenever mass is relocated or debris formed, material energies in the new or changed components are re-evaluated and the temperature updated to maintain thermal equilibrium, and any relevant geometric variables are recalculated to reflect the change in geometry. Failure of the core plate (or any steel structure providing support) due to decreasing yield strength at high temperatures is triggered whenever the steel temperature in a cell reaches a userspecified failure temperature for that axial level (TSFAIL on record CORZjj04) or by a user-defined control function specified on record CORijj07. 


\section{HEAT TRANSFER AND OXIDATION MODELS}

This section describes the models implemented in the COR package to treat various modes of heat transfer and oxidation within the core and lower plenum; lower head heat transfer models are discussed separately in Section 4. Radiation, conduction, and convection are covered in Sections 2.1,2.2, and 2.3, respectively, and oxidation is covered in Section 2.4. Section 2.5 describes the "dT/dz" model used by the COR package to obtain estimates of the local fluid temperatures and noncondensible mass fractions. Fission power generation in ATWS accident sequences (and in some experiments) is covered in Section 2.6.

Most of the constants (including exponents) used in the correlations described in this section have been implemented as sensitivity coefficients, thus allowing the user to change them from the default values described in this document if desired. Sensitivity coefficients are grouped into numbered arrays, Cnnnn(k), where 'nnnn' is an identifying number that refers to a set of related coefficients, such as the several constants appearing in a single correlation (see the MELGEN/MELCOR Users' Guide). Appendix A gives a table of sensitivity coefficients used in the COR package and their default values. Unless otherwise noted, all variables and dimensional constants are in SI units, in conformance to MELCOR coding conventions.

\subsection{Radiation}

Thermal radiation among components within COR cells, across cell boundaries, and from components to steam is modeled as exchange of radiation between pairs of gray surfaces with an intervening gray medium; the model is constructed along the description provided in Kreith [1]. The radiosity $J_{i}$ is defined as the total energy flux leaving the $i$-th surface ( $i=1$ or 2 in this model), both reflected and emitted:

$$
J_{i}=\left(1-\epsilon_{i}\right) G_{i}+\epsilon_{i} E_{b i}
$$

where

$$
\begin{array}{ll}
\varepsilon_{i} & =\text { emissivity of surface } i \\
G_{i} & =\text { radiation flux incident on surface } i \\
E_{b i} & =\text { blackbody emissive power of surface } i, \sigma T_{i}^{4}
\end{array}
$$

The net heat transfer rate from the $\mathrm{i}$-th surface is the difference between the radiosity and the incident radiation, multiplied by the area of surface $i, A_{i}$ : 
COR Package Reference Manual

$$
q_{i}=A_{i}\left(J_{l}-G_{i}\right)
$$

Combining Equations 2.1.1 and 2.1.2 gives $q_{i}$ in terms of the radiosity and blackbody emissive power:

$$
q_{i}=A_{i} \frac{\epsilon_{i}}{1-\epsilon_{i}}\left(E_{b i}-J_{i}\right)
$$

The net heat transfer rate from surface $i$ to surface $j$ is given in terms of the surface radiosities by the expression:

$$
q_{i j}=A_{i} F_{i j} \tau_{i j}\left(J_{i}-J_{j}\right)
$$

where

$$
\begin{aligned}
& F_{i j} \quad=\text { geometric view factor from surface } i \text { to surface } j \\
& \tau_{i j} \quad=\text { geometric mean transmittance between surfaces } i \text { and } j
\end{aligned}
$$

Radiation heat transfer also occurs between each of the surfaces and the steam medium, according to the expression:

$$
q_{i m}=A_{i} \epsilon_{m}\left(J_{i}-E_{b m}\right)
$$

where

$$
\begin{aligned}
& \varepsilon_{\mathrm{m}} \quad=\text { steam emissivity/absorptivity }=\left(1-\tau_{\mathrm{ij}}\right) \\
& \mathrm{E}_{\mathrm{bm}} \quad=\text { blackbody emissive power of medium, } \sigma \mathrm{T}_{\mathrm{m}}{ }^{4}
\end{aligned}
$$

With the additional requirement:

$$
q_{i}=q_{i m}+q_{i j}
$$

Equations 2.1.3, 2.1.4, 2.1.5, and 2.1.6 are solved in the COR package to obtain $q_{i}$ and $q_{i m}(i=1,2)$ for various pairs of surfaces. The subsections below discuss the calculation of surface and steam emissivities $\varepsilon_{\mathrm{i}}$ and $\varepsilon_{\mathrm{m}}$, the geometric view factors $F_{\mathrm{ij}}$ and the implementation logic (i.e., how pairs of surfaces are chosen for multiple cell components that may relocate during the course of a calculation). 
COR Package Reference Manual

\subsubsection{Emissivities}

The surface and steam emissivities are evaluated by models adapted from MARCON 2.1B [2], an extended version of MARCH 2 [3]. For cladding, canister, and particulate debris components, the surface emissivity of Zircaloy is used, which is calculated in these models as a function of temperature and oxide thickness from the equations used in MATPRO [4]. For Zircaloy surfaces whose maximum temperature has never reached $1500 \mathrm{~K}$, the surface emissivity is given by:

$$
\begin{array}{ll}
\epsilon_{\mathrm{l}}=0.325+0.1246\left(10^{6}\right) \Delta \mathrm{r}_{\text {ox }} & {\left[\Delta \mathrm{r}_{\mathrm{ox}}<3.88 \times 10^{-6}\right]} \\
\epsilon_{\mathrm{i}}=0.808642-50.0 \Delta \mathrm{r}_{\text {ox }} \quad\left[\Delta \mathrm{r}_{\mathrm{ox}} \geq 3.88 \times 10^{-6}\right]
\end{array}
$$

where $\Delta r_{o x}$ is the oxide thickness. For surfaces that have reached temperatures greater than $1500 \mathrm{~K}$ at some time, the emissivity is calculated by Equation 2.1.7 or 2.1.8 and then multiplied by the factor:

$$
F=\exp \left[\frac{1500.0-T_{i, \max }}{300.0}\right]
$$

where $T_{i, \max }$ is the maximum temperature the surface has reached. This factor is limited to a lower bound of 0.325 .

The surface emissivity of "other structure" in these models is calculated from the relation used in MARCON 2.1B for stainless steel, taken from Reference 5:

$$
\epsilon_{i}=0.042+0.0003474 \mathrm{~T}_{i}
$$

The steam emissivities, $\varepsilon_{m}$, are evaluated in these models from a table taken from Reference 6 (see Table 2.1.1), which specifies the steam emissivity versus steam temperature and optical depth (steam partial pressure times mean beam length $L_{e}$ ) at the high pressure limit. Mean beam lengths are currently supplied for each component type based only on representative distances for an intact core geometric configuration using these equations [7]:

$$
L_{\theta, \mathrm{Cl}}=3.5\left(P-2 \mathrm{r}_{\mathrm{cl}}\right)
$$


COR Package Reference Manual

$$
\begin{aligned}
& L_{\theta, c n}=L_{\theta, c b}=1.8 r_{c l, c n} \\
& L_{\theta, c b b}=L_{\ominus, o s}=1.8 r_{c n, c b} \\
& L_{\theta, c n b}=1.8 r_{c n, c n} \\
& L_{\theta, p d}=0
\end{aligned}
$$

where the second subscripts on the mean beam length represent cladding (cl); canister (not by blade) inner surface ( $\mathrm{cn}$ ); canister (by blade) inner surface (cb); canister (by blade) outer surface (cbb); "other structure" (os); canister (not by blade) outer surface (cnb); and debris (pd); and where $P$ is the fuel rod pitch, $r_{c l}$ is the cladding radius, $r_{c l, c n}$ is the distance between the outer fuel rods and the canister wall, $r_{c n, c b}$ is the distance between the canister and control blade, and $r_{c n, c n}$ is the distance between adjacent canister walls. It is anticipated that this model may be upgraded in the future to allow user specification of mean beam lengths for each component and better representation by these parameters for degraded conditions.

\subsubsection{View Factors}

The view factors $F_{i j}$ used in Equation 2.1.4 model the effects of surface orientation and are implemented as user-specified parameters. The surface areas $A_{i}$ used with $F_{i j}$ are the actual component areas for radiation between components within a cell and are cell boundary areas for inter-cell radiation. Values for the view factors are input by the user on record COR00003. These values should be based on standard expressions for simple geometries, where possible, or on experimental data or detailed radiation calculations for complicated geometries involving intervening surfaces, such as for radiation between "representative" structures in cells containing a number of similar structures (e.g., fuel rod bundles). In the absence of any information to aid in selection of view factors, they should be used as arbitrarily varied parameters to examine the effects of radiation on the course of a calculation. View factors are not dynamic, that is they do not change as the core degrades; however, they may be changed across a MELCOR restart. Because of reciprocity (i.e., $F_{12} A_{1}=F_{21} A_{2}$ ), the user-input component surface areas, unmodified by the effects of conglomerate debris, are always used with these constant view factors. 
COR Package Reference Manual

Table 2.1.1 Steam emissivity vs. temperature and optical depth [6]

\begin{tabular}{||r||l|l|l|l|l|l|l||}
\hline \hline \multirow{2}{*}{$\begin{array}{c}\text { Optical } \\
\text { Depth } \\
\text { (cm-atm) }\end{array}$} & \multicolumn{7}{|c||}{ Temperature (K) } \\
\cline { 2 - 8 } & 370 & 600 & 1000 & 1500 & 2000 & 2500 & 3000 \\
\hline \hline 1.0 & 0.12 & 0.09 & 0.041 & 0.02 & 0.01 & 0.0063 & 0.004 \\
\hline 3.2 & 0.25 & 0.195 & 0.11 & 0.06 & 0.03 & 0.019 & 0.011 \\
\hline 10.0 & 0.37 & 0.315 & 0.23 & 0.145 & 0.085 & 0.053 & 0.033 \\
\hline 32.0 & 0.47 & 0.425 & 0.37 & 0.29 & 0.20 & 0.135 & 0.086 \\
\hline 100.0 & 0.56 & 0.533 & 0.55 & 0.47 & 0.365 & 0.277 & 0.193 \\
\hline 320.0 & 0.65 & 0.625 & 0.70 & 0.66 & 0.555 & 0.47 & 0.35 \\
\hline 1000.0 & 0.73 & 0.71 & 0.82 & 0.80 & 0.74 & 0.65 & 0.52 \\
\hline 3200.0 & 0.79 & 0.78 & 0.92 & 0.90 & 0.88 & 0.78 & 0.65 \\
\hline 10000.0 & 0.85 & 0.85 & 1.00 & 0.92 & 0.92 & 0.85 & 0.73 \\
\hline \hline
\end{tabular}

Figure 2.1.1 depicts the conceptual framework for radiative heat transfer within a BWR COR cell. This framework is geared toward intact BWR cores but is general enough to treat PWR cores, as well as degraded cores and lower plenum radiation. "Other structure" (e.g., the control blade) is always treated as the innermost component in a cell; this component can radiate to adjacent cells only if no other components exist in the cell. The canister component not adjacent to the control blade $(\mathrm{CN})$ is always treated as the outermost component in a cell; no other cell components can radiate to adjacent radial cells if the canister component $\mathrm{CN}$ is present. Fuel rods and particulate debris (not shown) are both treated as existing within the canister walls (both $\mathrm{CN}$ and $\mathrm{CB}$ components, if present) and surrounding "other structure" (if present).

For intra-cell radiation, the user must input two view factors that control radiation between the "average" fuel rod (cladding component, or perhaps "bare" fuel) and canister walls (used for both canister components), and between the canister wall (component CB only) and "other structure":

$F_{c n, c l} \quad$ view factor for radiation between canister (both components $\mathrm{CN}$ and $\mathrm{CB}$ ) and fuel rods used with the canister component inside surface areas 
COR Package Reference Manual

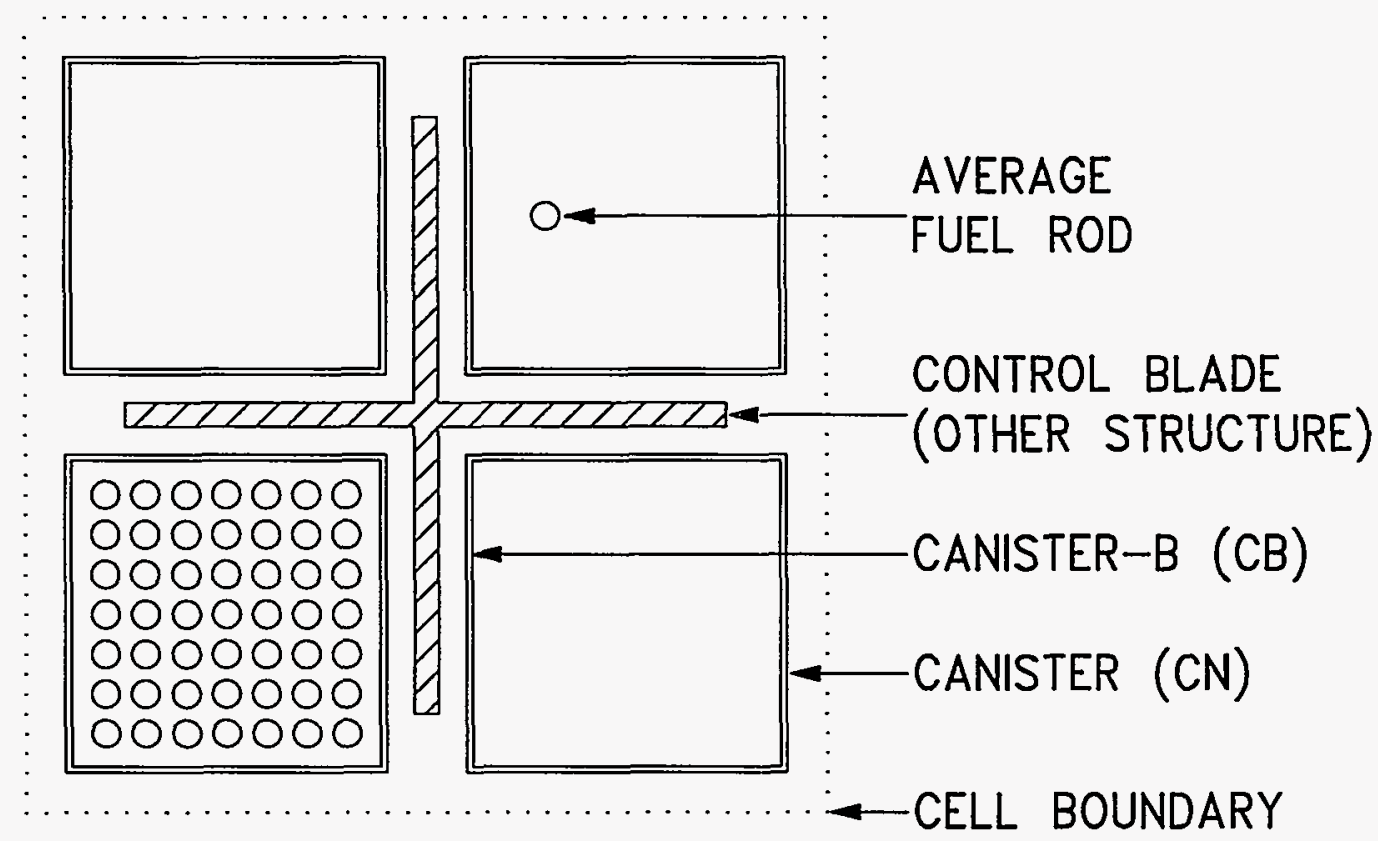

Figure 2.1.1 Radiative heat transfer frameworkBWR cell cross-section $\mathrm{F}_{\text {os,cn }}-\quad$ view factor for radiation between "other structure" and canister
(component $\mathrm{CB}$ only), used with "other structure" surface area

It is important to note that the view factor $F_{c n, c l}$ is used to model radiation to an "average" fuel rod, which is partially obstructed by the exterior rods of the fuel bundle, and should normally be given a value significantly less than 1.0 to reflect the presence of these intervening rods. The value input for $\mathrm{F}_{\mathrm{os}, \mathrm{cn}}$, on the other hand, should ordinarily be some value close to unity since the control blade is directly adjacent to the surface to which it radiates.

If particulate debris is present in a cell containing fuel rods, an implicit view factor $F_{c l, p d}$ of 1.0 is used with the cladding (or bare fuel) surface area to model radiation from the rods to the debris. Otherwise, if debris is present in a cell with either canister components or with "other structure," implicit view factors $F_{c n, p d}$ and $F_{o s, p d}$ of 1.0 are used with the canister or "other structure" surface areas to model radiation between these components and the debris.

For inter-cell radiation the user must input two view factors that control radiation in the radial and axial directions: 
COR Package Reference Manual

$\mathrm{F}_{\text {cell, }}$ - $\quad$ view factor for radiation radially from one cell to the next outer one, used with cell outer radial boundary area

$\mathrm{F}_{\text {cell,a }}$ - $\quad$ view factor for radiation axially from one cell to the next higher one, used with cell axial boundary area

The temperatures used for inter-cell radiation in the radial direction are those for the components outermost in the two cells. Again, however, it is important to note that radiation is calculated for representative "average" components in the cells, and the view factors input for the model should reflect the possible presence of intervening components of the same type, which will depend on the coarseness of the nodalization.

If no components exist in the next outer or higher cell, the radial ring or axial level beyond that is used, until a boundary heat structure is reached. Thus, components in one cell can communicate to nonadjacent cells all the way across the core if there are no components in intervening cells. The boundary heat structures, both radially and axially, receive energy from the outermost cells that contain a component, and are specified on records CORZjjO2 and CORRiii02. An additional view factor controls radiation to the liquid pool, if one exists, or to the lower head:

$F_{\mathrm{l}, \text { up }}$ - $\quad$ view factor for radiation axially from lowermost uncovered COR cell to lower head or liquid pool, used with lower head surface area

\subsubsection{Implementation Logic}

Figure 2.1.2 gives a flow chart of the logic embodied in the radiation model. The subscript $i$ denotes the current cell, the subscript $j$ denotes cells radially outward from cell $i$, and the subscript $k$ denotes cells axially upward from cell $i$. Beyond the furthest COR cells, boundary heat structures are used. The following description summarizes the radiation model logic shown in Figure 2.1.2.

If "other structure" is present in a cell, then the existence of other cell components within that cell is checked to determine which component the "other structure" radiates to, starting with the canister $\mathrm{CB}$ component, then fuel rod cladding or fuel pellets, then particulate debris, and then the canister $\mathrm{CN}$ component. If no other component in that cell is found, then the "other structure" radiates to adjacent radial and axial cells.

Next, if fuel rods (i.e., cladding component or bare fuel pellets) are present in a cell, then the existence of the canister $\mathrm{CN}$ component is checked. If the canister $\mathrm{CN}$ component is present in the cell, the fuel rods radiate to it; otherwise they radiate to the next adjacent radial cell. In either case, the fuel rods also radiate to the next adjacent axial cell. If the canister $\mathrm{CB}$ component is present in the cell, the fuel rods also radiate to it. If the canister $\mathrm{CB}$ component is present but fuel rods are not, $\mathrm{CB}$ radiates to the canister $\mathrm{CN}$ 


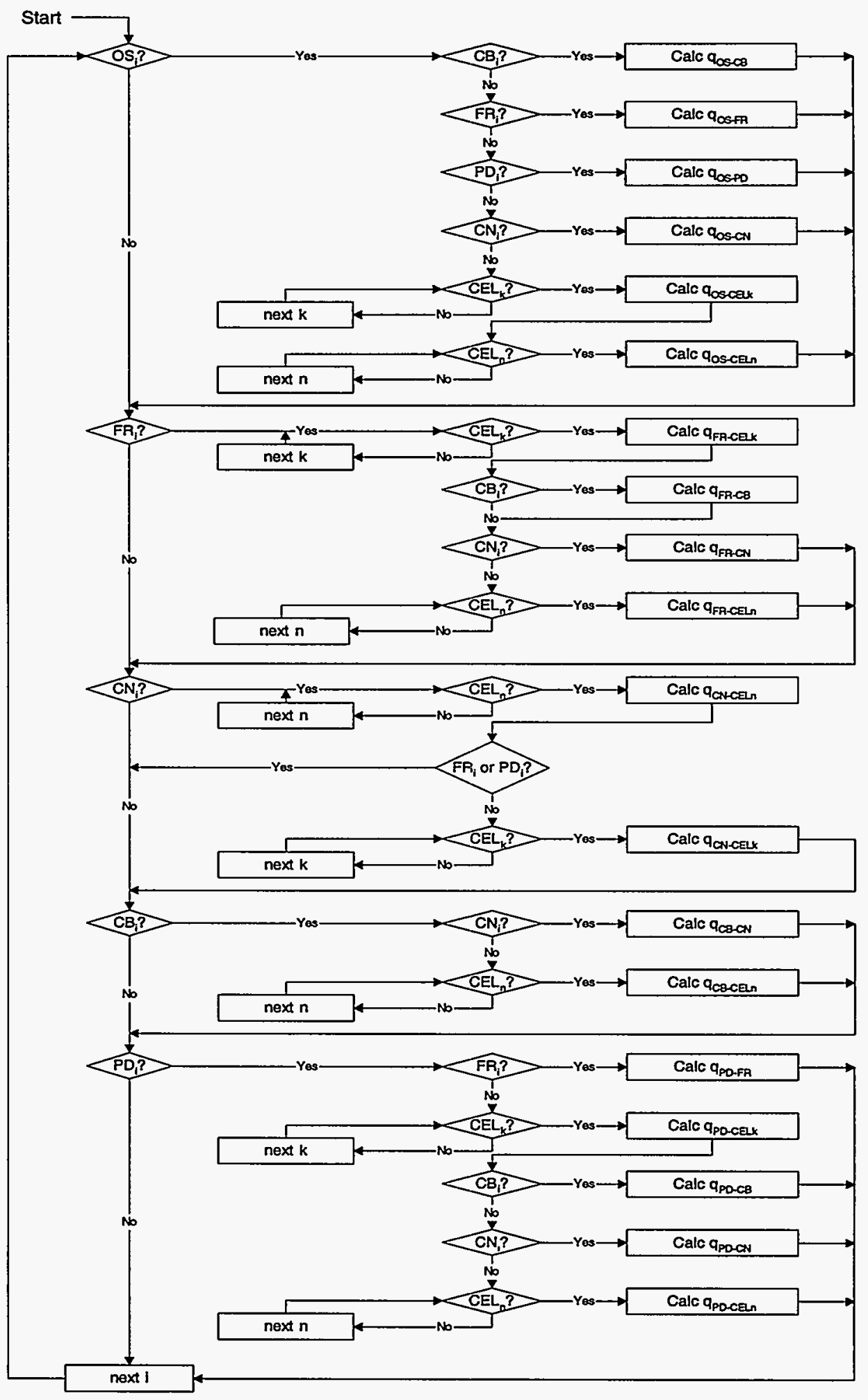

Figure 2.1.2 Radiation model logic flow chart 
component, if present, and otherwise to the next radial cell with an existing component.

The canister $\mathrm{CN}$ component is considered the outermost component in a cell. If canister component $\mathrm{CN}$ is present in the cell, it radiates to the next radial cell having an existing component. If neither fuel rods nor particulate debris are present in the cell, the canister also radiates to the next axial cell with an existing component.

Finally, if particulate debris is present in a cell, the possible existence of other components in the cell is checked to determine which one the debris radiates to. If fuel rods are present, the debris radiates to them. If no fuel rods are present, the debris radiates axially to the next adjacent cell with an existing component, and the presence of either of the canister components is checked. If either canister component is present, the debris radiates to it; otherwise the debris radiates radially to the next adjacent cell with an existing component.

For radiation between "other structure" and any component within the same cell, the "other structure" surface area and the view factor $F_{o s, c n}$ are used in Equation 2.1.4. For radiation between either of the two canister components and the cladding, the canister surface areas and the view factor $F_{c n, c l}$ are used. For radiation from any component to another cell, the appropriate cell boundary area and $F_{\text {cell,r }}$ or $F_{\text {cell,a }}$ are used in Equation 2.1.2, although the actual component temperatures are used. For radiation between the liquid pool or lower head and the first cell containing a component, the lower head surface area and $F_{l p, u p}$ are used in Equation 2.1.4.

\subsection{Conduction}

Conduction heat transfer in the axial direction is treated separately for each component except particulate debris, as described in Section 2.2.1. Radial conduction within components is not treated explicitly; a lumped parameter approach is utilized instead. Cell-to-cell radial conduction is not treated due to an assumed lack of physical contact, except that a component in the outermost ring may optionally be designated to conduct heat directly to the boundary heat structures. (This is useful in simulating some experiment geometries.) Radial conduction through the fuel pellets and across the gap to the cladding is calculated by an analytic expression, as described in Section 2.2.2. Conduction within the lower head is discussed in Section 4. 
COR Package Reference Manual

\subsubsection{Axial Conduction}

The heat transfer rate axially from one cell component to another is given by:

$$
q_{i j}=K_{e f f}\left(T_{1}-T_{j}\right)
$$

where $\mathrm{K}_{\text {eff }}$ is an effective conductance between the two cells, defined in terms of the individual component conductances by:

$$
\begin{aligned}
& K_{\text {eff }}=\frac{1}{\frac{1}{2 K_{i}}+\frac{1}{2 K_{i}}} \\
& K_{i}=K_{i} A_{i} / \Delta z_{i}
\end{aligned}
$$

and where

$k_{i}=$ thermal conductivity of component in cell $i$

$\mathrm{A}_{\mathrm{i}} \quad=$ conduction area of component in cell $\mathrm{i}$, updated as component masses change

$\Delta z_{i} \quad=$ axial length of cell $i$

$\mathrm{T}_{\mathrm{i}} \quad=$ temperature of component in cell $\mathrm{i}$

Axial conduction is generally insignificant except at the liquid level interface, where it can be very important due to the very steep temperature gradients that can exist there (see Figure 2.2.1). An approximate analytical model has been implemented in the COR package to more closely approximate this temperature gradient than is possible for the typically coarse grids using Equation 2.2.1. In this model (as well as in the convection model), the cell components in the level at which the liquid interface resides are represented with two separate regions whose temperatures are tied to the bulk component temperature $T_{i}:$ a hot, dry uncovered region at temperature $T_{h}$, and a cooler wet region covered by pool at temperature $T_{c}$. These temperatures are related by energy conservation (assuming constant heat capacities) to the atmosphere and pool fractions of the cell, $x_{a}$ and $x_{p}$ respectively: 


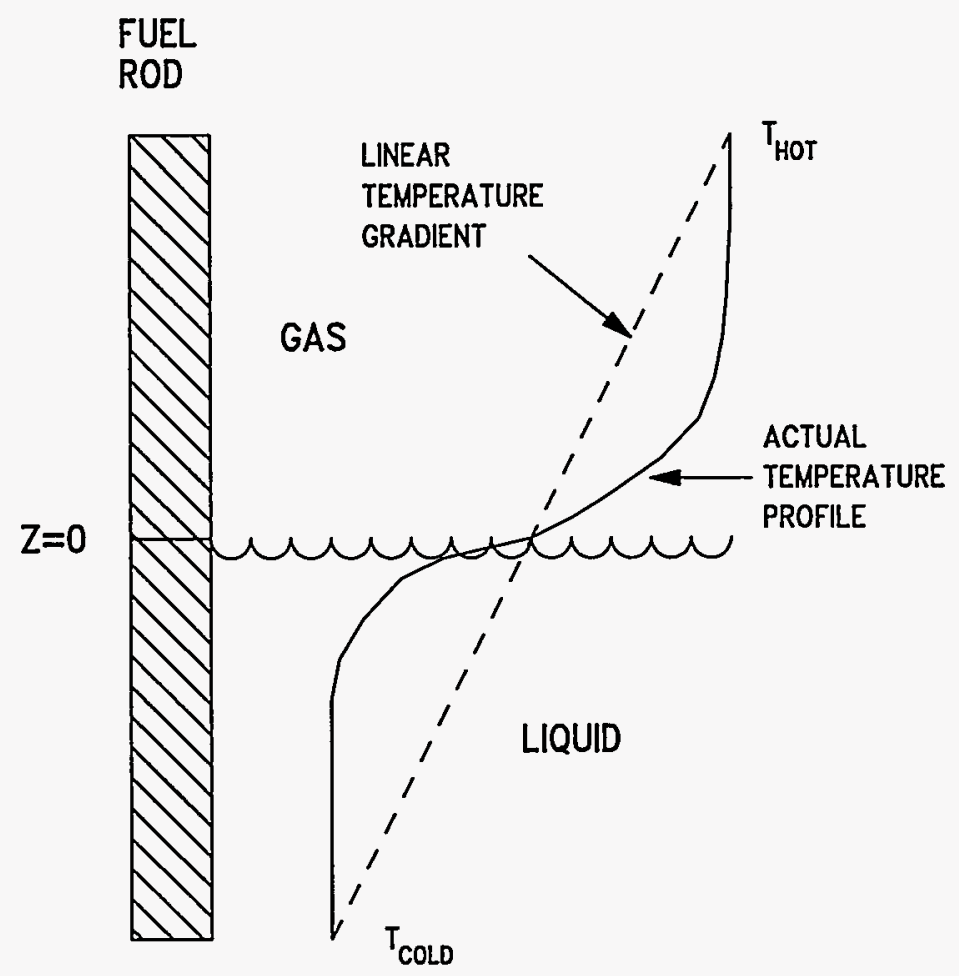

Figure 2.2.1 Component axial temperature gradient across liquid level

$$
T_{1}=x_{a} T_{h}+x_{p} T_{c}
$$

The temperatures of the two regions are determined by individual energy equations:

$$
\begin{gathered}
C_{p} x_{p}\left(T_{c}-T_{c}^{0}\right)=C_{p}\left(T_{h}^{0}-T_{c}^{0}\right) \max \left(0, x_{p}-x_{p}^{0}\right) \\
+\left[K\left(T_{h}-T_{c}\right)-h_{p} x_{p} A\left(T_{c}-T_{p}\right)+x_{p} Q\right] \Delta t \\
C_{p} x_{a}\left(T_{h}-T_{h}^{0}\right)=C_{p}\left(T_{c}^{0}-T_{h}^{0}\right) \max \left(0, x_{a}-x_{a}^{0}\right) \\
+\left[K\left(T_{c}-T_{h}\right)-h_{a} x_{a} A\left(T_{h}-T_{a}\right)+x_{a} Q\right] \Delta t
\end{gathered}
$$




\section{COR Package Reference Manual}

where $C_{p}$ is the total heat capacity of the component $\left(\sum m_{i} C_{p i}\right), K$ is an effective axial conductance (discussed below), $T_{p}$ and $T_{a}$ are pool and atmosphere fluid temperatures, respectively, and $Q$ is the net component heat input from other sources.

In each of these equations, the first term on the right hand side represents the averaging of a region $\left|\mathrm{x}_{\mathrm{p}}-\mathrm{x}_{\mathrm{p}}{ }^{\circ}\right|=\left|\mathrm{x}_{\mathrm{a}}-\mathrm{x}_{\mathrm{a}}{ }^{\circ}\right|$ that has just quenched or just uncovered with the old quenched or uncovered regions, respectively. The axial conduction term $K\left(T_{h}-T_{c}\right)$ is derived from a fin equation, as discussed below. Equations 2.2.4 through 2.2.6 can be solved simultaneously to eliminate $Q$ and determine $T_{c}$ and $T_{h}$ from known values of $x_{a}$, $x_{p}, T_{a}$, and $T_{p}$, and new or projected values for the bulk component temperature $T_{i}$. The pool and atmosphere heat transfer rates are calculated from these temperatures and the respective fluid temperatures, pool fractions, and heat transfer coefficients.

Because of the large temperature gradient at the liquid level interface, simply using Equation 2.2.1 with $\mathrm{K}_{\text {eff }}$ given by Equation 2.2.2 will significantly underpredict the conduction between the hot and cold regions. Instead, application is made of the onedimensional conduction equation for fins, given by the ordinary differential equation:

$$
k \frac{d^{2} T}{d z^{2}}-h \frac{A}{V}\left(T-T_{f}\right)+q=0
$$

where $q$ is the volumetric heat source, $A / V$ is the surface area to volume ratio and the thermal conductivity $\mathrm{k}$ is assumed constant. Assuming the following boundary conditions:

(a) above the interface $(z=0)$ the fluid temperature is a constant atmosphere temperature $T_{a}$; below the interface the fluid temperature is a constant pool temperature $\mathrm{T}_{\mathrm{p}}$;

(b) the heat transfer coefficient is much larger for the pool than for the atmosphere $\left(h_{p}>h_{a}\right)$;

(c) T approaches $T_{h}$ for $z$ above the interface and $T_{c}$ for $z$ below the interface, the steady state values of which are dependent on the volumetric heat source q;

the approximate solution for the temperature gradient at the liquid interface is:

$$
\frac{d T}{d z}(z=0) \approx \sqrt{\frac{h_{a} A}{k V}}\left(T_{h}-T_{c}\right)
$$

and therefore the value of $\mathrm{K}$ used in Equations 2.2.5 and 2.2.6 is 
COR Package Reference Manual

$$
K=k_{i} A_{i} \sqrt{\frac{h_{a} A}{k_{i} V}}
$$

\subsubsection{Fuel-Cladding Gap Heat Transfer}

Conduction radially across the fuel pellet and the fuel-cladding gap is calculated assuming a parabolic temperature profile across the fuel, negligible cladding thermal resistance, and a constant user-specified gap thickness (input on record COR00001). An effective total gap conductance is calculated by combining in conventional fashion the various serial and parallel resistances:

$$
\frac{1}{h_{\text {gap }}}=\frac{1}{h_{f}}+\frac{1}{\frac{1}{\frac{1}{h_{g}}+\frac{1}{h_{C F}}}+h_{\text {rad }}}
$$

where

$$
\begin{aligned}
& h_{f}=4 k_{f} / r_{f} \\
& h_{g}=k_{g} / \Delta r_{g} \\
& h_{r a d}=\frac{4 \sigma T_{a}^{3}}{\frac{1}{\epsilon_{f}}+\frac{1}{\epsilon_{c}}-1}
\end{aligned}
$$

and where

$$
\begin{aligned}
& \sigma \quad=\text { Stefan-Boltzmann constant } \\
& r_{f} \quad=\text { radius of fuel pellet }
\end{aligned}
$$


COR Package Reference Manual

$$
\begin{array}{ll}
\Delta r_{g} & =\text { thickness of fuel-cladding gap } \\
k_{f} & =\text { fuel thermal conductivity } \\
k_{g} & =\text { gap gas thermal conductivity } \\
h_{C F} & =\text { conductance calculated by control function } \\
T_{f} & =\text { fuel bulk temperature } \\
T_{c} & =\text { cladding bulk temperature } \\
T_{a} & =\text { average temperature }=\left(T_{f}+T_{c}\right) / 2 \\
\varepsilon_{f} & =\text { fuel surface emissivity } \\
\varepsilon_{c} & =\text { cladding inner surface emissivity }
\end{array}
$$

The term representing the thermal resistance of the fuel pellet, $1 / h_{f}$, is combined in series with an effective resistance of the gap. This gap resistance includes radiation across the gap in parallel with the conductive resistance of the gap gas. An additional resistance, $1 / h_{C F}$, calculated via a control function and added serially to the conductive resistance of the gap gas, may be specified by the user on record COR00004. The fuel and cladding emissivities used to calculate radiation across the gap are stored in sensitivity coefficient array $\mathrm{C} 1101$.

The total effective gap conductance is then used to calculate the heat transfer rate from the fuel to the cladding by the equation:

$$
q_{g a p}=h_{g a p} A_{f}\left(T_{f}^{0}-T_{c}^{n}\right)
$$

where $A_{f}$ is the surface area of fuel pellet and the superscripts " $O$ " and " $n$ " represent oldand new-time temperature values, respectively. The new-time value of the cladding temperature is used to prevent numerical oscillations. Therefore, the fuel-cladding gap heat transfer model is coupled to the cladding convection calculation (described below) to obtain the gap heat transfer rate. 
COR Package Reference Manual

\subsubsection{Conduction to Boundary Heat Structures}

Optionally, conduction from a designated component in the outermost radial ring to the radial boundary heat structures specified on input records CORZjj02 may be calculated. The heat flux is given by

$$
q_{C-H S}=\frac{T_{C}-T_{H S}}{R}
$$

where $T_{C}$ is the temperature of the core component and $T_{H S}$ is the temperature of the first node of the heat structure (typically an insulator), and $\mathrm{R}$ is the total contact resistance, defined as

$$
R=R_{\text {gap }}+R_{\text {dif }}
$$

where

$$
\begin{aligned}
& R_{\text {gap }}=\Delta r_{\text {gap }} / k_{\text {gap }} \\
& R_{\text {dif }}=\sqrt{\frac{\pi \Delta t}{\left(k \rho C_{p}\right)_{H S}}}
\end{aligned}
$$

In the above equations, $\Delta r_{\text {gap }}$ is the thickness of a gap between the core component and the heat structure, $\mathrm{k}_{\mathrm{gap}}$ is the thermal conductivity of the gap material (calculated from the Material Properties package), $\Delta t$ is the COR package time step, and $k, \rho$, and $c_{p}$ are the thermal conductivity, density, and specific heat, respectively, of the heat structure material. The thermal diffusive resistance $R_{\text {dif }}$ is used to mitigate temperature oscillations that may arise from the numerically explicit coupling between the COR and Heat Structure packages. The user may specify on input record COR00011 which core component is used in this model, what the gap material and thickness are, and the value of the thermal diffusion constant $\left(\pi / \mathrm{kpc}_{\mathrm{p}}\right)^{1 / 2}$ for the heat structure (since these properties are not currently accessed from the MP package). 
COR Package Reference Manual

\subsection{Convection}

Convective heat transfer is treated for a wide range of fluid conditions. Emphasis has been placed on calculating heat transfer to single-phase gases, since this mode is the most important for degraded core accident sequences. A simple set of standard correlations has been used for laminar and turbulent gas flow in both forced and free convection; these correlations give the Nusselt $(\mathrm{Nu})$ number as a function of Reynolds $(\mathrm{Re})$ and Rayleigh $(\mathrm{Ra})$ numbers. For convection to single-phase and two-phase liquid, a simplified boiling curve giving the heat transfer coefficient as a function of temperature difference and pressure has been implemented.

Since the COR cell nodalization is typically much finer than the Control Volume Hydrodynamics (CVH) nodalization, approximate temperature and mass fraction distributions in the control volumes interfacing with the core and lower plenum must be calculated in the COR package to properly determine the convective heat transfer rates for each COR cell. This temperature distribution is calculated in the COR package in what is termed the "dT/dz" model, which is described separately in Section 2.5.

Alternatively, the $d T / d z$ model may be turned off (with the CORTSTxx input record) and a fine $\mathrm{CVH}$ nodalization may be used (one control volume per core cell or small number of core cells). Momentum flux terms should be calculated in the core flow paths in this case (see the FL Package Users' Guide). Currently, however, the capability to perform such fine-scale natural circulation calculations is seriously limited by the increased CPU time required (due to a substantially larger flow matrix and a reduced material Courant time step limit) and by calculational difficulties during core degradation (caused by control volumes completely filling up with debris). Until these problems are resolved, it is recommended that the user exercise this option with great caution. In the discussion that follows, all fluid temperatures refer to local temperatures, whether calculated by the $\mathrm{dT} / \mathrm{dz}$ model or taken directly from a fine-scale $\mathrm{CVH}$ nodalization.

Heat transfer rates are calculated for each component by the equation:

$$
q=h A_{s}\left(T_{s}^{n}-T_{f}\right)
$$

where

$\mathrm{h} \quad=$ heat transfer coefficient

$\mathrm{A}_{\mathrm{s}} \quad=$ component surface area for heat transfer, accounting for the effects of conglomerate debris (see Section 3.1.5)

$T_{s}^{n} \quad=$ new-time component temperature 
$T_{f} \quad=$ local fluid temperature

The new-time component temperatures are used to prevent numerical oscillations in the component heat transfer rates. (In the actual numerical implementation, estimates are made in each subcycle of the new-time component temperatures, based on previous subcycle net heat transfer rates, rather than performing a truly implicit calculation of convective heat transfer rates.) The heat transfer coefficient is calculated from various correlations for the Nusselt number, which will be discussed in the following subsections:

$$
\mathrm{Nu}=\mathrm{h} \mathrm{D}_{\mathrm{h}} / \mathrm{k}
$$

where

$$
\begin{aligned}
& D_{h} \quad=\text { hydraulic diameter for each component surface, defined by the user on } \\
& \text { input record CORijj04 } \\
& k \quad=\text { fluid thermal conductivity }
\end{aligned}
$$

\subsubsection{Laminar Forced Convection}

For laminar forced flow in intact geometry, the Nusselt number is given by a constant, representing the fully developed Nusselt number for constant heat flux, multiplied by a developing flow factor:

$$
\mathrm{Nu}=\mathrm{C}(\mathrm{n}) g_{\mathrm{dev}}
$$

where the constant $C(n)$ is currently defined for both rod bundle arrays $(n=1)$ and circular tubes $(n=2)$ to be 4.36 and is implemented as sensitivity coefficient array $C 1212$. The developing flow factor is currently that used in MARCH 2 in connection with gaseous diffusion-limited oxidation [8], with Prandtl number used instead of Schmidt number:

$$
g_{d e v}=1+\frac{0.00826}{F(z)+0.0011}
$$

In Equation 2.3.4, the constants have been implemented in sensitivity coefficient array $C 1213$, and $F(z)$ is a nondimensional entrance length: 
COR Package Reference Manual

$$
F(z)=\frac{\left(z-z_{0}\right)}{D_{h} \operatorname{Re} \operatorname{Pr}}
$$

where $\left(z-z_{0}\right)$ is the distance from the flow entrance, $D_{h}$ is the hydraulic diameter, and $\operatorname{Pr}$ is the Prandtl number. In the present version of the code, $\left(z-z_{0}\right)$ is set to $1000 \mathrm{~m}$, effectively eliminating any developing flow effects.

\subsubsection{Turbulent Forced Convection}

For turbulent flow in channels, the Dittus-Boelter correlation [9] is used:

$$
\mathrm{Nu}=0.023 \mathrm{Re}^{0.8} \mathrm{Pr}^{0.4}
$$

The coefficients and exponents in Equation 2.3.6 are implemented in sensitivity coefficient array $\mathrm{C} 1214$.

Rather than defining a critical Reynolds number controlling whether laminar or turbulent correlations are used, both correlations are evaluated and the maximum of the turbulent and laminar Nusselt numbers is used to calculate the forced convection heat transfer coefficient.

\subsubsection{Laminar and Turbulent Free Convection}

For laminar free convection in narrow channels, the following correlation for an enclosed air space between vertical walls is used [10]:

$$
N u=0.18 R a_{f}^{1 / 4}\left(L / D_{h}\right)^{-1 / 9}
$$

where $L$ is the channel length. For turbulent free convection a similar correlation is used, differing only in the default values for the multiplicative constant and the exponent for the Rayleigh number [10]:

$$
N u=0.065 R a_{f}^{1 / 3}\left(L / D_{h}\right)^{-1 / 9}
$$

The coefficients and exponents in Equations 2.3.7 and 2.3.8 have been implemented as sensitivity coefficient arrays $\mathrm{C} 1221$ and $\mathrm{C} 1222$, respectively. 
As for forced convection, the maximum of the laminar and turbulent Nusselt numbers is used to evaluate the free convection heat transfer coefficient. The maximum of the forced and free convection heat transfer coefficients is then used in Equation 2.3.1 to calculate the heat transfer rate for a given component. This treatment alleviates some numerical difficulties that may occur if ranges are defined for the various flow regimes, with discontinuities in Nusselt number at the transition points between regimes.

\subsubsection{Convection from Particulate Debris}

For particulate debris, correlations for isolated spherical particles are currently used in the COR package for convection to gases. (Surface areas for particulate debris are normally so high that practically any correlation will almost completely equilibrate the gas temperature with the debris temperature.) For forced convection, the following correlation is used [11]:

$$
\mathrm{Nu}=2.0+0.6 \operatorname{Re}_{\mathrm{f}}^{1 / 2} \operatorname{Pr}_{\mathrm{f}}^{1 / 3}
$$

For free convection, the Reynolds number is replaced by the square root of the Grashof number [11]:

$$
\mathrm{Nu}=2.0+0.6 \mathrm{Gr}_{\mathrm{f}}^{1 / 4} \mathrm{Pr}_{\mathrm{f}}^{1 / 3}
$$

The coefficients and exponents in Equations 2.3.9 and 2.3.10 have been implemented as sensitivity coefficient arrays $\mathrm{C} 1231$ and $\mathrm{C} 1232$, respectively. In both equations, the properties are evaluated at the film temperature (i.e., the average of the debris and $\mathrm{dT} / \mathrm{dz}$ model fluid temperatures). The maximum of the free and forced convection Nusselt numbers is once again used to calculate the heat transfer coefficient.

\subsubsection{Boiling}

For liquid-covered components, the simplified boiling curves from the MARCH 2.0 code [3] are used to calculate the heat transfer coefficient:

$$
\begin{array}{ll}
h=34.5 P^{1 / 4} \Delta T^{1.523} & (\Delta T<23.4 K) \\
h=1.41\left(10^{7}\right) P^{1 / 4} \Delta T^{-2.575} & (\Delta T \geq 23.4 K)
\end{array}
$$




\section{COR Package Reference Manual}

where

$$
\begin{aligned}
& P \quad=\text { pressure } \\
& \Delta T \quad=\text { surface-liquid temperature difference, }\left(T_{s}-T_{1}\right)
\end{aligned}
$$

and the constants have been implemented as sensitivity coefficient arrays $\mathrm{C} 1241$ and C1242.

For the film boiling regime $(\Delta T \geq 23.4 \mathrm{~K})$, a radiation component is added to the convective heat transfer coefficient:

$$
h_{\mathrm{rad}}=\sigma \in \frac{\mathrm{T}_{\mathrm{s}}^{4}-\mathrm{T}_{1}^{4}}{\mathrm{~T}_{\mathrm{s}}-\mathrm{T}_{1}}
$$

where $\varepsilon$ is a hardwired constant emissivity of 0.4 .

\subsubsection{Debris Quenching and Dryout}

Heat transfer from debris to liquid water pools may occur in two distinct modes. In the falling-debris quench mode, failure of the core support plate triggers the relocation of a large mass of hot debris from the core region to the lower plenum. In this mode it is assumed that transient heat transfer rates may be sufficient to rapidly quench the hot debris and/or generate large steam pressure excursions. Following the quench mode it is assumed that continued decay heat generation in the stationary debris bed in the lower plenum will either boil off any remaining water in the lower plenum or quickly lead to debris-bed dryout with an overlying water pool. The heat transfer from the debris bed to the overlying pool of water following debris-bed dryout is relatively modest and is calculated with an appropriate dryout heat flux correlation described below.

The falling-debris quench model is inactive by default, with debris assumed to relocate instantaneously from the core region to an unquenched debris bed in the lower plenum. The model may be activated by specifying a positive value for the quench heat transfer coefficient on input record COR00012; other parameters on this record may optionally be changed. The heat transfer calculated by the model may or may not be sufficient to fully quench the debris before it reaches the bottom of the lower plenum, depending on the values chosen for the model parameters described below.

Beginning from the time of core support plate failure in each radial ring the elevation of the leading edge of the falling debris is determined assuming a constant user-specified 
COR Package Reference Manual

descent velocity (default of $5 \mathrm{~m} / \mathrm{s}$ ). The axial elevation of the leading edge of the falling debris is given by

$$
z_{d}=z_{\text {csp }}-v_{d}\left(t-t_{\text {fail }}\right)
$$

where $z_{\text {csp }}$ is the initial elevation of the core support plate, $v_{d}$ is the velocity of the falling debris, $t$ is the current time and $t_{\text {fail }}$ is the failure time of the support plate in the particular ring. Debris from core cells above elevation $z_{d}$ will be relocated downwards subject to the availability of free volume and the absence of additional supporting structures.

When the leading edge of the falling debris enters the pool of water in the lower plenum, quench heat transfer begins. The heat transfer surface area is the value calculated assuming the debris particles have an equivalent spherical diameter equal to the userspecified hydraulic diameter for particulate debris (input on record CORijj04). The userspecified quench heat transfer coefficient (input on record COR00012) is assumed to remain constant until the leading edge of the falling debris reaches the bottom of the lower plenum (the elevation of the lower head). After that time a decay factor initially equal to unity is applied to the user-specified heat transfer coefficient.

The decay factor is intended to simulate the reduction in heat transfer that occurs during the transition from the quench period to the debris bed configuration. During this period of transition, additional hot debris from the core region may relocate to the lower plenum as a result of radial spreading between the rings in the core region. Therefore, the decay factor has a time constant equal to the time constant for radial spreading of solid debris (see Section 3.2). The decay factor also includes a term to arrest the decay as long as significant amounts of debris continue to migrate into the failed ring from other core regions. Soon after the bulk of the debris has relocated the decay factor will quickly decrease. When the value of the decay factor falls below 0.01 , it is assumed that the transition to a stable debris bed geometry is complete, and all subsequent debris-to-pool heat transfer in that radial ring will be limited by the dryout heat flux correlation discussed below. The time-dependent heat transfer decay factor, $f(t)$, is given by

$$
f(t+\Delta t)=\min \left[1, f(t) \exp \left(-\Delta t / \tau_{s p r}\right)+V_{c o r} / V_{L P}\right]
$$

where $\tau_{\mathrm{spr}}$ is the time constant for radial spreading of solid debris described in Section 3.2, $V_{c o r}$ is the volume of debris which relocates into the ring from radial spreading in the core region during the core time step $\Delta t$ and $V_{\mathrm{LP}}$ is the volume of debris in the ring beneath the level of the core support plate.

During the short period between the failure of the core support plate and the time at which the leading edge of the falling debris reaches the lower head, the models for candling, dissolution and radial spreading of debris in the affected ring are deactivated. 


\section{COR Package Reference Manual}

This action is taken because those models implicitly assume a stationary debris configuration. In addition to the quench heat transfer coefficient, the user may specify a reactor vessel failure pressure (default value of $2.0 \mathrm{e} 7 \mathrm{~Pa}$ ). When the differential pressure between the lower plenum $\mathrm{CVH}$ volume and the reactor cavity $\mathrm{CVH}$ volume reaches the failure pressure, it is assumed that the lower head in all the core rings contained in the lower plenum $\mathrm{CVH}$ volume fails totally. When this happens all of the debris in the core cells above the failed lower head is ejected immediately, and further quench heat transfer in those rings is suppressed. Currently, it is suggested that users do not specify a failure pressure in excess of the critical pressure of water (2.2 $\mathrm{MPa}$ ) because the $\mathrm{CVH}$ package may encounter problems above that pressure.

Because of the relatively low value of the default value for the failure pressure (compared to actual failure pressures that may be much higher) the quench model may have a rather limited range of usefulness for some PWR calculations. If the PWR relief valves cycle around 16-17 $\mathrm{MPa}$, then there is very little margin (3-5 MPa) for steam generation between the relief pressure and the critical pressure; hence, even modest fuel-coolant interactions following support plate failure tend to cause "vessel failure."

For stationary particulate debris beds in liquid water pools, the heat transfer rate will be limited by hydrodynamic phenomena that limit the amount of liquid that can reach the debris particles. The conceptual view taken in the COR package is that liquid water will move downward from above to cool the debris, with vapor produced moving upward to restrict the flow of liquid. At some total bed heat flux, this vapor prevents any more liquid from reaching the debris. This is the point of incipient dryout.

The COR package uses the Lipinski zero-dimensional correlation [12] to calculate the dryout heat flux, $q_{d}$, which is then applied as a limiting maximum heat transfer rate from a particulate debris bed (using the cell cross-sectional area rather than the total particulate surface area) which may occupy one or more axial levels:

$$
q_{d}=0.756 h_{\mathrm{lv}}\left[\frac{\rho_{v}\left(\rho_{1}-\rho_{v}\right) g d \epsilon^{3}\left(1+\lambda_{c} / L\right)}{(1-\epsilon)\left[1+\left(\rho_{v} / \rho_{1}\right)^{1 / / 4}\right]^{4}}\right]^{1 / 2}
$$

In this equation, $h_{\mathrm{lv}}, \rho_{\mathrm{l}}$, and $\rho_{\mathrm{v}}$ are the latent heat and liquid and vapor densities of water, respectively, $g$ is the gravitational acceleration, $d$ is the debris particle diameter, $\varepsilon$ is the bed porosity, $L$ is the total bed depth, and $\lambda_{c}$ is the liquid capillary head in the debris bed,

$$
\lambda_{c}=\frac{6 \sigma \cos \theta(1-\epsilon)}{\epsilon d\left(\rho_{1}-\rho_{v}\right) g}
$$


where $\sigma$ is the water surface tension and $\theta$ is wetting angle. The leading constant, the nominal capillary head for $0.5 \mathrm{~mm}$ particles in water (approximately $0.089 \mathrm{~m}$ ), and the minimum bed porosity allowed in the correlation are accessible to the user as sensitivity coefficient array $\mathrm{C} 1244$. A default minimum porosity of 0.15 was selected to ensure some heat transfer occurs from molten debris pools. The actual capillary head is adjusted for particle diameter size within the model.

If one or more axial levels give heat transfer rates totaling the dryout maximum, no heat transfer is calculated for particulate debris or other intact structures below this point. Furthermore, in cells in which debris is undergoing quenching at the rate given by the dryout heat flux, no convective heat transfer to the pool is calculated for other components in that cell.

\subsection{Oxidation}

Oxidation of Zircaloy by both steam $\left(\mathrm{H}_{2} \mathrm{O}\right)$ and oxygen $\left(\mathrm{O}_{2}\right)$, and of steel and boron carbide $\left(\mathrm{B}_{4} \mathrm{C}\right)$ by $\mathrm{O}_{2}$, is modeled in the COR package. Metal oxidation is calculated using standard parabolic kinetics, with appropriate rate constant expressions used for Zircaloy and steel, and limited by gaseous diffusion considerations if necessary. The $\mathrm{B}_{4} \mathrm{C}$ reaction with steam is calculated with a model developed by ORNL for the MARCON 2.1B code [2], and is used whenever the steel in BWR control blades begins to melt. (The $B_{4} C$ in the intact steel absorber tubes is normally not exposed to steam.) The $\mathrm{B}_{4} \mathrm{C}$ model is inactive by default, but may be activated on MELCOR input record CORTST01.

Zircaloy oxidation is calculated for cladding, both canister components, and control rod guide tubes; steel oxidation is calculated for the "other structure" component. Both Zircaloy and steel oxidation are calculated for particulate debris. Oxidation of conglomerate debris (i.e., material that has melted and refrozen onto another existing component) is also modeled but may be selectively deactivated (on MELCOR input record CORTST01) independently of the oxidation of intact components. The oxidation model uses surface areas that account for the effects of conglomerate debris refrozen on the components; calculation of these surface areas is described in detail in Section 3.1.5. For BWR cores, oxidation of both sides of the canister walls (which may be exposed to differing environments) is modeled. A control function may be input on record CORijj07 to shut off oxidation on a cell by cell basis to simulate, for example, the effects of flow blockage. In addition, minimum and maximum oxidation cutoff temperatures have been implemented as sensitivity coefficient array $\mathrm{C} 1004$, with default values of $1100 \mathrm{~K}$ and $9900 \mathrm{~K}$, respectively.

To simulate the effects of steam starvation in the upper regions of the core, oxidation effects in the COR cells are processed in order from the inner ring out, then from the bottom level up (i.e., 101, 201, ..., 102, 202, ..., 103, etc.). The amount of steam available in the control volume interfaced to a COR cell is decreased, along with the 
COR Package Reference Manual

steam partial pressure, as the hydrogen mass and partial pressure are increased. (These local gas concentrations are also used in the convection model to obtain local properties for the heat transfer correlations.)

\subsubsection{Zircaloy and Steel}

The reaction equations for Zircaloy are given by:

$$
\begin{aligned}
& \mathrm{Zr}+2 \mathrm{H}_{2} \mathrm{O} \rightarrow \mathrm{ZrO}_{2}+2 \mathrm{H}_{2}+\mathrm{Q}_{\mathrm{ox}} \\
& \mathrm{Zr}+\mathrm{O}_{2} \rightarrow \mathrm{ZrO}_{2}+\mathrm{Q}_{\mathrm{ox}}
\end{aligned}
$$

For the purposes of oxidation, steel is divided into the constituent elements iron (Fe), chromium ( $\mathrm{Cr}$ ), nickel (Ni), and carbon (C) according to the mass fractions specified by the user (optionally) in Material Properties package input (converting to moles using the atomic weights for each element). The reaction equations for these species are given by:

$$
\begin{aligned}
& \mathrm{Fe}+\mathrm{H}_{2} \mathrm{O} \rightarrow \mathrm{FeO}+\mathrm{H}_{2}+\mathrm{Q}_{\mathrm{ox}} \\
& 2 \mathrm{Cr}+3 \mathrm{H}_{2} \mathrm{O} \rightarrow \mathrm{Cr}_{2} \mathrm{O}_{3}+3 \mathrm{H}_{2}+\mathrm{Q}_{\mathrm{ox}} \\
& \mathrm{Ni}+\mathrm{H}_{2} \mathrm{O} \rightarrow \mathrm{NiO}+\mathrm{H}_{2}+\mathrm{Q}_{\mathrm{ox}} \\
& \mathrm{C}+\mathrm{H}_{2} \mathrm{O} \rightarrow \mathrm{CO}+\mathrm{H}_{2}+\mathrm{Q}_{\mathrm{ox}}
\end{aligned}
$$

The reaction of steel with $\mathrm{O}_{2}$ is not calculated currently in the COR package. The reaction energies from Equations 2.4.1-6 are calculated from the enthalpies of the reactants and products. Since the equations of state used for the core materials currently do not have reference points consistent with each other or with the CVH and NCG equations of state for fluid materials, the following treatment must be used to obtain the reaction energies for arbitrary temperature $\mathrm{T}$ : 
COR Package Reference Manual

$$
\begin{aligned}
& Q_{o x}(T)=Q_{o x}\left(T_{0}\right)+H_{r p}(T)-H_{r p}\left(T_{0}\right) \\
& H_{r p}(T)=H_{r}(T)-H_{p}(T)
\end{aligned}
$$

where

$$
\begin{aligned}
& Q_{o x} \quad=\text { reaction energy generated } \\
& H_{r} \quad=\text { enthalpy of reactants } \\
& H_{p} \quad=\text { enthalpy of products } \\
& T_{0} \quad=\text { reference temperature }
\end{aligned}
$$

The reference temperature used is $298.15 \mathrm{~K}$ and the reaction energies at this temperature are set to nominal values of $5.797\left(10^{6}\right) \mathrm{J} / \mathrm{kg}_{\mathrm{zr}}$ for the Zircaloy- $\mathrm{H}_{2} \mathrm{O}$ reaction, $1.2065\left(10^{7}\right) \mathrm{J} / \mathrm{kg}_{\mathrm{Zr}}$ for the Zircaloy- $\mathrm{O}_{2}$ reaction, $-2.495\left(10^{5}\right) \mathrm{J} / \mathrm{kg}_{\mathrm{Fe}}$ for the iron- $\mathrm{H}_{2} \mathrm{O}$ reaction and $2.442\left(10^{6}\right) \mathrm{J} / \mathrm{kg}_{\mathrm{cr}}$ for the chromium $-\mathrm{H}_{2} \mathrm{O}$ reaction. The reaction energy for steel is determined by mass weighting the reaction energies for $\mathrm{Fe}$ and $\mathrm{Cr}$ by the relative masses of the two components in the steel composition (nickel, carbon and other components in the steel are currently ignored irrespective of their relative mass). All actual reaction energies during a transient are evaluated at the control volume temperature using Equations 2.4.7 and 2.4.8 and, for Zircaloy and steel oxidation, deposited in the component being oxidized.

Solid-state diffusion of oxygen through an oxide layer to unoxidized metal is represented by the parabolic rate equation:

$$
\frac{d\left(W^{2}\right)}{d t}=K(T)
$$

where $W$ is the mass of metal oxidized per unit surface area and $K(T)$ is a rate constant expressed as an exponential function of surface temperature T. Equation 2.4.9 is integrated analytically over a time step $\Delta t$ assuming a constant temperature (hence constant $\mathrm{K}(\mathrm{T})$ ) for the component:

$$
\left(W^{n+1}\right)^{2}=\left(W^{n}\right)^{2}+K\left(T^{n}\right) \Delta t
$$


COR Package Reference Manual

For the Zircaloy- $\mathrm{H}_{2} \mathrm{O}$ reaction, the rate constant is evaluated using the Urbanic-Heidrich constants [13], which are implemented (along with the transition temperature of $1853 \mathrm{~K}$ ) in sensitivity coefficient array C1001:

$$
\begin{aligned}
& K(T)=29.6 \exp \left(\frac{-16820.0}{T}\right) \quad \text { for } T<1853.0 \\
& K(T)=87.9 \exp \left(\frac{-16610.0}{T}\right) \quad \text { for } T \geq 1853.0
\end{aligned}
$$

For the Zircaloy- $\mathrm{O}_{2}$ reaction, the rate constant is evaluated using constants from Reference 19, which are also implemented in sensitivity coefficient array C1001:

$$
K(T)=50.4 \exp \left(\frac{-14630.0}{T}\right)
$$

For the steel- $\mathrm{H}_{2} \mathrm{O}$ reaction, the rate constant is evaluated using constants from White [14], which are implemented as sensitivity coefficient array C1002:

$$
K(T)=2.42\left(10^{9}\right) \exp \left(\frac{-42400.0}{T}\right)
$$

For very low oxidant concentrations, gaseous diffusion may limit the reaction rate. A mass transfer coefficient is calculated via a heat-mass transfer analogy from the heat transfer correlations in Section 2.3 by substituting the Schmidt number for the Prandtl number and the Sherwood number for the Nusselt number. The oxidation rate when limited by gaseous diffusion is given by:

$$
\frac{d W}{d t}=\frac{M W k_{c} P_{o x}}{n R T_{f}}
$$

where

$$
\begin{aligned}
& M W \quad=\text { molecular weight of metal being oxidized } \\
& k_{c} \quad=\text { mass transfer coefficient } \\
& P_{o x} \quad=\text { partial pressure of oxidant }\left(\mathrm{H}_{2} \mathrm{O} \text { or } \mathrm{O}_{2}\right)
\end{aligned}
$$


COR Package Reference Manual

$$
\begin{array}{ll}
n & =\text { number of moles of oxidant }\left(\mathrm{H}_{2} \mathrm{O} \text { or } \mathrm{O}_{2}\right) \text { consumed per mole of metal } \\
R & =\text { universal gas constant } \\
T_{f} & =\text { gas film temperature, }\left(T+T_{\text {gas }}\right) / 2
\end{array}
$$

The gaseous diffusion oxidation rate is used if it is less than the rate calculated by Equation 2.4.10. Although the molecular weight $\mathrm{MW}$ and the number of moles $\mathrm{n}$ of $\mathrm{H}_{2} \mathrm{O}$ consumed are defined by the reaction, the quantity $(\mathrm{MW} / \mathrm{nR})$ has been implemented for reactions with $\mathrm{H}_{2} \mathrm{O}$ as sensitivity coefficient array $\mathrm{C} 1003$ to allow the user a measure of separate control over the gaseous diffusion oxidation rate. That sensitivity coefficient is multiplied by two internally in the code to obtain an equivalent value for gaseous diffusion of oxygen $\left(n_{\mathrm{H} 2 \mathrm{O}}=2 n_{\mathrm{O} 2}\right)$.

For the oxidation of Zircaloy in environments containing both $\mathrm{H}_{2} \mathrm{O}$ and $\mathrm{O}_{2}$, the maximum oxidation rate calculated for the two gases is used:

$$
\frac{\mathrm{dW}}{\mathrm{dt}}=\max \left[\left(\frac{\mathrm{dW}}{\mathrm{dt}}\right)_{\mathrm{H}_{2} \mathrm{O}},\left(\frac{\mathrm{dW}}{\mathrm{dt}}\right)_{\mathrm{O}_{2}}\right]
$$

There are two options for partitioning the oxidant consumption between the oxygen and steam. The default option is recommended and does not permit the consumption of steam until all of the available oxygen has been consumed. This option is equivalent to assuming that all hydrogen produced by steam oxidation is instantaneously converted back to steam by combustion with the available oxygen. The default option should prevent time step reductions associated with the normal combustion of in-vessel hydrogen by the BUR package. For the second option the reactions given by Equations 2.4.1 and 2.4.2 are proportioned by the relative rates:

$$
\begin{aligned}
& \mathrm{f}_{\mathrm{H}_{2} \mathrm{O}}=\frac{\left(\frac{d W}{d t}\right)_{\mathrm{H}_{2} \mathrm{O}}}{\left(\frac{d W}{d t}\right)_{\mathrm{H}_{2} \mathrm{O}}+\left(\frac{d W}{d t}\right)_{\mathrm{O}_{2}}} \\
& \mathrm{f}_{\mathrm{O}_{2}}=1-\mathrm{f}_{\mathrm{H}_{2} \mathrm{O}}
\end{aligned}
$$


COR Package Reference Manual

\subsubsection{Boron Carbide}

The $\mathrm{B}_{4} \mathrm{C}$ in BWR control blades is reacted with steam using the model from MARCON 2.1B [2]. This model uses three reaction equations:

$$
\begin{aligned}
& \mathrm{B}_{4} \mathrm{C}+7 \mathrm{H}_{2} \mathrm{O}-2 \mathrm{~B}_{2} \mathrm{O}_{3}+\mathrm{CO}+7 \mathrm{H}_{2}+\mathrm{Q}_{1} \\
& \mathrm{~B} \mathrm{C}_{4}+8 \mathrm{H}_{2} \mathrm{O} \rightarrow 2 \mathrm{~B}_{2} \mathrm{O}_{3}+\mathrm{CO}_{2}+8 \mathrm{H}_{2}+\mathrm{Q}_{2} \\
& \mathrm{~B}_{4} \mathrm{C}+6 \mathrm{H}_{2} \mathrm{O} \rightarrow 2 \mathrm{~B}_{2} \mathrm{O}_{3}+\mathrm{CH}_{4}+4 \mathrm{H}_{2}+\mathrm{Q}_{3}
\end{aligned}
$$

Chemical equilibrium of reaction products is assumed, and the model uses the steam and hydrogen partial pressures and $\mathrm{B}_{4} \mathrm{C}$ temperature to determine the relative extent of each reaction. The equilibrium $\mathrm{CO} / \mathrm{CO}_{2}$ and $\mathrm{CO} / \mathrm{CH}_{4}$ mole ratios $\mathrm{y}_{\mathrm{CO} / \mathrm{CO} 2}$ and $\mathrm{y}_{\mathrm{CO} / \mathrm{CH} 4}$, respectively, are given by the expressions:

$$
\begin{aligned}
& y_{\mathrm{CO} / \mathrm{CO}_{2}}=\frac{P_{\mathrm{H}_{2}}}{\mathrm{P}_{\mathrm{H}_{2} \mathrm{O}}} \exp \left[\frac{-3605.0}{\mathrm{~T}}+3.427\right] \\
& \mathrm{y}_{\mathrm{CO} / \mathrm{CH}_{4}}=\frac{\mathrm{P}_{\mathrm{H}_{2} \mathrm{O}}}{\left(\mathrm{P}_{\mathrm{H}_{2}}\right)^{3}} \exp \left[\frac{-27350.0}{\mathrm{~T}}+30.50\right]
\end{aligned}
$$

where the steam and hydrogen partial pressures are in atmospheres. The extents of reactions 2.4.19-21, expressed as relative percentages of $\mathrm{CO}, \mathrm{CO}_{2}$, and $\mathrm{CH}_{4}$ produced ( $\mathrm{x}_{\mathrm{CO}}, \mathrm{x}_{\mathrm{CO} 2}$, and $\mathrm{x}_{\mathrm{CH} 4}$, respectively), can then be given in terms of the $\mathrm{CO} / \mathrm{CO}_{2}$ and $\mathrm{CO} / \mathrm{CH}_{4}$ mole ratios as:

$$
x_{\mathrm{CO}}=\frac{1}{1+1 / y_{\mathrm{CO}_{\mathrm{CO}}}+1 / y_{\mathrm{CO} / \mathrm{CH}_{4}}}
$$




$$
\begin{aligned}
& \mathrm{x}_{\mathrm{CO}_{2}}=\mathrm{x}_{\mathrm{CO}} / \mathrm{y}_{\mathrm{CO} / \mathrm{CO}_{2}} \\
& x_{\mathrm{CH}_{4}}=1-x_{\mathrm{CO}}-x_{\mathrm{CO}_{2}}
\end{aligned}
$$

The reaction energies (in $\mathrm{J} / \mathrm{kg}$-mole $\mathrm{B}_{4} \mathrm{C}$ reacted) for reaction Equations 2.4.19-21 are given by the equations:

$$
\begin{aligned}
& Q_{1}=8.238\left(10^{8}\right)-58380.0 T \\
& Q_{2}=8.674\left(10^{8}\right)-67060.0 T \\
& Q_{3}=1.056\left(10^{8}\right)-61430.0 T
\end{aligned}
$$

The gaseous reaction products are transferred to the $\mathrm{CVH}$ package, while the $\mathrm{B}_{2} \mathrm{O}_{3}$ generated is transferred to the Radionuclide (RN) package as an aerosol. All the energy generated by the $\mathrm{B}_{4} \mathrm{C}$ reaction is added to the $\mathrm{CVH}$ package. The reaction energies calculated by Equations 2.4.27-29 above are inconsistent with reaction energies that would be calculated using the present equations of state for the noncondensible gases and the $\mathrm{B}_{4} \mathrm{C}$ and $\mathrm{B}_{2} \mathrm{O}_{3}$ (i.e., the temperature dependence implied by those equations is not consistent with the actual temperature dependence of the equations of state used). This discrepancy is ignored at present, due to the lack of reliable enthalpy data for $\mathrm{B}_{4} \mathrm{C}$ and $\mathrm{B}_{2} \mathrm{O}_{3}$.

The $\mathrm{B}_{4} \mathrm{C}$ oxidation rate is given as a fractional change per second in the initial (intact) $\mathrm{B}_{4} \mathrm{C}$ mass by:

$$
\frac{d\left(M_{B_{4} C} / M_{B_{4}}^{\circ}\right)}{d t}=\frac{9.973\left(10^{6}\right)}{60} \exp \left(\frac{-22647.2}{T}\right)
$$

Given the amount of $\mathrm{B}_{4} \mathrm{C}$ reacted, the amounts of the various products are calculated from Equations 2.4.19-26 above. 


\section{COR Package Reference Manual}

\subsection{Control Volume Temperature Distribution (dT/dz) Model}

To accurately model the heat transfer to the gas from multiple COR cells interfaced to a single control volume, an estimate of the temperature distribution in the control volume atmosphere must be made in the COR package. Approximate local fluid temperatures are calculated for cells above the uppermost liquid level in the core; the remaining cells use control volume pool and atmosphere temperatures.

The so-called "dT/dz" model used for this approximation assumes steady gas flow upwards through the channel or bypass with known or specified inlet gas temperature and no cross-flow between core rings. Because fluid temperatures are defined in the CVH package only as volume-averaged quantities, and are not defined at particular flow path locations, a variety of different methods have been implemented to obtain a suitable inlet temperature for a control volume. First, the existence of a pool in the control volume is checked, and if a pool is present, the saturation temperature is used as the inlet temperature to the control volume atmosphere. If a pool is not present in the control volume, three options are available to the user (via the CORTINxx input record) to control how the inlet temperature to a control volume is determined.

As a first option, the user may specify that the inlet temperature for any control volume be taken as the exit temperature from the control volume directly below it, as calculated with the $\mathrm{dT} / \mathrm{dz}$ model described below. This option is the default except for the bottommost control volume in the reactor vessel (adjacent to the lower head). Alternatively, the user may specify that the inlet temperature for a control volume be taken as the $\mathrm{CVH}$ atmosphere temperature of some other control volume (or itself), as defined by the user. This option could be used for the lower head volume, for example, where the downcomer atmosphere temperature might be appropriate. As a third alternative, the user may specify that the value of a control function be used as the inlet temperature for a control volume. This option allows the user great flexibility in defining the inlet temperature, and may be appropriate for complex flows or geometries, such as flows from more than one control volume entering the channel or bypass.

Once the inlet temperature for a control volume is determined, the temperature at each successive COR cell axial location, moving up through the core or lower plenum, is obtained by performing a simple energy and mass balance. The basic energy balance relates the change in energy in a cell during a time step, $\Delta \mathrm{E}_{\text {stored, }}$ to the enthalpy flow through the cell, $\mathrm{H}_{\text {flow }}$, and any energy sources, q:

$$
\Delta E_{\text {stored }}+H_{\text {flow }} \Delta t=q \Delta t
$$

The terms in Equation 2.5.1 are expressed in terms of masses, mass flow rates, and temperatures at the entrance and exit to the cell (note the canceling quantities): 
COR Package Reference Manual

$$
\begin{aligned}
& \Delta E_{\text {stored }}=m^{n} h^{n}-m^{\circ} h^{0}=m^{\circ} c_{p}\left(T^{n}-T^{0}\right)+\left(\dot{m}_{\text {in }}-\dot{m}_{\text {out }}\right) h^{n} \Delta t \\
& H_{\text {flow }}=\dot{m}_{\text {out }} h^{n}-\dot{m}_{\text {in }} h_{\text {ln }}^{n}=\dot{m}_{\text {in }} c_{p}\left(T^{n}-T_{\text {in }}^{n}\right)-\left(\dot{m}_{\text {in }}-\dot{m}_{\text {out }}\right) h^{n} \\
& q=(h A)_{\theta}\left(T_{s, \theta}-T_{\text {out }}^{n}\right)+q_{\text {sou }}
\end{aligned}
$$

where

$$
\begin{aligned}
& \Delta t \quad=\text { time step } \\
& \mathrm{m} \quad=\text { fluid mass in cell } \\
& \dot{\mathrm{m}}=\text { mass flow rate } \\
& c_{\mathrm{p}} \quad=\text { gas specific heat } \\
& \mathrm{T} \quad=\text { cell temperature } \\
& (h A)_{e}=\text { effective average heat transfer coefficient times surface area for the } \\
& \mathrm{T}_{\mathrm{s}, \mathrm{e}} \quad=\text { effective surface temperature for cell components } \\
& \mathrm{q}_{\text {sou }}=\text { source heat rate, from fission product decay heat } \\
& \text { and } \mathrm{B}_{4} \mathrm{C} \text { reaction energy deposited in the atmosphere } \\
& \text { and from heat transfer from heat structures }
\end{aligned}
$$

and superscripts " $n$ " and "o" represent new and old time values, respectively.

The model solves for the value of $T^{n}$, which is then used as $T^{n}{ }_{\text {in }}$ for the next higher cell. Control volume average values for mass and mass flow rates are currently used at the inlet to the control volume, and are updated for the effects of oxidation for each cell. For multiple core rings within the same control volume, the inlet mass flow rate is multiplied by the fraction of the total flow area for each ring, thus partitioning the flow across all rings.

For the $\mathrm{dT} / \mathrm{dz}$ model to function correctly and model the phenomena appropriately, it is important that the heat structures representing the radial core boundary (e.g., core shroud) communicate with the temperatures calculated by this model. The outer ring core 
COR Package Reference Manual

cells must be specified as the fluid temperature boundary on input records HSCCCCCOO4 (see the HS Package Users' Guide) unless the IHSDT option switch provided on input record COR00006 has been set to 1 .

\subsection{Fission Power Generation}

For ATWS accident sequences (or for fission-powered experiments), fission power will be generated in addition to the decay heat. The COR package contains a simple model that calculates the fission power as a function of downcomer liquid level using the ChexalLayman correlation [15]:

$$
q_{f}=0.037\left(C_{u} H_{r}\right)^{0.7}\left(P / P_{r}\right)^{0.3}\left(H / H_{r}\right)^{0.7}
$$

where $H$ is defined in terms of the downcomer liquid level $L$ relative to the top of active fuel and the distance $L_{i}$ below the top of active fuel where fission power drops to zero:

$$
\begin{aligned}
& H=\max \left[0.0,\left(L+L_{\mathrm{f}}\right)\right] \\
& L_{\mathrm{f}}=2.4384\left(\mathrm{P} / \mathrm{P}_{\mathrm{r}}\right)^{0.45}
\end{aligned}
$$

and

$$
\begin{aligned}
& q_{i} \quad \begin{array}{l}
\text { fraction of full operating power, which is defined by the Decay Heat } \\
\text { package on input record DCHFPOW }
\end{array} \\
& \mathrm{C}_{u} \quad=\text { dimensional constant }=3.28084 \mathrm{~m}^{-1} \\
& \mathrm{H}_{\mathrm{r}} \quad=\text { arbitrary reference height, selected as } 1 \mathrm{~m} \\
& \mathrm{P} \quad=\text { system pressure } \\
& \mathrm{P}_{\mathrm{r}} \quad=\text { reference pressure, with default value } 7.65318 \mathrm{MPa} \\
& \mathrm{L} \quad=\text { height of downcomer water relative to the top of active fuel }
\end{aligned}
$$

The Chexal-Layman correlation is based largely on work presented in Reference 15, in which steady state power levels were calculated using coupled, 3-D neutronic and thermal-hydraulic models of the reactor power and fluid flow. The correlation assumes 
that the core inlet enthalpy is always at saturation. The constants in this correlation are implemented in sensitivity coefficient array C1301.

The downcomer liquid level must be calculated by a control function specified on record COR00004. Alternatively, this control function may directly calculate the fission power and the Chexal-Layman correlation is not used, as discussed in the input description for record COR00004.

The energy generated in the fission power model (as well as the decay heat if the RN Package is inactive) is distributed over the core cells using the radial and axial relative power densities input on records CORZjj03 and CORRii03. The user has the option (as described in the input description for record COR00004) for the fission energy to be deposited in the intact fuel components of all core cells (not lower plenum cells), or only in the intact fuel component of cells that are fully or partially liquid covered. For the latter case, the radial and axial relative power densities for these cells are renormalized to achieve this distribution. Further, the user has the option for fission power in a core cell to be distributed over the components and materials within that cell using sensitivity coefficients arrays $\mathrm{C} 1311$ and $\mathrm{C} 1312$. These coefficients specify relative absorbing efficiencies for the core materials and core components for a fraction of the fission power that is specified to "escape" the fuel. By default, all fission power is absorbed in the intact fuel component only, and any energy deposited in $\mathrm{UO}_{2}$ debris associated with other components is lost and will show up as an energy error. Thus,

$$
\begin{aligned}
& P_{i, j, k, U O_{2}}=P_{T} F_{c e l l}\left(1-f_{\text {osc }}+f_{e s c} F_{i, j, k, U O_{2}}\right) \\
& P_{i, j, k, m}=P_{T} F_{c e l l} f_{e s c} F_{i, j, k, m} \quad \text { for } m \neq U O_{2} \\
& F_{\text {cell }}=\frac{f_{i} f_{j} \sum_{k} M_{i, j, k, U O_{2}}}{\sum_{i} \sum_{j} f_{l} f_{j} \sum_{k} M_{l, j, k, U O_{2}}}
\end{aligned}
$$




$$
F_{i, j, k, m}=\frac{f_{m} M_{i, j, k, m}}{\sum_{k_{\text {act }}} f_{m} M_{i, j, k, m}}
$$

where

$$
\begin{aligned}
& \mathrm{P}_{\mathrm{T}} \quad=\text { total core fission power } \\
& \mathrm{P}_{\mathrm{i}, \mathrm{j}, \mathrm{k}, \mathrm{m}}=\text { fission power in material } \mathrm{m} \text { in component } \mathrm{k} \text { in cell } \mathrm{ijj} \\
& \mathrm{f}_{\mathrm{i}}=\text { radial relative power density (input record CORRii03) } \\
& \mathrm{f}_{\mathrm{j}} \quad=\text { axial relative power density (input record CORZjj03) } \\
& f_{m} \quad=\text { relative material absorbing efficiency for escaping fission gammas } \\
& \text { (sensitivity coefficient array 1311) } \\
& \mathrm{f}_{\text {esc }} \quad=\text { fraction of fission energy escaping } \mathrm{UO}_{2} \text { (sensitivity coefficient array 1312) } \\
& \mathrm{k}_{\mathrm{act}}=\text { active component flags (sensitivity coefficient array 1312) } \\
& \mathrm{M}_{\mathrm{i}, \mathrm{j}, \mathrm{k}, \mathrm{m}}=\text { mass of material } \mathrm{m} \text { in component } \mathrm{k} \text { in cell } \mathrm{ijj}
\end{aligned}
$$

\subsection{Material Interactions (Eutectics)}

The material interactions model is invoked by entering integer 1 on input record COR00006. When the model is active the conglomerate debris materials associated with any component are treated as part of a coherent mixture. In the formulation of the model, some of the materials are treated as mutually miscible, while all the others are considered mutually immiscible and treated as they are when the model is inactive (i.e. they melt and relocate independently of one another). As currently implemented, when the model is active all the materials are part of the miscible mixture. The material interactions model can only be activated during MELGEN execution and cannot be deactivated on a restart.

\subsubsection{Mixture Formation}

Molten material can enter the conglomerate debris mixture in one of three ways: (1) as a normal liquid formed when an intact solid reaches its melting point, (2) as a eutectic reaction product formed when two intact solids in mechanical contact within a core component reach their eutectic temperature, or (3) through the dissolution of an intact solid by an existing liquid mixture in the same core cell (e.g. the dissolution of $\mathrm{UO}_{2}$ fuel by the liquid mixture associated with the cladding in the same core cell as the fuel). Currently, there are three eutectic reactions considered which lead to early failure of fuel and control rods: (1) the eutectic reaction between Zircaloy cladding and Inconel grid spacers can lead to early failure of fuel rods, (2) the eutectic reaction between Zircaloy guide tubes and steel cladding can lead to early failure of PWR control rods and (3) the eutectic reaction between B4C powder and steel cladding can lead to early failure of 
COR Package Reference Manual

BWR control rods. The first two reactions occur at $1400 \mathrm{~K}$ by default, while the B4Csteel reaction occurs at $1520 \mathrm{~K}$, but all temperatures may be modified independently with sensitivity coefficients 1011 . The default values were chosen as temperatures at which these reactions become significant $[17,18]$. The molten material is placed in the conglomerate debris array associated with the component.

\subsubsection{Mixture Properties}

The properties of the mixture are mass weighted averages of the constituent properties. The solidus and liquidus temperatures of the mixture depend upon the composition of the mixture and are currently calculated as a mole weighted combination of the solidus temperatures determined by considering every binary combination of material pairs in the mixture. That is, the mixture solidus temperature is given by:

$$
\mathrm{TS}_{m i x}=\frac{\sum_{j} \sum_{i \neq j} \mathrm{f}_{i} \mathrm{f}_{\mathrm{j}} \mathrm{TS}_{i j}}{\sum_{j} \sum_{i \neq j} \mathrm{f}_{i} \mathrm{f}_{j}}
$$

where the f's are mole fractions and $\mathrm{TS}_{\mathrm{ij}}$ is the solidus temperature for a mixture of materials $i$ and $j$ with the same relative proportions as in the total mixture. $T S_{i j}$ can be obtained from pseudo-binary phase diagrams or simple mole weighting of the individual solidus temperatures. Presently, $\mathrm{TS}_{\mathrm{ij}}$ is given by the mole weighted average of the two solidus temperatures for all material pairs except for those listed in Table 2.7.1. For the pairs listed in the table, the solidus temperature is given by the mole weighted average of the eutectic temperature and solidus temperature of the component present in excess of the eutectic molar composition. (The molar ratios and eutectic temperatures in Table 2.7.1 are currently hardwired and not implemented as sensitivity coefficients.) Equation 2.7.1 correctly reduces to $\mathrm{TS}_{\mathrm{ij}}$ when only materials $\mathrm{i}$ and $\mathrm{j}$ are present in the mixture.

The liquidus temperature is set equal to the solidus temperature plus $.01 \mathrm{~K}$ (an artificially small melting range is used to avoid the separation of a two phase mixture into a solid and liquid of vastly different temperatures, which may occur under the assumption of congruent melting that requires the solid and liquid to have the same composition).

The specific enthalpy is calculated in three temperature ranges as follows (refer to Figure 2.7.1)[20]:

1. For temperatures less than the calculated solidus, the mass weighted individual enthalpies are summed with the exception that extrapolated solid enthalpies are used for any material that would ordinarily be liquid. 
COR Package Reference Manual

Table 2.7.1 Core eutectic reactions $[17,18]$

\begin{tabular}{||c|c|c|c|}
\hline \multicolumn{2}{|c|}{ Material Pairs } & Molar Ratio & Temperature \\
\hline \hline $\mathrm{Zr}$ & Inconel & $0.76 / 0.24$ & 1210 \\
\hline $\mathrm{Zr}$ & steel & $0.76 / 0.24$ & 1210 \\
\hline $\mathrm{ZrO}_{2}$ & $\mathrm{UO}_{2}$ & $0.50 / 0.50$ & 2800 \\
\hline $\mathrm{Zr}$ & $\mathrm{B}_{4} \mathrm{C}$ & $0.43 / 0.57$ & 1900 \\
\hline steel & $\mathrm{B}_{4} \mathrm{C}$ & $0.69 / 0.31$ & 1420 \\
\hline $\mathrm{Zr}$ & $\mathrm{Ag}-\mathrm{In}-\mathrm{Cd}$ & $0.67 / 0.33$ & 1470 \\
\hline
\end{tabular}

2. For temperatures greater than the calculated liquidus, the mass weighted individual enthalpies are summed with the exception that extrapolated liquid enthalpies are used for any material that would ordinarily be solid.

3. Otherwise, linear interpolation in enthalpy is used between the solidus and liquidus. The difference in enthalpy is the latent heat of fusion.

The Zircaloy and steel included in the mixture will oxidize unless disabled by user input on record CORTST01. The oxidation will reduce the metallic content of the mixture and increase the oxidic content.

\subsubsection{Chemical Dissolution of Solids}

If the enthalpy of the molten mixture exceeds its liquidus enthalpy, then the mixture will begin to dissolve certain solids if they are present in the same core cell. The dissolution of solids proceeds sequentially, and at most two distinct solids may be attacked by the mixture associated with a component on any given time step. Table 2.7.2 lists the hierarchy used in determining which solids are dissolved by the mixtures associated with each core component (intact fuel does not have a mixture associated with it). Note that certain solids are attacked only if the oxide shell surrounding the component has been breached, while others are attacked only if the shell is intact. Holdup by oxide shells is described in detail in Section 3.2.1. The hierarchy listed is based upon the assumed arrangement of materials in intact core components. For example, it is assumed that a eutectic mixture that escapes from a PWR control rod must dissolve the $\mathrm{ZrO}_{2}$ oxide shell that surrounds fuel rods before it can dissolve the $\mathrm{UO}_{2}$ pellets within. Similarly, mixtures 


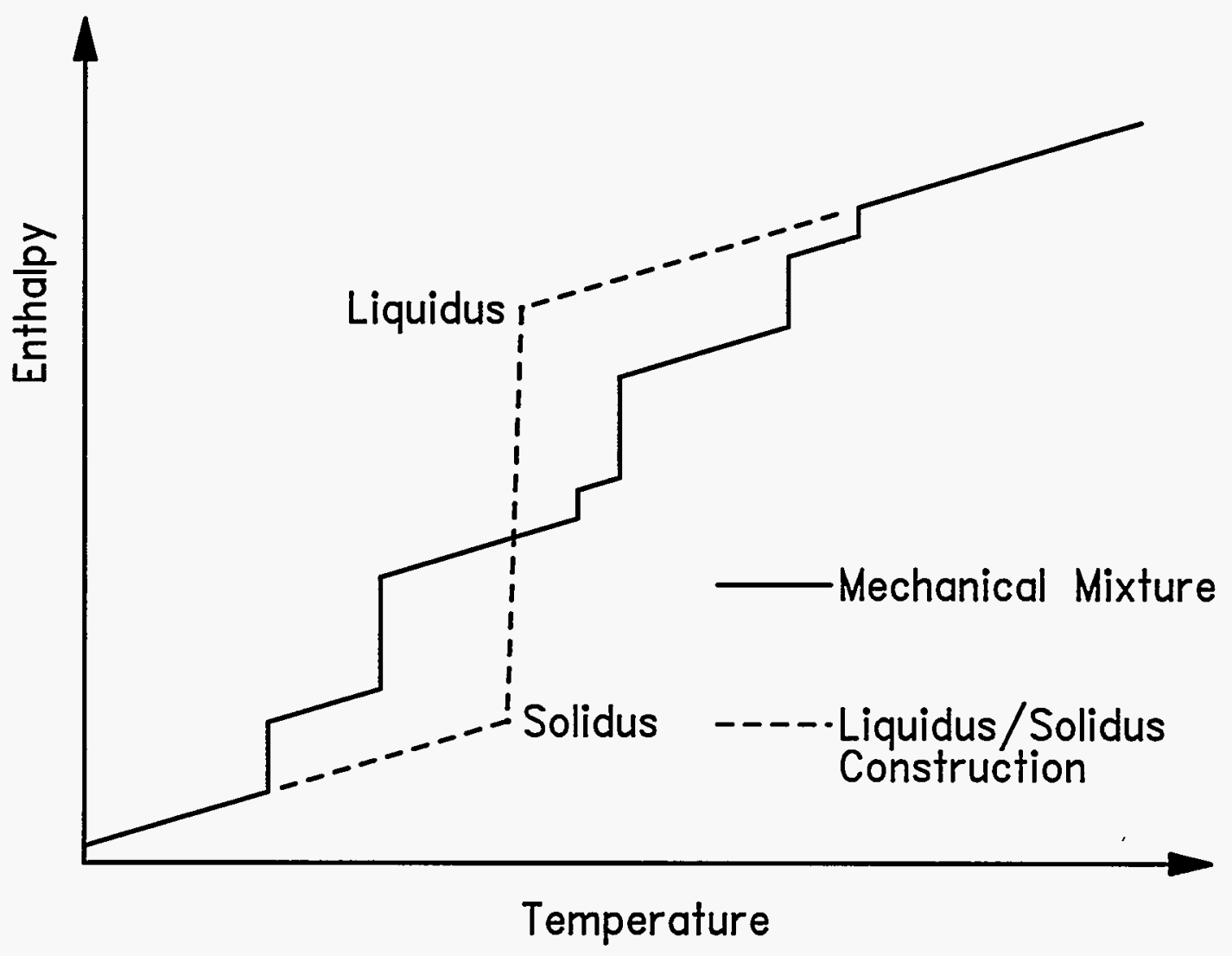

Figure 2.7.1 Two-phase construction for material mixture [19]

originating from BWR control blades encounter canisters. It should be noted that most intact components are eventually converted into particulate debris, so that even though the eutectic associated with BWR control blades is not assumed to reach intact fuel, once the blade becomes particulate debris the eutectic may have access to $\mathrm{UO}_{2}$.

Dissolution will proceed until the addition of solid lowers the updated gross mixture enthalpy to the liquidus enthalpy associated with the updated mixture composition or until the parabolic rate limitation associated with the dissolution reaction has been exceeded for the given time step. The solution is iterative, and the parabolic rate limitations are given by [17]:

$$
\left(x_{j}^{f}\right)^{2}=\left(x_{j}^{i}\right)^{2}+K_{j} \Delta t
$$


COR Package Reference Manual

$$
K_{l}=A_{j} \exp \left(B_{l} / T\right)
$$

where

$$
\begin{array}{ll}
x_{j}^{f} & =\text { final mass fraction of material } j \\
x_{j}^{i} & =\text { initial mass fraction of material } j \\
\Delta t & =\text { time step }(s) \\
T & =\text { component temperature }(K)
\end{array}
$$

and the constants $A_{j}$ and $B_{j}$ may be adjusted through sensitivity coefficient array C1010. Default values for $\mathrm{ZrO}_{2}$ and $\mathrm{UO}_{2}$ are taken from Reference 17:

$$
\begin{array}{ll}
\mathrm{A}_{\mathrm{ZrO2} 2}=1.47 \times 10^{14} & \mathrm{~A}_{\mathrm{UO2}}=1.02 \times 10^{15} \\
\mathrm{~B}_{\mathrm{ZrO2}}=8.01 \times 10^{4} & \mathrm{~B}_{\mathrm{UO2}}=8.14 \times 10^{4}
\end{array}
$$

These constants are based upon experiments using molten Zircaloy to dissolve $\mathrm{UO}_{2}$ and $\mathrm{ZrO}_{2}$, but the limits are applied to the dissolution of those solids by any mixture, irrespective of its composition. Consequently, as the fraction of Zircaloy in the mixture becomes small, the results from the model become suspect, and users are urged to conduct sensitivity studies to determine the effect of variations in the values of the constants in Equation 2.7.3. For the remaining materials, parabolic rate correlations have not been identified and no limitation is applied, although a limitation could be activated by supplying appropriate values for the sensitivity coefficients in Equation 2.7.3. 
Table 2.7.2 Solid dissolution hierarchy

\begin{tabular}{|c|c|}
\hline Component & Solids Dissolved by Mixture \\
\hline cladding & $\begin{array}{l}\mathrm{UO}_{2} \text { from intact fuel } \\
\mathrm{ZrO}_{2} \text { from intact cladding }\end{array}$ \\
\hline canister & $\begin{array}{l}\mathrm{ZrO}_{2} \text { from intact canister } \\
\mathrm{ZrO}_{2} \text { from intact cladding } \\
\mathrm{UO}_{2} \text { from intact fuel }\end{array}$ \\
\hline $\begin{array}{l}\text { other structure } \\
\text { (steel only) }\end{array}$ & steel oxide from other structure \\
\hline $\begin{array}{l}\text { other structure } \\
\text { (BWR control rod) }\end{array}$ & $\begin{array}{l}\text { steel oxide from other structure } \\
\mathrm{ZrO}_{2} \text { from intact canister" } \\
\mathrm{Zr} \text { from intact canister }\end{array}$ \\
\hline $\begin{array}{l}\text { other structure } \\
\text { (PWR control rod) }\end{array}$ & $\begin{array}{l}\text { steel oxide from other structure } \\
\mathrm{Zr} \text { from other structure } \\
\mathrm{ZrO}_{2} \text { from intact cladding } \\
\mathrm{UO}_{2} \text { from intact fuel }\end{array}$ \\
\hline particulate debris & $\begin{array}{l}\mathrm{UO}_{2} \text { from particulate debris } \\
\mathrm{ZrO}_{2} \text { from particulate debris } \\
\mathrm{ZrO}_{2} \text { from intact cladding } \\
\mathrm{UO}_{2} \text { from intact fuel }\end{array}$ \\
\hline
\end{tabular}

* indicates solid is attacked only if there is no holdup of the mixture in the component.

** indicates solid is attacked only if the mixture is being held up by the component. 
COR Package Reference Manual

COR-RM-56 
COR Package Reference Manual

\section{MASS RELOCATION MODELS}

This section describes the mass relocation models in the COR package. Candling of molten core materials, the transport of additional unmolten materials with the molten material, and the formation of flow blockages and molten pools are described in Section 3.1. The models for the radial relocation of molten pools and particulate debris are described in Section 3.2. Formation of particulate debris by various means from intact components is described in Section 3.3, and the relocation of this debris by gravitational settling and collapse of supporting components is described in Section 3.4.

\subsection{Candling}

The term candling is used here to refer to the downward flow of molten core materials and the subsequent refreezing of these materials as they transfer latent heat to cooler structures below. The COR package candling model is semi-mechanistic, based on fundamental thermal/hydraulic principles but incorporating user-specified refreezing heat transfer coefficients defined for each material on record COR00005. The model is adaptable to steady flow of either films or rivulets (with smaller contact area than a film) by appropriate adjustment of these refreezing coefficients.

The model does not solve a momentum equation for a flow velocity. Instead it assumes steady generation and flow of molten material, with all material generated within a time step reaching its final destination within that step. For a steady melt generation rate, the amount of material entering into the candling model is proportional to the time step, and so for small time steps the amount of material that refreezes at a particular location is also approximately proportional to the time step. In other words, if for a given time step a certain amount of molten material is calculated with varying amounts refreezing at different axial locations, the assumption is that for a time step twice as large, twice as much molten material would be generated and approximately twice as much would refreeze at each location. Thus, the cumulative behavior of the model should be relatively independent of time step history. For situations involving release of a larger amount of molten material built up over several time steps, alternative assumptions are used regarding the flow of that material and its contact time with structural surfaces to avoid time step dependencies, as described in Section 3.1.2.

\subsubsection{Steady Flow}

At the end of a COR package time step, following the heat transfer and oxidation calculations, there may be molten material existing at a given location within the core. This initial molten mass, $M_{m}$, is assumed to have been generated at a constant rate over the time step, $\Delta t$, and to have flowed down through a column of cells. (A model to hold up molten material by an oxide shell until it is breached is described below.) The amount 
COR Package Reference Manual

of mass $M_{m}$ that refreezes on each lower cell component is determined by integrating the heat transfer rate between the molten film and the component:

$$
q=h_{m} P_{w} \Delta z\left(T_{m}-T_{s}\right)
$$

over the time step $\Delta t$, where

$$
\begin{array}{ll}
h_{m} & =\text { user-specified refreezing heat transfer coefficient } \\
\Delta z & =\text { cell height } \\
P_{w} & =\text { film or rivulet width (area of contact divided by } \Delta z \text { ) } \\
T_{m} & =\text { temperature of the molten film } \\
T_{s} & =\text { temperature of the component }
\end{array}
$$

As energy is transferred to the component, $T_{s}$ will rise according to the expression:

$$
q=C_{p s} \frac{d T_{s}}{d t}
$$

where $\mathrm{C}_{\mathrm{ps}}$ is the total heat capacity of the component. The total amount of energy transferred to a given cell component is thus:

$$
Q=h_{m} P_{w} \Delta z\left(T_{m}-T_{s o}\right) \frac{1-\exp (-K \Delta t)}{K}
$$

where $T_{s 0}$ is the component temperature at the beginning of candling (after the regular heat transfer calculations have been done) and $\mathrm{K}$ is given by the expression:

$$
K=\frac{h_{m} P_{w} \Delta z}{C_{p s}}
$$

If $T_{m}$ is greater than the material melting temperature $T_{m p}$ (i.e., the molten material is superheated, carrying sensible heat in addition to latent heat), a portion $Q_{s h}$ of the total energy transfer $Q$ is used to cool the molten film down to its melting temperature without refreezing any mass: 
COR Package Reference Manual

$$
Q_{s h}=M_{m} c_{p, m}\left(T_{m}-T_{m p}\right)
$$

where $c_{p, m}$ is the molten film specific heat capacity. The mass refrozen on the component is then obtained by dividing the remaining (latent) energy transfer $\left(Q-Q_{\text {sh }}\right)$, if greater than zero, by the latent heat of fusion $\mathrm{H}_{\mathrm{f}}$ of the candling material:

$$
\Delta M_{m}=\frac{Q-Q_{s h}}{H_{f}}
$$

This refrozen mass (which initially exists at the material melting temperature) is then thermally equilibrated with the component temperature. If $Q_{s h}$ is greater than $Q$, no mass is refrozen, although sensible heat is transferred.

Molten mass is relocated downward in stepwise fashion according to Equation 3.1.6 until it has all refrozen on components in one or more lower cells or until it encounters a blockage (see Section 3.1.2). Figure 3.1.1 illustrates several steps in this process. The material refrozen on a component is termed conglomerate debris (as opposed to particulate debris), and becomes an integral part of that component.

If the material interactions (eutectics) model is not active, materials candle independently whenever their melting point is reached; otherwise, the molten portion of the conglomerate debris mixture candles as a congruently freezing mixture (i.e. when it freezes, the solid formed has the same composition as the liquid remaining).

Molten material originating in one type of component refreezes on the same component type in lower cells unless that component does not exist in those cells. If the originating component type does not exist in a cell, the molten material refreezes on an alternate component that depends on the originating component type and whether the cell is in the core or lower plenum. The refreezing logic, showing primary and alternate refreezing components, is summarized in Table 3.1.1. As indicated there, in the core the alternate refreezing component for material originating in cladding, canister, or "other structure" components is particulate debris, and the alternate component for material originating in particulate debris is cladding. In the lower plenum, the first alternate refreezing component is "other structure" and the second alternate component is particulate debris. If neither the originating component nor an alternate refreezing component is found in a cell, the molten material falls through to the next lower cell.

The volume occupied by molten and refrozen material during candling is tracked, and any related changes in component volumes are communicated to the $\mathrm{CVH}$ package as virtual volume changes. (The term "virtual volume" refers to space occupied by relocatable non$\mathrm{CVH}$ materials in a control volume. Changes in virtual volume affect liquid levels, pressure calculations, and so forth. For a detailed discussion of virtual volume concepts, 
COR Package Reference Manual

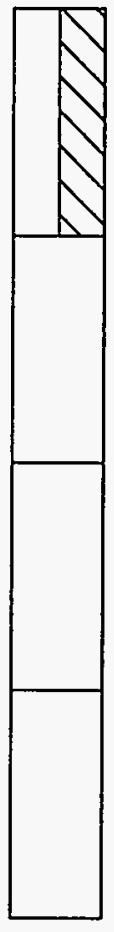

STEP 1

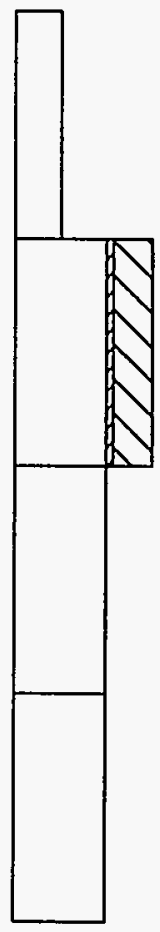

STEP 2

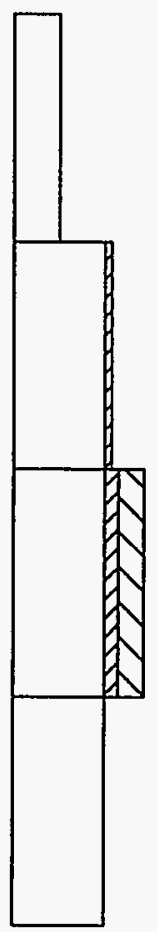

STEP 3

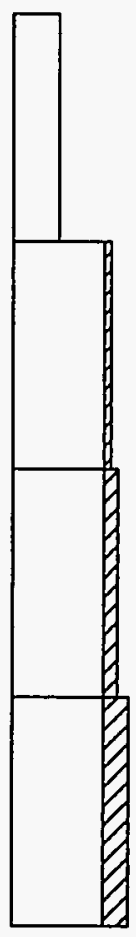

STEP 4
REFROZEN
D MOLTEN

Figure 3.1.1 Candling process steps 
COR Package Reference Manual

Table 3.1.1 Primary and alternate refreezing components

\begin{tabular}{||c||c|c|c|c||}
\hline \multirow{2}{*}{$\begin{array}{c}\text { Cell } \\
\text { Location }\end{array}$} & \multicolumn{4}{|c|}{ Originating Component Type } \\
\cline { 2 - 5 } & $\mathrm{CL}$ & $\mathrm{CN} / \mathrm{CB}$ & $\mathrm{OS}$ & $\mathrm{PD}$ \\
\hline \hline \multirow{3}{*}{ Core } & $\mathrm{CL}$ & $\mathrm{CN} / \mathrm{CB}$ & $\mathrm{OS}$ & $\mathrm{PD}$ \\
& $\mathrm{PD}$ & $\begin{array}{c}\mathrm{PD} \\
\text { fallthru }\end{array}$ & $\begin{array}{c}\mathrm{PD} \\
\text { fallthru }\end{array}$ & $\begin{array}{c}\mathrm{CL} \\
\text { fallthru }\end{array}$ \\
\hline \multirow{3}{*}{ Lower Plenum } & $\mathrm{OS}$ & $\mathrm{OS}$ & $\mathrm{OS}$ & $\mathrm{OS}$ \\
& $\mathrm{PD}$ & $\mathrm{PD}$ & $\mathrm{PD}$ & $\mathrm{PD}$ \\
& fallthru & fallthru & fallthru & fallthru \\
\hline
\end{tabular}

see the CVH Package Reference Manual.)

\subsubsection{Flow Blockages}

Flow blockages are allowed to form, as illustrated in Figure 3.1.2, whenever refrozen material completely fills all the available volume in a COR cell. When candling material reaches a flow blockage (or the lower head), the molten material is simply equilibrated with the primary or alternate refreezing component in the cell above the blockage, possibly forming a molten pool if that component cannot absorb all the latent heat. (If no designated refreezing component exists, the molten material becomes conglomerate debris connected with particulate debris, even though no particulate exists.) The model that transfers molten material between radial rings to achieve a uniform surface level across the pool is discussed below in Section 3.2.1. Candling of molten pools accumulated above a blockage after failure of that blockage is discussed below in Section 3.1.3.

To model the effects of flow area reduction or blockage due to core materials relocation, a control function argument, COR-AFLMIN.m.n, is available to control the area of a flow path valve; however, an appropriate control function referencing this argument must be explicitly included in the FL valve input. This argument is set to the minimum flow area in a column of cells between axial levels $m$ and $n$, inclusive. Multiple radial rings can be treated by combining the arguments for different rings in one or more control functions. For more details, see the COR and FL Users' Guides. 
COR Package Reference Manual

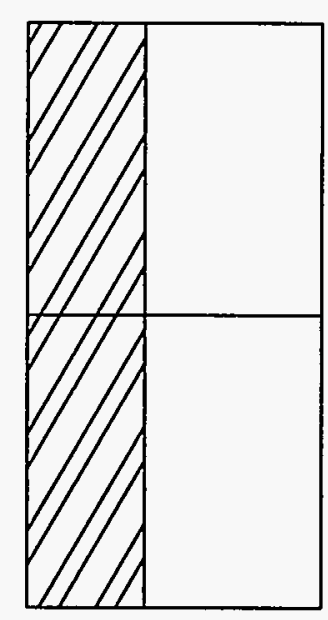

$t_{1}$

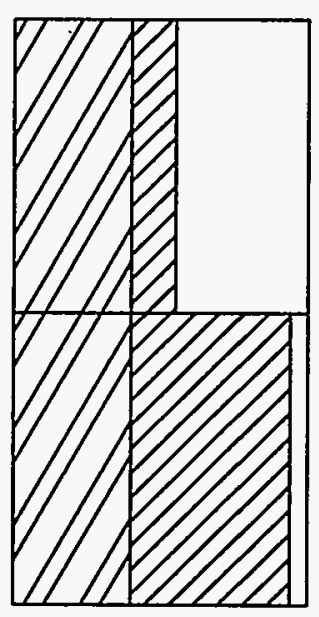

$\dagger_{4}$

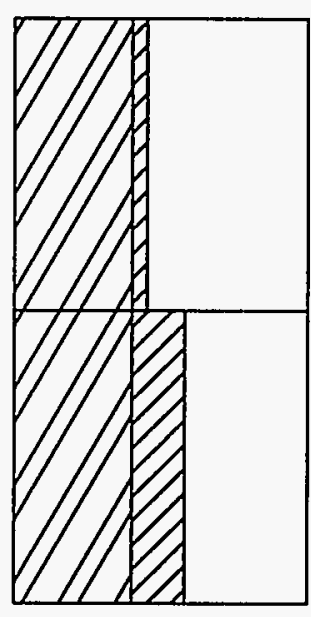

$t_{2}$
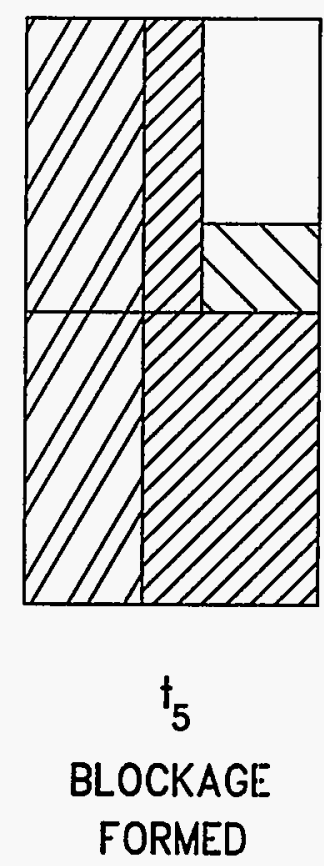

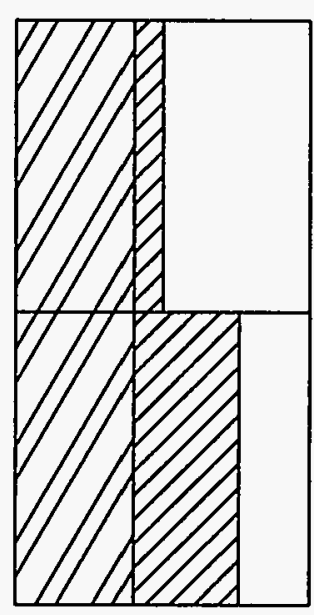

$t_{3}$

$\nabla$ intact

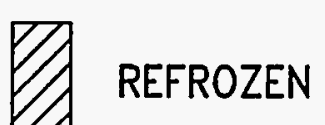

D MOLTEN

Figure 3.1.2 Flow blockage formation during candling 
COR Package Reference Manual

\subsubsection{Holdup by Oxide Shells}

A model has been implemented in the COR package for an oxide shell to hold up molten material until the shell is breached. Molten material is held up within a component if the oxide thickness is greater than a critical value $\Delta r_{\text {hold }}$ if the component temperature is less than a critical value $T_{\text {breach, }}$, and if no candling from the component in that cell has yet taken place. The parameters $\Delta r_{\text {hold }}$ and $T_{\text {breach }}$ may be set independently for steel and Zircaloy via sensitivity coefficient array $\mathrm{C}_{1131}$. The default values for these sensitivity coefficients are currently set so that the holdup model is effectively turned off.

When an oxide shell is first breached, or when a flow blockage or crust first fails, the assumption built into the candling model of constant generation of melt over the time step is no longer valid. Behavior of the model, i.e., the amounts of mass refrozen in lower core cells as described in Section 3.1, would thus be highly dependent on the size of the current time step. Therefore, for those situations involving the sudden release of a large mass of molten material, $M_{m}$, built up over perhaps several previous time steps, application of the candling model is modified slightly. For breach of an oxide shell, a constant time step $\Delta t_{\text {break }}$ is used in Equation 3.1.3 to avoid time step dependencies. For failure of a flow blockage holding up a molten pool, a time step $\Delta t_{\text {contact }}$ is used in Equation 3.1.3. This time step is calculated as a function of a parameter $\Gamma_{\max }$, which represents a maximum flow rate (per unit surface width) of the molten pool after breakthrough:

$$
\Delta t_{\text {contact }}=\max \left[\Delta t, \frac{M_{m} \Delta z}{\Gamma_{\max } A_{s}}\right]
$$

In other words, a large molten pool is allowed to discharge at a maximum rate of $\Gamma_{\max }$ and the amount refreezing onto structures below will be a linear function of the total mass of the pool. Both $\Delta t_{\text {break }}$ and $\Gamma_{\max }$ are accessible in sensitivity coefficient array $C 1141$; their default values of $1 \mathrm{~s}$ and $1 \mathrm{~kg} / \mathrm{m}$-s have been set so that this model is only active for large molten pools breaching a crust.

\subsubsection{Solid Material Transport}

A simple model has been implemented to allow transport of unmolten secondary materials (currently $\mathrm{ZrO}_{2}, \mathrm{UO}_{2}$, steel oxide, and control poison) via the candling process. This model could be used to treat the breaking off of pieces of thin oxide shells that are carried with the molten material or to simulate the dissolution of $\mathrm{UO}_{2}$ by molten $\mathrm{Zr}$. On input record COR00007, the user may specify relocation of a secondary material as either an input fraction $F_{1}$ of the molten mass $\Delta M_{m}$ deposited on a component:

$$
\Delta M_{s}=F_{1} \Delta M_{m}
$$


COR Package Reference Manual

or in fractional proportion to its existing fraction within a component:

$$
\Delta M_{s}=F_{2} \frac{M_{s}}{M_{m}} \Delta M_{m}
$$

where $F_{2}$ is an input parameter specifying the fraction of direct proportional relocation, $M_{s, \text { total }}$ is the total secondary material mass in the component in the cell of origin, $M_{m, \text { total }}$ is the total material mass (molten and solid) in the cell of origin, and $\Delta \mathrm{M}_{s}$ is the secondary material mass deposited with refrozen material $\Delta \mathrm{M}_{\mathrm{m}}$.

This model is inactive if the COR materials interactions (eutectics) model, which is described in Section 2.7 and treats dissolution mechanistically, is active.

\subsubsection{Surface Area Effects of Conglomerate Debris}

The addition of conglomerate debris refrozen on component structures affects the surface area exposed to fluid convection, oxidation, and further refreezing during candling. The following paragraphs describe how the effects of conglomerate debris are incorporated into the COR package.

Consider the candling process idealized for a fuel rod unit cell as shown in Figure 3.1.3. Molten debris refreezing on the rod is assumed to begin forming a half-cylinder on the rod at the point directly adjacent to the next rod (Figure 3.1.3(a,b)). As this half-cylinder of conglomerate continues to grow, its surface area expands, and the intact area shielded also grows, albeit at a lesser rate. Eventually it meets the conglomerate on the adjacent rod, and forms a bridge between the two rods (Figure 3.1.3(c)). As additional material is added, more of the intact rod is covered by the conglomerate, until a cylindrical void region centered in the interstitial region among a set of four rods is created (Figure 3.1.3(d)). This central void then shrinks to nothing as the interstitial area is completely plugged up (Figure 3.1.3(e)).

For purposes of calculation, the above-described process is divided into three stages. The first stage lasts until the conglomerate debris half-cylinders bridge the gap between rods, as shown in Figure 3.1.3(c). The second stage lasts until that bridge has widened to cover the entire surface area of the fuel rods, forming a central cylindrical void, as shown in Figure 3.1.3(d). The third stage continues until the central void is completely plugged up as shown in Figure 3.1.3(e). The surface area of the conglomerate debris in the unit cell is calculated in approximate fashion from the fraction of the interstitial volume that it occupies.

During the first stage, the surface area of the conglomerate debris $A_{c d}$ grows as the square root of its volume $V_{c d}$ up to some critical volume $V_{c 1}$ with surface area $A_{c 1}$. In 
COR Package Reference Manual

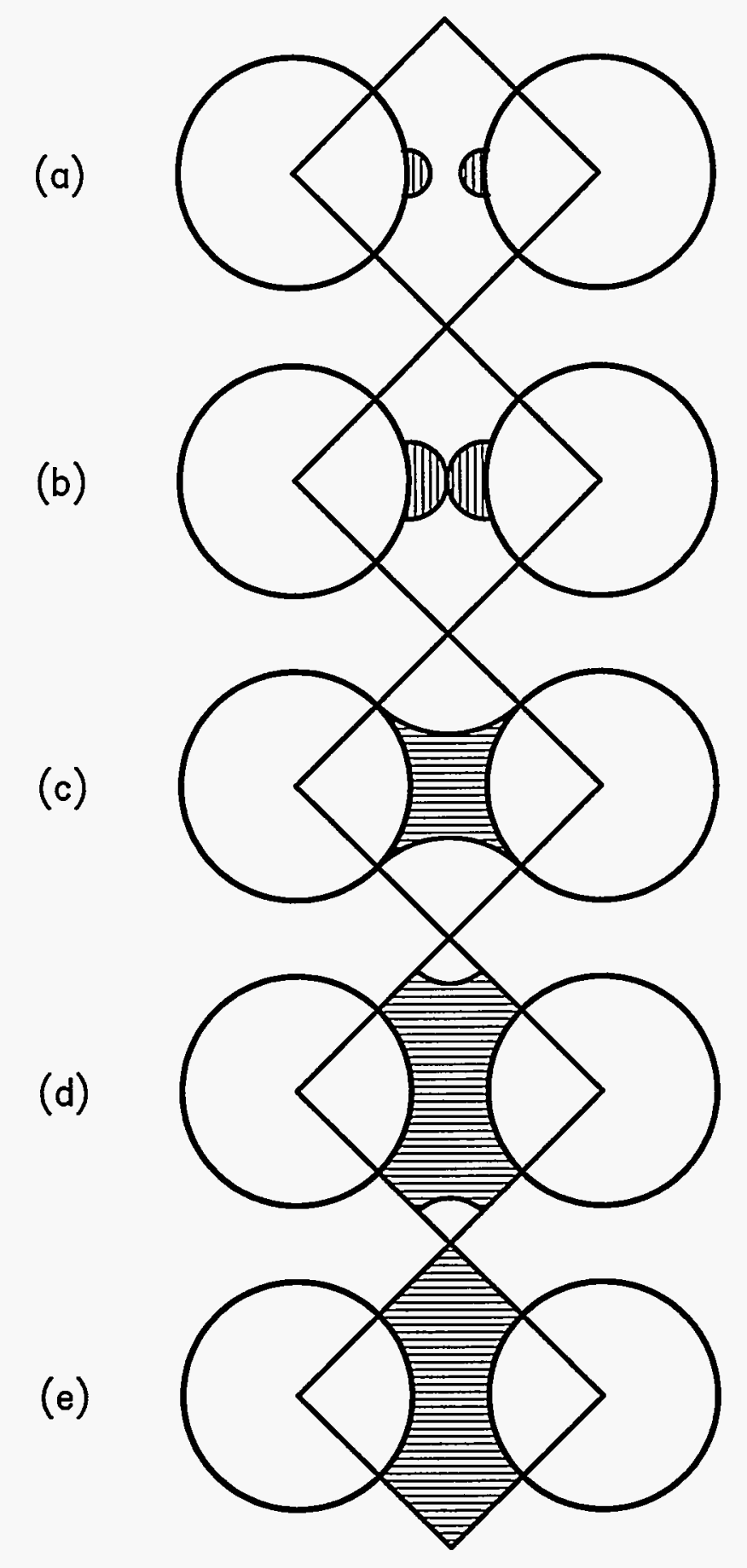

Figure 3.1.3 Conglomerate debris geometry in fuel rod bundles 


\section{COR Package Reference Manual}

terms of area and volume fractions relative to the unit cell rod surface area $A_{i}$ and initial interstitial volume $\mathrm{V}_{i}$ :

$$
\begin{aligned}
& A_{c d}=A_{i}\left(\frac{A_{c 1}}{A_{i}}\right)\left(\frac{V_{c d} / V_{i}}{V_{c 1} / V_{i}}\right)^{1 / 2} \\
& \frac{A_{c 1}}{A_{i}}=F_{A 1, \max }=\frac{P-2 R}{R} \\
& \frac{V_{c 1}}{V_{i}}=F_{V 1, \max }=\frac{\pi}{2} \frac{(P-2 R)^{2}}{\left(P^{2}-\pi R^{2}\right)}
\end{aligned}
$$

where $P$ is the rod pitch and $R$ is the rod radius.

During the third stage, beyond some critical volume $V_{c 2}$ with surface area $A_{c 2}$, the surface area of the conglomerate debris decreases as the square root of the empty volume $\left(V_{i}-V_{c o}\right)$. In terms of area and volume fractions:

$$
\begin{aligned}
& A_{c d}=A_{1}\left(\frac{A_{c 2}}{A_{1}}\right)\left(\frac{1-V_{c d} / V_{i}}{1-V_{c 2} / V_{1}}\right)^{1 / 2} \\
& \frac{A_{c 2}}{A_{1}}=F_{A 2, \max }=\frac{P / \sqrt{2}-2 R}{R} \\
& \frac{V_{c 2}}{V_{1}}=F_{V 2, \max }=1-\pi \frac{(P / \sqrt{2}-R)^{2}}{\left(P^{2}-\pi R^{2}\right)}
\end{aligned}
$$

A minimum area fraction $F_{A, \min }$ may be imposed for the third stage to prevent the surface area of central void from being completely reduced to zero. In any case, the surface area of conglomerate debris will not be reduced below a minimum surface-to-volume ratio as described below. 
During the second stage, the surface area of the conglomerate debris is interpolated linearly with volume between $A_{c 1}$ and $A_{c 2}$.

The area of the intact rods wetted by the conglomerate, and thus blocked from further oxidation and convection, is treated in two stages. For volumes greater than $V_{c 2}$, the fraction of intact surface area $A_{i}$ blocked is set to a maximum value:

$$
F_{b}=F_{b, \max }
$$

For volumes less than $\mathrm{V}_{\mathrm{c} 2}$, the fraction blocked is linearly interpolated:

$$
F_{b}=F_{b, \max } \frac{V_{c d}}{V_{c 2}}
$$

The parameters $F_{A 1, \max }, F_{V 1, \text { max }}, F_{A 2, \max }, F_{V 2, \max }, F_{A, \min }$, and $F_{b, \max }$ are accessible for each component as sensitivity coefficient array C1151. Currently, all components have the same default values based on typical BWR rod geometries with pitch $16 \mathrm{~mm}$ and rod radius $6.26 \mathrm{~mm}$.

For conglomerate debris that does not occupy interstitial volume (either the component does not have interstitial volume via the porosity input or the debris overflows what is available), a simple surface area to volume ratio is applied to the excess conglomerate debris volume $\mathrm{V}_{\mathrm{cd}, \mathrm{excess}}$ :

$$
A_{c d, \text { excess }}=V_{c d, e x c e s s} R_{S V}
$$

The parameter $R_{S V}$ is also accessible in sensitivity coefficient array $C 1151$ with a default value of 100 . The surface area of the excess debris is added to the area calculated from Equations 3.1.10 to 3.1.17. The total surface area of conglomerate debris (excess plus interstitial) cannot fall below the value obtained by multiplying the debris volume $V_{c d}$ by $R_{\text {sV. }}$

\subsection{Radial Relocation}

There are two radial relocation models-the first relocates molten core material which still exists following the candling/refreezing algorithm just described, and the second which follows the first relocates particulate debris. Both models are intended to simulate the gravitational leveling between adjacent core rings that will tend to equalize the hydrostatic head in a fluid medium. Either of the two radial relocation models can be deactivated by user input on MELCOR input record CORTST01, but they are both active by default. Model parameters are adjustable through sensitivity coefficient array C1020. 
COR Package Reference Manual

\subsubsection{Molten Material}

The molten material radial relocation models are called each core subcycle immediately after the axial relocation (candling) model. A simple algorithm loops over all the radial rings at each axial level in the core and compares the calculated liquid levels in adjacent rings if there are no intact BWR canister structures in either ring. If the levels are unequal, then a calculation is performed to determine the volume of molten material, $\mathrm{V}_{\text {eq, }}$ that must be moved between the rings to balance the levels. The relocation rate has a time constant of $\tau_{\text {spr }}$, which may be adjusted by user input, so that the actual volume relocated, $V_{\text {rel }}$, during the core time step, $\Delta \mathrm{t}_{c}$, is given by:

$$
V_{\text {rel }}=V_{\theta q}\left[1-\exp \left(-\Delta t_{c} / \tau_{s p r}\right)\right]
$$

The default value of $1 \mathrm{~s}$ for $\tau_{\mathrm{spr}}$ was chosen as an order-of-magnitude value based on the driving head of debris and numerical considerations.

If the volume of the material that must be relocated is trivial (less than $1 \%$ of the fluid volume, including molten volume, of the cell to which it would be moved), then no relocation is performed during that time step; otherwise, the fraction of the molten material that must be transferred from the "deep" ring to the "shallow" ring is determined by dividing the mass of melt that must be relocated by the total mass of melt in the deep ring. Then that fraction of molten mass is transferred from each core component in the deep ring to the conglomerate debris associated with the particulate debris component in the shallow ring, and the component volumes in each ring are adjusted accordingly. Any fission product transfers or virtual volume adjustments resulting from the relocation are performed by calls to interface routines with the RN Package and CVH Package, respectively.

Radial relocations are directed inward preferentially; that is, at each axial level the algorithm begins at the innermost ring, marches radially outward and transfers molten material from ring $i$ to ring $i-1$ if the liquid level in ring $i$ exceeds that in ring $i-1$. Following the march from ring 1 outward, a reverse march is made inward from the outermost ring to perform any outward relocations from ring $i$ to ring $i+1$ still required to achieve a uniform liquid level across the axial level.

\subsubsection{Particulate Debris}

The particulate debris leveling model is very similar to the molten material leveling model just described except that material is moved only from the particulate debris component in the "deep" ring to the particulate debris component in the "shallow" ring. The useradjustable time constant for particulate debris relocation has an ad hoc default value of 
COR Package Reference Manual

3 s. Particulate debris relocation is subject to the same constraints concerning BWR canisters as molten material relocation. Component volumes and associated fission products are adjusted following relocations.

\subsection{Particulate Debris Formation}

Currently several very simple particulate debris formation mechanisms have been implemented in the COR package. One mechanism specifies that particulate debris is formed whenever the unoxidized metal thickness of an intact component reaches some user-defined minimum value. Implicit in this model is the assumption that oxide layers on a component provide no structural strength to the component and that metal of a certain thickness is sufficient to support an arbitrary mass above that point; no stress calculations are performed. The user may define one minimum thickness parameter, $\Delta r_{c 1, m i n}$, that is used for Zircaloy in the cladding component and the two canister components, and another, $\Delta \mathrm{r}_{\mathrm{ss}, \mathrm{min}}$, that is used for steel in the "other structure" component. Both values may be input on record COR00008, with defaults of $0.1 \mathrm{~mm}$ for each. Whenever cladding in a COR cell fails, both fuel and cladding component masses in that cell are converted to particulate debris masses, based on the assumption that cladding integrity is the sole source of support for the stack of fuel pellets. Likewise, the component masses in "other structure" are converted to particulate debris masses whenever that component in a cell fails.

Setting $\Delta r_{c 1, \min }$ to zero will inhibit collapse of fuel rods and allow "bare" fuel pellets to remain standing. Also, if the user has specified electric heating element material in the fuel rods, formation of particulate debris is suppressed, based on assumed support by the heating element, and the minimum thickness parameter $\Delta r_{c 1, m i n}$ must be set to zero.

Particulate debris is also formed from intact components whenever lower components which normally provide support are eliminated by melting or failure. For example, intact fuel rods can fall to lower cells if the middle of the core melts away. For this to happen, the cell below must be completely empty, containing no components at all. Also, the second digit ("ones" digit) of the support flag ISUP for the level containing the intact component must be set to 0 on input record CORZjj02 (see Section 3.4). If both criteria are met, all components in the cell are converted immediately to particulate debris.

Other complex debris formation mechanisms, such as quench-induced shattering, have not been implemented in the COR package at this time.

Particulate debris is characterized by a single user-specified particle diameter, $D_{p d}$, entered as the hydraulic diameter on input record CORijj04. There is no provision at this point for allowing particulate debris to have more than one different representative diameter. Presently, all particulate debris is assumed to reside only within the channel 


\section{COR Package Reference Manual}

control volume. The surface area of the particulate portion of the debris is calculated from $D_{p d}$ and the total volume of the particulate, $V_{p d}$, as:

$$
A_{s, p d}=\frac{6 V_{p d}}{D_{p d}}
$$

The fraction of this area used for oxidizing the Zircaloy portion of the particulate debris is the fraction of the particulate debris volume that is Zircaloy plus $\mathrm{ZrO}_{2}$, and the fraction of this area used for oxidizing the steel portion of the particulate is the fraction of the particulate volume that is steel plus steel oxide. $\mathrm{ZrO}_{2}$ and steel oxide in particulate debris are modeled to exist as a layers covering the $\mathrm{Zr}$ and steel, respectively. The particulate areas of the debris are further modified by the addition of conglomerate debris according to the model described in Section 3.1.5 to obtain actual areas for oxidation and heat transfer.

\subsubsection{Debris Addition from Heat Structure Melting}

Molten steel masses from melting of the radial boundary heat structures (input on record CORZjj02), caused by intense radiative heating by hot core components, is passed to the COR package. (Currently such heat structure melting will be simulated only if the $\mathrm{BH}$ package is active for a BWR.) This model has particular application to the BWR core shroud, which is a relatively thin $(5 \mathrm{~cm})$ structure that surrounds the entire length of the core and extends into the upper plenum.

This model tracks the material mass and volume changes associated with molten material added to the core package. Heat structure melting is calculated by special application of the HS package degassing model using material type 'SS' (see the HSDGCCCCCx input records). Structures that can be considered for melting using this model are identified by the IHSOF2 array entered on the BH181KK input record series and normally correspond to the HS package structures used as radial boundaries of the core.

The molten steel produced from the degassing model is passed to the outermost radial ring (NRAD) in the axial segment corresponding to the origin of the melt. It is entered as particulate debris at an energy corresponding to fully molten steel with no superheat. The model is flexible to the extent that additional HS package structures above the core can also be identified to melt via the degassing model, with material passed to the uppermost axial segment (NAXL) in the outer ring. Subsequent relocation of the molten steel from its initial core position is performed by the candling model described in Section 3.1 and the particulate debris relocation logic discussed below. 
COR Package Reference Manual

\subsection{Gravitational Settling}

Relocation of particulate debris downwards by gravitational settling is modeled by logical processes (instead of rate processes) through consideration of volume, porosity, and support constraints. To describe these processes, it is necessary to first define terminology used in the discussion below with respect to volumes. Figure 3.4.1 illustrates the various types of volumes as defined below.

"Component volume" is the actual volume of the materials in a component, i.e., the sum of the material masses divided by material densities. For component $k$, it is:

$$
V_{c o m p, k}=\sum_{i} \frac{M_{i, k}}{\rho_{i}}
$$

"Effective volume" is the effective volume occupied by a component, calculated in terms of a user-specified porosity $\varepsilon_{k}$ defined on record CORZjj01 for intact components (currently only applied to fuel and cladding, together as rods) and for particulate debris:

$$
\mathrm{V}_{\text {eff,k }}=\frac{\mathrm{V}_{\text {comp, } \mathrm{k}}}{1-\epsilon_{\mathrm{k}}}
$$

As will be discussed in more detail below, the porosity for intact components can have an arbitrary value, and can be heuristically set to control the relocation behavior of debris.

"Interstitial volume" is the difference between effective volume and component volume, representing the interstitial space between discrete parts of the component (i.e., individual fuel rods or debris particles):

$$
V_{\text {int,k }}=V_{\text {eff,k }}-V_{\text {comp, } \mathrm{k}}=\epsilon_{\mathrm{k}} \mathrm{V}_{\text {eff,k }}
$$

"Free volume" is the difference between the total cell volume and the sum of the effective volumes for each component $\mathrm{k}$ in the cell; it represents the volume available for particulate debris material to relocate into the cell from above, but has no effect on candling:

$$
\mathrm{V}_{\text {free }}=\mathrm{V}_{\text {cell }}-\sum_{\mathrm{k}} \mathrm{V}_{\text {eff,k }}
$$

Depending on the component porosities and masses, the sum of the effective volumes may be greater than the total cell volume. In this case, which can arise because of 


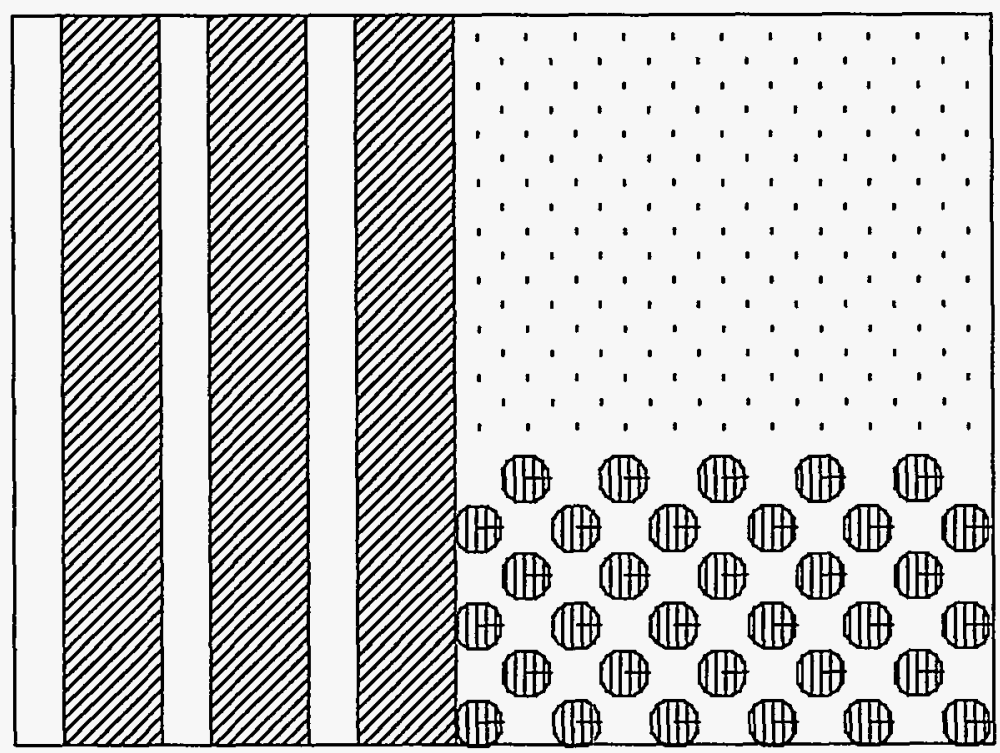

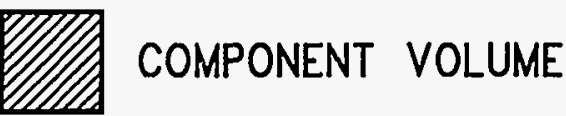

$\because$ FREE VOLUME

INTERSTITIAL VOLUME

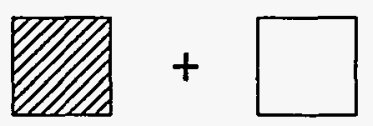

EFFECTIVE VOLUME

$\therefore+\square$ CVH VOLUME

Figure 3.4.1 Cell volumes

COR-RM-72 
COR Package Reference Manual

candling of materials onto components (which have fixed values of $\varepsilon_{k}$ ) or because of artificial values used for $\varepsilon_{\mathrm{k}}$ that do not correspond to the actual physical geometry, the free volume is set to zero.

"CVH volume" is the volume occupied by the $\mathrm{CVH}$ package fluids, i.e., the difference between the total cell volume and the sum of the component volumes:

$$
\mathrm{V}_{\mathrm{cVH}}=\mathrm{V}_{\text {cell }}-\sum_{\mathrm{k}} \mathrm{V}_{\text {comp }, \mathrm{k}}
$$

The initial CVH volume is defined by user input as the total cell flow area (channel plus bypass) times the cell height. The sum of the initial CVH volume and the initial component volumes for the cell give the total cell volume, which remains constant throughout execution; $\mathrm{CVH}$ volume will decrease as material relocates into a cell.

If a cell contains particulate debris, some or all of the debris may be relocated to lower cells until supported by "other structure" in a cell with the first digit ("tens" digit) of the support flag ISUP (initialized for each axial level on input record CORZij02) set to 1. Only the free volume in a cell is available for particulate debris relocation; interstitial volume (as defined by the user through the porosities $\varepsilon_{k}$ ) is deemed unavailable for occupation by solid particulate debris (although molten core materials may occupy this space via candling). The maximum component volume of debris that can be relocated to a lower cell is calculated as the free volume in that lower cell multiplied by the packing factor (equal to one minus the porosity of the particulate debris component):

$$
V_{\text {debris,max }}=V_{\text {fre日 }}\left(1-\epsilon_{p d}\right)
$$

The amount of interstitial volume, and hence effective volume, for a particular component is controlled by user input; i.e., for each component at each axial level, the effective porosity (for purposes of supporting particulate debris) must be defined by the user on record CORZjj01. For small time step sizes (below $1 \mathrm{~s}$ ), the mass of debris relocated downward is limited in proportion to the time step to allow the CVH package to resolve the associated virtual volume changes.

By setting the porosity of a particular component to some value arbitrarily close to but less than 1.0, the user can dictate that that component will support debris particles regardless of the component's mass. Such a treatment might be desired for fuel rod bundles, for example. Conversely, by setting the porosity of a particular component to zero, the user can allow debris particles to fall in amongst the discrete parts of the component (i.e., the interstices between rods). An intermediate value could be used to give a true representation of the effective volume occupied by a component. This treatment is recommended for the particulate debris component itself. Current modeling, 


\section{COR Package Reference Manual}

however, applies this treatment to fuel rods and particulate debris only; the porosity used for canisters and "other structure" is zero.

The support flag ISUP will be modified when the temperature of the "other structure" component reaches the failure temperature TSFAIL defined for that axial level on input record CORZjj04. At that point, the first ("tens") cligit of ISUP is reset to 0 and particulate debris will be allowed to fall through to lower cells.

The radial relocation of particulate debris that tends to limit radial variations in the "stacked" height of debris across any given axial level is discussed above in Section 3.2.2. 
COR Package Reference Manual

\section{LOWER HEAD MODEL}

The lower head nodalization framework was described in Section 1.1.2; the illustration in Figure 1.1.5 is repeated here as Figure 4.1.1 for convenience and with more detail depicting the lower head heat transfer logic. The lower head model physics described in this section is divided into three parts: heat transfer among the model elements, determination of failure at some penetration, and ejection of debris into the reactor cavity. Because much of the phenomena associated with lower head failure is very poorly understood, the lower head model is very simple and parametric, allowing the user significant flexibility in controlling lower head behavior.

\subsection{Heat Transfer}

Heat transfer from the debris to the lower head and its penetrations (e.g., instrumentation tubes, control rod guide tubes, or drain plugs) is modeled parametrically using heat transfer coefficients (specified on record COR00009), heat transfer areas (specified on records CORLHDii and CORPENnn), and masses (also specified on records CORLHDii and CORPENnn). The heat transfer rate from the debris in the bottommost axial level to the lower head is given by:

$$
q_{d, h}=h_{d, h} A_{h}\left(T_{d}-T_{h, s}\right)
$$

where

$$
\begin{aligned}
& q_{d, h}=\text { heat transfer rate between debris and lower head } \\
& h_{d, h}=\text { debris-lower head heat transfer coefficient } \\
& A_{h} \quad=\text { lower head surface area } \\
& T_{d} \quad=\text { debris temperature } \\
& T_{h, s} \quad=\text { lower head inner surface temperature }
\end{aligned}
$$

The heat transfer rate from the debris in the bottommost axial level to a penetration is similarly given by:

$$
q_{d, p}=h_{d, p} \frac{\Delta z_{d}}{\Delta z_{1}} A_{p}\left(T_{d}-T_{p}\right)
$$

where 
COR Package Reference Manual

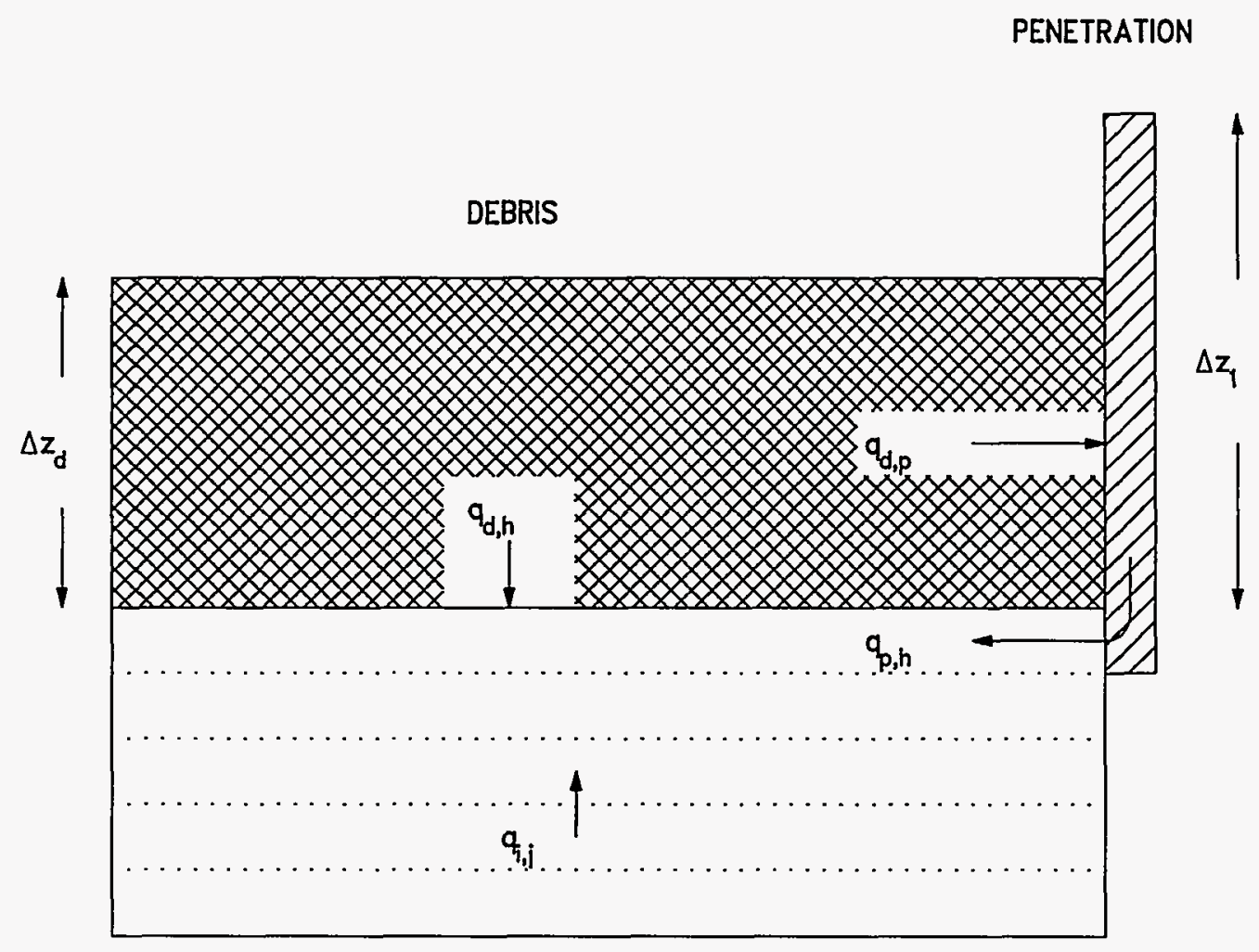

LOWER HEAD

Figure 4.1.1 Lower head nodalization

$q_{d, p} \quad=$ heat transfer rate between debris and penetration

$h_{d, p}=$ debris-penetration heat transfer coefficient

$A_{p} \quad=$ penetration area

$\Delta z_{\mathrm{d}} \quad=$ debris height in the bottom axial level

$\Delta z_{1} \quad=$ bottom axial level height

$\mathrm{T}_{\mathrm{p}} \quad$ = penetration temperature

The penetration area is based on the height of the bottom axial level, $z_{1}$, and the multiplier $\left(z_{d} / z_{1}\right)$ accounts for the partial covering of the penetration area by the debris of height $z_{\mathrm{d}}$. 
The heat transfer rate from the penetration to the top lower head node is based on the conduction area between the penetration and lower head specified by the user:

$$
q_{p, h}=k_{p} A_{p, h} \frac{T_{p}-T_{h, s}}{\Delta z_{1}}
$$

where

$$
\begin{aligned}
& q_{p, h} \quad=\text { heat transfer rate between penetration and lower head } \\
& k_{p} \quad=\text { penetration thermal conductivity } \\
& A_{p, h} \quad=\text { conduction area between penetration and head }
\end{aligned}
$$

The conduction area $A_{p, h}$ should be chosen to appropriately model the two-dimensional nature of the heat conduction; note that conduction to only the top lower head node is modeled.

Conduction heat transfer rates within the lower head are given by:

$$
q_{i, j}=k_{i, j} A_{h} \frac{T_{h, i}-T_{h, l}}{\Delta z_{i, j}}
$$

where

$$
\begin{aligned}
& q_{i, j} \quad=\text { heat transfer rate between head nodes } i \text { and } j \\
& k_{i, j} \quad=\text { average thermal conductivity of nodes } i \text { and } j \\
& T_{h, l} \quad=\text { temperature of lower head node } i \\
& \Delta z_{i, j} \quad=\text { length between nodes } i \text { and } j
\end{aligned}
$$

Convection heat transfer rates from the penetrations, debris, and lower head to the fluids in the lower plenum control volume ICVHC (specified on record CORijj01), $q_{p, v}, q_{d, v}$, and $\mathrm{q}_{\mathrm{h}, \mathrm{v}}$ respectively, are also modeled by the methods described in Section 2.3. The outer boundary of the lower head (in the reactor cavity control volume specified on record CORLHD01) is currently treated as adiabatic.

The net energy transfer for each of the model elements is given by the following equations: 
COR Package Reference Manual

$$
\begin{aligned}
& C_{p, p}\left(T_{p}^{n}-T_{p}^{0}\right)=\left(q_{d, p}-q_{p, h}-q_{p, v}\right) \Delta t \\
& C_{p, d}\left(T_{d}^{n}-T_{d}^{0}\right)=\left(q_{s}-q_{d, p}-q_{d, h}-q_{d, v}-q_{d, d}\right) \Delta t \\
& C_{p, h, n}\left(T_{h, n}^{n}-T_{h, n}^{0}\right)=\left(q_{n-1, n}+q_{d, h}+q_{p, h}-q_{h, v}\right) \Delta t \\
& C_{p, h, i}\left(T_{h, i}^{n}-T_{h, i}^{0}\right)=\left(q_{i-1, i}-q_{i, i+1}\right) \Delta t
\end{aligned}
$$

where

$$
\begin{aligned}
& C_{p, i}=\text { total heat capacity of model element } j,\left(M_{j} C_{p j}\right) \\
& q_{s} \quad=\text { debris heat source from oxidation and decay heat } \\
& q_{d, d} \quad=\text { debris cell-to-cell heat transfer rate } \\
& \Delta t \quad=\text { COR package time step }
\end{aligned}
$$

and superscripts $\mathrm{o}$ and $\mathrm{n}$ refer to old-time and new-time temperatures, respectively. All temperatures in Equations 4.1.1 through 4.1.4 are considered to be new time temperatures, and Equations 4.1.5 through 4.1.8 are solved implicitly for new-time temperatures by matrix inversion.

\subsection{Failure}

Failure of the lower head is assumed to occur whenever the temperature of the penetration or innermost lower head node reaches a failure temperature (TPFAIL) specified by the user on record COR00009. In addition, the user may specify a logical control function on record CORRii02 that will trigger lower head failure whenever the control function value is found to be.TRUE. For example, such a control function might refer to a table of differential failure pressures as a function of lower head temperature. Finally, if the falling-debris quench model is active (see Section 2.3.6), the lower head is allowed to fail from overpressure, with a default failure criterion of $20 \mathrm{MPa}$ that may be changed on input record CORO0012. 
Whenever any failure condition is satisfied, an opening with an initial diameter defined by the user on record CORPENnn is established, and the COR package control function argument COR-ABRCH (see Section 4 of the COR Package Users' Guide) is set to the initial failure flow area calculated from this diameter. COR-ABRCH can then be used to open a valve in the flow path from the lower plenum control volume to the reactor cavity control volume. COR-ABRCH may be increased by additional penetration failures (up to three per radial ring) or by ablation of the failure openings, as described in the next section.

\subsection{Debris Ejection}

After a penetration has failed, the mass of each material in the bottom axial level that is available for ejection (but not necessarily ejected) is calculated. Two simple options exist. In the default option (IDEJ $=0$ on record CORTST01), the masses of each material available for ejection are the total debris material masses, regardless of whether or how much they are molten. Note, however, that this option has been observed to lead to ejection of much more solid debris with the melt than is realistic.

In the second option (IDEJ = 1 on MELCOR record CORTST01), the masses of steel, Zircaloy, and $\mathrm{UO}_{2}$ available for ejection are simply the masses of these materials that are molten; the masses of steel oxide and control poison materials available for ejection are the masses of each of these materials multiplied by the steel melt fraction, based on an assumption of proportional mixing; and similarly the mass of $\mathrm{ZrO}_{2}$ available for ejection is the $\mathrm{ZrO}_{2}$ mass multiplied by the Zircaloy melt fraction. Additionally, the mass of solid $\mathrm{UO}_{2}$ available for ejection is the Zircaloy melt fraction times the mass of $\mathrm{UO}_{2}$ that could be relocated with the Zircaloy as calculated in the candling model using the secondary material transport model (see Section 3.1). An option parallel to the methodology used in the materials interactions (eutectics) model has not yet been developed.

Regardless of which of the options described above is chosen, other constraints have been imposed on the mass to be ejected at vessel failure. A total molten mass of 5000 $\mathrm{kg}$ or a melt fraction of 0.1 (total molten mass divided by total debris mass) is necessary before debris ejection can begin, to avoid calculational difficulties with the core-concrete interactions modeling. Also, whenever the bottom lower head node exceeds the penetration failure temperature TPFAlL, gross failure of the lower head in that ring is assumed and all debris in the bottom cell is discharged linearly over a $1 \mathrm{~s}$ time step, regardless of the failure opening diameter. However, no mass associated with either the lower head hemisphere or the penetrations is added to the core/lower plenum debris.

Once the total mass of all materials available for ejection has been determined, the fraction of this mass ejected during a single COR package subcycle is determined from hydrodynamic considerations. The velocity of material being ejected is calculated from the pressure difference between the lower plenum control volume and the reactor cavity 
COR Package Reference Manual

control volume, the gravitational head from the debris layer itself, and a user-specified flow discharge coefficient input on record COR00009, using the Bernoulli equation:

$$
v_{\theta j}=C_{d}\left(\frac{2 \Delta P}{\rho_{m}}+2 g \Delta z_{d}\right)^{1 / 2}
$$

where

$$
\begin{aligned}
& v_{\mathrm{ej}} \quad=\text { velocity of ejected material } \\
& \mathrm{C}_{\mathrm{d}} \quad \text { = flow discharge coefficient } \\
& \Delta P \quad=\text { pressure difference between lower plenum control } \\
& \text { volume and reactor cavity control volume } \\
& \rho_{\mathrm{m}} \quad=\text { density of material being ejected } \\
& \mathrm{g}=\text { gravitational acceleration } \\
& \Delta z_{d}=\text { debris height }
\end{aligned}
$$

If the expression in parentheses in Equation 4.3.1 is negative, the ejection velocity is set to zero.

The maximum mass of all materials that can be ejected during a single COR time step is:

$$
M_{\theta j}=\rho_{m} A_{f} v_{\theta j} \Delta t
$$

where

$$
\begin{aligned}
& M_{e j} \quad=\text { maximum mass ejected } \\
& A_{f} \quad=\text { penetration failure area } \\
& \Delta t \quad=\text { time step }
\end{aligned}
$$

The fraction of the total mass available for ejection that actually is ejected during the subcycle is simply $M_{\mathrm{ej}}$ divided by the total mass available to be ejected, up to a maximum value of 1.0. This fraction is applied to the mass of each material available for ejection, as described in the first three paragraphs of this section. 
COR Package Reference Manual

Mass and energy that is ejected from the COR package via the foregoing model is transferred to the Transfer Processes (TP) package. That package is a generalized interface utility for mass and energy transfers of core materials between packages and within the radionuclide (RN) package, and performs various bookkeeping functions related to different equation of state and mass species representations between packages. The cavity (CAV), fuel dispersal interactions (FDI), and RN packages may all call the TP package to transfer core materials into their domain. The 'IN' Transfer Process number that specifies the TP package input for transferring masses and energies from the COR package must be specified on record COR00004.

Ablation of the failure opening is modeled by calculating the heat transfer to the lower head by flowing molten debris. A simplified implementation of the ablation model by Pilch and Tarbell [16] is used, which gives the heat transfer coefficient for the flowing molten debris as the maximum of a tube correlation and a flat plate correlation:

$$
\begin{aligned}
& h_{\text {abl,tube }}=0.023 K_{p} v_{\text {ej }}^{0.8} / D_{f}^{0.2} \\
& h_{\text {abl,plate }}=0.0292 K_{p} v_{\text {ej }}^{0.8} / \Delta z_{h}^{0.2}
\end{aligned}
$$

where

$$
\begin{aligned}
& h_{a b l}=\text { ablation heat transfer coefficient } \\
& K_{\mathrm{p}}=k(\rho / \mu)^{0.8} \operatorname{Pr}^{1 / 3} \text { (using average property values from Pilch and Tarbell) } \\
& D_{\mathrm{f}} \quad=\text { failure diameter } \\
& \Delta \mathrm{z}_{\mathrm{h}} \quad=\text { lower head thickness }
\end{aligned}
$$

The ablation rate is then calculated as:

$$
\frac{d D_{f}}{d t}=\frac{2 h_{a b l}\left(T_{d}-T_{m, s}\right)}{\rho_{s}\left[c_{p, s}\left(T_{m, s}-T_{h, a v g}\right)+h_{f, s}\right]}
$$

where $\rho_{s}, c_{p, s}, h_{f, s}$, and $T_{m, s}$ are the density, heat capacity, latent heat of fusion, and melting temperature of the lower head steel, and $T_{d}$ and $T_{h, a v g}$ are the debris and average lower head temperatures. The diameter of the penetration failure is updated explicitly with time using Equation 4.3.5. The value of the control function argument $\mathrm{COR}-\mathrm{ABRCH}$ is then redefined to reflect the new failure opening diameter. 
COR Package Reference Manual

COR-RM-82 
COR Package Reference Manual

\section{DISCUSSION AND DEVELOPMENT PLANS}

Because of the intended purpose of MELCOR to be used in PRA and source term analyses, and because of the desire to achieve certain objectives, principally low CPU time and uncertainty/sensitivity analysis capabilities, much of the modeling in the COR package is fairly simple. There are several modeling areas within the COR package, however, that are recognized as being particularly weak, generally because the phenomena are poorly understood. Many of these areas have been noted in previous discussion. In some cases, fairly crude and simplistic parametric models have been implemented (e.g., the lower head model) until more advances have been made in furthering our understanding of the phenomena. In other cases, more sophisticated models are planned for implementation in the near future.

The following paragraphs have been adapted from a recent assessment of improvement needs for MELCOR in the area of core modeling, which was based in part on deficiencies identified as part of the MELCOR Peer Review [21]. Suggestions from users regarding additional modification and/or upgrading of the COR package are welcomed and should be directed to the MELCOR Code Development Group using the MELCOR Defect Investigation Report (DIR) forms.

\subsection{Coupling to Hydrodynamic Flows}

The inability of current modeling approaches to treat fine-scale natural circulation flows in the reactor vessel has been identified as a major deficiency. A new approach under development to address this is to utilize larger numbers of control volumes in the $\mathrm{CVH}$ package, to include momentum flux effects through $\mathrm{CVH} / \mathrm{FL}$ input, and to couple the hydrodynamic behavior to core debris blockages. Until this new natural circulation model is fully functional, there remains a need to upgrade the current $\mathrm{dT} / \mathrm{dz}$ model to treat reverse (downward) flow in channels. The inability to do so substantially decreases the code's ability to treat some transients.

\subsection{Radiation}

Radiation view factors in the COR package may now be controlled only on a global basis. Since correct characterization of many of these view factors is dependent on local geometry and nodalization, they should be controllable on a local cell basis. This upgrade is desired to give the user more freedom to satisfactorily model radiative heat transfer within the core, a dominant heat transfer mechanism in severe reactor accidents. 
COR Package Reference Manual

\subsection{Reflood Behavior}

To adequately assess the possibly deleterious effects of reflooding and the potential to avoid vessel failure, models to credibly predict the interactions between water and overheated fuel rods or core debris are desirable. This involves the ability to predict quenching rates in the geometries of interest, spallation of oxide from the fuel rod cladding with accelerated oxidation, shattering of the fuel rods during quench, the occurrence and effects of clad ballooning (discussed separately below), and the possibility of forming a molten pool.

\subsection{Cladding Ballooning}

Ballooning of the fuel rod cladding has been iclentified as a critical phenomenon as it significantly affects early phase melt progression in low pressure experiments such as LOFT LP-FP-2, PBF SFD 1.4, CORA-15, and the TMI-2 reactor. The LOFT assessment study [22] also identified the lack of a ballooning model as a major deficiency in MELCOR. Ballooning may substantially decrease the flow of gases through the affected core region and may expose the inner cladding surface to oxidation in the vicinity of rupture sites. MELCOR currently makes no provision for treating ballooning; this needs to be rectified to account for possible flow diversion and oxidation enhancement.

\section{5 $\mathrm{B}_{4}$ C-Steam Reaction}

Current modeling for the reaction of boron carbide with steam in MELCOR, which was taken from ORNL models, is now considered by ORNL to be outdated and to significantly underpredict the amount of methane produced. New modeling has been developed at ORNL which could be included in MELCOR in a straightfonward manner to address this.

However, there are two issues which must be addressed in the context of this modeling. First, the competition between the eutectic $\mathrm{B}_{4} \mathrm{C}$-steel interaction and the steam reaction must be factored in. This could perhaps be done by simply specifying via user input the fractions of $\mathrm{B}_{4} \mathrm{C}$ available for each process; some would be allowed to form a eutectic mixture, and some would be saved for later oxidation by steam. Second, from a thermalhydraulic standpoint, the reaction of $\mathrm{B}_{4} \mathrm{C}$ is not significant; rather, the chemical interactions of methane with iodine is the important phenomenon to treat for source term calculations, but is not now treated in the Radionuclide package. The RN deficiency must be addressed first before an upgrade here would make any significant difference in any calculation, but once that is done, this model may have a dominant effect on the source term if eutectic reactions permit it. 
COR Package Reference Manual

\subsection{Coupling of Blockages to CVH}

The COR package provides control function arguments (COR-AFLMIN) tied to the degree of blockage in a stack of core cells that can be used within the CF package to set up a control function to control a valve for the flow paths in the CVH package at the core inlet or outlet. However, this places a significant burden on the user to foresee the need to set this up via input (and to do it right), and other effects beside flow area (form and friction loss) are currently ignored. Because of the strong impact on in-vessel flow circulation, hydrogen generation, and core melt progression, these have been identified as serious deficiencies. There is a strong need to automatically couple blockages caused by core debris relocation or ballooning to the hydrodynamic calculations in the $\mathrm{CVH}$ package.

\subsection{Structure Support/Crust Failure}

We have long recognized the need to upgrade the logic associated with component structural failure and debris support and relocation to give the user increased flexibility in modeling things like core plate failure, etc. Because of the dominant impact on subsequent in-vessel behavior, a less parametric and more predictive capability may be needed for failure of bottom or side crusts of molten pools and supporting structures such as the core plate, instead of merely a parametric model in which the user can vary simple failure criteria. We also believe that the current parametric modeling may be a significant source of numerical sensitivities and that improvements in this area may eliminate significant branching behavior into dissimilar calculations.

\subsection{Lower Plenum Debris Behavior and Vessel Failure}

Several serious deficiencies connected with vessel failure have been identified. Current modeling in MELCOR is highly parametric. The existing model does not include consideration of natural circulation of a molten debris pool in the lower head. Such pools can form if the debris temperature and relocation rate are such as to prevent early failure of bottom head penetrations or if the plant (like some PWRs) has no such penetrations.

Simple mechanistic models to assess the failure modes of the vessel lower head need to be developed. These models should account for head curvature effects, freezing and remelting of core debris in penetrations, and crust formation, growth, and remelting with and without external cooling of the vessel. Failure criteria should be expanded to permit creep rupture failure of the head.

The Bottom Head package models, developed as part of the BWRSAT program at Oak Ridge National Laboratory (ORNL), address some of these deficiencies. However, the $\mathrm{BH}$ models currently treat only parts of some transients for BWRs only. If the $\mathrm{BH}$ 
COR Package Reference Manual

package were improved to broaden its scope and integrate with MELCOR for all plants and sequences, these phenomena could be treated there.

Furthermore, over the long term the interface between the $\mathrm{BH}$ and $\mathrm{COR}$ packages needs to be restructured to fully address differences in scope and modeling approach. Either the $\mathrm{BH}$ models should be much more completely and tightly coupled into existing COR models, or the domain for each package should be carefully redefined with overlap minimized and interfaces between them and between other MELCOR packages rigorously specified. Either way, the new BH lower plenum models should be made more flexible for more complete treatment of different accident scenarios (e.g., debris heat transfer before complete pool boiloff) and plant geometries (including PWRs) and to allow greater user control (e.g., with sensitivity coefficients). 
COR Package Reference Manual

\section{REFERENCES}

1. F. Kreith, Principles of Heat Transfer, 3rd Edition, Intext Educational Publishers, New York, NY, pp. 251-273 (1973).

2. L. J. Ott, C. F. Weber, and C. R. Hyman, "Station Blackout Calculations for Browns Ferry," Proceedings of the Thirteenth Water Reactor Safety Research Information Meeting, Gaithersburg, MD (October 1985).

3. R. O. Wooton, P. Cybulskis, and S. F. Quayle, "MARCH 2 (Meltdown Accident Response Characteristics) Code Description and User's Manual," NUREG/CR-3988, BMI-2115 (August 1984).

4. D. L. Hagrman, G. A. Reymann, and R. E. Mason, MATPRO-VERSION 11 (Revision 1) A Handbook of Materials Properties for Use in the Analysis of Light Water Reactor Fuel Rod Behavior, NUREG/CR-0497 and TREE-1280 Rev. 1 (February 1980).

5. L. J. Ott, "Thermal-Hydraulic Test Facility Bundle 3 In-Core Instrumentation and Operating History," NUREG/CR-2609, Chapter 8 (August 1982).

6. C. B. Ludwig and C. C. Ferriso, "Prediction of Total Emissivity of NitrogenBroadened and Self-Broadened Hot Water Vapor," J. Quant. Spectrosc. Radiat. Transfer, Vol. 7, pp. 7-26 (1967).

7. J. P. Holman, Heat Transfer, McGraw-Hill, Inc., New York, NY, pp. 305-307 (1976).

8. M. P. Manahan, "An Improved Zircaloy-Steam Reaction Model for Use with the MARCH 2 (Meltdown Accident Response Characteristics) Code," Proceedings of the International Meeting on Light-Water Reactor Severe Accident Evaluation, Cambridge, MA (August 1983).

9. F. W. Dittus and L. M. K. Boelter, University of California Pubs. Eng, 2, p. 433 (1930).

10. M. Jacob, Heat Transfer, Vol. I, John Wiley \& Sons, Inc., New York, NY (1949).

11. R. B. Bird, W. E. Stewart, and E. N. Lightfoot, Transport Phenomena, John Wiley \& Sons, Inc., New York, NY (1960).

12. R. J. Lipinski, "A Model for Boiling and Dryout in Particle Beds," NUREG/CR-2646, SAND82-0765 (June 1982). 
COR Package Reference Manual

13. V. F. Urbanic and T. R. Heidrich, "High-Temperature Oxidation of Zircaloy-2 and Zircaloy-4 in Steam," J. Nuc. Matls. 75, pp. 251-261 (1978).

14. J. F. White et al., "Fifth Annual Report-High Temperature Material Programs, Part A," GEMP-400A (February 1966).

15. "Reducing BWR Power by Water Level Control During an ATWS, a Quasi-Static Analysis," NSAC-69, S. Levy, Inc. Final Report (May 1984).

16. M. Pilch and W. W. Tarbell, "High Pressure Ejection of Melt from a Reactor Pressure Vessel-the Discharge Phase," NUREG/CR-4383, SAND85-0012 (September 1985).

17. P. Hofmann et al., "Reactor Core Materials Interactions at Very High Temperatures," Nuclear Technology, 87, pp. 146-186 August 1989.

18. W. Hering and K. Muller, "Modelling of Eutectic Interactions in KESS-III (Module EUTECT)," International CORA Workshop 1992, Karlsruhe, FRG, October 5-8, 1992.

19. A. S. Benjamin, D. J. McCloskey, D.A. Powers, and S. A. Dupree, Spent Fuel Heatup Following Loss of Water During Storage, SAND77-1371, NUREG/CR-0649, Sandia National Laboratories, Albuquerque, NM, March 1979.

20. R. K. Cole, et al., CORCON-Mod2: A Computer Program for Analysis of Molten-Core Concrete Interactions, NUREG/CR-3920, SAND84-1246, August 1984, pp. 64-65. 
COR Package Reference Manual

\section{APPENDIX A: Sensitivity Coefficients}

This appendix gives the sensitivity coefficients associated with various correlations and modeling parameters described in this reference manual.

Equation

2.4.11,

2.4.12

2.4 .13

2.4.14

2.4 .15

$\S 2.4$

$\S 2.7$

$\S 2.7$
Coefficient

C1001 $(1,1)$

C1001 $(2,1)$

C1001 $(3,1)$

C1001 $(4,1)$

C1001 $(5,1)$

C1001 $(1,2)$

C1001(2,2)

C1001 $(3,2)$

C1001(4,2)

C1001 $(5,2)$

C1002(1)

C1002(2)

C1003(1)

C1003(2)

C1004(1)

C1004(2)

C1010(1,2)

C1010 $(2,2)$

C1010 $(1,3)$

C1010(2,3) otherwise

C1010(1,J)

C1010(2,J)

C1011(1)

C1011(2)

C1011(3)
Value

29.6

16820.0

87.9

16610.0

1853.0

50.4

14630.0

0.0

0.0

10000.0

2.42E09

4.24E04

0.00548

0.00504

1100.0

9900.0

1.47E14

$8.01 \mathrm{E} 4$

1.02E15

$8.14 \mathrm{E} 4$

$-1$.

0.0

1400.

1400.

1520. $\underline{\text { Units }}$

$\mathrm{kg}^{2}(\mathrm{Zr}) / \mathrm{m}^{4}-\mathrm{s}$

$\mathrm{K}$

$\mathrm{kg}^{2}(\mathrm{Zr}) / \mathrm{m}^{4}-\mathrm{s}$

$\mathrm{K}$

$\mathrm{K}$

$\mathrm{kg}^{2}(\mathrm{Zr}) / \mathrm{m}^{4}-\mathrm{s}$

$\mathrm{K}$

$\mathrm{kg}^{2}(\mathrm{Zr}) / \mathrm{m}^{4}-\mathrm{s}$

$\mathrm{K}$

$\mathrm{K}$

$\mathrm{kg}^{2}$ (steel) $/ \mathrm{m}^{4}-\mathrm{s}$

$\mathrm{K}$

$\mathrm{kg}(\mathrm{Zr})-\mathrm{K} / \mathrm{Pa}-\mathrm{m}^{3}$

$\mathrm{kg}\left(\right.$ steel) $-\mathrm{K} / \mathrm{Pa}-\mathrm{m}^{3}$

$\mathrm{K}$

$\mathrm{K}$

K

-

K

K

$\mathrm{K}$

K

$\mathrm{K}$ 
COR Package Reference Manual

Equation

$\S 3.2 .1$

2.2 .13

$\S 3.1 .2$

3.1.7

$3.1 .10-$

3.1.18

2.3.3

2.3.4

2.3.6

2.3.7
Coefficient

$$
\begin{aligned}
& \text { C1020(1) } \\
& \text { C1020(2) } \\
& \text { C1020(3) } \\
& \text { C1020(4) } \\
& \text { C1020(5) }
\end{aligned}
$$

C1101(1)

C1101(2)

C1131(1)

C1131(2)

C1131(3)

C1131(4)

C1141(1)

C1141(2)

C1151(l,1)

C1151(1,2)

C1151 $(1,3)$

C1151(l,4)

C1151 $(1,5)$

C1151(ICL,6)

C1151 $(1,6),|\neq| \mathrm{ICL}$

C1151 $(I, 7)$

C1212(1)

C1212(2)

C1213(1)

C1213(2)

C1214(1)

C1214(2)

C1214(3)

C1221(1)

C1221(2)

C1221(3)
Value

$\underline{\text { Units }}$

3.0

1.0

0.0

0.0

1.0

0.8

0.325

0.001

2500.0

0.001

1700.0

1.0

1.0

0.556

0.807

0.143

0.396

0.0

1.0

0.0

100.0

4.36

4.36

0.00826

0.00110

0.023

0.8

0.4

0.18

0.25

$-1 . / 9$.

$s$

s

-

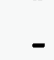

$\mathrm{m}$
$\mathrm{K}$
$\mathrm{m}$
$\mathrm{K}$

$s$

$\mathrm{kg} / \mathrm{m}-\mathrm{s}$

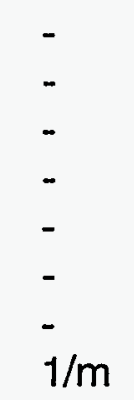

\section{$1 / \mathrm{m}$}
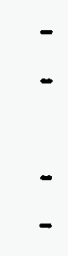
COR Package Reference Manual

Equation

2.3.8

2.3.9

2.3.10

2.3.11

2.3.12

2.3.16

2.6.1

$\S 2.6$
Coefficient

C1222(1)

C1222(2)

C1222(3)

C1231(1)

C1231(2)

C1231(3)

C1231(4)

C1232(1)

C1232(2)

C1232(3)

C1232(4)

C1241(1)

C1241(2)

C1241(3)

C1241(4)

C1242(1)

C1242(2)

C1242(3)

C1244(1)

C1244(2)

C1244(3)

C1301(1)

C1301(2)

C1301(3)

C1301(4)

C1301(5)

C1301(6)

C1311(1)

C1311(2)

C1311(3)

C1311(4)
Value

$\underline{\text { Units }}$

0.065

1./3.

$-1 . / 9$.

2.0

0.60

0.5

1./3.

2.0

0.60

0.25

$1 . / 3$.

34.5

0.25

1.523

23.4

1.41E07

0.25

$-2.575$

0.756

0.089

0.15

0.037

0.3

0.7

2.4384

0.45

7.65318E06

1.0

0.0

0.0

0.0
$W / m^{2}-K-P^{1 / 4}-K^{1.523}$

-

$\mathrm{K}$

$W / m^{2}-K-P a a^{1 / 4}-K^{-2575}$

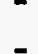

m

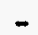

m

-

$\mathrm{Pa}$ 
COR Package Reference Manual

Equation

$\S 2.6$

$\S 1.2$

$\S 1.1 .1$

$\S 1.2$ $\underline{\text { Coefficient }}$

C1312(1)

C1312(2)

C1312(3)

C1312(4)

C1312(5)

C1312(6)
Value

1.0

0.0

0.0

0.0

0.0

0.0

1.6

0.8

$-1.0$

20.0

0.5

1.0

C1401(6)

C1501(1)

C1501(2)

C1501(3)

C1501(4)

C1501(5)
0.5

0.5

0.5

0.5

0.5

0.001

10.0
Units

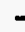

-

-

-

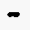

-
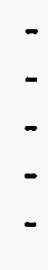

-

$-$

$-$

-

-

$-$

$\mathrm{kg}$

$\mathrm{kg}$ 


\title{
Thermal Hydraulic (CVH and FL) Packages Reference Manual
}

\author{
MELCOR Code Development Group \\ Modeling and Analysis Department \\ Nuclear Energy Technology Center \\ Sandia National Laboratories \\ Albuquerque, NM 87185-0739
}

Randall K. Cole, Jr

Two packages in the MELCOR code, the Control Volume Hydrodynamics (CVH) package and the Flow Path (FL) package, are responsible for modeling the thermal-hydraulic behavior of coolant liquids and gases. The former is concerned with control volumes and their contents, the latter with the connections which allow transfer of these contents between control volumes. The distinction between $\mathrm{CVH}$ and $\mathrm{FL}$ is useful primarily for discussion of MELCOR input and output. It will frequently be ignored in this Reference Manual, where many aspects of the thermal-hydraulic modeling will be described without concern for which package contains the relevant coding.

If phenomena modeled by other packages in MELCOR influence thermal-hydraulic behavior, the consequences are represented as sources and sinks of mass, energy, or available volume, or as changes in the area or flow resistance of flow paths in CVH. (Changes involving flow paths may currently be handled only through use of the Control Function (CF) package.)

Equations of state for the hydrodynamic materials are contained in the Control Volume Thermodynamics (CVT) package, which in turn makes use of the water properties (H2O) and NonCondensible Gas (NCG) packages.

This Reference Manual describes the assumptions, models, and solution strategies used in the various subroutines which make up the CVH and FL packages. The user is referred to the appropriate Reference Manuals and other documentation for details of the equations of state and the boundary conditions provided by other packages in MELCOR. 


\section{Contents}

1. INTRODUCTION AND OVERVIEW $\ldots \ldots \ldots \ldots \ldots \ldots \ldots \ldots \ldots \ldots$

2. BASIC CONTROL VOLUME CONCEPTS $\ldots \ldots \ldots \ldots \ldots \ldots \ldots \ldots \ldots$

2.1 Control Volume Geometry . . . . . . . . . . . . . . . . 11

2.2 Control Volume Contents .................... 13

2.3 Control Volume Thermodynamic Properties ............. 13

3. BASIC FLOW PATH CONCEPTS $\ldots \ldots \ldots \ldots \ldots \ldots \ldots \ldots \ldots \ldots \ldots \ldots$

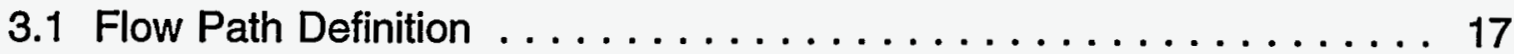

3.2 Flow Path Geometry . . . . . . . . . . . . . . . . . . 17

4. GOVERNING EQUATIONS $\ldots \ldots \ldots \ldots \ldots \ldots \ldots \ldots \ldots \ldots \ldots \ldots \ldots \ldots \ldots$

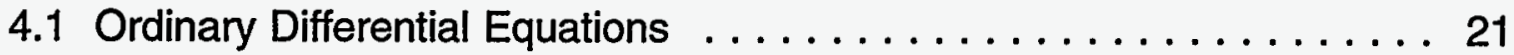

4.2 Finite Difference Equations . . . . . . . . . . . . . . . . . 24

4.2.1 Inclusion of Bubble-Separation Terms within the Implicit

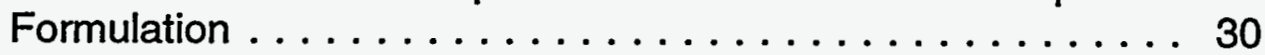

4.3 Solution Strategy $\ldots \ldots \ldots \ldots \ldots \ldots \ldots \ldots \ldots \ldots \ldots \ldots \ldots \ldots \ldots$

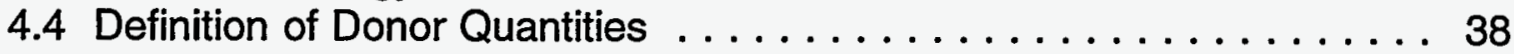

4.5 Timestep Control and Subcycling $\ldots \ldots \ldots \ldots \ldots \ldots \ldots \ldots \ldots$

5. CONSTITUTIVE RELATIONS ...................... 45

5.1 Pool/Atmosphere Mass and Energy Transfer . . . . . . . . . 45

5.1.1 Mass Transfer at the Pool Surface .............. 45

5.1.2 Heat Transfer to the Interface . . . . . . . . . . . . 49

5.1.3 Bubble Rise and Phase Separation ............. 50

5.1 .4 Fog Deposition ..................... 52

5.2 Flow Path Void Fractions $\ldots \ldots \ldots \ldots \ldots \ldots \ldots \ldots \ldots \ldots \ldots \ldots$

5.2.1 Normal Flow Paths ................... 52

5.2.2 Pool-First and Atmosphere-First Flow Paths . . . . . . 53

5.3 Hydrostatic (Gravitational) Heads . . . . . . . . . . . . . 54

5.4 Form Loss and Wall Friction $\ldots \ldots \ldots \ldots \ldots \ldots \ldots \ldots \ldots$

5.4 .1 Flow Path Segments .................. 56

5.4 .2 Single-Phase Friction Factor . . . . . . . . . . . 58

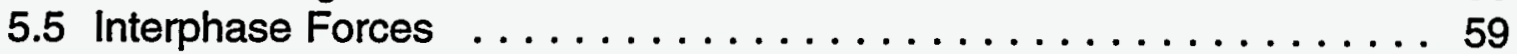

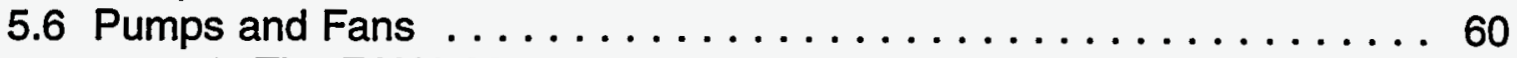

5.6.1 The FANA Model ....................6 60

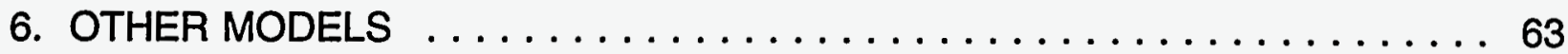

6.1 Bubble Physics ......................... 63

6.2 Time-Dependent (Specified) Flow Paths . . . . . . . . . . . 65

6.3 Critical Flow Models . . . . . . . . . . . . . . . . . 65

6.3.1 RETRAN Critical Flow Model ...............67 
CVH/FL Packages Reference Manual

6.4 Valves ........................... 67

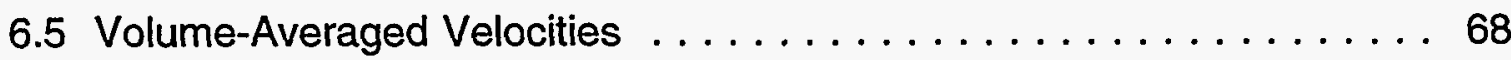

6.6 Special (Time-Specified) Volumes . . . . . . . . . . . . . . . . 69

7. DISCUSSION AND DEVELOPMENT PLANS $\ldots \ldots \ldots \ldots \ldots \ldots \ldots \ldots$

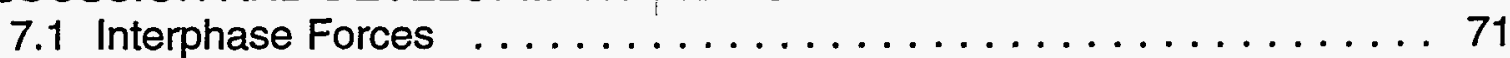

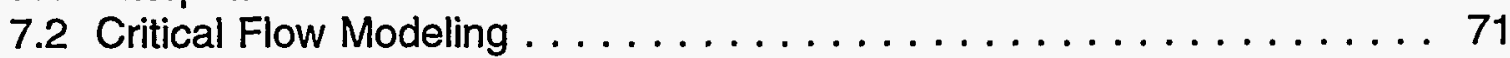

7.3 Flow Blockage Modeling . . . . . . . . . . . . . . . . . 71

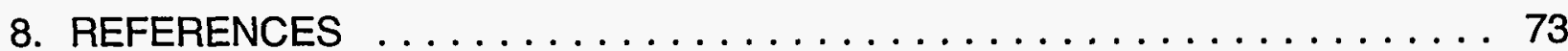

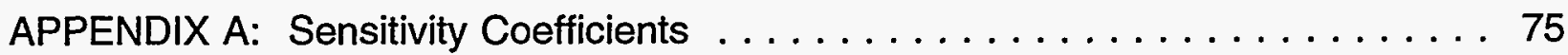

APPENDIX B: The Interphase Force and the Flooding Curve $\ldots \ldots \ldots \ldots 79$

APPENDIX C: Moody Critical Flow $\ldots \ldots \ldots \ldots \ldots \ldots \ldots \ldots \ldots$ 


\section{Figures}

2.1.1 Relation of Spatial Volume to Volume/Altitude Table . . . . . . . . . . . . 11

2.1.2 Virtual Volume and Associated Volume/Altitude Tables . . . . . . . . . . 12

2.2.1 Control Volume Contents and Pool Surface . . . . . . . . . . . . . 14

3.2.1 Junction Geometry . . . . . . . . . . . . . . . . . . . . . 18

3.2.2 Relationship among Junction Opening, Pool Surface Elevation, and Void Fraction .......................... 19

3.2.3 Multiple Flow Paths Connecting Two Volumes, to Model Natural Circulation 20 4.3.1 Solution of Hydrodynamics Equations $\ldots \ldots \ldots \ldots \ldots \ldots \ldots \ldots \ldots$

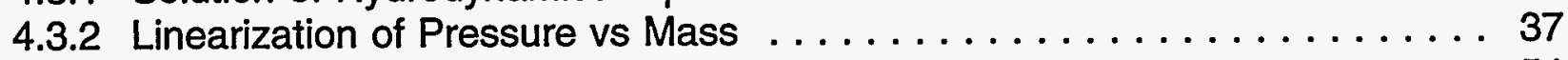

5.3.1 Elevations Involved in Gravitational Head Terms . . . . . . . . . . . . . 54

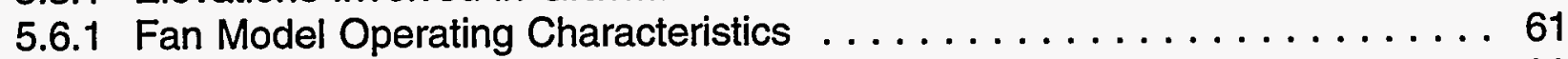

B.1 Drift Flux Lines and the Flooding Curve ............... 80

C.1 Moody Critical Flow Data and Approximate Fit $\ldots \ldots \ldots \ldots \ldots . \ldots . \ldots$ 
CVH/FL Packages Reference Manual 
CVH/FL Packages Reference Manual

\section{INTRODUCTION AND OVERVIEW}

Thermal-hydraulic processes interact with and are coupled to all aspects of severe accident phenomenology. In the MELCOR code, thermal-hydraulic data calculated by the Control Volume Hydrodynamics (CVH) and Flow Path (FL) packages provide boundary conditions to other phenomenological packages such as Burn (BUR), Cavity (CAV), Core (COR), Fuel Dispersal Interactions (FDI), and Heat Structures (HS). These packages, in turn, calculate sources and sinks of mass and energy for CVH. COR and HS also calculate changes to the volumes available to hydrodynamic materials. In some cases, CVH results are used directly by another package: the Radionuclide (RN) package uses $\mathrm{CVH}$ results for advection to transport aerosols and vapors from one calculational volume to another; RN also uses CVH results for the liquid water content of the atmosphere (fog) as the water content of aerosols, rather than integrating a separate equation for condensation and evaporation. Therefore, even though the primary interest in severe accident research is not simple thermal-hydraulics, the thermal-hydraulic modeling in $\mathrm{CVH}$ and FL forms the backbone of the MELCOR code.

The choice of modeling in CVH and FL was influenced by a number of often conflicting requirements. The packages were desired to be computationally fast, but also reliable and accurate. They should not produce minor nonphysical variations in behavior that would adversely affect the performance of other packages, and should not be unduly sensitive to such variations in the conditions calculated by other packages. They should permit great flexibility in nodalization to simplify sensitivity studies and should extract the maximum amount of information from coarse nodalizations while allowing more detailed ones for comparison to more specialized codes. In addition, they should be user friendly with respect to input.

The calculational method chosen uses a control volume/flow path approach similar to RELAP4 [1], HECTR [2], and CONTAIN [3]. The same models and solution algorithms are used for all volumes; primary, secondary, and containment volumes are modeled consistently and the resulting equations are solved simultaneously. Within the basic control volume formulation, the treatment is quite general; unlike the MAAP code [4], no specific nodalization is built in. No component models are explicitly included; pipes, vessels, pressurizers, steam generators, etc., are built through user input from control volumes, flow paths, and elements of other packages such as heat structures. Control logic used to simulate active or passive systems is introduced using control functions. (There are separate models for a few special safety systems including fan coolers and containment sprays.) We anticipate that, as experience with MELCOR grows, a set of "standard" nodalizations will be developed, validated, and employed for most calculations. However, the freedom exists to investigate sensitivities to variations in nodalization (and to develop representations of systems) entirely from code input, without modification to MELCOR itself. 


\section{CVH/FL Packages Reference Manual}

A semi-implicit (linearized) formulation of the governing equations is used to permit timesteps greater than the acoustic Courant limit. The numerical solution technique is similar to that in RELAP4 [1], with two major differences: (1) MELCOR uses a full twofluid treatment rather than the drift-flux formulation of RELAP4 and (2) the resulting equations are iterated when necessary so that the result is fully implicit with respect to pressures used in the momentum equation. A significant feature of this method is that the resulting equations are exactly conservative (to within machine roundoff) with respect to masses and to thermal energy.

All hydrodynamic material in a MELCOR calculation, together with its energy, resides in control volumes. "Hydrodynamic material" includes the coolant (water), its vapor, and noncondensible gases; it does not include the core or core debris, other structures, fission products, aerosols, or water films on heat structures. The hydrodynamic materials are divided into two independent fields referred to as pool and atmosphere. The names refer to the frequently-employed picture of separation under gravity within a control volume, but the actual interpretation is less restrictive. The shape of the volume is defined in enough detail to allow the elevation of the pool surface to be determined. Beyond this, a control volume has no internal structure and is characterized by a single pressure and two temperatures, one temperature for the pool and one for the atmosphere. (Of course, various constitutive models in $\mathrm{CVH} / \mathrm{FL}$ and other packages may infer greater detail such as boundary and interface temperatures, and temperature or pressure gradients, but they are not part of the $\mathrm{CVH} / \mathrm{FL}$ database.)

The control volumes are connected by flow paths through which the hydrodynamic materials may move without residence time, driven by a separate momentum equation for each field. Each control volume may be connected to an arbitrary number of others, and parallel flow paths (connecting the same pair of volumes) are permitted. There are no restrictions on the connectivity of the network built up in this way. Both pool and atmosphere, pool only, or atmosphere only may pass through each flow path, based on the elevations of the pool surfaces in the connected control volumes relative to the junctions with the flow paths. Appropriate hydrostatic head terms are included in the momentum equations for the flow paths, allowing calculation of natural circulation.

The control volumes and flow paths may be used to model physical systems in a variety of ways. In some cases, the control volumes may correspond to physical tanks, with the flow paths representing pipes (of negligible volume) connecting them. In others, the volumes may be geometrical regions-perhaps portions of larger physical rooms-with the flow paths representing the geometrical surfaces separating them. Representations approaching a finite difference approximation to the one-, two-, or three-dimensional hydrodynamic equations may be built up using the latter approach. However, because the momentum equation for each flow path is only one-dimensional and there is no momentum associated with a control volume, multidimensional effects associated with advection of momentum ("momentum flux") cannot be correctly calculated. (The onedimensional momentum flux term for the direction of flow may be optionally included.) 
In addition to phenomena within the CVH and FL packages, calculations performed in other packages in MELCOR may lead to sources and sinks of mass or energy in control volumes, or to changes in the volume available to hydrodynamic materials. These are imposed as numerically explicit boundary conditions in CVH/FL. In addition to heat sources from the Decay Heat (DCH) package, mass and energy source/sinks include heat from the HS, COR, CAV, and FDI packages, water from condensation or evaporation of films or melting of ice in the HS package or deposition of aerosol droplets in the RN package, and various gas sources from outgassing of structures in the HS package or from concrete ablation in the CAV package.

Oxidation chemistry in the COR and BUR packages is modeled as a sink of reactants (water vapor or oxygen in COR, hydrogen or carbon monoxide in BUR) and a source of reaction products (hydrogen in COR, water vapor or carbon dioxide in BUR). All equations of state referenced by the Control Volume Thermodynamics (CVT) package employ consistent thermochemical reference points, with the heat of formation included in the enthalpy functions as in JANAF tables [5]. Therefore, no energy source is involved in such a reaction; total energy is conserved, and the "heat of reaction" associated with changes in chemical bonding energies appears as sensible heat because of changes in the reference-point enthalpy of the system.

Changes in available volume result from such phenomena as candling (relocation of molten core materials by downward flow along fuel rods) and core collapse, which move nonhydrodynamic materials into or out of a control volume. Nonhydrodynamic materials may be moved by other packages either independently of $\mathrm{CVH} / \mathrm{FL}$ flows (e.g. core relocation) or piggybacked on the flows (e.g. motion of aerosols and associated radionuclides). 

" 
CVH/FL Packages Reference Manual

\section{BASIC CONTROL VOLUME CONCEPTS}

The basic concepts, definitions, and terminology associated with control volumes are described in this section. Most of the details of the models will be deferred until after the conservation equations have been presented and discussed.

\subsection{Control Volume Geometry}

The spatial geometry within a control volume is defined by a volume/altitude table. (The terms "altitude" and "elevation" will be used interchangeably in this manual.) Each point in the table gives an altitude and the total volume available to hydrodynamic materials in the $\mathrm{CVH}$ package below that altitude in that control volume. In this usage, "altitude" means elevation with respect to some reference point. This reference point is arbitrary, but must be consistent throughout all input for any problem (i.e., the same for all CVH, FL, COR, HS, and other data) to allow differences in elevation to be evaluated correctly.

The volume at the lowest altitude must be zero; the volume is assumed to be a linear function of altitude between table entries. This is equivalent to assuming a piecewiseconstant cross-sectional area as illustrated in Figure 2.1.1, which shows a simple geometric volume and a plot of the corresponding 4-point volume/altitude table. Note that the independent variable, altitude, is plotted vertically to facilitate comparison with the sketch.
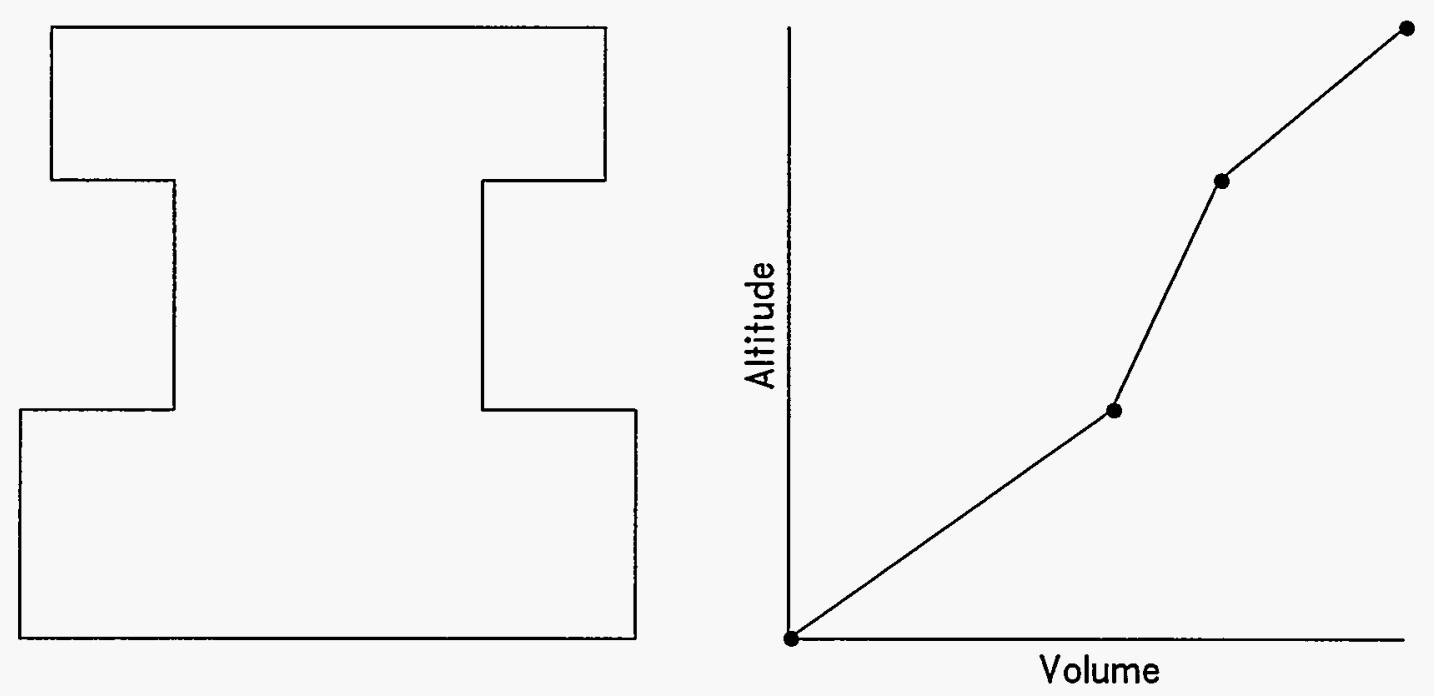

Figure 2.1.1 Relation of Spatial Volume to Volume/Altitude Table 


\section{CVH/FL Packages Reference Manual}

In addition to the hydrodynamic volume, a control volume may also contain virtual volume associated with nonhydrodynamic material (in some other package) that occupies space but is subject to relocation. If this material is relocated, the space which it occupied will become available to hydrodynamic materials. The principal example of this is the core, which initially occupies a large volume in the primary system, but may melt down and relocate to another part of the primary or containment system. This frees some or all of the original space to be occupied by hydrodynamic materials, while denying space to such materials in the new location.

The initial hydrodynamic volume is defined by input of CVnnnBk records to $\mathrm{CVH}$ in MELGEN, and the initial virtual volume is defined by input to other packages. Their sum is calculated in MELGEN for the. set of altitude points in the CVH input to define a total volume/altitude table which becomes part of the CVH database and does not change with time. The virtual volume is also carried in the CVH database as a volume/altitude table defined for the set of altitudes input to $\mathrm{CVH}$. The difference between total and virtual volume is available to hydrodynamic materials, and initially coincides with that specified in $\mathrm{CVH}$ input.

Virtual volume is illustrated by Figure 2.1.2, where the total volume is plotted as solid points and the virtual volume as open ones. Note that the points in the virtualvolume/altitude table correspond to the altitudes in the CVH database and not to those in whatever package defined the occupied (shaded) region.
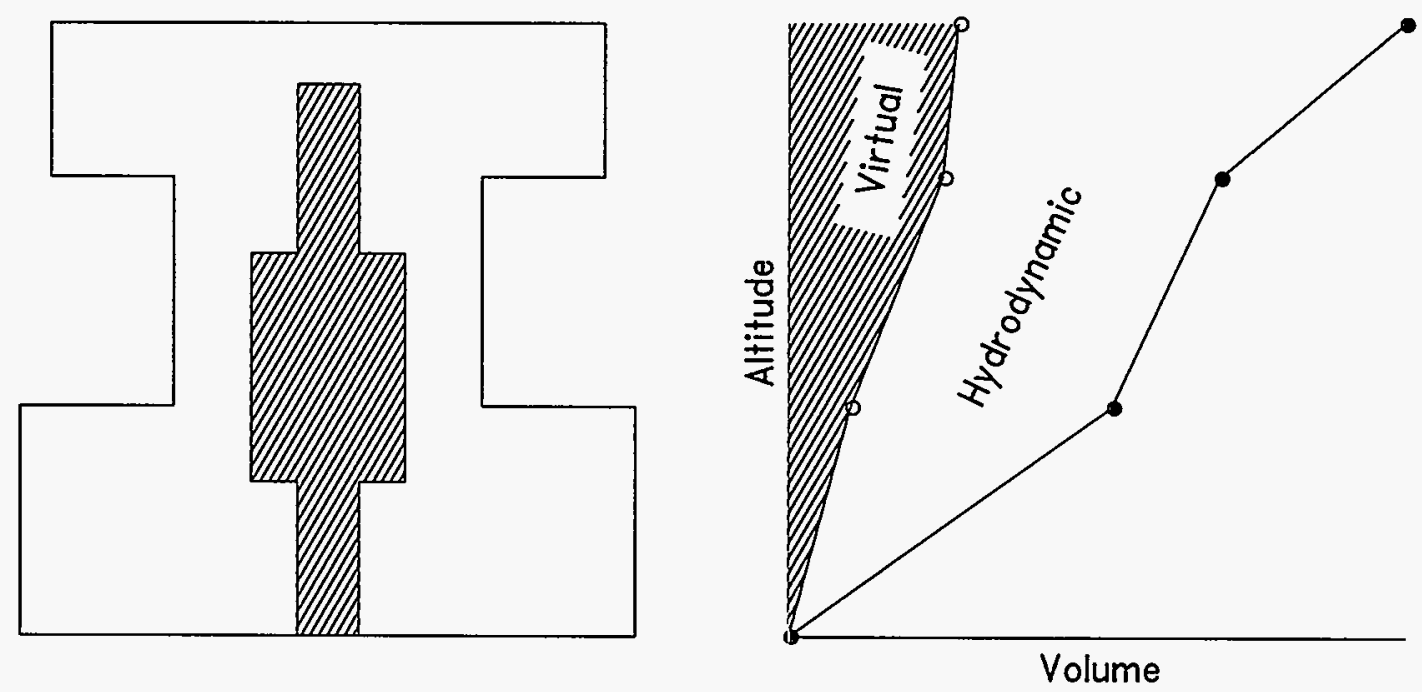

Figure 2.1.2 Virtual Volume and Associated Volume/Altitude Tables

Virtual volume within a control volume is modified as nonhydrodynamic materials are relocated by their controlling packages. In consequence, the hydrodynamic volume is 


\section{CVH/FL Packages Reference Manual}

also modified as the space which was occupied by nonhydrodynamic materials becomes available and the space it now occupies is denied to the hydrodynamic materials. The other packages may track the location of their materials in more (or less) detail than is permitted by the set of altitudes recognized by $\mathrm{CVH}$; this has no effect on hydrodynamic calculations.

\subsection{Control Volume Contents}

The contents of each volume are divided into a so-called pool and an atmosphere. These terms are evocative of a static, gravitationally separated situation, such as would exist in containment or in a primary system in the absence of strong forced circulation by pumps, and we conventionally depict the pool as occupying the lower portion of the control volume while the atmosphere fills the remainder. However, as discussed later, this picture is not interpreted so narrowly that it invalidates the use of MELCOR hydrodynamics in other situations.

The pool can be single phase liquid water or, in nonequilibrium volumes as discussed below, two-phase (bubbly) water. No noncondensible gases are resident in the pool, although they may flow through and interact with it during a timestep. The atmosphere contains water vapor and/or noncondensible gases, and may also include suspended water droplets, referred to as fog. The total volume is divided among pool, gaseous atmosphere, and fog, as shown in Figure 2.2.1. When needed by submodels, the pool surface is assumed to be a horizontal plane. Its elevation is defined from the volume of the pool by interpolation in the volume/altitude table for the control volume. Only the average void fraction in the pool is part of the $\mathrm{CVH}$ database, although a variation of void fraction with elevation may be assumed in submodels.

Materials are numbered in MELCOR. Materials 1,2, and 3 are always pool, fog, and atmospheric water vapor, respectively. In particular, material 1 includes all of the pool, both liquid water and vapor bubbles. Materials with numbers greater than 3 are noncondensible gases. They are present in a calculation only if specified by the user, in which case their identities depend on input to the NCG package.

\subsection{Control Volume Thermodynamic Properties}

Given the volume and the mass and energy contents of a control volume, all of its thermodynamic properties are defined by an equation of state. There are two basic options available, selected by user input on record CVnnnO0: equilibrium and nonequilibrium.

In MELCOR, equilibrium thermodynamics assumes that the pool and the atmosphere are in thermal and mechanical equilibrium, i.e., that they have the same temperature and 
CVH/FL Packages Reference Manual

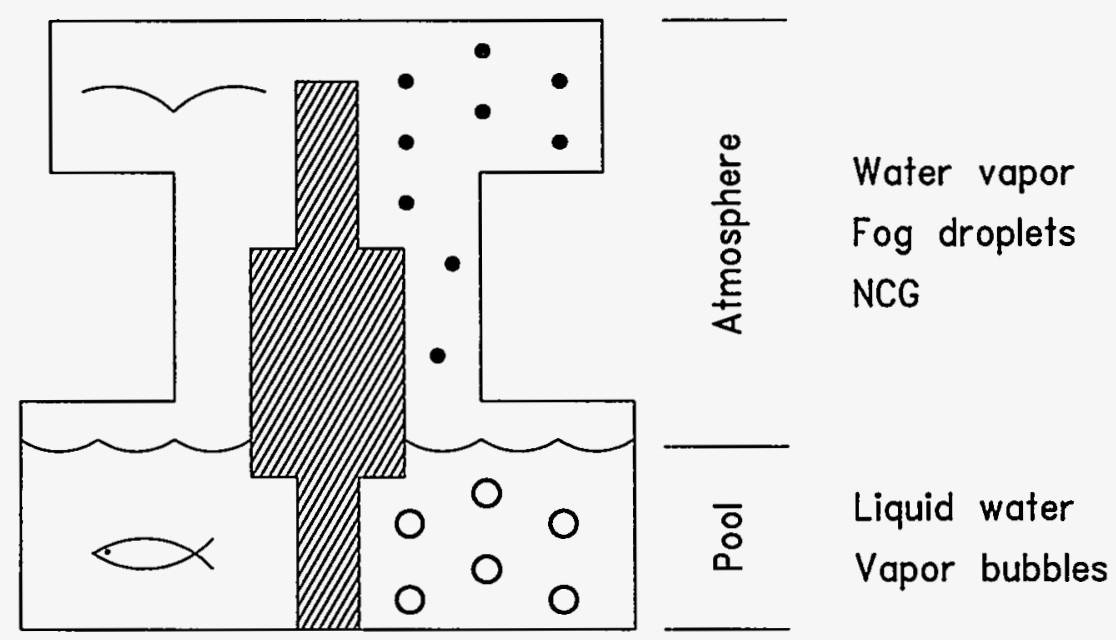

Figure 2.2.1 Control Volume Contents and Pool Surface

pressure. The two subvolumes, pool and atmosphere, are also assumed to be in equilibrium with respect to condensation/evaporation of water.

Nonequilibrium thermodynamics, on the other hand, assumes that while each subvolume is in internal equilibrium, it is in only mechanical equilibrium with the other. That is, neither thermal nor phase equilibrium is assumed between the pool and the atmosphere. (Note that this is not nonequilibrium in the sense of TRAC [6] or RELAP5 [7].) While the pressures of the pool and the atmosphere are equal, their temperatures may be different, and there may be a substantial driving force for condensation or evaporation. The distinction between equilibrium and nonequilibrium thermodynamics exists only if a control volume contains both a pool and an atmosphere. The calculations required to determine the necessary thermodynamic properties (pressure, temperature, etc) in either case are performed in the Control Volume Thermodynamics (CVT) package; for a detailed description, see the CVT Reference Manual.

For equilibrium thermodynamics, only the total energy content of a control volume is relevant, because CVT will reapportion the total energy so as to obtain equilibrium among species in the atmosphere and between the atmosphere and the pool. This implies effectively instantaneous mass and energy transfer between pool and atmosphere, and the explicit calculation of the exchange terms is eliminated in favor of simple assumptions. All water vapor is currently assumed to be in the atmosphere. Liquid water, however, can exist both in the pool and as fog in the atmosphere. An auxiliary calculation is used to determine the partition. For more details, see Section 2.4 of the CVT Reference Manual. 


\section{CVH/FL Packages Reference Manual}

The exchange terms must be calculated, however, for volumes in which nonequilibrium thermodynamics is prescribed. An additional term, the PdV work done by the pool on the atmosphere (or vice versa) as a result of motion of the pool surface, must also be kept in mind in the nonequilibrium case; it is actually accounted for (as P $\Delta V$ ) in CVT.

When nonhydrodynamic materials are relocated, changing the volume available to hydrodynamic materials, work is done in the process. This work is currently ignored in the package responsible for the relocation; that is, the energy inventory of that package is not affected. The error involved is insignificant in most cases because nonhydrodynamic materials are not ordinarily relocated through large pressure differentials and the net work done is therefore very small. Pressure differentials can be large during high pressure melt ejection in the Fuel Dispersal Interactions (FDI) package, but even there the work term is small compared to other energy exchanges. The work must be included in $\mathrm{CVH}$; for purposes of global energy accounting, it is treated as being created there.

The single pressure that $\mathrm{CVH}$ assigns to a control volume is assumed to correspond to the elevation of the pool/atmosphere interface. If there is no pool, this is taken as the bottom of the control volume; if there is no atmosphere, it is taken as the top. This choice (as opposed to a volume-centered pressure) simplifies the treatment of condensation/evaporation rates at the interface. As discussed below, the hydrostatic head corresponding to the difference between the pool-surface reference elevation and the junction of a flow path to a control volume is accounted for in the momentum equation-such a head term would be necessary for any definition of the reference elevation for the pressure in a control volume. 
CVH/FL Packages Reference Manual

\section{BASIC FLOW PATH CONCEPTS}

The basic concepts, definitions, and models associated with flow paths are described in this section. Most of the details will be deferred until after the conservation equations have been presented and their solution discussed.

\subsection{Flow Path Definition}

Each flow path connects two control volumes, specified on input record FLnnn00. One is referred to as the from volume and the other as the to volume, thus defining the direction of positive flow. An arbitrary number of flow paths may be connected to or from each control volume; parallel paths (connecting the same two volumes) are allowed.

Mass and energy are advected through the flow paths, from one volume to another, in response to solutions of the momentum (flow) equation. No volume, mass, or energy is associated with a flow path itself, and no heat structures are allowed to communicate directly with the material passing through it. Therefore, the effect of advection through a flow path is to remove mass and energy from one control volume and to deposit it directly into another control volume. The formulation is manifestly conservative with respect to both mass and energy, because there is a detailed balance between gains and losses in the two volumes connected by each flow path.

The cross-sectional area of a flow path is shared by pool and atmosphere in accordance with a calculated void fraction based on geometry and flow directions. The velocities of pool and atmosphere may be different if both are permitted to flow by the void fraction model; the directions of flow may even be opposite, i.e., countercurrent.

\subsection{Flow Path Geometry}

Flow path geometry is described on input records FLnnn00 and FLnnn01. Each flow path is characterized by a nominal area and a length. The area may be further modified by a user-controlled open fraction, which models (among other things) the effects of valves. The area is used in the conversion of volumetric flows to linear velocities, and is therefore involved in form-loss and critical flow modeling. The length is used in the momentum equation to define the inertia of the flow; as in other codes of this type, the ratio of length to area is the relevant parameter. It should be noted that (unlike some other codes) this inertial length is not used in the calculation of frictional pressure drops resulting from wall friction; segment data are used instead. Each flow path may be described in terms of a number of segments with differing lengths, areas, hydraulic diameters, surface roughnesses, etc. The details will be discussed in Section 5.4; for now, it is sufficient to note that in the calculation segment data are combined with the flow path form-loss 


\section{CVH/FL Packages Reference Manual}

coefficient (optionally defined on input record FLnnn03 for both forward and reverse flow) to form a single effective loss coefficient applied to the flow-path velocity.

Each connection of a flow path to a control volume is referred to as a junction, and is characterized by a nominal elevation and an opening height. The opening height defines a range of elevations about the junction elevation over which the flow path sees the contents of the control volume. These two quantities, in conjunction with the elevation of the pool surface, therefore determine whether pool, atmosphere, or both are available for outflow. The junction elevations and heights are also used in the calculation of hydrostatic head terms; the lengths of the flow paths are not.

A flow path may be defined through user input on record FLnnn02 to be horizontal or vertical. In a control volume/flow path formulation, the orientation of a flow path can not be rigorously defined; the specification affects the definition of junction geometry, below, and the (default) definition of the length over which interphase forces act, described in Section 5.5 .

The definition of a junction opening is illustrated in Figure 3.2.1, which also illustrates the possible truncation of the opening to match the associated control volume.

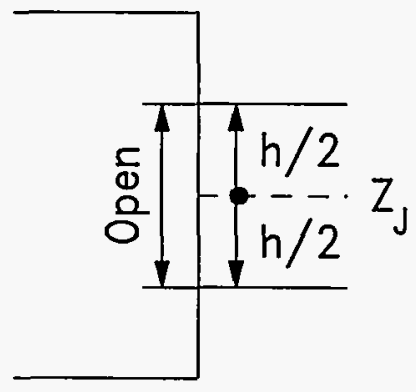

(a)

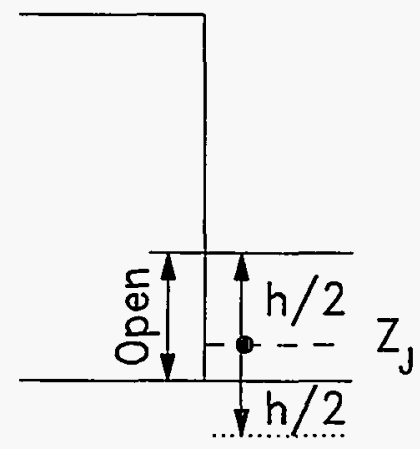

(b)

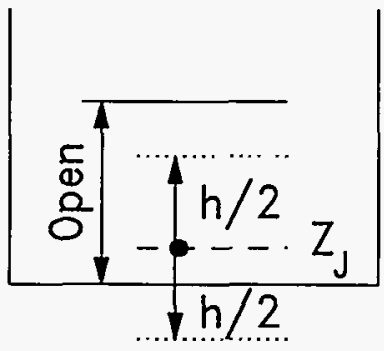

(c)

Figure 3.2.1 Junction Geometry

(a) Normal Junction

(b) Truncation for a horizontal path, opening height reduced

(c) Truncation for a vertical path, opening height preserved (if possible)

Each junction elevation is required to lie within the range of elevations associated with the control volume with which it connects; that is, the junction elevation $z_{j}$ is required to lie between the bottom, $z_{B}$, and the top, $z_{T}$, of the control volume (inclusive). The junction height, $h$, is normally considered to be centered on the junction elevation, one half below and the remainder above, and, if the resulting junction opening (between $z_{J}-h / 2$ and 
CVH/FL Packages Reference Manual

$z_{j}+h / 2$ ) extends beyond the limits of the volume, it is truncated. (The nominal junction elevation, $z_{J}$, is not modified.) In the case of a flow path specified by input as vertical (and in this case only), an attempt is made to preserve the full junction height. If the bottom of the junction opening is truncated, its top will be raised a corresponding amount above $z_{J}+h / 2$ (but not above $z_{T}$ ). A similar modification is applied if the top of the opening extends above the top of the volume. As currently implemented, this and the treatment of the interphase force are the only differences in treatment between horizontal and vertical flow paths. (Details of the interphase force model are presented in Section 5.5)

The junction void fraction is determined from the relative positions of the junction opening and the pool surface, and is taken as the fraction of the opening height occupied by atmosphere (in effect, the opening is treated as rectangular). This is illustrated in Figure 3.2.2. (Atmosphere fraction would be a more precise term than void fraction because fog flows with the gaseous component of the atmosphere and bubbles flow with the pool.)
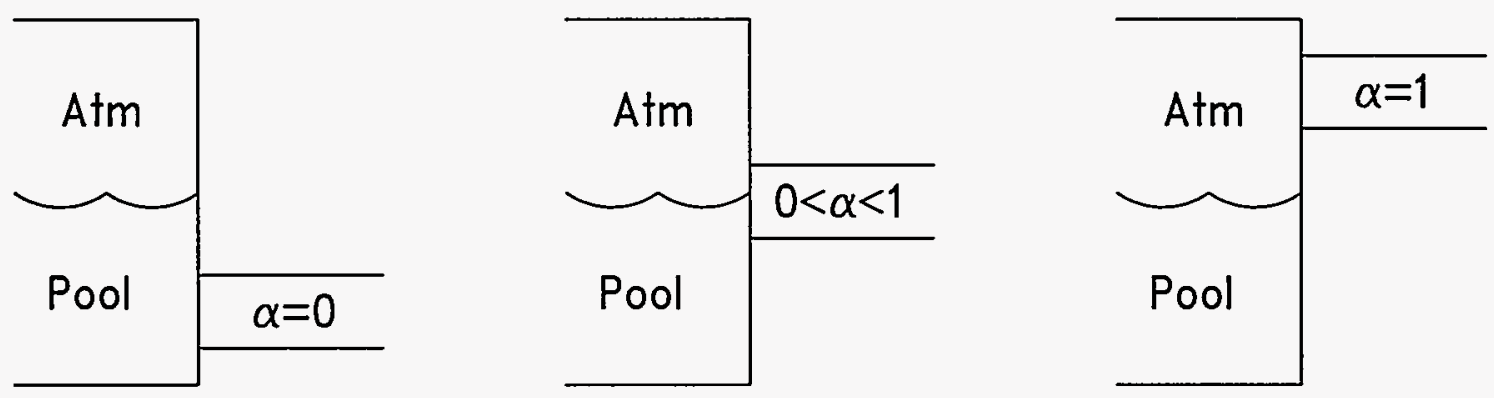

Figure 3.2.2 Relationship among Junction Opening, Pool Surface Elevation, and Void Fraction

In the tank-and-pipe limit of hydrodynamic modeling, the length, junction elevation and height have relatively clear physical interpretations. It is recommended that the junction height for connection of a vertical pipe to a tank should be taken as something like the pipe radius; this models to some extent the two-dimensional distortion of the pool surface when there is flow through such a connection, as well as eliminating the discontinuity in behavior which would otherwise occur when the pool surface crosses through the junction elevation. Because of this role in eliminating discontinuous behavior, the junction height may not be input as zero.

In the finite-difference limit, a "flow path" represents a surface which is a common boundary between the volumes connected; the length should be taken as roughly the center-to-center distance between volumes, and the elevations of both ends of the junction should be taken as the midpoint elevation of the common boundary. For horizontal flow through a vertical boundary, the junction height should be specified as 


\section{CVH/FL Packages Reference Manual}

large enough to include the entire boundary. For vertical flow through a horizontal boundary, the height has no rigorous interpretation; it serves only to define the range of elevations from which material may be drawn.

The flow equations include a term for the interphase force acting between the pool flow and the atmosphere flow in a single flow path. Among other things, this force tends to limit the relative velocity between the phases and can cause entrainment through a vertical flow path whenever both phases (pool and atmosphere) are present within the junction opening and the interphase force is large enough to overcome the head difference for them. In particular, a flow of atmosphere from a lower volume to a higher one can entrain an upward pool flow (and a downward pool flow can entrain a corresponding downward atmosphere flow), despite an opposing difference in pressure plus head, if the associated junction opening is sufficiently large that both pool and atmosphere are present within the opening height. This tends to "smear" the pool surface slightly for the purposes of flow calculations, and reduces the computational effort in cases where a rising (or falling) pool surface passes through the top (or bottom) of a control volume. We have found that use of an opening height which is a substantial fraction of the volume height frequently works well.

It is also possible to modify the finite difference limit by dividing the common boundary between two control volumes into two or more parallel flow paths with different elevations, whose areas sum to the correct geometrical total, as illustrated in Figure 3.2.3.

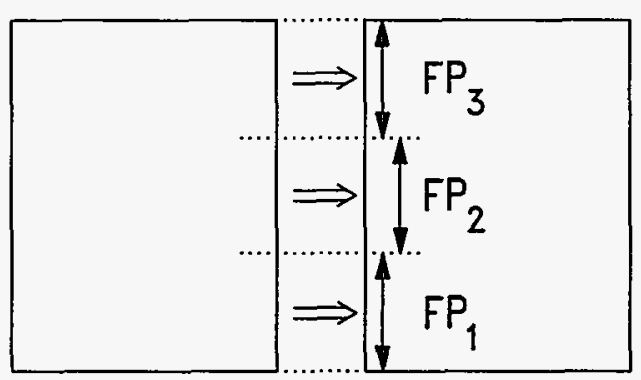

Figure 3.2.3 Multiple Flow Paths Connecting Two Volumes, to Model Natural Circulation

There is preliminary evidence that some aspects of natural convection may be calculable in this way.

A number of additional parameters are defined for flow paths; their definitions and interpretation will be deferred until later sections of this manual. 
CVH/FL Packages Reference Manual

\section{GOVERNING EQUATIONS}

The governing equations for thermal-hydraulic behavior in MELCOR are the equations of conservation of mass, momentum, and energy. These equations will be presented first as ordinary differential equations for the control-volume formulation, and then in the linearized-implicit finite difference form which is actually solved. They could, of course, be derived by suitable integration of the three-dimensional partial differential equations over a volume (for the scalar mass and energy equations) or along a line (for the vector momentum equation), but the insights to be gained do not justify including the derivation in this Reference Manual. See, for example, Reference 1.

\subsection{Ordinary Differential Equations}

The differential equation expressing conservation of mass for each material is

$$
\frac{\partial \rho}{\partial t}+\nabla \cdot(\rho v)=\Gamma
$$

where $\Gamma$ is the volumetric mass source density. Integrated over a control volume, the conservation of mass for material $\mathrm{m}$ in control volume $\mathrm{i}$ is then expressed by

$$
\frac{\partial M_{l, m}}{\partial t}=\sum_{J} \sigma_{l j} \alpha_{l, \phi} \rho_{j, m}^{d} v_{l, \phi} F_{j} A_{j}+\dot{M}_{l, m}
$$

Here

$M$ is total mass,

subscript $j$ refers to flow path, with $\sigma_{i j}$ accounting for the direction of flow in flow path $j$ with respect to volume $i$ as described below,

subscript $\phi$ refers to the phase, pool or atmosphere (later abbreviated as " $P$ " and " $A$ ", respectively), in which material $m$ resides,

$\alpha_{1, \phi}$ is the volume fraction of $\phi$ in flow path $j\left(\alpha_{i, A}+\alpha_{j, P}=1\right.$, see Section 5.2 for definitions),

$\rho$ is density,

superscript "d" denotes "donor", corresponding to the control volume from which material is flowing,

$v$ is flow velocity,

A is flow path area,

$F$ is the fraction of this area which is open, and

$\dot{M}$ includes all non-flow sources, such as condensation/evaporation, bubble separation, fog precipitation, and user-defined sources in CVH, and contributions from other packages in MELCOR. 


\section{CVH/FL Packages Reference Manual}

The summation in Equation 4.1.2 is over all flow paths, with

$$
\sigma_{i j} \equiv\left\{\begin{aligned}
&+1 \text { if path } j \text { is connected "to" volume } i \\
&-1 \text { if path } j \text { is connected "from" volume } i \\
& 0 \text { if path } j \text { is not connected to volume } i
\end{aligned}\right.
$$

accounting for which flow paths are actually connected to volume $\mathrm{i}$, and for the direction of positive flow in these paths. As used here, the density is defined by

$$
\rho_{m} \equiv \frac{M_{m}}{V_{\Phi}}
$$

where $\mathrm{V}_{\phi}$ is the volume of the phase containing material $\mathrm{m}$. Recall that the pool phase contains single- or two-phase water, while the atmosphere can contain water vapor, noncondensible gases, and liquid water fog.

The equations expressing conservation of energy in the pool and in the atmosphere are derived similarly from the partial differential equations, neglecting all gravitational potential energy and volurne-average kinetic energy terms. Conservation of energy in phase $\phi$ (pool or atmosphere) is then expressed by

$$
\frac{\partial E_{i, \phi}}{\partial t}=\sum_{j} \sigma_{l j} \alpha_{j, \phi}\left(\sum_{m} \rho_{j, m}^{d} h_{j, m}^{d}\right) v_{l, \phi} F_{j} A_{j}+\dot{H}_{I, \phi}
$$

where

$E$ is total internal energy,

$\mathrm{m}$ in the second summation runs over all materials in phase $\phi$,

$h$ is the specific enthalpy (the difference between $h$ and the specific internal energy, e, accounts for flow work), and

$\dot{H}$ is the non-flow energy source, inclucling the enthalpy of all relevant mass sources in equation 4.1.2.

Finally, the equations for pool flow and for atmosphere flow in a flow path are obtained from line integrals of the acceleration equations along a stream line from the center of the from volume to the center of the to volume. The temporal rate of change of the void fraction, $\partial \alpha / \partial t$, is neglected. The results (in nonconservative form) are expressed by

$$
\begin{aligned}
\alpha_{j, \phi} \rho_{j, \phi} L_{J} \frac{\partial v_{j, \phi}}{\partial t} & =\alpha_{j, \phi}\left(P_{i}-P_{k}\right)+\alpha_{j, \phi}(\rho g \Delta z)_{j, \phi}+\alpha_{j, \phi} \Delta P_{J} \\
& -\frac{1}{2} K_{j, \phi}^{*} \alpha_{j, \phi} \rho_{j, \phi}\left|v_{j, \phi}\right| v_{j, \phi}-\alpha_{j, \phi} \alpha_{j,-\phi} f_{2, J} L_{2, j}\left(v_{j, \phi}-v_{j,-\phi}\right) \\
& +\alpha_{j, \phi} \rho_{j, \phi} v_{j, \phi}(\Delta v)_{J, \phi}
\end{aligned}
$$

where

$L_{j}$ is the inertial length of the flow path, 
CVH/FL Packages Reference Manual

$i$ and $k$ are the "from" and "to" control volumes, respectively, for flow path $\mathrm{j}$,

$g$ is the acceleration of gravity,

$\Delta \mathrm{P}_{\mathrm{j}}$ represents any pump head developed in the flow path,

$K^{*}$ is the net form- and wall-loss coefficient,

$f_{2, j}$ is the interphase force (momentum exchange) coefficient,

$L_{2, j}$ is the effective length over which the interphase force acts (not necessarily equal to the inertial length, see Section 5.5),

$(\Delta v)_{1, \phi}$ represents the change in velocity through the flow path (the "momentum flux"), and

$-\phi$ denotes the "other" phase relative to $\phi$ (atmosphere if $\phi$ is pool and vice versa).

The density of a phase in a flow path is ordinarily taken as the density in the donor volume; the phase densities are evaluated from Equation 4.1.4, with a summation over materials for the atmosphere. In some pathological cases there may be very little (or no) mass of the appropriate phase in the alleged donor volume; in these cases, CVT returns a density which approaches zero. To avoid numerical problems, we determined to use a density which approximated the average density along the flow path. The actual equation used is

$$
\rho_{j, \phi}=\max \left(\rho_{j, \phi}^{d}, \frac{1}{2} \rho_{j, \Phi}^{a}\right)
$$

where the superscripts " $d$ " and "a" refer to the donor and acceptor volumes for the flow path.

The gravitational head term and the loss term are each somewhat complicated, and will be discussed in detail in Sections 5.3 and Section 5.4, respectively. The formulation of the interphase force represented by $f_{2, j}$ is described in Section 5.5, and the models available for the pump head are presented in Section 5.6. Note that, as written, the volume fraction, $\alpha_{\phi}$, cancels identically in this equation.

The last term in Equation 4.1.6, $v_{j, \phi}(\Delta v)_{j, \phi}$, represents the advection of momentum through the flow path, and arises from integration of the term $v(\partial v / \partial x)$ in the continuum equations. The formulation presented here is essentially one-dimensional; in more general geometries, $v$ in Equation 4.1.6 may be interpreted as the velocity component in the direction of flow (denoted by " $x$ "); however, the treatment will be incomplete because the cross terms arising from $v_{y}\left(\partial v_{x} / \partial y\right)$ are not included in the equations.

By default, even the diagonal momentum flux term in Equation 4.1.6 is neglected in solution of the hydrodynamic equations in MELCOR. This is consistent with omission of the kinetic energy in Equation 4.1.5. These terms (momentum flux and kinetic energy) have traditionally been sources of difficulty in control volume codes because they involve a volume-centered velocity, which requires a multi-dimensional formulation for proper definition. (Note that codes such as RELAP5 [7] make very specific geometric assumptions concerning the relationships between control volumes and flow paths.) The 


\section{CVH/FL Packages Reference Manual}

neglected terms in both equations are of order $\mathrm{Ma}^{2}$, where $\mathrm{Ma}$ is the Mach number based on volume-centered velocities, and are ordinarily small (although they may be important for flow boiling with large density gradients). Velocities in flow paths may be sonic or near sonic, but constancy of $h+1 / 2 v^{2}$ for adiabatic (not necessarily isentropic) flow assures that only volume-centered velocities appear in the equations. Choking is treated as an imposed limit on flows based on correlations (see Section 6.4). In any case, inclusion of the $v^{2}$ terms would require a proper definition of a volume-centered velocity, including multidimensional effects, and it is far from clear that this can be done in anything but a full finite difference code (see Section 6.6). In most cases, no difficulties will arise if MELCOR pressures and enthalpies are considered to be stagnation pressures and stagnation enthalpies.

\subsection{Finite Difference Equations}

The ordinary differential equations presented in Section 4.1 are converted to linearizedimplicit finite difference equations for solution in MELCOR.

For each timestep, $\Delta t$, the new (end-of-step) velocities are used in the advection (flow) terms in the mass and energy equations to write

$$
\begin{aligned}
& M_{i, m}^{n}=M_{i, m}^{o}+\sum_{j} \sigma_{i j} \alpha_{j, \phi}^{n} \rho_{j, m}^{d} v_{j, \phi}^{n} F_{j} A_{j} \Delta t+\delta M_{i, m} \\
& E_{i, \phi}^{n}=E_{i, \phi}^{o}+\sum_{j} \sigma_{i j} \alpha_{j, \phi}^{n}\left(\sum_{m} \rho_{j, m}^{d} h_{j, m}^{d}\right) v_{j, \phi}^{n} F_{j} A_{j} \Delta t+\delta H_{i, \phi}
\end{aligned}
$$

where

superscripts $\mathrm{n}$ and o refer to the new and old time levels, respectively, and $\delta \mathrm{M}$ and $\delta \mathrm{H}$ are the net external sources (integrals from $t^{\circ}$ to $t^{\circ}+\Delta t$ ).

The time levels on the donor properties are not explicitly shown in Equations 4.2.1 and 4.2.2; they are essentially old values $\left(a t t^{\circ}\right)$, but see the further discussion in Section 4.4.

It is clear that this formulation is conservative with respect to both masses and internal energies because every term representing a flow transfer from a volume is exactly balanced by a transfer to the volume at the other end of the flow path. Therefore, masses and energies are conserved to within the accumulation of roundoff on the computer used.

In the interest of numerical stability, linearized-implicit ("semi-implicit") differencing is used in several terms in the momentum equation (Equation 4.1.6). Specifically, the equation is differenced using projected end-of-step pressures and heads in the acceleration terms, 
and end-of-step velocities in the frictional loss and momentum exchange terms. Because of the nonlinearity of the frictional loss term, the resulting finite difference equation must be solved iteratively. (Because of nonlinearity of the equation of state used to project the end-of-step pressures, a further iteration may be required. We will return to this in Section 4.3.) We will first discuss the treatment of velocities and then define and discuss the other terms in the finite difference equation.

At each velocity iteration, the form- and wall-loss term is linearized about the best available estimate of $v^{n}$, denoted $v^{n-}$ (this is initially $v^{0}$ ), to obtain the finite difference equation for the estimated new, end-of-step velocity:

$$
\begin{aligned}
v_{j, \phi}^{n} & =v_{j, \phi}^{o+}+\frac{\Delta t}{\rho_{j, \phi} L_{j}}\left(P_{l}^{n}+\Delta P_{j}-P_{k}^{\tilde{n}}+(\rho g \Delta z)_{j, \phi}^{\tilde{n}}+v_{j, \phi}^{o}(\rho \Delta v)_{j, \phi}^{0}\right) \\
& -\frac{K_{j, \phi}^{*} \Delta t}{2 L_{j}}\left(\left|v_{j, \phi}^{n-}+v_{j, \phi}^{\prime}\right| v_{j, \phi}^{n}-\left|v_{j, \phi}^{\prime}\right| v_{j, \phi}^{n-}\right)-\frac{\alpha_{j,-\phi} f_{2, j} L_{2, j} \Delta t}{\rho_{j, \phi} L_{j}}\left(v_{j, \phi}^{n}-v_{j,-\phi}^{n}\right)
\end{aligned}
$$

The nature of the linearization in velocity is determined by the choice of $v^{\prime}$. For the first iteration, $v^{\prime}$ is taken as $v^{\circ}$, giving a tangent (Taylor series) linearization. For later iterations, it is taken as $v^{n-}$ from the previous iteration if the velocity did not reverse during that iteration, or as zero otherwise. The result is to approximate $v^{2}$ by the secant from the latest iterate through the next oldest iterate or by the secant through the origin, respectively. Note that the interphase force term is fully implicit with respect to velocities, and that the length over which this force acts, $L_{2, j}$, may differ from the inertial length of the flow path, $L_{\mathrm{j}}$.

The superscript "O+" on the velocity on the right-hand side of Equation 4.2.3 indicates that it has been modified from the old value to account for changes in the flow-path void fraction, as discussed below. This was found necessary to prevent initiation of a nonphysical transient whenever the motion of a pool surface through a (small) junction opening produced a major change in void fraction during a single timestep.

The problem is that the old velocities, $v^{\circ}$, were computed with the old void fraction, $\alpha^{\circ}$; with $\alpha^{n}$, they may correspond to a quite different flow state, both in mass flow and in total volumetric flow. This may require large accelerations (and pressure differentials) to maintain the "correct" flow. The cause is, in part, that the time derivative of the void fraction does not appear in the momentum equation. (There are further problems involving the time level of data on which $\alpha$ is based, and the fact that its treatment is not numerically implicit.)

The definition of "void fraction" in MELCOR is necessarily much more complicated than in a simple fine-zoned finite difference code, and an attempt to include $\partial \alpha / \partial t$ in the momentum equation seemed unlikely to be productive. Therefore, we have chosen to employ an ad hoc modification of the "old" velocities to account for changes in void 


\section{CVH/FL Packages Reference Manual}

fractions. (Sensitivity coefficient $\mathbf{4 4 0 8}$ may be used to disable this modification.) The criteria used are preservation of the total volumetric flux, expressed by

$$
\alpha_{j, A}^{n} v_{j, A}^{o+}+\alpha_{j, P}^{n} v_{j, P}^{o+}=\alpha_{j, A}^{o} v_{j, A}^{o}+\alpha_{j, P}^{o} v_{j, P}^{o}
$$

and preservation of the relative velocity between the phases, expressed by

$$
v_{j, A}^{0+}-v_{j, P}^{0+}=v_{j, A}^{0}-v_{j, P}^{0}
$$

This results in

$$
v_{j, \Phi}^{o+}=v_{j, \Phi}^{o}+\left(\alpha_{j, A}^{0}-\alpha_{j, A}^{n}\right)\left(v_{j, A}^{0}-v_{j, P}^{o}\right)
$$

It is interesting to note that there is an analogous relationship implicit in drift-flux codes. In such codes, the total mass flux (momentum density) is determined by a single momentum equation for each flow path, and a constitutive relation (the drift flux correlation) is then used to partition this flux into liquid and vapor components as a function of void fraction. Thus, when a new void fraction is computed at the start of a timestep, the total mass flux is preserved but the individual phase velocities and the total volumetric flux are not. MELCOR calculations more often involve quasi-steady flows than pressure waves; therefore, preservation of the volumetric flow rather than the momentum density (mass flux) was chosen as the default treatment. (Note that there is no way that both the mass fluxes and volumetric flows could be preserved as the void fraction changes.)

As noted previously, the momentum flux term, $v(\rho \Delta v)$ in Equation 4.2.3, will be omitted by default. We have found no need for implicit treatment of this term if it is included; therefore, start-of-step velocities are used in its evaluation. If the term is to be included in the momentum equation for flow path $j$, the user is required to specify on input record FLnnnMx the flow paths that are logically upstream and downstream from flow path $j$, as described in the FL Users' Guide. The specification of "no such flow path" is permitted, to allow treatment of a flow path connected to a clead-end volume or to one with no other appropriately-oriented connection.

The term $(\rho \Delta v)$, representing a spatial difference in momentum density, is treated as a donored quantity. It is evaluated based on the direction of flow through flow path $j$, as

$$
(\rho \Delta v)_{j, \phi}^{o}= \begin{cases}\rho_{i}\left(\frac{F_{j} A_{j-} v_{j-, \Phi}^{0}}{A_{i}}-\frac{F_{j} A_{j} v_{j, \phi}^{o}}{A_{k}}\right) & v_{j, \phi}^{0} \geq 0 \\ \rho_{k}\left(\frac{F_{j} A_{j} v_{j, \phi}^{o}}{A_{i}}-\frac{F_{j+} A_{j+} v_{j+, \phi}^{o}}{A_{k}}\right) & v_{j, \phi}^{0}<0\end{cases}
$$

Here

subscripts $i$ and $k$ denote the donor and acceptor volumes, respectively, 
$A_{i}$ and $A_{k}$ are the corresponding user-defined flow areas for these volumes in the direction of flow appropriate to flow path $j$, and

subscripts $j$ - and $j+$ refer to the designated flow paths that are logically upstream and down stream of $j$, and must connect to volumes $i$ and $k$, respectively.

The area ratios in Equation 4.2.7 serve to convert the momentum density in each flow path to corresponding densities at the volume center, under the assumption of incompressible flow. The volume areas, which may differ from those used in the control volume velocity calculation, must be specified by the user on record FLnnnMk. This allows more accurate description of the actual flow geometry. For example, most of the momentum of a small jet entering a large room will be dissipated close to the point of entry, leaving little momentum to be advected through a second flow path and, in general, this effect will be captured through the ratio of the (small) flow path area to the (large) volume area. However, if the two flow paths are closely aligned, so that a fluid jet from one will be captured by the other, the user may capture the effect by specifying a volume flow area appropriate for the jet.

If either flow path $j-$ or $j+$ is absent (as defined by user input), the corresponding term in Equation 4.2.7 is neglected, which is equivalent to setting the associated flow path area to zero.

As noted previously, the pressures, $P^{n}$, used in the acceleration terms in Equation 4.2.3 are predicted end-of-step pressures; they are calculated from the linearization of the equation of state about a reference point (denoted by "*n) as

$$
\begin{aligned}
P_{i}^{\tilde{n}}=P_{I}^{*} & +\sum_{m} \frac{\partial P_{i}^{*}}{\partial M_{i, m}}\left(M_{i, m}^{n}-M_{i, m}^{*}\right) \\
& +\frac{\partial P_{i}^{*}}{\partial E_{i, P}}\left(E_{i, P}^{n}-E_{i, P}^{*}\right)+\frac{\partial P_{i}^{*}}{\partial E_{i, A}}\left(E_{i, A}^{n}-E_{i, A}^{*}\right)
\end{aligned}
$$

The choice of the linearization point will be discussed in detail in Section 4.3.

The static head terms, $(\rho g \Delta z)^{n}$, are also predicted values at end-of-step. However, only changes in pool mass and hydrodynamic volume are included in the projection, with changes in atmosphere mass and phase densities neglected. Specifically,

$$
\begin{aligned}
(\rho g \Delta z)_{j, \Phi}^{\tilde{n}}=(\rho g \Delta z)_{j, \Phi}^{o} & +\frac{\partial(\rho g \Delta z)_{j, \Phi}}{\partial M_{i, P}}\left(M_{i, P}^{n}-M_{i, P}^{o+}\right) \\
& +\frac{\partial(\rho g \Delta z)_{j, \Phi}}{\partial M_{k, P}}\left(M_{k, P}^{n}-M_{k, P}^{o+}\right)
\end{aligned}
$$


CVH/FL Packages Reference Manual

In this equation $\mathrm{M}_{\mathrm{i}, \mathrm{P}}^{\circ+}$ is the mass of pool which can be accommodated below the former elevation of the pool surface at the old pool density. It differs from $M_{\mathrm{i}, \mathrm{p}}^{\circ}$ only if there has been a change in the volume/altitude table resulting from a change of virtual volume in control volume $i$. In this case, the difference accounts for the change in pool surface elevation-and therefore in static head-in the absence of a change in pool mass.

The new masses and new energies in Equation 4.2.8 and 4.2.9 are given by Equations 4.2.1 and 4.2.2, respectively. The derivatives $\partial \mathrm{P} / \partial \mathrm{M}$ and $\partial \mathrm{P} / \partial \mathrm{E}$ are calculated by the CVT package, and represent the linearized effect of changing mass and energy contents of the control volumes. See the CVT Reference Manual for further details. The derivatives $\partial(\rho \mathrm{g} \Delta \mathrm{z}) / \partial \mathrm{M}$ reflect the linearized effect of changing pool mass on the flowpath head terms; they are defined in Section 5.3.

When all terms associated with each flow are collected together for a given volume, the projected new pressure in Equation 4.2.8 has the form

$$
P_{i}^{\tilde{n}}=\hat{P}_{i}+\sum_{s, \psi} \frac{\partial P_{i}}{\partial V_{s, \psi}} \sigma_{i s} \alpha_{s, \psi} F_{s} A_{s} v_{s, \psi}^{n} \Delta t
$$

where

$$
\begin{aligned}
\hat{P}_{i}=P_{i}^{*} & +\sum_{m} \frac{\partial P_{i}^{*}}{\partial M_{i, m}}\left(\hat{M}_{i, m}-M_{i, m}^{*}\right) \\
& +\frac{\partial P_{i}^{*}}{\partial E_{i, P}}\left(\hat{E}_{i, P}-E_{i, P}^{*}\right)+\frac{\partial P_{i}^{*}}{\partial E_{i, A}}\left(\hat{E}_{i, A}-E_{i, A}^{*}\right) \\
\hat{M}_{i, m}= & M_{i, m}^{o}+\delta M_{i, m} \\
\hat{E}_{i, \phi}= & E_{i, \phi}^{o}+\delta H_{i, \phi}
\end{aligned}
$$

and

$$
\frac{\partial P_{i}}{\partial V_{S}}=\sum_{m} \frac{\partial P_{i}^{*}}{\partial M_{l, m}} \rho_{S, m}^{d}+\frac{\partial P_{i}^{*}}{\partial E_{i, P}}(\rho h)_{S, P}^{d}+\frac{\partial P_{i}^{*}}{\partial E_{l, A}}(\rho h)_{S, A}^{d}
$$

Here " $S$ " is used as an abbreviation for " $s, \Psi$ ", and

$$
(\rho h)_{S, \phi}^{d} \equiv \sum_{m \ln \phi} \rho_{S, m}^{d} h_{S, m}^{d}
$$


CVH/FL Packages Reference Manual

Because donor densities are used in the advection terms, they appear in the definition of $\partial \mathrm{P} / \partial \mathrm{V}$ in Equations 4.2.14 and 4.2.15. Therefore, $\partial \mathrm{P} / \partial \mathrm{V}$ depends on the direction of flow. In general, if $s, \psi$ represents a pool (atmosphere) flow, only the pool (atmosphere) energy and materials will be associated with non-zero donor densities in the evaluation of $\partial \mathrm{P}_{1} / \partial \mathrm{V}_{\mathrm{s}, \psi^{*}}$. However, the code is written with the greater generality of allowing atmosphere (pool) materials to be associated with pool (atmosphere) flows, and different donor density arrays are used to describe flows entering and leaving a flow path. This allows some interactions to be treated as occurring within a flow path. This capability is currently used in the SPARC model, as described in Section 6.1.

Substitution of the predicted pressures and heads into the velocity equation leads to a set of linear equations to be solved for the new velocities:

$$
\begin{aligned}
& \left(1+\frac{K_{j, \phi}^{*} \Delta t}{2 L_{j}}\left|v_{j, \phi}^{n-}+v_{j, \phi}^{\prime}\right|+\frac{\alpha_{j,-\phi} f_{2, j} L_{2, j} \Delta t}{\rho_{j, \phi} L_{j}}\right) v_{j, \phi}^{n}-\frac{\alpha_{j,-\phi} f_{2, j} L_{2, j} \Delta t}{\rho_{j, \phi} L_{j}} v_{j,-\phi}^{n} \\
& +\sum_{s, \psi} C(j, \phi: s, \psi) v_{s, \psi}^{n} \\
& =v_{j, \phi}^{o+}+\frac{K_{j, \phi}^{*} \Delta t}{2 L_{j}}\left|v_{j, \Phi}^{\prime}\right| v_{J, \phi}^{n-}+\frac{\Delta t}{\rho_{l, \phi} L_{j}}\left(\hat{P}_{i}+\Delta P_{j}-\hat{P}_{k}\right) \\
& +(\rho g \Delta z)_{j, \phi}^{o}+\frac{\partial(\rho g \Delta z)_{j, \Phi}}{\partial M_{l, P}}\left(M_{i, P}^{o}+\delta M_{l, P}-M_{i, P}^{o+}\right) \\
& \left.+\frac{\partial(\rho g \Delta z)_{l, \phi}}{\partial M_{k, P}}\left(M_{k, P}^{o}+\delta M_{k, P}-M_{k, P}^{o+}\right)\right]
\end{aligned}
$$

The summation on the left-hand side is over both phases, $\psi$, in all flow paths, $S$, although only those paths which connect either to volume $i$ or to volume $k$ contribute, as will be seen below. The coefficients in the sum are given by

$$
\begin{aligned}
& C(j, \phi: s, \Psi)=\frac{(\Delta t)^{2}}{\rho_{J, \phi} L_{j}} \alpha_{s, \Psi} A_{s} F_{s} \\
&\left\{-\sigma_{I s}\left[\frac{\partial P_{I}}{\partial V_{s, \psi}}+\delta_{\Psi P} \rho_{s, P}^{d} \frac{\partial(\rho g \Delta z)_{j, \phi}}{\partial M_{I, P}}\right]\right. \\
&\left.+\sigma_{k s}\left[\frac{\partial P_{k}}{\partial V_{s, \Psi}}-\delta_{\Psi} P \rho_{s, P}^{d} \frac{\partial(\rho g \Delta z)_{j, \phi}}{\partial M_{k, P}}\right]\right\}
\end{aligned}
$$

where 
CVH/FL Packages Reference Manual

$$
\delta_{i j}= \begin{cases}1 & i=j \\ 0 & i \neq j\end{cases}
$$

is the Kronecker delta. Because of the appearance of $\sigma_{\text {is }}$ and $\sigma_{\mathrm{ks}}$, the coefficient given by Equation 4.2.17 is non-zero only for flow paths which connect to volume $i$ or to volume $\mathrm{k}$; because of the appearance of $\delta_{\psi p}$, the head term appears only in cases where $s, \psi$ is a pool flow.

Equation 4.2.17 could be made somewhat more compact by obtaining the two sets of terms on the right (for volumes $i$ and $k$ ) from a sum over all volumes with appropriate coefficients to pick out the desired terms with the correct signs and eliminate the contributions of all others. However, this would only further conceal the essential point that two flows are coupled by the matrix if and only if there is a volume to which both connect, allowing each flow to affect the pressure differential driving the other.

As mentioned previously, the nonlinearity of the loss (friction) terms and the possibility of flow reversals affecting donor quantities require that the solution of the set of linear equations 4.2.16 be repeated until all the new velocities have converged. The control of this iteration is described in Section 4.3.

\subsubsection{Inclusion of Bubble-Separation Terms within the Implicit Formulation}

To this point, only the contribution of advection terms has been treated within a numerically implicit formulation. The effects of all sources were included in the $\delta \mathrm{M}$ and $\delta \mathrm{H}$ terms in Equations 4.2.1 and 4.2.2, which are then treated explicitly. These sources were considered to include several processes that could transfer mass and energy between the pool and atmosphere of a single volume within $\mathrm{CVH}$ : condensation/ evaporation, bubble separation, and fog deposition. Experience with MELCOR 1.8.2 showed that inclusion of the effects of bubble separation as part of the explicit sources could lead to severe numerical instabilities, particularly in problems involving boiling pools at low pressures. One problem is that the resulting large oscillations in the calculated elevation of the pool surface resulting from large oscillations in the calculated void (bubble) fraction in the pool can have a severe impact on heat transfer in the COR and HS packages. This was identified as a severe deficiency in the FLECHT SEASET assessment calculations [8].

As a result, the finite difference equations were modified for MELCOR 1.8.3 to include the transfer of vapor mass and energy from the pool to the atmosphere of a control volume within the implicit formulation. Because bubble separation is an intravolume process, its effects may be included along with those of the equation of state in defining a generalized form of Equation 4.2.8 in which bubble separation is included implicitly, and then 


\section{เย-พy-7 $\exists / H \wedge \supset$}

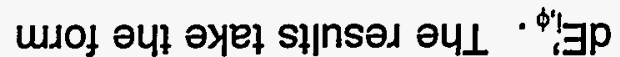

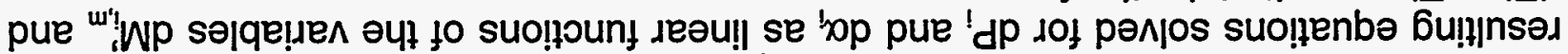

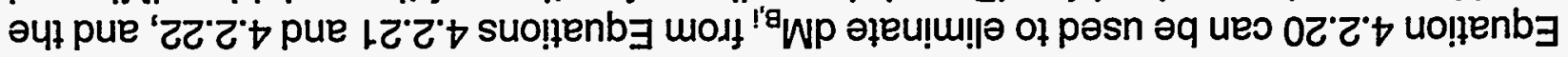

$$
\left(I^{\prime} \boldsymbol{w} p^{\wedge} u+\forall^{\prime \prime} \mid \exists p\right) \frac{\forall^{\prime \prime} \exists e}{{ }_{*}^{\prime} d e}+\left(I^{\prime} a w p^{\wedge} u-d^{\prime \prime} \mid \exists p\right) \frac{d^{\prime \prime} \exists e}{I^{\prime} d e}+
$$

(こて·でヤ)

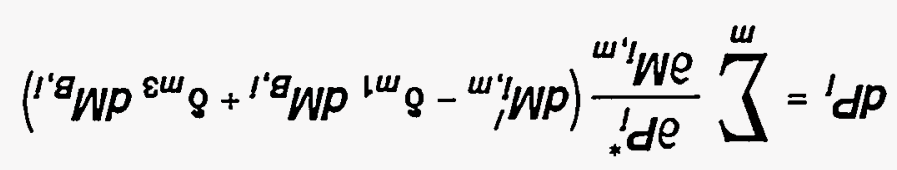

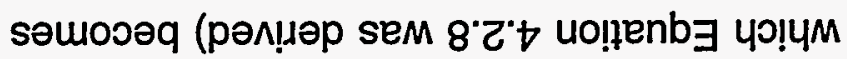

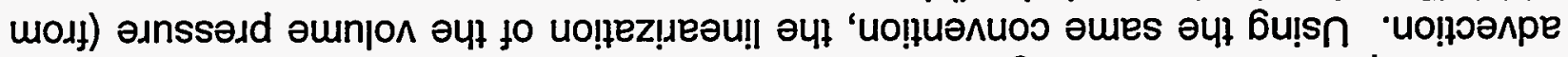

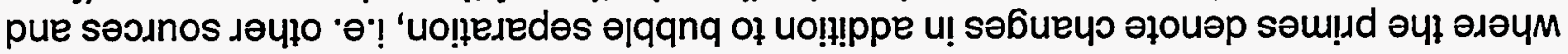

(Lででヤ)

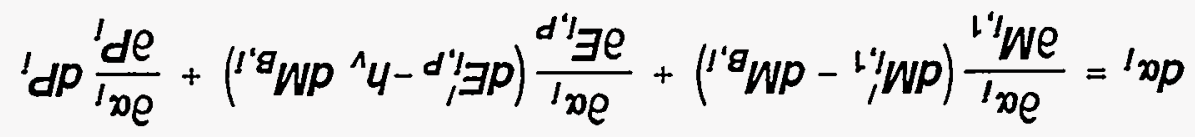

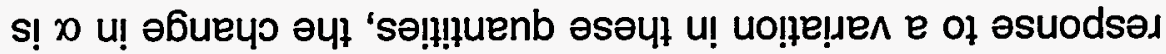

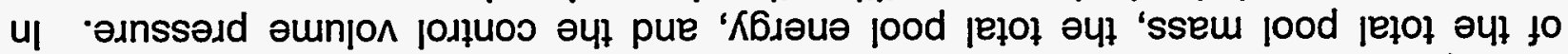

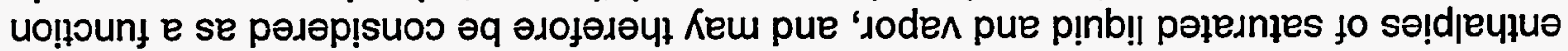

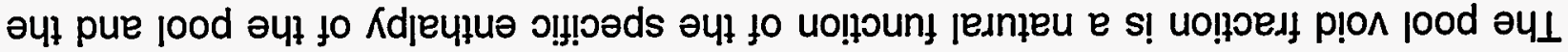

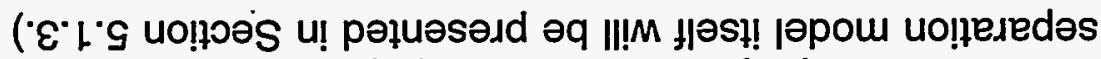

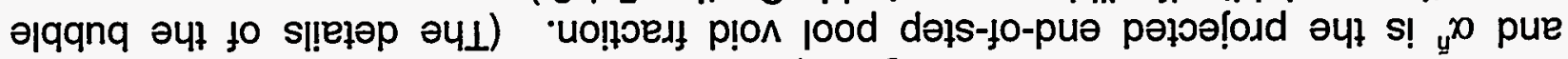
'

$\left(0 乙 \cdot Z^{\prime} \dagger\right)$

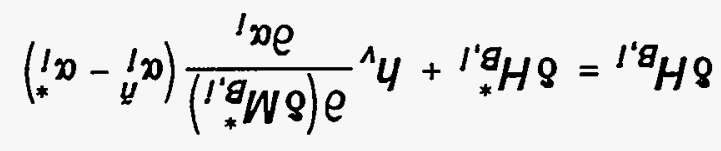

(6เでャ)

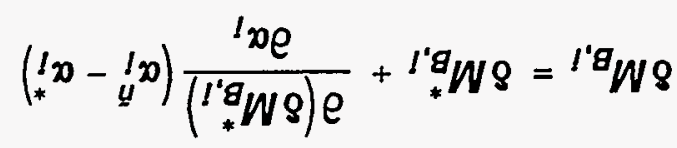

se əunjon

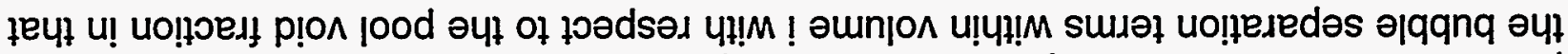

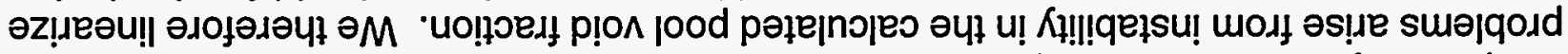

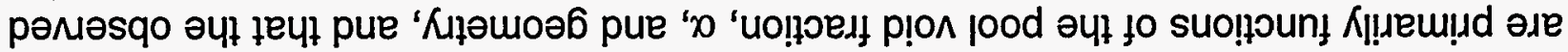

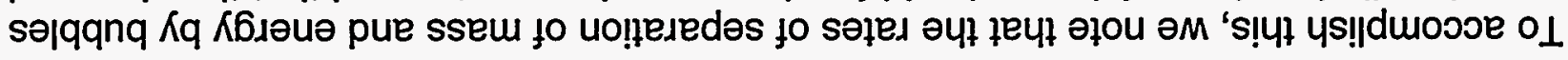

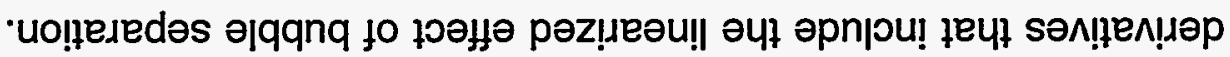

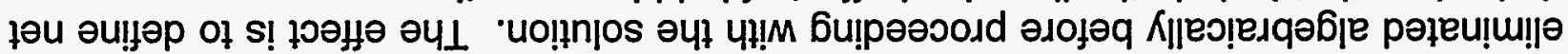

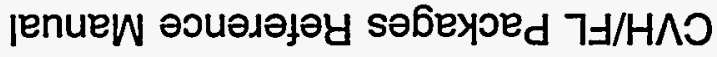


CVH/FL Packages Reference Manual

$$
\begin{aligned}
& d P_{i}=\sum_{m} \frac{\partial P_{i}^{*}}{\partial M_{l, m}^{\prime}} d M_{l, m}^{\prime}+\frac{\partial P_{I}^{*}}{\partial E_{l, P}^{\prime}} d E_{l, P}^{\prime}+\frac{\partial P_{I}^{*}}{\partial E_{l, A}^{\prime}} d E_{l, A}^{\prime} \\
& d \alpha_{I}=\sum_{m} \frac{\partial \alpha_{i}^{*}}{\partial M_{l, m}^{\prime}} d M_{l, m}^{\prime}+\frac{\partial \alpha_{I}^{*}}{\partial E_{l, P}^{\prime}} d E_{i, P}^{\prime}+\frac{\partial \alpha_{I}^{*}}{\partial E_{l, A}^{\prime}} d E_{l, A}^{\prime}
\end{aligned}
$$

Here the modified pressure derivatives are

$$
\frac{\partial P_{i}^{*}}{\partial X^{\prime}}=\frac{\frac{\partial P_{i}^{*}}{\partial X}-C_{i}\left(\frac{\partial \alpha_{i}^{*}}{\partial M_{B, i}} \frac{\partial P_{i}^{*}}{\partial X}-\frac{\partial P_{i}^{*}}{\partial M_{B, I}} \frac{\partial \alpha_{i}^{*}}{\partial X}\right) \Delta t}{1-C_{i}\left(\frac{\partial \alpha_{i}^{*}}{\partial M_{B, i}}+\frac{\partial \alpha_{i}^{*}}{\partial P_{I}} \frac{\partial P_{i}^{*}}{\partial M_{B, I}}\right) \Delta t}
$$

where $d X^{\prime}$ represents any of the variables $d M_{i, m}^{\prime}$ and $d E_{i, \phi}^{\prime}$ and

$$
\begin{aligned}
& \frac{\partial \alpha_{i}^{*}}{\partial M_{B, I}} \equiv-\left(\frac{\partial \alpha_{l}^{*}}{\partial M_{i, 1}}+h_{v} \frac{\partial \alpha_{l}^{*}}{\partial E_{I, P}}\right) \\
& \frac{\partial P_{l}^{*}}{\partial M_{B, I}} \equiv\left(\frac{\partial P_{i}^{*}}{\partial M_{I, 3}}+h_{v} \frac{\partial P_{l}^{*}}{\partial E_{l, A}}\right)-\left(\frac{\partial P_{l}^{*}}{\partial M_{l, 1}}+h_{v} \frac{\partial P_{l}^{*}}{\partial E_{i, P}}\right)
\end{aligned}
$$

are convenient combinations of the derivatives in Equations 4.2.21 and 4.2.22.

The momentum equation is constructed and solved as before, but now using Equation 4.2.23 to project the new pressures. The only differences that result are that the derivatives $\partial \mathrm{P}^{*} / \partial \mathrm{X}^{\prime}$ appear in Equations 4.2.11 and 4.2.14 rather than $\partial \mathrm{P}^{*} / \partial \mathrm{X}$, and that only $\delta \mathrm{M}^{*}$ and $\delta \mathrm{H}^{*}$ from Equations 4.2.19 and 4.2.20 are included in the source terms in Equations 4.2.12 and 4.2.13. During the solution, any change in bubble separation will be implicitly included by virtue of the modified pressure derivatives.

Once the new velocities are determined, the contribution of advection to new mass and energy inventories (the sums over flow paths in Equations 4.2.1 and 4.2.2) is determined as before. The additional mass and energy transfers resulting from the implicit change in bubble separation in Equations 4.2.19 and 4.2.20 must also be included-in addition to $\delta \mathrm{M}^{*}$ and $\delta \mathrm{H}^{*}$-in defining the new mass and energy inventories in Equations 4.2.1 and 4.2.2. Once the contribution of advection has been determined, the contribution of implicit bubble separation is evaluated from 


$$
\begin{aligned}
\alpha_{i}^{\tilde{n}}=\alpha_{i}^{*}+\sum_{m} & \frac{\partial \alpha_{i}^{*}}{\partial M_{i, m}^{\prime}}\left(\hat{M}_{i, m}+\delta M_{l, m, \text { advoct }}-M_{i, m}^{*}\right) \\
& +\frac{\partial \alpha_{i}^{*}}{\partial E_{i, P}^{\prime}}\left(\hat{E}_{i, P}+\delta H_{l, P, \text { advect }}-E_{i, P}^{*}\right) \\
& +\frac{\partial \alpha_{i}^{*}}{\partial E_{i, A}^{\prime}}\left(\hat{E}_{i, A}+\delta H_{l, A, \text { advoct }}-E_{i, A}^{*}\right)
\end{aligned}
$$

where the derivatives of the pool void fraction are given by

$$
\frac{\partial \alpha_{i}^{*}}{\partial X^{\prime}}=\frac{\frac{\partial \alpha_{i}^{*}}{\partial X}+\frac{\partial \alpha_{i}^{*}}{\partial P_{I}} \frac{\partial P_{i}^{*}}{\partial X}}{1-C_{l}\left(\frac{\partial \alpha_{I}^{*}}{\partial M_{B, I}}+\frac{\partial \alpha_{I}^{*}}{\partial P_{I}} \frac{\partial P_{I}^{*}}{\partial M_{B, I}}\right) \Delta t}
$$

in analogy with Equation 4.2.25, with the understanding that $\partial \alpha^{*} / \partial X$ is zero unless $X$ is $M_{1}$ or $\mathrm{E}_{\mathrm{p}}$.

\subsection{Solution Strategy}

As written, Equation 4.2.16 represents a set of linear equations for the latest estimates of the new velocities, $v_{i, \phi}^{n}$, and is solved by use of a standard linear equation solver. The complete solution procedure, however, is iterative on two levels. As already mentioned, the code requires convergence of the velocity field, so that the velocities $v_{j, \phi}^{n-}$ used in the loss terms in Equations 4.2.16 are acceptably close to the new velocities $v_{\mathrm{j}, \phi}^{\mathrm{n}}$ found by solution of these equations. This will, in general, involve iteration. In addition, the code requires that the final new pressures and pool void fractions, $P^{n}$ and $\alpha^{n}$, found from the full equation of state for the new masses and energies (Equations 4.2.1 and 4.2.2), agree well with the linearly-projected new pressures and void fractions, $P^{\tilde{n}}$ and $\alpha^{\tilde{n}}$, given by Equations 4.2.10 and 4.2.28. Once again, iteration may be required, this time on the definition of the point (deonoted by "**") about which pressure is linearized in Equation 4.2.8.

In general, the advancement of the hydrodynamic equations proceeds as shown in Figure 4.3.1 (details will be presented after the general approach has been described).

If either iteration fails to converge, the solution attempt is abandoned, the timestep, $\Delta t$ is reduced, the external sources are redefined appropriately, and the entire procedure 
CVH/FL Packages Reference Manual

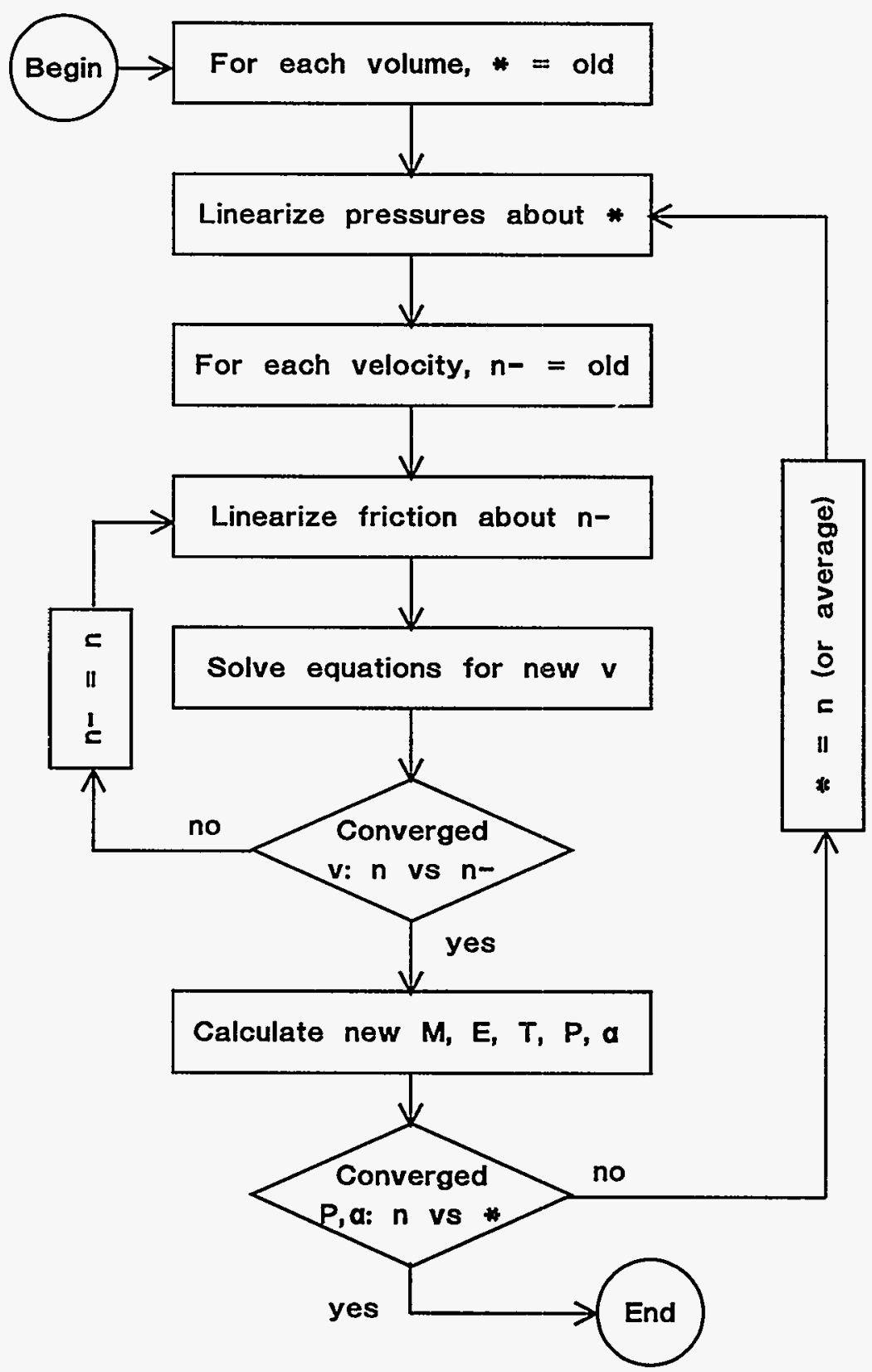

Figure 4.3.1 Solution of Hydrodynamics Equations

repeated starting from the original "old" state. As has already been intimated, and will be discussed in detail in Section 4.5, the thermal-hydraulic packages (CVH and FL) may "subcycle", i.e. several successive advancements may be used to advance the thermal-hydraulic solutions through a full MELCOR system timestep. In general, repetition of the solution with a reduced timestep will affect only a subcycle, and will be 
restricted to the hydrodynamic packages. Sources will be redefined under the assumption that external source rates are constant over a system timestep. If the resulting subcycle timestep would be excessively small with respect to the system step, however, CVH will call for a MELCOR fallback with all packages required to repeat their calculations with a reduced system timestep.

In order to avoid problems with coupling to other packages in MELCOR, large changes in conditions are not permitted to occur during a single system timestep. If any excessive change is observed after the advancement through a system timestep has been completed, the solution is abandoned, and CVH calls for a MELCOR system fallback.

The remainder of this section expands on the general outline given above, discusses special cases, and includes specific details such as convergence criteria.

In the inner (velocity) iteration, the solution of Equation 4.2.16 is repeated until the new velocities have converged. Convergence requires that no velocity has reversed with respect to the direction assumed in defining donor quantities, and that no velocity has changed in magnitude by more than $9 \%$ compared to the value that was used in linearizing the friction terms. (The latter criterion is coded using an absolute tolerance and a relative tolerance included as sensitivity coefficients in array C4401). Note that the relatively loose tolerance on magnitudes affects only friction terms; conservation of mass and energy is assured by the form of the equations. Our experience has shown that tightening the convergence criterion affects only the details of very rapid transients, which are of little significance in typical MELCOR calculations.

At each iteration, the friction terms are updated, replacing the velocity, $v^{n-}$, about which they are linearized by the latest iterate, $v^{n}$, for flows which have not converged. If one or more of the new velocities has reversed with respect to the direction assumed in defining donor quantities, these quantities are also redefined to reflect the correct flow direction. If there are no flow reversals, new velocities will also be accepted if the corresponding volumetric flows have converged (subject to the same tolerances), starting with the second iteration. The user may also require that after a number of iterations specified by sensitivity coefficient C4401(4) new velocities will be accepted-even if they have not converged to the stated tolerance-if the projected new pressures, $\mathrm{P}_{2}^{\bar{n}}$, have converged within $0.05 \%$ (comparing successive velocity iterations). Prior to Version 1.8.1 this was permitted on the eighth and following iterations. The current default is not to accept convergence on this basis.

In some cases, a phase (pool or atmosphere) is available within the junction opening height at only one end of a flow path; and its flow is therefore possible in one direction only. If the donoring assumed in construction of Equation 4.2.16 makes such a flow "impossible", the corresponding momentum equation is still carried as part of the equation set, but with its coupling to predicted new pressures eliminated by setting the contribution to new mass and energy inventories to zero in Equations 4.2.1 and 4.2.2. Therefore, a 


\section{CVH/FL Packages Reference Manual}

calculated "impossible" flow has no effect on "real" flows, but its sign indicates the direction the flow would take (if possible) in response to projected end-of-step pressures. If the sign indicates that the calculated new flow remains impossible, the flow will be set to zero. If the sign is reversed-and the flow is therefore possible-the equations must be re-solved with the assumed donor definition reversed.

If the iteration fails (either by exceeding the permitted number of iterations, or by entering an invalid region of the equation of state defined by the CVT package), the entire set of equations is reformulated with a shorter time step, and re-solved. In general, this is handled within the CVH/FL package by subcycling, rather than by calling for a fallback and a reduction of the MELCOR timestep.

After the new velocities are determined (by convergence of the iterative solution to the finite difference equations), they are used to update the masses and energies in the control volumes through Equations 4.2.1 and 4.2.2; in the process, the masses moved by flows are limited to the contents of the donor control volumes. While the mass, momentum, and energy equations could be solved simultaneously, this procedure assures that mass and energy are conserved as accurately as possible. Final end-of-step pressures and pool void fractions, $\mathrm{P}^{\mathrm{n}}$ and $\alpha^{\mathrm{n}}$, corresponding to the new masses and energies are now evaluated using the full nonlinear equation of state. If the discrepancy between $P^{n}$ and $P^{n}$ or $\alpha^{n}$ and $\alpha^{n}$ in one or more volumes is too great, the entire iterative solution of the momentum equation is repeated (for a maximum of six times), with a modified definition of the point * about which the equation of state is linearized (described later). The general criterion for convergence of pressure is agreement of $\mathrm{P}^{n}$ and $\mathrm{P}^{\mathrm{n}}$ within $0.5 \%$ (coded as a sensitivity coefficient C4408(2)); this is tightened to $0.1 \%$ if there is no pool in the control volume, and relaxed to $1.0 \%$ if there is no atmosphere. The criterion for convergence of pool void fraction is agreement of $\alpha^{n}$ and $\alpha^{\bar{n}}$ within $1.0 \%$ (coded as a sensitivity coefficient $\mathrm{C} 4412(1)$ ). If the outer iteration fails to converge within this tolerance, the subcycle timestep is cut.

The acceptable discrepancy between projected and actual new pressures should not be viewed simply as an accuracy tolerance for pressures; it comes into play only when conditions change sufficiently during a timestep that the nonlinearity of the equation of state becomes significant. For example, a large discrepancy between the projected and actual new pressures in a control volume can arise if the state in the volume has crossed the saturation line, going from saturated conditions ( $\partial \mathrm{P} / \partial \mathrm{M}$ relatively small) to subcooled conditions ( $\partial \mathrm{P} / \partial \mathrm{M}$ very large), or vice versa. It can also occur if there has been a change in the hydrodynamic volume (reflecting relocation of virtual volume), as a result of the omission of the term $\partial \mathrm{P} / \partial \mathrm{V} \delta \mathrm{V}$ in writing Equation 4.2.8. In either case, a projection over the entire timestep is invalid. Therefore, in the outer (pressure) iteration, the linearization point is taken as the best available estimate of the "new" state. On the first iteration, it is the "old" state "o"; on subsequent iterations, it is the latest "new" solution. This is illustrated (in a nonrigorous way) by Figure 4.3.2, which shows the connection to a conventional Newton iteration for a single-variable problem. In post-1.7 versions of 
CVH/FL Packages Reference Manual

MELCOR, after the third iteration the linearization point is defined as the average of the last two "new" solutions.

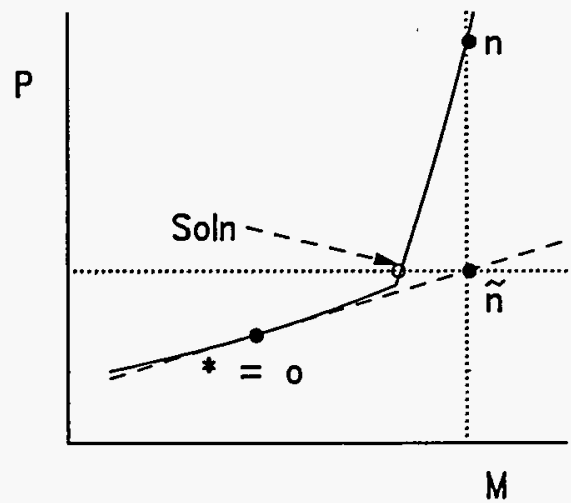

First Iteration

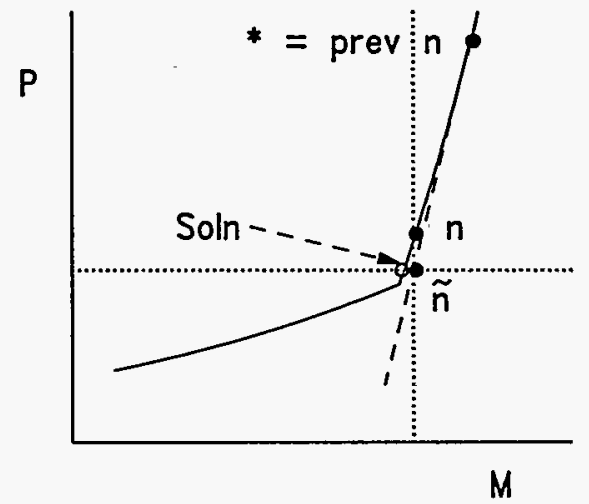

Second Iteration

Figure 4.3.2 Linearization of Pressure vs Mass

There is a slight subtlety in the redefinition of the linearization point because the PdV work done by the pool on the atmosphere (or vice versa) in a nonequilibrium volume is calculated in CVT rather than in CVH (note that it does not appear in Equation 4.2.2). Energy equal to the work done,

$$
W=P_{l}^{0}\left(V_{P}^{o}-V_{P}^{n}\right)
$$

based on the old (start-of-step) volume, will be transferred from the atmosphere to the pool in CVT. Therefore, if the new results returned by CVT are $M_{i, m}^{n}, E_{i, \phi}^{n}$, and $P_{i}^{n}$, and that solution is rejected, the work must be subtracted from these results in order to define conditions about which the equations may be linearized. That is, if a solution is rejected, the new linearization point is taken as

$$
\begin{aligned}
M_{l, m}^{*} & =M_{l, m}^{n} \\
E_{l, P}^{*} & =E_{l, P}^{n}-P_{I}^{o}\left(V_{P}^{o}-V_{P}^{n}\right) . \\
E_{l, A}^{*} & =E_{l, A}^{n}+P_{I}^{o}\left(V_{P}^{o}-V_{P}^{n}\right)
\end{aligned}
$$

where $n$ denotes the "new" solution returned by CVT. The essential point is that if $M^{n}$, $E^{n}$, and $V^{\circ}$ are sent as nonequilibrium arguments to CVT, an additional PdV work term will be computed, and the pressure and volumes returned will not be $\mathrm{P}^{\mathrm{n}}$ and $\mathrm{V}^{\mathrm{n}}$. If, on the other hand, the arguments sent to CVT are $\mathrm{M}^{*}, \mathrm{E}^{*}$, and $\mathrm{V}^{\circ}$, the work computed there will balance that subtracted off in Equations 4.3.2, and the desired values, $\mathrm{P}^{n}$ and $\mathrm{V}^{\mathrm{n}}$, will be returned. 


\section{CVH/FL Packages Reference Manual}

Note that the choice of the point * should have little effect on the results obtained (if the solution is successful) because, while the predicted new (end-of-step) pressures are used in the flow equation, they are required by the convergence criteria described earlier to agree well with the actual new pressures. Any small variations in the predictions can have only a modest effect on the results. Therefore, the primary effect of the choice of the point * is on the success of the solution procedure; a poor choice can slow or even prevent convergence.

After the thermal-hydraulic state of the system has been advanced through a MELCOR system timestep, which may involve convergence of the entire calculation described above for several $\mathrm{CVH}$ subcycles, the new pressures and temperatures in all control volumes are examined to determine if the changes from old values are acceptably small. The criteria are less than $10 \%$ change in pressure and less than $20 \%$ plus $1 \mathrm{~K}$ change in the temperature of each phase containing more than $1 \%$ of the mass in the control volume. These are coded as sensitivity coefficients included in the array C4400. If any change exceeds that permitted, a fallback is requested and the calculation repeated with a reduced MELCOR system timestep.

\subsection{Definition of Donor Quantities}

The preceding discussion concerns only the finite-difference equations and the solution technique. The definition of the donor densities and enthalpies, $\rho^{d}$ and $h^{d}$, in the matrix coefficients on the left-hand side of the set of flow equations is a completely independent question. (Of course, the choice can affect the accuracy and/or the numerical stability of the entire scheme.)

In the conventional approach, donor quantities are start-of-step ("old") values in the volume from which material is moved; in particular, they are not affected by sources. This is consistent with the fact that they are not affected by mass or energy moved through flow paths-there are no implicit terms in the donor quantities.

In MELCOR, the sources include changes of material identity resulting from chemical reactions in other packages (COR, BUR, and FDI) as well as from phase changes involving boiling/flashing or fog precipitation within the CVH package itself. The existence of negative mass sources can easily lead to the computation of a negative mass contents in a control volume for one or more materials. An example would be a volume where water vapor was consumed by a clad-oxidation reaction and was also allowed to flow out of the volume through flow paths.

One approach to the problem, as employed by CONTAIN [3] and HECTR [2], is to retain the conventional donor definition in terms of pre-source conditions, and to use timestep controls to prevent catastrophes. Non-negativity checks on individual material masses 


\section{CVH/FL Packages Reference Manual}

are a necessary part of this approach, and negative-mass fix-ups must sometimes be employed.

This does not seem practical for use in MELCOR, where (for example) clad oxidation may be extremely rapid. There may be conditions where, in the "real world", no steam leaves the volume where the reaction is taking place. However, if any is present at the start of the timestep, some would be calculated to leave it under the conventional definition of donor properties. Reduction of the timestep to follow the kinetics of the reaction is not a viable solution; all available steam is really consumed, leaving none available for flow out of the volume. Therefore, the problem is handled in MELCOR by modification of the donor quantities (mass and enthalpy) to include the effects of mass sources. The treatment of energy sources depends on the mass sources, as described below.

Mass additions are treated as taking place at constant pressure and temperature. This is a reasonable approximation if conditions in the control volume do not change much during a timestep; if conditions do change significantly, the timestep (or subcycle step) is too long by definition, and will be cut as a result of other checks. For each noncondensible gas, for liquid water, and for water vapor, constancy of pressure and temperature implies constancy of the specific volume and of the specific enthalpy. Thus, if liquid water and water vapor are considered to be separate materials, donor partial densities and specific enthalpies are unaffected by sources, and only the amount of each material available for flow is changed. In general, a modification of the volume of this material is involved.

Heat sources, as well as the difference between the enthalpy of added materials and the enthalpy that these materials would have at start-of-step conditions, are not included in this definition of donor quantities. For heat sources, this follows conventional practice. For mass sources, we argue that the enthalpy difference is exactly parallel to a simple heat source because "new" material will be mixed and equilibrated with old, and that it should therefore be treated in the same way as a heat source. The effect of this treatment of sources in MELCOR is to restrict the immediate heating effects of all sources to the control volumes in which they occur. While far from a rigorous proof of the correctness of our interpretation, it should be noted that all other approaches tried in the development of MELCOR led to violations of the second law of thermodynamics.

In the current coding, the total post-source mass of each material and its total enthalpy at the pre-source temperature and pressure are calculated, together with the corresponding volume of pool, of fog, and of the gaseous atmosphere. These are used to define donor quantities.

As implied above, addition of mass at constant pressure and temperature requires changes in the volume of the pool, of the fog, and/or of the atmosphere, which must be calculated. There is a complication in that temperature and pressure are not sufficient to define the state of saturated (two-phase) water. Thus, internal energy must be 


\section{CVH/FL Packages Reference Manual}

considered to determine the quality of water in the pool and the partition of atmospheric water between vapor and fog.

For a mixture of ideal gases, the total volume is given by

$$
V=\sum_{m} \frac{M_{m} R_{m} T}{P}
$$

where

$M_{m}$ is the mass of species $m$

$R_{m}$ is the corresponding gas constant, equal to the universal gas constant divided by the molecular weight,

$T$ is temperature, and

$P$ is pressure.

This equation is applied to the gaseous atmosphere to yield

$$
\delta V_{A}=\sum_{m} \frac{\delta M_{m} R_{m} T_{A}^{\circ}}{P_{A}^{\circ}}
$$

where the superscript "o" again denotes old (start-of step). The gas constant for water vapor is evaluated as

$$
R_{H 2 O}=\frac{P_{A, H 2 O}}{\rho_{A, H 2 O}^{o} T_{A}^{O}}
$$

As noted above, temperature and pressure are not sufficient to define the post-source state of two-phase water. Older versions of MELCOR considered the effects of energy sources, and the possibility of repartition of water between vapor and fog in the atmosphere and between liquid and vapor bubbles in the pool. This procedure was found to have several adverse effects that outweighed any increase in "accuracy."

Therefore, the calculation was changed in version 1.8.2 of MELCOR. It is now assumed that sources of atmospheric vapor and fog remain in those fields for the purposes of defining donor densities. Enthalpies and densities corresponding to the start of the advancement step are used if available; otherwise, appropriate saturation properties are assumed. Similarly, pool sources are now treated as having the same mass quality as the pool mass present at the start of the timestep. If there was none, saturated liquid properties at the old (total) pressure are used. 
CVH/FL Packages Reference Manual

\subsection{Timestep Control and Subcycling}

As mentioned in previous Sections of this Reference Manual, the thermal-hydraulic packages (CVH and $\mathrm{FL}$ ) are permitted to subcycle. That is, they may employ several successive sub-steps to advance the state of the system through a MELCOR system timestep from $t^{\circ}$ to $t^{n}=t^{\circ}+\Delta t$. Only the final state (at $\left.t^{n}\right)$ becomes part of the MELCOR database.

The code keeps track of the maximum subcycle timestep which it is willing to attempt, $\Delta t_{\text {sub,max }}$. Each attempted advancement starts from the last point successfully reached, $t^{\text {last }}$, with a step given by

$$
\Delta t_{\text {sub }}=\min \left(\Delta t_{\text {sub,max }}, t^{n}-t^{\text {last }}\right)
$$

Following a failed attempt, $\Delta \mathrm{t}_{\text {sub, } \max }$ is reduced by a factor of 2 . (The possible reasons for failure of a subcycle were discussed in Section 4.3.) Following a successful advancement, it is reevaluated as

$$
\Delta t_{\text {sub,max }}^{n}=\max \left(\Delta t, 1.6 F \Delta t_{\text {sub,max }}^{0}\right)
$$

where $F$ is a factor which allows a faster increase if the convergence of pressures in the outer iteration in the solution of the momentum equation was much closer than required by the tolerance. Specifically,

$$
F=\max \left(1,2-10 \frac{\left.|\varepsilon P| P\right|_{\max } ^{o}}{(\varepsilon P \mid P)_{\text {tol }}}\right)
$$

where

$\varepsilon P / P$ is the relative error in the predicted pressure (compared to the new pressure), the subscripts "max" and "tol" denote a maximum over volumes and a tolerance, respectively, and

the superscript "o" again denotes the previous subcycle.

The tolerance is coded as a sensitivity coefficient, part of the array C4408, with a default value of 0.005 .

If the failure of an attempted advancement results in a subcycle length, $\Delta t_{\text {sub }}$, which is less than $0.01 \Delta t$, the timestep is aborted, and the executive level of MELCOR is directed to perform a fallback. That is, the advancement of all packages is repeated from $t^{\circ}$ with a reduced value of $\Delta t$. As currently coded, this reduction is by a factor of 2 .

When, as a result of one or more steps, the thermal-hydraulic packages have advanced the state of the system from $t^{\circ}$ to $t^{n}$, the changes in pressures and temperatures in all control volumes are examined. As mentioned in Section 4.3, a change of more than $10 \%$ in pressure, or of more than $20 \%$ plus $1 \mathrm{~K}$ in the temperature of each phase containing 


\section{CVH/FL Packages Reference Manual}

more than $1 \%$ of the mass in a control volume, will result in a fallback, where the tolerances are coded as sensitivity coefficients included in the array C4400. (As currently coded, the fallback is not performed if the MELCOR system timestep is already within a factor of 2 of the minimum. The change is accepted, and the calculation is allowed to continue.)

If these tolerances are met, a maximum acceptable timestep is estimated for the next MELCOR step, such that certain stability and accuracy criteria will (most probably) be met. This estimate considers several factors.

First, changes in pressures and temperatures must be acceptably small. An acceptable step is estimated, based on the rates of change of temperatures and pressures for the just-completed step. For pressures, the change in the pressure of control volume $i$ is desired to be no more than $0.0+0.05 \mathrm{P}_{\mathrm{i}}^{\circ}$. This will (probably) be the case if the timestep is not greater than

$$
\Delta t_{P}^{n}=\min _{i}\left(\frac{0.0+0.05 P_{i}^{o}}{\left|P_{i}^{n}-P_{i}^{o}\right|}\right) \Delta t
$$

where $i$ includes all control volumes in the problem. Similar limiting timesteps are estimated for changes in temperatures, as

$$
\Delta t_{T_{\phi}}^{n}=\min _{I}\left(\frac{1.0+0.1 T_{\phi, I}^{o}}{\left|T_{\phi, I}^{n}-T_{\phi, I}^{o}\right|}\right) \Delta t
$$

where $\phi$ is $\mathrm{P}$ or $\mathrm{A}$. If a phase represents less than one percent of the mass in a control volume, it is excluded from these calculations. All of the constants in Equations 4.5 .4 and 4.5.5 (including the zero) are coded as sensitivity coefficients, included in array C4400, and can be modified by user input if desired. The default values provide a safety factor of two between the desired maximum changes and the changes which will lead to a fallback. Changes in timestep control should be made in parallel with changes in the corresponding fallback criteria.

The (material) Courant condition provides another restriction through the stability requirement that a timestep may not be long enough to permit replacement of all of the material in a volume. (While not a rigorous statement of the condition, this is a workable approximation to it.) This leads to the limitation that the timestep be no greater than

$$
\Delta t_{\text {Cou }}^{n}=0.5 \min _{1}\left(\frac{V_{i}^{+}}{\Delta V_{i, \text { out }}}\right) \Delta t
$$

where $\mathrm{V}_{\mathrm{i}}^{+}$is the total volume of materials initially in the volume, including mass sources (at the old temperature and pressure, see Section 4.4), and $\Delta V_{i, \text { out }}$ is the total volume, 
CVH/FL Packages Reference Manual

pool and atmosphere, moved out of the volume during the timestep. Note that $\Delta \mathrm{V}_{\mathrm{i}, \mathrm{out}}$ contains contributions both from positive flows in flow paths which connect from volume $i$ and from negative flows in flow paths which connect to it. The factor of 0.5 is coded as a sensitivity coefficient in the array C4400.

The accuracy of the solution of the momentum equation (as estimated by the linear equation solver) is also considered. It is used to define

$$
\Delta t_{\text {Mom }}^{n}= \begin{cases}0.9 \Delta t & N<2 \\ (N-0.9) \Delta t & N \geq 2\end{cases}
$$

where $\mathrm{N}$ is the number of significant figures in the velocities, as estimated by the solver.

Finally, the value given by the most restrictive of the desired constraints,

$$
\Delta t_{C V H}^{n}=\min \left(\Delta t_{P}^{n}, \Delta t_{T_{P}}^{n}, \Delta t_{T_{A}}^{n}, \Delta t_{C O u}^{n}, \Delta t_{M O M}^{n}\right)
$$

is chosen as an upper bound on the acceptable step and communicated to the executive routines for consideration in setting the next system timestep. 
CVH/FL Packages Reference Manual 
CVH/FL Packages Reference Manual

\section{CONSTITUTIVE RELATIONS}

\subsection{Pool/Atmosphere Mass and Energy Transfer}

When equilibrium thermodynamics is used in a control volume, mass and energy transfer between the pool and the atmosphere is implicitly determined by the assumption that the pool and the atmosphere are in thermal and evaporative equilibrium. In this case, CVT performs the transfers which are, effectively, instantaneous.

If a volume in which nonequilibrium thermodynamics is specified contains both a pool and an atmosphere, CVT will not transfer mass between them, and will only transfer energy in the amount of the PdV work done by one on the other. $\mathrm{CVH}$ must therefore calculate the energy exchange at the pool surface, the rate of evaporation or condensation there, and the rate of phase separation in the pool as bubbles rise and join the atmosphere or as fog settles into the pool. The mass/energy transfer at the pool surface, which is driven by convection and/or conduction, and any phase separation resulting from bubble rise, are treated as two separate processes. The deposition of fog is ordinarily treated by the aerosol dynamics portion of the RN package, but a simple, non-mechanistic limit on fog density, described in Section 5.1.4, is imposed by the CVH package when large fog densities are encountered.

Bubble rise is accounted for only in nonequilibrium volumes. Given the assumption that there are no noncondensible gases in the pool, the equilibrium assumptions prohibit the presence of bubbles in the pool whenever such gases are present. (Total pressure exceeds saturation pressure by the partial pressure of the noncondensible gases. The liquid water is therefore subcooled, and cannot be in equilibrium with a bubble containing only water vapor.) All water vapor in an equilibrium volume is therefore assumed to reside in the atmosphere to avoid a discontinuity in behavior, and the vapor content of the pool is always calculated as zero by CVT for equilibrium volumes.

\subsubsection{Mass Transfer at the Pool Surface}

Calculation of phenomena at the pool surface requires simultaneous solution of the equations of heat and mass transfer. It may be reduced to finding the temperature of the pool surface that satisfies the requirements that (1) the mass flux (evaporation or condensation) is that given by the mass diffusion equation for the existing gradient in the partial pressure of water vapor between the surface and the bulk atmosphere, (2) the net heat flux delivered to the interface by convection, conduction, and radiation is equal to the latent heat required by the evaporation or condensation heat flux, and (3) the partial pressure of water vapor at the pool surface corresponds to saturation at the surface temperature. 


\section{CVH/FL Packages Reference Manual}

In the presence of noncondensible gases, the mass flux, defined as positive for evaporation, is given by

$$
\dot{m}^{\prime \prime}=C \ln \left(\frac{P_{A}-P_{w, A}}{P_{A}-P_{w, I}}\right)
$$

where

$P_{A}$ is the total pressure,

$P_{w, A}$ is the partial pressure of water vapor in the bulk atmosphere,

$P_{w, 1}$ is the partial pressure of water vapor at the interface, and

$C$ is a coefficient.

This equation is also valid in the absence of noncondensibles, requiring only that $P_{w, 1}=P_{w, A}$; it will be used in a modified form (Equation 5.1.6) in which there is not even the appearance of a singularity.

Using the analogy between mass transfer and heat transfer [9], $\mathrm{C}$ is given by

$$
\frac{C L}{\rho_{v} D}=\frac{h_{A} L}{k}\left(\frac{S c}{P r}\right)^{\frac{3}{3}}
$$

where $\operatorname{Pr}$ and $\mathrm{Sc}$ are the Prandtl and Schmidt numbers given by

$$
\operatorname{Pr}=\frac{\mu_{A} C_{P A}}{k_{A}}
$$

and

$$
S c=\frac{\mu_{A}}{\rho_{A} D_{w A}}
$$

respectively. In these equations,

$L$ is a characteristic length, which cancels in the final result,

$h$ is the coefficient of convective heat transfer,

$\rho_{v}$ is the density of saturated water vapor at total pressure,

$\mathrm{C}_{\mathrm{p}}$ is the specific heat at constant pressure,

$\mu$ is dynamic viscosity,

$k$ is thermal conductivity,

$\rho$ is density,

$D_{w}$ is the mass diffusivity of water vapor, and

subscript $A$ refers to the atmosphere.

Coding in version 1.8.2 uses $\rho_{A}$ rather than $\rho_{v}$ in Equation 5.1.2; this will be corrected in subsequent versions. The error is approximately the ratio of the average molecular weight of the atmosphere to that of water vapor. 
CVH/FL Packages Reference Manual

Properties are calculated for the current bulk atmosphere composition. Density and specific heat are calculated in the CVT package, as described in the Control Volume Thermodynamics (CVT) Package Reference Manual, while the viscosity and thermal conductivity are calculated by the MP package, as described in the Material Properties Package Reference Manual. In version 1.8.2, the mass diffusivity is calculated as an effective binary diffusivity, as described in Reference 10, using air properties from the MP package for the $\mathrm{N}_{2}$ and $\mathrm{O}_{2}$ content and hydrogen properties from MP for the $\mathrm{H}_{2}$ content. in later versions, the general model in the MP package (also based on Reference 10, but using the complete composition of the atmosphere) will be used.

Conditions at the interface are assumed to be saturated, thus relating the partial pressure at the interface, $P_{\mathrm{w}, 1}$, to the temperature there, $T_{1}$, through

$$
P_{w, l}=P_{\text {sat }}\left(T_{l}\right)
$$

If equation 5.1.1 is solved for $P_{w, 1}$, the inverse of Equation 5.1.5 may be expressed as

$$
T_{I}=T_{\text {sat }}\left(P_{A}-\left(P_{A}-P_{w, A}\right) \exp \left(\frac{-\dot{m}}{C}\right)\right)
$$

Simultaneous with mass transfer, there are temperature-driven heat flows from the pool to the surface (interface), $Q_{\mathrm{PS}}$, and from the atmosphere to the surface, $Q_{\mathrm{AS}}$. These do not include mass-transfer effects, and may be approximated by using ordinary heat-transfer correlations. Processes (such as radiation) treated by other packages may also deposit energy directly "in" the surface, at a rate $Q_{\mathrm{RS}}$. The net heat flow to the surface is then related by conservation of energy to the evaporation rate by

$$
\dot{m}=\frac{Q_{P S}+Q_{A S}+Q_{R S}}{h_{f g}}
$$

where

$$
h_{f g} \equiv h_{g}-h_{f}
$$

is the latent heat of evaporation. In current coding, the enthalpies $h_{f}$ and $h_{g}$ are evaluated at bulk conditions for the pool and atmosphere, respectively. (Other interpretations are possible but, in all cases investigated, other choices had no significant effect on calculated results.)

The heat flows, $Q_{P S}$ and $Q_{A S}$, from the pool and atmosphere to the surface, may both be considered to be proportional to the corresponding temperature differences

$$
\begin{aligned}
& Q_{P S}=h_{P}^{*}\left(T_{P}-T_{1}\right) A_{S} \\
& Q_{A S}=h_{A}^{*}\left(T_{A}-T_{1}\right) A_{S}
\end{aligned}
$$




\section{CVH/FL Packages Reference Manual}

where $A_{S}$ is the surface area of the pool and the $h^{*}$ are effective heat transfer coefficients, including radiation within the CVH package, as discussed in section 5.1.2. This allows Equation 5.1.7 to be solved for $T_{1}$ in the form

$$
T_{l}=\frac{h_{P}^{*} T_{P}+h_{A}^{*} T_{A}+\left(Q_{R S}-\dot{m} h_{f g}\right) / A_{S}}{h_{P}^{*}+h_{A}^{*}}
$$

Equations 5.1.6 and 5.1.11 provide two simultaneous equations for $T_{1}$ and $\dot{m}$, which are solved iteratively with a bound-and-bisect method. The fact that $h_{p}^{*}, h_{A}^{*}$ and the mass transfer coefficient $C$ are themselves functions of the interface temperature, $T_{1}$, is accounted for during the iteration.

In MELCOR, the rate given by this solution is calculated using start-of-step conditions and is then applied to the entire step, $\Delta t$.

The resulting transfers of mass and energy are

$$
\begin{aligned}
& \Delta M_{P}=-\dot{m} \Delta t \\
& \Delta E_{P}=-\left(\dot{m} h_{f}+Q_{P S}\right) \Delta t \\
& \Delta M_{w, A}=\dot{m} \Delta t \\
& \Delta E_{A}=\left(\dot{m} h_{g}-Q_{A S}\right) \Delta t
\end{aligned}
$$

If condensation is occurring at a rate that exceeds $90 \%$ of the total water vapor in the atmosphere during the timestep, the mass transfer is limited to this value to avoid numerical problems. Equations 5.1.12 to 5.1.15 are then recalculated so as to conserve mass and energy. This limiting value is coded as a sensitivity coefficient in array C4407.

The energy transfers are written as internal energies, " $\Delta E$ "s, because they are added to the internal energy of the material, but are actually enthalpies, " $\Delta \mathrm{H}$ "s. The difference, $\mathrm{P} \Delta \mathrm{V}$, is later cancelled by the volume work accounted for in calculations in the CVT package. The necessity for this may be seen by considering a case where essentially all of the pool is evaporated; its energy inventory must be decremented by its total enthalpy to ensure that the final energy content will be near zero after the work term is accounted for in CVT.

This formulation clearly conserves both mass ancl energy, with the net heat added to the control volume being

$$
\Delta E_{P}+\Delta E_{A}=Q_{R S} \Delta t
$$

as is easily shown from the preceding equations. Note from equations 5.1.13 and 5.1.15 that the use of bulk values for $h_{f}$ and $h_{g}$ eliminates the possibility of nonphysical cooling 
of an evaporating subcooled pool or heating of a condensing superheated atmosphere. Other nonphysical results from the explicit numerics are avoided by limiting the sensible heat flow from the pool or atmosphere to the heat content above the interface temperature, as

$$
Q_{\phi S} \Delta t=\min \left[Q_{\phi S}^{0} \Delta t, M_{\phi} c_{P \phi}\left(T_{\phi}-T_{l}\right)\right] \quad \text { if } T_{\phi}>T_{1}
$$

where $M_{\phi}$ is the phase mass, $\phi$ is $P$ or $A$, and $Q_{\phi S}^{0}$ is the value calculated as described in the following section.

\subsubsection{Heat Transfer to the Interface}

The heat flows from pool and atmosphere to the interface (surface) are calculated as

$$
Q_{\phi S}=\left[h_{\phi}\left(T_{\phi}-T_{l}\right)+\sigma_{B}\left(T_{\phi}^{4}-T_{I}^{4}\right)\right] A_{S}
$$

where $\sigma_{B}$ is the Stefan-Boltzmann constant and all other variables were defined above. Note that view factors and emissivities of unity are assumed in the radiation contributions. The effective heat transfer coefficients, including radiation, are then

$$
h_{\phi}^{*}=h_{\phi}+\sigma_{B}\left(T_{\phi}^{2}+T_{l}^{2}\right)\left(T_{\phi}+T_{l}\right)
$$

The normal heat transfer coefficient, corresponding to convection or conduction in the absence of mass transfer, is defined by

$$
h_{\phi}=\max \left(h_{\text {forced, } \phi}, h_{\text {froe, } \phi}, k_{\phi} / L_{\phi}\right)
$$

The forced convection correlation, taken from TRAC [6], is appropriate for horizontal stratified flow:

$$
h_{\text {forced, } \phi}=0.02 \rho_{\phi} c_{P \phi} v_{V, \phi}
$$

The control-volume average velocity, $V_{V, \phi}$, is discussed in Section 6.5. The natural convection heat transfer used is taken as the maximum of laminar and turbulent correlations appropriate for horizontal surfaces [11] as

$$
\begin{aligned}
& h_{\text {freo, } P}=\max \left(0.25(G r P r)_{P}^{1 / 4}, 0.25(G r P r)_{P}^{1 / 4}\right) \frac{k_{P}}{X_{P}} \\
& h_{\text {freo, } A}=\max \left(0.54(G r P r)_{A}^{1 / 4}, 0.14(G r P r)_{A}^{1 / 3}\right) \frac{k_{A}}{X_{A}}
\end{aligned}
$$

where the characteristic dimension is

$$
x=\min \left(D_{s}, L\right)
$$


CVH/FL Packages Reference Manual

Here $\operatorname{Pr}$ is the Prandtl number, defined in Equation 5.1.3, and Gr is the Grashof number,

$$
G r=g \beta|\Delta T| X^{3}(\rho / \mu)^{2}
$$

In these equations, in addition to variables previously defined,

$B$ is the thermal expansion coefficient,

$L$ is thickness (depth),

$\mathrm{g}$ is the acceleration of gravity, and

$D_{S}$ is the diameter of the surface.

Note that the absolute value of the temperature difference is used in the Grashof number. Therefore, the same correlation is used for both signs of the temperature gradient, although it is only appropriate for one of them. In fact, the correlations were derived for rather simpler geometries than exist in reactor primary and containment systems. In particular, the effects of other heated or cooled surfaces may well be more important in establishing convection than is the pool surface itself. A recent review of the modeling in MELCOR [12] concluded that "Wall effects are probably sufficiently important and dependent upon geometric details that no general correlation could be constructed." This review also compared MELCOR to a number of other codes including TRAC [6], RELAP5 [7], HECTR [2], CONTAIN [3] and MAAP [4], and found that "there is no clearly accepted model. Treatment in the other codes suffers from limitations no less significant than those in MELCOR."

In Equations 5.1.22 and 5.1.23, the first expression refers to laminar convection and the second to turbulent. Note that the value for $(\mathrm{Gr} \mathrm{Pr})$ at the laminar-turbulent transition is implicitly defined such that the heat transfer coefficient is continuous there. All of the numerical constants in Equations 5.1.21, 5.1.22, and 5.1.23 are coded as sensitivity coefficients in the array $\mathrm{C} 4407$, and may therefore be modified through user input. In particular, a laminar-turbulent transition may be introduced into the correlation for free convection in the pool even though there is none in the default version of Equation 5.1.22. The final term in Equation 5.1.20, $\mathrm{k} / \mathrm{L}$, is the conduction limit.

\subsubsection{Bubble Rise and Phase Separation}

Boiling, as a result of heat deposition in the pool, or flashing, in response to a reduction in the pressure of a control volume, may cause vapor bubbles to appear in the pool. As these bubbles rise to the surface, they transport mass and energy from the pool to the atmosphere. In general, the velocity is insufficient to remove all the bubbles, resulting in a two-phase pool.

The bubble rise model in MELCOR is very simple. It assumes steady state with an upward volume flow of bubbles that varies linearly from zero at the bottom of the control volume to a value of $J_{\max }$ at the top, and a constant rise velocity, $v_{0}$, of $0.3 \mathrm{~m} / \mathrm{s}$ for the bubbles. This value is approximately correct for typical gas bubbles rising in water under 
near-atmospheric pressures, where the effect is most important, and is not seriously in error under other conditions. (The rise velocity is coded as a sensitivity coefficient in array C4407.) For a volume of constant cross-sectional area, the assumptions correspond to a uniform generation rate of vapor throughout the volume with no bubbles entering the bottom. Other assumptions would lead to different results, but within roughly a factor of 2 of those presented here.

Under the stated assumptions, the average void fraction and the volume of bubbles which leave the volume during a time $\Delta t$ are given by

$$
\begin{aligned}
& \bar{\alpha}=\frac{J_{\max } Z_{P}}{2 V_{0} V_{P}} \\
& \Delta V_{B} \equiv V_{B}^{\text {tot }}-V_{B}^{\text {final }}=J_{\text {max }} \Delta t
\end{aligned}
$$

where

$V_{p}$ is the total (swollen) volume of the pool,

$Z_{p}$ is its depth,

$V_{B}^{\text {lot }}$ is the sum of the initial volume of bubbles and the volume created in the pool as a result of sources during $\Delta t$,

and $V_{B}^{\text {tinal }}$ is the volume of bubbles remaining at the end of the step. Therefore, since

$$
V_{B}^{\text {Inal }}=\bar{\alpha} V_{P}
$$

the average void fraction may be eliminated to show that only a fraction

$$
f=\frac{V_{B}^{\text {final }}}{V_{B}^{\text {tot }}}=\frac{1}{1+2 v_{0} \Delta t / Z_{P}}
$$

of the bubbles that were in the pool during the timestep will remain after bubble-rise is accounted for.

The total mass of vapor in the pool is calculated as

$$
M_{v, P}^{\text {tot }}=\frac{h_{P}-h_{l}}{h_{v}-h_{l}} M_{P}
$$

where $M_{p}$ and $h_{p}$ are the total pool mass and enthalpy, including the vapor component. The specific enthalpies $h_{v}$ and $h_{1}$ correspond to saturated vapor and liquid, respectively, at the pressure of the control volume $\left(M_{v, p}^{\text {tot }}\right.$ is then limited to $\left.M_{P}\right)$. In accordance with Equation 5.1.30, all but a fraction $f$ of this is moved to the atmosphere; if this is insufficient to reduce the average void fraction in the pool to 0.40 or less, additional mass is moved to reach that limit. (This limit is coded as a sensitivity coefficient in array C4407. The default value is the approximate upper limit of the bubbly flow regime [13].) 


\section{CVH/FL Packages Reference Manual}

The mass moved takes with it the enthalpy of saturated vapor, $h_{\mathrm{v}}$. The limit is imposed after sources are accounted for, and again after the entire flow solution for a CVH subcycle has been successfully completed.

\subsubsection{Fog Deposition}

Fog in MELCOR consists of water droplets suspended in the atmosphere. If the RadioNuclide (RN) package is active, this fog also forms the water component of the aerosol field treated by the MAEROS [14] model, and is subject to various deposition mechanisms. The CVH package has no mechanistic models for fog removal and ordinarily relies on the MAEROS model to calculate these mechanisms. For cases where the RN package is not active, an upper limit (coded as a sensitivity coefficient, C4406(1)) is imposed on the average density of fog in a control volume atmosphere, and excess fog is removed as "rain." (This procedure will also be followed if the RN package is active but its calculated aerosol removal rate is insufficient to reduce the fog density below the limiting value.) The default value of the limit is $0.1 \mathrm{~kg} / \mathrm{m}^{3}$, is based on the practical upper limit observed in a number of MAEROS calculations. If the fog density in any volume exceeds that limit, the excess is summarily transferred to the pool in that volume. The possibility of such rain is considered after mass sources are added, and again after the entire flow solution for a CVH subcycle has been successfully completed.

\subsection{Flow Path Void Fractions}

The void fraction assigned to a flow path determines the extent to which it is shared by pool and atmosphere. It will depend in general on the conditions at the ends of the flow path (its junctions with the from and to control volumes), and on the direction of flow. Input options are provided to allow the user to override the geometrical calculation performed for normal flow paths and enforce preferential flow of pool or atmosphere. These options are discussed below.

\subsubsection{Normal Flow Paths}

A flow path connects two control volumes; a void fraction can therefore be defined at each junction, based on the fraction of the junction area that lies above the pool surface in the corresponding volume. The void fraction for the from connection is calculated as

$$
\alpha_{f m}=\frac{z_{T J, f m}-z_{P, f m}}{z_{T J, f m}-z_{B J, f m}}
$$

where $T J, B J$, and $P$ refer to the top of the junction, the bottom of the junction, and the pool, respectively, and "fm" denotes the from volume or connection. In effect, the 
opening is treated as if it were rectangular. The void fraction for the to connection is defined similarly.

From these two junction void fractions, a single flow path void fraction must be defined. Unless the flow, based on velocities from the previous iteration in the flow solution, is strictly countercurrent (meaning that pool and atmosphere velocities are non-zero and have opposite signs), the void fraction in the flow path is taken as that at the donor junction. That is, $\alpha_{j}$ is taken as $\alpha_{i m}$ if the flow is positive, and as $\alpha_{t o}$ if it is negative. (If there is no flow, so that both velocities are zero, $\alpha_{\mathrm{j}}$ is taken as $\alpha_{\mathrm{tm}}$.)

If the previous-iteration flows are countercurrent, the flow-path void fraction is taken as a weighted average of the junction values,

$$
\alpha_{j}=\frac{\rho_{A}^{-1 / 2}\left|v_{A}\right| \alpha_{A d}+\rho_{P}^{-1 / 2}\left|V_{P}\right| \alpha_{P d}}{\rho_{A}^{-1 / 2}\left|V_{A}\right|+\rho_{P}^{-1 / 2}\left|V_{P}\right|}
$$

(countercurrent)

where $\mathrm{Ad}$ and $\mathrm{Pd}$ refer to the donor junction for atmosphere flow and that for pool flow, respectively. While there is no rigorous basis for this procedure, it is motivated by an analysis of flooding, and also assures continuity in the definition as either velocity passes through zero.

There is a further check for over-extraction of pool from the donor volume. The void fraction is modified if necessary to ensure that the volume of pool which would be moved with the previous iterate velocity, $\left(1-\alpha_{j}\right)\left|v_{p}\right| F_{j} A_{j} \Delta t$, does not exceed the total volume of pool above the elevation of the bottom of the flow path opening in the pool-donor volume. There is a similar check for over-extraction of atmosphere based on the previous-iteration atmosphere velocity and the volume of atmosphere below the top of the flow path opening. These modifications were introduced to eliminate a number of problems with nonconvergence observed in test calculations.

\subsubsection{Pool-First and Atmosphere-First Flow Paths}

These options allow preferential movement of pool or atmosphere materials through a flow path. This is accomplished by overriding the normal definition of the void fraction for these flow paths. The void fraction is initially set to 0.0 for a pool-first path and to 1.0 for an atmosphere-first path if the preferred phase is present within the junction opening. This $\alpha$ is then subjected to the pool- or atmosphere-extraction limitation described in the preceding subsection. (In versions of MELCOR prior to 1.8.2, the treatment of atmosphere-first flow paths was different.) If the preferred phase is not available, the other phase is permitted to flow in the normal manner. 


\section{CVH/FL Packages Reference Manual}

\subsection{Hydrostatic (Gravitational) Heads}

The pressure differential acting on phase $\phi$ in flow path $j$, connecting control volumes $i$ and $k$, was abbreviated in Section 4 as $P_{i}-P_{k}+(\rho g \Delta z)_{i, \phi}$. Here $P_{i}$ and $P_{k}$ are the thermodynamic pressures in control volumes $i$ and $k$ respectively, and correspond to the altitudes of the pool surfaces. The term $(\rho \mathrm{g} \Delta \mathrm{z})_{i, \phi}$ contains all gravitational head terms within the control volumes and along the flow path. Figure 5.3.1 illustrates the elevation changes associated with a flow path.

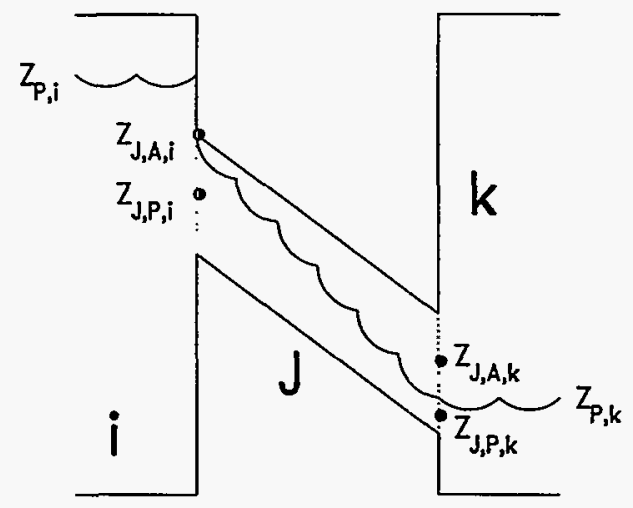

Figure 5.3.1 Elevations Involved in Gravitational Head Terms

Examination of Figure 5.3.1 shows that there are three contributions to the gravitational head. The first is the pressure difference between the pool surface at $z_{p, 1}$ (where the volume pressure is defined) and that at the average elevation, $z_{J, \phi, i}$ of the phase in the junction opening in volume $i$

$$
\left(P_{J, I}-P_{f}\right)_{\phi}= \begin{cases}\rho_{P, I} g\left(z_{P, I}-z_{J, \phi, I}\right) & z_{P, I} \geq z_{J, \phi, I} \\ \rho_{A, I} g\left(z_{P, I}-z_{J, \phi, I}\right) & z_{P, I}<z_{J, \phi, I}\end{cases}
$$

In this equation, the average elevations of the phases in the junction openings are given by

$$
\begin{aligned}
& z_{J, P, I}=\max \left\{z_{B J, I}, \frac{1}{2}\left[z_{B J, I}+\min \left(z_{P, I}+z_{T J, I}\right)\right]\right\} \\
& z_{J, A, I}=\min \left\{z_{T J, I}, \frac{1}{2}\left[z_{T J, I}+\max \left(z_{P, I}+z_{B J, I}\right)\right]\right\}
\end{aligned}
$$

where $\mathrm{BJ}$ and $\mathrm{TJ}$ again refer to the top and bottom of the junction opening, as in Section 5.2 . 
The second contribution to the static head comes from the corresponding pressure difference in volume $\mathrm{k}$

$$
\left(P_{J, k}-P_{k}\right)_{\phi}= \begin{cases}\rho_{P, k} g\left(z_{P, k}-z_{J, \phi, k}\right) & z_{P, k} \geq z_{J, \phi, k} \\ \rho_{A, k} g\left(z_{P, k}-z_{J, \phi, k}\right) & z_{P, k}<z_{J, \phi, k}\end{cases}
$$

and the third term is the gravitational head in phase $\phi$ along the flow path

$$
\left(P_{J, k}-P_{J, I}\right)_{\phi}=\bar{\rho}_{J, \phi} g\left(z_{J, \phi, I}-z_{J, \phi, k}\right)
$$

based on the density of that phase in the flow path. The density of a phase in a flow path is taken as the maximum of the volume values,

$$
\bar{\rho}_{j, \phi}=\max \left(\rho_{j, \phi}^{d}, \rho_{j, \phi}^{a}\right)
$$

because use of a donor value would introduce an unacceptable discontinuity in the gravitational head whenever the direction of a flow reversed. The maximum rather than a simple average is used because the value in a volume where the phase is not present may not be well defined.

The net gravitational head term is then defined as the sum of these three contributions:

$$
(\rho g \Delta z)_{J, \Phi}=\left(P_{J, I}-P_{I}\right)_{\phi}+\left(P_{J, k}-P_{J, i}\right)_{\Phi}-\left(P_{J, k}-P_{k}\right)_{\Phi}
$$

Figure 5.3.1 shows only two of the three possible cases: $z_{P}>z_{T J}$ and $z_{T J}>z_{P}>z_{B J}$, but the third $\left(z_{B J}>z_{P}\right)$ should be easily visualized.

The derivatives of equation 5.3.7 with respect to pool masses at constant densities are required for the implicit projection of the head terms as shown in Equation 4.2.9. These are then used in the implicit flow equation, Equations 4.2.16 and 4.2.17. Under the assumption of constant pool density, we have

$$
\frac{\partial}{\partial M_{P}}=\frac{1}{\rho_{P} A_{P}} \frac{\partial}{\partial z_{P}}
$$

where $A_{p}$ is the cross-sectional area of the control volume at $z_{p}$ (the area of the pool surface). Evaluation of the derivatives is greatly complicated by the fact that $\rho_{i, \phi}, \rho_{k, \phi}$, and $\bar{\rho}_{\mathrm{l}, \phi}$ are all potentially different. However, by ignoring this difference and neglecting all terms which contain $\rho_{A}$ rather than $\rho_{P}$, we may obtain the approximate result

$$
\frac{\partial(\rho g \Delta z)_{J, \phi}}{\partial M_{P, s}}= \begin{cases}\frac{\sigma_{J s} g}{A_{P, s}} & z_{\mathrm{P}, s}>z_{J, \phi, s} \\ 0 & z_{P, s} \leq z_{J, \phi, s}\end{cases}
$$

where $s$ is either $i$ or $k$, and $\sigma_{j s}$ provides the appropriate sign. This approximation has been found to be adequate in practice, and is currently employed in MELCOR. 


\section{CVH/FL Packages Reference Manual}

Equation 5.3.9 may be derived from the preceding equations by performing the indicated derivative under the stated assumptions and approximations. These assumptions and approximations are equivalent to considering only the effect of changes in $z_{p}$ on the pool contribution to the static head; this observation also allows the equation to be written down by inspection of Figure 5.3.1.

\subsection{Form Loss and Wall Friction}

The frictional pressure drops resulting from material flows contain contributions from both form loss and wall friction. The form-loss contribution is based on user-input coefficients; the wall-friction terms are computed within MELCOR, based on segment lengths and roughnesses input by the user. Because a single MELCOR flow path may be used to represent a rather complicated hydraulic path, the wall-friction terms may be computed for a path composed of one or more segments which are connected in series. (As will be noted below, a MELCOR segment may represent a number of parallel pipes.) This approach may also be used to account approximately for frictional losses within the control volumes themselves-MELCOR does not calculate any loss terms based on volume-centered velocities (see Section 6.5).

\subsubsection{Flow Path Segments}

If a flow path is imagined to consist of a number of pipe-like segments, the total frictional pressure drop for phase $\phi(P$ or $A)$ is given by

$$
\Delta P_{j, \phi}^{f}=\frac{1}{2} K_{j, \phi} \rho_{j, \phi}\left|v_{j, \phi}\right| v_{j, \phi}+\sum_{s} \frac{2 f_{\phi, s} L_{s}}{D_{s}} \rho_{\phi, s}\left|v_{\phi, s}\right| v_{\phi, s}
$$

where $\mathrm{K}$ is the form loss coefficient for the entire flow path, and $\mathrm{f}$ is the Fanning friction coefficient for segment $s$, which has length $L_{s}$ and hydraulic diameter $D_{s}$. The sum is over segments in the flow path.

In Equation 5.4.1, the pressure drops associated with sudden area changes or bends (the $\mathrm{K}$ term) and wall friction losses for the pipe segments (the $f$ terms) are quadratic in velocity but, as written, each term involves a different velocity. For each flow path, MELCOR computes phase velocities $v_{\mathrm{j}, \mathrm{P}}$ and $\mathrm{v}_{\mathrm{j}, \mathrm{A}}$ for the pool and the atmosphere. These define the volumetric flows of pool and atmosphere through the flow path,

$$
J_{j, \phi}=\alpha_{j, \phi} F_{j} A_{j} v_{j, \phi}
$$

where $A_{j}$ is the flow path area and $F_{i}$ is the fraction of that area which is open. If the flow is assumed to be incompressible, so that $\rho_{\phi, s}=\rho_{\mathrm{j}, \phi}$, the volumetric flow of each phase is constant, and the segment velocities are given by 
CVH/FL Packages Reference Manual

$$
v_{\phi, s} A_{s}=v_{j, \phi} F_{j} A_{j}
$$

where $A_{s}$ is the segment area. (Note that if a segment is to represent a number of parallel pipes, $A_{s}$ should be the total flow area while $D_{s}$ should be the hydraulic diameter of each pipe.) Therefore, all the loss terms may be combined to give an effective loss coefficient $K$,

$$
K_{j, \phi}^{*}=K_{l, \phi}+\sum_{s} \frac{4 f_{\phi, s} L_{s}}{D_{s}}\left(\frac{F_{j} A_{j}}{A_{s}}\right)^{2}
$$

to cast the frictional pressure loss in the form

$$
\Delta P_{J, \phi}^{f}=\frac{1}{2} K_{j, \phi}^{*} \rho_{J, \phi}\left|v_{J, \phi}\right| v_{J, \phi}
$$

The input form-loss coefficient for positive or negative flow (FRICFO or FRICRO on input record FLnnn03) is used for $\mathrm{K}_{\mathrm{j}, \phi}$ depending on the sign of $\mathrm{v}_{\mathrm{j}, \phi}$.

The wall-friction terms are calculated following the method of Beattie and Whalley [15]. A mixture Reynolds number is defined for each segment as

$$
R \theta_{s}=\frac{\left(\alpha \rho_{A}\left|v_{A}\right|+(1-\alpha) \rho_{P}\left|v_{P}\right|\right) D_{s}}{\mu_{m}}\left(\frac{F_{j} A_{j}}{A_{s}}\right)
$$

using a mixture viscosity

$$
\mu_{m}=\alpha \mu_{A}+(1-\alpha)(1+2.5 \alpha) \mu_{P}
$$

Here $\mu_{A}$ is calculated by the MP package for a mixture of gases with the composition of the atmosphere. The viscosity of liquid water is used for $\mu_{\mathrm{p}}$ (despite the fact that the pool may contain bubbles). Note that $\mu_{m}$ has the proper limits ( $\mu_{\mathrm{P}}$ or $\mu_{\mathrm{A}}$, respectively) as $\alpha$ goes to 0.0 or 1.0 .

The flow-path void fraction computed by MELCOR (Section 5.2.1) is used in Equations 5.4.6 and 5.4.7 rather than the homogeneous void fraction originally proposed in Reference 15. The constants in Equation 5.4 .7 are coded as sensitivity coefficients in array C4404, and may therefore be modified by user input if desired.

The Reynolds number calculated from Equation 5.4 .6 is used in a standard single-phase-flow friction correlation (which will be described in Section 5.4.2) to determine a single-phase friction factor $f_{1}$, which is used directly as $f_{p}$.

The flow quality,

$$
x=\frac{\alpha \rho_{A} v_{A}}{\alpha \rho_{A} v_{A}+(1-\alpha) \rho_{P} v_{P}}
$$




\section{CVH/FL Packages Reference Manual}

is used to interpolate the atmosphere friction factor $f_{A}$ linearly between the single-phase value $f_{1}$ when only atmosphere is flowing in the path $(x=1.0)$ and zero for $x \leq x_{0}$. $\left(x_{0}\right.$ is coded as sensitivity parameter C4404(12), with a default value of 0.9.) This is intended to reflect the tendency toward annular flow, with the gas phase preferentially occupying the center of a flow path, away from the walls and therefore not directly affected by wall frìction.

The wall friction terms depend only on the velocity in the segment. Therefore, for a given volumetric flow (Equation 5.4.2), they are independent of $F$ (the fraction of the flow path which is open). This is as it should be, since $F$ is intended to model a local restriction such as a valve which has no effect on wall losses in pipe segments.

On the other hand, the entire form loss $(K)$ term depends on the nominal flow path velocity which, for a given volumetric flow, is dependent on $F$. Thus, if $F$ can vary (i.e. if the flow path contains a valve), $F$ cannot be used to represent the effects of bends, contractions, and/or expansions in that flow path. This is not a serious defect because such losses may be modeled using equivalent lengths of pipe [16] in the segment data; in addition, most valves are either fully open or closed, and the current form is correct in either case. At some later date, the restriction may be removed by allowing form loss coefficients to be input for each segment, in addition to the single coefficient now permitted for the path, with the segment form losses based on the segment velocities rather than the MELCOR flow path velocities.

\subsubsection{Single-Phase Friction Factor}

The single-phase friction factor correlation used in MELCOR includes laminar, turbulent, and transition regions. In the laminar region, $0 \leq R e \leq 2000.0$, the expression used is

$$
f=\frac{16.0}{R \theta}
$$

The Colebrook-White Equation [17]

$$
\frac{1}{\sqrt{f}}=3.48-4.0 \log _{10}\left[\frac{2.0 \theta}{D}+\frac{9.35}{R \theta \sqrt{f}}\right]
$$

is used in the turbulent region $R e \geq 5000.0$. Here $e$ is the surface roughness. This equation must be solved iteratively. In the transition region $2000.0 \leq R e \leq 5000.0, \log (f)$ is linearly interpolated as a function of $\log (\mathrm{Re})$ between the limiting values for the laminar and turbulent regimes.

The various constants in these equations, including the limiting Reynolds numbers, are coded as sensitivity coefficients in the array $\mathrm{C4404}$, and may therefore be modified by user input. 
CVH/FL Packages Reference Manual

\subsection{Interphase Forces}

The force (momentum exchange) between pool and atmosphere flows sharing a single flow path is important both in entraining cocurrent flows and in limiting countercurrent ones. In the latter case, it is responsible for the phenomenon of flooding, the so-called countercurrent flow limitation (CCFL).

A model is required for use in MELCOR, but we hope to avoid introducing complicated flow-regime maps and constitutive equations of the type employed in TRAC [6] or RELAP5 [7]. Therefore, a simple form is used which will reproduce a flooding curve in the form given by Wallis [13]:

$$
\left(j_{g}^{*}\right)^{\frac{1}{2}}+\left(j_{f}^{*}\right)^{\frac{1}{2}}=1
$$

where $j_{g}^{*} \equiv \alpha v_{g} / v_{1}$ and $j_{f}^{*} \equiv(1-\alpha) v_{f} / v_{0}$ are scaled (dimensionless) volumetric flows of gas and fluid, respectively. In the following, we will adopt MELCOR notation, where the conventional subscripts" $g$ " and "ff" become " $A$ " and "P", respectively. As is shown in Appendix $B$, such a flooding curve will result if the relative velocity is modeled as a function of void fraction as

$$
\frac{1}{v_{r}} \equiv \frac{1}{v_{A}-v_{P}}=\frac{\alpha}{v_{1}}+\frac{1-\alpha}{v_{0}}
$$

Here $v_{1}$ and $v_{0}$ are the velocities used to scale $j_{A}$ and $j_{P}$, respectively; they also turn out to be the limiting values of $v_{r}$ for $\alpha$ equal 1.0 and 0.0 , respectively.

Appendix B also shows that the steady (time-independent) solution of the two phase momentum equation will agree with this result if the interphase force in Equation 4.1.5 is represented as

$$
f_{2}=g\left(\rho_{P}-\rho_{A}\right)\left(\frac{\alpha}{v_{1}}+\frac{1-\alpha}{v_{0}}\right)
$$

In the interest of simplicity, only the form of $v_{0}$ and $v_{1}$ [18],

$$
\frac{v_{0}}{v_{1}}=\sqrt{\frac{\rho_{A}}{\rho_{P}}}
$$

is used in MELCOR to write

$$
f_{2}=900 \cdot\left(\alpha \sqrt{\rho_{A}}+(1-\alpha) \sqrt{\rho_{P}}\right)
$$

in SI units. The constant chosen gives a value of about $0.3 \mathrm{~m} / \mathrm{s}$ for the limiting relative velocity as $\alpha$ goes to zero for vertical flow of gas and normal density water, corresponding to the terminal rise velocity of bubbles. This equation is applied to all geometries, and results are usually qualitatively acceptable. The term $\mathrm{f}_{2, \mathrm{j}}$ in the finite difference equation 
CVH/FL Packages Reference Manual

4.2.16 is multiplied by the length over which the interphase force acts rather than the inertial length of the flow path. In versions of MELCOR prior to 1.8.2, these lengths were assumed equal and the ratio was taken as unity. In later versions, a distinct length is used for momentum exchange. The default is taken as the inertial length for horizontal flow paths and as the difference in elevation between the lowest point and the highest point in the flow path (including junction openings) for vertical ones. Optional user input on record FLnnn05 is allowed to override these defaults for application to special geometries.

\subsection{Pumps and Fans}

A pump or fan model provides a functional relationship between the pressure head developed by such a device and the volumetric flow through it, with the operating speed as a parameter. Two models are currently available in MELCOR. One simply uses a control function to define the pressure head; this gives the user great flexibility, but requires that he accept complete responsibility for the results. An example of how this approach could be used to build a conventional homologous model for a reactor coolant pump is outlined in the Control Functions Users' Guide. The second model, referred to as "FANA", was originally intended to model a containment fan, but has also been used as an approximate representation of a constant-speed coolant pump in many calculations.

\subsubsection{The FANA Model}

This model was originally constructed to represent a simple fan, intended to move air (atmosphere) from compartment to compartment in containment. It can, however, be used to approximate a constant-speed coolant pump by appropriate choice of input parameters.

In the model, a parabolic relationship is assumed between the head, $\Delta \mathrm{P}$, developed by the fan and the volumetric flow, $\dot{V}$, through it. Three parameters define the resulting curve:

(1) the maximum pressure head developed, $\Delta P_{M}$,

(2) the corresponding volumetric flow, $\dot{V}_{M}$, and

(3) the volumetric flow, $\dot{V}_{0}$, at which the head is zero.

For a given volumetric flow $\dot{V}$, the pressure head is then given by 


$$
\left(\frac{\Delta P}{\Delta P_{M}}\right)^{2}= \begin{cases}1 & \dot{V}<\dot{V}_{M} \\ \frac{\dot{V}_{0}-\dot{V}}{\dot{V}_{0}-\dot{V}_{M}} & \dot{V}_{M} \leq \dot{V} \leq \dot{V}_{0} \\ 0 & \dot{V}_{0}<\dot{V}\end{cases}
$$

The resulting curve is illustrated in Figure 5.6.1. Suitable parameters may usually be chosen by comparison of this Figure with the constant-speed operating curve for the device in question (in the normal operation quadrant).

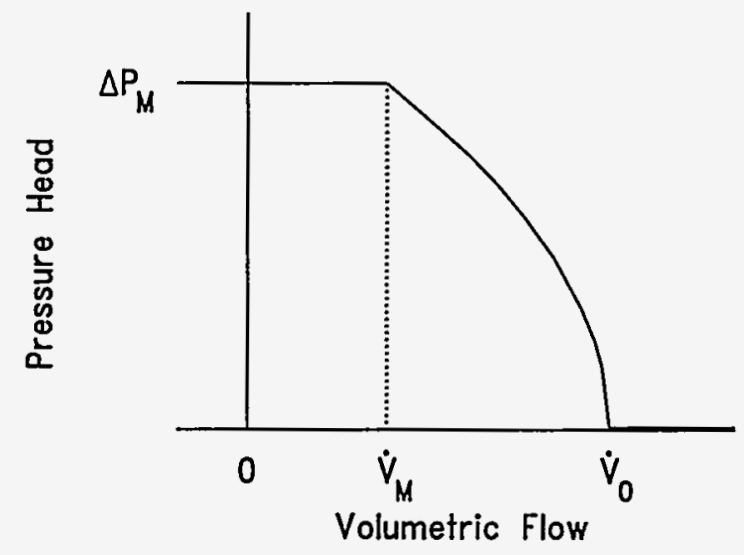

Figure 5.6.1 Fan Model Operating Characteristics

The "forward" direction for a pump need not correspond to the direction of positive flow in the associated flow path. The necessary sign conventions for treating a reversed pump are described in the FL Package Users' Guide.

A pump may be specified to be always on, or its operation may be controlled by a tabular function of time or by a control function of other arguments in the MELCOR database. The pump is off if the function is zero and on if it is non-zero. The model is implemented as an explicit momentum source, based on start-of-system-timestep velocities. Any functions which control the pump are also evaluated at the start of the MELCOR system timestep and treated as constant over the entire step. 
CVH/FL Packages Reference Manual

CVH-RM-62 


\section{OTHER MODELS}

\subsection{Bubble Physics}

If a flow of atmospheric materials enters a control volume below the elevation of the surface of the pool in that volume, it must pass through the pool to reach its final destination. This process is visualized as involving rising bubbles in the pool, and the user may specify that an interaction be allowed based on the thermal and condensation/ evaporation physics in SPARC [19]. If this option is not selected, no interaction occurs and the transported atmospheric materials are simply added, unchanged, to the atmosphere in the acceptor volume.

The physics modeled involves breakup of the injected gas stream into a swarm of bubbles, thermal equilibration of the gases with the pool, and saturation of the bubbles with water vapor at local conditions. These bubbles are not considered to reside in the pool, and do not contribute to pool swelling. The efficiency of the mass and energy transfer processes is affected by two factors, which are treated as independent.

The distance that gases must rise in order to reach the surface of the pool is involved in the breakup of the stream and the corresponding increase in surface area. It is modeled as an efficiency, $\varepsilon_{\mathrm{z}}$, represented as

$$
\varepsilon_{z}=\frac{z_{P}-z_{J}-0.01 \mathrm{~m}}{1.0 \mathrm{~h}}, 0 \leq \varepsilon_{z} \leq 1
$$

where

$z_{p}$ is the elevation of the pool surface in the acceptor volume

$z_{i}$ is the junction elevation in the acceptor volume, and

$h$ is the height of the junction opening.

That is, there is assumed to be no breakup until the bubbles have risen at least $1 \mathrm{~cm}$, and breakup is assumed to be complete if they must rise through the junction opening height plus $1 \mathrm{~cm}$.

The effect of subcooling of the pool is represented as an efficiency

$$
\varepsilon_{T}=\frac{T_{\text {sat }}(P)-T_{P}-0.1 \mathrm{~K}}{5.0 \mathrm{~K}}, 0 \leq \varepsilon_{T} \leq 1
$$

This requires subcooling by at least $0.1 \mathrm{~K}$ for any effect, and by at least $5.1 \mathrm{~K}$ for the maximum possible effect to be predicted.

The overall efficiency is taken as the product of these two efficiencies

$$
\varepsilon=\varepsilon_{z} \varepsilon_{T}
$$




\section{CVH/FL Packages Reference Manual}

If only water vapor and fog are present in the bubbles, it is assumed that a fraction $\varepsilon$ of the vapor condenses, and an equal fraction of the fog in the flow path is deposited in the pool, with the remainder passing through to the atmosphere; no modification is made to the specific enthalpy (temperature) of material which passes through. In this case, the entire flow will be deposited in the pool if the depth and subcooling are adequate.

If noncondensible gases are present, and the depth and subcooling are sufficiently large, it is assumed that bubbles leave the pool at the pool temperature and, further, that the relative humidity in the bubbles will be 0.99 , i.e., that the partial pressure of water vapor will be 0.99 of the saturation pressure at the pool temperature. If $\varepsilon=1$ as calculated from Equations 6.1.1, 6.1.2, and 6.1.3, this result is used directly, while the trivial result for no interaction is used for $\varepsilon=0$. For $0 \leq \varepsilon \leq 1$, a linear interpolation (on the overall $\varepsilon$, Equation 6.1.3) is performed between these limits. As in the case of no noncondensibles, a fraction $\varepsilon$ of the fog flow is assumed to be deposited in the pool, with the remainder transmitted to the atmosphere.

All constants in this model (those in Equations 6.1.1 and 6.1.2, and the limiting relative humidity) are coded as sensitivity coefficients, included in array C4405, and may therefore be modified by user input. The default values are those discussed here.

The effects of this model are implemented by appropriately modifying the definitions of donor properties; the normal donor properties are used for removal of atmospheric material from the actual donor volume, but a modified set of properties is used for the acceptor volume to which they are added. Specifically, if the volume of atmosphere moved through the flow path is

$$
\left|\Delta V_{j}\right|=\alpha_{j} F_{j} A_{j}\left|V_{j, A}\right| \Delta t
$$

the masses and energies removed from the donor volume, $d$, are

$$
\begin{aligned}
& \Delta M_{m, d}=-\left|\Delta V_{j}\right| \frac{M_{m, d}}{V_{A, d}} \\
& \Delta E_{A, d}=-\left|\Delta V_{J}\right| \frac{H_{A, d}}{V_{A, d}}
\end{aligned}
$$

where, of course, the material index $m$ in Equation 6.1 .5 is limited to materials in the atmosphere. The masses added to the acceptor volume, a, however, have the more general form

$$
\begin{aligned}
& \Delta M_{m, a}=\rho_{m, a}^{*}\left|\Delta V_{J}\right| \\
& \Delta E_{A, a}=(\rho h)_{A, a}^{*}\left|\Delta V_{J}\right|
\end{aligned}
$$




$$
\Delta E_{P, a}=(\rho h)_{P, a}^{*}\left|\Delta V_{j}\right|
$$

where $m$ in Equation 6.1.7 includes the pool. The SPARC model gives the masses and energies delivered to the acceptor volume $\left(\Delta \mathrm{M}_{\mathrm{m}, \mathrm{a}}, \Delta \mathrm{E}_{\mathrm{A}, \mathrm{a}}\right.$, and $\left.\Delta \mathrm{E}_{\mathrm{p}, \mathrm{a}}\right)$ in terms of the entering masses and energies $\left(\Delta \mathrm{M}_{\mathrm{m}, \mathrm{d}}\right.$ and $\left.\Delta \mathrm{E}_{\mathrm{A}, \mathrm{d}}\right)$. Therefore, Equations 6.1.7 through 6.1.9 serve as definitions of the quantities $\rho_{\mathrm{m}, \mathrm{a}}^{*}(\rho \mathrm{h})_{\mathrm{A}, \mathrm{a}}^{*}$, and $(\rho \mathrm{\rho h})_{\mathrm{P}, \mathrm{a}}^{*}$, which are subject to the constraints

$$
\begin{aligned}
& \rho_{1, a}^{*}+\rho_{2, a}^{*}+\rho_{3, a}^{*}=\frac{M_{2, d}+M_{3, d}}{V_{A, d}} \\
& \rho_{n, a}^{*}=\frac{M_{n, d}}{V_{A, d}} \\
& (\rho h)_{P, a}^{*}+(\rho h)_{A, a}^{*}=\frac{H_{A, d}}{V_{A, d}}
\end{aligned}
$$

For atmospheric materials, the differences reflect the changes in composition and specific enthalpy described above; the pool terms reflect heat and mass exchange with the pool. If evaporation takes place, $\rho_{1, a}$ can be negative. In this case, it is further constrained so that use of Equation 6.1.7 does not result in a negative pool mass.

\subsection{Time-Dependent (Specified) Flow Paths}

The velocity in any flow path may be defined by the user, either as a Tabular Function of time or as a Control Function of other arguments in the MELCOR database. The resulting velocity is imposed on both pool and atmosphere (if present), with the void fraction computed using the standard model described in Section 5.2.

\subsection{Critical Flow Models}

After the solution of the flow (momentum) equation is complete, the computed flow in each flow path is compared with a calculated critical flow to determine if choking should be imposed. The test is bypassed if neither the pool velocity nor the atmosphere velocity is greater than a threshold of $20.0 \mathrm{~m} / \mathrm{s}$, coded as a sensitivity coefficient in C4402. If the flow exceeds the critical value, the flow path is added temporarily to a list of specified-flow flow paths, and the entire solution is repeated with the velocity constrained to be the critical value. 


\section{CVH/FL Packages Reference Manual}

If only atmosphere is flowing through the path, the critical mass flux is taken as the sonic flux at the minimum section. For an ideal gas, this may be related to the sonic flux at stagnation conditions through the relation [20]

$$
G_{C, A}=\rho_{A}^{d} C_{s, A}^{d}\left(\frac{2}{\gamma+1}\right)^{\left(\frac{\gamma+1}{2(\gamma-1)}\right)}
$$

where

$G \equiv \rho v$ is mass flux,

subscript $C$ denotes "critical",

$\mathrm{C}_{\mathrm{s}}$ is the sonic velocity, and

$\gamma \equiv \mathrm{c}_{\mathrm{p}} / \mathrm{c}_{\mathrm{v}}$ is the ratio of the specific heat at constant pressure to that at constant volume.

The use of the superscript "d" reflects the fact that in MELCOR the donor volume is assumed to be at stagnation conditions. The sonic velocity is evaluated in the CVT package. The multiplier is only a very weak function of $\gamma$, having a value within $5 \%$ of 0.58 for $1.1 \leq \gamma \leq 1.8$, and is therefore evaluated at a nominal value of $\gamma=1.4$. There are two factors contributing to this function of $\gamma$. (1) reduction in density because of expansion and (2) reduction in sound speed because of cooling between stagnation conditions and the minimum section. CONTAIN [3] includes both factors, HECTR [2] only the latter.

If only pool is flowing, the RETRAN [21] model (to be discussed in Section 6.3.1) for the critical mass flux is used, based on the pressure and specific enthalpy of the pool,

$$
G_{C, P}=G_{C, \text { RETRAN }}\left(P^{d}, h_{P}^{d}\right)
$$

If both phases are flowing, the critical mass flux is taken as a weighted average of that for the two phases,

$$
\frac{\alpha \rho_{A}^{d}+(1-\alpha) \rho_{P}^{d}}{G_{C, 2 p h}}=\frac{\alpha \rho_{A}^{d}}{G_{C, A}}+\frac{(1-\alpha) \rho_{P}^{d}}{G_{C, P}}
$$

This rather peculiar averaging scheme was motivated by the observation that it provides an almost-exact representation of the Moody choking model if $G_{C, P}$ and $G_{C, A}$ are replaced by $G_{C, \text { Moody }}(\alpha=0)$ and $G_{C, \text { Moody }}(\alpha=1)$, respectively (see Appendix $C$ ).

If the mass flux evaluated using the new velocities calculated by the momentum equation exceeds the appropriate critical value, the velocity imposed (on both phases) is

$$
v_{C, J}=\frac{G_{C}}{\alpha_{J} \rho_{A}^{d}+\left(1-\alpha_{J}\right) \rho_{P}^{d}}
$$

Possible improvements in this model are described in Section 7.2. 
Discharge coefficients are available (on FLnnn03 input records) as multipliers for the critical flow values calculated by these models. Different values may be used for forward (positive) and reverse (negative) flows in each flow path; the default values are 1 . The appropriate discharge coefficient is included both in the test for choking in each flow path and in the velocity imposed if choking is detected. Use of a very large value is the only. way to eliminate the possibility of choking in a flow path.

\subsubsection{RETRAN Critical Flow Model}

The RETRAN critical flow model consists of two 36-parameter, double-polynomial fits to extended Henry-Fauske critical flow for subcooled water (below and above 300 psia), and two 36-parameter fits to Moody critical flow for saturated (two-phase) water (below and above $200 \mathrm{psia}$ ), all as functions of stagnation pressure and enthalpy. It also includes a 9-parameter expression for a "transition" enthalpy as a function of pressure. A linear transition is constructed between the Henry-Fauske model at and below this enthalpy and the Moody model at and above saturation. The reader is referred to Reference 21 for a description of the basic models and the fitting procedure employed.

Two modifications to the RETRAN model were made for use in MELCOR. First, the fits are stated in Reference 21 to be valid only above $170 \mathrm{BTU} / \mathrm{lbm}$, and were observed to yield unreasonable (sometimes negative) values not far below this value. Therefore, a linear interpolation was introduced between the fit at the lower limit of its applicability and the solution for orifice flow,

$$
G_{O}=\sqrt{2 P \rho_{p}}
$$

imposed at $h_{P}=0$. Second, it was observed that the transition enthalpy which defined the upper bound for application of the Henry-Fauske model was calculated as greater than the enthalpy of saturated liquid at the lower end of the pressure range (below about 21 psia). Therefore, the transition enthalpy was further bounded to be at least $10 \mathrm{BTU} / \mathrm{lbm}$ below saturation.

The fits themselves leave something to be desired; they appear to be excessively complicated, include modest discontinuities (several percent) at region boundaries, and have terrible extrapolation properties. Plans for improvement are described in Section 7.1 .

\subsection{Valves}

A valve may be included in any flow path in MELCOR. Its operation is modeled as a change in the fraction of the area of the flow path which is open. This fraction may be defined directly as a Tabular Function of time, or as a Control Function of other 


\section{CVH/FL Packages Reference Manual}

arguments in the MELCOR database. Trips may also be used to model irreversible changes in flow areas such as ruptures of vessels or compartment walls, or to model the hysteresis in the operation of, say, a relief valve. The open fraction is limited to the range $0.0 \leq F \leq 1.0$ and, if the controlling function returns a value outside this range, it will be suitably truncated. The upper bound corresponds to a flow area equal to that input for the flow path, the lower bound to a closed path in which no flow is permitted.

\subsection{Volume-Averaged Velocities}

Volume averaged (centered) velocities are used in MELCOR only in the calculation of forced-flow heat transfer coefficients (in a number of packages). This is because both kinetic energies and momentum flux terms are neglected in the governing hydrodynamic equations. The only forced-flow heat transfer coefficients used in the CVH or FL packages are those associated with the pool/atmosphere interface in nonequilibrium volumes (Section 5.1.2).

MELCOR is a one-dimensional code which is often used to model three-dimensional volumes. A rigorously defined volume-averaged velocity would involve multi-dimensional effects, but the essential geometric information is simply not available. The model used in RELAP5 [7], which is also a one-dimensional code, was considered for use in MELCOR. It may be written in the form

$$
\begin{aligned}
& J_{V, \phi}=\alpha_{V, \Phi} v_{V, \phi} A_{V}=\frac{1}{2}\left(\sum_{j t o v} J_{j, \phi}+\sum_{j \neq m V} J_{j, \phi}\right) \\
& J_{J, \Phi}=\alpha_{j, \phi} v_{j, \phi} F_{j} A_{j}
\end{aligned}
$$

where

$J$ is volumetric flow,

$\phi=\mathrm{P}$ or $\mathrm{A}$, and denotes pool or atmosphere,

$A_{V}$ is the flow area associated with volume $V$,

$\alpha_{v, \phi}$ are the area fractions for the volume flows,

and all other symbols have been defined before. The sums in Equation 6.5.1 are over flow paths which connect to or from volume $\mathrm{V}$.

Volume flows and velocities calculated from Equation 6.5.1 are strongly dependent on the logical direction of flow paths. For example, reversing both the sign of a velocity and the associated direction of positive flow (so that the actual volume moved from and to the connected volumes is unchanged) does not preserve the volume flow. In particular, the net flow in a volume with a flow $+J$ to it and $+J$ from it is $+J$, while the net flow in a volume with $+\mathrm{J}$ to it and $-\mathrm{J}$ to it is zero. This is because it is assumed in the RELAP5 formulation that all to connections are on the left of a volume and all from connections 
CVH/FL Packages Reference Manual

on the right; in the second case cited above, the flows cancel and there is no resulting flow at the volume center.

We have found that this is often not the desired result in MELCOR nodalizations. Furthermore the expected results cannot be obtained in any nodalization which connects volumes in a regular grid to approximate a finite-difference representation of a two-dimensional region; the best that can be done is to calculate the velocity component along one diagonal of the grid. Therefore, MELCOR uses a simplification of Equation 6.5.1 which treats all flow paths on an equal footing:

$$
J_{V, \phi}=\alpha_{V, \phi} v_{V, \phi} A_{V}=\frac{1}{2} \sum_{I}\left|J_{j, \phi}\right| \quad \text { (MELCOR) }
$$

where the sum is over all connected flow paths, and the void fraction associated with the volume flow is taken as a simple weighted average over connected flow paths in the form

$$
\alpha_{V}=\frac{\sum_{j} \alpha_{J} F_{l} A_{l}}{\sum_{J} F_{l} A_{J}}
$$

This model can be understood qualitatively using the simple argument that, under steady conditions, a flow through a volume is counted twice: once where it enters the volume and once where it leaves. It makes no attempt to assign a direction to the volume velocity, and would therefore be unacceptable if it were necessary to calculate the momentum flux terms arising from $\nabla \cdot(\rho \mathbf{v} v)$. In accord with this simple double-counting argument, a term is added to the sum in Equation 6.5.3 for the vapor flow to account for vapor generation in boiling in a nonequilibrium volume.

\subsection{Special (Time-Specified) Volumes}

MELCOR hydrodynamics allows boundary conditions to be defined by specifying the state of one or more volumes as functions of time. This is frequently necessary for simulation of experiments. It is also useful for defining the outside-containment environment for a full reactor plant calculation. In the simplest case, a volume may be specified as timeindependent, with properties that do not change as the calculation progresses. Several options are also available for specifying the pressures, temperatures, and compositions of such volumes in terms of user-defined tabular functions, external data files, or control functions, as explained in the CVH Users' Guide.

A time-specified volume can serve any of the functions of a normal volume. It can provide boundary conditions for in- or out-flows, or for heat transfer. All phenomena modeled by the RadioNuclide (RN) package will also be treated, with the sole exception 
CVH/FL Packages Reference Manual

that radionuclides are not allowed to advect out of such a volume. (This is intended to prevent radionuclides from reentering a failed containment building from the environment.) A time-specified volume can also be used in conjunction with a time-specified flow path (Section 6.3) to define a mass source with well-defined properties. This approach is particularly useful for water sources, for which temperature alone is insufficient to define the complete thermodynamic state; it also provides a way for gas sources to be made to participate in the bubble interactions described in Section 6.1.

Any mass or energy transferred to or from a time-specified volume is recorded as "created" in the CVH package for accounting purposes. 
CVH/FL Packages Reference Manual

\section{DISCUSSION AND DEVELOPMENT PLANS}

\subsection{Interphase Forces}

Revisions made in MELCOR 1.8.2 to the simple model for interphase forces (described in Section 5.5) appear to have eliminated the more obvious limitations of the previous implementation. Calculations need to be done and compared with data (as represented by more general slip correlations) to assess the overall adequacy of the revised model.

\subsection{Critical Flow Modeling}

Atmosphere velocities which are significantly supersonic have been observed in some calculations, despite the presence of the critical flow model. This can arise if the phase velocities calculated by the momentum equation are very different. (Because of its greater inertia the velocity of the pool is sometimes much less than that of the atmosphere before choking is considered.) The problem is that the net mass flux, calculated with the disparate velocities, may be subcritical (according to the current calculational model) even though one velocity is supersonic.

The entire concept of choking in a two-velocity model may need further examination. In the short term, however, the introduction of the interfacial momentum-exchange term, by reducing the differences between the calculated phase velocities, has gone a long way toward eliminating this problem.

The relatively complicated fits [21] used for Moody and Henry critical flow are not particularly good (a few percent). They are each constructed for two pressure ranges, and exhibit discontinuities of several percent at the matching line. The extrapolation properties are poor; the extrapolation often goes negative just outside the fit region. We have found (see Appendix C) that there are simpler representations, with comparable or better accuracy and good extrapolation properties; we will implement them into MELCOR when time permits.

\subsection{Flow Blockage Modeling}

When nonhydrodynamic materials are relocated by the Core package, flow areas and resistances should be changed in the hydrodynamic modeling. This is currently possible only through user input, by defining valves in the affected flow paths to modify the flow areas. For this purpose, the Core package provides control function arguments tied to the degree of blockage in one or more core cells. This places a significant burden on the user to foresee the need to set up this input, and to do it correctly. The effect on frictional losses are only indirectly represented through the form loss coefficients (see 


\section{CVH/FL Packages Reference Manual}

Section 5.4). The lack of blockage modeling was identified as a major deficiency in the LOFT assessment [22].

We are currently investigating methods to automatically include blockage effects. This may require definition of a new interface to the $\mathrm{CVH}$ package to allow other packages to actively control both the flow area and the form loss coefficients of flow paths. 
CVH/FL Packages Reference Manual

\section{REFERENCES}

1. RELAP4/MOD5 A Computer Program for Transient Thermal-Hydraulic Analysis of Nuclear Reactors and Relates Systems User's Manual, Volume 1, RELAP4/MOD5 Description, ANCR-NUREG-1335, Idaho Nuclear Engineering Laboratory, Idaho Falls, ID (September 1976).

2. S. E. Dingman, et al, HECTR Version 1.5 User's Manual, NUREG/CR-4507, SAND86-0101, Sandia National Laboratories, Albuquerque, NM (April 1986).

3. K. K. Murata, et al, User's Manual for CONTAIN 1.1, a Computer Code for Severe Nuclear Reactor Accident Containment Analysis, SAND87-2309, Sandia National Laboratories, Albuquerque, NM (1989).

4. "MAAP, Modular Accident Analysis Program User's Manual," Volumes 1 and 2, IDCOR $(1984,1987)$.

5. JANAF Thermochemical Tables, Dow Chemical Company, Thermal Research Laboratory, Midland, MI (1965).

6. TRAC-PF1, An Advanced Best-Estimate Computer Program for Pressurized Water Reactor Analysis, NUREG/CR-3567, LA-9944-MS, Los Alamos National Laboratory, Los Alamos, NM (February 1984).

7. V. H. Ransom, et al, RELAP5/MOD1 Code Manual Volume 1: System Model and Numerical Methods; Volume 2: Users Guide and Input Requirements, NUREG/CR-1826, EGG-2070, Idaho National Engineering Laboratory (March 1982).

8. L. N. Kmetyk, MELCOR 1.8.1 Assessment: FLECHT SEASET Natural Circulation Experiments, SAND91-2218, Sandia National Laboratories, Albuquerque, NM (December 1991)

9. J. G. Collier, Convective Boiling and Condensation, Second Edition, McGraw-Hill, Inc., New York, NY (1981), p. 326.

10. R. B. Bird, W. E. Stewart, and E. N. Lightfoot, Transport Phenomena, John Wiley \& Sons, Inc., New York, NY (1960). Equation 18.4-25.

11. See, for example, W. H. McAdams Heat Transmission, McGraw Hill Book Company, New York, NY (1959) The correlation for the atmosphere is for an unstable temperature gradient; that for the pool is for a stable gradient and a finite surface. The coefficients shown in this manual are those actually used Version 


\section{CVH/FL Packages Reference Manual}

1.8.2. The basis for the 0.25 coefficient in Equation 5.1 .22 has been lost; later versions of MELCOR will use a coefficient of 0.27 , as given in McAdams.

12. R. K. Cole, Jr., Letter Report to Ron Foulds, USNRC, "CVH Pool/Atmosphere Condensation," under FIN A1339 (August 1992)

13. G. B. Wallis, One-dimensional Two-phase Flow, McGraw-Hill Book Company, New York, NY (1969), Chapter 9.

14. F. Gelbard and J. H. Seinfeld, "Simulation of Multicomponent Aerosol Dynamics," J. Colloid and Interface Science, 78 (2) (December 1980).

15. D. R. H. Beattie and P. B. Whalley, "A Simple Two-Phase Frictional Pressure Drop Calculational Method," Int. J. Multiphase Flow, 8 (1) pp. 83-87 (1982).

16. "Flow of Fluids through Valves, Pipes, and Fittings," Technical Paper 410, Crane Co., Chicago, IL (1969).

17. R. D. Blevins, Applied Fluid Dynamics Handbook, Van Nostrand Reinhold Company, New York, NY (1984); Section 6.3, with conversion of the Darcy-Weisbach form to the Fanning form used in MELCOR.

18. G. B. Wallis, op. cit., Section 11.4 .

19. P. C. Owczarski, R. I. Schreck, and A. K. Postma, Technical Bases and User's Manual for the Prototype of a Suppression Pool Aerosol Removal Code (SPARC), NUREG/CR-3317, PNL-4742 (May 1985).

20. R. B. Bird, W. E. Stewart, and E. N. Lightfoot, op. cit., Equation 15.5-42, with identification of the sound speed as $(\gamma P / \rho)^{1 / 2}$.

21. RETRAN-02-A Program for Transient Thermal-Hydraulic Analysis of Complex Fluid Systems, Volumes 1-3, NP-1850-CCM, Electric Power Research Institute, Palo Alto, CA (May 1981).

22. L. N. Kmetyk, MELCOR 1.8.1 Assessment: LOFT Integral Experiment LP-FP-2, SAND92-1373, Sandia National Laboratories, Albuquerque, NM (December 1992) 
CVH/FL Packages Reference Manual

\section{APPENDIX A: Sensitivity Coefficients}

A number of sensitivity coefficients are available in the hydrodynamics (CVH and $F L$ ) packages. Their use is described in the Control Volume Hydrodynamics (CVH) Package Users' Guide, and most are mentioned at appropriate places in this Reference Manual. This appendix is intended to aid the user in finding those places.

Coefficient Default $\quad \underline{\text { Usage, reference }}$ $\underline{\text { Value }}$

C4400

(1)

(2)

(3)

(4)

(5)

(7)

(8)

(9)

(10)

(11)

C4401

(1)

(2)

(3)

(4)

C4402

(1)

C4404

(1)

(2)

(3)

(4)

(5)

(6)

(7)

(8)

(9)

(10)

(11)
0.5

0.9

0.15

0.05

0.0

0.1

0.0

0.1

1.0

0.2

1.0

0.09

0.0

0.0

0.0

20.0

\subsection{8}

4.0

2.0

9.35

$1 / \ln (10)$

1.0

14.14

0.0005

0.0

1.0

2.5

\section{Timestep Control}

Equation 4.5.6

Equation 4.5.7

Not discussed in this manual. Used only if no flow paths

Equation 4.5.4

Equation 4.5.4

Executive fallback, second paragraph after Equation 4.5.3

Executive fallback, second paragraph after Equation 4.5.3

Equation 4.5.5

Equation 4.5.5

Executive fallback, second paragraph after Equation 4.5.3

Executive fallback, second paragraph after Equation 4.5.3

\section{Velocity Convergence Criteria}

Fourth paragraph following outline of strategy, Section 4.3

Fourth paragraph following outline of strategy, Section 4.3

Implies iteration limit. See discussion in Users' Guide

Allows relaxed convergence tolerance. See Users' Guide

\section{Minimum Velocity to be Considered for Choking}

First paragraph, Section 6.3

\section{Friction Factor Parameters}

Colebrook-White, Equation 5.4.10

Colebrook-White, Equation 5.4.10

Colebrook-White, Equation 5.4.10

Colebrook-White, Equation 5.4.10

Used in solution of Colebrook-White, should not be modified Two-phase viscosity, Equation 5.4.7

Used in solution of Colebrook-White, should not be modified Used in solution of Colebrook-White, should not be modified Used in solution of Colebrook-White, should not be modified Two-phase viscosity, Equation 5.4.7

Two-phase viscosity, Equation 5.4.7 
CVH/FL Packages Reference Manual

Coefficient Default Usage, reference

Value

\section{C4404}

(12)

(13)

(14)

(15)

C4405

(1)

(2)

(3)

(4)

(5)

C4406

(1)

C4407

(1)

(2)

(3)

(4)

(5)

(6)

(7)

(8)

(9)

(10)

(11)

(12)

C4408

(1)

(2)

C4409

$(1-6)$
0.9

16.0

2000.0

5000.0

0.01

1.0

0.1

5.0

0.99

0.1

0.3

0.02

0.14

$1 / 3$

0.54

$1 / 4$

0.25

$1 / 4$

0.25

$1 / 4$

0.4

0.9

0.0

0.005
Bound for atmosphere friction, text following Equation 5.4.8 Laminar friction, Equation 5.4.9

Limiting Reynolds Number, text following Equation 5.4.10

Limiting Reynolds Number, text following Equation 5.4.10

SPARC Bubble Physics Parameters

Minimum rise distance, Equation 6.1.1

Rise scale, Equation 6.1.1

Minimum subcooling, Equation 6.1.2

Subcooling scale, Equation 6.1.2

Exit relative humidity, text following Equation 6.1.3

Maximum Allowed Fog Density

Text of Section 5.1.4

Pool/Atmos Heat/Mass Transfer Parameters

Bubble rise velocity, second paragraph, Section 5.1.3

Forced convection, Equation 5.1.21

Turbulent free convection in atmosphere, Equation 5.1.23

Turbulent free convection in atmosphere, Equation 5.1.23

Laminar free convection in atmosphere, Equation 5.1.23

Laminar free convection in atmosphere, Equation 5.1.23

Turbulent free convection in pool, Equation 5.1.22

Turbulent free convection in pool, Equation 5.1.22

Laminar free convection in pool, Equation 5.1.22

Laminar free convection in pool, Equation 5.1.22

Maximum pool void, text following Equation 5.1.31

Maximum condensation fraction, text following Equation 5.1.15

Pressure Iteration Parameters

Decimal digits used to disable several models (for debugging)

Subcycle step increase, pressure convergence, Equation 4.5.3

Limits and Tolerances for Time-Specified Volumes

These coefficients are used to test the acceptability and consistency of user input for time-specified volumes. They are not discussed in this reference manual; the description in the users' guide is complete and self-contained. 
CVH/FL Packages Reference Manual

$\underline{\text { Coefficient }} \frac{\text { Default }}{\text { Value }}$

C4410

(1)

(2)

1.0

1500.0

C4411

C4412

(1)

$\underline{\text { Usage, reference }}$

Vapor Velocity Enhancement during Direct Containment Heating

Multiplier on volume-averaged velocity

Minimum temperature of airborne debris for application

These coefficients can be used to increase heat transfer from the atmosphere of a volume in which direct containment heating is occurring by parametrically increasing the atmosphere velocity that will be used in heat transfer correlations.

Limits and Tolerances for Iterations in the CVT Package These coefficients are used to control iterative calculations in the CVT package. They are not discussed in this reference manual; the description in the users' guide is complete and self-contained.

Limits and Tolerances for Iterations in the CVH Package Void fraction convergence, discussion in Section 4.3. 
CVH/FL Packages Reference Manual 
CVH/FL Packages Reference Manual

\section{APPENDIX B: The Interphase Force and the Flooding Curve}

The interphase force results from exchange of momentum ("drag") between the two fields, pool and atmosphere in MELCOR, when they share a flow path. Many codes such as TRAC [6] and RELAP5 [7] contain detailed models for this force. These models are typically based on specific microscopic pictures of the state of the fluid, and therefore must contain a number of submodels for different flow regimes. There are at least two practical difficulties in constructing and validating such a model:

The force is not directly measurable; all observable quantities result from delicate balances among this force, wall forces, and gravitational forces. Inertial forces are sometimes involved.

Discontinuities between the submodels, or even a lack of smoothness in the transitions between them, can result in numerical problems so severe as to prevent calculation of acceptable solutions in any but the simplest cases.

Much of the complexity can be avoided-at the expense of accuracy in some cases-by considering only a single momentum equation, defining an average (mixture) velocity for the two fields, and modeling the relative velocity between them as a constitutive relation. In this approach, referred to as the "drift flux" model, the relative velocity is a function of the local conditions, but not of their history. RELAP4 [1] is typical of codes employing the drift flux model.

The drift flux model is conventionally cast in terms of the volumetric fluxes defined by

$$
\begin{aligned}
& j_{g} \equiv \alpha v_{g}=\alpha j+\alpha \varepsilon v_{r} \\
& j_{l} \equiv \varepsilon v_{l}=\varepsilon j-\alpha \varepsilon v_{r}
\end{aligned}
$$

where

$$
\begin{aligned}
& \varepsilon \equiv 1-\alpha \\
& j \equiv j_{g}+j_{l} \\
& v_{r} \equiv v_{g}-v_{l}
\end{aligned}
$$

and the fields are identified as $\ell$ and g, denoting "liquid" and "gas." (Note that the natural dimensions of the volumetric fluxes, $\mathrm{m}^{3} / \mathrm{m}^{2} . s$, are the same as those of the velocities.) In these relations, $v_{r}$ or, more usually

$$
j_{g l} \equiv \alpha \varepsilon v_{r}
$$

is considered to be defined by a constitutive equation as a function of $\alpha$, densities, and geometry. 


\section{CVH/FL Packages Reference Manual}

For a given value of $\alpha$, the locus of possible values of $j_{g}$ and $j_{l}$ as functions of $j$ form a straight line, referred to as a drift flux line, as shown in Figure B.1

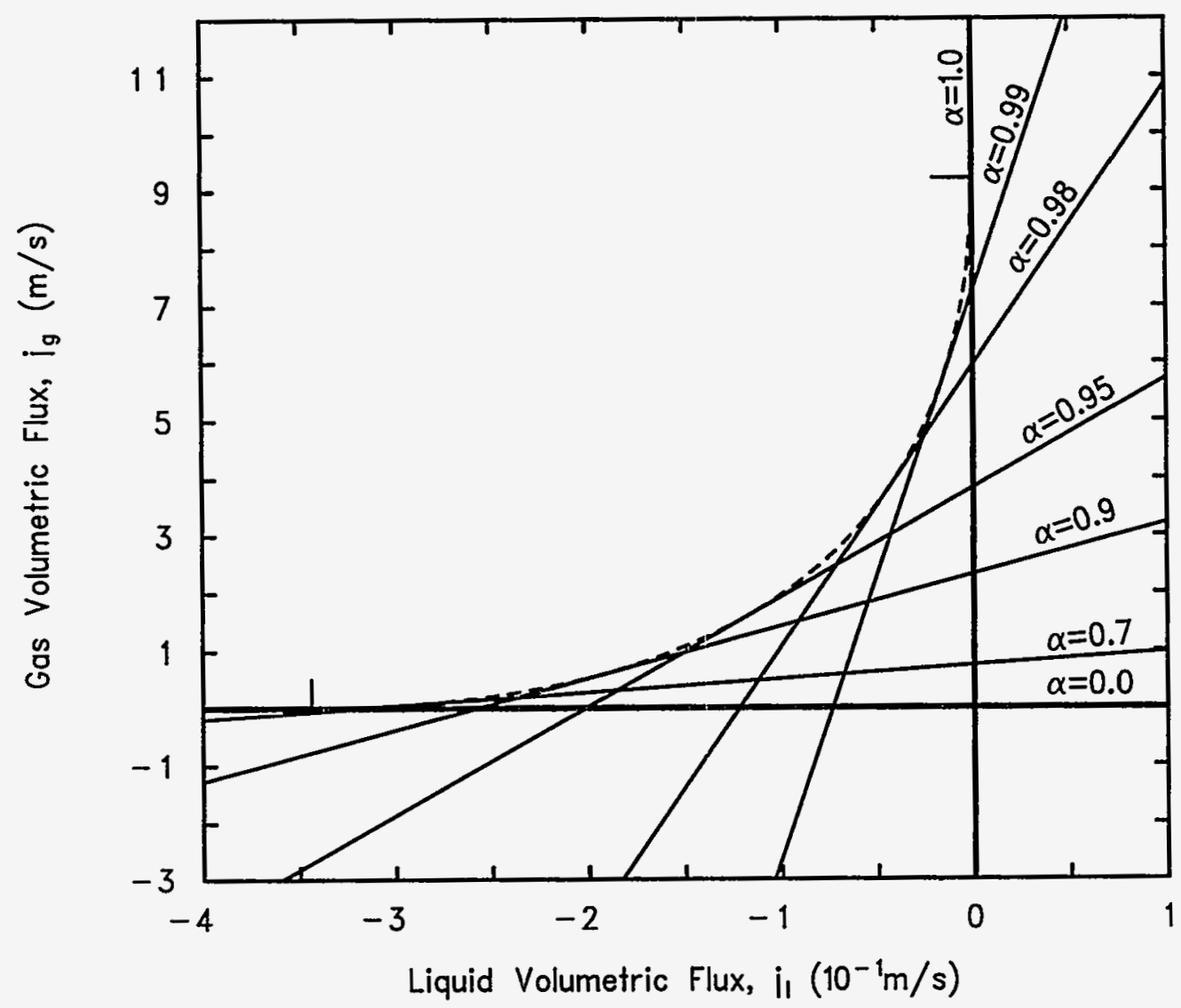

Figure B.1 Drift Flux Lines and the Flooding Curve

The upper lefthand quadrant of Figure B.1 represents a region of countercurrent flow where no quasi-steady solutions are possible. The boundary of this region, formed by the envelope of the drift-flux lines and shown as a dashed curve in the Figure, is called the flooding curve, and defines the limit of (quasi-steady) countercurrent flow. The curve may be parameterized by $\alpha$, and represents the locus of points where

$$
\left(\frac{\partial j_{g}}{\partial \alpha}\right)_{1}=0
$$


One empirical correlation which defines the flooding curve, as discussed by Wallis in Section 11.4 of Reference 12 has the form

$$
\left(\frac{j_{g, F}}{v_{1}}\right)^{\frac{1}{2}}+\left(\frac{j_{Q, F}}{v_{0}}\right)^{\frac{1}{2}}=1 .
$$

Here $j_{g, F}$ and $j_{\ell, F}$ define a point on the flooding curve, and $v_{0}$ and $v_{1}$ are scaling velocities independent of $\alpha$. Note that this equation is often written with a constant other than 1 on the right hand side and/or with a coefficient multiplying either or both terms on the lefthand side; these can be absorbed into the scaling velocities without loss of generality.

It is a straightforward exercise to show that if

$$
v_{r}(\alpha)=\frac{1}{\alpha / v_{1}+\varepsilon / v_{0}}
$$

the flooding curve defined by Equation B.7 is given by

$$
\begin{aligned}
& j_{g, F}=\frac{\alpha^{2} / v_{1}}{\left(\alpha / v_{1}+\varepsilon / v_{0}\right)^{2}}, \\
& j_{\ell, F}=-\frac{\varepsilon^{2} / v_{0}}{\left(\alpha / v_{1}+\varepsilon / v_{0}\right)^{2}} .
\end{aligned}
$$

Equations B.10 and B.11 clearly satisfy the Wallis flooding relation given by Equation B.8. In addition, they give a parameterization of that curve by the void fraction $\alpha$. MELCOR uses velocities rather than volumetric fluxes as the basic variables. In terms of velocities, the parameterization is

$$
\alpha_{F}=\frac{\left|v_{g, F}\right| / v_{0}}{\left|v_{g, F}\right| / v_{0}+\left|v_{\ell, F}\right| / v_{1}} .
$$

The drift flux model is most often used for quasi-steady, nearly incompressible flow. It is relatively simple to assure that a two-fluid model will give similar results in the corresponding regime. In this limit, where $\partial / \partial t \rightarrow 0$ and derivatives of density may be neglected, the momentum equations for the two fields-neglecting momentum flux $(v \partial v / \partial x)$ terms-may be written as

$$
\alpha \frac{\partial P}{\partial x}=\alpha \rho_{g} g_{x}-\alpha F_{g} v_{g}-\alpha \varepsilon F_{\ell g}\left(v_{g}-v_{\ell}\right)
$$


CVH/FL Packages Reference Manual

$$
\varepsilon \frac{\partial P}{\partial x}=\varepsilon \rho_{\ell} g_{x}-\varepsilon F_{\ell} v_{l}-\alpha \varepsilon F_{\ell g}\left(v_{l}-v_{g}\right)
$$

The coefficients $F_{g}, F_{\ell}$ and $F_{\ell g}$ in the various momentum exchange terms are abbreviations for the usual $2 \mathrm{f} \rho|\mathrm{v}| / \mathrm{D}$ terms, in the form most commonly employed in simulation codes for two-phase flow. In these equations, $g_{x}$ is the component of the gravitational acceleration in the $x$ direction; in particular, it is $-g$ if $x$ is measured positive in the upward vertical direction.

If the pressure gradient is eliminated between Equations B.13 and B.14, the result can be cast in the form

$$
j_{g}=\frac{\alpha\left(F_{l}+F_{l g}\right)}{\alpha F_{l}+\varepsilon F_{g}+F_{l g}} j-\frac{\alpha \varepsilon\left(\rho_{l}-\rho_{g}\right) g_{x}}{\alpha F_{l}+\varepsilon F_{g}+F_{l g}}
$$

Comparison of this equation with Equation B.1 shows that the quasi-steady solutions of the two-fluid equations will have a relative velocity given by

$$
v_{r}=-\frac{\left(\rho_{\ell}-\rho_{g}\right) g_{x}}{\alpha F_{l}+\varepsilon F_{g}+F_{\ell g}}
$$

and comparison of this result with Equation B.9 suggests that the interphase force be defined by

$$
\alpha F_{l}+\varepsilon F_{g}+F_{l g}=\left(\rho_{l}-\rho_{g}\right) g_{x}\left(\alpha / v_{1}+\varepsilon / v_{0}\right)
$$

In MELCOR, we are most concerned with the flooding curve, which defines the limit of countercurrent flow. In most cases of interest, the net wall force, $F_{\ell}+F_{g}$, is small compared to the interphase force when flooding occurs. Therefore, wall forces are neglected in Equation B.17, and the interphase force term, $F_{l g}$, is set directly equal to the righthand side of this equation.

Finally, when the differential form of the momentum equation is integrated from volume center to volume center, the integral of $g_{x} d x$ becomes $-g \Delta z$. 


\section{APPENDIX C: Moody Critical Flow}

During evaluation of critical flow models for incorporation into MELCOR, the Moody critical flow tables in RELAP4 [1] were compared to the analytic fits in RETRAN [21] for atmospheric and higher pressures. The two representations agree within a few percent in general, and within a few tenths of one percent at reactor operating pressures.

The data for each pressure were found to be fit extremely well by the simple expression

$$
\frac{\rho_{m}}{G_{C}(\alpha)}=\frac{\alpha \rho_{g}}{G_{C}(1)}+\frac{(1-\alpha) \rho_{\ell}}{G_{C}(0)}
$$

where

$$
\rho_{m} \equiv \alpha \rho_{g}+(1-\alpha) \rho_{\ell}
$$

is the mixture density. Equation C.1 states simply that the inverse of the mass-averaged velocity in critical flow is a linear function of the void fraction. We know of no theoretical basis for this, but the fit is quite good. Figure $\mathrm{C} 1$ shows a typical example. The data are from the RETRAN fits for a pressure of 400 psia; the dashed line shows an approximate linear representation. 
CVH/FL Packages Reference Manual

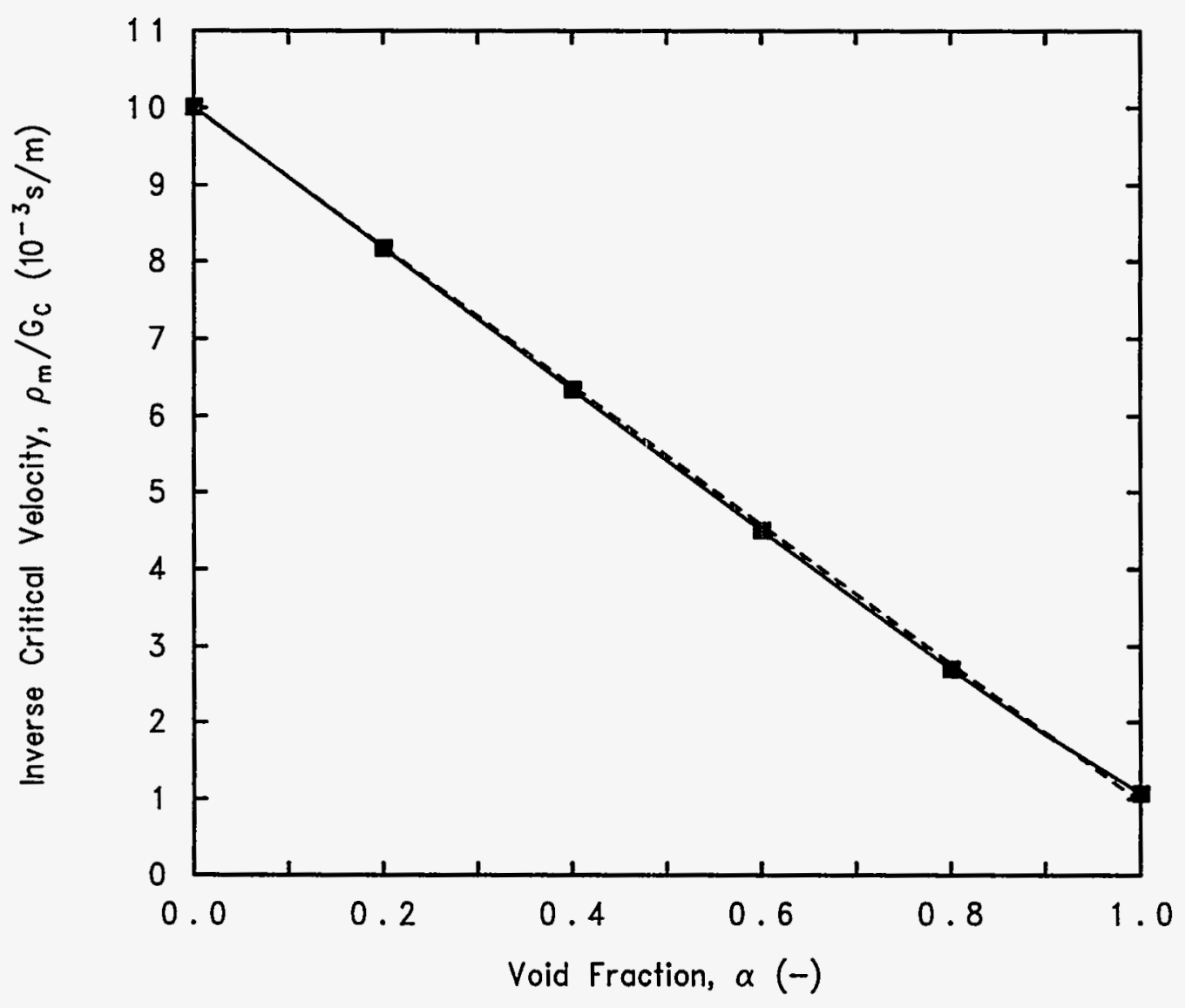

Figure C.1 Moody Critical Flow Data and Approximate Fit 


\title{
Control Volume Thermodynamics (CVT) Package Reference Manual
}

\author{
MELCOR Code Development Group \\ Modeling and Analysis Department \\ Nuclear Energy Technology Center \\ Sandia National Laboratories \\ Albuquerque, NM 87185-0739
}

Randall K. Cole, Jr.

The Control Volume Thermodynamics (CVT) package in the MELCOR code handles thermodynamic calculations for the control volumes included in a MELCOR calculation. Together with the Control Volume Hydrodynamics (CVH) and Flow (FL) packages, it is used to advance the description of the thermal/hydraulic state in the control volumes from one time level to the next. It obtains the properties of the materials which occupy these volumes from the water properties ( $\mathrm{H} 2 \mathrm{O}$ ) and NonCondensible Gas (NCG) packages. Details may be found in the Reference Manuals for these packages. This Reference Manual describes the assumptions, models, and solution strategies used in the various subroutines which make up the CVT package. Because there is no user input for this package, there is no Users' Guide for it. 


\section{Contents}

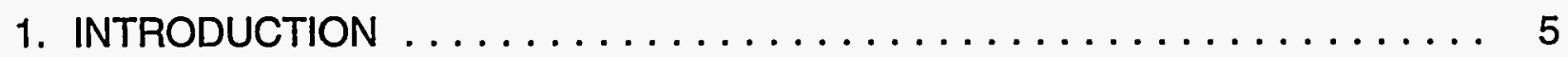

2. EQUILIBRIUM THERMODYNAMICS $\ldots \ldots \ldots \ldots \ldots \ldots \ldots \ldots \ldots$

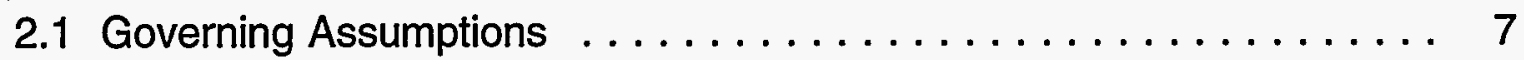

2.2 Governing Equations $\ldots \ldots \ldots \ldots \ldots \ldots \ldots \ldots \ldots \ldots$

2.3 Required Derivatives . . . . . . . . . . . . . . . . 13

2.4 Partition of Liquid Water between Pool and Atmosphere . . . . . . . 14

3. NONEQUILIBRIUM THERMODYNAMICS $\ldots \ldots \ldots \ldots \ldots \ldots \ldots \ldots$

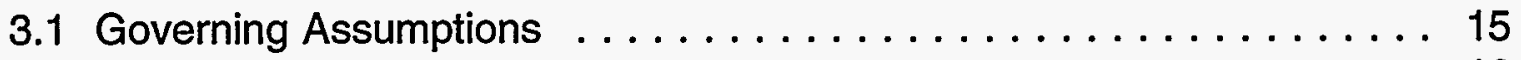

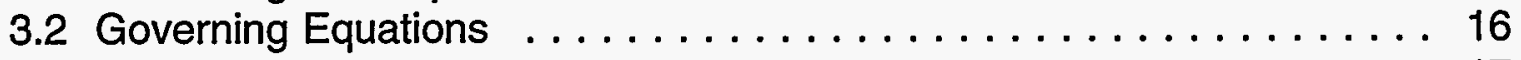

3.3 Required Derivatives . . . . . . . . . . . . . . . 17

3.4 Limit of Vanishing Pool or Atmosphere . . . . . . . . . . . 19

4. OTHER REQUIRED PROPERTIES $\ldots \ldots \ldots \ldots \ldots \ldots \ldots \ldots \ldots \ldots \ldots \ldots \ldots \ldots$

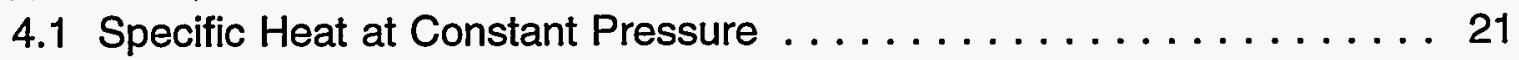

4.2 Sound Speed ............................ 21

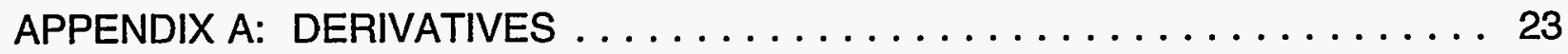

A.1 Derivatives of the Pressure . . . . . . . . . . . . . . 23

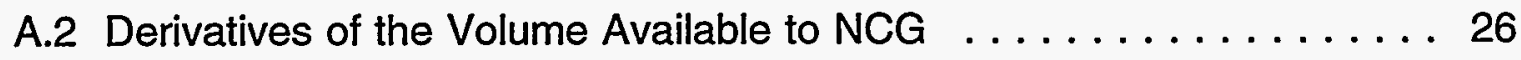

A.3 Derivatives of the Vapor Volume ................. 28 

b. 
CVT Package Reference Manual

\section{INTRODUCTION}

MELCOR's Control Volume Thermodynamics (CVT) package calculates the thermodynamic state of the materials in each control volume from the total volume, the energies, and the masses calculated by the Control Volume Hydrodynamics (CVH) package. The contents of the control volume may be divided into a pool containing water which may be subcooled (liquid) or saturated (two-phase), and an atmosphere containing water vapor, liquid water fog, and noncondensible gases (NCGs). While the terms "pool" and "atmosphere" suggest a quiescent, stratified configuration, the modeling in CVT assumes only that the two components occupy disjoint subvolumes of the total control volume. (Modeling in other areas of MELCOR, however, often assumes stratification.)

In addition to familiar thermodynamic properties such as pressure, heat capacity, and compressibility, the CVT package also calculates the derivatives of the pressure in the volume with respect to its energy and mass contents for use by the implicit flow solver in the CVH package.

Two thermodynamic options are available: equilibrium and nonequilibrium. In MELCOR, equilibrium thermodynamics assumes that the pool and the atmosphere are in thermal and mechanical equilibrium, i.e., that they have the same temperatures and pressures. This implies instantaneous energy and mass transfers between pool and atmosphere.

When the equilibrium option is used, the distinction between pool and atmosphere does not affect the thermodynamics. CVT uses the total mass and energy contents of the control volume to determine its pressure and temperature. All NCGs are assumed to reside in the atmosphere; the assignment of water to pool or atmosphere is made using time-dependent information from the CVH package. Under current modeling, no water vapor is assigned to the pool, but liquid water may be assigned to the atmosphere as fog.

Nonequilibrium thermodynamics, on the other hand, assumes mechanical equilibrium but not thermal equilibrium, so that pressures are equal but temperatures may be different. Complete equilibrium is assumed to exist within the subvolume occupied by the pool and within that occupied by the atmosphere, making this a more limited definition of nonequilibrium than is used in some other codes. The pool may contain water vapor, called void, and the atmosphere may contain fog. Energy and mass transfers between pool and atmosphere resulting from convection/conduction, radiation, and boiling are explicitly calculated in the CVH package. The elimination of void is also computed in the CVH package, using a bubble rise model. The precipitation of fog is treated by the RadioNuclide package (if it is active) and by the CVH package. The volume (PdV) work done by the pool on the atmosphere (or vice versa) must also be accounted for; this is handled in the CVT package itself.

When the nonequilibrium option is used, the thermodynamic state is calculated based on the mass and the total energy of the pool, the masses of the individual components of 


\section{CVT Package Reference Manual}

the atmosphere and their total energy as defined by $\mathrm{CVH}$, and the total volume available to be shared by pool and atmosphere. Part of CVT's job is to determine the partition of the total volume between the pool and the atmosphere such that the pressures of each are equal. Each subvolume is treated as adiabatic in this calculation; thus PdV work is accounted for within the CVT package but heat and mass transfer are not. Because the pool and the atmosphere are each in internal equilibrium, the nonequilibrium option requires application of the equilibrium assumptions within each subvolume.

The CVT package consists of various interfaces to a mixed-material (water and noncondensible gases) equation of state. Properties for water and for noncondensible gases are obtained from the $\mathrm{H} 2 \mathrm{O}$ and NCG packages, respectively. An important feature of the formulation is that it is analytic as well as thermodynamically consistent. Therefore, in contrast to equations of state based on tables or independent polynomial fits, all calculated properties are consistent (for example, a small change in mass or energy produces a change in pressure that agrees to several figures with that estimated from the derivatives). The structure of CVT modeling is illustrated in Figure 1. The block in the figure labeled "subvolume" implements the mixed-material equation of state in MELCOR as described in Section 2; its use in the nonequilibrium model is described in Section 3.

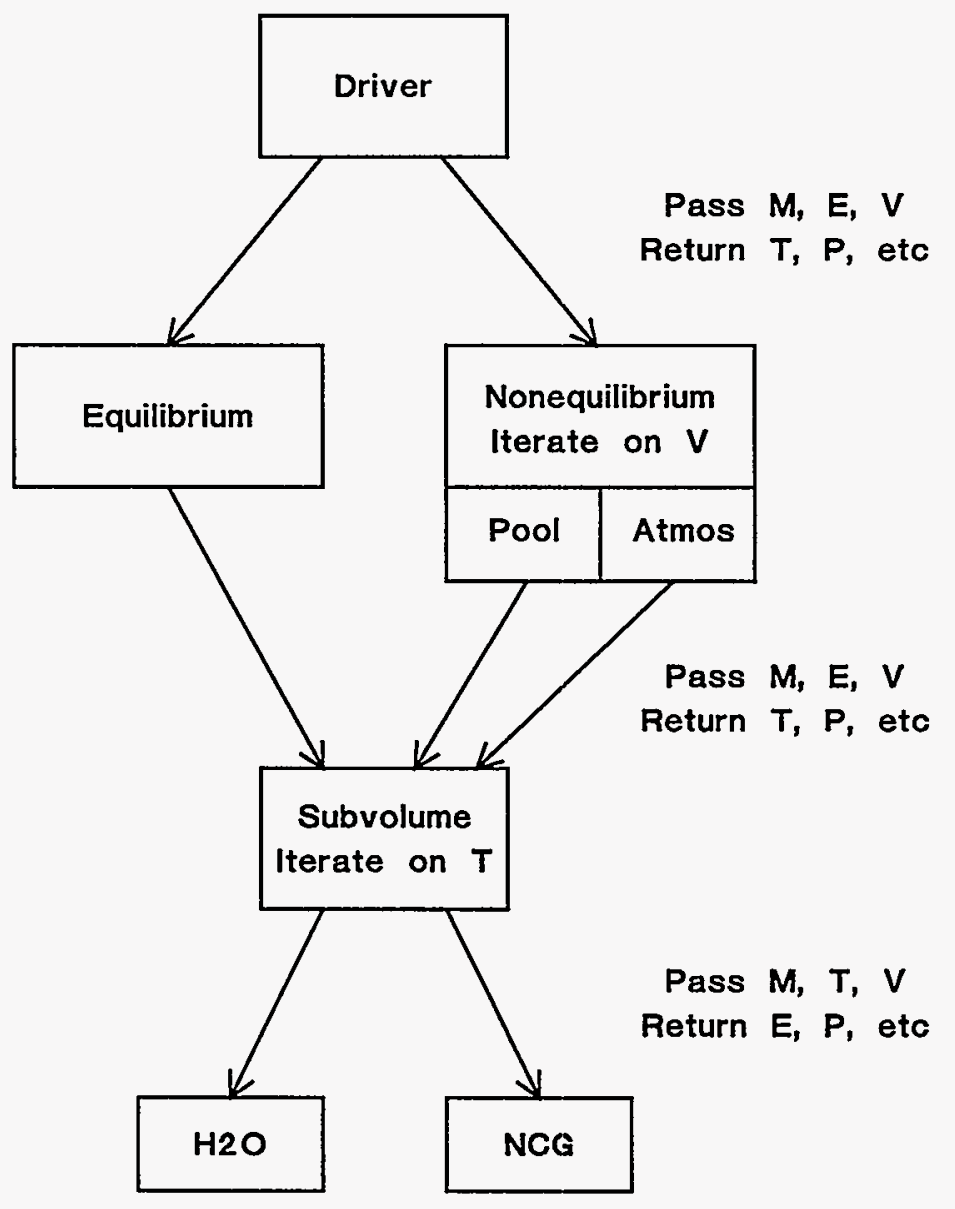

Figure 1. Structure of CVT Model 
CVT Package Reference Manual

\section{EQUILIBRIUM THERMODYNAMICS}

Central to all thermodynamics in MELCOR is a mixed material equilibrium equation of state that determines all thermodynamic properties of mixtures of water and noncondensible gases. This equation of state is applied directly to MELCOR control volumes for which the option of equilibrium thermodynamics has been specified. For volumes where nonequilibrium thermodynamics is specified, it is applied separately to the atmosphere and to the pool. In the latter case, it reduces to the equation of state for water, because NCGs are not currently permitted in the pool.

The remainder of this section describes the mixed material equation of state, in the context of its application to an equilibrium volume. The application to a nonequilibrium volume is described in Section 3.

\subsection{Governing Assumptions}

Equilibrium thermodynamics assumes that the pool and atmosphere temperatures are identical. Given the total volume, the total intemal energy, and the masses of water and NCGs, the problem is to calculate the temperature, the total pressure, the partial pressures of each material, and various other thermodynamic properties. Because all temperatures are assumed equal and surface tension effects are not modeled, the distinction between liquid water as fog or in the pool is immaterial within equilibrium thermodynamics, as is the distinction between water vapor in the atmosphere or in a saturated pool. The assignment of liquid and vapor water to the different possible locations is made after the equilibrium state is determined, using time-dependent information from the CVH package. Therefore, within this section, pool will be used to mean "liquid water" and atmosphere to mean "water vapor plus NCGs." In defining the pressure, there are three basic cases:

(1) If no atmosphere is present (which can only occur if there is no NCG), the pressure is that of the pool.

(2) If no pool is present, the NCGs occupy the total volume together with the water vapor; the total pressure is the sum of their partial pressures.

(3) If both pool and atmosphere are present, their pressures as well as their temperatures are equal, and the partial pressure of water in the atmosphere is the saturation pressure for that temperature. If the atmosphere contains NCG, the pool must be subcooled (its pressure is equal to the sum of the saturation pressure and the partial pressures of the NCGs), and its density is therefore greater than saturation density. Thus, the volume of the atmosphere is greater than that which would be occupied by water vapor in the absence of NCGs. As will be noted below, certain linearizations of the equation of state of water will be used to simplify this calculation. 
CVT Package Reference Manual

\subsection{Governing Equations}

The equilibrium state for a mixture of water and NCGs in a volume, under the assumptions that the NCGs are insoluble in liquid water and form an ideal mixture with water vapor, is given by the simultaneous solution of the equations

$$
\begin{aligned}
& \rho_{l}=\frac{M_{\ell}}{V_{l}}, \\
& \rho_{v}=\frac{M_{v}}{V_{v}}, \\
& M_{\ell}+M_{v}=M_{w}, \\
& V_{l}+V_{v}=V, \\
& g_{l}\left(\rho_{\ell}, T\right)=g_{v}\left(\rho_{v}, T\right), \\
& E=M_{\ell} \theta_{\ell}\left(\rho_{\ell}, T\right)+M_{v} \theta_{v}\left(\rho_{v}, T\right)+\sum_{i=4}^{N} M_{i} \theta_{l}(T), \\
& P=P_{\ell}\left(\rho_{\ell}, T\right)=P_{v}\left(\rho_{v}, T\right)+\sum_{i=4}^{N} \frac{M_{i} R_{i} T}{V_{v}},
\end{aligned}
$$

where
$\rho$ is density,
$M$ is mass,
$V$ is volume,
$g$ is Gibbs free energy,
$T$ is the temperature,
$E$ is the total internal energy,
$e$ is specific internal energy,
$P$ is pressure,
$R$ is gas constant,

and the subscripts $w, \ell, v$, and $i$ refer to water, liquid water, water vapor, and the $i^{\text {th }} N C G$, respectively. (Within MELCOR, $4 \leq i \leq N$ for $N C G$, where $N$ is the total number of materials in the problem.) If the Gibbs free energy, $g$, is considered a function of its natural variables $(P, T)$ rather than of $(\rho, T)$, then $g_{\ell}$ and $g_{v}$ are evaluated at $P_{\ell}\left(\rho_{\ell}, T\right)$ and 
$P_{v}\left(\rho_{v}, T\right)$, respectively. (It is helpful to keep in mind that when these equations are applied in MELCOR, it is the masses, the volume, and the total internal energy which are known, so that densities are more natural variables than are pressures. The temperature, which must actually be determined from densities and energy contents, will continue to be thought of as an independent variable in most cases.)

If water is present, but not NCGs, these relations define the equation of state for water (as calculated in the $\mathrm{H} 2 \mathrm{O}$ package), which may exist as liquid, as vapor, or as a two-phase mixture. Equations 2.2.5 and 2.2.7, expressing equality of the chemical potentials and of the pressures of the two phases, respectively, require that the phases can coexist at temperature $T$ only at the saturation pressure $P_{\text {sat }}^{\circ}(T)$, with densities $\rho_{\ell, \text { sat }}^{\circ}(T)$ and $\rho_{v, \text { sat }}^{\circ}(T)$, where the superscript "o" denotes "in the absence of NCGs."

In the presence of NCGs, the conditions for equilibrium between liquid water and water vapor are modified. The principal effect, that the pressure in the liquid must be the total pressure, is expressed in Equation 2.2.7. In addition, the partial pressure of water vapor at equilibrium is slightly modified by the presence of the NCGs. However, this change and most of its consequences are negligibly small for the temperature and pressure ranges of interest in MELCOR, as will be shown below.

If Equation 2.2.5 is expanded at fixed temperature about the equilibrium state for pure water, using $d g=v d P-s d T$, and noting that $g_{\ell}\left(\rho_{\ell, \text { sat }}^{\circ} T\right)=g_{v}\left(\rho_{v, \text { sat }}^{o} T\right)$, the result is

$$
\frac{P_{\ell}\left(\rho_{\ell, \text { sat }}, T\right)-P_{\text {sat }}^{o}(T)}{\rho_{\ell, \text { sat }}^{o}}=\frac{P_{V}\left(\rho_{V, \text { sat }}, T\right)-P_{\text {sat }}^{o}(T)}{\rho_{V, \text { sat }}^{o}} .
$$

Comparison with Equation 2.2.7 shows that the pressure of water vapor is increased by roughly $\rho_{v, \text { sat }}^{o} / \rho_{\ell, s a t}^{o}$ times the contribution of NCGs to the total pressure. This is a quite small correction under conditions of interest, because the ratio $\rho_{\mathrm{v}, \text { sat }}^{\circ} / \rho_{\ell, \text { sat }}^{\circ}$ is very small unless the pressure of water vapor is near the critical pressure. Even near the critical point of water, the pressure of the NCGs must be at least comparable to that of the water for the effect to be large. Problems in which such high (supercritical) pressures occur are outside the intended range of application of MELCOR. (Furthermore, if both water and NCG pressures are large, the assumption of ideality used to derive the correction is clearly in error and the correction calculated would be invalid.)

Therefore, we neglect the difference between $\rho_{v, \text { sat }}$ and $\rho_{v \text {,sat, }}^{\circ}$ and between $P_{\text {sat }}(T)$ and $P_{\text {sat }}^{o}(T)$. Because the change in saturation vapor pressure is neglected, all water vapor in equilibrium with liquid is treated as having unmodified saturation properties.

The presence of NCGs increases the pressure-and therefore the density-of the liquid compared to a state at the same temperature in the absence of NCGs. Although the resulting difference between $e\left(\rho_{\ell, \text { sat }}, T\right)$ and $e\left(\rho_{\ell, \text { sat }}^{\circ}, T\right)$ could be calculated, examination of Steam Tables (such as Keenan and Keyes) shows the difference to be comparable to the 


\section{CVT Package Reference Manual}

effect of a temperature change of only a fraction of a Kelvin for NCG pressures less than $100 \mathrm{MPa}$. In the interest of simplicity, this difference is neglected. However, the difference in the enthalpy, $h=e+P / \rho$, of the two states is significantly greater, and the difference between $\mathrm{h}$ and $\mathrm{e}$ is responsible for flow work done in the CVH package. Therefore, a first-order correction is made using $\mathrm{dh}=\mathrm{dP} / \mathrm{\rho}$, and the enthalpy of liquid at pressure $P$ in equilibrium with water vapor is taken as

$$
h_{\ell, s a t}(P, T)=h\left(\rho_{\ell, \text { sat }}^{o}, T\right)+\frac{P-P_{\text {sat }}(T)}{\rho_{\ell, \text { sat }}^{o}} .
$$

The most important effect of the compression of liquid water by the partial pressure of NCGs is the resulting increase in the volume available to those NCGs. This is included in detail in the model. (To understand its importance, consider the case where there would be no water vapor in the volume in the absence of NCGs. If the compression were ignored, there would be no volume available to the NCGs, and their pressure would be infinite.)

The compression also increases the volume available to water vapor and, because the density of the water vapor continues to be $\rho_{\mathrm{v}, \mathrm{sat}}^{\circ}$ under the present assumptions, the presence of NCGs acts to increase the mass of water vapor for a given temperature. In the extreme case where the water would be subcooled in the absence of NCGs (and there would be no water vapor in the volume), the NCGs will occupy a volume from which liquid water is excluded, and which therefore will contain water vapor. The associated change in the amount of each water phase is treated very simply as a small correction after the primary calculation has been completed. Any implications for the energy content of the mixture at a given temperature are ignored.

Under the approximations described above, the need for consideration of Equation 2.2.5 is eliminated, and Equation 2.2.6 may be replaced by

$$
\begin{aligned}
& E=M_{w} e_{w}\left(\rho_{w}, T\right)+\sum_{i=4}^{N} M_{i} e_{i}(T), \\
& \rho_{w}=\frac{M_{w}}{V},
\end{aligned}
$$

involving only the normal thermal equation of state for water in terms of its bulk density. Because the energy of the NCGs does not depend on their volume, Equation 2.2.10 may be solved for $T$ without the volume available to NCGs being known. This is done iteratively, with repeated calls to the water and NCG equations of state. Newton's method is used, with a secant (and ultimately a bisection) backup. When the iteration has converged, there are several cases to be considered: 
(1) If there are no NCGs in the volume, the solution is essentially complete at this point as the water equation of state returns mixed-phase properties when appropriate. The total pressure is that returned by the equation of state for water,

$$
P_{\text {tot }}=P_{w}\left(\rho_{w}, T\right)
$$

(2) If there is no liquid water in the volume, the entire volume is available to the NCG, and the total pressure is given by

$$
P_{\text {tot }}=P_{w}\left(\rho_{w}, T\right)+\sum_{i=4}^{N} \frac{M_{i} R_{i} T}{V} \quad \text { (no liquid) }
$$

(from Equation 2.2.7), which assumes that water vapor and NCG form an ideal mixture.

(3) Otherwise, the volume contains both liquid water and NCGs. (Note that if the water occupied the volume alone at the same temperature, the state might be either two-phase or subcooled.) As suggested by the discussion above, we will treat the effects of NCGs on the properties of water as a relatively small perturbation. In the absence of NCGs, the mass balance

$$
V_{\ell} \rho_{\ell, \text { sat }}+V_{v} \rho_{v, \text { sat }}=M_{w}
$$

may be used to show that a volume

$$
V_{v}=\min \left(V, \max \left(0, \frac{V \rho_{\ell, \text { sat }}(T)-M_{w}}{\rho_{\ell, \text { sat }}(T)-\rho_{v, \text { sat }}(T)}\right)\right)
$$

would be occupied by water vapor, and the remaining volume

$$
V_{\ell}=V-V_{v}
$$

would be occupied by liquid, where $\rho_{\ell, \text { sat }}(T)$ and $\rho_{v, \text { sat }}(T)$ are the densities of saturated liquid and vapor at the temperature $T$. (The coding contains a modification to the water phase boundary to maintain a continuous definition of "liquid" and "vapor" at high pressures and supercritical temperatures; while water should never reach such a state in a reactor, this region of the equation of state may be encountered during iterations within the code.)

The requirement that pool and atmosphere have the same pressure when NCGs are included is imposed by assuming: (1) that the presence of the NCGs causes a reduction of the volume of the liquid by $\delta \mathrm{V}$; (2) that the NCGs then occupy the volume

$$
V_{n}=V_{v}+8 V \quad ;
$$




\section{CVT Package Reference Manual}

and (3) that the resulting pressure is given by the linearization of Equation 2.2.7 as

$$
P_{t o t}= \begin{cases}P_{w}\left(\rho_{w}, T\right)+\frac{\delta V}{K V_{l}} & \text { (pool) } \\ P_{s a t}(T)+\sum_{i=4}^{N} \frac{M_{l} R_{l} T}{V_{V}+\delta V} & \text { (atmosphere) }\end{cases}
$$

where $\mathrm{P}_{\ell}$ in Equation 2.2.7 has been replaced by $\mathrm{P}_{w}$ (the two are equal in this case), and $P_{v}$ has been replaced by $P_{\text {sat }}(T)$, the partial pressure of water vapor in the atmosphere. $\mathrm{K}$ is defined in terms of the compressibility of the liquid phase as

$$
K=\left(\rho_{\ell} \frac{\partial P_{\ell}}{\partial \rho_{\ell}}\right)^{-1} \text {. }
$$

Equation 2.2.18 results in a quadratic equation for $\delta \mathrm{V}$,

$$
(\delta V)^{2}+\left(V_{v}+K V_{\ell} \Delta P\right) \delta V-K V_{\ell} \sum_{i=4}^{N} M_{i} R_{i} T=0,
$$

where

$$
\Delta P=P_{w}-P_{\text {sat }}(T) \quad ;
$$

and the fact that either $V_{v}$ or $\Delta P$ is zero has been used (the former if the water would be subcooled in the absence of NCGs, the latter if it would be two-phase). If the water is two-phase, the total pressure is best evaluated from the second form of Equation 2.2.18,

$$
P_{\text {tot }}=P_{w}\left(\rho_{w}, T\right)+\sum_{i=4}^{N} \frac{M_{i} R_{i} T}{V_{v}+\delta V}
$$

noting that $P_{w}\left(\rho_{w}, T\right)=P_{\text {sat }}(T)$. Otherwise, for pure liquid (saturated or subcooled), the first form gives

$$
P_{\text {tot }}=P_{w}\left(\mathrm{\rho}_{w}, T\right)+\frac{\delta V}{K V}
$$

noting that $V_{\ell}=V$.

At this point, the atmosphere volume, $V_{n}$, is greater than the volume of water vapor from the water equation of state, $V_{v}$, by an amount $\delta V$ (Equation 2.2.17). Therefore, in order to maintain the density of water vapor in the atmosphere as 
CVT Package Reference Manual

$\rho_{v, \text { sat }}(T)$, a mass of water equal to $\rho_{v, \text { sat }}(T) \delta V$ is transferred from the liquid to the vapor state by simply modifying the quality of water in the volume to be

$$
x^{\prime}=x+\frac{\rho_{v, s a t}(T) \delta V}{M_{w}}
$$

The mass involved is an extremely small fraction of the liquid mass because $\delta \mathrm{V}$ is much smaller than $V_{l}$ (liquid water is almost incompressible), and $\rho_{v, \text { sat }}(T)$ is much smaller than $\rho_{\ell, \text { sat }}(T)$. The energy implications of assigning vapor energy rather than liquid energy to this mass are also very small, and are dealt with by the final adjustment to internal energy described below.

Just as $V_{n}$ is greater that $V_{v}$, the remaining liquid volume is less than the value $V_{f}$ used in the water equation of state. In addition to the correction to the liquid enthalpy given by Equation 2.2.9, a correction is made to the liquid density. As discussed in conjunction with Equation 2.2.9, the effect on liquid internal energy is small, and has been ignored. Because the uncorrected value has been used consistently, there are no implications with respect to conservation of energy.

The solution is now complete. A temperature has been found such that the known total internal energy is matched within the convergence tolerance of the iterative solution procedure. The pressure and all other thermodynamic properties have been evaluated consistently using that temperature and the known volume and masses. Because the total internal energy is the primary - and conserved - quantity, a final adjustment is made to calculated specific internal energies so that Equation 2.2.10 is satisfied exactly. The adjustment is made either to the water or to the NCGs, depending on which has the greater total heat capacity.

\subsection{Required Derivatives}

A number of derivatives of the total pressure are required for the implicit solution of the flow equation (see the CVH/FL Reference Manual) or, as will be shown in a later section, for use in solving the nonequilibrium thermodynamic relations in volumes which employ that option. The natural variables for these derivatives are the total energy in the volume, $\mathrm{E}$, the vector of masses in the volume, $\mathbf{M}$, and the available hydrodynamic volume, $\mathrm{V}$. The required derivatives are $(\partial P / \partial E)_{M, V},\left(\partial P / \partial M_{w}\right)_{E, V},\left(\partial P / \partial M_{i}\right)_{E, V}$ where $4 \leq i \leq N$ denotes one of the NCGs, and $(\partial P / \partial V)_{E, M}$. Evaluation of these derivatives is straightforward but tedious. The required expressions are presented in Appendix A. 


\section{CVT Package Reference Manual}

\subsection{Partition of Liquid Water between Pool and Atmosphere}

The preceding material describes a mixed-material equation of state in which it is assumed that water vapor and noncondensible gases (if both are present) are mixed within a common (sub)volume. For a volume in which nonequilibrium thermodynamics is specified, this equation of state will be applied to the pool and atmosphere separately as described in Section 3. Separate mass inventories are calculated for the pool and the atmosphere, and the pool is assumed to contain no noncondensible gases. Therefore, water vapor in the pool is unambiguously interpreted as vapor bubbles (void) and liquid water in the atmosphere as vapor droplets (fog).

For a volume in which equilibrium thermodynamics is specified, and the equation of state is applied to the entire contents of the volume, the situation is not so simple. The reason is that heat and mass transfer between pool and atmosphere are implicitly included within CVT. Therefore, only the total water content and the total energy of the control volume are known, and not the energies and water contents of pool and atmosphere individually.

As stated in the introduction, a basic assumption of the model is that the pool contains water only. If NCGs are present in an equilibrium volume, any liquid water must be subcooled as a consequence of the additional partial pressures of the NCGs. The pool-which can contain no NCGs-can therefore contain no bubbles. In the absence of NCGs, there is no such restriction but, to avoid introduction of an unacceptable discontinuity between the two cases, the equilibrium model assumes that there is no void in the pool.

There is no such thermodynamic basis for defining the partition of liquid water between pool and fog. Both consist of subcooled (in the presence of NCGs) or saturated (in their absence) liquid water. As currently coded, the equilibrium model also assumes that there is preferential evaporation of, or condensation to, fog, so that the mass of water in the atmosphere is conserved if possible. That is, the new fog mass is calculated as

$$
M_{\text {fog }}^{\text {now }}=\max \left(M_{\text {fog }}^{\text {old }}+M_{\text {vap }}^{\text {old }}-M_{\text {vap }}^{\text {now }}, 0\right) .
$$

and any remaining mass of liquid water (as calculated by the equilibrium equation of state) is assigned to the pool. 
CVT Package Reference Manual

\section{NONEQUILIBRIUM THERMODYNAMICS}

As discussed in Section 1, the implementation of nonequilibrium thermodynamics in MELCOR is more restrictive than in some other codes. The underlying equation of state is strictly equilibrium, and does not allow subcooled vapor or superheated liquid. However, if the nonequilibrium option is selected, the pool and atmosphere within a control volume (which are also the two fields in the hydrodynamic equations) are not required to be thermal or evaporative equilibrium.

\subsection{Governing Assumptions}

Nonequilibrium thermodynamics assumes that the pool and the atmosphere have equal pressures but that their temperatures may be unequal. As currently implemented, it assumes that all NCGs are in the atmosphere. The pool may contain some water vapor as well as liquid, and the atmosphere may contain some liquid water (fog) in addition to vapor. For each field, the total water is determined by the mass inventory; the liquid/vapor state is determined implicitly by the energy content.

Given the total volume, the start-of-timestep subvolumes of the pool and of the atmosphere, the total internal energies of the pool and of the atmosphere at these start-of-timestep subvolumes, the mass of water in the pool, and the masses of water and NCGs in the atmosphere, the problem is to calculate the new subvolumes of the pool and of the atmosphere, the temperatures of each, and the common pressure. In computing the subvolumes, it is assumed that the boundary between pool and atmosphere is adiabatic because all heat and mass transfer has already been calculated in the CVH package. However the work done by displacement of the interface has not yet been calculated, and must be included in CVT. It is for this reason that the start-of-timestep subvolumes are needed.

The general equilibrium model described above for volumes in which equilibrium thermodynamics is specified is used to determine the properties of the atmosphere. It may be seen that the same three cases listed in Section 2.1 for equilibrium thermodynamics may occur:

(1) The atmosphere may contain liquid only (only if there are no NCGs),

(2) It may contain no liquid, and

(3) It may contain water vapor and/or NCGs in addition to liquid.

The first case, of course, has no physical significance because an "atmosphere" containing liquid water only is indistinguishable from "pool". It is included for completeness and then dealt with outside of the CVT package. 


\section{CVT Package Reference Manual}

Because of the assumption that there are no NCGs in the pool, it could be treated by using the equation of state for water alone. However, in the interest of consistency, the same general equilibrium model is also used to determine its properties. This will also simplify changes to allow NCGs in the pool if desired in future versions of MELCOR.

\subsection{Governing Equations}

If a volume is to be treated in the nonequilibrium approximation, the pool and the atmosphere are each individually described by equilibrium thermodynamics. If we consider the pressure to be a function of masses, energy, and volume, and denote by $P_{\text {equil }}(M, E, V)$ the function defined by the treatment of equilibrium thermodynamics in Section 2.2, the problem is to find the partition of the total volume, $V$, into two components $V_{p}$ and $V_{a}$ such that

$$
V_{p}+V_{a}=V
$$

and

$$
P_{\text {equil }}\left(M_{p}, E_{p}+P^{\text {old }}\left(V_{p}^{\text {old }}-V_{p}\right), V_{p}\right)=P_{\text {equil }}\left(M_{a}, E_{a}+P^{\text {old }}\left(V_{a}^{\text {old }}-V_{a}\right), V_{a}\right) \text {. }
$$

Here the superscript "old" refers to the value at the start of the timestep. The terms in Equation 3.2.2 involving the old pressure and the change in volume during the timestep represent the volume work done by the pool on the atmosphere or vice versa. The old pressure (rather than some average over the timestep) must be used for consistency because, for the solution scheme used in the CVH package, mass moved through the flow paths carries old enthalpies, and therefore does work with old pressures. For example, in an extreme case where all but an insignificant amount of the atmosphere leaves a control volume during a timestep, it will transport an energy of $M_{a}^{\text {old }} h_{a}^{\text {old }}$ in the limit as the remaining mass of the atmosphere goes to zero, consisting of its internal energy plus the volume work done by its motion. This will leave the remaining atmosphere with an energy approaching - $\mathrm{P}^{\text {old }} \mathrm{V}_{\mathrm{a}}^{\text {old }}$ before the work done on it by the pool is accounted for in CVT. Its new volume and new energy as determined by CVT must also go to zero, which can only happen if the old pressure is used in the volume work term.

Equation 3.2.2 is solved iteratively, subject to the constraint of Equation 3.2.1, by using Newton's method with a secant (and ultimately a bisection) backup. In order to avoid roundoff problems, the smaller of $V_{p}$ and $V_{a}$ is treated as the primary variable within the iteration. The same model used for equilibrium thermodynamics is used to evaluate $P_{\text {equit }}$ and its derivatives for the pool and for the atmosphere subvolumes. Because no heat transfer is included in CVT, the isentropic (adiabatic) derivatives of pressure with respect to volume 


$$
\left(\frac{\partial P}{\partial V}\right)_{S, M}=\left(\frac{\partial P}{\partial V}\right)_{E, M}-P\left(\frac{\partial P}{\partial E}\right)_{M, V}
$$

for the pool and for the atmosphere are used in the Newton iteration. This is consistent with inclusion of the PdV terms in Equation 3.2.2 (note that $(\partial E / \partial V)_{S, M}=-P$ ).

\subsection{Required Derivatives}

Once Equation 3.2.2 has been solved to determine the volumes $V_{p}$ and $V_{a}$, the derivatives required for solution of the flow equation are easily found from those already available for the subvolumes alone. For a differential change in some variable (mass, energy, or volume) for the pool or for the atmosphere, the differential change in pressure (under the current nonequilibrium assumptions) may be found by simultaneous solution of

$$
\begin{aligned}
d P_{p} & =\left(\frac{\partial P_{p}}{\partial E_{p}}\right)_{M_{p}, V_{p}}\left(d E_{p}-P d V_{p}\right)+\left(\frac{\partial P_{p}}{\partial M_{w, p}}\right)_{E_{p}, V_{p}} d M_{w, p} \\
& +\sum_{i=4}^{N}\left(\frac{\partial P_{p}}{\partial M_{l, p}}\right)_{E_{p}, V_{p}} d M_{i, p}+\left(\frac{\partial P_{p}}{\partial V_{p}}\right)_{E_{p}, M_{p}} d V_{p} \\
d P_{a} & =\left(\frac{\partial P_{a}}{\partial E_{a}}\right)_{M_{a}, V_{a}}\left(d E_{a}-P d V_{a}\right)+\left(\frac{\partial P_{a}}{\partial M_{w, a}}\right)_{E_{a}, V_{a}} d M_{w, a} \\
& +\sum_{l=4}^{N}\left(\frac{\partial P_{a}}{\partial M_{l, a}}\right)_{E_{a,}, V_{a}} d M_{l, a}+\left(\frac{\partial P_{a}}{\partial V_{a}}\right)_{E_{a}, M_{a}} d V_{a}
\end{aligned}
$$

subject to

$$
\begin{aligned}
& d P=d P_{p}=d P_{a}, \\
& d V_{p}+d V_{a}=0
\end{aligned}
$$

(The summation over NCGs in the pool is retained in Equation 3.3.1 to allow future generalization, but the corresponding NCG masses are identically zero under current modeling assumptions.) In these equations $P_{p}$ and $P_{a}$ are used to represent $P_{\text {equil }}$ (pool) and $P_{\text {equil }}$ (atmosphere) and, to avoid further complicating the notation, it has been assumed that a derivative with respect to a component mass is evaluated with all other component masses held constant. Note the inclusion of the PdV terms in Equations 3.3.1 


\section{CVT Package Reference Manual}

and 3.3.2; here $\mathrm{dE}$ includes only those changes in energy treated by the CVH package, which does not consider volume work done by the pool on the atmosphere of the same calculational volume (or vice versa).

Solution of these equations leads to the desired derivatives. For example, if only $d_{\mathrm{p}}$ is non-zero, Equations 3.3.1, 3.3.2, and 3.3.3 yield

$$
\begin{aligned}
& d P=d P_{p}=\left(\frac{\partial P_{p}}{\partial E_{p}}\right)_{M_{p}, V_{p}} d E_{p}+\left(\left(\frac{\partial P_{p}}{\partial V_{p}}\right)_{E_{p}, M_{p}}-P\left(\frac{\partial P_{p}}{\partial E_{p}}\right)_{M_{p}, V_{p}}\right) d V_{p}, \\
& d P=d P_{a}=\left(\left(\frac{\partial P_{a}}{\partial V_{a}}\right)_{E_{a}, M_{a}}-P\left(\frac{\partial P_{a}}{\partial E_{a}}\right)_{M_{a}, V_{a}}\right) d V_{a},
\end{aligned}
$$

On eliminating $d V_{p}$ and $d V_{a}$ by using Equation 3.3.4, and identifying the adiabatic derivatives defined by Equation 3.2.3, this leads to the result

$$
\left(\frac{\partial P}{\partial E_{p}}\right)_{E_{a}, M_{p}, M_{a}, V}=\frac{\left(\frac{\partial P_{a}}{\partial V_{a}}\right)_{S_{a}, M_{a}}\left(\frac{\partial P_{p}}{\partial E_{p}}\right)_{M_{p}, V_{p}}}{\left(\frac{\partial P_{a}}{\partial V_{a}}\right)_{S_{a}, M_{a}}+\left(\frac{\partial P_{p}}{\partial V_{p}}\right)_{S_{p}, M_{p}}} .
$$

The general expressions, from which all the required derivatives may be evaluated, may be seen to be

$$
\left(\frac{\partial P}{\partial \xi_{p}}\right)_{\{\ldots\}}=\frac{\left(\frac{\partial P_{a}}{\partial V_{a}}\right)_{S_{a, M a}}\left(\frac{\partial P_{p}}{\partial \xi_{p}}\right)_{\{\ldots\}}}{\left(\frac{\partial P_{a}}{\partial V_{a}}\right)_{S_{a}, M_{a}}+\left(\frac{\partial P_{p}}{\partial V_{p}}\right)_{S_{p}, M_{p}}},
$$

and

$$
\left(\frac{\partial P}{\partial \xi_{a}}\right)_{\{\ldots\}}=\frac{\left(\frac{\partial P_{p}}{\partial V_{p}}\right)_{S_{p}, M_{p}}\left(\frac{\partial P_{a}}{\partial \xi_{a}}\right)_{\{\ldots\}}}{\left(\frac{\partial P_{a}}{\partial V_{a}}\right)_{S_{a}, M_{a}}+\left(\frac{\partial P_{p}}{\partial V_{p}}\right)_{S_{p}, M_{p}}} .
$$

where $\xi_{\phi}$ is any one of the variables $E_{\phi}, M_{w, \phi}$, or $M_{i, \phi}$ " $\phi$ " is " $p$ " or "a", and $\{. .$.$\} denotes that$ set of variables which is to be kept constant under variation of $\xi_{\phi}$. 
CVT Package Reference Manual

\subsection{Limit of Vanishing Pool or Atmosphere}

The separate mass and energy inventories calculated by $\mathrm{CVH}$ for the pool and the atmosphere are used to determine the thermodynamic properties of nonequilibrium volumes. In the limit where either the pool or the atmosphere in such a volume becomes extremely small, any loss of precision in calculating the energy content of the vanishing subvolume will have a large effect on the calculated temperature, since its heat capacity goes to zero. Blind application of the model described above leads to unacceptably large excursions in the calculated temperatures of very small pools and atmospheres.

This problem is handled within current coding by switching to the equilibrium formulation whenever a volume specified as nonequilibrium contains only an extremely small $\left(10^{-6}\right)$ volume fraction of pool or of atmosphere. One result is that when a nonequilibrium volume becomes completely filled by a two-phase pool, application of the equilibrium model results in an inappropriate separation of the two-phase pool into a pool containing only saturated liquid and an atmosphere containing the saturated water vapor from the bubbles.

This is clearly not a satisfactory solution. The principal problem is that the equilibrium model does not correspond to the infinite mass-and-heat-transfer limit of the nonequilibrium model. However, making the treatment of equilibrium and nonequilibrium volumes completely consistent would not be trivial, and might require elimination of the assumption that a pool can contain no NCGs.

On the other hand, extending the nonequilibrium model to handle the limit of a vanishing pool or atmosphere would require some modification to constrain the calculated temperature difference between pool and atmosphere. This would almost certainly require inclusion of an implicit contribution to the heat transfer (and possibly the mass transfer) between the pool and the atmosphere, either in CVH or (more likely) within CVT. 
CVT Package Reference Manual 
CVT Package Reference Manual

\section{OTHER REQUIRED PROPERTIES}

Other thermodynamic properties may be calculated from those returned by the $\mathrm{H} 2 \mathrm{O}$ and NCG packages, using familiar thermodynamic relationships.

\subsection{Specific Heat at Constant Pressure}

The $\mathrm{H} 2 \mathrm{O}$ package does not return the specific heat of water at constant pressure. Where this is needed, it is evaluated from the standard relationship

$$
c_{p}=c_{v}+\frac{T\left(\frac{\partial P}{\partial T}\right)_{\rho}^{2}}{\rho^{2}\left(\frac{\partial P}{\partial \rho}\right)_{T}} .
$$

\subsection{Sound Speed}

The speed of sound in the pool and that in the atmosphere are calculated by CVT for use in other packages. The speed of sound in a material is defined in terms of the adiabatic bulk modulus as

$$
C_{s}^{2}=\left(\frac{\partial P}{\partial \rho}\right)_{s} .
$$

Through the use of standard thermodynamic manipulations, Equation 4.2.1 may be rec̈ast in the form

$$
C_{s}^{2}=\left(\frac{\partial P}{\partial \rho}\right)_{T}+\frac{\left(\frac{\partial P}{\partial T}\right)_{\rho}^{2}}{\rho^{2} c_{v}} ;
$$

all of the variables in the latter form are available from the $\mathrm{H} 2 \mathrm{O}$ and NCG packages. For a mixture, the sound speed calculated is that given by Equation 4.2.2 using mixture properties. It corresponds to an equilibrium (long-wavelength) limit, where there is adequate time for energy exchange between species. 
CVT Package Reference Manual 
CVT Package Reference Manual

\section{APPENDIX A: DERIVATIVES}

This Appendix presents the equations necessary for evaluation of the derivatives of the pressure of an equilibrium mixture with respect to energy, total volume, and various masses. Considerable care has been taken to indicate, using subscripts, what is kept constant in each derivative. When no subscripts are present, the explicit derivative is intended-that is, the derivative in terms of variables appearing explicitly in the definition of the function. However, subscripts are included in some cases where the derivative is, in fact, an explicit one. In order to avoid further complicating the notation, it has been assumed that a derivative with respect to a component mass is evaluated with all other component masses held constant.

In the following sections, the pressure is considered to be an explicit function of $\rho_{w}, T, V$, and $V_{n}$, and of $M_{i} R_{i}$ for each NCG. The chain rule will be used in evaluating the desired results. $V_{n}$ will be treated as an explicit function of $T, M_{w}, V$, and the $M_{i} R_{i}$, with derivatives given in Section A.2. $V_{v}$ will be treated as an explicit function of $T, M_{w}$, and $V$, with derivatives given in Section A.3.

\section{A.1 Derivatives of the Pressure}

The various results presented in Equations 2.2.12, 2.2.13, 2.2.22, and 2.2.23 reduce to only two cases. They are:

(1) If the water would be single-phase (saturated or subcooled) liquid in the absence of NCGs, the total pressure including the effects of NCG is given by Equation 2.2.23 (noting that $\delta V=V_{n}$ ) as

$$
P=P_{w}\left(\rho_{w}, T\right)+\frac{V_{n}}{K V},
$$

with explicit derivatives

$$
\begin{aligned}
& \frac{\partial P}{\partial \rho_{w}}=\frac{\partial P_{w}}{\partial \rho_{w}}, \\
& \frac{\partial P}{\partial T}=\frac{\partial P_{w}}{\partial T}, \\
& \frac{\partial P}{\partial V}=-\frac{V_{n}}{K V^{2}},
\end{aligned}
$$


CVT Package Reference Manual

$$
\begin{aligned}
& \frac{\partial P}{\partial V_{n}}=\frac{1}{K V}, \\
& \frac{\partial P}{\partial\left(M_{j} R_{i}\right)}=0 .
\end{aligned}
$$

(2) In all other cases, the pressure is

$$
P=P_{w}\left(\rho_{w}, T\right)+\sum_{i=4}^{N} \frac{M_{i} R_{i} T}{V_{n}},
$$

with explicit derivatives

$$
\begin{aligned}
& \frac{\partial P}{\partial \rho_{w}}=\frac{\partial P_{w}}{\partial \rho_{w}}, \\
& \frac{\partial P}{\partial T}=\frac{\partial P_{w}}{\partial T}+\sum_{i=4}^{N} \frac{M_{i} R_{i}}{V_{n}}, \\
& \frac{\partial P}{\partial V}=0, \\
& \frac{\partial P}{\partial V_{n}}=-\sum_{i=4}^{N} \frac{M_{i} R_{i} T}{V_{n}^{2}}, \\
& \frac{\partial P}{\partial\left(M_{i} R_{i}\right)}=\frac{T}{V_{n}} .
\end{aligned}
$$

The derivative of pressure with respect to energy is evaluated from

$$
\left(\frac{\partial P}{\partial E}\right)_{M, V}=\left(\frac{\partial P}{\partial T}\right)_{M, V} /\left(\frac{\partial E}{\partial T}\right)_{M, V},
$$

where

$$
\left(\frac{\partial P}{\partial T}\right)_{M, V}=\frac{\partial P}{\partial T}+\frac{\partial P}{\partial V_{n}}\left(\frac{\partial V_{n}}{\partial T}\right)_{M, V},
$$


CVT Package Reference Manual

$$
\left(\frac{\partial E}{\partial T}\right)_{M, V}=M_{w} c_{v, w}+\sum_{i=4}^{N} M_{l} c_{v, i}
$$

Here, $c_{\mathrm{v}}$ is the specific heat at constant volume, all water properties and their derivatives come from the $\mathrm{H} 2 \mathrm{O}$ package, and NCG properties come from the NCG package. Derivatives of $V_{n}$ will be discussed in Section A.2.

The derivative of pressure with respect to total volume is given by

$$
\left(\frac{\partial P}{\partial V}\right)_{E, M}=\frac{\partial P}{\partial V}+\frac{\partial P}{\partial V_{n}}\left(\frac{\partial V_{n}}{\partial V}\right)_{T, M}-\frac{\rho_{W}}{V} \frac{\partial P_{W}}{\partial \rho_{W}}+\left(\frac{\partial P}{\partial T}\right)_{M, V}\left(\frac{\partial T}{\partial V}\right)_{E, M} \text {. }
$$

Derivation of Equation A.1.16 requires multiple application of the chain rule since, for example, $V_{n}$ is an explicit function of $T$ rather than of $E$. The additional term is responsible for the appearance of $(\partial \mathrm{P} / \partial \mathrm{T})_{\mathrm{M}, \mathrm{V}}$ (Equation A.1.14) rather than simply $\partial \mathrm{P} / \partial \mathrm{T}$. Finally,

$$
\left(\frac{\partial T}{\partial V}\right)_{E, M}=-\left(\frac{\partial E}{\partial V}\right)_{T, M} /\left(\frac{\partial E}{\partial T}\right)_{M, V},
$$

in which

$$
\left(\frac{\partial E}{\partial V}\right)_{T, M}=-P_{w}+T \frac{\partial P_{w}}{\partial T} ;
$$

derivation of Equation A.1.18 requires use of the Maxwell relation $(\partial S / \partial V)_{T, M}=(\partial P / \partial T)_{M, V}$, and only water contributes because the internal energy of an ideal gas is independent of its volume.

The derivative of pressure with respect to water mass is given by

$$
\left(\frac{\partial P}{\partial M_{w}}\right)_{E, V}=\frac{\partial P}{\partial V_{n}}\left(\frac{\partial V_{n}}{\partial M_{w}}\right)_{T, V}+\frac{1}{V} \frac{\partial P_{w}}{\partial \rho_{w}}+\left(\frac{\partial P}{\partial T}\right)_{M, V}\left(\frac{\partial T}{\partial M_{w}}\right)_{E, V},
$$

where

$$
\begin{aligned}
& \left(\frac{\partial T}{\partial M_{W}}\right)_{E, V}=-\left(\frac{\partial E}{\partial M_{W}}\right)_{T, V} /\left(\frac{\partial E}{\partial T}\right)_{M, V} ; \\
& \left(\frac{\partial E}{\partial M_{W}}\right)_{T, V}=\theta_{W}\left(\rho_{w}, T\right)-\frac{1}{\rho_{W}}\left(\frac{\partial E}{\partial V}\right)_{T, M} ;
\end{aligned}
$$




\section{CVT Package Reference Manual}

the relation between $\left(\partial E / \partial M_{w}\right)_{T, V}$ and $(\partial E / \partial V)_{T, M}$ given by Equation $A .1 .18$ is easily seen from Equation 2.2.10.

The derivative of pressure with respect to the mass of the $i^{\text {th }}$ NCG is given by

$$
\left(\frac{\partial P}{\partial M_{i}}\right)_{E, V}=R_{i}\left(\frac{\partial P}{\partial\left(M_{i} R_{i}\right)}+\frac{\partial P}{\partial V_{n}} \frac{\partial V_{n}}{\partial\left(M_{i} R_{i}\right)}\right)-\left(\frac{\partial P}{\partial E}\right)_{M, V}\left(\frac{\partial E}{\partial M_{i}}\right)_{T, V},
$$

where

$$
\left(\frac{\partial E}{\partial M_{i}}\right)_{T, V}=e_{i}(T)
$$

\section{A.2 Derivatives of the Volume Available to NCG}

The equations in the preceding section contain derivatives of the volume available to NCGs, $V_{n}$. Unless there are both NCGs and liquid water in the volume, $\delta V$ is zero, $V_{n}$ is identical to $V_{v}$, and we have

$$
\begin{array}{ll}
\left(\frac{\partial V_{n}}{\partial V}\right)_{T, M}=\left(\frac{\partial V_{V}}{\partial V}\right)_{T, M} & \text { (no NCG or no liquid) } \\
\left(\frac{\partial V_{n}}{\partial T}\right)_{M, V}=\left(\frac{\partial V_{V}}{\partial T}\right)_{M, V} & \text { (no NCG or no liquid) } \\
\left(\frac{\partial V_{n}}{\partial M_{w}}\right)_{T, V}=\left(\frac{\partial V_{V}}{\partial M_{w}}\right)_{T, V} & \text { (no NCG or no liquid) }
\end{array}
$$

(Expressions for derivatives of $V_{v}$ are given in Section A.3.) The derivative with respect to NCG masses is more complicated, and must be found from the general case below.

If $\delta V$ is non-zero (case 3 of Section 2.2), we form the differential of Equation 2.2.20, the quadratic defining $\delta \mathrm{V}$. It may be put in the form

$$
\begin{aligned}
\left(V^{*}+2 \delta V\right) d V_{n} & =\left(V^{*}+\delta V-V_{n} \frac{\delta V}{V_{\ell}}\right) d V_{V}+\left(V_{n} \frac{\delta V}{V_{\ell}}\right) d V \\
& -K V_{\ell} \delta V d(\Delta P)+K V_{\ell} d\left(\sum_{i=4}^{N} M_{l} R_{l} T\right),
\end{aligned}
$$


CVT Package Reference Manual

where

$$
V^{*}=V_{v}+K V_{\ell} \Delta P,
$$

through use of Equation 2.2.20 itself. As noted in the discussion of Equation 2.2.20, either $V_{v}=0$ if the water is subcooled, or $\Delta P=0$ if it is saturated. The variable $V^{*}$ is used to simplify the analysis by reducing the number of cases to be considered.

From Equation A.2.4, we may identify the following derivatives (noting that the pressure derivatives vanish unless the water is subcooled, in which case $V_{\ell}=V$ ):

$$
\begin{aligned}
\left(V^{*}+2 \delta V\right)\left(\frac{\partial V_{n}}{\partial V}\right)_{T, M} & =\left(V^{*}+\delta V-V_{n} \frac{\delta V}{V_{l}}\right)\left(\frac{\partial V_{V}}{\partial V}\right)_{T, M} \\
& +V_{n} \frac{\delta V}{V_{\ell}}+K \delta V \rho_{W} \frac{\partial P_{w}}{\partial \rho_{W}} \\
\left(V^{*}+2 \delta V\right)\left(\frac{\partial V_{n}}{\partial T}\right)_{M, V}= & \left(V^{*}+\delta V-V_{n} \frac{\delta V}{V_{l}}\right)\left(\frac{\partial V_{V}}{\partial T}\right)_{M, V} \\
& +K V_{\ell}\left[\delta V\left(\frac{d P_{s a t}}{d T}-\frac{\partial P_{w}}{\partial T}\right)+\sum_{i=4}^{N} M_{l} R_{i}\right] \\
\left(V^{*}+2 \delta V\right)\left(\frac{\partial V_{n}}{\partial M_{w}}\right)_{T, V} & =\left(V^{*}+\delta V-V_{n} \frac{\delta V}{V_{\ell}}\right)\left(\frac{\partial V_{V}}{\partial M_{w}}\right)_{T, V}-K \delta V \frac{\partial P_{W}}{\partial \rho_{w}}
\end{aligned}
$$

and

$$
\left(V^{*}+2 \delta V\right)\left(\frac{\partial V_{n}}{\partial\left(M_{i} R_{l}\right)}\right)_{T, V}=K V_{\ell} T
$$

Unless there are both NCGs and liquid water, Equations A.2.6, A.2.7, and A.2.8 reduce to Equations A.2.1, A.2.2, and A.2.3, respectively.

If there are no NCGs, the derivative of pressure with respect to NCG mass, given by Equation A.2.9, reduces to 
CVT Package Reference Manual

$$
\left(\frac{\partial V_{n}}{\partial\left(M_{i} R_{i}\right)}\right)_{T, V}=\frac{K V_{\ell} T}{V^{*}}
$$

a result which could not have been obtained from the results derived in the absence of NCGs. Some care must be taken in evaluating Equation A.2.10 in the case of saturated liquid. Whether this situation is approached from the subcooled side $\left(V_{v}=0, P \rightarrow 0+\right)$ or from the two-phase side $\left(\Delta P=0, V_{v} \rightarrow 0+\right)$, the denominator $V$ goes to 0 .

Ideally, one should maintain consistency regardless of how this state of saturated liquid water and no NCG is approached, taking into account that it may involve either case 1 or case 2 in Section A.1. The current coding simply prevents the division by zero. This simple approach has not been found to cause any problems in practice.

\section{A.3 Derivatives of the Vapor Volume}

The equations in the preceding section contain derivatives of the volume which would be occupied by water vapor in the absence of NCG with respect to total volume, temperature, and water mass. There are three cases to be considered:

(1) If there is no liquid (no water, or vapor only), $V_{v}=V$, and

$$
\begin{aligned}
& \left(\frac{\partial V_{V}}{\partial V}\right)_{T, M_{W}}=1, \\
& \left(\frac{\partial V_{V}}{\partial T}\right)_{M_{W}, V}=0, \\
& \left(\frac{\partial V_{V}}{\partial M_{W}}\right)_{T, V}=0 .
\end{aligned}
$$

(2) If there is water but no vapor (liquid only), $V_{v}=0$, and

$$
\begin{aligned}
& \left(\frac{\partial V_{v}}{\partial V}\right)_{T, M_{W}}=0, \\
& \left(\frac{\partial V_{v}}{\partial T}\right)_{M_{W}, V}=0,
\end{aligned}
$$


CVT Package Reference Manual

$$
\left(\frac{\partial V_{v}}{\partial M_{w}}\right)_{T, V}=0
$$

(3) Otherwise (two-phase water), $V_{v}$ is given by the primary form of Equation 2.2.15 (not the bounds), and the derivatives are

$$
\begin{aligned}
& \left(\frac{\partial V_{V}}{\partial V}\right)_{T, M_{w}}=\frac{\rho_{\ell, \text { sat }}}{\rho_{\ell, \text { sat }}-\rho_{V, \text { sat }}}, \\
& \left(\frac{\partial V_{V}}{\partial T}\right)_{M_{w} V}=\frac{V_{\ell} \frac{d \rho_{\ell, \text { sat }}}{d T}+V_{v} \frac{d \rho_{V, \text { sat }}}{d T}}{\rho_{\ell, \text { sat }}-\rho_{V, \text { sat }}}, \\
& \left(\frac{\partial V_{V}}{\partial M_{w}}\right)_{T, V}=-\frac{1}{\rho_{\ell, \text { sat }}-\rho_{V, \text { sat }}} .
\end{aligned}
$$

The total derivatives of saturation densities with respect to temperature are, of course, to be taken along the phase boundaries. They are evaluated from tables included in the $\mathrm{H} 2 \mathrm{O}$ package. 


\title{
Decay Heat (DCH) Package Reference Manual
}

\author{
MELCOR Code Development Group \\ Modeling and Analysis Department \\ Nuclear Energy Technology Center \\ Sandia National Laboratories \\ Albuquerque, NM 87185-0739
}

Contributors:

Edward A. Boucheron

John L. Orman

Russell C. Smith

Randall M. Summers

The MELCOR decay heat package models the decay heat power resulting from the radioactive decay of fission products. Decay heat is evaluated for core materials in the reactor vessel and cavity and for suspended or deposited aerosols and gases. MELCOR couples thermal-hydraulic processes and fission product behavior during the calculation.

Both the radionuclides present in the reactor at the time of the accident and the radionuclide daughter products contribute to the decay heat. In the calculation of decay heat, MELCOR does not explicitly treat each decay chain, since detailed tracking of radionuclide decay chains would be too costly. When the RadioNuclide package is active, the decay heat is calculated for each radionuclide class by using pre-calculated tables from ORIGEN calculations. If the RadioNuclide package is not active, the wholecore decay heat is computed from one of several possible user-specified calculations.

This Reference Manual describes the various models and options available in the $\mathrm{DCH}$ package. User input for these models and options is described in the DCH Package Users' Guide. 

DCH Package Referencë Manual

\section{Contents}

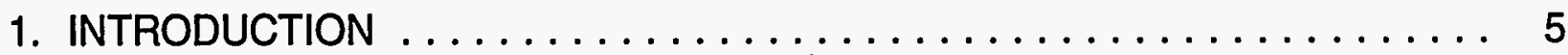

2. ELEMENTAL AND RADIONUCLIDE CLASS DECAY HEAT $\ldots \ldots \ldots \ldots \ldots 7$

2.1 SANDIA-ORIGEN Calculations $\ldots \ldots \ldots \ldots \ldots \ldots \ldots \ldots \ldots 7$

2.2 Radionuclide Classes . . . . . . . . . . . . . . . . . 9

3. WHOLE-CORE DECAY HEAT CALCULATION $\ldots \ldots \ldots \ldots \ldots \ldots \ldots$

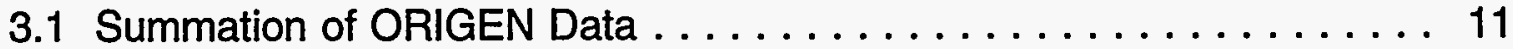

3.2 ANS Standard Calculation . . . . . . . . . . . . . . 11

3.3 User-Defined Functions $\ldots \ldots \ldots \ldots \ldots \ldots \ldots \ldots \ldots$

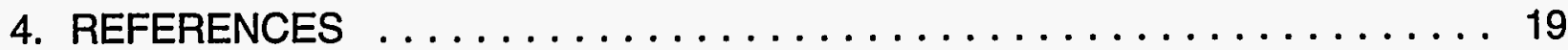


DCH Package Reference Manual

\section{List of Tables}

1. Default Radionuclide Classes $\ldots \ldots \ldots \ldots \ldots \ldots \ldots \ldots \ldots \ldots \ldots \ldots$

2. Tabular Values from ANS Standard Used in MELCOR $\ldots \ldots \ldots \ldots \ldots$.

3. DCH Package Input Variables for ANS Decay Heat Power ........ . . 17 
DCH Package Reference Manual

\section{INTRODUCTION}

The MELCOR Decay Heat Power (DCH) package models the heating from the radioactive decay of fission products. Decay heat power is evaluated for the fission products assumed to reside in reactor core materials, cavity materials, and in suspended or deposited aerosols and vapors. Decay heat power levels as a function of time are supplied as a utility function within MELCOR that may be called by other phenomenological packages. The DCH package is not involved in the calculation of fission product transport or chemical interactions. These processes are calculated by the RadioNuclide (RN) package (see the RN Package Reference Manual).

Both the radionuclides present in the reactor core and/or cavity from the time of reactor shutdown and the radionuclide daughters from decay contribute to the total decay heat power. In the calculation of decay heat power, the DCH package does not explicitly treat decay chains. Detailed tracking of radionuclide decay chains was seen as computationally costly and too detailed for MELCOR. Instead, when the RN package is active, elemental decay heat power information based on ORIGEN calculations $[1,2]$ is summed into the RN class structure, as described in Section 2.

There are also several options for calculating decay heat power when the RN package is not active (that is, when tracking of fission products is not desired). These are called whole-core calculations in the DCH package, although they may be applied to cavity inventories of melt debris as well, and are described in Section 3. 
DCH Package Reference Manual

\section{ELEMENTAL AND RADIONUCLIDE CLASS DECAY HEAT}

The DCH package models the decay heat power as a function of time and the total initial inventories of individual elements. The default decay heat curves and inventories were obtained from ORIGEN calculations [1], as described in Section 2.1. The grouping of elements into classes for use by the RadioNuclide package is described in Section 2.2.

\subsection{SANDIA-ORIGEN Calculations}

Calculations were made for prototypical BWR and PWR reactors using the Sandia National Laboratories version of the ORIGEN computer code, and tables of the associated fission product initial inventories and their decay heat powers out to ten days were generated $[1,2]$. In these tables, all isotopes of an element were summed, and daughters were assumed to remain with the parents. This resulted in 29 elemental groups accounting for over $99 \%$ of the decay heat power out to at least two days after reactor shutdown.

The base case ORIGEN run for a PWR used the following assumptions :

1. 3412 MWt Westinghouse PWR

2. end-of-cycle equilibrium core

3. three region core, each initially loaded with fuel enriched to $3.3 \%$ U-235

4. constant specific power density of $38.3 \mathrm{MW}$ per metric ton of $\mathrm{U}$

5. three year refueling cycle

6. $80 \%$ capacity factor

7. three regions having burnups of $11,000,22,000$ and $33,000 \mathrm{MWd}$ per metric ton of uranium.

The base case ORIGEN run for a BWR used the following assumptions :

1. 3578 MWt General Electric BWR

2. five types of assembly groups

3. initial enrichment for assemblies either $2.83 \%$ or $2.66 \%$ U-235, depending on assembly group 
DCH Package Reference Manual

4. assemblies in core for either 3 or 4 years, depending on assembly group

5. refueled annually

6. $80 \%$ capacity factor

Within the RadioNuclide package, daughter isotopes are assumed to be transported along with the parents. Thus, the daughter products are assumed to retain the physical characteristics of their parents. This assumption may not be appropriate in some cases, but the ORIGEN analyses showed that the decay heat from the parent elements is generally much greater than that of the daughter products. Because of these considerations, the decay heat of an element's daughter products is included in the decay heat tabulation for the parent element.

The ORIGEN decay heat data are represented in the $\mathrm{DCH}$ package in normalized form as decay heat power per unit of reactor operating power at 28 time values after reactor shutdown for each of the 29 elements treated. The ORIGEN results for the PWR were nearly the same as those for the BWR during the first few days after reactor shutdown (within 4\%). This similarity results because (1) both reactors use thermal fission of U-235 and $\mathrm{Pu}-239$ as the power source and (2) decay power during the first few days after shutdown results principally from short-lived radionuclides. Inventories of short-lived radionuclides are proportional to reactor operating power and are relatively insensitive to reactor design and fuel management. Therefore, a single table of normalized decay powers out to 10 days after shutdown is used in the $\mathrm{DCH}$ package as representative of both PWRs and BWRs. However, the user may redefine the decay heat power for a given element (or create one for a "new" element) using the DCHNEMnnOO and DCHNEMnnmm input records, or the user may apply multipliers to the default curves with sensitivity coefficients 3210 and 3211 , as described in the DCH Package Users' Guide.

In general, mass inventories of elements are sensitive to fuel burnup and reactor design. Therefore, two default mass inventories are included in the $\mathrm{DCH}$ package for the representative BWR and PWR used in the ORIGEN calculations. The inventory masses of the elements, normalized to grams per unit of reactor operating power (for the PWR and for the BWR), were given by ORIGEN at four times in the equilibrium fuel cycle: startof-cycle, one-third point, two-thirds point, and end-of-cycle. By default, end-of-cycle values are used, but the user may specify a different fraction of the equilibrium cycle (through sensitivity coefficient 3212), in which case linear interpolation is used to determine the elemental masses at shutdown. For analyses of specific reactors, for which fission product inventories are known (perhaps through separate ORIGEN calculations), the MELCOR user can directly input the element masses using the DCHNEMnnO0 input record (see the DCH Package Users' Guide). 
DCH Package Reference Manual

The decay heat power and mass for each element were summed over only core fission products and actinides. Thus, the total mass of zirconium in the core at the time of shutdown does not include the mass of the $\mathrm{Zr}$ in core structural materials.

The decay heat power for a given element at a certain time is estimated by logarithmic interpolation in time of the normalized decay heat powers and dividing by the normalized mass of the particular element in the reactor at the time of shutdown (which includes the masses of its daughter products and is therefore constant) to get a decay heat power per unit mass of the element.

\subsection{Radionuclide Classes}

The 29 radioactive elements treated by the $\mathrm{DCH}$ package are further grouped into chemical classes for tracking by the RN package. Table 1 lists the default classes treated by the $\mathrm{RN}$ and $\mathrm{DCH}$ packages. The remaining elements that do not contribute significant decay heat $(<1 \%)$ are enclosed in parentheses. More discussion on classes and their properties is given in the RN Package Reference Manual.

The decay heat power is computed for each class by weighting the elemental decay heats by the relative mass of each element in the class given by the ORIGEN calculations described in Section 2.1. The user may redefine the default class element compositions or define the composition of new classes through input (see input records DCHCLSnnn0 and DCHCLSnnnm in the DCH Package Users' Guide).

All packages that require decay heat power (i.e., COR, CAV, and RN) access a utility provided by the $\mathrm{RN}$ package to calculate the total power for the $\mathrm{RN}$ class masses residing at a particular location. When the RN package requests a class decay heat power from the DCH package for any problem time within the range of the present time step, the returned answer is the average of the class decay heat at the current problem time and the class decay heat at the end of the time step. Thus, the energy balance calculation is done consistently in the DCH package and the other MELCOR packages distributing the decay heat power. The DCH package edits also reflect this averaging. However, since the first time step size is not known during the MELGEN setup phase, the MELGEN edit does not show exactly the same decay heat powers as those shown in the first MELCOR edit. 
DCH Package Reference Manual

Table 1. Default Radionuclide Classes

Class Number and Name

1. Noble gases

2. Alkali Metals

3. Alkaline Earths

4. Halogens

5. Chalcogens

6. Platinoids

7. Transition Metals

8. Tetravalents

9. Trivalents

10. Uranium

11. More Volatile Main Group Metals

12. Less Volatile Main Group Metals

13. Boron

14. Water

15. Concrete

\section{Member Elements}

$\mathrm{Xe}, \mathrm{Kr},(\mathrm{Rn}),(\mathrm{He}),(\mathrm{Ne}),(\mathrm{Ar}),(\mathrm{H}),(\mathrm{N})$

Cs, Rb, (Li), (Na), (K), (Fr), (Cu)

$\mathrm{Ba}, \mathrm{Sr},(\mathrm{Be}),(\mathrm{Mg}),(\mathrm{Ca}),(\mathrm{Ra}),(\mathrm{Es}),(\mathrm{Fm})$

$\mathrm{I}, \mathrm{Br},(\mathrm{F}),(\mathrm{Cl}),(\mathrm{At})$

Te, Se, (S), (O), (Po)

$\mathrm{Ru}, \mathrm{Pd}, \mathrm{Rh},(\mathrm{Ni}),(\mathrm{Re}),(\mathrm{Os}),(\mathrm{Ir}),(\mathrm{Pt}),(\mathrm{Au})$

Mo, Tc, Nb, (Fe), (Cr), (Mn), (V), (Co), (Ta), (W)

$\mathrm{Ce}, \mathrm{Zr},(\mathrm{Th}), \mathrm{Np},(\mathrm{Ti}),(\mathrm{Hf}),(\mathrm{Pa}),(\mathrm{Pu}),(\mathrm{C})$

La, Pm, (Sm), Y, Pr, Nd, (Al), (Sc), (Ac), (Eu), (Gd), (Tb), (Dy), (Ho), (Er), (Tm), (Yb), (Lu), $(\mathrm{Am}),(\mathrm{Cm}),(\mathrm{Bk}),(\mathrm{Cf})$

$\mathrm{U}$

(Cd), (Hg), (Pb), ( $\mathrm{Zn}), \mathrm{As}, \mathrm{Sb},(\mathrm{Tl}),(\mathrm{Bi})$

Sn, Ag, (In), (Ga), (Ge)

(B), (Si), (P)

(Wt)

(Cc) 
DCH Package Reference Manual

\section{WHOLE-CORE DECAY HEAT CALCULATION}

If the RN package is not active in MELCOR, the decay heat power is calculated for the entire core. The user may specify one of four possible options on input record DCHDECPOW for this calculation:

(1) a summation of decay heat data from the ORIGEN-based fission product inventories for representative BWRs and PWRs [1, 2], scaled if necessary,

(2) the 1979 ANS standard for decay heat power [3],

(3) a tabular function of time, or

(4) a user-specified control function to define decay heat power.

Each option is described in the following subsections.

\subsection{Summation of ORIGEN Data}

As discussed in Section 2, a Sandia version of ORIGEN [2] has been used to perform decay heat calculations for prototypical PWR and BWR systems [1]. For the whole-core calculation, the tabulated results of the ORIGEN calculation are summed to produce a total reactor decay heat power, $P_{w c}$. No elemental or class information is retained; a single decay power value is returned when called by other packages. This is the default whole-core calculation and is the same for PWRs and BWRs.

\subsection{ANS Standard Calculation}

MELCOR can compute the total decay heat power from the American Nuclear Society's National Standard for light water reactors [3]. This standard prescribes fission product decay heat power for reactor operating histories. Currently, the DCH package uses a user-specified operating time (input on record DCHOPRTIME) with a constant reactor power, and it also assumes an instantaneous shutdown. The standard prescribes the recoverable energy release rates from fission product decay, but it does not specify the spatial distribution of the deposition of the energy in the reactor materials. This aspect of the problem is reactor specific and must be dealt with by the MELCOR Core package.

The decay heat power is related to the operating power of the reactor via the fission rate and the recoverable energy per fission during operation. The ANS standard assumes that the energy release per fission is independent of time and depends upon the energy spectrum of the neutron flux in the operating reactor and the composition of the reactor 


\section{DCH Package Reference Manual}

core. The energies per fission for U-235, Pu-239, and U-238 are defined in sensitivity coefficient array 3201.

Decay heat power from activation products in reactor structural materials is not specified in the standard, but decay heat powers from U-239 and Np-239 as prescribed by the standard are implemented in the DCH package. The effect of neutron capture in fission products is accounted for by using a formula from the ANS standard for the correction out to a time-since-shutdown of $10^{4}$ seconds. The $\mathrm{DCH}$ package then uses Table 10 from the standard that sets an upper bound on the effect of neutron capture and provides a conservative estimate of the decay heat power. The values from this table are reproduced here in Table 2. Because of the conservatism of this table, the ANS standard decay heat power actually contains a discontinuity manifested by a small increase at $10^{4}$ seconds.

MELCOR uses the tables from the ANS standard that prescribe decay heat power from products resulting from the fission of the major fissionable nuclides present in LWRs, specifically thermal fission of $\mathrm{U}-235$ and $\mathrm{Pu}-239$, and fast fission of $\mathrm{U}-238$. These values (from ANS standard Tables 4, 5, and 6) are also reproduced in Table 2. The values at the time of shutdown $(t=0.0)$ were calculated from Tables 7,8 , and 9 of the standard.

Table 2. Tabular Values from ANS Standard [3] Used in MELCOR

\begin{tabular}{lllll}
$\begin{array}{l}\text { Time After } \\
\text { Shutdown }\end{array}$ & $G_{\max }(t)$ & ${ }^{235} \mathrm{U}$ & $\begin{array}{c}\text { Decay Heat Power } F(t, \infty) \\
{ }^{239} \mathrm{Pu}\end{array}$ \\
\hline 1.0 & 1.020 & $1.231 \mathrm{E}+1$ & $1.027 \mathrm{E}+1$ & ${ }^{238} \mathrm{U}$ \\
1.5 & 1.020 & $1.198 \mathrm{E}+1$ & $1.003 \mathrm{E}+1$ & $1.419 \mathrm{E}+1$ \\
2.0 & 1.020 & $1.169 \mathrm{E}+1$ & 9.816 & $1.361 \mathrm{E}+1$ \\
4.0 & 1.021 & $1.083 \mathrm{E}+1$ & 9.206 & $1.316 \mathrm{E}+1$ \\
6.0 & 1.022 & $1.026 \mathrm{E}+1$ & 8.795 & $1.196 \mathrm{E}+1$ \\
8.0 & 1.022 & 9.830 & 8.488 & $1.07 \mathrm{E}+1$ \\
$1.0 \mathrm{E}+1$ & 1.022 & 9.494 & 8.243 & $1.029 \mathrm{E}+1$ \\
$1.5 \mathrm{E}+1$ & 1.022 & 8.882 & 7.794 & 9.546 \\
$2.0 \mathrm{E}+1$ & 1.022 & 8.455 & 7.476 & 9.012 \\
$4.0 \mathrm{E}+1$ & 1.022 & 7.459 & 6.707 & 7.755 \\
$6.0 \mathrm{E}+1$ & 1.022 & 6.888 & 6.251 & 7.052 \\
$8.0 \mathrm{E}+1$ & 1.022 & 6.493 & 5.929 & 6.572 \\
$1.0 \mathrm{E}+2$ & 1.023 & 6.198 & 5.685 & 6.217 \\
$1.5 \mathrm{E}+2$ & 1.023 & 5.696 & 5.262 & 5.621 \\
$2.0 \mathrm{E}+2$ & 1.025 & 5.369 & 4.982 & 5.241 \\
$4.0 \mathrm{E}+2$ & 1.028 & 4.667 & 4.357 & 4.464 \\
$6.0 \mathrm{E}+2$ & 1.030 & 4.282 & 3.993 & 4.072 \\
\hline
\end{tabular}


DCH Package Reference Manual

Table 2 (continued)

Time After

Decay Heat Power $F(t, \infty)$ Shutdown

$G_{\max }(t)$

${ }^{235} \mathrm{U}$

${ }^{239} \mathrm{Pu}$

${ }^{238} \mathrm{U}$

$8.0 \mathrm{E}+2 \quad 1.032$

4.009

3.726

3.804

$1.0 E+3 \quad 1.033$

3.796

3.516

3.598

$1.5 \mathrm{E}+3 \quad 1.037$

3.408

3.128

3.220

$2.0 \mathrm{E}+3$

3.137

2.857

2.954

$4.0 \mathrm{E}+3$

2.534

2.276

2.366

$6.0 \mathrm{E}+3$

2.234

2.002

2.078

$8.0 \mathrm{E}+3 \quad 1.060$

2.044

1.839

1.901

$1.0 \mathrm{E}+4$

1.908

1.727

1.777

$1.5 \mathrm{E}+4 \quad 1.074$

$2.0 \mathrm{E}+4 \quad 1.081$

1.685

1.548

1.578

$4.0 \mathrm{E}+4 \quad 1.098$

1.545

1.437

1.455

1.258

1.204

1.204

$6.0 \mathrm{E}+4$

1.117

1.081

1.077

$8.0 \mathrm{E}+4$

1.030

$1.0 \mathrm{E}+5$

1.119

9.691E-1

1.000

9.955E-1

$1.5 \mathrm{E}+5$

8.734E-1

$9.421 \mathrm{E}-1$

9.383E-1

$2.0 E+5$

$8.154 \mathrm{E}-1$

8.480E-1

8.459E-1

7.890E-1

7.884E-1

6.975E-1

$6.634 \mathrm{E}-1$

6.673E-1

$6.0 \mathrm{E}+5$

$6.331 \mathrm{E}-1$

$8.0 \mathrm{E}+5$

$5.868 \mathrm{E}-1$

$5.944 \mathrm{E}-1$

$6.002 \mathrm{E}-1$

$1.0 \mathrm{E}+6$

5.509E-1

$1.5 \mathrm{E}+6$

4.866E-1

$2.0 \mathrm{E}+6$

4.425E-1

$4.0 \mathrm{E}+6$

3.457E-1

$6.0 \mathrm{E}+6$

2.983E-1

$8.0 \mathrm{E}+6$

$2.680 \mathrm{E}-1$

$1.0 \mathrm{E}+7$

2.457E-1

$1.5 \mathrm{E}+7 \quad 1.233$

2.078E-1

5.462E-1

5.530E-1

5.097E-1

5.171E-1

4.464E-1

4.544E-1

4.046E-1

4.125E-1

3.163E-1

3.224E-1

2.741E-1

2.784E-1

2.477E-1

2.503E-1

2.282E-1

2.296E-1

$1.846 \mathrm{E}-1$

$1.945 \mathrm{E}-1$

1.941E-1

$2.0 \mathrm{E}+7 \quad 1.284$

$4.0 \mathrm{E}+7 \quad 1.444$

$6.0 \mathrm{E}+7 \quad 1.535$

$8.0 \mathrm{E}+7 \quad 1.586$

1.457E-1

1.308E-1

$1.222 \mathrm{E}-1$

$1.0 E+8 \quad 1.598$

1.165E-1

$1.728 \mathrm{E}-1$

1.717E-1

1.302E-1

1.299E-1

1.099E-1

1.113E-1

9.741E-2

1.001E-1

8.931E-2

9.280E-2

1.082E-1

7.859E-2

8.307E-2

$2.0 \mathrm{E}+8 \quad 1.343$

$4.0 \mathrm{E}+8 \quad 1.065$

1.032E-1

8.836E-2

7.344E-2

7.810E-2

7.613E-2

6.269E-2

6.647E-2

$6.0 \mathrm{E}+8 \quad 1.021$

6.570E-2

5.466E-2

5.746E-2

$8.0 \mathrm{E}+8$

1.012

4.783E-2

4.979E-2

$1.0 \mathrm{E}+9$

1.007

$5.678 \mathrm{E}-2$

4.195E-2

4.321E-2 
DCH Package Reference Manual

For the ANS standard option, the whole-core power, $\mathrm{P}_{\mathrm{wc}}(\mathrm{t})$, is given by:

$$
P_{w C}(t)=M_{u s e r} G(t) \sum_{i=1}^{3} \frac{P_{i} F_{i}(t, T)}{Q_{i}}+P_{d H E}(t, T)
$$

where

$$
\begin{array}{ll}
M_{u s e r} & =\text { user-input multiplier (default }=1 \text { ) } \\
G(t) & =\text { neutron capture correction factor } \\
t & =\text { time since reactor shutdown (s) } \\
i \quad & =\text { index for fissioning nuclides: } U-235, \text { Pu-239, U-238 } \\
T \quad & =\text { reactor operating time (s) } \\
P_{i} & =\text { power from fissioning of nuclide } i(W) \\
F_{i}(t, T) & =\text { decay power due to nuclide } i(M e V / f i s s i o n) \\
Q_{i} \quad=\text { Energy per fission of nuclide } i(M e V / f i s s i o n)
\end{array}
$$

The additive term $P_{\text {dHE }}(t, T)$ is the decay power from $U-239$ and Np-239, prescribed by the ANS standard as:

$$
P_{d H E}(t, T)=\sum_{i=1}^{3}\left(P_{i} / Q_{i}\right)\left[F_{239 u}(t, T)+F_{239 N p}(t, T)\right]
$$

where

$$
\begin{aligned}
F_{239 \cup}(t, T)= & E_{239 \mathrm{U}} \times R \times\left[1-\exp \left(-\lambda_{1} T\right)\right] \times \exp \left(-\lambda_{1} t\right) \\
F_{239 \mathrm{~Np}}(t, T)= & E_{\text {239Np }} \times R \times \\
& {\left[\lambda_{1} \times\left(1-\exp \left(-\lambda_{2} T\right)\right) \times \exp \left(-\lambda_{2} t\right) /\left(\lambda_{1}-\lambda_{2}\right)\right.} \\
& \left.-\lambda_{2} \times\left(1-\exp \left(-\lambda_{1} T\right)\right) \times \exp \left(-\lambda_{1} t\right) /\left(\lambda_{1}-\lambda_{2}\right)\right] \\
E_{239 U}= & \text { average energy from decay of one U-239 atom (MeV/atom) }
\end{aligned}
$$


DCH Package Reference Manual

$E_{\text {239Np }}=$ average energy from decay of one Np-239 atom (MeV/atom)

$\mathrm{R}=$ number of atoms of U-239 produced per second per fission per second at shutdown

$\lambda_{1}=$ decay constant for U-239

$\lambda_{2}=$ decay constant for Np-239

For shutdown times less than $10^{4}$ seconds, the neutron capture correction factor $G(t)$ is given by the ANS standard as:

$$
G(t)=1.0+\left(3.24 \times 10^{-6}+5.23 \times 10^{-10} t\right) T^{0.4} \Psi
$$

where $\psi$ is the number of fissions per initial fissile atom (user input). For times greater than $10^{4}$ seconds, $G(t)$ is given in tabular form by $G_{\text {MAX }}(t)$, which may be input as sensitivity coefficients or allowed to default to the values given by the ANS standard.

$F_{i}(t, T)$ is used in tabular form as given in the ANS standard. The values at each time $t$ are found by logarithmic interpolation between successive points in the ANS tables. This form of evaluation does not have significant accuracy loss and is much faster when compared with the primary ANS formulation expressed as a sum of exponentials.

Table 3 lists the MELCOR input variables and sensitivity coefficients that are used to implement the ANS decay heat power calculation.

\subsection{User-Defined Functions}

The whole-core decay heat power, $\mathrm{P}_{\mathrm{wc}}$, can be defined by a user-input tabular function of time after shutdown. Alternatively, $\mathrm{P}_{\text {wc }}$ can be defined as a user-specified control function of other MELCOR system variables. Either option may be specified on input record DCHDECPOW. 
DCH Package Reference Manual

Table 3. DCH Package Input Variables for ANS Decay Heat Power

\begin{tabular}{|c|c|c|}
\hline ANS Parameter & MELCOR Variable & Input Record \\
\hline$P_{i}, i=1,2,3$ & U235P, PU239P, U238P & DCHFPOW \\
\hline $\mathrm{T}$ & OPRTIM & DCHOPRTIME \\
\hline$\psi$ & PSINC & DCHNCPSI \\
\hline$Q_{i}, i=1,2,3$ & FEU235, FEP239, FEU238 & $\operatorname{SC} 3201(1), I=1,2,3$ \\
\hline$t$, time in tabular functions & $\operatorname{TIMDCH}(I), \mathrm{I}=1, \ldots, 56$ & $\operatorname{SC} 3202(l), l=1, \ldots, 56$ \\
\hline$F_{i}(t, \infty), i=1,2,3$ & $\begin{array}{r}\operatorname{DCHPOW}(\mathrm{I}, \mathrm{J}), \mathrm{l}=1, \ldots, 56, \\
\mathrm{~J}=1,2,3\end{array}$ & $\begin{array}{r}\operatorname{SC} 3203(\mathrm{l}, \mathrm{J}), \begin{array}{r}\mathrm{I}=1, \ldots, 56 \\
\mathrm{~J}=1,2,3\end{array}\end{array}$ \\
\hline$G_{\text {MAX }}(t) \quad\left\{10^{4}<t<10^{9}\right\}$ & CAPNEU(I), $\mathrm{I}=1, \ldots, 56$ & SC3204(I), I=1,..,56 \\
\hline$R$ & $\mathrm{R}$ & SC3205(1) \\
\hline$E_{239 U}$ & E239U & SC3205(2) \\
\hline$E_{239 N p}$ & E239NP & SC3205(3) \\
\hline$\lambda_{1}$ & DCU & SC3205(4) \\
\hline$\lambda_{2}$ & DCNP & SC3205(5) \\
\hline$M_{\text {user }}$ & ANSMUL & SC3200(1) \\
\hline
\end{tabular}




\section{REFERENCES}

1. R. M. Ostmeyer, An Approach to Treating Radionuclide Decay Heating for Use in the MELCOR Code System, NUREG/CR-4169, SAND84-1404, Sandia National Laboratories, Albuquerque, NM (May 1985).

2. D. E. Bennett, SANDIA-ORIGEN User's Manual, NUREG/CR-0987, SAND79-0299, Sandia National Laboratories, Albuquerque, NM (October 1979).

3. American Nuclear Society Standards Committee Working Group ANS-5.1, American National Standard for Decay Heat Power in Light Water Reactors, ANSI/ANS-5.1-1979, American Nuclear Society, La Grange Park, IL (1979). 


\title{
Fan Cooler (FCL) Package Reference Manual
}

\author{
MELCOR Code Development Group \\ Modeling and Analysis Department \\ Nuclear Energy Technology Center \\ Sandia National Laboratories \\ Albuquerque, NM 87185-0739
}

Randall M. Summers

The MELCOR ESF Package models the physics for the various Engineered Safety Features (ESFs) in a nuclear power plant. The Fan Cooler (FCL) package constitutes a subpackage within the ESF Package, and calculates the heat and mass transfer resulting from operation of the fan coolers. The removal of fission product vapors and aerosols by fan coolers is to be modeled within the RN package. Those models have not yet been implemented. This Reference Manual gives a description of the physical models and numerical solution schemes implemented in the FCL package.

User input for running MELGEN and MELCOR with the FCL package activated is described separately in the Fan Cooler Package Users' Guide. 

FCL Package Reference Manual

\section{Contents}

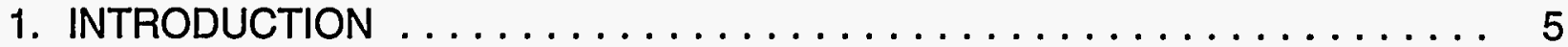

2. MODEL DESCRIPTION $\ldots \ldots \ldots \ldots \ldots \ldots \ldots \ldots \ldots \ldots \ldots$

3. DISCUSSION AND DEVELOPMENT PLANS $\ldots \ldots \ldots \ldots \ldots \ldots \ldots \ldots$

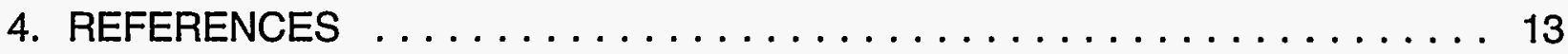

APPENDIX A: Sensitivity Coefficients $\ldots \ldots \ldots \ldots \ldots \ldots \ldots \ldots \ldots$

FCL-RM-3 
FCL Package Reference Manual

FCL-RM-4 
FCL Package Reference Manual

\section{INTRODUCTION}

The MELCOR ESF package models the thermal-hydraulic behavior of various Engineered Safety Features (ESFs) in nuclear power plants. One important ESF is a fan cooler, which is a large heat exchanger used to remove heat from the containment building. Such coolers circulate hot containment atmosphere gases over cooling coils through which flow secondary water coolant at low temperatures; thereby removing heat by convection and condensation heat transfer.

The Fan Cooler (FCL) package constitutes a subpackage within the ESF package and calculates the heat and mass transfer resulting from operation of the fan coolers. The MELCOR model is based on the fan cooler model in the MARCH 2.0 code [1]. An effective heat transfer area is calculated in MELGEN from the rated primary and secondary flows and temperatures, and from the heat transfer coefficient and cooler capacity at those conditions. The actual heat transfer rate during a transient is then calculated using that effective area by evaluating the heat transfer coefficient from the current water vapor mole fraction, and by determining the average temperatures of the primary gas and secondary coolant, which are themselves implicit functions of the heat transfer rate, for conditions during the transient. A detailed model description is presented in the next section.

Several extensions to the MARCH model have been made. The user may optionally specify a separate discharge control volume for the fan cooler outlet air flow. The user may also specify a control function to switch the cooler on or off. The maximum condensation rate is limited to the water vapor inlet flow rate. Finally, the MELCOR implementation roughly partitions the total heat transfer coefficient into separate convection and condensation components to try to account for the effects of noncondensible gases and superheated atmosphere. The user can control how this partitioning is made by adjusting the sensitivity coefficients used in the heat transfer correlation.

The removal of fission product vapors and aerosols by fan coolers is not modeled within the FCL package. Models to simulate those processes have not yet been implemented, but will eventually be included in the RadioNuclide (RN) package. 
FCL Package Reference Manual

FCL-RM-6 
FCL Package Reference Manual

\section{MODEL DESCRIPTION}

The total effective heat transfer coefficient, $h_{T}$, used in the MARCH fan cooler model is an empirical relation taken from the Oconee Power Reactor Final Safety Analysis Report [2] (British units of Btu/hr-ft $\mathrm{ft}^{2}-\mathrm{F}$ have been converted to SI units of $\mathrm{W} / \mathrm{m}^{2}-\mathrm{K}$ ):

$$
\begin{array}{ll}
h_{T}=590.54+3603.4 X_{H 2 O} & \text { for } X_{H 2 O} \leq 0.26 \\
h_{T}=h_{T}(0.26)+2325.25\left(X_{H 2 O}-0.26\right) & \text { for } X_{H 2 O}>0.26
\end{array}
$$

where $X_{H 2 O}$ is the water vapor mole fraction and $h_{T}(0.26)$ in Equation 2.2 is evaluated from Equation 2.1 for $X_{\mathrm{H} 2 \mathrm{O}}$ equal to 0.26 , yielding a value of 1527.42. This heat transfer coefficient is to be applied to a total effective fan cooler surface area, $A_{\text {eff }}$, and the temperature difference between the primary and secondary average fluid temperatures, $T_{P, \text { avg }}$ and $T_{S, a v g}$, respectively. In MELCOR, it is assumed that this heat transfer coefficient can be divided into two components: (1) a convective component, $h_{H}$, transferring only sensible heat, and (2) a condensation component, $h_{M}$, transferring only latent heat. The convective component is assumed to correspond to the heat transfer for completely dry conditions (i.e., $X_{\mathrm{H} 2 \mathrm{O}}=0.0$ ) times a sensitivity coefficient multiplier, $F_{\mathrm{H}}$ (default value of 1.0), such that

$$
\begin{aligned}
& h_{H}=590.54 F_{H} \\
& h_{M}=h_{T}-h_{H}
\end{aligned}
$$

The constants in Equations 2.1 through 2.4 have been implemented as sensitivity coefficient array 9001 (see Appendix A).

The total fan cooler heat transfer rate $Q_{T}$ is therefore

$$
Q_{T}=Q_{H}+Q_{M}
$$

where

$$
Q_{H}=h_{H} A_{\text {eff }}\left(T_{P, \text { avg }}-T_{S, \text { avg }}\right)
$$


FCL Package Reference Manual

$$
Q_{M}=h_{M} A_{\text {eff }}\left(T_{P, \text { avg }}-T_{S, \text { avg }}\right)
$$

The average primary and secondary fluid temperatures, $T_{p, \text { avg }}$ and $T_{S, a v g}$, respectively, are themselves functions of the primary and secondary fluid inlet temperatures, $T_{P, \text { in }}$ and $T_{S, \text { ins }}$ the primary and secondary mass flow rates in the cooler, $W_{P}$ and $W_{S}$, and the fan cooler heat transfer rates. The average primany temperature decreases only in response to sensible heat transfer, while the average secondary temperature increases in response to the total heat transfer:

$$
\begin{gathered}
T_{P, \text { avg }}=T_{P, \text { in }}-\frac{Q_{H}}{2 W_{P} c_{p P}} \\
T_{S, \text { avg }}=T_{S, \text { in }}+\frac{Q_{T}}{2 W_{S} c_{p s}}
\end{gathered}
$$

where $c_{p p}$ and $c_{p s}$ are specific heat capacities at constant pressure for the primary and secondary fluids. Noting that $Q_{H} / Q_{T}=h_{H} / h_{T}$, simple substitution of Equations 2.8 and 2.9 into Equations 2.4 through 2.7 gives

$$
Q_{T}=h_{T} A_{e f f}\left[T_{P, \text { in }}-T_{S, \text { in }}-\frac{Q_{T}}{2}\left(\frac{1}{W_{S} c_{p S}}+\frac{h_{H} / h_{T}}{W_{P} c_{p P}}\right)\right]
$$

Solving for the total heat transfer rate $Q_{T}$, Equation 2.10 gives

$$
Q_{T}=h_{T} A_{\text {eff }} \frac{T_{P, \text { in }}-T_{S, \text { in }}}{1+\frac{1}{2}\left(\frac{h_{T}}{W_{S} c_{p S}}+\frac{h_{H}}{W_{p} c_{p P}}\right) A_{e f f}}
$$

The maximum condensation heat transfer rate is also limited to the water vapor inlet flow rate:

$$
Q_{M, \text { max }}=Y_{H 2 O} W_{P} h_{f g}
$$


FCL Package Reference Manual

where $Y_{\mathrm{H} 2 \mathrm{O}}$ is the water vapor mass fraction and $\mathrm{h}_{\mathrm{fg}}$ is the latent heat of vaporization of water. If $Q_{M}$ is limited to $Q_{M, \max }, Q_{H}$ and $Q_{T}$ are recalculated from Equations 2.5 and 2.10.

The effective surface area $A_{\text {eff }}$ is calculated in MELGEN from the rated primary and secondary flows and temperatures $\left(\mathrm{W}_{\mathrm{PA}}, \mathrm{W}_{\mathrm{SR}}, \mathrm{T}_{\mathrm{PR}}\right.$, and $\left.\mathrm{T}_{\mathrm{SR}}\right)$, from the total and convective heat transfer coefficients evaluated at the rated water vapor mole fraction $\left(h_{T R}\right.$ and $\left.h_{H R}\right)$, and from the cooler capacity $Q_{R}$ at those conditions, using equation 2.10:

$$
A_{\text {eff }}=\frac{Q_{R}}{h_{T R}\left(T_{P R}-T_{S R}\right)-\frac{Q_{R}}{2}\left(\frac{h_{T R}}{W_{S R} c_{p S}}+\frac{h_{H R}}{W_{P R} c_{p P}}\right)}
$$

Note that, unlike the MARCH model, conditions actually used in the transient calculation in MELCOR may in general be different from rated flows and temperatures.

All mass and energy transfers calculated by the fan cooler model are communicated to the Control Volume Hydrodynamics $(\mathrm{CVH})$ package through the standard interface provided for such interpackage transfers.

Fan coolers may be specified for any control volume. The user may optionally specify a separate discharge control volume for the fan cooler outlet air flow, in which case the cooler functions somewhat like a flow path with a constant volumetric flow (that is cooled or dehumidified) from the inlet volume to the discharge volume. Operation of the cooler may be tied to other facets of the calculation by use of a control function to switch the cooler on or off. 
FCL Package Reference Manual

FCL-RM-10 
FCL Package Reference Manual

\section{DISCUSSION AND DEVELOPMENT PLANS}

The MELCOR Peer Review [3] found that use of the Oconee FSAR correlation for the total heat transfer coefficient and the MELCOR approach to partitioning it into a condensation component dependent on water vapor mole fraction and a constant sensible convection component to be deficient because they do not adequately represent the underlying physics. However, this model was deemed relatively unimportant for most PRA applications, since fan coolers either have far more capacity than is needed to remove decay heat or because the fan coolers are assumed inoperative.

However, for recovery scenarios investigated as part of accident management analyses, errors in calculating condensation rates would impact assessments of the dangers of deinerting the containment atmosphere and causing burns. Concern was also expressed if relatively low-capacity units (e.g., room coolers and non-safety grade fan coolers used for normal heat loads) were thought to be important and were modeled.

Mechanistic models (e.g., from CONTAIN [4]) could be fairly easily adapted for use in MELCOR if found necessary for accident management applications, but there are no current plans to do this. 
FCL Package Reference Manual 
FCL Package Reference Manual

\section{REFERENCES}

1. R. O. Wooton, P. Cybulskis, and S. F. Quayle, MARCH 2 (Meltdown Accident Response Characteristics) Code Description and User's Manual, NUREG/CR-3988, BMI-2115 (August 1984).

2. Duke Power Company, Oconee Nuclear Station Units 1, 2, and 3: Final Safety Analysis Report (1969).

3. B. E. Boyack, et al., MELCOR Peer Review, LA-12240, Los Alamos National Laboratory (March 1992).

4. K. K. Murata, et al., User's Manual for CONTAIN 1.1: A Computer Code for Severe Nuclear Reactor Accident Containment Analysis, NUREG/CR-5026, SAND87-2309, Sandia National Laboratories (November 1989). 

FCL Package Reference Manual

\section{APPENDIX A: Sensitivity Coefficients}

This section lists the sensitivity coefficients in the FCL package associated with various correlations and modeling parameters described in this reference manual.

\section{Equation}

2.1,

2.2 ,

2.3
Coefficient

C9001(1)

C9001(2)

C9001(3)

C9001(4)

C9001(5) $\underline{\text { Value }}$

590.54

1.0

0.26

3603.4

2325.25 $\underline{\text { Units }}$

$\mathrm{W} / \mathrm{m}^{2} \mathrm{~K}$

$W / m^{2} k$ $W / m^{2}-K$ 


\title{
Fuel Dispersal Interactions (FDI) Package Reference Manual
}

\author{
MELCOR Code Development Group \\ Modeling and Analysis Department \\ Nuclear Energy Technology Center \\ Sandia National Laboratories \\ Albuquerque, NM 87185-0739
}

\author{
Contributors: \\ Michael L. Corradini \\ Susan E. Dingman \\ M. H. Kim \\ Gregory A. Moses \\ M. D. Oh \\ Russell C. Smith \\ Samuel L. Thompson
}

This document describes in detail the various models incorporated in the Fuel Dispersal Interactions (FDI) Package in MELCOR. Details on input to the FDI Package can be found in the FDI Users' Guide. 
. 


\section{Contents}

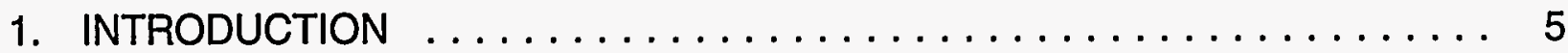

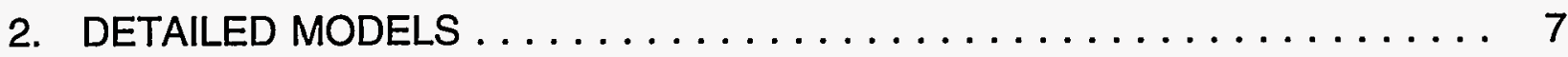

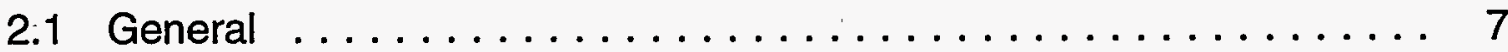

2.2 Low Pressure Melt Ejection (LPME) Modeling . . . . . . . . . 7

2.3 High Pressure Melt Ejection (HPME) Modeling . . . . . . . . . 11

3. DISCUSSION AND DEVELOPMENT PLANS $\ldots \ldots \ldots \ldots \ldots \ldots \ldots \ldots$

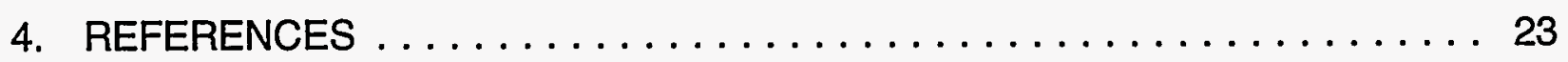

APPENDIX A: SENSITIVITY COEFFICIENTS $\ldots \ldots \ldots \ldots \ldots \ldots \ldots \ldots$ 
FDI Package Reference Manual

FDI-RM-4 
FDI Package Reference Manual

\section{INTRODUCTION}

The Fuel Dispersal Interactions (FDI) Package in MELCOR calculates the behavior of debris in containment unless or until it is deposited in a cavity modeled by the MELCOR Cavity (CAV) Package. Debris enters the package in basically two ways:

(1) if the Core (COR) package is active, debris enters the FDI package via the Transfer Process (TP) package after the failure of the reactor vessel, or

(2) in the stand-alone high pressure melt ejection (HPME) model, debris enters the FDI package through a user interface, which may be either tabular function input or input from an external data file (EDF) via the TP package.

Two types of phenomena are treated in the FDI package: (1) low pressure molten fuel ejection from the reactor vessel and (2) high pressure molten fuel ejection from the reactor vessel (direct containment heating). There is currently no plan to model steam explosions within or outside the FDI package in MELCOR.

There is no fission product modeling associated with the FDI package, with one minor exception. In particular there is no release of fission products from fuel debris modeled in the FDI package. In general, the only function performed by the FDI package with respect to radionuclide modeling is inventory transport. That is, if the FDI package transports fuel debris from one location to another, it calls the Radionuclide (RN) package and instructs it to transport the fission products associated with the fuel debris in exactly the same way.

The one exception to the foregoing concerns decay heat associated with debris deposited on heat structures by the HPME model. The decay heat associated with deposited debris is treated in essentially the same way as the decay heat associated with fission product aerosols and vapors that settle/deposit on heat structures in the RN package modeling. The Radionuclide Package Reference Manual discusses this modeling in detail. The decay heat associated with airborne debris in the HPME model and all debris during its short residence in the low pressure melt ejection (LPME) model is ignored; the energy error associated with its omission should be quite small. 
FDI Package Reference Manual

FDI-RM-6 
FDI Package Reference Manual

\section{DETAILED MODELS}

\subsection{General}

The FDI package becomes active whenever debris material enters the package. Debris material typically enters the FDI package in one of three ways. In a reactor plant accident calculation debris enters the FDI package via the TP package interface from the core (COR) package after failure of the reactor pressure vessel has been calculated. In a stand-alone direct containment heating (DCH) calculation debris material is sourced into the FDI package either directly from tabular function user input or via the TP package interface to a user provided external data file (EDF) containing the source. The Transfer Process Package Users' Guide and External Data File Package Users' Guide along with the FDI Package Users' Guide provide example input to illustrate the interfaces.

After the introduction of debris material, the FDI package classifies the ejection event as either a low or a high pressure melt ejection event on the basis of the ejection velocity passed through the TP package or a flag set by the user for stand-alone DCH calculations.

\subsection{Low Pressure Melt Ejection (LPME) Modeling}

The heart of the LPME model that has been incorporated into MELCOR was developed by Corradini et. al. [1] at the University of Wisconsin. In this model, heat is transferred from the molten debris to the water pool (if present in the associated control volume) as it breaks up and falls to the cavity floor. The heat transfer is normally dominated by radiation, but a lower bound determined by conduction through a vapor film (the Bromley model for film boiling) is also considered. All of the energy transfer from the molten debris is used to boil the pool water (i.e., a subcooled pool will remain subcooled and its temperature will not change). The LPME model does not consider oxidation of the metallic elements in the ejected debris. If no pool is present, material passes through FDI without any energy removal. At the cavity floor, the material is normally passed to the CAV package (CORCON) by way of the TP interface.

The first step in the LPME calculational sequence involves retrieving the variables describing the debris state entering the model at the beginning of each calculational cycle (time step). The debris variables are passed from the COR package to the TP package prior to execution of the FDI package, so the values of the variables are current for the time step. The variables retrieved from the TP package by the FDI package include the mass, composition and temperature of the debris ejected from the vessel during the time step and the velocity and diameter of the ejection stream (see COR reference manual for a description of the calculation of these variables). 


\section{FDI Package Reference Manual}

The second step in the LPME sequence is to determine the axial position of the head and tail of the ejected debris with respect to the FDI calculational volume. The user specifies $\mathrm{z}_{\mathrm{TOP}}$ and $\mathrm{z}_{\mathrm{BO}}$, the elevation of the top and bottom of the calculational volume, respectively, (which typically are equal to the elevation of the bottom of the reactor vessel and the bottom of the reactor cavity). Then the positions of the head and tail of the ejected debris and its length are given by

$$
\begin{aligned}
& z_{\text {HEAD }}=z_{\text {TOP }}-U_{f} \Delta t \\
& z_{\text {TAlL }}=z_{\text {HEAD }}+m_{f} /\left(\pi D_{f 0}^{2} \rho_{f} / 4\right) \\
& z_{\text {LEN }}=z_{\text {TAIL }}-z_{\text {HEAD }}
\end{aligned}
$$

where $U_{f}, m_{f}, D_{f 0}$ and $\rho_{f}$ are the velocity, mass, initial diameter (determined by the COR package and equal to the diameter of reactor vessel breach, which may increase if hole ablation occurs) and density of the ejection stream, respectively. Any debris below elevation $\mathrm{z}_{\mathrm{BOT}}$ accumulates on the cavity floor, and its mass is designated $\mathrm{m}_{\mathrm{FLR}}$ and given by

$$
m_{\text {FLR }}=m_{f} \operatorname{MAX}\left(0, \operatorname{MIN}\left(1,\left(z_{\text {BOT }}-z_{\text {HEAD }}\right) / z_{\text {LEN }}\right)\right)
$$

The portion of $m_{f}$ that does not reach the floor remains in the FDI calculational volume until the next time step and is designated $m_{\text {CAV }}$. If there was already mass in the volume ( $m_{\text {CAvo }}$ from the previous time step), then it is added to $m_{F L R}$ and deposited on the cavity floor on this time step. If $m_{f}$ is zero (i.e., if mass ejection from the vessel has ceased), then any pre-existing $m_{C A V O}$ is transferred to $m_{F L R}$. If $m_{f}$ is greater than zero, but $z_{H E A D}$ is greater than $\mathrm{z}_{\mathrm{BOT}}$, then only pre-existing $\mathrm{m}_{\mathrm{CAvO}}$ is deposited on the floor and given by

$$
\begin{aligned}
& m_{F L R}=\operatorname{MIN}\left(m_{f}, m_{C A V O}\right) \\
& m_{C A V}=m_{f}+m_{C A V O}-m_{F L R}
\end{aligned}
$$

In effect, this means that if mass is being ejected from the vessel but the time step is too short for newly ejected debris to reach the cavity floor, then pre-existing debris that has not reached the cavity floor is deposited on the cavity floor at a rate equal to the vessel ejection rate, and the newly ejected debris takes the place of the deposited debris. However, as soon as vessel ejection ceases, then all remaining debris that has not reached the cavity floor is immediately deposited on the cavity floor in a single time step.

After the mass of debris reaching the floor during the current time step has been determined, heat transfer to water in the cavity is evaluated. Although the heat transfer occurs during the passage of the debris through the cavity pool, the actual heat transfer associated with a given packet of debris is not transferred to the pool until that packet is 
FDI Package Reference Manual

deposited on the cavity floor. Debris which does not reach the floor during the current time step does not participate in heat transfer to the water until a later time step.

The rate of heat transfer from the debris to the water is determined primarily by the interfacial surface area which is a function of the debris particle size. The particle size for molten debris particles descending through the cavity pool is given by a modified theoretical correlation for droplet breakup under hydrodynamic force. The original correlation as formulated by Chu [2] for a water/air system is

$$
D_{f}(t)=D_{f 0} \exp \left(-C_{1} \tau^{0.772} W e^{0.246}\right)
$$

We is the Weber number, which is defined by

$$
W e=\rho_{c} U_{f}^{2} D_{i 0} / \sigma_{f}
$$

where $\rho_{c}$ is the coolant density, $U_{f}, D_{f 0}$ and $\sigma_{f}$ are the velocity, initial diameter and surface tension of the droplets, respectively. $\tau$ is the dimensionless time, which is defined by

$$
\tau=\left(U_{f} t / D_{f 0}\right)\left(\rho_{c} / \rho_{f}\right)^{1 / 2}
$$

where the time of descent, $t$, is zero when the debris is at the pool surface and increases as the debris descends through the pool. Constant, $\mathrm{C}_{1}$, taken to be

$$
C_{1}=0.171-0.149\left(\rho_{c} / \rho_{f}\right)^{1 / 2}
$$

To provide an easily integrable form for analytic use in MELCOR, Chu's correlation is modified as follows

$$
D_{1}(t)=D_{f 0} \exp \left(-C_{1} \tau W e^{0.254}\right)
$$

with constant, $\mathrm{C}_{1}$, taken to be

$$
C_{1}=0.1232-0.149\left(\rho_{c} / \rho_{f}\right)^{1 / 2}
$$

A comparison of Chu's correlation to this modified correlation for the water/air and corium/water systems reveals reasonable agreement [1]. Assuming constant velocity, $U_{f}$, Eq. 2.2.11 can be converted to a function of the elevation of the pool surface, $z_{\mathrm{POOL}}$, as shown below

$$
D_{f}(Z)=D_{f 0} \exp (-Z)
$$

for $z_{\mathrm{BOT}} \leq \mathrm{Z} \leq \mathrm{z}_{\mathrm{POOL}}$, where the variable $\mathrm{Z}$ is

$$
Z=\left(C_{1} W e^{0.254} / D_{f 0}\right)\left(\rho_{c} / \rho_{f}\right)^{1 / 2}\left(Z_{\mathrm{POOL}}-Z\right)
$$




\section{FDI Package Reference Manual}

Eq. 2.2.13 is valid only as long as the debris remains molten. After the debris solidifies, $\left(T_{f}<T_{\text {sol, }}\right.$ as determined by the solution of Eq. 2.2.17 to follow), there is no further breakup, and the heat transfer area is constant.

Another important factor affecting the rate of heat transfer is the heat transfer regime. In the early stage of heat transfer from the debris, the debris temperature is very high; hence, radiation heat transfer would be the dominant heat transfer mechanism. As the debris temperature falls, eventually other mechanisms become important.

Although radiation and conduction through the vapor film occur in parallel, the model incorporated into MELCOR only considers the dominant mechanism at any given time. Hence, the model switches from radiation-dominated to conduction-dominated film boiling heat transfer when the debris temperature falls below the "regime transition temperature". The regime transition temperature, $T_{\text {TRAN }}$, is defined as the temperature at which the net radiation heat flux between the debris and pool is equal to the conduction-dominated film boiling heat flux from the debris to the pool and is given by the solution to the following equation

$$
\sigma\left(T_{\text {TRAN }}{ }^{4}-T_{c}{ }^{4}\right)=h_{F B}\left(T_{\text {TRAN }}-T_{\text {sat }}\right)
$$

where $\sigma$ is the Stefan-Boltzmann constant (and the emissivity is assumed to be unity) and $h_{F B}$ is the conduction-dominated film boiling heat transfer coefficient given by Bromley [3]

$$
h_{F B}=1 / 2 k_{g}\left\{k_{g} \mu_{g} D_{f}\left(T_{g}-T_{s a t}\right) /\left[\rho_{g}\left(\rho_{c}-\rho_{g}\right) g i_{f g}\right]\right\}^{-1 / 4}
$$

where $k_{\mathrm{g}}$ and $\mu_{\mathrm{g}}$ are the thermal conductivity and viscosity of the vapor film, respectively, $\mathrm{i}_{\mathrm{ig}}$ is the latent heat of vaporization of water and $\mathrm{g}$ is the acceleration of gravity. To derive this equation, it was assumed that the vapor saturation temperature, $T_{\text {sat }}$, the debris diameter, $D_{f}$, and the vapor temperature, $T_{g}$, are constant. $T_{g}$ is the arithmetic average of the debris and saturation temperatures. Eq. 2.2.15 can be solved iteratively to yield $T_{\text {TRAN }}$, the heat transfer regime transition temperature.

The rate of change of the debris temperature, $T_{f}$, is given by

$$
\rho_{f} c_{v f}\left(\pi D_{f}^{3} / 6\right) U_{f} d T_{f} / d z=q_{f \rightarrow c}\left(\pi D_{f}^{2}\right)
$$

where $c_{v f}$ is the specific heat capacity of the debris and $q_{f \rightarrow c}$ is the heat flux from the debris to the coolant. For $T_{f}>T_{\text {sol, }}, D_{f}$ is given by Eq. 2.2.13; otherwise $D_{f}$ remains equal to its value at the instant solidification begins. For $T_{f}>T_{\text {TRAN }}, q_{f \rightarrow c}$ is calculated assuming only radiative heat transfer; otherwise, $\mathrm{q}_{\mathrm{i} \rightarrow \mathrm{c}}$ is calculated assuming only transition film boiling. Eq. 2.2.17 can be integrated from $z=z_{P O O L}$ to $z=z_{B O T}$ to yield $T_{f, B O T}$, the debris temperature at the bottom of the coolant pool. 
FDI Package Reference Manual

Once the debris temperature at the bottom of the pool is known, the total amount of heat transferred to the pool is given by

$$
Q_{f \rightarrow c}=H_{f}\left(T_{f 0}\right)-H_{f}\left(T_{f, B O T}\right)
$$

where

$$
H_{f}(T)=\sum_{i=1}^{N M A T}\left\{m_{i, F L R} h_{i}(T)\right\}
$$

and $h_{1}(T)$ is the specific enthalpy of debris component $i$ at temperature $T$. The mass of steam generated by the heat transfer is given by

$$
m_{\text {STEAM }}=Q_{f \rightarrow C} /\left(h_{\text {SCV }}-h_{\text {POOL }}\right)
$$

where $h_{\mathrm{scv}}$ is the specific enthalpy of saturated steam at the total pressure in the FDI control volume and $h_{\mathrm{POOL}}$ is the specific enthalpy of the water in the cavity pool. Note that all heat transfer is assumed to generate steam; hence, the pool temperature should not change. If $m_{\text {STEAM }}$ exceeds the mass of coolant in the pool, then $H_{f}\left(T_{f, B O T}\right)$ and $T_{f, B O T}$ are back-calculated to provide just enough heat transfer to vaporize the mass of coolant in the pool.

Following the calculation of steam generation, the increments to the pool and vapor masses and energies are passed to the CVH package, the debris deposited on the floor at temperature $T_{f, B O T}$ is passed to the CAV package, where core-concrete interactions are modeled, and the radionuclides associated with the debris passed to CAV are transferred from FDI to the radionuclide package.

\subsection{High Pressure Melt Ejection (HPME) Modeling}

If the velocity of the molten debris ejected from the reactor vessel exceeds a critical value prescribed by sensitivity coefficient 4602 (with an ad hoc default value of $10 \mathrm{~m} / \mathrm{s}$ ), or if the user has invoked the stand-alone option for high pressure melt ejection modeling, then the FDI will be treated by the high pressure model instead of the low pressure model.

The parametric high pressure model requires user input to control both the distribution of debris throughout the containment and the interaction of the hot debris with the containment atmosphere. The processes modeled include oxidation of the metallic components of the debris (zircaloy, aluminum and steel) in both steam and oxygen, surface deposition of the airborne debris by trapping or settling and heat transfer to the atmosphere and deposition surfaces. 


\section{FDI Package Reference Manual}

The HPME model does not include a mechanistic debris transport model; rather, the user specifies a set of debris destinations with a corresponding set of transport fractions that prescribe where the ejected debris is assumed to go. The debris destinations may include the atmosphere of any CVH control volume, the surface of any heat structure and cavities defined by the CAV package. The sum of the transport fractions over all the specified control volume atmospheres, heat structure surfaces and cavities must equal one. Transport of the ejected debris to its assumed destinations occurs instantaneously with no interactions occurring between the point of ejection and the destination sites. As long as the HPME model is active (i.e. as long as the ejection velocity exceeds the LPME/HPME transition velocity prescribed by sensitivity coefficient 4602 or if the user has invoked the stand-alone HPME model) the ejected debris will be partitioned among the destinations as specified by the transport fractions. When the ejection velocity falls below the LPME/HPME transition velocity for non-stand-alone applications, any debris subsequently ejected is passed to the LPME model, which uses LPME model input instead of the HPME transport model to determine the debris destination. However, debris that was transported to the HPME debris destinations before the model transition occurred will continue to be treated by the HPME model.

Debris which is transported to cavity destinations is not treated further by the FDI package; rather, subsequent treatment is provided by the CAV package. As implemented in the HPME model, surface deposition of debris can occur in two distinct ways. Ejected debris which impacts structures prior to any significant interaction with the atmosphere is sourced directly to the destination surface via the user-specified transport fraction for that surface. This process is referred to as trapping in MELCOR. Alternatively, debris which interacts significantly with the atmosphere should be sourced to the appropriate control volume, in which a user-specified settling time constant will determine the rate of deposition to the specified settling destination (either a heat structure surface or a cavity). This process is referred to as settling in MELCOR.

First-order rate equations with user-specified time constants for oxidation, heat transfer and settling are used to determine the rate of each process. Oxidation of airborne and deposited debris is only calculated if the debris temperature exceeds a minimum value, TOXMIN, which is adjustable through sensitivity coefficient 4609 and has a default value of $600 \mathrm{~K}$. If a pool of water exists in the reactor cavity at the time of debris ejection, then the water is ejected into the droplet field (fog) of the atmosphere at a rate proportional to the rate of injection of the debris into the pool. The proportionality constant is adjustable through sensitivity coefficient 4605 and has an ad hoc default value of 10 . This proportionality constant is strictly parametric and intended for exploratory purposes only. The rate of dispersal of the cavity water may be very important in determining containment loads, if interaction between the debris and cavity water is a primary contributor to the load. Excessive values of this coefficient may disperse the cavity water prematurely and limit subsequent interactions between ejected debris and cavity water, while deficient values will excessively limit the overall interaction of debris and water. Consequently, it is strongly recommended that the effects of variations in the value of this 
FDI Package Reference Manual

sensitivity coefficient be examined both because of its inherent uncertainty, and because of large impact it may have on containment loads. The HPME model does not consider any thermal interaction between the ejected debris and the water in the cavity pool such as that described above for the LPME model.

When the HPME model first initiates direct containment heating in a control volume, the FDI package requests a fallback of the cycle if the time step exceeds the recommended start-up value prescribed by sensitivity coefficient 4607 (with a default value of $10^{-4} \mathrm{~s}$ ). The value of the start-up value should be reasonably small both to avoid numerical problems associated with excessive energy transfers to the CVH atmosphere per time step and to capture the detail associated with the HPME phenomena, which occurs on a time scale comparable to the user-specified time constants for the phenomena. Experience has indicated that for most realistic scenarios the rapid excursions in pressure and temperature caused by direct containment heating dictate the use of very small time steps for several cycles following DCH initiation. See the input record SOFTDTMIN in the executive package users' guide for help with this requirement.

The airborne masses of $\mathrm{UO}_{2}$ and other materials that neither oxidize nor are the products of oxidation are described by the following first order linear differential equation:

$$
\frac{d m_{i, k}(t)}{d t}=-\frac{m_{i, k}(t)}{\tau_{S T, i}}+S_{i, k}
$$

where $m_{i, k}(t)$ is the mass of component $k$ in control volume $i$ at time $t, \tau_{S T, i}$ is the time constant for settling in control volume $i$ and $S_{i, k}$ is the constant mass source rate of component $\mathrm{k}$ in control volume $\mathrm{i}$ associated with the high pressure melt ejection process. The solution of Eq. 2.3.1 is given by:

$$
m_{i, k}(t)=\left\{m_{i, k}\left(t_{0}\right)-S_{i, k} \tau_{S T, i}\right\} \exp \left\{-d t / \tau_{S T, i}\right\} \quad+S_{i, k} \tau_{S T, i}
$$

where $m_{i, k}\left(t_{0}\right)$ is the mass at arbitrary initial time $t_{0}$, and dt is the difference between the final time, $t$, and time $t_{0}$. The airborne masses of $Z r, A l$ and steel (the only materials that are oxidized in the presence of oxygen or steam) are described by the following first order linear differential equation:

$$
\frac{d m_{i, k}(t)}{d t}=-\frac{m_{i, k}(t)}{\tau_{s o, i}}+S_{i, k}
$$

where $\tau_{\text {so,l, }}$, the time constant for simultaneous oxidation and settling/trapping, is given by: 
FDI Package Reference Manual

$$
\tau_{\mathrm{s}, \mathrm{i}}^{-1}=\tau_{\mathrm{sT}, \mathrm{i}}^{-1}+\tau_{\mathrm{OX}, \mathrm{i}}^{-1}
$$

and where $\tau_{\text {ox, } i}$ is the oxidation time constant in control volume $i$. The solution to Eq. 2.3.3 is identical to Eq. 2.3.2 except that $\tau_{\mathrm{ST}, \mathrm{i}}$ is replaced by $\tau_{\mathrm{sO}, \mathrm{i}}$. The airborne masses of $\mathrm{ZrO}_{2}$ and other materials that are products of oxidation reactions are given by:

$$
\frac{d m_{i, k}(t)}{d t}=-\frac{m_{i, k}(t)}{\tau_{S T, i}}+R \frac{m_{i, S}(t)}{\tau_{O X, i}}+S_{i, k}
$$

where $\mathrm{R}$ is the mass of product $\mathrm{k}$ formed by the oxidation of a unit mass of reactant $\mathrm{I}$. The solution of Eq. 2.3.5 is:

$$
\begin{aligned}
m_{i, k}(t)=\left\{m_{i, k}\left(t_{0}\right)-\right. & \left.C_{1}-C_{2}\right\} \exp \left(-d t / \tau_{s T, i}\right) \\
& +C_{2} \exp \left(-d t / \tau_{s O, i}\right)+C_{1}
\end{aligned}
$$

where

$$
C_{1}=\left(S_{i, k}+R S_{i, i} \tau_{S O, i} / \tau_{O X, i}\right) \tau_{S T, i}
$$

and

$$
\mathrm{C}_{2}=\mathrm{R}\left\{\mathrm{S}_{\mathrm{i}, 1} \tau_{\mathrm{sO}, \mathrm{i}}-\mathrm{m}_{\mathrm{i}, 1}\left(\mathrm{t}_{0}\right)\right\}
$$

The HPME model contains two options for oxidation modeling. The user invokes the sequential oxidation option, in which the order of oxidation is $\mathrm{Zr}$, Al then steel (typical metallic elements associated with reactor cores and/or simulation experiments), by specifying a positive value for the oxidation time constant, $\tau_{\text {ox, }}$. For control volumes in which the user would prefer simultaneous oxidation of the metals, a negative value of $\tau_{\mathrm{ox}, \mathrm{i}}$ is specified and the time constant will be equal to the absolute value of $\tau_{o x, j}$. Under normal conditions where the metallic constituents exist in a more or less well mixed state, the sequential oxidation option is recommended because it is more realistic. Elements with high oxidation potentials will be oxidized preferentially.

In the sequential oxidation model a separate oxidation rate is first calculated for each metal independently of all others with the given value of $\tau_{\text {ox,i }}$. Then the mass of metal B consumed will be converted into an equivalent mass of metal $A$, where metal $A$ is assumed to oxidize in preference to metal $B$, until all of metal $A$ is consumed. Hence, steel (and Inconel, which is included in the steel mass in the FDI package) will not be consumed until all the $\mathrm{Zr}$ and $\mathrm{Al}$ have been consumed, and Al will not be consumed until the $Z r$ is exhausted. This implies that the effective time constant for metal $A$ oxidation when metal $B$ is present may be significantly shorter than $\tau_{\text {ox, } i^{*}}$. The actual values of the 
FDI Package Reference Manual

effective oxidation time constants will be used in determining the end of time step airborne mass inventories in Eq. 2.3.2 and Eq. 2.3.6 above.

Of course both oxidation options are constrained by the availability of oxygen or steam. Steam oxidation will only be calculated if there is insufficient oxygen available in the control volume to support the prescribed oxidation rate. If there is insufficient oxidant to support the calculated rates of oxidation for zirconium and iron, then the zirconium will have first priority. The oxidation reactions will proceed at the initial time step values of debris temperature in each control volume, and hydrogen formed by the steam reaction will enter the atmosphere at that temperature.

The temperature of the airborne debris is effected by debris sources, oxidation and heat transfer from the debris to the atmosphere. The temperature of the atmosphere, $T_{\text {gas }}$, is assumed to remain constant and equal to the beginning of time step value obtained from the CVH package data base. This explicit coupling between FDI and $\mathrm{CVH}$ may limit the time step size during energetic transients, as discussed below. The enthalpy of the airborne debris is given by the solution of the following simple equation:

$$
\frac{\mathrm{d} \mathrm{H}(\mathrm{t})}{\mathrm{dt}}=\dot{\mathrm{E}}_{\mathrm{OX}, \mathrm{i}}(\mathrm{t})-\dot{\mathrm{Q}}_{\mathrm{GAS}, \mathrm{i}}(\mathrm{t})+\mathrm{S}_{\mathrm{H}, \mathrm{i}}
$$

where $\dot{E}_{\mathrm{OX,i}}(t)$ is the rate of heat generation by the oxidation reaction, $\mathrm{S}_{\mathrm{H}, \mathrm{i}}$ is the enthalpy source rate associated with the high pressure melt ejection source, and where the rate of heat transfer to the gas is approximated as:

$$
\dot{Q}_{\mathrm{GAS}, \mathrm{i}}(\mathrm{t})=\frac{\mathrm{Q}_{\mathrm{g}, \mathrm{i}}(\mathrm{t})}{\tau_{\mathrm{HT}, \mathrm{i}}}=\frac{\mathrm{H}_{\mathrm{i}}\left(\mathrm{T}_{\mathrm{dbr}}\right)-\mathrm{H}_{\mathrm{i}}\left(\mathrm{T}_{\mathrm{gas}}\right)}{\tau_{\mathrm{HT}, \mathrm{i}}}
$$

where $Q_{g, i}(t)$ is the enthalpy available for transfer to the gas, $\tau_{H T, i}$ is the user specified time constant for heat transfer from the airborne debris to the atmosphere in control volume $i, H_{1}\left(T_{d b r}\right)$ is the enthalpy content of the debris at its actual temperature, $T_{d b r}$, and $H_{i}\left(T_{g a s}\right)$ is the enthalpy content of the debris in equilibrium with the gas at temperature, $T_{\text {gas. }}$. The solution to Eq. 2.3.7 is given by:

$$
H_{i}(t)=H_{i}\left(t_{0}\right)+E_{o x, i}(t)-Q_{G A S, i}(t)
$$

where $H_{1}\left(t_{0}\right)$ is the enthalpy of the debris following the addition of the integrated enthalpy source, $S_{H, l} \mathrm{dt}$, and following adjustments to its composition associated with the oxidation reaction, where $E_{o x, i}(t)$ is the oxidation enthalpy generated between times $t_{0}$ and $t$ and 


\section{FDI Package Reference Manual}

where $Q_{G A S, i}(t)$ is the amount of heat transferred to the gas between times $t_{0}$ and $t$. $Q_{G A S, i}(t)$ is given by:

$$
Q_{G A S, i}(t)=\int_{t_{0}}^{t_{0}+d t}\left\{Q_{g, i}(t) / \tau_{H T, i}\right\} d t
$$

where the available enthalpy, $Q_{\mathrm{g}, \mathrm{i}}(\mathrm{t})$, increases as a result of oxidation and the addition of high temperature debris source material and decreases as enthalpy is transferred to the gas. $Q_{g, i}(t)$ satisfies:

$$
\begin{aligned}
& \frac{d Q_{g, i}(t)}{d t}=-\frac{Q_{g, i}(t)}{\tau_{H T, i}}+\left\{Q_{S R C, i}+\left(E_{O X, i}+Q_{O X, i}\right) / d t\right\} \\
& Q_{S R C, i}=S_{H, i}\left(T_{S r C}\right)-S_{H, i}\left(T_{g a s}\right) .
\end{aligned}
$$

is the available source enthalpy and

$$
Q_{o x, i}=H_{o x, i}\left(T_{d b r}\right)-H_{o x, i}\left(T_{\text {gas }}\right)
$$

is the available enthalpy created by composition adjustments during oxidation. The solution to Eqs. 2.3.10 and 2.3.11 is:

$$
\begin{gathered}
Q_{G A S, i}(t)=Q_{O L D, i}\left\{1-\exp \left(-d t / \tau_{H T, i}\right)\right\}+\left\{Q_{S R C, i}+\left(E_{O X, i}+Q_{O X, i}\right) / d t\right\} \\
\left\{d t-\tau_{H T, i}\left(1-\exp \left(-d t / \tau_{H T, i}\right)\right)\right\}
\end{gathered}
$$

where $Q_{O L D, i}=H_{i}\left(T\left(t_{0}\right)\right)-H_{i}\left(T_{\text {gas }}\right)$ is the initial available enthalpy.

The inclusion of the HPME source terms in Eqs. 2.3.1 through 2.3.12 reduces some timestep dependencies that would arise if the sources were added prior to the calculation of oxidation, heat transfer and settling/trapping. After the total enthalpy at the advanced time, $t$, is determined, it is compared to the enthalpy corresponding to a maximum permissible temperature, $H_{\text {MAX. }}$. If $H_{i}(t)$ exceeds $H_{M A X}$, then Eq. 2.3.9 is solved for $Q_{G A S, i}(t)$ with $H_{i}(t)$ set equal to $H_{\text {MAX }}$ as follows:

$$
Q_{G A S, i}(t)=H_{i}\left(t_{0}\right)+E_{O X, i}(t)-H_{M A X}
$$


so that the heat transferred to the gas is increased sufficiently to limit the advanced time debris temperature to the maximum prescribed value, $T_{\operatorname{MAX}}$. $T_{\text {MAX }}$ is given by:

$$
T_{\text {MAX }}=\operatorname{MAX}\left(T_{\text {gas }}, T_{d b r}\left(t_{0}\right), T_{d b r}\left(t^{\prime}\right), T 4603\right)
$$

where $T_{\text {gas }}$ is the gas temperature, $T_{d b r}\left(t_{0}\right)$ is the debris temperature at the beginning of the time step, $T_{d b r}\left(t^{3}\right)$ is the debris temperature after addition of new source material to the initial inventory and T4603 is the temperature limit prescribed by sensitivity coefficient 4603 , which normally exceeds the other arguments in the max function of Eq. 2.3.14. The default value of $\mathrm{T4603}$ is approximately equal to the boiling temperature of $\mathrm{UO}_{2}-$ temperatures much in excess of this value would likely result in very rapid fragmentation of debris droplets and significantly increased droplet-to-gas heat transfer.

After an advanced time temperature for the airborne debris has been determined, the projected change in the $\mathrm{CVH}$ atmosphere temperature as a result of direct containment heating during the time step is calculated. If the change exceeds a value prescribed by sensitivity coefficient 4604 (with a default value of $500 \mathrm{~K}$ ), then the FDI package requests a fallback with a decreased time step. This feature provides control over numerical problems associated with excessive energy transfers to the $\mathrm{CVH}$ atmosphere. If the value of sensitivity coefficient 4604 is set too high, it is possible that the CVH package will encounter numerical difficulties that cannot be resolved by $\mathrm{CVH}$ fallbacks. In practice, the default value was found to prevent numerical problems in $\mathrm{CVH}$ without excessively limiting the time step.

Following the determination of the advanced time temperature for the airborne debris, the advanced time mass equations, Eqs. 2.3.1 through 2.3.6, are used to determine how much material is removed from the atmosphere by settling/trapping. The settled material and its energy content are removed from the airborne inventory and deposited on the appropriate surface specified by user input. After the settling calculation has been performed, the advanced time total airborne mass in each control volume is determined by summing over all components. If the advanced time total airborne mass is insignificant compared to the total mass of material sourced into the control volume atmosphere over the duration of the DCH event, then all of the remaining airborne mass in the control volume is immediately deposited on the appropriate settling surface and a message is issued to notify the user that direct containment heating has ceased in that particular control volume. The ratio used to determine when the airborne mass has become insignificant is adjustable through sensitivity coefficient 4606 and has a default value of 0.001 . This implies that only 0.1 per cent of the mass source will be prematurely deposited, which was judged to be a reasonable compromise between the demands of accuracy and calculational effort.

\section{Deposited Debris}


FDI Package Reference Manual

The mass of material $k$ on surface $i$ at time $t$ is given by

$$
m_{i, k}(t)=m_{i, k}\left(t_{0}\right)+S_{i, k}^{\prime} d t
$$

where

$$
S_{i, k}^{\prime}=S_{i, k}+\sum_{j} \int_{t_{0}}^{t_{0}+d t}\left\{m_{j, k}\left(t^{\prime}\right) / \tau_{S T, j}\right\} d t^{\prime} / d t
$$

and $S_{i, k}$ is the constant mass source rate of component $k$ to surface $i$ from trapping. The second term on the right hand side of Eq. 2.3.16 accounts for settling to the surface, and the sum is over all control volumes that have surface $i$ as the user-specified settling surface. $m_{j, k}(t)$ and $\tau_{S T, j}$ are the airborne mass of component $k$ in control volume $j$ and the settling time constant in control volume j, respectively.

For $\mathrm{UO}_{2}$ and other materials not associated with oxidation the settling term is given by

$$
\begin{aligned}
\int_{t_{0}}^{t_{0}+d t}\left\{m_{j, k}\left(t^{\prime}\right) / \tau_{S T, j}\right\} d t^{\prime}=m_{j, k}\left(t_{0}\right)[1 & -\exp \left(-d t / \tau_{S T, j}\right] \\
& +S_{j, k}\left[d t-\tau_{S T, j}\left\{1-\exp \left(-d t / \tau_{S T, j}\right)\right\}\right]
\end{aligned}
$$

For metals that oxidize the settling term is given by

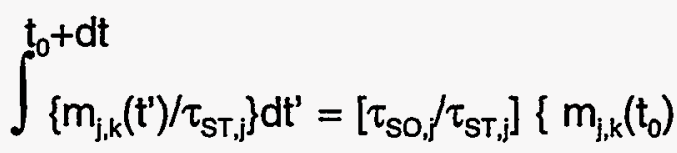

$$
\begin{aligned}
& t_{0} \\
& \left.\left[1-\exp \left(-\mathrm{dt} / \tau_{\mathrm{so}, j}\right)\right]+\mathrm{S}_{\mathrm{j}, \mathrm{k}}\left[\mathrm{dt}-\tau_{\mathrm{so}, \mathrm{j}}\left\{1-\exp \left(-\mathrm{dt} / \tau_{\mathrm{so}, \mathrm{j}}\right)\right\}\right]\right\}
\end{aligned}
$$

which reduces to Eq. 2.3.17 if $\tau_{\mathrm{Ox}, \mathrm{j}}>\tau_{\mathrm{ST}, \mathrm{j}}$, because in that case $\tau_{\mathrm{SO}, \mathrm{j}} \approx \tau_{\mathrm{ST}, \mathrm{j}}$ as shown by Eq. 2.3.4. For oxidation products the settling term is given by

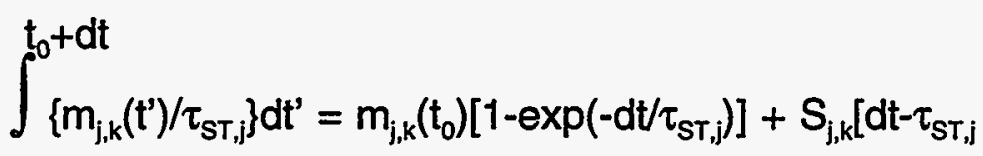

$$
\begin{aligned}
& t_{0} \\
& \left.\left\{1-\exp \left(-\mathrm{dt} / \tau_{\mathrm{sT}, j}\right)\right\}\right]+R\left\{[ \tau _ { \mathrm { so } , j } / \tau _ { \mathrm { ox } , j } ] \left[m_{\mathrm{j}, 1}\left(\mathrm{t}_{0}\right)+\mathrm{S}_{\mathrm{j}, \mathrm{l}}\left\{\mathrm{dt}-\tau_{\mathrm{so}, \mathrm{j}}\right.\right.\right.
\end{aligned}
$$

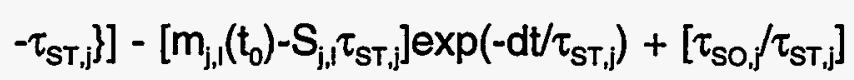


FDI Package Reference Manual

$$
\left.\left[\mathrm{m}_{\mathrm{j}, 1}\left(\mathrm{t}_{0}\right)-\mathrm{S}_{\mathrm{j}, \mathrm{l}} \tau_{\mathrm{so}, j}\right] \exp \left(-\mathrm{dt} / \tau_{\mathrm{so}, \mathrm{f}}\right)\right\}
$$

where material $I$ is the metal from which the oxide is formed and $R$ is the mass of product $\mathrm{k}$ formed by the oxidation of a unit mass of reactant $\mathrm{l}$.

The energy of the deposited debris is calculated with equations almost identical to Eqs. 2.3.7-2.3.14 except the source term $S_{H, i}$ also includes the enthalpy associated with debris settling. It is assumed that the enthalpy of the settled debris is equal to the end of time step value calculated with Eq. 2.3.9. The settled mass with the end of step enthalpy is applied to the deposition surface during the time step at a constant rate as implied by Eq. 2.3.15. The other difference between the treatment of the energy of airborne and deposited debris concerns heat transfer. As discussed above, the user specifies a time constant for heat transfer from the airborne debris to the atmosphere. However, for heat transfer from deposited debris to the structure a different approach is taken. Because the $\mathrm{CVH}$ package does not recognize the deposited debris temperature as the effective surface temperature, in order to effectively simulate the heat transfer from the hot debris to the CVH pool and/or atmosphere associated with the surface it is necessary to tightly couple the debris temperature to the HS surface temperature that $\mathrm{CVH}$ does recognize.

The debris temperature and HS surface temperature will be tightly coupled if the effective heat transfer coefficient from the debris to the surface, $h_{\mathrm{SPF}}$, is large compared to the heat transfer coefficient from the surface to the first interior node in the structure, which is given by $\mathrm{K}_{\mathrm{HS}, 1} / \Delta \mathrm{x}_{\mathrm{HS}, 1}$ (structure thermal conductivity divided by the node thickness). In order to generate a large value of $h_{\mathrm{SRF}}$, a very small time constant equal to the minimum of half the surface oxidation time constant and a value of $.001 \mathrm{~s}$ is used to calculate the amount of heat transfer from the debris to the deposition surface using the analog of Eq. 2.3.12 for heat transfer to surfaces. The value obtained is then used to determine $h_{\mathrm{SRF}}$ as follows:

$$
h_{\mathrm{SRF}}=Q_{\mathrm{SRF}, \mathrm{i}}(\mathrm{t}) /\left(\mathrm{A}_{\mathrm{SRF}} \Delta \mathrm{T} d \mathrm{t}\right)
$$

where $A_{S A F}$ is the surface area of the structure, $\Delta T$ is the difference between the beginning of time step debris temperature and the structure surface temperature and $Q_{\text {SRF }}$ is the value obtained from the analog of Eq. 2.3.12. This value will almost always exceed the value of $k_{\mathrm{HS}, 1} / \Delta \mathrm{x}_{\mathrm{HS}, 1}$. In fact, the value of $h_{\mathrm{SRF}}$ may be large enough to induce oscillations in the structure surface temperature because of the explicit coupling between FDI and HS. Therefore, a limit is placed on the value of $h_{\text {SRF. }}$. If $h_{\text {SAF }}$ exceeds a maximum value, $h_{S R F, \max }$, specified by sensitivity coefficient 4608 (default value 1000 . $\left.W / m^{2}-K\right)$, then the value of $Q_{\mathrm{SRF}}$ is reduced by the ratio $h_{\mathrm{SRF}, \mathrm{max}} / \mathrm{h}_{\mathrm{SPF}}$ to limit it to the value consistent with $h_{\mathrm{SRF}, \max }$. Whenever the $\mathrm{Q}_{\mathrm{SRF}}$ is limited by $\mathrm{h}_{\mathrm{SRF}, \max }$ the direction of heat transfer (i.e. debris-to-surface or surface-to-debris) is compared to the direction from the previous time step; if the direction is alternating, that indicates that the surface temperature has probably been driven into an oscillation about the debris temperature because the time step exceeds the stability limit associated with the explicit coupling 
FDI Package Reference Manual

between the FDI and HS packages. In such cases, FDI requests a system fallback with the time step reduced by a factor of one half. Normally, the value of $h_{\text {SRF, max }}$ should be chosen large enough to promote rapid equilibration of the debris and surface temperatures, yet not so large as to induce instability in the surface temperature for reasonable values of the time step. Users should refer to the HS Reference Manual for a further discussion of stability/accuracy concerns associated with structure nodalization and time step size.

If the MELCOR Radionuclide (RN) Package is active, then FDI will call RN1 anytime fuel is moved so that the associated radionuclides can be moved simultaneously. Furthermore, the decay heat associated with the radionuclides will be deposited in the appropriate location. 
FDI Package Reference Manual

\section{DISCUSSION AND DEVELOPMENT PLANS}

The simple direct containment heating model described above in Section 2.3 is not intended to predict all details of DCH events from first principles. Nodalization requirements would be much greater than normal MELCOR models. Rather, it is intended to allow users to evaluate the overall effect of varying the relative rates of the most important processes controlling DCH loads.

HPME model results are sensitive to the relative values of $\tau_{\mathrm{OX}, \mathrm{i}} \tau_{\mathrm{HT}, \mathrm{i}}$ and $\tau_{\mathrm{ST}, \mathrm{i}}$ specified by the user for each control volume. Reasonable values for these time constants can be obtained in basically two ways. First, results from detailed codes such as CONTAIN can be used to obtain appropriate values; or, second, reasonable assumptions concerning particle sizes and velocities in conjunction with simplified hand calculations can yield a range of time constants in the correct range. In most cases this second method should be adequate for parametric PRA studies. Specified time constants of less than $10^{-6} \mathrm{~s}$ will be reset to that value to avoid potential numerical problems associated with vanishing time constants. For time scales of interest, a time constant of $10^{-6} \mathrm{~s}$ implies an essentially instantaneous process (i.e., instantaneous complete oxidation, instantaneous thermal equilibration with the atmosphere or instantaneous settling).

Users are CAUTIONED that the absence of mechanistic debris transport in the HPME model currently limits the scope of phenomena that may be investigated. Specifically, decoupling the debris transport from the vessel blowdown precludes accurately investigating effects associated with the coherence between the debris and steam ejection. If the severity of the DCH threat is primarily limited by the amount of thermal and chemical energy available in the ejected debris, then the model should prove useful. However, if the threat is primarily limited by the amount of steam that has an opportunity to interact with the airborne debris, then the model may fail to capture the important phenomena and can underpredict the true threat. The user should suspect that this condition may exist whenever the following two conditions hold:

1. Most of the debris is specified to not reach the main volume of the containment.

2. In the cavity and/or subcompartment volumes which are specified to receive most of the debris, maximum gas temperatures approach the initial debris temperature and/or oxidant concentrations $\left(\mathrm{O}_{2}+\mathrm{H}_{2} \mathrm{O}\right)$ fall to low levels during the time period that airborne debris concentrations are relatively high. 

FDI Package Reference Manual

\section{REFERENCES}

1. M. H. Kim, M. D. Oh, G. A. Moses, and M. L. Corradini, "MELCOR Fuel Dispersion Interactions Model," University of Wisconsin, Reactor Safety Research, Nuclear Engineering Department document (November 1986).

2. C. C. Chu, M. L. Corradini, "One-Dimensional Transient Model for Fuel-Coolant Fragmentation and Mixing," Proc. Int'l Mtg. on Thermal Reactor Safety, San Diego CA (February 1986).

3. L. A. Bromley, "Heat Transfer in Stable Film Boiling," Chemical Engineering Progress, Vol. 46, No. 5, pp. 221-227, 1950. 

FDI Package Reference Manual

\section{APPENDIX A: SENSITIVITY COEFFICIENTS}

4602 Vessel ejection velocity at transition between high and low pressure ejection modeling.

(default $=10$., units $=\mathrm{m} / \mathrm{s}$, equiv $=$ none)

4603 Airborne debris temperature above which oxidation energy is deposited directly in the atmosphere-approximate vaporization point.

(default $=3700$., units $=\mathrm{K}$, equiv $=$ none)

4604 Maximum change in the temperature of the $\mathrm{CVH}$ atmosphere permitted without a time-step cut.

(default $=500$., units $=\mathrm{K}$, equiv $=$ none)

4605 Ratio of the mass of water ejected from a pool into the reactor cavity atmosphere to the mass of the debris injected from the vessel into the cavity pool.

(default $=10$, units $=$ none, equiv $=$ none $)$

4606 Ratio of the current airborne debris mass to the integrated airbome debris mass source in a control volume below which the mass will be deposited onto the settling surface associated with the control volume-deactivates DCH when the remaining airborne mass becomes insignificant.

(default $=0.001$, units $=$ none, equiv $=$ none $)$

4607 Initial time-step size for HPME initiation.

(default $=0.0001$, units $=s$, equiv $=$ DTHPME)

4608 Maximum Debris-to-Surface Heat Transfer Coefficient

(default $=1000$., units $=W / \mathrm{m}^{2}-\mathrm{K}$, equiv $=\mathrm{HTCMAX}$ )

4609 Minimum Temperature for Oxidation

(default $=600$., units $=K$, equiv $=$ TOXMIN) 


\title{
Heat Structure (HS) Package Reference Manual
}

\author{
MELCOR Code Development Group \\ Modeling and Analysis Department \\ Nuclear Energy Technology Center \\ Sandia National Laboratories \\ Albuquerque, NM 87185-0739
}

Contributors:

Michael K. Carmel

Randall K. Cole, Jr.

Paul N. Demmie

Russell C. Smith

Samuel L. Thompson

Stephen W. Webb

The MELCOR Heat Structure (HS) package calculates heat conduction within an intact, solid structure and energy transfer across its boundary surfaces into control volumes. The modeling capabilities of heat structures are general and can include pressure vessel internals and walls, containment structures and walls, fuel rods with nuclear or electrical heating, steam generator tubes, piping walls, etc.

This document provides detailed information about the models, solution methods, and time-step control that are utilized by the HS package. Section 1 is an introduction to heat structure modeling and the calculation procedure. Section 2 provides details on the heat and mass transfer models. The solution methods utilized are discussed in Section 3, and time-step control is summarized in Section 4.

Information which is necessary to execute the HS package with other packages in the MELCOR Code System is found in the HS Users' Guide. 
HS Package Reference Manual

HS-RM-2 


\section{Contents}

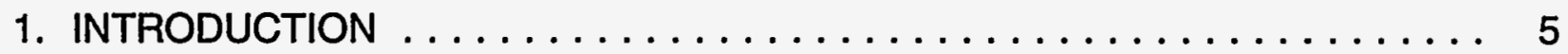

2. DETAILED MODELS $\ldots \ldots \ldots \ldots \ldots \ldots \ldots \ldots \ldots \ldots \ldots \ldots \ldots$

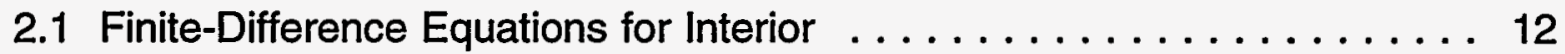

2.1.1 Nodalization at Interior Temperature Nodes . . . . . . . . . . 12

2.1.2 Difference Approximation at Interior Nodes . . . . . . . . . . . 16

2.1.3 Finite-Difference Equations at Interior Temperature Nodes . . . . . 17

2.2 Finite-Difference Equations at Boundary Surfaces . . . . . . . . . . 17

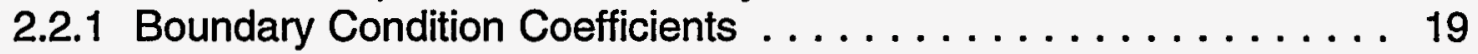

2.2.1.1 Symmetry (Adiabatic) ................. 19

2.2.1.2 Convective (Calculated or Specified Heat Transfer Coefficients) ...................... 19

2.2.1.3 Specified Surface Heat Flux .............. 20

2.2.1.4 Specified Surface Temperature ............. 20

2.2.2 Nodalization at Boundary Temperature Nodes . . . . . . . . . . 20

2.2.3 Difference Approximation at Boundary Nodes . . . . . . . . . . 24

2.2.3.1 Finite-Difference Equation at Left (Inside) Boundary . . . . 24

2.2.3.2 Finite-Difference Equation at Right (Outside) Boundary . . 27

2.3 Power Sources . . . . . . . . . . . . . . . . . . . 27

2.3.1 Internal Power Sources . . . . . . . . . . . . . . . 27

2.3.2 Surface Power Sources . . . . . . . . . . . . . . . 28

2.3.3 Energy Transferred by Other Packages . . . . . . . . . 28

2.4 Pool Fractions . . . . . . . . . . . . . . . . . . . . 29

2.4.1 Rectangular Geometry ... . . . . . . . . . . . . . 31

2.4 .2 Cylindrical Geometry . . . . . . . . . . . . . . . 31

2.4.3 Spherical Geometry ...................... 33

2.4.4 Hemispherical Geometry ................. 33

2.5 Thermal Properties . . . . . . . . . . . . . . . . . . 33

2.5.1 Thermal Conductivity and Volumetric Heat Capacity ........ 33

2.5.2 Modifications for Degassible Materials . . . . . . . . . . 33

2.6 Heat Transfer . . . . . . . . . . . . . . . . . . . . . 34

2.6.1 Atmosphere Convection Heat Transfer . . . . . . . . . . . . . 37

2.6.1.1 Conduction/convection through Liquid Films (film tracking

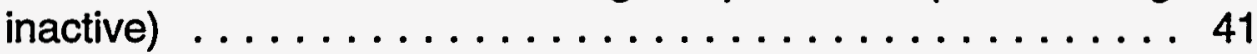

2.6.1.2 Conduction/convection through Liquid Films (film tracking active) ....................... 44

2.6.2 Atmosphere Radiation Heat Transfer . . . . . . . . . . . . . . . 45

2.6.3 Pool Convection Heat Transfer . . . . . . . . . . . . . . . 46

2.6.4 Pool Boiling Heat Transfer . . . . . . . . . . . . . . . 49

2.6.4.1 Nucleate Boiling . . . . . . . . . . . . . 49

2.6.4.2 Critical Heat Flux ................... 51

2.6.4.3 Minimum Film Boiling Heat Flux . . . . . . . . 51 
HS Package Reference Manual

2.6.4.4 Stable Film Boiling $\ldots \ldots \ldots \ldots \ldots \ldots \ldots \ldots \ldots \ldots$

2.6.4.5 Transition Boiling ................... 52

2.6.4.6 Radiation During Boiling ............... 53

2.6.5 Energy Transfer to Control Volumes ............... 53

2.7 Mass Transfer . . . . . . . . . . . . . . . . . . . . . . . . 54

2.7.1 Sherwood Number for Diffusion Mass Transfer . . . . . . . . . . . 55

2.7.2 Condensation and Evaporation with Noncondensibles ...... 56

2.7.3 Mass-Energy Transfer to Control Volumes . . . . . . . . . . . . 57

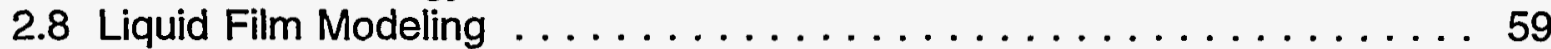

2.8.1 Film Models ........................ 59

2.8.2 Film Tracking Model . . . . . . . . . . . . . . . . 60

2.9 Stored Energy of a Heat Structure $\ldots \ldots \ldots \ldots \ldots \ldots \ldots \ldots \ldots 61$

2.10 Degassing Model ......................... 63

2.11 Ice Condenser Model . . . . . . . . . . . . . . . . . . . . . 64

2.12 Steel Melt Model ......................... 65

2.13 Communication with Other Packages $\ldots \ldots \ldots \ldots \ldots \ldots \ldots 65$

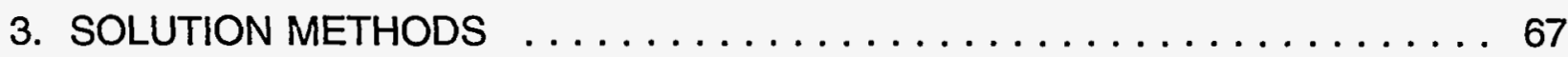

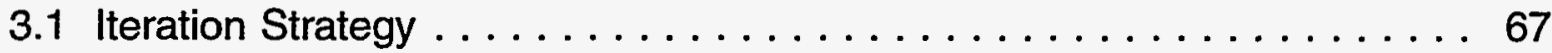

3.2 Steady-state Convergence Criteria . . . . . . . . . . . . . . . 69

3.3 Transient Convergence Criteria $\ldots \ldots \ldots \ldots \ldots \ldots \ldots \ldots \ldots \ldots$

$3.4 \mathrm{CVH}$ Heat Transfer Damping $\ldots \ldots \ldots \ldots \ldots \ldots \ldots \ldots \ldots \ldots$

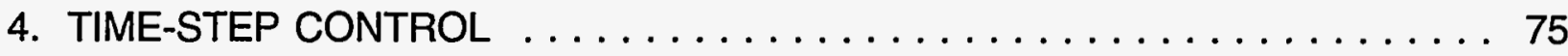

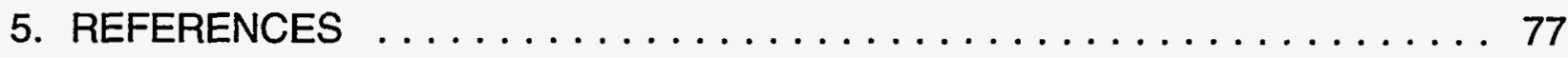

APPENDIX A: Sensitivity Coefficients $\ldots \ldots \ldots \ldots \ldots \ldots \ldots \ldots \ldots \ldots$ 
HS Package Reference Manual

\section{INTRODUCTION}

The Heat Structure (HS) package calculates heat conduction within an intact, solid structure and energy transfer across its boundary surfaces into control volumes. This document is the reference manual for the HS package. It contains the following information for this package:

(1) detailed models

(2) solution methods

(3) time-step control

This section describes the modeling of a heat structure in the MELCOR Code System and provides a discussion of the calculation procedure which is used to obtain the temperature distribution for each heat structure and to calculate its interactions with structures in other packages.

A heat structure is an intact, solid structure which is represented by one-dimensional heat conduction with specified boundary conditions at each of its two boundary surfaces. The modeling capabilities of heat structures are general and can include pressure vessel internals and walls, containment structures and walls, fuel rods with nuclear or electrical heating, steam generator tubes, and piping walls.

Figure 1.1 illustrates a heat structure in a control volume. A heat structure is inclined at some angle with respect to the vertical and is partially immersed in the pool of a control volume. Although the geometry shown here is rectangular, a heat structure may have a rectangular, cylindrical, spherical, or hemispherical geometry.

The heat structure in Figure 1.1 is nodalized with $\mathrm{N}$ temperature nodes. The nodalization is specified by user input and may be nonuniform, i.e. the distance between temperature nodes need not be the same. Node 1 is the temperature node at the left boundary surface for a rectangular geometry or at the inside boundary surface for a cylindrical, spherical, or hemispherical geometry. Node $\mathrm{N}$ is the temperature node at the right boundary surface for a rectangular geometry or at the outside boundary surface for the other geometries.

The region between two adjacent temperature nodes is called a mesh interval. Each mesh interval may contain a different material. The material in each mesh interval is specified by user input. The Material Properties package provides thermal properties for each material through an interface with the HS package. Most materials commonly found in PWRs and BWRs are included in the Material Properties package default data base, and properties for materials which are not included can easily be defined through Materials Properties package user input (refer to the MP package documentation). 
HS Package Reference Manual

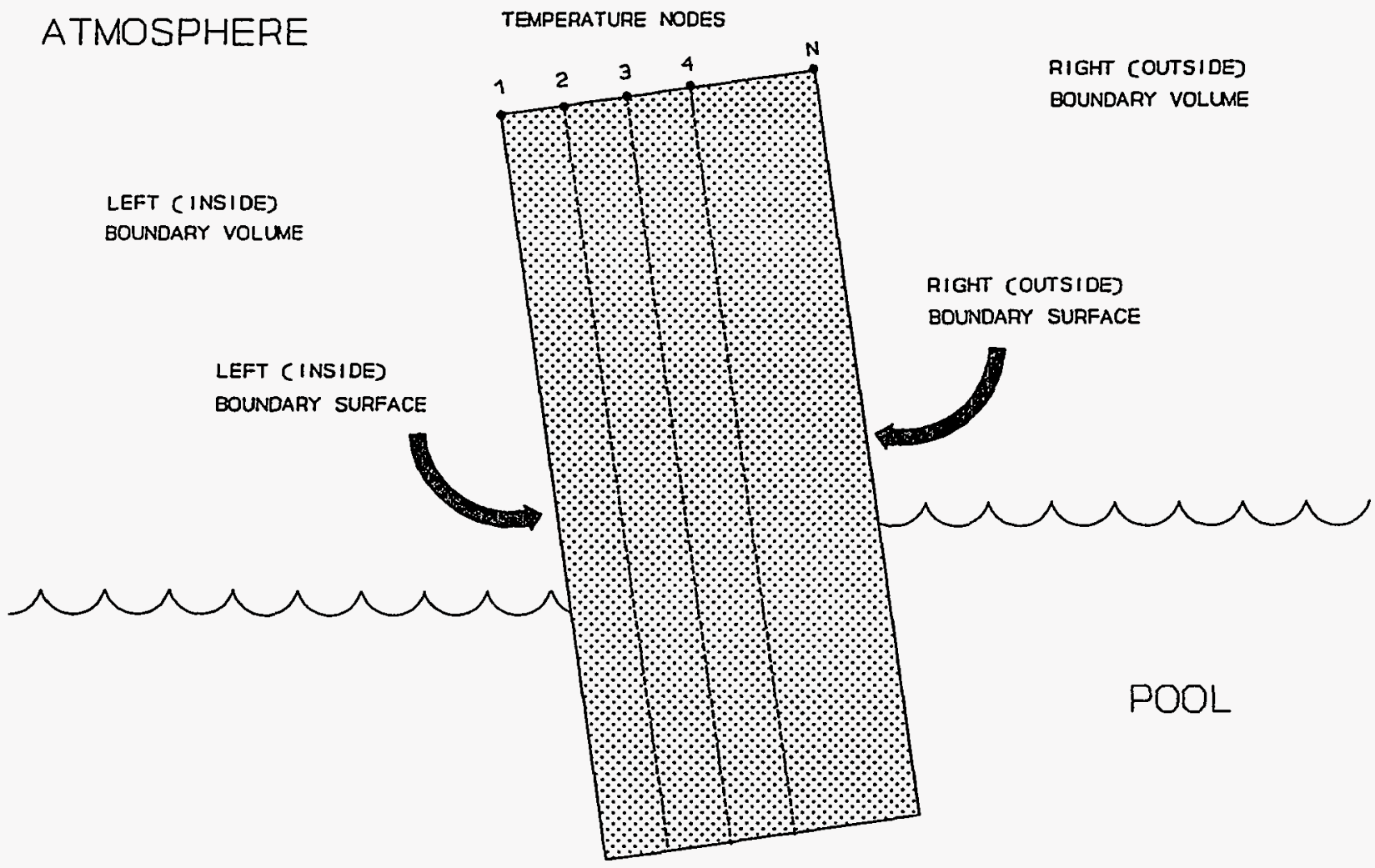

Figure 1.1 Heat Structure in a Control Volume

An internal power source may be specified for a heat structure. Its spatial dependence is specified by user input and may vary for each mesh interval. Its time dependence is given by a user-specified tabular function or control function.

Each heat structure has two boundary surfaces - left and right for rectangular geometries or inside and outside for cylindrical, spherical, or hemispherical geometries. At each boundary surface one of the following boundary conditions is specified:

(1) symmetry (adiabatic)

(2) convective with calculated heat transfer coefficient

(3) convective with calculated heat transfer coefficient and a specified surface power source function

(4) convective with specified heat transfer coefficient function

(5) specified surface temperature function

(6) specified surface heat flux function

If a convective boundary condition is selected for a boundary surface, a control volume must be specified as its boundary volume. Furthermore, the entire boundary surface must fit within its boundary volume--that is, the bottom of the surface (user value HSALT) 
HS Package Reference Manual

must equal or exceed the elevation of the bottom of the control volume specified in the CVH user input, and the top of the surface (calculated from HSALT and the surface length and orientation) must not exceed the elevation of the top of the control volume. No boundary volume is permitted for a symmetry or specified surface temperature boundary condition and a boundary volume for the specified heat flux boundary condition is a user option.

If a boundary volume is specified for a surface, then some additional data are required through user input. For each boundary surface with a boundary volume, these data are its

(1) surface area

(2) characteristic length (the dimension used in calculating the Reynolds, Grashof, Nusselt, and Sherwood numbers)

(3) axial length (length of structure along boundary surface, used to determine pool fraction)

(4) type of flow over the surface (internal or external; used in calculating the Nusselt number)

(5) critical pool fractions for pool and atmosphere heat transfer

The pool fraction of a heat structure boundary surface is the fraction of its surface area in the pool of its boundary volume. Pool fractions and critical pool fractions permit a weighting of heat and mass transfer to the boundary volume atmosphere and pool. These are discussed in detail in Section 2.4.

If a convective boundary condition with calculated heat transfer coefficient is specified, then an extensive set of correlations is available for calculating natural or forced convection to the pool and atmosphere. Pool boiling heat transfer is calculated if the temperature of a heat structure surface is above the boundary volume saturation temperature by utilizing correlations for nucleate boiling, critical heat flux, film boiling, and transition boiling.

Radiation heat transfer from a heat structure surface to the boundary volume pool is calculated during boiling. Radiation heat transfer can also be specified between a heat structure surface and the boundary volume atmosphere. NOTE, however, that radiation heat transfer to the atmosphere will occur only if the atmosphere contains water vapor (steam) and/or carbon dioxide; all other gases are considered to be non-absorbing by MELCOR. Two options, an equivalent band model and a gray gas model, are currently available. A future version of the code which will incorporate radiation heat transfer between heat structures is planned. Radiation heat transfer between the COR structures and HS structures is discussed in the COR package documentation.

Mass transfer between a heat structure surface and the boundary volume atmosphere is modeled using correlations or expressions for calculating mass flux. Models include 
HS Package Reference Manual

condensation and evaporation in the presence of noncondensibles with an appropriate limit for pure steam, and flashing in any environment. Liquid films on heat structure surfaces are also modeled so that condensate transferred from the boundary volume atmosphere and liquid deposited by other packages can be treated. An optional film tracking model is available to track condensate film drainage from structure to structure. The film tracking model is activated when the user defines one or more network(s) of connected structures, such as stacked cylindrical sections to represent the steam generator tubes and/or cylindrical shells capped by a hemisphere to represent a containment dome. The user also specifies a drainage pattern for each network, which consists of drainage destinations and fractions for the drainage from each structure in the network. Drainage from a structure surface may be partitioned between three destination types: (1) the surface of one or more additional structures in the network, (2) "rain" which is passed to the MELCOR Containment Sprays (SPR) Package via the Transfer Process Package and/or (3) the pool of the CVH volume associated with the surface. The user may also designate an external source of water for any structure in the network via tabular function input or a control function. External sources are primarily intended to allow the user to model the source for a passive containment cooling system or some such similar cooling device. When the film tracking model is active, the film thickness is calculated as a function of the condensate flow rate throughout the network.

Mass transfer affects the temperature distribution within a heat structure by its energy flux at the surface. This energy flux due to mass transfer is included in the boundary conditions for the conduction calculations, and film/atmosphere interfacial temperatures are calculated simultaneously with the structure node temperatures. The volume occupied by liquid films affects the virtual volume tracked by the CVH package, and the presence of liquid films also affects the rate and accumulation of radionuclides deposited on the surfaces by the RN package (see RN documentation). Decay heat from deposited radionuclides is treated as power source at the surface in the equation for the surface temperature.

Finite-difference equations are used to advance the temperature distribution of a heat structure in time during MELCOR execution or to obtain its steady-state temperature distribution during MELGEN execution if specified by user input. These equations are obtained from an integral form of the one-dimensional heat conduction equation and boundary condition equations utilizing a fully-implicit numerical method. The finitedifference approximation is a tridiagonal system of $\mathrm{N}$ equations (or $\mathrm{N}+1$ or $\mathrm{N}+2$ if there is a liquid film on one or both surfaces of the structure) for a heat structure with $\mathrm{N}$ temperature nodes (or $\mathrm{N}+1$ or $\mathrm{N}+2$ temperature nodes if there is a liquid film on one or both surfaces of the structure). The solution of this system is obtained using the standard solution algorithm for a tridiagonal system of linear equations.

A degassing model is provided for the release of gases from materials which are contained in heat structure mesh intervals. Input may be provided, for example, to represent the release of water vapor or carbon dioxide from concrete as its temperature 
increases. The HS package calculates a constant gas release rate over the degassing temperature range and modifies thermal properties over this range to account for the energy which is required for gas production and release. The degassing model is also used in a modified form to treat ice condensers.

Communication of mass and energy changes to other packages is achieved through welldefined interfaces.

The remainder of the reference manual amplifies this calculation procedure. An enumeration and description of all models employed in the HS package calculations are included in Section 2. The solution methods used by the HS package are discussed in Section 3. Section 4 elaborates on the time-step control used by this package.

The references for the HS Package Reference Manual are found in Section 5. Appendix A contains information on the sensitivity coefficients used in the HS package. 
HS Package Reference Manual 
HS Package Reference Manual

\section{DETAILED MODELS}

The modeling of a heat structure in the MELCOR Code System and the calculation procedure for the HS package are discussed in Section 1. This section provides a detailed description of the models that are utilized by the HS package in the calculation procedure.

Heat conduction within a heat structure is modeled by the heat conduction equation in one spatial dimension. This equation and the specification of boundary conditions constitute a well-defined mathematical problem for the temperature distribution of a heat structure. However, (a) the generality of boundary conditions, (b) the inclusion of surface power sources and mass transfer at each boundary surface, (c) temperature-dependent thermal properties, (d) spatial-dependent materials, and (e) the variety of geometries preclude the possibility of analytic solutions for the temperature distribution. Therefore, the HS package utilizes numerical methods for the determination of the temperature distribution for each heat structure. The description of detailed models in the HS package begins in Section 2.1 with a presentation of the finite-difference equations that approximate the heat conduction equation within a heat structure. The finite-difference equations that approximate the heat conduction equation at the boundary surfaces are presented in Section 2.2.

The finite-difference equations of Sections 2.1 and 2.2 require specification or calculation of the following:
(1) power sources
(2) pool fractions
(3) thermal properties
(4) heat transfer coefficients
(5) mass transfer
(6) liquid film properties

Sections 2.3 through 2.8 provide the detailed models which specify these items.

Knowledge of the temperature distribution of a heat structure permits the calculation of its stored energy. The definition of stored energy of a heat structure is given in Section 2.9 within the context of the approximations of the HS package.

The thermal interactions between heat structures and control volumes result in the transfer of mass and energy between the CVH and HS packages. The HS package calculates such transfers between modules for the following:
(1) heat flux
(2) liquid film evaporation and condensation
(3) degassing 
HS Package Reference Manual

The detailed modeling of these phenomena in the HS package is discussed in Sections 2.6, 2.8, and 2.10. The COR package calculates heat transfer from the core to the bounding heat structures and passes the resulting energy transfers to the appropriate heat structures through an interface with the HS package (see COR package documentation for further details).

\subsection{Finite-Difference Equations for Interior}

The equation that governs conduction heat transfer in the interior of a heat structure is the one-dimensional heat conduction equation. This equation has the form

$$
C_{p} \frac{\partial T}{\partial t}=\frac{1}{A} \frac{\partial}{\partial x} \quad\left(k A \frac{\partial T}{\partial x}\right)+U
$$

where

$\mathrm{C}_{\mathrm{p}}=$ volumetric heat capacity (product of heat capacity at constant pressure and density)

$T=$ temperature

$\frac{\partial}{\partial t}=$ partial derivative with respect to time

$\mathrm{A}=$ heat transfer area

$\mathrm{k}=$ thermal conductivity

$\frac{\partial}{\partial x}=$ partial derivative with respect to spatial variable

$\mathrm{U}=$ volumetric power

The heat conduction equation is a parabolic partial differential equation. The HS package must solve it with boundary and initial conditions to determine the temperature distribution at each point in a heat structure. Sections 2.1.1 and 2.1.2 discuss the finite-difference approximation of Equation 2.1.1 in the interior of a heat structure.

\subsubsection{Nodalization at Interior Temperature Nodes}

The finite-difference approximation of the heat conduction equation requires a spatial partitioning of the heat structure into a finite number of temperature nodes. Temperature nodes must be located at the boundary surfaces and at interfaces between different materials. Additional nodes may be located at arbitrary locations within individual materials. The region between two adjacent temperature nodes is called a mesh interval. For rectangular geometries, the node locations are relative to the node at the left boundary; for cylindrical geometries, they are relative to the axis of the cylinder; and for spherical or hemispherical geometries, they are relative to the center of the sphere. The 

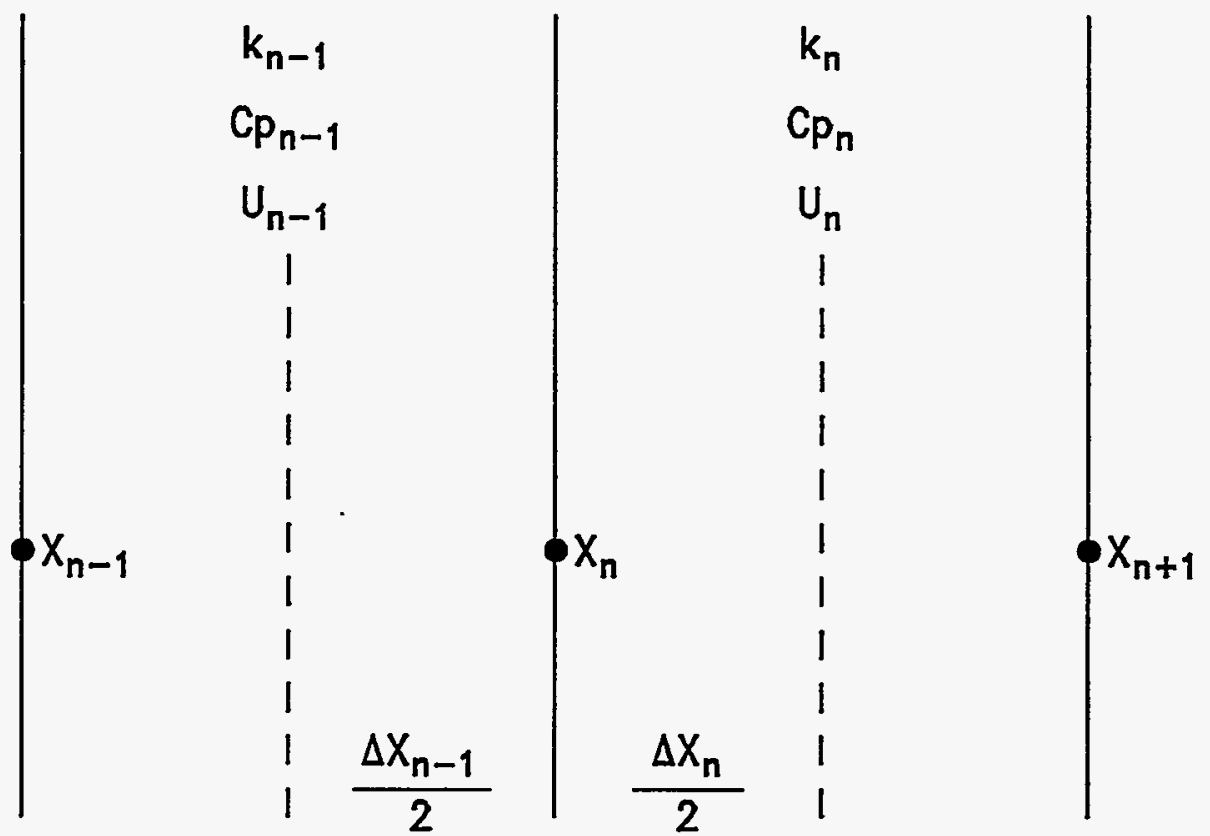

Figure 2.1 Nodalization in Interior of a Heat Structure

location of the temperature nodes increases in a monotonic manner from the node at the left or inside boundary surface.

Figure 2.1 illustrates the nodalization of the interior of a heat structure near the n-th temperature node. This figure contains three temperature nodes and the mesh intervals for which they are the boundary points. For a rectangular geometry, the volume which is depicted in Figure 2.1 is part of a rectangular solid; for a cylindrical geometry, it is part of a cylindrical shell; and for a spherical or hemispherical geometry, it is part of a spherical shell. The quantities represented in Figure 2.1 are:

$$
\begin{aligned}
& N=\text { number of temperature nodes in heat structure } \\
& n=\text { interior node number }(2,3, \ldots, N-1) \\
& X \quad=\text { location of temperature node } \\
& \Delta X_{n}=X_{n+1}-X_{n}, \text { length of } n \text {-th mesh interval } \\
& k \quad=\text { thermal conductivity of material }
\end{aligned}
$$


HS Package Reference Manual

$$
\begin{aligned}
& C_{p}=\text { volumetric heat capacity of material } \\
& U=\text { volumetric power source weights }
\end{aligned}
$$

This figure also shows thermal properties and volumetric power source weights in the mesh intervals adjacent to the $n$-th temperature node. These quantities are present in the finite-difference equations and are discussed in Sections 2.3 and 2.5.

To allow a more general representation of the equations and to condense expressions that define the numerical approximation, the following geometrical quantities are used [11]:

$\mathrm{HSL}_{n}=$ left surface weight for $\mathrm{n}$-th temperature node

$H V L_{n}=$ left volume weight for $n$-th temperature node

$\mathrm{HSR}_{\mathrm{n}}=$ right surface weight for $\mathrm{n}$-th temperature node

$\mathrm{HVR}_{\mathrm{n}}=$ right volume weight for $\mathrm{n}$-th temperature node

The surface and volume weights in the interior of a heat structure are defined in Table 2.1. The interior temperature nodes correspond to $n=2,3, \ldots, N-1$. The weights for $n=1$ and $\mathrm{N}$ are defined in Section 2.2.1.

The surface and volume weights may be interpreted by considering for each geometry the rectangular solids, cylindrical shells, and spherical shells which are bordered a temperature node and have thicknesses equal to half the length of the mesh intervals adjacent to this node. For all geometries, each surface weight has a factor that is the reciprocal of the length of the appropriate mesh interval. These weights appear in the gradient terms of the difference equations. For rectangular geometries, the other factors in the surface weight and the volume weight are the surface area and volume per unit area of one of the solids, respectively. For cylindrical geometries, they are the surface area and volume per unit axial length of one of the shells; and for spherical or hemispherical geometries, they are the surface area and volume of one of the shells. By definition, $\mathrm{HSL}_{\mathrm{n}+1}=\mathrm{HSR}_{\mathrm{n}}$ for all geometries, which ensures conservation. 
HS Package Reference Manual

\section{Table 2.1 Surface and Volume Weights in Interior}

Rectangular Geometries

$$
\begin{aligned}
& H S L_{n}=1 / \Delta X_{n-1} \\
& H V L_{n}=\Delta X_{n-1} / 2 \\
& H S R_{n}=1 / \Delta X_{n} \\
& H V R_{n}=\Delta X_{n} / 2
\end{aligned}
$$

Cylindrical Geometries

$$
\begin{aligned}
& \mathrm{HSL}_{n}=2 \pi\left(\mathrm{X}_{n}-\Delta \mathrm{X}_{n-1} / 2\right) / \Delta \mathrm{X}_{n-1} \\
& \mathrm{HVL}_{n}=\pi\left[\mathrm{X}_{n}^{2}-\left(\mathrm{X}_{n}-\Delta \mathrm{X}_{n-1} / 2\right)^{2}\right] \\
& \mathrm{HSR}_{n}=2 \pi\left(\mathrm{X}_{n}+\Delta \mathrm{X}_{n} / 2\right) / \Delta \mathrm{X}_{n} \\
& \mathrm{HVR}_{n}=\pi\left[\left(\mathrm{X}_{n}+\Delta \mathrm{X}_{n} / 2\right)^{2}-\mathrm{X}_{n}^{2}\right]
\end{aligned}
$$

Spherical Geometries

$$
\begin{aligned}
& \mathrm{HSL}_{n}=4 \pi\left(\mathrm{X}_{n}-\Delta \mathrm{X}_{n-1} / 2\right)^{2} / \Delta \mathrm{X}_{n-1} \\
& \mathrm{HVL}_{n}=4 \pi / 3\left[\mathrm{X}_{n}^{3}-\left(\mathrm{X}_{n}-\Delta \mathrm{X}_{n-1} / 2\right)^{3}\right] \\
& \mathrm{HSR}_{n}=4 \pi\left(\mathrm{X}_{n}+\Delta \mathrm{X}_{n} / 2\right)^{2} / \Delta \mathrm{X}_{n} \\
& \mathrm{HVR}_{n}=4 \pi / 3\left[\left(\mathrm{X}_{n}+\Delta \mathrm{X}_{n} / 2\right)^{3}-\mathrm{X}_{n}^{3}\right]
\end{aligned}
$$

Hemispherical Geometries

$$
\begin{aligned}
& H S L_{n}=2 \pi\left(X_{n}-\Delta X_{n-1} / 2\right)^{2} / \Delta X_{n-1} \\
& H V L_{n}=2 \pi / 3\left[X_{n}^{3}-\left(X_{n}-\Delta X_{n-1} / 2\right)^{3}\right] \\
& H S R_{n}=2 \pi\left(X_{n}+\Delta X_{n} / 2\right)^{2} / \Delta X_{n} \\
& H V R_{n}=2 \pi / 3\left[\left(X_{n}+\Delta X_{n} / 2\right)^{3}-X_{n}^{3}\right]
\end{aligned}
$$




\section{HS Package Reference Manual}

\subsubsection{Difference Approximation at Interior Nodes}

The finite-difference equations are obtained from an integral form of the heat conduction equation. Consider multiplying Equation 2.1.1 by the area term and integrating the result over a heat structure. This integral equals the sum of integrals each of which is evaluated over a solid that is bounded by the dashed lines in Figure 2.1. The finitedifference approximation at the $n$-th interior temperature node is obtained from the integral of this equation over the solid that is bounded by these dashed lines. This approximation has the form

$$
\begin{aligned}
G_{n}\left(T_{n}^{m+1}-T_{n}^{m}\right) / \Delta t_{m} & =k_{n-1} H S L_{n}\left(T_{n-1}-T_{n}\right)+k_{n} H S R_{n}\left(T_{n+1}-T_{n}\right) \\
& +\left(U_{n-1} H V L_{n}+U_{n} H V R_{n}\right)
\end{aligned}
$$

where

$$
\begin{aligned}
& T_{n}^{m}=\text { temperature of } n \text {-th node at time } t_{m} \\
& G_{n}=C_{p n-1} H V L_{n}+C_{p n} H V R_{n} \\
& U_{n}=\text { volumetric power for } n \text {-th mesh interval } \\
& \Delta t_{m}=\text { time step for } m \text {-th computational cycle }
\end{aligned}
$$

subscript $n$ denotes quantity at $n$-th temperature node or mesh interval superscript $m$ denotes quantity at time $t_{m}$ superscript $m+1$ denotes quantity at time $t_{m}+\Delta t_{m}$

The time superscript for most of the terms in this equation is omitted. If all are $m$, then the finite-difference formulation is fully explicit. If all are $m+1$, then the formulation is fully implicit. The fully implicit method is used by the HS package, so

$$
G_{n}^{m+1}\left(T_{n}^{m+1}-T_{n}^{m}\right) / \Delta t_{m}=d_{n}^{m+1}
$$

where

$$
d_{n}^{i}=\text { right side of Equation 2.1.18 at time } t_{i}
$$

For steady-state initialization calculations, the appropriate difference equation is

$$
d_{n}=0
$$


HS Package Reference Manual

\subsubsection{Finite-Difference Equations at Interior Temperature Nodes}

The finite-difference equation at each interior temperature node is obtained by expanding Equation 2.1.19 or 2.1.20 and collecting the temperature terms at the $m+1$ time level on the left. This equation is

$$
A_{n-1}^{m+1} T_{n-1}^{m+1}+B_{n}^{m+1}+C_{n}^{m+1} T_{n+1}^{m+1}=D_{n}^{m+1}
$$

where, in addition to previously defined quantities,

$$
\begin{aligned}
& A_{n}^{m+1}=-k_{n-1}^{m+1} H S L_{n} \Delta t_{m} \\
& C_{n}^{m+1}=-k_{n}^{m+1} H S R_{n} \Delta t_{m} \\
& B_{n}^{m+1}=-A_{n}^{m+1}-C_{n}^{m+1}+a G_{n}^{m+1} \\
& \begin{aligned}
D_{n}^{m+1}= & a G_{n}^{m+1} T_{n}^{m}+\left(U_{n-1}^{m+1 / 2} H V L_{n}+U_{n}^{m+1 / 2} H V R_{n}\right) \Delta t_{m} \\
a & =1 \text { for transient calculations } \\
& =0 \text { for steady-state calculations } \\
& n=2,3, \ldots, N-1
\end{aligned}
\end{aligned}
$$

The value of the power, $U$, is evaluated as the average of old and new time values in order to more accurately reflect the desired input energy. The result of applying Equation 2.1.21 to a heat structure with $\mathrm{N}$ temperature nodes is a tridiagonal system of $\mathrm{N}-2$ equations for the interior temperature nodes.

\subsection{Finite-Difference Equations at Boundary Surfaces}

The numerical calculation of the temperature distribution of a heat structure not only requires a finite-difference approximation of the heat conduction equation at interior temperature nodes, but also a finite-difference approximation of this equation and the boundary condition at each boundary surface.

There are two basic cases to consider at the surfaces of a structure: (1) the case when there is no liquid film on the surface, and (2) the case when there is a liquid film on the surface.

If there is no liquid film, then a boundary condition is applied to the structure surface and used to calculate the structure surface temperature. If a liquid film exists, then an additional mesh interval, consisting of the film bounded by the structure surface temperature node on the inside and the film/atmosphere interfacial temperature node on 


\section{HS Package Reference Manual}

the outside, is defined, and a conduction equation for the film/atmosphere interfacial temperature is added to the set of $\mathrm{N}$ equations for the structure node temperatures. In this case, the equation for the structure surface (i.e., the structure/film interface) temperature is similar to the equations for the temperatures at the interior nodes, except that the half mesh interval on the outside consists of half of the liquid film instead of structure material. Hence, if there is no liquid film on either surface of the structure, the tridiagonal set will consist of $\mathrm{N}$ equations ( $\mathrm{N}-2$ for interior nodes and 2 for the two surface node temperatures), while the set will consist of $\mathrm{N}+1$ (or $\mathrm{N}+2$ ) temperature equations, if there is a liquid film on one (or both) surfaces of the structure.

Only certain types of boundary conditions are permitted if mass transfer (liquid film condensation/evaporation) is to be treated; film formation is prohibited if an adiabatic, specified surface heat flux or specified surface temperature boundary condition is imposed.

In the discussion that follows, it is to be unclerstood that the boundary condition is applied at the film/atmosphere interface and not the structure/film interface if a liquid film exists on the surface of the structure. The general form of the boundary condition at the surface of a heat structure is

$$
\alpha T+\beta \frac{d T}{d N}=\gamma
$$

where

$$
\begin{array}{ll}
\alpha & =\text { first boundary condition coefficient } \\
\beta & =\text { second boundary condition coefficient } \\
\gamma & =\text { third boundary condition coefficient } \\
T & =\text { temperature of surface } \\
\frac{d T}{d N} & =\text { gradient of temperature in direction of outward normal }
\end{array}
$$

This expression is implicit in the surface temperature, which is determined iteratively. All variables in this expression that are part of the heat structure package data base (structure temperatures and properties that are functions of the structure temperature) are treated implicitly during the iteration procedure. Variables from other MELCOR packages (CVH temperatures and energy deposited by other packages) must be treated explicitly because of the explicit coupling between all MELCOR packages. All permitted boundary conditions can be put into this form as shown below. 


\subsubsection{Boundary Condition Coefficients}

\subsubsection{Symmetry (Adiabatic)}

The symmetry boundary condition is represented by

$$
\frac{d T}{d N}=0
$$

For this boundary condition, the boundary condition coefficients are

$$
\begin{aligned}
& \alpha=0 \\
& \beta=1 \\
& \gamma=0
\end{aligned}
$$

\subsubsection{Convective (Calculated or Specified Heat Transfer Coefficients)}

The convective boundary condition is represented by

$$
\begin{aligned}
-k \frac{d T}{d N}+S & =\left(h_{\text {atm }}+h_{\text {atmr }}\right)\left(1-x_{\text {pool }}\right)\left(T-T_{a t m}\right) \\
& +h_{\text {pool }} x_{\text {pool }}\left(T-T_{\text {pool }}\right)
\end{aligned}
$$

where

$$
\begin{aligned}
& \mathrm{k}=\text { thermal conductivity } \\
& \mathrm{S}=\text { surface energy flux (flowing into heat structure) } \\
& \mathrm{h}_{\mathrm{atm}}=\text { atmosphere heat transfer coefficient } \\
& \mathrm{h}_{\mathrm{atmr}}=\text { atmosphere radiation heat transfer coefficient } \\
& \mathrm{X}_{\text {pool }}=\text { fraction of surface in pool of boundary volume } \\
& \mathrm{T}_{\text {atm }}=\text { temperature of atmosphere in boundary volume } \\
& \mathrm{h}_{\text {pool }}=\text { pool heat transfer coefficient } \\
& \mathrm{T}_{\text {pool }}=\text { temperature of pool in boundary volume }
\end{aligned}
$$

For these boundary conditions, the boundary condition coefficients are

$$
\begin{aligned}
& \alpha=h_{\text {pool }} x_{\text {pool }}+\left(h_{\text {atm }}+h_{\text {atmr }}\right)\left(1-x_{\text {pool }}\right) \\
& \beta=k \\
& \gamma=h_{\text {pool }} x_{\text {pool }} T_{\text {pool }}+\left(h_{\text {atm }}+h_{\text {atmr }}\right)\left(1-x_{\text {pool }}\right) T_{\text {atm }}+S
\end{aligned}
$$


HS Package Reference Manual

\subsubsection{Specified Surface Heat Flux}

For specified heat flux at the surface, the boundary condition is represented by

$$
-k \frac{d T}{d N}=q^{\prime \prime}
$$

where

$$
q^{\prime \prime}=\text { specified heat flux at surface (positive out) }
$$

For these boundary conditions, the boundary condition coefficients are

$$
\begin{aligned}
& \alpha=0 \\
& \beta=k \\
& \gamma=-q^{\prime \prime}
\end{aligned}
$$

\subsubsection{Specified Surface Temperature}

The boundary condition for specified surface temperature is represented by

$$
T=T_{\text {surf }}=\text { specified surface temperature }
$$

For these boundary conditions, the boundary condition coefficients are

$$
\begin{aligned}
& \alpha=1 \\
& \beta=0 \\
& \gamma=T_{\text {surf }}
\end{aligned}
$$

\subsubsection{Nodalization at Boundary Temperature Nodes}

Figure 2.2 illustrates the geometry of a heat structure near the surface temperature nodes of a heat structure. This figure contains two temperature nodes and the mesh intervals for which they are the boundary points at both surfaces. It also depicts the condensate films which may or may not be present on each boundary surface. For all geometries, the volumes which are depicted in this figure are as described in Section 2.1.1. The quantities represented in Figure 2.2 are:

$$
\begin{aligned}
& N=\text { number of temperature nodes in heat structure } \\
& X=\text { location of temperature node } \\
& \Delta X_{n}=X_{n+1}-X_{n} \text {, length of } n \text {-th mesh interval } \\
& k=\text { thermal conductivity of material } \\
& C_{p}=\text { volumetric heat capacity of material } \\
& U=\text { volumetric power } \\
& S=\text { surface power }
\end{aligned}
$$


HS Package Reference Manual

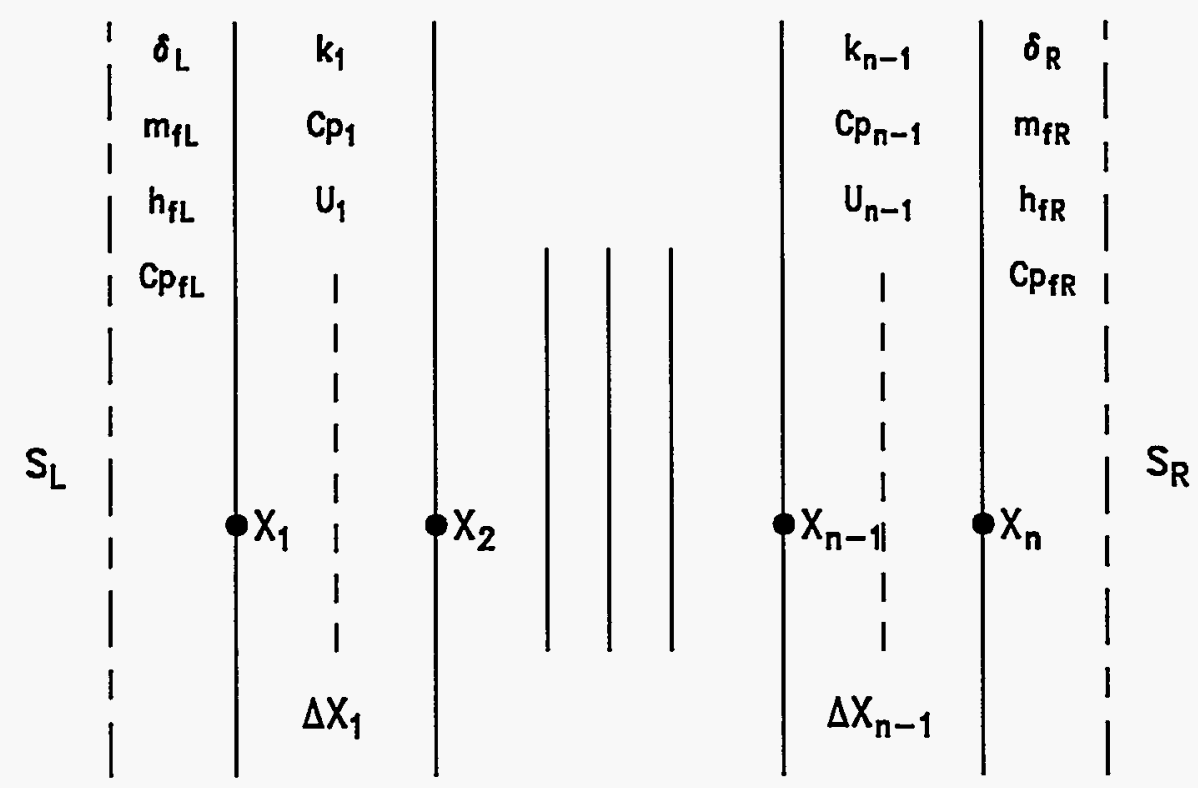

Figure 2.2 Nodalization at Boundary Surfaces of a Heat Structure

$$
\begin{aligned}
& \delta_{f}=\text { thickness of liquid film } \\
& m_{f}=\text { mass of liquid film } \\
& h_{f}=\text { specific enthalpy of liquid film } \\
& c_{p f}=\text { specific heat of liquid film }
\end{aligned}
$$

The figure also shows thermal properties and volumetric power sources in the mesh intervals adjacent to the boundary nodes. These quantities are present in the finitedifference equations and are discussed in Sections 2.3 and 2.5.

The surface and volume weights are also defined at the boundary surfaces. The definitions are given in Table 2.2 for the case when no liquid film exists on either surface. The surface and volume weights for the case involving liquid films are similar, except there is one additional temperature node on each side that has a liquid film, and the mesh interval (with a thickness equal to that of the liquid film, $\delta_{f}$ ) between the additional node (on the outside) and the structure surface node (on the inside) contains the liquid film. The surface and volume weights may be interpreted as discussed in Section 2.1.1 except (a) the left volume weight at the left (inside) temperature node and the right volume weight at the right (outside) temperature node are zero and (b) the left surface weight at the left (inside) temperature node and the right surface weight at the right (outside) boundary surface are the areas of these respective surfaces. 
HS Package Reference Manual

Table 2.2 Surface and Volume Weights at Boundary Surfaces

Rectangular Geometries

$$
\begin{aligned}
& \mathrm{HSL}_{1}=1 \\
& \mathrm{HVL}_{1}=0 \\
& \mathrm{HSR}_{1}=1 / \Delta \mathrm{X}_{1} \\
& \mathrm{HVR}_{1}=\Delta \mathrm{X}_{1} / 2 \\
& \mathrm{HSL}_{\mathrm{N}}=1 / \Delta \mathrm{X}_{\mathrm{N}-1} \\
& \mathrm{HVL}_{\mathrm{N}}=\Delta \mathrm{X}_{\mathrm{N}-1} / 2 \\
& \mathrm{HSR}_{\mathrm{N}}=1 \\
& \mathrm{HVR}_{\mathrm{N}}=0
\end{aligned}
$$

\section{Cylindrical Geometries}

$$
\begin{aligned}
& \mathrm{HSL}_{1}=2 \pi \mathrm{X}_{1} \\
& \mathrm{HVL}_{1}=0 \\
& \mathrm{HSR}_{1}=2 \pi\left(\mathrm{X}_{1}+\Delta \mathrm{X}_{1} / 2\right) / \Delta \mathrm{X}_{1} \\
& \mathrm{HVR}_{1}=\pi\left[\left(\mathrm{X}_{1}+\Delta \mathrm{X}_{1} / 2\right)^{2}-\mathrm{X}_{1}^{2}\right] \\
& \mathrm{HSL}_{N}=2 \pi\left(\mathrm{X}_{\mathrm{N}}-\Delta \mathrm{X}_{\mathrm{N}-1} / 2\right) / \Delta \mathrm{X}_{\mathrm{N}-1} \\
& \mathrm{HVL}_{\mathrm{N}}=\pi\left[\mathrm{X}_{N}^{2}-\left(\mathrm{X}_{\mathrm{N}}-\Delta \mathrm{X}_{\mathrm{N}-1} / 2\right)^{2}\right] \\
& \mathrm{HSR}_{\mathrm{N}}=2 \pi \mathrm{X}_{\mathrm{N}} \\
& \mathrm{HVR}_{\mathrm{N}}=0
\end{aligned}
$$


HS Package Reference Manual

Table 2.2 Surface and Volume Weights at Boundary Surfaces (cont.)

\section{Spherical Geometries}

$$
\begin{aligned}
& \mathrm{HSL}_{1}=4 \pi \mathrm{X}_{1}^{2} \\
& \mathrm{HVL}_{1}=0 \\
& \mathrm{HSR}_{1}=4 \pi\left(\mathrm{X}_{1}+\Delta \mathrm{X}_{1} / 2\right)^{2} / \Delta \mathrm{X}_{1} \\
& \mathrm{HVR}_{1}=4 \pi / 3\left[\left(\mathrm{X}_{1}+\Delta \mathrm{X}_{1} / 2\right)^{3}-\mathrm{X}_{1}^{3}\right] \\
& \mathrm{HSL}_{\mathrm{N}}=4 \pi\left(\mathrm{X}_{\mathrm{N}}-\Delta \mathrm{X}_{\mathrm{N}-1} / 2\right)^{2} / \Delta \mathrm{X}_{\mathrm{N}-1} \\
& \mathrm{HVL}_{\mathrm{N}}=4 \pi / 3\left[\mathrm{X}_{\mathrm{N}}^{3}-\left(\mathrm{X}_{\mathrm{N}}-\Delta \mathrm{X}_{\mathrm{N}-1} / 2\right)^{3}\right] \\
& \mathrm{HSR}_{\mathrm{N}}=4 \pi \mathrm{X}_{\mathrm{N}}^{2} \\
& \mathrm{HVR}_{\mathrm{N}}=0
\end{aligned}
$$

\section{Hemispherical Geometries}

$$
\begin{aligned}
& \mathrm{HSL}_{1}=2 \pi \mathrm{X}_{1}^{2} \\
& \mathrm{HVL}_{1}=0 \\
& \mathrm{HSR}_{1}=2 \pi\left(\mathrm{X}_{1}+\Delta \mathrm{X}_{1} / 2\right)^{2} / \Delta \mathrm{X}_{1} \\
& \mathrm{HVR}_{1}=2 \pi / 3\left[\left(\mathrm{X}_{1}+\Delta \mathrm{X}_{1} / 2\right)^{3}-\mathrm{X}_{1}^{3}\right] \\
& \mathrm{HSL}_{\mathrm{N}}=2 \pi\left(\mathrm{X}_{\mathrm{N}}-\Delta \mathrm{X}_{\mathrm{N}-1} / 2\right)^{2} / \Delta \mathrm{X}_{\mathrm{N}-1} \\
& \mathrm{HVL}_{\mathrm{N}}=2 \pi / 3\left[\mathrm{X}_{\mathrm{N}}^{3}-\left(\mathrm{X}_{\mathrm{N}}-\Delta \mathrm{X}_{\mathrm{N}-1} / 2\right)^{3}\right] \\
& \mathrm{HSR}_{\mathrm{N}}=2 \pi \mathrm{X}_{\mathrm{N}}^{2} \\
& \mathrm{HVR}_{\mathrm{N}}=0
\end{aligned}
$$


HS Package Reference Manual

\subsubsection{Difference Approximation at Boundary Nodes}

The finite-difference equations at boundary nodes are obtained from an integral form of the heat conduction equation. The finite-difference approximation at the boundary temperature nodes is obtained from the integral of Equation 2.1.1 (multiplied by the area term) over the solid that is bounded by the film surface and the dashed line in Figure 2.2.

\subsubsection{Finite-Difference Equation at Left (Inside) Boundary}

By using Equation 2.2.1 to eliminate the spatial derivative term, the finite-difference approximation has the following form at the left (inside) boundary surface:

$$
\begin{gathered}
G_{1}^{m+1}\left(T_{1}^{m+1}-T_{1}^{m}\right) / \Delta t_{m} \\
=\left(k_{1}\left(\gamma_{L}-\alpha_{L} T_{1}\right) / \beta_{L}\right) H S L_{1}+k_{1}\left(T_{2}-T_{1}\right) H S R_{1}+U_{1} H V R_{1}-m_{f, L}^{m} \Delta h_{f, L} / f
\end{gathered}
$$

if there is no liquid film on that surface (i.e., there was and is no film, or there was a film that completely evaporated or was transferred to the pool associated with the boundary volume). If there is a liquid film, then the equations for the film surface temperature and structure surface temperature are:

$$
\begin{aligned}
& G_{f, L}^{m+1}\left(T_{f, L}^{m+1}-T_{f, L}^{m}\right) / \Delta t_{m}=H S R_{f, L} H_{f, L}\left(T_{1}-T_{f, L}\right) \\
& +H_{L_{f, L}}\left[\left(1-x_{p o o l, L}\right)\left(H_{a t m, L}+H_{a t m r, L}\right)\left(T_{a t m, L}-T_{f, L}\right)+x_{p o o l, L} H_{p o o l, L}\left(T_{p o o f, L}-T_{f, L}\right)\right] \\
& +\left[\left(1-x_{p o o l, L}\right) A_{L} / f\right]\left[\left(h_{v, L}-h_{f, L}\right) \max \left(0, \dot{m}_{c, L}\right)+\left(h_{v, L}-\bar{h}_{f, L}\right) \min \left(0, \dot{m}_{c, L}\right)\right] \\
& \left(G_{1}^{m+1}+G_{f, L}^{m+1}\right)\left(T_{1}^{m+1}-T_{1}^{m}\right) / \Delta t_{m}=H S R_{1} k_{1}\left(T_{2}-T_{1}\right) \\
& \quad-H_{f S R_{f, L}} H_{f, L}\left(T_{1}-T_{f, L}\right)+\left[\left(1-x_{p o o l, L}\right) A_{L} / f\right]\left(h_{f, L}-\bar{h}_{f, L}\right) \max \left(0, \dot{m}_{c, L}\right) \\
& +U_{1} H_{V R}
\end{aligned}
$$

where

$$
G_{1}^{m+1}=C_{p 1}^{m+1} H V R_{1}
$$


HS Package Reference Manual

$f \quad=$ geometry factor

= surface area of heat structure for rectangular geometries

$=$ axial length of heat structure for cylindrical geometries

$=1.0$ for spherical and hemispherical geometries

$\mathrm{m}_{\mathrm{f}}^{\mathrm{m}}=$ (old) mass of film evaporated (or transferred) this time step

$\Delta h_{f}=$ specific enthalpy added to $m_{f}^{m}$ before its removal

$=$ latent heat of vaporization if film evaporated

$=0.0$ if film was transferred to pool

$\mathrm{HSR}_{\mathrm{f}}=\mathrm{HSR}$ evaluated at film mass median surface

$H S L_{F}=H S L$ evaluated at film/atmosphere interface

$A=$ structure surface area

$x_{\text {pool }}=$ fraction of boundary surface in pool of boundary volume

$\mathrm{H}_{\mathrm{atm}}=$ convective heat transfer coefficient to atmosphere

$\mathrm{H}_{\mathrm{atmr}}=$ radiative heat transfer coefficient to atmosphere

$\mathrm{H}_{\text {pool }}=$ convective heat transfer coefficient to pool

$\mathrm{H}_{\mathrm{f}}$ = convective/conductive heat transfer coefficient through film

$\mathrm{T}_{\mathrm{atm}}=$ temperature of atmosphere in boundary volume

$\mathrm{T}_{\text {pool }}=$ temperature of pool in boundary volume

$m_{f}=$ mass of film

$\dot{\mathrm{m}}_{\mathrm{c}}=$ condensation/evaporation mass flux ( $+/-$ for cond/evap)

$\mathrm{c}_{\mathrm{pf}}=$ specific heat capacity of film

$G_{f}^{m+1}=0.5 m_{f}^{m+1} c_{p f}^{m+1} / f$

$h_{v}=$ specific enthalpy of vapor in boundary volume

$h_{\mathrm{f}, \mathrm{L}}=$ specific enthalpy of film evaluated at film/atmosphere interfacial temperature

$h_{t, 1}=$ specific enthalpy of film evaluated at structure/film interfacial temperature

$\bar{h}_{f}=0.5 \times\left(h_{f, L}+h_{f, 1}\right)$

subscript $L$ denotes quantity at left (inside) boundary surface subscript $i$ denotes quantity at $i$-th temperature node or mesh interval superscript $m$ denotes quantity at time $t_{m}$

superscript $m+1$ denotes quantity at time $t_{m}+\Delta t_{m}$

Equation 2.2.38 does not apply when $\beta=0$. This corresponds to the specified surface temperature boundary condition, in which case $T_{1}^{m+1}=T_{\text {surf,L }}^{m+1}$ and the presence of surface films and mass transfer is not permitted.

The time superscript for each term on the right side of Eqs. 2.2.38 is omitted. If all are $\mathrm{m}$, then the finite-difference formulation is fully explicit. If all are $m+1$, then the formulation is fully implicit. The fully implicit numerical method is used by the HS package. Eqs. 2.2.38 are used for both steady-state (MELGEN) and transient (MELCOR) calculations, except that for steady-state calculations the old time values $(\mathrm{m})$ are overwritten with the new time values $(m+1)$ after each iteration. Hence, when 


\section{HS Package Reference Manual}

convergence is achieved in MELGEN, temperatures that do not change with time (steadystate) have been determined. In MELGEN the time-step size is given by the value of sensitivity coefficient $C 4051(3)$, which is $10^{5} \mathrm{~s}$ by default.

The finite-difference equation(s) at the left (inside) boundary temperature node(s) are obtained by expanding Equations 2.2.38 and collecting the temperature terms at the $m+1$ time level on the left. Eq. 2.2.38 reduces to

$$
B_{1}^{m+1} T_{1}^{m+1}+C_{1}^{m+1} T_{2}^{m+1}=D_{1}^{m+1}
$$

where for $\beta_{L}$ not zero,

$$
\begin{aligned}
B_{1}^{m+1}= & G_{1}^{m+1}-C_{1}^{m+1}+\left(\alpha_{L}^{m+1} k_{1}^{m+1} H S L_{1} \Delta t_{m}\right) / \beta_{L}^{m+1} \\
C_{1}^{m+1}= & -k_{1}^{m+1} H S R_{1} \Delta t_{m} \\
D_{1}^{m+1}= & G_{1}^{m+1} T_{1}^{m}+\left(\gamma_{L}^{m+1} k_{1}^{m+1} H S L_{1} \Delta t_{m}\right) / \beta_{L}^{m+1}+U_{1}^{m+1 / 2} H V R_{1} \Delta t_{m} \\
& -m_{f L}^{m} \Delta h_{i, L} / f
\end{aligned}
$$

and for $\beta_{L}$ zero,

$$
\begin{aligned}
& B_{1}^{m+1}=1 \\
& C_{1}^{m+1}=0 \\
& D_{1}^{m+1}=\gamma_{L}^{m+1}=T_{\text {surf,L }}^{m+1}
\end{aligned}
$$

Eq. 2.2.38a and Eq. 2.2.38b reduce to

$$
\begin{aligned}
& B_{L}^{m+1} T_{L}^{m+1}+C_{L}^{m+1} T_{1}^{m+1}=D_{L}^{m+1} \\
& A_{1}^{m+1} T_{1, L}^{m+1}+B_{1}^{m+1} T_{1}^{m+1}+C_{1}^{m+1} T_{2}^{m+1}=D_{1}^{m+1}
\end{aligned}
$$

where,

$$
\begin{aligned}
B_{L}^{m+1}= & G_{f, L}^{m+1}-C_{L}^{m+1}+H S L_{f, L}\left[\left(1-x_{p o o l, L}\right)\left(H_{a t m, L}^{m+1}+H_{a t m r, L}^{m+1}\right)+x_{p o o l, L} H_{p o o l, L}^{m+1}\right] \Delta t_{m} \\
C_{L}^{m+1}= & -H_{f, L}^{m+1} H S R_{f, L} \Delta t_{m} \\
D_{L}^{m+1}= & G_{f, L}^{m+1} T_{f, L}^{m}+H S L_{f, L}\left[\left(1-x_{p o o l, L}\right)\left(H_{a t m, L}^{m+1}+H_{a t m r, L}^{m+1}\right) T_{a t m, L}+x_{p o o l, L} H_{p o o l, L}^{m+1} T_{p o o l, L}\right] \Delta t_{m} \\
& \quad+\left[\left(1-x_{p o o l, L}\right) A_{L} / f\right]\left[\left(h_{v, L}-h_{f, L}^{m+1}\right) \max \left(0, \dot{m}_{c, L}^{m+1}\right)+\left(h_{v, L}-\bar{h}_{f, L}^{m+1}\right) \min \left(0, \dot{m}_{c, L}^{m+1}\right)\right] \Delta t_{m}
\end{aligned}
$$


HS Package Reference Manual

$$
\begin{aligned}
A_{1}^{m+1}= & C_{L}^{m+1} \\
B_{1}^{m+1}= & G_{1}^{m+1}+G_{f, L}^{m+1}-A_{1}^{m+1}-C_{1}^{m+1} \\
C_{1}^{m+1}= & -k_{1}^{m+1} H S R_{1} \Delta t_{m} \\
D_{1}^{m+1}= & \left.\left(G_{1}^{m+1}+G_{f, L}^{m+1}\right) T_{1}^{m}+\left[\left(1-x_{p o o f, L}\right) A_{L} / f\right]\left(h_{f, L}^{m+1}-\bar{h}_{f, L}^{m+1}\right) \max \left(0, \dot{m}_{c, L}^{m+1}\right)\right] \Delta t_{m} \\
& \quad+U_{1}^{m+1 / 2} H V R_{1} \Delta t_{m}
\end{aligned}
$$

\subsubsection{Finite-Difference Equation at Right (Outside) Boundary}

The finite-difference equation(s) at the right (outside) boundary surface are exactly analogous to those at the left (inside) boundary surface. The subscripts 1,2 and $L$ are merely replaced by subscripts $\mathrm{N}, \mathrm{N}-1$ and $R, H S L$ and HSR are reversed, HVL and HVR are reversed and matrix elements $\mathrm{A}$ and $\mathrm{C}$ are reversed.

\subsection{Power Sources}

Power sources are included in the calculation of the temperature distribution of each heat structure. These sources include the following:
(1) internal power source
(2) surface power source
(3) energy which is transferred to each boundary surface by packages other than the HS package

These items are discussed in Sections 2.3.1 through 2.3.3, respectively.

\subsubsection{Internal Power Sources}

The internal power source is included in the temperature evolution equations as volumetric power terms in each mesh interval. User input specifies the spatial distribution of the power source for each heat structure that contains an internal power source. These data are used to calculate the fraction of power from a tabular function or control function that is applied to each mesh interval. The HS package calculates the volumetric power terms, $U$, that appear in Equations 2.1.21, 2.2.41, and 2.2.45. For the $n$-th mesh interval, these terms are

$$
U_{n}=x_{P_{n}} P_{\text {int }} /\left(H V L_{n+1}+H V R_{n}\right) / f
$$

where 
HS Package Reference Manual

$$
\begin{array}{ll}
\mathrm{n}= & 1,2, \ldots, \mathrm{N}-1 \\
\mathrm{~N}-1 & =\text { number of mesh intervals } \\
\mathrm{x}_{\mathrm{p}} & =\text { fraction of power from tabular function that is applied to this mesh interval } \\
& \text { (user-input) } \\
\mathrm{P}_{\mathrm{int}} \quad= & \text { average of power from internal source tabular function at old and new times } \\
& \text { or power from a specified control function for transient calculations and time } \\
& \text { zero value for initialization calculations } \\
\mathrm{HVL} & =\text { left (inside) volume weights defined in Sections } 2.1 .1 \text { and } 2.2 .1 \\
\mathrm{HVR} & =\text { right (outside) volume weights defined in Sections } 2.1 .1 \text { and 2.2.1 } \\
\mathrm{f} & =\text { geometry factor with the following values for different geometries } \\
= & \text { surface area of heat structure for rectangular geometries } \\
= & \text { axial length of heat structure for cylindrical geometries } \\
= & 1.0 \text { for spherical and hemispherical geometries }
\end{array}
$$

\subsubsection{Surface Power Sources}

For a convective boundary condition with calculated heat transfer coefficients, a surface power source may be specified by a user-input control function or a tabular function of time. This source is included in Equations 2.2.41 and 2.2.45 as energy fluxes which are added to the boundary condition coefficients, $\gamma$, in Equation 2.2.1. The HS package calculates these fluxes, $q_{\text {surf }}$, prior to calculating the temperature distribution of each heat structure. For each boundary surface, these terms are

$$
q_{\text {surf }}^{\prime \prime}=P_{\text {surf }} / A_{\text {surf }}
$$

where

$$
\begin{aligned}
& \mathrm{q}_{\text {surf }}^{\prime \prime}=\text { energy flux at boundary surface from surface power source } \\
& \mathrm{P}_{\text {sur }}=\text { average of surface power from tabular function at old and new times } \\
& \text { for transient calculations and time zero value for initialization } \\
& \text { calculations } \\
& \mathrm{A}_{\text {surf }}=\text { area of boundary surface }
\end{aligned}
$$

\subsubsection{Energy Transferred by Other Packages}

The energy which is transferred to a heat structure surface by other packages is obtained from an array in the HS package data base whose elements are updated using an interface subroutine that can be called any package. This energy includes, for example, the radiant energy from a core cell, conduction from debris deposited on the structure surface by the high-pressure-melt-ejection (HPME) model of the FDI package or the decay-heat energy of radionuclides deposited on each heat structure surface. This energy is included in Equations 2.2.41 and 2.2.45 as energy fluxes which are added to 
HS Package Reference Manual

the boundary condition coefficients $\gamma$ in Equation 2.2.1. The HS package calculates these fluxes, $q^{\prime \prime}{ }_{\text {ext }}$, prior to calculating the temperature distribution of each heat structure. For each boundary surface, these terms are

$$
q^{\prime \prime}{ }_{\text {ext }}=E_{\text {ext }} / A_{\text {surf }} / \Delta t
$$

where

$$
\begin{aligned}
& q^{\prime \prime}{ }_{\text {ext }} \quad=\text { energy flux at boundary surface from energy which is transferred } \\
& \text { by other packages } \\
& E_{\text {ext }} \quad=\text { energy which is transferred to boundary surface by other packages } \\
& A_{\text {surf }}=\text { area of boundary surface } \\
& \Delta \mathrm{t} \quad=\text { computational time step }
\end{aligned}
$$

For each boundary surface, the surface energy flux term $S$ in Equation 2.2.3 used in determining the boundary coefficient $\gamma$ is the sum of $q_{\text {surf }}^{\prime \prime}$ and $q_{\text {ext }}$ obtained from Equations 2.3.2 and 2.3.3.

\subsection{Pool Fractions}

When a heat structure with a convective boundary condition is in contact with a CVH volume containing either single-phase liquid or vapor, the implementation of the boundary condition is straight forward. However, if the surface is partially submerged, then it is necessary to partition the heat transfer between the pool and the atmosphere as described in section 2.2.1.2. In this case, heat transfer is partitioned on the basis of a calculated fraction of the heat structure surface that is submerged as depicted in Figure 1.1. The fraction is called the pool fraction with a range of 0 to 1 . This section describes how the pool fraction is calculated for each type of geometry and controls available to the user.

The user has no control over how the surface area is partitioned between the pool and atmosphere. There are two input parameters for each surface, CPFPL and CPFAL, which allow the user to disable heat transfer to the pool and/or atmosphere as a function of the pool fraction. The range of each is 0 to 1 . Heat transfer to the pool is calculated only when the pool fraction exceeds the critical pool fraction CPFPL. Similarly, heat and mass transfer to the atmosphere occur only when the pool fraction falls below the critical pool fraction CPFAL. Note that CPFPL and CPFAL are completely independent. Furthermore, disabling heat transfer to either phase will not affect heat transfer to the other phase directly. Also, when permitted, the heat transfer rates are independent of the values of CPFPL and CPFAL. When heat transfer from either phase is permitted, it occurs over the fraction of the surface area that is in contact with that phase (as given 


\section{HS Package Reference Manual}

by $x_{\text {pool }}$ for the pool and $1-x_{\text {pool }}$ for the atmosphere in Eq. 2.2.3). When heat transfer to either phase is disabled it is as though there is a perfectly insulating layer at the interface.

The primary use of this input feature is to prohibit simultaneous heat transfer to both pool and atmosphere when such an occurrence will generate unrealistic results. The most common situation to be avoided occurs when a vertical structure is in contact with both a cool liquid pool and a hot atmosphere. In this case, if the heat structure is allowed to communicate with both phases simultaneously, the relatively large heat transfer coefficient to the pool pulls the one-dimensional structure surface temperature down to a value much closer to the pool temperature than the atmosphere temperature. Consequently, heat transfer from the atmosphere to the structure is much greater than should be expected. The net effect is an artificially large heat transfer from the atmosphere to the pool via the structure surface. This situation can be avoided by specifying equal values of CPFPL and CPFAL so that structure only communicates to either the pool or atmosphere.

For situations in which the pool and atmosphere temperatures in the boundary control volume are nearly the same and heat transfer to both phases is expected to be significant, the user should enable simultaneous communications with both phases by specifying a value of zero for CPFPL and one for CPFAL. This option is often used for steam generator heat structures. This should also be used for horizontal floors and ceiling for which the pool fraction is specially modified as described in Section 2.4.1.

If CPFPL is greater than CPFAL, there will be a dead band with no communications to either the pool or atmosphere. This unlikely situation is not currently treated as a fatal input error.

If CPFPL is less than CPFAL, there will be a band with simultaneous heat transfer to both pool and atmosphere.

If CPFPL is equal to CPFAL, heat transfer will switch from one phase to the other as the pool fraction crosses the critical value. In the special case where the calculated pool fraction is exactly equal to the common value of CPFPL and CPFAL, communications will be to the pool if the value is greater than or equal to 0.5 and to the atmosphere otherwise.

Because of the potential for serious problems when unequal values of CPFPL and CPFAL are specified, MELGEN will generate a warning message to alert the user to the potential for unrealistic results. Nevertheless, if simultaneous heat transfer to both the pool and atmosphere is unlikely to cause serious problems, then CPFPL and CPFAL should be chosen to permit simultaneous heat transfer (i.e., set $C P F P L=0$ and $C P F A L=1$ ) because it usually occurs in most situations.

The pool fraction for a surface is set to 0.0 if its lowest point is above the pool and set to 1.0 if it is completely immersed in the pool. If the pool/atmosphere interface is very 
close to the top or bottom of a heat structure surface (less than the maximum film thickness), the pool fraction is set to 1.0 or 0.0 , respectively. For all other situations, the expressions given below are evaluated for the pool fraction. Sections 2.4.1 through 2.4.4 present these expressions for rectangular, cylindrical, spherical, and hemispherical geometries, respectively.

\subsubsection{Rectangular Geometry}

The pool fraction for a surface with a rectangular geometry is given by

$$
x_{\text {pool }}=Z / L \cos (\alpha)
$$

where

$$
\begin{array}{ll}
Z \quad= & \text { depth of pool in boundary volume of this surface relative to the altitude } \\
& \text { of the lowest point on this surface }
\end{array}
$$

For horizontal surfaces, such floors and ceilings, where $\cos (\alpha)=0$ in (2.4.1), the pool fraction is defined to vary from zero to one as the pool surface ascends through a vertical distance of the maximum of liquid film thickness (see section 2.8 ) and $10^{-6}$. This eliminates the step change in pool fraction that would result from the previous definition.

\subsubsection{Cylindrical Geometry}

The following quantities are used for defining the pool fraction for a surface with a cylindrical geometry:

$$
\begin{aligned}
& \mathrm{R}=\text { radius of cylinder containing the surface } \\
& \mathrm{L}=\text { axial length of this surface } \\
& \alpha \quad=\text { angle between this surface and the vertical } \\
& \mathrm{a}=\text { vertical projection of cylinder diameter, } 2 \mathrm{R} \sin (\alpha) \\
& \mathrm{b}=\text { vertical projection of cylinder axial length, } \mathrm{L} \cos (\alpha) \\
& \mathrm{Z}=\text { depth of pool in boundary volume of this surface relative to the altitude } \\
& \quad \text { of the lowest point on this surface }
\end{aligned}
$$

The pool fraction for a vertical surface, $\cos (\alpha)=1$, with a cylindrical geometry is given by

$$
x_{\text {pool }}=Z / L
$$


HS Package Reference Manual

The pool fraction for a horizontal surface, $\cos (\alpha)=0$, with a cylindrical geometry is given by

$$
x_{\text {pool }}=\Theta / \pi
$$

where

$$
\Theta=\cos ^{-1}[(R-Z) / R]
$$

The pool fraction for a cylinder inclined at an angle $\alpha$ between vertical and horizontal is given as follows:

$$
X_{\text {pool }}=R \sin (\alpha)[T E R M L(Z)+\operatorname{TERMR}(Z)] / b
$$

where TERML( $Z)$ and TERMR(Z) are functions of $Z$ that are derived by considering whether or not the pool surface intersects the bottom and/or top flat surfaces of the cylinder. Defining

$$
X L=1-Z /[R \sin (\alpha)]
$$

it can be shown that, if the pool intersects the bottom surface $(X L>-1)$, then

$$
\text { TERML }=\left[\left\{1-X L^{2}\right\}^{0.5}-X L \cos ^{-1}(X L)\right] / \pi
$$

Otherwise, the bottom surface is completely submerged, and

$$
\text { TERML }=-X L
$$

Similarly, defining

$$
X U=(a+b-z) /[R \sin (\alpha)]-1
$$

it can be shown that

$$
\text { TERMR }=\left[X U \cos ^{-1}(X U)-\left\{1-X U^{2}\right\}^{0.5}\right] / \pi
$$

when the surface intersects the top end $(X U<1)$; otherwise,

$$
\text { TERMR }=0
$$




\subsubsection{Spherical Geometry}

The pool fraction for a surface with a spherical geometry is given by

$$
x_{\text {pool }}=Z / 2 R
$$

\subsubsection{Hemispherical Geometry}

The pool fraction for a surface with a hemispherical geometry is given by

$$
x_{\text {pool }}=Z / R
$$

\subsection{Thermal Properties}

The conduction equations require the thermal conductivity and volumetric heat capacity (product of heat capacity and density) of the material in each mesh interval. These thermal properties are discussed in Section 2.5.1. Their modification for a degassible material is discussed in Section 2.5.2.

\subsubsection{Thermal Conductivity and Volumetric Heat Capacity}

The thermal conductivity, heat capacity, and density of the material in each mesh interval are obtained as a function of temperature using an interface with the Material Properties package. They are obtained for the material in each mesh interval at a temperature that is the average of the temperatures of the nodes which are the boundaries of this mesh interval.

\subsubsection{Modifications for Degassible Materials}

The volumetric heat capacity of a degassible material whose temperature is in the degassing temperature range is increased by an amount equal to the product of the heat of reaction and the source density divided by the degassing temperature range. The volumetric heat capacity is therefore replaced by

$$
C_{p}+\Delta h_{R} \rho_{\text {gas }} / \Delta T_{\text {gas }}
$$

where

$\mathrm{C}_{\mathrm{p}}=$ volumetric heat capacity from Material Properties package, $\mathrm{kJ} / \mathrm{m}^{3} \cdot \mathrm{K}$

$\Delta h_{R}=$ heat of reaction of gas source, $\mathrm{kJ} / \mathrm{kg}$

$\rho_{\text {gas }}=$ density of gas in source, $\mathrm{kg} / \mathrm{m}^{3}$ 
HS Package Reference Manual

$$
\Delta T_{\text {gas }}=\text { degassing temperature range of gas source, } \mathrm{K}
$$

This modification accounts for the energy which is required to produce and release the gas.

\subsection{Heat Transfer}

The methods of calculating heat transfer at a heat structure surface are discussed in this section for the following:

(1) specified temperature boundary conditions

(2) specified heat flux boundary conditions

(3) convective boundary conditions

If the temperature of a surface is specified by a tabular function, the heat flux is calculated from a finite-difference approximation which expresses the surface heat flux in terms of temperatures at the surface and adjacent nodes and quantities known in the interior of the heat structure. For the left boundary surface, this heat flux is given by

$$
q_{L}^{\prime \prime}=\left[-k_{1}^{m+1}\left(T_{1}^{m+1}-T_{2}^{m+1}\right) H S R_{1}+U_{1} H V R_{1}-C_{p 1}^{m} \frac{T_{1}^{m+1}-T_{1}^{m}}{\Delta t_{m}} H V R_{1}\right] / H S L_{1}
$$

For the right boundary surface, this heat flux is

$$
q_{R}^{\prime \prime}=\left[-k_{N}^{m+1}\left(T_{N}^{m+1}-T_{N-1}^{m+1}\right) H S L_{N}+U_{N} H V L_{N}-C_{p N}^{m} \frac{T_{N}^{m+1}-T_{N}^{m}}{\Delta t_{m}} H V L_{N}\right] / H S R_{N}
$$

where

$$
\begin{array}{ll}
k^{m} & =\text { thermal conductivity of heat structure at time } t_{m} \\
C_{p}^{m} & =\text { volumetric heat capacity of heat structure at time } t_{m} \\
H S L & =\text { left (inside) surface weight defined in Section } 2.2 .1 \\
H S R & =\text { right (outside) surface weight defined in Section 2.2.1 } \\
H V L & =\text { left (inside) volume weight defined in Section 2.2.1 } \\
H V R & =\text { right (outside) volume weight defined in Section 2.2.1 } \\
U^{m} & =\text { volumetric power source at time } t_{m} \\
T^{m} & =\text { node temperature at time } t_{m} \\
T^{m+1} & =\text { node temperature at time } t_{m+1} \\
\Delta t & =\text { time step size, } t_{m+1}-t_{m}
\end{array}
$$

If the surface heat flux is specified by a tabular function, the heat flux is known from the value of the tabular function. 
If a convective boundary condition is specified, the heat flux is the product of the heat transfer coefficient and the temperature difference between the surface (film surface, if a liquid film is present) and the atmosphere or pool of the boundary volume. The heat transfer coefficient is either calculated or provided by a tabular function of time or temperature.

If a convective boundary condition with calculated heat transfer coefficients is specified, then correlations are available for the following heat transfer regimes:

(1) natural convection to atmosphere

(2) forced convection to atmosphere

(3) natural convection to pool

(4) forced convection to pool

(5) pool boiling

The HS package calculates convective heat transfer between a heat structure and the boundary volume atmosphere whenever the pool fraction at a boundary surface is less than or equal to its critical pool fraction for atmosphere heat transfer. Atmosphere heat transfer occurs through a gas boundary layer and, if condensate is present on the surface, through a liquid layer between the surface and the boundary layer. Radiation heat transfer also occurs between a heat structure and the boundary volume atmosphere. Radiation and convection to the structure surface (or the film surface, if a liquid film exists) occur in parallel with one another (and in series with conduction/convection through the liquid film to the structure surface).

Heat transfer through the gas boundary layer is accounted for by a heat transfer coefficient obtained from correlations for natural or forced convection heat transfer. User input must specify whether an internal flow or external flow correlation is to be used when calculating atmosphere heat transfer coefficients for each boundary surface. These correlations are given in Section 2.6.1 for atmosphere heat transfer. Section 2.6.1.1 describes the modeling of heat transfer through liquid films when the film tracking model is inactive. The modeling of heat transfer through liquid films flowing over structures included in user-defined film tracking networks is discussed in Section 2.6.1.2.

Radiation heat transfer between a heat structure surface and the boundary volume atmosphere is modeled in either of two ways. The user has the option of employing the equivalent band model or the gray gas model for radiation heat transfer. These models are presented in Section 2.6.2.

At any surface, an arbitrary, user-specified nonnegative scaling factor may be applied to the calculated convective and radiative heat transfer coefficients to the atmosphere. The user may also apply a separate, arbitrary nonnegative scaling factor to the condensation/evaporation mass transfer coefficient. Users are cautioned that the application of significantly different heat and mass transfer scaling factors at the same 


\section{HS Package Reference Manual}

surface may lead to nonphysical results and numerical problems. The scaling factors are provided primarily for conducting sensitivity studies associated with uncertainties related to surface fouling, local fluid effects, etc.

The HS package calculates heat transfer between a heat structure and the boundary volume pool whenever the pool fraction at a boundary surface is greater than or equal to its critical pool fraction for pool heat transfer. Pool heat transfer is by natural convection, forced convection, or pool boiling. The HS package utilizes an extensive set of correlations for natural or forced convection pool heat transfer. User input must again specify whether an internal flow or external flow correlation is to be used when calculating pool heat transfer coefficients for each boundary surface. These correlations are exhibited in Section 2.6.3.

Pool boiling heat transfer is calculated at a surface if its pool fraction is greater than the critical pool fraction and its temperature is greater than the saturation temperature of its boundary volume (at total pressure). In calculating pool boiling heat transfer, the HS package utilizes a set of correlations for nucleate boiling, critical heat flux, minimum film boiling, and stable film boiling. Radiation heat transfer between a surface and the pool of its boundary volume is calculated during stable film and transition boiling. Correlations for pool boiling heat transfer as well as models for pool radiation heat transfer are discussed in Section 2.6.4.

The HS package obtains the boiling heat transfer coefficient at a boundary surface as the quotient of the boiling heat flux and the difference between the temperature of this surface and the saturation temperature of its boundary volume (at total pressure).

The correlation of experimental heat transfer data is usually accomplished with dimensionless variables which are obtained by dimensional analysis or physical reasoning. These variables include:

$$
\begin{aligned}
& \text { Reynolds Number }(\operatorname{Re})=\rho \mathrm{V} \mathrm{L}_{\mathrm{c}} / \mu \\
& \text { Prandtl Number (Pr) }=\mu c_{p} / k \\
& \text { Grashof Number (Gr) }=\mathrm{g} \beta \Delta \mathrm{t}_{\mathrm{c}}^{3} \rho^{2} / \mu^{2} \\
& =\mathrm{g}\left|\rho_{\mathrm{sr}}-\rho\right| L_{\mathrm{c}}^{3} \rho / \mu^{2} \text { (during condensation) } \\
& \text { Nusselt Number }(\mathrm{Nu})=\mathrm{h} \mathrm{L}_{\mathrm{c}} / \mathrm{k} \\
& \text { Rayleigh Number }(\mathrm{Ra})=\mathrm{Gr} \cdot \mathrm{Pr}
\end{aligned}
$$

where

$$
\begin{aligned}
& \rho=\text { density of atmosphere (pool), } \mathrm{kg} / \mathrm{m}^{3} \\
& \rho_{\text {sf }}=\text { density of atmosphere evaluated at film surface temperature }
\end{aligned}
$$


HS Package Reference Manual

$$
\begin{aligned}
& \mathrm{V}=\text { velocity of atmosphere (pool), } \mathrm{m} / \mathrm{s} \\
& L_{c} \quad=\text { characteristic length of surface, } m \\
& \mu=\text { viscosity of atmosphere (pool), } \mathrm{kg} / \mathrm{m} \cdot \mathrm{s} \\
& c_{p}=\text { heat capacity at constant pressure of atmosphere (pool), } \mathrm{J} / \mathrm{kg} \cdot \mathrm{K} \\
& \mathrm{k}=\text { thermal conductivity of atmosphere (pool), } \mathrm{W} / \mathrm{m} \cdot \mathrm{K} \\
& \mathrm{g}=\text { acceleration of gravity, } \mathrm{m} / \mathrm{s}^{2} \\
& \beta=\text { volume coefficient of expansion of atmosphere (pool), } \mathrm{K}^{-1} \\
& \Delta t=\text { magnitude of difference between temperatures of surface and } \\
& \text { atmosphere (pool), } \mathrm{K} \\
& \mathrm{h}=\text { atmosphere (pool) heat transfer coefficient, } \mathrm{W} / \mathrm{m}^{2} \cdot \mathrm{K}
\end{aligned}
$$

The HS package uses these variables for selecting the appropriate heat transfer correlation or in expressing the functional form of the correlation for all heat transfer regimes except pool boiling. The pool boiling correlations are not expressed in a dimensionless form.

\subsubsection{Atmosphere Convection Heat Transfer}

Natural, forced, or mixed convection heat transfer to the atmosphere is determined at a surface by the following criteria:

- Natural Convection

$$
\mathrm{Re}^{2}<1.0 \mathrm{Gr}
$$

- Forced Convection

$$
\operatorname{Re}^{2}>10.0 \mathrm{Gr}
$$

- Mixed Convection

$$
1.0 \mathrm{Gr} \leq \mathrm{Re}^{2} \leq 10.0 \mathrm{Gr}
$$

where

Re $=$ Reynolds number for atmosphere

$\mathrm{Gr}=$ Grashof number for atmosphere

$\mathrm{Ra}=$ Rayleigh number for atmosphere

The constants in Equations 2.6.3-2.6.5 are implemented as sensitivity coefficient array C4060. 
HS Package Reference Manual

The atmosphere natural convection heat transfer correlations have the following form:

$$
\mathrm{Nu}=\mathrm{CRa}{ }^{\mathrm{m}}+\mathrm{D}
$$

where

$$
\begin{aligned}
& \mathrm{Nu}=\text { Nusselt number } \\
& \mathrm{Ra}=\text { Rayleigh number } \\
& \mathrm{C}, \mathrm{m}, \mathrm{D} \quad=\text { constants dependent on flow condition and geometry }
\end{aligned}
$$

The constants $C, m$, and $D$ in Equation 2.6.6 have been implemented as sensitivity coefficient arrays C4101-C4112 and are presented in Table 2.6 for the various flow conditions and geometries.

The atmosphere forced convection heat transfer correlations have the following form:

$$
\mathrm{Nu}=\mathrm{C} \mathrm{Re}^{\mathrm{m}} \mathrm{Pr}^{\mathrm{n}}+\mathrm{D}
$$

where

$$
\begin{array}{ll}
\mathrm{Nu} & =\text { Nusselt number } \\
\mathrm{Re} & =\text { Reynolds number } \\
\mathrm{Pr} & =\text { Prandtl number } \\
\mathrm{C}, \mathrm{m}, \mathrm{n}, \mathrm{D} & =\text { constants dependent on flow condition and geometry }
\end{array}
$$

The constants $C, m, n$, and $D$ in Equation 2.6.7 have been implemented as sensitivity coefficient arrays C4113-C4124 and are presented in Table 2.6 for the various flow conditions and geometries.

The Nusselt number in the mixed convection regime is a linear interpolation between the Nusselt numbers for the natural and forced convection regimes, based on the ratio $\mathrm{Re}^{2} / \mathrm{Gr}$. That is,

$$
\mathrm{Nu}_{\text {mixed }}=\left[\left(\mathrm{Re}^{2} / \mathrm{Gr}-1\right) / 9\right]\left[\mathrm{Nu}_{\text {forced }}-\mathrm{Nu}_{\text {natural }}\right]+\mathrm{Nu}_{\text {natural }}
$$

The constants in Equation 2.6.8 are, of course, derived from the sensitivity coefficients that define the limits of natural and forced convection. If the values of these coefficients do not define a proper transition-specifically if the upper limit for natural convection, C4060(1) (default value 1.0) is negative or is greater than or equal to the lower limit for forced convection, C4060(2) (default value 10.0)-no mixed convection regime is considered. Instead, convection heat transfer to the atmosphere is assumed to be given by the greater of the values defined by the natural and forced convection correlations. This simple and often used treatment may be specified in MELCOR by deliberate modification of the sensitivity coefficients. 
HS Package Reference Manual

Table 2.6 Constants for HS Package Heat Transfer Correlations

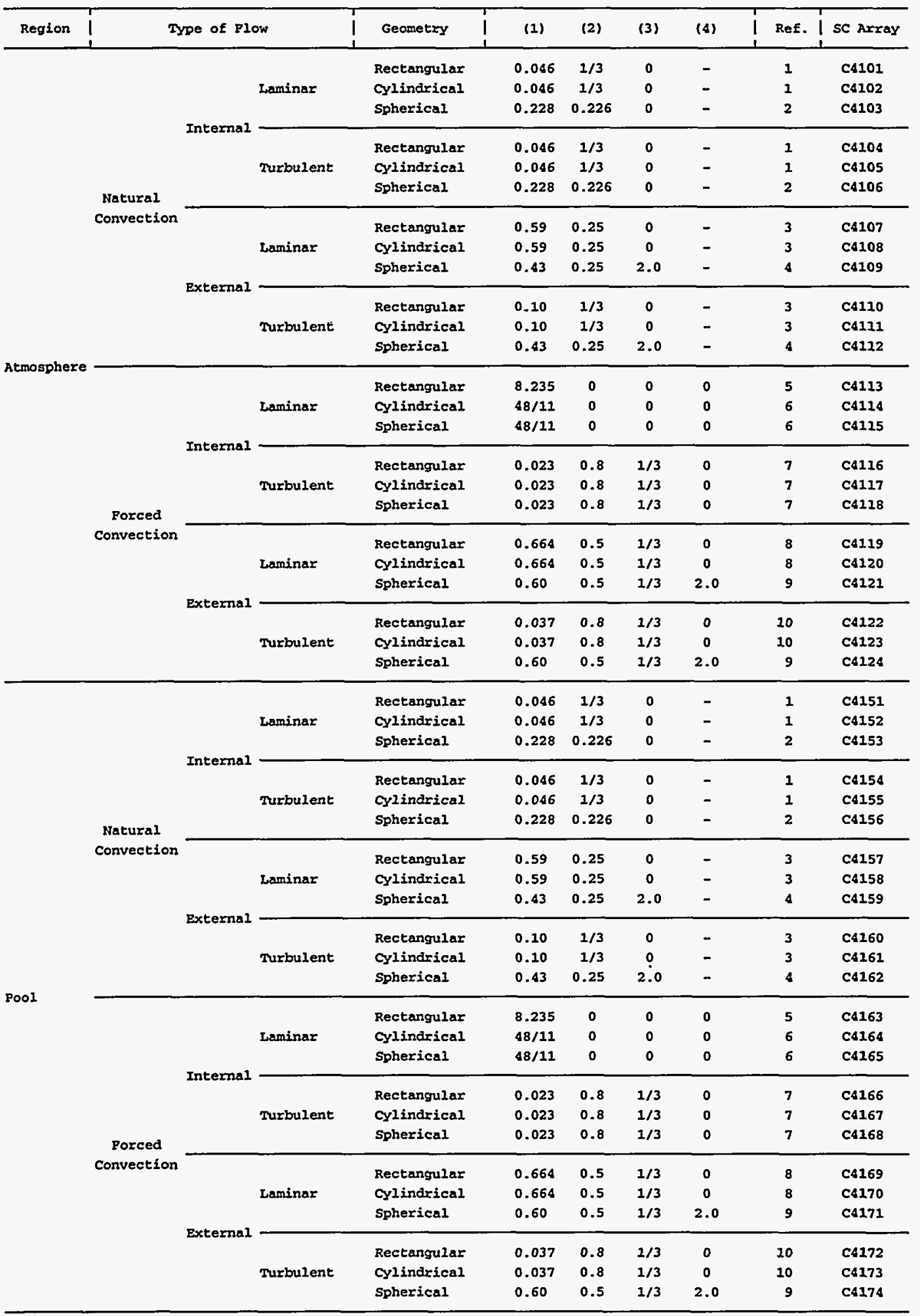




\section{HS Package Reference Manual}

Laminar or turbulent natural convection heat transfer to the atmosphere is determined at a surface by the following criteria:

- Laminar Natural Convection

$\mathrm{Ra}<10^{9}$

- Turbulent Natural Convection

$\operatorname{Ra}>10^{10}$

- Transition between Laminar and Turbulent Natural Convection

$$
10^{9} \leq \mathrm{Ra} \leq 10^{10}
$$

The constants in Equations 2.6.9-2.6.11 are implemented as sensitivity coefficient arrays C4061-C4063 for rectangular, cylindrical, and spherical (hemispherical) geometries.

Laminar or turbulent forced convection heat transfer to the atmosphere is determined at a surface by the following criteria:

- Laminar Forced Convection

$\operatorname{Re}<3 \times 10^{5}$ (rectangular)

$\operatorname{Re}<2 \times 10^{3}$ (cylindrical/spherical)

- Turbulent Forced Convection

Re $>6 \times 10^{5}$ (rectangular)

$\mathrm{Re}>1 \times 10^{4}$ (cylindrical/spherical)

- Transition between Laminar and Turbulent Forced Convection

$$
\begin{aligned}
& 3 \times 10^{5} \leq \operatorname{Re} \leq 6 \times 10^{5} \text { (rectangular) } \\
& 2 \times 10^{3} \leq \operatorname{Re} \leq 1 \times 10^{4} \text { (cylindrical/spherical) }
\end{aligned}
$$

The constants in Equations 2.6.12-2.6.14 are implemented as sensitivity coefficient arrays C4064-C4066 for rectangular, cylindrical, and spherical (hemispherical) geometries.

The Nusselt number in the transition region is a linear interpolation between the Nusselt numbers for the laminar and turbulent regimes. The interpolation is based on the Rayleigh number for natural convection and the Reynolds number for forced convection. 
HS Package Reference Manual

An example is the Nusselt number in the transition region for forced convection with rectangular geometries:

$$
\mathrm{Nu}_{\text {transition }}=\left[\left(\operatorname{Re}-3 \times 10^{5}\right) / 3 \times 10^{5}\right]\left[\mathrm{Nu}_{\text {turbulent }}-\mathrm{Nu}_{\text {laminar }}\right]+\mathrm{Nu}_{\text {laminar }}
$$

The constants in Equation 2.6.15 are, of course, derived from the sensitivity coefficients that define the limits of laminar and turbulent convection. If the values of these coefficients do not define a proper transition-specifically if the upper limit for laminar convection, $\mathrm{C} 406 \mathrm{~m}(1)$ is negative or is greater than or equal to the lower limit for turbulent convection, $\mathrm{C} 406 \mathrm{~m}(2)$-no transition regime is considered. Instead, convection heat transfer to the atmosphere is assumed to be given by the greater of the values defined by the laminar and turbulent convection correlations. This simple and often used treatment may be specified in MELCOR by deliberate modification of the sensitivity coefficients.

\subsubsection{Conduction/convection through Liquid Films (film tracking inactive)}

Liquid film modeling is discussed in detail in Section 2.8. Heat transfer through a liquid film is accounted for by a heat transfer coefficient, $H_{f}$, which is used in Eqs. 2.2.38 and 2.2.39. The value of $H_{f}$ used when the structure is included in a user-defined film tracking network is discussed in Section 2.6.1.2. When film tracking is inactive the value of $H_{f}$ used is the greater of two values: (1) a value obtained from a steady-state correlation appropriate for the geometry and film conditions (zero is used if none exists) and (2) the quotient of the thermal conductivity of the liquid and the transient film thickness. Thus, the liquid film heat transfer coefficient is given by

$$
H_{f}=\max \left(H_{f, \text { corr }}, k_{f} / \delta_{f}\right)
$$

where

$k_{f} \quad=$ thermal conductivity of liquid film, W/m.K

$\delta_{\mathrm{f}} \quad=$ liquid film thickness, $m$

and $\mathrm{H}_{\mathrm{t}, \text { corr }}$ is a function of surface geometry and film flow conditions. Laminar or turbulent heat transfer through the condensate film is determined by the following criteria:

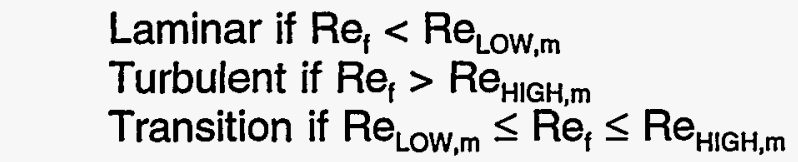


HS Package Reference Manual

where

$$
R e_{\mathrm{f}}=\text { Reynolds number for the film flow }
$$

The laminar heat transfer coefficient through the film, $h_{f, l}$ is given by

$$
h_{f, 1}=\left(k_{f} / L\right) \times N u_{f, l}
$$

where the laminar film Nusselt number, $\mathrm{Nu}_{\mathrm{f}, \mathrm{l}}$ is given by

$$
N u_{i, l}=C_{l, m} \times\left\{g \rho_{f}\left(\rho_{f}-\rho_{v}\right) h_{f g} L^{3} \sin \theta /\left[\mu_{f} k_{f}\left(T_{s a t}-T_{s r f}\right)\right]\right\}^{e l, m}
$$

The turbulent heat transfer coefficient through the film, $h_{f, t}$ is given by

$$
h_{\mathrm{f}, \mathrm{t}}=\left\{\mathrm{k}_{\mathrm{f}} /\left[\left(\mu_{\mathrm{f}} / \rho_{\mathrm{f}}\right)^{2} / \mathrm{g}\right]^{\mathrm{et1}, \mathrm{m}}\right\} \times N u_{\mathrm{f}, \mathrm{t}}
$$

where the turbulent film Nusselt number, $\mathrm{Nu}_{\mathrm{i}, \mathrm{t}}$ is given by

$$
N u_{t, t}=\left(R e_{i}^{e t 2, m}+C_{t, m} R e_{t}^{e t 3, m} \operatorname{Pr}_{f}^{e t 4, m}\right)^{e t 5, m}
$$

The transition heat transfer coefficient through the film, $h_{t, t r}$, is given by linear interpolation of $\mathrm{Re}_{\mathrm{f}}$ as

$$
h_{f, t r}=h_{f, l}^{\prime}+\left[h_{f, t}^{\prime}-h_{f, l}^{\prime}\right] \times\left[R e_{f}-R e_{L O W, m}\right] /\left[R e_{H I G H, m}-R e_{L O W, m}\right]
$$

In each of these equations,

$$
\begin{aligned}
& k_{\mathrm{f}} \quad=\text { thermal conductivity of film } \\
& L \quad=\text { characteristic length of surface } \\
& \rho_{\mathrm{f}} \quad=\text { density of film } \\
& \rho_{\mathrm{v}} \quad=\text { density of vapor } \\
& \mathrm{g} \quad=\text { acceleration of gravity } \\
& h_{\mathrm{fg}}=\text { latent heat of vaporization corrected for sensible heat } \\
& \left(h_{f g}+0.68 c_{p, t}\left(T_{f}-T_{s t r}\right)\right) \\
& \mathrm{c}_{\mathrm{p}, \mathrm{f}} \quad=\text { specific heat capacity of film } \\
& T_{f}, \quad=\text { temperature of film/atmosphere interface } \\
& T_{\text {srf }}=\text { temperature of film/structure interface } \\
& \mu_{\mathrm{f}} \quad=\text { viscosity of film } \\
& \theta \quad=\text { angle between horizontal and structure surface or axis (cyl.) } \\
& h_{f, 1}^{\prime} \quad=h_{f, 1} \text { evaluated with } R e_{f}=C 42 m 0(1) \\
& h_{f, t}^{\prime} \quad=h_{f, t} \text { evaluated with } R e_{f}=C 42 m 0(2)
\end{aligned}
$$

and 
$\mathrm{m} \quad=1$ for upward-facing rectangular geometries

$=2$ for horizontal cylindrical geometries

$=3$ for spherical or hemispherical geometries

$R e_{\text {Low, }}, R e_{H I G, m}$ and the minimum permissible value of $\sin \theta$ ( $\cos \theta$ for cylindrical geometry) have been implemented as sensitivity coefficients $42 \mathrm{mo} . \mathrm{C}_{1, \mathrm{~m}}$ and el,m have been implemented as sensitivity coefficients $42 \mathrm{m1}$, and $C_{t, m}$ and etn,m have been implemented as sensitivity coefficients $42 \mathrm{~m} 2$.

For downward-facing rectangular geometries, the laminar/turbulent transition criteria are given by:

Laminar if $R a_{f}<R a_{\text {TRAN }}$

Turbulent, otherwise

where

$\mathrm{Ra}_{\mathrm{f}}=$ Rayleigh number for the film flow

The heat transfer coefficient through the film is given by

$$
h_{f}=\left\{k_{f} /\left[\sigma_{f} /\left\{g\left(\rho_{f}-\rho_{v}\right) \cos \theta\right\}\right]^{1 / 2}\right\} \times N u_{f}
$$

where the film Nusselt number is given by

$$
\mathrm{Nu}_{\mathrm{f}}=\mathrm{C}_{\mathrm{l}, 4} \times\left\{\max \left[R \mathrm{a}_{\mathrm{MIN}}, \mathrm{Ra}_{\mathrm{f}}\right\}^{\mathrm{el,4}}\right.
$$

for laminar film flow, and

$$
\mathrm{Nu}_{\mathrm{f}}=\mathrm{C}_{\mathrm{t}, 4} \times\left\{\min \left[\mathrm{Ra}_{\mathrm{MAX}}, \mathrm{Ra}_{\mathrm{f}}\right\}^{\mathrm{et}, 4}\right.
$$

for turbulent film flow. $R a_{\text {TRAN }}, R a_{\text {MIN }}, R a_{\text {MAX }}$ and the minimum value of $\cos \theta$ have been implemented as sensitivity coefficients $4213, \mathrm{C}_{1,4}$ and el,4 have been implemented as sensitivity coefficients 4214 and $C_{t, 4}$ and et, 4 have been implemented as sensitivity coefficients 4215 .

Early in its formation, the transient film thickness determines the rate of heat transfer; while its steady-state value is limited by the greater of the correlation value or $k_{\mathrm{p}} / \delta_{\max }$, where $\delta_{\max }$ is the user-specified maximum film thickness discussed in Section 2.8.1 below. Note, that because the film convective heat transfer correlations are functions of the flow conditions, and the flow conditions are a function of the rate of heat transfer, the convective heat transfer coefficient through the film must be determined iteratively as part of the overall solution for the temperature profile through a heat structure and its 
HS Package Reference Manual

associated films. This is implied by the new time superscript $(m+1)$ of $\mathrm{H}_{\mathrm{t}, \mathrm{L}}^{\mathrm{m}}$ in Eq. 2.2.39b.

\subsubsection{Conduction/convection through Liquid Films (film tracking active)}

Section 2.8.2 discusses the film tracking model. This section only describes the correlations used to evaluate heat transfer through films being treated by the film tracking model. The correlations used are the same for all geometries and treat both laminar and turbulent film flow conditions. Laminar or turbulent heat transfer through the condensate film is determined by the following criteria:

Laminar if $\mathrm{Re}_{\mathrm{f}}<\mathrm{Re}_{\mathrm{LOW}}$

- Turbulent if $R e_{\mathrm{f}}>\mathrm{Re}_{\mathrm{HIGH}}$

- Transition if $R e_{\text {LOW }} \leq R e_{f} \leq R e_{\text {HIGH }}$

where

$R e_{\mathrm{f}}=$ Reynolds number for the film flow

The laminar heat transfer coefficient through the film, $h_{f, l}$, is given by

$$
h_{\mathrm{f}, \mathrm{l}}=\mathrm{k}_{\mathrm{f}} / \max \left(\delta_{\mathrm{f}, \mathrm{l}}, \delta_{\text {min }}\right)
$$

where the laminar film thickness, $\delta_{\mathrm{f}, \mathrm{b}}$ is obtained from the film tracking model solution, and $\delta_{\min }$ is the user-adjustable minimum film thickness implemented as sensitivity coefficient 4251 (1) (see Section 2.8.2). The turbulent heat transfer coefficient through the film, $h_{\mathrm{f}, t}$ is given by

$$
h_{f, t}=\left\{k_{f} /\left[\left(\mu_{f} / \rho_{f}\right)^{2} /(g \cdot \sin \theta)\right]^{1 / 3}\right\} \times N u_{f, t}
$$

where the turbulent film Nusselt number, $\mathrm{Nu}_{\mathrm{f}, \mathrm{t}}$ is given by

$$
\mathrm{Nu}_{\mathrm{f}, \mathrm{t}}=\left(\mathrm{Re}_{\mathrm{f}}^{\mathrm{et1}}+\mathrm{C}_{\mathrm{t}} \mathrm{Re}_{\mathrm{f}}^{\mathrm{et} 2} \mathrm{Pr}_{\mathrm{f}}^{\mathrm{et} 3}\right)^{\mathrm{et} 4}
$$

The transition heat transfer coefficient through the film, $h_{f, t r}$ is given by linear interpolation of $\mathrm{Re}_{\mathrm{f}}$ as

$$
h_{f, t r}=h_{f, 1}^{\prime}+\left[h_{f, t}^{\prime}-h_{f, 1}^{\prime}\right] \times\left[R e_{f}-R e_{L O w}\right] /\left[R e_{H I G H}-R e_{\text {Low }}\right]
$$

In each of these equations,

$\mathrm{k}_{\mathrm{f}} \quad=$ thermal conductivity of film

$\rho_{\mathrm{f}} \quad=$ density of film 
HS Package Reference Manual

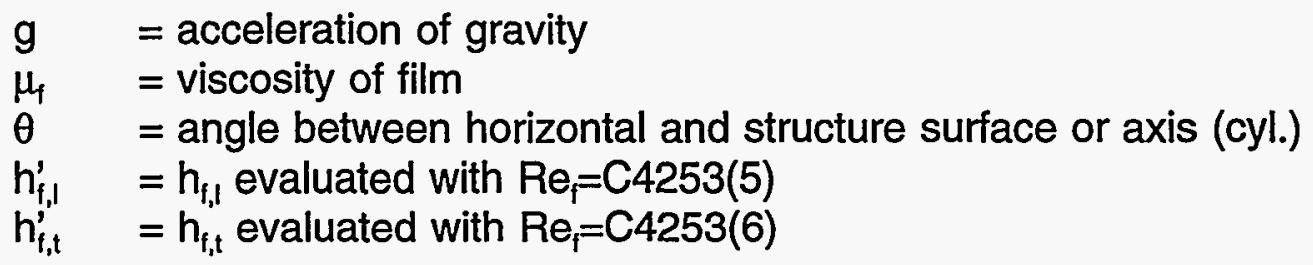

$R e_{\text {Low }}, R_{e_{H G H}}, C_{t}$ et1, et2, et3 and et 4 have been implemented as sensitivity coefficients 4253.

\subsubsection{Atmosphere Radiation Heat Transfer}

In addition to the convective boundary condition options, radiative heat transfer between the surface and the boundary volume atmosphere can be specified. Two options are currently available. They are:

(1) Equivalent Band Model

(2) Gray Gas

The equivalent band model is based on work by Edwards, et al. $[12,13]$ in which the total radiation properties can be used to adequately calculate radiation heat transfer without resorting to a band model. The equivalent band equation is:

$$
q_{E B}=\left\{\begin{array}{cl}
\sigma\left(F_{g} T_{g}^{4}-F_{g w} T_{w}^{4}\right) & \text { for } T_{g} \neq T_{w} \\
0 & \text { for } T_{g}=T_{w}
\end{array}\right.
$$

where

$$
\begin{aligned}
\sigma & =\text { Stefan-Boltzmann constant } \\
F_{g} & =\varepsilon_{w} \varepsilon_{g 1} /\left(1-\rho_{w} \tau_{g b}\right) \\
F_{g w} & =\varepsilon_{w} \alpha_{g w 1} /\left(1-\rho_{w} \tau_{g b w}\right) \\
\tau_{g b} & =\left(\varepsilon_{g 2}-\varepsilon_{g 1}\right) / \varepsilon_{g 1} \\
\tau_{g b w} & =\left(\alpha_{g w 2}-\alpha_{g w 1}\right) / \alpha_{g w 1}
\end{aligned}
$$

and $\varepsilon$ and $\alpha$ are the emissivity and absorptivity, respectively. Subscripts $g, w, g w, 1$, and 2 , refer to the gas, the wall, the gas at the wall temperature, 1 path length, and 2 path lengths. The values of the gas emissivity $\left(\varepsilon_{g}\right)$ and absorptivity $\left(\alpha_{g w}\right)$ are obtained from the model in CONTAIN [14] which is a function of the gas composition including the pressure of water vapor, $\mathrm{CO}$, and $\mathrm{CO}_{2}$ as well as the radiation path length, which is user-specified. 
HS Package Reference Manual

The wall emissivity $\varepsilon_{w}$, is given by user input, $\varepsilon_{w, u s e r}$, that is overwritten if a liquid film is present. The emissivity of the film covered wall becomes

$$
\varepsilon_{w}=1-\rho_{f}-\rho_{w} \tau_{f} /\left(1-\rho_{f} \rho_{w}\right)
$$

where

$$
\begin{aligned}
& \tau_{f}=\exp (-1000 \delta) \\
& \rho_{f}=\left(1-\varepsilon_{H 2 O}\right)\left(1-\tau_{f}\right) \\
& \rho_{w}=1-\varepsilon_{w, u s e r} \\
& \varepsilon_{H 2 O}=0.96
\end{aligned}
$$

and $\delta$ is the film thickness in meters.

The gray gas model equation is:

$$
q_{G G}=\sigma\left[\left(1 / \varepsilon_{g}\right)+\left(1 / \varepsilon_{w}\right)-1\right]^{-1}\left(T_{g}^{4}-T_{w}^{4}\right)
$$

where the gas emissivity is calculated for one path length.

\subsubsection{Pool Convection Heat Transfer}

Natural, forced, or mixed convection heat transfer to the pool is determined at a surface by the following criteria:

- Natural Convection

$$
\operatorname{Re}^{2}<1.0 \mathrm{Gr}
$$

- Forced Convection

$$
\operatorname{Re}^{2}>10.0 \mathrm{Gr}
$$

- Mixed Convection

$$
1.0 \mathrm{Gr} \leq \mathrm{Re}^{2} \leq 10.0 \mathrm{Gr}
$$

where 
HS Package Reference Manual

Re $=$ Reynolds number for pool

$\mathrm{Gr}=$ Grashof number for pool

$\mathrm{Ra}=$ Rayleigh number for pool

The constants in Equations 2.6.21-2.6.23 are implemented as sensitivity coefficient array C4080.

The pool natural convection heat transfer correlations have the following form:

$$
\mathrm{Nu}=\mathrm{CR} \mathrm{a}^{\mathrm{m}}+\mathrm{D}
$$

where

$$
\begin{aligned}
& \mathrm{Nu}=\text { Nusselt number } \\
& \mathrm{Ra}=\text { Rayleigh number } \\
& \mathrm{C}, \mathrm{m}, \mathrm{D} \quad=\text { constants dependent on flow condition and geometry }
\end{aligned}
$$

The constants $C, m$, and $D$ in Equation 2.6.24 have been implemented as sensitivity coefficient arrays C4151-C4162 and are presented in Table 2.6 for the various flow conditions and geometries.

The pool forced convection heat transfer correlations have the following form:

$$
\mathrm{Nu}=\mathrm{C} \operatorname{Re}^{\mathrm{m}} \mathrm{Pr}^{\mathrm{n}}+\mathrm{D}
$$

where

$$
\begin{array}{ll}
\mathrm{Nu} & =\text { Nusselt number } \\
\mathrm{Re} & =\text { Reynolds number } \\
\mathrm{Pr} & =\text { Prandtl number } \\
\mathrm{C}, \mathrm{m}, \mathrm{n}, \mathrm{D} & =\text { constants dependent on flow condition and geometry }
\end{array}
$$

The constants $C, m, n$, and $D$ in Equation 2.6.25 have been implemented as sensitivity coefficient arrays C4163-C4174 and are presented in Table 2.6 for the various flow conditions and geometries.

The Nusselt number in the mixed convection regime is a linear interpolation between the Nusselt numbers for the natural and forced convection regimes, based on the ratio $\mathrm{Re}^{2} / \mathrm{Gr}$. This is the same method employed for atmosphere heat transfer, and an example is shown in Section 2.6.1. As with atmosphere heat transfer, the sensitivity coefficients defining the limits of natural and forced convection (sensitivity coefficient array C4080) may be chosen to eliminate the mixed convection regime for the pool in favor of use of the maximum of natural and forced convection heat transfer. 


\section{HS Package Reference Manual}

Laminar or turbulent natural convection heat transfer to the pool is determined at a surface by the following criteria:

- Laminar Natural Convection

$\mathrm{Ra}<10^{9}$

- Turbulent Natural Convection

$$
\mathrm{Ra}>10^{10}
$$

- Transition between Laminar and Turbulent Natural Convection

$$
10^{9} \leq \mathrm{Ra} \leq 10^{10}
$$

The constants in Equations 2.6.26-2.6.28 are implemented as sensitivity coefficient arrays C4081-C4083 for rectangular, cylindrical, and spherical (hemispherical) geometries.

Laminar or turbulent forced convection heat transfer to the pool is determined at a surface by the following criteria:

- Laminar Forced Convection

$$
\begin{aligned}
& \text { Re }<3 \times 10^{5} \text { (rectangular) } \\
& \operatorname{Re}<2 \times 10^{3} \text { (cylindrical/spherical) }
\end{aligned}
$$

- Turbulent Forced Convection

$$
\begin{aligned}
& R e>6 \times 10^{5} \text { (rectangular) } \\
& R e>1 \times 10^{4} \text { (cylindrical/spherical) }
\end{aligned}
$$

- Transition between Laminar and Turbulent Forced Convection

$$
\begin{aligned}
& 3 \times 10^{5} \leq \operatorname{Re} \leq 6 \times 10^{5} \text { (rectangular) } \\
& 2 \times 10^{3} \leq \operatorname{Re} \leq 1 \times 10^{4} \text { (cylindrical/spherical) }
\end{aligned}
$$

The constants in Equations 2.6.29-2.6.31 are implemented as sensitivity coefficient arrays C4084-C4086 for rectangular, cylindrical, and spherical (hemispherical) geometries.

The Nusselt number in the transition region is a linear interpolation between the Nusselt numbers for the laminar and turbulent regimes. The interpolation is based on the Rayleigh number for natural convection and the Reynolds number for forced convection. This is the same method employed for atmosphere heat transfer, and an example is shown in Section 2.6.1. As with atmosphere heat transfer, the sensitivity coefficients 
defining the limits of laminar and turbulent convection (sensitivity coefficient arrays $\mathrm{C} 408 \mathrm{~m}$ ) may be chosen to eliminate the transition regime for the pool in favor of use of the maximum of laminar and turbulent convection heat transfer.

\subsubsection{Pool Boiling Heat Transfer}

If a heat structure is submerged in a pool or a film is present and the heat structure surface temperature, $T_{\text {surf }}$ is greater than the saturation temperature, $T_{\text {sat, }}$ at the total control volume pressure, pool boiling heat transfer from the heat structure is assumed. Using the heat structure surface temperature and various liquid properties, the logic for choosing the appropriate pool boiling regime is given by:

Nucleate Boiling (Rohsenow) is calculated if

$$
q_{n b}^{\prime \prime} \text { (Rohsenow) } \leq q_{\text {cht }}^{\prime} \text { (Zuber) }
$$

Film Boiling (modified Bromley) is calculated if

$$
q_{\text {film }}^{\prime \prime} \text { (modified Bromley) } \geq q_{\text {mfilm }}^{\text {(Zuber) }}
$$

where

$$
\begin{array}{ll}
q_{n b}^{\prime \prime} & =\text { nucleate boiling heat flux given by Eq. } 2.6 .32, \mathrm{~W} / \mathrm{m}^{2} \\
\mathrm{q}_{\mathrm{nht}}^{\prime \prime} & =\text { critical heat flux given by Eq. } 2.6 .34, \mathrm{~W} / \mathrm{m}^{2} \\
\mathrm{q}_{\text {film }}^{\prime \prime} \quad \text { film boiling heat flux given by Eq. } 2.6 .36, \mathrm{~W} / \mathrm{m}^{2} & \\
\mathrm{q}_{\text {mflim }}^{\prime \prime} \quad=\text { minimum film boiling heat flux given by Eq. } 2.6 .35, \mathrm{~W} / \mathrm{m}^{2}
\end{array}
$$

If neither of these conditions is met, the surface is in transition boiling and a linear interpolation of the surface temperature is used to determine the heat flux at that temperature.

For all the above cases, once a heat flux has been determined, an effective heat transfer coefficient is evaluated as the ratio of heat flux over the difference between the surface and pool temperatures. This heat transfer coefficient is used as the boundary heat transfer coefficient in the solution of the heat conduction equations.

\subsubsection{Nucleate Boiling}

The nucleate boiling heat flux is obtained through the Rohsenow relation [15] 
HS Package Reference Manual

$$
\left[\frac{C_{p l}\left(T_{\text {surf }}-T_{\text {saf }}\right)}{h_{\mathrm{fg}}}\right]=C_{\mathrm{si}}\left[\frac{q_{\mathrm{nb}}^{\prime \prime}}{\mu h_{\mathrm{fg}}}\left(\frac{\sigma}{g\left(\rho_{1}-\rho_{v}\right)}\right)^{1 / 2}\right]^{n} \operatorname{Pr} m
$$

where

$$
\begin{aligned}
& \mathrm{q}_{\mathrm{nb}}^{\prime \prime} \quad=\text { nucleate boiling heat flux, } W / \mathrm{m}^{2} \\
& \mathrm{C}_{\mathrm{pl}} \quad=\text { heat capacity of liquid at } \mathrm{T}_{\text {sat }}, \mathrm{J} / \mathrm{kg} \cdot \mathrm{K} \\
& \mathrm{T}_{\text {surf }}=\text { temperature of surface, } \mathrm{K} \\
& \mathrm{T}_{\text {sat }} \quad=\text { saturation temperature in boundary volume, } \mathrm{K} \\
& \mathrm{C}_{\mathrm{sf}} \quad=\text { constant determined empirically for different surfaces and fluids } \\
& \text { (default }=0.013 \text { ) } \\
& \mu \quad=\text { dynamic viscosity of liquid at } T_{\text {avg }}, \mathrm{kg} / \mathrm{m} \cdot \mathrm{s} \\
& \mathrm{h}_{\mathrm{fg}}=\text { latent heat in boundary volume of this surface, } \mathrm{J} / \mathrm{kg} \\
& \sigma \quad=\text { surface tension at } T_{\text {avg }}, \mathrm{N} / \mathrm{m} \\
& \mathrm{g}=\text { acceleration of gravity, } \mathrm{m} / \mathrm{s}^{2} \\
& \rho_{1} \quad=\text { density of liquid at } T_{\text {sat }}, \mathrm{kg} / \mathrm{m}^{3} \\
& \rho_{\mathrm{v}} \quad=\text { density of vapor at } \mathrm{T}_{\text {sat, }}, \mathrm{kg} / \mathrm{m}^{3} \\
& \mathrm{n} \quad=\text { constant (default }=0.33 \text { ) } \\
& \mathrm{Pr} \quad=\text { Prandtl number of liquid in boundary volume } \\
& \mathrm{m} \quad=\text { constant (default }=1.0 \text { ) } \\
& T_{\text {avg }}=\left(T_{\text {surf }}+T_{\text {sat }}\right) / 2, K
\end{aligned}
$$

The constants $\mathrm{C}_{\mathrm{sf}}, \mathrm{m}$, and $\mathrm{n}$ in Equation 2.6.32 have been implemented as sensitivity coefficient array C4180.

The surface tension of water is given as a function of temperature by

$$
\sigma=0.2358\left(1-0.625 T_{R}\right) T_{R}^{1.256}+c
$$

where

$$
\begin{aligned}
& \sigma \quad=\text { surface tension, } \mathrm{N} / \mathrm{m} \\
& \mathrm{T}=\text { temperature, } \mathrm{K} \\
& T_{\mathrm{R}}=1-\mathrm{T} / 647.3 \\
& \mathrm{C} \quad \text { constant (default }=0.0 \text { ) }
\end{aligned}
$$

The constants in Equation 2.6.33, including c, have been implemented as sensitivity coefficient array C4000. 
HS Package Reference Manual

\subsubsection{Critical Heat Flux}

The critical heat flux is given by

$$
q^{\prime \prime}{ }_{\text {chf }}=0.18 \rho_{v} h_{f g}\left[\sigma\left(\rho_{l}-\rho_{v}\right) g / \rho_{v}^{2}\right]^{1 / 4}\left[\rho_{l} /\left(\rho_{l}+\rho_{v}\right)\right]^{1 / 2}
$$

where

$$
\begin{aligned}
& q_{c}^{\prime \prime}=\text { critical heat flux, } W / \mathrm{m}^{2} \\
& \rho_{v}=\text { density of vapor at } T_{\text {sat }}, \mathrm{kg} / \mathrm{m}^{3} \\
& \rho_{1}=\text { density of liquid at } T_{\text {sat }}, \mathrm{kg} / \mathrm{m}^{3} \\
& h_{\mathrm{tg}}=\text { latent heat in boundary volume, } \mathrm{J} / \mathrm{kg} \\
& \mathrm{g}=\text { acceleration of gravity, } \mathrm{m} / \mathrm{s}^{2} \\
& \sigma=\text { surface tension at } T_{\text {avg }}, \mathrm{N} / \mathrm{m} \\
& T_{\text {avg }}=\left(\mathrm{T}_{\text {surf }}+\mathrm{T}_{\text {sat }}\right) / 2, \mathrm{~K} \\
& \mathrm{~T}_{\text {sat }}=\text { saturation temperature in boundary volume, } \mathrm{K} \\
& \mathrm{T}_{\text {surf }}=\text { temperature of this surface, } \mathrm{K}
\end{aligned}
$$

The constants in Equation 2.6.34 have been implemented as sensitivity coefficient array C4181. Zuber [17] gives a leading coefficient of 0.131 , while 0.18 is the value suggested by Rohsenow [20].

\subsubsection{Minimum Film Boiling Heat Flux}

The minimum film boiling heat flux is given by Zuber [17] as

$$
q_{\text {mfilm }}^{\prime \prime}=0.09 \rho_{v} h_{f g}\left[\sigma\left(\rho_{1}-\rho_{v}\right) g / \rho_{1}^{2}\right]^{1 / 4}\left[\rho_{1} /\left(\rho_{1}+\rho_{v}\right)\right]^{1 / 2}
$$

where

$$
q_{\text {mfilm }}^{\prime \prime}=\text { minimum film boiling heat flux, } \mathrm{W} / \mathrm{m}^{2}
$$

The constants in Equation 2.6.35 have been implemented as sensitivity coefficient array C4182.

\subsubsection{Stable Film Boiling}

The film boiling heat flux is given by Bromley [17] as

$$
q_{\text {film }}^{\prime \prime}=0.943\left[\rho_{v}\left(\rho_{1}-\rho_{v}\right) g k_{v}^{3}\left(h_{f g}+1 / 2 c_{p v} \Delta T\right) / \mu_{v} L_{c}\right]^{1 / 4} \Delta T^{0.75}
$$

where 


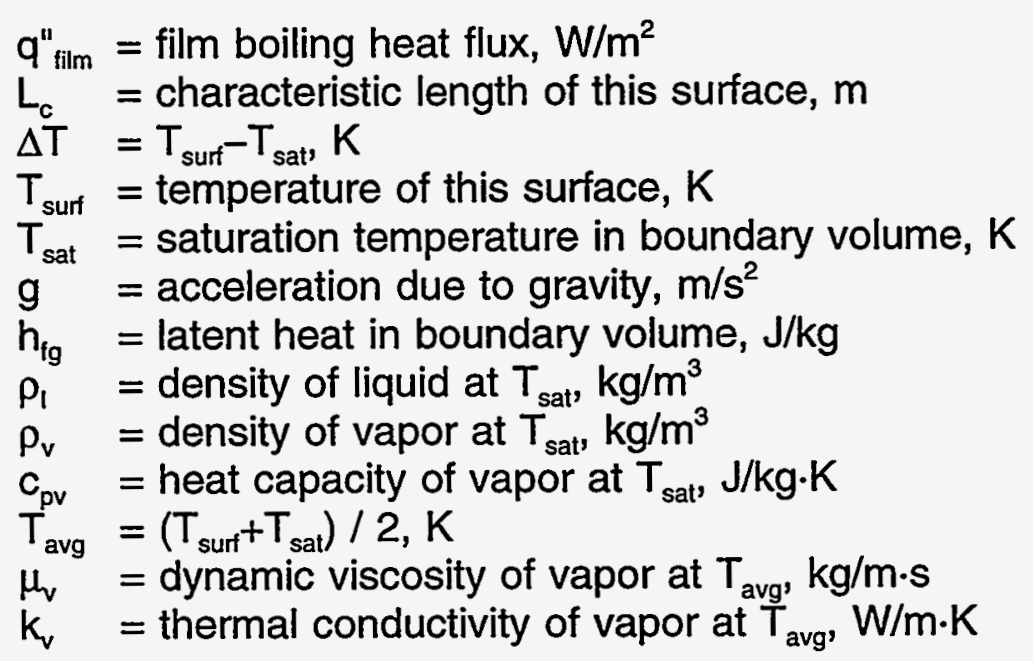

The constants in Equation 2.6.36 have been implemented as sensitivity coefficient array C4183.

\subsubsection{Transition Boiling}

If transition boiling occurs at a surface, the heat flux is calculated as follows. First the surface temperatures at critical heat flux and minimum film boiling are calculated from

$$
\begin{aligned}
& T_{c}=T_{\text {sat }}+\left(q^{\prime \prime}{ }_{c} \Delta T^{3} / q^{\prime \prime}{ }_{N B}\right)^{1 / 3} \\
& T_{\text {mfilm }}=T_{\text {sat }}+\left[q_{\text {mfilm }}^{\prime \prime} \Delta T^{0.75} /\left(q_{\text {film }}^{\prime \prime}+q_{\text {rad }}^{\prime \prime}\right)\right]^{4 / 3}
\end{aligned}
$$

where

$$
\begin{aligned}
& \mathrm{T}_{\text {sat }} \quad=\text { saturation temperature in boundary volume, } \mathrm{K} \\
& \Delta T=T_{\text {surf }}-T_{\text {sat, }}, K \\
& q^{\prime \prime} \text {. = critical heat flux given by Eq. 2.6.34, W/m } / \mathrm{m}^{2} \\
& \mathrm{q}^{\mathrm{n}}{ }_{\mathrm{NB}} \quad=\text { nucleate boiling heat flux given by Eq. } 2.6 .32, \mathrm{~W} / \mathrm{m}^{2} \\
& \mathrm{q}_{\text {milm }}^{\prime \prime}=\text { minimum film boiling heat flux given by Eq. 2.6.35, W/m } \mathrm{m}^{2} \\
& \mathrm{q}_{\text {film }} \text { = film boiling heat flux given by Eq. 2.6.36, W/m } \\
& \mathrm{q}_{\text {rad }}^{\prime \prime}=\text { radiation to pool heat flux given by Eq. } 2.6 .40, \mathrm{~W} / \mathrm{m}^{2}
\end{aligned}
$$

The constants in Equations 2.6.37 and 2.6.38 are sensitivity coefficients 4180(4) and $4183(3)$, respectively.

With these temperatures known, the transition boiling heat flux is then obtained by logarithmic interpolation between the critical heat flux and the minimum film boiling heat 
flux based on ( $\left.T-T_{\text {sat }}\right)$ values and includes the radiation heat flux. Therefore, after simplification, the transition boiling heat flux is given by

$$
\begin{aligned}
\mathrm{q}_{\text {tran }}^{\prime \prime}= & \exp \left\{\left[\ln \left(\mathrm{q}_{c}^{\prime \prime}\right)\left(\ln \Delta \mathrm{T}_{\text {surf }}-\ln \Delta \mathrm{T}_{\text {mfilm }}\right)\right.\right. \\
& \left.\left.+\ln \left(\mathrm{q}_{\text {mfilm }}^{\prime \prime}\right)\left(\ln \Delta \mathrm{T}_{\mathrm{c}}-\ln \Delta \mathrm{T}_{\text {surf }}\right)\right] /\left[\ln \Delta \mathrm{T}_{\mathrm{c}}-\ln \Delta \mathrm{T}_{\text {mfilm }}\right]\right\}+\mathrm{q}_{\text {rad }}^{\prime \prime}
\end{aligned}
$$

where

$$
\begin{array}{ll}
\mathrm{q}_{\text {tran }}^{\prime \prime} & =\text { transition boiling heat flux, } \mathrm{W} / \mathrm{m}^{2} \\
\Delta \mathrm{T}_{\text {surf }} & =\mathrm{T}_{\text {surf }}-\mathrm{T}_{\text {sat }}, \mathrm{K} \\
\Delta \mathrm{T}_{\text {mfim }} & =\mathrm{T}_{\text {mfilm }}-\mathrm{T}_{\text {sat, }}, \mathrm{K} \\
\Delta \mathrm{T}_{\mathrm{c}} & =\mathrm{T}_{\mathrm{c}}-\mathrm{T}_{\text {sat }}, \mathrm{K} \\
\mathrm{q}_{\text {rad }}^{\prime \prime} & =\text { radiation heat flux calculated by Equation } 2.6 .40, \mathrm{~W} / \mathrm{m}^{2}
\end{array}
$$

\subsubsection{Radiation During Boiling}

Radiation heat transfer between a surface and the boundary volume pool is calculated during stable film and transition boiling. The radiation to pool heat flux is given by

$$
q_{\text {rad }}^{\prime \prime}=C \sigma\left(T_{\text {surf }}^{4}-T_{\text {pool }}^{4}\right)
$$

where

$$
\begin{aligned}
& q^{\prime \prime} \text { rad }=\text { radiation to pool heat flux, } \mathrm{W} / \mathrm{m}^{2} \\
& T_{\text {surf }}=\text { temperature of surface, } \mathrm{K} \\
& T_{\text {pool }}=\text { temperature of pool in boundary volume, } \mathrm{K} \\
& \sigma^{2}=\text { Stefan-Boltzmann constant, } 5.669 \times 10^{-8} \mathrm{~W} / \mathrm{m}^{2}-\mathrm{K}^{4}
\end{aligned}
$$

The constant $C$ in Equation 2.6.40 defaults to 1.0 and has been implemented as sensitivity coefficient array C4184.

\subsubsection{Energy Transfer to Control Volumes}

The energy that is transferred from a heat structure surface to the boundary volume pool is:

$$
\Delta Q_{p \text { ool }}^{m}=q_{\text {pool }}^{\prime \prime m} x_{\text {pool }} A \Delta t_{m}
$$

Likewise, the energy that is transferred from a heat structure surface to the boundary volume atmosphere is: 
HS Package Reference Manual

$$
\Delta Q_{a t m}^{m}=q_{a t m}^{u m}\left(1-x_{p o o l}\right) A \Delta t_{m}
$$

where

$$
\begin{aligned}
& \Delta Q_{p o o l}^{m}=\begin{array}{l}
\text { energy transferred between heat structure surface and pool } \\
\text { between times } t_{m-1} \text { and } t_{m}, J
\end{array} \\
& \Delta Q_{a t m}^{m}=\begin{array}{l}
\text { energy transferred between heat structure surface and atmosphere } \\
\text { between times } t_{m-1} \text { and } t_{m}, J
\end{array} \\
& q_{\text {pool }}^{\prime \prime m}=\text { heat flux to pool at time } t_{m}, W / m^{2} \\
& q_{a \text { atm }}^{\prime \prime m}=\text { heat flux to atmosphere at time } t_{m}, W / m^{2} \\
& A=\text { heat structure boundary surface area, } m^{2} \\
& x_{\text {pool }}=\text { fraction of boundary surface in pool of boundary volume } \\
& \Delta t_{m}=\text { time-step size }\left(t_{m}-t_{m-1}\right), s
\end{aligned}
$$

These time-surface integrals are evaluated at each boundary surface to determine the total energy transferred between each heat structure and its respective boundary volume atmosphere and pool. These integrals are used to update the energy communication arrays for the $\mathrm{CVH}$ package.

\subsection{Mass Transfer}

Condensation occurs on a structure surface if its temperature is below the dew point of the associated atmosphere and mass transfer from that surface has been enabled through user input (see the description for record HSCCCCC400 in the HS Users' Guide). The dew point is the saturation temperature corresponding to the partial pressure of steam in the bulk atmosphere of the boundary volume (obtained from the CVH data base). Evaporation from an existing film on a heat structure surface occurs if the surface temperature of the film exceeds the dew point. (A model to treat film flashing at the structure/film interface, when the temperature exceeds the boiling temperature, has not been activated because it has been unnecessary.)

In nearly pure steam environments, the rate of condensation is limited only by heat transfer through the structure, i.e. by the ability of the structure to dissipate the latent heat of vaporization that is released by condensation. Hence, in nearly pure steam environments, the rates of condensation and evaporation will self-adjust to whatever values are required to maintain the saturation temperature at the film/atmosphere interface.

As noncondensibles are introduced into the condensing steam, their accumulation near the film surface from local steam depletion tends to inhibit the flow of fresh steam to the film surface and restricts the rate of condensation. Consequently, when the ratio of the steam partial pressure to the total pressure in the boundary volume (obtained from the CVH data base) falls below a user-prescribed threshold, VPFRAC (with a default value 
of 0.9995), a mass transfer rate limitation is imposed on the rate of condensation. Experimental evidence indicates that the value of VPFRAC (below which diffusion rate limitations to condensation mass transfer become significant) depends on the degree of turbulence in the condensing atmosphere. As the atmosphere becomes less turbulent, the value of VPFRAC should be increased to account for the inhibiting effect of even very small amounts of noncondensibles in a stagnant environment. Conversely, in a wellmixed system, the value of VPFRAC may have to be reduced to avoid artificially limiting the condensation rate. It is suggested that the user vary the value of VPFRAC in sensitivity studies, if uncertainty in the rate of condensation is of much concern.

The mass transfer rate limitation is a function of the diffusion mass transfer coefficient, which is calculated at a heat structure boundary surface whenever the surface is exposed to the atmosphere of its boundary volume. This coefficient is related to the atmosphere Nusselt number through a heat transfer analogy and is calculated by a Sherwood number correlation involving the Nusselt, Prandtl, and Schmidt numbers. This correlation is presented in Section 2.7.1.

The mass transfer rate-limited expression for condensation or evaporation at a surface exposed to a noncondensible-bearing atmosphere is formulated using a mechanistic approach which models the diffusion of a condensible vapor through a gas layer that contains noncondensible gases. Section 2.7.2 discusses this expression. If the surface temperature is greater than the critical temperature, $647.2 \mathrm{~K}$, diffusion mass transfer is not calculated. However, the diffusion mass transfer coefficient is still calculated using Eq. 2.7.2 since the radionuclide package requires this quantity.

\subsubsection{Sherwood Number for Diffusion Mass Transfer}

The mass transfer coefficient is related to the atmosphere Nusselt number by a heat and mass transfer analogy. In addition to the use of the Nusselt, Reynolds, and Prandtl . numbers, the HS package uses the following dimensionless variables for its mass transfer calculations:

Schmidt Number $(S c)=\mu / \rho D$

Sherwood Number $(S h)=h_{D} L_{c} / D$

where

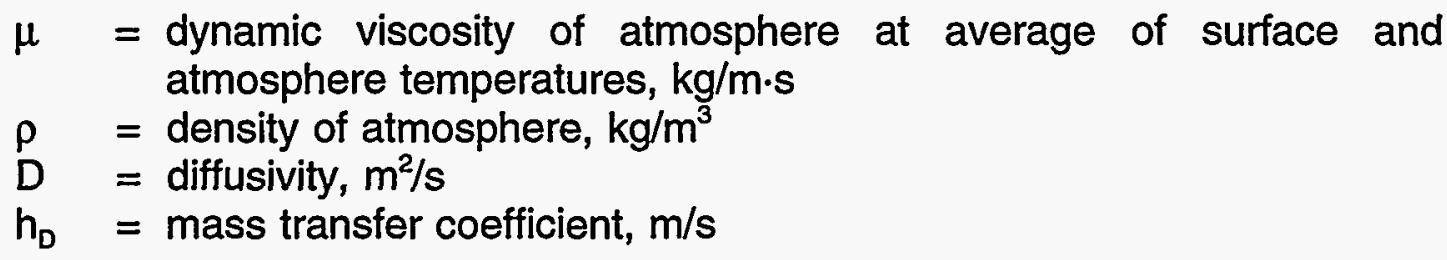


HS Package Reference Manual

$\mathrm{L}_{c} \quad=$ characteristic length or dimension of surface, $m$

A Sherwood number correlation is used to calculate a diffusion mass transfer coefficient. The correlation is

$$
\mathrm{Sh}=\mathrm{CNu^{a }} \mathrm{Sc}^{\mathrm{b}} \mathrm{Pr}^{\mathrm{d}}
$$

where

$\mathrm{Nu}=$ Nusselt number

$\operatorname{Pr}=$ Prandtl number

The constants $\mathrm{C}, \mathrm{a}, \mathrm{b}$, and d have been implemented as sensitivity coefficient array C4201. The default values are:

$$
\begin{aligned}
& c=1.0 \\
& a=1.0 \\
& b=1 / 3 \\
& d=-1 / 3
\end{aligned}
$$

The mass transfer coefficient is then obtained by

$$
h_{D}=F_{m} \operatorname{Sh} D / L_{c}
$$

where $F_{m}$ is an arbitrary, nonnegative scaling factor (with a default value of 1.0) that may be specified by the user at any surface. Refer to Section 2.6 for further discussion of this scaling factor and a caution concerning its use.

\subsubsection{Condensation and Evaporation with Noncondensibles}

The principal expression for condensation or evaporation mass flux at a surface exposed to an atmosphere with a significant partial pressure of noncondensible gases (i.e., $P_{s t m}$ $<$ VPFRAC $\times P_{\text {tot }}$ ) is formulated using a mechanistic approach which models the diffusion of a condensible vapor through a gas layer that contains noncondensible gases [18]. The condensation mass flux is given by:

$$
\dot{\mathrm{m}}_{\mathrm{c}}=\mathrm{h}_{\mathrm{D}} \rho_{\mathrm{v}} \ln \left(\Delta \mathrm{P}_{\mathrm{str}} / \Delta \mathrm{P}_{\mathrm{atm}}\right)
$$

where

$$
\begin{array}{ll}
\dot{m}_{c} & =\text { mass flux at this surface, } \mathrm{kg} / \mathrm{m}^{2} \cdot \mathrm{s} \\
h_{D} & =\text { mass transfer coefficient, } \mathrm{m} / \mathrm{s} \\
\rho_{v} & =\text { density of vapor at } T_{\text {sat }}\left(P_{\text {tot }}\right), \mathrm{kg} / \mathrm{m}^{3}
\end{array}
$$


HS Package Reference Manual

$$
\begin{aligned}
\Delta \mathrm{P}_{\text {sff }}= & \mathrm{P}_{\text {tot }}-\mathrm{P}_{\text {srt }}=\text { noncondensible partial pressure at the surface } \\
& \text { temperature, } \mathrm{Pa} \\
\Delta \mathrm{P}_{\text {atm }}= & \mathrm{P}_{\text {tot }}-\mathrm{P}_{\text {stm }}=\text { noncondensible partial pressure in the bulk atmosphere, } \\
& \mathrm{Pa} \\
\mathrm{P}_{\text {tot }}= & \text { total control volume pressure, } \mathrm{Pa} \\
\mathrm{P}_{\text {srf }}=\text { saturation pressure of steam at the surface temperature, } \mathrm{Pa} & \mathrm{P}_{\mathrm{stm}}=\text { steam partial pressure in the control volume, } \mathrm{Pa}
\end{aligned}
$$

Because Eq. 2.7.3 is singular when the $P_{\text {sff }}$ reaches $P_{\text {tot }}$ it is necessary to bound the rate of evaporation as the surface temperature reaches $T_{\text {sat }}\left(P_{\text {tot }}\right)$. This is done by using a flashing heat transfer coefficient to limit the rate of evaporation as follows:

$$
\begin{aligned}
& \dot{\mathrm{m}}_{\mathrm{e}}=\mathrm{h}_{\mathrm{e}} \min \left(0, \mathrm{~T}_{\mathrm{dew}}-\mathrm{T}_{\mathrm{srf}}\right) / \mathrm{h}_{\mathrm{fg}} \\
& \dot{\mathrm{m}}=\max \left(\dot{\mathrm{m}}_{\mathrm{c}}, \dot{\mathrm{m}}_{\mathrm{e}}\right)
\end{aligned}
$$

where

$$
\begin{aligned}
& h_{\mathrm{e}}=\text { flashing heat transfer coefficient, } \mathrm{W} / \mathrm{m}^{2}-\mathrm{K} \\
& \mathrm{h}_{\mathrm{fg}}=\text { latent heat of vaporization for steam, J/kg } \\
& \mathrm{T}_{\text {dew }}=\text { control volume dew point temperature, } \mathrm{K} \\
& \mathrm{T}_{\text {srf }}=\text { surface temperature, } \mathrm{K}
\end{aligned}
$$

and $h_{e}$ has been implemented as sensitivity coefficient 4202 , with a default value of $5 . \times 10^{5} \mathrm{~W} / \mathrm{m}^{2}-\mathrm{K}$.

\subsubsection{Mass-Energy Transfer to Control Volumes}

The mass which is transferred between the surface of a heat structure and the atmosphere of its boundary volume between times $t_{m-1}$ and $t_{m}$ is the value of the integral from $t_{m-1}$ to $t_{m}$ of the product of the mass flux and the area of the surface which is exposed to the atmosphere:

$$
\Delta m^{m}=\dot{m} A\left(1-x_{p 001}\right) \Delta t_{m}
$$

where

$$
\begin{aligned}
& \Delta \mathrm{m}^{\mathrm{m}}=\text { mass transferred between heat structure surface and atmosphere } \\
& \text { between times } t_{m-1} \text { and } t_{m}, \mathrm{~kg} \\
& \dot{m}=\text { mass flux at heat structure surface, } \mathrm{kg} / \mathrm{m}^{2} \cdot \mathrm{s}
\end{aligned}
$$


HS Package Reference Manual

$A=$ heat structure boundary surface area, $m^{2}$
$x_{\text {pool }}=$ fraction of boundary surface in pool of boundary volume
$\Delta t_{m}=$ system time-step size $\left(t_{m}-t_{m-1}\right), s$

Mass transfer is not considered if the pool fraction is greater than the critical pool fraction CPFAL for the structure as defined in section 2.4.

The time-surface integral of the mass flux is evaluated during each computational cycle for each surface to determine the total mass of the liquid on each heat structure boundary surface. Its value is constrained so that no more steam is condensed than is present in its boundary volume and no more liquid is evaporated or flashed than is present on the surface.

If more than a user-specified fraction (sensitivity coefficient $4203(2)$, with a default value of $90 \%$ ) of the steam in a control volume is condensed during a computational cycle, then remedial action is taken. If the current time-step size is greater than a user-specified value (sensitivity coefficient $4203(1)$, with a default value of $-1 . s$ ), then the HS package requests that the computational cycle be repeated with a smaller time-step size to eliminate the excessive condensation. The requested time-step size is equal to the current value times the ratio of the maximum amount of steam that may condense divided by the actual, excessive amount that would have condensed without the requested fallback. If the current time-step size is less than the value prescribed by sensitivity coefficient 4203(1), then the condensation flux (mass transfer rate) on each surface associated with this boundary volume is reduced by the same factor that would have been applied to the time-step size with the fallback option. The HS (not the entire MELCOR cycle) calculation is then repeated with the modified mass transfer rates. The fallback option is the default and recommended option because it does not alter the mechanistically calculated condensation rates. The scaling option may falsify the solution and should be avoided, if possible. Excessive condensation is a result of violating a timestep size constraint imposed by the explicit coupling between the HS and CVH packages (and is akin to the material Courant time-step limit). In some situations, it may be possible to avoid excessive condensation by re-nodalizing the problem to reduce the ratio of the surface area for condensation to the volume of steam available for condensation.

The liquid mass which is transferred to a heat structure surface by other packages is obtained from an array in the HS package data base whose elements are updated using an interface routine that can be called by any package.

For each heat structure surface, the mass and energy transfer is calculated for the steam which was condensed from or added to its boundary volume atmosphere and the liquid deposited in the boundary volume pool. The results of these calculations are used to update the mass and energy communication arrays for the $\mathrm{CVH}$ package. If the heat structure surface is part of a film tracking network, then the film thickness will be determined dynamically as a function of the film flow rate and the drainage from the 
surface will be partitioned between the boundary volume pool, the boundary volume fog and the surfaces of other heat structures in the user-specified network. The film tracking model is discussed in Section 2.8.2.

\subsection{Liquid Film Modeling}

The mass, thickness, and specific enthalpy of a liquid film on a heat structure boundary surface are first determined during the initialization procedure in MELGEN execution. Calculation of these properties is also carried out during MELCOR execution. The models that are used to determine liquid film properties are described in Section 2.8.1. Section 2.8.2 describes the film tracking model, which is based on the model in CONTAIN [14] and is user-activated to track film drainage over a user-specified network of connected structure surfaces.

\subsubsection{Film Models}

During MELGEN and MELCOR execution; the mass of a liquid film on a heat structure boundary surface is determined from (1) calculation of the mass which is transferred between this surface and its boundary volume by condensation, evaporation or draining, (2) the liquid mass which is transferred to this surface by other packages and (3) the liquid mass which is transferred to this surface by external sources (tabular function or control function) or film drainage from other heat structure surfaces, if the surface is part of a user-defined film tracking network. These mass transfers are discussed in Section 2.7.3. The mass of the liquid film and the film surface and structure surface temperatures enable its thickness and specific enthalpy to be determined. The film equations are nodalized so that half of the film mass is associated with the film/structure interfacial node and the other half is associated with the atmosphere/film interfacial node. Therefore, the average specific enthalpy of the film is given by $0.5 \times\left[h_{f}\left(T_{s, s f}\right)+h_{f}\left(T_{f, s t}\right)\right]$, where $h_{f}(T)$ is the specific enthalpy of the film at temperature $T, T_{s, s r}$ is the film/structure interfacial temperature and $T_{\mathrm{f}, \mathrm{sr}}$ is the atmosphere/film interfacial temperature.

For structures which are not part of a film tracking network, the condensate and deposited liquid is permitted to accumulate on a surface until the film thickness reaches a maximum. If the liquid mass is sufficiently large that the film thickness exceeds this maximum, then the excess liquid is deposited in the pool of the boundary volume of the surface. The maximum thickness of a liquid film on a surface is determined in one of two ways: (1) for geometries for which the convective heat transfer coefficient through the film (see Section 2.6.1.1) is obtained from a correlation as a function of the Reynolds number of the film flow, the Reynolds number is also used to obtain the film thickness from the correlations used by the film tracking model (see Section 2.8.2 below) or (2) for all other geometries the maximum film thickness is obtained from a user-adjustable value. The user- 
HS Package Reference Manual

adjustable value, $\delta_{\max }$, has been implemented as sensitivity coefficient $4251(2)$ with a default value of $5 \times 10^{-4} \mathrm{~m}$.

\subsubsection{Film Tracking Model}

For structures which are part of a film tracking network, the film thickness on a surface is determined iteratively as a function of the Reynolds number of the film flow rate as follows. First, the Reynolds number of the film flow is given by

$$
\operatorname{Re}_{\mathrm{f}}=2 \cdot\left(\dot{\mathrm{m}}_{\text {in }}+\dot{\mathrm{m}}_{\text {out }}\right) /\left(w \mu_{\mathrm{f}}\right)
$$

where $\dot{m}_{\text {in }}$ is the mass inflow rate $(\mathrm{kg} / \mathrm{s})$ from film drainage to the surface from other surfaces in the network and water deposited on the surface by other MELCOR packages, $\dot{\mathrm{m}}_{\text {out }}$ is the mass outflow rate $(\mathrm{kg} / \mathrm{s})$ from film drainage from this surface (which is to be determined iteratively), $w$ is the width of this surface and $\mu_{f}$ is the bulk viscosity of the film. As an initial guess $\dot{m}_{\text {out }}$ is set equal to zero. The film thickness as a function of $R e_{f}$ is given by the following correlation

$$
\begin{aligned}
& \delta_{\mathrm{f}}=\mathrm{C}_{\mathrm{f}, \mathrm{l}} \cdot \delta^{*} \cdot R e_{\mathrm{f}}^{\mathrm{e}, \mathrm{f}, \mathrm{f}} \text {, if } R e_{\mathrm{f}}<R e_{\mathrm{LAM}} \\
& =C_{\mathrm{f}, \mathrm{t}} \cdot \delta^{*} \cdot R e_{\mathrm{f}}^{\text {ef,t }} \text {, if } R e_{\mathrm{f}}>R e_{\text {TURB }} \\
& =\text { determined by interpolation between limits at } R e_{\text {LAM }} \text { and } R e_{\text {TURB }} \text {, otherwise } \\
& \delta^{*}=\left[\left(\mu_{f} / \rho_{f}\right)^{2} /(g \cdot \sin \theta)\right]^{1 / 3}
\end{aligned}
$$

where the constants $C_{f, x}$ exponents ef, $x$ and limits $R e_{x}$ (where $x$ represents laminar or turbulent) in Eq. 2.8.2 have been implemented as sensitivity coefficients 4253 , and $p_{f}$ and $\theta$ are the film density and angle of inclination of the surface from horizontal, respectively. The film thickness can also be determined from the conservation of film mass as

$$
\delta_{\mathrm{f}}=\left[\mathrm{m}_{\mathrm{f}, 0}+\left(\dot{\mathrm{m}}_{\text {in }}+\dot{\mathrm{m}}_{\mathrm{c}}-\dot{\mathrm{m}}_{\text {out }}\right) \cdot \Delta \mathrm{t}\right] /\left(\rho_{\mathrm{f}} \mathrm{A}_{\mathrm{srr}}\right)
$$

where $m_{t, 0}$ is the film mass at the start of the time step $\Delta t, \dot{m}_{c}$ is the condensation rate (a negative value indicates evaporation) and $A_{\text {sf }}$ is the surface area. Eq. 2.8.3 has been presented for the case of rectangular geometry; the equations for cylindrical and spherical geometry are different because the film thickness is related to film volume differently.

For given values of $m_{\mathrm{r}, 0}, \dot{\mathrm{m}}_{\mathrm{in}}$, and $\dot{\mathrm{m}}_{\mathrm{c}}$, Eqs. 2.8.2 and 2.8.3 can be solved simultaneously by iterating on the value of $\dot{m}_{\text {out }}$ to determine consistent values of $\delta_{f}$ and $\dot{m}_{\text {out }}$. Note, however, that if the value of $\delta_{\mathrm{f}}$ given by Eq. 2.8.2 with $\dot{\mathrm{m}}_{\text {out }}=0$ exceeds the value of $\delta_{\mathrm{f}}$ given by Eq. 2.8.3 with $\dot{m}_{\text {out }}=0$, then the film thickness cannot possibly achieve the steadystate value consistent with Eq. 2.8.2 during the given time step. When a steady-state 
value consistent with Eq. 2.8.2 is impossible for a time step, $\dot{\mathrm{m}}_{\text {out }}$ is set equal to zero and Eq. 2.8.3 is used to determine $\delta_{\text {. }}$.

A user-specified minimum film thickness, $\delta_{\min }$, has been implemented as sensitivity coefficient 4251(1) to prevent film flow when the film thickness is less than the specified value (default value is $10^{-9} \mathrm{~m}$ ). This can be used to inhibit film flow on rough surfaces until a reasonably thick film is established. Hence, when the solution to Eqs. 2.8.2 and 2.8.3 is less than $\delta_{\min }$, then $\delta_{\mathrm{f}}$ in Eq. 2.8.3 is set equal to $\delta_{\min }$ to determine the value of $\dot{\mathrm{m}}_{\text {out }}$, if a positive value is possible; otherwise, $\delta_{\mathrm{f}}$ is equal to the value obtained from Eq. 2.8.3 with $\dot{m}_{\text {out }}$ set equal to zero.

The outflow (drainage) from the film tracking solution, $\dot{m}_{\text {out }}$, is partitioned between the CVH pool associated with the surface, "rain" passed to the SPR package via the TP package and the other drainage surfaces associated with the given surface through the user-specified film tracking network.

\subsection{Stored Energy of a Heat Structure}

The total stored energy of each heat structure, including surface films, is initialized during MELGEN execution. The stored energy of the structure itself is obtained by integrating the product of the volumetric heat capacity weight and the absolute temperature over the volume of the heat structure. The energy of the fiims is added to that total to arrive at a total structure energy storage. Therefore, the initial stored energy is

$$
E^{\circ}=\underset{i=1}{f} \sum^{N} G_{i}^{m} T_{i}^{\circ}+m_{f i l m, L}^{\circ} h_{f i l m, L}^{\circ}+m_{f i l m, R}^{\circ} h_{f i l m, R}^{\circ}
$$

where

$$
\begin{aligned}
& \mathrm{E}^{\mathrm{o}} \quad=\text { initial stored energy of heat structure, } \mathrm{J} \\
& \mathrm{f}=\text { geometry factor } \\
& =\text { surface area of heat structure for rectangular geometries, } \mathrm{m}^{2} \\
& =\text { axial length of heat structure for cylindrical geometries, } \mathrm{m} \\
& =1.0 \text { for spherical and hemispherical geometries } \\
& \mathrm{G}_{\mathrm{i}}^{0} \quad=\text { volumetric heat capacity weight } \\
& =\mathrm{C}_{\mathrm{pi}}^{\circ} H \mathrm{HVR}_{\mathrm{i}} \quad \text { for } \mathrm{i}=1 \\
& =C_{p i-1}^{o} H V L_{i}+C_{p i}^{o} H V R_{i} \quad \text { for } i=2, \ldots, N-1 \\
& =\mathrm{C}_{\mathrm{p} i-1}^{o} H V L_{i} \quad \text { for } \mathrm{i}=\mathrm{N}
\end{aligned}
$$


HS Package Reference Manual

$\mathrm{C}_{\mathrm{pi}}^{\circ} \quad=$ initial volumetric heat capacity of mesh interval $\mathrm{i}, \mathrm{J} / \mathrm{m}^{3} \cdot \mathrm{K}$

$H V L_{i}=$ left (inside) volume weight for mesh interval $i$, defined in Sections 2.1.1 and 2.2.1

$\mathrm{HVR}_{\mathrm{i}}=$ right (outside) volume weight for mesh interval $\mathrm{i}$, defined in Sections 2.1.1 and 2.2.1

$\mathrm{T}_{\mathrm{i}}^{\circ} \quad=$ initial temperature of node $\mathrm{i},{ }^{\circ} \mathrm{C}$

$\mathrm{T}_{\mathrm{i}-1}^{\mathrm{o}} \quad=$ initial temperature of node $\mathrm{i}-1,{ }^{\circ} \mathrm{C}$

$m_{\text {film, }}^{\circ}=$ initial mass of film on left boundary surface, $\mathrm{kg}$

$h_{\text {film, } L}^{o}=$ initial specific enthalpy of film on left boundary surface, $\mathrm{J} / \mathrm{kg}$

$m_{\text {film, } \mathrm{R}}^{o}=$ initial mass of film on right boundary surface, $\mathrm{kg}$

$h_{\mathrm{film}, \mathrm{R}}^{\circ}=$ initial specific enthalpy of film on right boundary surface, $\mathrm{J} / \mathrm{kg}$

During MELCOR execution, the change in the stored energy of each heat structure is calculated every cycle. This is obtained by integrating the product of the volumetric heat capacity weight and the change in temperature between times $t_{m-1}$ and $t_{m}$ over the volume of the heat structure, and including the energy change of the surface films. Therefore,

$$
\begin{aligned}
& \Delta E^{m}=f \quad \sum_{i=1}^{N} G_{i}^{m}\left(T_{i}^{m}-T_{i}^{m-1}\right)+m_{f i l m, L}^{m} h_{f i l m, L}^{m}-m_{f i l m, L}^{m-1} h_{f i l m, L}^{m-1} \\
& +m_{f i l m, R}^{m} h_{f i l m, R}^{m}-m_{f i l m, R}^{m-1} h_{f i l m, R}^{m-1}
\end{aligned}
$$

where

$$
\begin{aligned}
\Delta E^{m}= & \text { change in stored energy of heat structure between times } t_{m-1} \text { and } t_{m}, \\
G_{i}^{m} & =\text { volumetric heat capacity weight } \\
= & C_{p i}^{m} H V R_{i} \quad \text { for } i=1 \\
= & C_{p i-1}^{m} H V L_{i}+C_{p i}^{m} H V R_{i} \quad \text { for } i=2, \ldots, N-1 \\
= & C_{p i-1}^{m} H V L_{i} \quad \text { for } i=N \\
C_{p i}^{m} \quad= & \text { volumetric heat capacity of mesh interval } i \text { at time } t_{m}, J / m^{3} \cdot K \\
T_{i}^{m} & =\text { temperature of node } i \text { at time } t_{m},{ }^{\circ} \mathrm{C} \\
T_{i}^{m-1} & =\text { temperature of node } i \text { at time } t_{m-1},{ }^{\circ} \mathrm{C}
\end{aligned}
$$


HS Package Reference Manual

$m_{\text {film, }, L}=$ mass of film on left boundary surface, $\mathrm{kg}$

$h_{\text {film,L }}=$ specific enthalpy of film on left boundary surface, $\mathrm{kg}$

$m_{\text {film, } R}=$ mass of film on right boundary surface, $\mathrm{kg}$

$h_{\text {film,R }}=$ specific enthàlpy of film on right boundary surface, $\mathrm{kg}$

superscript $m$ denotes quantity at time $t_{m}$

superscript $m+1$ denotes quantity at time $t_{m}+\Delta t_{m}$

\subsection{Degassing Model}

The HS package degassing model assumes that the gas release occurs uniformly over the degassing temperature range. The contribution to the degassing rate for each mesh interval whose temperature exceeds the previously attained maximum is the product of the source density, volume of the mesh interval, and the fraction of the degassing temperature range that the present maximum represents. Therefore,

$$
g_{k}^{m}=\Sigma f \rho_{\text {gas }}(H V L+H V R) \frac{\left(T_{2}-T_{1}\right)}{\left(T_{D G \max }-T_{D G \min }\right)} / \Delta t_{m}
$$

where

$$
\begin{array}{ll}
g_{k}^{m} & =\text { degassing rate for } \mathrm{k} \text {-th source at time } t_{m}, \mathrm{~kg} / \mathrm{s} \\
\Sigma & =\text { sum over all heat structure nodes containing gas sources } \\
f & =\text { geometry factor } \\
& =\text { surface area of heat structure for rectangular geometries, } \mathrm{m}^{2} \\
& =\text { axial length of heat structure for cylindrical geometries, } \mathrm{m} \\
& =1.0 \text { for spherical or hemispherical geometries } \\
\rho_{\text {gas }} & =\text { source density, } \mathrm{kg} / \mathrm{m}^{3} \\
H V L & =\text { volume weight for left surface (Tables } 2.1 \text { and } 2.2) \\
H V R & =\text { volume weight for right surface (Tables } 2.1 \text { and } 2.2) \\
T_{2} & =\min \left(T_{n \max }^{m}, T_{D G \max }\right),{ }^{\circ} \mathrm{C} \\
T_{1} & =\min \left(T_{n \max }^{\mathrm{m}-1}, T_{D G \max }\right),{ }^{\circ} \mathrm{C} \\
T_{n \max }^{m} & =\operatorname{maximum} \text { temperature in mesh interval } \mathrm{n} \text { at time } t_{m},{ }^{\circ} \mathrm{C} \\
T_{n \max }^{m-1} & =\operatorname{maximum} \text { temperature in mesh interval } \mathrm{n} \text { at time } t_{m-1},{ }^{\circ} \mathrm{C}
\end{array}
$$


HS Package Reference Manual

$$
\begin{aligned}
& T_{D G \max }=\text { upper temperature in degassing temperature range, }{ }^{\circ} \mathrm{C} \\
& T_{D G \min }=\text { lower temperature in degassing temperature range, }{ }^{\circ} \mathrm{C} \\
& \Delta t_{m}=\text { system time-step size }\left(t_{m}-t_{m-1}\right), s
\end{aligned}
$$

The HS package calculates the mass and internal energy of the gas (at the boundary volume temperature) which is released by each source through the present computational cycle. These data are then used to update the mass and energy transfer communication arrays for the $\mathrm{CVH}$ package.

\subsection{Ice Condenser Model}

The ice condenser model allows the description of certain features found in Westinghouse PWR ice condenser containments. This model is a specially modified application of the heat structure degassing model described in section 2.10. The user activates the ice condenser logic by including a prescribed keyword in the input for multiple solid, vertical cylindrical structures. A special gas source is defined to release liquid water into the pool of the outer associated $\mathrm{CVH}$ volume. The degassing temperature range should have a lower temperature of $274 \mathrm{~K}$ to avoid problems associated with limits of the thermodynamic and material properties routines. The upper temperature of the degassing range should be the saturation temperature to account for the sensible heating of the melt water. The heat of reaction of the gas source should include sensible heating of the ice from its actual subcooled temperature to the melting point, the latent heat of fusion, and the sensible heat addition to the melt water from melt to the upper value of the specified degassing temperature range. A special ice condenser Nusselt number multiplier has been added to the gas source input to account for effects not explicitly modeled that may affect the rate of heat transfer to the ice cylinder. Similarly, an ice condenser RN deposition surface area enhancement factor has been added to account for unmodeled effects that will enhance the rate of radionuclide deposition on the ice condenser. Finally, a parameter has been added that can be adjusted by user input to vary the rate of decrease of the ice surface area as the ice melts. The ice surface area will vary as

$$
\left(V / V_{0}\right)^{\text {EXPICE }}
$$

where

$$
\begin{array}{ll}
V & =\text { current ice volume } \\
V_{0} & =\text { initial ice volume } \\
\text { EXPICE } & =\text { user specified parameter }
\end{array}
$$

The total surface area for heat transfer to the ice condenser (ice and baskets) is the initial surface area of the cylindrical ice columns, $A_{0}$, multiplied by the factor 
HS Package Reference Manual

$$
\left[R N D I C E+(1-R N D I C E) \times\left(V / V_{0}\right)^{\text {EXPICE }}\right]
$$

to provide a smooth transition to the minimum surface area of the ice baskets, RNDICE $x A_{o}$, where RNDICE is user defined. The total surface area for RN deposition is equal to the ice surface area plus the surface area of the ice baskets. The "gas" source density is that of liquid water.

MELCOR will automatically account for the volume change associated with the reduction in ice mass as melting proceeds. The user should define tabular input to specify properties for the metal baskets that hold the granular ice. The appropriate density is the value of the metal mass divided by the total volume occupied by the baskets. The thermal conductivity should exceed the value associated with ice to account for steam penetration into the granular matrix and conduction in the metal. The specified heat capacity is that of the metal.

\subsection{Steel Melt Model}

To allow for BWR core shroud heating and subsequent melting, an option has been included in the degassing model to allow the user to input stainless steel as a degassing source. This option has been included only for use when the BH Package is being utilized and is ignored otherwise. The implementation of the stainless steel degassing source is very similar to that used for ice as part of the ice condenser model (described above) except the heat of reaction of the stainless steel gas source should only include the latent heat of fusion. Because stainless steel is not a hydrodynamic material included in the CVH Package, the volume of the melting stainless steel is associated with the COR Package materials. As such, these materials are represented by the CVH Package as "virtual volume" and, as with the ice condenser model, the volume changes due to melting are explicitly represented.

To prevent potential problems of adding a large amount of heat to a stainless steel degassing structure with an insignificant residual mass, a sensitivity coefficient, 4205 , has been provided as a lower limit such that if the remaining unmelted structure mass falls below this limit, then the structure is assumed to have completely melted.

\subsection{Communication with Other Packages}

After completing the calculations discussed in Sections 2.1 through 2.11, the HS package communicates various changes to other packages using well-defined communication interfaces. The HS package communicates to the CVH package any mass, energy, and virtual volume changes in each control volume due to the following mechanisms: 
HS Package Reference Manual

(1) heat transfer between each heat structure and the pool and atmosphere of its boundary volumes

(2) condensation of steam onto each heat structure from the atmosphere of its boundary volumes

(3) evaporation or flashing of liquid from each heat structure boundary surface into the atmosphere of its boundary volumes

(4) deposition of liquid from each heat structure into the pool of its boundary volumes

(5) degassing of materials within each heat structure

The virtual volume with which the HS package is concerned is the volume occupied by all liquid films, ice condenser ice and meltable (degassible) steel associated with the BWR core shroud melting model. Initial values of virtual volume are calculated during MELGEN execution and changes in virtual volume are calculated each computational cycle during MELCOR execution.

Prior to communication of control volume mass and energy changes to the CVH package, the HS package determines if these changes will lead to a negative mass of some material. If a negative mass is detected, the HS package requests that the present computational cycle be repeated with a time-step reduction and the changes are not communicated to the $\mathrm{CVH}$ package.

During MELCOR execution, the HS package calculates and communicates to the Radionuclide (RN) package the fraction of liquid mass on each heat structure boundary surface deposited during each computational cycle in the pool of its boundary volume. These fractions are used to calculate the relocation of radionuclides from deposition surfaces to the pools of their boundary volumes. 
HS Package Reference Manual

\section{SOLUTION METHODS}

The finite-difference approximation to the heat conduction equation with boundary conditions utilized by the HS package results in a tridiagonal system of $\mathrm{N}$ equations $(\mathrm{N}+1$ or $\mathrm{N}+2$ if there is a liquid film on one or both surfaces) for a heat structure with $\mathrm{N}(\mathrm{N}+1$ or $\mathrm{N}+2$ ) temperature nodes. In order to reduce roundoff problems, the temperature of the heat structure relative to the minimum value of that heat structure is used to set up and solve the equations. The solution procedure is usually more complex than the standard solution for a tridiagonal system of equations. The boundary conditions often include energy input due to mass transfer and may include the deposition of energy from other sources such as decay-heat of radionuclides. Furthermore, the temperature nodes near the surface of a heat structure may be too closely spaced to accurately calculate the temperature at the surface, or the computational time step may be large. This section discusses some of the special solution procedures that are used to obtain the steadystate and transient temperature distribution of a heat structure.

\subsection{Iteration Strategy}

By default an iterative procedure is employed to determine the temperature profile in each heat structure. This procedure repeats the following calculations until either convergence is attained or a maximum number of iterations is performed:

(1) thermal properties

(2) heat transfer coefficients

(3) mass transfer

(4) boundary condition coefficients

(5) temperature distribution

Convergence is determined by testing the relative error in several dependent variables calculated during the temperature iteration: (1) the temperature at each node in the structure (including the film interfacial temperature(s)), (2) the mass of the film(s) (if the film thickness exceeds $10^{-5} \mathrm{~m}$ ), and (3) the boiling heat transfer coefficient(s).

The relative error for dependent variable $X$ is defined as

$$
E R R_{X}=X^{m} / X^{m-1}-1
$$

where

$$
\begin{array}{ll}
X^{m-1}= & \text { value of } X \text { at iteration } m-1 \\
X^{m}= & \text { value of } X \text { at iteration } m
\end{array}
$$




\section{HS Package Reference Manual}

If the relative error in the temperature profile falls below a threshold value $\left(E R R_{\text {prp }}\right.$ in Section 3.3 below) during an iteration, then material properties are generally not recalculated for that iteration step. Values from the previous iteration step are used until the relative error again becomes higher than $E R R_{p r p}$ or until convergence is achieved. However, during degassing, properties must be updated after every iteration to ensure sufficient accuracy of the degassing rate.

Relaxation of the pool boiling heat transfer coefficient may be required in some situations, since it is extremely sensitive to changes in the surface temperature. Because relaxation effectively falsifies the value of the heat transfer coefficient until the relaxed value stabilizes, it is necessary to check the relative difference (error) between the unrelaxed value (which is determined by the latest surface temperature iterate) and the relaxed value. When pool boiling occurs, the pool heat transfer coefficient $h_{\text {pool }}^{m}$ is relaxed between temperature iterations as follows:

$$
W_{B} h_{\text {pool }}^{m-1}+\left(1-W_{B}\right) h_{p o o l}^{m}
$$

where

$$
\begin{aligned}
& h_{\text {pool }}^{m-1}=\text { pool heat transfer coefficient at iteration } m-1, W / m^{2} \cdot K \\
& h_{\text {pool }}^{m}=\text { pool heat transfer coefficient at iteration } m, W / m^{2} \cdot K
\end{aligned}
$$

and $W_{B}$ is the modified relaxation parameter, which is set to an initial value that depends on whether it is a steady-state or transient iteration ( $\mathrm{RLX}_{\mathrm{B}}$ in Sections 3.2 and 3.3 below), and which is then decreased by a factor of 0.95 for each iteration during which the relative error in the boiling surface temperature is greater than -0.5 (i.e., the boiling surface temperature is not oscillating excessively so that relaxation may be reduced).

The system of equations describing the transient temperatures within a structure can become ill-conditioned if the time step becomes too large. A precision limit $\left(P_{\text {illmat }}\right.$ in Section 3.3) is imposed in the routine that performs the direct inversion of the tridiagonal coefficient matrix. If the relative difference between terms used in evaluating a nonzero difference in the algorithm is less than this limit, then there are too few significant figures in the difference to achieve the requested degree of precision. During MELGEN execution this condition is fatal but may be corrected by reducing the value of $\Delta \mathrm{t}_{\mathrm{o}}$, discussed in Section 3.2 below. During MELCOR execution the cycle will be repeated with a smaller time step in an attempt to alleviate the problem.

There are three levels of convergence criteria used: the desired convergence criteria, a more stringent override convergence criterion and the less stringent acceptance convergence criteria. The desired and acceptance criteria may be assigned different 
values for MELGEN and MELCOR execution, as discussed in Sections 3.2 and 3.3, respectively.

The desired convergence criteria are normally stringent enough to ensure reasonable accuracy in overall results in the absence of phenomena that demand very high temperature resolution. During the occurrence of phenomena such as degassing or mass transfer (condensation/evaporation), however, very small errors in temperature can cause quite large errors in degassing and mass transfer rates. Therefore, during the occurrence of degassing or mass transfer the desired temperature convergence criteria are overridden by the override temperature convergence criterion (as long as it is more stringent). The override temperature convergence criterion is contained in sensitivity coefficient array 4055 discussed in Section 3.3 below.

The iteration procedure for a heat structure will continue until either the desired criteria (or the override criterion during degassing or mass transfer) have been met or the iteration count reaches a prescribed maximum. During override, convergence is declared after the maximum number of iterations if the desired criteria have been met, even though the more stringent criterion has not been satisfied. If the acceptance criteria have not been satisfied for all tested variables on a heat structure after the maximum number of permitted iterations is performed, then failure is declared for that heat structure. If the acceptance criteria have been met but the desired criteria have not been met, then success is declared but a message is issued to warn the user that the desired criteria were not met.

\subsection{Steady-state Convergence Criteria}

During MELGEN execution, an initial temperature distribution is calculated for a given heat structure if specified by user input. The following constants are the iteration parameters used for steady-state heat conduction calculations. They are implemented as sensitivity coefficient array C4051.

$$
\begin{aligned}
\mathrm{ITR}_{\mathrm{ss}}= & \begin{array}{l}
\text { maximum number of permitted steady-state iterations } \\
\text { (default }=400)
\end{array} \\
\mathrm{ERR}_{\mathrm{ss}}=\begin{array}{l}
\text { desired relative error tolerance for temperatures during steady-state } \\
\text { calculations (default }=10^{-5} \text { ) }
\end{array} & \\
\Delta \mathrm{t}_{\mathrm{o}} \quad= & \text { initial steady-state time step (default } \left.=10^{5} \mathrm{~s}\right) \\
\mathrm{ERF}_{\mathrm{ss}}= & \begin{array}{l}
\text { desired relative error tolerance for film mass for steady-state } \\
\text { calculations (default }=10^{-2} \text { ) }
\end{array} \\
\mathrm{DIE}_{\mathrm{ss}}= & \begin{array}{l}
\text { acceptable relative error tolerance for temperature during steady- } \\
\text { state calculations (default }=10^{-2} \text { ) }
\end{array}
\end{aligned}
$$


HS Package Reference Manual

There is no acceptance criterion for film mass; the iteration procedure will continue for $I T R_{s s}$ iterations in an attempt to satisfy the desired criterion, ERF iterations the film mass value is declared acceptable no matter what. The following coefficients are the iteration relaxation parameters used for steady-state heat conduction calculations to mitigate temperature oscillations. They are implemented as sensitivity coefficient array C4052.

$$
\begin{aligned}
\mathrm{RLX}_{\mathrm{B}}= & \text { steady-state boiling heat transfer coefficient relaxation parameter } \\
& \text { (default }=0.0 \text { ) } \\
\mathrm{ERR}_{\mathrm{B}}= & \text { desired steady-state boiling heat transfer coefficient error tolerance } \\
& (\text { default }=0.05 \text { ) }
\end{aligned}
$$

The boiling heat transfer coefficient relative error acceptance criterion is $100 \%$, that is it may double or vanish.

If any heat structure fails to meet the acceptance criteria, then a restart file is not written and MELCOR execution may not begin.

\subsection{Transient Convergence Criteria}

During MELCOR execution, an iterative procedure is invoked if specified by user input (and highly recommended). The following constants are the iteration parameters used for transient heat conduction calculations. They are implemented as sensitivity coefficient array $\mathrm{C} 4055$.

$$
\begin{aligned}
& \mathrm{ITR}_{\mathrm{tm}}=\text { maximum number of transient iterations (default }=30 \text {.) } \\
& \mathrm{ERR}_{\mathrm{tm}}=\text { desired relative error tolerance for temperature during transient } \\
& \text { conduction calculations (default }=0.0005 \text { ) } \\
& I T R_{\text {cut }}=\text { minimum number of transient iterations required to prevent increase } \\
& \text { of the time-step size (default }=31 \text {.) } \\
& \mathrm{ERR}_{\mathrm{prp}}=\text { minimum relative error tolerance for material property determination } \\
& \text { (default }=0.01 \text { ) } \\
& \mathrm{P}_{\text {illmat }}=\text { tri-diagonal matrix solver precision requirement } \\
& \text { (default }=1.0 \times 10^{-10} \text { ) } \\
& \mathrm{ERR}_{\text {ovr }}=\text { error tolerance override during degassing/mass transfer } \\
& \text { (default }=5.0 \times 10^{-6} \text { ) } \\
& \mathrm{ERF}_{\mathrm{tm}}=\text { maximum relative error tolerance for film mass during transient } \\
& \text { conduction calculations (default }=0.01 \text { ) } \\
& \mathrm{DIE}_{\mathrm{tm}}=\text { maximum relative error tolerance for transient temperature during } \\
& \text { conduction calculations (default }=.005 \text { ) }
\end{aligned}
$$

There is no acceptance criterion for film mass; the iteration procedure will continue for $I T R_{t m}$ in an attempt to satisfy the desired criterion, $E R F_{t m}$, but after ITR ${ }_{t m}$ iterations the film 
HS Package Reference Manual

mass value is declared acceptable no matter what. The boiling heat transfer coefficient relative error acceptance criterion is $100 \%$, that is it may double or vanish.

Although inactive by default, the value of ITR cut can be adjusted downward (below ITR to prevent the MELCOR system time step from increasing if the HS package is taking too many iterations per time step. Judicious use of this feature requires comparing total CPU usage for various strategies.

The following constants are the relaxation parameters used for transient calculations. These parameters are implemented as sensitivity coefficient array C4056:

$$
\begin{aligned}
\mathrm{RLX}_{\mathrm{B}}= & \text { transient boiling heat transfer coefficient relaxation parameters } \\
& \text { (default }=0.9) \\
\mathrm{ERR}_{\mathrm{T}}= & \text { transient boiling heat transfer coefficient error tolerance } \\
& \text { (default }=0.05 \text { ) }
\end{aligned}
$$

If the temperature solution fails for any structure during a calculational cycle, the HS package will immediately request that the cycle be repeated with the time step reduced by a factor of one half. Failure may occur for several reasons, including excessive error in the temperatures, excessive error in the boiling heat transfer coefficient, numerical problems associated with finite precision or the generation of an out-of-range temperature (less than $273 \mathrm{~K}$ or greater than $4990 \mathrm{~K}$ ), either legitimately or from divergence of the iterative algorithm.

\subsection{CVH Heat Transfer Damping}

In addition to temperature and boiling heat transfer coefficient relaxation, a modification may be made to calculated heat transfer coefficients for the pool or atmosphere in the $\mathrm{CVH}$ control volumes associated with heat structure boundary surfaces. This modification (a reduction of the true heat transfer coefficient) is not intended to promote convergence of the heat structure temperature calculation, but rather to mitigate oscillations in the CVH atmosphere temperature caused by the numerically explicit coupling between the $\mathrm{CVH}$ and HS packages.

The calculated heat transfer coefficients are multiplied by the factor

$$
M=\left[1+\operatorname{MAX}\left\{0, C 4070(1) \cdot \Delta t_{n} / \tau-C 4070(2)\right\}\right]^{-1}
$$

where

$$
\tau=\left(m C_{p}\right)_{c v} /\left(\Sigma_{k=1}^{N} h_{k} A_{k}\right)
$$


HS Package Reference Manual

and

$\begin{array}{lll}\Delta t_{n} & = & \text { time step } \\ \left(\mathrm{mC}_{\mathrm{p}}\right)_{\mathrm{cv}} & = & \text { thermal inertia of the associated pool or atmosphere } \\ \mathrm{h}_{\mathrm{k}} & = & \begin{array}{l}\text { uncorrected heat transfer coefficient from surface } \mathrm{k} \text { to the pool or } \\ \text { atmosphere }\end{array} \\ \mathrm{A}_{\mathrm{k}} & =\quad \text { area of surface } \mathrm{k} \text { which bounds the pool or atmosphere } \\ \mathrm{C} 4070(1) & =\quad \text { sensitivity coefficient multiplier (default }=1.0) \\ \mathrm{C} 4070(2) & = & \text { minimum value of corrective factor (default }=0.2)\end{array}$

\section{CAUTION !!}

Inappropriate application of these sensitivity coefficients will falsify the true heat transfer rates.

In some cases, the heat transfer coefficients may be significantly reduced below their true values, resulting in a corresponding increase in the temperature difference. For example, a steam generator in nucleate boiling with heat transfer coefficients on the order of $10^{4}$ $\mathrm{W} / \mathrm{m}^{2}-\mathrm{K}$ and temperature differences on the order of $10^{-1} \mathrm{~K}$, which might demand a timestep size no greater than $0.1 \mathrm{~s}$ for numerical stability, could be treated with heat transfer coefficients on the order of $10^{3} \mathrm{~W} / \mathrm{m}^{2}-\mathrm{K}$ and temperature differences on the order of $1 \mathrm{~K}$ with a stable time step of $1 \mathrm{~s}$. Presumably falsifying the actual temperatures by $1 \mathrm{~K}$ does not lead to serious errors in the overall response of the reactor system.

Care must be taken in using heat transfer damping to achieve numerical stability. In closed systems in which the temperature differences decrease as heat transfer proceeds (i.e., an equilibrium is being achieved between a single heat structure and a control volume), the damping factors will adequately simulate the response of the heat structure and the pool or atmosphere. However, for situations in which heat is continuously transferred from hot surfaces to cold surfaces via mutual CVH boundary volumes, the application of damping factors may lead to serious underpredictions of heat transfer rates, resulting in overpredictions of temperature differences. In such situations, damping is inappropriate unless the resulting errors do not seriously affect the overall solution. Currently, the only alternatives to damping are reduced time-step size or, possibly, renodalization to increase the thermal inertia associated with the CVH boundary volumes. A time step control algorithm has been implemented to prevent serious heat transfer damping errors, as described in Section 4. 
Energy transfer from other packages (see Section 2.3.3) are also a potential source of numerical problems. There is little that can be done within the Heat Structures Package to remedy these problems, but the packages from which the energy transfers originate often contain user input or sensitivity coefficients which can be adjusted to reduce or eliminate the numerical problems. For example, the high-pressure-melt-ejection (HPME) model in the Fuel Dispersal Interactions (FDI) Package can be directed to deposit large amounts of hot core debris on heat structure surfaces following reactor vessel failure. The resulting heat transfer (conduction) from the hot debris to the heat structure can become sufficiently large to induce oscillations in the structure temperatures because of the explicit coupling of the HS and FDI packages. However, the FDI package contains a sensitivity coefficient (4608), which effectively limits the rate of heat transfer between the debris and structure. Temperature oscillations caused by heat transfer from debris deposits can always be eliminated by sufficiently reducing the value of this sensitivity coefficient. 
HS Package Reference Manual 
HS Package Reference Manual

\section{TIME-STEP CONTROL}

Time-step control is exercised by the Heat Structure package if:

(a) condensation is causing excessive steam depletion in the CVH package as discussed in Section 2.7.4 or,

(b) the temperature solution for a heat structure fails to converge within the prescribed maximum number of iterations as discussed in Section 3.3. (a timestep reduction request to one-half the current time-step will also be made if a physically unreasonable value is detected during the iterative solution algorithm) or,

(c) the heat transfer damping factors calculated by Eq. 3.4.1 to prevent numerical oscillations in the CVH temperature become too small.

In cases (a) and (b) the HS package will request that the current time step be repeated with a smaller time-step size to correct the problem.

In case (c) a request will be made to limit the next time step taken to a value that will avoid CVH temperature oscillations without the necessity of overdamping the heat transfer rates (as described in Section 3.4). To avoid limiting the time step because of high heat transfer rates caused by huge heat transfer coefficients but relatively modest temperature differences (e.g., nucleate boiling in a steam generator), the user may specify a critical temperature difference for both pool and atmosphere heat transfer on each heat structure surface. Whenever the actual temperature difference between the surface and the pool or atmosphere is less than the critical temperature difference, heat transfer from that surface will be excluded from the calculation that is performed to determine how much the time step must be cut to avoid CVH temperature oscillations.

Therefore, the time-step size is limited by the minimum value of $\tau_{i}$ over all volumes $i$ to a value given by

$$
\Delta \mathrm{t}_{\text {req }}=\operatorname{MAX}\left\{\mathrm{C} 4070(3), \mathrm{C} 4070(2) \cdot \mathrm{MIN}_{\mathrm{i}} \tau_{\mathrm{i}} / \mathrm{C} 4070(1)\right\}
$$

where

$$
\tau_{i}=\left(m C_{p}\right)_{c v, i} /\left(\sum_{k=1}^{N} h_{k} A_{k} f_{k}\right)
$$

with the symbols defined as in Eq. 3.4.1 and where

$$
f_{k}=\operatorname{MIN}\left(1, \operatorname{MAX}\left(0, \Delta T_{k} / \Delta T_{\text {crit,k }}-1\right)\right)
$$


HS Package Reference Manual
$\Delta T_{k} \quad=\quad$ temperature difference between surface $k$ and the pool or atmosphere
$\Delta T_{\text {crit, } k}=$ critical temperature difference for pool or atmosphere heat transfer specified by user input for surface $k$ (input variables CTDPL and CTDAL for the pool and atmosphere on the left hand side of structures described by record HSCCCCC 400 and CTDPR and CTDAR for the pool and atmosphere on the right hand side of structures described by record HSCCCCC600 with default values of $100 \mathrm{~K}$ )

C4070(1) = sensitivity coefficient multiplier (default $=1.0$ )

$\mathrm{C} 4070(2)=$ minimum value of corrective factor $($ default $=0.2$ )

The user can dictate the minimum time-step size that will be requested; when the time step falls below this size, no further time-step cuts will be requested and the damping coefficients described above in Section 3.4 will decrease to whatever values are necessary to prevent $\mathrm{CVH}$ temperature oscillations.
C4070(3) = time-step size threshold below which the time step will not be reduced in order to limit damping (i.e., when the time step falls below this value $M$ may become very small to prevent temperature oscillations that would further reduce the time step as a result of the oscillations) (default $=0$. s, i.e., no limit)

If the HS package requests repeating a cycle with a reduced time-step during MELCOR execution, a message indicating the cause is printed. MELCOR execution ceases after a time-step reduction only if the new time step is less than the minimum for the problem. In such a situation, a restart file is written and an edit of all current data is performed. 
HS Package Reference Manual

\section{REFERENCES}

1. J. P. Holman, Heat Transfer, Fifth Edition, McGraw-Hill, Inc., New York, 1981, p. 288.

2. J. P. Holman, op. cit., p. 289.

3. J. P. Holman, op. cit., p. 275.

4. J. P. Holman, op. cit., p. 286.

5. J. P. Holman, op. cit., p. 233.

6. J. P. Holman, op. cit., p. 208.

7. C. O. Bennett and J. E. Myers, Momentum, Heat, and Mass Transfer, Third Edition, McGraw-Hill, Inc., New York, 1982, p. 341.

8. C. O. Bennett and J. E. Myers, op. cit., p. 395.

9. C. O. Bennett and J. E. Myers, op. cit., p. 370.

10. C. O. Bennett and J. E. Myers, op. cit., p. 375.

11. V.H. Ransom, et al., RELAP5/MOD1 Code Manual Volume 1: System Models and Numerical Methods, NUREG/CR-1826, EGG-2070, R2, September 1981.

12. D. K. Edwards, On the Use of Total Radiation Properties of Gases, ANL/RAS 75-12, April 1975.

13. D. K. Edwards, and R. Matavosian, "Scaling Rules for Total Absorptivity and Emissivity of Gases," Trans. ASME, JHT, Vol. 106, pp. 684-689, November 1984.

14. K. D. Bergeron, et al., User's Manual for CONTAIN 1.0, A Computer Code for Severe Nuclear Reactor Accident Containment Analysis, NUREG/CR-4085, SAND84-1204, Version 1.06, March 1987.

15. J. G. Collier, Convective Boiling and Condensation, Second Edition, McGraw-Hill, Inc., New York, 1981, p. 126.

16. J. P. Holman, op. cit., p. 426.

17. J. G. Collier, op. cit., p. 132. 
HS Package Reference Manual

18. J. G. Collier, op. cit., p. 324.

19. M. M. El-Wakil, Nuclear Heat Transport, The American Nuclear Society, La Grange Park, Illinois, 1978, p. 318.

20. W. M. Rohsenow and H. Y. Choi, Heat, Mass and Momentum Transfer, Prentice-Hall, Inc., Englewood Cliffs, New Jersey, 1961, p. 229. 
HS Package Reference Manual

\section{APPENDIX A: Sensitivity Coefficients}

This appendix provides the sensitivity coefficients associated with various correlations and modeling parameters used in the HS package and described in this reference manual.

Equation

2.6.33

Section 3.2

Section 3.2

Section 3.3

Section 3.3

2.6.3, 2.6.5

2.6.4, 2.6.5

2.6.9, 2.6.11

2.6.10, 2.6.11
Coefficient

C4000(1)

C4000(2)

C4000(3)

C4000(4)

C4000(5)

$\mathrm{C} 4000(6)$

C4000(7)

C4051(1)

C4051(2)

C4051(3)

C4051(4)

C4051(5)

C4052(1)

C4052(2)

C4055(1)

C4055(2)

C4055(3)

C4055(4)

C4055(5)

C4055(6)

C4055(7)

C4055(8)

C4056(1)

C4056(2)

C4060(1)

C4060(2)

C4061(1)

C4061(2)
Value Units

$0.2358 \quad \mathrm{~N} / \mathrm{m}$

1.0

$-0.625$

1.256

0.

1.0

647.3

$\mathrm{K}^{-1}$

$\mathrm{N} / \mathrm{m}$

K

400.

$10^{-5}$

$10^{5}$

0.01

0.01

0.0

0.05

30.

0.0005

31.

0.01

$10^{-10}$

$5 . \times 10^{-6}$

0.01

0.005

0.9

0.05

1.0

10.0

$10^{9}$

$10^{10}$ 
HS Package Reference Manual

Equation

2.6.9, 2.6.11

2.6.10, 2.6.11

2.6.9, 2.6.11

2.6.10, 2.6.11

2.6.12a, 2.6.14a

2.6.13a, 2.6.14a

2.6.12b, 2.6.14b

2.6.13b, 2.6.14b

2.6.12b, 2.6.14b

2.6.13b, 2.6.14b

3.2.1

2.6.21, 2.6.23

2.6.22, 2.6 .23

2.6.26, 2.6 .28

2.6.27, 2.6 .28

$2.6 .26,2.6 .28$

2.6.27, 2.6 .28

2.6.26, 2.6.28

2.6.27, 2.6.28

2.6.29a, 2.6.31a

2.6.30a, 2.6.31a

2.6.29b, 2.6.31b

2.6.30b, 2.6.31b

2.6.29b, 2.6.31b

2.6.30b, 2.6.31b

2.6.6
Coefficient

C4062(1)

C4062(2)

C4063(1)

C4063(2)

C4064(1)

C4064(2)

C4065(1)

C4065(2)

C4066(1)

C4066(2)

C4070(1)

C4070(2)

C4070(3)

C4080(1)

C4080(2)

C4081(1)

C4081(2)

C4082(1)

C4082(2)

C4083(1)

C4083(2)

C4084(1)

C4084(2)

C4085(1)

C4085(2)

C4086(1)

C4086(2)

C4101(1)

C4101(2)

C4101(3)
Value

Units

$10^{9}$

$10^{10}$

$10^{9}$

$10^{10}$

$3.0 \times 10^{5}$

$6.0 \times 10^{5}$

$2.0 \times 10^{3}$

$10^{4}$

$2.0 \times 10^{3}$

$10^{4}$

1.0

0.2

0.0

s

1.0

10.0

$10^{9}$

$10^{10}$

$10^{9}$

$10^{10}$

$10^{9}$

$10^{10}$

$3.0 \times 10^{5}$

$6.0 \times 10^{5}$

$2.0 \times 10^{3}$

$10^{4}$

$2.0 \times 10^{3}$

$10^{4}$

0.046

$1 / 3$

0 . 
HS Package Reference Manual

Equation

2.6.6

2.6.6

2.6.6

2.6.6

2.6.6

2.6.6

2.6.6

2.6.6

2.6.6

2.6.6

2.6.6
Coefficient

C4102(1)

C4102(2)

C4102(3)

C4103(1)

C4103(2)

C4103(3)

C4104(1)

C4104(2)

C4104(3)

C4105(1)

C4105(2)

C4105(3)

C4106(1)

C4106(2)

C4106(3)

C4107(1)

C4107(2)

C4107(3)

C4108(1)

C4108(2)

C4108(3)

C4109(1)

C4109(2)

C4109(3)

C4110(1)

C4110(2)

C4110(3)

C4111(1)

C4111(2)

C4111(3)

C4112(1)

C4112(2)

C4112(3)
Value Units

0.046

$1 / 3$

0.

0.228

0.226

0 .

0.046

$1 / 3$

0 .

0.046

$1 / 3$

0 .

0.228

0.226

0 .

0.59

0.25

0 .

0.59

0.25

0.

0.43

0.25

2.0

0.10

$1 / 3$

0 .

0.10

$1 / 3$

0 .

0.43

0.25

2.0 
HS Package Reference Manual

Equation

2.6.7

2.6.7

2.6.7

2.6.7

2.6 .7

2.6.7

2.6.7

\subsection{7}

Coefficient

C4113(1)

C4113(2)

C4113(3)

C4113(4)

C4114(1)

C4114(2)

C4114(3)

C4114(4)

C4115(1)

C4115(2)

C4115(3)

C4115(4)

C4116(1)

C4116(2)

C4116(3)

C4116(4)

C4117(1)

C4117(2)

C4117(3)

C4117(4)

C4118(1)

C4118(2)

C4118(3)

C4118(4)

C4119(1)

C4119(2)

C4119(3)

C4119(4)

C4120(1)

C4120(2)

C4120(3)

C4120(4)
Value Units

8.235

0.

0.

0 .

$48 / 11$

0.

0 .

0 .

$48 / 11$

0.

0.

0 .

0.023

0.8

$1 / 3$

0 .

0.023

0.8

$1 / 3$

0 .

0.023

0.8

$1 / 3$

0.

0.664

0.5

$1 / 3$

0.

0.664

0.5

$1 / 3$

0. 
HS Package Reference Manual

Equation

2.6.7

2.6.7

2.6.7

2.6.7

2.6 .24

2.6 .24

2.6 .24

2.6 .24

2.6.24
Coefficient

C4121(1)

C4121(2)

C4121(3)

C4121(4)

C4122(1)

C4122(2)

C4122(3)

C4122(4)

C4123(1)

C4123(2)

C4123(3)

C4123(4)

C4124(1)

C4124(2)

C4124(3)

C4124(4)

C4151(1)

C4151(2)

C4151(3)

C4152(1)

C4152(2)

C4152(3)

C4153(1)

C4153(2)

C4153(3)

C4154(1)

C4154(2)

C4154(3)

C4155(1)

C4155(2)

C4155(3)
Value Units

0.60

0.5

$1 / 3$

2.0

0.037

0.8

$1 / 3$

0 .

0.037

0.8

$1 / 3$

0 .

0.60

0.5

$1 / 3$

2.0

0.046

$1 / 3$

0.

0.046

$1 / 3$

0 .

0.228

0.226

0 .

0.046

$1 / 3$

0 .

0.046

$1 / 3$

0 . 
HS Package Reference Manual

Equation

2.6 .24

2.6 .24

2.6.24

2.6.24

2.6 .24

2.6 .24

2.6.24

2.6 .25

2.6 .25

2.6 .25
Coefficient

C4156(1)

C4156(2)

C4156(3)

C4157(1)

C4157(2)

C4157(3)

C4158(1)

C4158(2)

C4158(3)

C4159(1)

C4159(2)

C4159(3)

C4160(1)

C4160(2)

C4160(3)

C4161(1)

C4161(2)

C4161(3)

C4162(1)

C4162(2)

C4162(3)

C4163(1)

C4163(2)

C4163(3)

C4163(4)

C4164(1)

C4164(2)

C4164(3)

C4164(4)

C4165(1)

C4165(2)

C4165(3)

C4165(4)
Value Units

0.228

0.226

0.

0.59

0.25

0 .

0.59

0.25

0.

0.43

0.25

2.0

0.10

$1 / 3$

0.

0.10

$1 / 3$

0.

0.43

0.25

2.0

8.235

0 .

0.

0.

$48 / 11$

0 .

0.

0.

$48 / 11$

0 .

0.

0. 
HS Package Reference Manual

Equation

Coefficient

Value Units

2.6 .25

C4166(1)

C4166(2)

C4166(3)

C4166(4)

2.6 .25

C4167(1)

C4167(2)

C4167(3)

C4167(4)

2.6.25

C4168(1)

C4168(2)

C4168(3)

C4168(4)

2.6 .25

C4169(1)

C4169(2)

C4169(3)

C4169(4)

2.6 .25

C4170(1)

$\mathrm{C} 4170(2)$

C4170(3)

C4170(4)

2.6 .25

2.6.25

C4171(1)

C4171(2)

C4171(3)

C4171(4)

C4172(1)

C4172(2)

C4172(3)

C4172(4)

C4173(1)

C4173(2)

C4173(3)

C4173(4)

2.6.25

0.023

0.8

$1 / 3$

0 .

0.023

0.8

$1 / 3$

0 .

0.023

0.8

$1 / 3$

0 .

0.664

0.5

$1 / 3$

0 .

0.664

0.5

$1 / 3$

0 .

0.60

0.5

$1 / 3$

2.0

0.037

0.8

$1 / 3$

0.

0.037

0.8

$1 / 3$

0 . 
HS Package Reference Manual

Equation

Coefficient

Value Units

2.6 .25

$\begin{array}{ll}\text { C4174(1) } & 0.60 \\ \text { C4174(2) } & 0.5 \\ C 4174(3) & 1 / 3 \\ \text { C4174(4) } & 2.0\end{array}$

2.6.32

C4180(1)

C4180(2)

C4180(3)

C4180(4)

0.013

0.5

1.0

0.33

2.6 .34

C4181(1)

C4181(2)

C4181(3)

0.18

0.25

0.5

2.6.35

C4182(1)

C4182(2)

C4182(3)

0.09

0.25

0.5

2.6.36

C4183(1)

0.943

C4183(2)

0.25

C4183(3)

0.75

2.6 .40

C4184(1)

0.943

Section 2.7

C4200(1)

0.9995

2.7.1

C4201(1)

C4201(2)

C4201(3)

1.0

1.0

C4201(4)

$1 / 3$

$-1 / 3$

2.7.4

C4202(1)

$5 . \times 10^{5}$

$W / m^{2}-K$

Section 2.7.4

C4203(1)

$-1.0$

0.9

Section 2.6.1.1

C4210(1)

C4210(2)

C4210(3)

C4210(4)
30.

100.

(not used)

.1686289 
HS Package Reference Manual

Equation

Coefficient

Value

Units

Section 2.6.1.1

C4211(1)

C4211(2)

0.943

0.25

Section 2.6.1.1

C4212(1)

C4212(2)

C4212(3)

C4212(4)

C4212(5)

C4212(6)

Section 2.6.1.1

C4213(1)

$\mathrm{C} 4213(2)$

C4213(3)

C4213(4)

.3333333

$-.44$

$5.82 \times 10^{-6}$

0.8

.3333333

0.5

C4214(1)

C4214(2)

$10^{6}$

$10^{8}$

$10^{10}$

.9715642

Section 2.6.1.1

C4215(1)

C4215(2)

0.6

0.2

Section 2.6.1.1

C4220(1)

C4220(2)

C4220(3)

C4220(4)

0.72

0.19

Section 2.6.1.1

C4221(1)

C4221(2)

30.

100.

(not used)

.9715642

Section 2.6.1.1

C4222(1)

C4222(2)

C4222(3)

C4222(4)

C4222(5)

C4222(6)

0.729

0.25

Section 2.6.1.1

C4230(1)

C4230(2)

30.

100.

Section 2.6.1.1

C4231(1)

C4231(2)

0.815

0.25

.3333333

$-.44$

$5.82 \times 10^{-6}$

0.8

.3333333

0.5

.

100. 
HS Package Reference Manual

Equation

Section 2.6.1.1

Section 2.6.1.1

Section 2.8.1

Sections 2.6.1.2 \& 2.8.2
Coefficient

C4232(1)

C4232(2)

C4232(3)

C4232(4)

C4232(5)

C4232(6)

C4251(1)

C4251(2)

C4253(1)

$\mathrm{C} 4253(2)$

C4253(3)

C4253(4)

$\mathrm{C} 4253(5)$

C4253(6)

$\mathrm{C} 4253(7)$

C4253(8)

C4253(9)

C4253(10)

C4253(11)
Value

Units

.3333333

$-.44$

$5.82 \times 10^{-6}$

0.8

.3333333

0.5

$\begin{array}{ll}10^{-9} & \mathrm{~m} \\ 0.0005 & \mathrm{~m}\end{array}$

0.909

0.3333333

0.115

0.6

1000.

3000 .

$-0.44$

$5.82 \cdot 10^{-6}$

0.8

0.3333333

0.5 


\title{
Material Properties (MP) Package Reference Manual
}

\author{
MELCOR Code Development Group \\ Modeling and Analysis Department \\ Nuclear Energy Technology Center \\ Sandia National Laboratories \\ Albuquerque, NM 87185-0739
}

Contributors:

Edward A. Boucheron

Randall K. Cole, Jr.

Robert Gross

David S. Stuart

Arnold Elsbernd

The MELCOR Material Properties package models many of the properties needed by the various physics packages. This is done by using analytical laws, correlations, or linear tables. New materials and their properties may be defined through user input, and properties for default materials may be redefined by user input.

This document identifies the default material property values and functions used in the MELCOR MP package. References for the data are provided. Detailed descriptions of input requirements are provided in the MP Package Users' Guide.

The thermodynamic properties of water vapor and liquid water are contained in the $\mathrm{H}_{2} \mathrm{O}$ package and cannot be modified through user input. Properties of noncondensible gases are calculated by the NCG package. A description of the default values and available user input options is provided in the MELCOR NonCondensible Gas (NCG) Package Users' Guide.

CORCON and VANESA properties are included in the Cavity (CAV) and RadioNuclide (RN) packages, respectively. See the reference manuals and users' guides for those packages. 


\section{Contents}

1. DEFAULT MATERIAL PROPERTIES $\ldots \ldots \ldots \ldots \ldots \ldots \ldots \ldots \ldots$

2. SPECIFIC ENTHALPY AS A FUNCTION OF TEMPERATURE $\ldots \ldots \ldots \ldots 11$

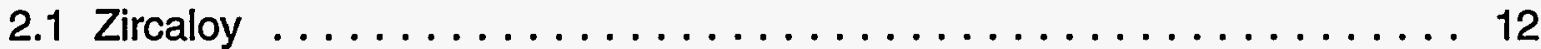

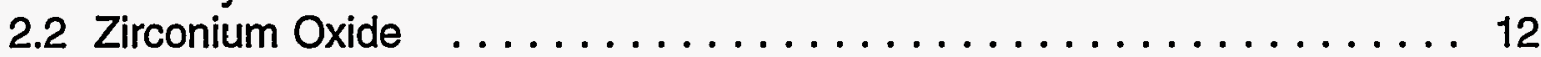

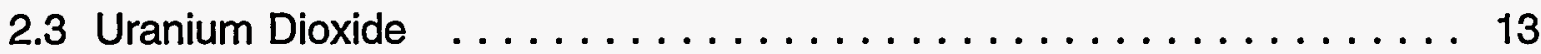

2.4 Stainless Steel $\ldots \ldots \ldots \ldots \ldots \ldots \ldots \ldots \ldots \ldots \ldots \ldots \ldots \ldots 14$

2.5 Stainless Steel Oxide . . . . . . . . . . . . . . . . . . . 15

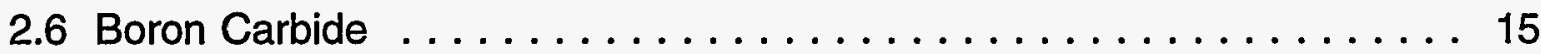

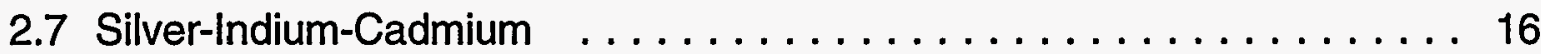

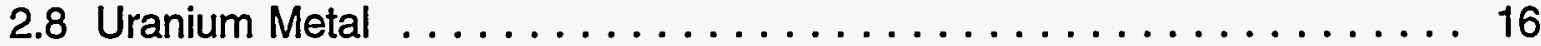

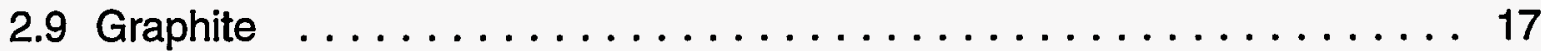

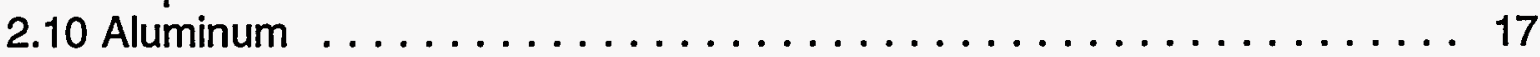

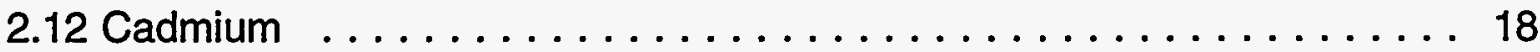

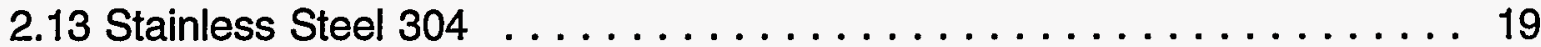

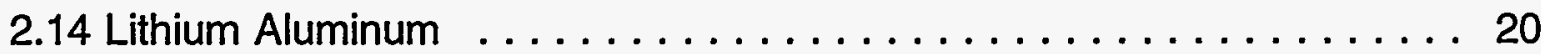

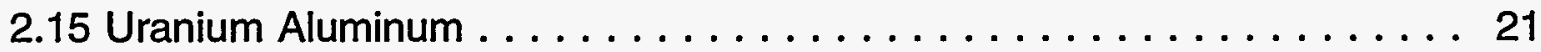

3. TEMPERATURE AS A FUNCTION OF SPECIFIC ENTHALPY $\ldots \ldots \ldots \ldots 23$

4. SPECIFIC HEAT CAPACITY AS A FUNCTION OF TEMPERATURE $\ldots \ldots .25$

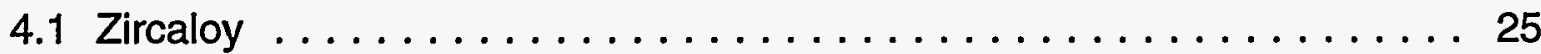

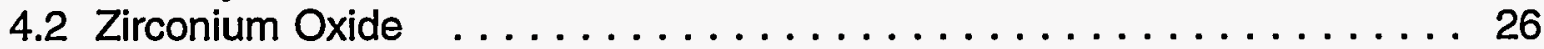

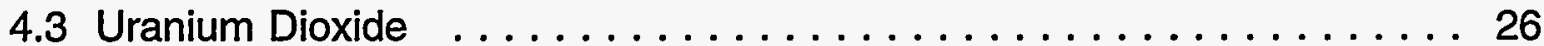

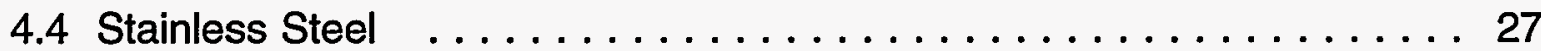

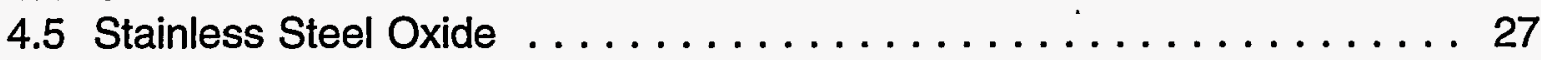

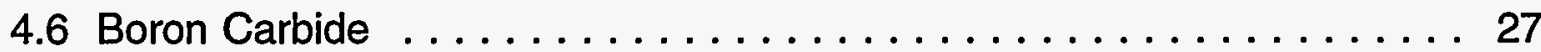

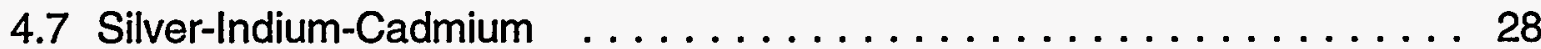

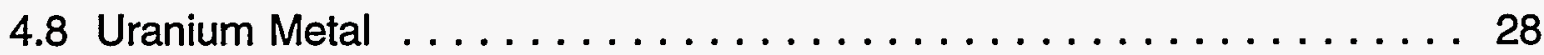

4.9 Graphite . . . . . . . . . . . . . . . . . . . . . 29

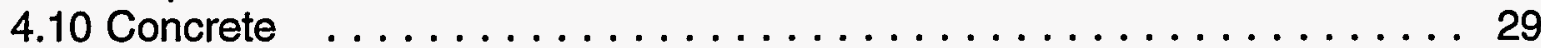

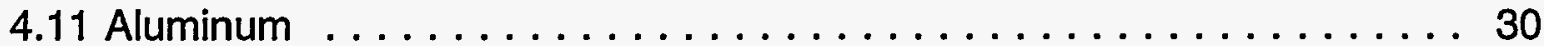

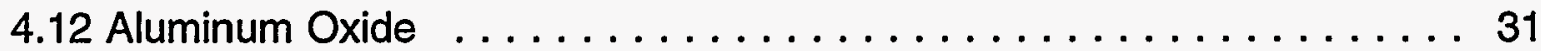

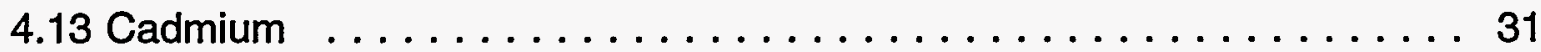

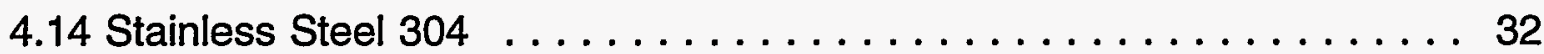

4.15 Lithium Aluminum $\ldots \ldots \ldots \ldots \ldots \ldots \ldots \ldots \ldots \ldots \ldots$

4.16 Uranium Aluminum $\ldots \ldots \ldots \ldots \ldots \ldots \ldots \ldots \ldots \ldots \ldots \ldots \ldots \ldots$

5. THERMAL CONDUCTIVITY AS A FUNCTION OF TEMPERATURE $\ldots \ldots .35$

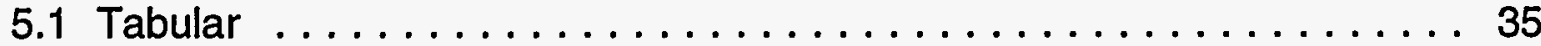

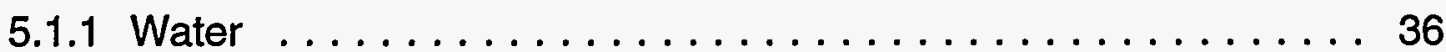

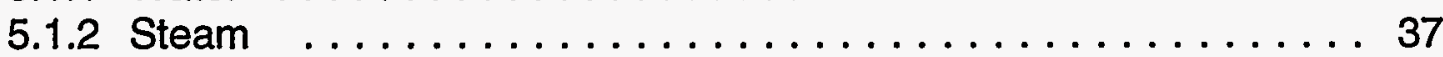

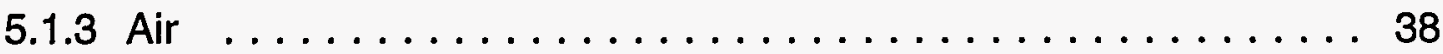


MP Package Reference Manual

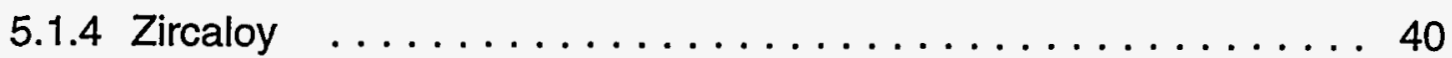

5.1 .5 Zirconium Oxide $\ldots \ldots \ldots \ldots \ldots \ldots \ldots \ldots \ldots \ldots \ldots$

5.1 .6 Uranium Dioxide $\ldots \ldots \ldots \ldots \ldots \ldots \ldots \ldots \ldots \ldots \ldots \ldots \ldots$

5.1 .7 Stainless Steel (SS) $\ldots \ldots \ldots \ldots \ldots \ldots \ldots \ldots \ldots \ldots . \ldots \ldots$

5.1 .8 Stainless Steel Oxide $\ldots \ldots \ldots \ldots \ldots \ldots \ldots \ldots \ldots \ldots 42$

5.1 .9 Boron Carbide ....................... 42

5.1 .10 Silver-Indium-Cadmium $\ldots \ldots \ldots \ldots \ldots \ldots \ldots \ldots \ldots \ldots \ldots$

5.1 .11 Uranium Metal $\ldots \ldots \ldots \ldots \ldots \ldots \ldots \ldots \ldots \ldots \ldots$

5.1 .12 Graphite $\ldots \ldots \ldots \ldots \ldots \ldots \ldots \ldots \ldots \ldots \ldots \ldots . \ldots 44$

5.1 .13 Concrete $\ldots \ldots \ldots \ldots \ldots \ldots \ldots \ldots \ldots \ldots \ldots \ldots 4 . \ldots \ldots$

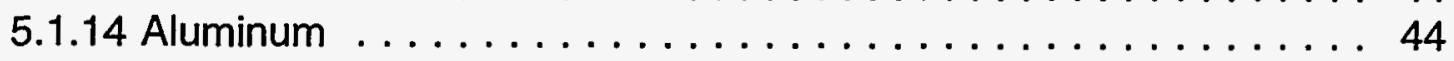

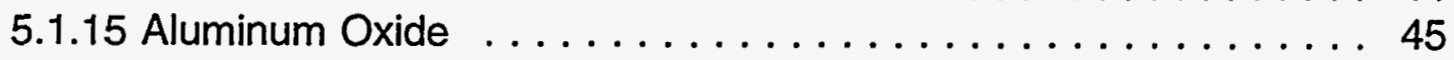

5.1 .16 Cadmium . .................... 46

5.1.17 Stainless Steel $304 \ldots \ldots \ldots \ldots$. . . . . . . . . . . . . . 47

5.1 .18 Lithium Aluminum $\ldots \ldots \ldots \ldots \ldots \ldots \ldots \ldots \ldots$

5.1 .19 Uranium Aluminum $\ldots \ldots \ldots \ldots \ldots \ldots \ldots \ldots$

5.2 Eucken Correlation for a Single, Pure Gas .............. 50

5.3 Wassijewa Equation for a Combination of Low Pressure Gases . . . . 51

6. DYNAMIC VISCOSITY AS A FUNCTION OF TEMPERATURE $\ldots \ldots \ldots \ldots 53$

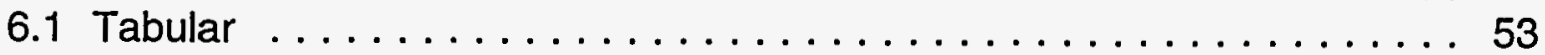

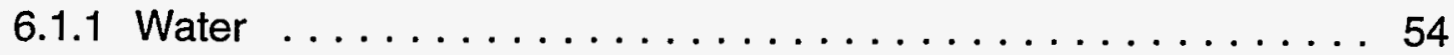

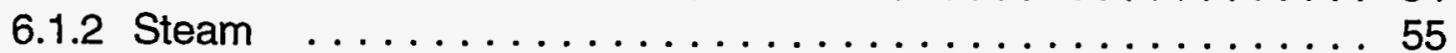

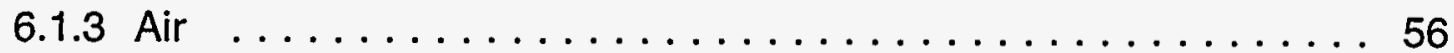

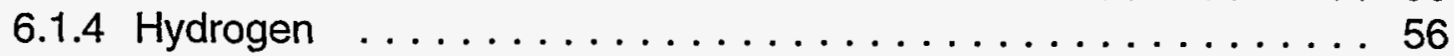

6.1 .5 Deuterium ........................ 57

6.2 Chapman-Enskog Equation for a Single, Pure Gas ... . . . . . . 58

6.3 Chapman-Enskog Equation for a Combination of Low Pressure Gases . 60

7. BINARY MASS DIFFUSION COEFFICIENT ... . . . . . . . . . 61

7.1 Binary Mass Diffusion Coefficient as a Function of Temperature and Pressure ........................6 61

7.2 Chapman-Enskog Equation for a Pair of Low Pressure Gases . . . . . . 62

7.3 Chapman-Enskog Equation for a Combination of Low Pressure Gases . 64

8. DENSITY ............................. 65

8.1 Constant Density ....................... 65

8.2 Tabular as a Function of Temperature $\ldots \ldots \ldots \ldots \ldots \ldots \ldots 66$

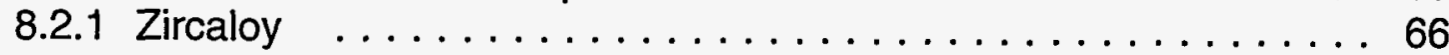

8.2.2 Zirconium Oxide $\ldots \ldots \ldots \ldots \ldots \ldots \ldots \ldots \ldots \ldots \ldots$

8.2.3 Uranium Dioxide $\ldots \ldots \ldots \ldots \ldots \ldots \ldots \ldots \ldots \ldots \ldots \ldots$

8.2 .4 Stainless Steel $\ldots \ldots \ldots \ldots \ldots \ldots \ldots \ldots \ldots \ldots \ldots 67$

8.2 .5 Stainless Steel Oxide $\ldots \ldots \ldots \ldots \ldots \ldots \ldots \ldots \ldots \ldots 67$

8.2 .6 Boron Carbide . . . . . . . . . . . . . . . . . . . 68

8.2.7 Silver-Indium-Cadmium $\ldots \ldots \ldots \ldots \ldots \ldots \ldots \ldots$ 
MP Package Reference Manual

8.2.8 Uranium Metal $\ldots \ldots \ldots \ldots \ldots \ldots \ldots \ldots \ldots \ldots 696 \ldots$

8.2 .9 Graphite $\ldots \ldots \ldots \ldots \ldots \ldots \ldots \ldots \ldots \ldots \ldots \ldots \ldots 6 . \ldots \ldots$

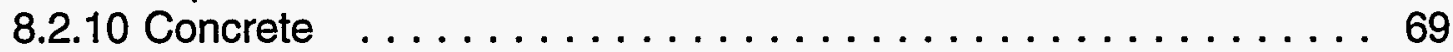

8.2.11 Aluminum .................... 70

8.2.12 Aluminum Oxide $\ldots \ldots \ldots \ldots \ldots \ldots \ldots \ldots \ldots \ldots$

8.2.13 Cadmium ...................... 71

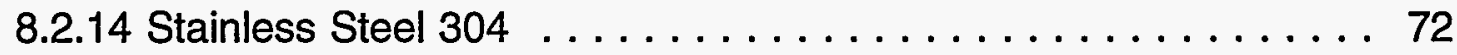

8.2.15 Lithium Aluminum $\ldots \ldots \ldots \ldots \ldots \ldots \ldots \ldots \ldots \ldots \ldots \ldots$

8.2.16 Uranium Aluminum $\ldots \ldots \ldots \ldots \ldots \ldots \ldots \ldots \ldots \ldots \ldots$

8.3 Calculated as a Function of Temperature and Pressure $\ldots \ldots \ldots \ldots 74$

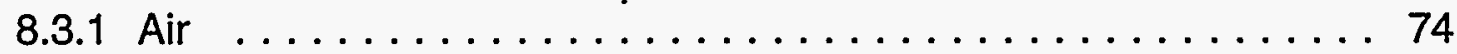

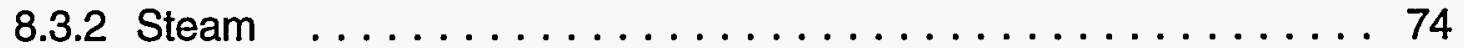

9. CONSTANT MELTING TEMPERATURE $\ldots \ldots \ldots \ldots \ldots \ldots \ldots$

10. CONSTANT LATENT HEAT OF FUSION $\ldots \ldots \ldots \ldots \ldots \ldots \ldots \ldots$

11. REFERENCES $\ldots \ldots \ldots \ldots \ldots \ldots \ldots \ldots \ldots \ldots \ldots \ldots \ldots \ldots$ 
MP Package Reference Manual

MP-RM-6 
MP Package Reference Manual

\section{DEFAULT MATERIAL PROPERTIES}

The MELCOR Material Properties (MP) package models many common properties needed by the various phenomenological packages through the use of analytical laws, correlations, and tabulated values. These properties include thermodynamic state and transport properties needed for structural materials, as well as transport properties for water and noncondensible gases. (Thermodynamic state properties for these fluids are provided separately by the $\mathrm{H} 2 \mathrm{O}$ and NCG packages; see the NCG/H2O Reference Manual.)

In a few cases, stand-alone codes that have been wholly integrated into MELCOR still use properties defined within those codes; a notable example is CORCON, which has been integrated into the Cavity (CAV) package. Also, properties unique to a package, such as those for trace species used in the RadioNuclide (RN) package, are generally modeled within that package. The Core (COR), Fuel Dispersal Interactions (FDI), and Heat Structures (HS) packages use principally the structural materials properties, while the Control Volume Hydrodynamics (CVH), Engineered Safety Features (ESF), Containment Sprays (SPR), and RN packages use principally the fluid transport properties.

The following 34 materials, listed with their mnemonic identifiers, are defined in the Material Properties package:

1. Water (WATER)

2. Steam (STEAM)

3. Air (AIR)

4. Hydrogen $(\mathrm{H} 2)$

5. Helium (HE)

6. Argon (AR)

7. Deuterium (D2)

8. Zircaloy (ZR)

9. Zirconium Oxide (ZRO2)

10. Uranium Dioxide (UO2)

11. Stainless Steel (SS)

12. Stainless Steel Oxide (SSOX)

13. Boron Carbide (B4C)

14. Silver-Indium-Cadmium (AGINC)

15. Uranium Metal (UMETL)

16. Graphite (GRAPH)

17. Concrete (CON)
18. Oxygen (O2)

19. Carbon Dioxide (CO2)

20. Carbon Monoxide (CO)

21. Nitrogen (N2)

22. Nitric Oxide (NO)

23. Nitrous Oxide (N2O)

24. Ammonia (NH3)

25. Acetylene (C2H2)

26. Methane ( $\mathrm{CH} 4)$

27. Ethylene (C2H4)

28. Uranium Hexafluoride (UF6)

29. Aluminum (ALUM)

30. Aluminum Oxide (AL203)

31. Cadmium (CADM)

32. Stainless Steel 304 (SS304)

33. Lithium Aluminum (LIAL)

34. Uranium Aluminum (UAL)

Material 11, Stainless Steel (SS), is a type 347 stainless steel and is typically used in the Core package, whereas material 32 (SS304) is a type 304 stainless steel. 


\section{MP Package Reference Manual}

The following properties are defined in the package:

1. Enthalpy as a function of temperature

2. Temperature as a function of enthalpy

3. Specific Heat Capacity as a function of temperature

4. Thermal Conductivity as a function of temperature

a. From tables

b. From Eucken correlation and Wassijewa equation

5. Dynamic Viscosity as a function of temperature

a. From tables

b. From Chapman-Enskog equations and Lennard-Jones potential parameters

6. Binary Diffusion Coefficient

a. Function of temperature and pressure

b. From Chapman-Enskog equations and Lennard-Jones potential parameters

7. Density

a. Constant

b. Function of temperature

c. Function of temperature and pressure

8. Melting Temperature

9. Latent Heat of Fusion

\begin{tabular}{ll} 
Type & Units \\
\hline Tabular & $\mathrm{J} / \mathrm{kg}$ \\
Tabular & $\mathrm{K}$ \\
Tabular & $\mathrm{J} / \mathrm{kg}-\mathrm{K}$ \\
Tabular & $\mathrm{W} / \mathrm{m}-\mathrm{K}$ \\
Calculated & $\mathrm{W} / \mathrm{m}-\mathrm{K}$ \\
Tabular & $\mathrm{kg} / \mathrm{m}-\mathrm{s}$ \\
Calculated & $\mathrm{kg} / \mathrm{m}-\mathrm{s}$ \\
Calculated & $\mathrm{m}^{2} / \mathrm{s}$ \\
Calculated & $\mathrm{m}^{2} / \mathrm{s}$ \\
Constant & $\mathrm{kg} / \mathrm{m}^{3}$ \\
Tabular & $\mathrm{kg} / \mathrm{m}^{3}$ \\
Calculated & $\mathrm{kg} / \mathrm{m}^{3}$ \\
Constant & $\mathrm{K}$ \\
Constant & $\mathrm{J} / \mathrm{kg}$
\end{tabular}

Default values are provided for some, but not all, combinations of materials and physical properties. Table 1.1 summarizes the default values available. A ' $T$ ' indicates that the default function can be changed through user-defined tabular functions and an MPMATnnnmm input record. $A$ ' $C$ ' indicates that the default function can be changed through user-defined constant values input on an MPMATnnnmm record. An ' $X$ ' indicates that the default function cannot be changed through user input. A blank space indicates that no default is provided, but may be supplied by the user, although in some cases that property for that material may not be used by MELCOR.

Also shown is the mnemonic(s) used to add new values or alter the default values through user input for those properties which can be changed.

Sections 2.0 through 10.0 , below, identify the default values for those combinations defined in MELCOR. User definition of the materials properties is also discussed in each section. 
MP Package Reference Manual

Table 1.1: Default material properties, property mnemonics, and user input capabilities

\begin{tabular}{|c|c|c|c|c|c|c|c|c|c|c|c|c|c|c|}
\hline Propenty: & 1 & 2 & 3 & $4 a$ & $4 b$ & $5 a$ & $5 b$ & $6 a$ & $6 b$ & $7 a$ & $7 b$ & $7 c$ & 8 & 9 \\
\hline Mnemonic: & ENH & TMP & CPS & THC & $\begin{array}{l}\text { SIG } \\
\text { EPS }\end{array}$ & VIS & $\begin{array}{l}\text { SIG } \\
\text { EPS }\end{array}$ & $n / a$ & $\begin{array}{l}\text { SIG } \\
\text { EPS }\end{array}$ & DEN & RHO & $n / a$ & MLT & LHF \\
\hline WATER & & & & $T$ & & $T$ & & & & & & & & \\
\hline STEAM & & & & $T$ & $c$ & $T$ & $c$ & & $c$ & & & $x$ & & \\
\hline AIR & & & & $T$ & C & $T$ & C & & c & & & $x$ & & \\
\hline H2 & & & & & c & $T$ & $c$ & & c & & & & & \\
\hline HE & & & & & c & & C & & c & & & & & \\
\hline AR & & & & & c & & C & & C & & & & & \\
\hline D2 & & & & & c & $T$ & c & & $c$ & & & & & \\
\hline ZR & $T$ & $T$ & $T$ & $T$ & & & & & & c & $T$ & & c & C \\
\hline ZRO2 & $T$ & $T$ & $T$ & $T$ & & & & & & c & $T$ & & c & c \\
\hline UO2 & $T$ & $T$ & $T$ & $T$ & & & & & & c & $T$ & & c & C \\
\hline ss & $T$ & $T$ & $T$ & $T$ & & & & & & c & $T$ & & c & C \\
\hline ssox & $T$ & $T$ & $T$ & $T$ & & & & & & c & $T$ & & c & C \\
\hline$B 4 C$ & $T$ & $T$ & $T$ & $T$ & & & & & & c & $T$ & & c & c \\
\hline AGINC & $T$ & $T$ & $T$ & $T$ & & & & & & c & $T$ & & C & c \\
\hline UMETL & $T$ & $T$ & $T$ & $T$ & & & & & & c & $T$ & & c & c \\
\hline GRAPH & $T$ & $T$ & $T$ & $T$ & & & & & & c & $T$ & & c & \\
\hline CON & & & $T$ & $T$ & & & & & & & $T$ & & & \\
\hline 02 & & & & & $\mathrm{c}$ & & c & & $c$ & & & & & \\
\hline $\mathrm{CO} 2$ & & & & & C & & c & & c & & & & & \\
\hline co & & & & & c & & c & & c & & & & & \\
\hline N2 & & & & & c & & c & & c & & & & & \\
\hline NO & & & & & c & & c & & c & & & & & \\
\hline $\mathrm{N} 2 \mathrm{O}$ & & & & & $c$ & & c & & c & & & & & \\
\hline NH3 & & & & & C & & c & & c & & & & & \\
\hline $\mathrm{C} 2 \mathrm{H} 2$ & & & & & C & & c & & c & & & & & \\
\hline $\mathrm{CH} 4$ & & & & & C & & c & & c & & & & & \\
\hline $\mathrm{C} 2 \mathrm{H}_{4}$ & & & & & c & & c & & c & & & & & \\
\hline UFB & & & & & C & & c & & c & & & & & \\
\hline STEAM + AIR & & & & & & & & $x$ & & & & & & \\
\hline STEAM + H2 & & & & & & & & $x$ & & & & & & \\
\hline ALUM & $T$ & $T$ & $T$ & $T$ & & & & & & c & $T$ & & c & c \\
\hline AL2O3 & $T$ & $T$ & $T$ & $T$ & & & & & & c & $T$ & & c & $c$ \\
\hline CADM & $T$ & $T$ & $T$ & $T$ & & & & & & c & $T$ & & c & c \\
\hline $5 S 304$ & $T$ & $T$ & $T$ & $T$ & & & & & & $\mathrm{c}$ & $T$ & & c & $c$ \\
\hline LAL & $T$ & $T$ & $T$ & $T$ & & & & & & c & $T$ & & C & c \\
\hline UAL. & $T$ & $T$ & $T$ & $T$ & & & & & & c & $T$ & & c & $c$ \\
\hline
\end{tabular}

$T$ - The default function can be changed using tabular functions and an MPMATnnnmm input record.

$C$ - The default function can be changed using constant values input on an MPMATnnnmm record.

$X$ - The default function cannot be changed through user input.

"See page 5 for a full description of these properties. 
MP Package Reference Manual

MP-RM-10 


\section{SPECIFIC ENTHALPY AS A FUNCTION OF TEMPERATURE}

The specific enthalpy may be computed from either a user-specified tabular function or a MELCOR default table.

The user-specified tabular function to define a new material or to override the default table for an existing material is invoked by using a standard tabular function (see the TF Package Users' Guide) to input the enthalpy $(\mathrm{J} / \mathrm{kg})$ as a function of temperature (K). Negative enthalpies are permitted. Currently, there are no checks made on the consistency of user-input values for enthalpy, specific heat capacity, melting temperature, and latent heat of fusion; this will be rectified in future code versions.

The following materials have default tables for enthalpy:

Zircaloy
Zirconium Oxide
Uranium Dioxide
Stainless Steel
Stainless Steel Oxide
Boron Carbide
Silver-Indium-Cadmium
Uranium Metal
Graphite

Aluminum

Aluminum Oxide

Cadmium

Stainless Steel 304

Lithium Aluminum

Uranium Aluminum

The default specific enthalpy values are computed by linear interpolation of the tabulated values listed below. The tabular values were computed by integrating the tables of specific heat capacities from Section 4 . The latent heat of fusion from Section 10 was added at the melting point given in Section 9 over a range of $0.01 \mathrm{~K}$. 
MP Package Reference Manual

\subsection{Zircaloy}

The default tabular values of specific enthalpy as a function of temperature for Zircaloy are listed below. Linear extrapolation is allowed from both ends of the tabulated range.

\begin{tabular}{cc} 
Temperature $(\mathrm{K})$ & \multicolumn{2}{c}{ Specific Enthalpy $(\mathrm{J} / \mathrm{kg})$} \\
\cline { 2 - 2 } 300.0 & 0.0 \\
400.0 & 21915.0 \\
640.0 & 105110.0 \\
1090.0 & 263960.0 \\
1093.0 & 265275.5 \\
1113.0 & 276195.5 \\
1133.0 & 288245.5 \\
1153.0 & 301585.5 \\
1173.0 & 316935.5 \\
1193.0 & 332795.5 \\
1213.0 & 346685.5 \\
1233.0 & 357565.5 \\
1248.0 & 363753.0 \\
2098.0 & 666353.0 \\
2098.01 & 891353.0 \\
3598.0 & 1425353.0
\end{tabular}

\subsection{Zirconium Oxide}

The default tabular values of specific enthalpy as a function of temperature for Zirconium Oxide are listed below. Linear extrapolation is allowed from both ends of the tabulated range.

Temperature (K) Specific Enthalpy $(\mathrm{J} / \mathrm{kg})$

300.0

2990.0

0.0

2990.01

3500.0

1464167.0

2171167.0

2448760.0 


\subsection{Uranium Dioxide}

The default tabular values of specific enthalpy as a function of temperature for Uranium Dioxide are listed below. Linear extrapolation is allowed from both ends of the tabulated range.

\begin{tabular}{cr} 
Temperature $(\mathrm{K})$ & Specific Enthalpy $(\mathrm{J} / \mathrm{kg})$ \\
\cline { 2 - 2 } 300.0 & 33143.0 \\
400.0 & 58419.0 \\
500.0 & 85883.0 \\
600.0 & 114638.0 \\
700.0 & 144257.0 \\
800.0 & 174517.0 \\
900.0 & 205288.0 \\
1000.0 & 236492.0 \\
1100.0 & 268080.0 \\
1200.0 & 300023.0 \\
1300.0 & 332309.0 \\
1400.0 & 364947.0 \\
1500.0 & 397973.0 \\
1600.0 & 431455.0 \\
1700.0 & 465502.0 \\
1800.0 & 500266.0 \\
1900.0 & 535945.0 \\
2000.0 & 572782.0 \\
2100.0 & 611064.0 \\
2200.0 & 651111.0 \\
2300.0 & 693275.0 \\
2400.0 & 737927.0 \\
2500.0 & 785450.0 \\
2600.0 & 836232.0 \\
2700.0 & 890656.0 \\
2800.0 & 949096.0 \\
2900.0 & 1011906.0 \\
3000.0 & 1079422.0 \\
3113.0 & 1161764.0 \\
3113.01 & 1435764.0 \\
3513.0 & 1636964.0 \\
& \\
\hline
\end{tabular}


MP Package Reference Manual

\subsection{Stainless Steel}

The default tabular values of specific enthalpy as a function of temperature for Stainless Steel are listed below. Linear extrapolation is allowed from both ends of the tabulated range.

\begin{tabular}{cr} 
Temperature $(\mathrm{K})$ & Specific Enthalpy $(\mathrm{J} / \mathrm{kg})$ \\
\hline & 0.0 \\
300.0 & 48926.0 \\
400.0 & 99624.0 \\
500.0 & 152092.0 \\
600.0 & 206332.0 \\
700.0 & 262343.0 \\
800.0 & 320125.0 \\
900.0 & 379679.0 \\
1000.0 & 441003.0 \\
1100.0 & 504099.0 \\
1200.0 & 568966.0 \\
1300.0 & 635604.0 \\
1400.0 & 704014.0 \\
1500.0 & 774194.0 \\
1600.0 & 846146.0 \\
1700.0 & 1114146.0 \\
1700.01 & 1186986.0 \\
1800.0 & 2643786.0
\end{tabular}


MP Package Reference Manual

\subsection{Stainless Steel Oxide}

The default tabular values of specific enthalpy as a function of temperature for Stainless Steel Oxide are listed below. Linear extrapolation is allowed from both ends of the tabulated range.

\begin{tabular}{cr} 
Temperature (K) & Specific Enthalpy \\
\hline & \\
300.0 & 0.0 \\
1870.0 & 785000.0 \\
1870.01 & 1383000.0 \\
3500.0 & 2198000.0
\end{tabular}

\subsection{Boron Carbide}

The default tabular values of specific enthalpy as a function of temperature for Boron Carbide are listed below. Linear extrapolation is allowed from both ends of the tabulated range.

Temperature (K)

300.0

2620.0

2620.01

3500.0
Specific Enthalpy $(\mathrm{J} / \mathrm{kg})$

0.0

1160000.0

1660000.0

2100000.0 
MP Package Reference Manual

\subsection{Silver-Indium-Cadmium}

The default tabular values of specific enthalpy as a function of temperature for Silver-Indium-Cadmium are listed below. Linear extrapolation is allowed from both ends of the tabulated range.

\begin{tabular}{cr} 
Temperature $(K)$ & Specific Enthalpy \\
\cline { 2 - 2 } 300.0 & 0.0 \\
400.0 & 21759.0 \\
500.0 & 44031.0 \\
600.0 & 66801.0 \\
700.0 & 90091.0 \\
800.0 & 113890.0 \\
900.0 & 138200.0 \\
1000.0 & 163010.0 \\
1075.0 & 211000.0 \\
1075.01 & 309000.0 \\
1100.0 & 315350.0 \\
5000.0 & 1306600.0
\end{tabular}

\subsection{Uranium Metal}

The default tabular values of specific enthalpy as a function of temperature for Uranium Metal are listed below. Linear extrapolation is allowed from the lower end of the tabulated range. No extrapolation is allowed from the upper end of the tabulated range.

Temperature (K)

300.0

400.0

600.0

800.0

1000.0

1200.0

1406.0

1406.01

5000.0
Specific Enthalpy $(\mathrm{J} / \mathrm{kg})$
0.0
12050.0
39150.0
71350.0
106950.0
141050.0
172259.0
222499.0
732847.0 
MP Package Reference Manual

\subsection{Graphite}

The default tabular values of specific enthalpy as a function of temperature for Graphite are listed below. Linear extrapolation is allowed from the lower end of the tabulated range. No extrapolation is allowed from the upper end of the tabulated range.

Temperature (K) Specific Enthalpy $(\mathrm{J} / \mathrm{kg})$

$\begin{array}{rr}300.0 & 0.0 \\ 773.0 & 547910.0 \\ 1273.0 & 1414010.0 \\ 1773.0 & 2381110.0 \\ 2273.0 & 3405060.0 \\ 2773.0 & 4464560.0 \\ 3866.0 & 6879871.0 \\ 5000.0 & 9456545.0\end{array}$

\subsection{Aluminum}

The default tabular values of specific enthalpy as a function of temperature for Aluminum are listed below. Linear extrapolation is allowed from both ends of the tabulated range.

Temperature (K)

273.15

313.15

353.15

393.15

433.15

473.15

513.15

553.15

593.15

633.15

673.15

713.15

753.15

793.15

833.15

873.15

913.15

933.00

933.01

1000.00

1500.00

2000.00
Specific Enthalpy (J/kg)

0.00
36056.00
72822.00
110304.00
148506.00
187432.00
227088.00
267464.00
308580.00
350458.00
393086.00
436470.00
480616.00
525528.00
571210.00
617668.00
664908.00
688643.00
1086443.00
1165269.00
1753519.00
2341769.00


MP Package Reference Manual

\subsection{Aluminum Oxide}

The default tabular values of specific enthalpy as a function of temperature for Aluminum Oxide are listed below. Linear extrapolation is allowed from both ends of the tabular range.

\begin{tabular}{cr} 
Temperature (K) & Specific Enthalpy \\
\cline { 2 - 2 } 273.15 & 0.0 \\
298.0 & 19243.0 \\
350.0 & 62146.0 \\
400.0 & 107619.0 \\
500.0 & 2064.37 .0 \\
600.0 & 312785.0 \\
800.0 & 540165.0 \\
1000.0 & 780637.0 \\
1500.0 & 1410855.0 \\
2327.0 & 2518696.0 \\
2327.01 & 3588710.0 \\
5000.0 & 73864.14 .0
\end{tabular}

\subsection{Cadmium}

The default tabular values of specific enthalpy as a function of temperature for Cadmium are listed below. Linear extrapolation is allowed from both ends of the tabulated range.

Temperature (K)

298.15

400.00

500.00

594.00

594.01

600.00

700.00

800.00

900.00

1000.00

1040.00
Specific Enthalpy (J/kg)
0.00
24093.00
48813.00
73079.00
128347.00
129933.00
156373.00
182813.00
209253.00
235693.00
246269.00 


\subsection{Stainless Steel 304}

The default tabular values of specific enthalpy as a function of temperature for Stainless Steel 304 are listed below. Linear extrapolation is allowed from both ends of the tabulated range.

\begin{tabular}{cr} 
Temperature $(\mathrm{K})$ & Specific Enthalpy $(\mathrm{J} / \mathrm{k}$ \\
\hline & \\
300.00 & 0.00 \\
400.00 & 52005.00 \\
500.00 & 105370.00 \\
600.00 & 160085.00 \\
700.00 & 216155.00 \\
800.00 & 273585.00 \\
900.00 & 332375.00 \\
1000.00 & 392520.00 \\
1100.00 & 454020.00 \\
1200.00 & 516880.00 \\
1300.00 & 581095.00 \\
1400.00 & 646665.00 \\
1500.00 & 713630.00 \\
1600.00 & 781950.00 \\
1700.00 & 851590.00 \\
1700.01 & 1120790.00 \\
1800.00 & 1200800.00 \\
1900.00 & 1280810.00 \\
2000.00 & 1360820.00 \\
2500.00 & 1760870.00 \\
3000.00 & 2160920.00
\end{tabular}


MP Package Reference Manual

\subsection{Lithium Aluminum}

The default tabular values of specific enthalpy as a function of temperature for Lithium Aluminum are listed below. Linear extrapolation is allowed from both ends of the tabulated range.

\begin{tabular}{cc} 
Temperature $(\mathrm{K})$ & Specific Enthalpy $(\mathrm{J} / \mathrm{kg})$ \\
\cline { 2 - 2 } 298.15 & 0.00 \\
313.15 & 14357.00 \\
353.15 & 53199.00 \\
393.15 & 92877.00 \\
433.15 & 133411.00 \\
473.15 & 174815.00 \\
513.15 & 217007.00 \\
533.15 & 259879.00 \\
593.15 & 303449.00 \\
633.15 & 347739.00 \\
673.15 & 392737.00 \\
713.15 & 438455.00 \\
753.15 & 484913.00 \\
793.15 & 532121.00 \\
833.15 & 580081.00 \\
873.15 & 628799.00 \\
917.00 & 683118.00 \\
917.01 & 1081568.00 \\
1000.00 & 1183866.00 \\
1100.00 & 1307111.00 \\
1200.00 & 1430341.00
\end{tabular}


MP Package Reference Manual

\subsection{Uranium Aluminum}

The default tabular values of specific enthalpy as a function of temperature for Uranium Aluminum are listed below. Linear extrapolation is allowed from both ends of the tabulated range.

$\underline{\text { Temperature }(\mathrm{K})}$
Specific Enthalpy $(\mathrm{J} / \mathrm{kg})$
0.00
26818.00
54172.00
82068.00
110512.00
139512.00
169072.00
199198.00
229900.00
261184.00
293056.00
325524.00
358596.00
392278.00
426578.00
461506.00
484411.00
484421.00
522131.00
589676.00
663125.00
667919.00
957919.00
1040285.00
1111757.00
1140519.00
1281719.00
1717519.00 
MP Package Reference Manual 
MP Package Reference Manual

\title{
3. TEMPERATURE AS A FUNCTION OF SPECIFIC ENTHALPY
}

The temperature as a function of specific enthalpy may be computed from either a user-specified tabular function or a MELCOR default table.

The user-specified tabular function to define a new material or to override the default table for an existing material is invoked by using a standard tabular function (see the TF Package Users' Guide) to input the temperature (K) as a function of enthalpy $(\mathrm{J} / \mathrm{kg})$. Currently, there are no checks made on the consistency of user-input values for enthalpy, specific heat capacity, melting temperature, and latent heat of fusion; this will be rectified in future code versions.

The following materials have default tables for temperature as a function of enthalpy:

\author{
Zircaloy \\ Zirconium Oxide \\ Uranium Dioxide \\ Stainless Steel \\ Stainless Steel Oxide \\ Boron Carbide \\ Silver-Indium-Cadmium \\ Uranium Metal \\ Graphite \\ Aluminum \\ Aluminum Oxide \\ Cadmium \\ Stainless Steel 304 \\ Lithium Aluminum \\ Uranium Aluminum
}

The default specific enthalpy values are calculated by linear interpolation of tabulated values computed by inverting the tables of specific enthalpy as a function of temperature from Section 2. Extrapolation rules are the same as those listed in Section 2. 

MP Package Reference Manual

\section{SPECIFIC HEAT CAPACITY AS A FUNCTION OF TEMPERATURE}

The specific heat capacity at constant pressure may be computed from either a user-specified tabular function or a MELCOR default table defined in subroutine MPDFVL.

The user-specified tabular function to define a new material or to override the default table for an existing material is invoked by using a standard tabular function (see the TF Package Users' Guide) to input the specific heat capacity $(\mathrm{J} / \mathrm{kg}-\mathrm{K})$ as a function of temperature (K). There are no checks made on the consistency of user-input values for enthalpy, specific heat capacity, melting temperature, and latent heat of fusion.

The following materials have default tables for specific heat capacity:

$\begin{array}{ll}\text { Zircaloy } & \text { Concrete } \\ \text { Zirconium Oxide } & \text { Aluminum } \\ \text { Uranium Dioxide } & \text { Aluminum Oxide } \\ \text { Stainless Steel } & \text { Cadmium } \\ \text { Stainless Steel Oxide } & \text { Stainless Steel } 304 \\ \text { Boron Carbide } & \text { Lithium Aluminum } \\ \text { Silver-Indium-Cadmium } & \text { Uranium Aluminum } \\ \text { Uranium Metal } & \\ \text { Graphite } & \end{array}$

The default specific enthalpy values are computed by linear interpolation of the tabulated values listed below. Data sources are given with each table.

\subsection{Zircaloy}

The default tabular values of specific heat capacity as a function of temperature for Zircaloy are listed below. No extrapolation is allowed.

\section{Temp (K) Specific Heat Capacity (J/kg-K) Data Source}

$\begin{array}{rll}273.1 & 275.0 & \text { Ref. 1, extrapolated } \\ 400.0 & 302.0 & \text { Ref. 1 } \\ 640.0 & 331.0 & \text { Ref. 1 } \\ 1090.0 & 375.0 & \text { Ref. 1 } \\ 1093.0 & 502.0 & \text { Ref. 1 } \\ 1113.0 & 590.0 & \text { Ref. 1 } \\ 1133.0 & 615.0 & \text { Ref. 1 } \\ 1153.0 & 719.0 & \text { Ref. 1 } \\ 1173.0 & 816.0 & \text { Ref. 1 } \\ 1193.0 & 770.0 & \text { Ref. 1 } \\ 1213.0 & 619.0 & \text { Ref. 1 } \\ 1233.0 & 469.0 & \text { Ref. 1 } \\ 1248.0 & 356.0 & \text { Ref. 1 } \\ 2098.0 & 356.0 & \text { Ref. 1 } \\ 5000.0 & 356.0 & \text { Ref. 1, extrapolated } \\ & & \end{array}$




\section{MP Package Reference Manual}

\subsection{Zirconium Oxide}

The default tabular values of specific heat capacity as a function of temperature for Zirconium Oxide are listed below. No extrapolation is allowed.

Temp (K) Specific Heat Capacity $(\mathrm{J} / \mathrm{kg}-\mathrm{K})$ Data Source

$\begin{array}{ccc}273.15 & 544.3 & \text { Ref. } 1 \\ 5000.0 & 544.3 & \text { Ref. } 1\end{array}$

\subsection{Uranium Dioxide}

The default tabular values of specific heat capacity as a function of temperature for Uranium

Dioxide are listed below. No extrapolation is allowed.

Temp (K) Specific Heat Capacity (J/kg-K) Data Source

$\begin{array}{lll}273.15 & 230.22 & \text { Ref. 1, extrapolated } \\ 400.0 & 265.84 & \text { Ref. 1 } \\ 500.0 & 282.07 & \text { Ref. 1 } \\ 600.0 & 292.36 & \text { Ref. 1 } \\ 700.0 & 299.67 & \text { Ref. 1 } \\ 800.0 & 305.31 & \text { Ref. 1 } \\ 900.0 & 309.98 & \text { Ref. 1 } \\ 1000.0 & 314.03 & \text { Ref. 1 } \\ 1100.0 & 317.69 & \text { Ref. 1 } \\ 1200.0 & 321.15 & \text { Ref. 1 } \\ 1300.0 & 324.59 & \text { Ref. 1 } \\ 1400.0 & 328.24 & \text { Ref. 1 } \\ 1500.0 & 332.40 & \text { Ref. 1 } \\ 1600.0 & 337.43 & \text { Ref. 1 } \\ 1700.0 & 343.76 & \text { Ref. 1 } \\ 1800.0 & 351.84 & \text { Ref. 1 } \\ 1900.0 & 362.14 & \text { Ref. 1 } \\ 2000.0 & 375.09 & \text { Ref. 1 } \\ 2100.0 & 391.08 & \text { Ref. 1 } \\ 2200.0 & 410.45 & \text { Ref. 1 } \\ 2300.0 & 433.45 & \text { Ref. 1 } \\ 2400.0 & 460.23 & \text { Ref. 1 } \\ 2500.0 & 490.88 & \text { Ref. 1 } \\ 2600.0 & 525.40 & \text { Ref. 1 } \\ 2700.0 & 563.71 & \text { Ref. 1 } \\ 2800.0 & 605.67 & \text { Ref. 1 } \\ 2900.0 & 651.09 & \text { Ref. 1 } \\ 3000.0 & 699.73 & \text { Ref. 1 } \\ 3113.0 & 758.23 & \text { Ref. 1 } \\ 3113.01 & 503.0 & \text { Ref. 1 extrapolated } \\ 5000.0 & 503.0 & \end{array}$




\subsection{Stainless Steel}

The default tabular values of specific heat capacity as a function of temperature for 347 Stainless Steel are listed below. No extrapolation is allowed.

Temp (K) Specific Heat Capacity (J/kg-K) Data Source

$\begin{array}{lll}273.15 & 475.6 & \text { Ref. 1, extrapolated } \\ 400.0 & 498.1 & \text { Ref. 1 } \\ 500.0 & 515.8 & \text { Ref. } 1 \\ 600.0 & 533.5 & \text { Ref. } 1 \\ 700.0 & 551.3 & \text { Ref. } 1 \\ 800.0 & 569.0 & \text { Ref. } 1 \\ 900.0 & 586.7 & \text { Ref. } 1 \\ 1000.0 & 604.4 & \text { Ref. } 1 \\ 1100.0 & 622.1 & \text { Ref. } 1 \\ 1200.0 & 639.8 & \text { Ref. } 1 \\ 1300.0 & 657.5 & \text { Ref. } 1 \\ 1400.0 & 675.2 & \text { Ref. } 1 \\ 1500.0 & 693.0 & \text { Ref. } 1 \\ 1600.0 & 710.7 & \text { Ref. } 1 \\ 1700.0 & 728.4 & \text { Ref. } 1 \\ 1700.01 & 728.4 & \text { Ref. } 1 \\ 1800.0 & 728.4 & \text { Ref. } 1 \\ 5000.0 & 728.4 & \text { Ref. 1, extrapolated }\end{array}$

\subsection{Stainless Steel Oxide}

The default tabular values of specific heat capacity as a function of temperature for Stainless Steel Oxide are listed below. No extrapolation is allowed.

\section{Temp (K) Specific Heat Capacity $(\mathrm{J} / \mathrm{kg}-\mathrm{K})$ Data Source}

$\begin{array}{lll}273.15 & 500.0 & \text { Estimated } \\ 5000.0 & 500.0 & \text { Estimated }\end{array}$

\subsection{Boron Carbide}

The default tabular values of specific heat capacity as a function of temperature for Boron Carbide are listed below. No extrapolation is allowed.

Temp (K) Specific Heat Capacity (J/kg-K) Data Source

$\begin{array}{ccc}273.15 & 500.0 & \text { Estimated } \\ 5000.0 & 500.0 & \text { Estimated }\end{array}$




\section{MP Package Reference Manual}

\subsection{Silver-Indium-Cadmium}

The default tabular values of specific heat capacity as a function of temperature for SilverIndium-Cadmium are listed below. Linear extrapolation below $300 \mathrm{~K}$ is permitted.

$\underline{\text { Temp }(\mathrm{K})}$ Specific Heat Capacity $(\mathrm{J} / \mathrm{kg}-\mathrm{K})$ Data Source

$\begin{array}{rrr}300.0 & 215.04 & \text { Ref. 2 } \\ 400.0 & 220.14 & \text { Ref. 2 } \\ 500.0 & 225.23 & \text { Ref. 2 } \\ 600.0 & 230.33 & \text { Ref. 2 } \\ 700.0 & 235.42 & \text { Ref. 2 } \\ 800.0 & 240.52 & \text { Plef. 2 } \\ 900.0 & 245.61 & \text { Ref. 2 } \\ 1000.0 & 250.71 & \text { Ref. 2 } \\ 1075.0 & 254.15 & \text { Pef. 2 } \\ 5000.0 & 254.15 & \text { Ref. 2 }\end{array}$

\subsection{Uranium Metal}

The default $t_{c}$, "lar values of specific heat capacity as a function of temperature for Uranium Metal arc. liste, below. No extrapolation is allowed.

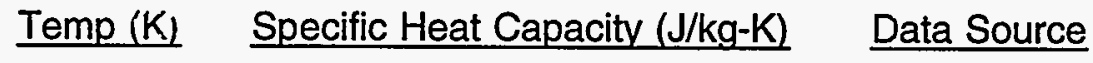

$\begin{array}{rll}273.15 & 113.6 & \text { Ref. } 4, \text { p. } 758, \text { extrapolated } \\ 300.0 & 116.0 & \text { Ref. } 4, \text { p. } 758 \\ 400.0 & 125.0 & \text { Ref. } 4, \text { p. } 758 \\ 600.0 & 146.0 & \text { Ref. } 4, \text { p. } 758 \\ 800.0 & 176.0 & \text { Ref. } 4, \text { p. } 758 \\ 1000.0 & 180.0 & \text { Ref. } 4, \text { p. } 758 \\ 1200.0 & 161.0 & \text { Ref. } 4, \text { p. } 758 \\ 1406.0 & 142.0 & \text { Ref. } 4, \text { p. 758, extrapolated } \\ 5000.0 & 142.0 & \text { Constant from melting point of } \\ & & \text { 1406 K }\end{array}$




\subsection{Graphite}

The default tabular values of specific heat capacity as a function of temperature for Graphite are listed below. No extrapolation is allowed.

Temp (K) Specific Heat Capacity $(\mathrm{J} / \mathrm{kg}-\mathrm{K})$ Data Source

$\begin{array}{rr}273.15 & 665.16 \\ 298.0 & 711.7 \\ 773.0 & 1601.3 \\ 1273.0 & 1863.0 \\ 1773.0 & 2005.3 \\ 2273.0 & 2090.6 \\ 2773.0 & 2147.5 \\ 3866.0 & 2272.0 \\ 5000.0 & 2272.0\end{array}$

Ref. 5, p. 180, generic graphite, extrapolated Ref. 5, p. 180, generic graphite Ref. 5, p. 180, generic graphite Ref. 5 , p. 180 , generic graphite Ref. 5, p. 180, generic graphite Ref. 5, p. 180 , generic graphite Ref. 5, p. 180, generic graphite Ref. 5, p. 180, generic graphite, extrapolated Constant from melting point of $3866 \mathrm{~K}$

\subsection{Concrete}

The default tabular values of specific heat capacity as a function of temperature for Concrete are listed below. No extrapolation is allowed.

\section{Temp (K) Specific Heat Capacity $(\mathrm{J} / \mathrm{kg}-\mathrm{K})$ Data Source}

$273.15 \quad 837.3$

$5000.0 \quad 837.3$
Ref. 3, p. 635, stone concrete @ $294 \mathrm{~K}$ Ref. 3, p. 635, stone concrete @ 294 K 
MP Package Reference Manual

\subsection{Aluminum}

The default tabular values of specific heat capacity as a function of temperature for Aluminum are listed below. Constant extrapolation is allowed from both ends of the tabulated range.

Temp (K) Specific Heat Capacity $(\mathrm{J} / \mathrm{kg}-\mathrm{K})$ Data Source

$\begin{array}{rrr}273.15 & 892.60 & \text { Ref. 18 } \\ 313.15 & 910.20 & \text { Ref. 18 } \\ 353.15 & 928.10 & \text { Ref. 18 } \\ 393.15 & 946.00 & \text { Ref. 18 } \\ 433.15 & 964.10 & \text { Ref. 18 } \\ 473.15 & 982.20 & \text { Ref. 18 } \\ 513.15 & 1000.60 & \text { Ref. 18 } \\ 553.15 & 1018.20 & \text { Ref. 18 } \\ 593.15 & 1037.60 & \text { Ref. 18 } \\ 633.15 & 1056.30 & \text { Ref. 18 } \\ 673.15 & 1075.10 & \text { Ref. 18 } \\ 713.15 & 1094.10 & \text { Ref. 18 } \\ 753.15 & 1113.20 & \text { Ref. 18 } \\ 793.15 & 1132.40 & \text { Ref. 18 } \\ 833.15 & 1151.70 & \text { Ref. 18 } \\ 873.15 & 1171.20 & \text { Ref. 18 } \\ 913.15 & 1190.80 & \text { Ref. 18 } \\ 933.00 & 1200.60 & \text { Ref. 18 } \\ 933.01 & 1176.50 & \text { Ref. 18 } \\ 1000.00 & 1176.50 & \text { Ref. 18 } \\ 1500.00 & 1176.50 & \text { Ref. 18 } \\ 2000.00 & 1176.50 & \text { Ref. 18 }\end{array}$




\subsection{Aluminum Oxide}

The default tabular values of specific heat capacity as a function of temperature for Aluminum Oxide are listed below. Constant extrapolation is allowed from both ends of the tabulated range.

\section{Temp (K) Specific Heat Capacity $(\mathrm{J} / \mathrm{kg}-\mathrm{K})$ Data Source}

$\begin{array}{crr}273.15 & 774.38 & \text { Ref. } 20 \\ 298.0 & 774.38 & \text { Ref. 20 } \\ 350.0 & 875.73 & \text { Ref. 20 } \\ 400.0 & 943.20 & \text { Ref. } 20 \\ 500.0 & 1033.16 & \text { Ref. } 20 \\ 600.0 & 1093.80 & \text { Ref. } 20 \\ 800.0 & 1180.00 & \text { Ref. 20 } \\ 1000.0 & 1224.72 & \text { Ref. 20 } \\ 1500.0 & 1296.15 & \text { Ref. 20 } \\ 2327.0 & 1383.03 & \text { Ref. 20 } \\ 2327.01 & 1420.77 & \text { Ref. 20 } \\ 5000.0 & 1420.77 & \text { Ref. 20 }\end{array}$

\subsection{Cadmium}

The default tabular values of specific heat capacity as a function of temperature for Cadmium are listed below. Constant extrapolation is allowed from both ends of the tabulated range.

Temp (K) Specific Heat Capacity $(\mathrm{J} / \mathrm{kg}-\mathrm{K})$ Data Source

$\begin{array}{rrr}298.15 & 231.30 & \text { Ref. 18 } \\ 400.00 & 241.80 & \text { Ref. 18 } \\ 500.00 & 252.60 & \text { Ref. 18 } \\ 594.00 & 263.70 & \text { Ref. 18 } \\ 594.01 & 264.40 & \text { Ref. 18 } \\ 600.00 & 264.40 & \text { Ref. 18 } \\ 1040.00 & 264.40 & \text { Ref. 18 }\end{array}$


MP Package Reference Manual

\subsection{Stainless Steel 304}

The default tabular values of specific heat capacity as a function of temperature for Stainless Steel 304 are listed below. Constant extrapolation is allowed from both ends of the tabulated range.

\section{Temp (K) Specific Heat Capacity $(\mathrm{J} / \mathrm{kg}-\mathrm{K})$ Data Source}

$\begin{array}{rll}300.00 & 513.20 & \text { Ref. 18 } \\ 400.00 & 526.90 & \text { Ref. 18 } \\ 500.00 & 540.40 & \text { Ref. 18 } \\ 600.00 & 553.90 & \text { Ref. 18 } \\ 700.00 & 567.50 & \text { Ref. 18 } \\ 800.00 & 581.10 & \text { Ref. 18 } \\ 900.00 & 594.70 & \text { Ref. 18 } \\ 1000.00 & 608.20 & \text { Ref. 18 } \\ 1100.00 & 621.80 & \text { Ref. 18 } \\ 1200.00 & 635.40 & \text { Ref. 18 } \\ 1300.00 & 648.90 & \text { Ref. 18 } \\ 1400.00 & 662.50 & \text { Ref. 18 } \\ 1500.00 & 676.80 & \text { Ref. 18 } \\ 1600.00 & 689.60 & \text { Ref. 18 } \\ 1700.00 & 703.20 & \text { Ref. 18 } \\ 1700.01 & 800.10 & \text { Ref. 18 } \\ 1800.00 & 800.10 & \text { Ref. 18 } \\ 3000.00 & 800.10 & \text { Ref. 18 }\end{array}$




\subsection{Lithium Aluminum}

The default tabular values of specific heat capacity as a function of temperature for Lithium Aluminum are listed below. Constant extrapolation is allowed from both ends of the tabulated range.

\begin{tabular}{|c|c|c|}
\hline Temp (K) & Specific Heat Capacity $(\mathrm{J} / \mathrm{kg}-\mathrm{K})$ & Data Source \\
\hline 298.15 & 953.50 & Ref. 18 \\
\hline 313.15 & 960.80 & Ref. 18 \\
\hline 353.15 & 981.30 & Ref. 18 \\
\hline 393.15 & 1002.60 & Ref. 18 \\
\hline 433.15 & 1024.10 & Ref. 18 \\
\hline 473.15 & 1046.10 & Ref. 18 \\
\hline $513.10^{*}$ & 1063.50 & Ref. 18* \\
\hline 553.15 & 1080.10 & Ref. 18 \\
\hline 593.15 & 1098.40 & Ref. 18 \\
\hline 633.15 & 1116.10 & Ref. 18 \\
\hline 673.15 & 1133.80 & Ref. 18 \\
\hline 713.15 & 1152.10 & Ref. 18 \\
\hline 753.15 & 1170.80 & Ref. 18 \\
\hline 793.15 & 1189.60 & Ref. 18 \\
\hline 833.15 & 1208.40 & Ref. 18 \\
\hline 873.15 & 1227.50 & Ref. 18 \\
\hline 917.00 & 1250.00 & Ref. 18 \\
\hline 917.01 & 1232.50 & Ref. 18 \\
\hline 1000.00 & 1232.50 & Ref. 18 \\
\hline 1100.00 & 1232.40 & Ref. 18 \\
\hline 1200.00 & 1232.20 & Ref. 18 \\
\hline
\end{tabular}

* Value differs slightly from reference. MELCOR/SR-Mod3 Fortran value is used. 


\section{MP Package Reference Manual}

\subsection{Uranium Aluminum}

The default tabular values of specific heat capacity as a function of temperature for Uranium Aluminum are listed below. Constant extrapolation is allowed from both ends of the tabulated range.

\begin{tabular}{|c|c|c|}
\hline Temp (K) & Specific Heat Capacity $(\mathrm{J} / \mathrm{kg}-\mathrm{K})$ & Data Source \\
\hline 293.15 & 663.80 & Ref. 18 \\
\hline 333.15 & 677.10 & Ref. 18 \\
\hline 373.15 & 690.60 & Ref. 18 \\
\hline 413.15 & 704.20 & Ref. 18 \\
\hline 453.15 & 718.00 & Ref. 18 \\
\hline 493.15 & 732.00 & Ref. 18 \\
\hline 533.15 & 746.00 & Ref. 18 \\
\hline 573.15 & 760.30 & Ref. 18 \\
\hline 613.15 & 774.80 & Ref. 18 \\
\hline 653.15 & 789.40 & Ref. 18 \\
\hline 693.15 & 804.20 & Ref. 18 \\
\hline 733.15 & 819.20 & Ref. 18 \\
\hline 773.15 & 834.40 & Ref. 18 \\
\hline 813.15 & 849.70 & Ref. 18 \\
\hline 853.15 & 865.30 & Ref. 18 \\
\hline 893.15 & 881.10 & Ref. 18 \\
\hline 919.00 & 891.10 & Ref. 18 \\
\hline 919.01 & 877.20 & Ref. 18 \\
\hline 962.00 & 877.20 & Ref. 18 \\
\hline 1039.00 & 877.20 & Ref. 18 \\
\hline 1123.00 & 871.60 & Ref. 18 \\
\hline 1223.00 & 871.60 & Ref. 18 \\
\hline 1305.00 & 871.60 & Ref. 18 \\
\hline 1338.00 & 871.60 & Ref. 18 \\
\hline 1500.00 & 871.60 & Ref. 18 \\
\hline
\end{tabular}




\section{THERMAL CONDUCTIVITY AS A FUNCTION OF TEMPERATURE}

The thermal conductivity may be computed from two different methods. One method, used for structural materials in the COR and HS packages, utilizes tabular data which may be either a user-specified tabular function or a MELCOR default table. The other method, used for noncondensible gases and optionally for steam and air, utilizes the Eucken correlation for single, low pressure gases and the Wassijewa equation for a combination of gases.

\subsection{Tabular}

The user-specified tabular function to define a new material or to override the default table for an existing material is invoked by using a standard tabular function to input the thermal conductivity $(\mathrm{W} / \mathrm{m}-\mathrm{K})$ as a function of temperature $(\mathrm{K})$.

The following materials have default tables for thermal conductivity:

Water
Steam
Air
Zircaloy
Zirconium Oxide
Uranium Dioxide
Stainless Steel
Stainless Steel Oxide
Boron Carbide
Silver-Indium-Cadmium
Uranium Metal
Graphite
Concrete
Aluminum
Aluminum Oxide
Cadmium
Stainless Steel 304
Lithium Aluminum
Uranium Aluminum

The default thermal conductivity values are computed by linear interpolation of the tabulated values listed below. Data sources are given with each table. 
MP Package Reference Manual

\subsubsection{Water}

The default tabular values of thermal conductivity as a function of temperature for liquid water are listed below. No extrapolation is allowed.

\section{Temp (K) Thermal Conductivity (W/m-K) Data Source}

255.37

273.15

283.15

293.15

303.15

313.15

323.15

333.15

343.15

353.15

363.15

373.15

383.15

393.15

403.15

413.15

423.15

433.15

443.15

453.15

463.15

473.15

483.15

493.15

503.15

513.15

523.15

533.15

543.15

553.15

563.15

573.15

583.15

593.15

603.15

613.15

623.15

633.15

647.245
0.551

0.569

0.586

0.602

0.617

0.630

0.643

0.653

0.662

0.669

0.675

0.680

0.683

0.685

0.687

0.687

0.686

0.684

0.681

0.676

0.671

0.664

0.657

0.648

0.639

0.629

0.617

0.604

0.589

0.573

0.557

0.540

0.522

0.503

0.482

0.460

0.435

0.401

0.318
Ref. 7

Ref. 7

Ref. 7

Ref. 7

Ref. 7

Ref. 7

Ref. 7

Ref. 7

Ref. 7

Ref. 7

Ref. 7

Ref. 7

Ref. 7

Ref. 7

Ref. 7

Ref. 7

Ref. 7

Ref. 7

Ref. 7

Ref. 7

Ref. 7

Ref. 7

Ref. 7

Ref. 7

Ref. 7

Ref. 7

Ref. 7

Ref. 7

Ref. 7

Ref. 7

Ref. 7

Ref. 7

Ref. 7

Ref. 7

Ref. 7

Ref. 7

Ref. 7

Ref. 7

Ref. 7, extrapolated to critical point 


\section{MP Package Reference Manual}

\subsubsection{Steam}

The default tabular values of thermal conductivity as a function of temperature for Steam are listed below. Constant extrapolation is allowed from the upper end of the tabulated range. No extrapolation is allowed from the lower end of the tabulated range.

\begin{tabular}{lcl} 
Temp $(K)$ & Thermal Conductivity $(W / \mathrm{m}-\mathrm{K})$ & Data Source \\
\cline { 2 - 3 } 255.37 & & \\
273.15 & 0.0144 & Ref. 7 \\
293.15 & 0.0176 & Ref. 7 \\
313.15 & 0.0188 & Ref. 7 \\
333.15 & 0.0201 & Ref. 7 \\
353.15 & 0.0216 & Ref. 7 \\
373.15 & 0.0231 & Ref. 7 \\
393.15 & 0.0245 & Ref. 7 \\
413.15 & 0.0260 & Ref. 7 \\
433.15 & 0.0277 & Ref. 7 \\
453.15 & 0.0295 & Ref. 7 \\
473.15 & 0.0313 & Ref. 7 \\
493.15 & 0.0331 & Ref. 7 \\
513.15 & 0.0351 & Ref. 7 \\
533.15 & 0.0371 & Ref. 7 \\
553.15 & 0.0391 & Ref. 7 \\
573.15 & 0.0412 & Ref. 7 \\
593.15 & 0.0433 & Ref. 7 \\
613.15 & 0.0455 & Ref. 7 \\
633.15 & 0.0478 & Ref. 7 \\
653.15 & 0.0501 & Ref. 7 \\
673.15 & 0.0525 & Ref. 7 \\
693.15 & 0.0548 & Ref. 7 \\
713.15 & 0.0573 & Ref. 7 \\
733.15 & 0.0597 & Ref. 7 \\
753.15 & 0.0622 & Ref. 7 \\
773.15 & 0.0648 & Ref. 7 \\
793.15 & 0.0673 & Ref. 7 \\
813.15 & 0.0699 & Ref. 7 \\
833.15 & 0.0725 & Ref. 7 \\
853.15 & 0.0752 & Ref. 7 \\
873.15 & 0.0778 & Ref. 7 \\
893.15 & 0.0805 & Ref. 7 \\
913.15 & 0.0832 & Ref. 7 \\
933.15 & 0.0859 & Ref. 7 \\
953.15 & 0.0887 & Ref. 7 \\
& 0.0914 & Ref. 7 \\
\hline & &
\end{tabular}

(Continued on next Page) 
MP Package Reference Manual

(Continued)

Temp (K) Thermal Conductivity (W/m-K)

973.15
993.15
1013.15
1033.15
1053.15
1073.15
1200.00
1400.00
1600.00
1800.00
2000.00
2200.00
2400.00
2600.00
2800.00
3000.00
3200.00
3400.00
3600.00
3800.00
4000.00

0.0942

0.0970

0.0998

0.1026

0.1054

0.1081

0.130

0.187

0.219

0.263

0.333

0.459

0.690

1.110

1.820

2.940

4.495

6.625

7.610

7.765

7.280

\section{Data Source}

Ref. 7

Ref. 7

Ref. 7

Ref. 7

Ref. 7

Ref. 7

Ref. 7

Ref. 7

Ref. 7

Ref. 7

Ref. 7

Ref. 7

Ref. 7

Ref. 7

Ref. 7

Ref. 7

Ref. 7

Ref. 7

Ref. 7

Ref. 7

Ref. 7

\subsubsection{Air}

The default tabular values of thermal conductivity as a function of temperature for Air are listed below. Linear extrapolation is allowed from the upper end of the tabulated range. No extrapolation is allowed from the lower end of the tabulated range.

\begin{tabular}{ccc} 
Temp (K) & Thermal Conductivity $(\mathrm{W} / \mathrm{m}-\mathrm{K})$ & Data Source \\
\cline { 2 - 3 } 255.370 & 0.0227081 & Ref. 17 \\
310.926 & 0.0270005 & Ref. 17 \\
366.482 & 0.0311544 & Ref. 17 \\
422.038 & 0.0360006 & Ref. 17 \\
477.594 & 0.0399815 & Ref. 17 \\
533.150 & 0.0425777 & Ref. 17 \\
588.706 & 0.0458662 & Ref. 17 \\
644.262 & 0.0491547 & Ref. 17 \\
699.818 & 0.0524432 & Ref. 17 \\
755.374 & 0.0553856 & Ref. 17 \\
810.930 & 0.0583280 & Ref. 17 \\
& (Continued on next page)
\end{tabular}


(Continued)

\begin{tabular}{|c|c|c|}
\hline Temp (K) & Thermal Conductivity $(\mathrm{W} / \mathrm{m}-\mathrm{K})$ & Data Source \\
\hline 866.486 & 0.0610972 & Ref. 17 \\
\hline 922.042 & 0.0638665 & Ref. 17 \\
\hline 977.598 & 0.0664627 & Ref. 17 \\
\hline 1033.154 & 0.0690589 & Ref. 17 \\
\hline 1088.710 & 0.0718282 & Ref. 17 \\
\hline 1144.266 & 0.0740782 & Ref. 17 \\
\hline 1199.822 & 0.0763283 & Ref. 17 \\
\hline 1255.378 & 0.0785783 & Ref. 17 \\
\hline 1310.934 & 0.0808284 & Ref. 17 \\
\hline 1366.490 & 0.0830784 & Ref. 17 \\
\hline 1422.046 & 0.0853284 & Ref. 17 \\
\hline 1477.602 & 0.0874054 & Ref. 17 \\
\hline 1533.158 & 0.0896554 & Ref. 17 \\
\hline 1588.714 & 0.0920786 & Ref. 17 \\
\hline 1644.270 & 0.0941555 & Ref. 17 \\
\hline 1699.826 & 0.0960594 & Ref. 17 \\
\hline 1755.382 & 0.0979633 & Ref. 17 \\
\hline 1810.938 & 0.0998672 & Ref. 17 \\
\hline 1866.494 & 0.101425 & Ref. 17 \\
\hline 1922.050 & 0.103156 & Ref. 17 \\
\hline 1977.606 & 0.105060 & Ref. 17 \\
\hline 2033.162 & 0.107137 & Ref. 17 \\
\hline 2088.718 & 0.209040 & Ref. 17 \\
\hline 2144.274 & 0.110425 & Ref. 17 \\
\hline 2199.830 & 0.111810 & Ref. 17 \\
\hline 2255.386 & 0.113367 & Ref. 17 \\
\hline 2310.942 & 0.115098 & Ref. 17 \\
\hline 2366.498 & 0.116829 & Ref. 17 \\
\hline 2422.054 & 0.113367 & Ref. 17 \\
\hline 2477.610 & 0.120118 & Ref. 17 \\
\hline 2533.166 & 0.121675 & Ref. 17 \\
\hline
\end{tabular}




\section{MP Package Reference Manual}

\subsubsection{Zircaloy}

The default tabular values of thermal conductivity as a function of temperature for Zircaloy are listed below. No extrapolation is allowed.

\begin{tabular}{ccl} 
Temp $(\mathrm{K})$ & Thermal Conductivity $(\mathrm{W} / \mathrm{m}-\mathrm{K})$ & \\
\cline { 2 - 3 } 273.15 & 12.1 & Data Source \\
293.2 & 12.6 & Ref. 1, p. 218, formula \\
473.2 & 14.5 & Ref. 1, p. 221, Zircaloy-2 \\
673.2 & 17.0 & Ref. 1, p. 221, Zircaloy-2 \\
873.2 & 19.9 & Ref. 1, p. 221, Zircaloy-2 \\
1073.2 & 23.1 & Ref. 1, p. 221, Zircaloy-2 \\
1269.2 & 26.2 & Ref. 1, p. 221, Zircaloy-2 \\
1508.2 & 31.7 & Ref. 1, p. 219, Zircaloy-4 \\
1624.2 & 36.3 & Ref. 1, p. 219, Zircaloy-4 \\
1771.2 & 41.8 & Ref. 1, p. 219, Zircaloy-4 \\
2098.2 & 58.4 & Ref. 1, p. 219, Zircaloy-4 \\
5000.0 & 58.4 & Ref. 1, p. 218, formula \\
& & Constant beyond melting point \\
& & of 2098 K
\end{tabular}

\subsubsection{Zirconium Oxide}

The default tabular values of thermal conductivity as a function of temperature for Zirconium Oxide are listed below. No extrapolation is allowed.

\begin{tabular}{|c|c|c|}
\hline Temp (K) & Thermal Conductivity $(\mathrm{W} / \mathrm{m}-\mathrm{K})$ & Data Source \\
\hline 273.15 & 1.94 & Ref. 1, p. 224 , formula \\
\hline 500.0 & 1.98 & Ref. 1 , p. 224 , formula \\
\hline 750.0 & 2.06 & Ref. 1 , p. 224 , formula \\
\hline 1000.0 & 2.17 & Ref. 1, p. 224 , formula \\
\hline 1250.0 & 2.28 & Ref. 1 , p. 224 , formula \\
\hline 1500.0 & 2.39 & Ref. 1 , p. 224 , formula \\
\hline 2000.0 & 2.49 & Ref. 1, p. 224 , formula \\
\hline 5000.0 & 2.49 & $\begin{array}{l}\text { Constant beyond maximum } \\
\text { at } 2000 \mathrm{~K}\end{array}$ \\
\hline
\end{tabular}


MP Package Reference Manual

\subsubsection{Uranium Dioxide}

The default tabular values of thermal conductivity as a function of temperature for Uranium Dioxide are listed below. No extrapolation is allowed.

\begin{tabular}{|c|c|c|}
\hline Temp (K) & Thermal Conductivity $(\mathrm{W} / \mathrm{m}-\mathrm{K})$ & Data Source \\
\hline 273.15 & 9.24 & Ref. 6, p. 104 , extrapolated \\
\hline 366.3 & 7.79 & Ref. 6, p. 104 \\
\hline 539.0 & 6.53 & Ref. 1, p. 30 \\
\hline 757.0 & 4.92 & Ref. 1, p. 30 \\
\hline 995.0 & 3.87 & Ref. 1, p. 30 \\
\hline 1182.0 & 3.20 & Ref. 1, p. 30 \\
\hline 1490.0 & 2.53 & Ref. 1, p. 30 \\
\hline 1779.0 & 2.19 & Ref. 1, p. 30 \\
\hline 1975.0 & 2.17 & Ref. 1, p. 30 \\
\hline 2181.0 & 2.25 & Ref. 1, p. 30 \\
\hline 2373.0 & 2.56 & Ref. 1, p. 30 \\
\hline 2577.0 & 2.80 & Ref. 1, p. 35 \\
\hline 2773.0 & 3.15 & Ref. 1, p. 35 \\
\hline 3026.0 & 3.75 & Ref. 1, p. 35 \\
\hline 3113.0 & 3.96 & Ref. 1, p. 35 , extrapolated \\
\hline 5000.0 & 3.96 & $\begin{array}{l}\text { Constant beyond melting point } \\
\text { of } 3113 \mathrm{~K}\end{array}$ \\
\hline
\end{tabular}

\subsubsection{Stainless Steel (SS)}

The default tabular values of thermal conductivity as a function of temperature for Stainless Steel (SS), type 347, are listed below. No extrapolation is allowed.

$\underline{\text { Temp }(\mathrm{K})}$ Thermal Conductivity $(\mathrm{W} / \mathrm{m}-\mathrm{K})$ Data Source

$\begin{array}{rr}273.15 & 13.8 \\ 400.0 & 15.8 \\ 600.0 & 18.9 \\ 800.0 & 21.9 \\ 1000.0 & 24.7 \\ 1700.0 & 34.5 \\ 5000.0 & 34.5\end{array}$

Ref. 4, p. 757, extrapolated

Ref. 4, p. 757

Ref. 4, p. 757

Ref. 4 , p. 757

Ref. 4, p. 757

Ref. 4, p. 757, extrapolated Constant beyond melting point of $1700 \mathrm{~K}$ 


\section{MP Package Reference Manual}

\subsubsection{Stainless Steel Oxide}

The default tabular values of thermal conductivity as a function of temperature for Stainless Steel Oxide are listed below.

Temp (K) Thermal Conductivity (W/m-K) $\quad$ Data Source

$\begin{array}{ccc}273.15 & 20.0 & \text { Estimated }\end{array}$

$\begin{array}{lll}5000.0 & 20.0 & \text { Estimated }\end{array}$

\subsubsection{Boron Carbide}

The default tabular values of thermal conductivity as a function of temperature for Boron Carbide are listed below. No extrapolation is allowed.

Temp (K) Thermal Conductivity $(\mathrm{W} / \mathrm{m}-\mathrm{K})$ Data Source

$\begin{array}{lll}273.15 & 2.0 & \text { Estimated }\end{array}$

\subsubsection{Silver-Indium-Cadmium}

The default tabular values of thermal conductivity as a function of temperature for SilverIndium-Cadmium are listed below. No extrapolation is allowed.

Temp (K) Thermal Conductivity $(\mathrm{W} / \mathrm{m}-\mathrm{K})$ Data Source

$\begin{array}{rrr}300.0 & 57.088 & \text { Ref. 2 } \\ 400.0 & 64.992 & \text { Ref. 2 } \\ 500.0 & 72.010 & \text { Ref. 2 } \\ 600.0 & 78.140 & \text { Ref. 2 } \\ 700.0 & 83.384 & \text { Ref. 2 } \\ 800.0 & 87.740 & \text { Ref. 2 } \\ 900.0 & 91.208 & \text { Ref. 2 } \\ 1000.0 & 93.790 & \text { Ref. 2 } \\ 1050.0 & 94.748 & \text { Ref. 2 } \\ 1075.0 & 48.000 & \text { Ref. 2 } \\ 5000.0 & 48.000 & \text { Ref. 2 }\end{array}$


MP Package Reference Manual

\subsubsection{Uranium Metal}

The default tabular values of thermal conductivity as a function of temperature for Uranium Metal are listed below. No extrapolation is allowed.

\begin{tabular}{|c|c|c|}
\hline Temp (K) & Thermal Conductivity $(\mathrm{W} / \mathrm{m}-\mathrm{K})$ & Data Source \\
\hline 273.15 & 24.31 & Ref. 6, p. 104 , extrapolated \\
\hline 298.0 & 25.12 & Ref. 6, p. 104 \\
\hline 366.3 & 27.34 & Ref. 6, p. 104 \\
\hline 421.9 & 28.38 & Ref. 6, p. 104 \\
\hline 477.4 & 29.34 & Ref. 6, p. 104 \\
\hline 533.0 & 30.28 & Ref. 6, p. 104 \\
\hline 588.6 & 31.32 & Ref. 6 , p. 104 \\
\hline 644.1 & 32.22 & Ref. 6, p. 104 \\
\hline 699.7 & 33.22 & Ref. 6, p. 104 \\
\hline 755.2 & 34.09 & Ref. 6, p. 104 \\
\hline 810.8 & 35.04 & Ref. 6, p. 104 \\
\hline 866.3 & 35.90 & Ref. 6, p. 104 \\
\hline 921.9 & 36.68 & Ref. 6, p. 104 \\
\hline 977.4 & 37.37 & Ref. 6, p. 104 \\
\hline 1033.0 & 38.07 & Ref. 6, p. 104 \\
\hline 1406.0 & 42.77 & Ref. 6, p. 104, extrapolated \\
\hline 5000.0 & 42.77 & $\begin{array}{l}\text { Constant beyond melting point of } \\
1406 \mathrm{~K}\end{array}$ \\
\hline
\end{tabular}


MP Package Reference Manual

\subsubsection{Graphite}

The default tabular values of thermal conductivity as a function of temperature for Graphite are listed below. No extrapolation is allowed.

Temp (K) Thermal Conductivity $(\mathrm{W} / \mathrm{m}-\mathrm{K}) \quad$ Data Source

$\begin{array}{ccc}273.15 & 35.55 & \text { Ref. 8, irradiated graphite } \\ 5000.0 & 35.55 & \text { Ref. 8, irradiated graphite }\end{array}$

\subsubsection{Concrete}

The default tabular values of thermal conductivity as a function of temperature for Concrete are listed below. No extrapolation is allowed.

Temp (K) Thermal Conductivity $(\mathrm{W} / \mathrm{m}-\mathrm{K}) \quad$ Data Source

$\begin{array}{lll}273.15 & 0.9344 & \text { Ref. 3, p. 635, stone concrete } \\ & & \text { @ } 294 \mathrm{~K} \\ 5000.0 & 0.9344 & \text { Ref. } 3, \mathrm{p} .635, \text { stone concrete } \\ & & @ 294 \mathrm{~K}\end{array}$

\subsubsection{Aluminum}

The default tabular values of thermal conductivity as a function of temperature for Aluminum are listed below. Constant extrapolation is allowed from both ends of the tabulated range.

\begin{tabular}{rrr} 
Temp $(\mathrm{K})$ & Thermal Conductivity $(\mathrm{W} / \mathrm{m}-\mathrm{K})$ & Data Sour \\
\cline { 2 - 3 } 273.15 & 236.00 & Ref. 18 \\
300.00 & 237.00 & Ref. 18 \\
350.00 & 240.00 & Ref. 18 \\
400.00 & 240.00 & Ref. 18 \\
500.00 & 237.00 & Ref. 18 \\
600.00 & 232.00 & Ref. 18 \\
700.00 & 226.00 & Ref. 18 \\
800.00 & 220.00 & Ref. 18 \\
900.00 & 213.00 & Ref. 18 \\
933.00 & 211.00 & Ref. 18 \\
933.01 & 90.70 & Ref. 18 \\
1000.00 & 93.00 & Ref. 18 \\
1100.00 & 96.40 & Ref. 18 \\
1200.00 & 99.40 & Ref. 18 \\
1300.00 & 102.00 & Ref. 18
\end{tabular}




\subsubsection{Aluminum Oxide}

The default tabular values of thermal conductivity as a function of temperature for Aluminum Oxide are listed below. Constant extrapolation is allowed from both ends of the tabular range.

\begin{tabular}{|c|c|c|}
\hline Temp (K) & Thermal Conductivity $(\mathrm{W} / \mathrm{m}-\mathrm{K})$ & Data Source \\
\hline 273.15 & 18.73 & Ref. 20 \\
\hline 300.0 & 17.27 & Ref. 20 \\
\hline 350.0 & 15.12 & Ref. 20 \\
\hline 400.0 & 13.47 & Ref. 20 \\
\hline 500.0 & 11.11 & Ref. 20 \\
\hline 600.0 & 9.49 & Ref. 20 \\
\hline 700.0 & 8.31 & Ref. 20 \\
\hline 800.0 & 7.41 & Ref. 20 \\
\hline 900.0 & 6.69 & Ref. 20 \\
\hline 1000.0 & 6.11 & Ref. 20 \\
\hline 1200.0 & 5.22 & Ref. 20 \\
\hline 1400.0 & 4.57 & Ref. 20 \\
\hline 1600.0 & 4.07 & Ref. 20 \\
\hline 1800.0 & 3.68 & Ref. 20 \\
\hline 2000.0 & 3.36 & Ref. 20 \\
\hline 2400.0 & 2.87 & Ref. 20 \\
\hline 2800.0 & 2.51 & Ref. 20 \\
\hline 3400.0 & 2.12 & Ref. 20 \\
\hline 4200.0 & 1.77 & Ref. 20 \\
\hline 5000.0 & 1.42 & Ref. 20 \\
\hline
\end{tabular}


MP Package Reference Manual

\subsubsection{Cadmium}

The default tabular values of thermal conductivity as a function of temperature for Cadmium are listed below. Constant extrapolation is allowed from both ends of the tabulated range.

\begin{tabular}{|c|c|c|}
\hline Temp (K) & Thermal Conductivity $(\mathrm{W} / \mathrm{m}-\mathrm{K})$ & Data Source \\
\hline 273.15 & 97.50 & Ref. 18 \\
\hline 283.15 & 97.30 & Ref. 18 \\
\hline 293.15 & 97.00 & Ref. 18 \\
\hline 303.15 & 96.80 & Ref. 18 \\
\hline 313.15 & 96.60 & Ref. 18 \\
\hline 323.15 & 96.40 & Ref. 18 \\
\hline 333.15 & 96.20 & Ref. 18 \\
\hline 343.15 & 96.00 & Ref. 18 \\
\hline 353.15 & 95.70 & Ref. 18 \\
\hline 363.15 & 95.50 & Ref. 18 \\
\hline 373.15 & 95.30 & Ref. 18 \\
\hline 383.15 & 95.10 & Ref. 18 \\
\hline 393.15 & 94.90 & Ref. 18 \\
\hline 403.15 & 94.70 & Ref. 18 \\
\hline 413.15 & 94.40 & Ref. 18 \\
\hline 423.15 & 94.20 & Ref. 18 \\
\hline 433.15 & 94.00 & Ref. 18 \\
\hline 443.15 & 93.70 & Ref. 18 \\
\hline 453.15 & 93.50 & Ref. 18 \\
\hline 463.15 & 93.20 & Ref. 18 \\
\hline 473.15 & 92.90 & Ref. 18 \\
\hline 483.15 & 92.60 & Ref. 18 \\
\hline 493.15 & 92.30 & Ref. 18 \\
\hline 503.15 & 91.90 & Ref. 18 \\
\hline 513.15 & 91.60 & Ref. 18 \\
\hline 523.15 & 91.20 & Ref. 18 \\
\hline 533.15 & 90.80 & Ref. 18 \\
\hline 543.15 & 90.40 & Ref. 18 \\
\hline 553.15 & 89.90 & Ref. 18 \\
\hline 563.15 & 89.40 & Ref. 18 \\
\hline 573.15 & 88.90 & Ref. 18 \\
\hline 583.15 & 88.40 & Ref. 18 \\
\hline 594.00 & 87.90 & Ref. 18 \\
\hline 594.01 & 41.60 & Ref. 18 \\
\hline 600.00 & 42.00 & Ref. 18 \\
\hline 700.00 & 49.00 & Ref. 18 \\
\hline 800.00 & 55.90 & Ref. 18 \\
\hline 1040.00 & 72.50 & Ref. 18 \\
\hline
\end{tabular}




\subsubsection{Stainless Steel 304}

The default tabular values of thermal conductivity as a function of temperature for Stainless Steel $\mathbf{3 0 4}$ are listed below. Constant.extrapolation is allowed from the lower end of the tabulated range. Linear extrapolation is allowed from the upper end of the tabulated range.

Temp (K) Thermal Conductivity (W/m-K) Data Source

$\begin{array}{rrr}300.00 & 13.00 & \text { Ref. } 18 \\ 400.00 & 14.60 & \text { Ref. } 18 \\ 500.00 & 16.20 & \text { Ref. } 18 \\ 600.00 & 17.80 & \text { Ref. } 18 \\ 700.00 & 19.40 & \text { Ref. } 18 \\ 800.00 & 21.10 & \text { Ref. } 18 \\ 900.00 & 22.70 & \text { Ref. } 18 \\ 1000.00 & 24.30 & \text { Ref. } 18 \\ 1100.00 & 25.90 & \text { Ref. } 18 \\ 1200.00 & 27.50 & \text { Ref. } 18 \\ 1300.00 & 29.10 & \text { Ref. } 18 \\ 1400.00 & 30.80 & \text { Ref. } 18 \\ 1500.00 & 32.40 & \text { Rèf. } 18 \\ 1600.00 & 34.00 & \text { Ref. } 18 \\ 1700.00 & 35.60 & \text { Ref. } 18 \\ 1700.01 & 17.80 & \text { Ref. } 18 \\ 1800.00 & 18.10 & \text { Ref. } 18 \\ 1900.00 & 18.50 & \text { Ref. } 18 \\ 2000.00 & 18.80 & \text { Ref. } 18 \\ 2100.00 & 19.10 & \text { Ref. } 18 \\ 2200.00 & 19.40 & \text { Ref. } 18 \\ 2300.00 & 19.80 & \text { Ref. } 18 \\ 2400.00 & 20.10 & \text { Ref. } 18 \\ 2500.00 & 20.40 & \text { Ref. } 18 \\ 2600.00 & 20.70 & \text { Ref. } 18 \\ 2700.00 & 21.10 & \text { Ref. } 18 \\ 2800.00 & 21.40 & \text { Ref. } 18 \\ 2900.00 & 21.70 & \text { Ref. } 18 \\ 3000.00 & 22.00 & \text { Ref. } 18\end{array}$




\section{MP Package Reference Manual}

\subsubsection{Lithium Aluminum}

The default tabular values of thermal conductivity as a function of temperature for Lithium Aluminum are listed below. Constant extrapolation is allowed from both ends of the tabulated range.

$\underline{\text { Temp }(K)}$ Thermal Conductivity $(\mathrm{W} / \mathrm{m}-\mathrm{K})$

$\begin{array}{rr}273.15 & 236.00 \\ 300.00 & 237.00 \\ 350.00 & 240.00 \\ 400.00 & 240.00 \\ 500.00 & 237.00 \\ 600.00 & 232.00 \\ 700.00 & 226.00 \\ 800.00 & 220.00 \\ 900.00 & 213.00 \\ 933.00 & 211.00 \\ 933.01 & 90.70 \\ 1000.00 & 93.00 \\ 1100.00 & 96.40 \\ 1200.00 & 99.40 \\ 1300.00 & 102.00\end{array}$

\section{Data Source}

Ref. 18, Aluminum value Ref. 18, Aluminum value Ref. 18, Aluminum value Ref. 18, Aluminum value Ref. 18, Aluminum value Ref. 18, Aluminum value Ref. 18, Aluminum value Ref. 18, Aluminum value Ref. 18, Aluminum value Ref. 18, Aluminum value Ref. 18, Aluminum value Ref. 18, Aluminum value Ref. 18, Aluminum value Ref. 18, Aluminum value Ref. 18, Aluminum value 


\subsubsection{Uranium Aluminum}

The default tabular values of thermal conductivity as a function of temperature for Uranium Aluminum are listed below. Constant extrapolation is allowed from both ends of the tabulated range.

\begin{tabular}{rrr} 
Temp (K) & Thermal Conductivity $(\mathrm{W} / \mathrm{m}-\mathrm{K})$ & Data Sour \\
\cline { 2 - 3 } 293.15 & 142.60 & Ref. 18 \\
333.15 & 144.90 & Ref. 18 \\
373.15 & 146.80 & Ref. 18 \\
413.15 & 148.20 & Ref. 18 \\
453.15 & 149.20 & Ref. 18 \\
493.15 & 149.70 & Ref. 18 \\
533.15 & 149.80 & Ref. 18 \\
573.15 & 149.50 & Ref. 18 \\
613.15 & 148.80 & Ref. 18 \\
653.15 & 147.50 & Ref. 18 \\
693.15 & 145.90 & Ref. 18 \\
733.15 & 143.80 & Ref. 18 \\
773.15 & 141.30 & Ref. 18 \\
813.15 & 138.30 & Ref. 18 \\
853.15 & 134.90 & Ref. 18 \\
893.15 & 131.10 & Ref. 18 \\
919.00 & 128.40 & Ref. 18 \\
919.01 & 96.60 & Ref. 18 \\
962.00 & 96.60 & Ref. 18 \\
1039.00 & 97.00 & Ref. 18 \\
1123.00 & 98.60 & Ref. 18 \\
1223.00 & 99.60 & Ref. 18 \\
1305.00 & 100.00 & Ref. 18 \\
1338.00 & 100.00 & Ref. 18 \\
1500.00 & 100.00 & Ref. 18 \\
& &
\end{tabular}


MP Package Reference Manual

\subsection{Eucken Correlation for a Single, Pure Gas}

The thermal conductivity, $\lambda_{1}$, of a single low pressure gas may be computed using the Eucken correlation [14]:

$$
\lambda_{l}=\left(C_{v l}+\frac{9 R}{4 M_{l}}\right) \mu_{l} W / m-K
$$

where,

$$
\begin{aligned}
& \mathrm{C}_{\mathrm{vl}}=\quad \begin{array}{l}
\text { heat capacity at constant volume }(\mathrm{J} / \mathrm{kg}-\mathrm{K}) \text {, calculated by the NCG package (see } \\
\text { the NCG/H2O Package Reference Manual }
\end{array} \\
& R=\quad \text { universal gas constant, } 8.31441 \mathrm{~J} / \mathrm{mol}-\mathrm{K} \\
& \left.\mu_{1}=\quad \text { viscosity }(\mathrm{kg} / \mathrm{m}-\mathrm{s}), \text { calculated by the MP package (see Section } 6\right) \\
& M_{1}=\quad \text { molecular weight }(\mathrm{kg} / \mathrm{mol}) \text {, set by the NCG package }
\end{aligned}
$$




\subsection{Wassijewa Equation for a Combination of Low Pressure Gases}

The thermal conductivity, $\lambda_{\text {mlx }}$ of a combination of gases may be computed using the Wassijewa equation with the Mason and Saxena modification for the $A_{i j}$ term [14]:

$$
\lambda_{m i x}=\sum_{i=1}^{n} \frac{\lambda_{l} y_{l}}{\sum_{j=1}^{n} y_{j} A_{i j}}
$$

where,

$$
\begin{aligned}
y_{1} & =\text { mole fraction of gas } i \\
\lambda_{1} & =\text { thermal conductivity of pure gas } i \text { (see Section 5.2) } \\
A_{l}= & \frac{\left[1+\left(\mu_{l} / \mu_{l}\right)^{1 / 2}\left(M_{l} / M_{l}\right)^{1 / 4}\right]^{2}}{\left[8\left(1+M_{l} / M_{j}\right)\right]^{1 / 2}} \\
& =\frac{1}{\sqrt{8}}\left(\frac{M_{l}}{M_{l}}\right)\left(\frac{M_{l}}{M_{l}+M_{l}}\right)^{1 / 2}\left[\left(\frac{M_{l}}{M_{l}}\right)^{1 / 4}+\left(\frac{\mu_{l}}{\mu_{j}}\right)^{1 / 2}\right]^{2}
\end{aligned}
$$

$\mu_{1} \quad=$ viscosity of pure gas $\mathrm{i}(\mathrm{kg} / \mathrm{m}-\mathrm{s})$, calculated by the MP package (see Section 6 )

$M_{1}$ = molecular weight of gas $\mathrm{i}(\mathrm{kg} / \mathrm{mol})$, set by the NCG package

The mole fractions, $y_{1}$, may be expressed in terms of the gas masses, $m_{1}$, using,

$$
y_{l}=\frac{m_{l} / M_{l}}{\sum_{j=1}^{n} m_{j} / M_{j}}
$$

yielding,

$$
\lambda_{m l x}=\sum_{i=1}^{n} \frac{m \lambda_{l}}{\sum_{j=1}^{n} m_{j}\left(\frac{M_{l}}{M_{j}}\right) A_{l j}}
$$

or 
MP Package Reference Manual

$$
\lambda_{\text {mix }}=\sqrt{8} \sum_{i=1}^{n} \frac{m_{i}}{\sum_{j=1}^{n} m_{l}\left(\frac{M_{i}}{M_{j}+M_{l}}\right)^{1 / 2}\left[\left(\frac{M_{i}}{M_{j}}\right)^{1 / 4}+\left(\frac{\mu_{i}}{\mu_{j}}\right)^{1 / 2}\right]^{2}}
$$




\section{DYNAMIC VISCOSITY AS A FUNCTION OF TEMPERATURE}

The dynamic viscosity may be computed from two different methods. One method, used for structural materials in the COR and HS packages, utilizes tabular data which may be either a user-specified tabular function or a MELCOR default table. The other method, used for noncondensible gases and optionally for steam and air, utilizes the Chapman-Enskog equations for low pressure gases based on constant Lennard-Jones potential parameters, $\sigma$ and $\varepsilon / k$, which may be either user-specified or MELCOR default values.

\subsection{Tabular}

The user-specified tabular function to define a new material or to override the default table for an existing material is invoked by using a standard tabular function (see the TF Package Users' Guide) to input the viscosity ( $\mathrm{kg} / \mathrm{m}-\mathrm{s})$ as a function of temperature (K).

The following materials have default tables for viscosity:
Water
Steam
Air
Hydrogen
Deuterium

The default viscosity values are computed by linear interpolation of the tabulated values listed below. Data sources are given with each table. 


\section{MP Package Reference Manual}

\subsubsection{Water}

The default tabular values of dynamic viscosity as a function of temperature for liquid water are listed below. No extrapolation is allowed.

\begin{tabular}{lll} 
Temp $(\mathrm{K})$ & Dynamic Viscosity $(\mathrm{kg} / \mathrm{m}-\mathrm{s})$ & Data Source \\
\cline { 2 - 3 } 255.370 & 0.00264402 & Ref. 6 \\
283.148 & 0.00130962 & Ref. 6 \\
310.926 & 0.000681596 & Ref. 6 \\
338.704 & 0.000434554 & Ref. 6 \\
366.482 & 0.000305081 & Ref. 6 \\
394.260 & 0.000235136 & Ref. 6 \\
422.038 & 0.000186025 & Ref. 6 \\
449.816 & 0.000156261 & Ref. 6 \\
477.594 & 0.000135426 & Ref. 6 \\
499.850 & 0.000117267 & Ref. 6 \\
522.050 & 0.000106999 & Ref. 6 \\
544.250 & 0.0000985165 & Ref. 6 \\
566.450 & 0.0000915221 & Ref. 6 \\
588.750 & 0.0000833372 & Ref. 6 \\
610.950 & 0.0000723248 & Ref. 6 \\
633.150 & 0.0000581872 & Ref. 6 \\
647.245 & 0.0000492111 & Ref. $9, p .103$
\end{tabular}




\subsubsection{Steam}

The default tabular values of dynamic viscosity as a function of temperature for Steam are listed below. Linear extrapolation is allowed from the upper end of the tabulated range. No extrapolation is allowed from the lower end of the tabulated range.

Temp (K) Dynamic Viscosity ( $\mathrm{kg} / \mathrm{m}-\mathrm{s}) \quad$ Data Source

$\begin{array}{rll}255.15 & 0.00000724 & \text { Ref. 7 } \\ 273.15 & 0.00000804 & \text { Ref. 7 } \\ 313.15 & 0.00000966 & \text { Ref. 7 } \\ 353.15 & 0.0000113 & \text { Ref. 7 } \\ 393.15 & 0.0000129 & \text { Ref. 7 } \\ 433.15 & 0.0000146 & \text { Ref. 7 } \\ 473.15 & 0.0000162 & \text { Ref. 7 } \\ 513.15 & 0.0000178 & \text { Ref. 7 } \\ 553.15 & 0.0000194 & \text { Ref. 7 } \\ 593.15 & 0.0000211 & \text { Ref. 7 } \\ 633.15 & 0.0000227 & \text { Ref. 7 } \\ 673.15 & 0.0000243 & \text { Ref. 7 } \\ 713.15 & 0.0000260 & \text { Ref. 7 } \\ 753.15 & 0.0000276 & \text { Ref. 7 } \\ 793.15 & 0.0000292 & \text { Ref. 7 } \\ 833.15 & 0.0000308 & \text { Ref. 7 } \\ 873.15 & 0.0000325 & \text { Ref. 7 } \\ 913.15 & 0.0000341 & \text { Ref. 7 } \\ 953.15 & 0.0000357 & \text { Ref. 7 } \\ 993.15 & 0.0000375 & \text { Ref. 7 } \\ 1033.15 & 0.0000391 & \text { Ref. 7 } \\ 1073.15 & 0.0000406 & \text { Ref. 7 } \\ 1200.00 & 0.0000454 & \text { Ref. 7 } \\ 1400.00 & 0.0000512 & \text { Ref. 7 } \\ 1600.00 & 0.0000563 & \text { Ref. 7 } \\ 1800.00 & 0.0000612 & \text { Ref. 7 } \\ 2000.00 & 0.0000659 & \text { Ref. 7 } \\ 2200.00 & 0.0000703 & \text { Ref. 7 } \\ 2400.00 & 0.0000742 & \text { Ref. 7 } \\ 2600.00 & 0.0000775 & \text { Ref. 7 } \\ 2800.00 & 0.0000798 & \text { Ref. 7 } \\ 3000.00 & 0.0000810 & \text { Ref. 7 } \\ 3200.00 & 0.0000814 & \text { Ref. 7 } \\ 3400.00 & 0.0000816 & \text { Ref. 7 } \\ 3600.00 & 0.0000825 & \text { Ref. 7 } \\ 3800.00 & 0.0000851 & \text { Ref. 7 } \\ 4000.00 & 0.0000895 & \text { Ref. 7 }\end{array}$




\section{MP Package Reference Manual}

\subsubsection{Air}

The default tabular values of dynamic viscosity as a function of temperature for Air are listed below. Linear extrapolation is allowed from the upper end of the tabulated range. No extrapolation is allowed from the lower end of the tabulated range.

\begin{tabular}{rcr} 
Temp $(\mathrm{K})$ & Dynamic Viscosity $(\mathrm{kg} / \mathrm{m}-\mathrm{s})$ & Data Sol \\
\cline { 2 - 3 } 99.820 & 0.00000852739 & Ref. 7 \\
299.820 & 0.0000184686 & Ref. 7 \\
499.820 & 0.0000267132 & Ref. 7 \\
699.820 & 0.0000333208 & Ref. 7 \\
899.820 & 0.0000389908 & Ref. 7 \\
1099.820 & 0.0000439763 & Ref. 7 \\
1299.820 & 0.0000484856 & Ref. 7 \\
1499.820 & 0.0000525781 & Ref. 7 \\
1699.820 & 0.0000564325 & Ref. 7 \\
1899.820 & 0.0000599596 & Ref. 7 \\
2099.820 & 0.0000640075 & Ref. 7 \\
2299.820 & 0.0000671625 & Ref. 7 \\
2499.820 & 0.0000698561 & Ref. 7 \\
2699.820 & 0.0000723414 & Ref. 7
\end{tabular}

\subsubsection{Hydrogen}

The default tabular values of dynamic viscosity as a function of temperature for Hydrogen are listed below. Linear extrapolation is allowed from the upper end of the tabulated range. No extrapolation is allowed from the lower end of the tabulated range.

$\begin{array}{rr}\text { Temp }(\mathrm{K}) & \text { Dynamic Viscosity }(\mathrm{kg} / \mathrm{m}-\mathrm{s}) \\ 100.0 & 0.0000042105 \\ 200.0 & 0.0000068129 \\ 250.0 & 0.0000079232 \\ 280.0 & 0.0000085523 \\ 300.0 & 0.0000089594 \\ 400.0 & 0.000010867 \\ 500.0 & 0.000012642 \\ 600.0 & 0.000014290 \\ 700.0 & 0.000015846 \\ 800.0 & 0.000017335 \\ 900.0 & 0.000018756 \\ 1000.0 & 0.000020128 \\ 1100.0 & 0.000021440 \\ 1200.0 & 0.000022754 \\ 1300.0 & 0.000024078 \\ 4000.0 & 0.000059839\end{array}$

\section{Data Source}

Ref. 10, p.284

Ref. 10, p.284

Ref. 10, p.284

Ref. 10, p.284

Ref. 10, p.284

Ref. 10, p.284

Ref. 10, p.284

Ref. 10, p.284

Ref. 10, p.284

Ref. 10, p.284

Ref. 10, p.284

Ref. 10, p.284

Ref. 10, p.284

Ref. 11

Ref. 11

Ref. 11, extrapolated 
MP Package Reference Manual

\subsubsection{Deuterium}

The default tabular values of dynamic viscosity as a function of temperature for Deuterium are listed below. No extrapolation is allowed from the lower end of the tabulated range. Linear extrapolation is allowed from the upper end of the tabulated range.

Temp (K) Dynamic Viscosity (kg/m-s) Data Source

$\begin{array}{lll}100.0 & 0.00000579 & \text { Ref. } 18 \\ 120.0 & 0.00000662 & \text { Ref. 18 } \\ 140.0 & 0.00000739 & \text { Ref. 18 } \\ 160.0 & 0.00000814 & \text { Ref. 18 } \\ 180.0 & 0.00000885 & \text { Ref. 18 } \\ 200.0 & 0.00000955 & \text { Ref. 18 } \\ 220.0 & 0.00001022 & \text { Ref. 18 } \\ 240.0 & 0.00001087 & \text { Ref. 18 } \\ 260.0 & 0.00001151 & \text { Ref. 18 } \\ 280.0 & 0.00001214 & \text { Ref. 18 } \\ 300.0 & 0.00001274 & \text { Ref. 18 } \\ 320.0 & 0.00001332 & \text { Ref. 18 } \\ 340.0 & 0.00001388 & \text { Ref. 18 } \\ 360.0 & 0.00001445 & \text { Ref. 18 } \\ 380.0 & 0.00001501 & \text { Ref. } 18 \\ 400.0 & 0.00001554 & \text { Ref. 18 } \\ 420.0 & 0.00001606 & \text { Ref. } 18 \\ 440.0 & 0.00001658 & \text { Ref. } 18 \\ 460.0 & 0.00001709 & \text { Ref. 18 } \\ 480.0 & 0.00001758 & \text { Ref. 18 } \\ 500.0 & 0.00001805 & \text { Ref. 18 }\end{array}$




\section{MP Package Reference Manual}

\subsection{Chapman-Enskog Equation for a Single, Pure Gas}

The viscosity, $\mu_{1}$, of a single, low pressure gas may be computed using the Chapman-Enskog viscosity equation [15]:

$$
\mu_{i}=2.6693 \times 10^{-6} \frac{\sqrt{1000 M T}}{\sigma^{2} \Omega_{v}} \quad \mathrm{~kg} / \mathrm{m}-\mathrm{s}
$$

where

$$
\begin{array}{rlrl}
M & =\text { molecular weight }(\mathrm{kg} / \mathrm{mol}) & \\
T & =\text { gas temperature }(\mathrm{K}) & \\
\sigma & =\text { collision diameter }(\AA) & \\
\Omega_{v} & =\text { collision integral } & \\
& =2.785\left(\frac{T^{*}}{0.3}\right)^{-0.4} & & T^{*}<0.3 \text { (extrapolated) } \\
& =f\left(T^{*}\right) \quad \text { fromTable6.1 below } & & 0.3 \leq T^{*}<100 \\
& =0.5882\left(\frac{T^{*}}{100}\right)^{-0.145} & & T^{*} \geq 100 \text { (extrapolated) } \\
T^{*} & =\frac{k T}{\varepsilon} & &
\end{array}
$$

$\varepsilon / \mathrm{k}=$ characteristic energy/Boltzmann's constant $(\mathrm{K})$

The following materials have default tables for the Lennard-Jones potential parameters, $\sigma$ and $\varepsilon / k[14,19]$ :

$\underline{\sigma(\AA)} \quad \underline{\varepsilon / \mathrm{K}(\mathrm{K})}$

$\begin{array}{lcc}\text { Steam } & 2.641 & 809.1 \\ \text { Air } & 3.711 & 78.6 \\ \text { Hydrogen } & 2.827 & 59.7 \\ \text { Helium } & 2.551 & 10.22 \\ \text { Argon } & 3.542 & 93.3 \\ \text { Deuterium } & 2.948 & 39.3 \\ \text { Oxygen } & 3.467 & 106.7 \\ \text { Carbon Dioxide } & 3.941 & 195.2 \\ \text { Carbon Monoxide } & 3.690 & 91.7 \\ \text { Nitrogen } & 3.798 & 71.4 \\ \text { Nitric Oxide } & 3.492 & 116.7 \\ \text { Nitrous Oxide } & 3.828 & 232.4 \\ \text { Ammonia } & 2.900 & 558.3 \\ \text { Acetylene } & 4.033 & 231.8 \\ \text { Methane } & 3.758 & 148.6 \\ \text { Ethylene } & 4.163 & 224.7 \\ \text { Uranium Hexafluoride } & 5.967 & 236.8\end{array}$


MP Package Reference Manual

The default values for $\sigma$ and $\varepsilon / \mathrm{k}$ may be changed using the mnemonics SIG and EPS as described in the MP Users' Guide.

Table 6.1 Collision Integral, $\Omega_{y_{2}}$ as a Function of the Dimensionless Temperature, $T^{*}[15]$

\begin{tabular}{|l|l|l|l|l|l|}
\hline$T^{*}$ & $\Omega_{v}$ & $T^{*}$ & $\Omega_{v}$ & $T^{*}$ & $\Omega_{v}$ \\
\hline & & & & & \\
0.30 & 2.785 & 1.65 & 1.264 & 4.00 & 0.9700 \\
0.35 & 2.628 & 1.70 & 1.248 & 4.10 & 0.9649 \\
0.40 & 2.492 & 1.75 & 1.234 & 4.20 & 0.9600 \\
0.45 & 2.368 & 1.80 & 1.221 & 4.30 & 0.9553 \\
0.50 & 2.257 & 1.85 & 1.209 & 4.40 & 0.9507 \\
0.55 & 2.156 & 1.90 & 1.197 & 4.50 & 0.9464 \\
0.60 & 2.065 & 1.95 & 1.186 & 4.60 & 0.9422 \\
0.65 & 1.982 & 2.00 & 1.175 & 4.70 & 0.9382 \\
0.70 & 1.908 & 2.10 & 1.156 & 4.80 & 0.9343 \\
0.75 & 1.841 & 2.20 & 1.138 & 4.90 & 0.9305 \\
0.80 & 1.780 & 2.30 & 1.122 & 5.00 & 0.9269 \\
0.85 & 1.725 & 2.40 & 1.107 & 6.00 & 0.8963 \\
0.90 & 1.675 & 2.50 & 1.093 & 7.00 & 0.8727 \\
0.95 & 1.629 & 2.60 & 1.081 & 8.00 & 0.8538 \\
1.00 & 1.587 & 2.70 & 1.069 & 9.00 & 0.8379 \\
1.05 & 1.549 & 2.80 & 1.058 & 10.00 & 0.8242 \\
1.10 & 1.514 & 2.90 & 1.048 & 20.00 & 0.7432 \\
1.15 & 1.482 & 3.00 & 1.039 & 30.00 & 0.7005 \\
1.20 & 1.452 & 3.10 & 1.030 & 40.00 & 0.6718 \\
1.25 & 1.424 & 3.20 & 1.022 & 50.00 & 0.6504 \\
1.30 & 1.399 & 3.30 & 1.014 & 60.00 & 0.6335 \\
1.35 & 1.375 & 3.40 & 1.007 & 70.00 & 0.6194 \\
1.40 & 1.353 & 3.50 & 0.9999 & 80.00 & 0.6076 \\
1.45 & 1.333 & 3.60 & 0.9932 & 90.00 & 0.5973 \\
1.50 & 1.314 & 3.70 & 0.9870 & 100.00 & 0.5882 \\
1.55 & 1.296 & 3.80 & 0.9811 & & \\
1.60 & 1.279 & 3.90 & 0.9755 & & \\
\hline & & & & & \\
\hline
\end{tabular}


MP Package Reference Manual

\subsection{Chapman-Enskog Equation for a Combination of Low Pressure Gases}

The viscosity of a mixture of gases can be computed by combining the individual viscosities of the pure substances using the following equation with the Wilke's approximation for the term, $\phi_{i 1}[14]$ :

$$
\mu_{m i x}=\sum_{i=1}^{n} \frac{y \mu_{i}}{\sum_{j=1}^{n} y_{j} \phi_{i j}}
$$

where,

$y_{i}=$ mole fraction of gas $\mathrm{i}$

$\mu_{i} \quad=$ viscosity of pure gas $i$ (see Section 6.2)

$$
\begin{aligned}
\phi_{i j} & =\frac{\left[1+\left(\mu_{f} / \mu_{j}\right)^{1 / 2}\left(M_{j} / M_{i}\right)^{1 / 4}\right]^{2}}{\left[8\left(1+M_{l} / M_{j}\right)\right]^{1 / 2}} \\
& =\frac{1}{\sqrt{8}}\left(\frac{M_{f}}{M_{i}}\right)\left(\frac{M_{i}}{M_{j}+M_{i}}\right)^{1 / 2}\left[\left(\frac{M_{i}}{M_{j}}\right)^{1 / 4}\left(\frac{\mu_{l}}{\mu_{j}}\right)^{1 / 2}\right]^{2}
\end{aligned}
$$

$M_{1}=$ molecular weight of gas $i(\mathrm{~kg} / \mathrm{mol})$, set by the NCG package

The mole fractions, $y_{1}$, may be expressed in terms of the gas masses, $m_{1}$, using,

$$
y_{i}=\frac{m_{l} / M_{l}}{\sum_{k=1}^{n} m_{j} / M_{J}}
$$

yielding,

$$
\mu_{m l x}=\sum_{j=1}^{n} \frac{m \mu_{l}}{\sum_{j=1}^{n} m_{l}\left(\frac{M_{l}}{M_{j}}\right) \phi_{l j}}
$$

or

$$
\mu_{m x}=\sqrt{8} \sum_{l=1}^{n} \frac{m \mu_{l}}{\sum_{j=1}^{n} m_{j}\left(\frac{M_{i}}{M_{l}+M_{l}}\right)^{1 / 2}\left[\left(\frac{M_{l}}{M_{l}}\right)^{1 / 4}+\left(\frac{\mu_{l}}{\mu_{l}}\right)^{1 / 2}\right]^{2}}
$$




\section{BINARY MASS DIFFUSION COEFFICIENT}

The binary diffusion coefficients are computed using two different methods depending on which MELCOR package requires the information. The diffusion coefficients required for $\mathrm{COR}, \mathrm{CVH}$, and HS packages are computed by the MP package using the equations given in Section 7.1, below. RN1 utilizes the MP package noncondensible gas Lennard-Jones parameters for the calculation of fission product vapor binary diffusion coefficients as described in Section 7.2.

\subsection{Binary Mass Diffusion Coefficient as a Function of Temperature and Pressure}

The diffusion coefficient is computed from different correlations for each pair of materials. The diffusion coefficient $\left(\mathrm{m}^{2} / \mathrm{s}\right)$ is defined as a function of temperature $(K)$ and pressure $(\mathrm{Pa})$ for two pairs of materials.

For steam and air, the following correlation is used (origin unknown):

$$
D=4.7931 \times 10^{-5}\left(\frac{T^{1.9}}{P}\right)
$$

For steam and hydrogen, the correlation is taken from Reference 12:

$$
D=6.60639 \times 10^{-4}\left(\frac{T^{1.68}}{P}\right)
$$

An error message is printed if the input temperature or pressure is less than zero. There is currently no means by which the user can change these correlations. 


\section{MP Package Reference Manual}

\subsection{Chapman-Enskog Equation for a Pair of Low Pressure Gases}

The binary diffusion coefficient, $D_{A B}$, for a pair of low pressure gases may be computed using the Chapman-Enskog equation [15]:

$$
D_{A B}=1.88292 \times 10^{-2} \frac{\sqrt{T^{3}\left(\frac{0.001}{M_{A}}+\frac{0.001}{M_{B}}\right)}}{P \sigma_{A B}^{2} \Omega_{D, A B}} \quad \mathrm{~m}^{2} / \mathrm{s}
$$

where,

$$
\begin{aligned}
& M_{A}=\text { molecular weight of gas } A(\mathrm{~kg} / \mathrm{mol}) \\
& M_{B}=\text { molecular weight of gas } B(\mathrm{~kg} / \mathrm{mol}) \\
& T=\text { gas temperature }(K) \\
& \mathrm{P} \quad=\text { gas pressure }(\mathrm{Pa}) \\
& \sigma_{\mathrm{A}}=\text { collision diameter of gas } \mathrm{A}(\AA) \\
& \sigma_{B}=\text { collision diameter of gas } B(\AA) \\
& \sigma_{\mathrm{AB}}=\text { effective collision diameter of gas } \mathrm{A} \text { and } \mathrm{B}(\AA) \\
& =1 / 2\left(\sigma_{\mathrm{A}}+\sigma_{\mathrm{B}}\right) \\
& \Omega_{\mathrm{D}, \mathrm{AB}}=\text { collision integral } \\
& =2.662\left(\mathrm{~T}_{\mathrm{AB}} \cdot \mathbf{0} /\right)^{-0.5} \\
& =f\left(T_{A B}{ }^{*}\right) \text { from Table } 7.1 \text { below } \quad 0.3 \leq T_{A B}{ }^{*}<100 \\
& =0.5170\left(T_{A B} / 100\right)^{-0.155} \quad T_{A B}{ }^{*} \geq 100 \text { (extrapolated) } \\
& T_{A B}^{*}=\left(k T / \varepsilon_{A B}\right) \\
& \varepsilon_{A B} / k=\text { effective characteristic energy/Boltzmann's constant for gas } A \text { and } B(K) \\
& =1 / \mathrm{k}\left(\varepsilon_{\mathrm{A}} \varepsilon_{\mathrm{B}}\right)^{1 / 2} \\
& \varepsilon_{A} / k=\text { effective characteristic energy/Boltzmann's constant for gas } A(K) \\
& \varepsilon_{B} / k=\text { effective characteristic energy/Boltzmann's constant for gas } B(K)
\end{aligned}
$$

The table of Lennard-Jones potential parameters, $\sigma$ and $\varepsilon / k$, is given on page 29. The default values for $\sigma$ and $\varepsilon / k$ may be changed using the mnemonics SIG and EPS as described in the MP Users' Guide. 
MP Package Reference Manual

Table 7.1 Collision Integral, $\Omega_{\Omega}$, as a Function of Dimensionless Temperature, $T_{A B} \cdot[15]$

\begin{tabular}{|c|c|c|c|c|c|}
\hline $\mathrm{T}_{\mathrm{AB}} \cdot$ & $\Omega_{D}$ & $T_{A B} \cdot$ & $\Omega_{D}$ & $T_{A B} \cdot$ & $\Omega_{D}$ \\
\hline 0.30 & 2.662 & 1.65 & 1.153 & 4.00 & 0.8836 \\
\hline 0.35 & 2.476 & 1.70 & 1.140 & 4.10 & 0.8788 \\
\hline 0.40 & 2.318 & 1.75 & 1.128 & 4.20 & 0.8740 \\
\hline 0.45 & 2.184 & 1.80 & 1.116 & 4.30 & 0.8694 \\
\hline 0.50 & 2.066 & 1.85 & 1.105 & 4.40 & 0.8652 \\
\hline 0.55 & 1.966 & 1.90 & 1.094 & 4.50 & 0.8610 \\
\hline 0.60 & 1.877 & 1.95 & 1.084 & 4.60 & 0.8568 \\
\hline 0.65 & 1.798 & 2.00 & 1.075 & 4.70 & 0.8530 \\
\hline 0.70 & 1.729 & 2.10 & 1.057 & 4.80 & 0.8492 \\
\hline 0.75 & 1.667 & 2.20 & 1.041 & 4.90 & 0.8456 \\
\hline 0.80 & 1.612 & 2.30 & 1.026 & 5.00 & 0.8422 \\
\hline 0.85 & 1.562 & 2.40 & 1.012 & 6.00 & 0.8124 \\
\hline 0.90 & 1.517 & 2.50 & 0.9996 & 7.00 & 0.7896 \\
\hline 0.95 & 1.476 & 2.60 & 0.9878 & 8.00 & 0.7712 \\
\hline 1.00 & 1.439 & 2.70 & 0.9770 & 9.00 & 0.7556 \\
\hline 1.05 & 1.406 & 2.80 & 0.9672 & 10.00 & 0.7424 \\
\hline 1.10 & 1.375 & 2.90 & 0.9576 & 20.00 & 0.6640 \\
\hline 1.15 & 1.346 & 3.00 & 0.9490 & 30.00 & 0.6232 \\
\hline 1.20 & 1.320 & 3.10 & 0.9406 & 40.00 & 0.5960 \\
\hline 1.25 & 1.296 & 3.20 & 0.9328 & 50.00 & 0.5756 \\
\hline 1.30 & 1.273 & 3.30 & 0.9256 & 60.00 & 0.5596 \\
\hline 1.35 & 1.253 & 3.40 & 0.9186 & 70.00 & 0.5464 \\
\hline 1.40 & 1.233 & 3.50 & 0.9120 & 80.00 & 0.5352 \\
\hline 1.45 & 1.215 & 3.60 & 0.9058 & 90.00 & 0.5256 \\
\hline 1.50 & 1.198 & 3.70 & 0.8998 & 100.00 & 0.5170 \\
\hline 1.55 & 1.182 & 3.80 & 0.8942 & & \\
\hline 1.60 & 1.167 & 3.90 & 0.8888 & & \\
\hline
\end{tabular}


MP Package Reference Manual

\subsection{Chapman-Enskog Equation for a Combination of Low Pressure Gases}

The effective binary diffusion coefficient, $D_{1 m}$, for gas $i$ in a mixture of $m$ low pressure gases can be computed as [15]:

$$
\frac{1-y_{i}}{D_{l m}}=\sum_{j=1, * i}^{m}\left(\frac{y_{j}}{D_{i j}}\right)
$$

where,

$y_{i}=$ mole fraction of gas $i$, and

$D_{i j}=$ binary diffusion coefficient for gas pair $i, j\left(\mathrm{~m}^{2} / \mathrm{s}\right)$. 


\section{DENSITY}

The density of most materials may be computed as a constant value, a user-specified tabular function or a MELCOR default table. The default function for the densities of air and steam, however, are fixed by the code and cannot be changed through user input.

\subsection{Constant Density}

The constant density may be input by the user or read from a MELCOR default table. There are no checks made on the consistency of user-input values for enthalpy, specific heat capacity, melting temperature, and latent heat of fusion.

The following materials have default values for the constant density:

\begin{tabular}{lcl} 
Material & Density $\left(\mathrm{kg} / \mathrm{m}^{3}\right)$ & Data Source \\
\cline { 2 - 3 } & & \\
Zircaloy & 6500.0 & Ref. 13 \\
Zirconium Oxide & 5600.0 & Ref. 13 \\
Uranium Dioxide & 10960.0 & Ref. 13 \\
Stainless Steel & 7930.0 & Ref. 13 \\
Stainless Steel Oxide & 5180.0 & Ref. 13 \\
Boron Carbide & 2520.0 & Ref. 13 \\
Silver-Indium-Cadmium & 9689.4 & Ref. 2, @ 1000 K \\
Uranium Metal & 18210.0 & Ref. 6, p. 78 \\
Graphite & 1730.0 & Ref. 5, p. 436
\end{tabular}




\section{MP Package Reference Manual}

\subsection{Tabular as a Function of Temperature}

The user-specified tabular function to define a new material or to override the default table for an existing material is invoked by using a standard tabular function (see the TF Package Users' Guide) to input the density $\left(\mathrm{kg} / \mathrm{m}^{3}\right)$ as a function of temperature $(\mathrm{K})$. The densities used by the COR and FDI packages (see the users' guides for these packages) for userdefined tabular functions will be determined by evaluating the respective tabular functions at $1000 \mathrm{~K}$. If the input tabular function does not allow an evaluation to be made at $1000 \mathrm{~K}$, an input error occurs. Currently, only constant functions should be user-input, since temperature dependent values are not addressed by the HS package.

The following materials have default tables for density which may be altered through user input tabular functions:

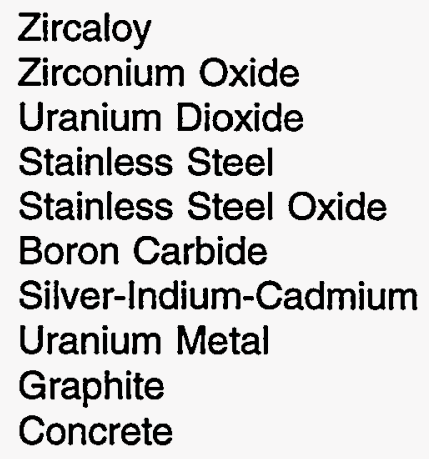

The default density values for the above materials are computed by linear interpolation of the tabulated values listed in Sections 8.2.1 through 8.2.11, below. Data sources are given with each table.

\subsubsection{Zircaloy}

The default tabular values of density as a function of temperature for Zircaloy are listed below. No extrapolation is allowed.

$\begin{array}{ccc}\text { Temp (K) } & \text { Density }\left(\mathrm{kg} / \mathrm{m}^{3}\right) & \text { Data Sour } \\ 273.15 & 6500.0 & \text { Ref. 13 } \\ 5000.0 & 6500.0 & \text { Ref. 13 }\end{array}$


MP Package Reference Manual

\subsubsection{Zirconium Oxide}

The default tabular values of density as a function of temperature for Zirconium Oxide are listed below. No extrapolation is allowed.

$\underline{\text { Temp (K) } \quad \text { Density }\left(\mathrm{kg} / \mathrm{m}^{3}\right) \quad \text { Data Source }}$

273.15

5600.0

Ref. 13

5000.0

5600.0

Ref. 13

\subsubsection{Uranium Dioxide}

The default tabular values of density as a function of temperature for Uranium Dioxide are listed below. No extrapolation is allowed.

$\underline{T e m p(K)}$

273.15

5000.0
Density $\left(\mathrm{kg} / \mathrm{m}^{3}\right)$

10960.0

10960.0
Data Source

Ref. 13

Ref. 13

\subsubsection{Stainless Steel}

The default tabular values of density as a function of temperature for Stainless Steel are listed below. No extrapolation is allowed.

$\underline{\text { Temp }(\mathrm{K})} \quad$ Density $\left(\mathrm{kg} / \mathrm{m}^{3}\right) \quad$ Data Source

273.15

7930.0

Ref. 13

5000.0

7930.0

Ref. 13

\subsubsection{Stainless Steel Oxide}

The default tabular values of density as a function of temperature for Stainless Steel Oxide are listed below. No extrapolation is allowed.

$\underline{T e m p ~(K)}$

273.15

5000.0
Density $\left(\mathrm{kg} / \mathrm{m}^{3}\right)$

5180.0

5180.0

\section{Data Source}

Ref. 13

Ref. 13 


\section{MP Package Reference Manual}

\subsubsection{Boron Carbide}

The default tabular values of density as a function of temperature for Boron Carbide are listed below. No extrapolation is allowed.

\begin{tabular}{ccl} 
Temp (K) & Density $\left(\mathrm{kg} / \mathrm{m}^{3}\right)$ & Data Source \\
\cline { 2 - 3 } 273.15 & 2520.0 & Ref. 13 \\
5000.0 & 2520.0 & Ref. 13
\end{tabular}

\subsubsection{Silver-Indium-Cadmium}

The default tabular values of density as a function of temperature for Silver-Indium-Cadmium are listed below. No extrapolation is allowed.

\begin{tabular}{lcl} 
Temp $(\mathrm{K})$ & Density $\left(\mathrm{kg} / \mathrm{m}^{3}\right)$ & Data Source \\
\cline { 2 - 3 } 273.15 & 9689.4 & Ref. 2, @ 1000 K \\
5000.0 & 9689.4 & Ref. 2, @ 1000 K
\end{tabular}




\subsubsection{Uranium Metal}

The default tabular values of density as a function of temperature for Uranium Metal are listed below. No extrapolation is allowed.

\begin{tabular}{cc} 
Temp (K) & Density (k \\
\cline { 2 - 2 } 273.15 & 19080.0 \\
298.0 & 19050.0 \\
366.3 & 18970.0 \\
477.4 & 18870.0 \\
588.6 & 18760.0 \\
699.7 & 18640.0 \\
810.8 & 18500.0 \\
921.9 & 18330.0 \\
1406.0 & 17580.0 \\
5000.0 & 17580.0
\end{tabular}

\section{Data Source}

Ref. 6, p. 78, extrapolated

Ref. 6 p. 78

Ref. 6 p. 78

Ref. 6 p. 78

Ref. 6 p. 78

Ref. 6 p. 78

Ref. 6 p. 78

Ref. 6 p. 78

Ref. 6, p. 78, extrapolated

Constant beyond melting

point of $1406 \mathrm{~K}$

\subsubsection{Graphite}

The default tabular values of density as a function of temperature for Graphite are listed below. No extrapolation is allowed.

\begin{tabular}{ccl} 
Temp (K) & Density $\left(\mathrm{kg} / \mathrm{m}^{3}\right)$ & Data Source \\
\cline { 2 - 3 } 273.15 & 1730.0 & $\begin{array}{l}\text { Ref. 5, p. 436, nuclear } \\
\text { graphite, grade A }\end{array}$ \\
5000.0 & 1730.0 & $\begin{array}{l}\text { Ref. 5, p. 436, nuclear } \\
\text { graphite, grade A }\end{array}$
\end{tabular}

\subsubsection{Concrete}

The default tabular values of density as a function of temperature for Concrete are listed below. No extrapolation is allowed.

\begin{tabular}{ccl} 
Temp (K) & Density $\left(\mathrm{kg} / \mathrm{m}^{3}\right)$ & Data Source \\
\cline { 2 - 3 } 273.15 & 2306.7 & $\begin{array}{l}\text { Ref. 3, p. 635, stone } \\
\text { concrete @ 294 K }\end{array}$ \\
5000.0 & 2306.7 & $\begin{array}{l}\text { Ref. 3, p. 635, stone } \\
\text { concrete @ 294 K }\end{array}$
\end{tabular}




\section{MP Package Reference Manual}

\subsubsection{Aluminum}

The default tabular values of density as a function of temperature for Aluminum are listed below. Constant extrapolation is allowed from the lower end of the tabulated range. Linear extrapolation is allowed from the upper end of the tabulated range.

\begin{tabular}{rcc} 
Temp $(\mathrm{K})$ & Density $\left(\mathrm{kg} / \mathrm{m}^{3}\right)$ & Data So \\
\cline { 2 - 3 } & & \\
273.15 & 2705.00 & Ref. 18 \\
300.00 & 2701.00 & Ref. 18 \\
400.00 & 2681.00 & Ref. 18 \\
500.00 & 2661.00 & Ref. 18 \\
600.00 & 2639.00 & Ref. 18 \\
800.00 & 2591.00 & Ref. 18 \\
933.00 & 2559.00 & Ref. 18 \\
933.01 & 2385.00 & Ref. 18 \\
1000.00 & 2365.00 & Ref. 18 \\
1200.00 & 2305.00 & Ref. 18 \\
1400.00 & 2255.00 & Ref. 18
\end{tabular}

\subsubsection{Aluminum Oxide}

The default tabular values of density as a function of temperature for Aluminum Oxide are listed below. Linear extrapolation is allowed from the upper end of the tabulated range.

Temp (K)

273.15

5000.0
Density $\left(\mathrm{kg} / \mathrm{m}^{3}\right)$

4000.0

4000.0
Data Source

Ref. 20

Ref. 20 


\subsubsection{Cadmium}

The default tabular values of density as a function of temperature for Cadmium are listed below. Constant extrapolation is allowed from both ends of the tabulated range.

\begin{tabular}{rrr} 
Temp $(\mathrm{K})$ & Density $\left(\mathrm{kg} / \mathrm{m}^{3}\right)$ & \\
\cline { 2 - 3 } 273.15 & & Data Sour \\
283.15 & 8670.0 & Ref. 18 \\
293.15 & 8660.0 & Ref. 18 \\
303.15 & 8650.0 & Ref. 18 \\
313.15 & 8640.0 & Ref. 18 \\
323.15 & 8630.0 & Ref. 18 \\
333.15 & 8620.0 & Ref. 18 \\
343.15 & 8610.0 & Ref. 18 \\
353.15 & 8600.0 & Ref. 18 \\
363.15 & 8590.0 & Ref. 18 \\
373.15 & 8580.0 & Ref. 18 \\
383.15 & 8570.0 & Ref. 18 \\
393.15 & 8561.0 & Ref. 18 \\
403.15 & 8551.0 & Ref. 18 \\
413.15 & 8541.0 & Ref. 18 \\
423.15 & 8531.0 & Ref. 18 \\
433.15 & 8521.0 & Ref. 18 \\
443.15 & 8511.0 & Ref. 18 \\
453.15 & 8501.0 & Ref. 18 \\
463.15 & 8491.0 & Ref. 18 \\
473.15 & 8481.0 & Ref. 18 \\
483.15 & 8470.0 & Ref. 18 \\
493.15 & 8460.0 & Ref. 18 \\
503.15 & 8450.0 & Ref. 18 \\
513.15 & 8439.0 & Ref. 18 \\
523.15 & 8428.0 & Ref. 18 \\
533.15 & 8417.0 & Ref. 18 \\
543.15 & 8406.0 & Ref. 18 \\
553.15 & 8395.0 & Ref. 18 \\
563.15 & 8384.0 & Ref. 18 \\
573.15 & 8372.0 & Ref. 18 \\
583.15 & 8360.0 & Ref. 18 \\
594.00 & 8348.0 & Ref. 18 \\
594.01 & 8336.0 & Ref. 18 \\
600.00 & 8016.0 & Ref. 18 \\
800.00 & 8010.0 & Ref. 18 \\
1000.00 & 7805.0 & Ref. 18 \\
1040.00 & 7590.0 & Ref. 18 \\
& 7547.0 & Ref. 18
\end{tabular}


MP Package Reference Manual

\subsubsection{Stainless Steel 304}

The default tabular values of density as a function of temperature for Stainless Steel 304 are listed below. Constant extrapolation is allowed from both ends of the tabulated range.

\begin{tabular}{|c|c|c|}
\hline Temp (K) & Density $\left(\mathrm{kg} / \mathrm{m}^{3}\right)$ & Data Source \\
\hline 273.15 & 8025.00 & Ref. 18 \\
\hline 323.15 & 8003.00 & Ref. 18 \\
\hline 373.15 & 7981.00 & Ref. 18 \\
\hline 423.15 & 7958.00 & Ref. 18 \\
\hline 473.15 & 7936.00 & Ref. 18 \\
\hline 523.15 & 7914.00 & Ref. 18 \\
\hline 573.15 & 7891.00 & Ref. 18 \\
\hline 623.15 & 7869.00 & Ref. 18 \\
\hline 673.15 & 7847.00 & Ref. 18 \\
\hline 723.15 & 7824.00 & Ref. 18 \\
\hline 773.15 & 7802.00 & Ref. 18 \\
\hline 823.15 & 7780.00 & Ref. 18 \\
\hline 873.15 & 7757.00 & Ref. 18 \\
\hline 923.15 & 7735.00 & Ref. 18 \\
\hline 973.15 & 7713.00 & Ref. 18 \\
\hline 1023.15 & 7690.00 & Ref. 18 \\
\hline 1073.15 & 7668.00 & Ref. 18 \\
\hline 1123.15 & 7646.00 & Ref. 18 \\
\hline 1173.15 & 7623.00 & Ref. 18 \\
\hline 1223.15 & 7601.00 & Ref. 18 \\
\hline 1273.15 & 7579.00 & Ref. 18 \\
\hline 1373.15 & 7534.00 & Ref. 18 \\
\hline 1473.15 & 7489.00 & Ref. 18 \\
\hline 1573.15 & 7445.00 & Ref. 18 \\
\hline 1673.15 & 7400.00 & Ref. 18 \\
\hline 1700.00 & 7388.00 & Ref. 18 \\
\hline 1700.01 & 6926.00 & Ref. 18 \\
\hline 1800.00 & 6862.00 & Ref. 18 \\
\hline 1900.00 & 6785.00 & Ref. 18 \\
\hline 2000.00 & 6725.00 & Ref. 18 \\
\hline 2100.00 & 6652.00 & Ref. 18 \\
\hline 2200.00 & 6576.00 & Ref. 18 \\
\hline 2300.00 & 6498.00 & Ref. 18 \\
\hline 2400.00 & 6416.00 & Ref. 18 \\
\hline 2500.00 & 6331.00 & Ref. 18 \\
\hline 2600.00 & 6243.00 & Ref. 18 \\
\hline 2700.00 & 6152.00 & Ref. 18 \\
\hline 2800.00 & 6058.00 & Ref. 18 \\
\hline 2900.00 & 5961.00 & Ref. 18 \\
\hline 3000.00 & 5861.00 & Ref. 18 \\
\hline
\end{tabular}


MP Package Reference Manual

\subsubsection{Lithium Aluminum}

The default tabular values of density as a function of temperature for Lithium Aluminum are listed below. Constant extrapolation is allowed from the lower end of the tabulated range. Linear extrapolation is allowed from the upper end of the tabulated range.

\begin{tabular}{rcc} 
Temp (K) & Density $\left(\mathrm{kg} / \mathrm{m}^{3}\right)$ & \\
\cline { 2 - 3 } 273.15 & 2664.00 & Data Sou \\
300.00 & 2660.00 & Ref. 18 \\
400.00 & 2640.00 & Ref. 18 \\
500.00 & 2620.00 & Ref. 18 \\
600.00 & 2600.00 & Ref. 18 \\
800.00 & 2551.00 & Ref. 18 \\
917.00 & 2524.00 & Ref. 18 \\
917.01 & 2348.00 & Ref. 18 \\
1000.00 & 2328.00 & Ref. 18 \\
1200.00 & 2269.00 & Ref. 18 \\
1400.00 & $2120.00^{*}$ & Ref. 18 \\
& & Ref. 18
\end{tabular}

* Value differs slightly from reference. MELCOR/SR-Mod3 Fortran value is used.

\subsubsection{Uranium Aluminum}

The default tabular values of density as a function of temperature for Uranium Aluminum are listed below. Constant extrapolation is allowed from both ends of the tabulated range.

\begin{tabular}{|c|c|c|}
\hline Temp (K) & Density $\left(\mathrm{kg} / \mathrm{m}^{3}\right)$ & Data Sol \\
\hline 400.00 & $3507.00^{*}$ & Ref. $18^{*}$ \\
\hline 500.00 & 3469.00 & Ref. 18 \\
\hline 600.00 & 3448.00 & Ref. 18 \\
\hline 700.00 & 3425.00 & Ref. 18 \\
\hline 800.00 & 3402.00 & Ref. 18 \\
\hline 919.00 & 3371.00 & Ref. 18 \\
\hline 919.01 & 3202.00 & Ref. 18 \\
\hline 962.00 & 3196.00 & Ref. 18 \\
\hline 1005.00 & 3180.00 & Ref. 18 \\
\hline 1005.01 & 3260.00 & Ref. 18 \\
\hline 1039.00 & 3197.00 & Ref. 18 \\
\hline 1123.00 & 3159.00 & Ref. 18 \\
\hline 1223.00 & 3117.00 & Ref. 18 \\
\hline 1323.00 & 3076.00 & Ref. 18 \\
\hline 1338.00 & 3071.00 & Ref. 18 \\
\hline 1400.00 & 3051.00 & Ref. 18 \\
\hline
\end{tabular}

* Value differs slightly from reference. MELCOR/SR-Mod3 Fortran value is used. 
MP Package Reference Manual

\subsection{Calculated as a Function of Temperature ancl Pressure}

The default density functions for air and steam are described in Sections 8.3.1 and 8.3.2, below. These default functions may not be altered through user-input.

\subsubsection{Air}

The density $\left(\mathrm{kg} / \mathrm{m}^{3}\right)$ of air is computed from the gas law:

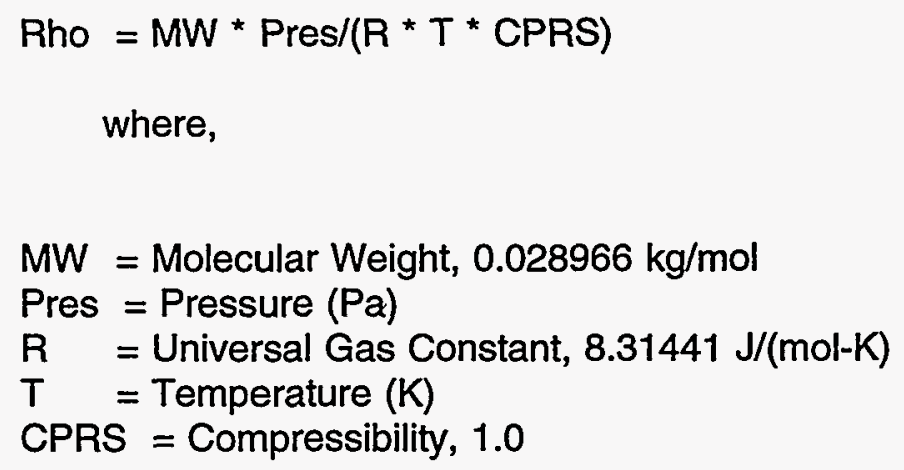

\subsubsection{Steam}

The density $\left(\mathrm{kg} / \mathrm{m}^{3}\right)$ of steam is computed from the gas law:

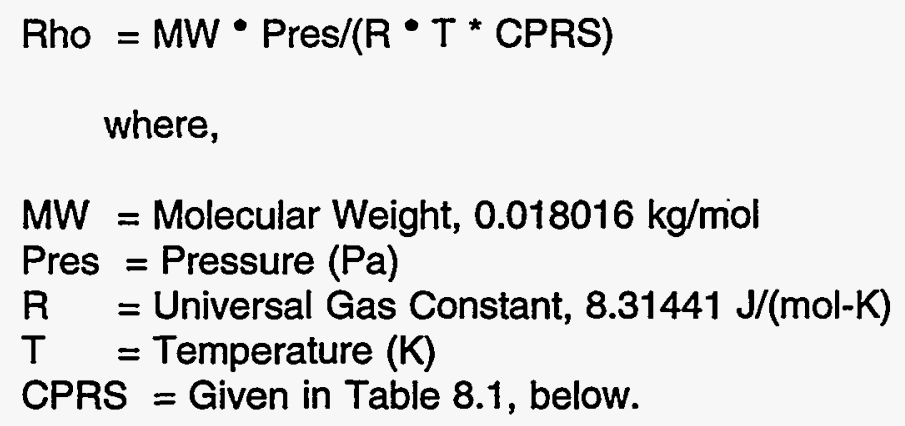


The value of CPRS is determined by standard interpolation on $T$ and $P$ for those points bounded by values from Table 8.1. For those points which lie outside the bounds of the table, various methods are used for determining CPRS. Figure 8.1 is a graphic illustration of the values shown on Table 8.1. The figure is divided into 10 regions, each of which has its own method for computing the compressibility.

Region 1: Points in this region are assigned a compressibility of 0.9978 . This corresponds to the value of CPRS at $(0.0068884 \mathrm{MPa}, 311.72 \mathrm{~K})$.

Region 2: CPRS for points in this region are computed by linear interpolation on temperature of the values for the pressure, $\mathrm{P}=0.0068884 \mathrm{MPa}$.

Region 3: Points in this region are assigned a compressibility of 1.0000 . This corresponds to the value of CPRS at $(0.0068884 \mathrm{MPa}, 1033.0 \mathrm{~K})$.

Region 4: CPRS for points in this region are computed by linear interpolation on pressure of the smallest values for the pressures on the left and right sides of $(P, T)$.

Region 5: CPRS for points in this region are computed by linear interpolation, first on temperature, then on pressure, of the bounding values on the left side and the value corresponding to the minimum temperatures on the right side.

Region 6: CPRS for points in this region are computed by linear interpolation, first on temperature, then on pressure, of the bounding values.

Region 7: Points in this region are assigned the maximum value for compressibility, 1.0000.

Region 8: Points in this region are assigned a compressibility of 0.9134 . This corresponds to the value of CPRS at (1.3786 MPa, 467.37 K).

Region 9: CPRS for points in this region are computed by linear interpolation on temperature of the values for the pressure, $\mathrm{P}=1.3786 \mathrm{MPa}$.

Region 10: Points in this region are assigned a compressibility of 0.9995 . This corresponds to the value at (1.3786 MPa, $1366.33 \mathrm{~K})$. 


\section{MP Package Reference Manual}

Table 8.1 Compressibility of Steam as a Function of Temperature (K) and Pressure (MPa) (Ref. 7)

\begin{tabular}{|c|c|c|c|c|c|c|c|}
\hline Pressure & 0.006888 & 0.034462 & 0.068953 & 0.10130 & 0.13786 & 0.27572 & 0.41358 \\
\hline \multicolumn{8}{|l|}{ Temp } \\
\hline \multicolumn{8}{|l|}{311.72} \\
\hline \multicolumn{8}{|l|}{345.34} \\
\hline \multicolumn{8}{|l|}{362.55} \\
\hline 366.33 & 0.9991 & 0.9946 & 0.9889 & & & & \\
\hline \multicolumn{8}{|l|}{372.99} \\
\hline \multicolumn{8}{|l|}{381.87} \\
\hline \multicolumn{8}{|l|}{388.55} \\
\hline \multicolumn{8}{|l|}{388.56} \\
\hline \multicolumn{8}{|l|}{403.70} \\
\hline \multicolumn{8}{|l|}{410.77} \\
\hline \multicolumn{8}{|l|}{410.78} \\
\hline \multirow{2}{*}{\multicolumn{8}{|c|}{$\begin{array}{l}417.85 \\
428.59\end{array}$}} \\
\hline & & & & & & & \\
\hline 433.00 & 0.9997 & 0.9976 & 0.9950 & 0.9925 & 0.9898 & 0.9786 & 0.9672 \\
\hline \multicolumn{8}{|l|}{437.37} \\
\hline \multicolumn{8}{|l|}{444.83} \\
\hline \multicolumn{8}{|l|}{451.38} \\
\hline \multicolumn{8}{|l|}{455.22} \\
\hline \multicolumn{8}{|l|}{457.22} \\
\hline \multicolumn{8}{|l|}{462.52} \\
\hline \multicolumn{8}{|l|}{467.37} \\
\hline \multicolumn{8}{|l|}{477.44} \\
\hline \multicolumn{8}{|l|}{$\begin{array}{l}499.67 \\
505.22\end{array}$} \\
\hline 505.22 & & & & & & & \\
\hline $\begin{array}{l}505.22 \\
533.00\end{array}$ & 1.0000 & 0.9991 & 0.9980 & 0.9969 & 0.9959 & 0.9913 & 0.9867 \\
\hline \multicolumn{8}{|l|}{560.78} \\
\hline 588.56 & 1.0000 & 0.9995 & 0.9987 & 0.9981 & 0.9973 & 0.9941 & 0.9911 \\
\hline \multirow{3}{*}{$\begin{array}{l}644.11 \\
699.67 \\
755.22\end{array}$} & 1.0000 & 0.9996 & 0.9992 & 0.9986 & 0.9982 & 0.9959 & 0.9938 \\
\hline & 1.0000 & 0.9998 & & 0.9991 & 0.9987 & 0.9971 & 0.9956 \\
\hline & & & & & & & \\
\hline \multirow{7}{*}{$\begin{array}{c}810.78 \\
921.89 \\
1033.00 \\
1144.11 \\
1255.22 \\
1366.33 \\
1477.44\end{array}$} & 1.0000 & 1.0000 & 0.9998 & 0.9996 & 0.9994 & 0.9985 & 0.9976 \\
\hline & 1.0000 & 1.0000 & 1.0000 & 0.9999 & 0.9998 & 0.9992 & 0.9987 \\
\hline & 1.0000 & 1.0000 & 1.0000 & 1.0000 & 0.9999 & 0.9997 & 0.9992 \\
\hline & & & & 1.0000 & 1.0000 & 0.9998 & 0.9998 \\
\hline & & & & & & 1.0000 & 1.0000 \\
\hline & & & & & & & 1.0000 \\
\hline & & & & & & & \\
\hline
\end{tabular}


MP Package Reference Manual

Table 8.1: Compressibility of Steam as a Function of Temperature (K) and Pressure (MPa) (Ref. 7) (Cont)

\begin{tabular}{|c|c|c|c|c|c|c|c|}
\hline Pressure & 0.55145 & 0.68931 & 0.82717 & 0.96502 & 1.1029 & 1.2407 & 1.3786 \\
\hline \multirow{2}{*}{\multicolumn{8}{|c|}{$\begin{array}{c}\text { Temp } \\
311.72\end{array}$}} \\
\hline & & & & & & & \\
\hline \multicolumn{8}{|l|}{345.34} \\
\hline \multicolumn{8}{|l|}{362.55} \\
\hline \multicolumn{8}{|l|}{366.33} \\
\hline \multicolumn{8}{|l|}{372.99} \\
\hline \multicolumn{8}{|l|}{381.87} \\
\hline \multicolumn{8}{|l|}{388.55} \\
\hline \multicolumn{8}{|l|}{388.56} \\
\hline \multicolumn{8}{|l|}{403.70} \\
\hline \multicolumn{8}{|l|}{410.77} \\
\hline \multicolumn{8}{|l|}{410.78} \\
\hline \multicolumn{8}{|l|}{417.85} \\
\hline 428.59 & 0.9528 & & & & & & \\
\hline 433.00 & 0.9552 & & & & & & \\
\hline 437.37 & & 0.9432 & & & & & \\
\hline 444.83 & & & 0.9383 & & & & \\
\hline 451.38 & & & & 0.9316 & & & \\
\hline 455.22 & 0.9646 & 0.9550 & 0.9449 & 0.9347 & & & \\
\hline 457.22 & & & & & 0.9255 & & \\
\hline 462.52 & & & & & & 0.9193 & \\
\hline 467.37 & & & & & & & 0.9134 \\
\hline 477.44 & 0.9714 & 0.9637 & 0.9561 & 0.9478 & 0.9397 & 0.9310 & 0.9223 \\
\hline 499.67 & 0.9766 & 0.9703 & & & & & \\
\hline 505.22 & & & 0.9657 & 0.9595 & 0.9533 & 0.9469 & 0.9406 \\
\hline 533.00 & 0.9822 & 0.9775 & 0.9727 & 0.9681 & 0.9630 & 0.9580 & 0.9532 \\
\hline 560.78 & & & 0.9779 & 0.9741 & 0.9701 & 0.9663 & 0.9622 \\
\hline 588.56 & 0.9880 & 0.9850 & 0.9819 & 0.9787 & 0.9756 & 0.9723 & 0.9691 \\
\hline 644.11 & 0.9916 & 0.9895 & 0.9872 & 0.9852 & 0.9830 & 0.9807 & 0.9785 \\
\hline 699.67 & 0.9940 & 0.9924 & 0.9909 & 0.9893 & 0.9877 & 0.9861 & 0.9845 \\
\hline 755.22 & & & & & & 0.9899 & 0.9887 \\
\hline 810.78 & 0.9967 & 0.9958 & 0.9950 & 0.9941 & 0.9933 & 0.9924 & 0.9916 \\
\hline 921.89 & 0.9982 & 0.9976 & 0.9971 & 0.9966 & 0.9962 & 0.9956 & 0.9951 \\
\hline 1033.00 & 0.9990 & 0.9986 & 0.9983 & 0.9980 & 0.9977 & 0.9974 & 0.9970 \\
\hline 1144.11 & 0.9994 & 0.9992 & 0.9990 & 0.9989 & 0.9986 & 0.9984 & 0.9983 \\
\hline 1255.22 & 0.9998 & 0.9996 & 0.9995 & 0.9994 & 0.9993 & 0.9991 & 0.9990 \\
\hline 1366.33 & 1.0000 & 0.9999 & 0.9998 & 0.9998 & 0.9997 & 0.9996 & 0.9995 \\
\hline 1477.44 & & 1.0000 & & & 1.0000 & & \\
\hline
\end{tabular}




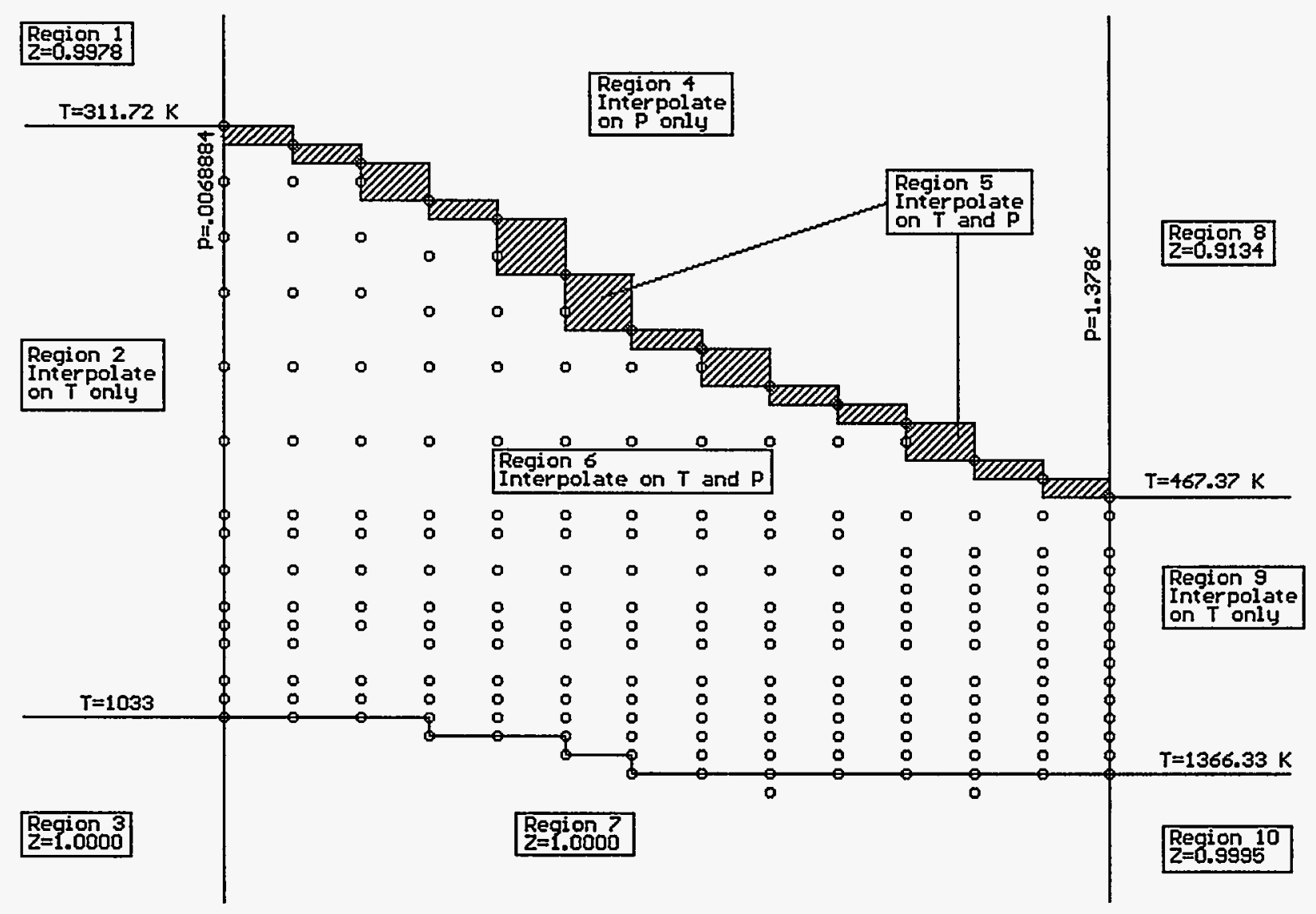

Figure 8.1: Methods for Computing the Compressibility from Table 8.1 data 


\section{CONSTANT MELTING TEMPERATURE}

The melting temperature may be input by the user or read from a MELCOR default table. There are no checks made on the consistency of user-input values for enthalpy, specific heat capacity, melting temperature, and latent heat of fusion.

The following materials have default tables for the melting temperature:

Material

Zircaloy

Zirconium Oxide

Uranium Dioxide

Stainless Steel

Stainless Steel Oxide

Boron Carbide

Silver-Indium-Cadmium

Uranium Metal

Graphite

Aluminum

Aluminum Oxide

Cadmium

Stainless Steel 304

Lithium Aluminum

Uranium Aluminum
Melt Temperature (K) Data Source

2098.0

2990.0

3113.0

1700.0

1870.0

2620.0

1075.0

1406.0

3866.0

933.0

2327.0

594.0

1700.0

917.0

1128.5
Ref. 1

Ref 13

Ref. 1

Estimated

Ref. $13, \mathrm{Fe}_{3} \mathrm{O}_{4}$

Ref. 13

Ref. 2

Ref. 13

Ref. 5

Ref. 18

Ref. 20

Ref. 18

Ref. 18

Ref. 18

Ref. 18 , average of solidus and liquidus points 
MP Package Reference Manual

MP-RM-80 


\section{CONSTANT LATENT HEAT OF FUSION}

The latent heat of fusion may be input by the user or read from a MELCOR default table. There are no checks made on the consistency of user-input values for enthalpy, specific heat capacity, melting temperature, and latent heat of fusion.

The following materials have default tables for the latent heat of fusion:

\begin{tabular}{lll} 
Material & Heat of Fusion $(\mathrm{J} / \mathrm{kg})$ & Data Source \\
\cline { 2 - 3 } Zircaloy & $2.25 \mathrm{E} 5$ & Ref. 1 \\
Zirconium Oxide & $7.07 \mathrm{E} 5$ & Ref 13 \\
Uranium Dioxide & $2.74 \mathrm{E} 5$ & Ref 1 \\
Stainless Steel & $2.68 \mathrm{E} 5$ & Estimated \\
Stainless Steel Oxide & $5.98 \mathrm{E} 5$ & Ref. $13, \mathrm{Fe}_{3} \mathrm{O}_{4}$ \\
Boron Carbide & $5.00 \mathrm{E} 5$ & Estimated \\
Silver-Indium-Cadmium & $9.80 \mathrm{E} 4$ & Ref. 2 \\
Uranium Metal & $5.025 \mathrm{E} 4$ & Ref. 5 \\
Aluminum Oxide & $1.07 \mathrm{E} 6$ & Ref. 21 \\
Aluminum & $3.978 \mathrm{E} 5$ & Ref. 18 \\
Cadmium & $5.500 \mathrm{E} 4$ & Ref. 18 \\
Stainless Steel 304 & $2.692 \mathrm{E} 5$ & Ref. 18 \\
Lithium Aluminum & $3.9845 \mathrm{E} 5$ & Ref. 18 \\
Uranium Aluminum & $2.900 \mathrm{E} 5$ & Ref. 18
\end{tabular}


MP Package Reference Manual

MP-RM-82 
MP Package Reference Manual

\section{REFERENCES}

1. D. L. Hagrman, G. A. Reymann, and R. E. Mason, MATPRO VERSION 11 (Revision 1) A Handbook of Materials Properties for Use in the Analysis of Light Water Reactor Fuel Rod Behavior, NUREG/CR-0497 and TREE-1280 Rev. 1, EG\&G Idaho, Inc., Idaho Falls, ID (February 1980).

2. D. L. Hagrman, Materials Properties for Severe Core Damage Analysis, EGG-CDD-5801, EG\&G, Idaho Falls, ID (May 1982).

3. F. Kreith, Principles of Heat Transfer, Third Edition, Intext Educational Publishers, New York (1973).

4. F. P. Incropera and D. P. Dewitt, Fundamentals of Heat Transfer, John Wiley and Sons, New York (1981).

5. CRC Handbook of Tables for Applied Engineering Science, 2nd Edition, Ed. by R. E. Bolz and G. L. Tuve, CRC Press, Inc., Boca Raton FL (1973).

6. M. M. Wakil, Nuclear Heat Transport, International Textbook Co., New York (1971).

7. N. B. Vargaftik, Handbook of Physical Properties of Liquids and "Gases: Pure Substances and Mixtures, Second Edition, Springer-Verlag (1975).

8. Heard, et al., N-Reactor Safety Enhancement Report HEDL-TC 2977 , Westinghouse Hanford Company, September 1987.

9. 1967 Steam Tables, Electrical Research Association, St. Martin's Press, New York (1967).

10. J. Hilsenrath, et al., Tables of Thermodynamic and Transport Properties, Pergamon Press, New York (1960).

11. D. R. Pitts and L. E. Sissom, Schaum's Outline of Theory and Problems of Heat Transfer, McGraw-Hill, New York (1977).

12. L. Baker and C. Just, Studies of Metal-Water Reactions at High temperatures; III. Experimental and Theoretical Studies of the Zirconium-Water Reaction, ANL6548, Argonne National Laboratory, Chicago (May 1962).

13. CRC Handbook of Chemistry and Physics, $63^{\text {rd }}$ Edition, CRC Press, Inc., Boca Raton FL (1982). 
MP Package Reference Manual

14. R. Reid, et al., The Properties of Gases and Liquids, McGraw-Hill, New York (1970).

15. R. Bird, et al., Transport Phenomena, John Wiley and Sons, Inc., New York (1960).

16. J. Keenan, F. Keyes, et al., Steam Tables, John Wiley and Sons, Inc., New York (1978).

17. E. R. G. Eckert and R. M. Drake, Jr., Heat and Mass Transfer, McGraw-Hill, New York (1959).

18. R. C. Nause, M. T. Leonard, Thermophysical Property Assessment Report for Savannah River Site Production Reactor Materials, Science Applications International Corporation, SAIC Report No. 89/6507, Rev. 1 (May 1990).

19. J. K. Fink, R. Simms, B. A. Brock, Material Properties for HWR-NPR Severe Accident Studies, Argonne National Laboratory, ANL/NPR-90/005 (March 1990).

20. Thermodynamic and Transport Properties for the CONTAIN Code, Sandia National Laboratories, NUREG/CR-5173 (December 1988).

21. CRC Handbook of Chemistry and Physics, $71^{\text {st }}$ Edition, CRC Press, Inc., Boca Raton, FL (1990). 


\title{
NonCondensible Gas (NCG) and Water (H2O) Packages Reference Manual
}

\author{
MELCOR Code Development Group \\ Modeling and Analysis Department \\ Nuclear Energy Technology Center \\ Sandia National Laboratories \\ Albuquerque, NM 87185-0739
}

Contributors:

Randall K. Cole, Jr.

J. Michael McGlaun

Samuel L. Thompson

Randall M. Summers

Noncondensible gases in the Control Volume Hydrodynamics (CVH) package are modeled as ideal gases. The constant volume heat capacity is approximated as an analytic function of temperature. The equation of state for water is based on the analytic expression for the Helmholtz function used to generate the familiar Keenan and Keyes Steam Tables. This document describes the constitutive relations used for the water and noncondensible gases equations of state, and it lists the default values of the associated constants for the gases provided in the NCG library.

User input requirements for the NCG package are described in the NCG Users' Guide. There is no input allowed for the $\mathrm{H} 2 \mathrm{O}$ package. 
NCG and H2O Packages Reference Manual

\section{NCG/H2O-RM-2}




\section{Contents}

1. NCG EQUATION OF STATE $\ldots \ldots \ldots \ldots \ldots \ldots \ldots \ldots \ldots \ldots \ldots \ldots$

1.1 Integration Constants in the Energy Function $\ldots \ldots \ldots \ldots \ldots$

2. H2O EQUATION OF STATE $\ldots \ldots \ldots \ldots \ldots \ldots \ldots \ldots \ldots \ldots \ldots \ldots$

2.1 Single-Phase Properties $\ldots \ldots \ldots \ldots \ldots \ldots \ldots \ldots \ldots \ldots$

2.2 Mixed-Phase Properties $\ldots \ldots \ldots \ldots \ldots \ldots \ldots \ldots \ldots$

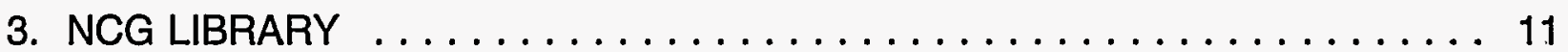

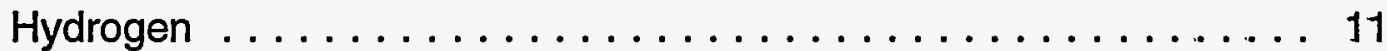

Deuterium . . . . . . . . . . . . . . . . 11

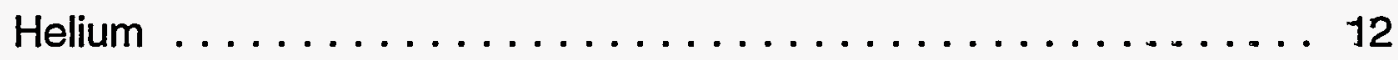

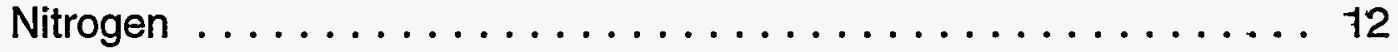

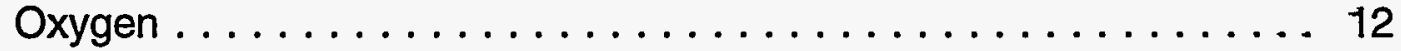

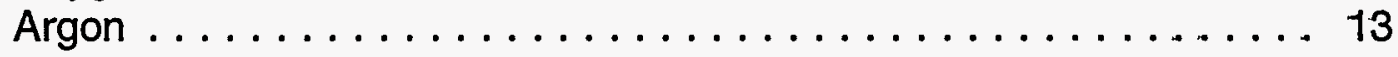

Methane ....................... 13

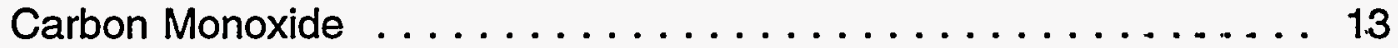

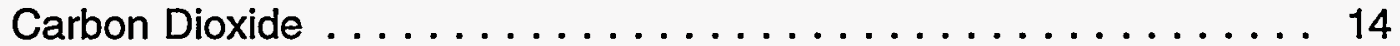

Acetylene ......................... 14

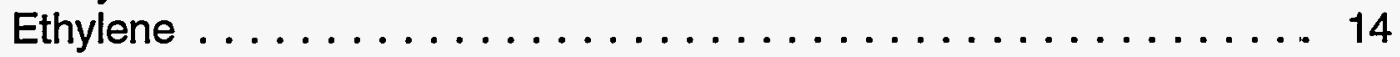

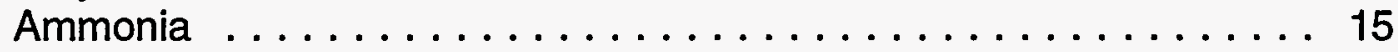

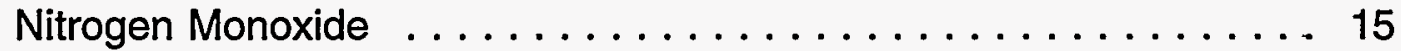

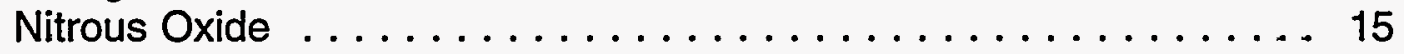

User Defined Gases . . . . . . . . . . . . . . . . . . 16

4. REFERENCES $\ldots \ldots \ldots \ldots \ldots \ldots \ldots \ldots \ldots \ldots \ldots \ldots \ldots \ldots$ 
NCG and H2O Packages Reference Manual 
NCG and H2O Packages Reference Manual

\section{NCG EQUATION OF STATE}

Noncondensible gases in the Control Volume Hydrodynamics (CVH) package are modeled as ideal gases. The specific internal energy and enthalpy of an ideal gas is a function only of its temperature, $T$, the natural state (reference) temperature $T_{n}$, its energy of formation, $e_{\text {form }}$, its enthalpy of formation, $h_{\text {form }}$, the universal gas constant, $R$, and its molecular weight, $\mathrm{w}$.

$$
\begin{aligned}
& \theta(T)=\int_{T_{n}}^{T} c_{v}(t) d t+\theta_{\text {form }} \\
& h(T)=\int_{T_{n}}^{T}\left(c_{v}(t)+\frac{R}{W}\right) d t+h_{\text {form }}
\end{aligned}
$$

The pressure, $P$, is a function of the mass density, $\rho$, the temperature, $T$, the universal gas constant, $R$, and the molecular weight, $w$,

$$
P=\frac{\rho R T}{w}
$$

The noncondensible gases in MELCOR are characterized by the temperature dependent constant volume specific heat, $c_{v}(T)$, the natural state (reference) temperature, $T_{n}$, the energy of formation, $e_{\text {form }}$, the entropy at the reference temperature, $S_{0}$ (this quantity is not currently used in the calculation but is included for completeness), and the molecular weight of the material, $w$.

The specific heat for each noncondensible gas calculated from an analytic fit in the general form

$$
c_{v}(T)=c_{v 0}+c_{v 1} T+c_{v 2} T^{2}+c_{v 3} T^{3}+\frac{c_{v s q r t}}{\sqrt{T}}+\frac{c_{v m 1}}{T}+\frac{c_{v m 2}}{T^{2}}
$$

for the temperature range $T_{\text {low }} \leq T \leq T_{\text {up }}$, where $T_{\text {low }}$ and $T_{\text {up }}$ may be different for each gas. The value at $T_{\text {low }}$ is used for $T<T_{\text {low }}$, and the value at $T_{\text {up }}$ is used for $T>T_{\text {up }}$.

Using this constitutive relation for the specific heat, the internal energy is given by

$$
\begin{aligned}
\theta(T) & =\theta_{0}+c_{v 0} T+\frac{1}{2} c_{v 1} T^{2}+\frac{1}{3} c_{v 2} T^{3}+\frac{1}{4} c_{v 3} T^{4} \\
& +2 c_{v s q r} \sqrt{T}+c_{v m 1} \ln (T)-\frac{c_{v m 2}}{T}
\end{aligned}
$$


NCG and H2O Packages Reference Manual

for $T_{\text {low }} \leq T \leq T_{h}$, and is extrapolated outside that range using the constant limiting specific heat at $T_{\text {low }}$ or $T_{\text {hi }}$. Here

$$
\begin{aligned}
e_{0} & =e_{\text {form }}-c_{v o} T_{n}-\frac{1}{2} c_{v 1} T_{n}^{2}-\frac{1}{3} c_{v 2} T_{n}^{3}-\frac{1}{4} c_{v 3} T_{n}^{4} \\
& -2 c_{v s q r t} \sqrt{T_{n}}-c_{v m 1} \ln \left(T_{n}\right)+\frac{c_{v m 2}}{T_{n}}
\end{aligned}
$$

Each of the coefficients can be specified via user input, as described in the NCG Users' Guide. Appropriate default coefficients for gases of interest from JANAF [1] and other sources are included in the noncondensible gas equation of state library, as described in Section 2. The default natural temperature used is $298.15 \mathrm{~K}$; this may be changed with sensitivity coefficient 2090.

The reader may note that the definition of $e_{0}$ is actually inconsistent unless $T_{n}$ lies in the range $T_{\text {low }} \leq T_{n} \leq T_{\text {hi }}$. For a number of gases $\left(N_{2}, \mathrm{O}_{2}, C H_{4}, C O\right.$ and $\left.C_{2}\right), T_{\text {low }}$ is $300 \mathrm{~K}$ while $T_{n}$ is 298.15. In these cases, the discrepancy is less than $10 \mathrm{~J} / \mathrm{kg}$ and is totally insignificant compared to heats of reaction (several $\mathrm{MJ} / \mathrm{kg}$ ). Although the discrepancy for $D_{2}\left(T_{\text {low }}=600 \mathrm{~K}\right)$ is significantly greater, this gas is not used in light water reactor simulations.

\subsection{Integration Constants in the Energy Function}

A modified thermochemical reference point is used in the NCG package. That is, all heats of formation of compounds are included in the enthalpy functions, as in JANAF tables. The advantage is that all heats of reaction are implicitly contained in the enthalpy functions. For example, in a reaction

$$
A+B \rightarrow A B
$$

taking place at constant temperature and pressure, total enthalpy is conserved. The heat released is the difference between the enthalpy of the reactants and that of the products. This is simply the chemists' definition of the heat of reaction,

$$
Q_{R}(T)=h_{A}(P, T)+h_{B}(P, T)-h_{A B}(P, T)
$$

Therefore, chemical reactions (such as gas combustion simulated by the Burn package) can be treated simply as changes in the masses of various materials; the associated heat effects are accounted for automatically through the equations of state.

Since only differences in enthalpy are significant, one integration constant may be chosen for each element represented in the collection of gases in the database. Conventional practice is to choose these integration constants such that the enthalpy of each element is zero in its standard state $\left(25^{\circ} \mathrm{C}, 1 \mathrm{~atm}\right.$, with the material in its most stable state). 
However, water properties in MELCOR are defined (in the $\mathrm{H} 2 \mathrm{O}$ package) consistent with Keenan and Keyes Steam Tables [2], as discussed in Section 2. Because water is formed from hydrogen and oxygen, the integration constants for hydrogen, oxygen, and water may not be chosen independently. The conventional integration constant is used for hydrogen in the NCG package, but the integration constant for oxygen has therefore been chosen such that the reference point for water vapor is consistent with that used by Keenan and Keyes. This results in a shift in the integration constant for every oxygencontaining gas in the NCG package compared to its conventional JANAF value. For all other gases, the integration constants are consistent with conventional practice.

In actuality, the reference point used will be significant only if a gas is chemically active. For current MELCOR models, the only such gases are $\mathrm{H}_{2}, \mathrm{D}_{2}, \mathrm{O}_{2}, \mathrm{CO}, \mathrm{CO}_{2}$, and $\mathrm{CH}_{4}$. $\left(\mathrm{CH}_{4}\right.$ is active only if the $\mathrm{B}_{4} \mathrm{C}$ reaction in the COR package is enabled, in which case the heat of reaction data used there are not fully compatible with NCG data.) Thus, the user need not worry much about the reference points for other (in particular, user-defined) gases. If chemically active gases are modified, the reference point energy must not be arbitrarily redefined. 
NCG and H2O Packages Reference Manual 
NCG and H2O Packages Reference Manual

\section{H2O EQUATION OF STATE}

The equation of state for water is based on the analytic expression for the Helmholtz function, $\Psi(\rho, T)$, that was used to generate the familiar Keenan and Keyes Steam Tables [2]. The expression, involving a double power series with log and exponential terms, may be found in the Appendix to the 1969 tables. It contains approximately 50 constant coefficients. These cannot be changed in MELCOR.

The Keenan and Keyes formulation is augmented by JANAF data [1] for temperatures greater than $1589 \mathrm{~K}\left(2400^{\circ} \mathrm{F}\right)$. The resulting equation of state is valid for temperatures greater than $273.15 \mathrm{~K}$ and for pressures less than $100 \mathrm{MPa}$.

\subsection{Single-Phase Properties}

The $\mathrm{H} 2 \mathrm{O}$ package determines all single-phase thermodynamic properties of water as functions of density and temperature from the equation for $\Psi$. For example, pressure and internal energy may be expressed in terms of the first derivatives of $\Psi$ as

$$
\begin{aligned}
& P=\rho^{2}(\partial \Psi / \partial \rho)_{T} \\
& \theta=\Psi+T s=\Psi-T(\partial \Psi / \partial T)_{\rho}
\end{aligned}
$$

where $s$ is entropy. These are evaluated from the equation for $\Psi$ and those for its analytic, term-by-term derivatives. The quantities $(\partial \mathrm{P} / \partial \mathrm{T})_{\rho},(\partial \mathrm{P} / \partial \rho)_{T}$, and $c_{v}=(\partial e / \partial T)_{\rho}$, which involve the three independent second derivatives of $\Psi$, are evaluated similarly.

\subsection{Mixed-Phase Properties}

The coexistence curve (the saturation line) is defined by points where $P, T$, and the Gibbs function $g=\Psi+P / \rho$ are equal for two different values of $\rho$. This curve was determined by a calculation external to MELCOR. All properties of each phase were tabulated at $1 \mathrm{~K}$ intervals and are included as data in the $\mathrm{H} 2 \mathrm{O}$ package. The properties of two-phase states are evaluated from these tables, using the lever rule. 
NCG and H2O Packages Reference Manual 


\section{NCG LIBRARY}

A library of data for gases of interest is available for use. Any of the numbers may be changed via user input. The available gases and the associated constants are defined below. Ten user-defined gases called GASk, where $k$ is any letter from $A$ to $\mathrm{J}$, can also be used, but the user must define all the values for the associated constants.

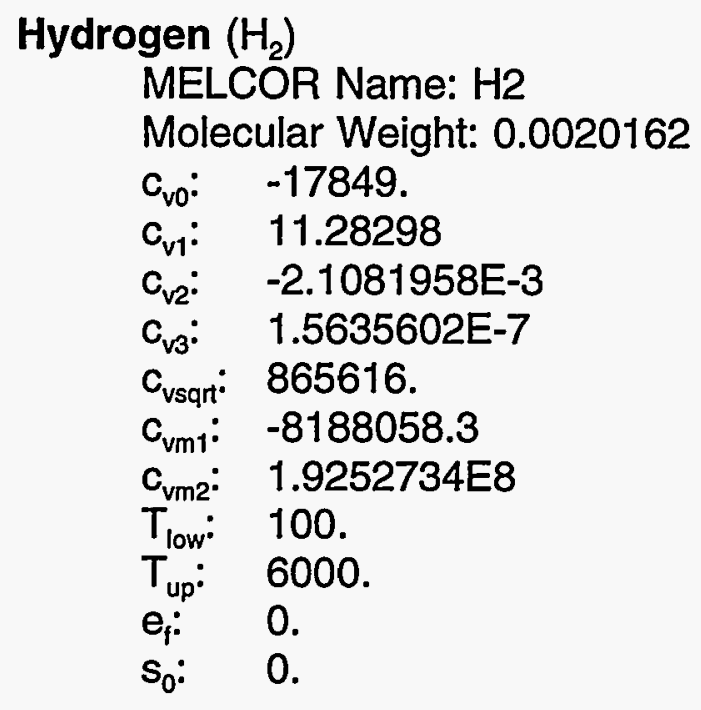

Deuterium $\left(D_{2}\right)$

MELCOR Name: D2

Molecular Weight: .00400

$\mathrm{c}_{\mathrm{vo}}: \quad 5508.8$

$c_{\mathrm{v} 1}: \quad-2.0277$

$\mathrm{C}_{\mathrm{v} 2}: \quad 3.3827 \mathrm{E}-3$

$c_{v 3}: \quad-1.0842 E-6$

$c_{\text {vsqur }}: 0$.

$\mathrm{c}_{\mathrm{vm} 1}: 0$.

$\mathrm{c}_{\mathrm{vm2} 2}: 0$.

$\mathrm{T}_{\text {low: }}$ : 600 .

$\mathrm{T}_{\text {up }}$ : 1500.

$e_{f:}: 0$.

$s_{0}: \quad 0$. 
NCG and H2O Packages Reference Manual

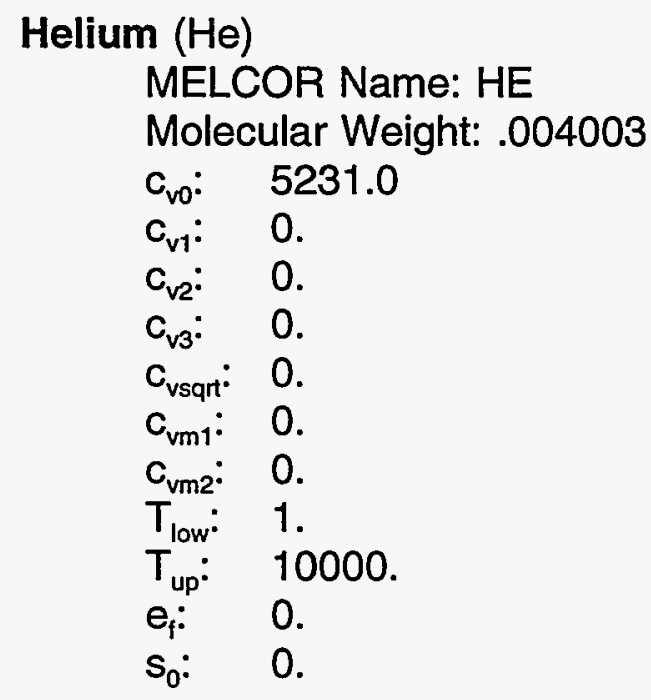

\section{Nitrogen $\left(N_{2}\right)$}

MELCOR Name: N2

Molecular Weight: .02801

$\mathrm{C}_{\mathrm{vo}}: \quad 1.117 \mathrm{E} 3$

$\mathrm{c}_{\mathrm{v} 1}: 0$.

$\mathrm{c}_{\mathrm{v} 2}: 0$.

$\mathrm{c}_{\mathrm{v} 3}: 0$.

$\mathrm{c}_{\mathrm{vsqu}}: 0$.

$\mathrm{C}_{\mathrm{vm} 1}: \quad-2.880 \mathrm{E} 5$

$\mathrm{C}_{\mathrm{vm} 2}: \quad 5.348 \mathrm{E} 7$

$\mathrm{T}_{\text {low: }}: 300$.

$T_{\text {up }}: 5000$.

$e_{f}: 0$.

$s_{0}: 0$.

\section{Oxygen $\left(\mathrm{O}_{2}\right)$}

MELCOR Name: $\mathrm{O} 2$

Molecular Weight: .032

$\mathrm{c}_{\mathrm{v} 0}: 1245$.

$\mathrm{c}_{\mathrm{v} 1}: 0$.

$\mathrm{c}_{\mathrm{v} 2}: 0$.

$\mathrm{c}_{\mathrm{v} 3}: 0$.

cusart: -16763 .

$\mathrm{c}_{\mathrm{vm} 1}: 1.111 \mathrm{E} 5$

$\mathrm{c}_{\mathrm{vm} 2}: 0$.

$\mathrm{T}_{\text {low: }}$ : 300 .

$\mathrm{T}_{\text {up }}$ : 2778.

$\mathrm{e}_{\mathrm{f}}$ : $\quad 1.7828 \mathrm{E} 7$

$s_{0}: 0$. 


\section{Argon (Ar)}

MELCOR Name: AR

Molecular Weight: .03994

$\mathrm{C}_{\mathrm{vo}}: \quad 525.26$

$\mathrm{c}_{\mathrm{v} 1}: 0$.

$\mathrm{c}_{\mathrm{v} 2}: 0$.

$\mathrm{c}_{\mathrm{v} 3}: 0$.

$\mathrm{c}_{\mathrm{vsqu}}: 0$.

$c_{\mathrm{vm} 1}: 0$.

$c_{\mathrm{vm} 2}: 0$.

$\mathrm{T}_{\text {low }}: 1$.

$T_{\text {up: }} \quad 10000$.

$e_{f}: 0$.

$\mathrm{s}_{0}: \quad 0$.

Methane $\left(\mathrm{CH}_{4}\right)$

MELCOR Name: $\mathrm{CH} 4$

Molecular Weight: .0160324

$c_{\mathrm{vo}}: \quad 660.6$

$c_{v 1}: \quad 3.462$

$\mathrm{c}_{\mathrm{v} 2}: 0$.

$c_{\mathrm{v} 3}: 0$.

$\mathrm{c}_{\mathrm{vsqu}}: 0$.

$\mathrm{c}_{\mathrm{vm} 1}: 0$.

$\mathrm{c}_{\mathrm{vm} 2}: 0$.

$\mathrm{T}_{\text {low: }}$ : 300 .

$T_{\text {up: }} 833$.

e: $\quad-4.5153 \mathrm{E} 6$

$s_{0}: 0$.

\section{Carbon Monoxide (CO)}

MELCOR Name: CO

Molecular Weight: 028

$c_{\mathrm{vo}}: \quad 1.116 \mathrm{E} 3$

$c_{\mathrm{v} 1}: 0$.

$\mathrm{c}_{\mathrm{v} 2}: 0$.

$c_{\mathrm{v} 3}: 0$.

$\mathrm{c}_{\text {vsqri }}: 0$.

$\mathrm{c}_{\mathrm{vm} 1}: \quad-2.7312 \mathrm{E} 5$

$\mathrm{C}_{\mathrm{ym} 2}: 4.9348 \mathrm{E} 7$

$T_{\text {low: }} 300$.

$\mathrm{T}_{\text {up }}: 5000$.

$\mathrm{e}_{\mathrm{i}:}: \quad 6.3286 \mathrm{E} 6$

$\mathrm{s}_{0}: \quad 0$. 
NCG and H2O Packages Reference Manual

\section{Carbon Dioxide $\left(\mathrm{CO}_{2}\right)$}

MELCOR Name: CO2

Molecular Weight: .044

$c_{v 0}: \quad 1351.35$

$\mathrm{c}_{\mathrm{v} 1}: 0$.

$\mathrm{c}_{\mathrm{v} 2}: 0$.

$\mathrm{c}_{\mathrm{v} 3}: 0$.

$\mathrm{c}_{\text {vsqur }}: 0$.

$C_{\mathrm{vm} 1}: \quad-3.4497 \mathrm{E} 5$

$\mathrm{C}_{\mathrm{vm} 2}: \quad 4.138 \mathrm{E} 7$

$\mathrm{T}_{\text {low }}: 300$.

$T_{\text {up }}: 3500$.

$\mathrm{e}_{\mathrm{f}}: \quad 4.0785 \mathrm{E} 6$

$\mathrm{s}_{0}: \quad 0$.

Acetylene $\left(\mathrm{C}_{2} \mathrm{H}_{2}\right)$

MELCOR Name: $\mathrm{C} 2 \mathrm{H} 2$

Molecular Weight: .026016

$\mathrm{c}_{\mathrm{vo}}: \quad 1.1457 \mathrm{E} 3$

$\mathrm{c}_{\mathrm{v} 1}: 0$.

$c_{\mathrm{v} 2}: 0$.

$\mathrm{c}_{\mathrm{v} 3}: 0$.

$\mathrm{c}_{\mathrm{vsqu}}: 0$.

$\mathrm{c}_{\mathrm{vm} 1}: 0$.

$\mathrm{c}_{\mathrm{vm} 2}: 0$.

$T_{\text {low: }}: 1$

$T_{\text {up: }} 10000$.

$\mathrm{e}_{\mathrm{i}}: \quad$ 8.8104E6

$\mathrm{s}_{0}: \quad 0$.

Ethylene $\left(\mathrm{C}_{2} \mathrm{H}_{4}\right)$

MELCOR Name: $\mathrm{C} 2 \mathrm{H} 4$

Molecular Weight: .028032

$\mathrm{c}_{\mathrm{vo}}: \quad 334.51$

$\mathrm{c}_{\mathrm{v} 1}: \quad 1.7568$

$\mathrm{c}_{\mathrm{v} 2}: 0$.

$\mathrm{c}_{\mathrm{v} 3}: 0$.

$c_{\text {vsqurt }} 0$.

$\mathrm{c}_{\mathrm{vm} 1}: 0$.

$\mathrm{c}_{\mathrm{vm} 2}: 0$.

$T_{\text {low: }}: 194$.

$T_{\text {up }}: \quad 611.1$

e: $\quad 1.9536 \mathrm{E} 6$

$s_{0}: 0$. 
NCG and H2O Packages Reference Manual

\section{Ammonia $\left(\mathrm{NH}_{3}\right)$}

\section{MELCOR Name: NH3}

Molecular Weight: .017029

$c_{\mathrm{vo}}: \quad 1.7012 \mathrm{E} 3$

$\mathrm{c}_{\mathrm{v} 1}: 0$.

$\mathrm{c}_{\mathrm{v} 2}: 0$.

$c_{\mathrm{v} 3}: 0$.

$\mathrm{c}_{\text {vsqrit: }} 0$.

$c_{v m 1}: 0$.

$\mathrm{c}_{\mathrm{vm} 2}: 0$.

$\mathrm{T}_{\text {low }}: 1$.

$T_{\text {up: }}: 10000$.

$e_{\mathrm{f}}: \quad-2.557 \mathrm{E} 6$

$s_{0}: \quad 0$.

Nitrogen Monoxide (NO)

MELCOR Name: NO

Molecular Weight: .03005

$c_{v 0}: \quad 6.8985 \mathrm{E} 2$

$\mathrm{c}_{\mathrm{v} 1}: 0$.

$\mathrm{c}_{\mathrm{v} 2}: 0$.

$c_{v 3}: 0$.

$c_{\text {vsqrit }}: 0$.

$\mathrm{c}_{\mathrm{vm} 1}: 0$.

$\mathrm{c}_{\mathrm{vm} 2}: 0$.

$\mathrm{T}_{\text {low: }} 1$.

$\mathrm{T}_{\text {up: }} \quad 10000$.

$\mathrm{e}_{\mathrm{i}}: \quad 6.561 \mathrm{E} 6$

$s_{0}: 0$.

Nitrous Oxide $\left(\mathrm{N}_{2} \mathrm{O}\right)$

MELCOR Name: N2O

Molecular Weight: .04401

$\mathrm{c}_{\mathrm{vo}}: \quad 736.32$

$c_{\mathrm{v} 1}: 0$.

$\mathrm{c}_{\mathrm{v} 2}: 0$.

$\mathrm{c}_{\mathrm{v} 3}: 0$.

$\mathrm{c}_{\mathrm{vsqn}}: 0$.

$c_{\mathrm{vm} 1}: 0$.

$\mathrm{c}_{\mathrm{vm} 2}: 0$.

$\mathrm{T}_{\text {low: }} 1$.

$T_{\text {up: }} 10000$.

$\mathrm{e}_{\mathrm{i}}: \quad 4.6699 \mathrm{E} 6$

$s_{0}: \quad 0$. 
NCG and H2O Packages Reference Manual

\section{User Defined Gases (-)}

MELCOR Name: GASk, $k=A, B, \ldots, J$

Molecular Weight: -1 .

$c_{v 0}:-1$.

$\mathrm{c}_{\mathrm{v} 1}:-1$.

$c_{\mathrm{v} 2}:-1$.

$c_{\mathrm{v} 3}:-1$.

$c_{\text {vsart }}:-1$.

$c_{\mathrm{vm} 1}:-1$.

$c_{\mathrm{vm} 2}:-1$.

$T_{\text {low }}:-1$.

$T_{\text {up }}:-1$.

$e_{f}: \quad-1$

$s_{0}: \quad-1$. 
NCG and H2O Packages Reference Manual

\section{REFERENCES}

1. JANAF Thermochemical Tables, Dow Chemical Company, Thermal Research Laboratory, Midland, MI (1965).

2. J. H. Keenan et al., Steam Tables: Thermodynamic Properties of Water, Including Vapor, Liquid, and Solid Phases (SI Units), John Wiley \& Sons, Inc., New York (1978). 


\title{
RadioNuclide (RN) Package Reference Manual
}

\author{
MELCOR Code Development Group \\ Modeling and Analysis Department \\ Nuclear Energy Technology Center \\ Sandia National Laboratories \\ Albuquerque, NM 87185-0739
}

Contributors:

Edward A. Boucheron

Randall K. Cole, Jr.

Russell C. Smith

Randall M. Summers

Stephen W. Webb

The RadioNuclide (RN) package models the behavior of fission product aerosols and vapors and other trace species, including release from fuel and debris, aerosol dynamics with vapor condensation and revaporization, deposition on structure surfaces, transport through flow paths, and removal by engineered safety features. The package also allows for simplified chemistry controlled by the user.

Boundary conditions for the various models are obtained from other MELCOR packages: fluid conditions are obtained from the Control Volume Hydrodynamics (CVH) package, fuel and debris temperatures are obtained from the Core (COR) and Cavity (CAV) packages, and structure surface temperatures are obtained from the Heat Structures (HS) package. The COR and CAV packages also provide information regarding bulk debris relocation, allowing the RN package to perform relocation of unreleased fission products in parallel. Likewise, advection of radionuclides between control volumes is done using $\mathrm{CVH}$ flows, and wash-off of radionuclides deposited on heat structures is determined from drainage of water films calculated by the HS package. The RN package determines decay heat power for current radionuclide inventories from the Decay Heat Power (DCH) package when requested by each of these packages.

This document describes in detail the various models incorporated in the RN package in MELCOR. Details on input to the RN package can be found in the RN Users' Guide. 
RN Package Reference Manual

RN-RM-2 
RN Package Reference Manual

\section{Contents}

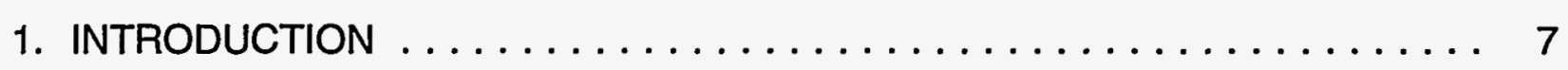

2. DETAILED MODELS $\ldots \ldots \ldots \ldots \ldots \ldots \ldots \ldots \ldots \ldots \ldots \ldots \ldots \ldots$

2.1 General . ............................ 11

2.2 Initial Radionuclide Inventories . . . . . . . . . . . . . 14

2.3 Release of Radionuclides $\ldots \ldots \ldots \ldots \ldots \ldots \ldots \ldots \ldots \ldots \ldots \ldots \ldots \ldots \ldots$

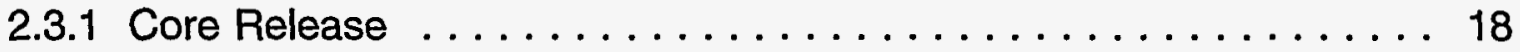

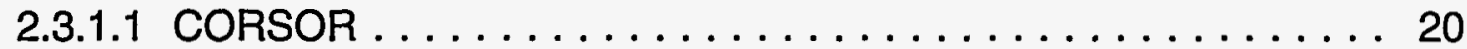

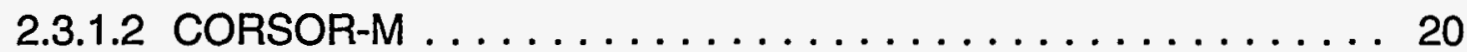

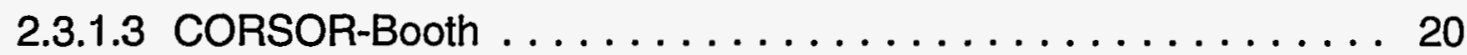

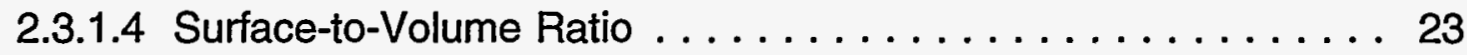

2.3.1.5 Class Combination at Release . . . . . . . . . . . 23

2.3.2 Fuel-Cladding Gap . . . . . . . . . . . . . . . . . . 24

2.3.3 Cavity Release . . . . . . . . . . . . . . . . . . 24

2.4 Aerosol Dynamics . . . . . . . . . . . . . . . . . . . . 25

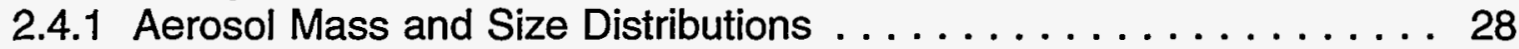

2.4.2 MAEROS Equations $\ldots \ldots \ldots \ldots \ldots \ldots \ldots \ldots \ldots \ldots$

2.4.2.1 Agglomeration ...................... 34

2.4.2.2 Deposition, Settling, and Fallout $\ldots \ldots \ldots \ldots \ldots \ldots \ldots . \ldots \ldots$

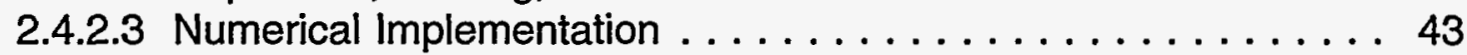

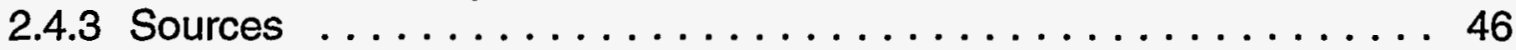

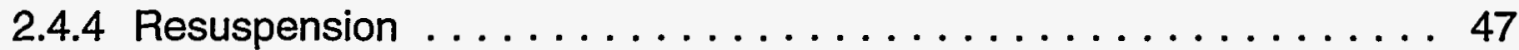

2.5 Condensation/Evaporation . . . . . . . . . . . . . . . 47

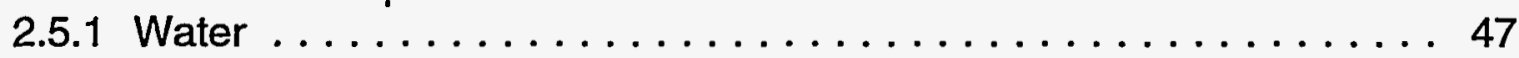

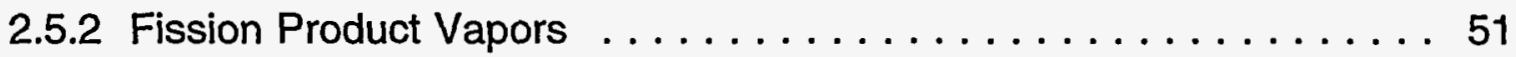

2.6 Decay Heat Distribution . . . . . . . . . . . . . . . . . 55

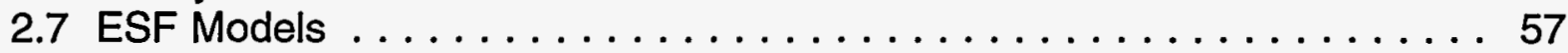

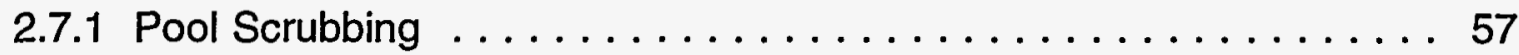

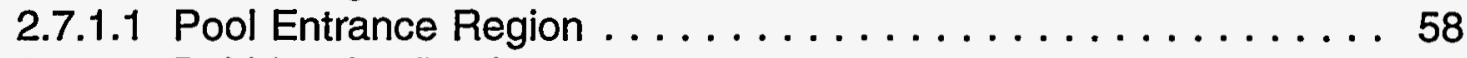

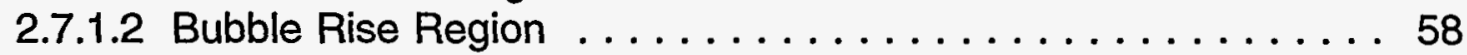

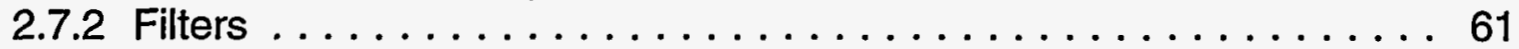

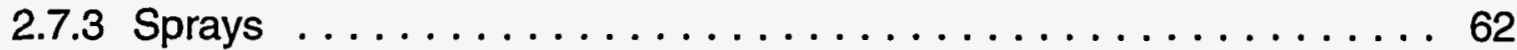

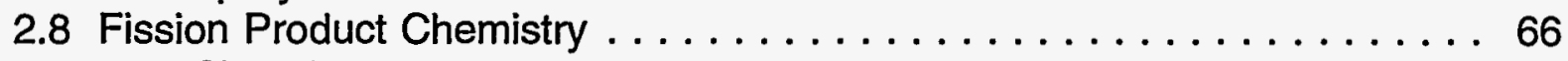

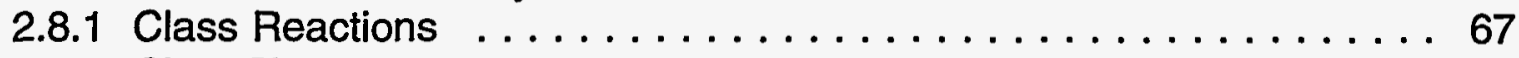

2.8.2 Class Transfers $\ldots \ldots \ldots \ldots \ldots \ldots \ldots \ldots \ldots \ldots \ldots \ldots \ldots 6 . \ldots \ldots$

2.8.3 Example ....................... 68

3. DISCUSSION AND DEVELOPMENT PLANS $\ldots \ldots \ldots \ldots \ldots \ldots \ldots \ldots 71$

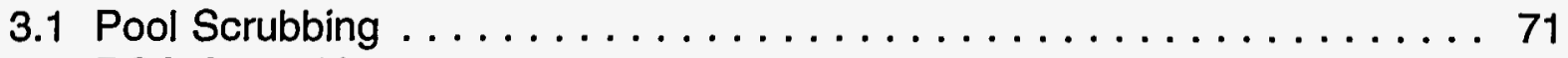

3.2 RCS Deposition ....................... 71

3.3 Chemical Reactions with Surfaces $\ldots \ldots \ldots \ldots \ldots \ldots \ldots \ldots \ldots \ldots$ 
RN Package Reference Manual

3.4 Aqueous Chemistry . . . . . . . . . . . . . . . 72

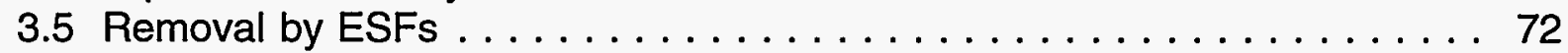

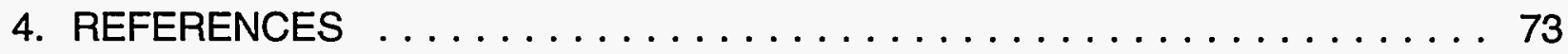

APPENDIX A: RN Package Sensitivity Coefficients $\ldots \ldots \ldots \ldots \ldots \ldots 77$

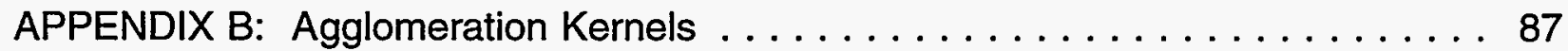

APPENDIX C: Aerosol Surface Area . . . . . . . . . . . . . . . 91

APPENDIX D: Pool Scrubbing Deposition Velocities . . . . . . . . . . . . 93 
RN Package Reference Manual

\section{List of Figures}

2.4.1 MAEROS Aerosol Model $\ldots \ldots \ldots \ldots \ldots \ldots \ldots \ldots \ldots \ldots \ldots \ldots \ldots$

D-1. Bubble Geometry . . . . . . . . . . . . . . . . . . 94

\section{List of Tables}

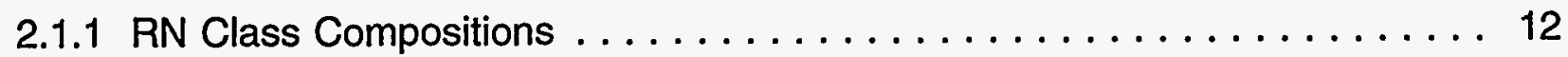

2.1 .2 COR Material to $\mathrm{RN}$ Class Mapping $\ldots \ldots \ldots \ldots \ldots \ldots \ldots$

2.1.3 RN Class to VANESA Species Mapping . . . . . . . . . . . . . 14

2.1.4 VANESA Species to RN Class Mapping $\ldots \ldots \ldots \ldots \ldots \ldots \ldots \ldots$ 
RN Package Reference Manual

\section{RN-RM-6}


RN Package Reference Manual

\section{INTRODUCTION}

Since MELCOR is intended as a tool for Probabilistic Risk Assessment (PRA), it must account for the release and transport of radioactive fission products that upon release to the environment become the source term, which is one major product of the overall severe accident calculation in MELCOR. Source terms are then used to calculate consequences as the end product of the PRA. Such processes as thermal-hydraulics and core degradation are calculated in MELCOR to support calculation of the source term.

The Radionuclide (RN) package in MELCOR calculates the release and transport behavior of fission product vapors and aerosols. Most of the models and concepts included in the RN package are discussed in detail in the fission product phenomena assessment report prepared at the beginning of MELCOR development [1]. Only a brief overview of the concepts and models is included in this section; Section 2 contains detailed descriptions of the models used in the RN package.

As a source term code, MELCOR is especially concerned with those fission products (and daughters) released during an accident, which are particularly important for determining consequences and risks. However, to model the transport of these important fission products properly, it is necessary to model the transport of other mass that affects the transport of radionuclide mass. For example, radiocesium will exist as $\mathrm{CsOH}$, so the mass of the hydroxide must be modeled, and if the $\mathrm{CsOH}$ aerosol interacts with concrete or water aerosols, the transport and thus the mass of the latter must also be modeled. Accordingly, MELCOR treats the molecular forms of all important fission products and also models the transport of all nonradioactive masses (water and concrete or other structural aerosols) with which fission products may interact. Therefore, in this manual the term radionuclide is generally taken to mean all masses, both radioactive and nonradioactive masses, that affect fission product transport.

Rather than tracking all fission product isotopes, the masses of all the isotopes of an element are modeled as a sum; that is, the total element mass, not its individual isotopes, is modeled. Furthermore, elements are combined into material classes, groups of elements with similar chemical behavior. Fifteen material classes are typically used, thirteen containing fission products, plus water and concrete oxides. Combination of classes to form new classes upon release, such as Cs $+I$ to Csl, is permitted. The decay heat power per unit initial mass for each class is determined by the Decay Heat Power (DCH) package based on the class compositions.

Initial radionuclide inventories for each class are generally based on whole-core inventories calculated using the ORIGEN code [2,3], and distributions may be specified for the fuel in the core, the fuel-cladding gap, any initial cavity debris, and the atmosphere and pool of any control volume. Until released as vapors or aerosols, fission products within the fuel are transported with the fuel as it relocates from core cell to core cell or is ejected to the reactor cavity. The decay heat power from radionuclides contained in 
a control volume, both those that are gas borne and those deposited on heat structure surfaces or contained in water pools, can be apportioned among the atmosphere, surfaces, and pools according to specifications supplied by the user, thus allowing the different penetrating powers of $\alpha, \beta$, and $\gamma$ radiation to be modeled appropriately. Radiation is allocated to various surfaces in the control volume on the basis of area.

Release of radionuclides can occur from the fuel-cladding gap by exceeding a failure temperature criterion or losing intact geometry, from material in the core using the various CORSOR empirical release correlations $[4,5]$ based on fuel temperatures, and during core-concrete interactions in the reactor cavity using the VANESA [6] release model. After release to a control volume, masses may exist as aerosols and/or vapors, depending on the vapor pressure of the radionuclide class and the volume temperature.

Aerosol dynamic processes and the condensation and evaporation of fission product vapors after release from fuel are considered within each MELCOR control volume. The aerosol dynamics models are based on MAEROS [7], a multisection, multicomponent aerosol dynamics code, but without calculation of condensation. Aerosols can deposit directly on surfaces such as heat structures and water pools, or can agglomerate and eventually fall out once they exceed the largest size specified by the user for the aerosol size distribution. Aerosols deposited on surfaces cannot currently be resuspended.

The condensation and evaporation of radionuclide vapors at the aerosol surfaces, pool surfaces, and heat structure surfaces are decoupled from MAEROS. These processes are evaluated by the rate equations from the TRAP-MELT2 code [8], which are based on the surface area, mass transfer coefficients, and the difference between the present surface concentration and the saturation surface concentration.

The steam condensation/evaporation is also decoupled from the MAEROS solution for agglomeration and deposition in order to reduce the stiffness of the differential equation set. The amount of steam condensed or aerosol water evaporated is calculated by thermodynamics routines called by the Control Volume Hydrodynamics (CVH) package.

Water droplets are transported as fog by the CVH package and treated as water-class aerosol by the RN package. (Water in pools or condensed on surfaces is not treated by the $\mathrm{RN}$ package.) Other radionuclide aerosols and vapors are transported between control volumes by bulk fluid flow of the atmosphere and the pool, assuming zero slip between the radionuclides and the host medium (steam, water, etc.). In addition, in the absence of bulk flow, aerosols may move by Brownian motion or by gravitational settling through openings between control volumes.

The difference between $\mathrm{CVH}$ fog and RN water-class masses in a control volume at the end of the CVH advancement represents net condensation of water onto or evaporation from the aerosols in that volume. The net change in water mass is imposed on the 
water-class inventory in the RN package, which then uses the Mason equation [9] to distribute the mass change over the aerosol size distribution in the control volume.

Models are available for the removal of radionuclides by pool scrubbing, filter trapping, and containment spray scrubbing. The pool scrubbing model is based on the SPARC code [10], and treats both spherical and elliptical bubbles. The model includes condensation at the pool entrance, Brownian diffusion, gravitational setting, inertial impaction, and evaporative forces for the rising bubble. Currently, only aerosols are removed by pool scrubbing in the RN package. Water condensation and evaporation are calculated within the $\mathrm{CVH}$ package using its own implementation of SPARC modeling (see the CVH Reference Manual). The filter model can remove aerosols and fission product vapors with a specified maximum mass loading. The containment spray model is based on the model in HECTR 1.5 [11] and removes both vapors and aerosols from the atmosphere.

Chemistry effects can be simulated in MELCOR through the class reaction and class transfer models, which are controlled entirely by user-specified parameters. The class reaction process uses a first-order reaction equation to simulate reversible chemical reactions. The class transfer process, which can instantly change the material class or location of a radionuclide mass, can be used to simulate fast, irreversible chemical reactions. With these two processes, phenomena including adsorption, chemisorption and other important chemical reactions can be simulated. Only fission product vapors are currently treated with these mechanisms.

Most intravolume processes involving radionuclides are calculated first in the RN package, including fission product release, aerosol agglomeration and deposition, fission product condensation and evaporation, distribution of decay heat, and chemical interactions. The effects of these processes are included in the hydrodynamic transport and thermodynamic calculations performed in the $\mathrm{CVH}$ package, executed subsequently.

The transport of fission products is inferred from the transport of hydrodynamic materials, but the CVH package may subcycle during a MELCOR time step. Since radionuclide advection must also abide by the Courant limit, the transport calculations are performed by RN package utility routines called from within the CVH subcycle loop. Part of this transport process includes removal of fission product aerosols and vapors by filters.

After CVH has advanced through the full MELCOR system time step, the additional intervolume process of pool scrubbing is calculated. While water condensation/ evaporation is an intravolume process, it also is calculated after the CVH package thermodynamics calculations have been performed so that the mass of water condensed in a control volume during the time step is known. 
RN Package Reference Manual

RN-RM-10 
RN Package Reference Manual

\section{DETAILED MODELS}

\subsection{General Framework}

The RN package operates on the principle of material classes, which are groups of elements that have similar chemical properties. The number of classes is specified on the RN1001 input record, with a default of 15 classes. The grouping of the different elements into these classes, as suggested in Reference 1, is shown in Table 2.1.1. Classes are generally referred to by their class name or representative element. Combination of masses in these classes upon release to form compounds in other classes, such as $\mathrm{Cs}+\mathrm{I}$ to $\mathrm{Csl}$, is permitted subject to stoichiometric constraints (e.g., excess $\mathrm{Cs}$ is retained in the Cs class). For the RN package, the classes must be in numerical order without any gaps. A maximum of 20 classes can presently be employed.

Each class is described by the following set of properties for use in various models:

1. release rates in core

2. molecular weights

3. vapor pressure

4. vapor diffusivity

5. decay heat power (see Section 2.3)

(see Section 2.3)

(see Section 2.5)

(see Section 2.5)

(see DCH Package Users' Guide)

Two molecular weight values are used for each class, the elemental molecular weight (i.e., the element's atomic weight) and the compound molecular weight, which are specified in sensitivity coefficient array 7120 (see Appendix A). The elemental molecular weight is used to determine the number of moles of radioactive material that are released and available for combination with other RN classes. The compound molecular weight is used to increase the released mass due to combination upon release with nonradioactive materials if that is expected to occur (e.g., Cs with $\mathrm{H}_{2} \mathrm{O}$ to form $\mathrm{CsOH}$ ). Total class masses after release therefore include both radioactive and nonradioactive masses. In addition, nonradioactive masses from bulk materials in the Core or Cavity package (e.g., cladding Zircaloy, structural steel, control poison, or concrete) may be released as vapors or aerosols and added to the total class masses but not to the radioactive masses of the class to which the materials are assigned.

Some models in the RN package use groupings of elements different from the groupings defined in Table 2.1.1. Transfers of masses between various models must therefore use mapping strategies.

For the transfer of bulk, nonradioactive, Core package structural masses released by the CORSOR models to the RN classes (see Section 2.3), the default mapping defined in Table 2.1.2 is employed. This mapping may be changed with input records RNCRCLXX, but this practice is discouraged. Note from Table 2.1.2 that $\mathrm{B}_{4} \mathrm{C}$ control poison in BWRs 
RN Package Reference Manual

Table 2.1.1 RN Class Compositions

Class Name

1. Noble Gases

2. Alkali Metals

3. Alkaline Earths

4. Halogens

5. Chalcogens

6. Platinoids

7. Early Transition Elements

8. Tetravalent

9. Trivalents

10. Uranium

11. More Volatile Main Group Cd

12. Less Volatile Main Group Sn

13. Boron

14. Water

15. Concrete

Cs

$\mathrm{Ba}$

$\mathrm{Te}$

$\mathrm{Ru}$

Mo

U

\section{Representative Member Elements}

Xe $\quad \mathrm{He}, \mathrm{Ne}, \mathrm{Ar}, \mathrm{Kr}, \mathrm{Xe}, \mathrm{Rn}, \mathrm{H}, \mathrm{N}$

$\mathrm{Li}, \mathrm{Na}, \mathrm{K}, \mathrm{Rb}, \mathrm{Cs}, \mathrm{Fr}, \mathrm{Cu}$

$\mathrm{Be}, \mathrm{Mg}, \mathrm{Ca}, \mathrm{Sr}, \mathrm{Ba}, \mathrm{Ra}, \mathrm{Es}, \mathrm{Fm}$

$\mathrm{F}, \mathrm{Cl}, \mathrm{Br}, \mathrm{I}, \mathrm{At}$

$\mathrm{O}, \mathrm{S}, \mathrm{Se}, \mathrm{Te}, \mathrm{Po}$

$\mathrm{Ru}, \mathrm{Rh}, \mathrm{Pd}, \mathrm{Re}, \mathrm{Os}, \mathrm{Ir}, \mathrm{Pt}, \mathrm{Au}, \mathrm{Ni}$

$\mathrm{V}, \mathrm{Cr}, \mathrm{Fe}, \mathrm{Co}, \mathrm{Mn}, \mathrm{Nb}, \mathrm{Mo}, \mathrm{Tc}, \mathrm{Ta}$, W

Ti, Zr, Hf, Ce, Th, Pa, Np, Pu, C

Al, Sc, Y, La, Ac, Pr, Nd, Pm, Sm, $\mathrm{Eu}, \mathrm{Gd}, \mathrm{Tb}, \mathrm{Dy}, \mathrm{Ho}, \mathrm{Er}, \mathrm{Tm}, \mathrm{Yb}, \mathrm{Lu}$, $\mathrm{Am}, \mathrm{Cm}, \mathrm{Bk}, \mathrm{Cf}$

U

$\mathrm{Cd}, \mathrm{Hg}, \mathrm{Zn}, \mathrm{As}, \mathrm{Sb}, \mathrm{Pb}, \mathrm{Tl}, \mathrm{Bi}$

$\mathrm{Ga}, \mathrm{Ge}, \mathrm{In}, \mathrm{Sn}, \mathrm{Ag}$

B, Si, P

$\mathrm{H}_{2} \mathrm{O}$ 
is mapped totally into the boron class, whereas Ag-In-Cd control poison in PWRs is split between the $\mathrm{Cd}$ and $\mathrm{Sn}$ classes using the percentages shown.

The VANESA model for radionuclide releases from debris in the cavity (see Section 2.3) recognizes 25 different species groups (for most, several different compounds of one element), and mapping must be used both to transfer RN class masses in the debris (as initially specified and as transferred from the COR and/or Fuel Dispersal Interactions [FDI] packages) to the VANESA groups and also to transfer them back again into the RN classes as VANESA calculates releases. The default mappings for to-VANESA and fromVANESA transfers are defined in Tables 2.1.3 and 2.1.4, respectively. These mappings may be changed with input records RNCLVNXX and RNVNCLXX.

In addition to the 25 VANESA groups, two additional groups can be transferred to VANESA but are changed before VANESA uses them. They are I (VANESA group 26), which is combined automatically with $\mathrm{Cs}$, and Xe (VANESA group 27), which VANESA releases immediately. VANESA assumes that $\mathrm{Cs}$ is in excess so that no elemental I remains as debris is added to the cavity. Also, aerosol products from concrete ablation (VANESA groups 12 through 16) are automatically transferred to the RN concrete class, and bulk gases (VANESA group 1) are transferred directly to the CVH package. The user should not specify mapping values for any of these VANESA groups.

Table 2.1.2 COR Material to RN Class Mapping

\begin{tabular}{|c|c|c|c|c|}
\hline \multicolumn{2}{|c|}{$\underline{\text { COR Material }}$} & \multicolumn{3}{|c|}{$\underline{\text { RN Class (Rep. Element) }}$} \\
\hline 1 & UO2 & 10 & U & \\
\hline 2 & $\mathrm{Zr}$ & 8 & $\mathrm{Ce}$ & \\
\hline 3 & ZrO2 & 8 & $\mathrm{Ce}$ & \\
\hline 4 & Steel & 7 & Mo & \\
\hline 5 & Steel Oxide & 7 & Mo & \\
\hline 6 & Control Rod Poison & $\begin{array}{l}13 \\
11 \\
12\end{array}$ & $\begin{array}{l}\text { B } \\
\text { Cd } \\
\text { Sn }\end{array}$ & $\begin{array}{r}100 \% \text { BWR / } 0 \% \text { PWR } \\
0 \% \text { BWR / 5\% PWR } \\
0 \% \text { BWR / } 95 \% \text { PWR }\end{array}$ \\
\hline
\end{tabular}


RN Package Reference Manual

Table 2.1.3 RN Class to VANESA Species Mapping

\begin{tabular}{ccccl}
\hline \multicolumn{2}{c}{ RN Class } & \multicolumn{2}{c}{ VANESA Species } \\
\cline { 2 - 4 } 1 & $\mathrm{Xe}$ & 27 & $\mathrm{Xe}$ (released instantaneously) \\
2 & $\mathrm{Cs}$ & 19 & $\mathrm{Cs}$ \\
3 & $\mathrm{Ba}$ & 20 & $\mathrm{Ba}$ \\
4 & $\mathrm{I}$ & 26 & $\mathrm{I}$ (immediately forms CsI) \\
5 & $\mathrm{Te}$ & 9 & $\mathrm{Te}$ \\
6 & $\mathrm{Ru}$ & 6 & $\mathrm{Ru}$ \\
7 & $\mathrm{Mo}$ & 5 & $\mathrm{Mo}$ \\
8 & $\mathrm{Ce}$ & 23 & $\mathrm{Ce}$ \\
9 & $\mathrm{La}$ & 22 & $\mathrm{La}$ \\
10 & $\mathrm{U}$ & 17 & $\mathrm{U}$ \\
11 & $\mathrm{Cd}$ & 8 & $\mathrm{Sb}$ \\
12 & $\mathrm{Sn}$ & 7 & $\mathrm{Sn}$ \\
13 & $\mathrm{~B}$ & 0 & (RN class not present in fuel) \\
14 & $\mathrm{H}$ & 0 & (RN class not present in fuel) \\
15 & $\mathrm{Concrete}$ & 0 & (RN class not present in fuel)
\end{tabular}

Warning: If a class is redefined from the default values, or if a new class is added, all of the properties, including mappings, should be evaluated and possibly redefined through the RN sensitivity coefficients. Default values for these properties are defined based on the elements in each class. Whether default values are appropriate when classes are modified must be determined by the user. Note that the DCH package might also have to be redefined in a consistent manner.

\subsection{Initial Radionuclide Inventories}

Initial inventories and distributions of radionuclides must be specified for the core, for the cavity, and for control volume pools and atmospheres. (Inventories for some locations may be zero initially.) Masses can be distributed among core cells according to radial and axial decay heat power profiles in the core. In addition, a fraction of the radionuclides in a core cell can be designated as residing in the fuel-cladding gap.

Total radioactive class masses are normally determined by the $\mathrm{DCH}$ package from the operating power of the reactor and the mass of each element in the class per unit of operating power (see the DCH Package Reference Manual and Users' Guide). RN 
RN Package Reference Manual

Table 2.1.4 VANESA Species to RN Class Mapping

\section{VANESA Species}

1 bulk gases (from CORCON)

$2 \mathrm{Fe}$

$3 \mathrm{Cr}$

$4 \quad \mathrm{Ni}$

5 Mo

$6 \mathrm{Ru}$

7 Sn

$8 \mathrm{Sb}$

$9 \mathrm{Te}$

$10 \mathrm{Ag}$

$11 \mathrm{Mn}$

12 Ca (from concrete ablation)

13 Al (from concrete ablation)

$14 \mathrm{Na}$ (from concrete ablation)

$15, \mathrm{~K}$ (from concrete ablation)

16 Si (from concrete ablation)

$17 \mathrm{U}$

$18 \mathrm{Zr}$

19 Cs

$20 \mathrm{Ba}$

$21 \mathrm{Sr}$

$22 \mathrm{La}$

$23 \mathrm{Ce}$

$24 \mathrm{Nb}$

25 CsI

26 I

$27 \mathrm{Xe}$

\section{RN Class}

(released by CAV pkg to CVH)

7 Mo

7 Mo

$6 \mathrm{Ru}$

7 Mo

$6 \mathrm{Ru}$

12 Sn

11 Cd

$5 \mathrm{Te}$

12 Sn

7 Mo

15 Concrete

15 Concrete

15 Concrete

15 Concrete

15 Concrete

$10 \mathrm{U}$

$8 \mathrm{Ce}$

2 Cs

$3 \mathrm{Ba}$

$3 \mathrm{Ba}$

9 La

$8 \mathrm{Ce}$

7 Mo

2 Cs and 4 ।

(combined with Cs by VANESA)

(released by VANESA)

package input generally defines only the initial distribution of these masses in the core and cavity through reference values and multipliers specified on the RNFPNijjXX input records. However, options are provided to use these records to specify the class masses directly. These options are useful for analysis of experiments.

The total mass inventories for all RN classes in a particular core cell or in a cavity are normally calculated from user-specified multipliers $r_{1}$ and $r_{2}$ as

$$
M_{x}=r_{1} r_{2} M_{x, \text { ref }}
$$




\section{RN Package Reference Manual}

where $M_{x, \text { ref }}$ is a reference value for class $x$ that may be taken as the total class mass defined by the $\mathrm{DCH}$ package or as the inventory in some other core cell or cavity location, depending on the option chosen. For core cells, $r_{1}$ and $r_{2}$ typically represent axial and radial multipliers to specify the decay heat power profile in the core, while for cavities they are arbitrary. If the DCH package option is chosen, however, the mass of the uranium class (default class 10) is calculated by decrementing the total uranium mass in the Core package, $M_{U, C O R}$ by the sum of the masses in the remaining classes, i.e.,

$$
M_{U, R N}=M_{U, C O R}-\sum_{i \neq U} M_{i} \quad \text { (Uranium class only) }
$$

Optionally, as specified on the RNFPNij]XX records, the mass for a specified class in a particular core cell or cavity location may be input directly as

$$
M_{x}=r_{1} r_{2}
$$

where $r_{1}$ is typically chosen as the total mass, with $r_{2}$ defined as the fraction of that mass in the core cell or cavity location. The various options are additive and may be combined as may be convenient. Note that masses can also be reduced if a negative multiplier is used.

The masses given by Equations 2.2.1 through 2.2.3 determine the total radioactive mass of radionuclides in a particular core cell, including the fuel-cladding gap. The fraction of radioactive mass that resides in the gap is determined by the parameter $r_{1}$ input on the RNGAPijJXX input record series (different from $r_{1}$ input on RNFPNijjXX). Depending on the input option chosen, the gap fraction $F_{x}$ may be specified directly for each class as

$$
F_{x}=r_{1}
$$

or it may be calculated as a proportion of the gap fraction $F_{x, \text { rel }}$ at some other location,

$$
F_{x}=r_{1} F_{x, \text { ref }}
$$

For a core cell, the radioactive masses residing in the fuel and gap, $M_{x, \text { fuel }}$ and $M_{x, g a p, A}$, respectively, are thus given by

$$
\begin{aligned}
& M_{x, \text { fuel }}=\left(1-F_{x}\right) M_{x} \\
& M_{x, \text { gap }, R}=F_{x} M_{x}
\end{aligned}
$$

The total masses residing in the gap must be calculated to account for the addition of nonradioactive material from presumed chemical reactions following release from the fuel. (See the discussion of total vs. radioactive masses in Section 2.1.) If the gap fraction has been specified directly from Equation 2.2.4, the total gap mass $M_{x, g a p, T}$ is given by 
RN Package Reference Manual

$$
M_{x, \text { gap }, T}=r_{2} M_{x, \text { gap }, R}
$$

where $r_{2}$ is the ratio of total mass to radioactive mass (usually the ratio of compound to elemental molecular weights, matching the values in sensitivity coefficient array 7120 ; see Appendix A), whereas if the gap fraction has been specified as a proportion $r_{1}$ of the gap fraction at some other location with Equation 2.2.5, the total gap mass is that same fraction of the total gap mass $M_{\mathrm{x}, \mathrm{gap}, \mathrm{T}, \mathrm{ref}}$ at the other location,

$$
M_{x, \text { gap }, T}=r_{1} M_{x, \text { gap, }, \text {,ref }}
$$

in which case no value is needed for $r_{2}$ since it is already reflected in $M_{x, \text { gap, }, \text {,ref }}$ (any value input for $r_{2}$ is ignored).

The distribution of radionuclide masses between fuel and gap in a core cell will change with time due to release and the relocation of fuel. When fuel is relocated by the COR package, the radionuclides still residing in the fuel are transported with it. Relocation of the gap radionuclide mass is not necessary since cladding failure and gap release will always occur before fuel relocates (see Section 2.3.2).

In addition to the radioactive masses initially residing in the fuel or fuel-cladding gap, nonradioactive bulk masses in other packages, such as Zircaloy fuel rod cladding, may be released as vapors or aerosols by the RN package release models. Initial inventories for these bulk masses are already available in the appropriate package database and no additional input is needed for the RN package. Release of core or cavity masses by the RN package does not change the mass values in the other packages. For example, the mass of Zircaloy in the COR package is not modified by release of Zircaloy aerosols in the RN package. The errors introduced by this assumption should be very small since the fractions of core and cavity materials that are released as vapors and aerosols are very small. Nevertheless, the user should be aware that mass is not explicitly conserved in this modeling.

The user may also directly specify the initial radionuclide aerosol and/or vapor inventory for any class in any control volume by using the RNAGXXX, RNALXXX, RNVGXXX, and RNVLXXX input record series.

\subsection{Release of Radionuclides}

Release of radionuclides can occur from the core fuel (with nonradioactive releases from other core structures), from the fuel-cladding gap, and from material in the cavity. At present, no material can be released from the reactions treated in the FDI package. The release models used in each of these areas are discussed below. 
RN Package Reference Manual

\subsubsection{Core Release}

Radioactive and nonradioactive material may be released from the core. As described in Sections 2.1 and 2.2, the radionuclides residing in the COR package fuel are assumed to be in elemental form and therefore to have only radioactive mass (no associated molecular mass). Upon release from fuel, the total class masses are converted to compound form with a corresponding increase in mass from the added nonradioactive material (e.g., the hydroxide mass in $\mathrm{CsOH}$ ). By default the release models are used to calculate the release of radioactive radionuclides from core fuel material (i.e. $\mathrm{UO}_{2}$ ) only, which exists in the intact fuel component, in refrozen fuel material on other components and in particulate debris.

In order to apply the release models to core materials other than fuel, such as the fuel rod cladding, the user must change the default values of the core material release multipliers contained in sensitivity coefficient array 7100 . For these other core materials, the mapping scheme described in Section 2.1 (with defaults in Table 2.1.2) determines the apportioning of the core masses among the RN classes, and the entire masses are considered nonradioactive. Hence, by changing the release multiplier for $\mathrm{Zr}$ from 0.0 to 0.5 , for example, the user will obtain half the fractional release rates calculated by the release correlations for $\mathrm{Zr}$ in the cladding, canisters and particulate debris. However, because the mass of structural $\mathrm{Zr}$ in the cladding component is enormous compared to the mass of $\mathrm{Zr}$ class fission products in the fuel component, the actual release rate (fractional rate times the available mass) from the cladding may be quite large. Because the core release models were developed for fuel releases, their use to calculate the release of structural materials in other components is questionable.

Before cladding failure has occurred, radionuclides released from the fuel in the core are transferred to the gap inventory and are released to the surrounding atmosphere of control volume only upon cladding failure. (However, they are reported by RN output as "released.") After cladding failure, radionuclides released from the core are transferred to the atmosphere of control volumes as specified in the Core package input, which defines channel and bypass control volumes for each core cell. These volumes are used by the RN package as follows: 
RN Package Reference Manual

Core Component

Intact:

Fuel

Cladding

Control Rods

Canisters

Conglomerate Debris:

Refrozen on Cladding

Refrozen on Control Rods

Refrozen on Canisters $\underline{\text { RN Release Volume }}$

Channel

Channel

Bypass

Split Equally Between Channel and Bypass

Particulate Debris:

All

Channel

Bypass

Channel

In addition to releases in the core calculated by the $\mathrm{RN}$ package, the reaction modeled in the Core package of $\mathrm{B}_{4} \mathrm{C}$ in control rods with steam can release $\mathrm{B}_{2} \mathrm{O}_{3}$ to the $R N$ package. The class specified on the RN1001 input record for $\mathrm{B}_{2} \mathrm{O}_{3}$ receives this mass in the bypass control volume defined for that core cell.

Three options are currently available for the release of radionuclides from the core fuel component; the CORSOR, CORSOR-M [4] or CORSOR-Booth [5] model may be specified on input record RNFP000. The CORSOR-BOOTH model contains low and high burn-up options. In addition, the CORSOR and CORSOR-M release rates can be modified to be a function of the component surface-to-volume ratio as compared to a base value, derived from the experimental data on which CORSOR is based. The surface areas, volumes, and temperatures of the components used in the calculation are obtained from the COR package database. Because none of these radionuclide release models can be considered truly general or universally applicable, it is strongly recommended that concerned users refer to the release model references $[4,5]$ for a more complete description of modeling assumptions and limitations.

The reduction in release rate of the tellurium class by the presence of unoxidized zirconium can be modeled if desired. The parameters affecting this option are controlled by sensitivity coefficient array 7105 for CORSOR and CORSOR-M and within array 7107 for CORSOR-Booth (see Appendix A). The release rate of $\mathrm{Te}$ is reduced by a release rate multiplier (with a default value of $1 / 40=0.025$ ) until the mass of unoxidized intact metal cladding falls below a cut-off fraction (default value of 0.7 ) of the total mass of intact cladding (including the oxide mass). The default values are based on discussion in Reference 12.

Note that for each core component, the same correlation is used to calculate the release rate for a given class using the individual temperature of that component. That is, the 
RN Package Reference Manual

calculation of release of radionuclides from fuel, cladding, canisters, control rods, and particulate debris differs only in the temperature used. Separate correlations for these components, as presented in the CORSOR Users' Manual [4], are not employed since their form is not compatible with the MELCOR structure.

\subsubsection{CORSOR}

The original CORSOR model correlates the fractional release rate in exponential form,

$$
\dot{f}=A \exp (B T) \quad \text { for } T \geq T_{i}
$$

where $f$ is the release rate (fraction per minute), $A$ and $B$ are empirical coefficients based on experimental data, and $T$ is the core cell component temperature in degrees Celsius. Different values for $A$ and $B$ are specified for three separate temperature ranges. The lower temperature limit $T_{i}$ for each temperature range and the $A$ and $B$ values for that range are defined for each class in sensitivity coefficient array 7101 (see Appendix A). If the cell temperature is below the lowest temperature limit specified, no release is calculated.

\subsubsection{CORSOR-M}

The CORSOR-M model correlates the same release data used for the CORSOR model using an Arrhenius form,

$$
\dot{f}=k_{o} \exp (-Q / R T)
$$

The values of $k_{0}, Q$, and $T$ are in units of $\mathrm{min}^{-1}, \mathrm{kcal} / \mathrm{mole}$, and $K$, respectively. The value of $R$ is $1.987 \times 10^{-3}$ in the appropriate units. The values of $k_{o}$ and $Q$ for each class are implemented in sensitivity coefficient array 7102 (see Appendix A).

\subsubsection{CORSOR-Booth}

The CORSOR-Booth model considers mass transport limitations to radionuclide releases and uses the Booth model for diffusion with empirical diffusion coefficients for cesium releases. Release fractions for other classes are calculated relative that for cesium. The classical or effective diffusion coefficient for cesium in the fuel matrix is given by 


$$
D=D_{0} \exp (-Q / R T)
$$

where $R$ is the universal gas constant, $T$ is the temperature, $Q$ is the activation energy, and the pre-exponential factor $D_{0}$ is a function of the fuel burn-up. For fuel with burn-up in excess of $30,000 \mathrm{MWD} / \mathrm{MTU}$ the model uses a value for $\mathrm{D}_{0}$ five times larger than the value it uses for fuels with lower burn-up. The two default values for $D_{0}$, the transition burn-up value, and the activation energy $Q$, based on experimental data for the release of fission gases from fuel test samples [14], are all given in sensitivity coefficient array 7106 (see Appendix A).

The cesium release fraction at time $t$ is calculated from an approximate solution of Fick's law for fuel grains of spherical geometry [13],

$$
\begin{array}{ll}
f=6 \sqrt{\frac{D^{\prime} t}{\pi}}-3 D^{\prime} t & \text { for } D^{\prime} t<1 / \pi^{2} \\
f=1-\frac{6}{\pi^{2}} \exp \left(-\pi^{2} D^{\prime} t\right) & \text { for } D^{\prime} t>1 / \pi^{2}
\end{array}
$$

where

$$
\begin{array}{ll}
D^{\prime} t & =D t / a^{2} \text { (dimensionless) } \\
a & =\text { equivalent sphere radius for the fuel grain }
\end{array}
$$

The release rate of $C s$ during a time interval $t$ to $t+\Delta t$ from the fuel grain is calculated as

$$
\text { Release Rate }{ }_{\mathrm{Cs}}=\frac{\left[f\left(\sum D^{\prime} \Delta t\right)_{t+\Delta t}-f\left(\sum D^{\prime} \Delta t\right)_{t}\right] V \rho}{F \Delta t}
$$

where $\rho$ is the molar density in the fuel, $V$ is the fuel volume, $F$ is the fraction of the $C s$ inventory remaining in the fuel grain, and the summations are done over the time steps up to time $(t+\Delta t)$ and $t$, respectively.

The release rate formulation in the CORSOR-Booth model is also limited by mass transfer through the gas phase. The gas phase mass transport release rate from the fuel rod for species $k, \dot{m}_{k}$, is calculated using an analogy from heat transfer as 
RN Package Reference Manual

$$
\frac{1}{\dot{m}_{k}}=\frac{D_{\text {fuel }} R T}{A_{\text {fuel }} \operatorname{Nu~} D_{k, \text { gas }} P_{k, \text { eq }}}
$$

where

$$
\begin{aligned}
& D_{\text {fuel }}=\text { diameter of fuel pellet } \\
& A_{\text {fuel }}=\text { fuel rod flow contact area } \\
& D_{k, g a s}=\text { diffusivity of class } \mathrm{k} \text { in the gas mixture } \\
& \mathrm{Nu}=\text { Nusselt number } \\
& P_{k, \text { eq }}=\text { equilibrium vapor pressure of class } \mathrm{k} \text { at temperature } T
\end{aligned}
$$

The effective release rate for Cs given by Equation 2.3.6 is a combination of the rates given by diffusion and by gas phase mass transport. Therefore, the contribution from diffusion only is taken as

$$
\operatorname{DIFF}_{\mathrm{cs}}=\left[\frac{1}{\text { Release Rate }_{\mathrm{cs}}}-\frac{1}{\dot{\mathrm{m}}_{\mathrm{cs}}}\right]^{-1}
$$

The diffusion release rate for species other than cesium is given by multiplying the cesium release rate by an appropriate scaling factor $S_{k}$ for each $R N$ class $k$ :

$$
\operatorname{DIFF}_{\mathrm{k}}=\operatorname{DIFF}_{\mathrm{Cs}} \mathrm{S}_{\mathrm{k}}
$$

Nominal values for $S_{k}$ are given in sensitivity coefficient array 7103 . For certain conditions of cladding oxidation and temperature, the scaling factors must be modified for some classes. When the oxide mass fraction exceeds a critical value $F_{k 1}$ and the temperature exceeds a critical value $T_{k 1}$, the class scaling factor is given by

$$
S_{k}=S_{k 1} \exp \left(C_{k} T\right)
$$

where $T$ is not allowed to exceed a maximum value $T_{\max }$. When the oxide mass fraction is below a minimum value $F_{k 2}$, the class scaling factor is given by

$$
S_{k}=S_{k 2}
$$

Values for $F_{k 1}, T_{k 1}, S_{k 1}, C_{k}, T_{\text {max }}, F_{k 2}$, and $S_{k 2}$ are all contained within sensitivity coefficient array 7107. 
RN Package Reference Manual

The combined mass transport and diffusion release rate $\dot{m}_{\mathrm{tot}, \mathrm{k}}$ for class $\mathrm{k}$ is then

$$
\dot{\mathrm{m}}_{\mathrm{tot}, \mathrm{k}}=\frac{1}{\mathrm{DIFF}_{\mathrm{k}}^{-1}+\dot{\mathrm{m}}_{\mathrm{k}}^{-1}}
$$

The fractional release rate for the inventory of class $k$ is calculated as

$$
\dot{f}_{k} \text { (fraction/s) }=\frac{\dot{m}_{\text {tot }, k}}{\rho V}\left[F-\frac{P_{k, b u l k}}{P_{k, e q}}\right]
$$

\subsubsection{Surface-to-Volume Ratio}

In the CORSOR and CORSOR-M release expressions, the effect on the release rate of the surface-to-volume ratio of the material from which release occurs is not treated. An option has been added to include the effect of this ratio as follows:

$$
\dot{\mathrm{f}}=\dot{\mathrm{f}}_{\text {CORSOR(-M) }}(\mathrm{S} / \mathrm{V})_{\text {structure }} /(\mathrm{S} / \mathrm{V})_{\text {base }}
$$

where the $(S / N)_{\text {base }}$ value has been derived from the original CORSOR data with a value of $422.5 \mathrm{~m}^{-1}$ that is stored in sensitivity coefficient array 7104 (see Appendix A). Values for $(S / N)_{\text {structure }}$ are calculated from component surfaces and volumes in the Core package (see Section 3 of the COR Package Reference Manual) and thus reflect the effects of core degradation on the surface-to-volume rations of core components.

\subsubsection{Class Combination at Release}

The release model also can provide for the combination of different donor classes into a new class based on the elemental molecular wejghts. An example could be the combination upon release of $\mathrm{Cs}$ and I atoms to form CsI molecules, which is modeled by moving stoichiometric amounts of $C s$ and I mass from the $C s$ and I classes into a new CsI class. The number of moles of each class that combine is defined by RNCLSNNXX input data. This combination occurs instantaneously upon release and is only limited by the availability of the released mass during that time step. If there is an excess of any donor class during the time step, that excess material stays in the original class. Chemical reactions that take place once release has been completed can be approximated using the models discussed in Section 2.8. 
RN Package Reference Manual

Note: The class combination model is only used for release from the fuel in the core and not for tabular or control function input sources defined using the RNASXXX or RNVSXXX records.

\subsubsection{Fuel-Cladding Gap}

Release of the radionuclides in the fuel-cladding gap (initial inventory plus masses from fuel release) occurs on cladding failure. Cladding failure is assumed to occur if either a temperature criterion is exceeded or if the intact cladding geometry has been lost due to candling or oxidation. It is assumed that the gaps in each radial ring can communicate axially between core cells, so when cladding in one axial level in a radial ring fails, the gap inventory for that entire ring is released. The cladding failure temperature for each core cell is specified on the RNGAPijj00 input record, with a default value of $1173 \mathrm{~K}$ $\left(900^{\circ} \mathrm{C}\right)[15]$. The control volume that receives the gap release is the channel control volume associated with the core cell where failure occurs, as defined by the CORijj01 input records (see the COR Package Users' Guide).

\subsubsection{Cavity Release}

For release of radionuclides from the cavity due to core-concrete interactions, the VANESA model [6] has been implemented in MELCOR and is coupled to CORCON [16] during every time step. The control volume for cavity releases is specified in the Cavity package input. If a water pool is present, pool scrubbing calculations are performed to apportion the released mass between the pool and the atmosphere.

A number of changes have been made to the stand-alone VANESA program to allow it to function within the MELCOR framework. The major changes are:

1. The concrete composition used in VANESA is converted from CORCON input using the following mapping, rather than input independently:

$\underline{\text { CORCON Mass Fraction }}$

$\mathrm{CaO}+\mathrm{MgO}$

$\mathrm{Al}_{2} \mathrm{O}_{3}$

$\mathrm{Na}_{2} \mathrm{O}$

$\mathrm{K}_{2} \mathrm{O}$

$\mathrm{SiO}_{2}$

$\mathrm{Fe}_{2} \mathrm{O}_{3}$ (converted to $\mathrm{FeO}$ ) $+\mathrm{MnO}$

$\mathrm{Ti}_{2} \mathrm{O}$

$\mathrm{Cr}_{2} \mathrm{O}_{3}$

Rebar
VANESA Mass Fraction
$\mathrm{CaO}$
$\mathrm{Al}_{2} \mathrm{O}_{3}$
$\mathrm{Na}_{2} \mathrm{O}$
$\mathrm{K}_{2} \mathrm{O}$
$\mathrm{SiO}_{2}$
$\mathrm{FeO}$
$\mathrm{Ti}_{2} \mathrm{O}$
$\mathrm{Cr}_{2} \mathrm{O}_{3}$
$\mathrm{Fe}$ 
RN Package Reference Manual

2. The rate of addition of concrete decomposition products (gases and condensed-phase oxides) is now derived from CORCON results by forward differences, rather than the central difference scheme originally in VANESA, to assure conservation of mass in the calculations.

3. Core debris masses (and associated radionuclides) may be added as a function of time throughout the transient.

4. Both radioactive and total masses are tracked. The fraction of the radioactive mass released is assumed to be the same as the fraction of total mass released.

5. The radioactive inventory is used (by default) to calculate the decay heat in the Cavity package. It is partitioned between the metallic and oxidic phases according to the assumed chemical state of the VANESA class. This partitioning accounts for the difference between elemental mass (e.g., $\mathrm{Ba}$ ) and compound mass (e.g., $\mathrm{BaO}$ ) and the mapping of released structural materials (e.g., $\mathrm{Fe}$ ) into the nonradioactive portions of RN inventories.

6. Pool scrubbing calculations are done by the RN package rather than the model in stand-alone VANESA.

\subsection{Aerosol Dynamics}

This section describes the models used in the RN package to predict the behavior of aerosols during an accident in a LWR. Fission products may be aerosolized as they are released from fuel early in a LWR accident and later expelled from the reactor coolant system. Other events and processes that occur late in the accident, such as coreconcrete interactions, pool boiling, direct containment heating, and deflagrations, may also generate (or resuspend) aerosols. High structural temperatures may also result in aerosolization of nonradioactive materials.

The principal aerosol quantities of interest are the mass and composition of aerosol particles and their distribution throughout the reactor coolant system and containment. The calculation of aerosol agglomeration and deposition processes is based on the MAEROS [7] computer code, but without direct inclusion of condensation or evaporation within the MAEROS solution framework. Vapor condensation on and evaporation from aerosol particles are handled separately to reduce the stiffness of the differential equation set and to ensure consistency with the calculation of these processes by other models and packages, as described later.

MAEROS is a multisectional, multicomponent aerosol dynamics code that evaluates the size distribution of each type of aerosol mass, or component, as a function of time. This size distribution is described by the mass in each size bin, or section. Each section may 


\section{RN Package Reference Manual}

have a different chemical composition as described by the masses of various components for that section. In other words, a section is an aerosol size grouping and a component is a particular type of aerosol material. Since MELCOR operates on a radionuclide class structure, as discussed earlier, a mapping between RN classes and MAEROS aerosol components must be specified by the user.

Figure 2.4.1 illustrates the sectional representation of a two-component aerosol with 5 sections. The mass concentrations of component 1 in the five sections are given by the stair-stepped line that bounds the lower crosshatched region. The total aerosol mass concentrations in the five sections are given by the uppermost stair-stepped line. Therefore, the mass concentrations of component 2 in the five sections are given by the upper shaded region.

One powerful feature of MELCOR is that water condensation on and evaporation from aerosols is modeled in a manner consistent with the thermal/hydraulic calculations in the $\mathrm{CVH}$ and $\mathrm{HS}$ packages. That is, the latent heat associated with the coolant mass transfer between the atmosphere and aerosol surfaces is incorporated in the total internal energy transfer to and from the atmosphere. In addition, condensation and evaporation of fission product vapors on aerosols is calculated in parallel with condensation on and evaporation from heat structure surfaces, but without consideration of the latent heat of condensation of the vapor, since it is negligible compared to the energy of the atmosphere and the heat structure.

The MELCOR calculation of changes in aerosol distribution and location within a plant considers the following general processes:

1 aerosol phenomenological sources from other packages, such as release from fuel rods or during core-concrete interactions, and/or arbitrary user-specified sources;

2 condensation and evaporation of water and fission products to and from aerosol particles;

3 particle agglomeration (or coagulation), whereby two particles collide and form one larger particle;

4 particle deposition onto surfaces or settling through flow paths into lower control volumes;

5 advection of aerosols between control volumes by bulk fluid flows; and

6 removal of aerosol particles by engineered safety features (ESFs), such as filter trapping, pool scrubbing, and spray washout. 
RN Package Reference Manual

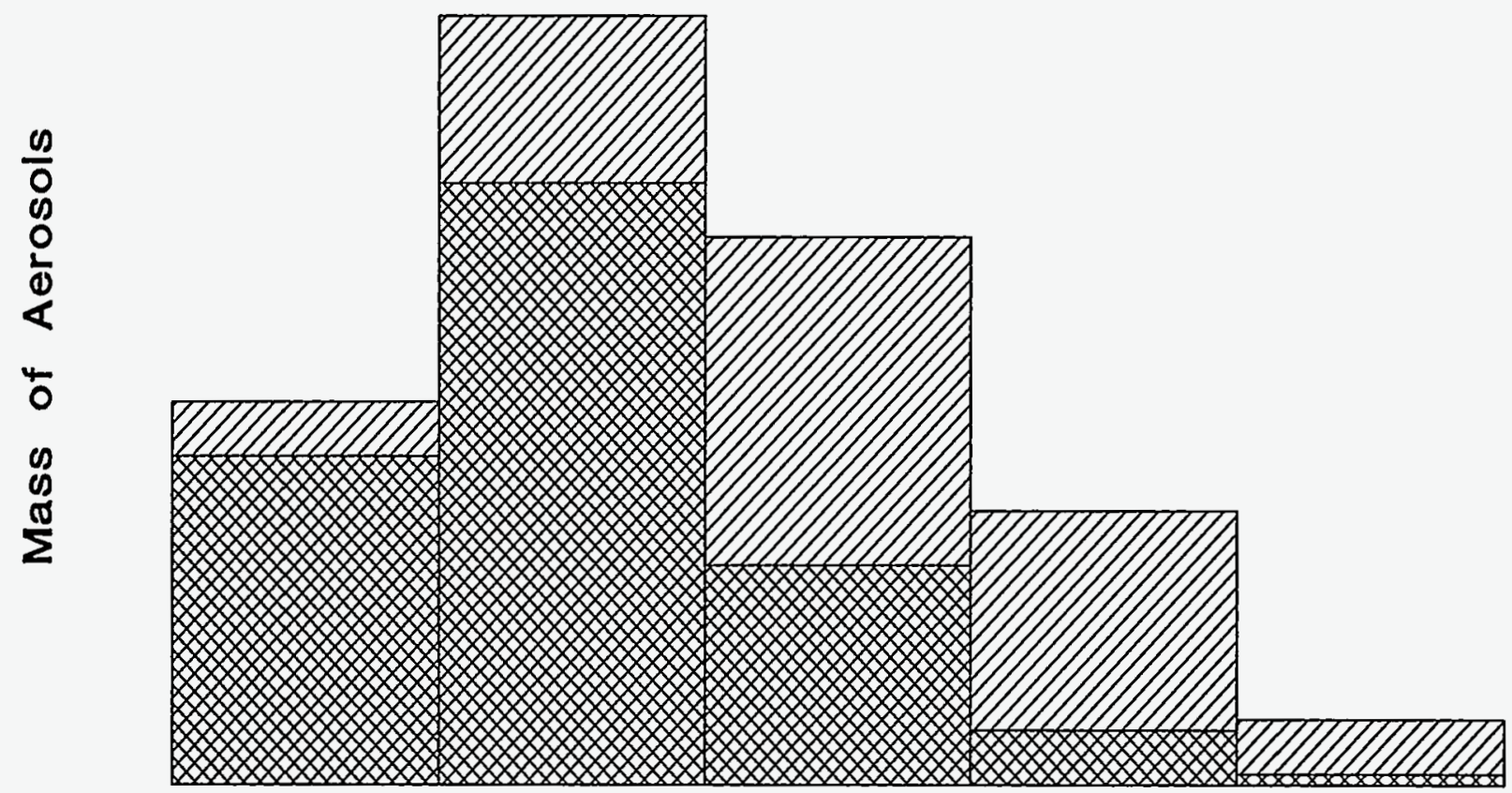

\section{Section 1 Section 2 Section 3 Section 4 Section 5 Log (diameter)}

Component 1

VIIIA Component 2

Figure 2.4.1 MAEROS Aerosol Model

RN-RM-27 


\section{RN Package Reference Manual}

The RN package includes models to simulate each of these processes, but only userdefined aerosol sources and agglomeration and deposition processes are formally coupled in the MAEROS integrated solution framework. Aerosol sources from other phenomenological packages in MELCOR and condensation on and evaporation from aerosols are decoupled and treated outside the MAEROS solution. This section describes principally the details of the implementation of MAEROS within MELCOR. Section 2.4.1 describes in more detail how the component/class mapping scheme works and how the particle size distribution is represented in MELCOR. The general MAEROS equations and the specific models for aerosol agglomeration and deposition are described in Section 2.4.2. Section 2.4.3 provides information on how various aerosol sources are treated, and Section 2.4.4 discusses the MELCOR aerosol resuspension model (not yet implemented).

Condensation and evaporation processes for both aerosols and heat structure surfaces are described later in Section 2.5, and Section 2.6 describes the modeling for advection of aerosols between control volumes. Section 2.7 describes the removal of aerosols by ESFs.

\subsubsection{Aerosol Mass and Size Distributions}

In the stand-alone version of MAEROS, a component is used for each type of mass that the user wants to track. It was thought that if this approach were used in MELCOR for each of the 15 default RN material classes, the aerosol calculations could easily become prohibitively expensive in terms of computational speed and memory storage requirements. Therefore, a scheme was developed for MELCOR to allow the user to combine RN material classes into components for the MAEROS calculations.

In MELCOR, one or more RN classes can be assigned to a component, as specified on the RNCCXXX input records, but a particular class cannot be assigned to more than one component. For each control volume, the fractions within a particular component of each class assigned to that component are determined before the aerosol dynamics calculation is performed to determine the new size distribution. These fractions necessarily sum to unity. After the aerosol dynamics calculation, the masses for each aerosol size, the deposited masses, and the fallout masses for each class are determined by multiplying the appropriate component mass values by the previously calculated class mass fraction. In effect, all classes assigned to the same component are assumed to have the same size distribution.

The aerosol particle size distribution is discretized into particle size bins called sections. The distribution of aerosol mass within a section is treated as constant with respect to the logarithm of particle mass. The user may input any arbitrary initial aerosol size distribution for any fission product class by specifying the mass in each size section at the initial time (see the RNAGXXX and RNALXXX input records). The initial aerosol 
RN Package Reference Manual

water mass (fog) is determined from the CVH package input data only and is put in the smallest aerosol section; an error message is generated if an attempt is made to initialize water aerosol mass through RN input.

The number of sections and components to be used in the aerosol calculations, as well as the minimum and maximum aerosol diameters, are specified by the user (see input records RN1001 and RN1100). Individual section boundaries are calculated from these values so that the ratio of the upper and lower bound diameter of each section is the same. A check is also made that the ratio of the upper to lower mass boundary for each section is greater than or equal to two to assure that the calculations will conform to the assumptions made in the derivation of the MAEROS equations. If this constraint is not met, an error message is generated and the calculation terminates.

Although the aerosol component distributions from the MAEROS calculation are not stored permanently, the class distributions are used to calculate the mass median diameter and geometric standard deviation for the wet, dry and component distributions in each control volume for editing. The wet distribution is the sum over all classes including water; the dry distribution, which is commonly determined experimentally, is the sum over all classes excluding water; and the component distribution is the sum over all classes assigned to the particular component. The mass median diameter is defined to be the diameter above and below which half the total mass (wet, dry or component mass) in the distribution occurs,

$$
0.5 \times \int_{0}^{\infty} f_{m}(D) d D=\int_{0}^{D^{\prime}} f_{m}(D) d D
$$

where $D^{\prime}$ is the mass median diameter and $f_{m}(D) d D$ is the mass in the distribution between diameter $D$ and $D+d D$. The geometric standard deviation, $\sigma_{G}$, is defined as

$$
\left(\ln \sigma_{G}\right)^{2}=\frac{\int_{0}^{\infty} \ln ^{2}(D / \bar{D}) f_{m}(D) d D}{\int_{0}^{\infty} f_{m}(D) d D}
$$

where $\bar{D}$ is the logarithmic mass mean diameter defined by 
RN Package Reference Manual

$$
\ln (\bar{D})=\frac{\int_{0}^{\infty} \ln (D) f_{m}(D) d D}{\int_{0}^{\infty} f_{m}(D) d D}
$$

In MELCOR, any aerosol particles that are calculated to grow larger than the maximum size section are assumed to fall out onto either floor-type heat structures or into adjacent lower control volumes. Aerosols that fall out into a lower control volume are put in the largest size section of the aerosol distribution in that control volume and thus should quickly deposit or fall out onto floor structures. This is described in more detail in Section 2.4.2.2.

\subsubsection{MAEROS Equations}

The aerosol agglomeration and deposition models from MAEROS are used to calculate the changing aerosol size distributions as these processes affect the aerosol in each control volume at each time step. Particle agglomeration, deposition onto heat structure surfaces, fallout onto floors or into lower control volumes, and the effects of user-defined aerosol sources are all integrated in the MAEROS calculation.

The modeling of the aerosol size distribution is governed by a complex integro-differential equation. MAEROS was developed as a method of discretizing this equation into a form that can be solved numerically. In their method (and using their notation), the full range of aerosol masses is divided into $m$ contiguous arbitrarily sized sections, and $Q_{\ell}$ is defined as the total mass of aerosol per unit volume of fluid in section $\ell$ at time $t$. Thus,

$$
Q_{\ell}(t)=\sum_{k=1}^{s} Q_{\ell, k}(t)
$$

where $Q_{\ell, k}(t)$ is the mass of component $k$ in section $l$, and $s$ is the total number of components. The upper bound of section $\ell-1$ is equal to the lower bound of section $\ell$ for $\ell=2,3, \ldots \mathrm{m}$. These equations can be written

where

$$
\begin{aligned}
\mathrm{dQ}_{\ell, \mathrm{k}}(\mathrm{t}) / \mathrm{dt}= & \begin{array}{l}
\text { time rate of change of aerosol mass of component } \mathrm{k} \text { (per unit } \\
\text { volume) in section } \ell \text { at time } \mathrm{t} ;
\end{array}
\end{aligned}
$$


RN Package Reference Manual

$\mathrm{k}=$ aerosol component (for example, water or a specific FP) $=1,2, \ldots \mathrm{N}_{\mathrm{a}}$;

$\ell=$ discretized section (or physical size range) of the aerosol $=1,2,3, \ldots \mathrm{m}$;

$\ell+1=\ell-1$ for condensation, or $\ell+1$ for evaporation;

Each term in Equation 2.4.5 represents a distinct mechanism for changes in mass concentration of component $\mathrm{k}$ in a particular section. Time integration of Equation 2.4.5 requires that the coefficients used in each term be known on a sectional basis. These sectional coefficients correspond to the following mechanisms:

$\bar{\beta}$ Agglomeration (or coagulation), $\mathrm{m}^{3} / \mathrm{s}-\mathrm{kg}$,

G Gas-to-particle conversion (condensation/evaporation), $s^{-1}$,

$\underline{S}$ Sources, $\mathrm{kg} / \mathrm{m}^{3}-\mathrm{s}$,

$\Re$ Removal (deposition) $\mathrm{kg} / \mathrm{m}^{3}$-s.

The $\bar{\beta}$ 's are called sectional coagulation coefficients, and they can be evaluated by using a variety of formulas that incorporate the effects of the different physical processes. These processes include gravitational agglomeration (a larger particle overtakes a smaller one as they both fall) and agglomeration through diffusion (either Brownian or turbulent), and are described in more detail in Section 2.4.2.1. The six agglomeration terms in the Gelbard-Seinfeld approach refer respectively to the following processes:

${ }^{1 a} \bar{\beta}_{i, j, \ell}$ addition of component $k$ in section $\ell$, by removal of component $k$ in section $j$ when a particle in section $\mathrm{j}$ coagulates with a particle in section $\mathrm{i}$ to form a particle in section $\ell$.

${ }^{15} \bar{\beta}_{i, 1, \ell}$ addition of component $k$ in section $\ell$, by removal of component $k$ in section $i$ when a particle in section $i$ coagulates with a particle in section $j$ to form a particle in section $\ell$.

${ }^{2 a} \bar{\beta}_{i, \ell}$ removal of component $\mathrm{k}$ in section $\ell$, resulting from a particle in section $\mathrm{i}$ coagulating with a particle in section $\ell$.

${ }^{2 \mathrm{~b}} \bar{\beta}_{\mathrm{i}, \ell}$ addition of component $\mathrm{k}$ in section $\ell$, resulting from a particle in section $\mathrm{i}$ coagulating with a particle in section $\ell$, with the resulting particle remaining in section $\ell$.

${ }^{3} \bar{\beta}_{\ell, \ell} \quad$ removal of component $\mathrm{k}$ in section $\ell$, by two particles in section $\ell$ coagulating and the resulting particle is in a section higher than $\ell$.

${ }^{4} \bar{\beta}_{\mathrm{l}, \ell} \quad$ removal of component $\mathrm{k}$ in section $\ell$, by a particle in section $\ell$ coagulating with a particle in section $i$, where $i>\ell$. 


\section{RN Package Reference Manual}

The four condensation terms represented by the $\bar{G}$ coefficients correspond to the following processes:
${ }^{1} \bar{G}_{\ell, k}$
addition (removal) of component $k$ within section $\ell$ by condensation (evaporation) of component $k$ onto (from) particles in that section;

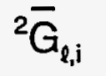
transfer of existing component $k$ from section $\ell$ to section $\ell+1(\ell-1)$ by condensation (evaporation) of component $i$ onto (from) particles in section $\ell$;

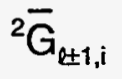
transfer of existing component $k$ from section $l-1(l+1)$ to section $\ell$ by condensation (evaporation) of component $i$ onto (from) particles in section $\ell-1(\ell+1)$; and

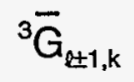
transfer of changed mass of component $k$ from section $l-1(l+1)$ to section $\ell$ by condensation (evaporation) of component $k$ onto (from) particles in section $\ell-1(\ell+1)$. This term vanishes in the limit that aerosol masses are large compared to molecular masses.

Water condensation on and evaporation from aerosol particles are the principal couplings between thermal-hydraulics and aerosol behavior. However, these terms are not used directly in the MELCOR implementation of MAEROS. As described in Section 2.5.1, water condensation and evaporation are treated separately (but still using the MAEROScalculated coefficients for water, as discussed in Section 2.5.1) for consistency with the water thermodynamics calculated in the CVH package.

Furthermore, fission product condensation onto and evaporation from aerosols are also integrated with the calculation of fission product condensation and evaporation on heat structure surfaces by the TRAP-MELT model, as described in Section 2.5.2, and are thus treated outside the MAEROS framework as well.

In Equation 2.4.5, particle removal (or deposition) is addressed by the $\bar{\Re}$ term. Deposition occurs through a number of processes, including gravitational settling, diffusion to surfaces, thermophoresis (a Brownian process causing migration of particles toward lower temperatures), and diffusiophoresis (deposition induced by condensation of water vapor onto structural surfaces). The sectional deposition coefficients are described in more detail in Section 2.4.2.2.

Aerosol sources are included by the $\bar{S}$ term in Equation 2.4.5. Currently, only sources defined by the user as tabular functions of time are directly included in the MAEROS equations. Sources from phenomenological models are added directly to the aerosol sectional distributions as described later in Section 2.4.3. 
RN Package Reference Manual

Intraparticle chemical reactions can occur between constituents of the aerosol. The modeling of aerosol size/composition changes resulting from chemical reactions is not currently implemented in MELCOR, but this phenomenon could easily be included in the sectional model.

Simplifications in the coefficients and in Equation 2.4.5 occur if the geometric constraint

$$
m_{i+1} / m_{i}>2
$$

is satisfied, where $m_{i}$ is the particle mass at the lower boundary of section $i$. The geometric constraint ensures that the agglomeration of two particles results in a new particle that will fit into either the section that contains the larger of the two original particles or the section just above it. This constraint thus reduces the number of sectional agglomeration coefficients. As stated earlier in Section 2.4.1, input specifying the section boundaries is checked to verify that this constraint is met.

Equation 2.4.5 is used in MELCOR to describe the evolution of the aerosol size and composition distributions within each control volume. Each control volume has its own particle size and chemical composition distributions, and the aerosols are carried from one control volume to another by gas flow and may be removed by ESFs, as described in Section 2.7.

\subsubsection{Agglomeration}

When two aerosol particles collide, they can combine to form a larger particle. This process is known as agglomeration or coagulation. The sectional method used in MAEROS treats four agglomeration processes: Brownian diffusion, differential gravitational settling, and turbulent agglomeration by shear and inertial forces. A basic assumption about these processes is that simultaneous agglomeration of three or more particles is negligible.

The full dependence of the agglomeration coefficients $\beta\left(\mathrm{m}^{3} / \mathrm{s}\right)$ upon the aerosol and atmosphere properties as implemented in MELCOR is given in the equations in Appendix B. The dependence on atmosphere properties is not considered to be a major source of uncertainty in the aerosol calculations. The dependence on particle diameter and key modeling parameters can be summarized as follows:

$\begin{array}{lll}\text { Brownian: } & \beta_{\mathrm{B}} & \propto \gamma \chi^{-1} \mathrm{f}\left(\mathrm{d}_{\mathrm{i}}, \mathrm{d}_{\mathrm{j}}\right) ; \\ \text { Gravitational: } & \beta_{\text {grav }} & \propto \varepsilon_{g} \gamma^{2} \chi^{-1}\left(d_{\mathrm{i}}+\mathrm{d}_{\mathrm{j}}\right)^{2}\left(\mathrm{~d}_{\mathrm{i}}^{2}-\mathrm{d}_{\mathrm{j}}^{2}\right) ; \\ \text { Turbulent, Shear: } & \beta_{\mathrm{Tl}} & \propto \gamma^{3} \varepsilon^{1 / 2}\left(d_{\mathrm{i}}+d_{\mathrm{j}}\right)^{3} ; \text { and }\end{array}$




\section{RN Package Reference Manual}

Turbulent, Inertial: $\beta_{\mathrm{T} 2} \propto \gamma^{2} \chi^{-1} \varepsilon^{3 / 4}\left(d_{i}+d_{j}\right)^{2}\left(d_{i}^{2}-d_{j}^{2}\right)$.

In these proportionalities, $\gamma$ and $\chi$ are the agglomeration and dynamic shape factors, respectively, and $\varepsilon$ is the turbulent energy dissipation density, all of which are specified on user input record RNMS000. Variables $d_{i}$ and $d_{i}$ are the diameters of the two interacting particles, with $d_{i}>d_{i}$. The collision efficiency for gravitational agglomeration is represented by $\varepsilon_{g}$, with a specific value (discussed below) calculated in the code. The magnitude of the Brownian kernel increases with increasing values of the size ratio $d_{j} / d_{j}$. The role of the various parameters appearing in the kernels is also discussed below.

Except when they include significant amounts of liquid, aerosol particles are not usually assumed to be spherical, and the effective aerosol densities may be significantly less than the bulk density of the materials of which the aerosols are composed. In aerosol codes, these effects may be taken into account by using a formalism based on fully dense spherical aerosols modified through the use of the agglomeration shape factor $\gamma$ and the dynamic shape factor $\chi$. The shape factors $\gamma$ and $\chi$ are input by the user to represent the effect of nonspherical shape upon aerosol collision cross sections and aerosolatmosphere drag forces, respectively. Unit values of the shape factors correspond to dense aerosol of spherical shape, while porous spherical agglomerates lead, in theory, to values somewhat greater than unity. Highly irregular aerosols and agglomerates can have shape factors substantially greater than unity, often with $\gamma$ and $\chi$ being quite unequal.

Given experimental data for aerosol shapes and densities applicable to LWR severe accidents, shape factors could, in principle, be derived theoretically. Because this is not practical, empirical values are obtained by fitting code calculations to the results of aerosol experiments. The values obtained may be sensitive to aerosol composition and to atmospheric conditions, especially to relative humidity. Humid conditions tend to produce more nearly spherical aerosols due to condensation of water on aerosol agglomerates. Only limited information is available concerning the dependence of shape factors upon the relevant parameters (for example, particle characteristics and atmospheric conditions), and these parameters are themselves quite uncertain under accident conditions. Default values of unity are set for both factors in MELCOR.

Agglomeration rates can be enhanced by turbulence in the atmosphere. In the past, very little attention has been given to estimating values of turbulent energy dissipation density $\varepsilon$ appropriate for accident conditions, and uncertainty in its value may contribute to uncertainty in the aerosol agglomeration rates. In MELCOR, the user can input the value of $\varepsilon$ or use the default value of $0.001 \mathrm{~m}^{2} / \mathrm{s}^{3}$.

The gravitational collision efficiency $\varepsilon_{g}$ of unity corresponds to the assumption that collision cross sections are equal to the geometric cross sections. It is well known that hydrodynamic interactions between particles (i.e., the tendency of a particle to follow streamlines in flow around another particle) can yield collision efficiencies much less than 
RN Package Reference Manual

unity, especially for particles that are unequal in size. The problem of collisions between falling (spherical) aerosols has been the object of much detailed theoretical and experimental study, and may be more complex than can be represented by the simple expressions normally used in aerosol codes. In MELCOR, the value of $\varepsilon_{g}$ is given by

$$
\varepsilon_{g}=1.5 d_{j}^{2} /\left(d_{i}+d_{j}\right)^{2}
$$

where $d_{j}$ is the smaller of the two aerosol particle diameters. It has been argued $[17,18]$ that using 0.5 instead of 1.5 as the coefficient in Equation 2.4.7 gives a better representation and that other corrections are needed when the size ratio $d_{i} / d_{i}$ is less than about 2 and/or $d_{i}$ is greater than about $20 \mu \mathrm{m}$. However, more recent experimental measurements of collision efficiencies by Gelbard et al. [19] do not support these proposed revisions and, instead, gave collision efficiencies in reasonable agreement with Equation 2.4.7. These measurements involved studying the collisions of spheres at higher Reynolds numbers than those typical of aerosols and the results therefore may not be totally conclusive; however, arguments for modifying Equation 2.4.7 are not judged to be any more convincing.

The agglomeration model used in MELCOR receives temperature, pressure, and mass flow rate information from the $\mathrm{CVH}$ package. The turbulent agglomeration kernels are combined as

$$
\beta_{\mathrm{TT}}=c_{\mathrm{s}}\left(\beta_{\mathrm{T} 1}^{2}+\beta_{\mathrm{T} 2}^{2}\right)^{1 / 2}
$$

where $c_{s}$ is a particle sticking coefficient (default value of unity), which may be specified on input record RNMS000. (This sticking coefficient also appears in the other Brownian and gravitational agglomeration kernels.) The total turbulent kernel is added to the Brownian and gravitational kernels to obtain a total agglomeration kernel $\beta_{T}$ which is then integrated over sections for use in Equation 2.4.5:

$$
\beta_{\mathrm{T}}=\beta_{\mathrm{B}}+\beta_{\mathrm{grav}}+\beta_{\mathrm{TT}}
$$

Examination of the relations for the agglomeration kernels in the proportionalities given above shows that the effects of gravitational collision efficiency, aerosol shape factors, and turbulence are coupled together in a highly nonlinear fashion. The dependence upon the various parameters differs among the different agglomeration mechanisms, and the net effects are strongly size-dependent. Hence, it is possible to give only a few generalizations. 


\section{RN Package Reference Manual}

All the agglomeration processes are enhanced by large values of the agglomeration shape factor $\gamma$, with the effect being largest for turbulent shear agglomeration and smallest for Brownian agglomeration. Large values of the dynamic shape factor reduce all the kernels (calculational coefficients) except the turbulent shear kernel, which is unaffected. Hence, large values of the shape factors enhance the relative importance of turbulence, especially for the turbulent shear effect. Reference 18 includes sensitivity studies examining the implications of uncertainties in these shape factors as well as in the turbulent energy dissipation density $\varepsilon$.

\subsubsection{Deposition, Settling, and Fallout}

Aerosols can directly deposit onto heat structure and water pool surfaces through four processes calculated within MAEROS. All heat structure surfaces are automatically designated as deposition surfaces for aerosols using information from the HS package, unless made inactive through user input. The parameters obtained from the HS package are:

1. Geometric orientation

2. Surface area in the atmosphere

3. Surface heat flux

4. Mass transfer coefficient

5. Water condensation mass flux

Each surface of a MELCOR heat structure must be designated as a ceiling, a floor, or a wall, since MAEROS only calculates deposition kernels for these orientations. The default treatment is:

The upper surface of a rectangular heat structure with an angle of inclination less than 45 degrees is considered to be a floor, and the lower surface a ceiling. The heat structure orientation parameter ALPHA on HS input record HSCCCCCOO2 determines both the inclination and whether the "left" surface is the upper or the lower surface.

Both surfaces of a rectangular heat structure with an angle of inclination greater than 45 degrees, and both surfaces of cylinders and spheres are treated as walls.

The inner (left) surface of a bottom-half hemisphere is treated as a floor and the outer (right) surface as a ceiling. For a top-half hemisphere, the treatment is reversed.

The user can override these default orientations or deactivate a surface for aerosol deposition through the RNDSXXX input records. However, if the surface of a structure is deactivated for the purposes of deposition, it is also removed from consideration in the calculation of condensation and evaporation of fission product vapors, as discussed in 
Section 2.5. (Note that the orientation of a structure does not otherwise affect the rate of condensation or evaporation.)

If a control volume contains a water pool, the pool surface is treated as a floor for the purposes of deposition. The area of the water pool is extracted from the CVH database.

Aerosols can also settle from one control volume to another through flowthrough areas (i.e., the gravitational settling and Brownian diffusion kernels in MAEROS described below are applied to flowthrough areas in addition to HS and pool surfaces). Such areas will ordinarily correspond to open flow paths between the control volumes, through which aerosols and radionuclide vapors are also advected. The appropriate flow area, path elevation, etc. are specified in the RNSETXXX input records. Aerosols are not transported through these areas if the flow path is blocked by a water pool.

Finally, aerosols can agglomerate and become larger than the user-specified maximum diameter. These aerosols are assumed to immediately deposit onto water pools or horizontal heat structure surfaces or to settle from one control volume to another through flowthrough areas defined as part of RN input. The term fallout in MELCOR is used exclusively for this immediate deposition or settling of aerosols larger than the maximum user-specified diameter. All control volumes must have at least one upward-facing deposition surface (floor) or flowthrough area defined to receive fallout aerosols generated by this mechanism. During MELGEN a check is made for the existence of at least one such area; if none is present, an error message is generated and no restart file is written.

The MAEROS deposition kernel for each type of surface is made up of four contributions: gravitational deposition, Brownian diffusion to surfaces, thermophoresis, and diffusiophoresis. Of these natural depletion processes, gravitational deposition is often the dominant mechanism for large control volumes such as those typically used to simulate the containment, although phoretic effects may be significant in some cases (e.g., diffusiophoresis during water condensation). Particle diffusion is generally considered to be a relatively unimportant deposition process. The contribution of each of these processes to the deposition kernel for each type of heat structure surface and for pools and flowthrough areas in MELCOR is summarized below: 
RN Package Reference Manual

Surface

Heat Structure

Floor

Wall

Ceiling

Pool

Flowthrough Area
Deposition Kernel $^{1}$

grav BD therm diffus

1 The symbols,+ 0 , and - mean a positive contribution, no contribution, and a negative contribution, respectively. Of course, the total deposition kernel for any surface can not be less than zero.

2 Included in the general formulation but currently zeroed out internally.

The velocities calculated for each of these deposition processes are defined below.

Gravitational Deposition

Gravitational deposition is effective only for upward-facing surfaces (i.e., floors and water pools) and flowthroughs to lower control volumes; for downward-facing surfaces (i.e., ceilings), this mechanism works to oppose other deposition processes. The gravitational deposition velocity is given by

$$
v_{\text {grav }}=\frac{d_{p}^{2} \rho_{p} g C_{m}}{18 \mu \chi}
$$

where

$$
\begin{array}{ll}
v_{\text {grav }}= & \text { the downward terminal velocity }(\mathrm{m} / \mathrm{s}) \\
d_{p} & =\text { the particle diameter }(\mathrm{m}) ; \\
\rho_{p} & =\text { the particle density }\left(\mathrm{kg} / \mathrm{m}^{3}\right) ; \\
g & =\text { acceleration of gravity }=9.8 \mathrm{~m} / \mathrm{s}^{2} ; \\
C_{m} & =\text { the particle mobility, or Cunningham slip correction factor, which }
\end{array}
$$


The particle mobility, or Cunningham slip correction factor, in the equation above is expressed as

$$
C_{m}=1+\frac{2 \lambda}{d_{p}}\left[F_{\text {slip }}+0.4 \exp \left(-1.1 d_{p} / 2 \lambda\right)\right]
$$

where

$$
\begin{array}{ll}
\lambda & =\text { mean free path of air at } 298 \mathrm{~K}\left(\sim 0.069 \cdot 10^{-6} \mathrm{~m}\right) \\
\mathrm{F}_{\text {slip }} & =\text { slip factor specified on input record RNMS000 (default value of } 1.257) \\
\mu & =\text { viscosity of air at } 298 \mathrm{~K}\left(\sim 1.8 \cdot 10^{-5}\left(\mathrm{~N} \cdot \mathrm{s} / \mathrm{m}^{2}\right)\right) ; \text { and } \\
\chi & =\text { dynamic shape factor. }
\end{array}
$$

This model assumes that the aerosol particle Reynolds number Re, based on particle diameter and net deposition velocity, is much less than 1 . This physically means that inertial effects of the flow may be neglected. This Reynolds number is not to be confused with the bulk mass flow (air, steam, aerosol particles) Reynolds number based on the dimensions and velocities calculated by the CVH package, which is typically much greater than one.

\section{Brownian Diffusion}

Deposition can also result from diffusion of aerosols in a concentration gradient from a higher to a lower concentration region. The diffusive deposition velocity is given by

$$
v_{\text {diff }}=\frac{\sigma T C_{m}}{3 \pi \mu \chi d_{p} \Delta}
$$

where

$$
\begin{array}{ll}
v_{\text {diff }} & =\text { diffusion deposition velocity }(\mathrm{m} / \mathrm{s}) \\
\sigma & =\text { Boltzmann Constant }=1.38 \cdot 10^{-23}\left(\mathrm{~J} / \mathrm{s}-\mathrm{m}^{2} \mathrm{~K}^{4}\right) \\
T & =\text { atmosphere temperature }(\mathrm{K}) \\
\mu & =\text { viscosity }\left(\mathrm{N} \cdot \mathrm{s} / \mathrm{m}^{2}\right) ; \\
\chi & =\text { dynamic shape factor; and } \\
\Delta & =\text { user-specified diffusion boundary layer thickness specified on input } \\
& \text { record RNMS000 (default value of } \left.10^{-5} \mathrm{~m}\right)
\end{array}
$$

under the assumption that there is no gas velocity perpendicular to the deposition surface. This impaction mechanism is most effective for larger aerosol particle sizes. 


\section{RN Package Reference Manual}

\section{Thermophoresis}

This aerosol deposition mechanism results from the force exerted on aerosol particles by temperature gradients in the bulk gas. The thermophoretic deposition velocity $v_{\text {therm }}$ is given by

$$
v_{\text {therm }}=\frac{3 \mu C_{m}\left(c_{t} K n+k_{\text {gas }} / k_{p}\right)}{2 \chi \rho_{\text {gas }} T\left(1+3 F_{\text {slip }} K n\right)\left(1+2 c_{t} K n+k_{\text {gas }} / k_{p}\right)} \nabla T
$$

where

$$
\begin{aligned}
\mathrm{Kn}= & 2 \lambda / \mathrm{d}_{\mathrm{p}} \text { (Knudsen number); } \\
\mathrm{k}_{\text {gas }} / \mathrm{k}_{\mathrm{p}}= & \text { ratio of thermal conductivity of gas over that for aerosol particle } \mathrm{k}_{\mathrm{p}} \text {, and } \\
& \text { is user-specified (on input record RNMSO00); } \\
\nabla T= & \text { structure surface temperature gradient }(\mathrm{K} / \mathrm{m}) ; \\
\rho_{\text {gas }}= & \text { gas density }\left(\mathrm{kg} / \mathrm{m}^{3}\right) ; \\
\mathrm{T} & \text { wall temperature; } \\
\mathrm{F}_{\text {slip }}= & \text { slip factor; and } \\
\mathrm{C}_{\mathrm{t}}= & \text { constant associated with the thermal accommodation coefficients } \\
& \text { (specified on input record RNMSO00 with default value of } 1.0) .
\end{aligned}
$$

The coefficient of $\nabla T$ in Equation 2.4.13 is calculated for each of the four aerosol coefficient sets at minimum/maximum temperature and pressure and stored, as described in Section 2.4.2.3. The actual temperature gradient at each heat structure surface, calculated from the heat flux $q^{\prime \prime}$ obtained from the HS package as

$$
\nabla T=-q^{\prime \prime} / k_{\text {air }}
$$

is used with an interpolated coefficient (see Section 2.4.2.3) to calculate the actual diffusion velocity. The thermal conductivity of air, $k_{\text {air }}$ is evaluated at the surface temperature of the heat structure using the properties of air for consistency with the evaluation of the aerosol coefficients with air properties.

\section{Diffusiophoresis}

When water condenses on (evaporates from) a structure surface, composition gradients will exist in the adjacent gas which will affect aerosol deposition on the surface. Two related mechanisms produce these gradients. First, a net molar flux of gas toward (away from) the condensing (evaporating) surface will exist, and this net flux, commonly called the Stefan flow [20], will tend to move aerosol particles with it. Second, differences in the momentum transferred by molecular impacts on opposite sides of the particle will tend to drive the particle in the direction of decreasing concentration of the heavier constituent. 
RN Package Reference Manual

By some definitions, only this second component constitutes diffusiophoresis; however, in this discussion the term "diffusiophoresis" will be used to represent the net result of both effects and the equations given include both effects. Note that when the noncondensible gas is heavier than steam, as in air-steam mixtures, the differential molecular impact effect opposes the Stefan flow (which dominates the net result); the effects are in the same direction if the noncondensible gas is lighter than steam.

The treatment in MELCOR is valid for particle sizes large compared with molecular mean free paths, a condition which will generally apply for severe accident analyses. A diffusiophoretic deposition velocity (including the Stefan flow) $v_{\text {diffusio }}$ is calculated from

$$
\begin{aligned}
& v_{\text {diffusio }}=\left(\frac{\sqrt{M_{s}}}{X_{s} \sqrt{M_{s}}+X_{N C} \sqrt{M_{N C}}}\right)\left(\frac{W_{\text {cond }}}{\rho_{b}}\right) \text { if } W_{\text {cond }} \geq 0 \text { (condensation) } \\
& \mathrm{V}_{\text {diffusio }}=\mathrm{W}_{\text {cond }} / \rho_{\mathrm{s}} \quad \text { if } \mathrm{W}_{\text {cond }}<0 \quad \text { (evaporation) }
\end{aligned}
$$

where

$$
\begin{aligned}
& M_{s}=\text { molecular weight of water }(\mathrm{kg} / \mathrm{kgmole}) ; \\
& M_{N C}=\text { molecular weight of noncondensible gases (air) } \\
& W_{\text {cond }}=\text { condensation mass flux to the surface }\left(\mathrm{kg} / \mathrm{s}-\mathrm{m}^{2}\right) ; \\
& \rho_{\mathrm{b}}=\text { density of bulk gas }\left(\mathrm{kg} / \mathrm{m}^{3}\right) ; \\
& \rho_{\mathrm{s}}=\text { saturation density of water vapor }\left(\mathrm{kg} / \mathrm{m}^{3}\right) ; \\
& X_{s}=\text { mole fraction of water vapor in the bulk gas; and } \\
& X_{N C}=\text { mole fraction of noncondensible gases in the bulk gas. }
\end{aligned}
$$

The condensation mass flux is obtained from the HS package. Note that the differential molecular impact effect is ignored in MELCOR for evaporation $\left(W_{\text {cond }}<0\right)$. The velocity calculated is toward the surface for condensation and away from the surface for evaporation.

MELCOR calculates these four velocities, representing deposition by gravity, diffusion, thermophoresis, and diffusiophoresis, for each surface. The sum gives the aerosol removal rate term $\Re_{\ell, \mathrm{k}}\left(\mathrm{kg} / \mathrm{m}^{3} \cdot \mathrm{s}\right)$ in Equation 2.4.5 in the form

$$
\overline{\mathfrak{R}}_{\ell, \mathrm{k}}=\sum_{\mathrm{j}=1}^{\mathrm{N}_{\mathrm{er}}} \mathrm{K}_{\mathrm{j}, \ell} \mathrm{Q}_{\ell, \mathrm{k}}
$$

where 
RN Package Reference Manual

$\mathrm{N}_{\text {str }}=$ total number of heat structure surfaces and/or pool surfaces for aerosol deposition in the control volume;

$\mathrm{K}_{\mathrm{j}, \ell}=$ deposition rate for the heat structure $\mathrm{j}$ for aerosol section $\ell\left(\mathrm{s}^{-1}\right)$; and

$Q_{\ell, k}=$ aerosol density for section $\ell$ of component $\mathrm{k}\left(\mathrm{kg} / \mathrm{m}^{3}\right)$.

$\mathrm{K}_{\mathrm{j}, \mathrm{e}}$ in Equation 2.4.17 is defined as

$$
K_{j, \ell}=\frac{A_{j}}{V}\left(v_{\text {grav }}+v_{\text {diff }}+v_{\text {therm }}+v_{\text {diffusio }}\right)
$$

where

$$
\begin{aligned}
& A_{j} \quad=\text { area of heat structure surface } \mathrm{j}\left(\mathrm{m}^{2}\right) ; \text { and } \\
& V \quad=\text { control volume atmosphere volume }\left(\mathrm{m}^{3}\right) .
\end{aligned}
$$

The total component mass that deposits on all surfaces from each section is calculated by MAEROS. The fraction $\mathrm{Fr}_{\mathrm{j} 2}$ of the mass in each section that deposits on surface $\mathrm{j}$ in the control volume is given by the simple expression

$$
F r_{j, \ell}=\frac{A_{j} K_{j, \ell}}{\sum_{j}^{N_{s e r}} A_{j} K_{j, \ell}}
$$

For fallout aerosols the procedure is similar except that the areas are summed for the floor heat structures, pool, and flowthrough areas; no kernels are involved since any kernel would be common to all surfaces involved. The total fallout mass calculated by agglomeration in MAEROS is then distributed over the floor heat structures, pools, and passed through flowthrough areas proportional to the area of each as follows:

$$
\mathrm{Fr}_{i}=A_{i} / \sum_{i}^{N_{\text {sur }}} A_{i}
$$

where $\mathrm{N}_{\text {sur }}$ is the total number of surfaces and flowthrough areas.

If part or all of a water film drains from a surface of a heat structure to the pool in the associated control volume, any fission products deposited on that surface or in the water film are normally relocated with the water, in proportion to the fraction of the film that is drained. However, the user may change this for any class by resetting the corresponding value in sensitivity coefficient array 7136 to the fraction of the class assumed to be dissolved in, and therefore to relocate with, the film. 
When a phase (pool or atmosphere) in a control volume ceases to exist, the aerosols it contains must be relocated. If the pool in a volume completely evaporates, any aerosols in the pool are distributed between the floor heat structures and the flowthrough areas according to Equation 2.4.20. If the atmosphere in a control volume that is almost completely filled with water completely condenses, all the suspended aerosol mass is added to the aerosol mass in the pool because it is assumed that the pool will then completely fill the control volume.

\subsubsection{Numerical Implementation}

In stand-alone MAEROS, the full aerosol dynamics equations are integrated using a conventional Runge-Kutta integration routine [21]. Because the integration is stopped and restarted only at times when an edit is desired, this approach is both accurate and efficient. However, in MELCOR the integration must be stopped at the end of each system time step and restarted at the beginning of the next to account for the continuous coupling with other MELCOR models, most of which must be exercised outside the MAEROS framework. These include aerosol release from fuel in the Core package, aerosol generation during core-concrete interactions by the MELCOR implementation of VANESA, fog condensation or evaporation calculated by CVH package thermodynamics, simultaneous condensation or evaporation of fission product vapors on heat structure and aerosol particle surfaces, and advection of aerosols between control volumes as controlled by CVH flow rates. Because of this, the Runge-Kutta solver can be very inefficient (the startup costs become excessive) and, for very short steps, there is little or no increase in accuracy over an explicit (forward Euler) integration.

Therefore, in MELCOR appropriate rates of change are evaluated at the beginning of each system time step and, if an explicit step will produce only small changes in the sectional densities, the distribution is updated using this explicit Euler step. Otherwise, the Runge-Kutta solver is used to advance the equations. The criteria for "small change in the sectional densities" and the error tolerances for the Runge-Kutta solution are controlled by the sensitivity coefficients in array 7000 (see Appendix A). If the RungeKutta solver does not converge within the requested tolerances, the RN package will reduce the time step to one-half the current value and write a message to the output and diagnostic files informing the user.

Whether the new aerosol distribution is calculated by an explicit step or by the RungeKutta solver, a check is performed to assure that component masses are conserved within a suitable tolerance (given by a sensitivity coefficient in array 7000; see Appendix A). If this check fails, the RN package will reduce the time step to one-half the current value and write a message to the output and diagnostic file informing the user.

The calculation of the MAEROS coefficients is somewhat costly; a full calculation for 20 sections requires about $10 \mathrm{~s}$ processing time on a CRAY $1 \mathrm{~S}$ computer. Therefore, the 


\section{RN Package Reference Manual}

coefficients are calculated on the first call to the aerosol model for use throughout the entire problem. Input records describing these coefficients (the RNCFXXX series) are written to a file automatically and may be read in from this file on a subsequent restart if called for on the RNACOEF record, but this practice is not recommended because of the possibility of user file handling errors. Sensitivity coefficient array 7001 contains error tolerances for numerical integration of the MAEROS coefficients.

Use of a constant set of coefficients imposes some modeling constraints, however, because various parameters embedded in the coefficients, such as material properties for the $\mathrm{CVH}$ atmosphere, are also effectively held fixed despite the fact that they should vary with changing conditions during the problem. Several of the terms in Equation 2.4.5 also contain driving forces. The coefficients of these forces are calculated and stored.

The following constraints pertain to the current coefficient set:

a The aerosol material density is assumed to be the same for all components (specified by the user on input record RN1100).

b The aerosol shape, as modeled by the dynamic and agglomeration shape factors (specified by the user on input record RNMSO00), is independent of aerosol composition.

c The medium in which the aerosol processes are assumed to occur has fixed properties, taken as those for air.

d The degree of turbulent agglomeration is fixed throughout the problem, specified by the user on input record RNMSO00.

e Other parameters that control deposition rates do not depend on particle composition. For example, the ratio of the thermal conductivity of air to that of the aerosol material is fixed.

The pressure and temperature of the atmosphere are embedded in these coefficients and are fixed for a single set of coefficients. However, the aerosol module actually calculates four sets of coefficients at points given by combinations of two temperatures $\left(T_{\min }\right.$ and $\left.T_{\max }\right)$ and two pressures $\left(P_{\min }\right.$ and $\left.P_{\max }\right)$, all of which may be specified by the user. The effects of changing thermal-hydraulic conditions during the problem are approximated by interpolating between these sets of coefficients. The $T_{\min }, T_{\max }, P_{\min }$, and $P_{\max }$ parameters are chosen to bound the temperatures and pressures expected in the calculation, and are specified on user input record RNPTO0O.

The interpolated sectional coefficients $\mathrm{CF}_{\mathrm{i}}$ for agglomeration or deposition mechanism $\mathrm{i}$ are given by 
RN Package Reference Manual

where

$$
\begin{aligned}
& A C_{11, i}= \begin{array}{l}
\text { the aerosol coefficient for mechanism } i \text { for the lower atmospheric } \\
\text { temperature }\left(T_{\text {min }}\right) \text { and pressure }\left(P_{\text {min }}\right),
\end{array} \\
& A C_{12, i}=\begin{array}{l}
\text { the aerosol coefficient for mechanism } i \text { for the lower atmospheric } \\
\text { temperature }\left(T_{\min }\right) \text { and higher pressure }\left(P_{\max }\right),
\end{array} \\
& A C_{21, i}=\begin{array}{l}
\text { the aerosol coefficient for mechanism } i \text { for the higher atmospheric } \\
\text { temperature }\left(T_{\max }\right) \text { and lower pressure }\left(P_{\min }\right) \text {, and }
\end{array} \\
& A C_{22, i=} \begin{array}{l}
\text { the aerosol coefficient for mechanism } i \text { for the higher atmospheric } \\
\text { temperature }\left(T_{\text {max }}\right) \text { and pressure }\left(P_{\text {max }}\right) .
\end{array}
\end{aligned}
$$

and $F_{T}$ and $F_{p}$ in Equation 2.4.21 are defined as

$$
F_{T}=\left(\frac{T_{\text {gas }}-T_{\text {min }}}{T_{\text {max }}-T_{\text {min }}}\right)
$$

and

$$
F_{p}=\left(\frac{P_{\text {gas }}-P_{\text {min }}}{P_{\text {max }}-P_{\text {min }}}\right)
$$

where

$$
\begin{aligned}
& T_{\text {gas }}=\text { cell temperature }(\mathrm{K}), \text { and } \\
& \mathrm{P}_{\text {gas }}=\text { cell pressure }(\mathrm{Pa}) .
\end{aligned}
$$

At the expense of larger sets of coefficients, some of the constraints above could be removed by interpolating to accommodate other changing parameters or by separating the coefficients so that a relevant parameter is not embedded, but this is not currently allowed through user input. 
RN Package Reference Manual

\subsubsection{Sources}

In stand-alone MAEROS, sources of aerosols are included in the differential equation solution at a constant source rate over that time step. In MELCOR, however, only userdefined sources are treated in this way; sources generated by models in other packages are currently added as a single increment because of the explicit coupling of these packages. Since masses that are added to the aerosol scheme could be from the previous time step or the present time step, depending on the calling sequence of the various packages, all mass to be added from other models is lumped together and added to the aerosol size distribution at the start of the time step.

Sources of aerosols are calculated in-vessel by the fuel-cladding gap release model and the CORSOR release models, as described in Section 2.3.1. Aerosols generated by these models are put into the smallest aerosol section, consistent with the production of small particles by gas-to-particle conversion. Sources of aerosols are also calculated exvessel by the VANESA model, as described in Section 2.3.2. The size distribution for these aerosols is assumed to be log-normal, with median diameter and standard deviation given by VANESA.

A number of time-dependent aerosol sources (specified on record RN1001) can also be specified for a control volume by the user (see the RNASXXX input record series). The aerosols can be put in either the control volume pool or atmosphere, with the time rate of the source specified by a tabular function. The mass added is determined by multiplying the mass addition rate (an input constant times the value of the tabular function at the midpoint of the current time step) by the time step, or

$$
M_{\text {added }}=\left[\frac{\mathrm{dM}}{\mathrm{dt}}\right] \Delta \mathrm{t}=[\mathrm{C} \times \mathrm{TF}(\mathrm{t}+\Delta \mathrm{t} / 2)] \Delta \mathrm{t}
$$

where $C$ is the mass addition constant XM on the RNASXXX input records, TF is the tabular function value, and $t$ and $\Delta t$ are the time and time step, respectively. The size distribution of the source can be uniform, log-normal with respect to log diameter, or userspecified, and is constant with time.

\subsubsection{Resuspension}

The resuspension model in MELCOR depends on other packages for activation. A package can call for an arbitrary fraction of deposited aerosols in a control volume to be resuspended at any time. However, no package presently has a model to calculate the fraction of deposited mass to be resuspended. User input is not available to activate resuspension. Therefore, resuspension is currently not calculated. When implemented, however, the user will be allowed to specify the size distribution of resuspended mass on the RNARXXX input records. 
RN Package Reference Manual

\subsection{Condensation/Evaporation}

Fission products and water can condense onto or evaporate from aerosols, heat structure surfaces, and water pools. Aerosol water is identified with "fog" in the CVH package. The change in fog mass is determined by thermodynamics calculated within the $\mathrm{CVH}$ package and is distributed over aerosol sections by the RN package as described below in Section 2.5.1. Water condensation and evaporation for heat structure and water pool surfaces is treated solely in the HS and CVH packages, respectively. The calculation of fission product vapor condensation and evaporation in the RN package is described in Section 2.5.2.

\subsubsection{Water}

The stand-alone version of MAEROS includes terms, given in Equation 2.4.5, for particle growth resulting from condensation of water onto (and shrinkage from evaporation of water from) aerosols. In MELCOR, these terms are not included with the MAEROS numerical solution for agglomeration and deposition. The reason is that inclusion of these terms makes the MAEROS equations "stiff" and therefore computationally difficult to solve, because the characteristic time for mass transfer is small compared to other characteristic times in the problem.

In MELCOR, we neglect hygroscopic and surface tension effects, and any temperature difference between the atmosphere and the aerosols. We further assume that mass transfer to and from aerosols is sufficiently rapid that the atmosphere can never become significantly supersaturated, and can be significantly subsaturated only if there is no water available to evaporate from the aerosols. In short, we assume that the system of atmosphere plus aerosol is in thermodynamic equilibrium.

This makes the aerosol assumptions consistent with the equation of state as described in the Control Volume Thermodynamics (CVT) Package Reference Manual, and avoids the need to estimate the disequilibrium between liquid and vapor within a basically equilibrium formulation of thermodynamics or to reconcile calculations including rate effects in the RN package with calculations based on equilibrium thermodynamics within the CVT package. It also allows the water on aerosols to be identified with "fog" in the CVT package.

This reduces the task of the RN package to one of distributing the total change in fog mass, as calculated by equilibrium thermodynamics in the CVT package, among the aerosol sections. In general, this is done with changes in sectional water masses proportional to the appropriate relative rates, which are all proportional to the same superor sub-saturation driving force, and the actual driving force need not be calculated. However, in a few cases (e.g., a sudden decompression in a volume with little or no initial 


\section{RN Package Reference Manual}

aerosol content) the condensation rate necessary to maintain equilibrium may exceed that possible on existing aerosols. In such cases, a very rough estimate of the limiting condensation rate is made (as described below), and the excess water is assumed to form new aerosols in the smallest aerosol section by spontaneous nucleation.

The MAEROS equations do not account for the distribution of composition of particles within a single section. This major simplification of the general equations resulted from approximating all material densities as equal, rendering the agglomeration and deposition coefficients independent of composition. Thus the evolution of particle composition and size distribution is independent of composition for these two processes. The composition distribution can be important in cases of water condensation or evaporation, where a change in water mass can carry a wet aerosol particle from one size section to another. A full treatment would require both the tracking of a more general size-and-composition distribution, and the inclusion of models to account for the differing rates of condensation of water on particles of differing composition.

In MELCOR, two assumptions are permitted for condensation/evaporation of water. The first is equivalent to assuming that all particles within a section have the same composition, and allows changes in water mass to freely carry particles of other materials from one size section to another. If water condenses on and then evaporates from a dry aerosol, the final distribution calculated using this treatment will not match the initial one - even in the absence of agglomeration or deposition - and may contain particles smaller than any initially present. The alternative assumption is that condensation and evaporation of water are ineffective in moving other materials from section to section. This is sometimes described as "allowing water to condense only on water." The errors in this treatment are different from-but no less serious than-those in the first treatment. The two options, while not necessarily representing limiting cases, allow a user to investigate the potential importance of the effects modeled.

Condensation within a section is evaluated explicitly. The total change in water mass is taken as proportional to the sum over sections of the ${ }^{1} \mathrm{G}$ term in Equation 2.4.5 for water, using start-of-step aerosol masses (the ${ }^{2} G$ growth terms cancel when summed over all sections, while the ${ }^{3} \mathrm{G}$ terms are infinitesimal contributors in the differential limit and are ignored). Since the new total water mass on aerosols is equal to the new fog mass calculated by the $\mathrm{CVH}$ package, the normalization constant, $\mathrm{A}$, can therefore be determined from the equation

$$
\Delta \mathrm{m}_{\mathrm{w}}=A \Delta \mathrm{t} \sum_{\ell}{ }^{1} \overline{\mathrm{G}}_{\ell, \mathrm{w}} \mathrm{Q}_{\ell}
$$

where $\Delta m_{w}$ is the total mass of water which must be condensed, as required by the $\mathrm{CVH}$ package. 
The rate of growth of an individual aerosol particle as a result of condensation is given by the Mason equation [9] as

$$
\begin{aligned}
\frac{d m}{d t} & =\rho_{1} 4 \pi r\left(r \frac{d r}{d t}\right) \\
& =\frac{4 \pi r(S-1)}{a+b}
\end{aligned}
$$

where $a$ and $b$ are heat flux and vapor diffusion terms, respectively,

$$
\begin{aligned}
& a=\frac{M_{w} i_{f g}^{2}}{k_{v} R T^{2}} \\
& b=\frac{R T}{P_{\text {sat }} D M_{w}}
\end{aligned}
$$

and where

$$
\begin{array}{ll}
m & =\text { particle mass } \\
\rho_{1} & =\text { particle density } \\
S & =\text { ambient saturation ratio } \\
r & =\text { mean aerosol particle radius of section } i \\
M_{w} & =\text { molecular weight of water } \\
\mathrm{i}_{\mathrm{fg}} & =\text { latent heat of water } \\
\mathrm{K}_{v} & =\text { vapor thermal conductivity } \\
\mathrm{R} & =\text { gas constant } \\
T & =\text { ambient temperature } \\
\mathrm{P}_{\text {sat }} & =\text { saturation pressure at } T \\
\mathrm{D} & =\text { diffusivity of water vapor in air }
\end{array}
$$

Equations 2.5.1 and 2.5.3 can be combined to relate the normalization constant $A$ and the ${ }^{1} G_{\ell, w}$ term to the Mason equation:

(2.5.6) 


\section{RN Package Reference Manual}

where $N_{\ell}$ is the number of particles in section $\ell$ and the angle brackets denote an appropriate sectional average. Therefore, the MAEROS coefficient ${ }^{1} \bar{G}_{\ell, \mathrm{w}}$ can be evaluated as an appropriate sectional average of $4 \pi \mathrm{r} / \mathrm{m}$ and $A$ can be taken as the term $(S-1) /(a+b)$, which is independent of size. Equations 2.5.1 and 2.5.6 are consistent if an effective value of the saturation ratio $S$, which varies through the time step, is chosen appropriately. A limiting rate on condensation can be estimated from Equation 2.5.6, using an upper bound on the saturation ratio based on the assumption that all vapor destined to condense exists in the vapor phase at the start of the step. That is,

$$
S_{\max }=1+\Delta m_{w} / m_{v, \text { sat }}
$$

where $\Delta m_{w}$ is again the mass of water to be condensed and $m_{v, s a t}$ is the mass of water vapor at saturation in the atmosphere. If the required condensation exceeds this limiting rate, $A$ in Equation 2.5.1 is set to the limiting value, $\left(S_{\max }-1\right) /(a+b)$, and the excess water is simply put into the smallest aerosol section, consistent with the assumption that excess water that cannot condense on existing aerosol, structures, or pools condenses by homogeneous nucleation, forming small fog droplets.

Transfer from section to section by growth of aerosols is evaluated implicitly; that is, the ${ }^{2} \bar{G}_{1, w}$ terms are evaluated using end-of-step masses. For condensation, aerosols can only grow, and by definition there can be no growth into the smallest section. This allows the new masses to be evaluated in a single pass from the smallest section to the largest by forward substitution,

$$
\begin{aligned}
Q_{1, \mathrm{k}}^{n} & =\frac{Q_{1, \mathrm{k}}^{0+}}{1+A \Delta \mathrm{t}^{2} \bar{G}_{1, \mathrm{w}}} \\
Q_{\ell, \mathrm{k}}^{n} & =\frac{Q_{\ell, \mathrm{k}}^{0+}+A \Delta \mathrm{t}^{2} \bar{G}_{\ell-1, \mathrm{w}} Q_{\ell-1, \mathrm{k}}^{\mathrm{n}}}{1+A \Delta \mathrm{t}^{2} \mathrm{G}_{\ell, \mathrm{w}}}
\end{aligned}
$$

where $Q_{\ell, k}{ }^{0+}$ is the start-of-step mass for all classes but water, in which case it includes the explicitly calculated condensation. Note that, from a strictly numerical standpoint, no negative masses can be predicted by this equation if there were none at the start of the step.

The treatment of evaporation is very similar to that for condensation. Evaporation within a section is calculated explicitly, and the total is normalized to the change in water mass required by the $\mathrm{CVH}$ package, but no rate limit is considered. If one or more explicitly calculated water masses would be negative, they are set to zero and the remaining (positive) masses renormalized to the correct total. 
As in condensation, the section-to-section transfers are evaluated implicitly in a single pass, this time from the largest to the smallest. Experience has shown that one further modification is necessary. If the limit and renormalize procedure just mentioned is used, the value of $A$ used for section-to-section transfers out of each section must be made to agree with the effective value of $A$ used for evaporation from that section. This is easily done by defining

$$
A_{s} \Delta t=\frac{Q_{\ell, w}^{\circ+}-Q_{\ell, w}^{0}}{{ }^{1} G_{\ell, w} Q_{\ell}}
$$

where $A_{s}$ is simply the normalization constant $A$ in cases where no dryout occurred.

\subsubsection{Fission Product Vapors}

The condensation and evaporation of fission product vapors to and from heat structures, pool surfaces, and aerosols is evaluated by the same equations as in the TRAP-MELT2 code [8]. The fission product vapor masses in the control volume atmosphere and condensed on the aerosol and heat structure surfaces are determined by rate equations based on the surface areas, mass transfer coefficients, atmosphere concentration, and the saturation concentrations corresponding to the temperatures of the surfaces:

$$
\begin{aligned}
& \frac{d M_{a}}{d t}+\sum_{i} \frac{d M_{i}}{d t}=0 \\
& \frac{d M_{i}}{d t}=A_{i} k_{i}\left(C_{a}-C_{i}^{s}\right)
\end{aligned}
$$

where

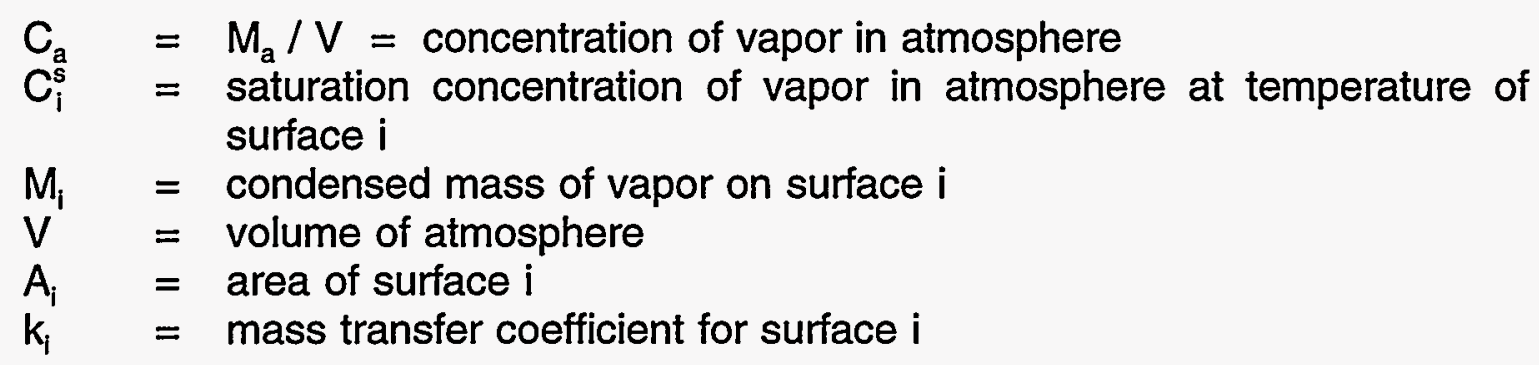

and subscript $i$ denotes any heat structure surface, pool surface, or aerosol section. 
RN Package Reference Manual

These differential equations can be solved as in TRAP-MELT2 to yield the following algebraic equations:

$$
\begin{aligned}
& C_{a}=M_{a} N=\frac{\beta}{\alpha}-\left(\frac{\beta}{\alpha}-C_{a 0}\right) e^{-\alpha \Delta t} \\
& M_{i}=M_{i 0}+A_{i} k_{i}\left(\frac{\beta}{\alpha}-C_{i}^{s}\right) \Delta t-A_{i} k_{i}\left(\frac{\beta}{\alpha}-C_{a 0}\right)\left(\frac{1-e^{-\alpha \Delta t}}{\alpha}\right)
\end{aligned}
$$

where

$$
\begin{aligned}
& \alpha=\sum_{i} A_{i} k_{i} / V \\
& \frac{\beta}{\alpha}=\frac{\sum_{i} A_{i} k_{i} C_{i}^{s}}{\sum_{i} A_{i} k_{i}}
\end{aligned}
$$

and subscript 0 denotes the value at start of the time step, $\Delta t$.

Total sectional areas $A_{p}$ for aerosols are calculated from the average particle in each section, as derived in Appendix C:

$$
A_{p}=12 \pi\left(\frac{3}{4 \pi}\right)^{2 / 3} \frac{M}{\ln \left(m_{2} / m_{1}\right)}\left(m_{1}^{-1 / 3}-m_{2}^{-1 / 3}\right)
$$

The mass transfer coefficient $k_{p}$ for aerosols is based on zero slip flow, or Sherwood number $=2.0$.

All HS package heat structures are automatically included for condensation and evaporation of fission product vapors unless made inactive through user input on RNDSXXX records. The area of the heat struciure in the atmosphere $A_{w}$ is used to define the net area for fission product vapor interactions. This area is the total heat structure area times the fraction of the heat structure in the atmosphere as determined by the HS package. 
Although fission products may condense on pool surfaces, evaporation of fission products residing in control volume pools is not permitted. The fission product vapor location within a phase in a control volume (pool or atmosphere) may change when one phase is no longer present. Any vapor mass associated with a disappearing phase is added to the remaining phase in that control volume.

The mass transfer coefficient for condensation of fission product vapors onto heat structure surfaces, $k_{w}$, is calculated based on the mass transfer coefficient, $k_{H S}$, for water condensation onto a heat structure surface calculated by the HS package, which uses the steam-air diffusivity, $D_{\text {st, }}$ :

$$
k_{w}=k_{H S} D_{k, g} / D_{s t, a}
$$

The vapor diffusivity for the fission product vapors in the bulk gas, $D_{k, g}$, is calculated from the following equation as presented in Welty, Wicks, and Wilson [22]:

$$
D_{k, g}=\frac{1-y_{k}}{\sum_{n}\left(y_{n} / D_{k, n}\right)}
$$

where

$$
\begin{array}{ll}
y_{k} & =\text { mole fraction of trace vapor } k \\
y_{n} & =\text { mole fraction of bulk gas } n \\
D_{k, n} & =\text { binary diffusivity of vapor } k \text { in gas } n
\end{array}
$$

The binary diffusivities are evaluated from the following expression from Bird, Stewart, and Lightfoot [23]:

$$
D_{A, B}=0.0018583 \frac{\left[T^{3}\left(M_{A}^{-1}+M_{B}^{-1}\right)\right]^{1 / 2}}{P \sigma_{A B}^{2} \Omega_{D, A B}}
$$

with

$$
\begin{array}{ll}
D_{A, B} & =\text { binary diffusivity in } \mathrm{cm}^{2} / \mathrm{s} \\
T & =\text { temperature in } \mathrm{K} \\
P & =\text { pressure in atmospheres } \\
M_{i} & =\text { molecular weight in } \mathrm{kg} / \mathrm{kg}-\text { mole } \\
\sigma_{A B} & =\text { collision diameter in Angstroms }=0.5\left(\sigma_{A}+\sigma_{B}\right) \\
\Omega_{D, A B} & =\text { collision integral = function of } \mathrm{kT} / \varepsilon \text { (see Table B-2 of Reference 23) }
\end{array}
$$




\section{RN Package Reference Manual}

The actual calculation of $D_{A B}$ is performed by a model in the Material Properties (MP) package, using data for the collision integral contained in the MP database. Values for the Lennard-Jones potential parameters $\sigma$ and $\varepsilon / k$ for the bulk gases are obtained from the MP database, while values for some of the fission product vapors, obtained from Reference 23, are stored in RN sensitivity coefficient array 7111 (see Appendix A). Actual values are used for $\mathrm{Xe}$ and $\mathrm{I}_{2}$; other classes are defaulted to values for air due to a lack of information. (The values for the bulk gases are the same ones used for calculation of viscosity in the absence of tabular data; they may be changed through MP input if desired.)

In addition to being used to determine the amount of each material class present as aerosol and as fission product vapor, the vapor pressure is used in the model for condensation and evaporation to determine the saturation concentrations, $\mathrm{C}_{\mathrm{i}}^{\mathrm{s}}$, calculated from the perfect gas law,

$$
C_{i}^{s}=\frac{P\left(T_{i}\right) M_{w}}{R T_{i}}
$$

The expression for the vapor pressure is

$$
\log _{10}(P)=-A / T+B+C \log _{10}(T)
$$

with $P$ and $T$ in units of $m m$ of $\mathrm{Hg}$ and $K$, respectively. The coefficients $A, B$, and $C$ for each class are stored in sensitivity coefficient array 7110 for different temperature ranges (see Appendix A). The default values are based on preliminary data in Reference 24 with some minor adjustments to make $\mathrm{P}$ a continuous function of $\mathrm{T}$. However, the majority of classes are assumed to have a default vapor pressure curve characteristic of a nonvolatile ceramic (zero vapor pressure below $3000 \mathrm{~K}$ and the vapor pressure of $\mathrm{UO}_{2}$ above $3000 \mathrm{~K}$ ); nondefault vapor pressure coefficients are defined only for classes 2 (Cs), $4(\mathrm{I}), 5(\mathrm{Te})$, and 16 (normally Csl), and class $1(\mathrm{Xe})$ is always a vapor. (See the RN Package Users' Guide for details on defining temperature ranges and forcing classes to always be an aerosol or always a vapor.)

For temperatures above a maximum temperature value, $T_{\max }$, the correlation is extrapolated. However, direct use of the correlation outside its range of applicability can return a pressure that decreases with increasing temperature, because $C$ is negative and $C \log _{10}(T)$ can dominate $-A / T$. Therefore, the extrapolation uses

$$
\log _{10}(P)=-A^{\prime} / T+B^{\prime}
$$


The coefficients $A^{\prime}$ and $B^{\prime}$ are derived from the last range coefficient values $A, B$, and $C$ by demanding that $P$ and $d P / d T$ be continuous at the matching temperature $T_{\max }$. This requires

$$
\begin{aligned}
& A^{\prime}=A+C \log _{10}(e) T_{\max } \\
& B^{\prime}=B+C\left[\log _{10}(e)+\log _{10}\left(T_{\max }\right)\right]
\end{aligned}
$$

\subsection{Decay Heat Distribution}

All decay heat released by radionuclides in a control volume pool is assumed to be absorbed by that pool. None of this decay heat is added directly to any heat structure surface or to the atmosphere of the control volume.

The decay heat released by radionuclides in the control volume atmosphere and from those deposited on the various heat structure surfaces can be apportioned according to user specifications among the volume atmosphere, the surfaces of heat structures in that volume, and the pool surface (if a pool is present). Fractions may also be specified as going to the atmosphere and surfaces of other volumes to simulate decay radiation transmitted through flow paths. Defaults are provided, as discussed below.

Approximately one half of decay heat is generated as gamma radiation and one half as beta radiation. Because typical gaseous atmospheres are nearly transparent to typical gammas and fairly opaque to typical betas, deposition of decay heat in a volume atmosphere results primarily from absorption of beta radiation. (The split and the characteristic energies are not modeled by MELCOR.) These observations and solid angle considerations led to the default splits suggested by Reference 3:

\section{Decay Heat from Radionuclides in the Atmosphere}
Atmosphere of current CV
$-50 \%$
Surfaces of current CV
- $50 \%$
Atmosphere of other CVs
- $0 \%$
Surfaces of other CVs
- $0 \%$ 
RN Package Reference Manual

\begin{tabular}{cc} 
Decay Heat from Radionuclides on Heat Structure Surfaces \\
\hline Current Heat Structure & $-50 \%$ \\
Atmosphere of current CV & $-25 \%$ \\
Other Surfaces of current CV & $-25 \%$ \\
Atmosphere of other CVs & $-0 \%$ \\
Surfaces of other CVs & $-0 \%$
\end{tabular}

All fractions are independent of the RN class. Those for airborne radionuclides can be changed on a volume-by-volume basis using the RNDHVXXX and RNDHVSXXX input record series. Those for radionuclides on surfaces can be modified similarly, on a surface-by-surface basis, using the RNDHSXXX and RNDHSSXXX input record series.

Decay heat from airborne or deposited radionuclides that is absorbed by surfaces in the same control volume is allocated among the surfaces in proportion to their areas. (Note that for deposited radionuclides the bearing surface is not included.) The areas considered are the portions of heat structure surfaces exposed to the atmosphere, and the surface of the pool (if a pool is present). If there are no such surfaces, the fraction of decay heat allocated to the surfaces of a control volume is deposited instead in the atmosphere of that control volume.

The fractions specified as going to the local control volume atmosphere (by default or user input) are interpreted as the values appropriate for complete absorption of beta radiation. They must be reduced for small volumes or low densities, where the thickness of the atmosphere is insufficient to permit compete absorption of beta rays. This reduction is by a factor

$$
\min \left(\rho_{A} D_{C V} / R_{B}, 1.0\right)
$$

where $\rho_{A}$ is the atmosphere density, $D_{C V}$ is the characteristic dimension for absorption in the control volume, and $R_{\beta}$ is the range of a typical beta particle (given in sensitivity coefficient array 7002 , with a default value of $1.2 \mathrm{~kg} / \mathrm{m}^{2}$; see Appendix A). $D_{\mathrm{cv}}$ has a default value given by the minimum of the cube root of the volume and the square root of the flow area from the CVH database (so as to be reasonable for both tanks and pipes). It can be modified using the RNDHLENXXX input record series.

Any reduction in deposition to the local atmosphere is compensated by proportionate increase in energy distributed to other surfaces in the volume and to the atmosphere and surfaces of other control volumes. (The calculation is bypassed if the sum of these other split coefficients is zero.) 
RN Package Reference Manual

\subsection{ESF Models}

Models are currently available for the removal of radionuclides by pool scrubbing, filter trapping, and spray scrubbing. These models are described in the following subsections. The normal RN deposition and condensation models described in Sections 2.4 and 2.5 are applied to heat structures used to model ice condensers; see the HS Package Reference Manual for a detailed description of methods used to model ice condensers, including a surface area enhancement factor for radionuclide deposition.

\subsubsection{Pool Scrubbing}

The pool scrubbing models in the RN package [25] are similar to those in the SPARC code [10], although a number of corrections and changes were made [26]. (The thermalhydraulic aspects of pool scrubbing are modeled in the CVH package.) Only aerosols are removed by pool scrubbing; vapors are not currently considered. The model includes the effect of steam condensation at the pool entrance and aerosol deposition by Brownian diffusion, gravitational setting, and inertial impaction, subject also to evaporative forces, for the rising bubble. Decontamination is calculated only for those flow paths activated on the FLnnn02 input record (see the FL Package Users' Guide). As further specified by the user on input record RN2PLSXX, the model treats regular flow paths that vent through pools, as well as gases generated by core-concrete interactions flowing through overlying pools, and either spherical or elliptical bubbles can be specified. For consistency with the $\mathrm{CVH}$ package, pool scrubbing is only calculated if the submerged depth of the flow path is greater than the zero efficiency bubble rise height given in $\mathrm{CVH}$ sensitivity coefficient array 4405 .

The decontamination factor (DF) is defined as the ratio of the aerosol mass entering the pool to that leaving, and has a value greater than or equal to unity. Pool scrubbing of aerosols occurs in two distinct regions; the pool entrance region and the bubble rise region, and the total DF is the product of values calculated individually for these two regions,

$$
D F_{\text {tot }}=D F_{\text {ent }} \times D F_{\text {rise }}
$$

\subsubsection{Pool Entrance Region}

Steam condensation at the pool entrance removes aerosols as they enter the pool. Other entrance effects are ignored. The decontamination factor for steam condensation at the pool entrance assumes thermal equilibrium at the pool entrance and is simply

$$
D F_{\text {ent }}=X_{\text {ent }} / X_{i}
$$


RN Package Reference Manual

where

$$
\begin{aligned}
& X_{\text {ent }}=\begin{array}{l}
\text { mole fraction of noncondensibles at the pool temperature and entrance } \\
\text { pressure (including the pool static head term) }
\end{array} \\
& X_{i}=\text { mole fraction of noncondensibles before entering the pool }
\end{aligned}
$$

\subsubsection{Bubble Rise Region}

The decontamination factor for aerosols in a rising bubble can be expressed as a function of the deposition velocity $(v)$ normal to the bubble surface, which can be derived from various deposition mechanisms:

$$
D F_{\text {rise }}=\exp \left\{\int \mathrm{V}^{-1} \int \mathrm{vdA} d t\right\}
$$

The local net deposition velocity is integrated over the appropriate bubble surface area (A). After division by the bubble volume (V), this deposition velocity integral is then integrated again with respect to time as the bubble rises in the pool.

A positive local net deposition velocity indicates that aerosol particles will be deposited on the bubble wall at that particular location; the magnitude of the net velocity determines the deposition rate. A zero or negative value of the local net deposition velocity results in no aerosol deposition at that bubble wall location.

The time integral is evaluated by dividing the bubble rise region into ten intervals of equal height, evaluating the deposition velocity integral at the mid-point in each interval, and summing the results to get the total DF during the bubble rise as

$$
D F_{\text {rise }}=\exp \left\{\sum_{j} v^{-1} \int v d A \Delta t_{j}\right\}
$$

where the time step, $\Delta \mathrm{t}_{\mathrm{j}}$, is the interval height, $\Delta \mathrm{z}$, divided by the rise velocity of the bubble swarm, or

$$
\Delta t_{i}=\Delta z / v_{\text {swarm }}
$$

and $v_{\text {swarm }}$ is user-specified on the RN2PLSXX input record.

The bubble volume in Equation 2.7.4 is a function of time, since it changes as the bubble rises through the pool due to the decreasing static head term. The variation is evaluated as 
RN Package Reference Manual

$$
V=V_{\text {in }} \times P_{\text {NCG,ent }} / P_{\mathrm{NCG}}
$$

where $V_{\text {In }}$ is the inlet bubble volume based on the user specified bubble diameter at the entrance, $P_{\text {NCG }}$ is the local noncondensible gas pressure, and the subscript "ent" refers to the entrance location. As implemented, it is assumed that there is no bubble breakup or coalescence and that the bubble is isothermal at the pool temperature and initially at saturated conditions, but that as it rises the steam partial pressure falls somewhat below saturation to the relative humidity given by $\mathrm{CVH}$ sensitivity coefficient $\mathrm{C} 4405$ (5) (with a default value of 0.99 ).

A fully coupled approach as described in Reference 25 is used to model the interaction between the various deposition mechanisms:

$$
\int v_{\text {net }} d A=\int\left(v_{g}+v_{i}+v_{d}-v_{v}\right) d A
$$

where $v_{g}, v_{i}, v_{d}$, and $v_{v}$ are the deposition velocities for gravitational settling, inertial impaction, Brownian diffusion, and evaporation of pool water at the bubble surface, respectively.

\section{Spherical Bubbles}

Using the deposition velocities given in Appendix $D$, this integral can be evaluated analytically as

$$
\begin{aligned}
\int v_{\text {net }} d A=\pi R^{2}\left\{\left[v_{s} \sin ^{2} \theta-2 / 3 v_{\text {imax }} \cos \theta\left(\sin ^{2} \theta+2\right)\right.\right. & \\
& \left.+v_{v} \cos \theta\right] \mid \begin{array}{l}
\theta_{2} \\
\theta_{1}
\end{array} \\
& \left.-\left[v_{d} \cos \theta\right] \mid \begin{array}{c}
\theta_{2 L} \\
\theta_{1 L}
\end{array}\right\}
\end{aligned}
$$

The integration limits 1 and 2 are the values where the local net deposition velocity goes to zero. The limits $1 L$ and $2 L$ are the limits constrained by $\pi / 4$ and $3 \pi / 4$.

The Brownian diffusion removal mechanism is assumed to occur only in the middle portion of the bubble. Therefore, the bubble angles where the deposition velocity goes 


\section{RN Package Reference Manual}

to zero must be evaluated with and without Brownian diffusion. The angles are first evaluated with Brownian diffusion removal included. If an angle is outside of the range $\pi / 4$ to $3 \pi / 4$, then the angle must be recalculated without Brownian diffusion. The equation for determination of the angles is

$$
\theta_{m}=\cos ^{-1}\left\{\left[v_{s} \pm\left\{v_{s}^{2}+4 v_{i \max }\left(v_{i \max }+v_{d-v}\right)\right\}^{1 / 2}\right] /\left[2 v_{i \max }\right]\right\}
$$

where

$$
\begin{aligned}
& v_{d-v}=-v_{v} \text { for } 0<\theta<\pi / 4 \text { and } 3 \pi / 4<\theta<\pi \\
& v_{d-v}=v_{d}-v_{v} \text { for } \pi / 4 \leq \theta \leq 3 \pi / 4
\end{aligned}
$$

\section{Elliptical Bubbles}

The fully coupled model for elliptical bubbles has not been implemented in MELCOR. Instead, the elliptical correction factors first presented by Demitrack and Moody [27] and modified by Moody are used to modify the spherical bubble velocities:

$$
\int v_{\text {net }} d A=\int\left(F_{g} v_{g}+F_{i} v_{i}+F_{d} v_{d}-F_{v} v_{v}\right) d A
$$

where

$$
\begin{aligned}
F_{g} \text { (gravitational) }= & r^{2 / 3} \\
F_{i} \text { (inertial) }= & 1 / 3 r^{4 / 3}\left\{s^{2}+s^{3 / 2}(s-1) \tan ^{-1}(x)\right\} / \\
& \left\{x-r^{2} \tan ^{-1}(x)\right\}^{2} \\
F_{d}(\text { Brownian })= & 1.88 s\{1+(4+2 s)\}^{-1 / 2} \times \\
& \left\{\left(1.76 r^{2} / s-2^{1 / 2}\right) /\left(r^{2} \tan ^{-1}(x) / x-1\right)\right\}^{1 / 2}
\end{aligned}
$$

and $\mathrm{r}$ is the major to minor axis ratio for elliptical bubbles (entered on input record RN2PLSXX with a default value of 1.5 ), with

$$
\begin{aligned}
& s=r^{2}-1 \\
& x=s^{1 / 2}
\end{aligned}
$$


RN Package Reference Manual

\subsubsection{Filters}

The MELCOR RN package contains a simple filter model. When aerosols and vapors are transported through flow paths with the bulk fluid flow of pool and/or atmosphere calculated by the CVH package, some fraction of the transported RN materials may be removed by the action of filters in the flow path. A single filter can remove either aerosols or fission product vapors, but not both. However, a flow path can contain more than one filter. The efficiency of each filter is defined by decontamination factors, specified by user input. By default, a single decontamination factor is applied to all RN classes except water, for which the default DF is 1.0. Additional user input may be used to modify the DF on a class-by-class basis, including the water class. The parameters for the filter characteristics are specified on the RN2FLTXXYY input record series.

A maximum loading may be specified for each filter; when this loading is reached, no further RN materials will be removed (i.e., the DF is set to unity).

The effect of filter loading on the flow resistance of the associated flow path may be modeled through user input. This requires construction of a control function to link the laminar loss coefficient for the flow path (SLAM, input on segment record FLnnnSk; see the FL Package Users' Guide) to the filter loading. The filter loading may be obtained from one or more of the RN2-AMFLT or RN2-VMFLT control function arguments described in Section 5 of the RN Package Users' Guide.

The decay heat energy from radionuclides deposited on filters is given to the downstream control volume according to the vapor flow direction.

\subsubsection{Sprays}

The containment spray model used in MELCOR is the same as that in the HECTR code. The MELCOR Containment Sprays (SPR) package, which calculates the thermalhydraulic behavior associated with spray systems, is coupled to the RadioNuclide package for the calculation of aerosol washout and atmosphere decontamination by the sprays.

The SPR Package Reference. Manual describes the thermal-hydraulic modeling of the spray systems. To summarize here, the spray droplets are assumed to be spherical and isothermal and to fall through containment at their terminal velocity without a horizontal velocity component. Droplet heatup and cooldown in a steam environment are modeled using a correlation for forced convection heat transfer coefficients. Similarly, evaporation and condensation are modeled using a correlation for mass transfer coefficients. A standard integrator is used to integrate these transfer rates over the fall height of the spray droplet to obtain the final droplet mass and temperature. By comparing the droplet 


\section{RN Package Reference Manual}

mass and temperature at the bottom of the compartment to the inlet conditions, the heat and mass transfer to a given droplet is computed. Total heat and mass transfer rates are calculated by multiplying the rates for one droplet by the total number of droplets of that size and summing over all droplet sizes.

The SPR-RN interface may produce nonphysical results if the SPR package is required to make multiple passes (numerically) through the same control volume on a given time step. Therefore, the user is strongly encouraged to avoid this situation by limiting the spray activity to a single drop size in each spray train. The user must also insure that only one spray train passes through each control volume. These restrictions are necessary only when the SPR and RN packages are used at the same time.

The RN removal by sprays is a mechanistic treatment of removal processes, closely coupled to the thermal-hydraulic behavior calculated by the spray package. The user is cautioned to use a single drop size and spray train per volume because of the method by which the RN removal calculation is "piggybacked' onto the Spray package thermalhydraulic calculations. The thermal-hydraulic stepwise integration over the spray train height is made first, then the RN removal processes are calculated by a simple trapezoidal integration over the step, using the appropriate end-of-interval values. Because each droplet size is integrated over the full height of fall separately, there exists the possibility of competing radionuclide removal through differing drop sizes and competing removal by different spray trains. The effects of competing spray trains and differing drop sizes are unknown and the model may calculate physically unreasonable results.

The RN removal from sprays are modeled as a first order rate process,

$$
\frac{d M_{k}}{d t}=-\lambda_{k, i} M_{k}
$$

where

$$
\begin{aligned}
& M_{k}=\text { mass of class } k \\
& \lambda_{k, i} \quad=\text { rate constant, class } k \text {, droplet size } \mathrm{i}
\end{aligned}
$$

The actual physical removal processes for vapors and aerosols are different and therefore different rate constants, $\lambda$, are associated with each process.

Vapor removal by adsorption is calculated using a stagnant film model for the adsorption efficiency. The vapor removal is calculated as an injection spray removal rate; no recirculation of spray liquid is considered. The expression for the rate constant is $[28,29,30]$ : 
RN Package Reference Manual

$$
\lambda_{k, i}=\frac{F_{i} E_{k, i} H}{V}
$$

where

$$
\begin{array}{ll}
F_{i} & =\text { volumetric flow rate for droplets of size } i \\
E_{k, i} & =\text { adsorption efficiency for vapor class } \mathrm{k} \\
H & =\text { partition coefficient for partition of the vapor between spray water and gas } \\
V & =\text { volume of control volume }
\end{array}
$$

The vapor absorption efficiency is given by the expression [31]

$$
E_{k, i}=1-\exp \left[-\frac{6 k_{g} t_{e}}{2 r_{j}\left(H+k_{g} / k_{l}\right)}\right]
$$

where $k_{g}$, the gas boundary layer mass transfer coefficient, is calculated using the Ranz and Marshall approximation [32] to the Frossling equation [33],

$$
k_{g}=\frac{D_{k, g a s}}{2 r_{i}}\left(2.0+0.60 R e^{1 / 2} S c^{1 / 3}\right)
$$

and $k_{\ell}$, the liquid boundary layer mass transfer coefficient, is calculated using Griffith's approximation for diffusion in a rigid drop [34],

$$
k_{l}=\frac{\pi^{2} D_{k, H_{2} \mathrm{O}}}{3 r_{i}}
$$

In these equations,

$$
\begin{array}{ll}
r_{i} & =\text { drop radius } \\
t_{e} & =\text { drop exposure time } \\
D_{k, g a s} & =\text { diffusivity of vapor } k \text { through bulk gas } \\
D_{k, H 2 O} & =\text { diffusion constant for vapor } k \text { in liquid water } \\
R e & =\text { Reynolds number, } 2 \rho_{g} v_{d} r_{i} / \mu_{g} \\
S c & =\text { Schmidt number, } \mu_{g} / \rho_{g} D_{k, g a s} \\
v_{d} & =\text { drop velocity }
\end{array}
$$




\section{RN Package Reference Manual}

Under LWR accident conditions iodine may exist as a vapor over relatively long periods in containment pressure/temperature conditions. Other materials have low vapor pressures at accident conditions that preclude their extended existence as vapors; that is, they will condense to aerosol forms quickly. The RN input record series RN2SPRXX allows the user to specify a limit on iodine adsorption by spray droplets using a partition coefficient. The partition coefficient for iodine, defined as the equilibrium ratio of the iodine density in the liquid to its density in the gas,

$$
H=\rho_{\ell, \mathrm{eq}} / \rho_{\mathrm{g}, \mathrm{eq}}
$$

is specified by the user for sprays containing different additives, with various recommended values ranging from 500 to 100,000 [35] listed in the RN Package Users' Guide.

Aerosol removal is calculated primarily by inertial impaction and interception; diffusiophoresis and diffusion effects are also included. No droplet interactions are considered. Impaction and interception are the primary removal mechanisms as long as droplet radii are in the 10-100 micron size range. From 1-10 microns diffusiophoresis becomes an important contributor; diffusion only becomes important for droplets with radii $<0.1$ micron. The expression for the rate constant is [35]

$$
\lambda_{k, i}=\frac{3 F_{i} h E_{i, j}}{4 V r_{i}}
$$

where $F_{i}, V$, and $r_{i}$ are as defined before, $h$ is the fall height of the drops, and $E_{i, j}$ is the efficiency of collection of aerosol particles in size section $\mathrm{j}$ by drops of size $\mathrm{i}$.

For viscous flow around a sphere, the collection efficiency for interception (denoted by subscript In) is given by the expression [36]

$$
\varepsilon_{\mathrm{In}, \mathrm{Vis}}=(1+\mathrm{I})^{2}\left[1-\frac{3}{2(1+\mathrm{I})}+\frac{1}{2(1+\mathrm{I})^{3}}\right]
$$

where $I=r_{p} / r_{d}$ and $r_{p}$ and $r_{d}$ are the radii of the particle and the drop, respectively. For potential flow around a sphere, the collection efficiency for interception is given by the expression [36]

$$
\varepsilon_{\mathrm{ln}, \text { Pot }}=(1+1)^{2}-(1+1)^{-1}
$$


For potential flow around a sphere, the collection efficiency for inertial impaction (denoted by subscript $(\mathrm{m})$ is given by the expression [37]

$$
\varepsilon_{\mathrm{Im}, \mathrm{Pot}}=\left[\frac{\mathrm{Stk}}{\mathrm{Stk}+0.5}\right]^{2}
$$

for $S t k \geq 0.2$, is zero for $S t k \leq 0.0834$, and is given by interpolation for $0.0834<$ Stk $<0.2$. For viscous flow around a sphere, the collection efficiency for inertial impaction is given by the expression [36]

$$
\varepsilon_{\text {Im, Vis }}=\left[1+\frac{0.75 \log _{e}(2 \text { Stk })}{\text { Stk }-1.214}\right]^{-2}
$$

for Stk $>1.214$, and is zero otherwise. Stk is the Stokes number,

$$
\text { Stk }=\frac{2 r_{p}^{2} \rho_{p}\left(v_{d}-v_{p}\right)}{9 \mu r_{d}}
$$

where $v_{d}$ and $v_{p}$ are the terminal settling velocities of the drop and particle, respectively, and $\mu$ is the bulk gas viscosity. An interpolation scheme from Reference 37 is used to combine the potential and viscous efficiencies for both interception and inertial impaction:

$$
\varepsilon_{x}=\frac{\varepsilon_{x, \text { Vis }}+\varepsilon_{x, \text { Pot }}(\operatorname{Re} / 60)}{1+(\operatorname{Re} / 60)}
$$

where Re is the drop Reynolds number and subscript $x$ is either In (interception) or Im (inertial impaction).

The collection efficiency due to diffusion is given by the expression [28]

$$
\varepsilon_{\text {diff }}=3.02 \mathrm{Re}^{1 / 6} \mathrm{Pe}^{-2 / 3}+1.14(\mathrm{Re} / \mathrm{Pe})^{1 / 3}\left|+0.57 \mathrm{Re}^{1 / 3}\right|^{2}
$$

where $P e$ is the Peclet number, $2 r_{d}\left(v_{d}-v_{p}\right) / D$.

The collection efficiency due to diffusiophoresis is given by the expression

where $W_{s}$ is the mass condensation rate of steam on drops, $M$ is molecular weight, $X$ is mole fraction, $\mathrm{c}$ is the molar concentration of bulk gases, and subscripts $\mathrm{s}$ and $\mathrm{g}$ refer to 
RN Package Reference Manual

$$
\varepsilon_{\text {diffusio }}=\frac{4}{3} \frac{r_{d}}{F h}\left[\frac{M_{s}^{1 / 2}}{X_{s} M_{s}^{1 / 2}+X_{g} M_{g}^{1 / 2}}\right] \frac{W_{s}}{c M_{s}}
$$

steam and noncondensible bulk gases, respectively.

Finally, the collection efficiencies for different processes are combined using the following expression

$$
E_{i, j}=1-\prod_{k}\left(1-\varepsilon_{i j k}\right)
$$

where subscript $k$ refers to the collection process.

\subsection{Fission Product Chemistry}

Chemistry effects can be simulated in MELCOR through the use of class reactions and class transfers. The class reaction process uses a first-order reaction equation with forward and reverse paths. The class transfer process, which can change the material class or location of a radionuclide mass, can be used to simulate fast chemical reactions. With these two processes, phenomena including adsorption, chemisorption, and chemical reactions can be simulated.

Note: only fission product vapors are considered in the chemistry models.

\subsubsection{Class Reactions}

The reaction process model in MELCOR is a first order reversible reaction for a class going from state $C$ in the gas phase to state $C_{1}$ on a surface, or

where

$$
\frac{d M_{c}}{d t}=-\left\{\frac{k_{m} A / V}{k_{m} A / V+k_{f}}\right\}\left(k_{f} M_{c}-k_{r} M_{C r}\right)
$$

$$
\begin{aligned}
& k_{m}=\begin{array}{l}
\text { mass transfer rate constant for the process, based on the mass transfer } \\
\text { coefficient calculated by the HS package. }
\end{array} \\
& k_{f}=\text { forward reaction rate constant from user input, }\left(\sec ^{-1}\right) \\
& k_{r}=\text { reverse reaction rate constant from user input, }\left(\sec ^{-1}\right)
\end{aligned}
$$


$A / V=$ surface-to-volume ratio, where the surface area is that for the reaction and the volume is that of the control volume.

The mass transfer rate constant is calculated in the same manner as the vapor condensation/evaporation diffusivity given in Section 2.5 .

The solution technique is the same as for vapor condensation/evaporation under the assumption that the mass of $\mathrm{C} 1$ does not change during the time step. This assumption avoids solving a differential equation and allows the use of the same algebraic solution given in Section 2.5.

Alternatively, if the user specifies the use of a deposition velocity instead of the forward and reverse reaction rate constants,

$$
\frac{\mathrm{dM}_{\mathrm{C}}}{\mathrm{dt}}=-\mathrm{V}_{\mathrm{d}}(\mathrm{A} / \mathrm{V}) \mathrm{C}=-\frac{\mathrm{dM}_{\mathrm{C} 1}}{\mathrm{dt}}
$$

where $V_{d}$ is the user input reaction deposition velocity in $\mathrm{m} / \mathrm{sec}$.

The reaction only occurs in user specified control volumes and depends on the availability of the various classes as determined by the user input reaction stoichiometry. The first "from" class in the reaction must be in the vapor phase, while all the other specified classes must be deposited on the surface when the reaction occurs. Surfaces that can undergo reactions include heat structures, the pool surface, and aerosol surfaces as specified by the user. A flag to specify whether the reaction still occurs when a water film is present is also available. At the present time, water mass should not be used in the class reaction model.

In addition to the masses, reaction energy can also be specified for both the forward and reverse directions. The energy is in terms of the mass of the first "from" reacting class. This energy is added to the atmosphere in the case of reaction with aerosols, to the pool for a pool reaction, and to the heat structure if a surface reaction occurs.

\subsubsection{Class Transfers}

Mass transfers between classes may be accomplished by the transfer mechanisms. The user may change the class and location of aerosols and/or vapors in an arbitrary fashion. Therefore, this feature must be carefully used.

A stoichiometric reaction is specified, and the permitted control volumes and "from" and "to" states are given. The permitted states are aerosols or condensed vapors on a given surface of a heat structure, or aerosols or vapors in either the atmosphere or pool. A flag to determine if the transfer will proceed with a water film present is also available. Water should not be used in the class transfer model. 
RN Package Reference Manual

The mass transfer rate is given by the user as is the energy transfer information. The masses are changed as follows:

$$
\begin{aligned}
& M_{\text {from }, t+\Delta t}=M_{\text {from }, t}-\frac{d M}{d t} \Delta t \\
& M_{t o, t+\Delta t}=M_{t o, t}+\frac{d M}{d t} \Delta t
\end{aligned}
$$

where $\mathrm{dM} / \mathrm{dt}$ is the user specified mass transfer rate. Thus, with this option, aerosols of Class $A$ in the pool may be, for example, changed into condensed vapors of Class $B$ on a heat structure. This model is used for fast reactions with the "from" and "to" state generally the same.

\subsubsection{Example}

As an example of both class reactions and class transfers, consider the adsorption of CsI on a surface with a known deposition velocity which is then transformed immediately to $\mathrm{CsOH}$ plus $\mathrm{HI}$ when adsorbed water is present. After the transformation, the revaporization of $\mathrm{CsOH}$ is delayed until the surface temperature reaches $T_{1}$ while the $\mathrm{HI}$ revaporization is simply mass transfer limited. In this case, $\mathrm{Csl}, \mathrm{CsOH}$, and $\mathrm{HI}$ are separate material classes, and the reaction diagram can be written as

$$
\begin{array}{lll}
\mathrm{Csl}(\mathrm{g}) & \rightarrow & \mathrm{Csl}(\mathrm{ad}) \\
& & \downarrow \mathrm{H}_{2} \mathrm{O} \\
\mathrm{CsOH}(\mathrm{g}) & \leftrightarrow & \mathrm{CsOH}(\mathrm{ad}) \\
& & \left.+ \text { (depends on } \mathrm{T}_{1}\right) \\
\mathrm{HI}(\mathrm{g}) & \leftrightarrow & \mathrm{HI}(\mathrm{s})
\end{array}
$$

where (g), (ad), and (s) are gaseous, adsorbed, and solid states, respectively.

This reaction can be simulated by the RN package by the following sequential class reactions and transfers:

$$
\begin{aligned}
& \mathrm{Csl}(\mathrm{g}) \rightarrow \mathrm{Csl}(\mathrm{ad}) \\
& \text { rate constant for adsorption is supplied through input } \\
& \mathrm{Csl}(\mathrm{ad}) \rightarrow \mathrm{CsOH}(\mathrm{ad})+\mathrm{HI}(\mathrm{s})
\end{aligned}
$$


RN Package Reference Manual

instantaneous and complete transfer between classes when water is present. Note that the water mass is not included in the model; water mass is not explicitly conserved.

$\mathrm{CsOH}(\mathrm{g}) \rightarrow \mathrm{CsOH}(\mathrm{ad})$

rate constant for adsorption supplied or condensation limited.

$\mathrm{CsOH}(\mathrm{ad}) \rightarrow \mathrm{CsOH}(\mathrm{g})$

reaction with zero rate constant below $T_{1}$ positive value or instantaneous above $T_{1}$

$\mathrm{HI}(\mathrm{s}) \leftrightarrow \mathrm{HI}(\mathrm{g})$

controlled by condensation/evaporation 
RN Package Reference Manual 
RN Package Reference Manual

\section{DISCUSSION AND DEVELOPMENT PLANS}

\subsection{Pool Scrubbing}

The MELCOR Peer Review [38] expressed a major concern about the implementation of the aerosol pool scrubbing model, which is based on the physics in the SPARC code. This concern was based on observations that calculated decontamination factors (DFs) were much lower (by several orders of magnitude) in some calculations than DFs calculated by the implementation of SPARC in the Source Term Code Package. This has not yet been addressed, partly due to the difficulty in obtaining direct comparisons for DFs for the same hydrodynamic conditions and partly because of the anecdotal nature of the observations. Nevertheless, this must be pursued because of the very high impact pool scrubbing has on the source term.

The MELCOR Peer Review also noted the absence of modeling for removal of fission product vapors that may condense as they pass through the pool. This missing model was placed by the MELCOR Peer Review on the list of the most important missing models in MELCOR. As discussed in that report, examples of sequences where this process would be important would include low pressure BWR sequences with discharge of vapor through the safety relief valve (SRV) lines to the suppression pool or low pressure PWR containment bypass sequences with discharge to a water pool in the auxiliary building. In such sequences, this phenomenon could be of utmost importance for the calculation of the source term, especially when other fission product removal mechanisms are weak. To remedy this deficiency, the current version of SPARC will be obtained and the models, which include vapor scrubbing, will be implemented in MELCOR.

\subsection{RCS Deposition}

The MELCOR Peer Review also placed the omission of some aerosol deposition processes, principally inertial impaction and turbulent deposition, on the list of the most important missing models in MELCOR. These processes, which are not generally important in containment and which therefore are not included in MAEROS, may assume primary importance in the reactor coolant system. As discussed in the MELCOR Peer Review, experimental data and calculations using more comprehensive aerosol deposition models indicate that the neglect of these processes may result in a significant understatement of the retention of aerosols in the primary system, especially for low pressure sequences in which gas velocities are high. However, Marviken assessment calculations [39] showed good agreement with primary system retention data for both aerosols and fission product vapors, indicating the possibility of compensating processes. 
RN Package Reference Manual

\subsection{Chemical Reactions with Surfaces}

The MELCOR Peer Review also identified the lack of explicit modeling in MELCOR for chemical reactions between deposited fission products and structures in the primary system as one of the most important missing models. Such reactions can greatly affect deposition (chemisorption) and revaporization rates. Although a framework exists in the RN package for allowing user specification of chemical reactions, it is largely untested and unused. Because user input is basically unconstrained, the generation of errors through unexpected reactions is quite possible. The MELCOR Peer Review notes that the lack of explicit modeling applies to all accident sequences and is particularly serious for cesium hydroxide and tellurium compounds.

\subsection{Aqueous Chemistry}

The MELCOR Peer Review separately identified fission product chemistry in water pools as a less critical but still important modeling omission. The chief concern expressed in the MELCOR Peer Review was that release of iodine to the environment may be understated because MELCOR neglects processes that can occur in water pools to transform cesium iodide into more volatile forms of iodine (e.g., reaction with methane to form methyl iodide). Although the RN package includes provision for user specification of such chemical reactions, it is unwieldy at best and needs to be enhanced by in-code models for the more important chemical reactions that can be expected to occur.

\subsection{Removal by ESFs}

There is currently no model in MELCOR for the removal of fission products by fan coolers, and aside from aerosols, only $\mathrm{I}_{2}$ vapor is considered in removal of fission products by containment sprays. Both of these deficiencies will be evaluated for their overall impact and addressed accordingly. 
RN Package Reference Manual

\section{REFERENCES}

1. Powers, D. A., Fission Product Behavior During Severe LWR Accidents: Modeling Recommendations for the MELCOR Code System, Vol 1; Fission Product Release from Fuel, NUREG/CR-4481, Sandia National Laboratories (September, 1988).

2. D. E. Bennett, SANDIA-ORIGEN User's Manual, NUREG/CR-0987, SAND79-0299, Sandia National Laboratories, Albuquerque, NM (October 1979).

3. Ostmeyer, R. M., An Approach to Treating Radionuclide Decay Heating for Use in the MELCOR Code System, SAND84-1404, NUREG/CR-4169, May 1985.

4. Kuhlman, M. R., D. J. Lehmicke, and R. O. Meyer (1985), CORSOR User's Manual, BMI-2122, NUREG/CR-4173, March 1985.

5. M.Ramamurthi, M.R.Kuhlman, Final Report on Refinement of CORSOR - An Empirical In-Vessel Fission Product Release Model, Battelle Memorial Institute, October 31, 1990.

6. Powers, D. A., J. E. Brockmann, and A. W. Shiver (1985), VANESA: A Mechanistic Model of Radionuclide Release and Aerosol Generation During Core Debris Interactions with Concrete, SAND85-1370, NUREG/CR-4308, September 1985 Draft.

7. Gelbard, F. (1982), MAEROS User Manual, SAND80-0822, NUREG/CR-1391, December 1982.

8. Jordan, H. and M. R. Kuhlman (1985), TRAP-MELT2 Users Manual, BMI-2124, NUREG/CR-4205, May 1985.

9. Mason, B. J. (1971), The Physics of Clouds, Clarendon, Oxford.

10. Owczarski, P. C., R. I. Schreck, and A. K. Postma (1985), Technical Bases and User's Manual for the Prototype of a Suppression Pool Aerosol Removal Code (SPARC), NUREG/CR-3317, PNL-4742, May 1985.

11. S. E. Dingman, A. L. Camp, C. C. Wong, D. B. King, and R. D. Gasser, HECTR Version 1.5 User's Manual, NUREG/CR-4507, SAND86-0101, Sandia National Laboratories, Albuquerque, NM (February 1986). 
RN Package Reference Manual

12. Lorenz, R. A., E. C. Beahm, and R. P. Wichner (1983), "Review of Tellurium Release Rates from LWR Fuel Elements Under Accident Conditions," Proceedings International Meeting on Light Water Reactor Severe Accident Evaluation, Cambridge, MA, August 28 to September 1, 1983.

13. T. Nakamura and R. A. Lorenz, "A Study of Cesium and Krypton Releases Observed in $\mathrm{HI}$ and VI Tests Using a Booth Diffusion Model," ORNL Research Paper (May 1987).

14. T. Nakamura and R. A. Lorenz, "Effective Diffusion Coefficients Calculated from ORNL FP Release Test Results," ORNL Research Paper (April 1989).

15. Gieseke, J. A., Cybulskis, P., Denning, R. S., Kuhlman, M. R., Lee, K. W. and Chen, H., Radionuclide Release Under Specific LWR Accident Conditions, BMI-2104, July, 1984.

16. Cole, Jr., R. K., D. P. Kelly, and M. A. Ellis (1984), CORCON-Mod2: A Computer Program for Analysis of Molten-Core Concrete Interactions, SAND84-1246, NUREG/CR-3920, August 1984.

17. I. H. Dunbar and S. N. Ramsdale, "Improvements in the Modeling of Sedimentation and Gravitational Agglomeration," CSNI Specialists' Meeting on Nuclear Aerosols in Reactor Safety, Karlsruhe, Germany (September 4-6, 1984)

18. D. C. Williams, K. D. Bergeron, P. E. Rexroth, and J. L. Tills, "Integrated Phenomenological Analysis of Containment Response to Severe Core Damage Accidents," Progress in Nuclear Energy, Vol. 19 (1987).

19. F. Gelbard, "Modeling Aerosol Growth by Vapor Condensation," Aerosol Science and Technology, 12, p. 399 (1990).

20. W. C. Hinds, Aerosol Technology, John Wiley \& Sons, New York, NY (1982).

21. Shampine, L. F. and H. A. Watts (1976), Practical Solution of Ordinary Differential Equations by Runge-Kutta Methods, SAND76-0585, 1976.

22. Welty, J. R., C. E. Wicks, and R. E. Wilson, Fundamentals of Momentum, Heat, and Mass Transfer, John Wiley and Sons, 1984.

23. R. B. Bird, W. E. Stewart, and E. N. Lightfoot (1960), Transport Phenomena, John Wiley \& Sons, New York, 1960. 
RN Package Reference Manual

24. C. D. Leigh and J. L. Sprung, "Fission Product Transport and Deposition including Vapor Condensation and Aerosol Agglomeration," Chapter 5 in Fission Product Behavior During Severe LWR Accidents: Modeling Recommendations for the MELCOR Code System, Vol 2, NUREG/CR-4481, Sandia National Laboratories (September 1988).

25. Webb, S. W., A Fully Coupled Model for Aerosol Removal Mechanisms in Rising Bubbles, NUREG/CR-5091, Sandia National Laboratories (April 1990).

26. Webb, S. W. (1985), Letter to Mark Cunningham (USNRC) from Stephen W. Webb, SNL, December 18, 1985.

27. Demitrack, T. and F. J. Moody (1983), "Planetary Ellipsoid Bubble Model for Fission Product Scrubbing," Trans. ANS, Vol. 45, p. 483- 485.

28. A. K. Postma, et al., Models for Predicting the Removal of Airborne Contaminants by Reactor Containment Sprays, BNWL-B-417 (1975).

29. A. K. Postma, et al., Technological Bases for Models of Spray Washout of Airborne Contaminants in Containment Vessels, NUREG/CR-0009 (1978).

30. A. E. J. Eggleton, Theoretical Examination of lodine-Water Partition Coefficients, AERE-R-4887 (1967).

31. A. K. Postma and W. F. Pasedag, A Review of Mathematical Models for Predicting Spray Removal of Fission Products in Reactor Containment Vessels, WASH-1329 (1973).

32. W. E. Ranz and W. R. Marshall, "Evaporation from Drops," Chem. Eng. Prog., 48, No. 3, 141 and 48 , No. 173 (1952).

33. N. Frossling, Gerlands Beitr. Geophys., 52, p. 170 (1938), as referenced by Reference 23, p. 409.

34. V. Griffiths, The Removal of lodine from the Atmosphere by Sprays, Report No. AHSB(S)R45, UKAEA, London (1963).

35. D. R. Grist, Spray Removal of Fission Products in PWR Containments, Report SRD R267, Safety and Reliability Directorate, UKAEA, England (1982).

36. Fuchs, N. A. (1964), The Mechanics of Aerosols, Permagon Press.

37. I. Langmuir, J. Meteor., 5 , 175 (1948). 
RN Package Reference Manual

38. B. E. Boyack, et al., MELCOR Peer Review, LA-12240, Los Alamos National Laboratory (March 1992).

39. L. N. Kmetyk, MELCOR 1.8.1 Assessment: Marviken-V Aerosol Transport Tests ATT-2b / ATT-4, SAND92-2243, Sandia National Laboratories (January 1993).

40. Moody, F. J., and S. G. Nagy (1983), "Estimated Effects of Interfacial Vaporization on Fission Product Scrubbing," Proceedings International Meeting on Light Water Reactor Severe Accident Evaluation, Cambridge, MA. 
RN Package Reference Manual

\section{APPENDIX A: RN Package Sensitivity Coefficients}

This appendix gives the sensitivity coefficients associated with various correlations and modeling parameters described in this reference manual.

Equation or Section Coefficient

$\S 2.4 .2 .3$
$\mathrm{C} 7000(1)$
$\mathrm{C} 7000(2)$
$\mathrm{C} 7000(3)$
C7000(4)
C7000(5)

$\underline{\text { Value }}$

$1.0 \mathrm{E}-18$

0.001

0.1

0.1

$1.0 \mathrm{E}-12$ $\underline{\text { Units }}$

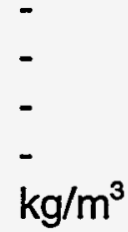

Aerosol Coefficient Criteria

C7001(1)

C7001(2)
$1.0 \mathrm{E}-18$

0.001

Fission Product Decay Beta Range

$\S 2.6$

C7002(1)

1.2

$\mathrm{kg} / \mathrm{m}^{2}$

COR Material Release Multipliers

$\S 2.3 .1$
C7100(1)
C7100(2)
C7100(3)
C7100(4)
C7100(5)
C7100(6)
C7100(7)

1.0

0.0

0.0

0.0

0.0

0.0

0.0

CORSOR Coefficients

$\begin{array}{lcl}C 7101(1,1, k), k \neq 5 & 900.0 & K \\ C 7101(2,1, k), k \neq 5 & 1400.0 & K \\ C 7101(3,1, k), k \neq 5 & 2200.0 & K \\ C 7101(1,1,5) & 900.0 & \mathrm{~K} \\ C 7101(2,1,5) & 1600.0 & \mathrm{~K} \\ \text { C7101(3,1,5) } & 2000.0 & \mathrm{~K} \\ \text { C7101(1,2,1) } & 7.02 \mathrm{E}-9 & \mathrm{~min}^{-1} \\ \text { C7101(2,2,1) } & 2.02 \mathrm{E}-7 & \mathrm{~min}^{-1}\end{array}$


RN Package Reference Manual

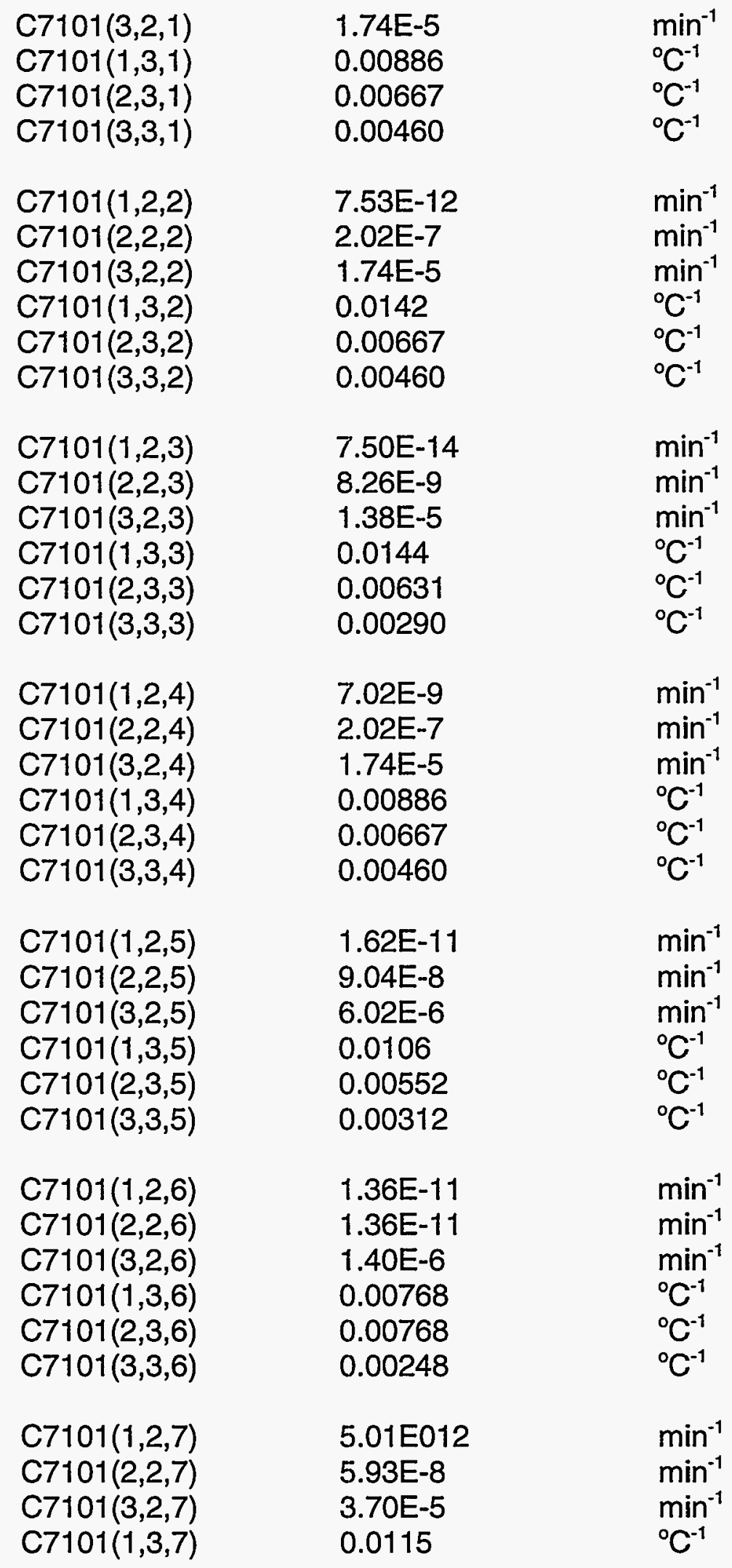


RN Package Reference Manual

\begin{tabular}{|c|c|c|}
\hline $\begin{array}{l}C 7101(2,3,7) \\
C 7101(3,3,7)\end{array}$ & $\begin{array}{l}0.00523 \\
0.00200\end{array}$ & $\begin{array}{l}{ }^{\circ} \mathrm{C}^{-1} \\
{ }^{\circ} \mathrm{C}^{-1}\end{array}$ \\
\hline $\begin{array}{l}\text { C7101 }(1,2,8) \\
\text { C7101 }(2,2,8) \\
\text { C7101 }(3,2,8) \\
\text { C7101 }(1,3,8) \\
\text { C7101 }(2,3,8) \\
\text { C7101 }(3,3,8)\end{array}$ & $\begin{array}{l}6.64 \mathrm{E}-12 \\
6.64 \mathrm{E}-12 \\
1.48 \mathrm{E}-7 \\
0.00631 \\
0.00631 \\
0.00177\end{array}$ & $\begin{array}{l}\min ^{-1} \\
\min ^{-1} \\
\min ^{-1} \\
{ }^{\circ} \mathrm{C}^{-1} \\
{ }^{\circ} \mathrm{C}^{-1} \\
{ }^{\circ} \mathrm{C}^{-1}\end{array}$ \\
\hline $\begin{array}{l}C 7101(1,2,9) \\
C 7101(2,2,9) \\
C 7101(3,2,9) \\
C 7101(1,3,9) \\
C 7101(2,3,9) \\
C 7101(3,3,9)\end{array}$ & $\begin{array}{l}5.00 \mathrm{E}-13 \\
5.00 \mathrm{E}-13 \\
5.00 \mathrm{E}-13 \\
0.00768 \\
0.00768 \\
0.00768\end{array}$ & $\begin{array}{l}\min ^{-1} \\
\min ^{-1} \\
\min ^{-1} \\
{ }^{\circ} \mathrm{C}^{-1} \\
{ }^{\circ} \mathrm{C}^{-1} \\
{ }^{\circ} \mathrm{C}^{-1}\end{array}$ \\
\hline $\begin{array}{l}C 7101(1,2,10) \\
C 7101(2,2,10) \\
C 7101(3,2,10) \\
C 7101(1,3,10) \\
C 7101(2,3,10) \\
C 7101(3,3,10)\end{array}$ & $\begin{array}{l}5.00 \mathrm{E}-13 \\
5.00 \mathrm{E}-13 \\
5.00 \mathrm{E}-13 \\
0.00768 \\
0.00768 \\
0.00768\end{array}$ & $\begin{array}{l}\min ^{-1} \\
\min ^{-1} \\
\min ^{-1} \\
{ }^{\circ} \mathrm{C}^{-1} \\
{ }^{\circ} \mathrm{C}^{-1} \\
{ }^{\circ} \mathrm{C}^{-1}\end{array}$ \\
\hline $\begin{array}{l}C 7101(1,2,11) \\
C 7101(2,2,11) \\
C 7101(3,2,11) \\
C 7101(1,3,11) \\
C 7101(2,3,11) \\
C 7101(3,3,11)\end{array}$ & $\begin{array}{l}1.90 \mathrm{E}-12 \\
5.88 \mathrm{E}-9 \\
2.56 \mathrm{E}-6 \\
0.0128 \\
0.00708 \\
0.00426\end{array}$ & $\begin{array}{l}\min ^{-1} \\
\min ^{-1} \\
\min ^{-1} \\
{ }^{\circ} \mathrm{C}^{-1} \\
{ }^{\circ} \mathrm{C}^{-1} \\
{ }^{\circ} \mathrm{C}^{-1}\end{array}$ \\
\hline $\begin{array}{l}C 7101(1,2,12) \\
C 7101(2,2,12) \\
C 7101(3,2,12) \\
C 7101(1,3,12) \\
C 7101(2,3,12) \\
C 7101(3,3,12)\end{array}$ & $\begin{array}{l}1.90 \mathrm{E}-12 \\
5.88 \mathrm{E}-9 \\
2.56 \mathrm{E}-6 \\
0.0128 \\
0.00708 \\
0.00426\end{array}$ & $\begin{array}{l}\min ^{-1} \\
\min ^{-1} \\
\min ^{-1} \\
{ }^{\circ} \mathrm{C}^{-1} \\
{ }^{\circ} \mathrm{C}^{-1} \\
{ }^{\circ} \mathrm{C}^{-1}\end{array}$ \\
\hline $\begin{array}{l}C 7101(1,2,13: 20) \\
C 7101(2,2,13: 20) \\
C 7101(3,2,13: 20) \\
C 7101(1,3,13: 20) \\
C 7101(2,3,13: 20) \\
C 7101(3,3,13: 20)\end{array}$ & $\begin{array}{l}0.0 \\
0.0 \\
0.0 \\
0.0 \\
0.0 \\
0.0\end{array}$ & $\begin{array}{l}\min ^{-1} \\
\min ^{-1} \\
\min ^{-1} \\
{ }^{\circ} \mathrm{C}^{-1} \\
{ }^{\circ} \mathrm{C}^{-1} \\
{ }^{\circ} \mathrm{C}^{-1}\end{array}$ \\
\hline
\end{tabular}


RN Package Reference Manual

CORSOR-M Coefficients

\begin{tabular}{|c|c|c|c|}
\hline 2.3.2 & $\begin{array}{l}\text { C7102(1,1) } \\
\text { C7102(2,1) }\end{array}$ & $\begin{array}{l}2.0 \mathrm{E} 5 \\
63.8\end{array}$ & $\begin{array}{l}\min ^{-1} \\
\mathrm{kcal} / \mathrm{mole}\end{array}$ \\
\hline & $\begin{array}{l}C 7102(1,2) \\
C 7102(2,2)\end{array}$ & $\begin{array}{l}2.0 \mathrm{E} 5 \\
63.8\end{array}$ & $\begin{array}{l}\min ^{-1} \\
\mathrm{kcal} / \mathrm{mole}\end{array}$ \\
\hline & $\begin{array}{l}C 7102(1,3) \\
\text { C7102(2,3) }\end{array}$ & $\begin{array}{l}2.95 \mathrm{E} 5 \\
100.2\end{array}$ & $\begin{array}{l}\min ^{-1} \\
\mathrm{kcal} / \text { mole }\end{array}$ \\
\hline & $\begin{array}{l}C 7102(1,4) \\
C 7102(2,4)\end{array}$ & $\begin{array}{l}2.0 \mathrm{E} 5 \\
63.8\end{array}$ & $\begin{array}{l}\min ^{-1} \\
\mathrm{kcal} / \text { mole }\end{array}$ \\
\hline & $\begin{array}{l}C 7102(1,5) \\
C 7102(2,5)\end{array}$ & $\begin{array}{l}2.0 \mathrm{E} 5 \\
63.8\end{array}$ & $\begin{array}{l}\min ^{-1} \\
\mathrm{kcal} / \text { mole }\end{array}$ \\
\hline & $\begin{array}{l}C 7102(1,6) \\
C 7102(2,6)\end{array}$ & $\begin{array}{l}1.62 E 6 \\
152.8\end{array}$ & $\begin{array}{l}\min ^{-1} \\
\mathrm{kcal} / \text { mole }\end{array}$ \\
\hline & $\begin{array}{l}\text { C7102(1,7) } \\
\text { C7102(2,7) }\end{array}$ & $\begin{array}{l}0 . \\
0 .\end{array}$ & $\begin{array}{l}\min ^{-1} \\
\mathrm{kcal} / \mathrm{mole}\end{array}$ \\
\hline & $\begin{array}{l}C 7102(1,8) \\
C 7102(2,8)\end{array}$ & $\begin{array}{l}2.67 \mathrm{E} 8 \\
188.2\end{array}$ & $\begin{array}{l}\min ^{-1} \\
\mathrm{kcal} / \mathrm{mole}\end{array}$ \\
\hline & $\begin{array}{l}\text { C7102(1,9) } \\
\text { C7102(2,9) }\end{array}$ & $\begin{array}{l}0 . \\
0 .\end{array}$ & $\begin{array}{l}\min ^{-1} \\
\mathrm{kcal} / \mathrm{mole}\end{array}$ \\
\hline & $\begin{array}{l}\text { C7102 }(1,10) \\
\text { C7102(2,10) }\end{array}$ & $\begin{array}{l}1.46 E 7 \\
143.1\end{array}$ & $\begin{array}{l}\mathrm{min}^{-1} \\
\mathrm{kcal} / \mathrm{mole}\end{array}$ \\
\hline & $\begin{array}{l}\text { C7102(1,11) } \\
\text { C7102 }(2,11)\end{array}$ & $\begin{array}{l}0 . \\
0 .\end{array}$ & $\begin{array}{l}\min ^{-1} \\
\mathrm{kcal} / \mathrm{mole}\end{array}$ \\
\hline & $\begin{array}{l}\text { C7102 }(1,12) \\
\text { C7102 }(2,12)\end{array}$ & $\begin{array}{l}5.95 \mathrm{E} 3 \\
70.8\end{array}$ & $\begin{array}{l}\mathrm{min}^{-1} \\
\mathrm{kcal} / \mathrm{mole}\end{array}$ \\
\hline & $\begin{array}{l}\text { C7102 }(1,13) \\
\text { C7102(2,13) }\end{array}$ & $\begin{array}{l}0.0 \\
0.0\end{array}$ & $\begin{array}{l}\min ^{-1} \\
\mathrm{kcal} / \text { mole }\end{array}$ \\
\hline
\end{tabular}


RN Package Reference Manual

CORSOR-Booth Class Scaling Factors: Nominal Values

$\begin{array}{ll}C 7103(1) & 1.0 \\ C 7103(2) & 1.0 \\ C 7103(3) & 3.33 E-3 \\ C 7103(4) & 1.0 \\ C 7103(5) & 1.0 \\ C 7103(6) & 1.0 E-4 \\ C 7103(7) & 1.0 E-3 \\ C 7103(8) & 3.34 E-5 \\ C 7103(9) & 1.0 E-4 \\ C 7103(10) & 1.0 E-4 \\ C 7103(11) & 5.0 E-2 \\ C 7103(12) & 5.0 E-2 \\ C 7103(13: 20) & 0.0\end{array}$

Release Surface-to-Volume Ratio

$\begin{array}{lll}\mathrm{C} 7104(1) & 422.5 & \mathrm{~m}^{-1}\end{array}$

Modification of Release Rates for Tellurium

$\S 2.3 .1$

$\begin{array}{ll}\text { C7105(1) } & 5.0 \\ \text { C7105(2) } & 0.7 \\ \text { C7105(3) } & 0.025\end{array}$

CORSOR-Booth Coefficients for Cesium

2.3.3
C7106(1)
C7106(2)
C7106(3)
C7106(4)
C7106(5)

$5.0 \mathrm{E}-8$
$2.5 \mathrm{E}-7$
$3.0 \mathrm{E} 4$
$3.8 \mathrm{E} 5$
$1.0 \mathrm{E}-5$

$\mathrm{m}^{2} / \mathrm{s}$ $\mathrm{m}^{2} / \mathrm{s}$ MWD/MTU $\mathrm{J} / \mathrm{kg}-\mathrm{mole}$

$\mathrm{m}$

CORSOR-Booth Class Scaling Factors: Oxidation Modified

$\begin{array}{lll}C 7107(6,3) & 0.05 & - \\ C 7107(7,3) & 0.05 & - \\ C 7107(6,5) & 0.70 & - \\ C 7107(7,5) & 0.025 & - \\ & & - \\ C 7107(1,6) & 0.75 & - \\ C 7107(2,6) & 2300.0 & K \\ C 7107(3,6) & 1.06792 E-20 & -\end{array}$


RN Package Reference Manual

$\begin{array}{lll}\text { C7107(4,6) } & 0.0159923 & \mathrm{~K}^{-1} \\ \text { C7107(5,6) } & 2700.0 & \mathrm{~K} \\ \text { C7107(6,9) } & 0.05 & - \\ \text { C7107(7,9) } & 0.10 & - \\ \text { C7107(1,11:12) } & 0.75 & - \\ \text { C7107(2,11:12) } & 2000.0 & \mathrm{~K} \\ \text { C7107(3,11:12) } & 3.194 \mathrm{E}-9 & - \\ \text { C7107(4,11:12) } & 0.008283 & \mathrm{~K}^{-1} \\ \text { C7107(5,11:12) } & 2300.0 & \mathrm{~K} \\ & & \\ \text { otherwise } & & \\ \text { C7107(1,i) } & 1.1 & - \\ \text { C7107(2,i) } & 0.0 & \mathrm{~K} \\ \text { C7107(3,i) } & 0.0 & - \\ \text { C7107(4,i) } & 0.0 & \mathrm{~K}^{-1} \\ \text { C7107(5,i) } & 0.0 & - \\ \text { C7107(6,i) } & -1.0 & - \\ \text { C7107(7,i) } & 0.0 & \end{array}$

\section{Vapor Pressure}

2.5 .22

\begin{tabular}{|c|c|c|}
\hline C7110 $(1,1,1)$ & 0.0 & $\mathrm{~K}$ \\
\hline$C 7110(1,2,1)$ & -1.0 & $\mathrm{~K}$ \\
\hline$C 7110(2,1,1)$ & 10000.0 & $\mathrm{~K}$ \\
\hline$C 7110(1,1,2)$ & 600.0 & $\mathrm{~K}$ \\
\hline $\mathrm{C} 7110(1,2,2)$ & 94.00 .0 & $\mathrm{~K}$ \\
\hline C7110(1,3,2) & 21.59 & - \\
\hline$C 7110(1,4,2)$ & -3.75 & - \\
\hline C7110(2,1,2) & 1553.0 & $\mathrm{~K}$ \\
\hline$C 7110(2,2,2)$ & 6870.778 & $\mathrm{~K}$ \\
\hline C7110(2,3,2) & 7.994503 & - \\
\hline C7110 $(2,4,2)$ & 0. & - \\
\hline$C 7110(1,1,3)$ & 3000.0 & $\mathrm{~K}$ \\
\hline C7110 $(1,2,3)$ & 18000.0 & K \\
\hline$C 7110(1,3,3)$ & 8.875 & - \\
\hline$C 7110(1,4,3)$ & 0. & - \\
\hline $\mathrm{C} 7110(2,1,3)$ & 10000. & K \\
\hline
\end{tabular}


RN Package Reference Manual

\begin{tabular}{|c|c|}
\hline $\begin{array}{l}C 7110(1,1,4) \\
C 7110(1,2,4) \\
C 7110(1,3,4) \\
C 7110(1,4,4)\end{array}$ & $\begin{array}{l}298.0 \\
3578.0 \\
17.72 \\
-2.51\end{array}$ \\
\hline $\begin{array}{l}C 7110(2,1,4) \\
C 7110(2,2,4) \\
C 7110(2,3,4) \\
C 7110(2,4,4)\end{array}$ & $\begin{array}{l}387.0 \\
3205.0 \\
23.66536 \\
-5.18\end{array}$ \\
\hline C7110 $(3,1,4)$ & 457.0 \\
\hline $\begin{array}{l}C 7110(1,1,5) \\
C 7110(1,2,5) \\
C 7110(1,3,5) \\
C 7110(1,4,5)\end{array}$ & $\begin{array}{l}298.0 \\
13940.0 \\
23.51 \\
-3.52\end{array}$ \\
\hline$C 7110(2,1,5)$ & 10000.0 \\
\hline $\begin{array}{l}C 7110(1,1,6: 15) \\
C 7110(1,2,6: 15) \\
C 7110(1,3,6: 15) \\
C 7110(1,4,6: 15)\end{array}$ & $\begin{array}{l}3000.0 \\
18000.0 \\
8.875 \\
0 .\end{array}$ \\
\hline$C 7110(2,1,6: 15)$ & 10000. \\
\hline $\begin{array}{l}C 7110(1,1,16) \\
C 7110(1,2,16) \\
C 7110(1,3,16) \\
C 7110(1,4,16)\end{array}$ & $\begin{array}{l}600.0 \\
10420.0 \\
19.70 \\
-3.02\end{array}$ \\
\hline $\begin{array}{l}C 7110(2,1,16) \\
C 7110(2,2,16) \\
C 7110(2,3,16) \\
C 7110(2,4,16)\end{array}$ & $\begin{array}{l}894.0 \\
9678.0 \\
20.34569 \\
-3.52\end{array}$ \\
\hline C7110 $(3,1,16)$ & 1553.0 \\
\hline $\begin{array}{l}C 7110(1,1,17: 20) \\
C 7110(1,2,17: 20) \\
C 7110(1,3,17: 20) \\
C 7110(1,4,17: 20)\end{array}$ & $\begin{array}{l}3000.0 \\
18000.0 \\
8.875 \\
0 .\end{array}$ \\
\hline$C 7110(2,1,17: 20)$ & 10000. \\
\hline
\end{tabular}

RN-RM-83 
RN Package Reference Manual

Vapor Diffusivity Constants

2.5 .20

C7111(1,1)
C7111(2,1)
C7111(1,2:3)
C71111(2,2:3)
C7111(1,4)
C7111(2,4)
C7111(1,5:20)
$C 7111(2,5: 20)$

4.055

229.0

3.617

97.0

4.982

550.0

3.617

97.0
$\AA$

$\mathrm{K}$

$\AA$

$\mathrm{K}$

$\AA$

$\mathrm{K}$

$\AA$

$\mathrm{K}$

Class Molecular Weights

$\S 2.1$
131.3

131.3

132.905

149.913

137.34

137.34

253.8008

253.8008

127.6

143.6

101.07

101.07

95.94

95.94

140.12

140.12

138.91

138.91

238.03 $\mathrm{kg} / \mathrm{kg}$-mole

$\mathrm{kg} / \mathrm{kg}$-mole

$\mathrm{kg} / \mathrm{kg}$-mole

$\mathrm{kg} / \mathrm{kg}$-mole

$\mathrm{kg} / \mathrm{kg}$-mole $\mathrm{kg} / \mathrm{kg}$-mole

$\mathrm{kg} / \mathrm{kg}-\mathrm{mole}$ $\mathrm{kg} / \mathrm{kg}$-mole

$\mathrm{kg} / \mathrm{kg}$-mole $\mathrm{kg} / \mathrm{kg}$-mole

$\mathrm{kg} / \mathrm{kg}$-mole $\mathrm{kg} / \mathrm{kg}$-mole

$\mathrm{kg} / \mathrm{kg}$-mole $\mathrm{kg} / \mathrm{kg}-\mathrm{mole}$

$\mathrm{kg} / \mathrm{kg}$-mole $\mathrm{kg} / \mathrm{kg}-\mathrm{mole}$

$\mathrm{kg} / \mathrm{kg}$-mole $\mathrm{kg} / \mathrm{kg}$-mole

$\mathrm{kg} / \mathrm{kg}-\mathrm{mole}$ 
RN Package Reference Manual

\begin{tabular}{|c|c|c|}
\hline$C 7120(2,10)$ & 270.03 & $\mathrm{~kg} / \mathrm{kg}$-mole \\
\hline$C 7120(1,11)$ & 112.4 & $\mathrm{~kg} / \mathrm{kg}-\mathrm{mole}$ \\
\hline$C 7120(2,11)$ & 112.4 & $\mathrm{~kg} / \mathrm{kg}-\mathrm{mole}$ \\
\hline$C 7120(1,12)$ & 118.69 & $\mathrm{~kg} / \mathrm{kg}-\mathrm{m}$ \\
\hline$C 7120(2,12)$ & 118.69 & $\mathrm{~kg} / \mathrm{kg}-\mathrm{mo}$ \\
\hline$C 7120(1,13)$ & 69.622 & $\mathrm{~kg} / \mathrm{kg}-\mathrm{mc}$ \\
\hline $\mathrm{C} 7120(2,13)$ & 69.622 & $\mathrm{~kg} / \mathrm{kg}-\mathrm{mo}$ \\
\hline$C 7120(1,14)$ & 18.016 & $\mathrm{~kg} / \mathrm{kg}-\mathrm{mc}$ \\
\hline$C 7120(2,14)$ & 18.016 & $\mathrm{~kg} / \mathrm{kg}-\mathrm{mo}$ \\
\hline$C 7120(1,15)$ & 28.97 & $\mathrm{~kg} / \mathrm{kg}-\mathrm{mc}$ \\
\hline $\mathrm{C} 7120(2,15)$ & 28.97 & $\mathrm{~kg} / \mathrm{kg}-\mathrm{mo}$ \\
\hline$C 7120(1,16)$ & 259.8054 & $\mathrm{~kg} / \mathrm{kg}-\mathrm{mc}$ \\
\hline$C 7120(2,16)$ & 259.8054 & $\mathrm{~kg} / \mathrm{kg}-\mathrm{mo}$ \\
\hline$C 7120(1,17: 20)$ & 28.97 & \\
\hline $\mathrm{C} 7120(2,17: 20)$ & 28.97 & $\mathrm{~kg} / \mathrm{kg}-\mathrm{mc}$ \\
\hline
\end{tabular}

Solubility of RN Classes in Water Films

$\S 2.4 .2 .2$

C7136(1:20)

1.0

7140 - Release from Molten U-AI Pools

(Not used with LWR COR package)

7141 - Solubility of Classes in Al-U Alloy

(Not used with LWR COR package)

7142 - Debris Particle of Average Surface Area

(Not used with LWR COR package)

7143 - Molten Fraction Criterion for Release from U-Al Pools

(Not used with LWR COR package) 
RN Package Reference Manual

7144 - Temperature Criterion for Release from Intact Fuel

(Not used with LWR COR package) 
RN Package Reference Manual

\section{APPENDIX B: Agglomeration Kernels}

The agglomeration kernels currently implemented in the MELCOR implementation of MAEROS are summarized in this appendix. These kernels are those that are recommended by Powers, Sprung, and Leigh [1].

\section{Brownian}

$$
\begin{aligned}
& \beta=2 \pi\left(D_{i}+D_{j}\right)\left(\gamma_{i} d_{i}+\gamma_{j} d_{j}\right) / F \\
& D_{i}=\frac{k T}{3 \pi d_{i} \mu \chi_{i}} C_{i} \\
& C_{i}=1+K n_{i}\left[c_{m}+0.4 \exp \left(-1.1 / K n_{i}\right)\right] \\
& F=\frac{d_{i}+d_{j}}{d_{i}+d_{i}+2 g_{i, j}}+\frac{8\left(D_{i}+D_{j}\right)}{v_{i, j}\left(d_{i}+d_{j}\right) c_{s}} \\
& g_{i, j}=\left(g_{i}^{2}+g_{j}^{2}\right)^{1 / 2} \\
& v_{i, j}=\left(v_{i}^{2}+v_{j}^{2}\right)^{1 / 2} \\
& g=\frac{1}{3 d_{i} I_{i}}\left\{\left(d_{i}+l_{i}\right)^{3}-\left(d_{i}^{2}+l_{i}^{2}\right)^{3 / 2}\right\}-d_{i} \\
& I=\frac{8 D_{i}}{\pi v_{i}} \\
& v=\left(\frac{8 k T}{\pi m_{i}}\right)^{1 / 2} \\
& K n_{i}=2 \lambda / d_{i} \\
& \lambda=\frac{\mu}{\rho_{g}}\left(1.89 \times 10^{-4} M_{w, g} / T\right)^{1 / 2} \\
& \rho_{g}=1.21 \times 10^{-4} P M_{w, g} / T
\end{aligned}
$$

$\mu$ - values for air; from the Material Properties (MP) package 
RN Package Reference Manual

\section{Gravitational}

$$
\begin{aligned}
& \beta=\varepsilon_{g} \frac{\pi}{4} c_{s}\left(\gamma_{i} d_{i}+\gamma_{j} d_{i}\right)^{2}\left|V_{\pi i}-V_{T j}\right| \\
& V_{T i}=\frac{\rho_{p i} g d_{i}^{2} C_{i}}{18 \mu \chi_{i}} \\
& \varepsilon_{g}=1.5\left\{\frac{\min \left(d_{i}, d_{j}\right)}{\left(d_{i}+d_{j}\right)}\right\}^{2}
\end{aligned}
$$

\section{Turbulent}

$$
\begin{aligned}
& \beta=c_{s}\left(\beta_{T 1}^{2}+\beta_{T 2}^{2}\right)^{1 / 2} \\
& \beta_{T 1}=\left(\frac{\pi \varepsilon_{T} \rho_{g}}{120 \mu}\right)^{1 / 2}\left(\gamma_{i} d_{i}+\gamma_{j} d_{j}\right)^{3} \\
& \beta_{T 2}=\frac{0.04029 \rho_{g}^{1 / 4} \varepsilon_{T}^{3 / 4}}{\mu^{5 / 4}}\left(\gamma_{i} d_{i}+\gamma_{j} d_{j}\right)^{2}, \frac{\rho_{p 1} c_{1} d_{1}^{2}}{\chi_{1}}-\frac{\rho_{p 2} C_{2} d_{2}^{2}}{\chi_{2}}
\end{aligned}
$$

Nomenclature

$$
\begin{array}{ll}
\mathrm{c}_{\mathrm{m}} & =\text { particle slip coefficient } \\
\mathrm{c}_{\mathrm{s}} & =\text { particle sticking coefficient } \\
\mathrm{c}_{\mathrm{t}} & =\text { thermal accommodation coefficient } \\
\mathrm{C} & =\text { particle mobility } \\
\mathrm{d} & =\text { particle diameter } \\
\mathrm{D} & =\text { diffusion coefficient } \\
\mathrm{k} & =\text { Boltzmann constant } \\
\mathrm{k}_{\mathrm{g}} / \mathrm{k}_{\mathrm{s}} & =\text { ratio of thermal conductivity of the gas over that for the particle } \\
\mathrm{Kn} & =\text { Knudsen number } \\
\mathrm{m} & =\text { particle mass } \\
\mathrm{M}_{\mathrm{w}} & =\text { molecular weight } \\
\mathrm{P} & =\text { pressure } \\
\mathrm{T} & =\text { temperature } \\
\mathrm{V} & =\text { volume }
\end{array}
$$


Greek

$$
\begin{aligned}
& \beta=\text { coagulation kernel }\left(\mathrm{m}^{3} / \mathrm{s}\right) \\
& \varepsilon_{\mathrm{T}}=\text { turbulence dissipation density } \\
& \rho=\text { density } \\
& \mu=\text { viscosity } \\
& \lambda=\text { mean free path } \\
& \gamma=\text { agglomeration shape factor } \\
& \chi=\text { dynamic shape factor }
\end{aligned}
$$

Subscripts

$$
\begin{aligned}
& \mathrm{b}=\text { bulk } \\
& \mathrm{g}=\text { gas (air assumed) } \\
& \mathrm{i}, \mathrm{j}=\text { particle identifier } \\
& \mathrm{p}=\text { particle } \\
& \mathrm{s}=\text { steam }
\end{aligned}
$$


RN Package Reference Manual 
RN Package Reference Manual

\section{APPENDIX C: Aerosol Surface Area}

The aerosol surface area is used for fission product vapor condensation and evaporation of aerosols. The general equation for the surface area is:

$$
A_{T}=\int_{x_{1}}^{x_{2}} n(x) A(x) d x
$$

where

$A_{T}=$ total surface area

$A(x)=$ area of a particle as a function of $x$

$n(x)=$ number of particles as a function of $x$

MAEROS assumes that the aerosol size distribution in each section is constant with respect to the natural log of the mass, so the number density can be expressed as (Gelbard [7]):

$$
n(x)=\frac{M}{m\left(\ln m_{2}-\ln m_{1}\right)} d(\ln m)
$$

$A$ and $m$ can be expressed in terms of $\ln m$ as follows:

$$
\begin{aligned}
m & =e^{\ln m} \\
A & =4 \pi r^{2} \\
& =4 \pi\left(\frac{3 m}{4 \pi \rho}\right)^{2 / 3} \\
& =4 \pi\left(\frac{3 e^{\ln m}}{4 \pi \rho}\right)^{2 / 3}
\end{aligned}
$$


RN Package Reference Manual

The equation $\mathrm{C}-1$ becomes

$$
A_{T}=4 \pi\left(\frac{3}{4 \pi \rho}\right)^{2 / 3} \frac{M}{\ln \left(m_{2} / m_{1}\right)} \int_{\ln m_{1}}^{\ln m_{2}} \exp (-1 / 3 \ln m) d(\ln m)
$$

and, after integration,

$$
A_{T}=12 \pi\left(\frac{3}{4 \pi \rho}\right)^{2 / 3} \frac{M}{\ln \left(m_{2} / m_{1}\right)}\left\{m_{1}^{-1 / 3}-m_{2}^{-1 / 3}\right\}
$$


RN Package Reference Manual

\section{APPENDIX D: Pool Scrubbing Deposition Velocities}

The deposition velocities for a spherical bubble are easily derived as presented by Fuchs [36]. Using the Stokes equation for the settling velocity of aerosol particles, the particle velocity due to gravitational settling is

$$
v_{s}=\frac{\rho_{p} d_{p}^{2} C_{m} g}{18 \mu}
$$

Referring to Figure $\mathrm{F}-1$, the net velocity normal to the wall, $v_{g}$, is

$$
v_{g}=v_{s} \cos \theta
$$

For the inertial impaction, the velocity of the aerosol particles normal to the bubble wall is

$$
v_{i}=\frac{9 v_{b}^{2} v_{s}}{4 R g} \sin ^{2} \theta=v_{i \max } \sin ^{2} \theta
$$

For Brownian diffusion, the average velocity over the region from $\pi / 4$ to $3 \pi / 4$ is used, which is (see Bird, Stewart, and Lightfoot [23] or Owczarski, et al. [10])

$$
v_{d}=\left(D v_{b} / R\right)^{1 / 2}
$$

For the evaporative velocity, Moody and Nagy [40] have developed an expression based on the assumptions of

1. local thermal and vapor equilibrium (saturation) of the bubble at any pool depth, and

2. uniform vapor velocity around the bubble surface. 
RN Package Reference Manual

These assumptions are discussed in detail in their paper. Their expression for the evaporative velocity is

$$
v_{v}=\frac{v_{b}(V / A)}{\left[P_{d}-P_{s a t}\left(T_{p}\right)\right] / \rho_{p}}
$$

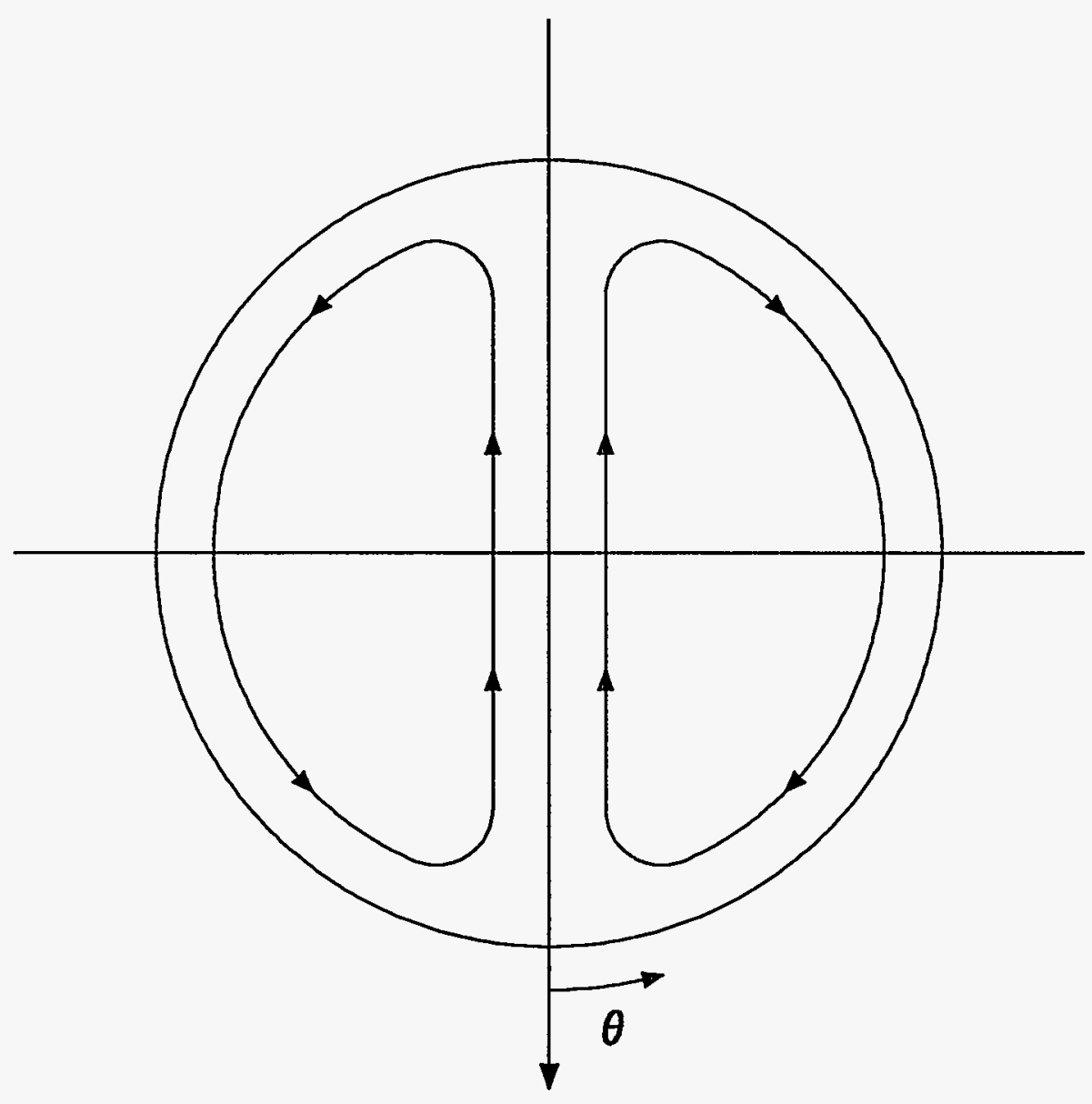

Figure D-1. Bubble Geometry 


\title{
Containment Sprays (SPR) Package Reference Manual
}

\author{
MELCOR Code Development Group \\ Modeling and Analysis Department \\ Nuclear Energy Technology Center \\ Sandia National Laboratories \\ Albuquerque, NM 87185-0739
}

Contributors:

Susan E. Dingman

Randall M. Summers

The Containment Sprays (SPR) package models the heat and mass transfer between spray water droplets and the containment building atmosphere. The SPR package models were extracted from the HECTR 1.5 code.

This Reference Manual describes the models employed in the SPR package. Detailed descriptions of the user input requirements can be found in the SPR Package Users' Guide. 
SPR Package Reference Manual

SPR-RM-2 
SPR Package Reference Manual

\section{Contents}

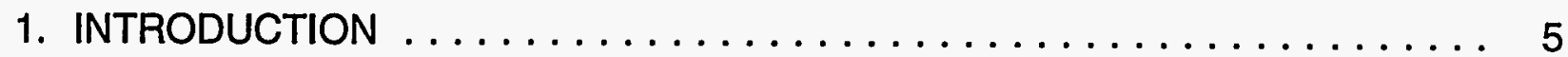

2. MODEL DESCRIPTION $\ldots \ldots \ldots \ldots \ldots \ldots \ldots \ldots \ldots \ldots \ldots$

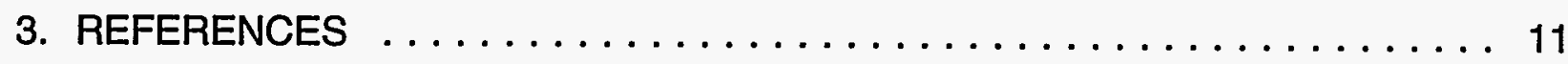


SPR Package Reference Manual 


\section{INTRODUCTION}

Where possible, MELCOR uses a generic building-block approach to modeling engineered safety features (ESFs) through use of control volumes, flow paths, heat structures, and control functions. However, for containment sprays, separate models tailored to this system have been implemented in MELCOR.

The MELCOR Containment Sprays (SPR) package models the heat and mass transfer resulting from operation of containment spray systems. The removal of fission product vapors and aerosols by ESFs is modeled within the RadioNuclide (RN) package. See the RN Package Reference Manual for details on this modeling. 
SPR Package Reference Manual 
SPR Package Reference Manual

\section{MODEL DESCRIPTION}

The Containment Sprays (SPR) package models the heat and mass transfer between spray droplets and the containment building atmosphere. The modeling in the SPR package was taken virtually intact from the HECTR 1.5 code [1], following the recommendations of the MELCOR phenomena assessment on modeling containment spray systems [2]. The model assumes that spray droplets are spherical and isothermal and that they fall through containment atmospheres at their terminal velocity with no horizontal velocity component.

An arbitrary number of spray sources may be placed at various heights in any containment control volume. The source of water for each spray may be associated with the pool in any CVH control volume or it may be left unspecified. If a CVH pool is specified as the spray source reservoir, then input ("dryout" pool depth) may be specified to determine whether there is sufficient water in the pool to permit spray operation. Input (resumption pool depth) may also be specified to determine when spray operation may resume following "dryout". If the pool depth for spray source resumption exceeds the pool depth for spray source "dryout", then there will be a hysteresis in the spray operation curve that will prevent excessive cycling between episodes of spray operation. In a special application, the spray model also receives water from the Heat Structures (HS) package film-tracking model that "rains" off of inverted surfaces into the containment atmosphere.

For each spray source, except for sources associated with "rain" from the HS film tracking model, the user must specify an initial droplet temperature and flow rate, each of which may be controlled by a control function. The user may turn the sprays on and off with a separate control function for each spray source. A droplet size distribution also may be input for each spray source. In other words, the spray droplets for each source may be divided into a number of different size bins, with individual drops representing the average droplet size being tracked during their fall through the control volume; the total heat and mass transfer for the spray source is obtained by summing the heat and mass transfers calculated for all sizes.

For each droplet type in each control volume, the following differential equations are solved to determine the heat and mass transfer rates and the terminal fall velocity as a function of drop size:

$$
\frac{d m}{d t}=-2 \pi \rho_{g} D\left(1+0.25 R e^{1 / 2} S c^{1 / 3}\right) D_{c} \ln (1+B)
$$


SPR Package Reference Manual

$$
\begin{aligned}
& \frac{d T}{d t}=\frac{1}{m c_{p l}}\left[\frac{c_{p v}\left(T-T_{c v}\right)}{(1+B)^{1 / L e}-1}+h_{f g}\right] \frac{d m}{d t} \\
& \frac{d z}{d t}=\left[\frac{4\left(\rho_{d}-\rho_{g}\right) g D}{3 \rho_{g} C_{d}}\right]^{1 / 2}
\end{aligned}
$$

In these equations, the terms are defined as

$\mathrm{m}=$ droplet mass,

$T, T_{c v}=$ droplet, control volume atmosphere temperatures,

$z \quad=$ droplet fall height,

$\rho_{d}, \rho_{g}=$ droplet, atmosphere densities,

$\mathrm{c}_{\mathrm{pl}}=$ droplet specific heat capacity,

$\mathrm{c}_{\mathrm{pv}}=$ control volume atmosphere specific heat capacity

$h_{\mathrm{fg}} \quad=$ latent heat of vaporization

D = droplet diameter,

$\operatorname{Re} \quad=$ Reynolds number,

Sc = Schmidt number,

Le = Lewis number,

$\mathrm{D}_{\mathrm{c}} \quad=$ diffusion coefficient,

$\mathrm{C}_{\mathrm{d}} \quad=$ drag coefficient,

and $B$ is the mass transfer driving force,

$$
B=\frac{x_{b}-x_{i}}{x_{i}-1}
$$


SPR Package Reference Manual

where $x_{b}$ and $x_{i}$ are $\mathrm{H}_{2} \mathrm{O}$ mass fractions in the bulk atmosphere and at the liquid-gas interface (corresponding to saturation). Equations 2.1 through 2.4 are based on forced convection heat transfer and evaporation and condensation correlations that have been formulated specifically for high temperature atmospheres, such as might be encountered during a hydrogen burn [3]. The constants in Equation 2.1 have been implemented in sensitivity coefficient array 3001 .

Correlations for the drag coefficient of spheres, $C_{d}$, are used for the following Reynolds number regimes, with the various constants implemented in sensitivity coefficient array 3000:

$$
\begin{array}{ll}
C_{d}=27 R e^{-0.84} & \text { for } \quad R e<78 \\
C_{d}=0.271 R e^{0.217} & \text { for } \quad 78<R e<10000 \\
C_{d}=2 & \text { for } 10,000<R e
\end{array}
$$

The transfer rates given by Equations 2.1 through 2.3 are integrated by a Runge-Kutta method over the fall height of the spray droplet to obtain the final droplet mass and temperature. By comparing the droplet mass and temperature at the bottom of the compartment to the inlet conditions, the heat transfer and mass transfer to a given droplet are computed. Total heat and mass transfer rates are calculated by multiplying the rates for one droplet by the total number of droplets of that size and summing over all droplet sizes. It is assumed that this total heat and mass transfer rate is constant over a given time step, and it is also assumed that the containment atmosphere conditions do not change significantly during the fall time of the drop.

The user can describe how droplets falling from one control volume are to be carried over to lower volumes. A control volume may be designated as the containment spray sump. Droplets leaving designated control volumes and not carried over to other volumes will be placed in the pool of the sump. Droplets reaching the bottom of a control volume and not being carried over to other volumes or placed in the sump are put into the pool of the control volume.

It should be noted that the SPR package does not model interactions between spray droplets and other structures (nor does any other MELCOR package). Thus, it is not 


\section{SPR Package Reference Manual}

possible to model either core sprays or steam generator auxiliary feed water sprays properly using the SPR package.

The SPR package is coupled to the RadioNuclide ( $R N$ ) package for the calculation of aerosol washout and atmosphere decontamination by the sprays. Current limitations of this interface require some restrictions on the input to the SPR package to avoid nonphysical results associated with multiple calculations in the same control volume. When the SPR and RN packages are both active, the user should limit the spray input so that only one spray train passes through each control volume and only a single drop size is used in each spray train. 


\section{REFERENCES}

1. S. E. Dingman, A. L. Camp, C. C. Wong, D. B. King, and R. D. Gasser, HECTR Version 1.5 User's Manual, NUREG/CR-4507, SAND86-0101, Sandia National Laboratories, Albuquerque, NM (February 1986).

2. G. G. Weigand, ed., Thermal-Hydraulic Process Modeling in Risk Analysis: An Assessment of the Relevant Systems, Structures, and Phenomena, SAND84-1219, NUREG/CR-3986 (August 1984).

3. F. A. Williams, Combustion Theory, Addison-Wesley Publishing Company, Inc., Reading, MA (1965). 


\section{Distribution:}

U. S. Nuclear Regulatory Commission (24)

Attn: C. Ader, TWF-10F13

S. Basu, TWF-10K8

K. M. Campe, OWFN-8C11

Y. S. Chen, TWF-10K8

M. A. Cunningham, TWF-9F31

A. Drozd, OWFN-8E1

D. Ebert, TWF-10G6

F. Eltawila, TWF-10K8

R. B. Foulds, TWF-10K8

C. Gingrich, TWF-10K8

W. Hodges, TWF-10E37

M. D. Houston, ACRS

W. Jenson, Jr., OWFN-8E2

L. Lancaster, TWF-C16

R. Landry, OWFN-11D23

N. Lauben, TWF-10G6

J. D. Monninger, OWF8E1

R. Palla, OWFN 8E1

J. N. Ridgely, TWF E44

C. P. Ryder, TWF-9F31

J. H. Schaperow, TWF-10F13

E. D. Throm, OWFN-11D23

C. G. Tinkler, TWF-10K8

L. Soffer, TWF-10F13

Washington, DC 20555

S. Y. Chen

Argonne National Laboratory

9700 South Cass Avenue

Argonne, IL 60439

Battelle Columbus Laboratories (3)

Attn: M. Carmel

R. S. Denning

J. Gieseke

505 King Avenue

Columbus, $\mathrm{OH} 43201$

Bettis Atomic Power Laboratory (3)

P. O. Box 79

Attn: Richard Beyer

Carmen DiGuilio

Joe Semancik

West Mifflin, PA 15122
Brookhaven National Laboratory (3)

Attn: I. K. Madni

L. Neymotin

T. Pratt

Bldg. 130

32 Lewis

Upton, NY 11973

Gary Miller

Carolina Power and Light Company

1 Hannover Square

Mail Location OHS-5

412 South Wilmington St.

Raleigh, NC 27601

John Bolin

CEGA

P. O. Box 85608

San Diego, CA 92186-9784

Commonwealth Edison Co. (2)

Attn: J. Hawley

F. G. Lentine

1400 Opus Place

Suite 300

Downers Grove, IL 60521

Professor K. B. Cady

Nuclear Science and Engineering

Cornell Universioty

Ward Laboratory

Ithaca, NY 14853-7701

Electric Power Research Institute

Attn: R. N. Oehlberg

$$
\text { J. Maly }
$$

P. O. Box 10412

Palo Alto, CA 94303

M. Khatib-Rahbar

Energy Research Inc.

P. O. Box 2034

Rockville, MD 20852 
Energy Services Center (2)

Attn: M. Withrow

D. Rao

Grand Gulf Nuclear Station

Entergy Operations Corporation

P.O. Box 756

Port Gibson, MS 39150

M. Plys

Fauske \& Associates

16W070 West 83rd Street

Burr Ridge, IL 60521

Dave Miskiewicz

Florida Power Corp.

3201 Thirty-fourth Street

P.O. Box 14042

St Petersberg, FL 33733

M. A. Kenton

Gabor, Kenton \& Associates

770 Pasquinelli Drive. Suite 426

Westmont, IL 60559

Jim Loomis

GE Nuclear Energy, M/C 747

175 Curtner Avenue

San Jose, CA 95125

General Electric Company (3)

Knolls Atomic Power Laboratory

Attn: P. Dobreff, Bldg P3, Rm 172

D. F. McMullan, Bldg P3, Rm 172

E. Mennard, BIdg P3, Rm 172

P. O. Box 1072

Schenectady, NY 12301-1072

GPU Nuclear Corporation (2)

Attn: N. Trikouros

M. Alammar

One Upper Pond Road

Parsippany, NJ 07054

Professor Herbert S. Isbin

2815 Monterey Parkway

St. Louis Park, MN 55416-3959
Idaho National Engineering Laboratory (3)

EG\&G Idaho

Aitn: C. Allison

D. Brownson

D. W. Golden

P. O. Box 1625

Idaho Falls, ID 83404

Los Alamos National Laboratory (2)

Aitn: B. E. Boyack, K-551

S. Rodriguez, K-551

P. O. Box 1663

Los Alamos, NM 87545

B. Raychaudhuri

Nebraska Public Power District

PRA \& Engineering Review Group

P. O. Box 499

Columbus, NE 68601

John Ward

Manager, Nuclear Systems Analyses

New York Power Authority

123 Main Street

White Plains, NY 10601

Oak Ridge National Laboratory (8)

Attn: S. R. Greene

J. Carbajo

S. K. Kim

R. L. Sanders

S. A. Hodge

C. R. Hyman

R. P. Taleyarkhan

S. Valenti

P. O. Box 2009, MS-8057

Oak Ridge, TN 37831-8057

Professor T. Baratta

Penn State University

231 Sackett

University Park, PA 16802

David Leaver

Polestar Applied Technology, Inc.

Four Main Street

Los Altos, CA 94022 
Professor R. Viskanta

Purdue University

Heat Transfer Laboratory

School of Mechanical Engineering

West Lafayette, IN 47907

Alfred Torri

Risk Management Associates, Inc.

1421 Hymettus Ave.

Leucadia, CA 92024-1750

Savannah River Laboratory (2)

Attn: D. Kaninich

$$
\text { T. Long }
$$

992-1W

Westinghouse Savannah River Co.

Aiken, SC 29809

M. T. Leonard

Science Applications Intl. Corp.

2109 Air Park Rd. SE

Albuquerque, NM 87106

Frank Elia

Stone \& Webster Engineering Corp.

P.O. Box 2325

Boston, MA 02107

Professor V. K. Dhir

UCLA

2445 22nd Street

Santa Monica, CA 90403

Professor T. Theofanous

University of California

ERC-CRSS

Santa Barbara, CA 93106

Professor J. C. Lee

University of Michigan

Dept. of Nuclear Engineering

Cooley Building, North Campus

College of Engineering

Ann Arbor, MI 48109-2104

Professor F. E. Haskin

University of New Mexico

Department of Chemical and Nuclear Engineering

Albuquerque, NM 87131
Steve Manson

Office of the Dean, College of Engineering

University of Texas

Austin, TX 78712

University of Wisconsin

Attn: Professor M. L. Corradini

Professor R. J. Witt

Dept. of Nuclear Engineering

Engineering Research Building

1500 Johnson Drive

Madison, WI 53706

Ramu K. Sundaram

Manager, LOCA Analysis Group

Nuclear Engineering

Yankee Atomic Electric Company

580 Main Street

Bolton, MA 01740

Prof. Dr. Johann Korkisch

Institute of Analytical Chemistry

University of Vienna

A-1090 Vienna, Wăringerstrasse 38

AUSTRIA

TRACTABEL (3)

Attn: M. Auglaire

J. Snoeck

E. Stubbe

Avenue Ariane 7

B-1200 Brussels

BELGIUM

Samir S. Girgis

Atomic Energy of Canada Limited

CANDU Operations

Sheridan Park Research Community

Mississagua, Ontario

CANADA L5K1B2

Paul J. Fehrenbach

Chalk River Nuclear Laboratories

Fuel Engineering Branch, RSR Division

Chalk River, Ontario

CANADA KOJ1JO 
Department of Reactor Technology (3)

Attn: Dr. Bohumir Kujal

Zbynek Parduba

Dr. Frantisek Pazdera

Nuclear Research Institute

$25068 \mathrm{Rez}$

CZECH REPUBLIC

Technical Research Centre of Finland (2)

Nuclear Engineering Laboratory

Attn: Lasse Mattila Ilona LIndholm

P. O. Box 208 (Tekniikantie 4)

SF-002151 Espoo

FINLAND

Jorma V. Sandberg

Finnish Center Radiation \& Nucl. Safety, Dept. of Nuclear Safety

P. O. Box 268

SF-00101 Helsinki

FINLAND

Dr. Lothar Wolf

Battelle Institute EV

AM Romerhof 35, D-6000

Frankfurt/Main90

GERMANY

Martin Sonnenkalb

Gesellschaft fur Anlagen-und

Reaktorsicherheit

Schwertnergasse 1

D-5000 Koln 1

GERMANY

Kernforschungzentrum, Karisruhe (3)

Attn: P. Hofmann

Werner Scholtyssek

Philipp Schmuck

P. O. Box 3640

D-7500 Karlsruhe 1

GERMANY

Professor U. Brockmeier

Ruhr-University of Bochum

Universitatsstrasse 150

D-4630 Bochum

GERMANY
Gyorgy Gyenes

Central Research Institute for Physics Institute for Atomic Energy Research

H-1525 Budapest, P. O. Box 49

HUNGARY

Dr. Lajos Voross

Institute for Electric Power Research

(VEIKI)

Budapest, V. Zrinyl u. 1

H-1368 Budapest, POB 233

HUNGARY

Pal Kostka

Institute for Electric Power Research

$\mathrm{H}-1051$ Budapest

Zrinyi u. 1

HUNGARY

Dr. Laszlo Czibolya

Hungarian Atomic Energy Commission

P.O. Box 565

H-1374 Budapest

HUNGARY

Dr. Yanos Gado

Academy of Science

Director, Central Research Institute for

Physics

Budapest

HUNGARY

Joint Research Center (2)

Commission of the European Communities

Attn: Alan Jones lain Shepherd

Safety Technology Institute 21020 Ispra (Va)

ITALY

ANPA (2)

Attn: G. Saponaro

G. Furrer

Natl. Comm. for R\&D of Nuclear Energy

Via Vitaliano Brancati, 48

00144 Rome

ITALY 
Mr. Pezzilli

ENEA

Via Vitaliano Brancati, 48

00144 Rome

ITALY

Japan Atomic Energy Research Institute (3)

Attn: K. Hashimoto

Akihide Hidaka

Kunihisa Soda

Tokai-mura, Naka-gun

Ibaraki-ken 319-11, JAPAN

Masao Ogino

Mitsubishi Atomic Power Industries

4-1 Shibakoen 2-Chome

Minatoku Tokyo

JAPAN

Institute of Nuclear Safety

Nuclear Power Engineering Corporation (3)

Attn: Dr. M. Shiba, Director General

K. Takumi

H. Okada

Fujita Kankou Toranoman Bldg. 7F

3-17-1, Toranoman, Minato-Ku, Tokyo 105

JAPAN

Hirohide Oikawa

Toshiba Corporation

8, Shin-Sugita, Isogo-ku

Yokohama

JAPAN

Shingo Ueno

Safety Engerneering Dept.

Mitsubishi Research Institute, Inc.

Time \& Life Building, 3-6, Otemachi 2-chome

Chiyoda-ku, Tokyo 100, JAPAN

Algirdas Kaliatka

Lithuanian Energy Institute

3 Breslaujos

Kaunas 3035

LITHUANIA
Rafael Amador Cano

CNSNS

Dr. Barragan 779

Col Narvarte

03020 MEXICO, D.F.

Institute of Nuclear Energy Research (2)

Attn: Shih-Kuei Cheng

Shih-Jen Wang

P. O. Box 3-3

Lung-Tan, Taiwan

REPUBLIC OF CHINA

Mr. Yi-Bin Chen

Department of Nuclear Technology

Atomic Energy Council, 67, Lane 144

Keelung Road, Section 4

Taipei, Taiwan, REPUBLIC OF CHINA

Russian Academy of Science (3)

Attn: Dr. Valery F. Strizhov

Leonid Bolshov

Vladimir Nosatov

Institute of Nuclear Safety

Moscow, B. Tulsky, 52

113191, RUSSIA

Nuclear Safety Institute (2)

Attn: V. Asmolov

V. Proklov

RRC "Kurchatov Institute"

Kurchatov Square

Moscow 123182, RUSSIA

Alexander Gutsalov

First Deputy Chairman

Federal Nuclear Radiation Authority of

Russia (GAN)

Taganskaya,34

Moscow, 109147 RUSSIA

Institut Josef Stefan (2)

Attn: B. Mavko

J. Marn

Odsek za Reaktorsko Tehniko

P.O. Box 100

61111 Ljubljana

Jamova 39

SLOVENIA 
Nuclear Regulatory Auth. of the Slovak Republic (3)

Attn: V. Petenyi

V. Pokorny

M. Stubna

Okuzna 5, 91864 Trnava

SLOVAKIA

Korea Atomic Energy Research Inst. (3)

Attn: Dong-Ha Kim Hee-Dong Kim Jae Hong Park

P. O. Box 7, Daeduk Danji

Taejon

SOUTH KOREA 305-353

Yong-Jin Cho

Korea Institute of Nuclear Safety

P.O. Box 114, Yusong

Taejon, 305-600

SOUTH KOREA

Universidad Politecnica de Madrid (2)

Attn: Augustin Alonzo Santos, Francisco Martin-Fuertes

E.T.S. Ingenieros Industriales Jose Gutierrez Abascal, 2 28006 Madrid

SPAIN

Consejo de Seguridad Nuclear (2)

Attn: Jose E. DeCarlos Jose A. Martinez

Justo Dorado, 11

28040, Madrid

SPAIN

Statens Karnkraftinspektion

Attn: L. Hammar Oddbjorn Sandervag Wiktor Frid

Swedish Nuclear Power Inspectorate Box 27106 S 10252 Stockholm SWEDEN

B. Raj Sehgal

Department of Nuclear Power Safety

Royal Institute of Technology

Brinellvagen 60

S-100 44 Stockholm, SWEDEN
Swiss Federal Nuclear Safety Inspectorate

Attn: S. Chakraborty

$$
\text { Sang Lung Chan }
$$

U. Schmocker

CH-5232 Villigen-HSK

SWITZERLAND

Dante Killian

Utrechtseweg 310

6812 AR Arnhem

THE NETHERLANDS

Netherlands Energy Research Foundation

Attn: K. J. Brinkmann

P. O. Box 1

S. Spoelstra

P. M. Stoop

1755 ZG Petten

THE NETHERLANDS

Nikolai Steinberg, Chairman

Ukranian State Committee on Nuclear

Radiation and Safety

11-1 Observatorna Street

25403, Kiev

UKRAINE

United Kingdom Atomic Energy Authority

Winfrith Technology Center

Attn: T. Haste

B. Turland

Winfrith, Dorchester, Dorset

UNITED KINGDOM, DT2 8DH

United Kingdom Atomic Energy Authority

Safety \& Reliability Directorate

Attn: M. Robertson

Wigshaw Lane, Culcheth, Warrington

Cheshire, WA3 4NE

UNITED KINGDOM

AEA Technology

Attn: Geoffrey Brown

Consultancy Services

Thomson House

Risley, Warrington WA3 6AT

UNITED KINGDOM 


\section{Internal Distribution:}

$\begin{array}{ll}\text { MS } 0736 & \text { N. R. Ortiz, 6400 } \\ \text { MS } 0744 & \text { W. A. von Riesemann, 6403 } \\ \text { MS } 0744 & \text { D. A. Powers, 6404 } \\ \text { MS } 0747 & \text { A. L. Camp, 6412 } \\ \text { MS } 0747 & \text { S. E. Dingman, 6412 } \\ \text { MS } 0748 & \text { F. T. Harper, 6413 } \\ \text { MS } 0742 & \text { J. E. Kelly, 6414 } \\ \text { MS } 0739 & \text { K. D. Bergeron, 6421 } \\ \text { MS } 0739 & \text { R. K. Cole, Jr., 6421 } \\ \text { MS } 0739 & \text { F. J. Davis, 6421 } \\ \text { MS } 0739 & \text { A. A. Elsbernd, 6421 } \\ \text { MS } 0739 & \text { R. O. Griffith, 6421 } \\ \text { MS } 0739 & \text { L. N. Kmetyk, 6421 } \\ \text { MS } 0739 & \text { K. K. Murata, 6421 } \\ \text { MS } 0739 & \text { R. C. Smith, 6421 } \\ \text { MS } 0739 & \text { D. W. Stamps, 6421 } \\ \text { MS } 0739 & \text { D. S. Stuart, 6421 } \\ \text { MS } 0739 & \text { R. M. Summers, 6421 (9 copies) } \\ \text { MS } 0739 & \text { E. L. Tadios, 6421 } \\ \text { MS } 0739 & \text { D. C. Williams, 6421 } \\ \text { MS } 1137 & \text { M. D. Allen, 6422 } \\ \text { MS } 1137 & \text { N. E. Bixler, 6422 } \\ \text { MS } 1139 & \text { K. O. Reil, 6423 } \\ \text { MS } 1139 & \text { R. O. Gauntt, 6423 } \\ \text { MS } 1139 & \text { R. C. Schmidt, 6423 } \\ \text { MS } 0899 & \text { Technical Library, 13414 (5 copies) } \\ \text { MS } 0619 & \text { Technical Publications, 12613 } \\ \text { MS } 9018 & \text { Central Technical Files, 8523-2 }\end{array}$




\begin{tabular}{|c|c|}
\hline $\begin{array}{c}\text { BIBLIOGRAPHIC DATA SHEET } \\
\text { (See instructions on the reverse) }\end{array}$ & $\begin{array}{l}\text { 1. REPORT NUMBER } \\
\text { (Auslgned by NRC. Add Vol., Supp., Rev.," } \\
\text { and Addendum Numbers, if iny.) } \\
\text { NUREG/CR } 6119 \\
\text { SAND93-2185 }\end{array}$ \\
\hline \multirow{4}{*}{$\begin{array}{l}\text { 2. TITLE AND SUBTITLE } \\
\text { MELCOR Computer Code Manuals } \\
\text { Reference Manuals } \\
\text { Version } 1.8 .3 \text { September } 1994\end{array}$} & Vol. 2 \\
\hline & 3. DATE REPORT PUBLISHED \\
\hline & \begin{tabular}{|c|c|} 
MONTH & YEAR \\
March & 1995 \\
\end{tabular} \\
\hline & $\begin{array}{l}\text { 4. FIN OR GRANT NUMBER } \\
\text { A1339 }\end{array}$ \\
\hline $\begin{array}{l}\text { 5. AUTHOR(S) } \\
\text { R. M. Summers, R. K. Cole, Jr., R. C. Smith, D. S. Stuart, } \\
\text { S. L. Thompsom, S. A. Hodge,* C. R. Hyman,* R. L. Sanders* }\end{array}$ & $\begin{array}{l}\text { 6. TYPE OF REPORT } \\
\text { Technical } \\
\end{array}$ \\
\hline & 7. PERIOD COVERED (Inclusive Dates) \\
\hline \multicolumn{2}{|c|}{$\begin{array}{l}\text { 8. PERFORMING ORGAANIZATION - NAME AND ADDRESS (If NRC, provide Division, Office or Region, U.S. Nuclear Regulatory Commission, and mailing address; if contractor, provide } \\
\text { nama and mallhng address) }\end{array}$} \\
\hline \multicolumn{2}{|c|}{$\begin{array}{lr}\text { Sandia National Laboratories } & \text { *0ak Ridge National Laboratory } \\
\text { Albuquerque, NM } 87185-0739 & \text { Oak Ridge, TN 37831-8057 }\end{array}$} \\
\hline \multicolumn{2}{|c|}{ 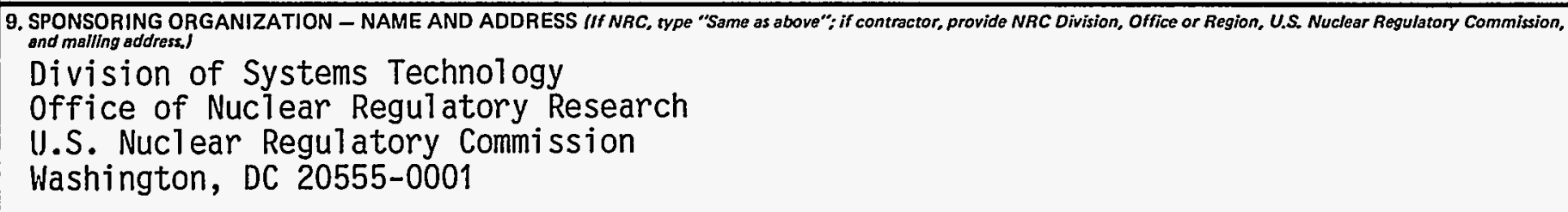 } \\
\hline \multicolumn{2}{|l|}{ 10. SUPPLEMENTARY NOTES } \\
\hline \multicolumn{2}{|l|}{ 11. ABSTRACT (200 words or less) } \\
\hline \multicolumn{2}{|c|}{$\begin{array}{l}\text { MELCOR is a fully integrated, engineering-level computer code that models the } \\
\text { progression of severe accidents in light water reactor nuclear power plants. MELCOR } \\
\text { is being developed at Sandia National Laboratories for the U. S. Nuclear Regulatory } \\
\text { Commission as a second-generation plant risk assessment tool and the successor to the } \\
\text { Source Term Code Package. A broad spectrum of severe accident phenomena in both } \\
\text { boiling and pressurized water reactors is treated in MELCOR in a unified framework. } \\
\text { These include: thermal-hydraulic response in the reactor coolant system, reactor cavity, } \\
\text { containment, and confinement buildings; core heatup, degradation, and relocation; core- } \\
\text { concrete attack; hydrogen production, transport, and combustion; fission product release } \\
\text { and transport; and the impact of engineered safety features on thermal-hydraulic and } \\
\text { radionuclide behavior. Current uses of MELCOR include estimation of severe accident } \\
\text { source terms and their sensitivities and uncertainties in a variety of applications. }\end{array}$} \\
\hline \multirow{5}{*}{$\begin{array}{l}\text { 12. KEY WORDS/DESCR!PTORS (List words or phrseses chat will assist researchers in locating the report.) } \\
\text { Severe accidents, probabilistic risk assessment (PRA), sourcei term, } \\
\text { computer code, nuclear, reactor safety, MELCOR, thermal-hydraulic behavior, } \\
\text { fission product transport, core meltdown, containment response }\end{array}$} & $\begin{array}{l}\text { 13. AVAILABILLTY STATEMENT } \\
\text { Unl imited }\end{array}$ \\
\hline & 14. SECURITY CLASSIFICATION \\
\hline & This Pagel \\
\hline & $\begin{array}{l}\text { Unclassified } \\
\text { 15. NUMBER OF PAGES }\end{array}$ \\
\hline & 16. PRICE \\
\hline
\end{tabular}

